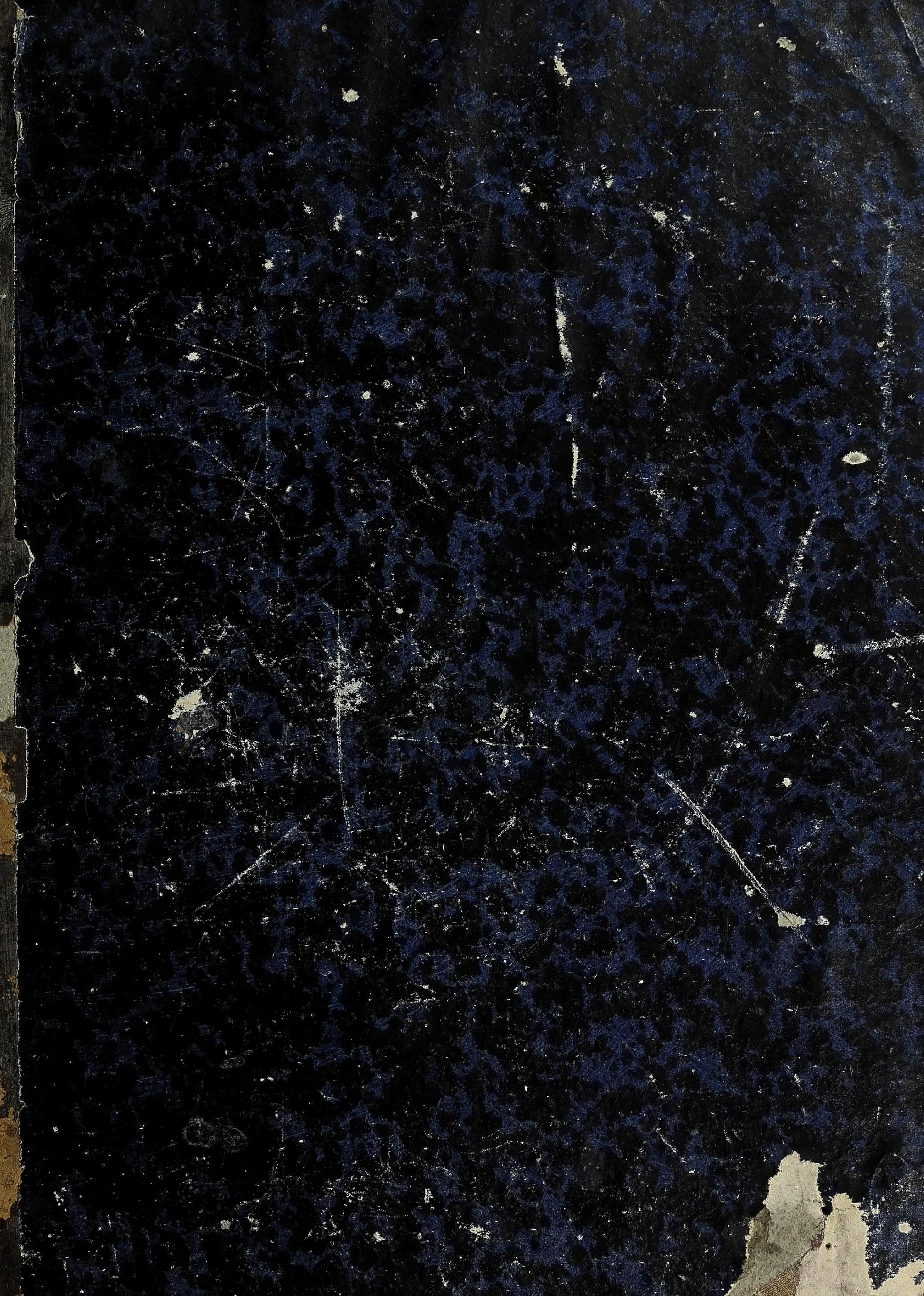




$$
\begin{aligned}
& 27 \\
& 4
\end{aligned}
$$


CEIG

$$
D B 4602850
$$

Sithes 400

16 Leares Detlors letter Preos

$$
\text { est+1000-1500 }
$$

Blec wriptoc

perte 240 dannty

alan col

$$
18^{42}
$$




\section{LORE UNIVERSELLE}

\section{PAR LETELLIER,}

Docur-médecin, ex-voyageur-naturaliste du Muséum, membre de plusieurs sociétés d'histoire naturelle, auteur

d'une histoire des champignons avec 120 figures, d'un supplément à Bulliard, 108 planches coloriées, d'un avis sur les ressemblances entre les champiguons alimentaires et les vénéneux, etc., etc.

\section{PLANTES I’ORANGERIE, IIE SERRES PROIDE ET TENPÉRÉE}

UN CARIFR DI 25 FHUIITES PAE MOIS, noir, 1 fr. 25 c.; colorié, 2 fr. 50 c.; chaque feuille séparée, noire, 5 c.; coloriée, 15 c.

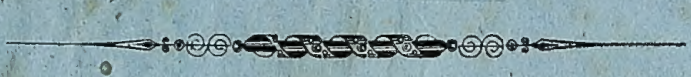

Cette partie d'une Flore générale sera spécialement utile :

1. Aux Botanistes, qui y trouveront les caractères et les détails anatomiques aussi complets que possible;

$2^{\circ}$ Aux Fleuristes et aux Dessinateurs, qui ont besain de modèles;

$3^{\circ}$ Aux Amateurs d'horticulture, qui ne craindront plus les descriptions pompeuses et mensongères de quelques marchands, et pourront choisir selon leur goût, sans craindre de coutteuses déceptions;

$4^{\circ}$ Aux Jardiniers, qui ne voudront pas laisser périr, par ignorance, les fleurs, qu'ils sont chargés de soigner;

$5^{0}$ Aux Horticulteurs, qui auront des espèces nouvelles, rares ou curieuses à faire connaitre; car ils y trouveront une publicité considérable et sans frais, puisqu'il leur suffira d'en donner avis (franc de port) à notre bureau, pour voir leur adresse imprimée sur nos feuilles.

Tous tes avis concernant le perfectionnement de cet ouvrage sans augmentation de prix seront requs avec reconnaissance.

Il y aura aussi des cahiers spéciaux pour $1^{\circ}$ les plantes d'agrément et de pleine terre; $2^{\circ}$ les plantes ufiles et dangereuses; $3^{\circ}$ les plantes sauvages ou flores locales.

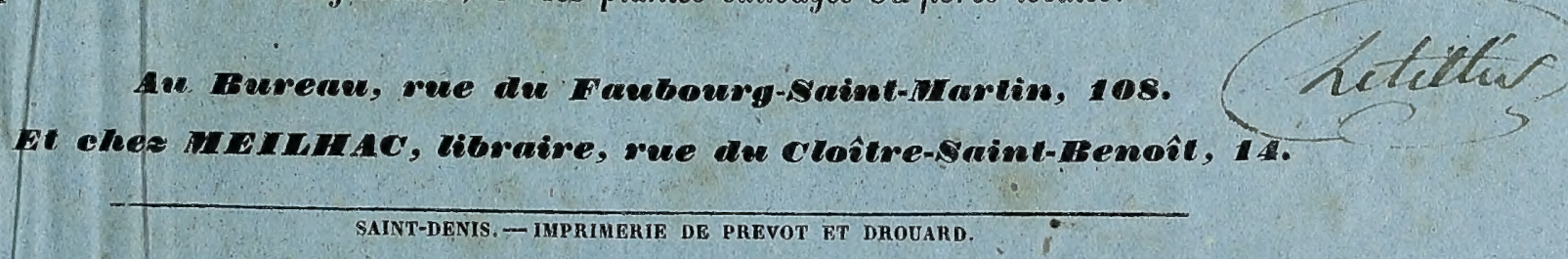




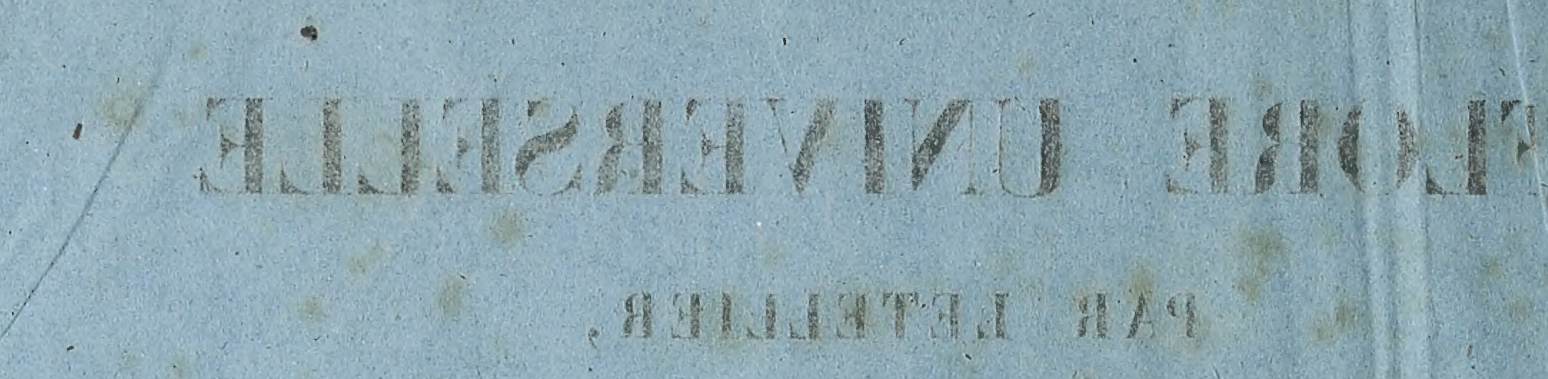

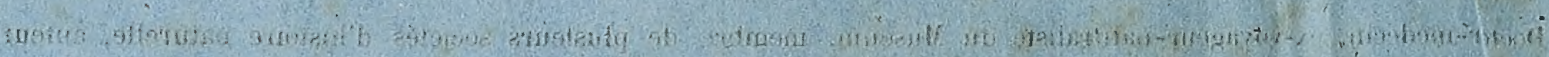

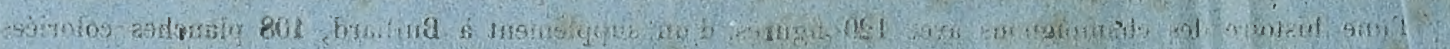

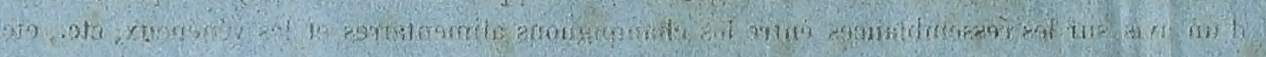

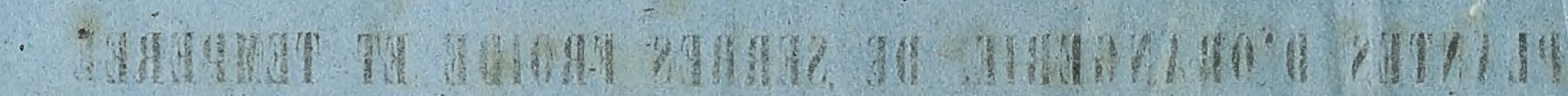

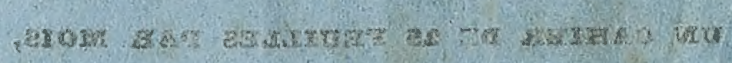

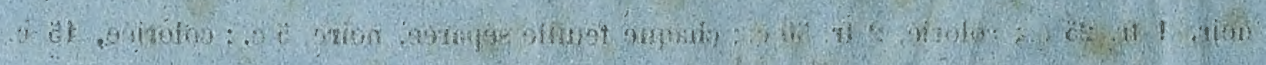

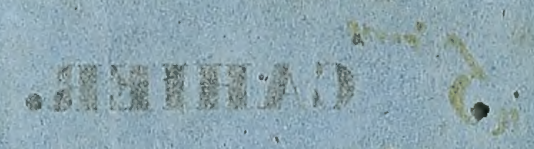

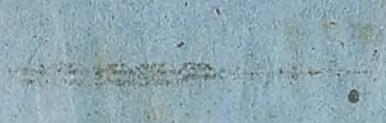

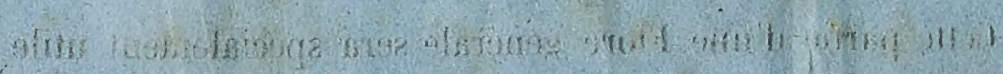

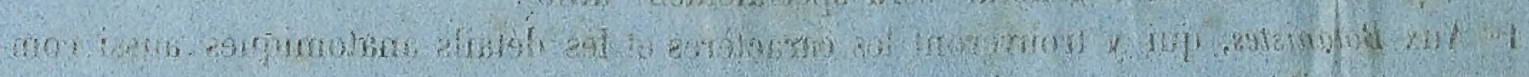

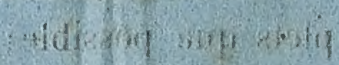

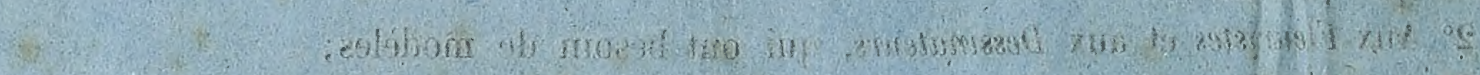

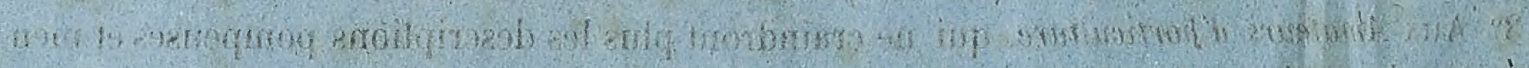

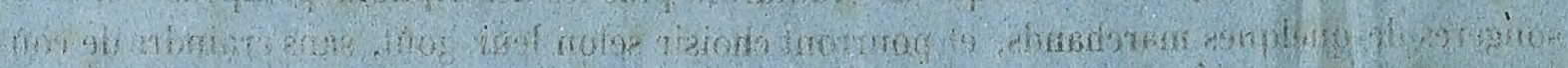

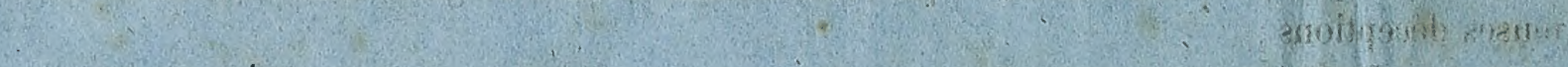

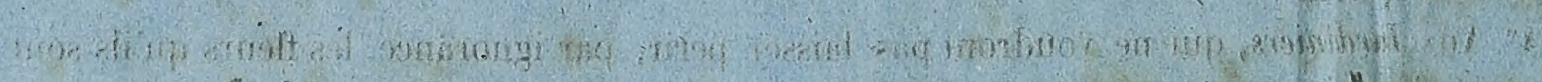

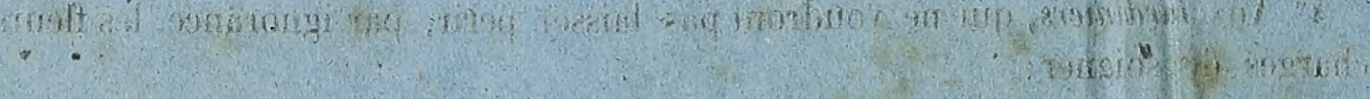

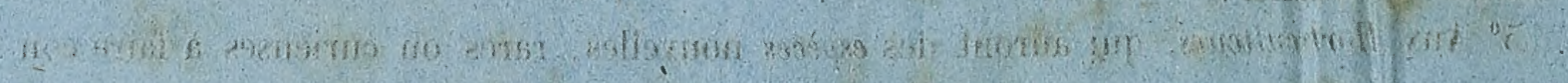

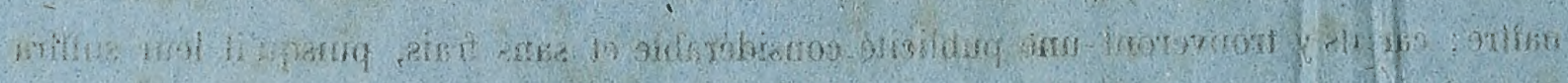

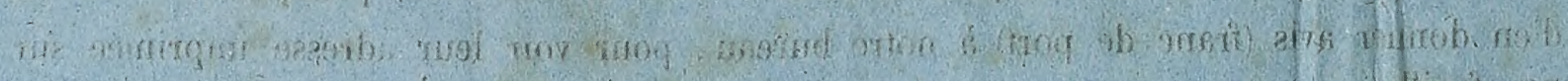

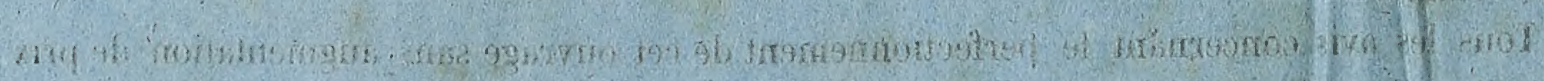

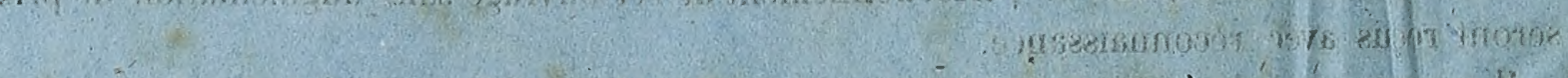

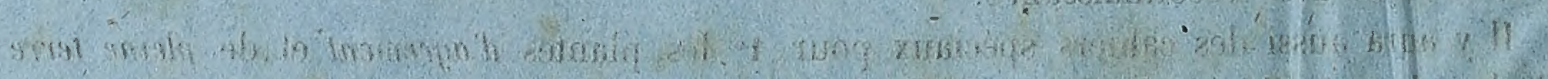

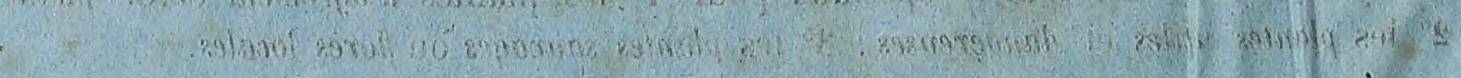

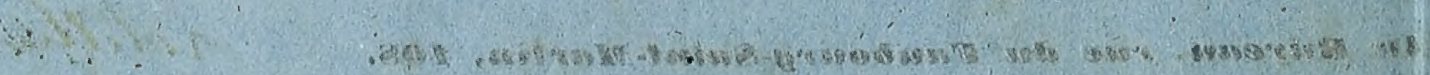

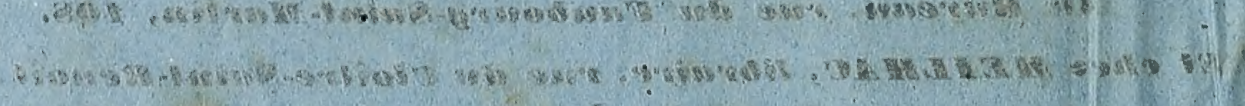




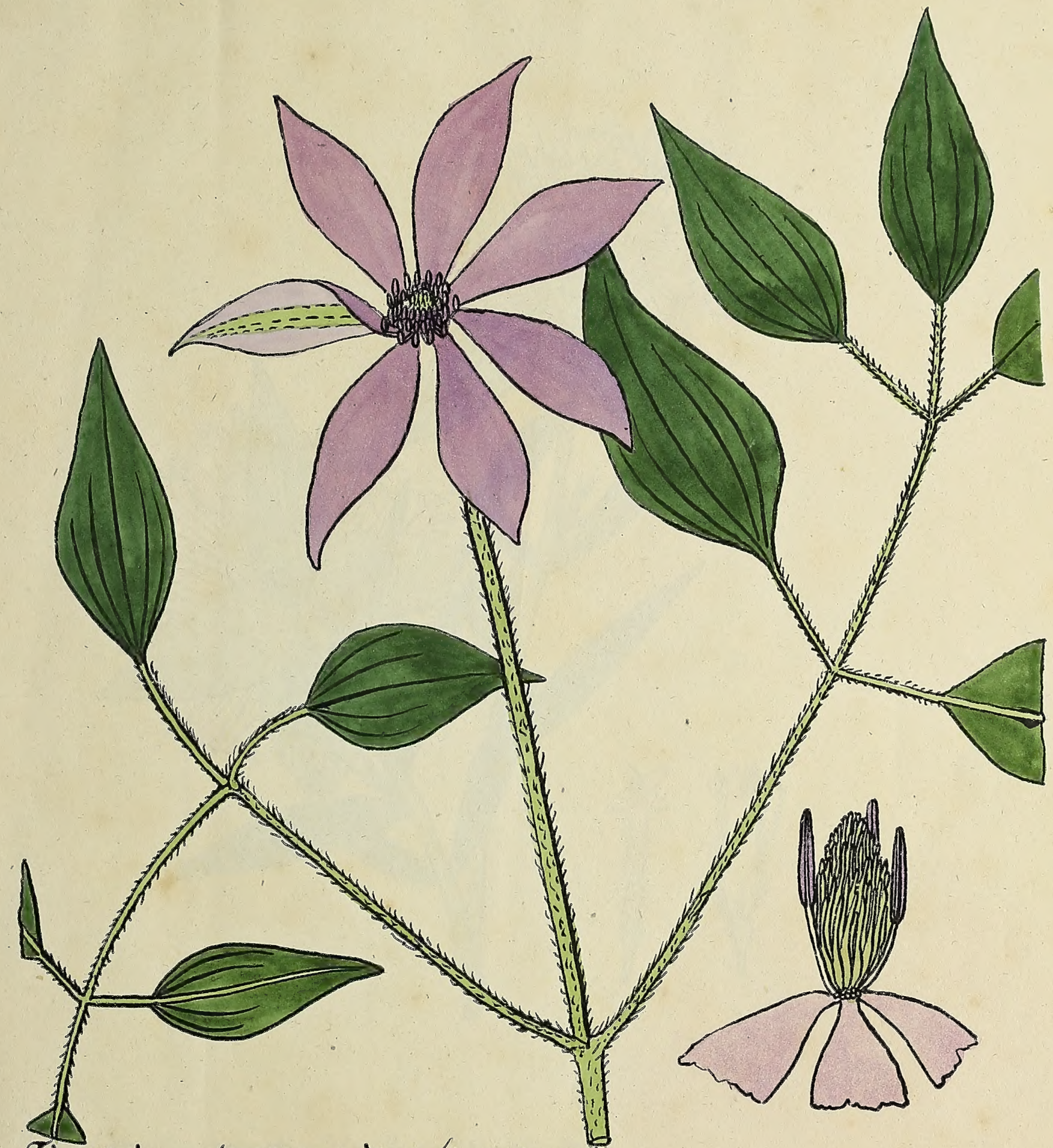

Tige Grimpante J'1: 2 mètred ligneuse velue Feuilles opyrosés, pétiole velu, 5 folwetes ovales pointued vertipate en Dessous Fleurs terminales solitaires lauges de 8 a 10 centimitred. $6: 8$ pétales obovales pointus viofacés

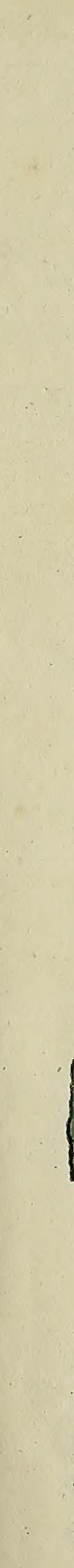

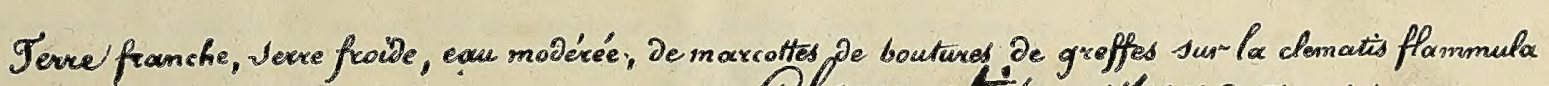
Clematis afurea sieberter 



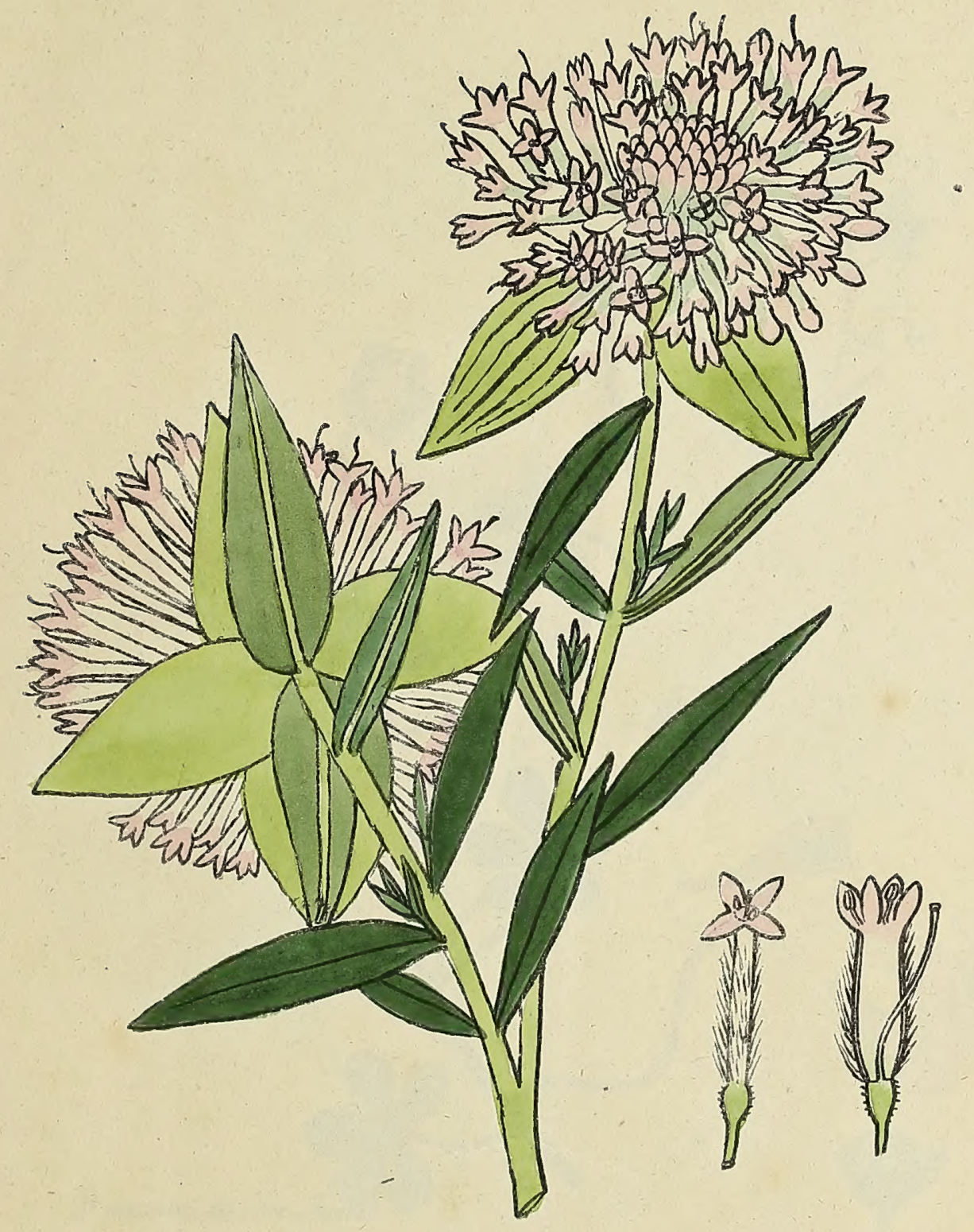

Tige lignense ramende glabre de 60 à 80 centimitres

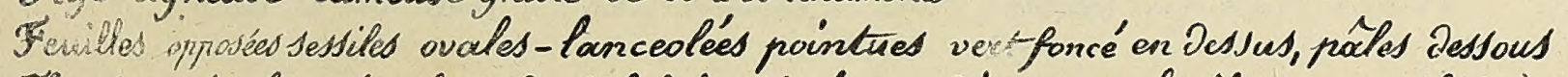

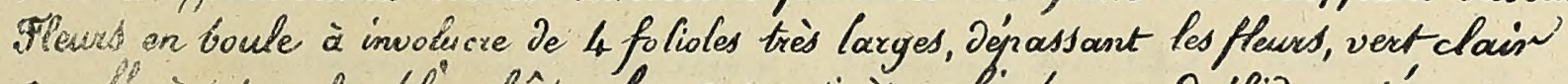
corolle à tube velu blanchâtre, Pong ge 2 centimètres, limbe quadrifide rosé

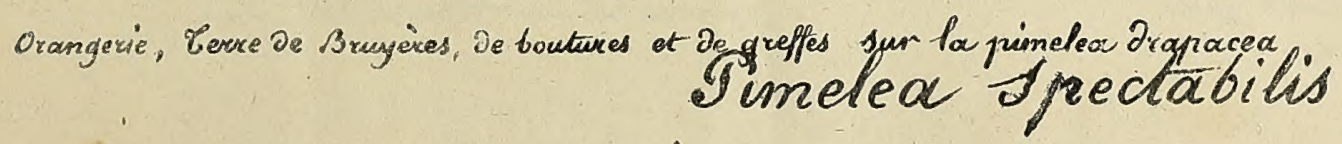




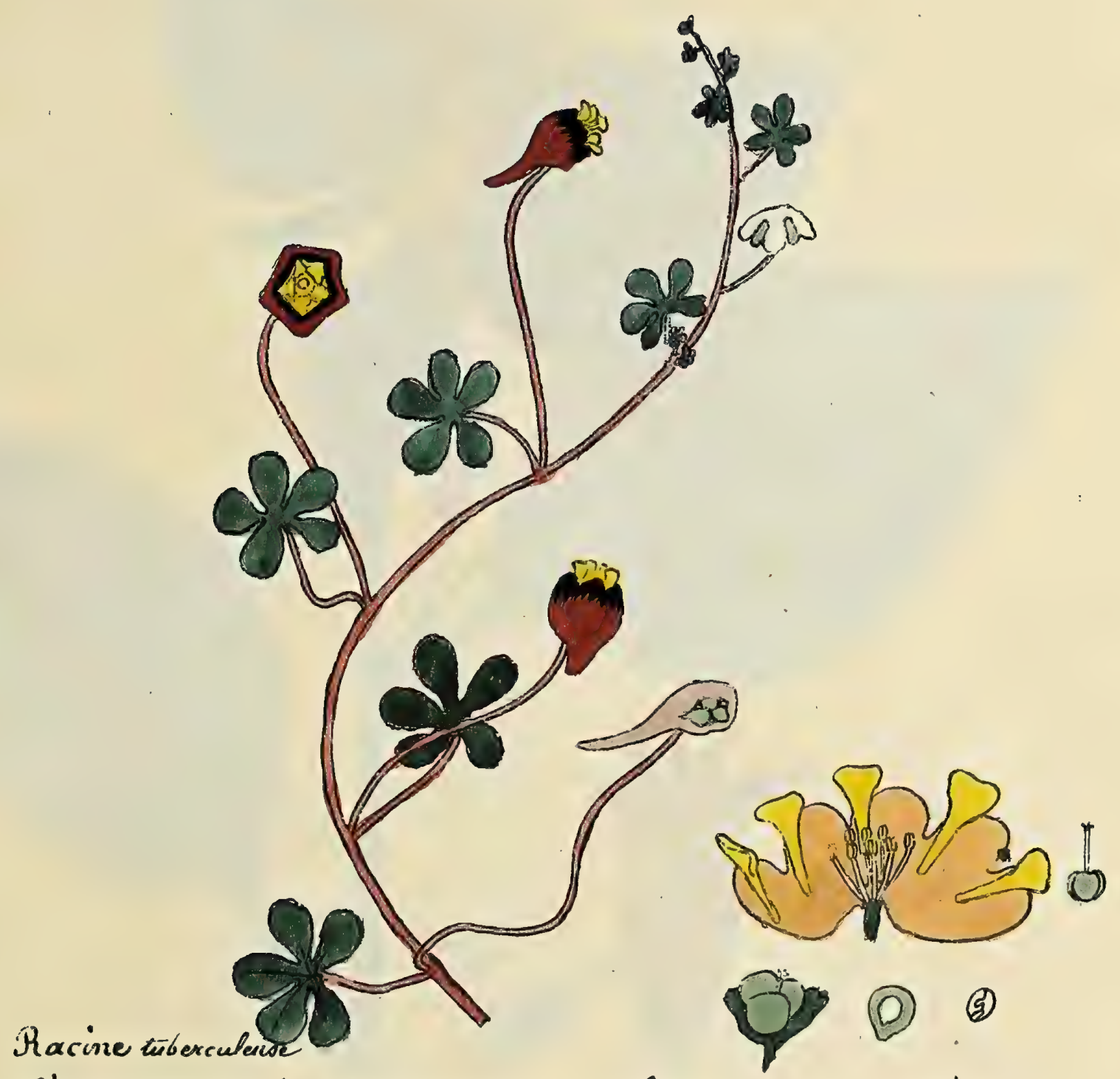

Eiry rampante à base ligneudel, tammes, glabre, de o, Go centinnètres

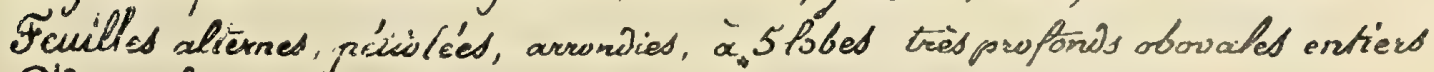
Seloncules axiltivires, solitaired, simples, très Longs, glorbres Calices vernillons, à 5 lobes arrondis, noirs. 5 Sétales régulient jauned.

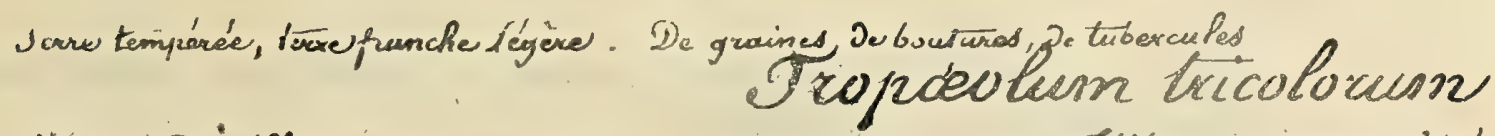

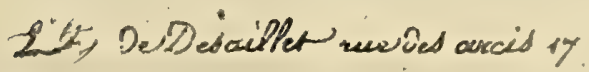
chez Tinisonst ine I moun 45 



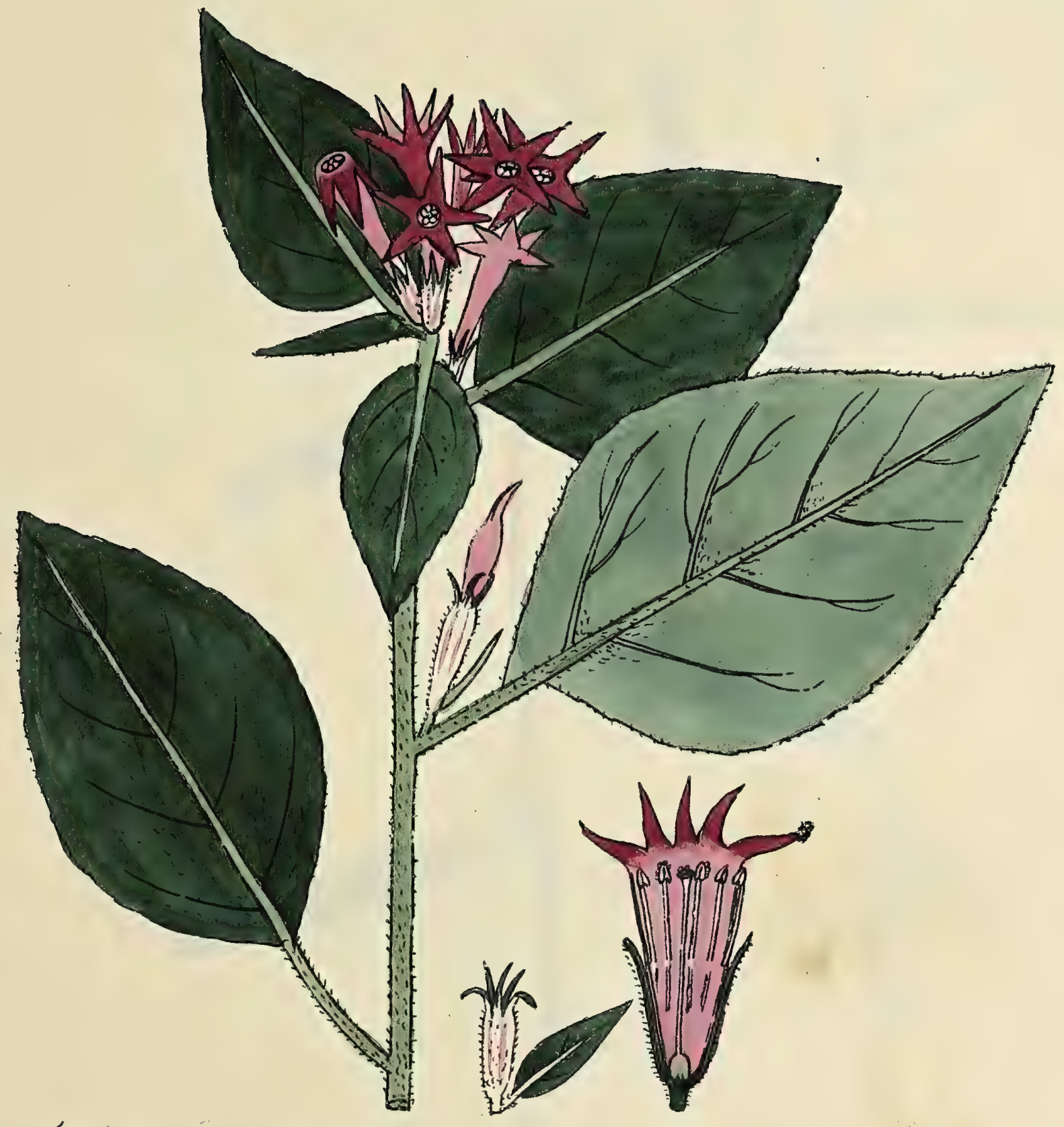

Tige ligneude Jroite rameuse velue J's mètre

Fruilles alternes, pétíflés, ovales amincies acux 2 bouts, velues Jed 2 cîtéd

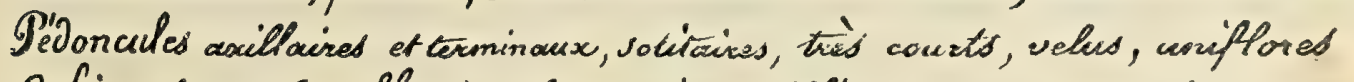

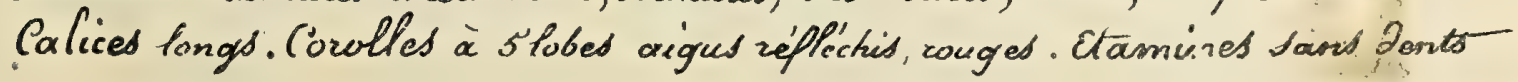

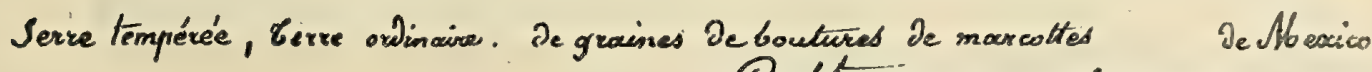
Cestruin roseum kuntos

Imp. Pitt De Desaciter rese Dos axcis oy

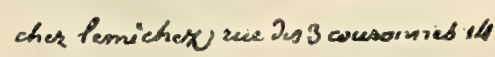


- 


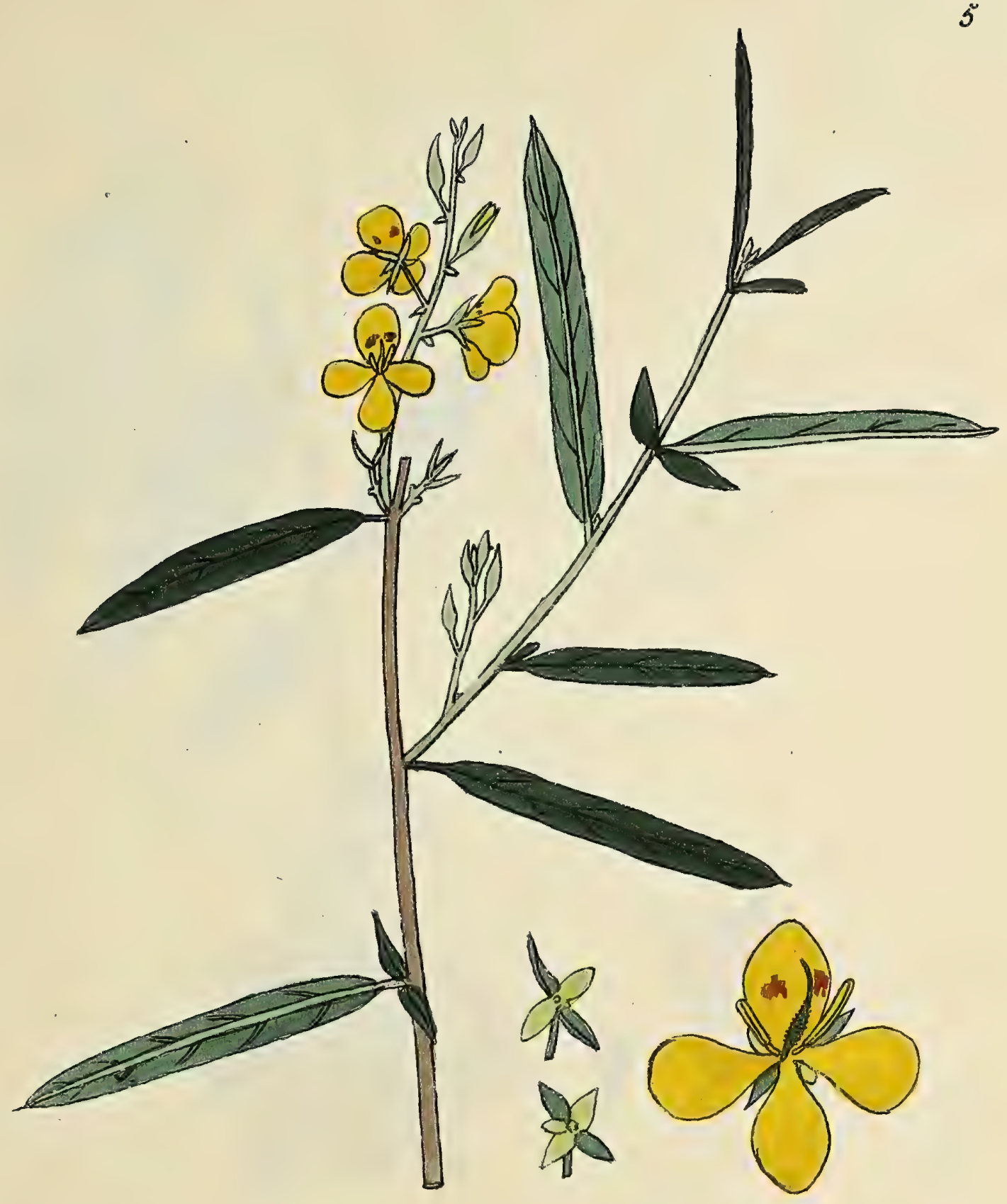

Tige lignouse ranneuse drsite glabre ve $0,30=0,45$ centimetres

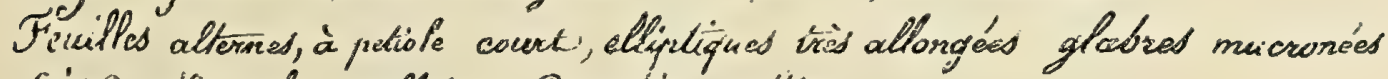
Gris Je pédoncules waillainces; Braciées petîtes

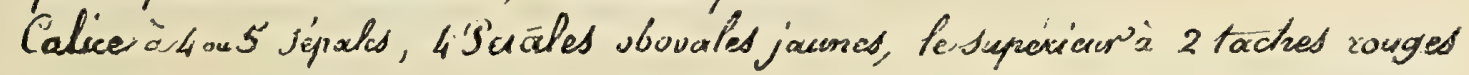

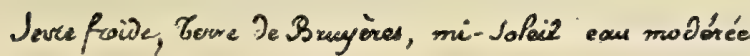
Pabichea punctata 


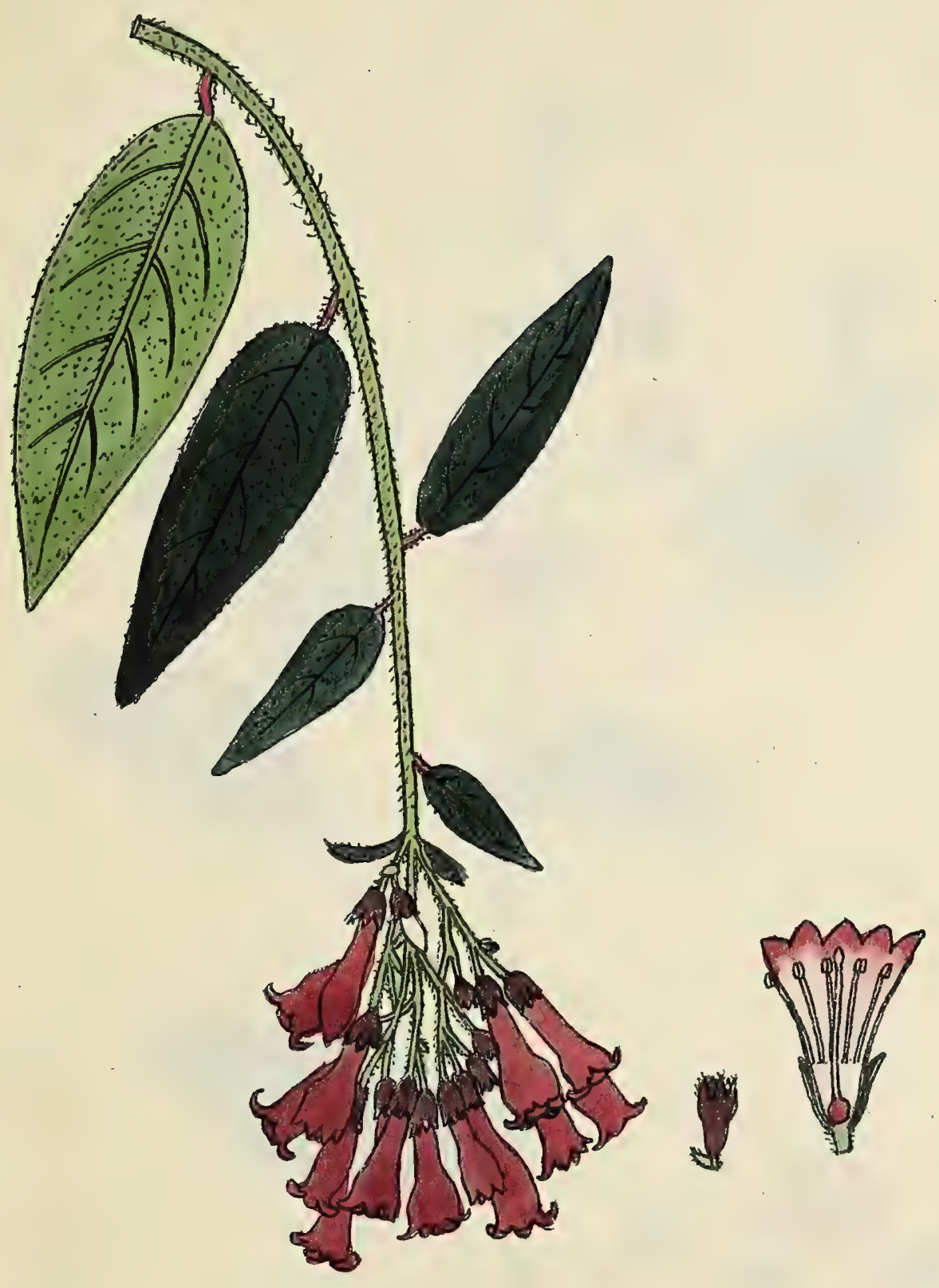

Qige ligneuse 2roite. De 2 à 4 mètres rameaux nombracux ffexibles pendoconts Fewilles alternes, ä pétiole carret rouge velu, ovales pointered. velues suntout on dessous Panicules texminales de pévoncules velus munid souvent de bructées Calices presque glabres, Corolles à 5 jents réfléchies rouge laques

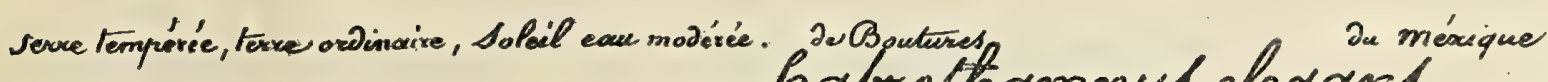
baboltramsus elegans

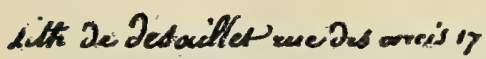
chel Lemiehen we des 3 couronned its 



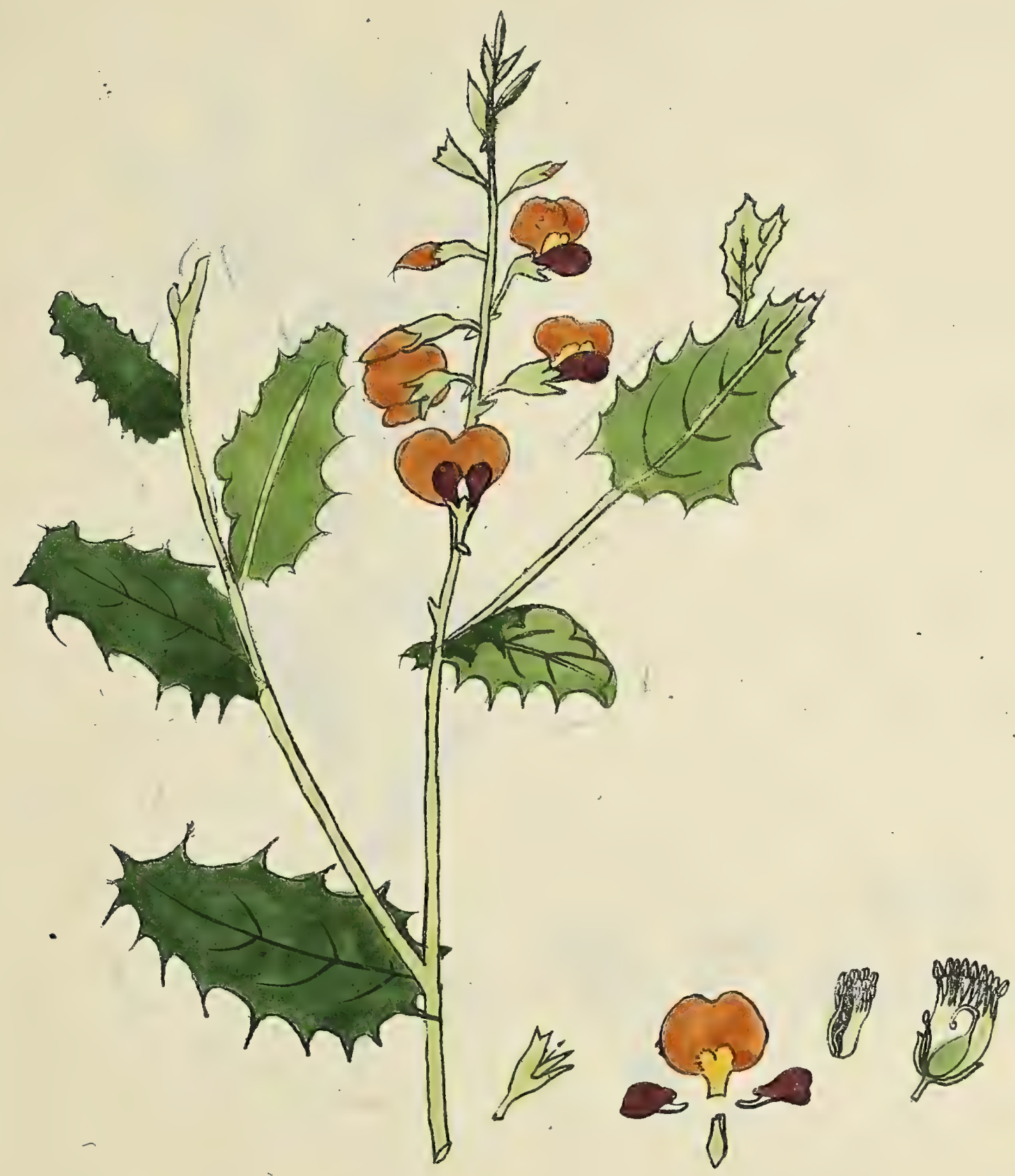

Tige ligneuse varnouse cylindrique haute J't mitre, Jroite glabre

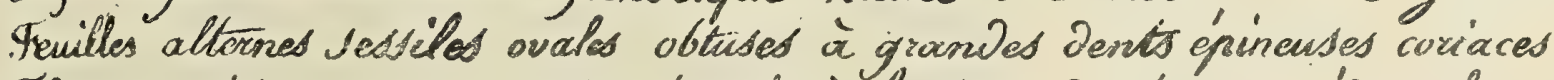

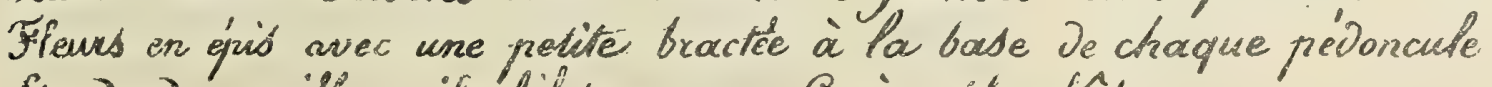
Elendard vermillon vif, Atiles powgreses, Carène blanchâtre

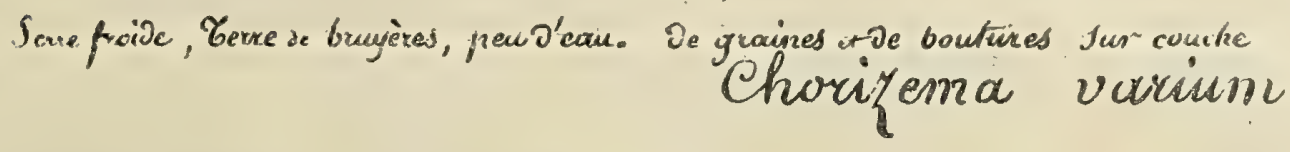

Imp Iit Desaille, llopis rese Des axcis ny 



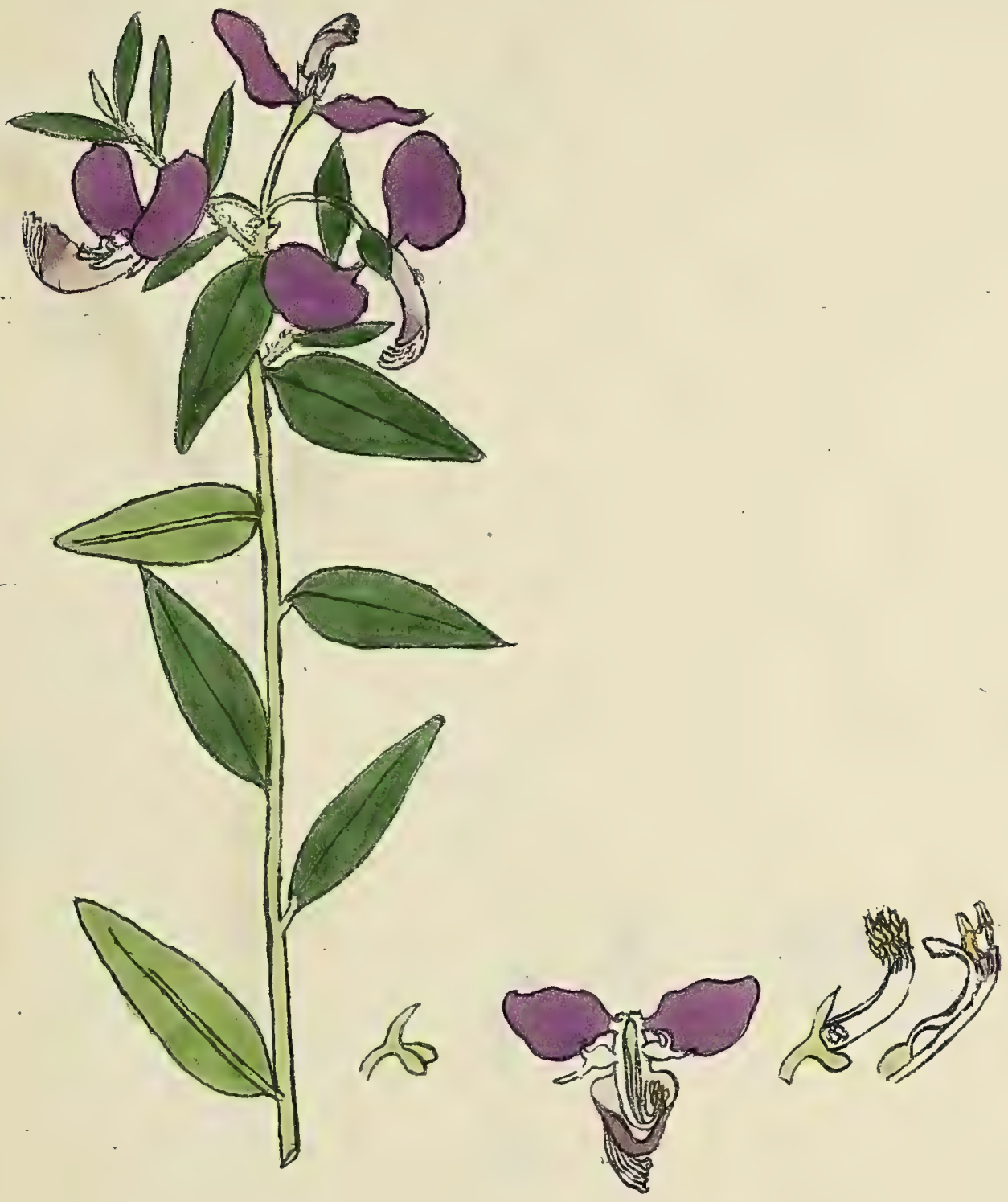

Tige lignause rumense $\partial^{\prime} 1$ mètre. Rameaux cylininiques velis Fevilles alternices un peu petiolées persistantes ylavres

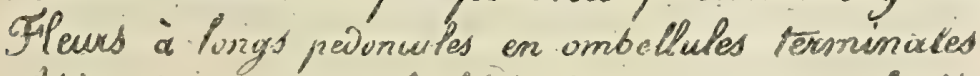

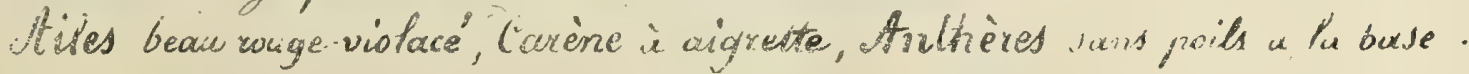

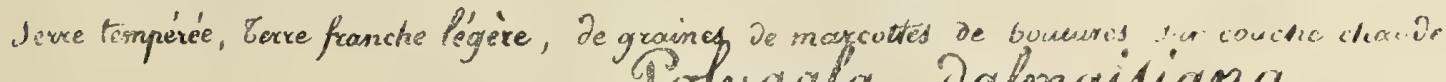
Polygala Dalmaisiana an Jidin a'kivier ause chanyss Elysées 



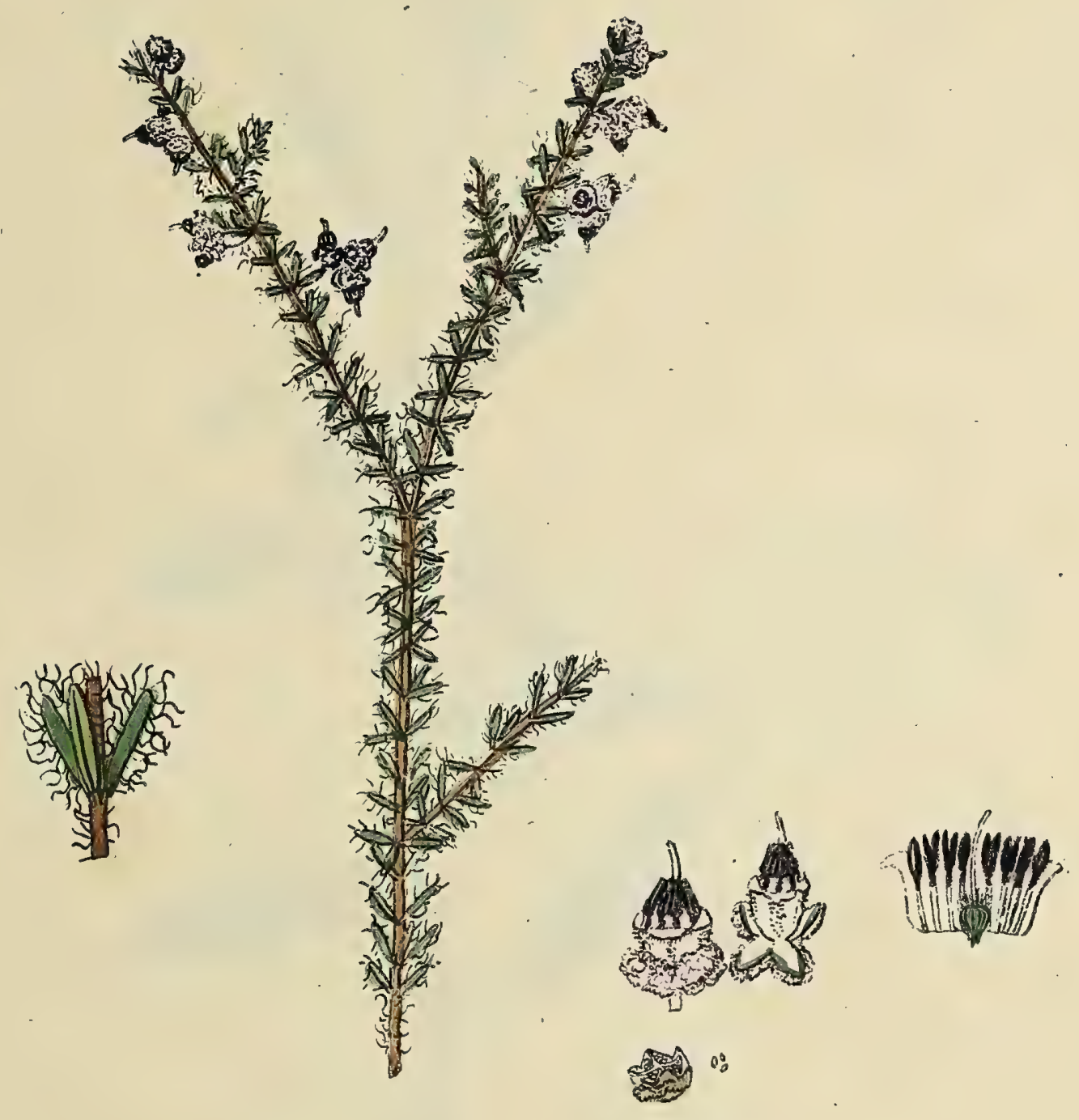

Sigicines chovelues

Tige lignende arrondie rancude groilue tougeâtre de 0 , 4 rention.

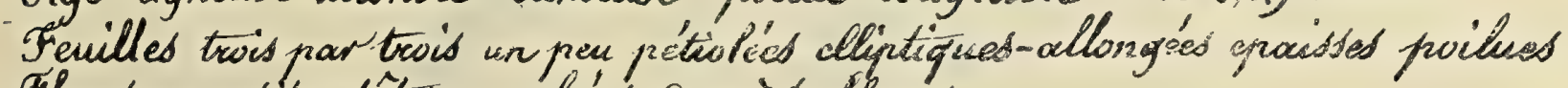
Fleurt en petútes tôtes zenchíes de 2 à 4 fleurs Corlices tres velus, Corolle pubescente er cloche P'egalarnt, Staininzed excluded

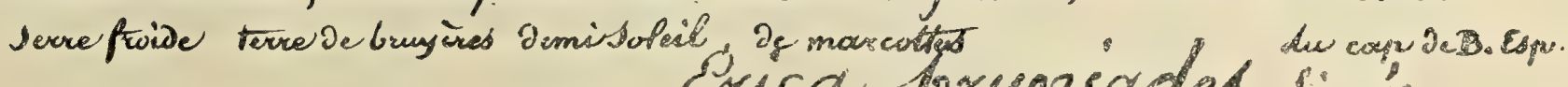
creca bunncades binné

Imp, fita, De Dedailtet, llopis, we des orris of

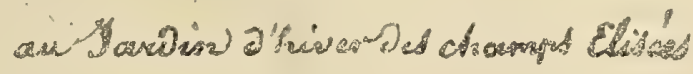





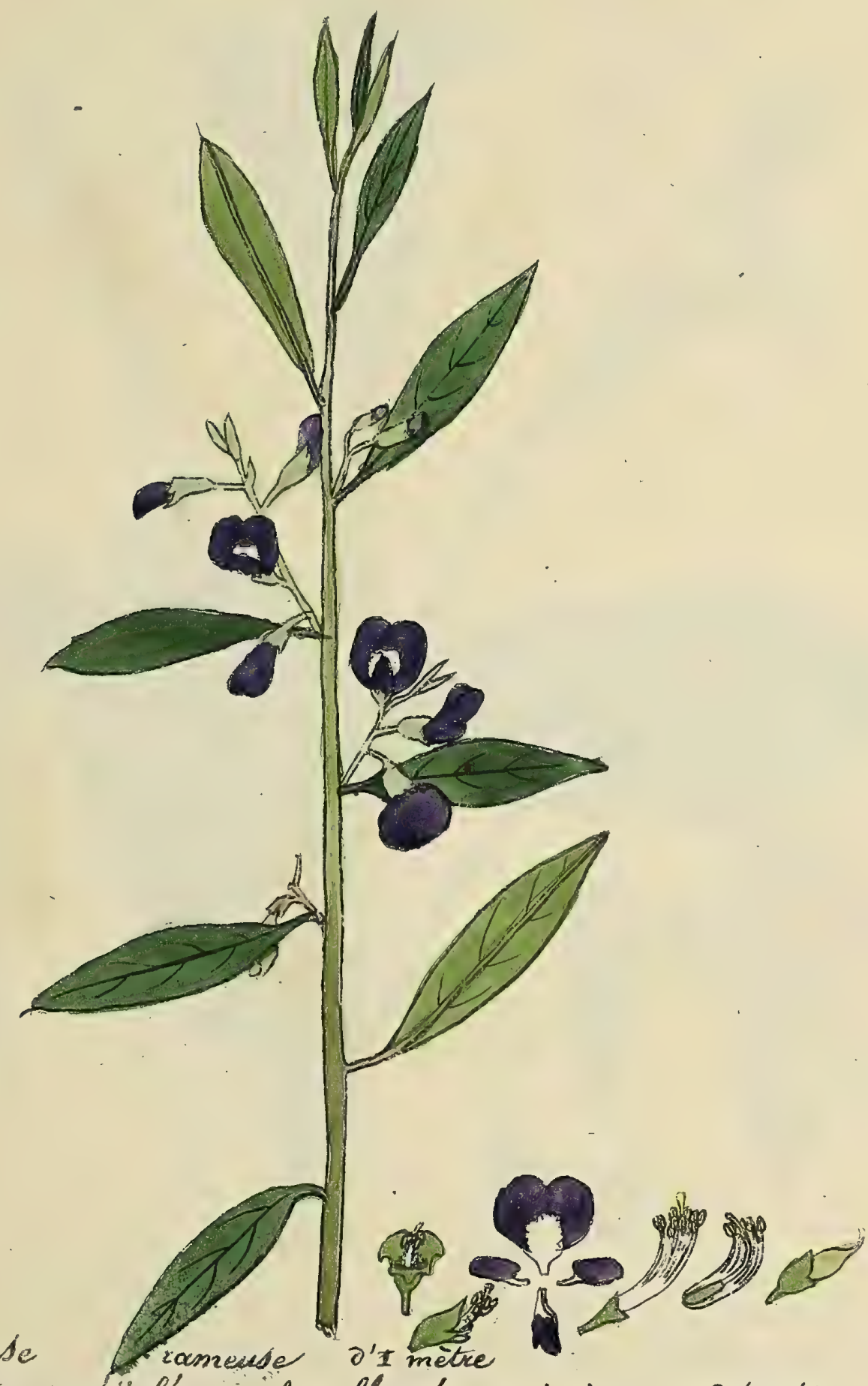

10

Tige lignense

Ficwilles altermes, pétiolées, ovales allongées, amincies aura 2 bouts

Eris axillacires, De 3 à 5 pleurs pétio lées, foliolés an bout

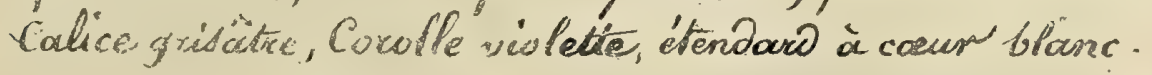

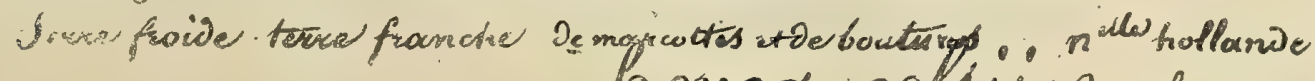

boved cels ï Bomplexno

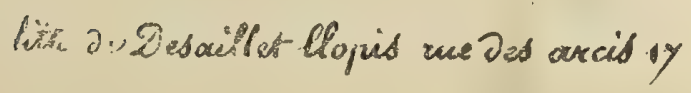

cher moirtine rue Jesbourguig, und gy 



$$
x^{4}
$$





$$
2
$$





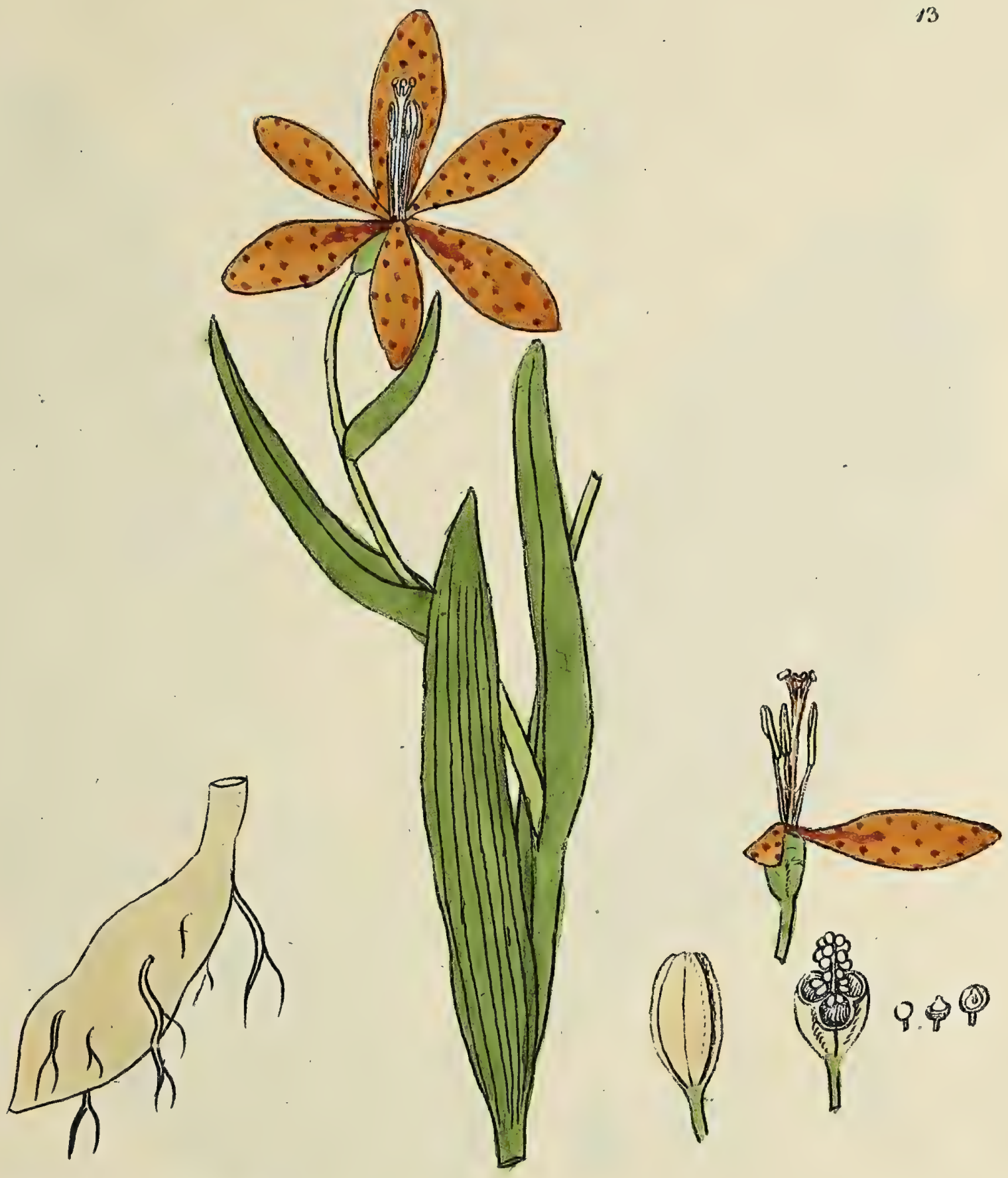

Racine in tabercules

Tige compreimée bifurquée De o, 45 centimìtres Freuilles en éfiée alternes Jessiles embrustsaniés glabres à newures parallietes Peidoncules terminaux Jolitaires

Fleurs Saframées tachetees de rouge

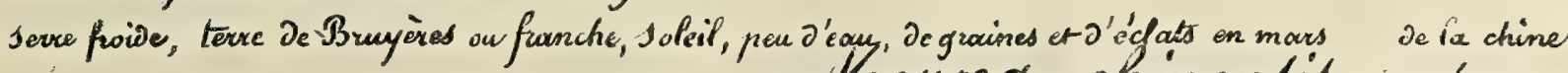
thorced chinemsis ininberg

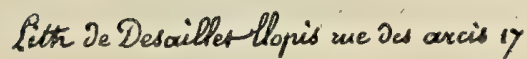


, 


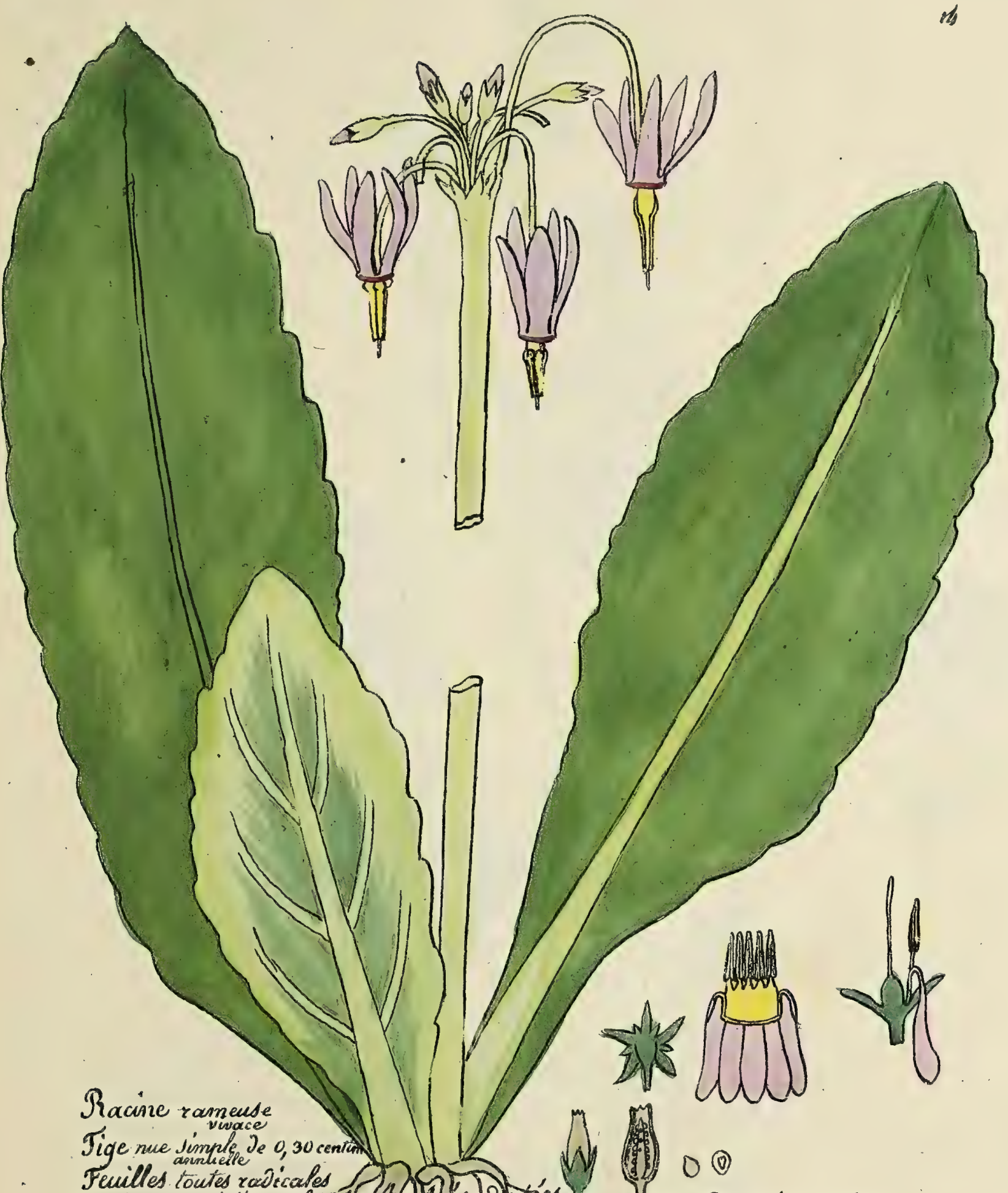

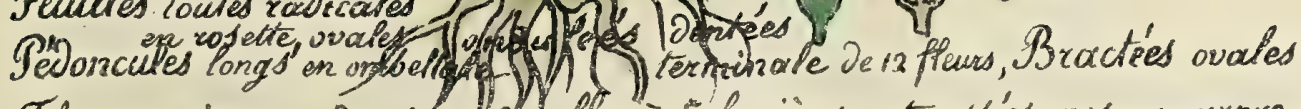

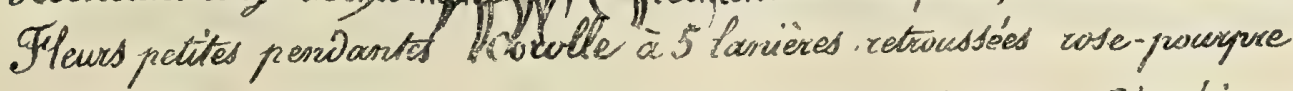

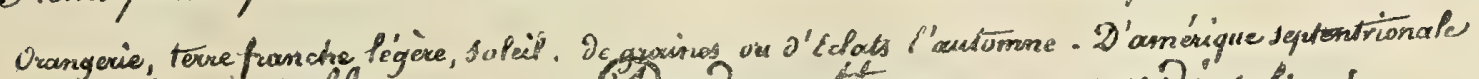

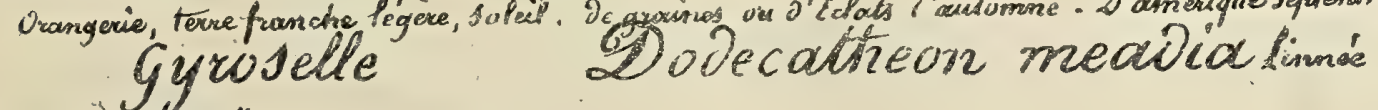

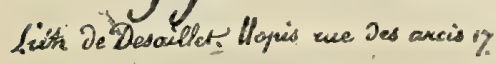




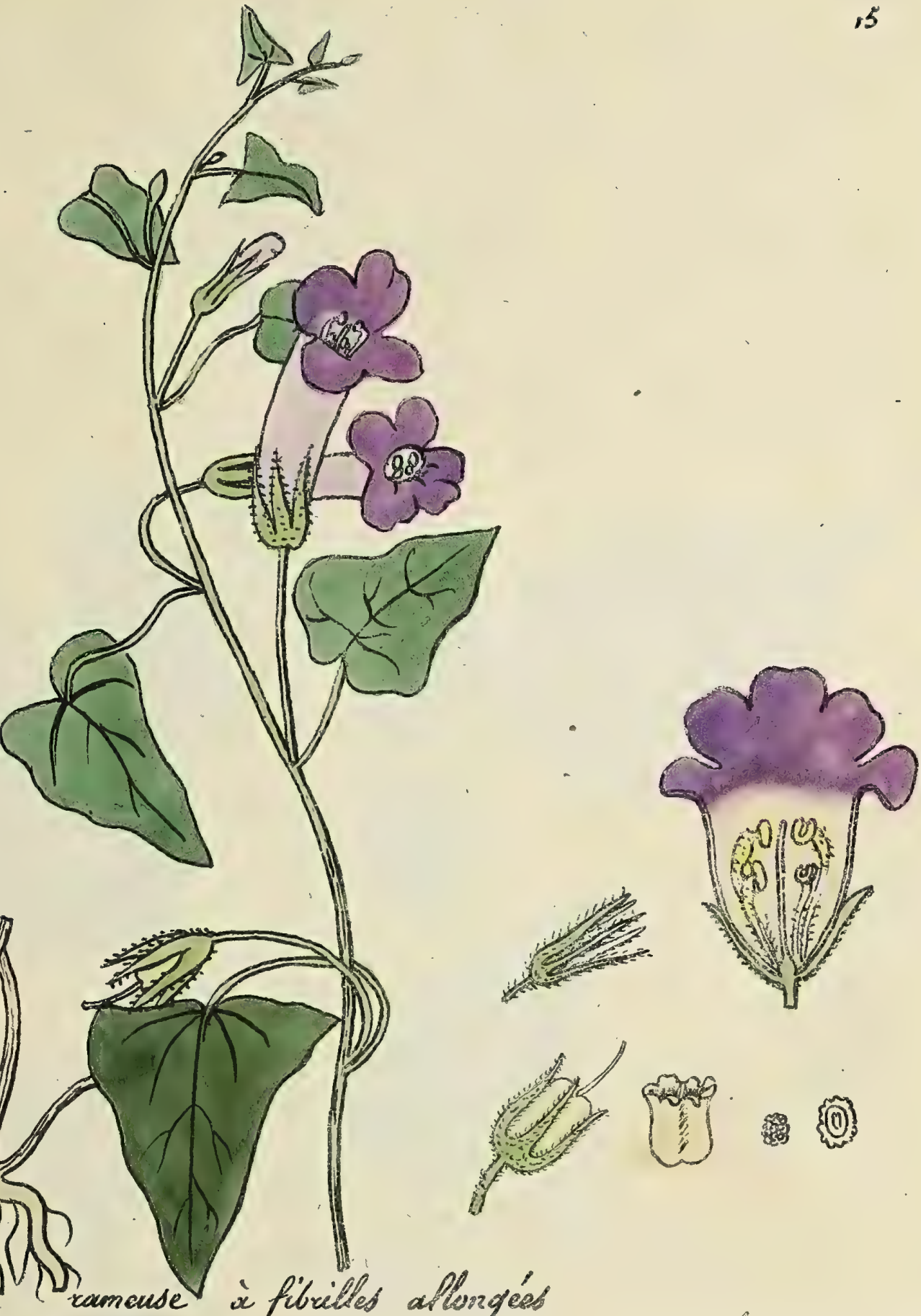

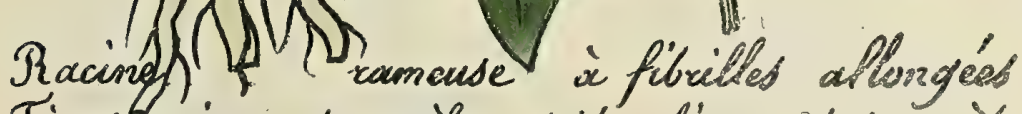

Tiges grimpiantes grèles striées lisses a's à 2 mètres rameuses lignenses à la base Fevilles alternes pétiolés en ciecur nointur on en hache

Sídoncules axillaires solitaires égalant les pétioled

Calice à 5 lanières étruites acigues velues Corofle à gorge ouverte, limberviolet Capsule glabre mince Jéche

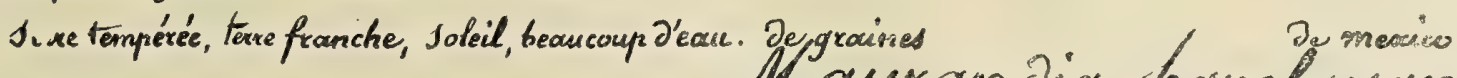
Mawerndia barclayand linat. 


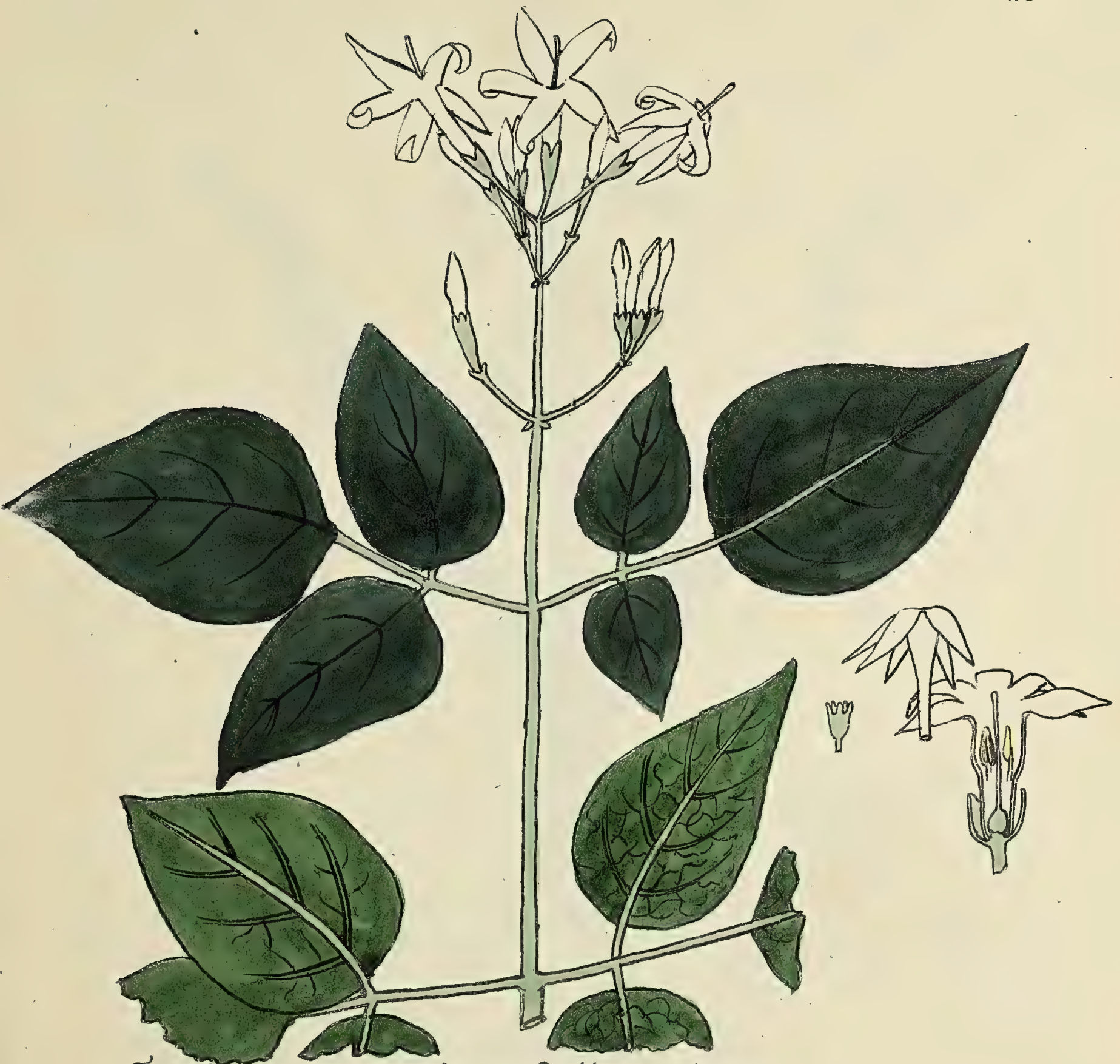

Tige ligneuse D's métre à 1,50 owite en arbribsexw

Fenilled opyosées à a folibles petiolées ovoiles pointues glabres persistantes coriaces Sivincules axiltaires of terminaux Jivisés en 3

Calice proche à 5 dents obtuses, Corolle flanche à 5 lanièred aigues, odeur suave Orangeric terrefanche, solcil, de graines de marcottes Je rejetons
Yabminum arocicum famé
- Des agored

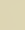




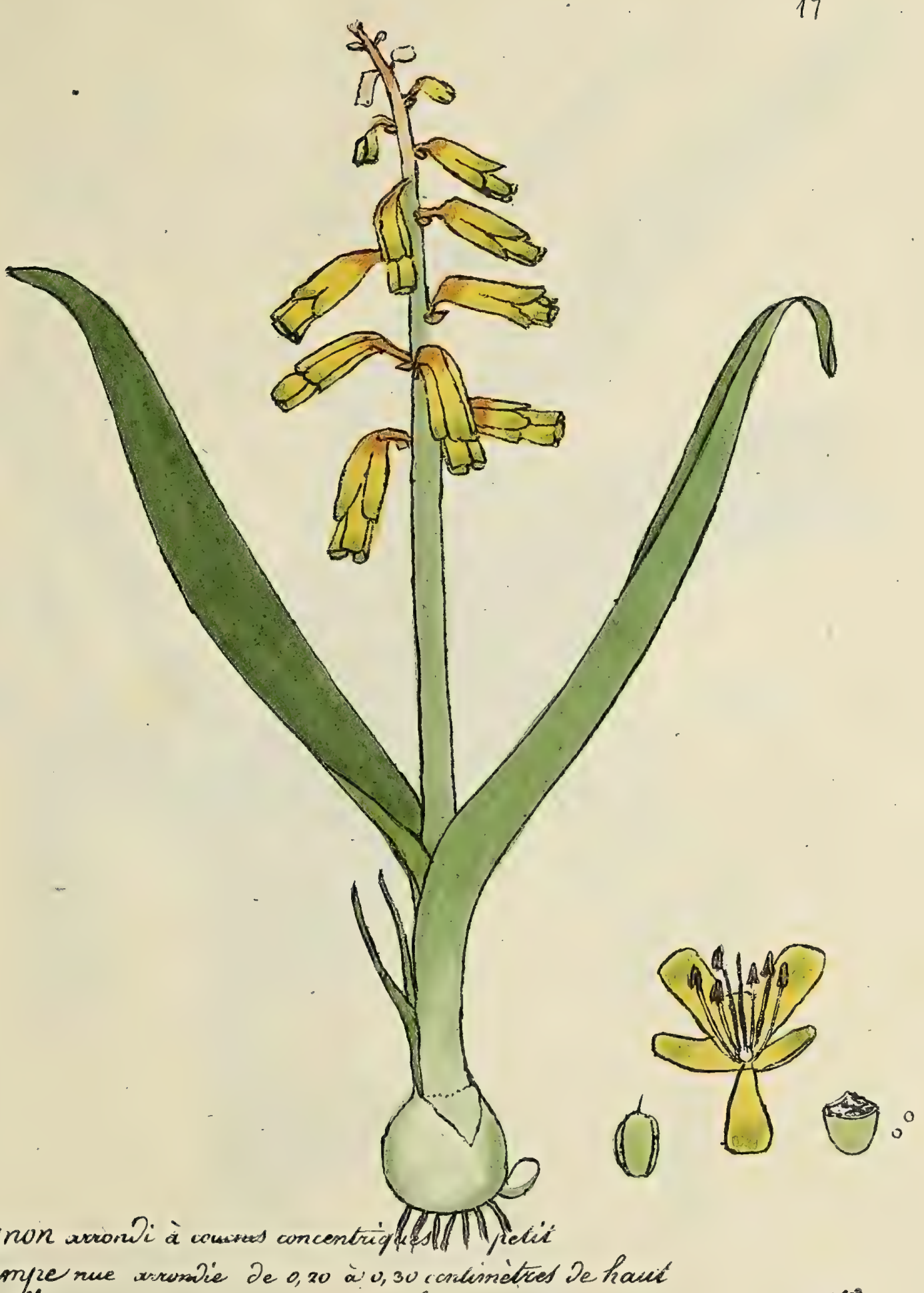

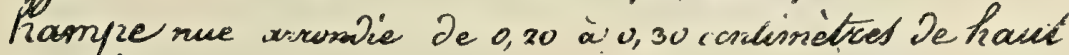

Feniltes enguinant ta hampe on large courwie in nevoves paralli's

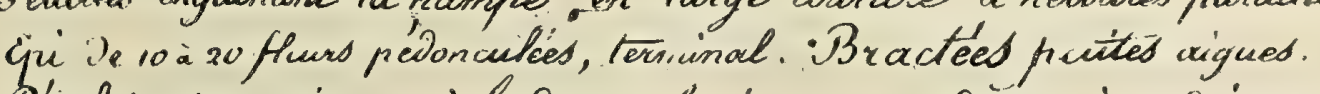

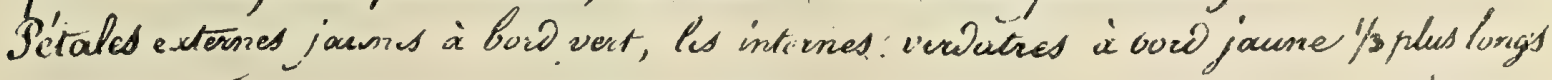

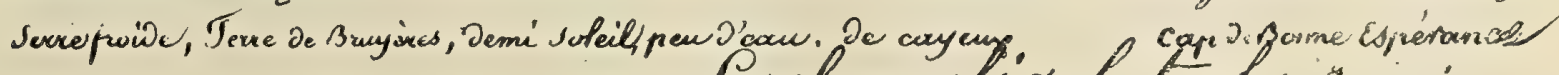

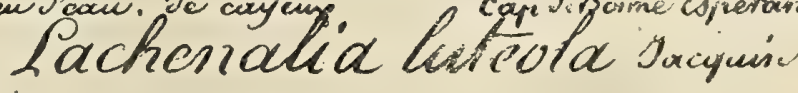




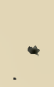




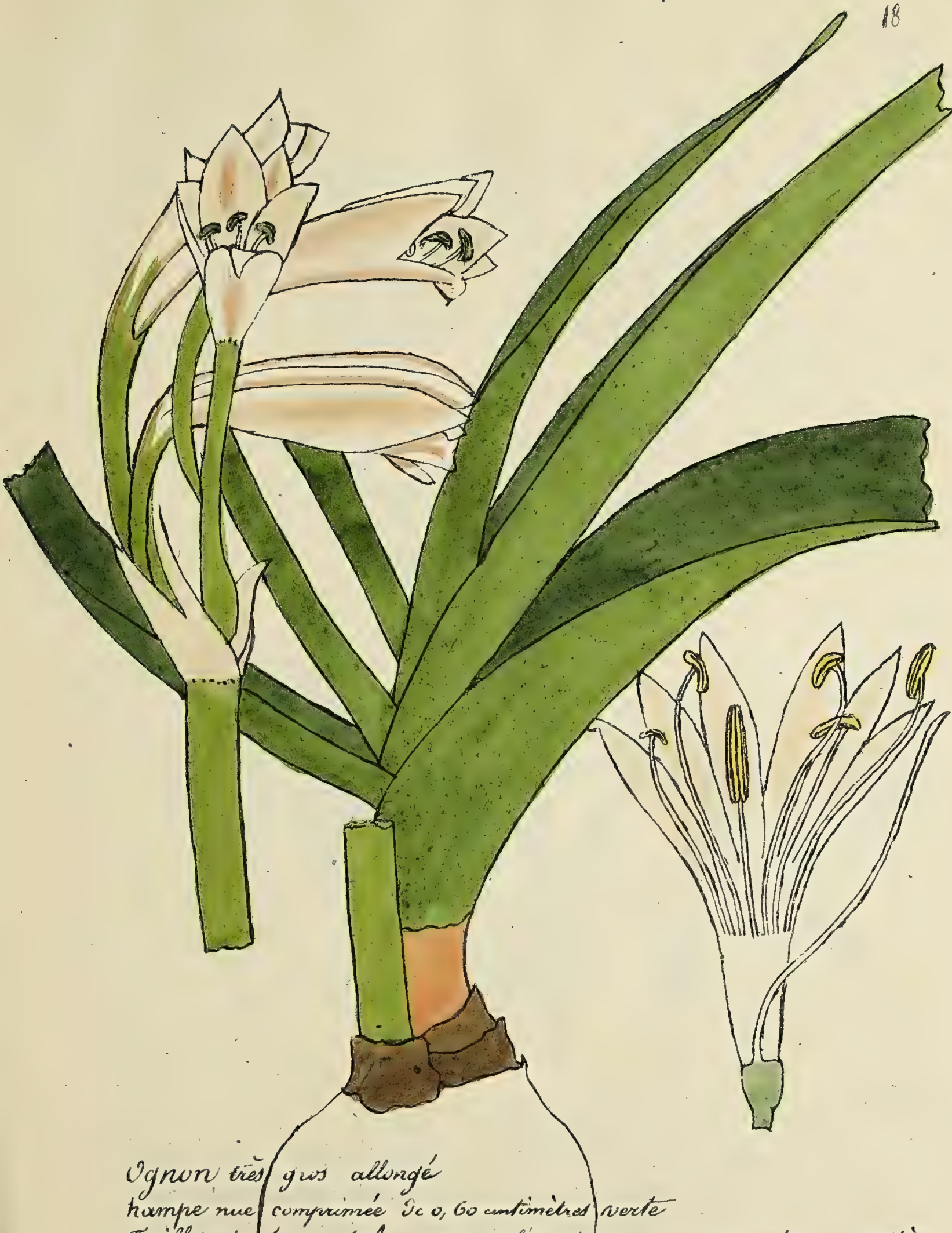

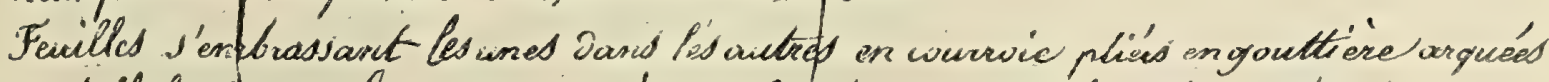

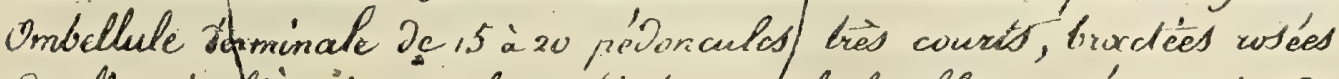

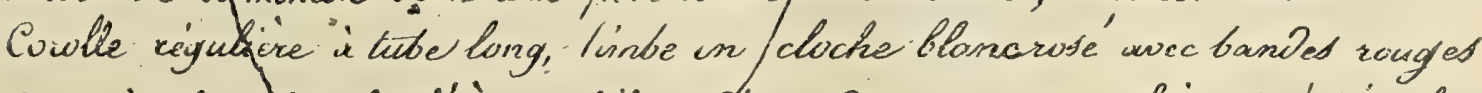

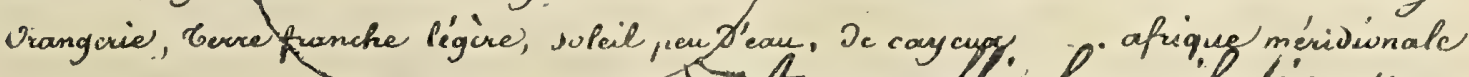
(1) 



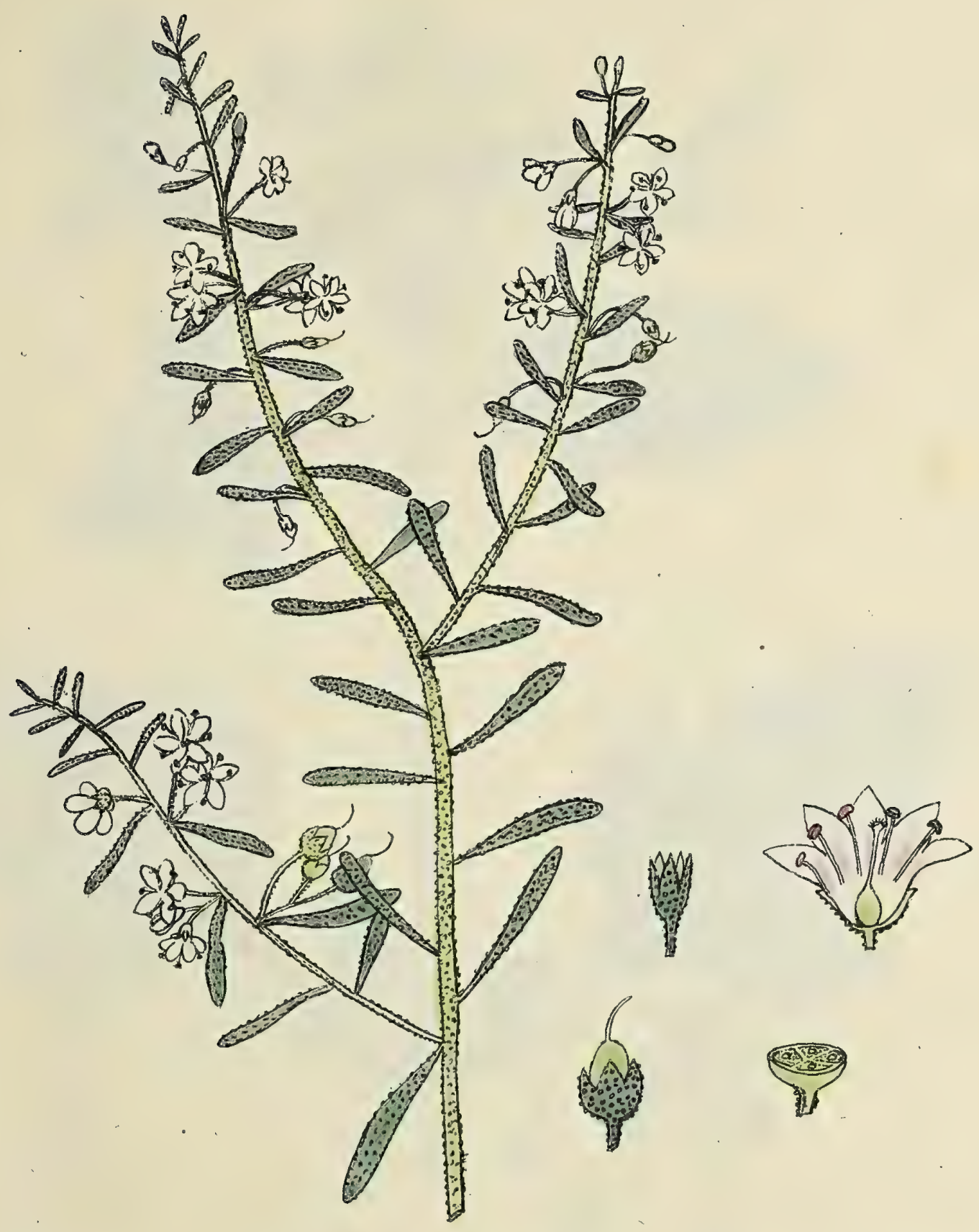

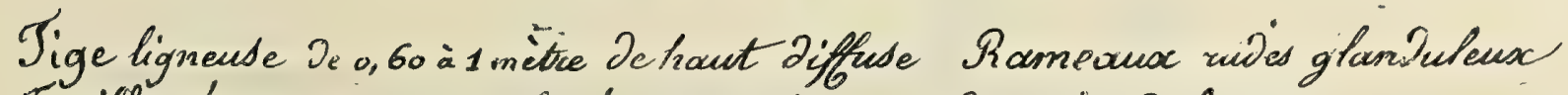

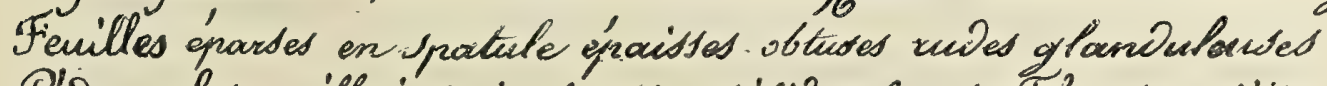

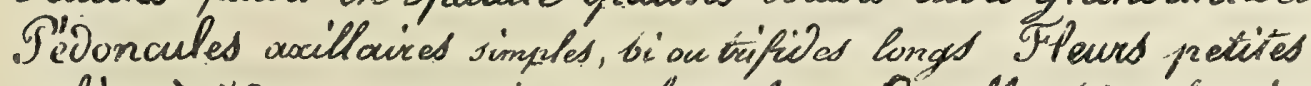
calices à 5 dents un preu acigues, glanouleux, Pardlles blanches inodured

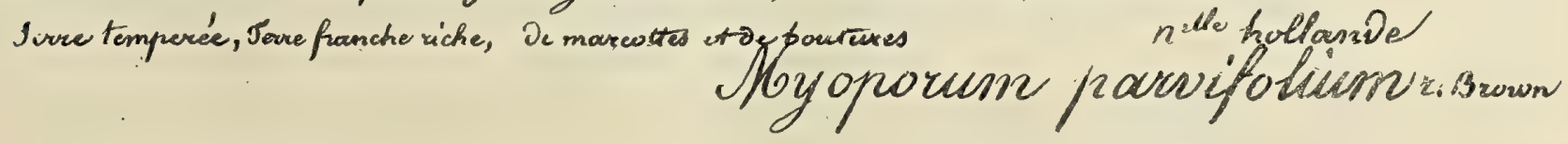

Rith De Desoiller. Hlopis rue Des arcis sy 


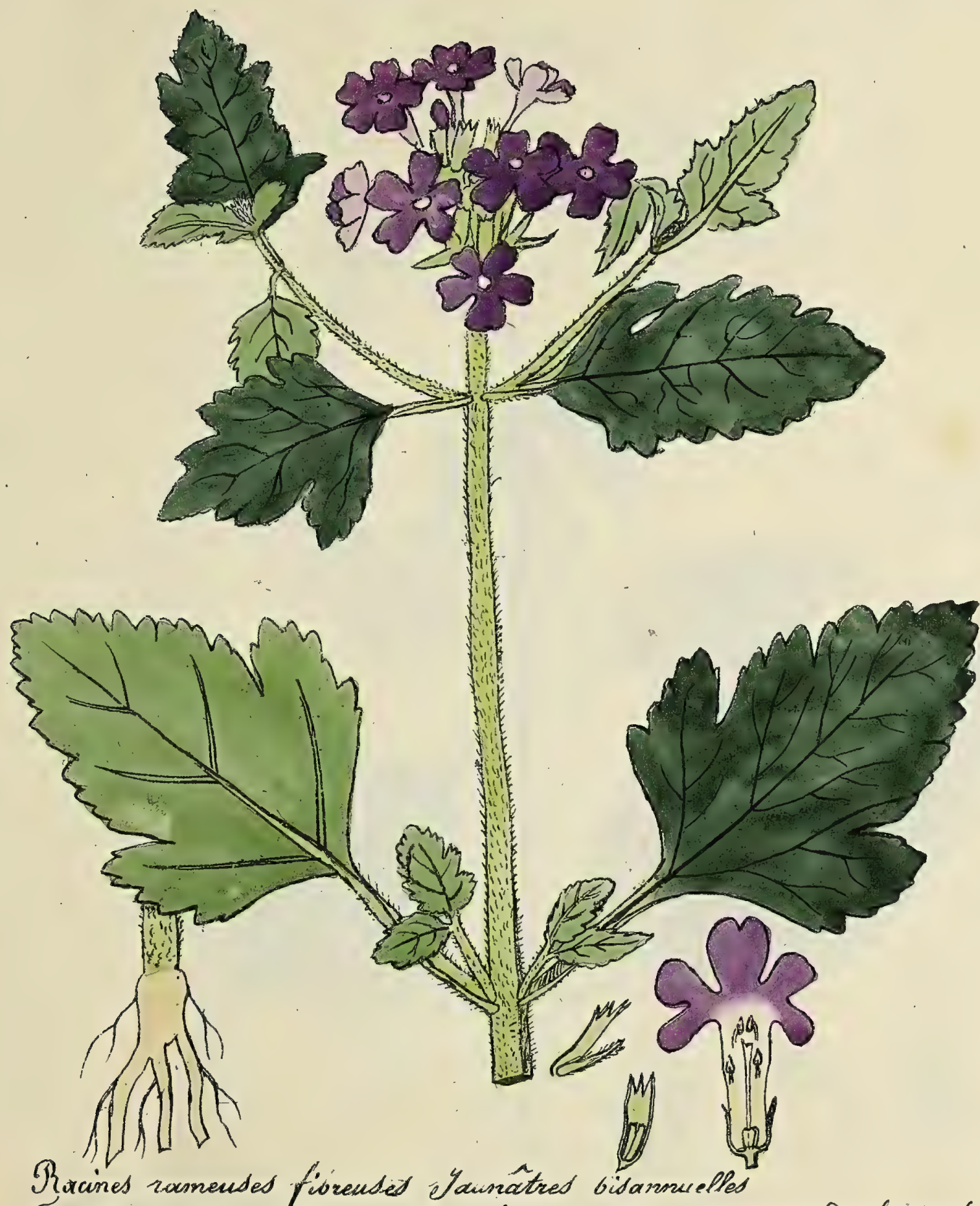

Tige Dwite un couchée puis reDressée houte de 0,30 rent. we herbacé Fevilles opyusées pétiolées ovales à 3 Pobes ou pinnatifides Deritées ylabres quis terminawa solitaires Laches, Bractées suveites. longues veluas Flewns petites rasices verts curolles poinfures

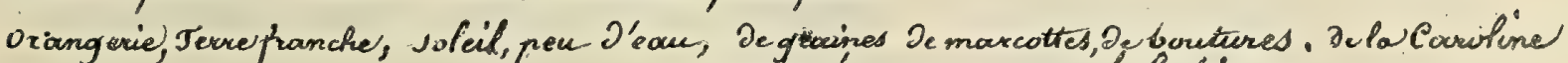
verberza dubletic yacquin 



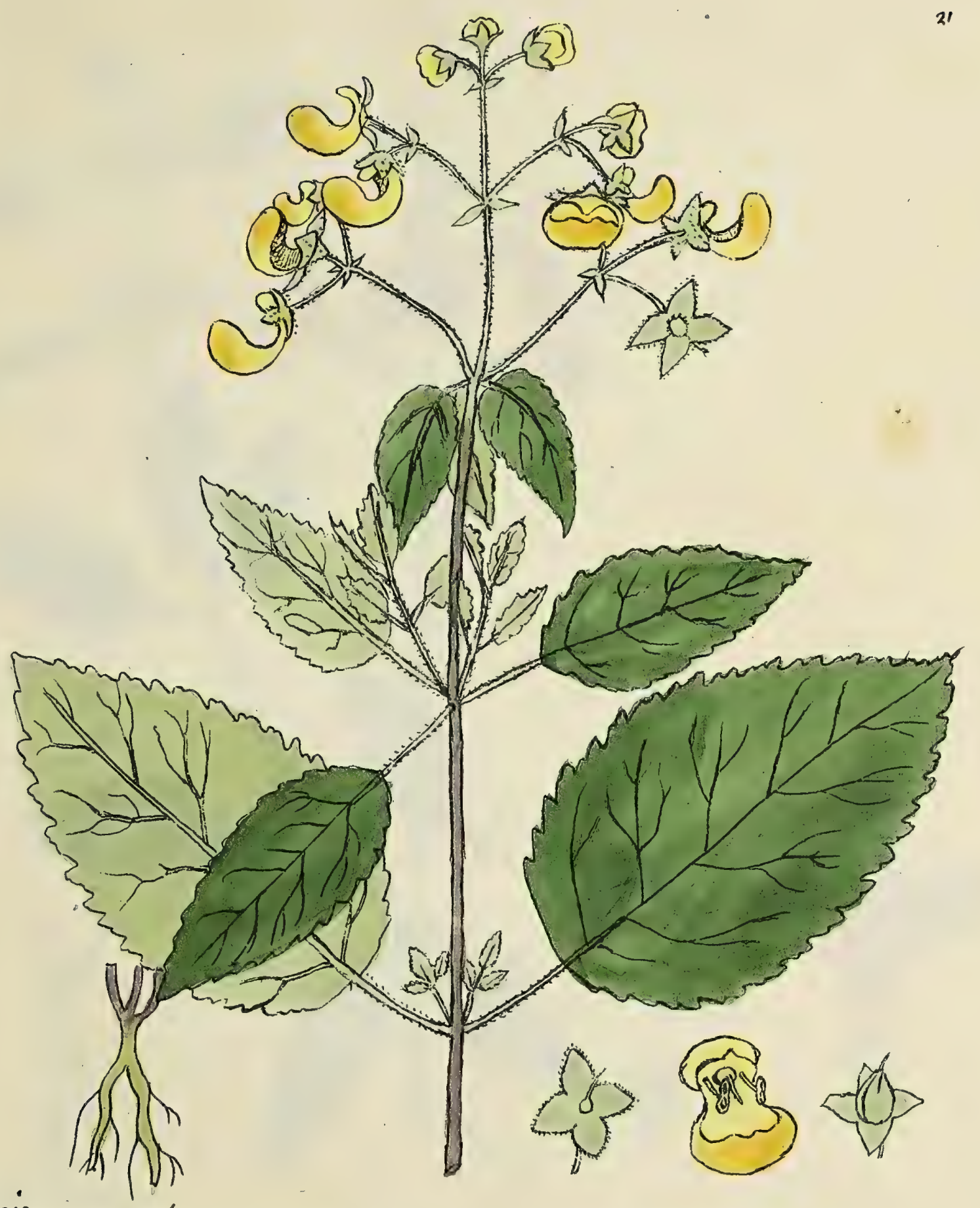

Racine rameube

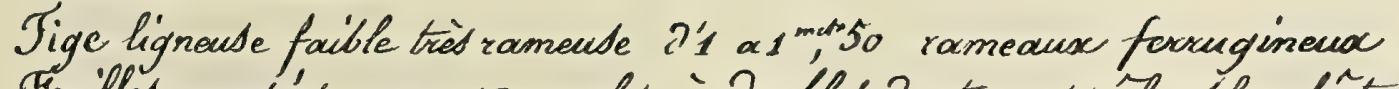

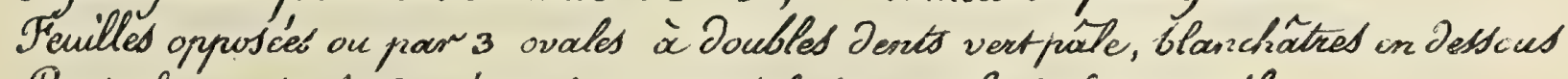
Panicule terminale de pédoncules bi un tricholomes glanduleux poilus

cowtles jaune pâte ì levire imferieure triple de la suprérieure et plus foncée

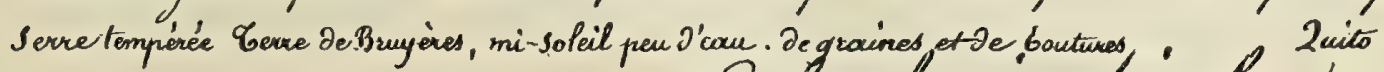

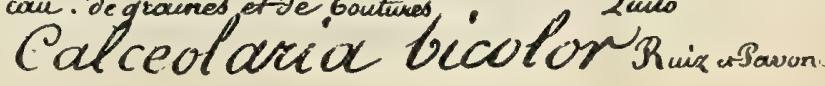





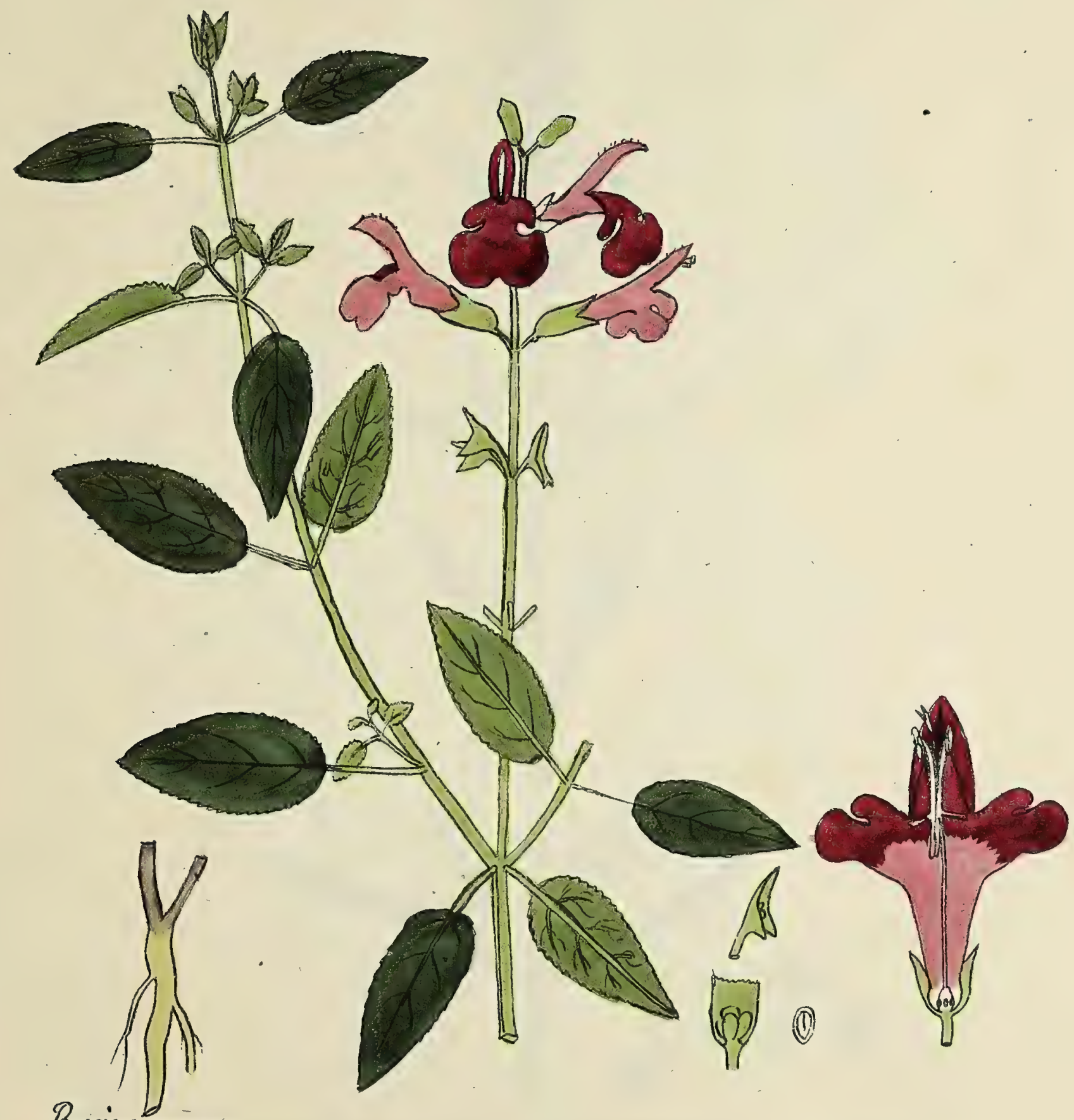

Racine ramente

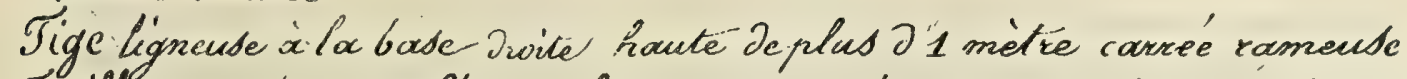
Fevilles opposées petiolées ovales aigues Dentées colvinneubed preibidtanted

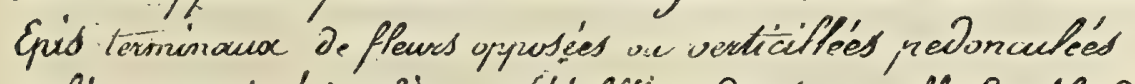

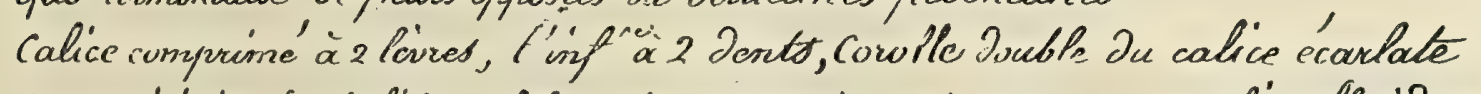

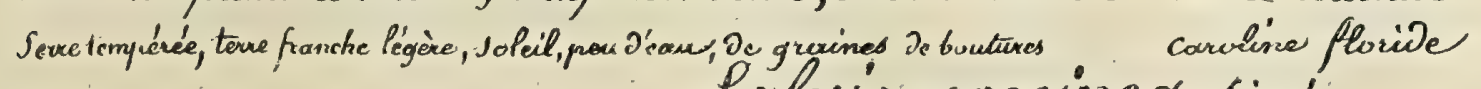
Poblix cocciried timnée 



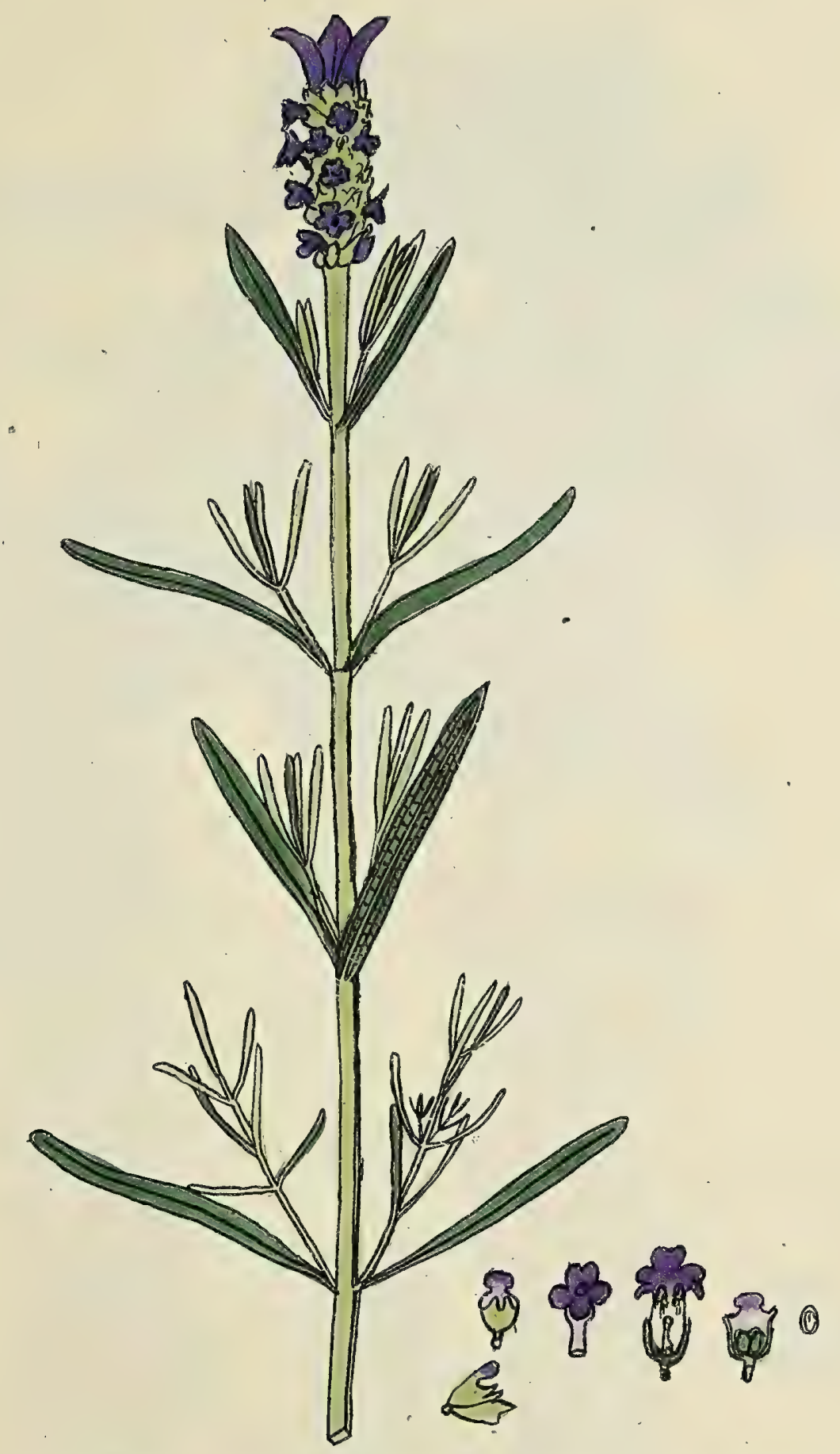

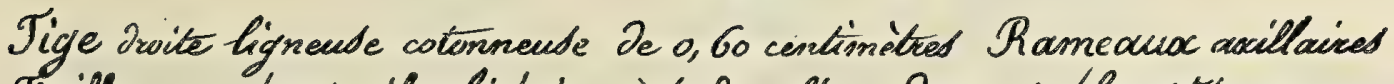

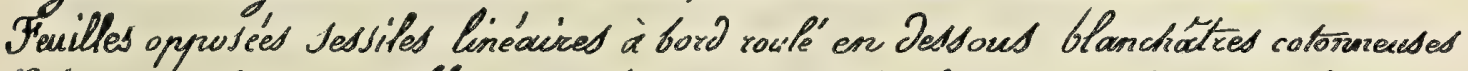

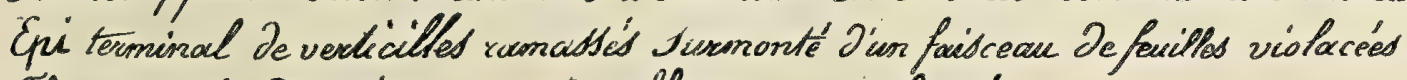
Fleurs sessiles Bractées vectes. Corcolles pouyzre foncé Orangovie, Tene P'égère, Soleil, preu D'eau, De grainess Pewandula jicectidus Sinné 



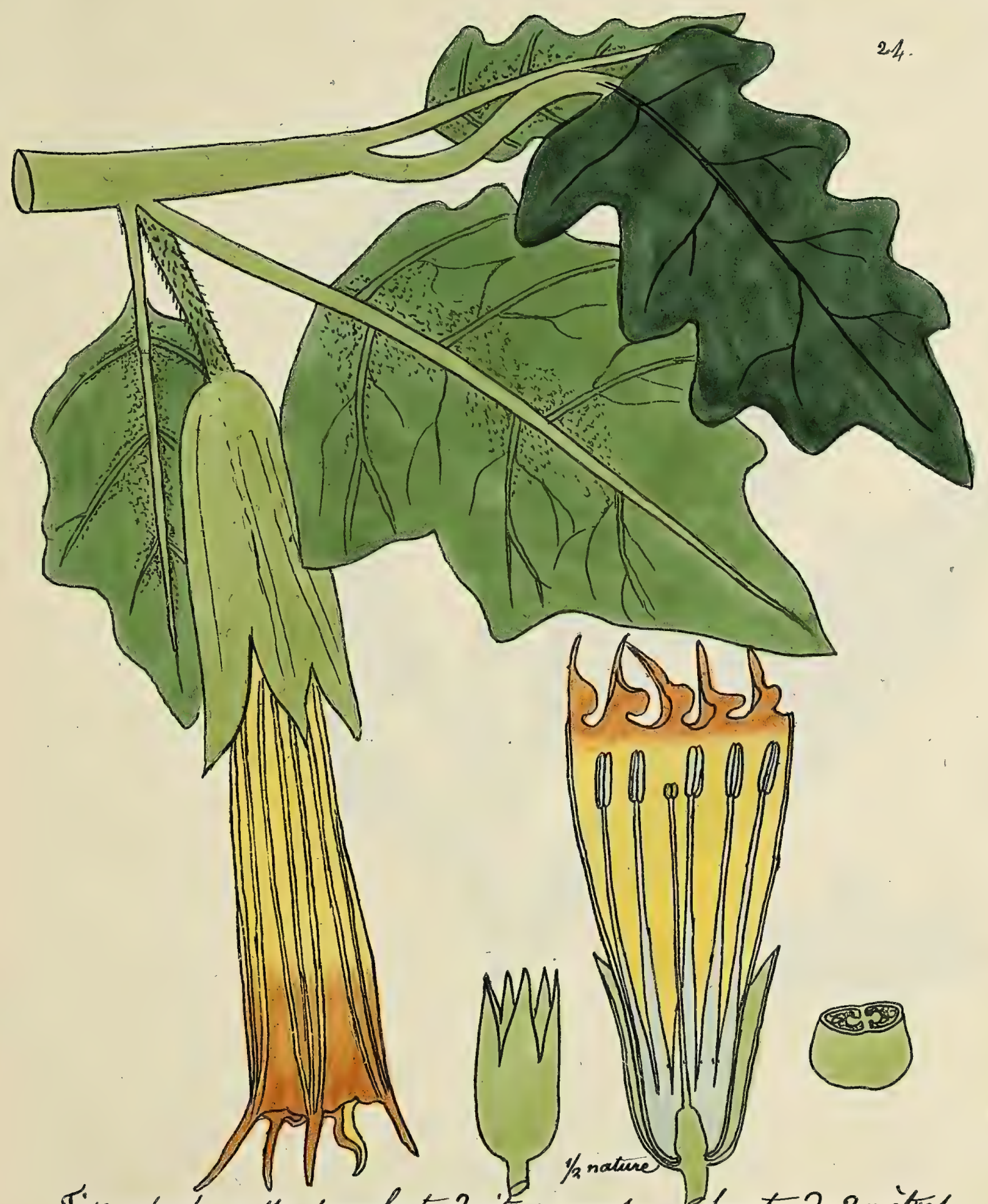

Tige anforée grosse succuleste droite rameuse haute de 2 mètres Teuilles alternes pótislées ovales aigues jinucés dentées pubescentes Sênoncules solitaives accillaices pendants velus

Calice large à Jents sowent sowiés Cordle orange'vif, Fruit glabre Serre temprever, Terre à Orangers. Soleil, beaucounz a'eay, De Boutures . Amerique meridionule Dalurac Janguined Ruiz er Savon. 

25

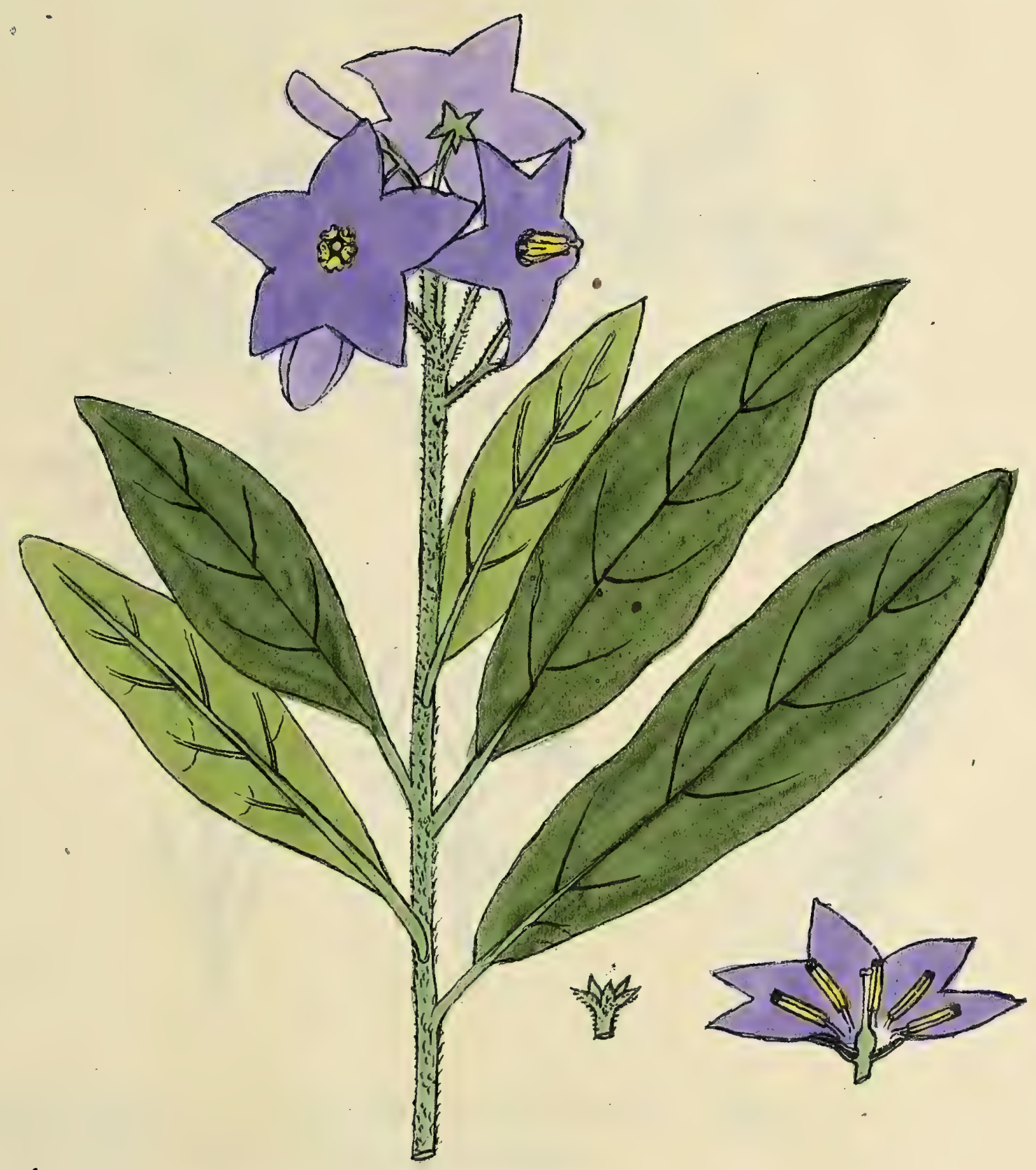

Tige ligneude Jroite sans épines I'1 mètre, à vameauep velus

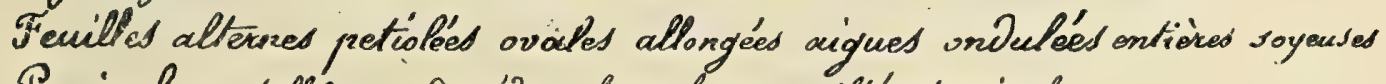
Paricule ombelliforme de, rédoncules velus ramifiés, tormina'e Corolles violaceés, étamines égales calices velus

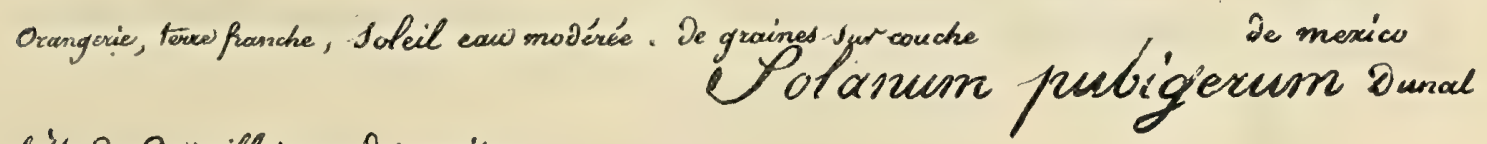
fith De Dejuiller we des axcis 19 



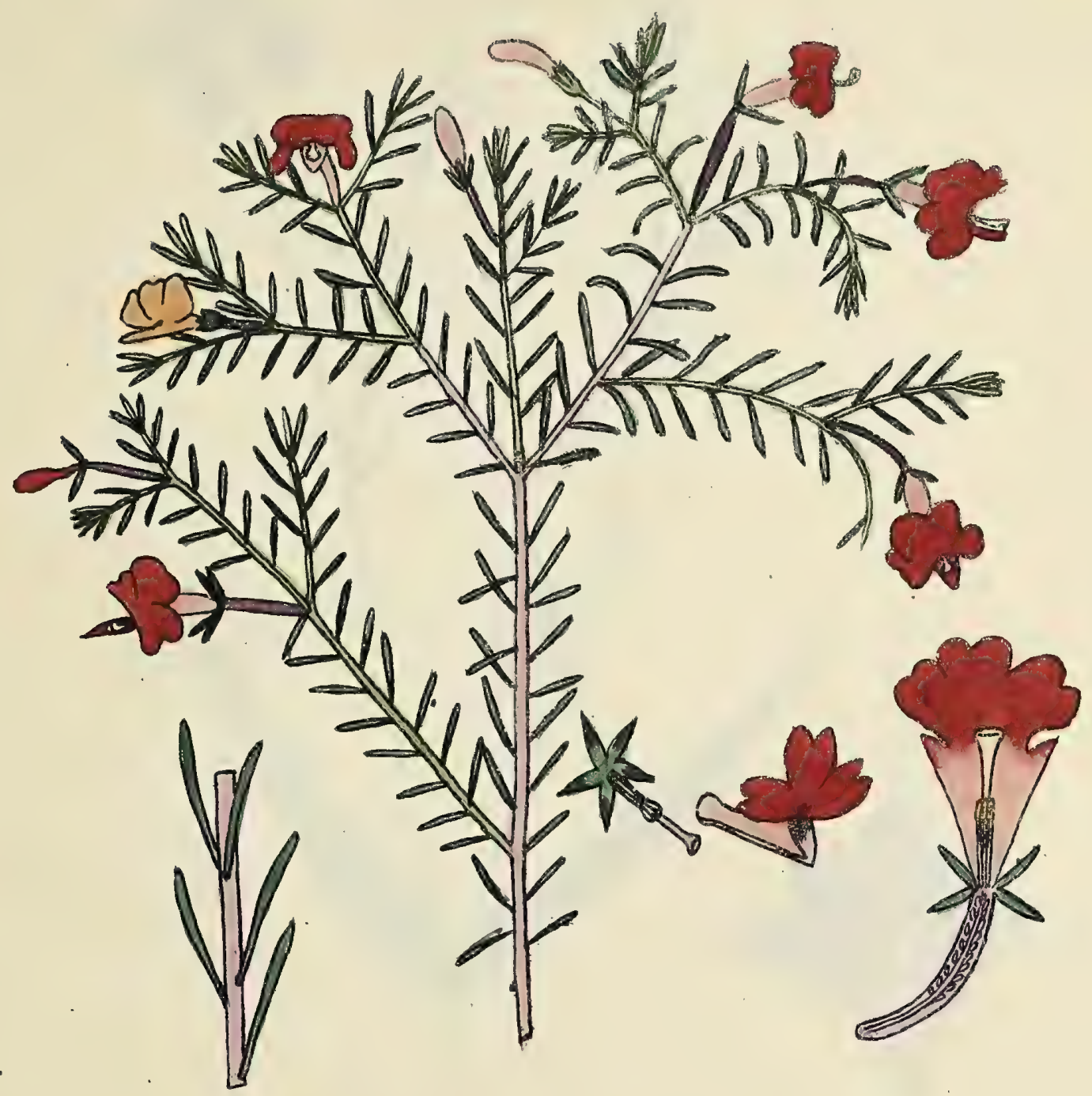

Fige ligneuse de o,40 centim. tries ramense cyliswrigsze viofacié

Seuilles ínacses sessiles lonéacied obtuses raides

Flewrs sessiles solitaives dans l'aisselle des ramuscules

Ovaice viofacé, calice vert, Corolle rouge-vif

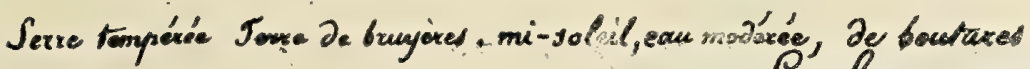

Lechenaultia oblata

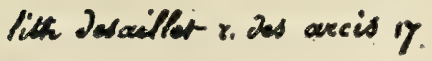



ay

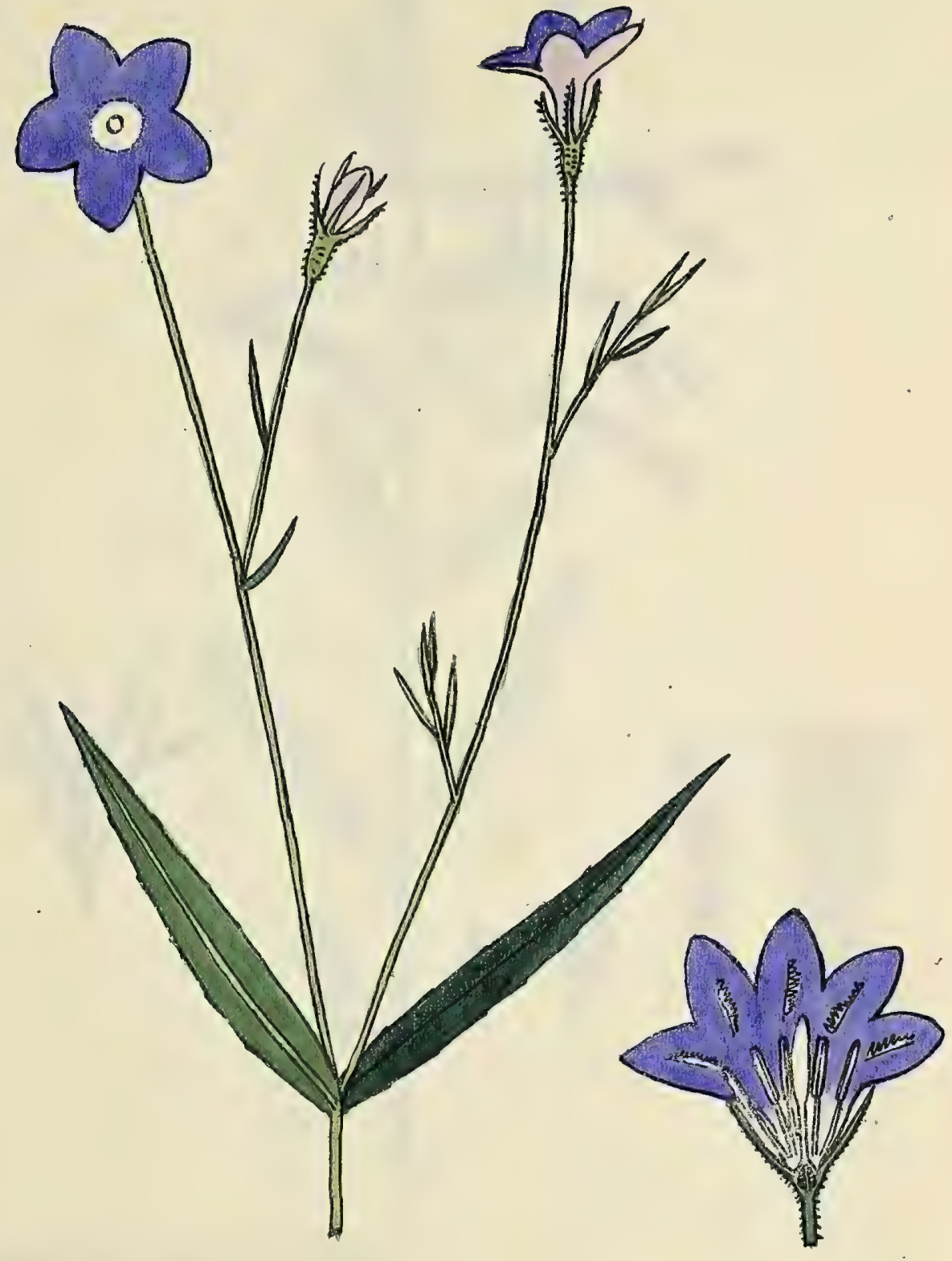

Thane visace

Tige Jroite rainense grele cylindrique verte haute $\partial$ 's metre glabre herbacie Freuilles finéaires fanceoties pointues à bord cartilagineux un neu dearé

Jesoncules songs solitaines simples fteurs droites

Calices poihs cowlled blewes avec une ligne barbue blassche sin chaque tobe

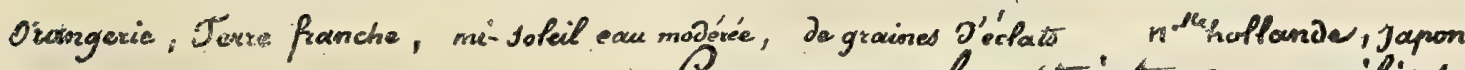
Camyramula stridat. Sn. gracilis furs Lith aesocilfer- Des ancis 7 cher Chousvière use de fauroguette 104 



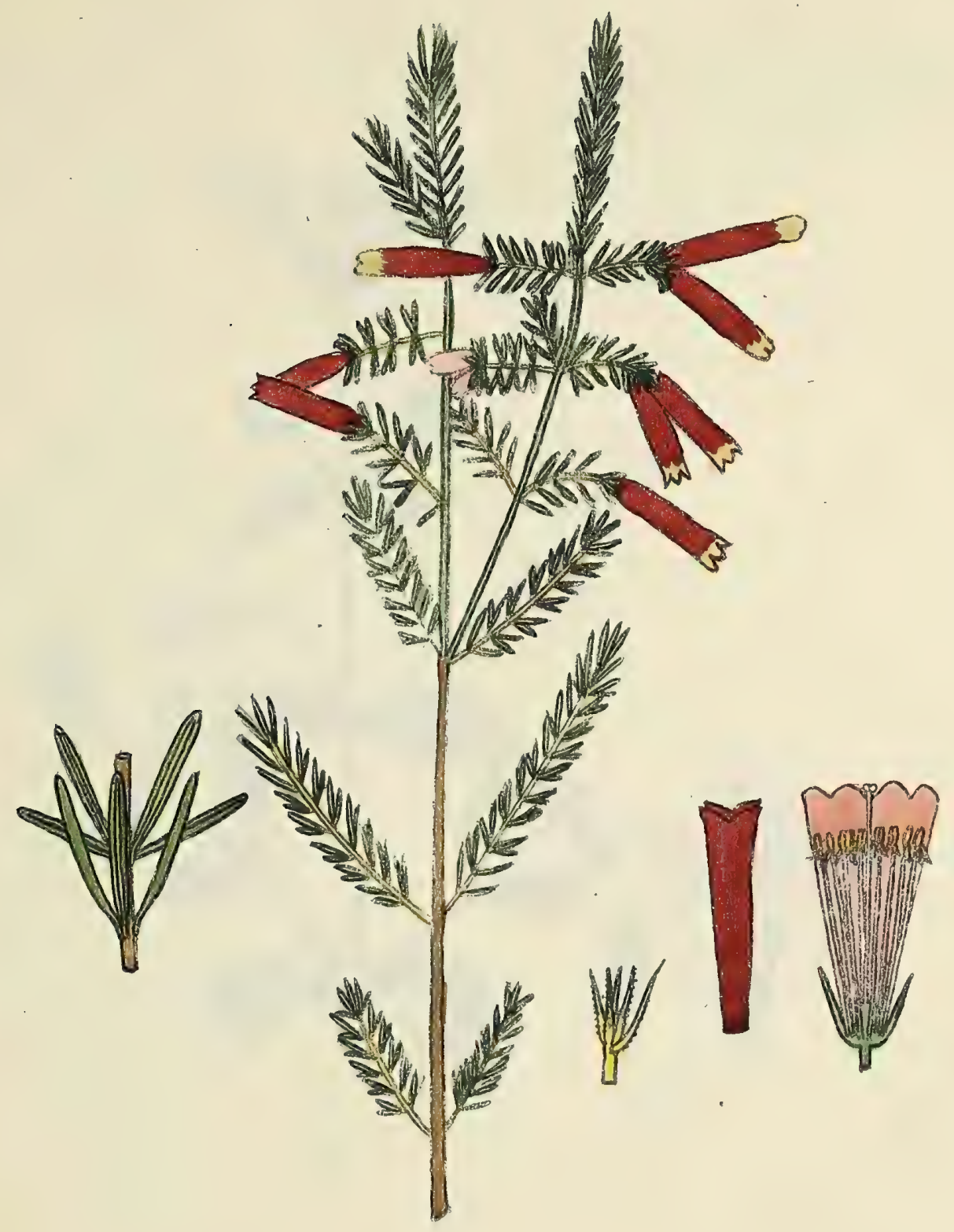

Tige droive rameubs brume lisse glabtre

Frevilles 4 par-4 owertes lineavices à with rares er conrest

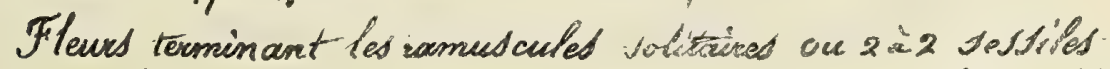

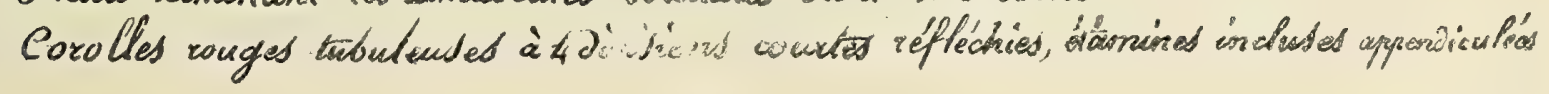

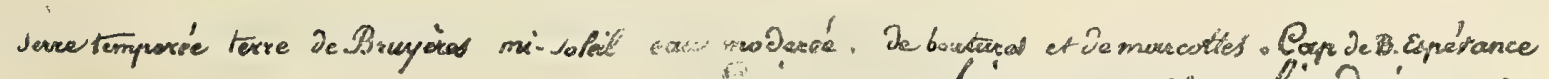
with Dosailtet $=$ Jos axcis ty

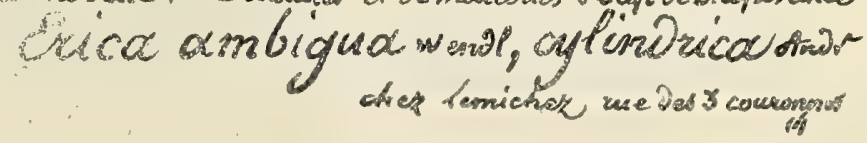





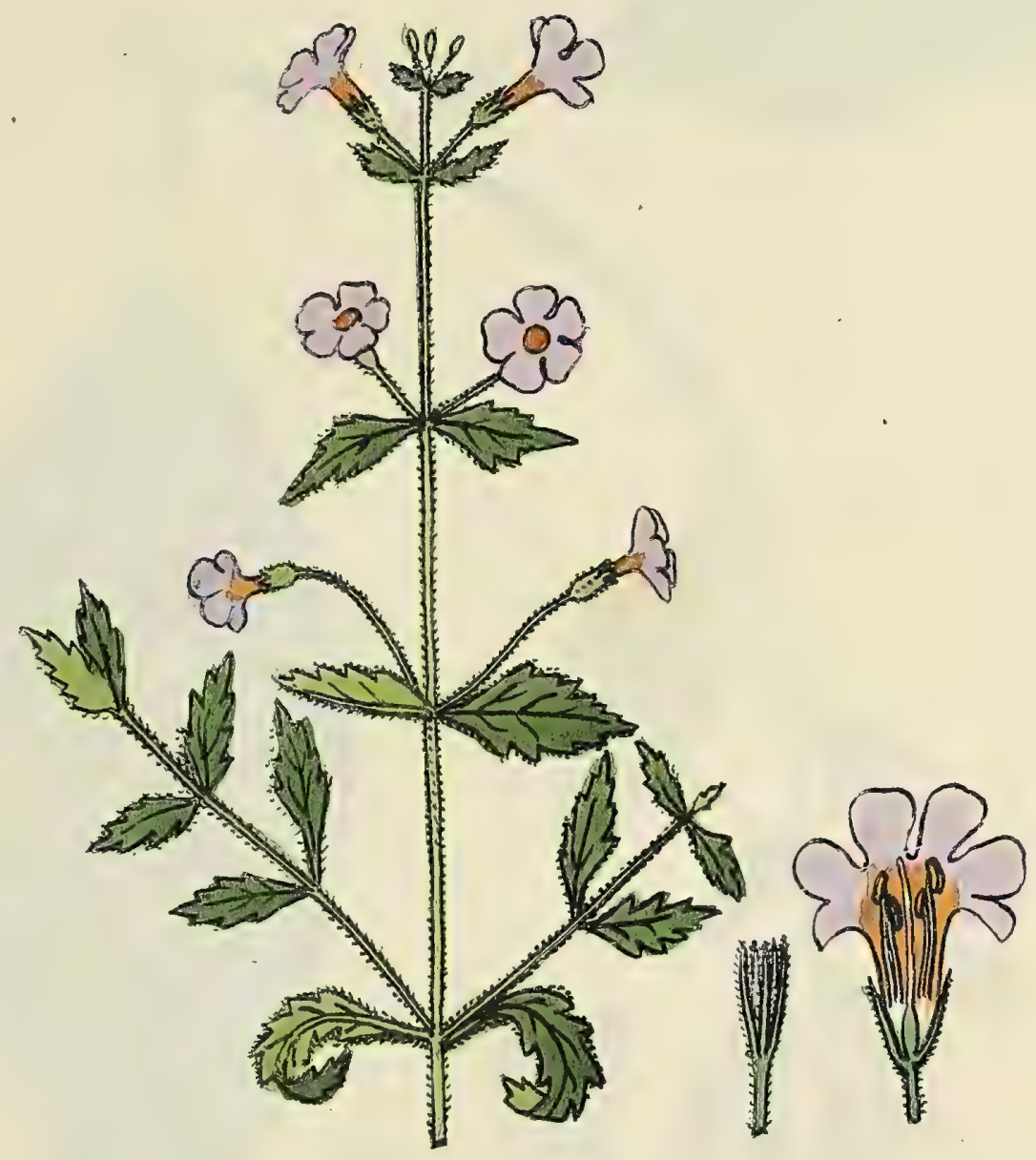

Tige droite rouneubse ligneude à la base de 0,30 à 0,45 contion. poilue Teuilles opposés ellipliques pointures inciséa-denties velues vert-pâte Jessous Pejoncules axillaires oyposés solitaires, vimples, Pongs, velus Corolle violet-clair à tube orange

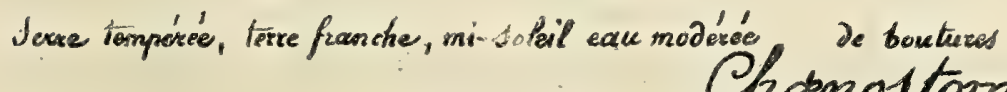
Oranostoma polyantína Siñ Jesaifler race acs accis iy cher tribout rue 5 maur 45 



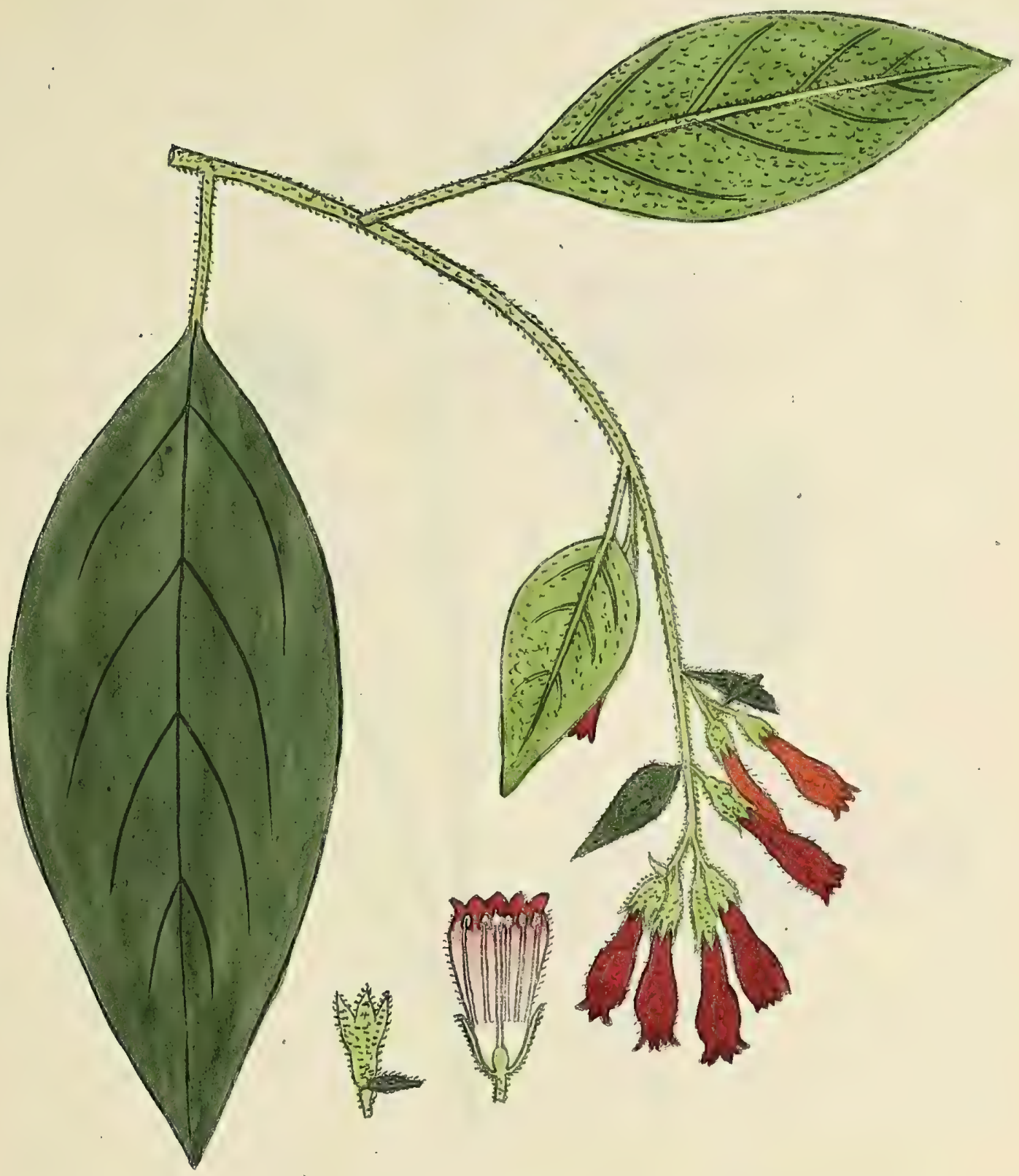

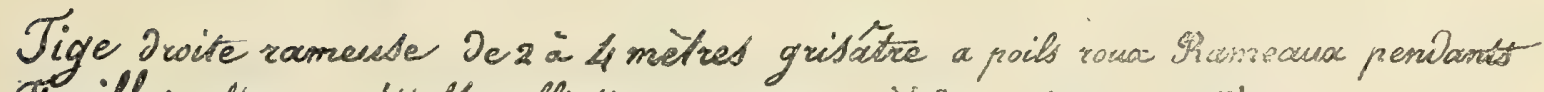

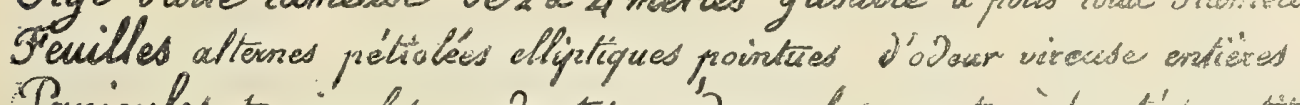

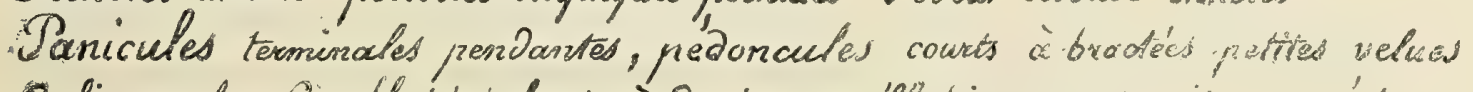

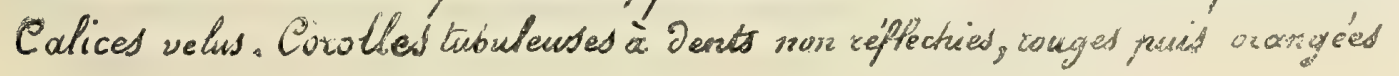

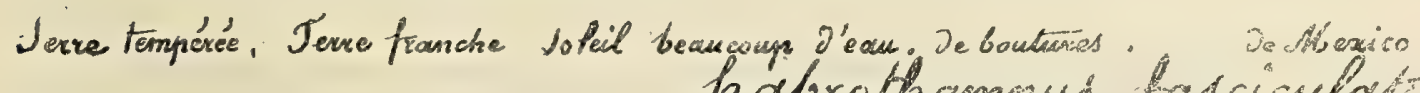
lith Deseilter t. jes axcis ng habrothammes fasciculartut Brogn. cher lemicher. 



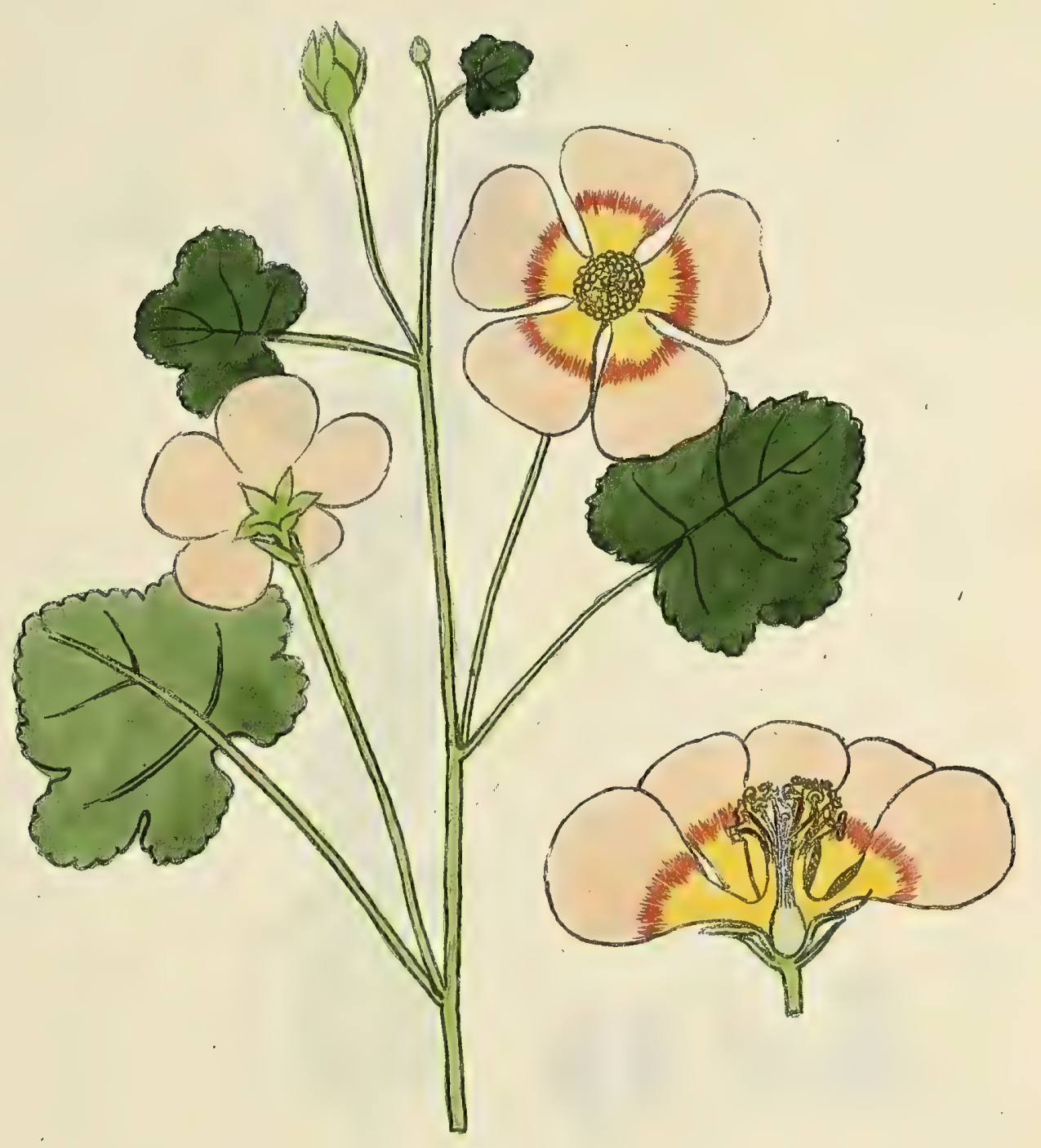

Tige J's Hère droite ramense cylinorique verte

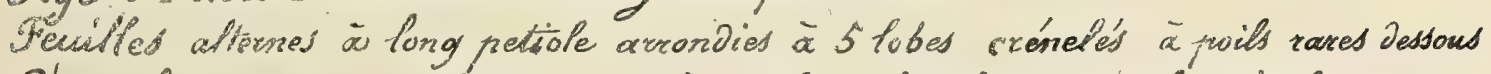
Sedoncules tolitaxires axillaices simples poilus plus Pongas que fes pe'tioles Setales obovates grands à limbe rose-briqueté onglet jumne vepaucé prar un arc rouge Orangerie Terrefranche, mi-soteil, eau mòérée, ae graines J'éclats Mabra lakeritia

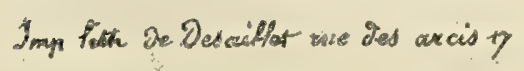
chac Chouvière r. Je. Pa Roquelte 104 



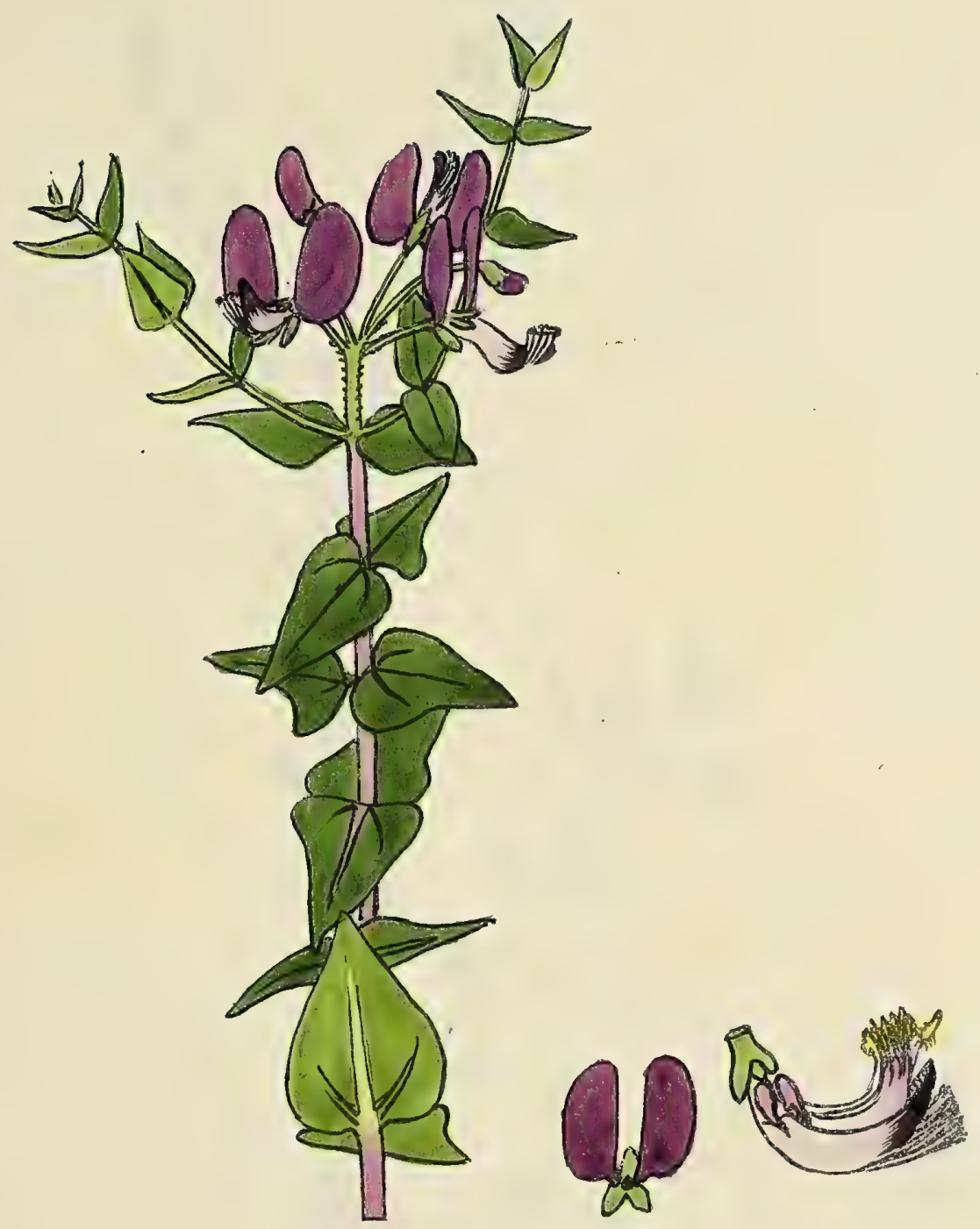

Tige ligneuse tamende cylindrique de 0,60 centirn. rameaux un pau velus

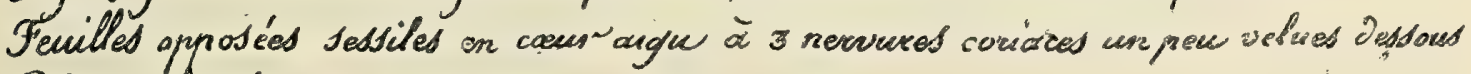
Sedoncules longs en épi très court torminzal

Ailes beau viulet, carène à aigrette, Anttàres barbued

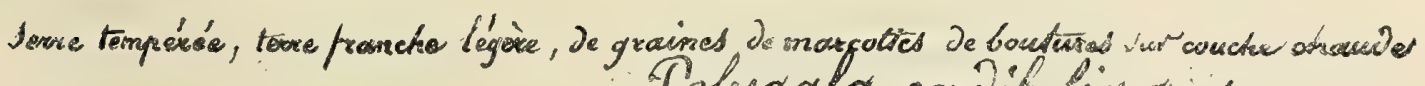

lith Jescillet $x$. des arcis in

Tolygata corifoild minbery

cher Hiboust r. Stmoint 45 



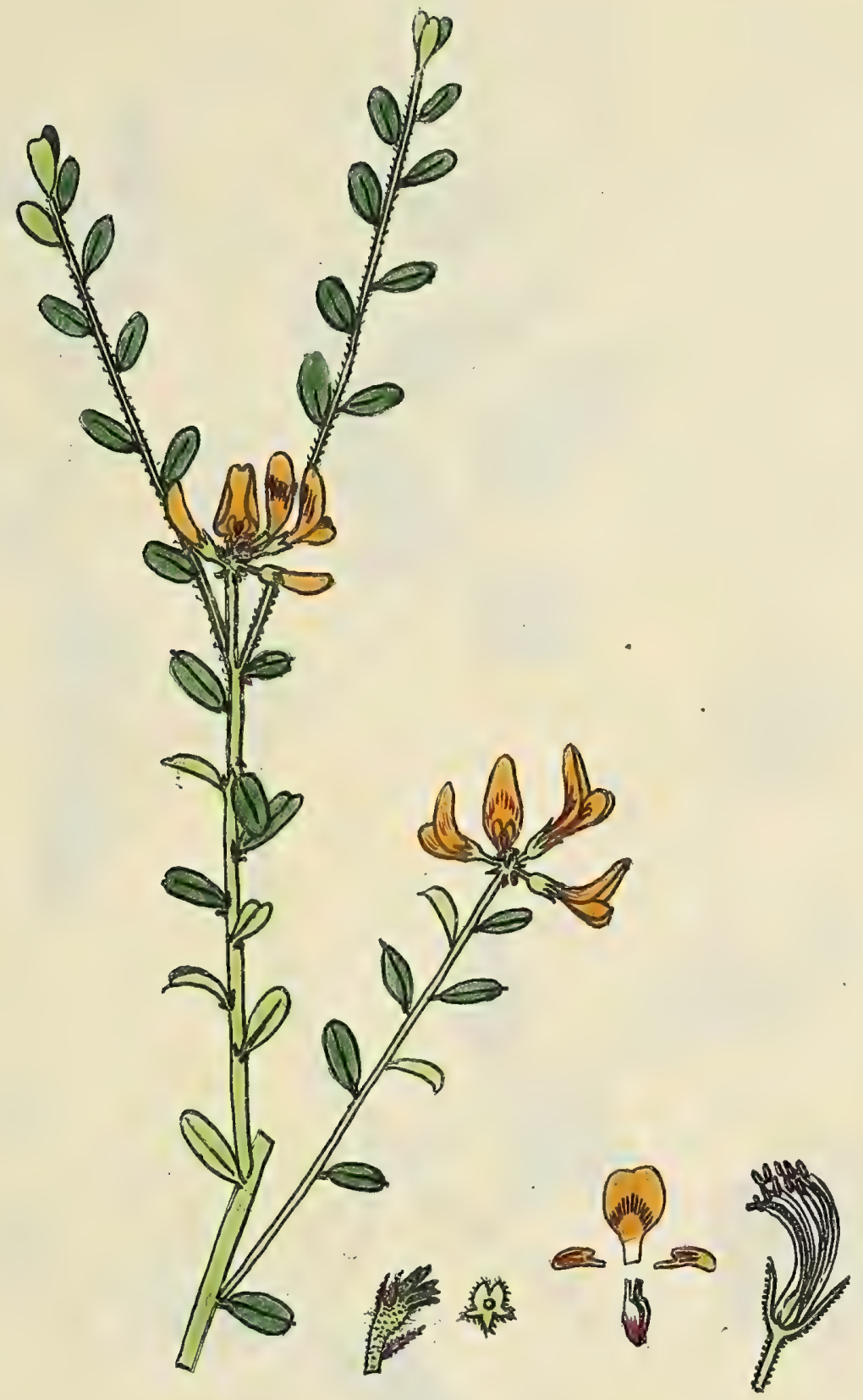

Tige ligneuse de 0,60 cont rameuse en truffe serrée, grite cyfindrique Feuilles alternes a tres court piétiole obovales mucronés glabies Pedoncules courts on tetes terminales, Jaýnules pelites aigurs rouges caliced velus, ciendard etailes muzdorés, Cariene rougenlaque Segumed velus

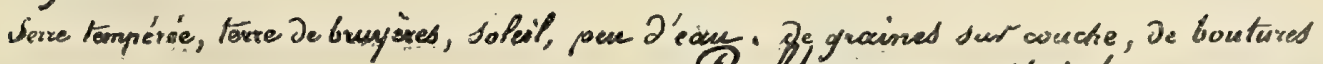
Sullerrea Strictá curct lith Josaiflot i. Jos arcis 17 . 



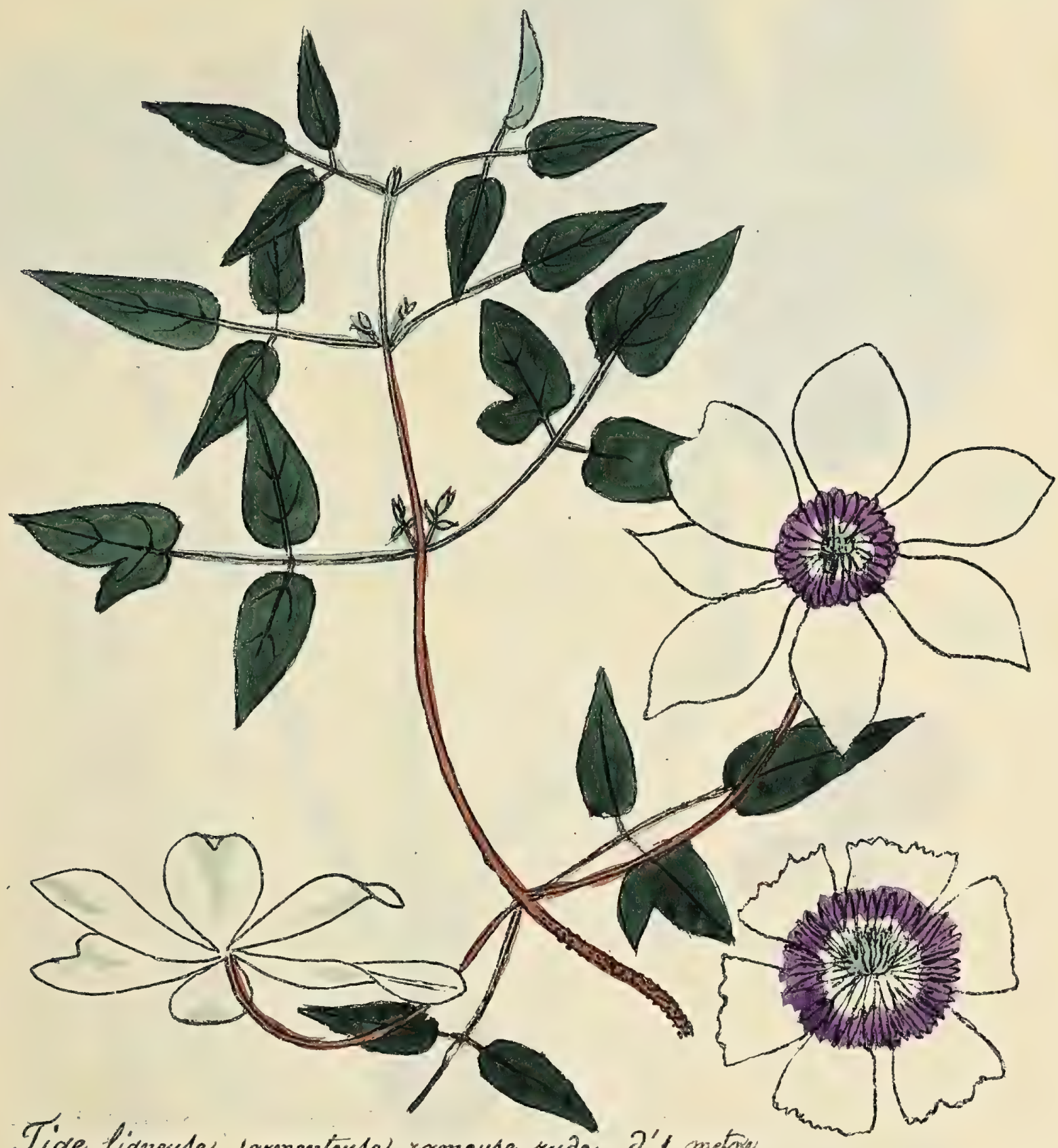

Tige fignente saronertensel rameuse rude $\partial^{\prime} 1$ metrie

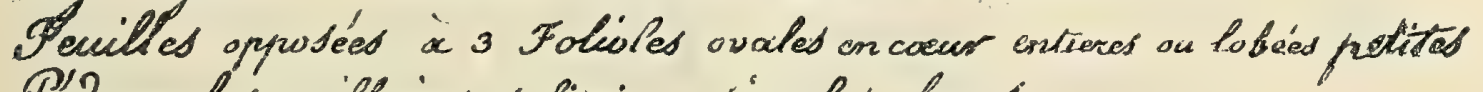
Pejoncules wacilliciced solitiasires simplest longs

Ietaled blarred au nombre Del Gaiy, Clamined beaw vislet.

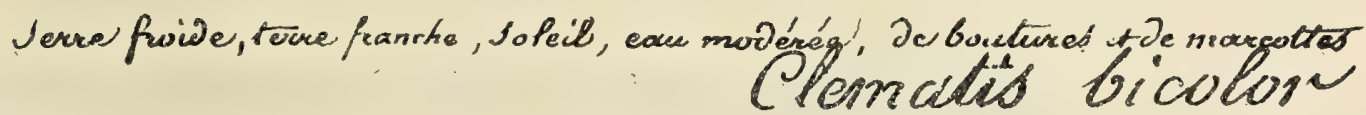

Rith. Desaillar Raw axisis if 



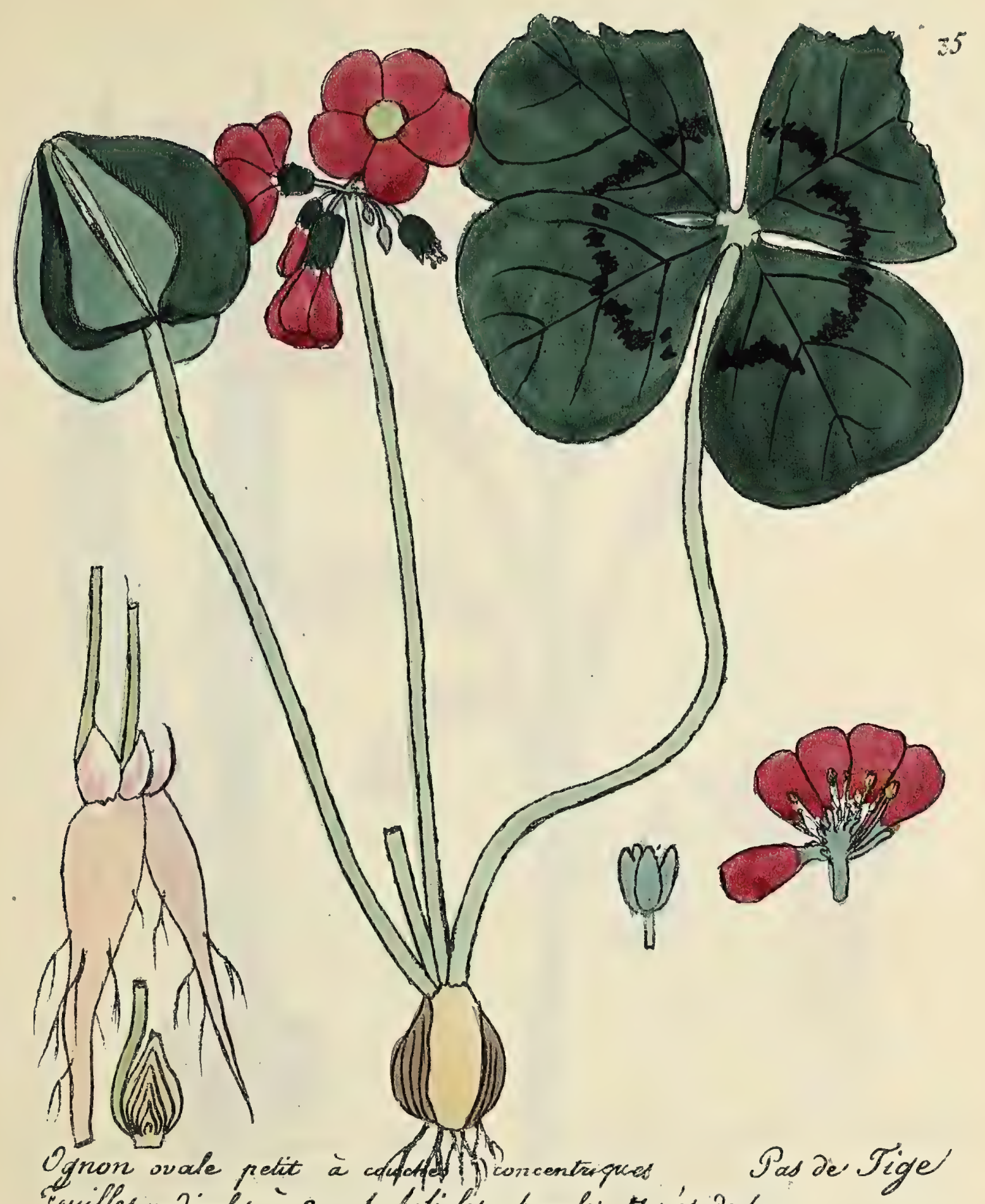

reuilles radicales à 3 an 4 fotioles obovales Zones de bruov

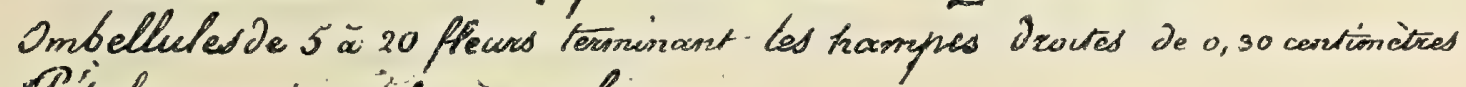
Tetoles caumin pale à orgles vivt

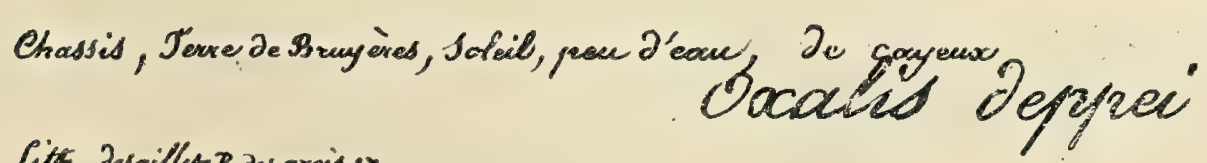

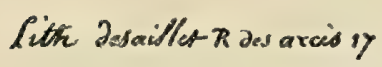





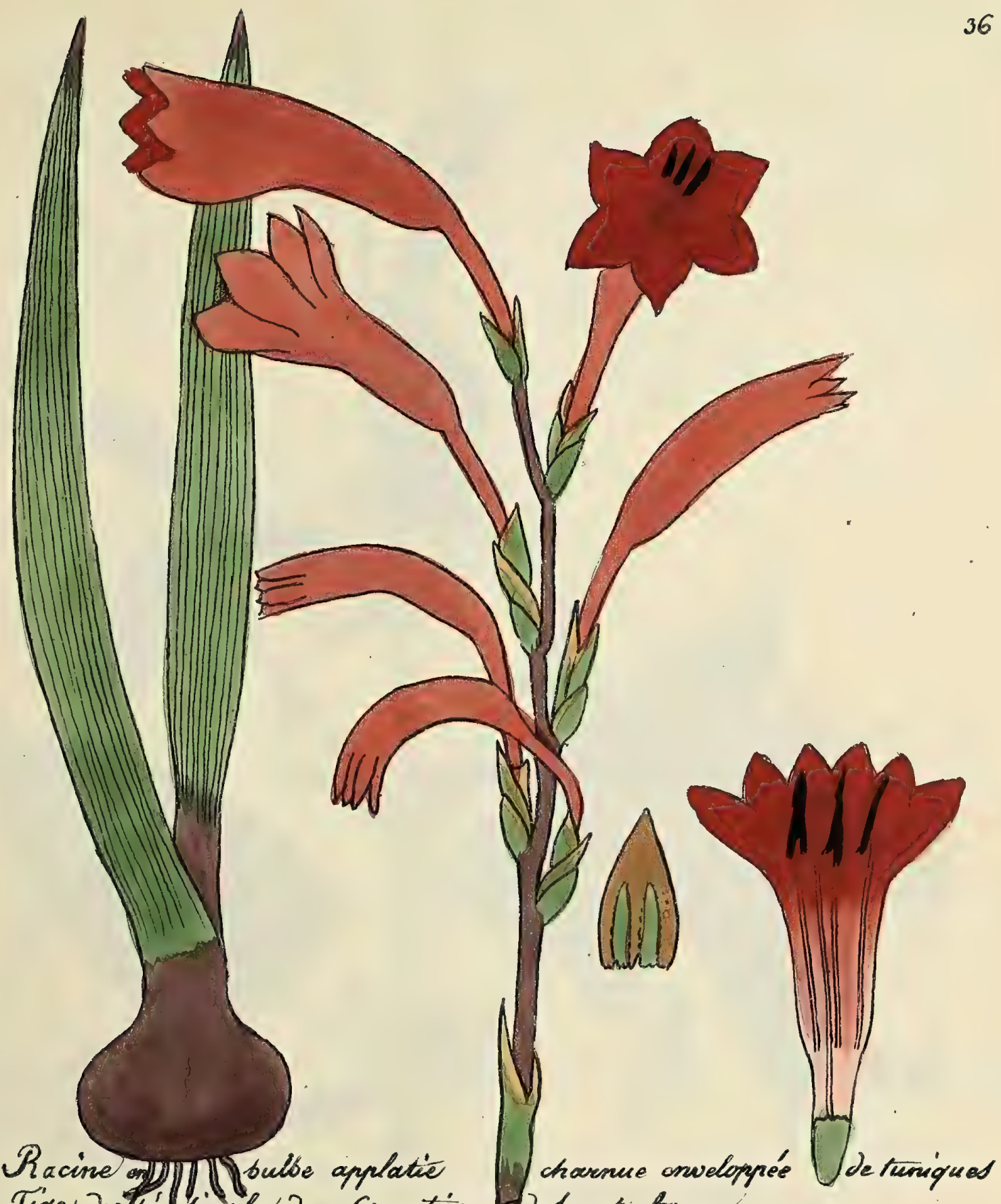

36 Tige Jratiec, Simple, Je 0, 6o cention. De hout forme Fewilles en épée pointures amplexicountas altornet sestites Gris deflawrs sessiles, ontourées de bracotés corcutes obturdes, Fleurst vermillon-carminé

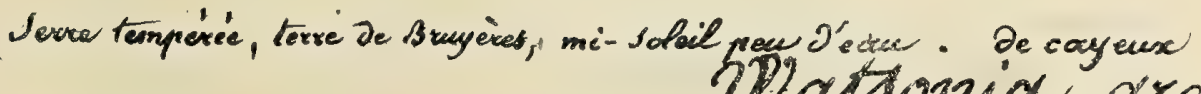

liot Desaitiet me des arcis oy

VW atsonia grandiflora 



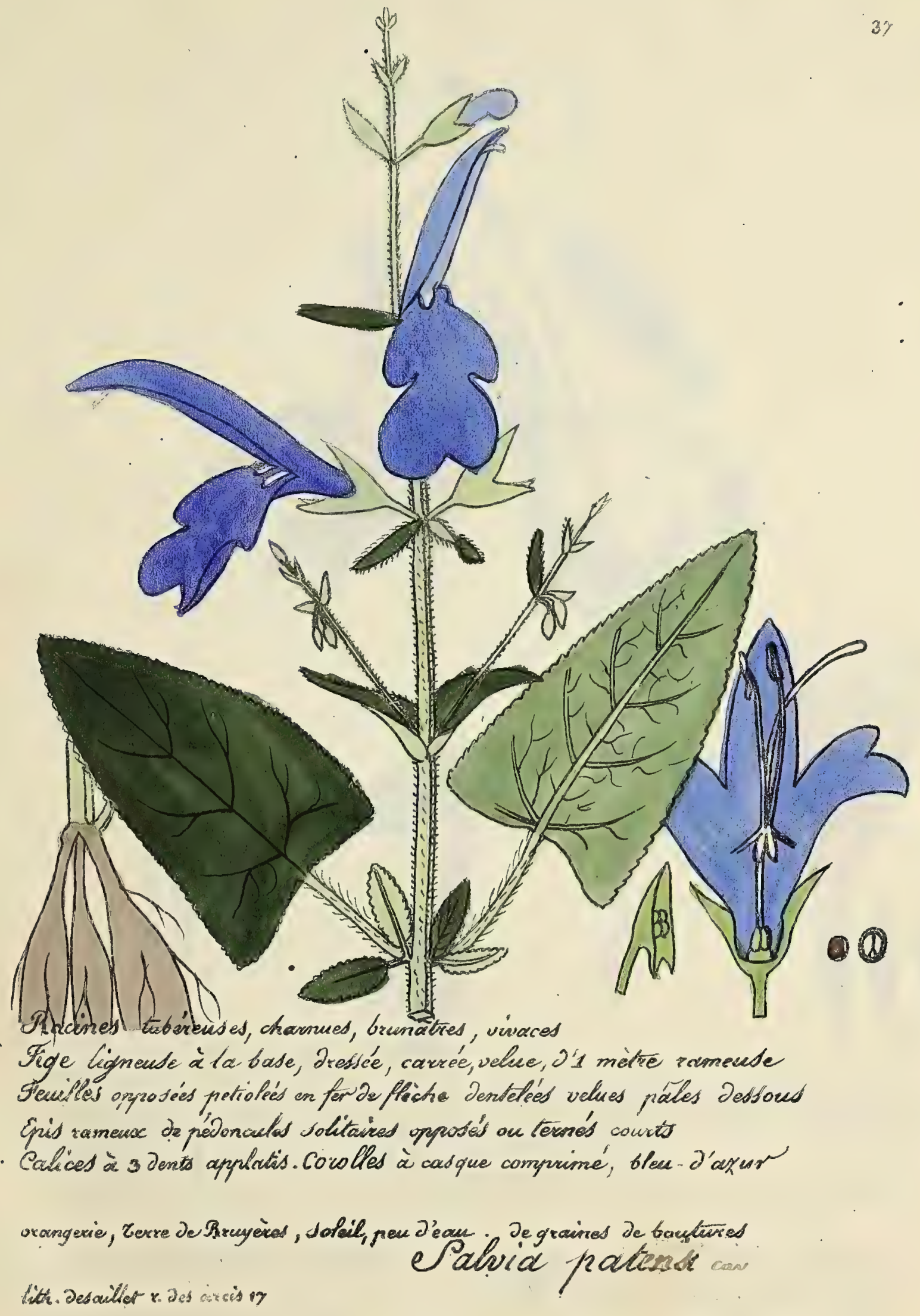




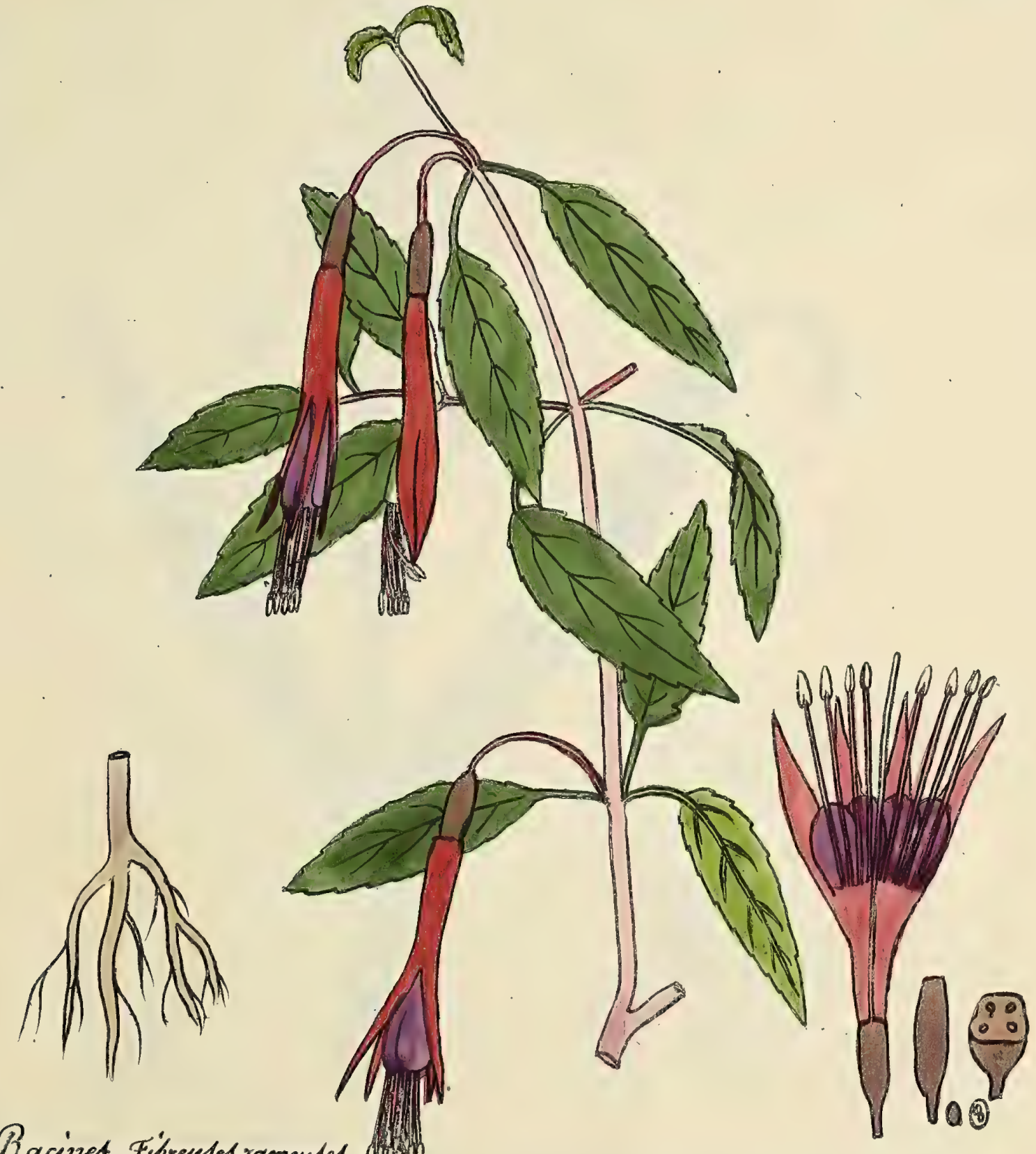

Racines Fibrendes ramendes Whill

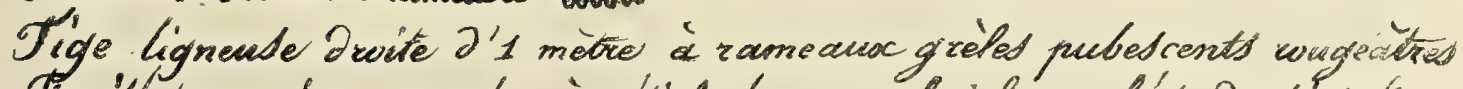

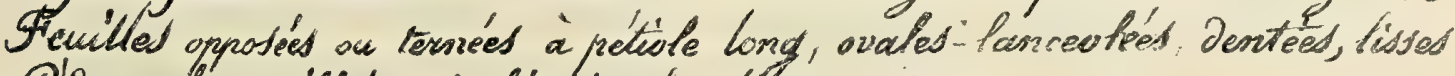
Sevoncules axiliaires isolés simples longs perndants.

Calires tries hangs rouge-vif, pétates violacés, étarnimes vess saitlantes

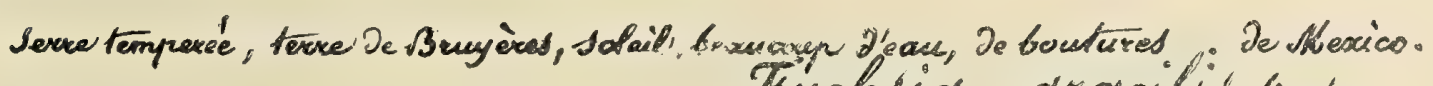
Sith Jesciller : Des axcis 19 Fichsia gracilis kinstey 


$$
\text { - }
$$

.

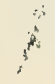

•

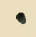




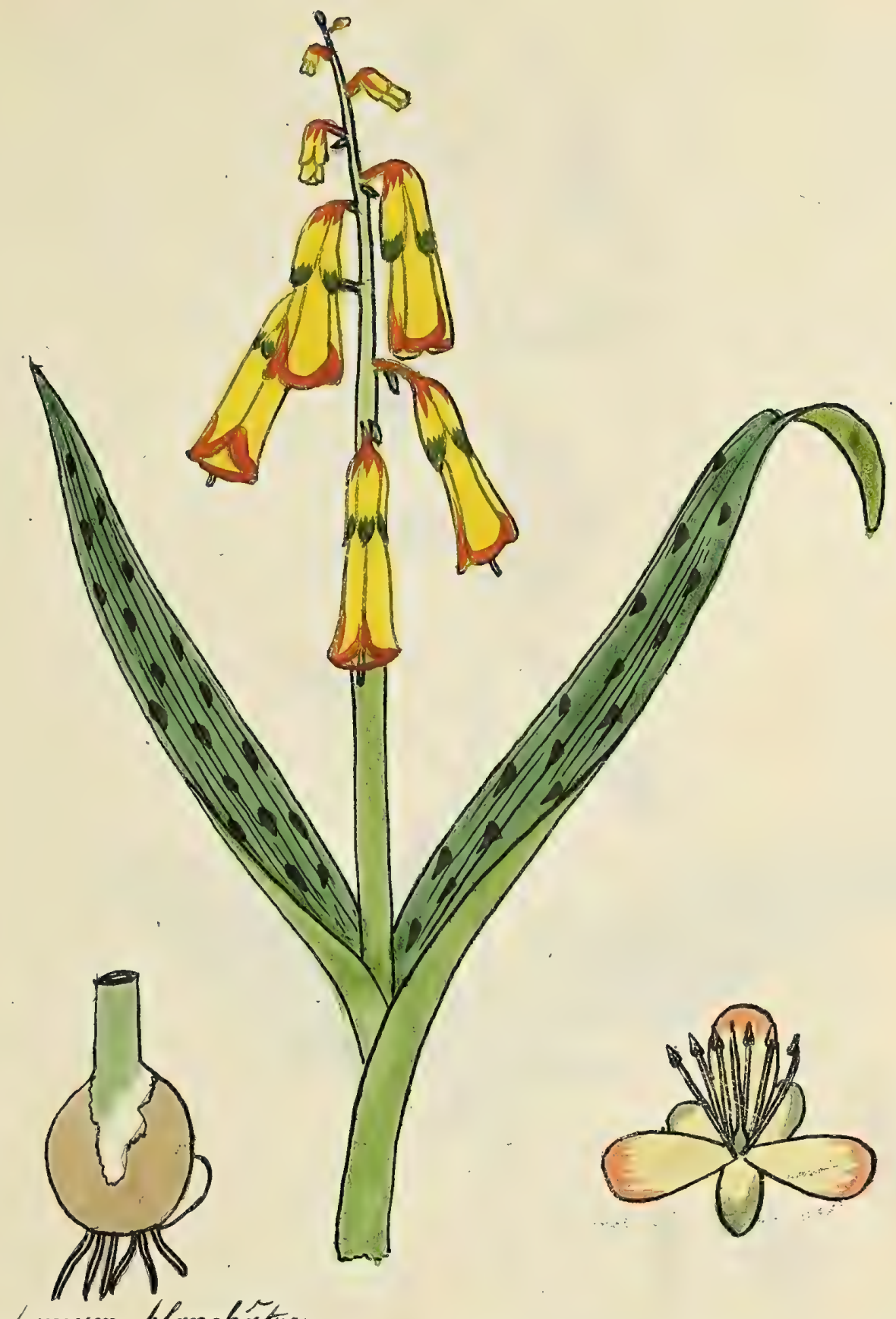

Ognon moyen blanchatie

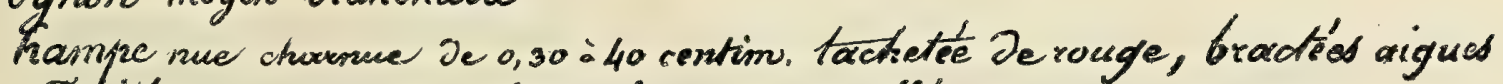
2 Fewilles engainourtes, en for Je fance, pointillées de pourpre au bout. Sici long, de 20 à 40 pédoncules perwants

Pétales internes echancrés bordés de pourpure, tes extornos jaunes bordés Je vert

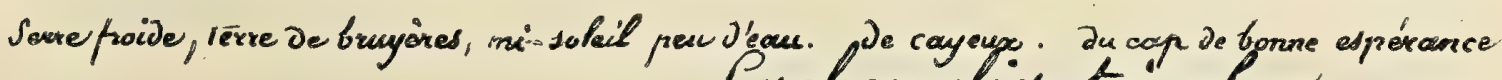
Lacherralid tucolor jaequin

Lidt Jesaillor 2 Jes arcis 17 



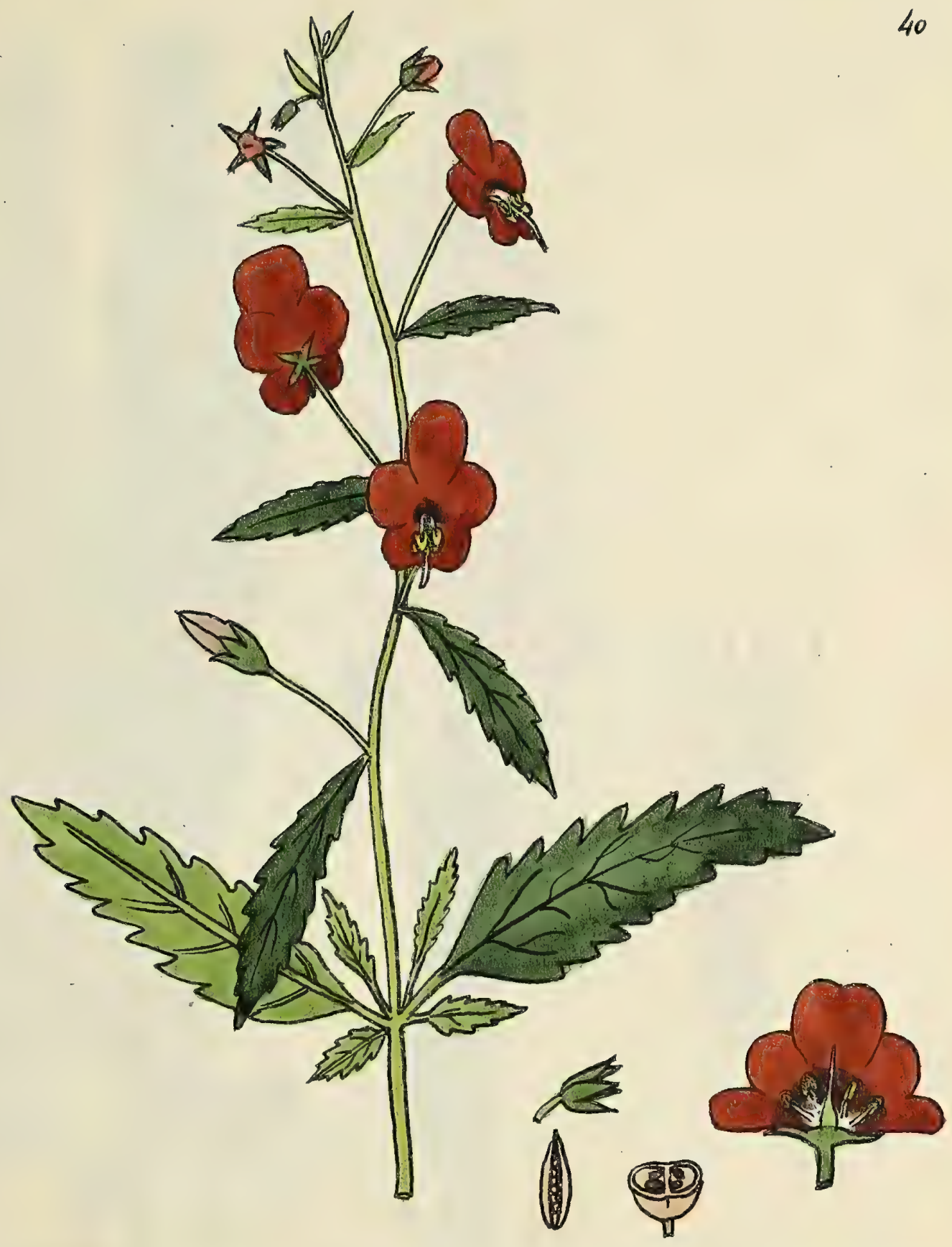

Tige ligneuse à la bade de 0,30 à 0,60 centim. cameaux nombreux herbacés Heuilles opporées en bas alterres an haut persistantos petiofés ovales incisées-Dentées

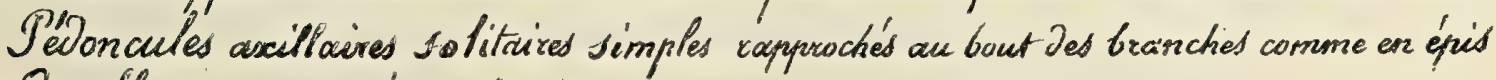
Cowtles ponceau-vif Arthères jaumes

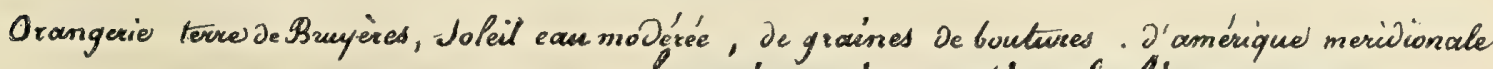
hemimeris urticafília willonow.

Sith. Desaillet r. Des arcis 17 



$$
\text { W/ }
$$







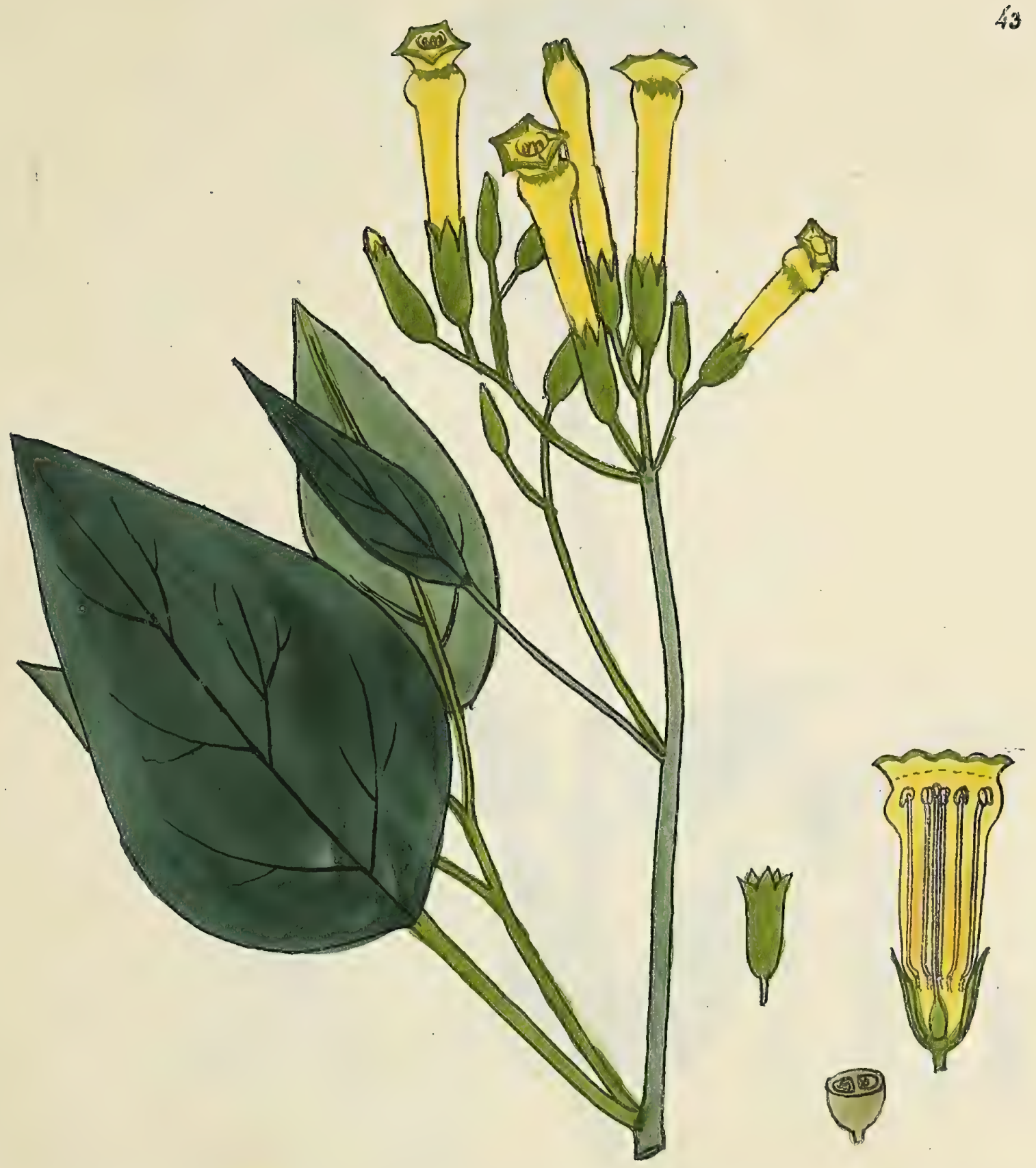

Tige Jressé cylindrique très rasneuse glauque ligneuse J'i à mètred Fevilles alternes petiolées ovales-pointures vert sombre glauques Panicules torminales de flewers nombreuses Corolles tongues renffées à for gorge jaunnes

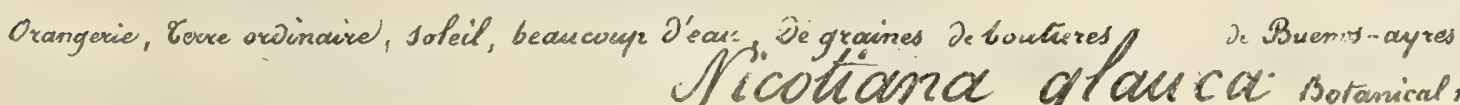
Lithe Jesacillet. 8 . Des axcis in 

44

Racine fibreuse ramense

Tiges nombreuses ligneuses à la base Simples droites de Gu corroùn. velues

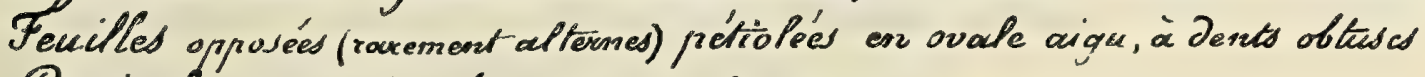
Ponsicule ternininale, bractées ens aleine

Calice comnun velw corolle on tuble violer chair

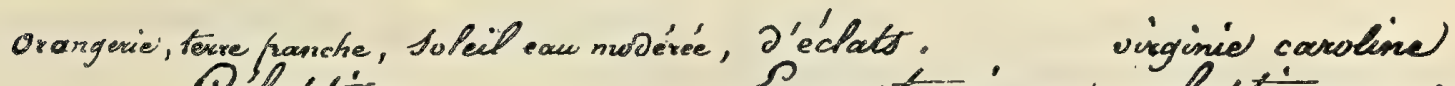
Celestivie

Cupatorium celestisumutionrée

fith Dedailler $x$ aes arcis ig 



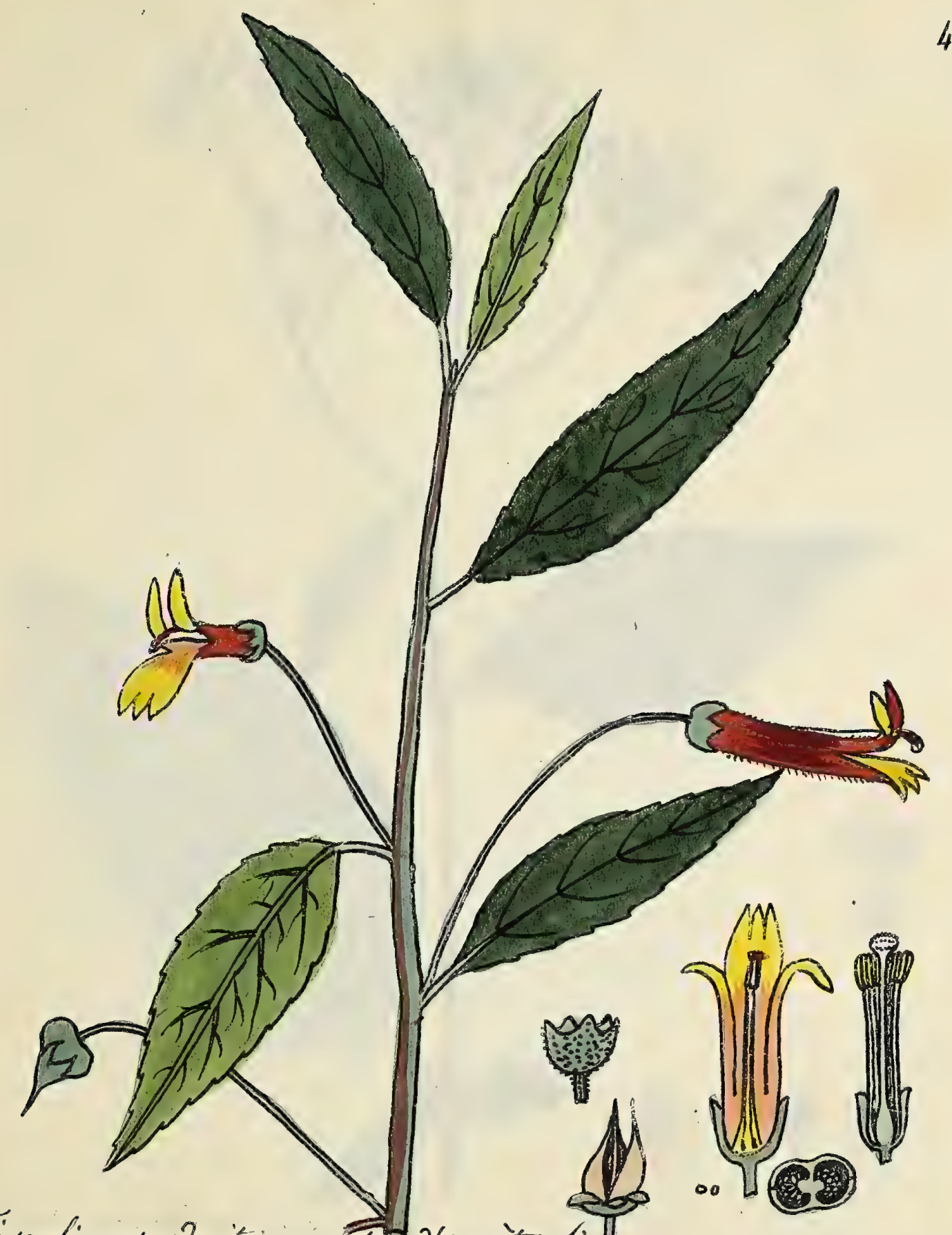

Tige lignense Jroite comente J's metre list

Feriltes alternes petiolés ovales aigues dentées glabres Pidoncules axiltaires solitaices Jinyles long'

Callice court. Powotle vermillon en dorout, jaure en dedand

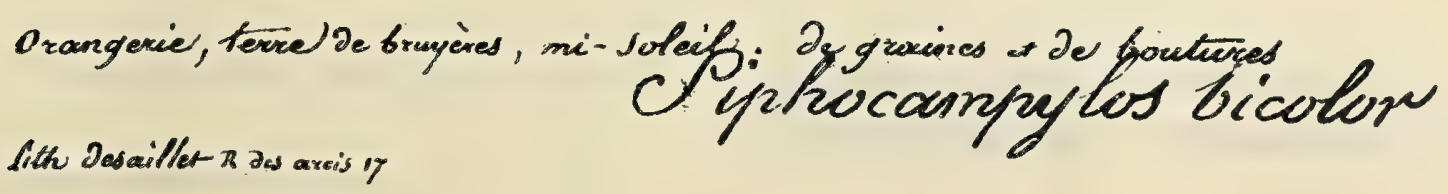





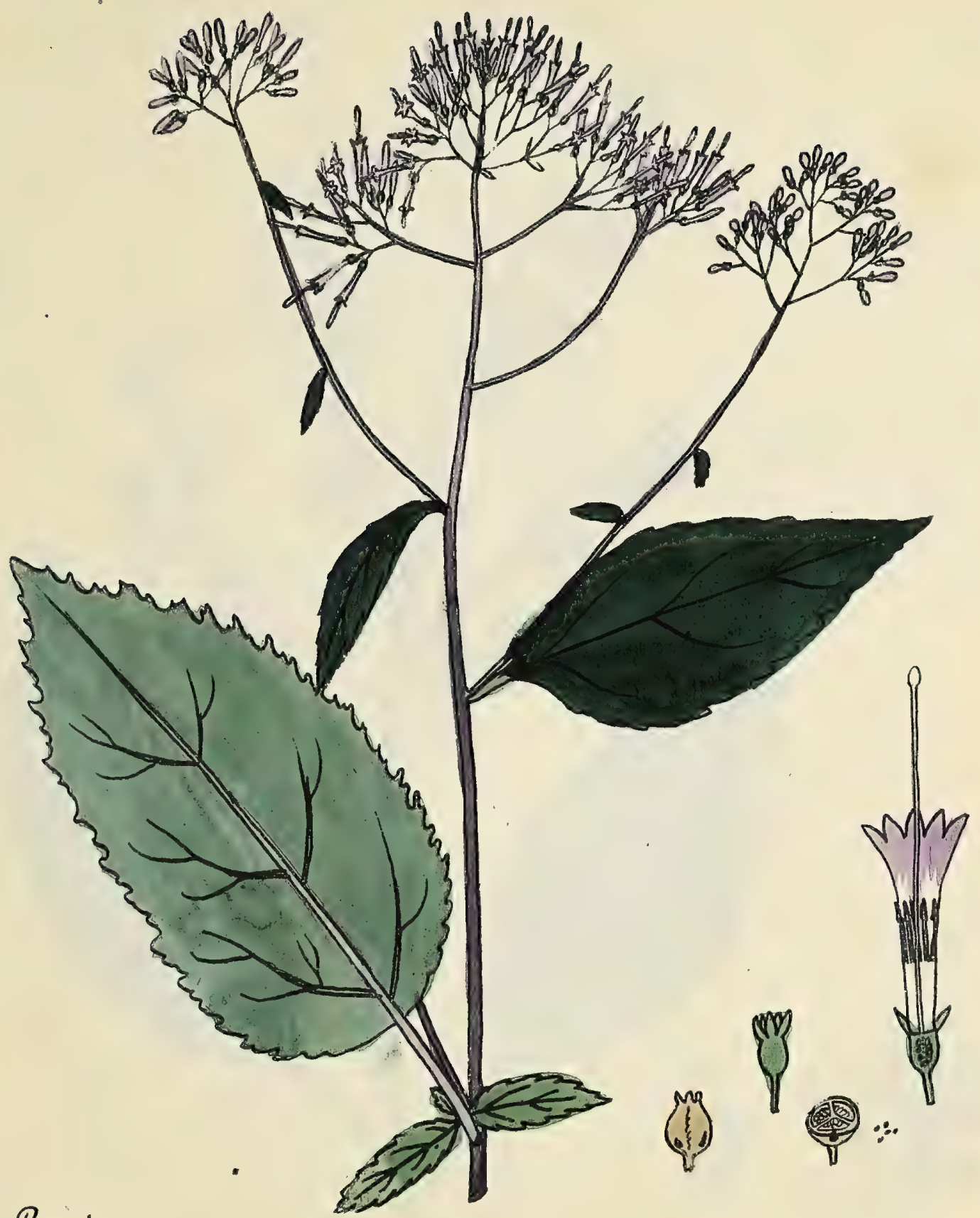

Racinel raineute

Tige bisannuelte on vivare un peu ligneude à la babe, raneude de 45 contim it Feuilles alterenes petiolées ovales, pointues, dentées irrégulievement glabres Panicules teminales, à pretites bractées, Fleurs petites entubes bleu violace'

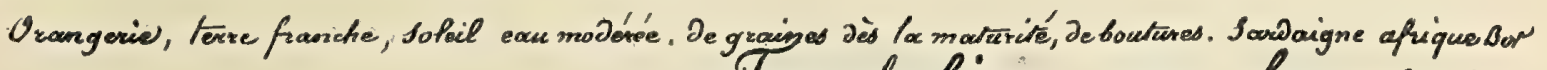
- Tracheliunz coerculeum linsée fith Desaiflér rós arcis is 



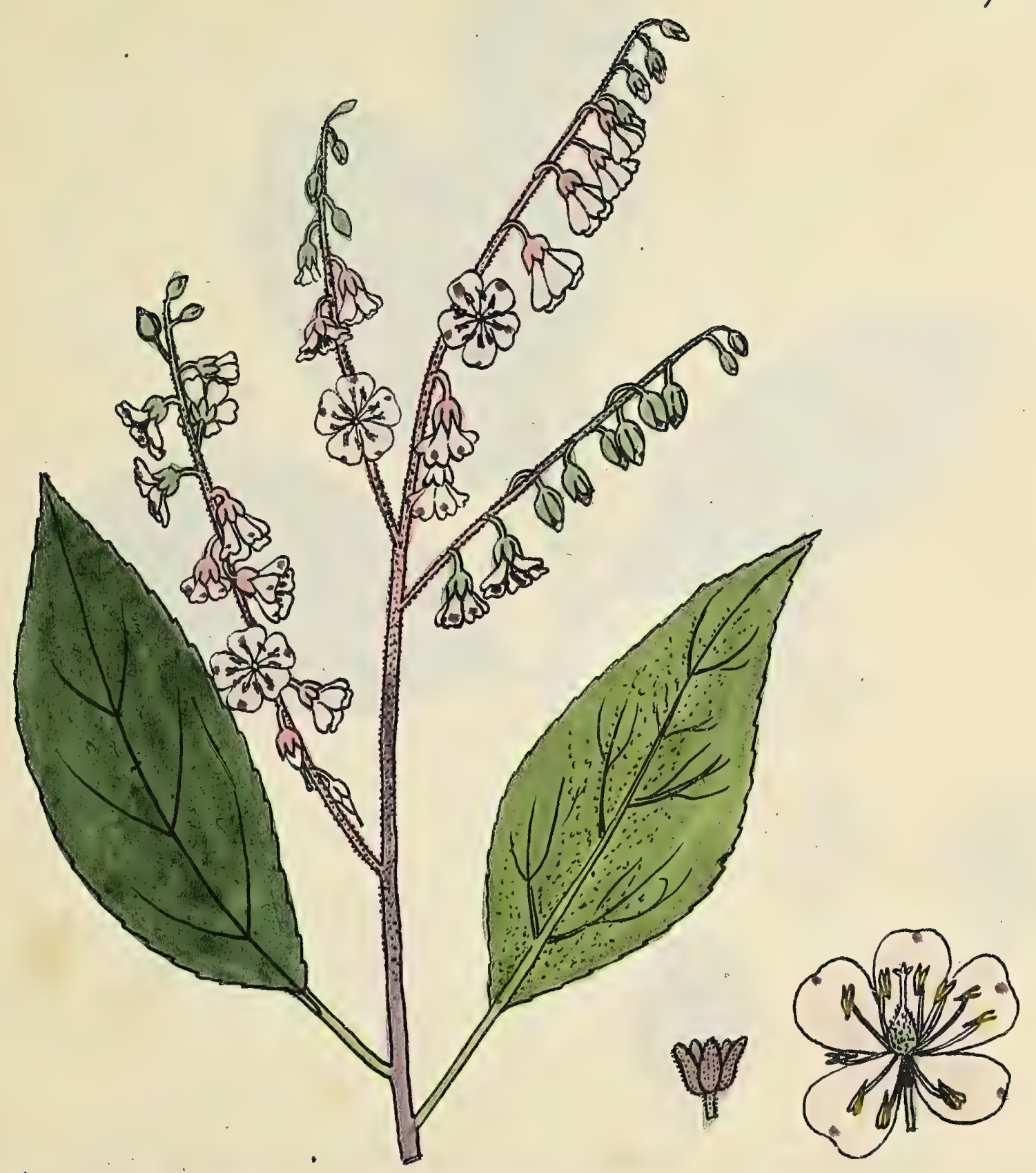

Tigel en arbie Jroite rameuse de $2: 3$ mètres

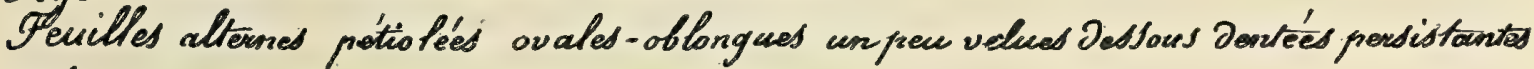
Gnis rameux terminawx velus sans bracteas Setales J'un blanc-rosé J'ócur-suave

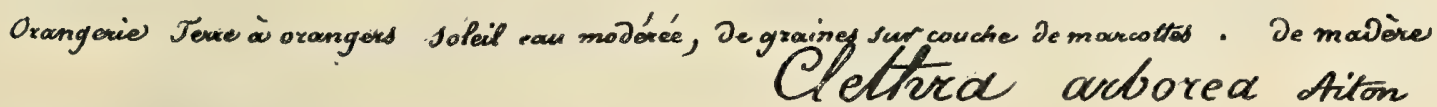
Lich Dowaillet r. Jos atcis nf 



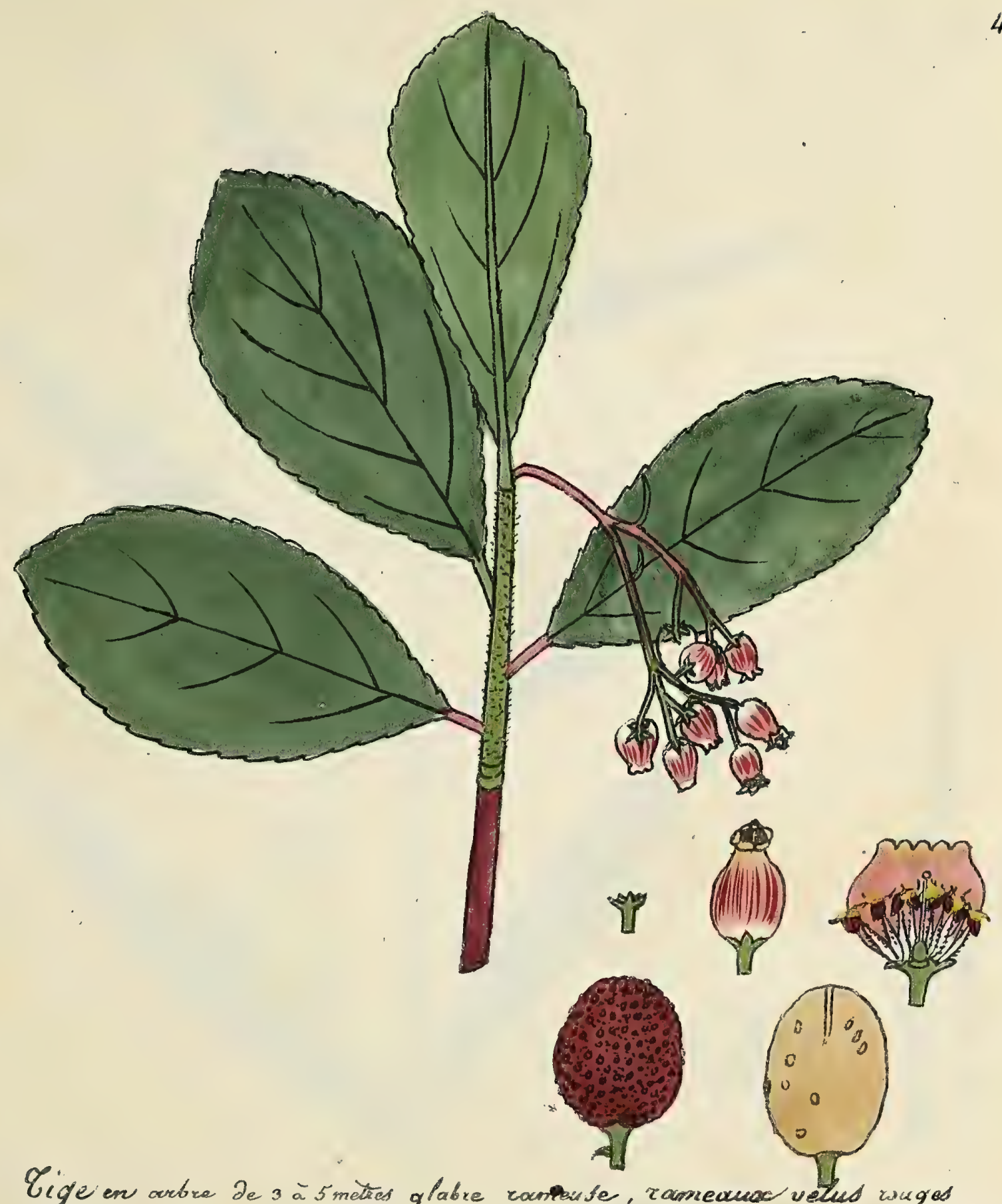

Vige en arbre de 3 à 5 metres glabre romprise, ramewnoc velud wuged

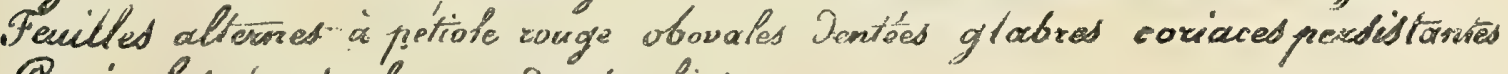
Saniculed terminates pondanted lisses

Fllourd rouges ou blanches, quelque fois doubled Fruits semblabted à ded fraided 'd' your fade.

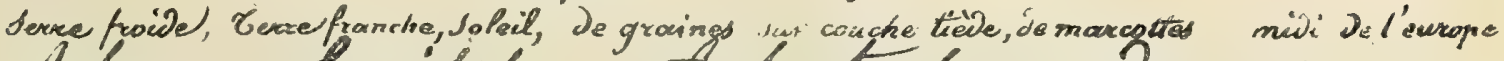

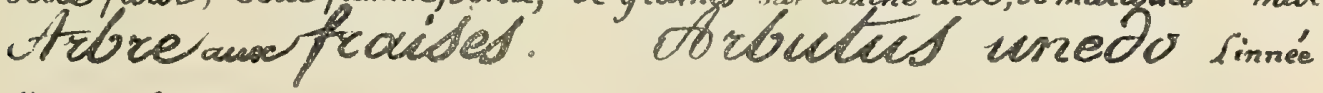

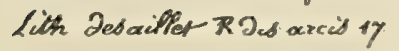





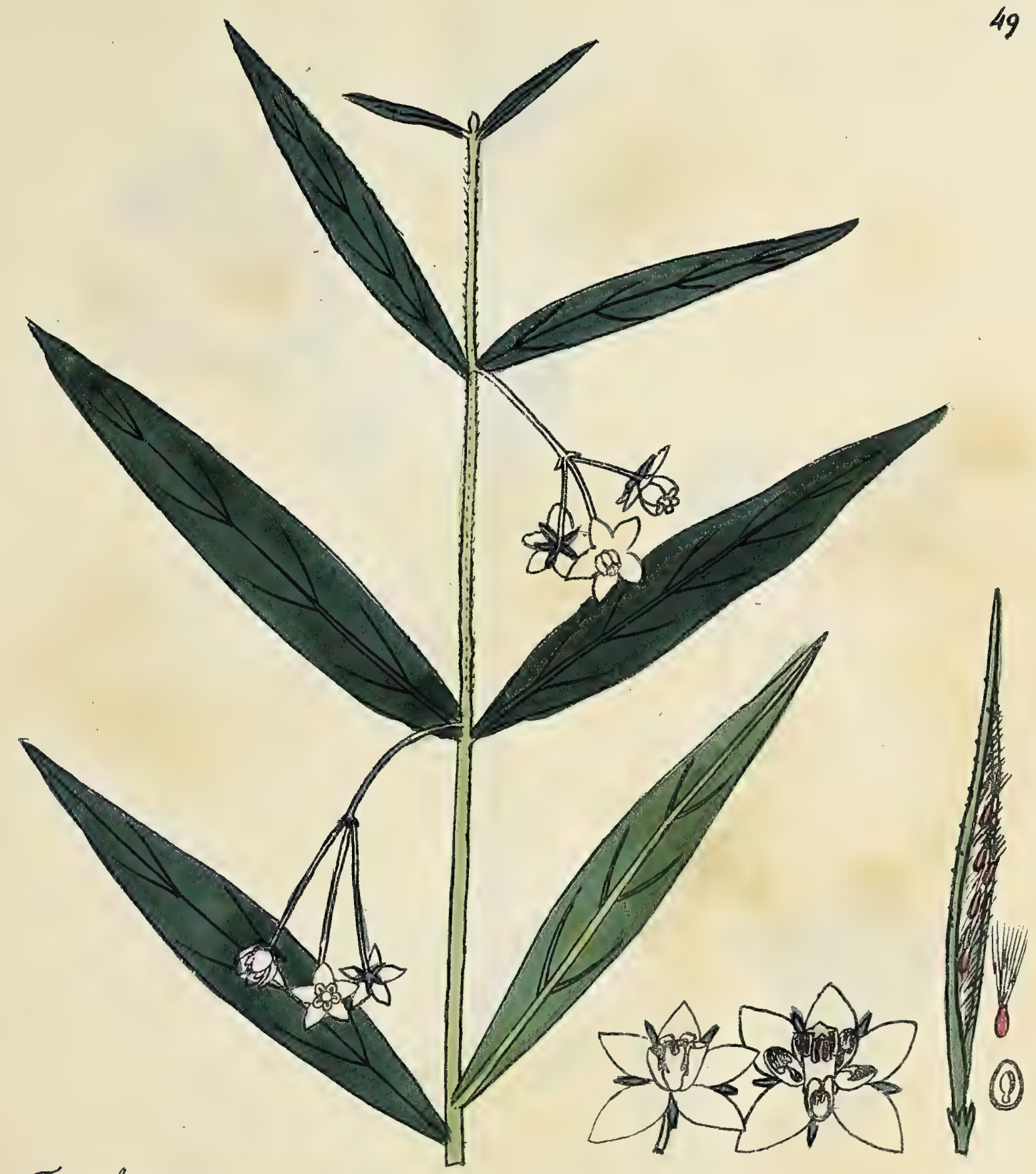

Tiges ligneuded Droites gtabres de 2 mètres à tameaux pubescents Feuilled oppuséed et grauses en lance pointues enziteros glariques Ombelluleis axillaires pendantes pédonculées

Fleund blanctred, 5 cornets sur les étarnined

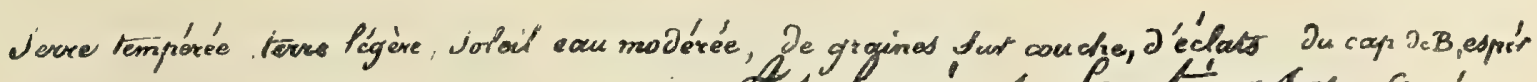
fith Desaitler $R$ jes arce's 17

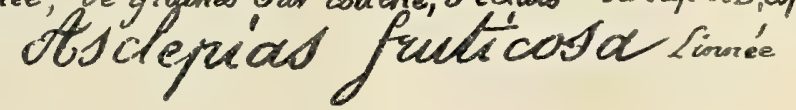





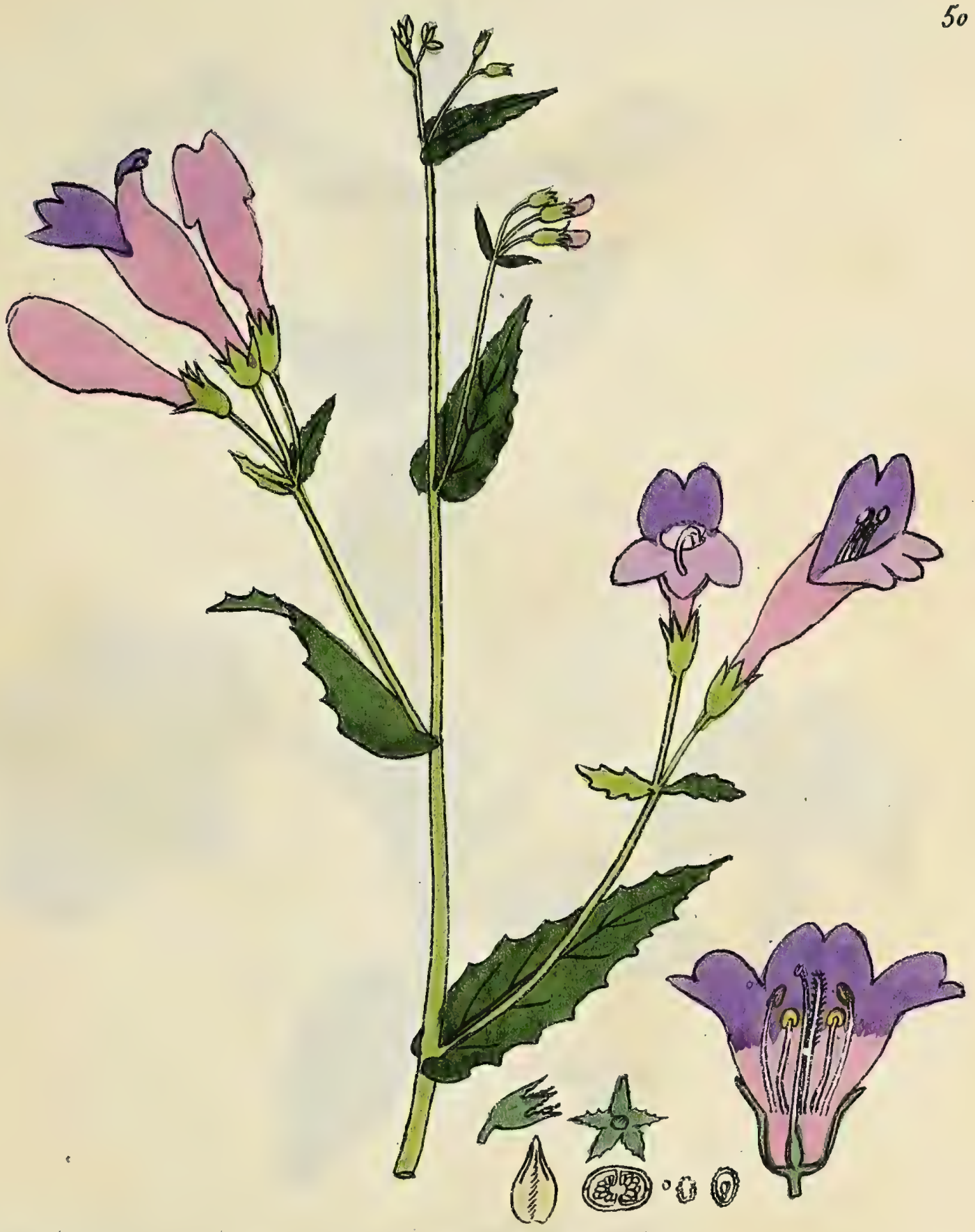

Tige ligneuse à la base zarneuse J's mètres

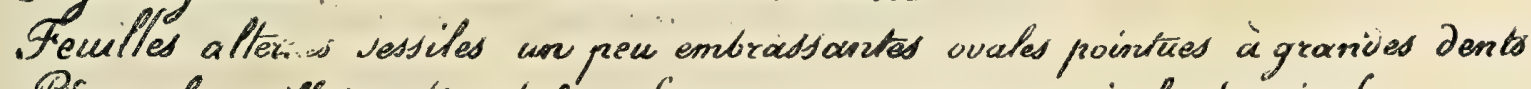

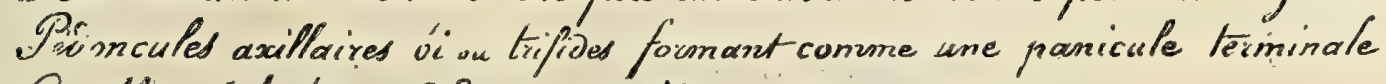
Corntles violaciés en Jelans rougeâtres en Dehrous Orangerie, Texce franche légure, mi-soleil, peu geam, Je graines sur coucrie, et J'éclats. Sith Desailler-K Jes excis in Tentastemon arguturn 



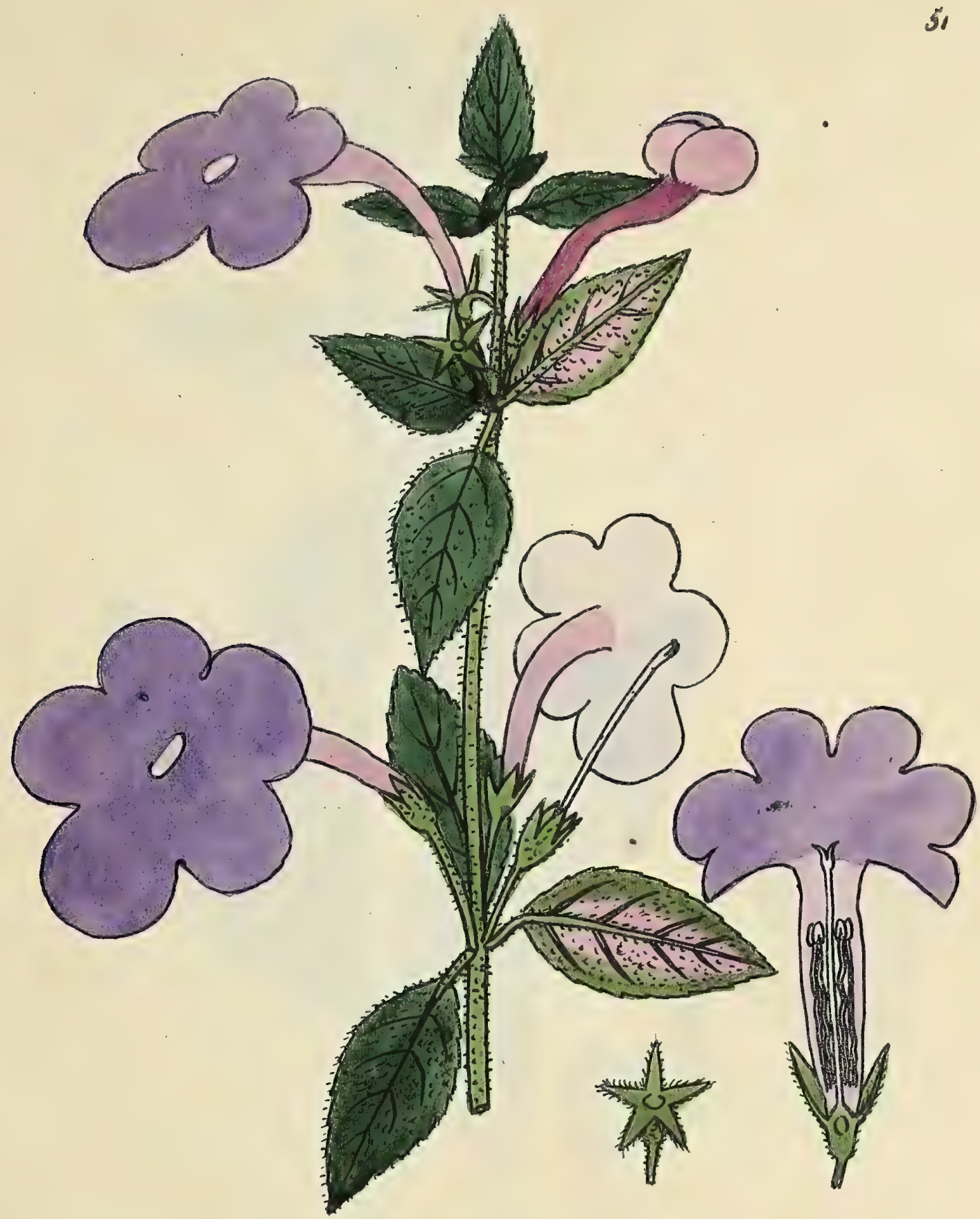

Tige ligneuse à la base à rameanox herbacós velus

Feuilles 3 par 3 petiolées ovales pointues, dentés, rougeátres en dessous Pédoncules axilflacires, Jolitaices simples velus

Porolle à tube long, courbé, rougeâtre, limbe d'aumoins śrentimnètres, violet.

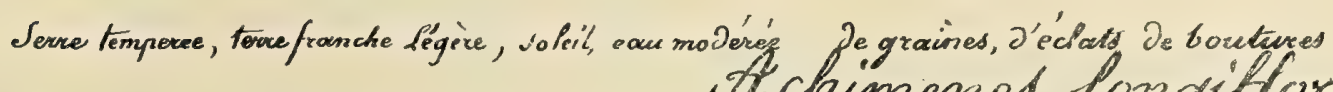

Lith Desaillet $\mathrm{k}$ Jed axcis $1 \mathrm{y}$

cher fornicher $R$ bes 3 couronnes 14 
.

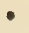

- 


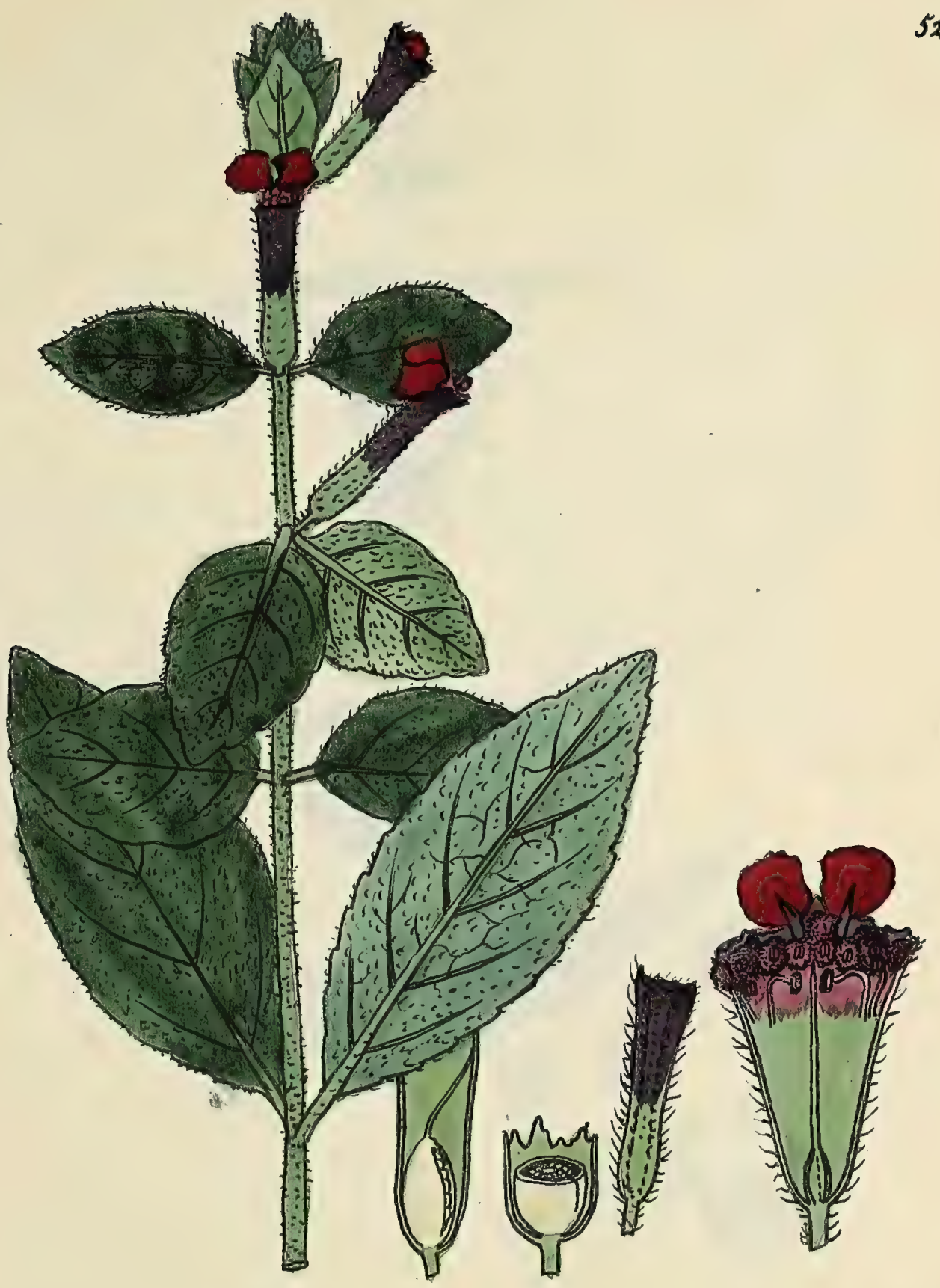

Tiged rameuded, cylindriques, à poils wöwes, de 30 à 50 centimètres Feuilles arzusées à pétiole court, elligntiques, dentées, poilues, les suprérieured avorondris

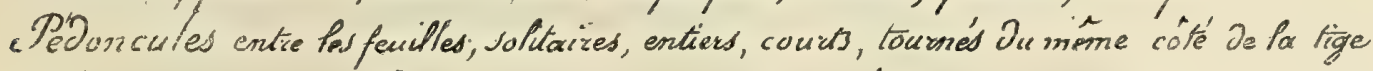

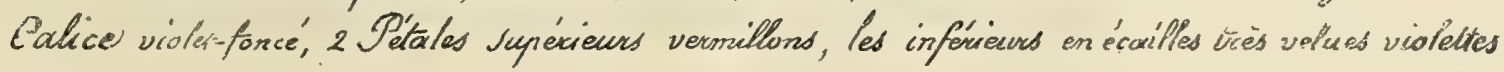

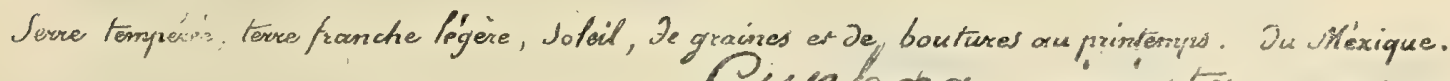
Lith Jesociltit 20 Des arcis ng

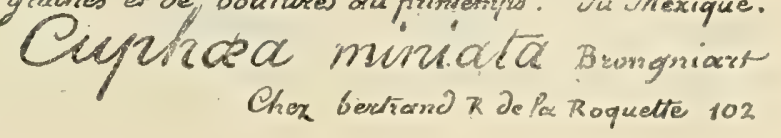





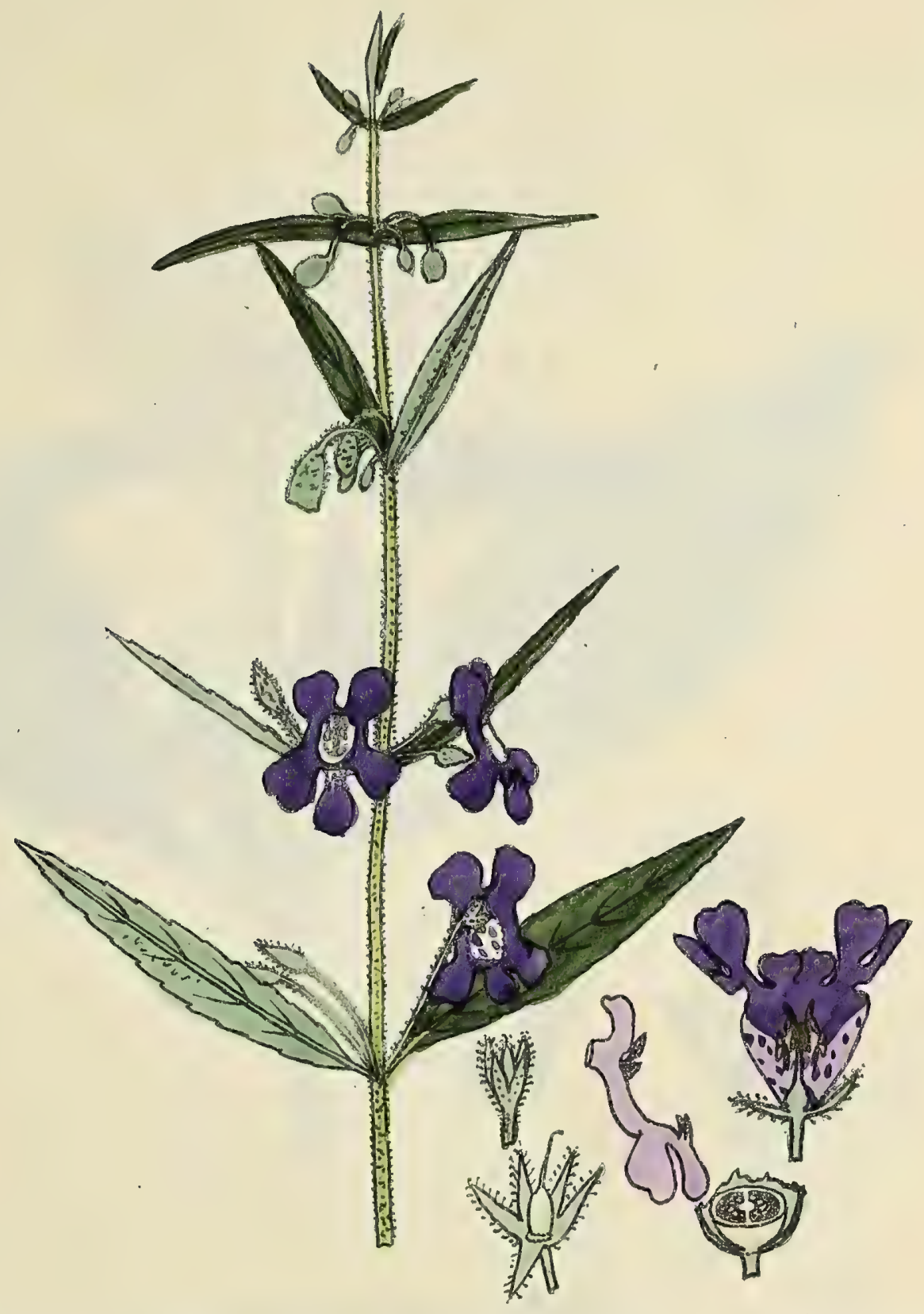

Tige ligneuse à la base, zannewe, cylindrique, velue, de 30 à is centivinèred Feuilles opprosées, à prétiote court, ovales-lancéolées, Dentés, Pedoncules axillaixes, simples, 2 parr2, velus.

Cocolle violette, à gorge plus pầle, mourtetée de foncé

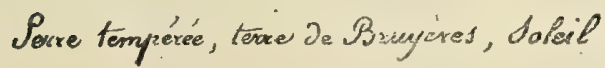

Lith desailler-k Jes arcis if

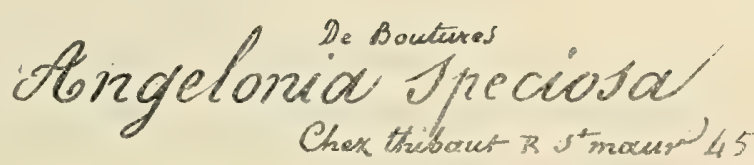





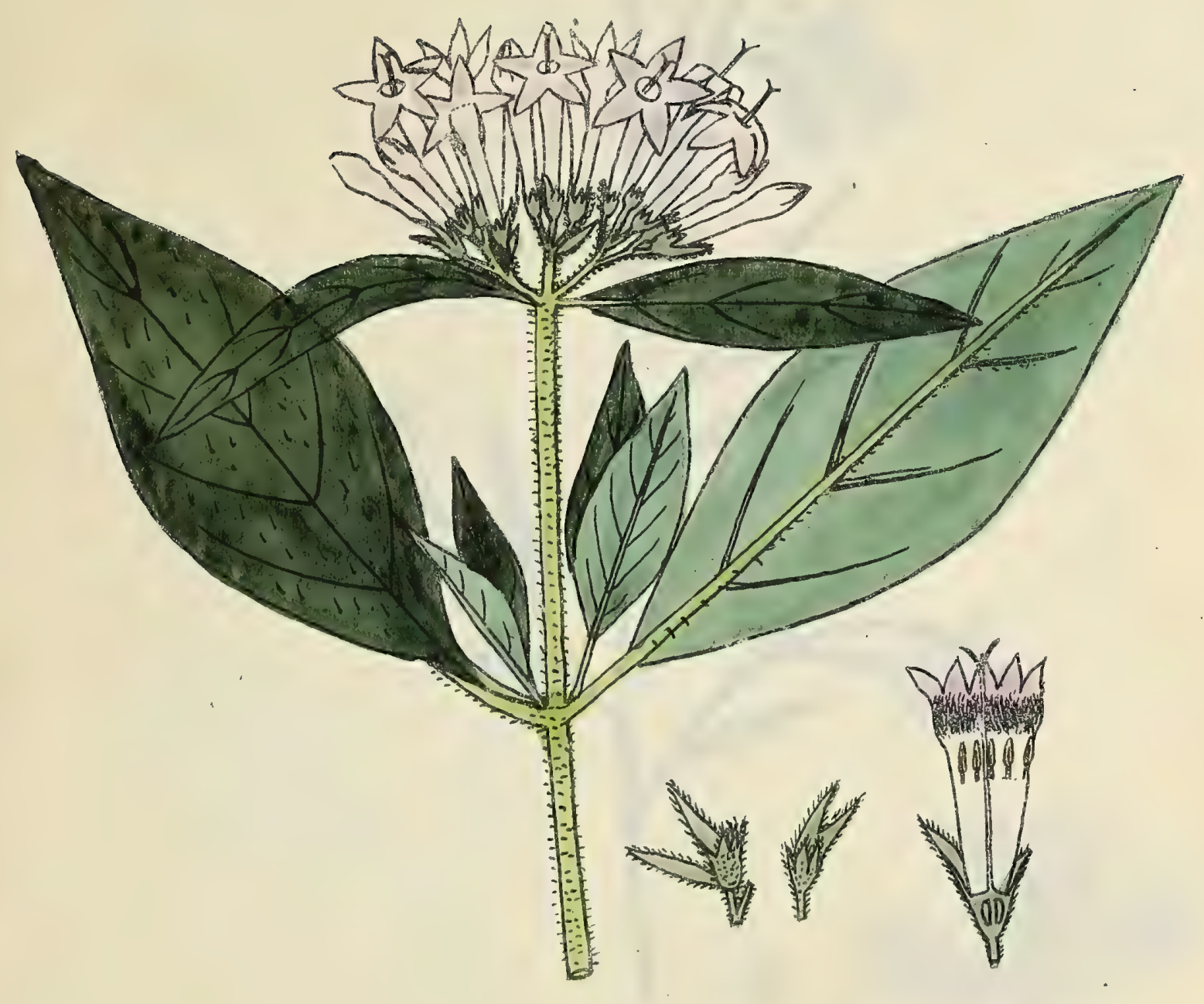

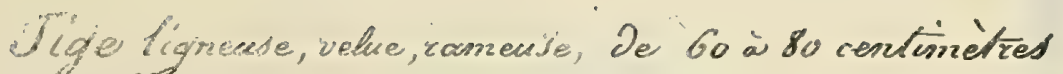

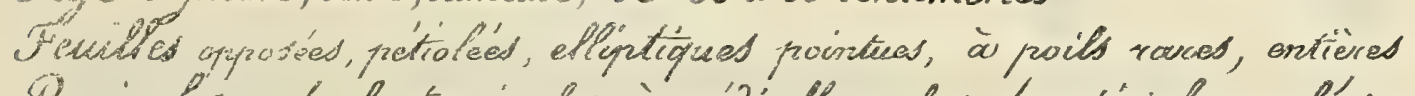

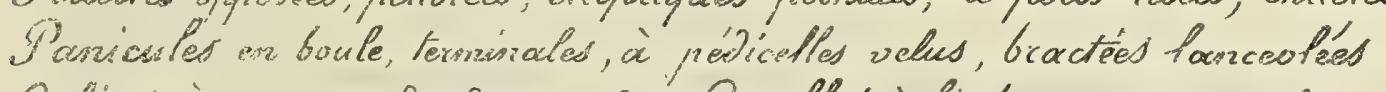

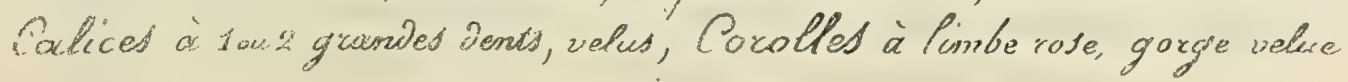

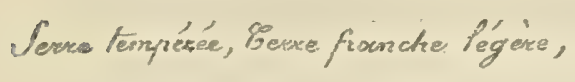

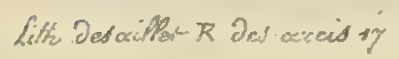

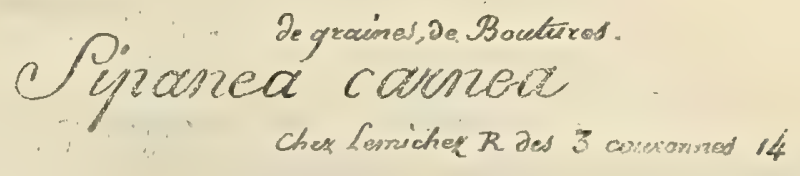





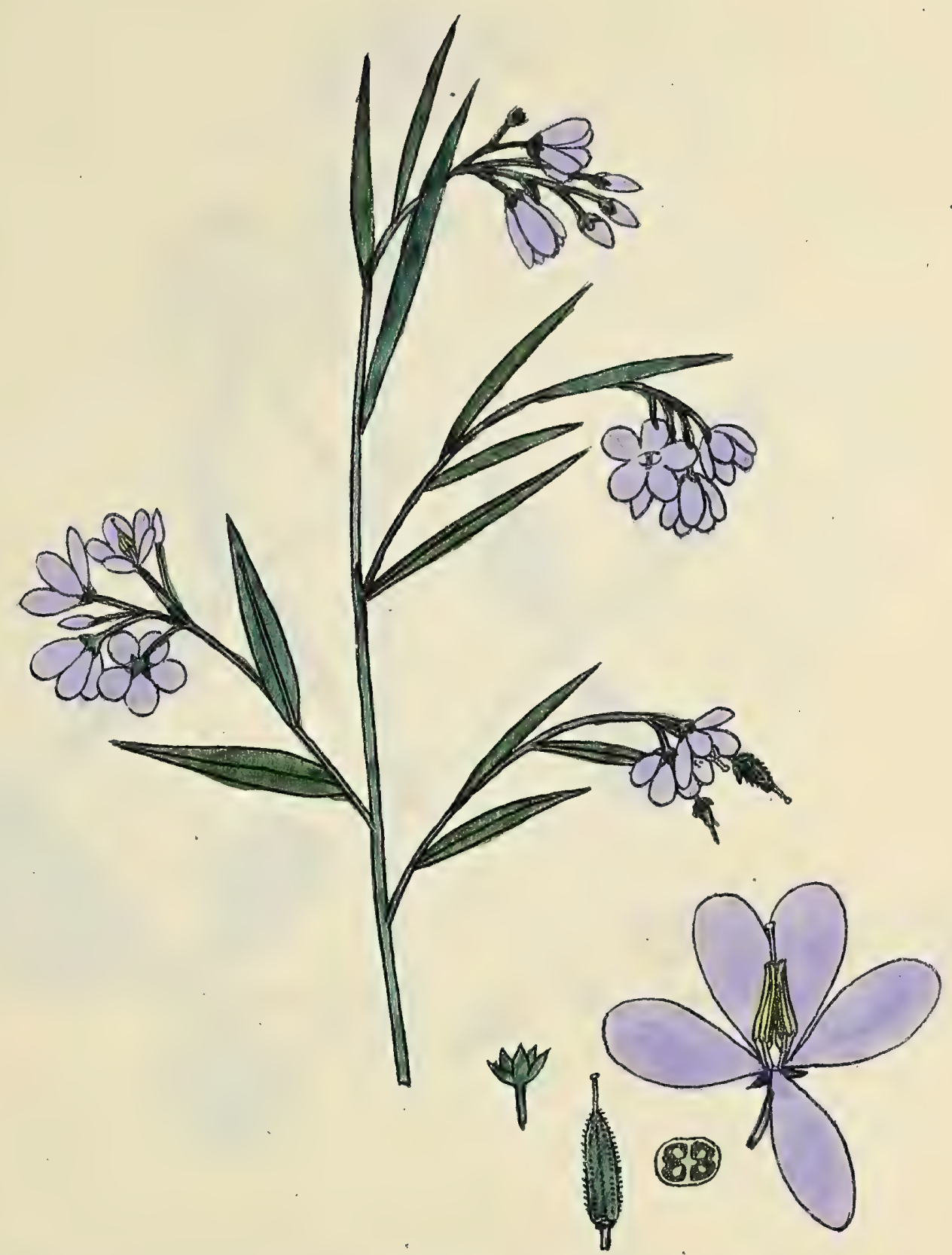

Tigè lignende, cy hiswrigue, romeude, glabre, de 40 à to centimètres Teuilles alternes, sessiles, lineaiced-lanceolés pointues, glabres, cntières Gis ow Paniculed de 4 à 8 Fleurs, fateraund et terminaux Tétales auper foncé, antheices conniventes

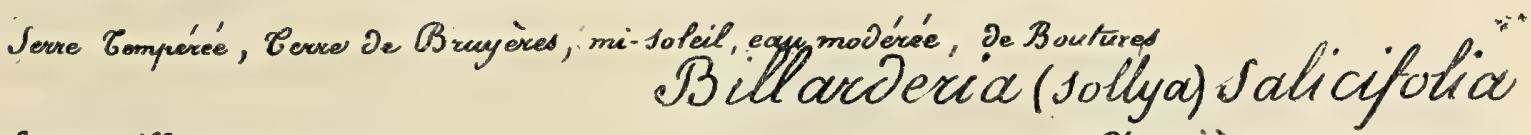
fitt Desocillet $R$ Jes axcis 'y chen Chouvière Rarfa roquedto 104 



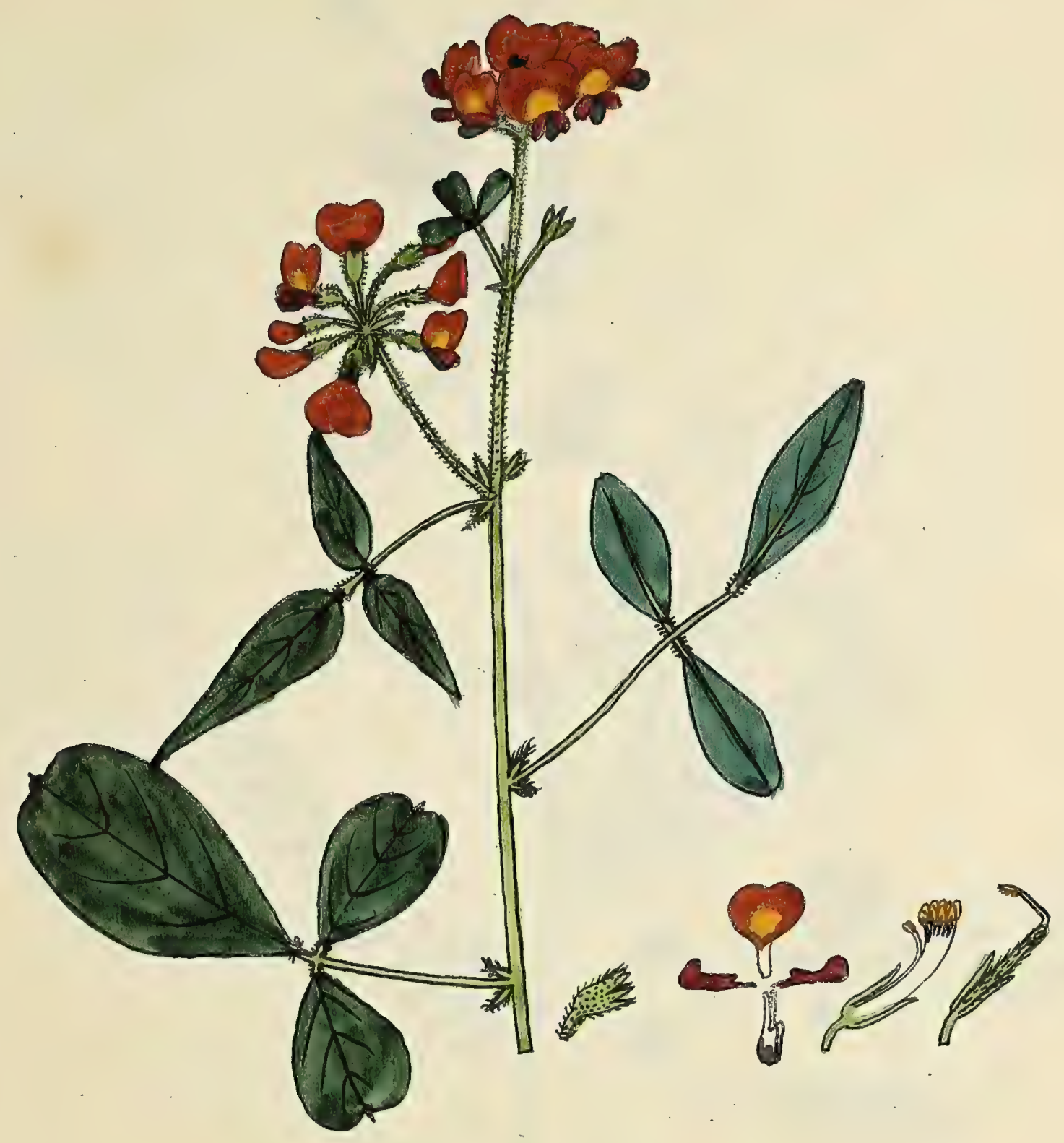

Tige faible volubile De so à 60 centinietres verte glabre Feuilles altrornes, pétiole lorg, 3 foliofes on lance en hout obcordées en bas, prériolules Pêtes de 6-1ofreurs à piédoncules velus, axillaices et terminacusa

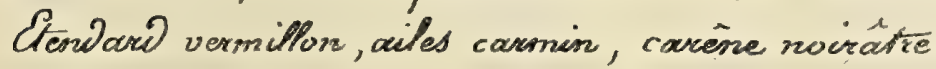
Peguome glatire

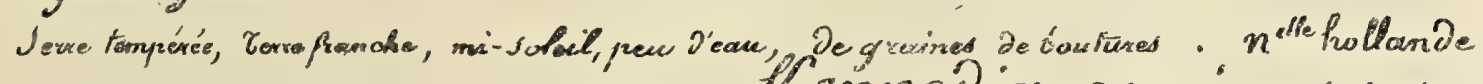
Reruncia coccinzea venternat

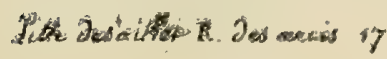

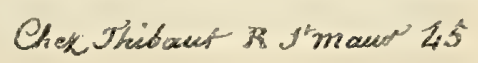





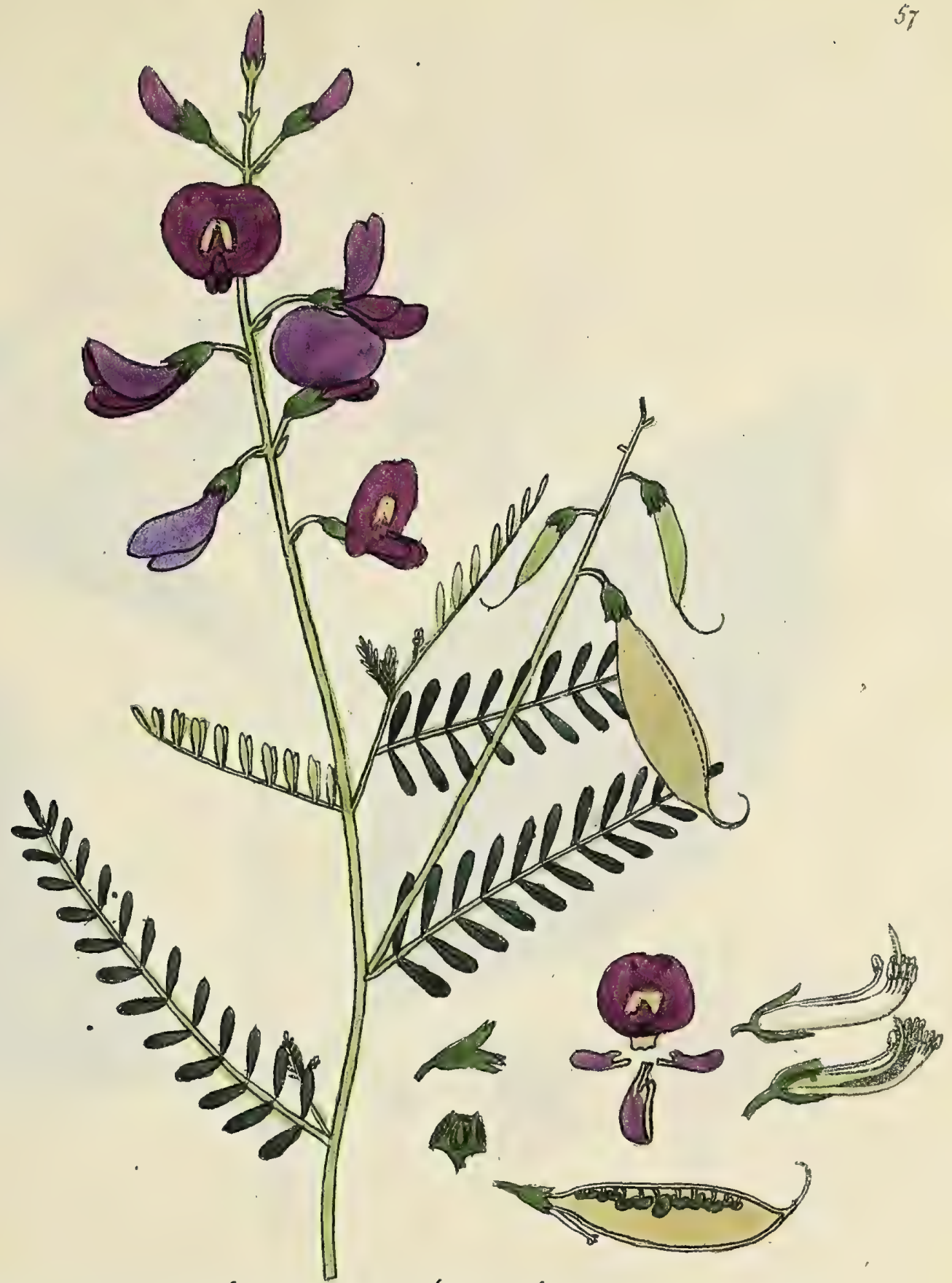

Tige fignause, ramense, cylintorique, droite ferne, glabre, de 60 à 80 centimètres Feuilles altermes de 19 à 25 fofioles opprosees sestited, obovales

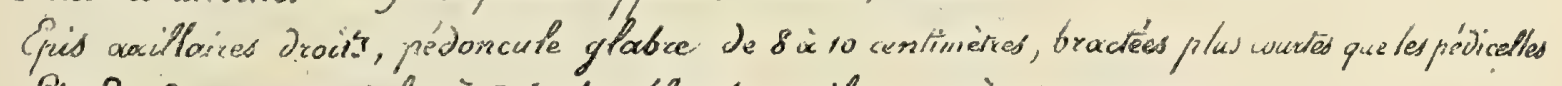

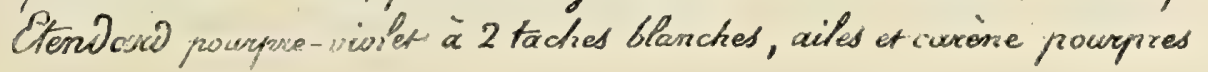

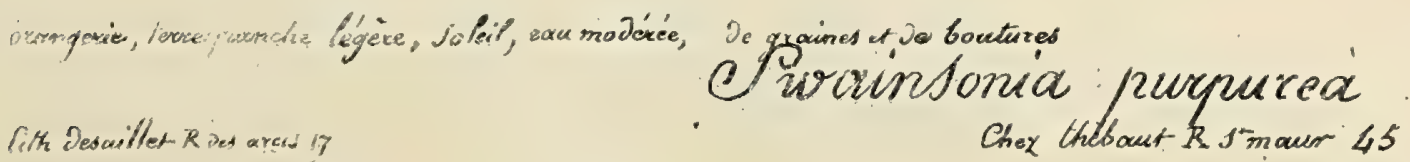





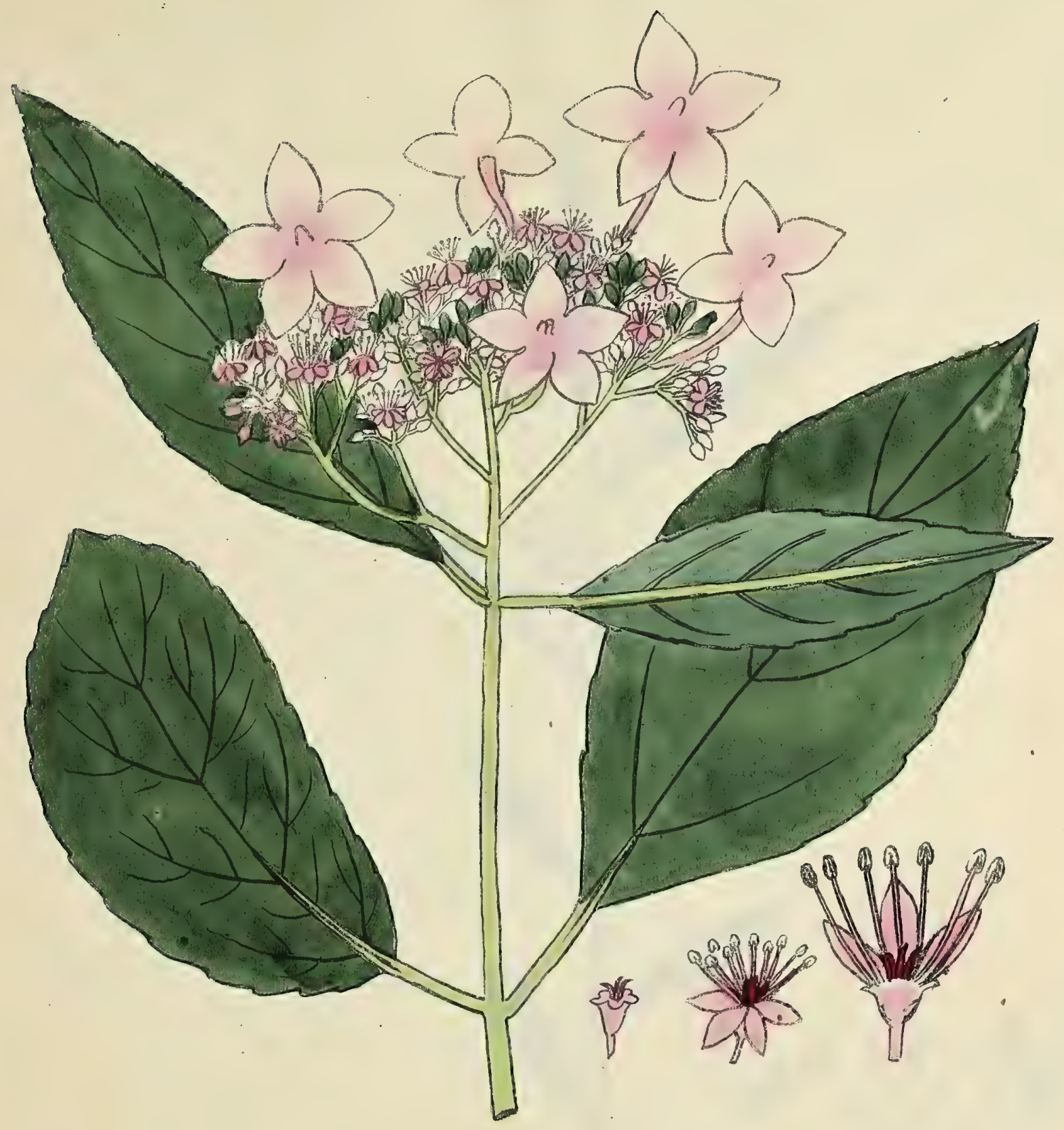

Tide ligneuse, tres rameuse, arrondie, glabre, J'1 métre.

Feuilles opposées, pétiolées, ellyztiques, pointures, dentées, grabres.

Panicutes terminales, très larges, on boule.

Técales et involucres (fleurs stériles) woses

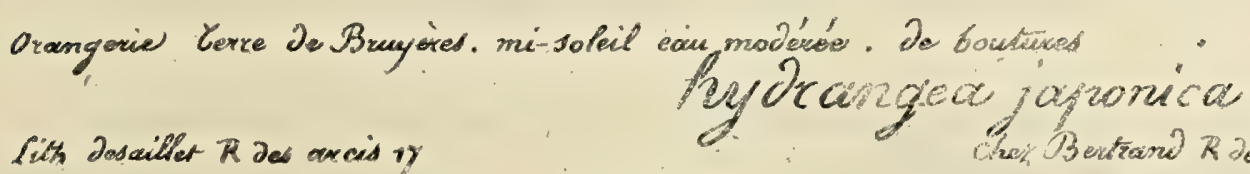

Chey Bentrand $R$ de fa Rorvette $10 \%$ 



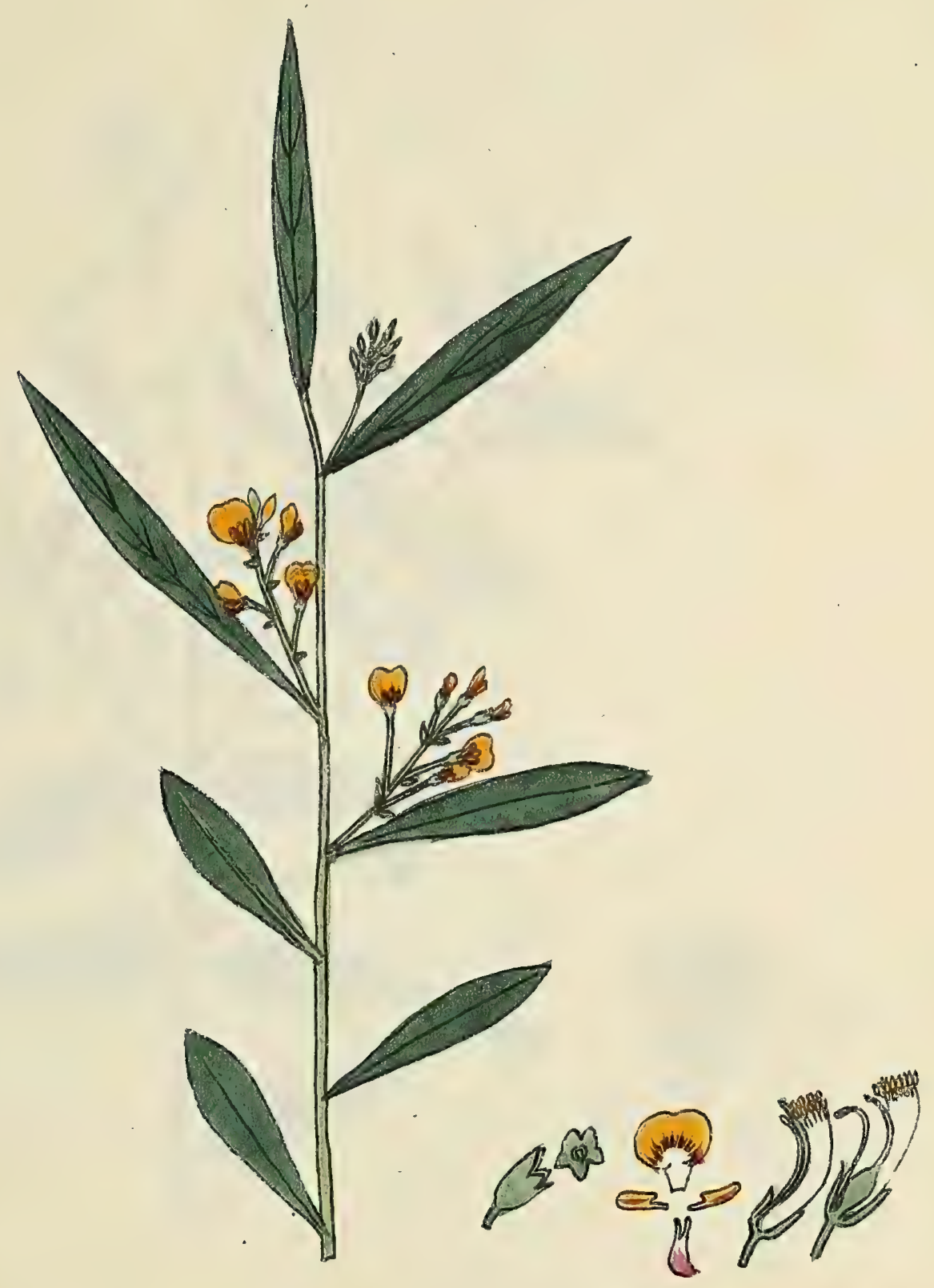

Tige ligneuse Droite ramense gylinorique

Feuiltes alternes à peine pretiofées oú-ovales lancéolés, glabres

Gris axiltaires de G:8 fleurs à predicelles longs, bractées courtes aigues Pendaw et Atiles jaune-fauve rayés de rouge, Parione brune

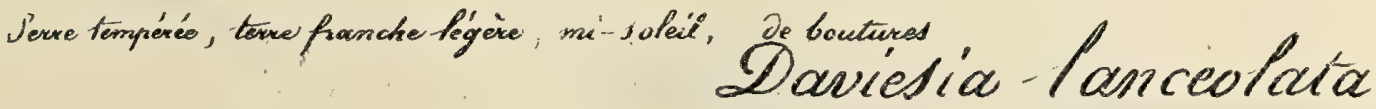

Lith Descriller Ras aresis chec Lemiches $R$ Das 3 roustonties 14 



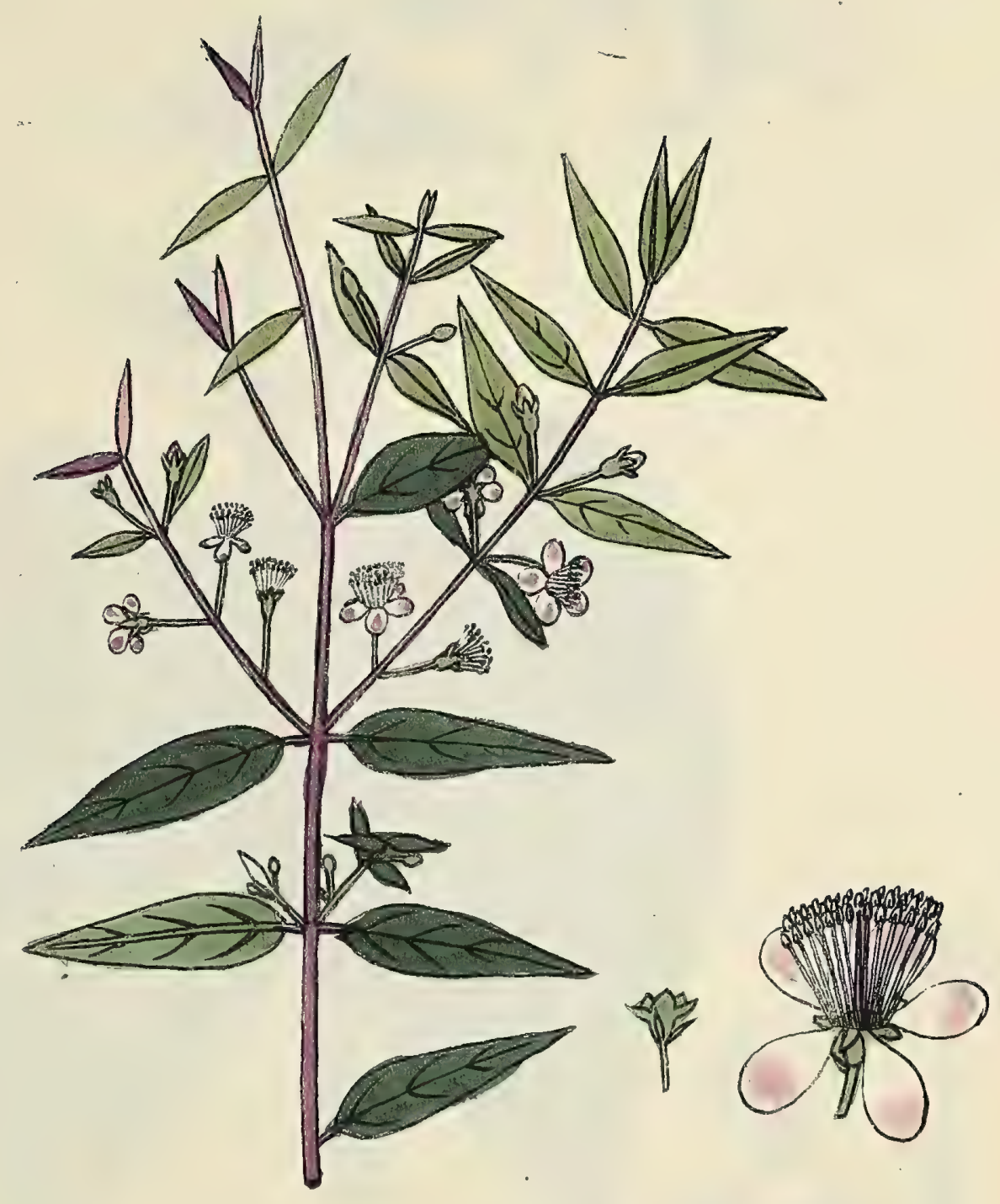

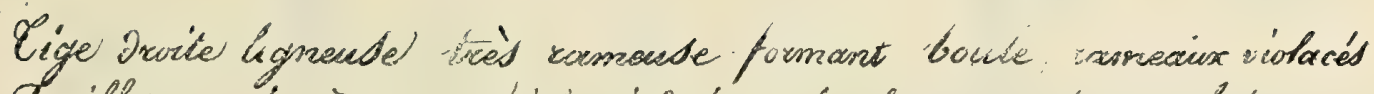

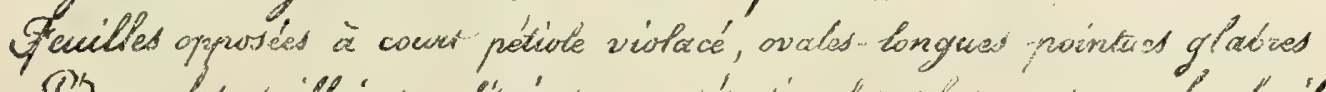

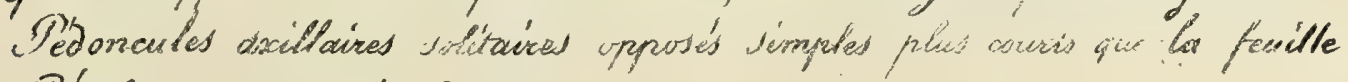
Pitales blonnce tachés oe rose

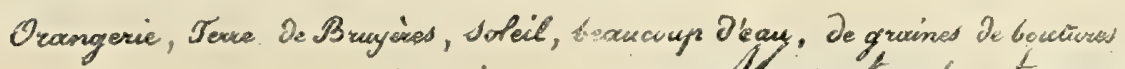
Sith Desciller $R$ des ancios y Moyretus tonserifolica 



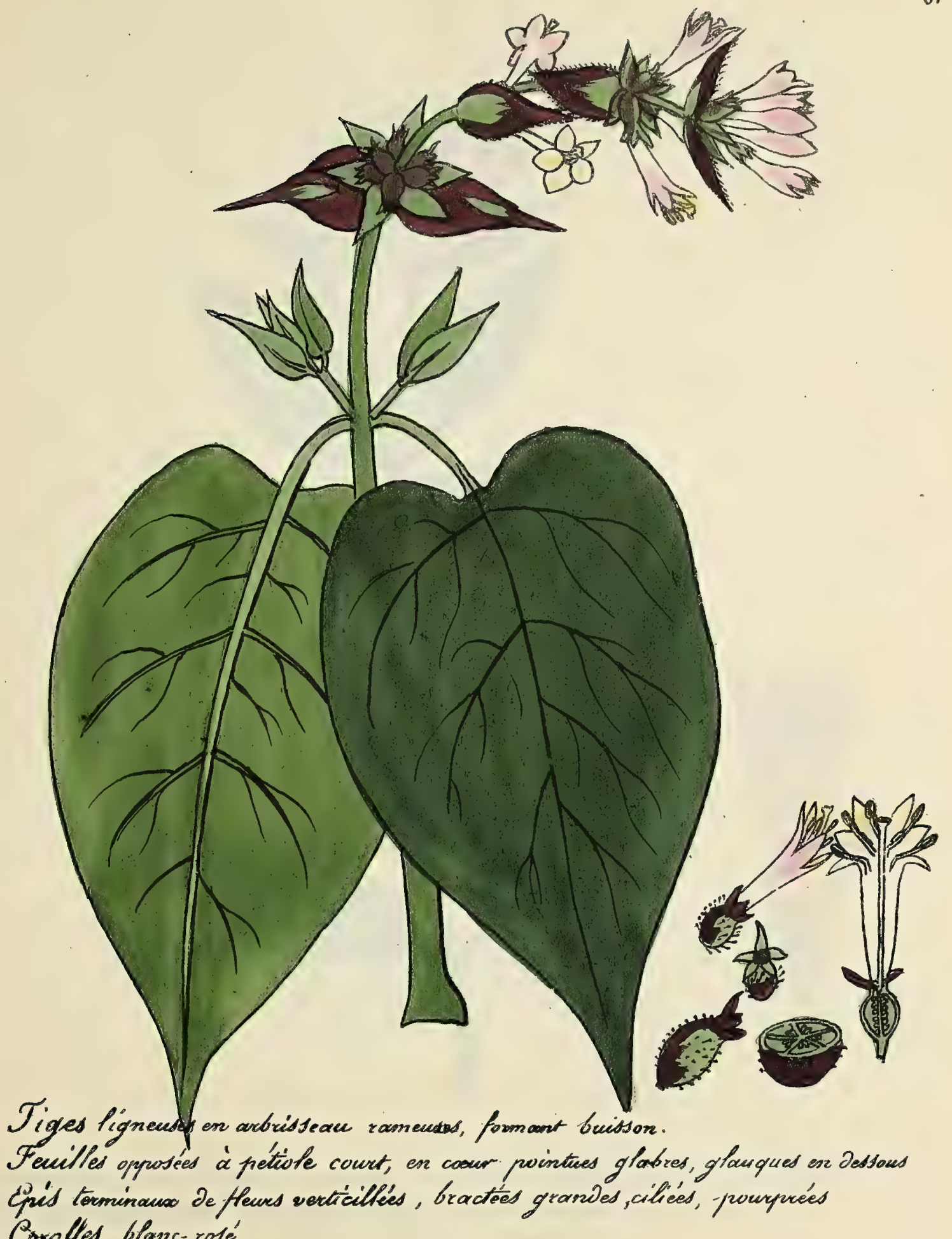
Paroltes blancerosé

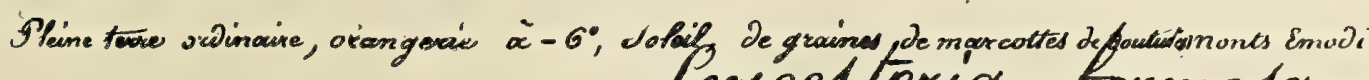

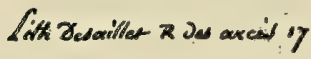
leycesteria formosa wallich 

62

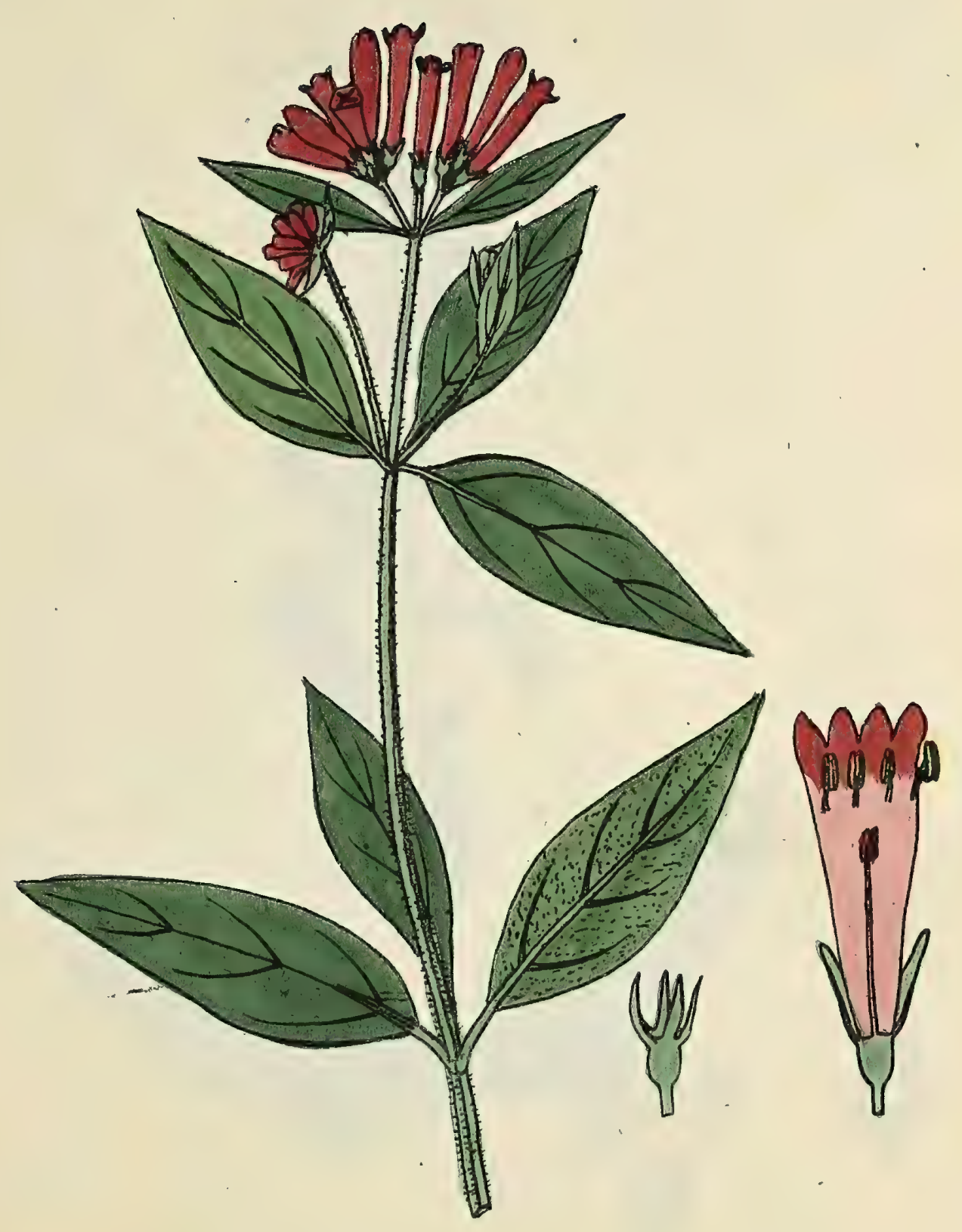

Tiges figneuses rameuses de so centimeitres rameausc trigorres pubesconts Feuilles ternées ovates - oblonques, prointues, pubes centos en dessous Panicules trichotomes terminaled un peu en boule Calice cownt, Corolle prestque cyfindrigue powypre

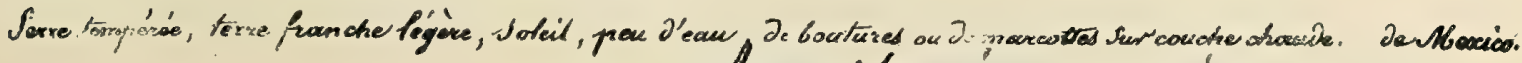
houstoria coicinzed inviens

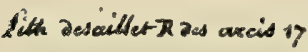





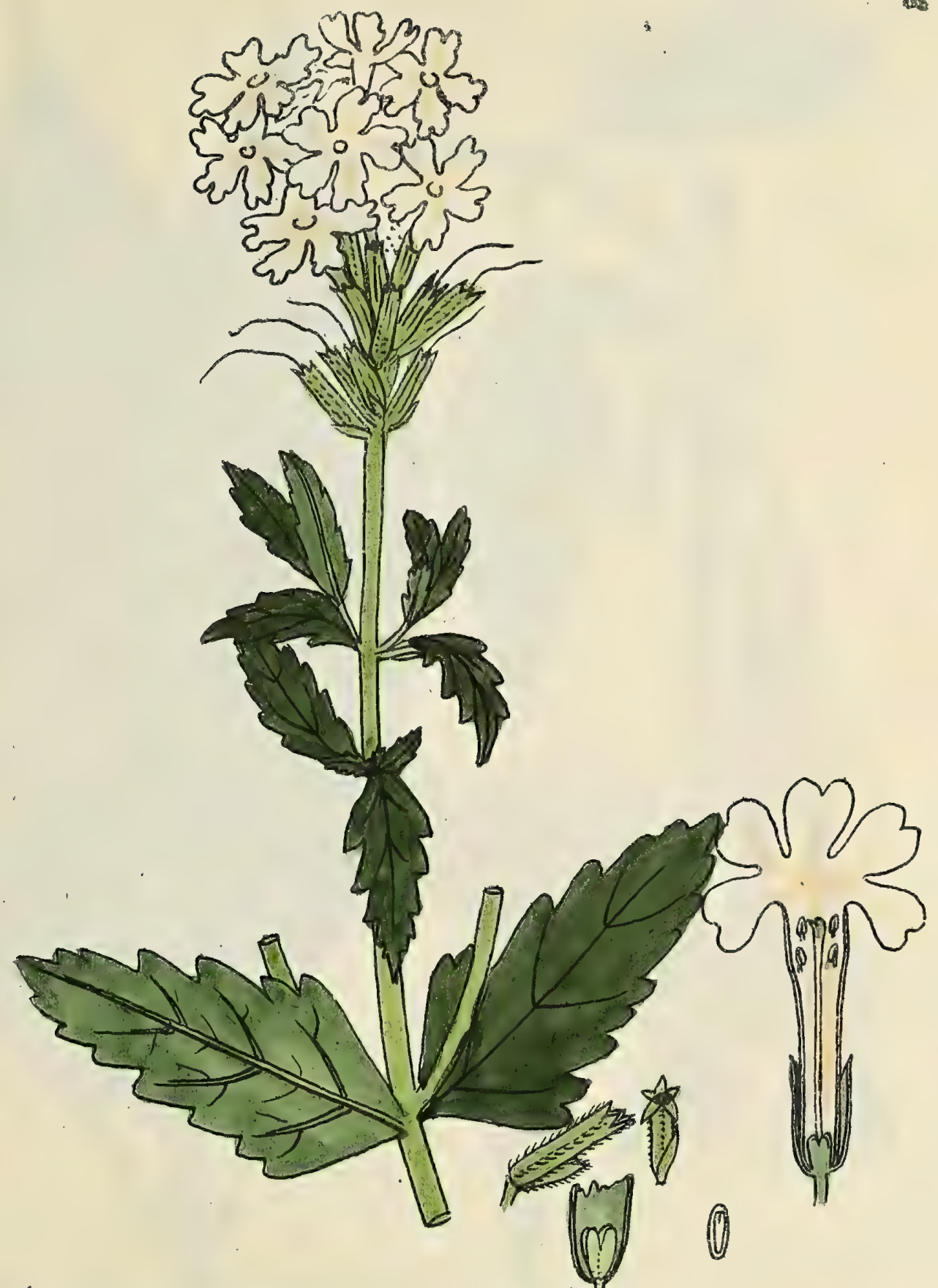

Tige couchée à labase sulement, rameuse, herbacée tou Jommet Fevilles opposiés Jessiles ovales à tries grosses dents Gris terminaux, Drvits, de fleurs Sabsiles nombreused, dervied Corolles blanchâtred à odeur Douce

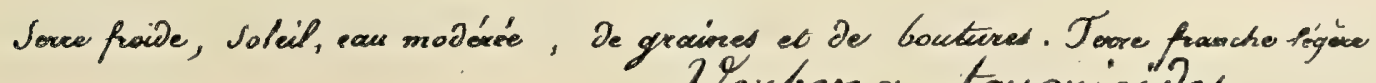
Site Desaither $x$ in arcis sy 



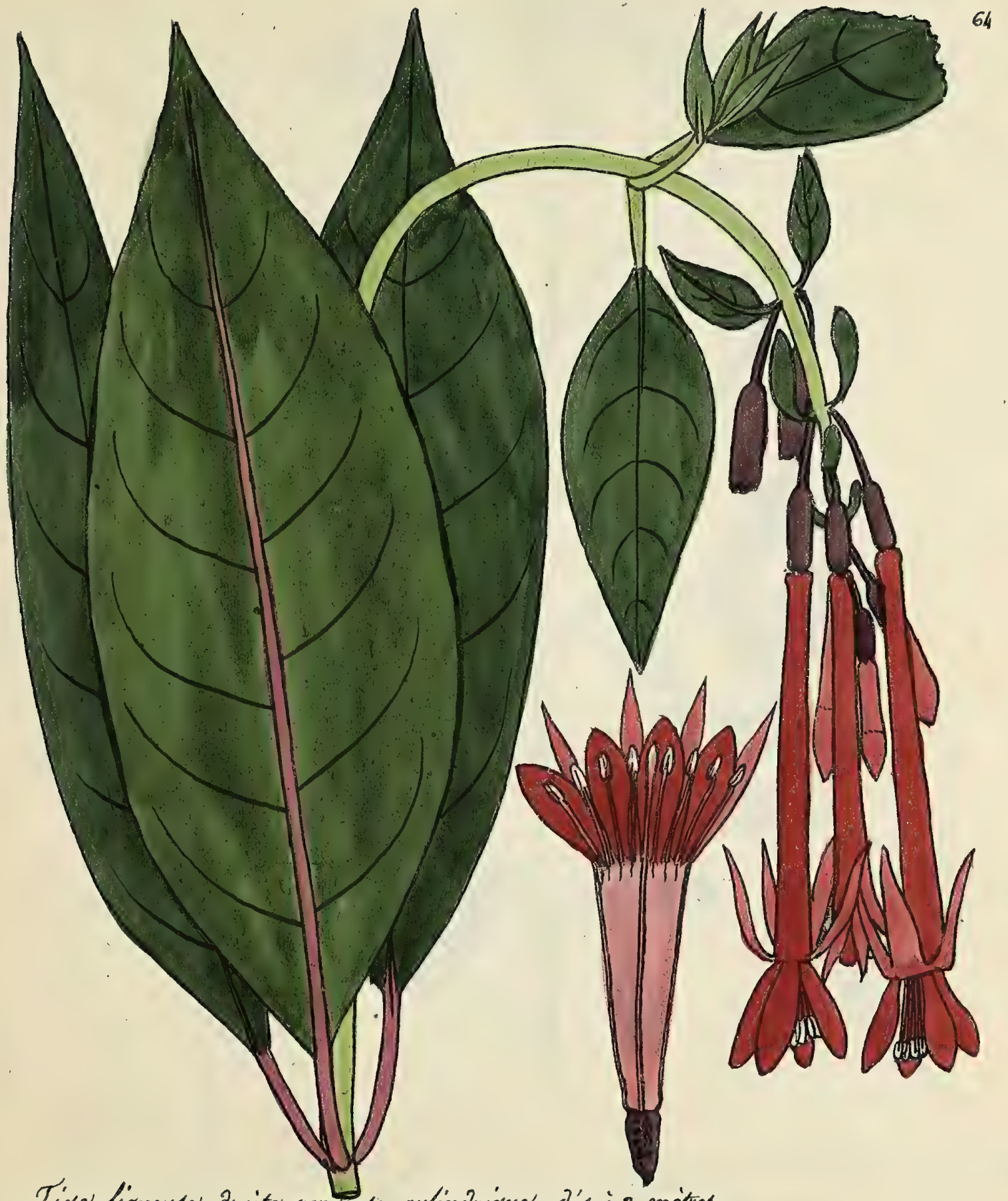

Tigel ligneuse aroite rameuse cylinelriquel J's à 2 metres

Faulles opyrosées et terriées ellijitigues-fongues, prointured, à pitiofe court.

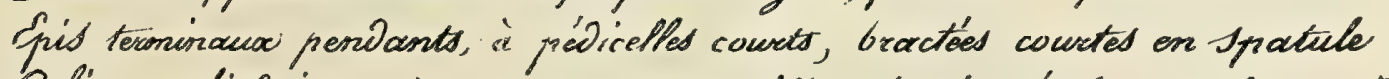

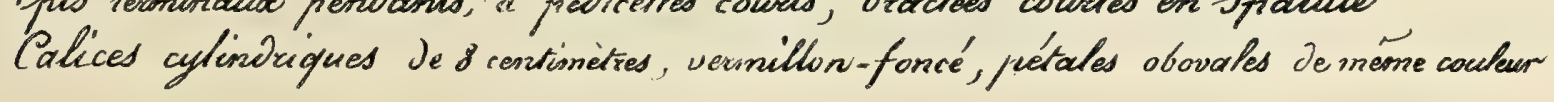

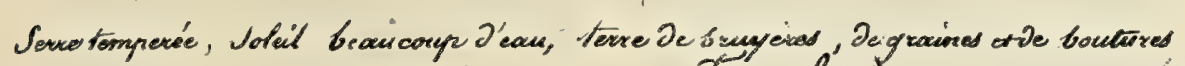
Fuclisid conymeth flord nuiger Paron

fich Detaritter $R$ pes arces in 



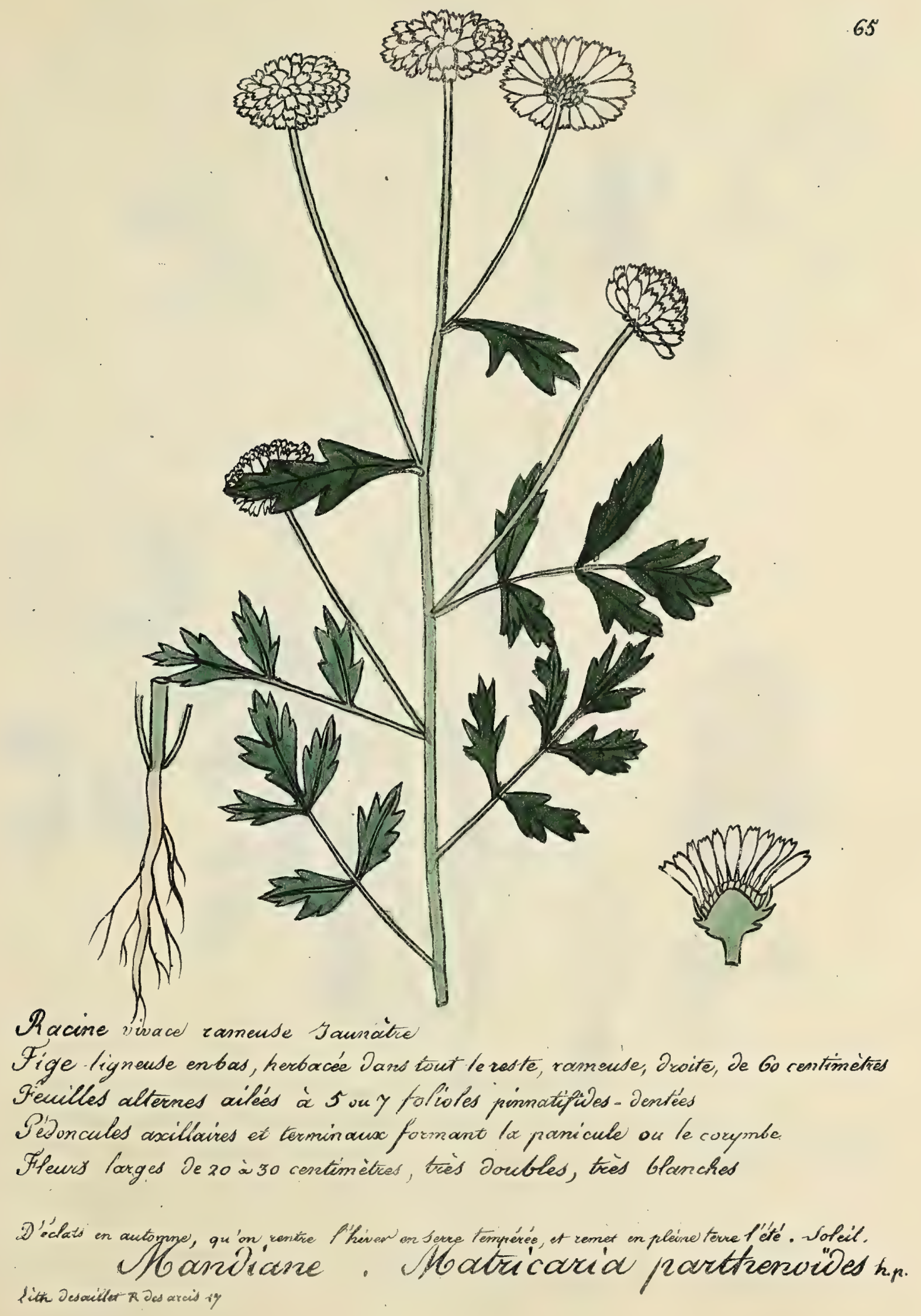





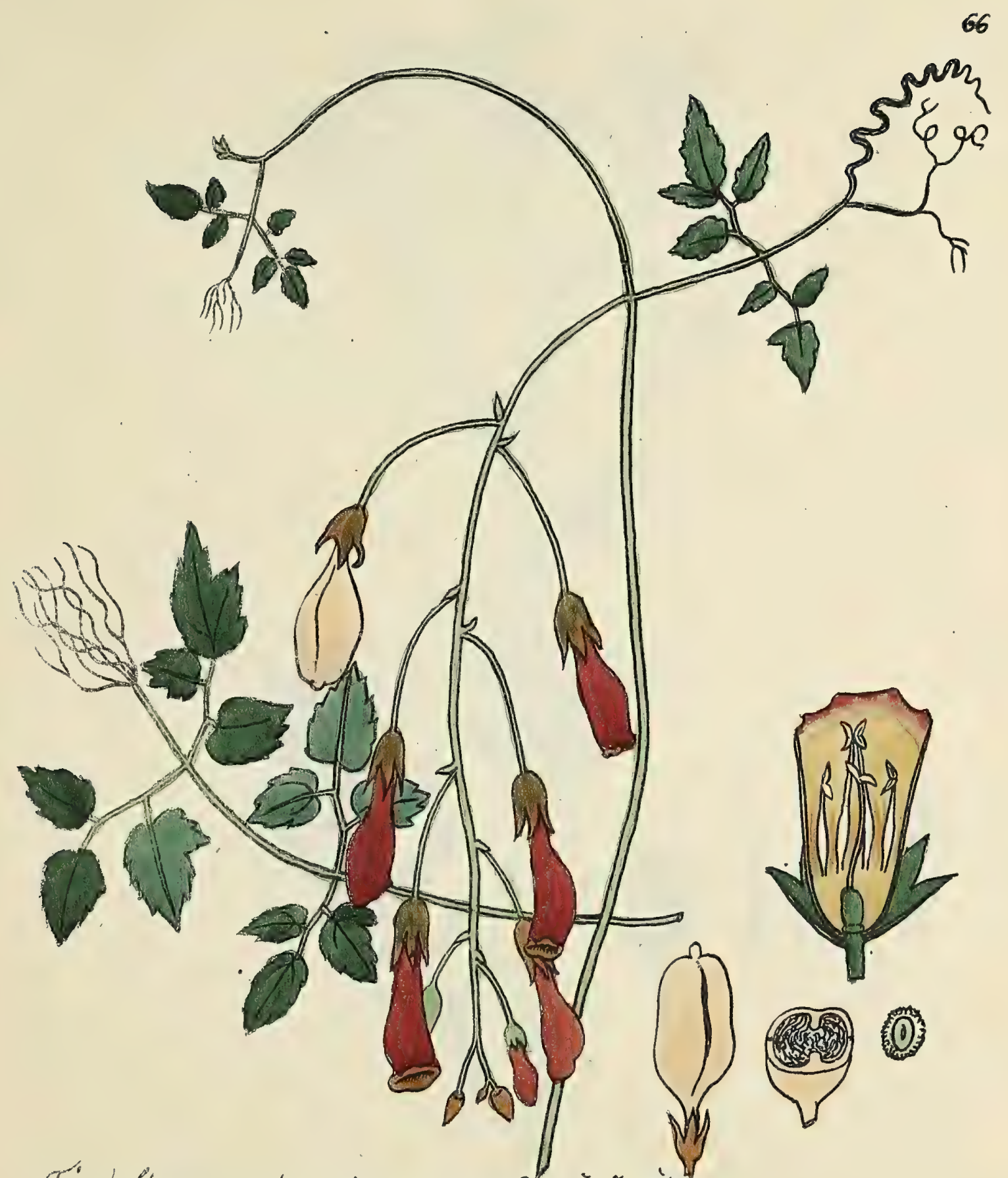

Tigel ligneute grimpante rameuse de 2 à smètres

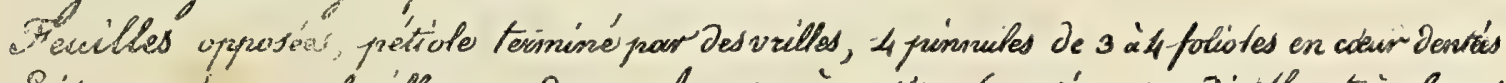

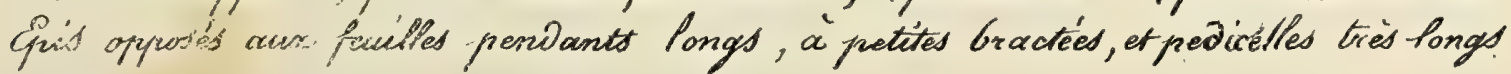

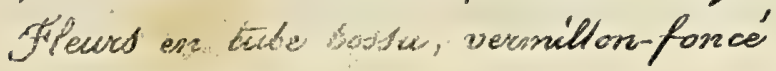

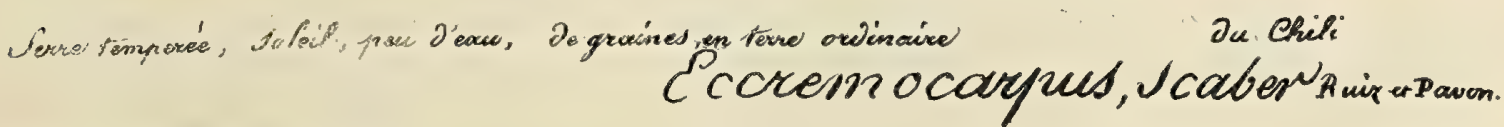

Sitc Desaillet R acs arcid ty 



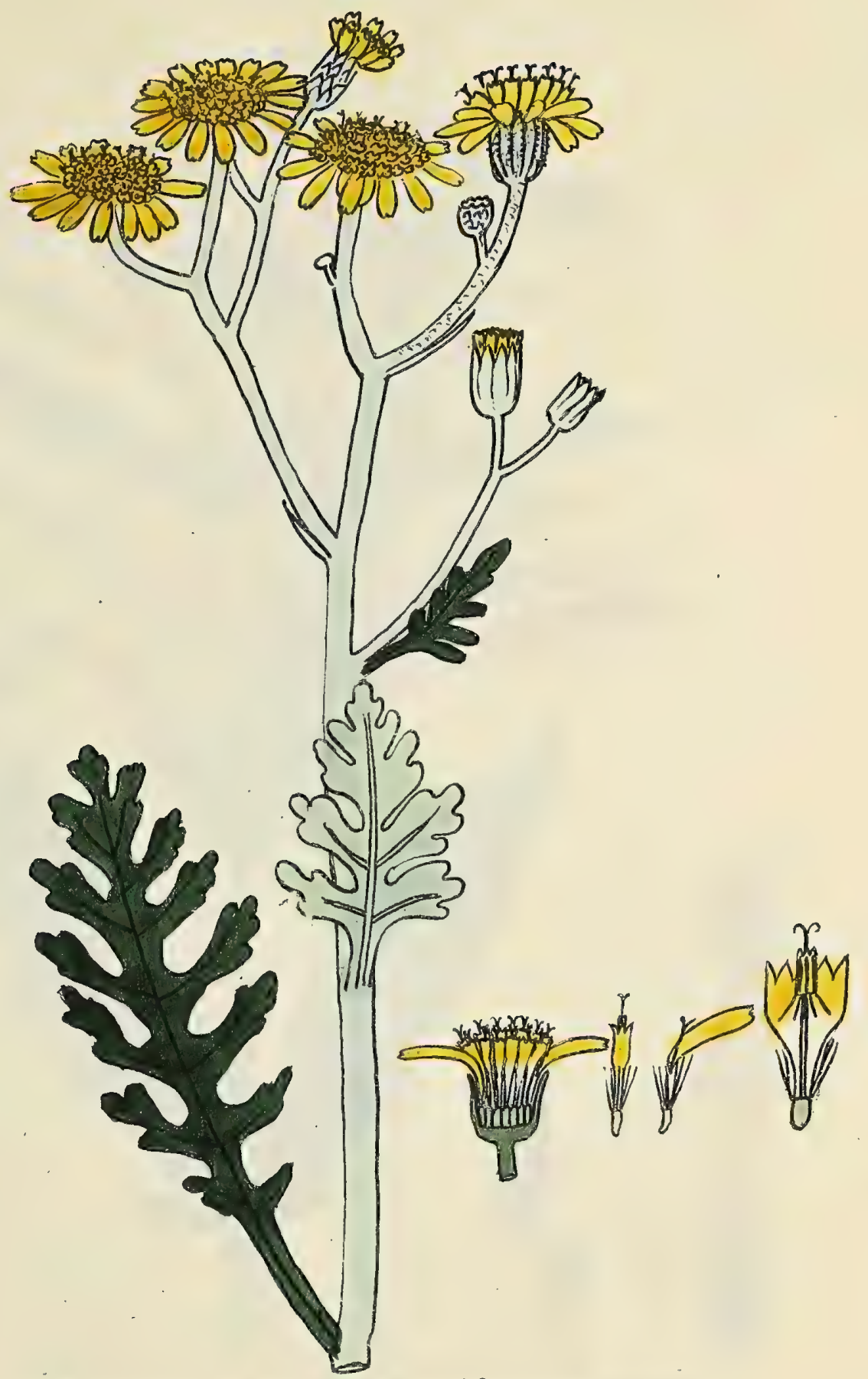

Tigo Ligneuse Droite romende de Go cenvimètres blanche cotorimense

Feuilles alternes pirinatifides à lobes arrondis à 3 rue 4 Dents, blanches coturneudes Dexsous Paricule en corymbe de fleurs nombreuses

Calice treis cotonnewx, Parofles toutes jaunes

0

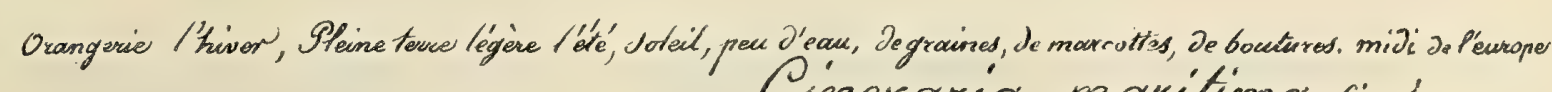
Ciscercuria mavitima simné .

Libt Desailler $\$$ Jes arcis 17. 



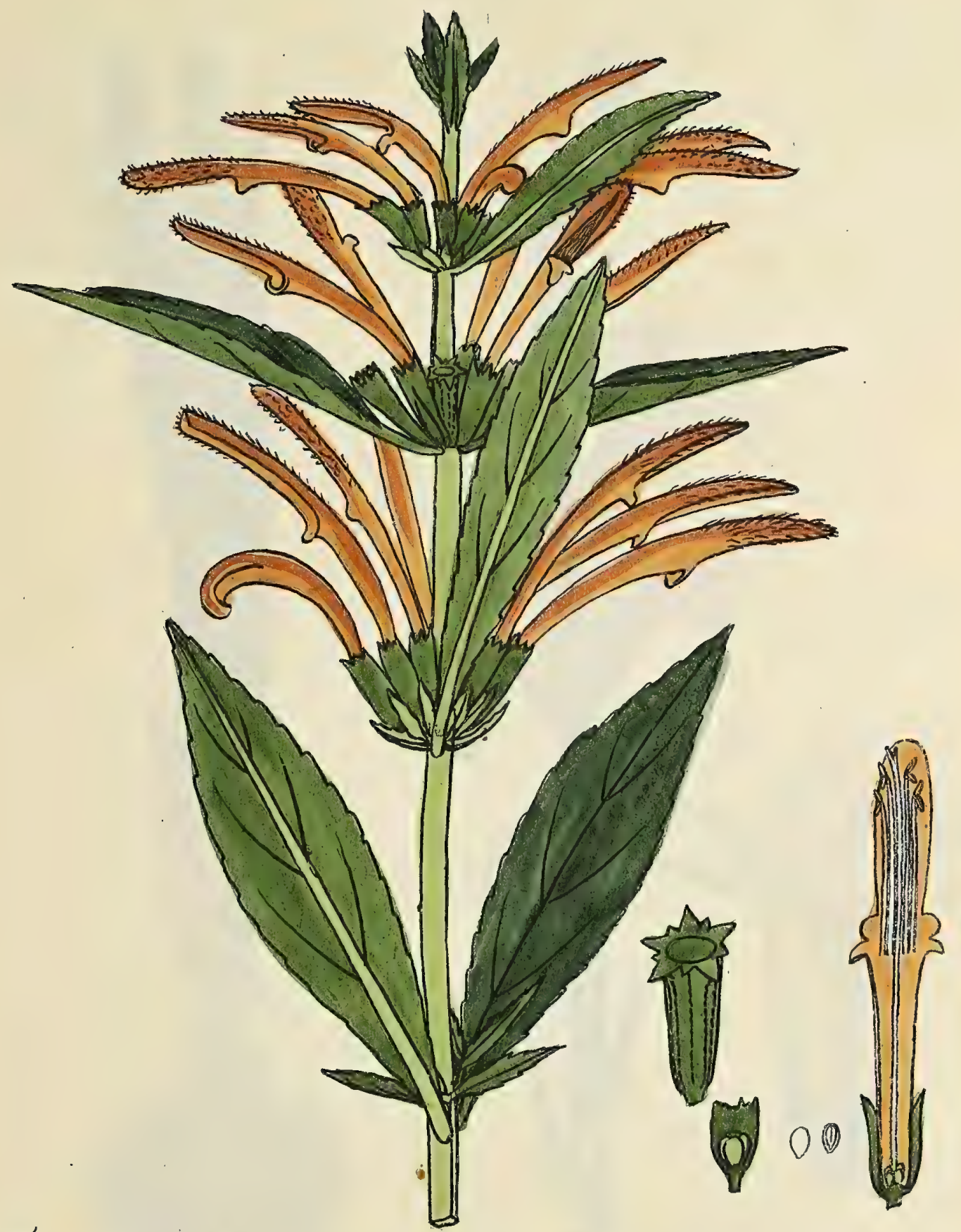

Tige lignense, Oroite, rameuse de 1 à 2 mètres cylindrique, ramoducor carrés

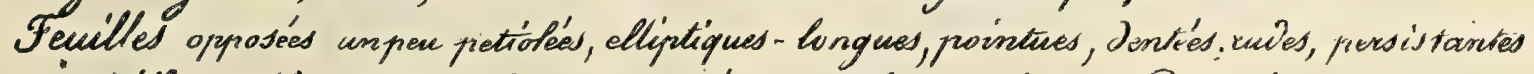
Vexticittes de flewrs sessifes formant des épis simples, torminaux, Braciées courtes Calicet prismatigue glabre à dents courtes recourbées. Corolfes longues aurores

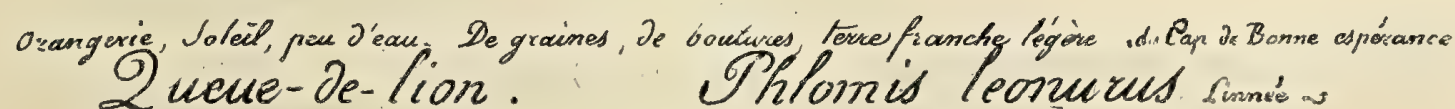
Lith Jes aiflet $R$ jes arrex' in. 


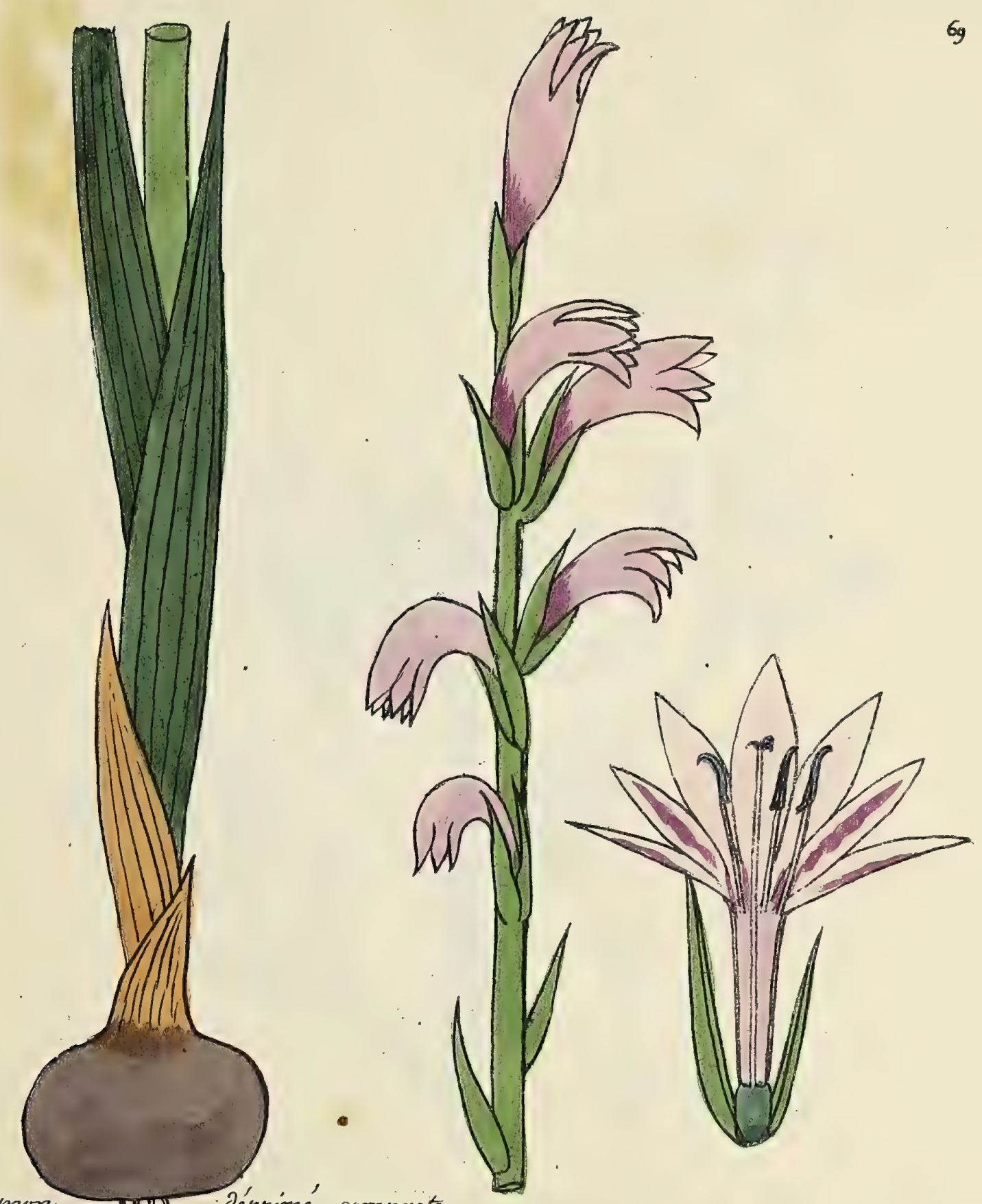

Ogrow ThK Déprimé compacte Sige Jroitel ferme herbacée Jimple J's mitre Leculltes engainantes alternes formes en éreé Eni. De 15 à 20 frewes alternes se cowibant touttos D'un mêne coré Fleurs rodes-violacées

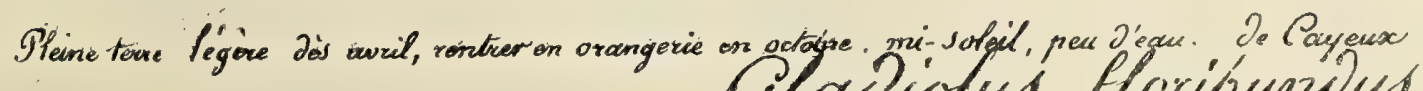

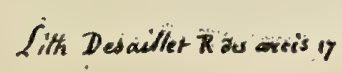
Glabions flovioundus 



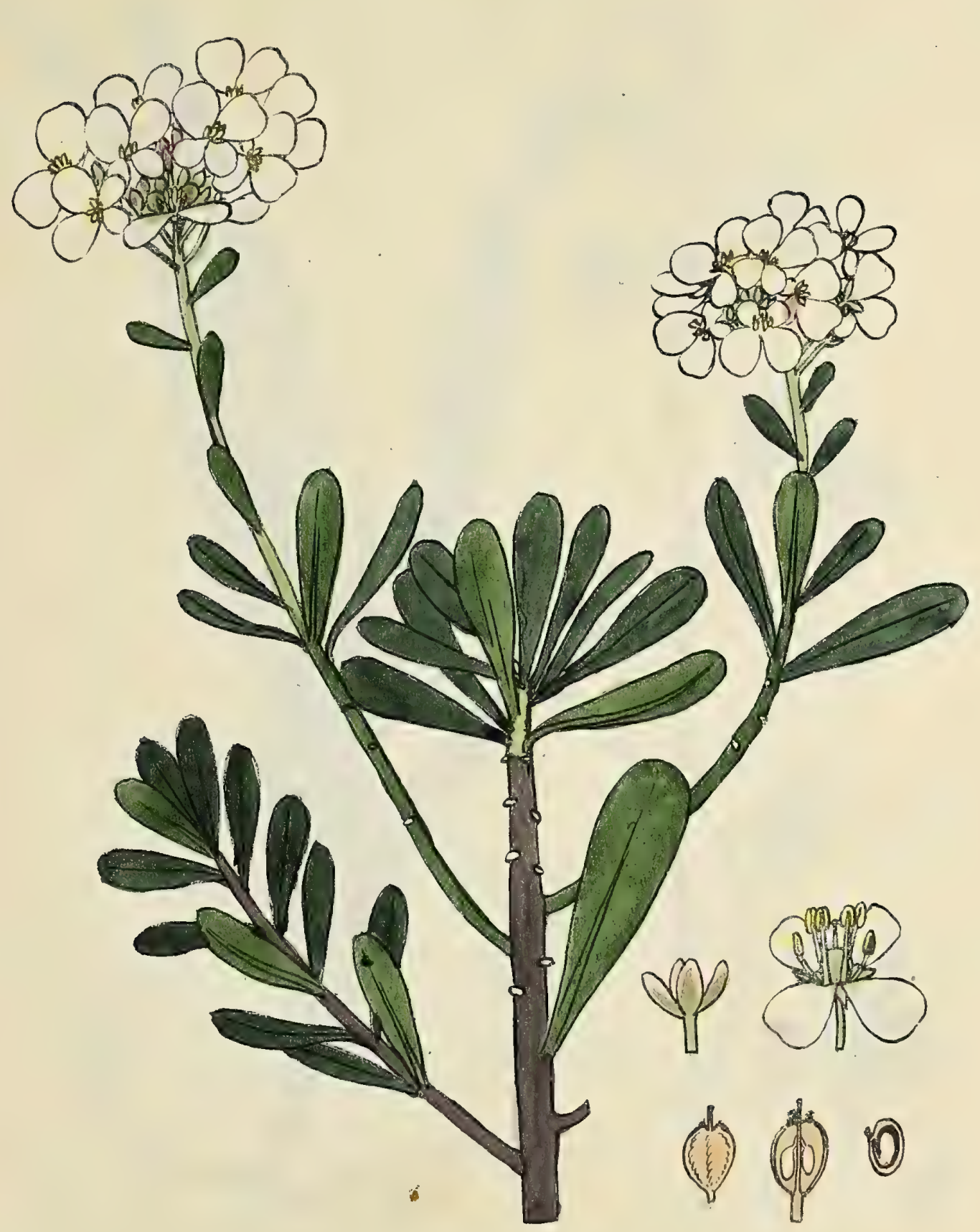

Tige lignewse Jroite de 50 à 60 rentimètres, rameaux ligpreux nombreux on tete F'escilies éracies sesfites en spatule très entières, glabres cociaces épaissed persistantes pis termiraus sowis foomant corymbes

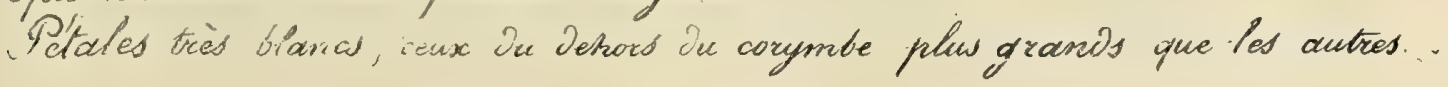

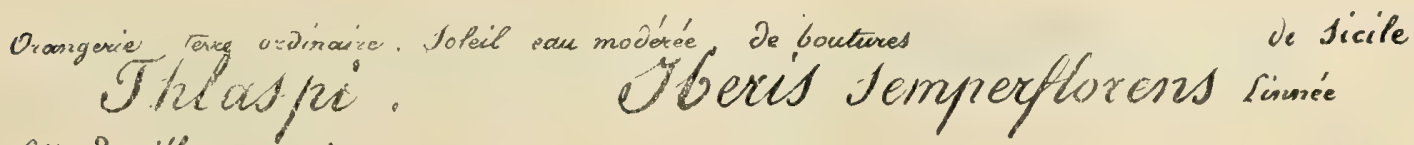
Sith Desaillet $x$ sis axeis $y$ 



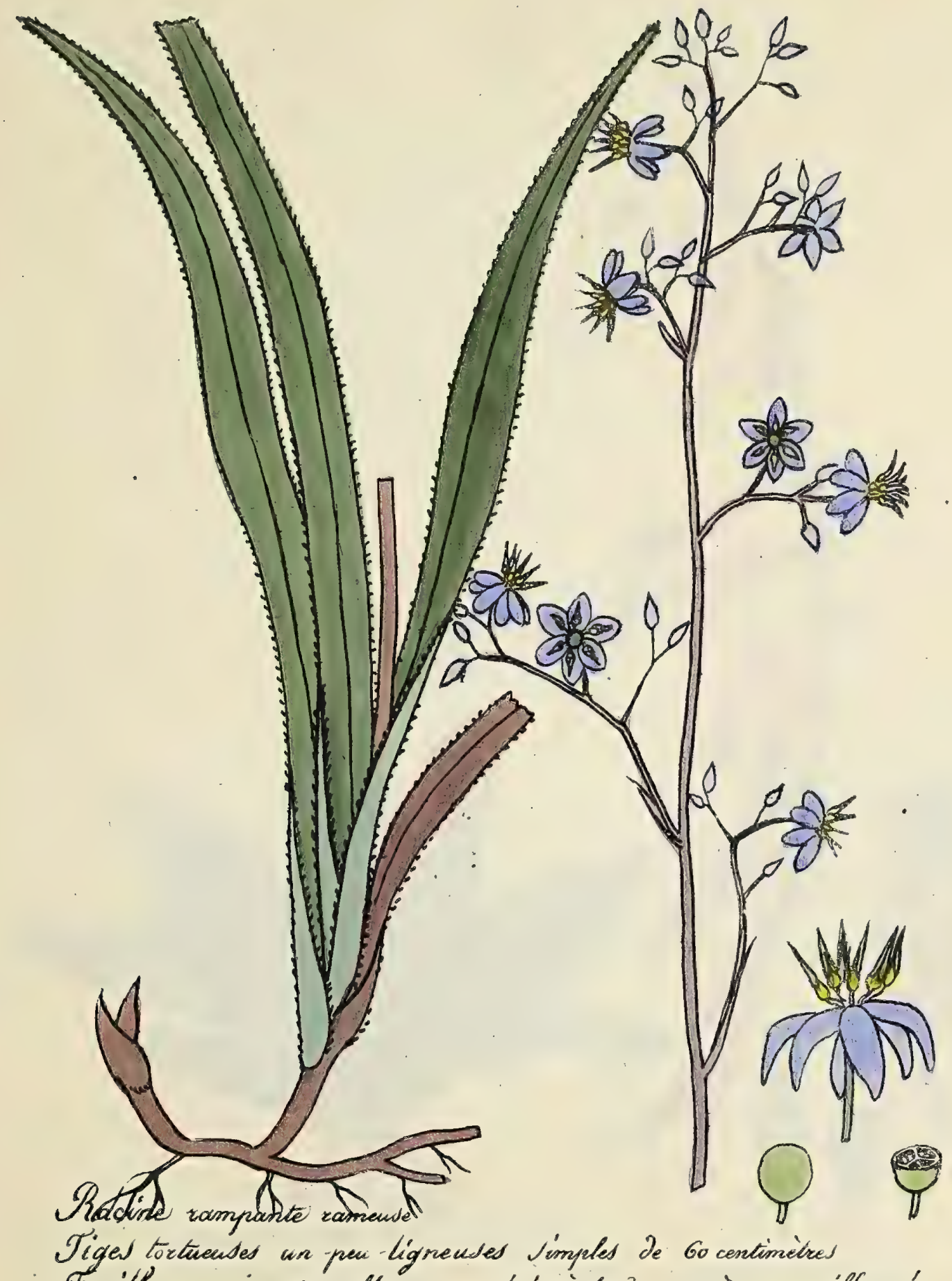

Feuilles engainantes alternes en éréé, à bouds et cariène auguillonnés, persistanstes. Panicule terminale, longue, làche, étagée,

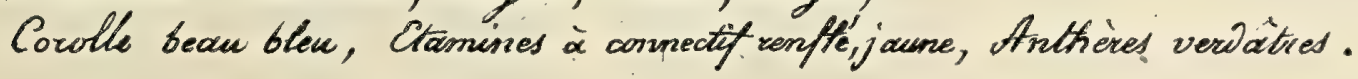

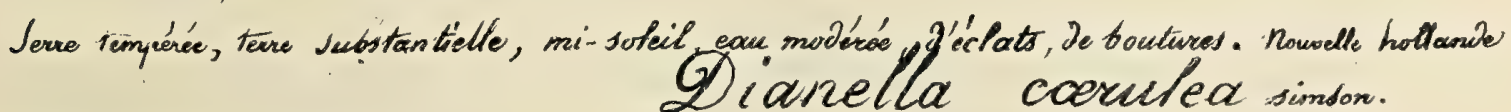

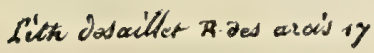





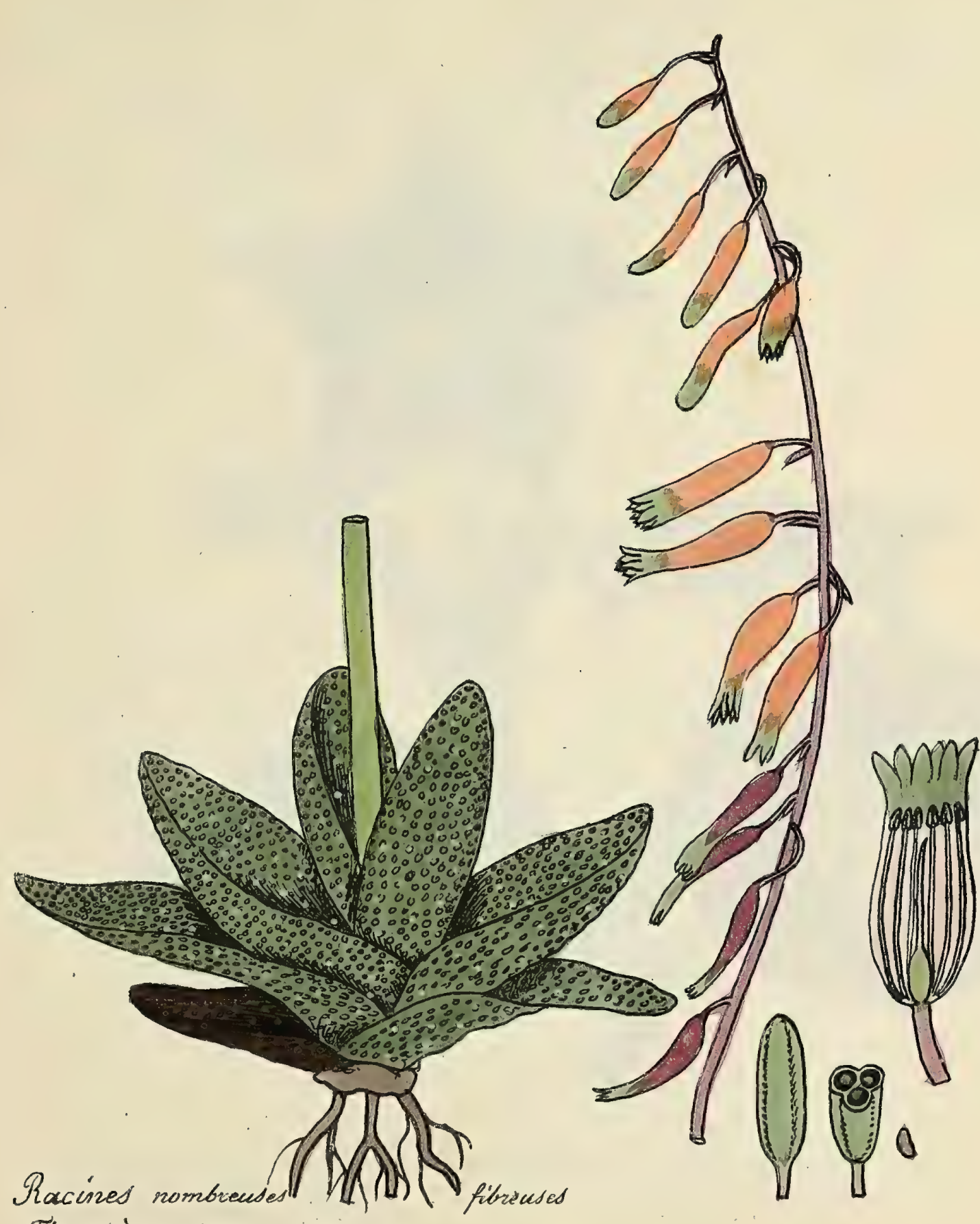

Tige tries courte grosse, charniue

Fecuilles alternes embrass antes, ovales. Longues reigues ì verrues nombreus as des 2 cortes Spi tres long de flewrs pentantes

Fleurs courbes rouges à la base, vertes au sommet

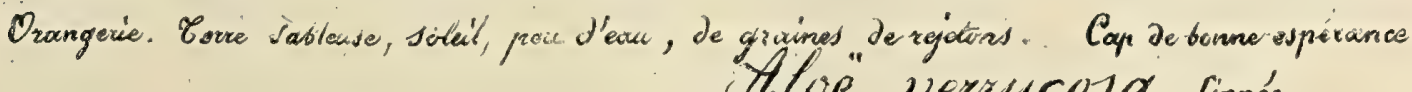

Lim desailler R Des ariat y 



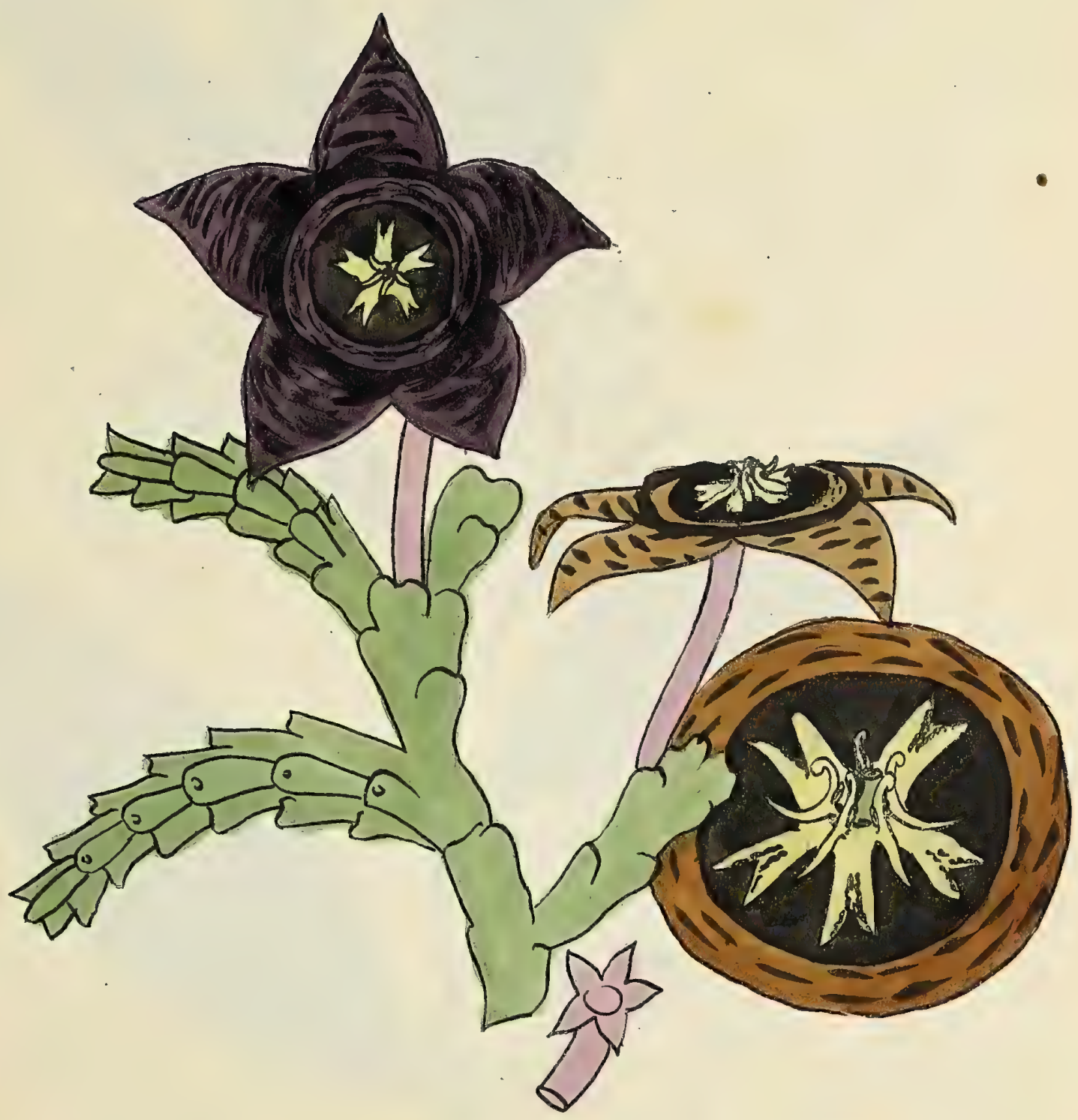

Tige churine vivace anguleuse denté de 40 à 50 contimeitres pas de Feuilles

Písoncules solitaices simples

Corolle brunâtre tachée de pliss foncé, guirge 'élevée en cercle, languatties bifides

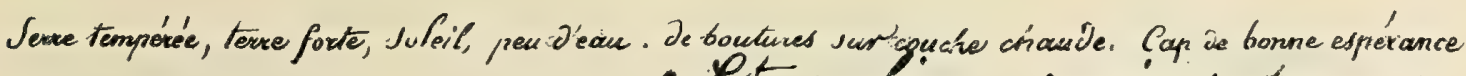
Lith Dos ailter $k$ Des 17 Prapelia variegata fimmé 



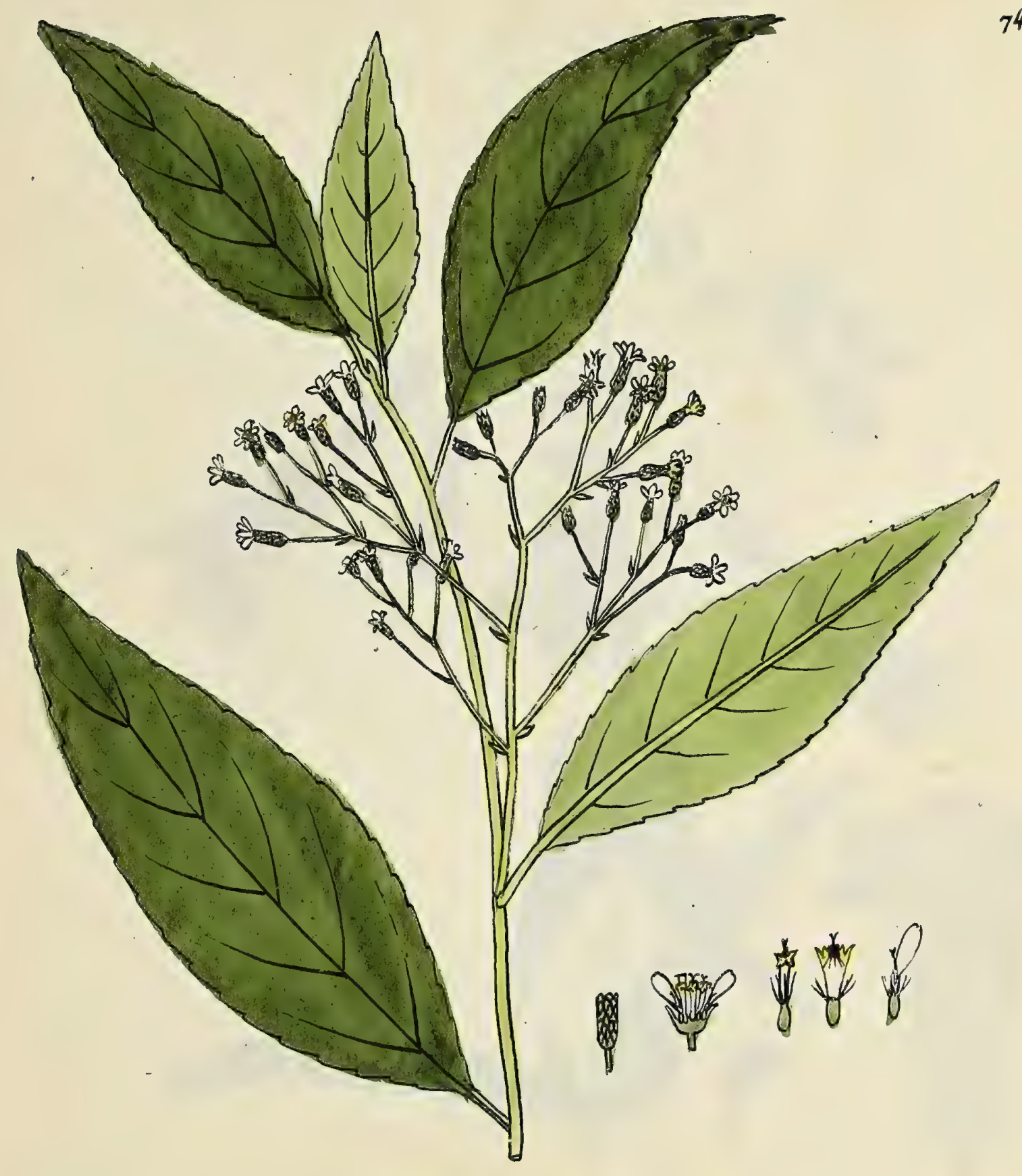

Tige ligneussen Jroite de 2 à ş mèrres, rameaux cotorneux nomb́reux

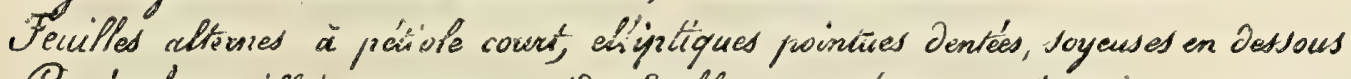
Panicules axillaires in pyramide, de flewrs nombreuses petises Palice glabie, 3 à 6 Demi-plesewns grisaties, fleurons jaunes.

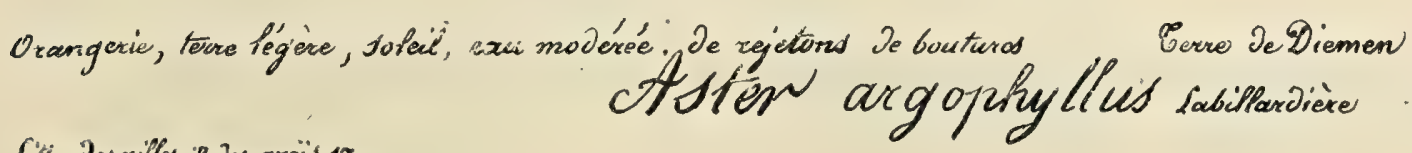

Silt Des ailler $R$ Jes axcios 17 



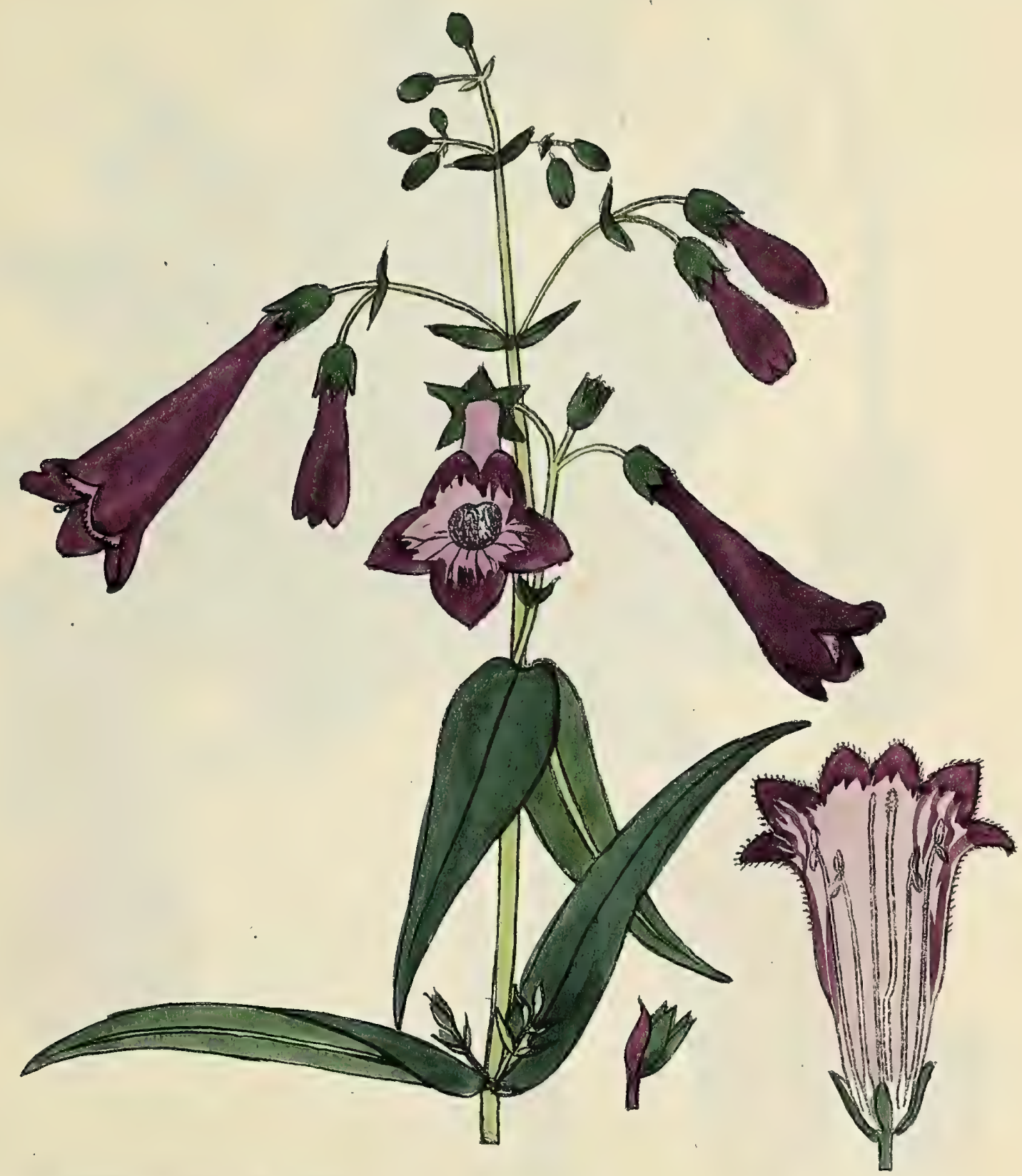

Tige droite ligneuse à la base, rameuse, J's mètre Fenilles opyrosés, sessites, en fance, tries pointues, très entiéres. Pedoncules axillaires et terminaux bi ou tuifides, formant une pranicule lacke. Palice aigu, Porolle wuge-bun.

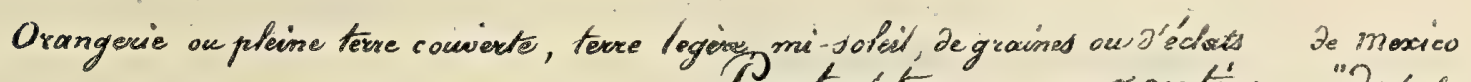
Sith Desaillet $R$ Des arcis it Sentastemon gentianoides himboint 



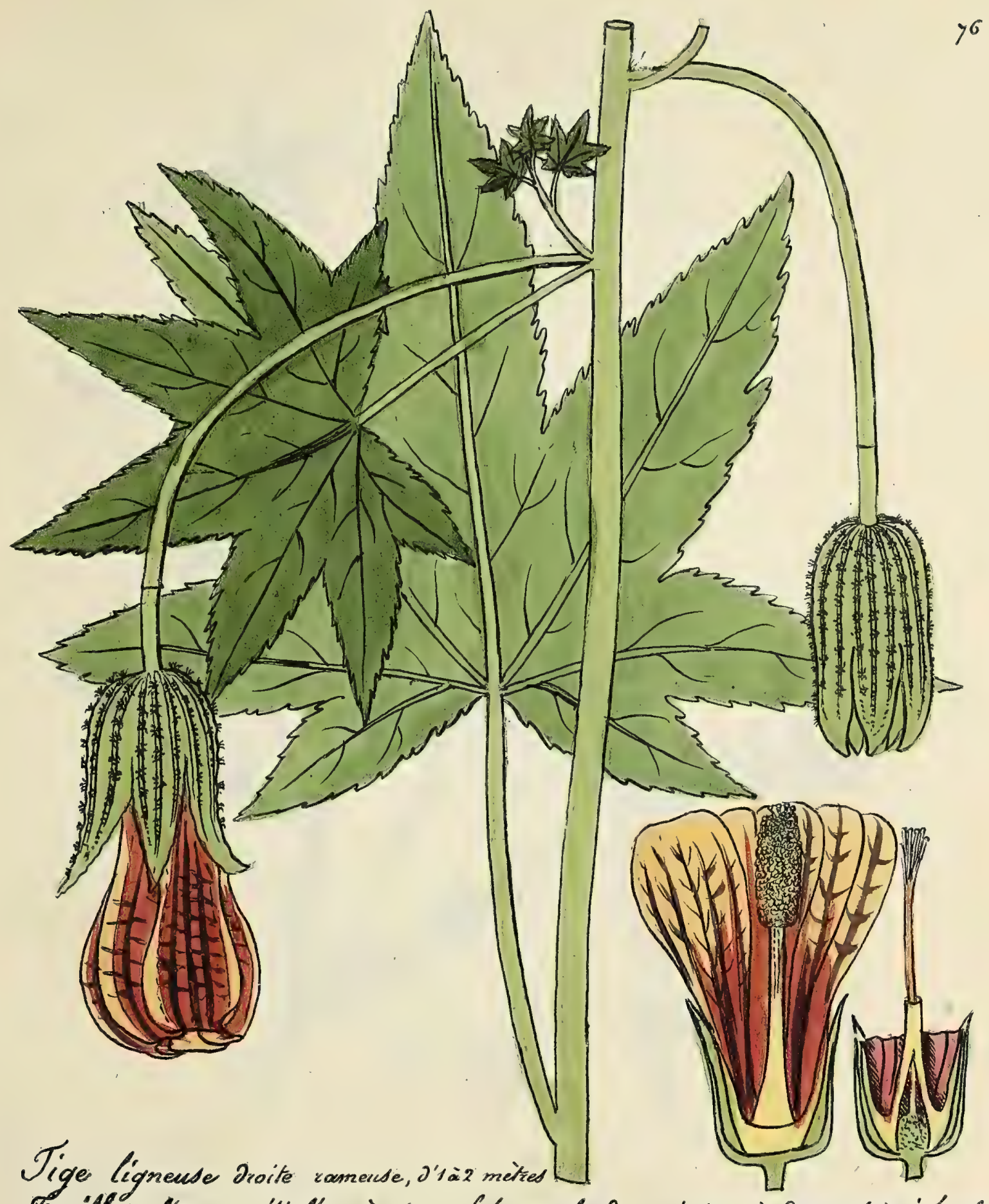

Tige liqneuse Droite rouneuse, d'sàz mitres Feuilfes alternes pétiolés. is 5 ou y lobes profonds pointus, à dents très inégates Hewes axillaired à tres longs pitiofes simples Solitaires, pendants. Palice à poils en étoile, pétales joune-rougeâtre rayés de rouge-brun.

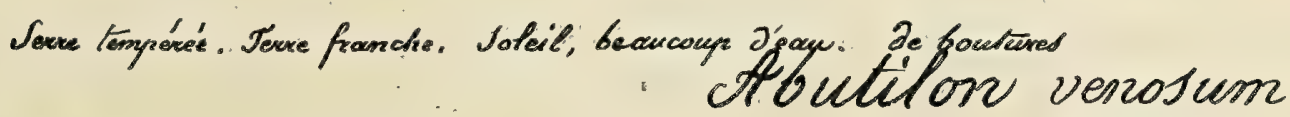

fith Desaillet $R$ Des axeis $y$ Chez Bactiand R de la Roguetritor 



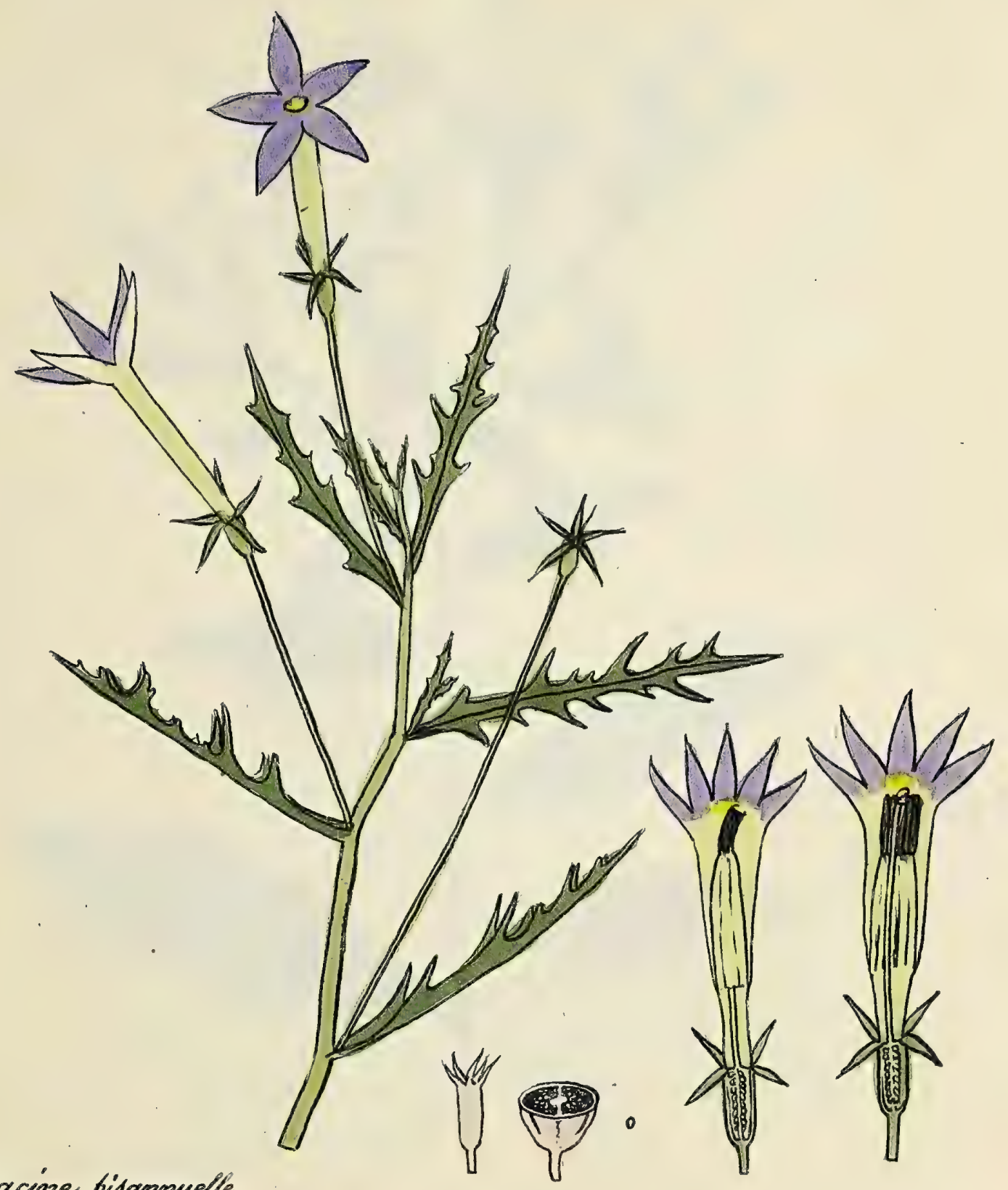

Racine bisannuelle

Tige herbacée, étallé, rameuse

Feuilles álternes, sessiles, pinnatifides, à lobes inégaux, liviéaires, un peu Dentés Pedoncules acaillacires simpled allarages

Porolle presque réguliere, blewatre

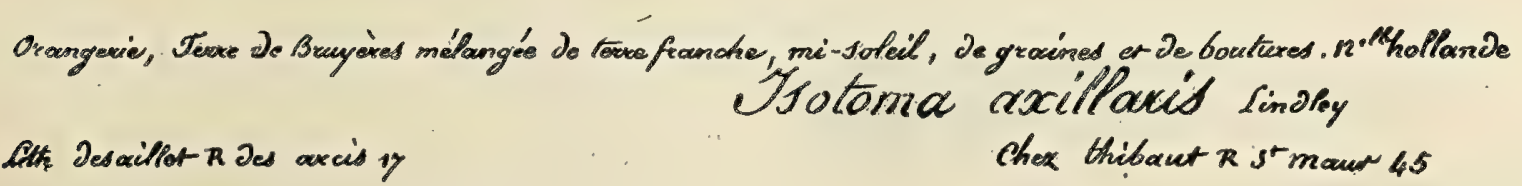





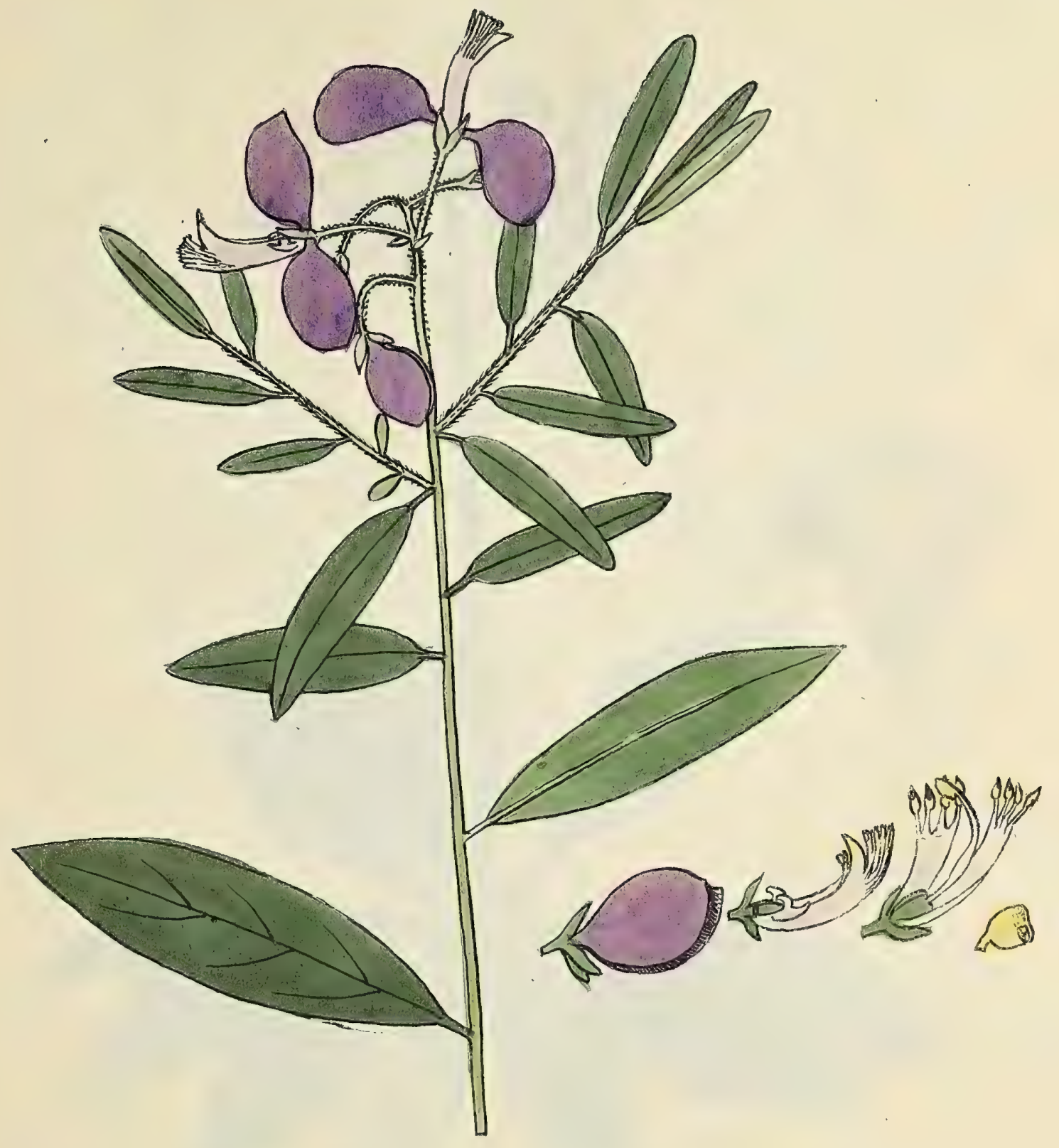

Tige Oraite ligneuse rannense cylinivique, rameoux velus Fevilles altornes un paw pétiolées, ellipitiques, allongées, grovedor. Tedoricules en éfís courts simples torminaux.

Afiles rouge-violacé. Caxine d̀ aigrette; Anthères sans poils is la bade

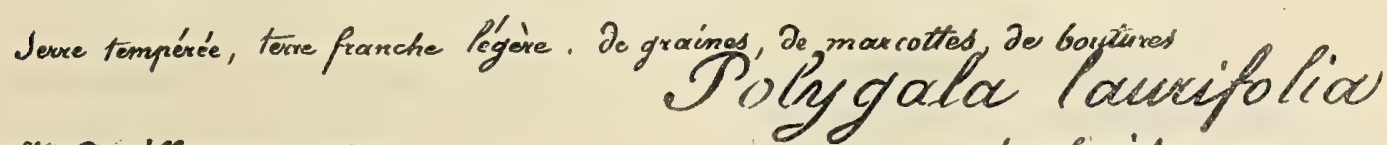

Littu Desaifles- $R$ Des arcis if.

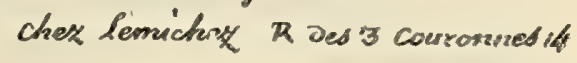





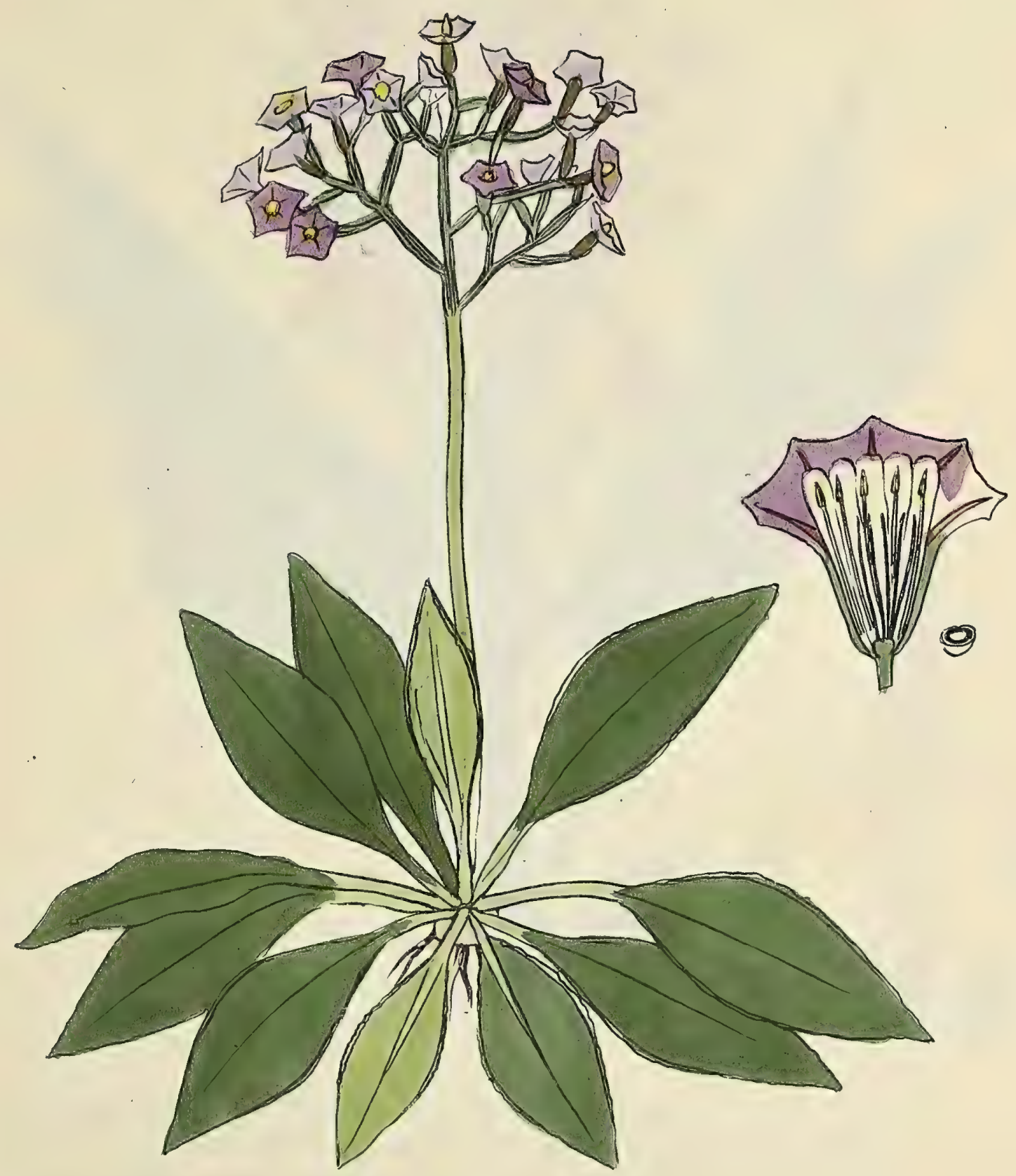

Tige très counte époisse Oroite Simple,

Fuilles tres capprochées, packaissount tradicales, petrolées, thomboilales, à tords

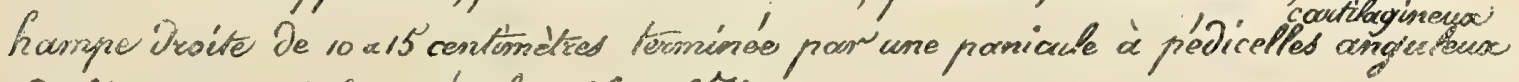
Calice sec, vioter, pétâles blasshâtres

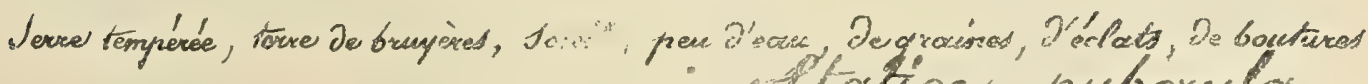

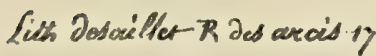





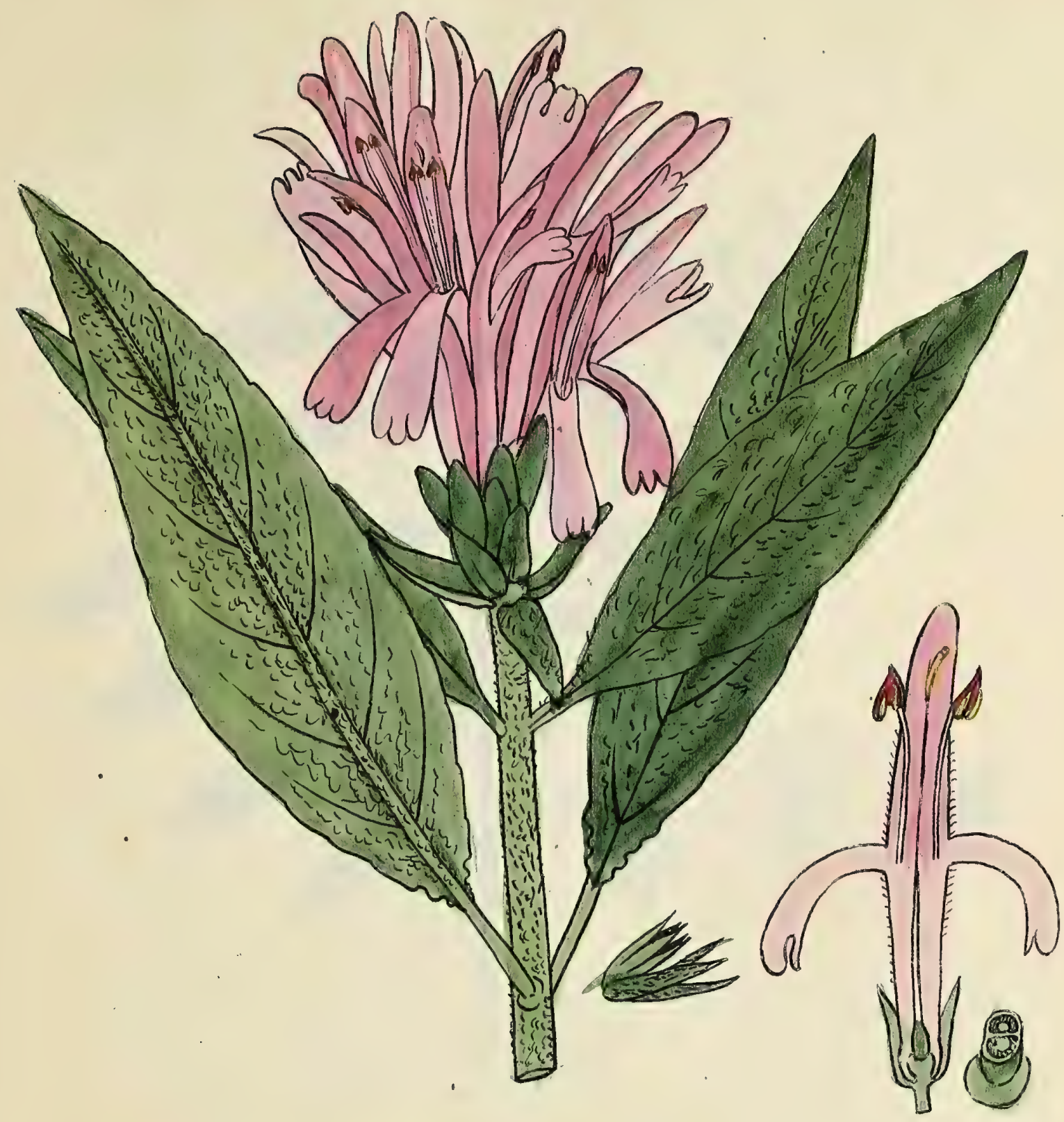

Tige ligneuse aroite ramense d's mètre un pren velue

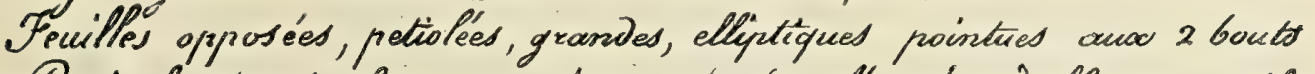
Tanicules terminales, ramassées en boule altongée, Je fleurs sessiles Corolle grande, rose-cauné, anrtières éloignzées

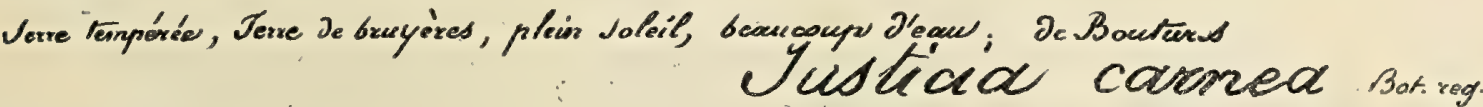
Lin Desaillet $R$ des arcis ay ches Bertrand R Je Ra.Roquelte 102 



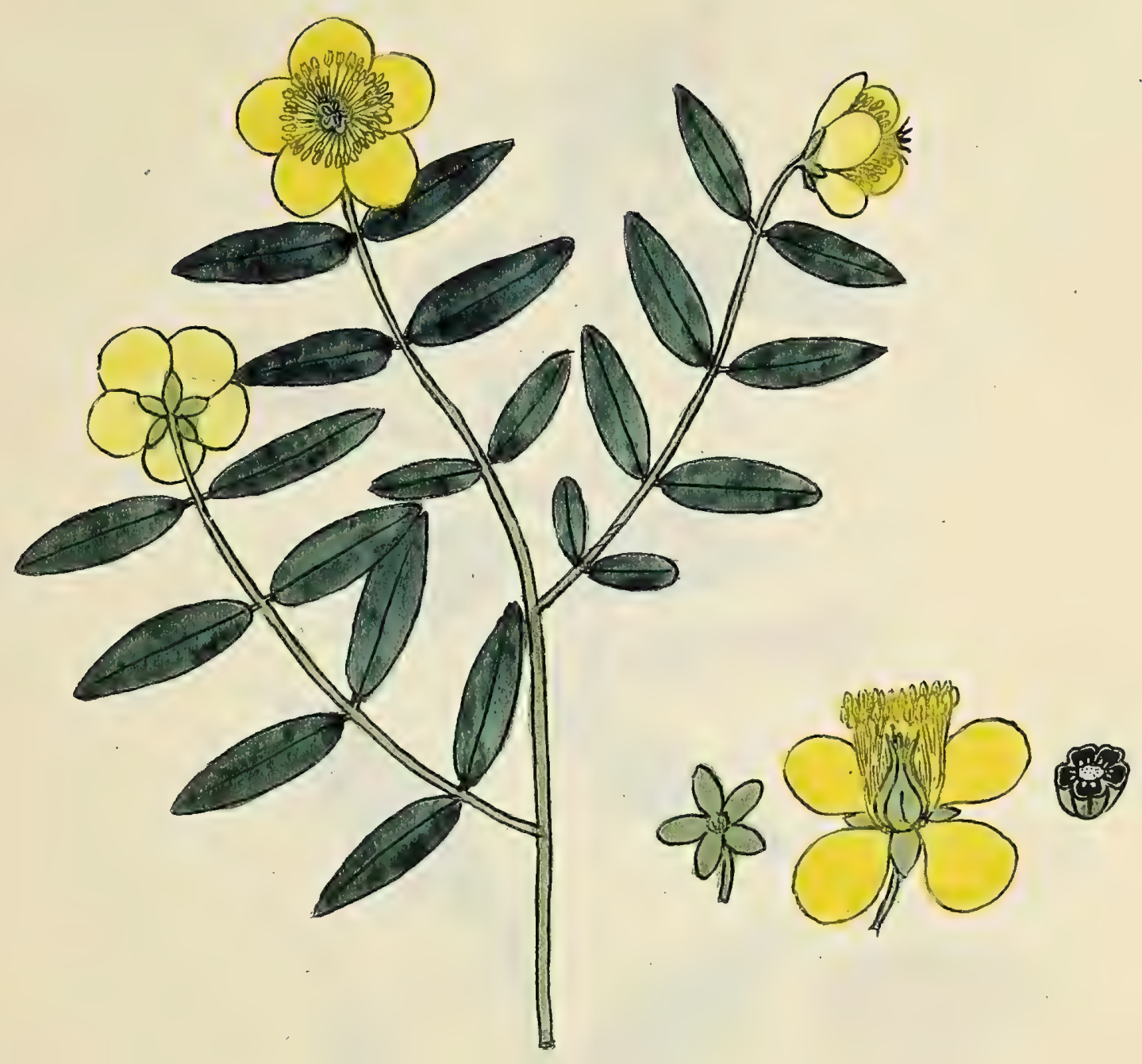

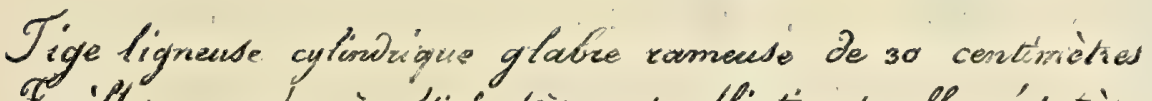
Feculles opyrostées à pétiole très court, ellyztiques allongées, très cntières, glanducteuses. Hleurs sofitaires, terminant les rasneaues Calices obtues, sans grandes, pétales jaunes, 5 styles

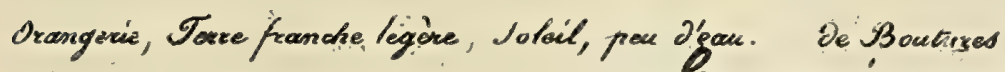
Pypericusn nepaulense

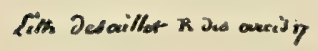
ches Phouwiòne Rocla Roquette 104 

$8 x$

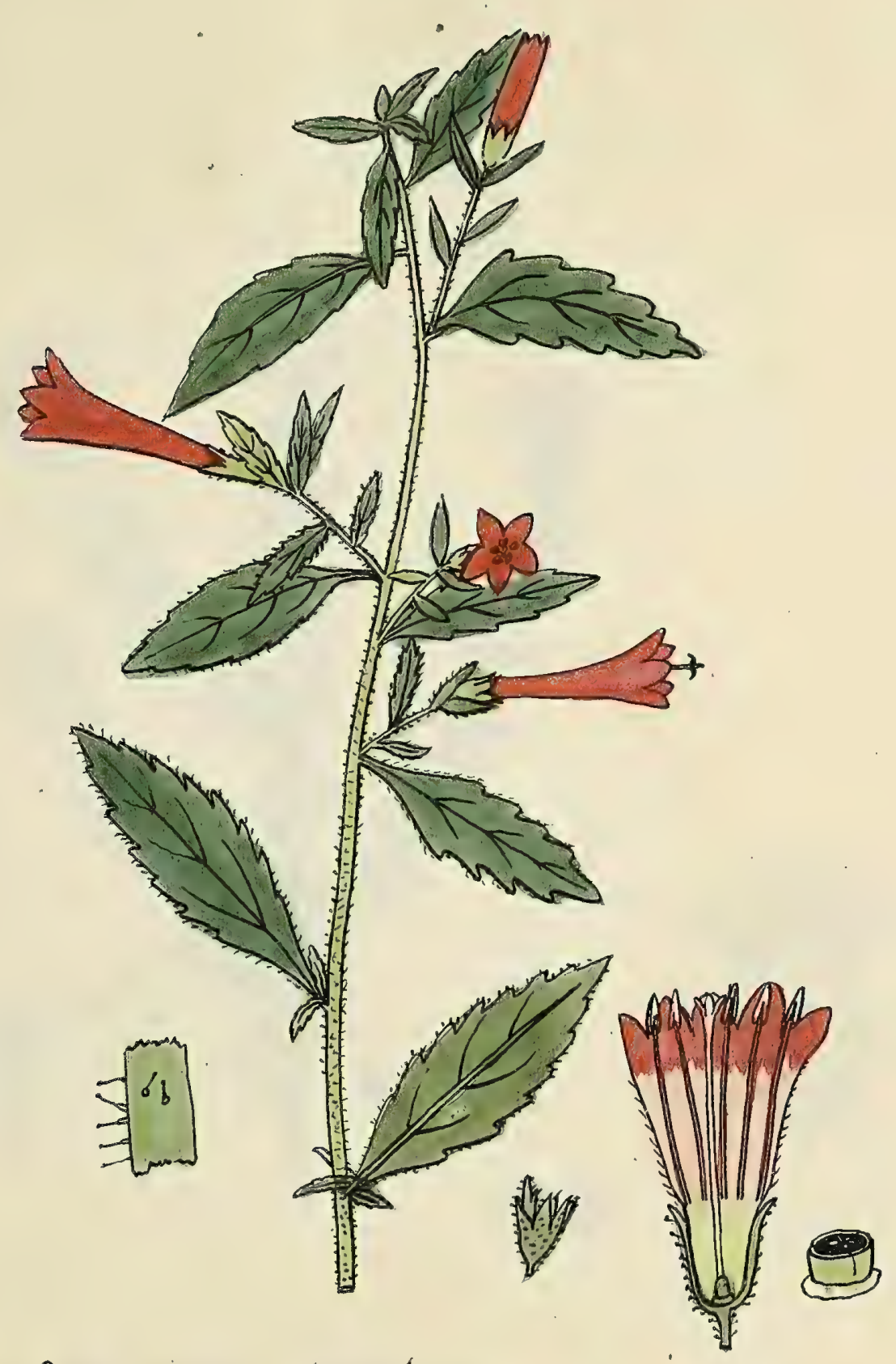

Tige Lignuse Droite, rameaux, herbacés, velus.

Fevilles alternes ix petiste tress court elliptiques-pointues dentees, à poils glanduleux

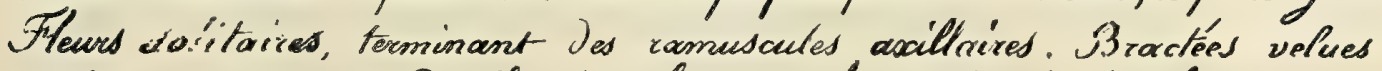
Calice" ylanoulecux, Protle tubulause à limbe évasé, écarlate

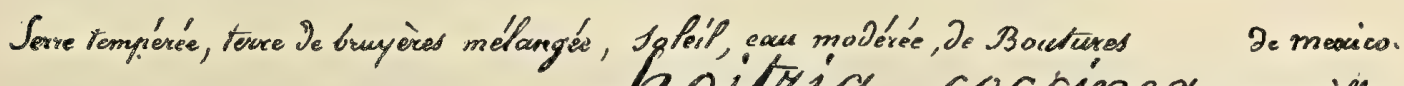

Lith. descuillat R jes arcis y

Chez Chouwière $R$ de la Roguctte 104 



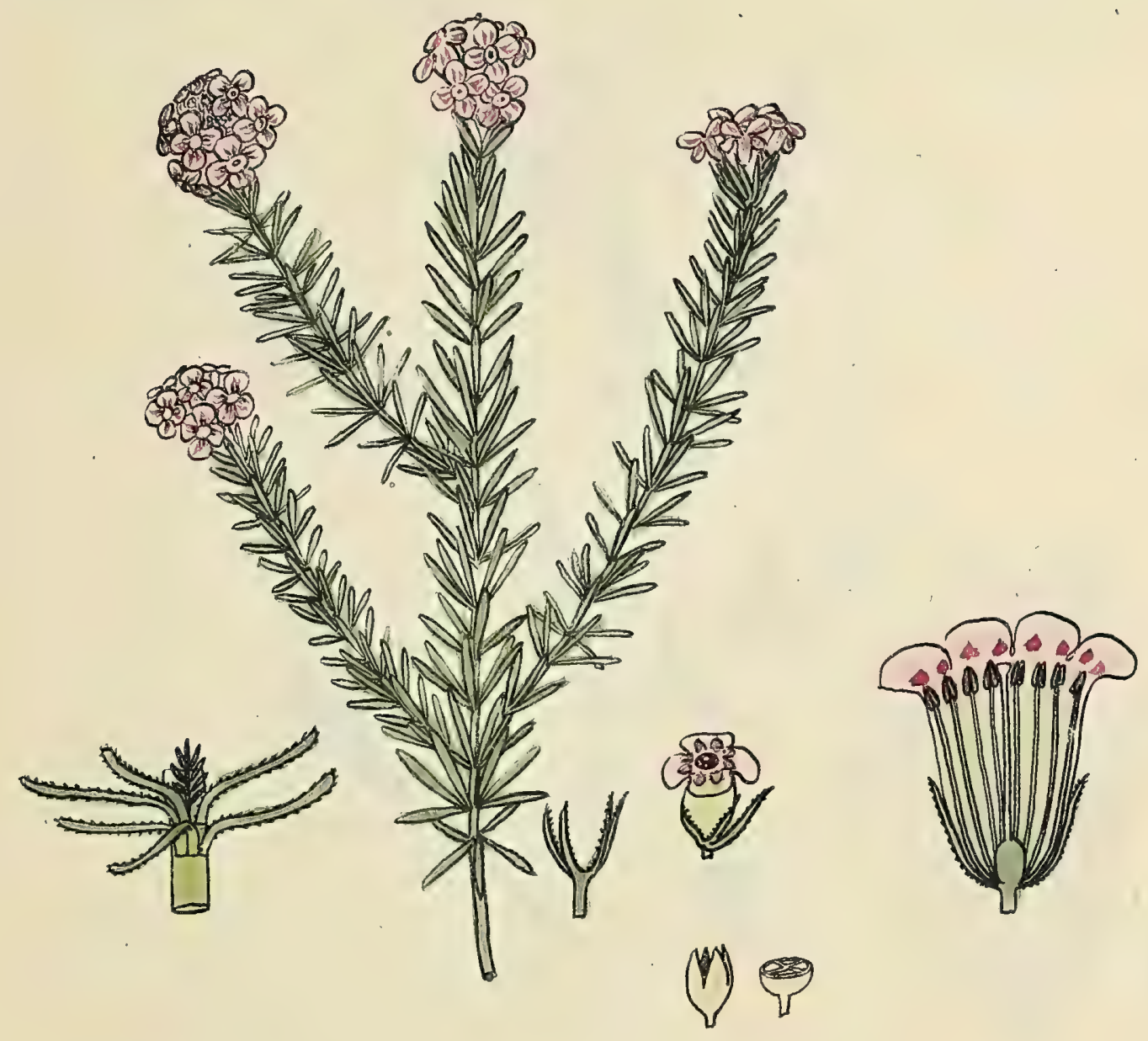

Gige ligneuse, Dressée, tices rameuse gilabre de $\sigma_{0}$ centimères Femilles verticillées par 6, rapprochées, triquidres ciliés

Têtes terminales de 6 à 10 frewrs. Corotle en assynoule rose moucheté De rouge Antrières incluses sand appeinitices

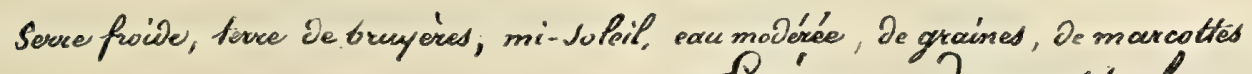
Crica Deprestula (voyer fes notas)

fith.Jesoifter $R$ des arcis $\eta$ Jardin J'hiver aux champs élisées 



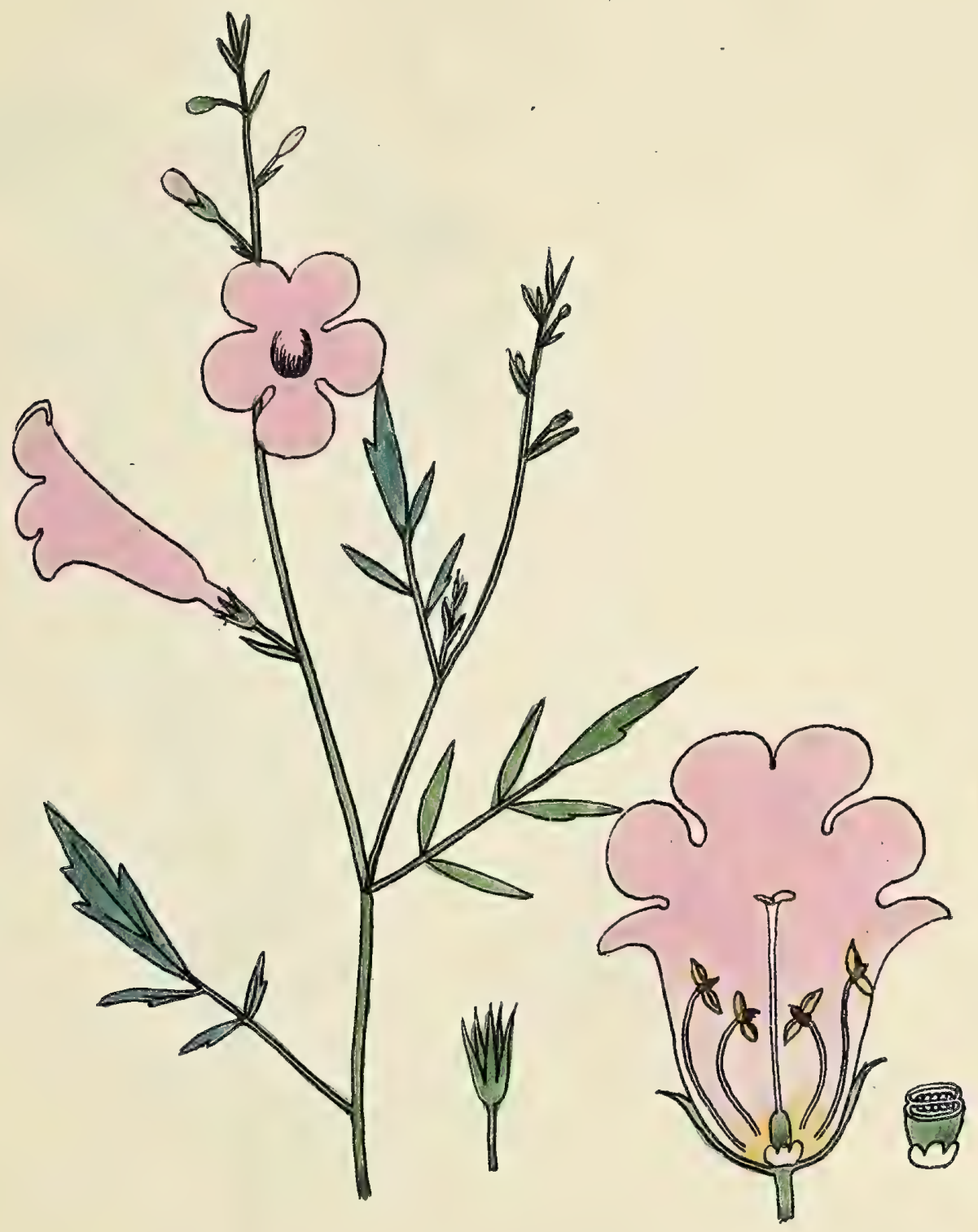

Tige lignense à la base, romense, Droite

Fesilles alterines à 3 ou 5 folioles entieres on à grandes Jents

Giis opposés aux fenilles, pédoncules cowris, brcrctés écroites, pointures

Palice à.5 Pronières aigues, Corofle grande, rose, Cramined courtes

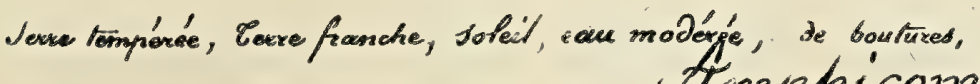

Arnythicome arguta

Lith Descuillat $\pi$ Des asreis $\Rightarrow$ 
.

- 


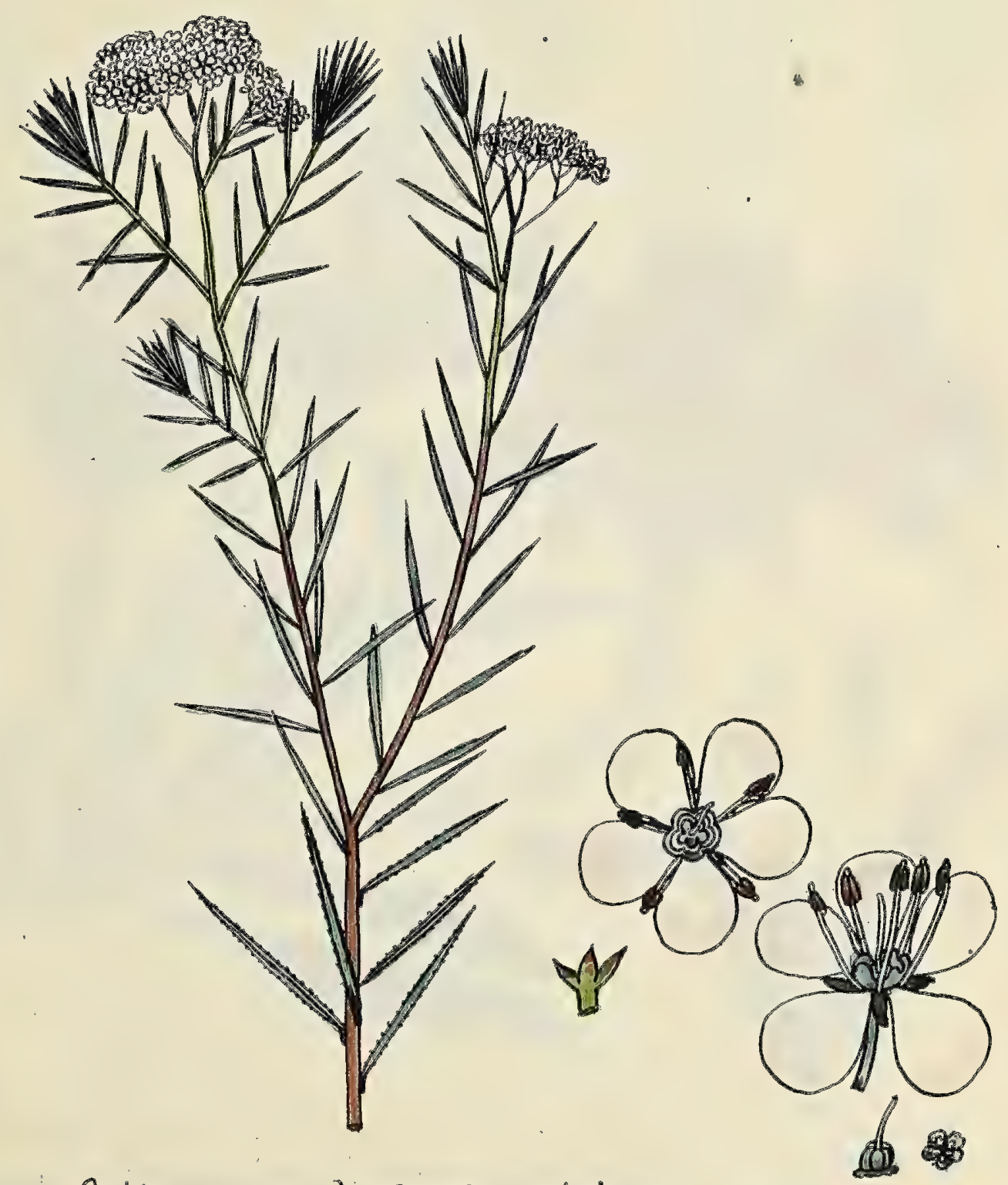

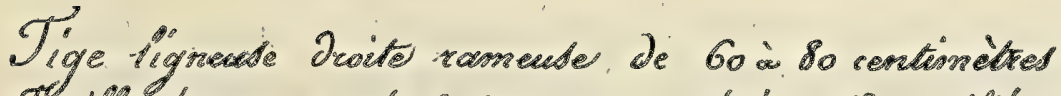

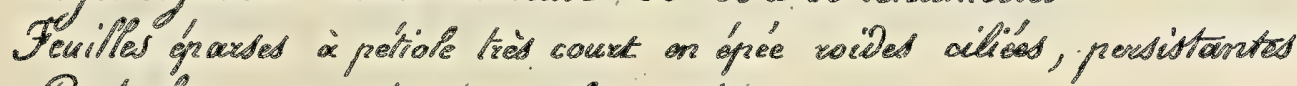
Panicules on corymbes, ternzinales, peticis Jisque perigyne ¿̀ 5 lobes, pêtriles glabres, blanc-zosé, en étoite

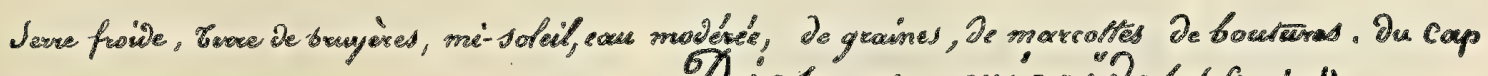
Diasma exícoiles (Limber)

Sifs Dedaiflet R Des orzid

Cher bhatount $R$ or moure 45 



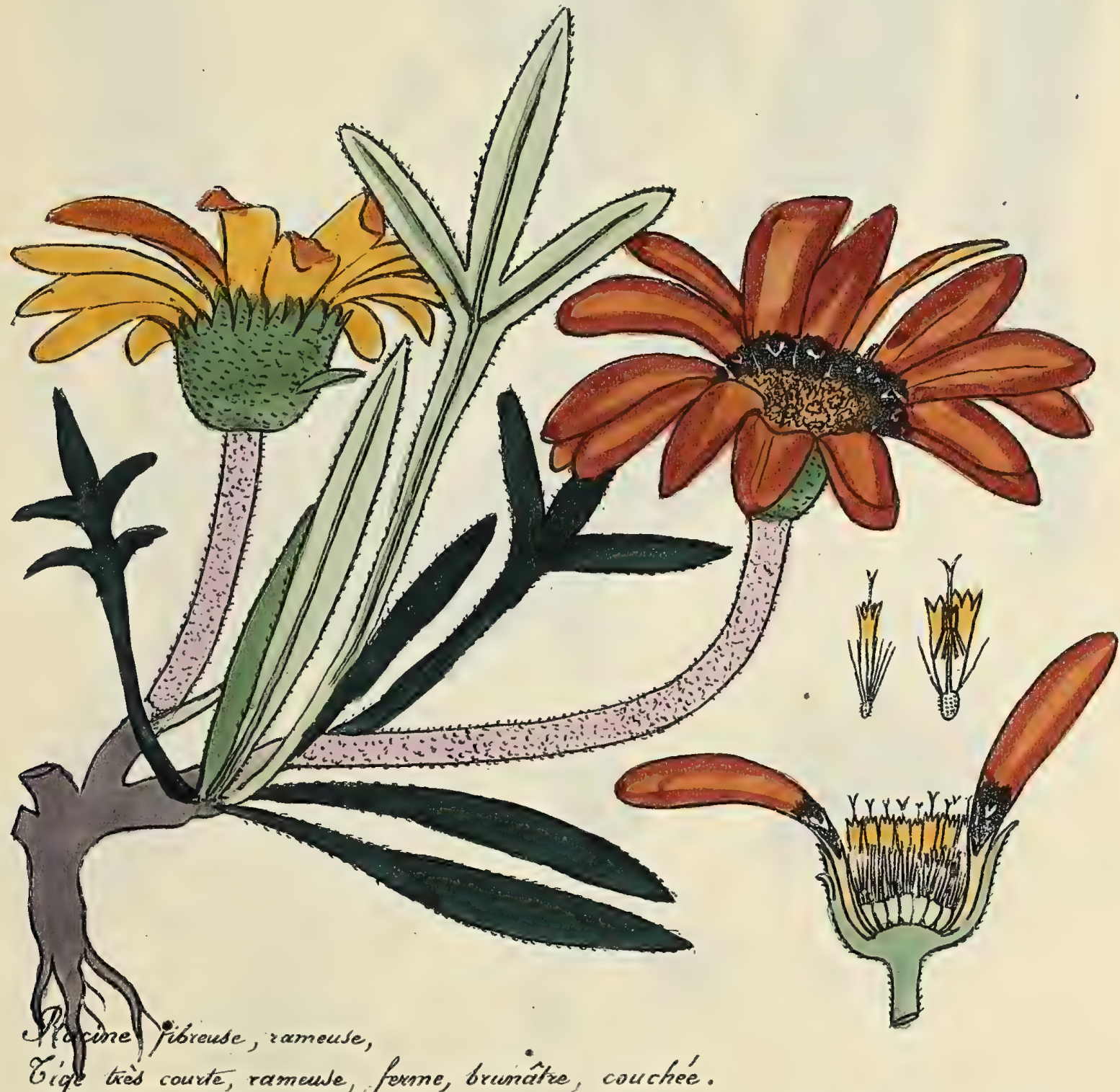

Fewilles ramadiées, persistaniés, on spatulestongued, ow tri-pirmaitifides, blanched Pejoncules longs terminéd par ure fleur - F/our large de $y$ às centimètres aurute-foncé, base des \% fleurons tachóe de blanc Juor

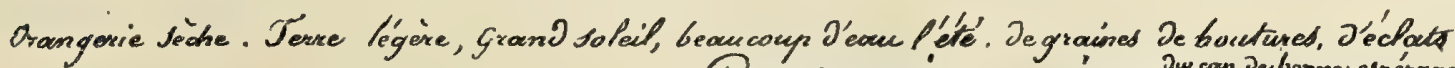
Lith Jesocillet $x$ Des corcis $y$

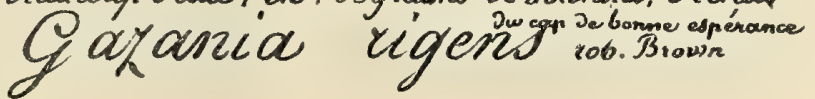





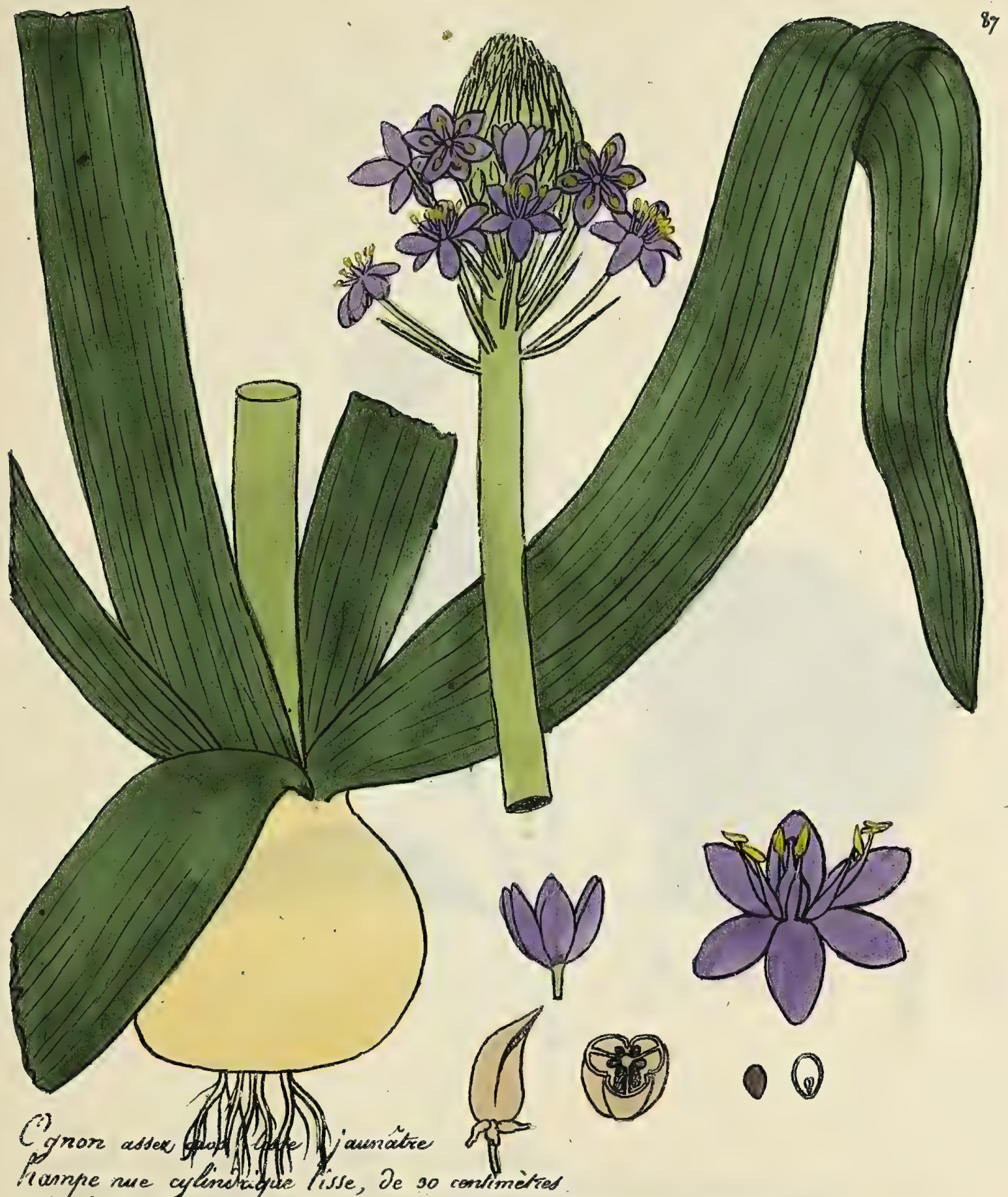

Tanpe nue cylindridule lisse, de so contimitred

Freuilles toutes radicales en larges couveroied, molles, ondufiés, ciliéd. Spi terminal conique, régulies, court. Bradées lanceolées, fongues. Porolles planes bleues, Anthéred blasestale.

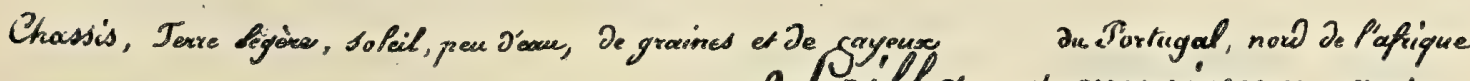

Lith Jescinter Ras ancis in

Ccilla peruviona sinnoe 



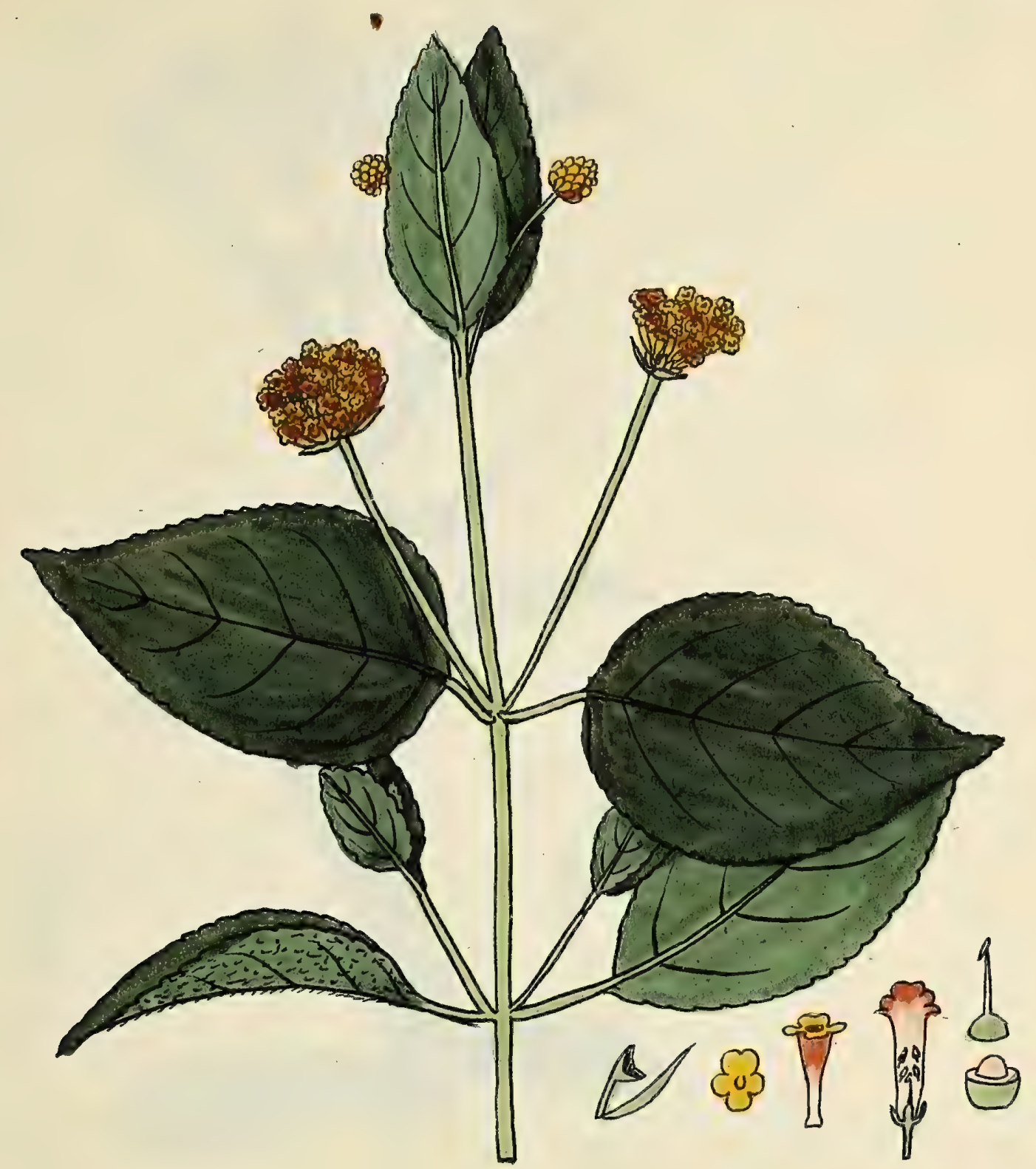

Gige figneude rameude 'O'1 mêtre Fenilles opprosées, pótiofies, ovales, Jentiées, persistantes, velues en dessous Ombellules à fong péDoncule, Axillaire, Bractées lineaires courtes Powlte J'abord jaune puis auwre, D'odeur Désagréable

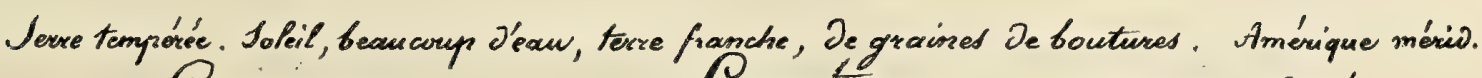
Paniara Pantana camara limée

fith desailler $x$ des arreis of 



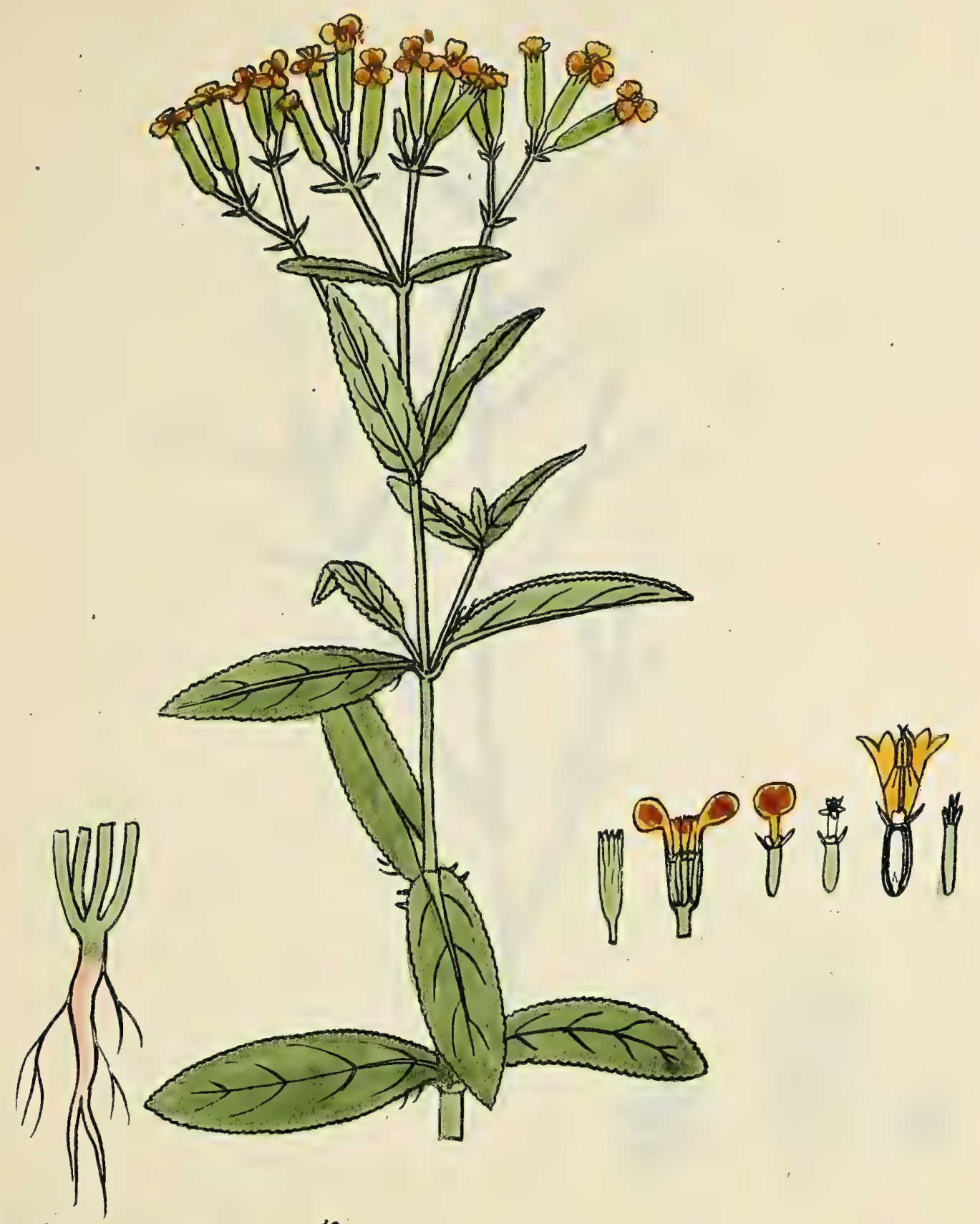

Racine conique fibrilleude

Tiges Ligmeuses à la vade, presque simples, Dressiés, De o, so sentimètres Feuilles opposées, amplexicrueles, ellyitiques-Lonques, à Dents tiès fines. Pancicule en coumbe, terminale de peciies frewes.

Calice tubulaire, 3 Doni-fleurons orcongés, plusieurs flewrons jaunes. odeur d'anus

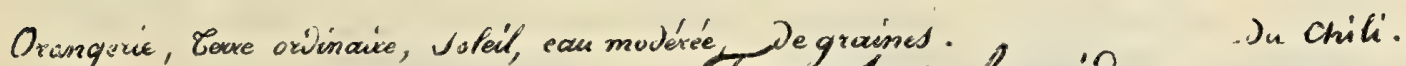
Jageted Iucida. cavanilhs. Sith Jesailler $x$ Des arcis $y$. 



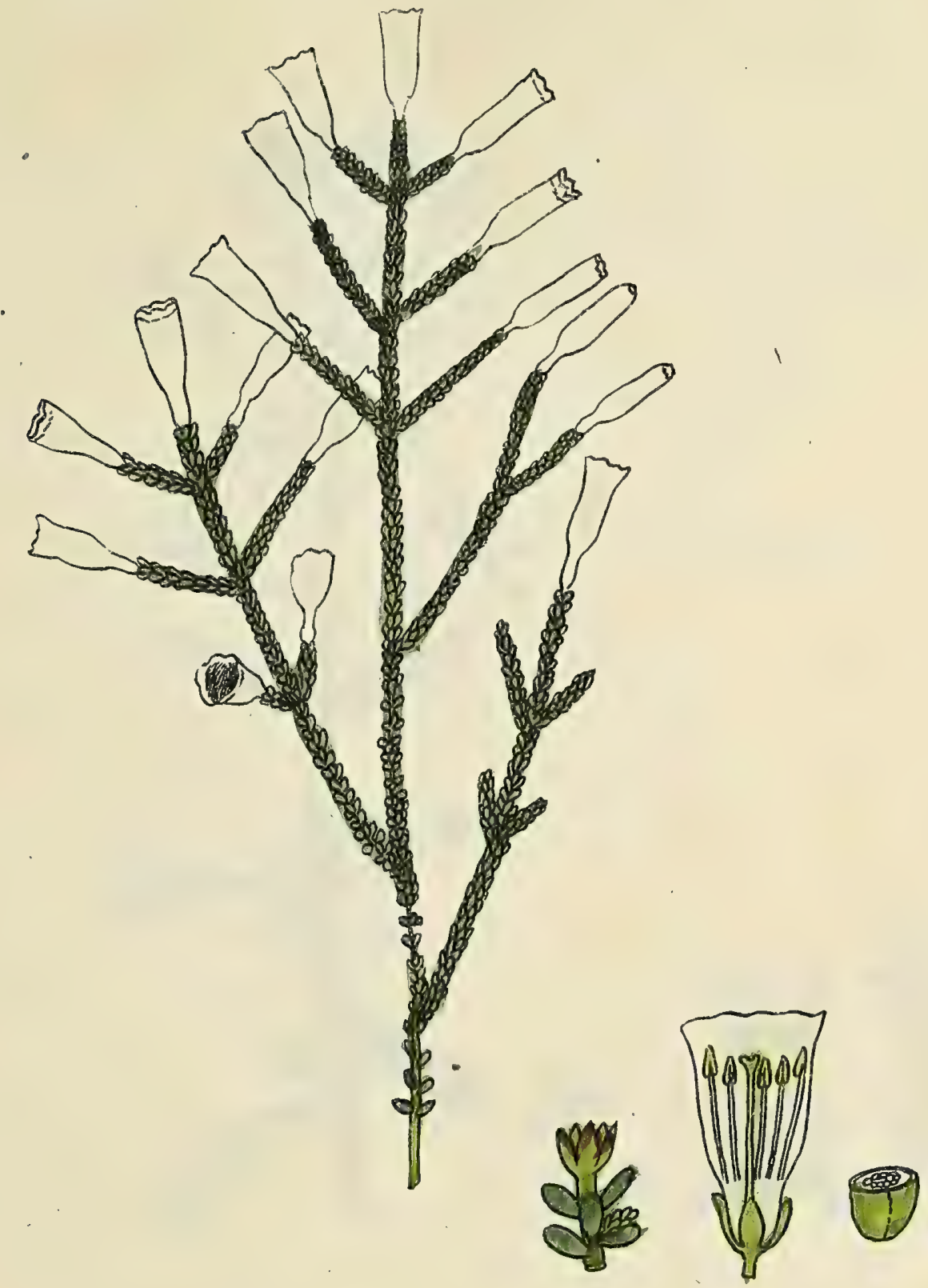

Tige ligneuse, Jroite, effileé, très rameuse 2 's à 2 mitres Feuilles inbriquées, tiès cowites, charnues, recouvrant entièrenent les rameaux Fleurs solitaires sessiles terminales et rxilfiried nombreuses Porolles tubulaired blanches.

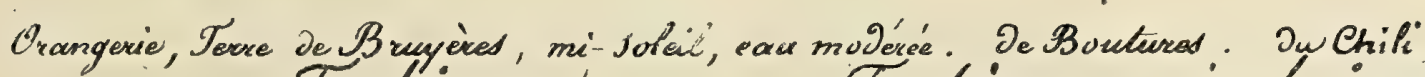
Sirh Jescillet R Jes arris iy

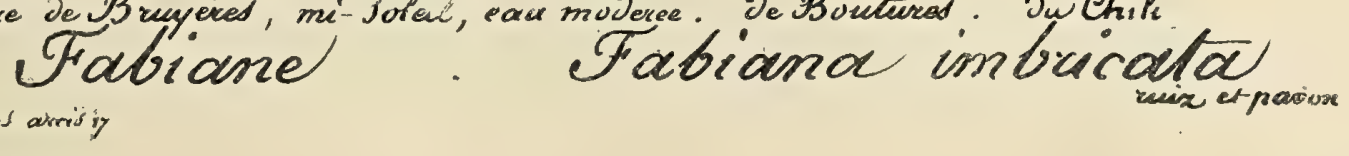


- 


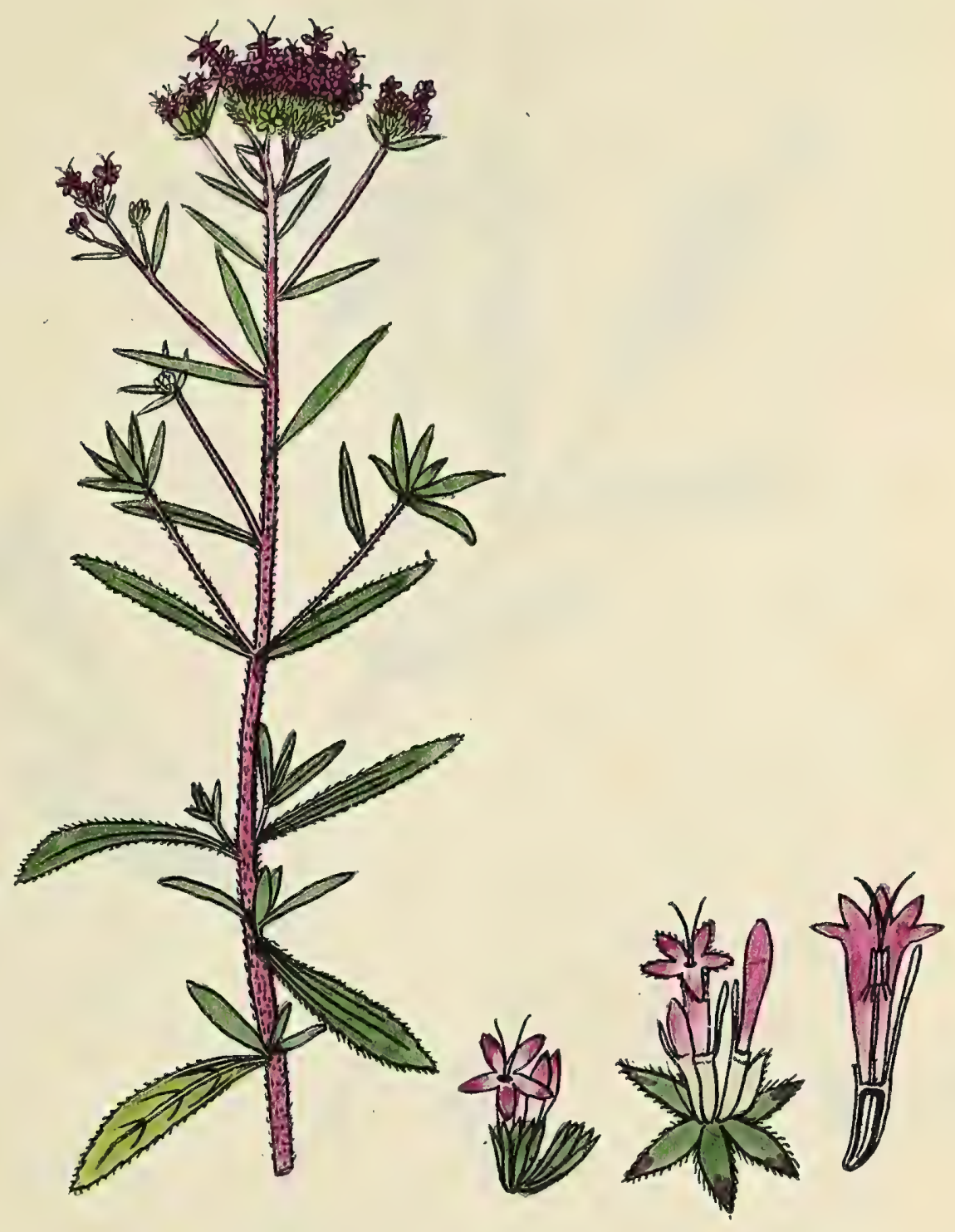

Tige figneuse, Droite, rameude, velue, de 0,50 rentionètres

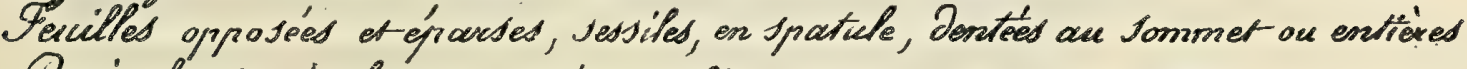
Panuicules torminales ramassées de fleurs très nombroused, pietited Porofles rouges, aigrette à 5 arietes?

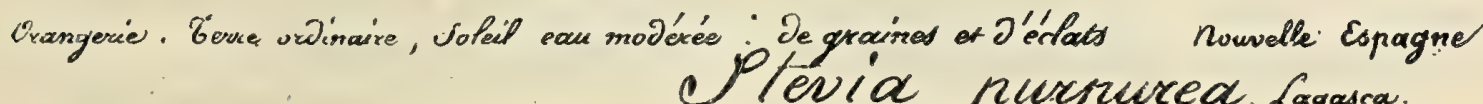
Sith Desaiffor $x$ des ercis $y$ 



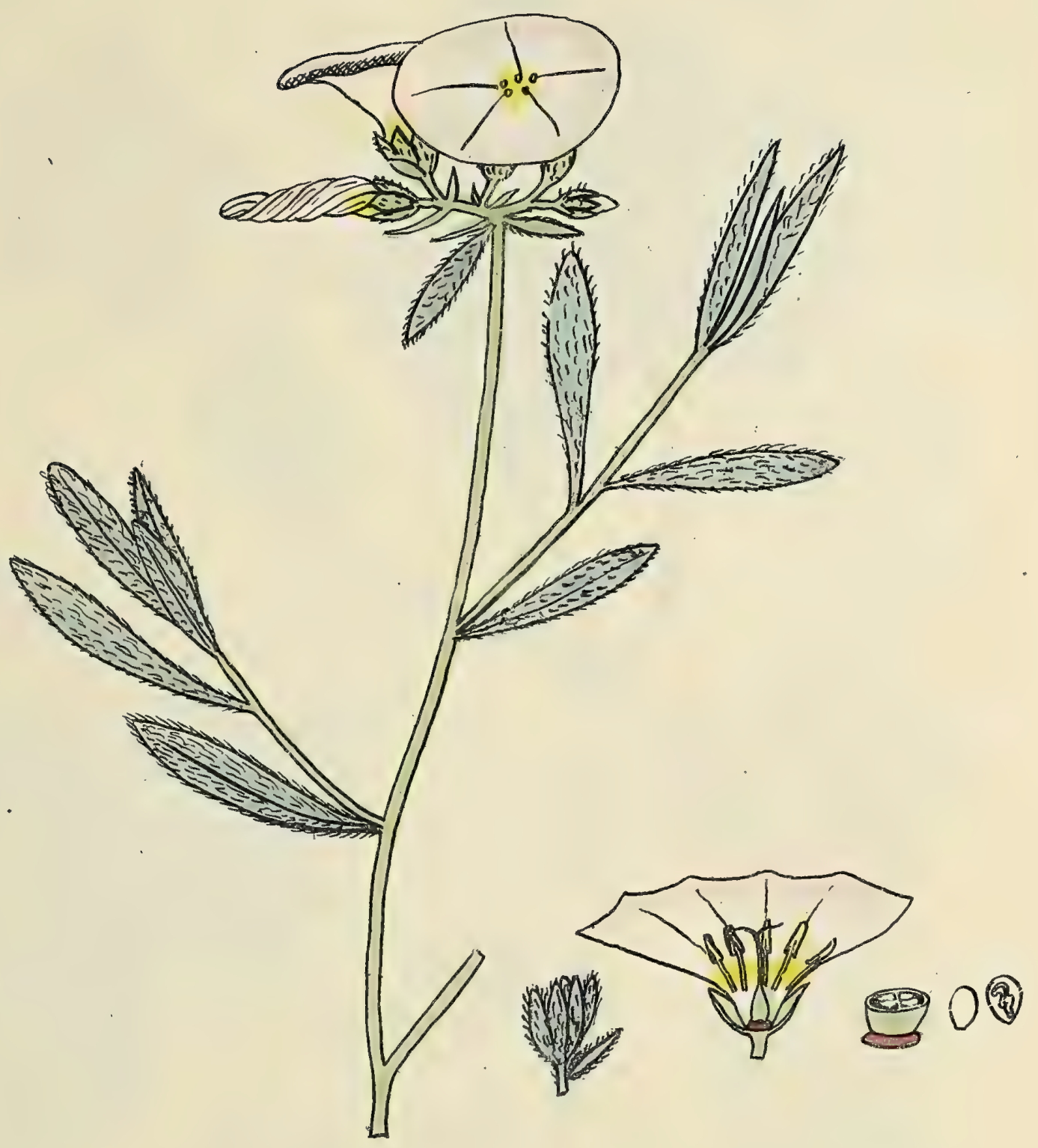

Tige ligneube rameude couchée De 0,60 contimétres Feuilles alternes on jpatute, entieres, persistantes, à Juvet soyeux Paniaules terminales de preu de flours rapprochées. Palices velus. Powlles blanched lavées de rose

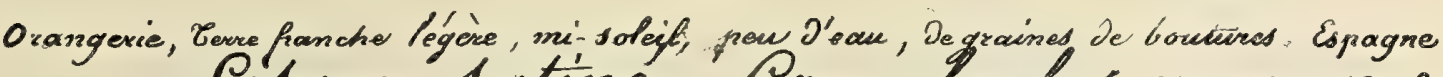

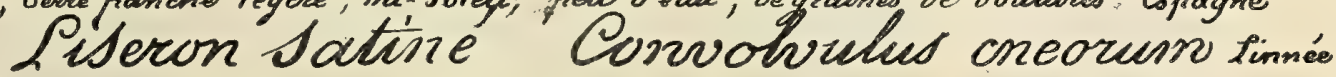
Sith Jescifter-R Jas arcis on 



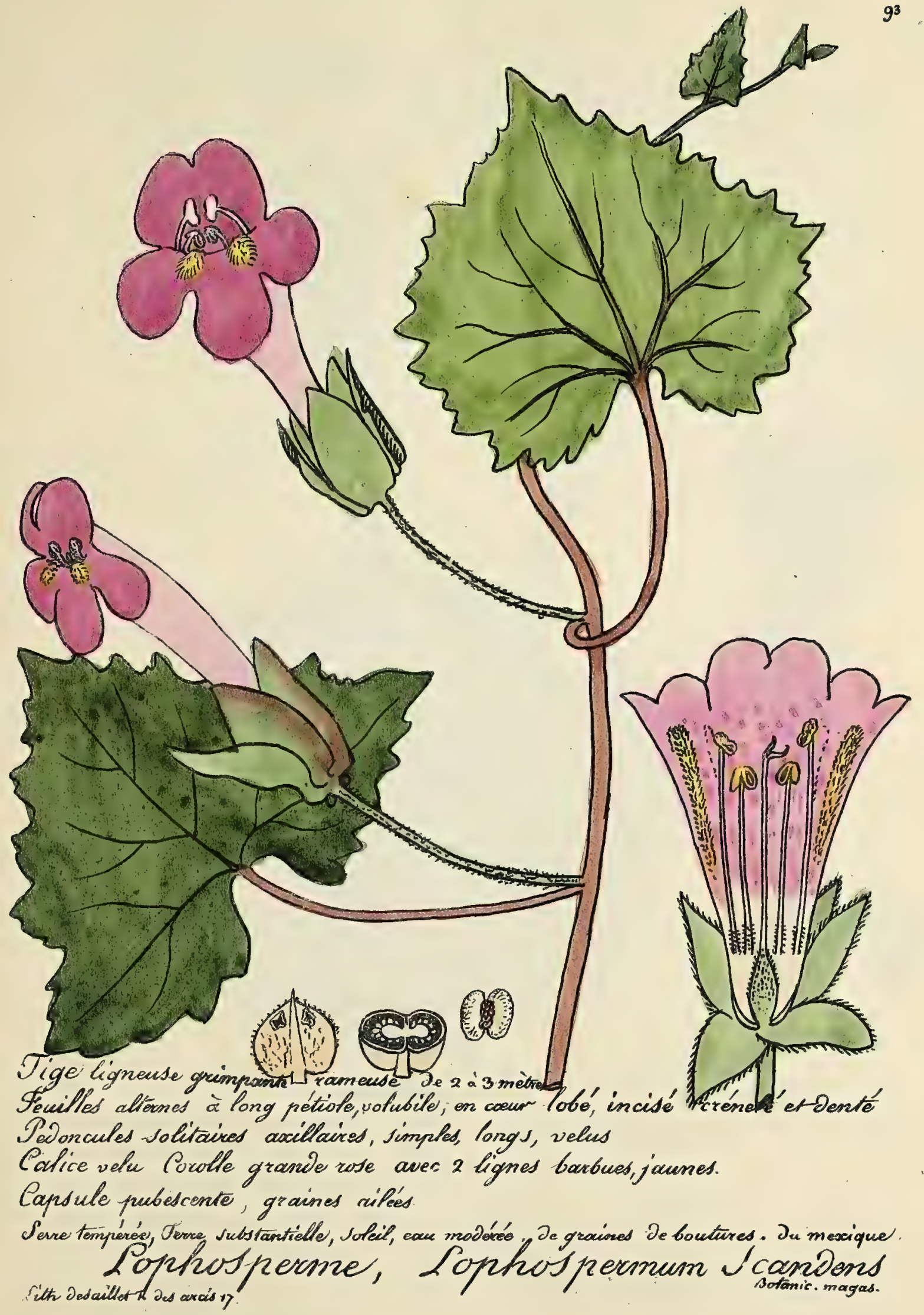





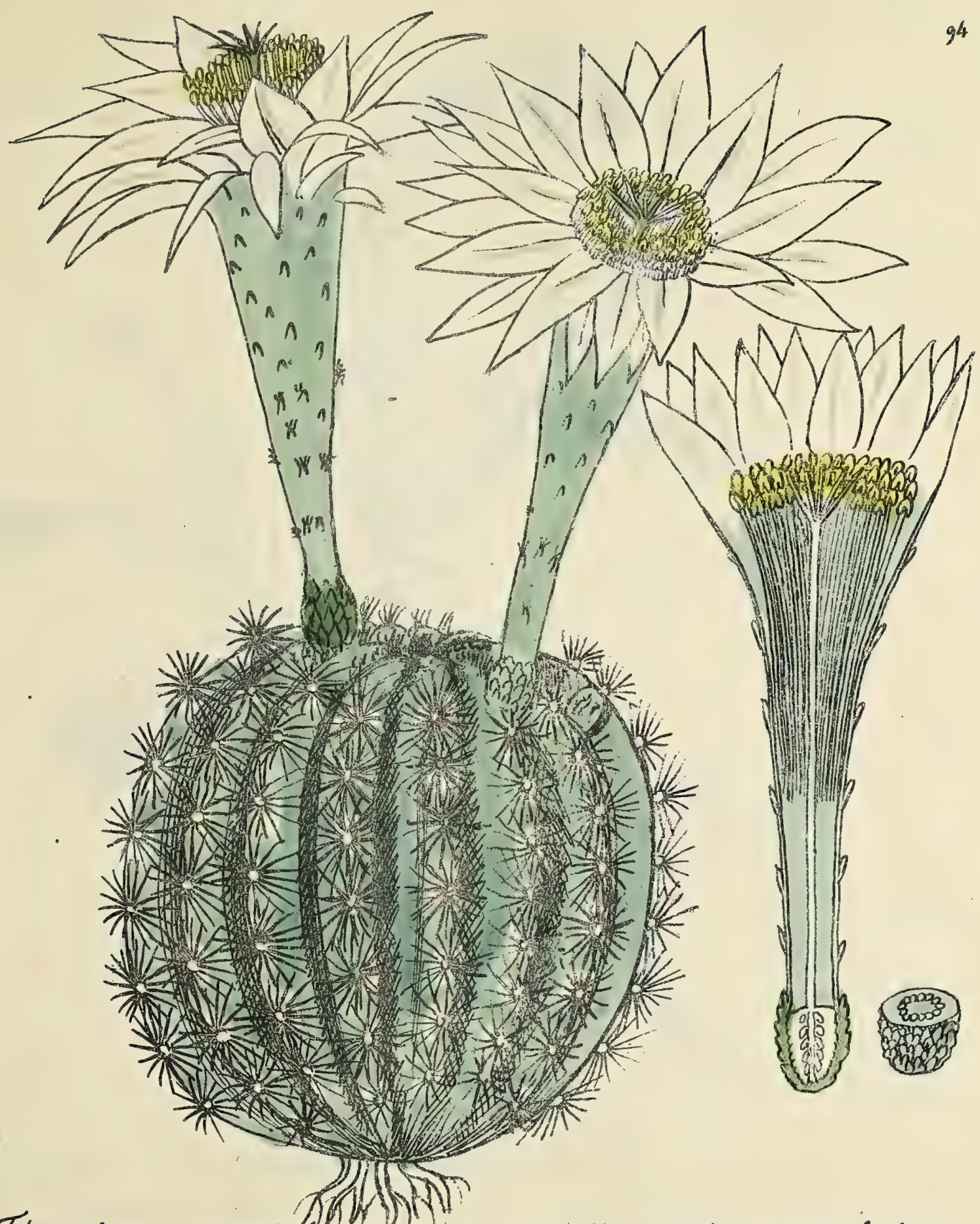

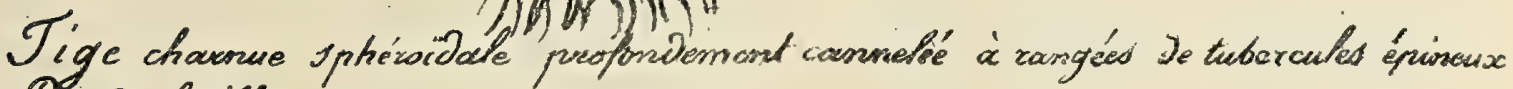
Pas de feuilles

Fleurd isoleed sediled sortant des subercules

Tibbe écuifleux vert, Péraled bfarted

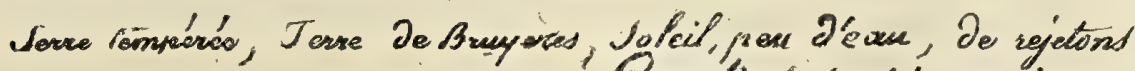

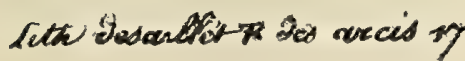

Caclins (cchinopisis) Julcatus 



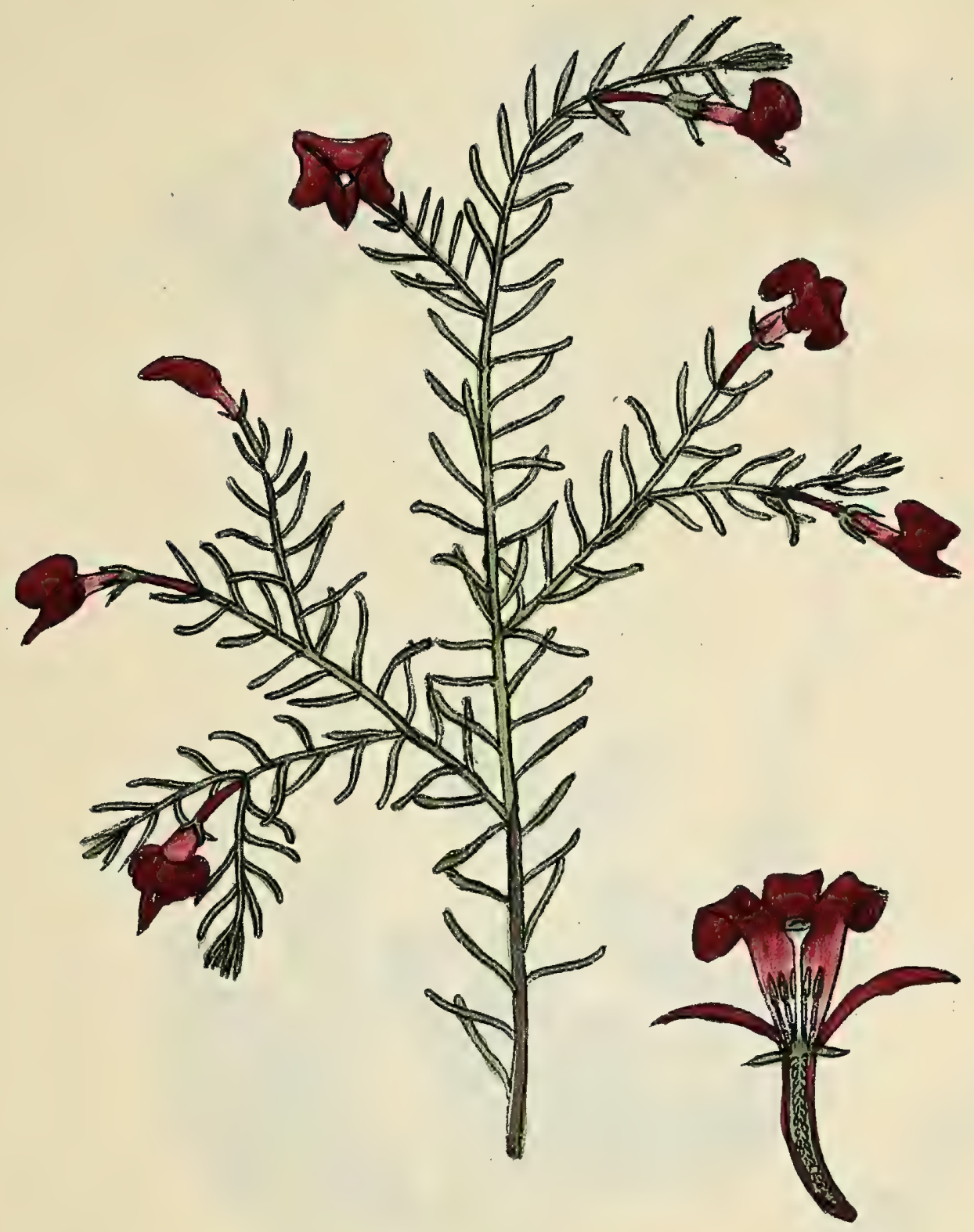

Tige ligneuse, tres ramause, Jroite, De o, so contimeibes Feuilles épordes, en atène, glabres, ponctuées

Flewes solitaires, sessites axill aires, on Jans fa dichotimie su aubout bes Porolles glabres, vermillon-poweprer

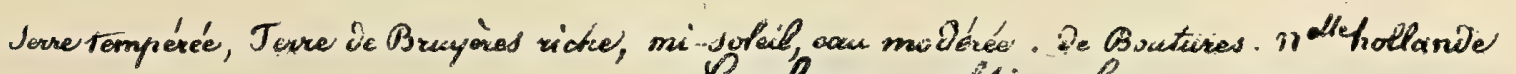
Pechenacitia formos a Robut Brom

fith Desaitler $R$ Des akeis $1 y$ 


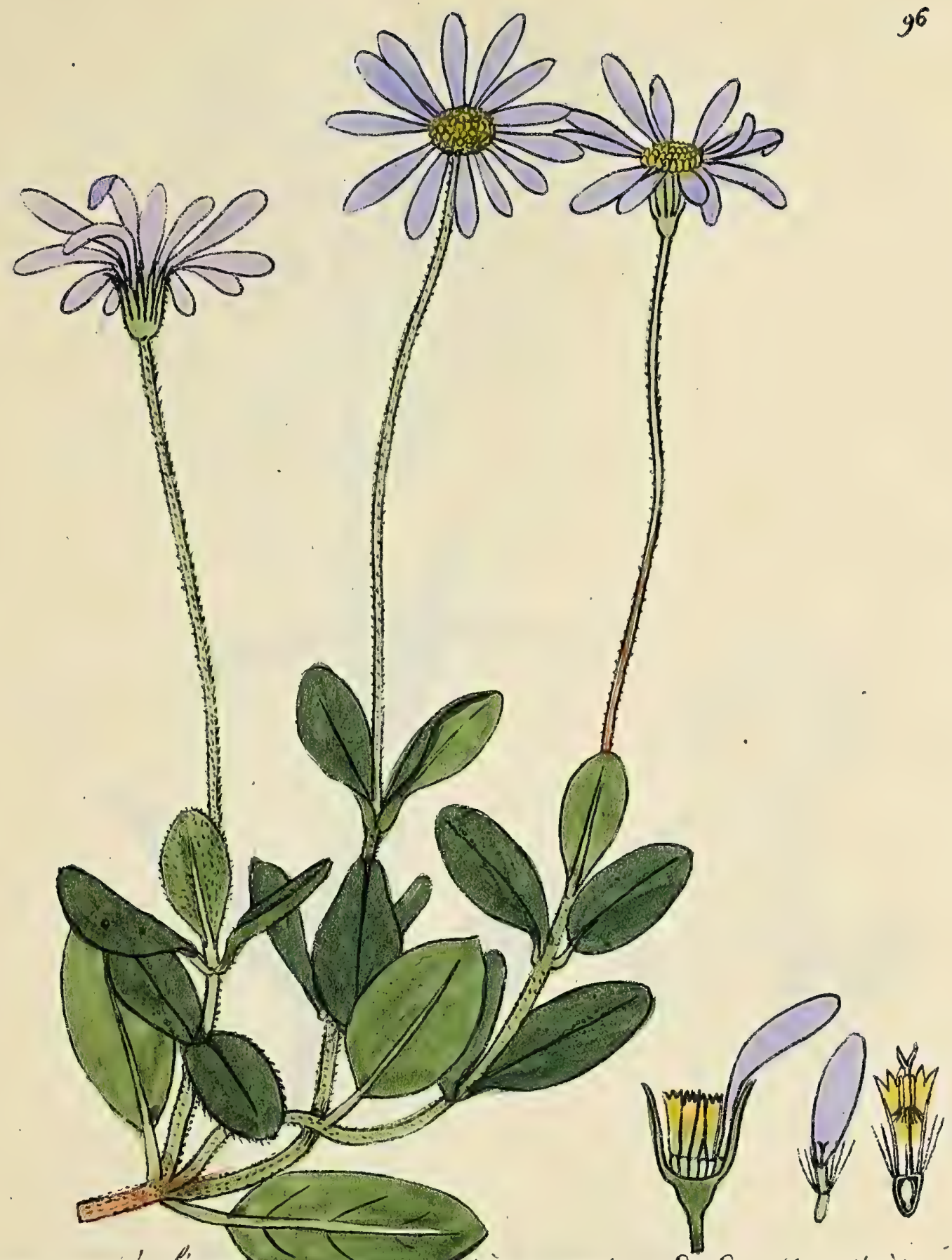

Tige un prew coucricé, lignewd

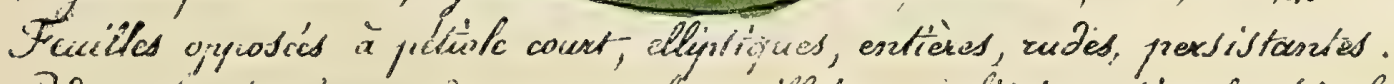

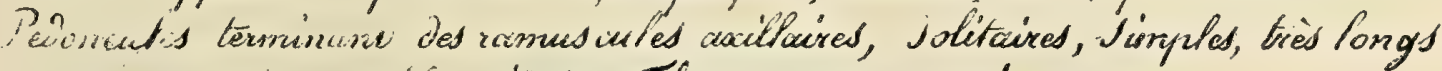

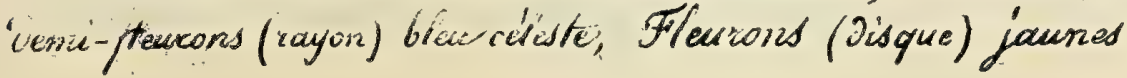

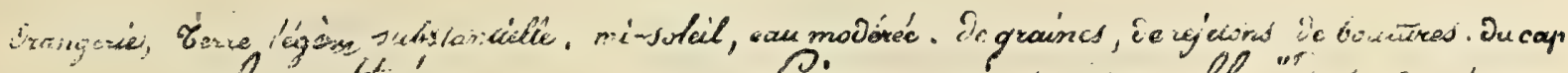

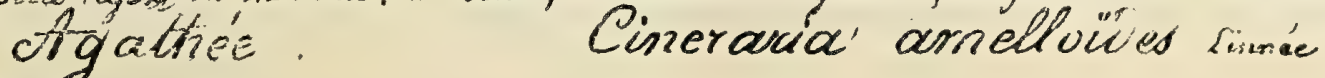

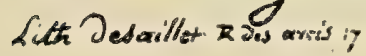





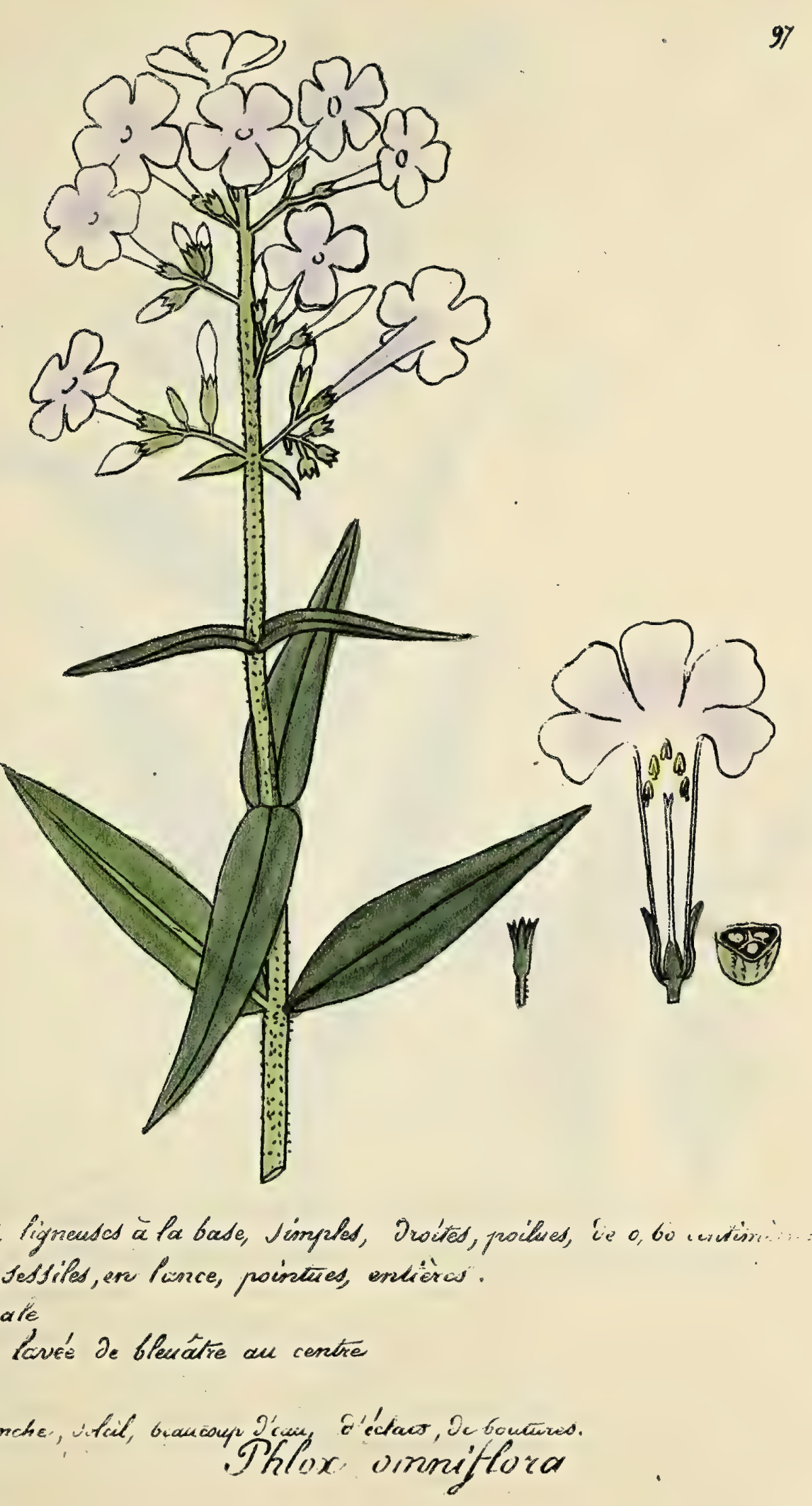





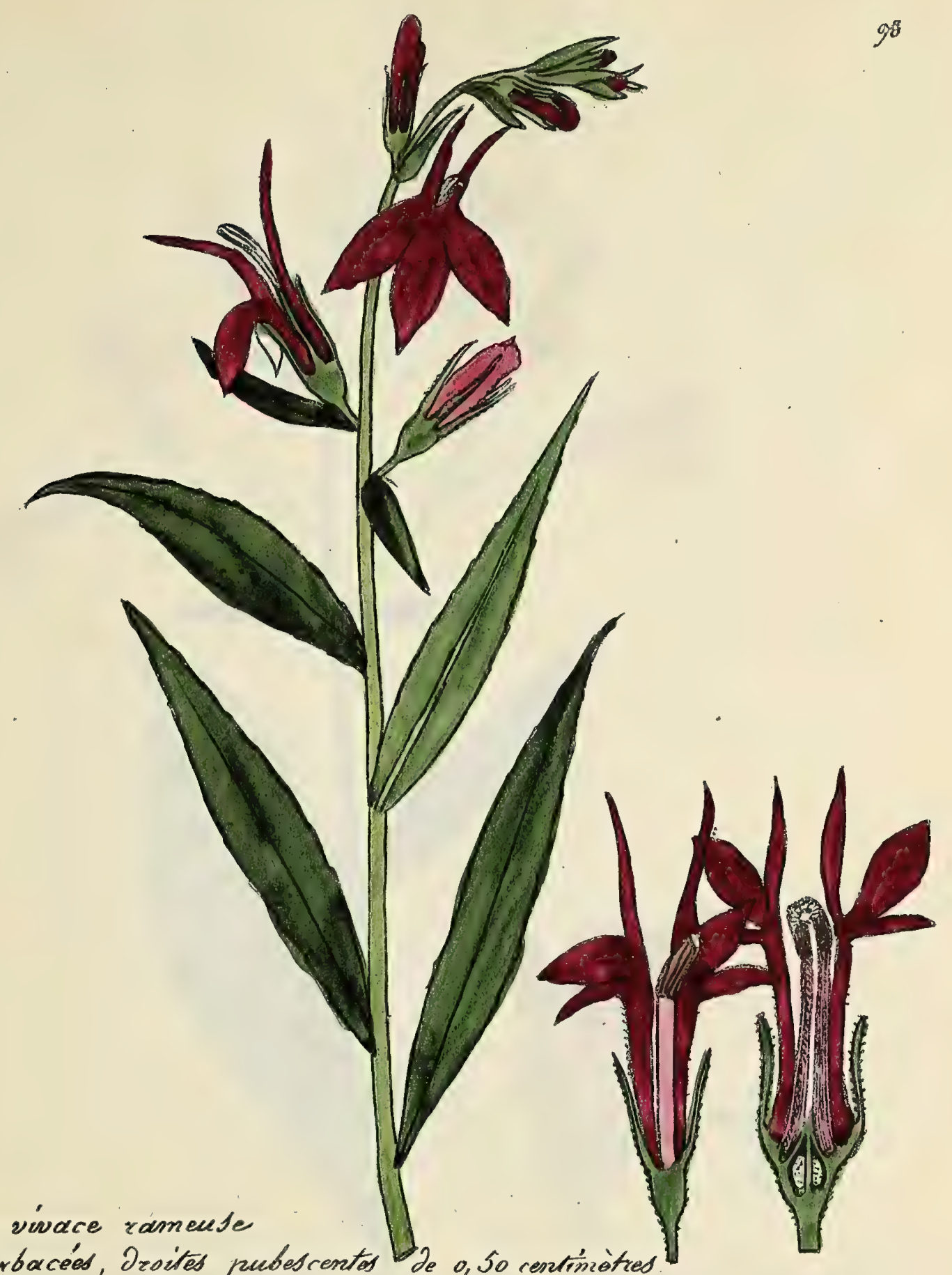

Racine vivace rameuse

Tiges kerbacées, Droites pubescentes de o, So centimiòtres.

Fruilles en lance alterries sessiles pubescentes, à boris roulés en desiveus Cpis terminanx simples

Flewrs tries gravides, bean rouges pubescentes

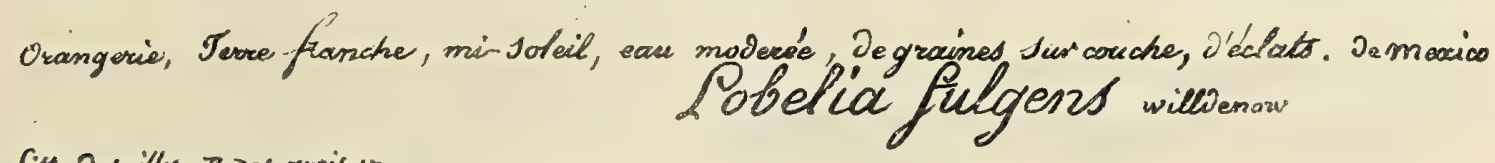

Sith Desaillow $R$ des ourcis 'y 



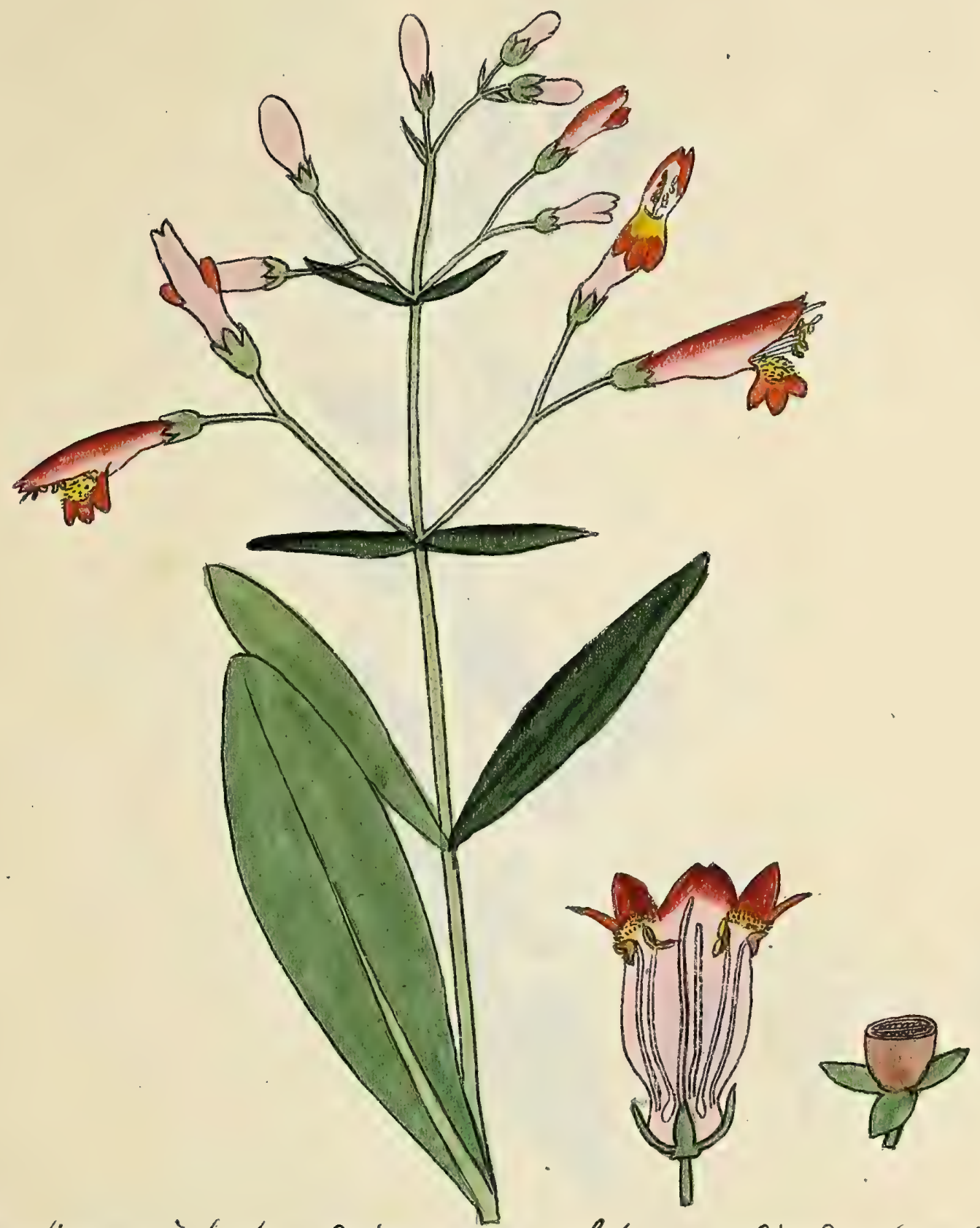

Tige ligneuse à la base, Draite, ramewe, glabre, arro, dies, de o, bo contionètres Hewilles sedsiles glabres, les jupériaures en Parce, les infórieures on spatule. Panicule ternimale à peoboncules perrchiés

Porolles écoulates, à tcure inforién re couverte de poils dorés et de ligmed rouges

Orangorie, Terre franche, De grained Jur couche ou J'écliats, Soleil, eau modéree. Des meacico Qhelone baubata cavanilles

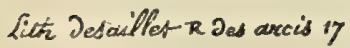





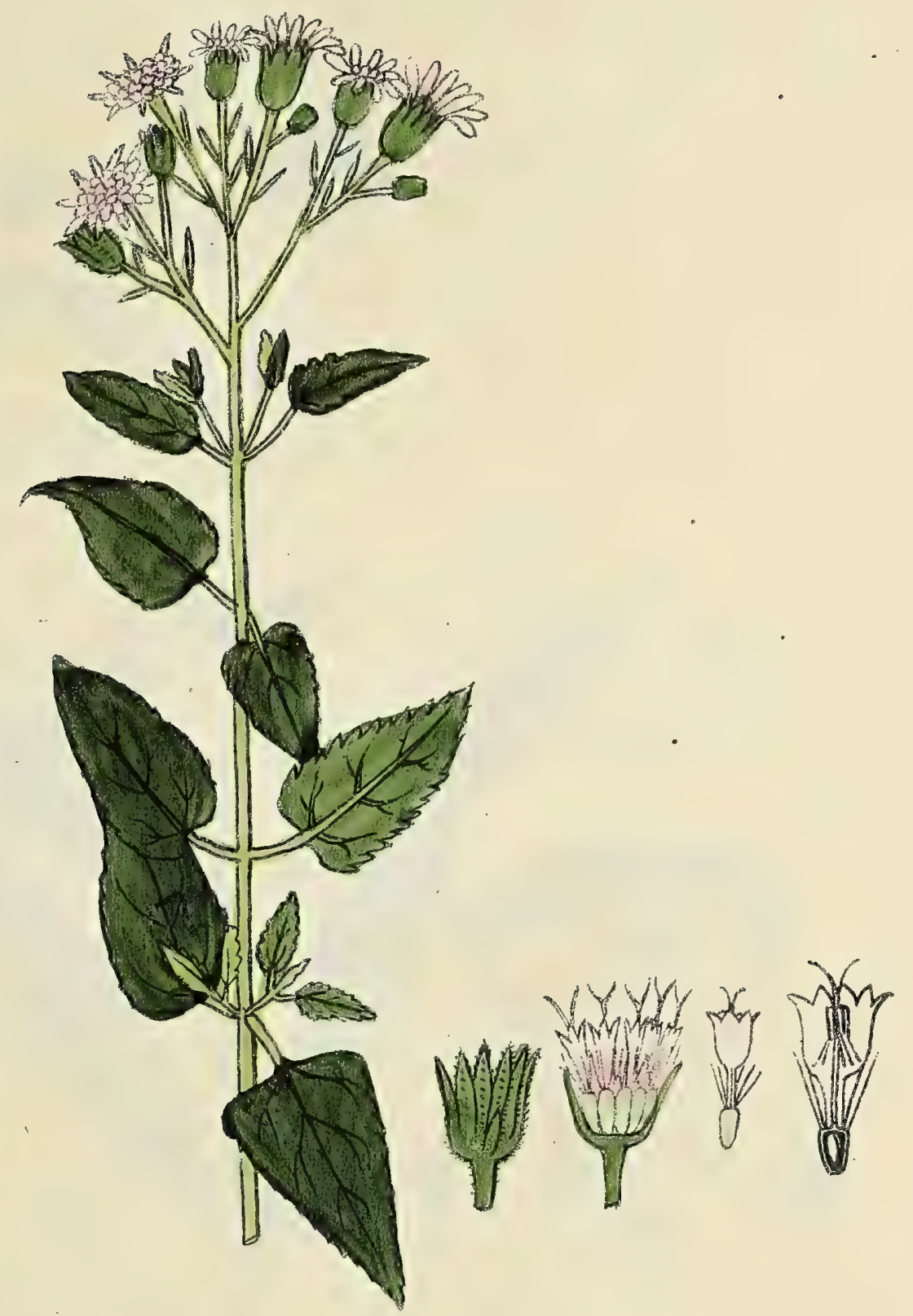

Tiges ligneises ramsuses, srocied.

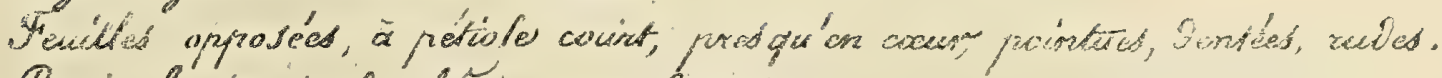
Tamiaide terminale, lache, peu fournie,

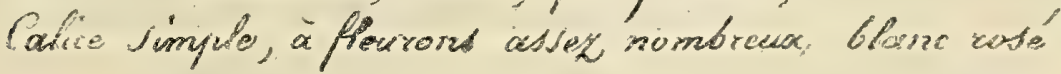

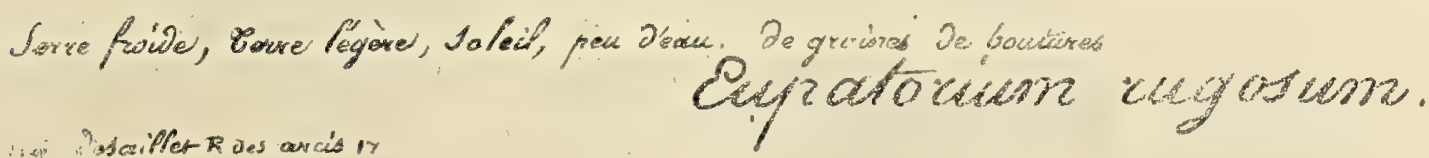





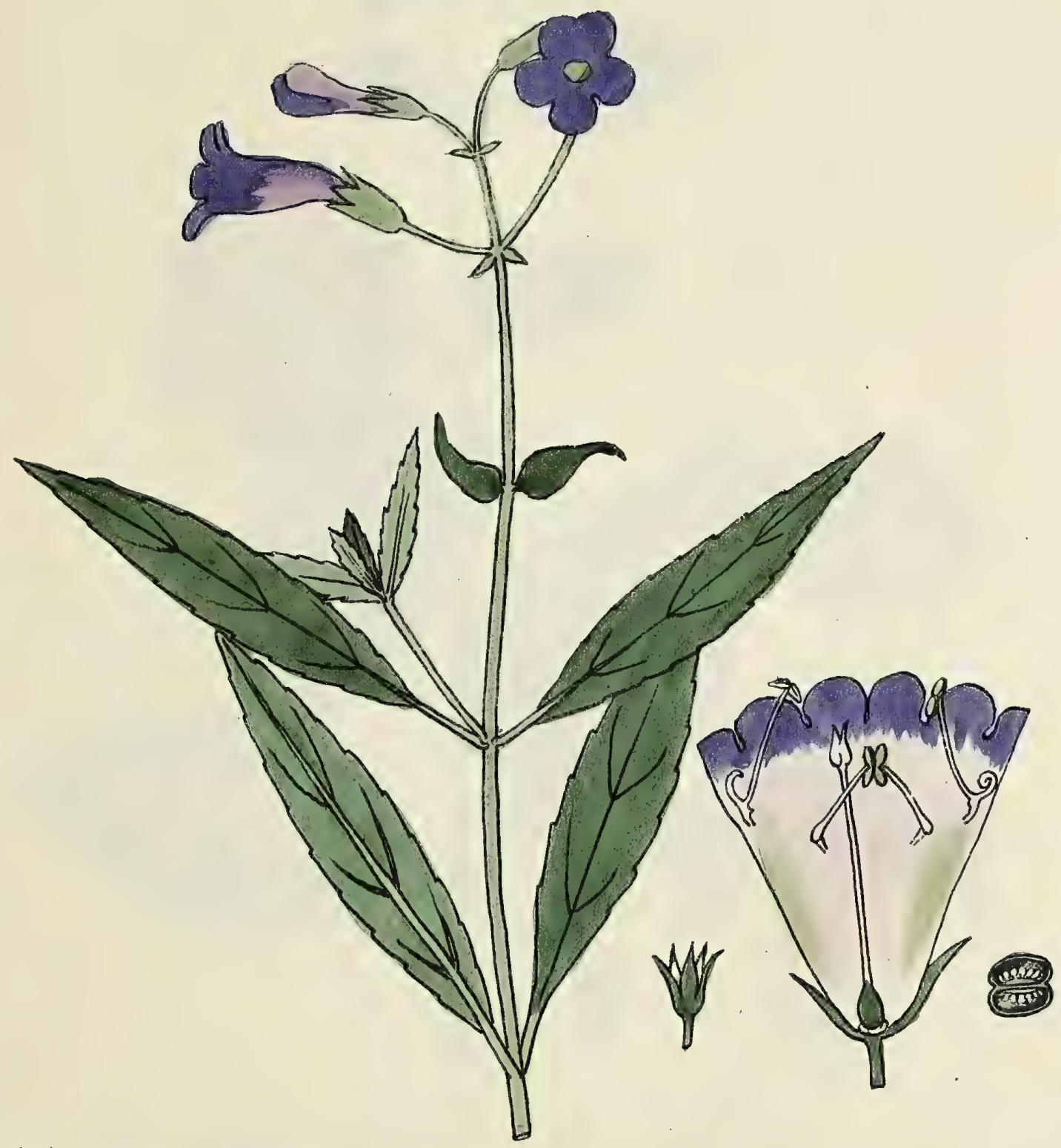

Tige úgnande à la base, Jressáe, vamense, y labre.

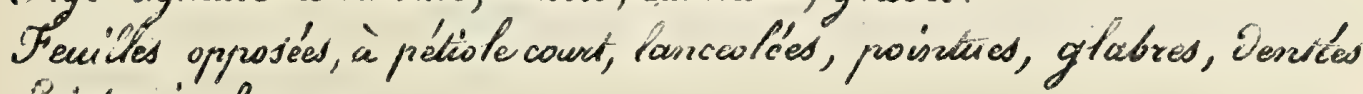
Gu terninal

Calice à lanvières augues, Porolle asser grande, violette

Serve tempérée, Zenre De Bruyères, mi-soleil, eau'nzodérée. De graines cr-De boutüres.

Sith Desaifler $\mathrm{R}$ Jes arcis iy

$$
\text { Yasenia finzuriata }
$$





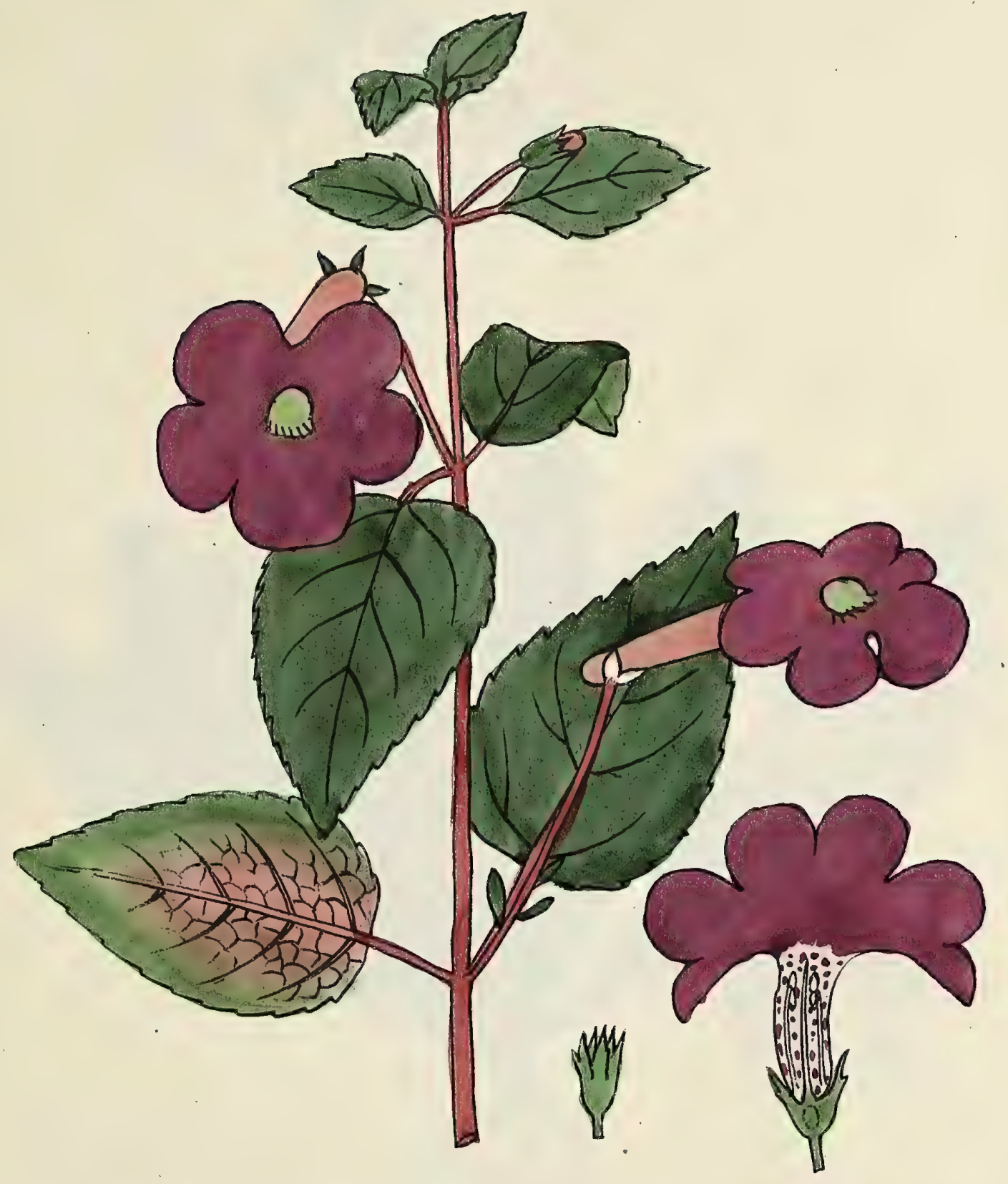

Gige ligncuse, pur ramense, Dressíe, glaíre, wuge Funilles oppwsées à pétiole court, ovales pointües, Dentées, rougeâtios en Dessous $\mathcal{P}$ doncules axillaires, Jolitaircs, sionples, portant le petites bractés Corolle prolongée en éperon à la base, à linbe large, rouge

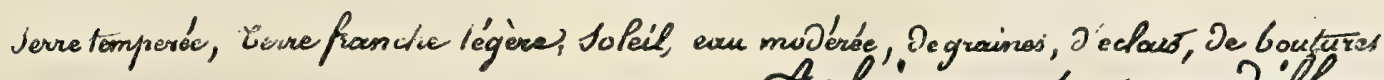
Achimenes granifloca fitro Dasirles-R Des urvis oy cher Somicher $R$ Jed 3 Pouronnes it 



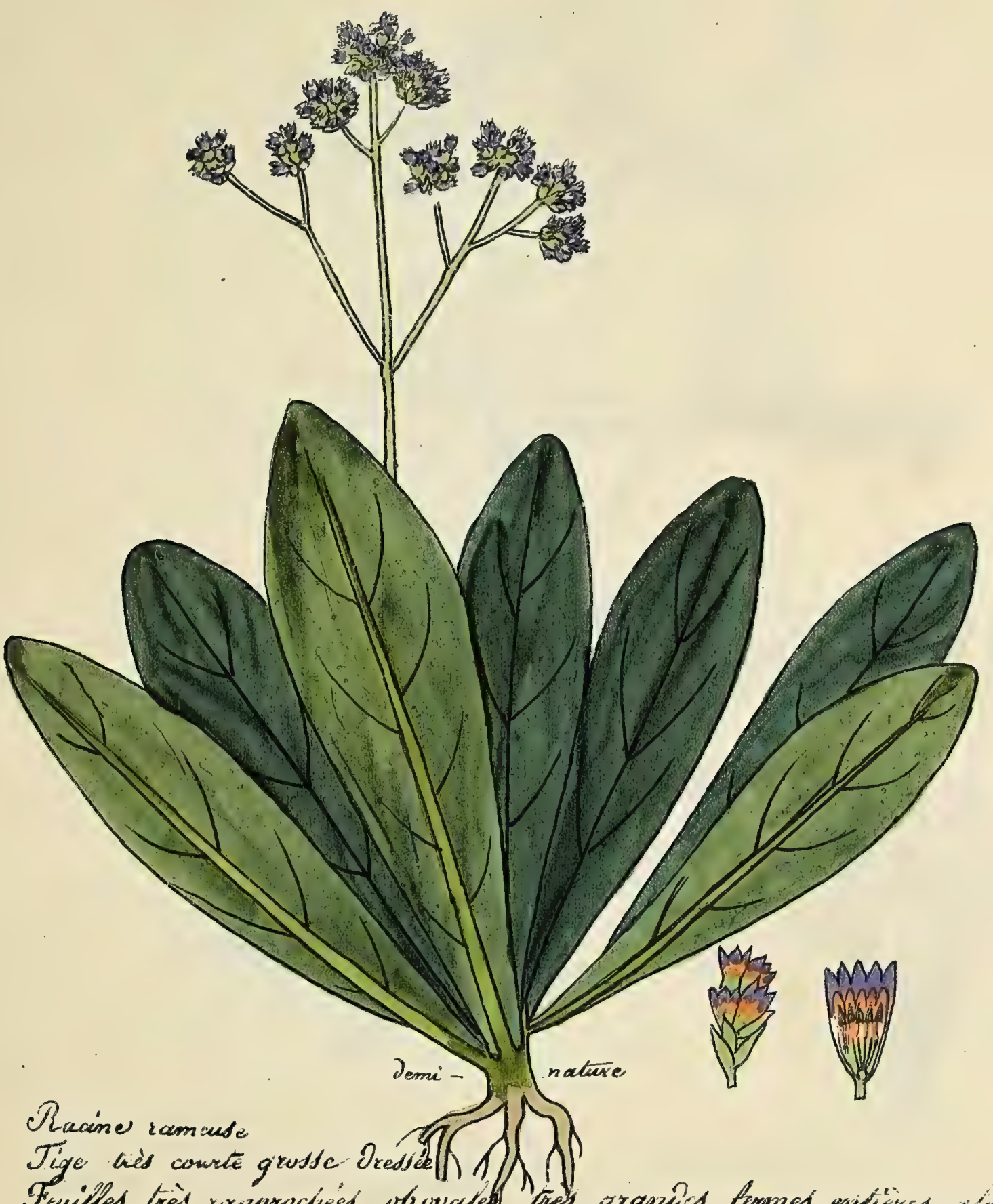

Racine ramoude

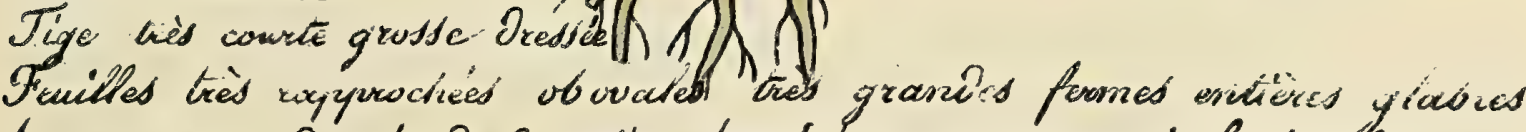
hannic ruie Dresiée de 60 cention. terminee par une panicule tries Pounnie. Calices vorts à la base, rouges an miliew, viorebs an bord. Pétales brès sourts

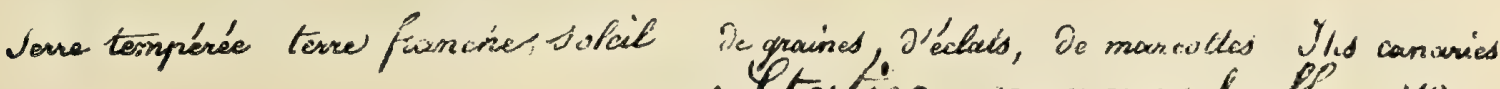
Stalice niacroptylia wition Sitto Jusailler R Ju aincs "y Cher Bertiño Rdeta Roquolte $10 \mathrm{~A}$ 



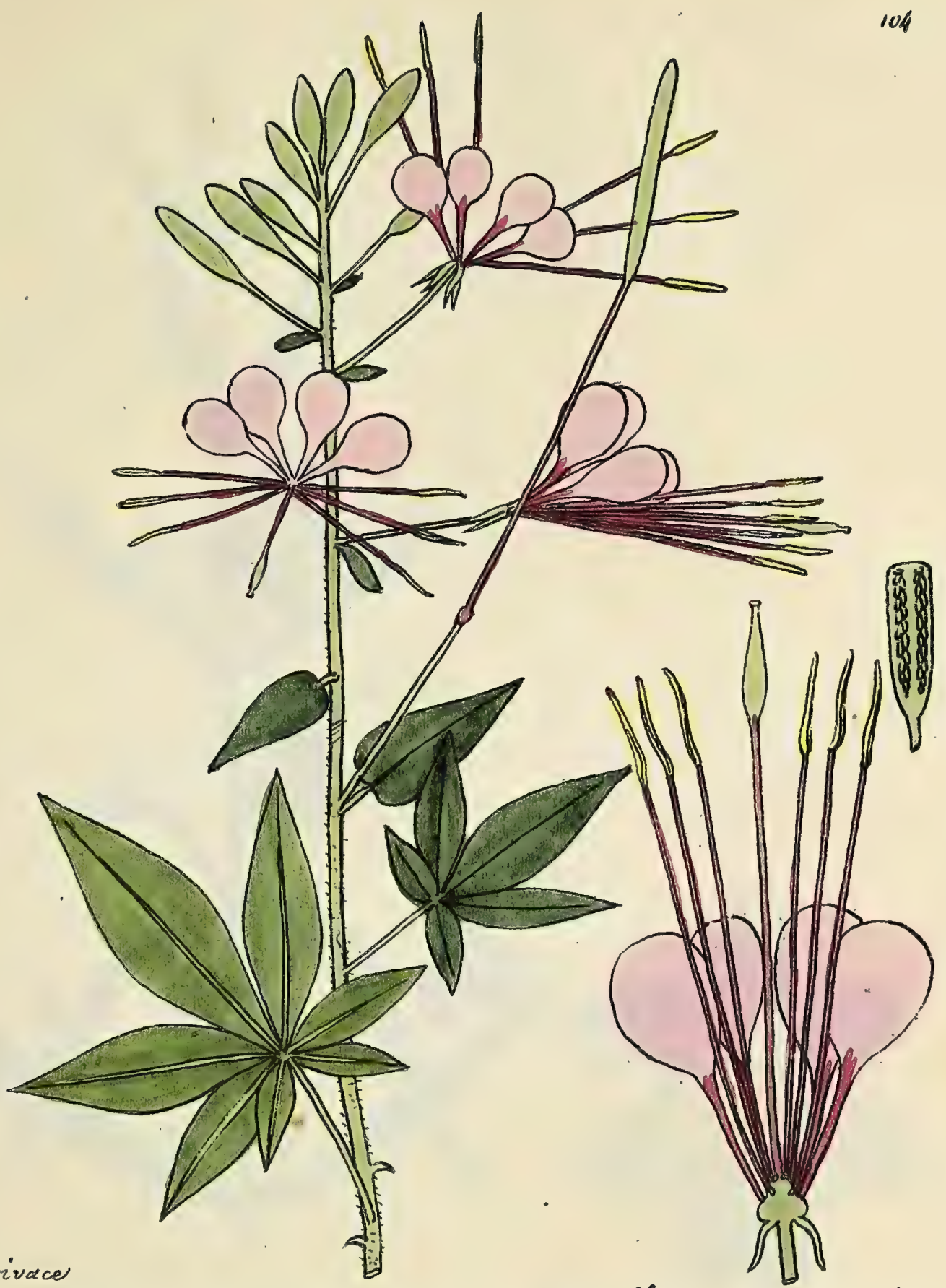

Raine vivace

Fige herbacée, Juessée, rameuse, proilue, purtant Des aiguillons, De phis J'1 mètre Fevilles altermes à long pítiole, de 5 à y foliwles ovales pointues Jigités glabres

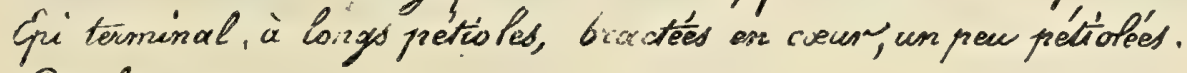

Pelates roses

Silique à long Jusyzort

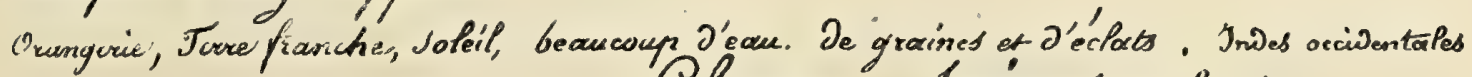

Cleome Jpinzosa Pinnée

Libso Desouffer- $\pi$ ars aresis 7

Chor Chouvière R Je la Roquette 104 



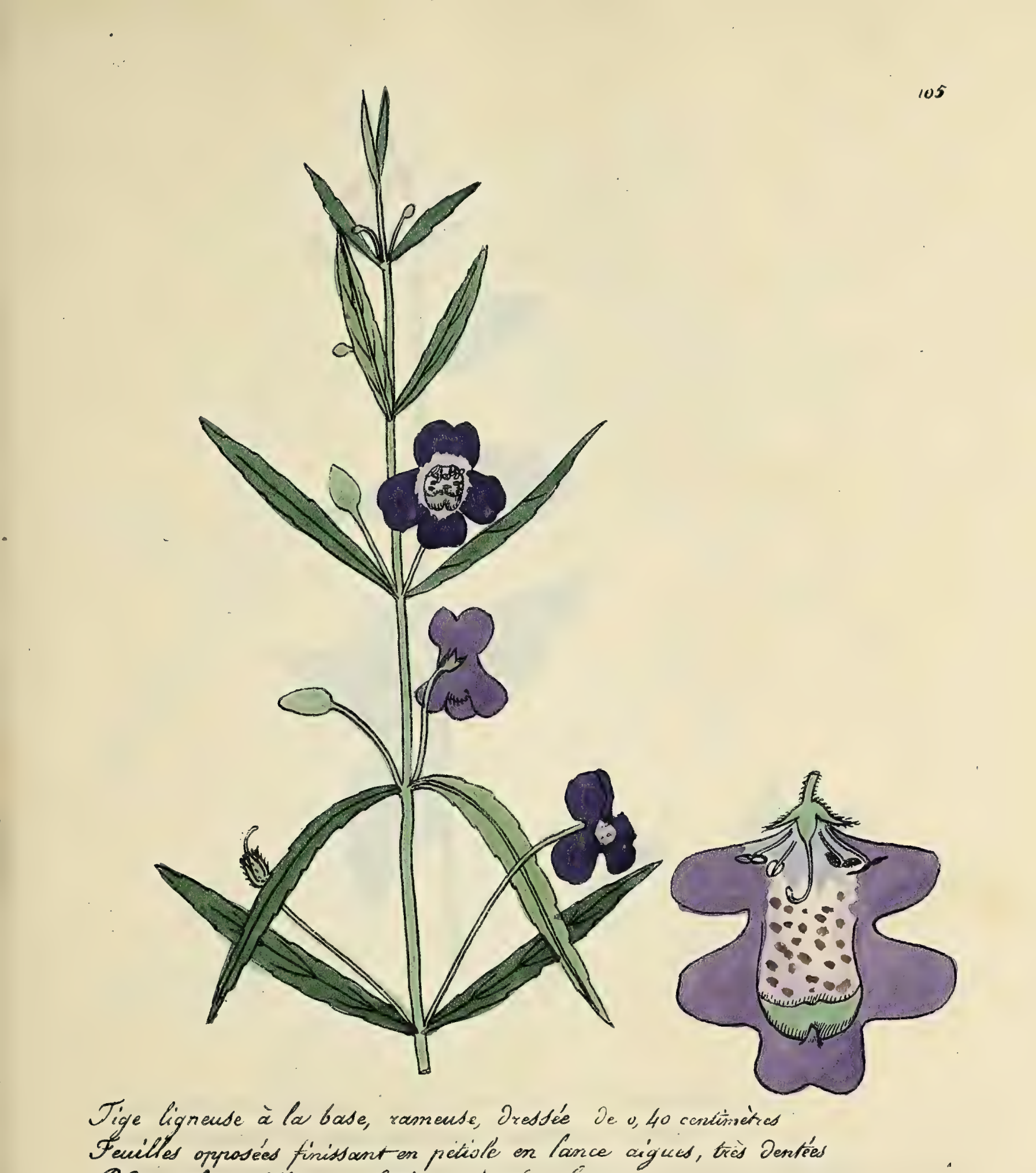



100

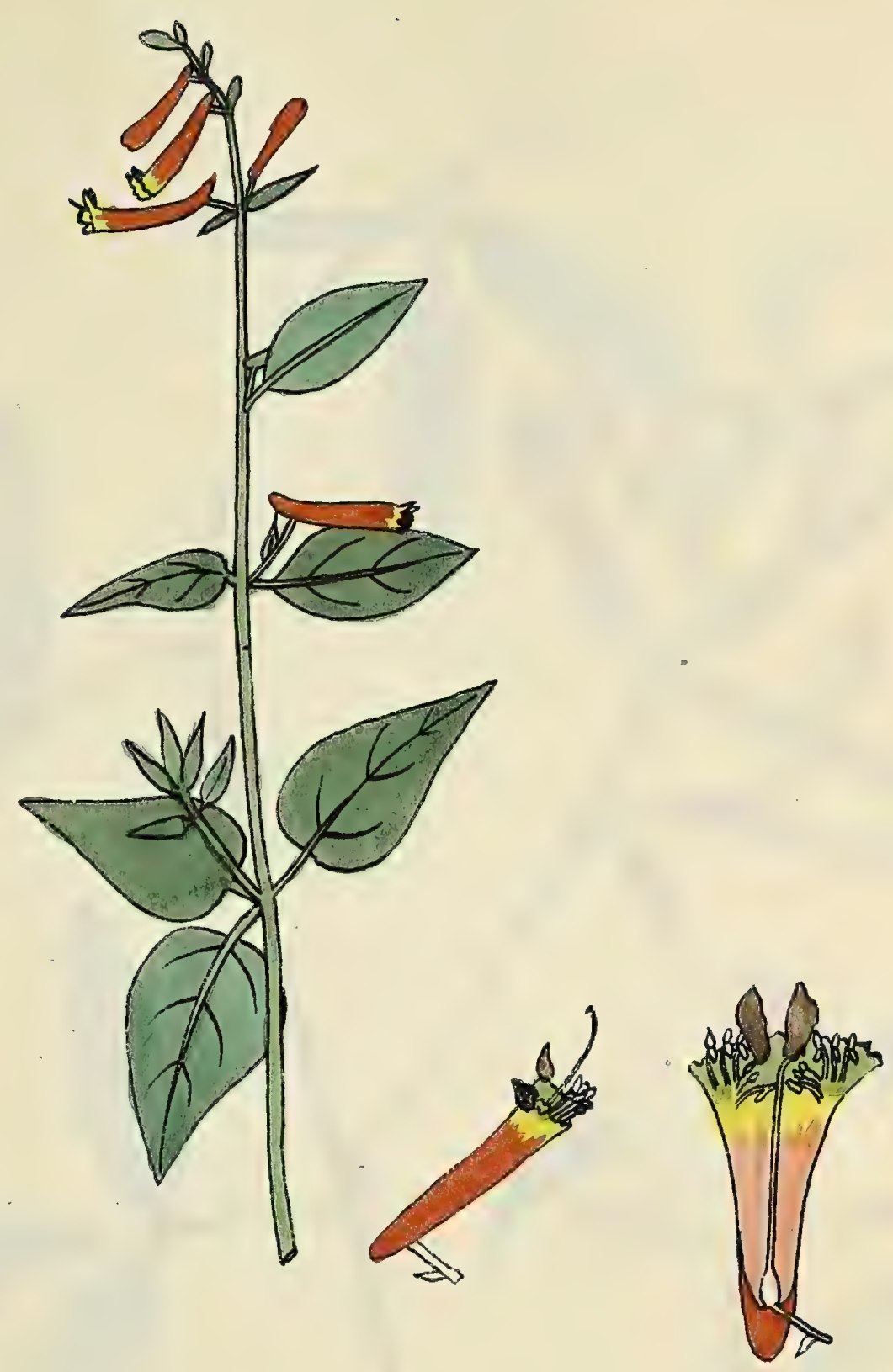

Tige ligneuse, rameuse, cyliswingue, de o, 10 concionètres Truilles opprosiés, quelquefois ternées, potiolées en coeur.

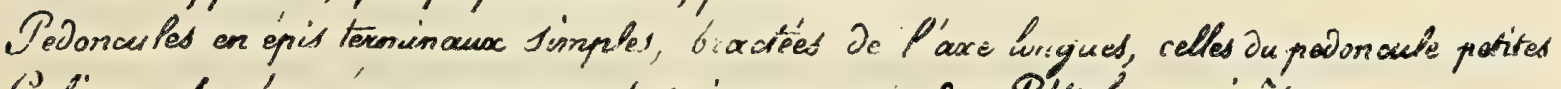

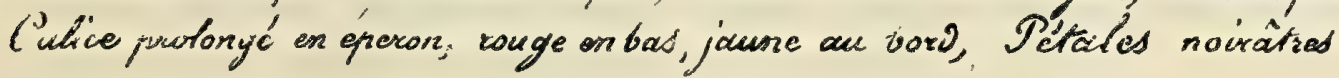

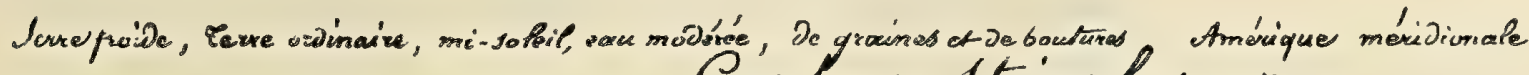
Cuphea Jtingelosa. Kurth

Lith Jesrilter $k$ aw is in Chov Bortand $R$ de la Roquelte 102 



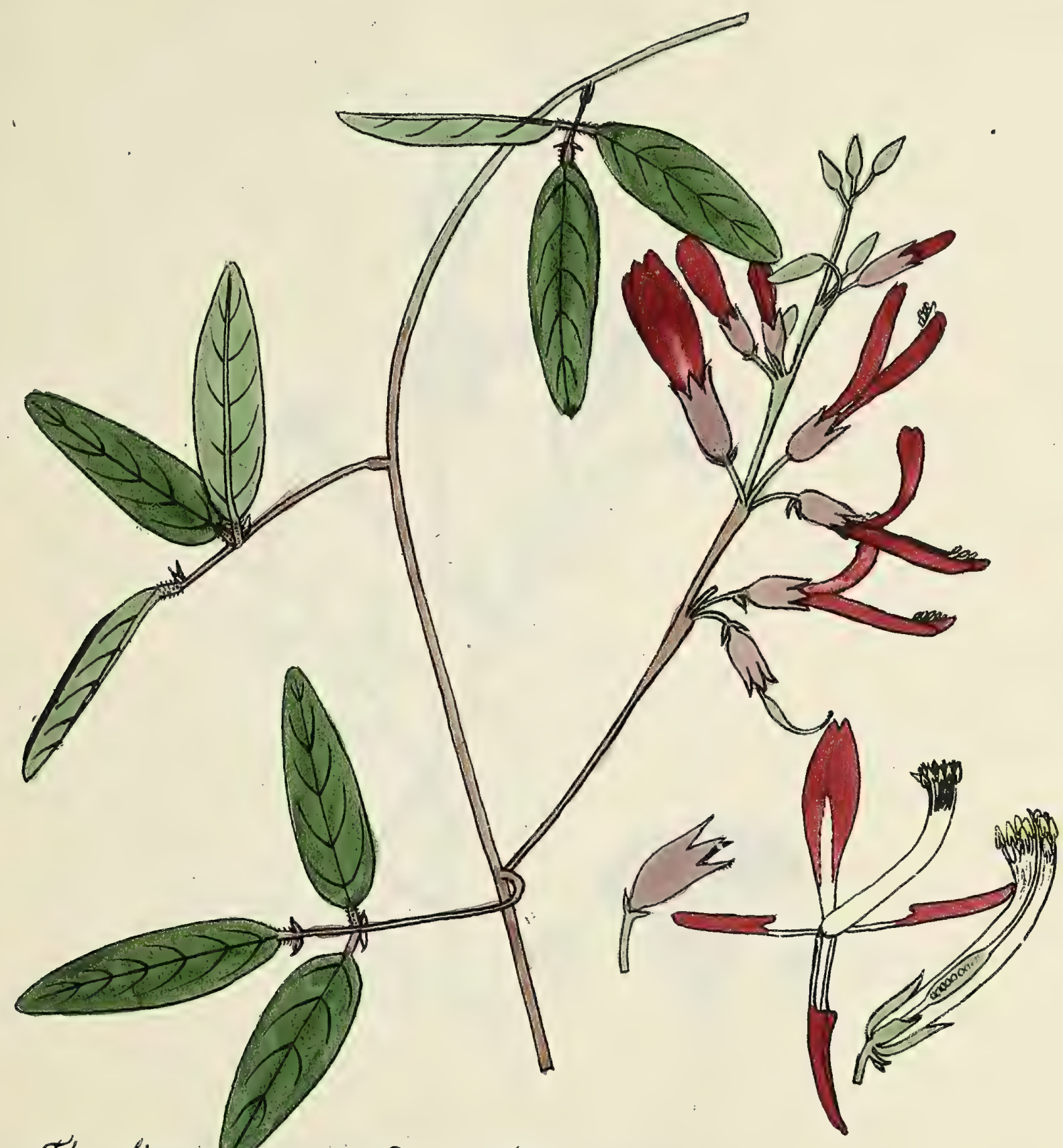

Tige lignecisel rameise de ra's netros

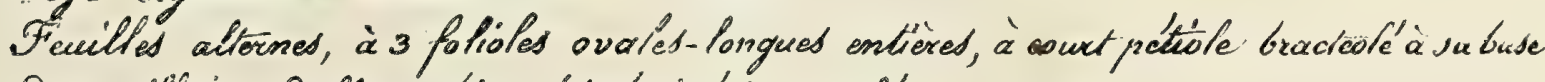
Gris axallacies Deflewes bi ou trigéminées, penchées

Calices à dents aigues, bractéoles à la base. Porolle écartate.

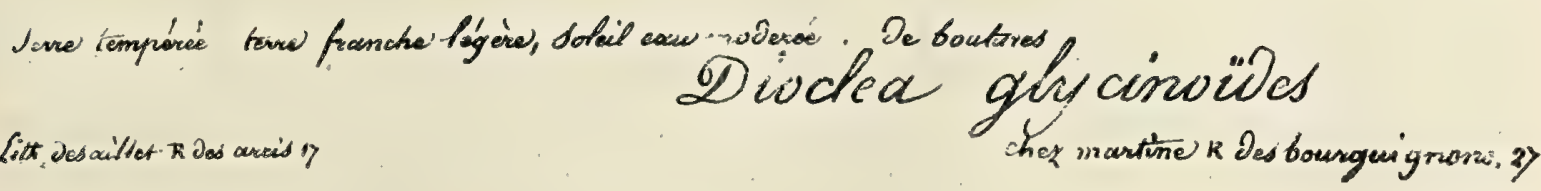



108

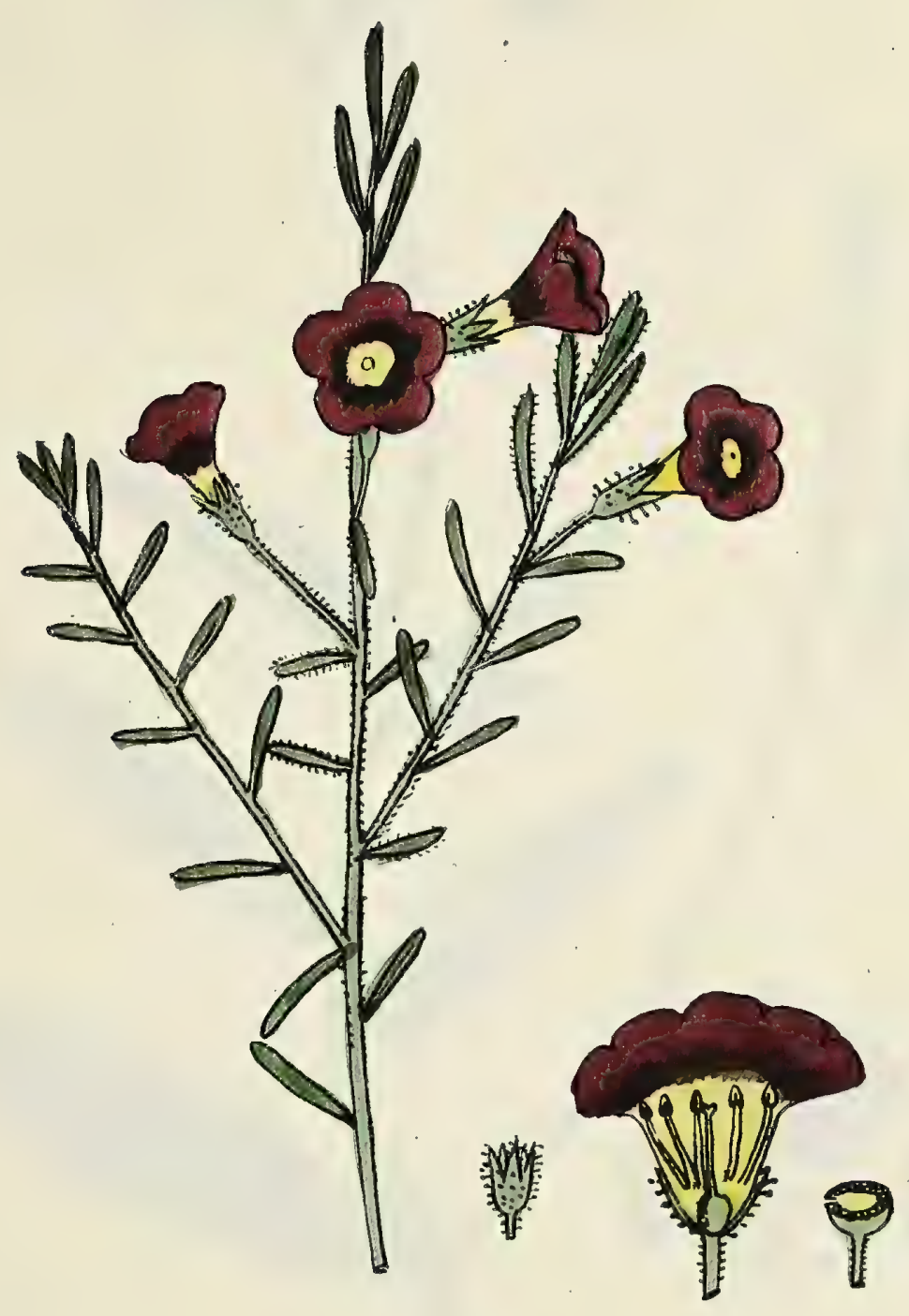

Tige lignneuse à la base, ramense, velue, De 0,80 contimeitred

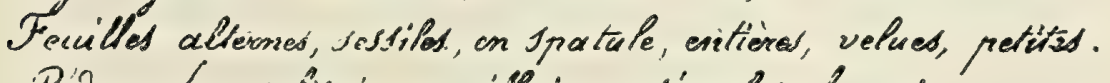

Pedoncules soliticaices axiffaires, Jimples, Pongis

Calices a Dents aigues, pwils glandulewox, Cowolte à tuber jausse, limber noir-viotacé

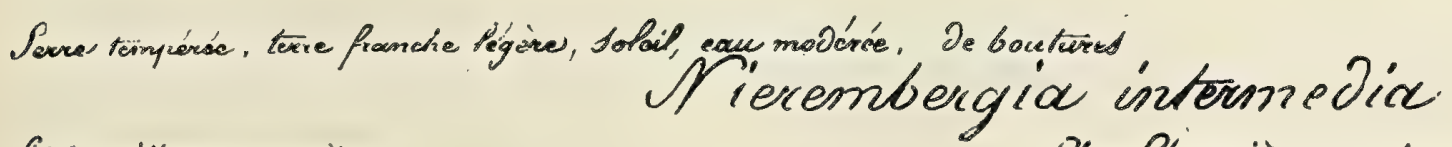

Ciik Jessiller $R$ oes arcis $n$

Thax Phawière R de la Rogridite 104 



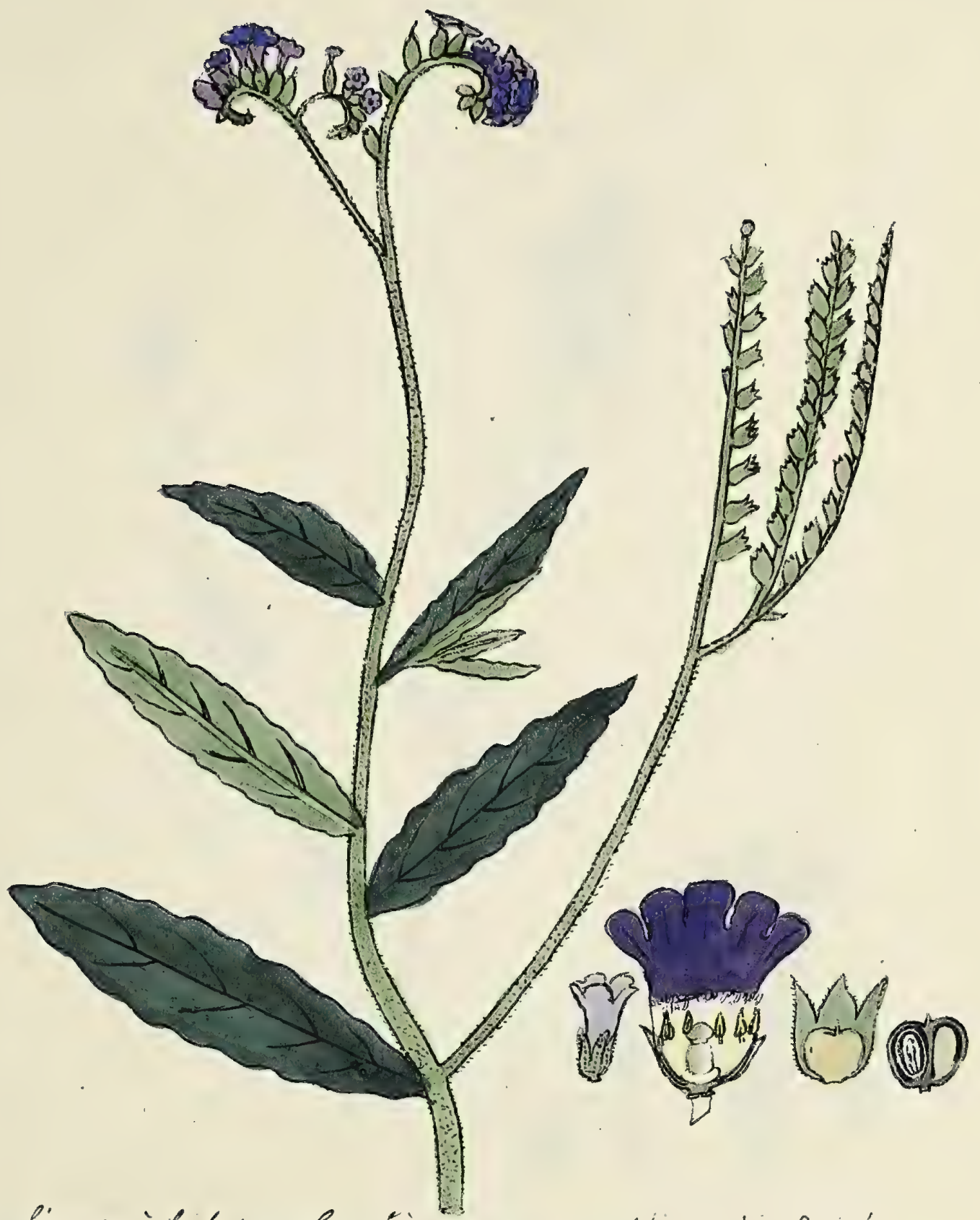

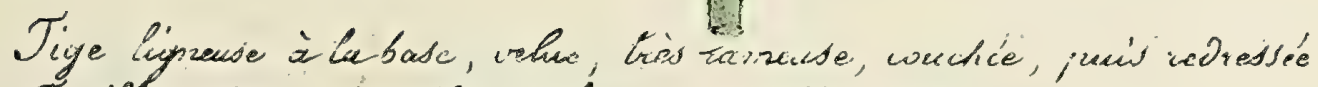

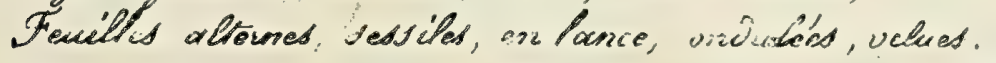

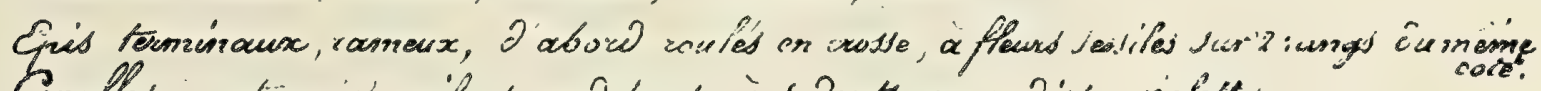

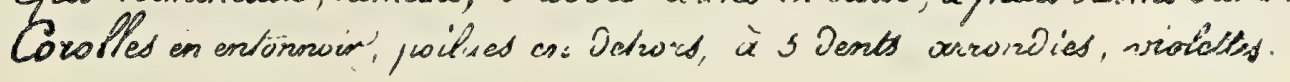

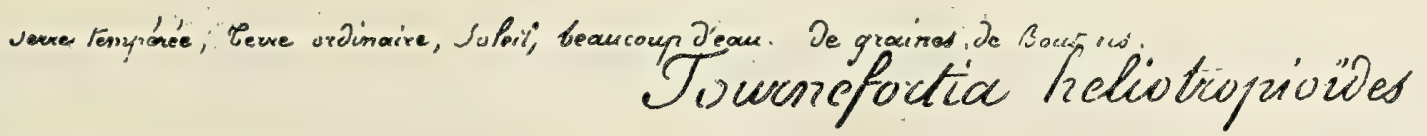

Lith Descillet a dis areas of 



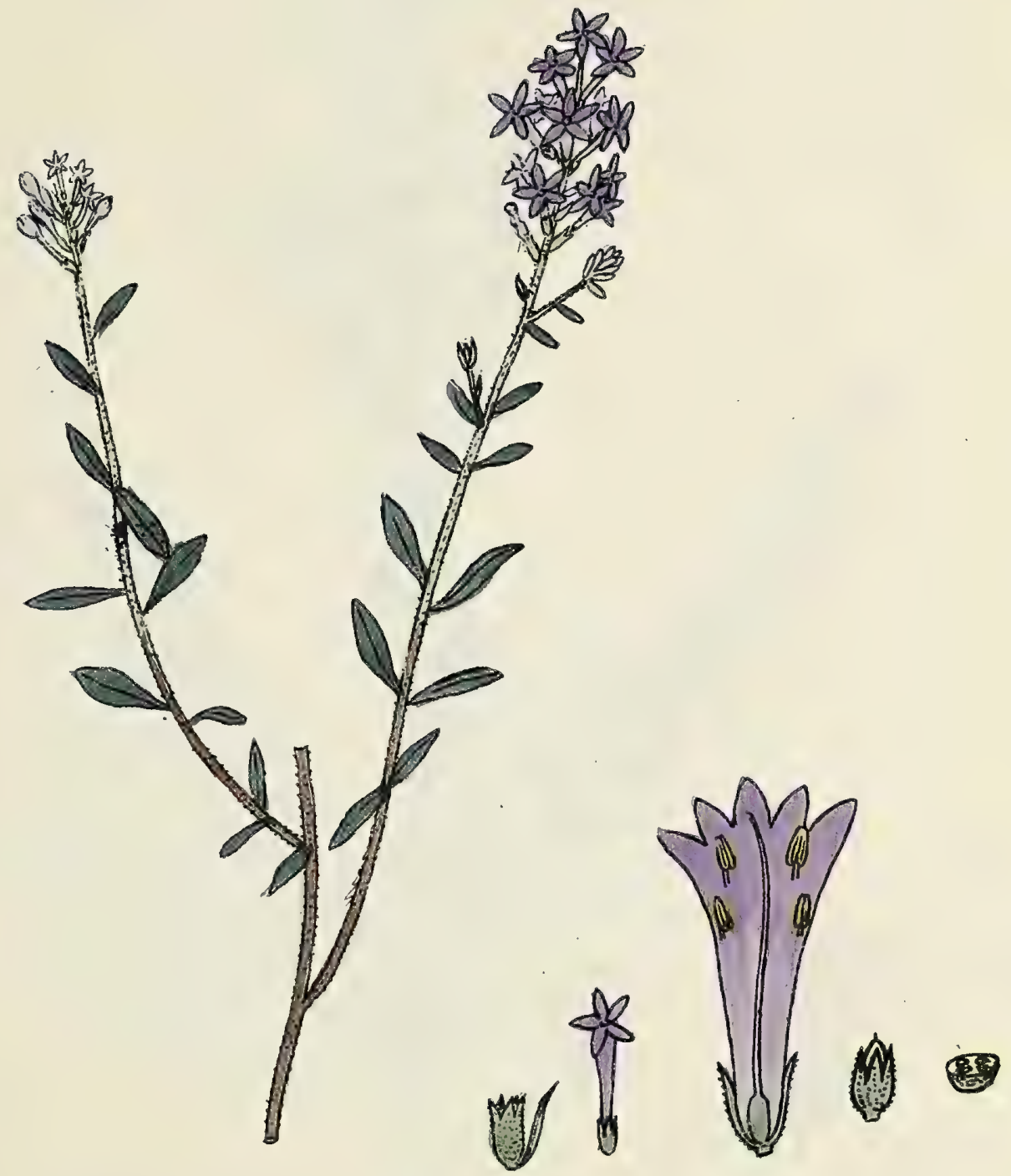

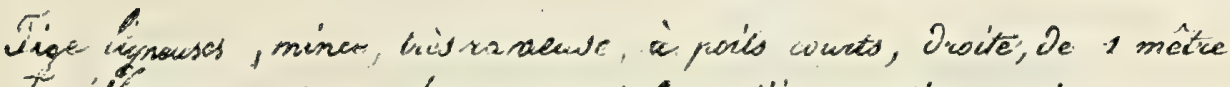

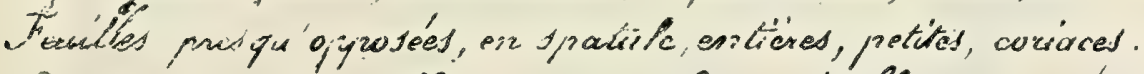

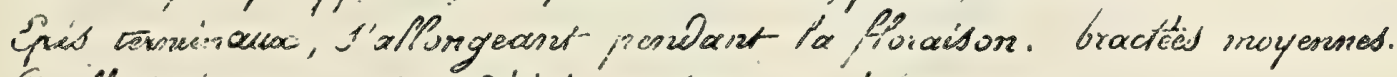

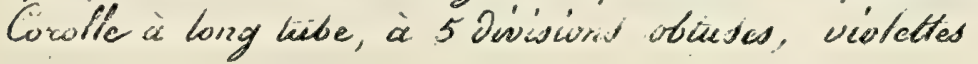

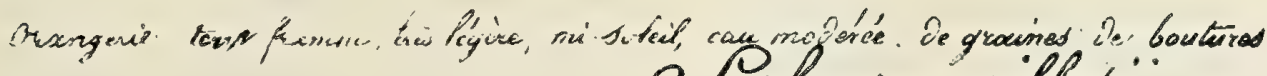

$$
\begin{aligned}
& \text { Littwadailler } 7 \text { Jer werd } \\
& \text { C elago quPfetic }
\end{aligned}
$$




\section{,}




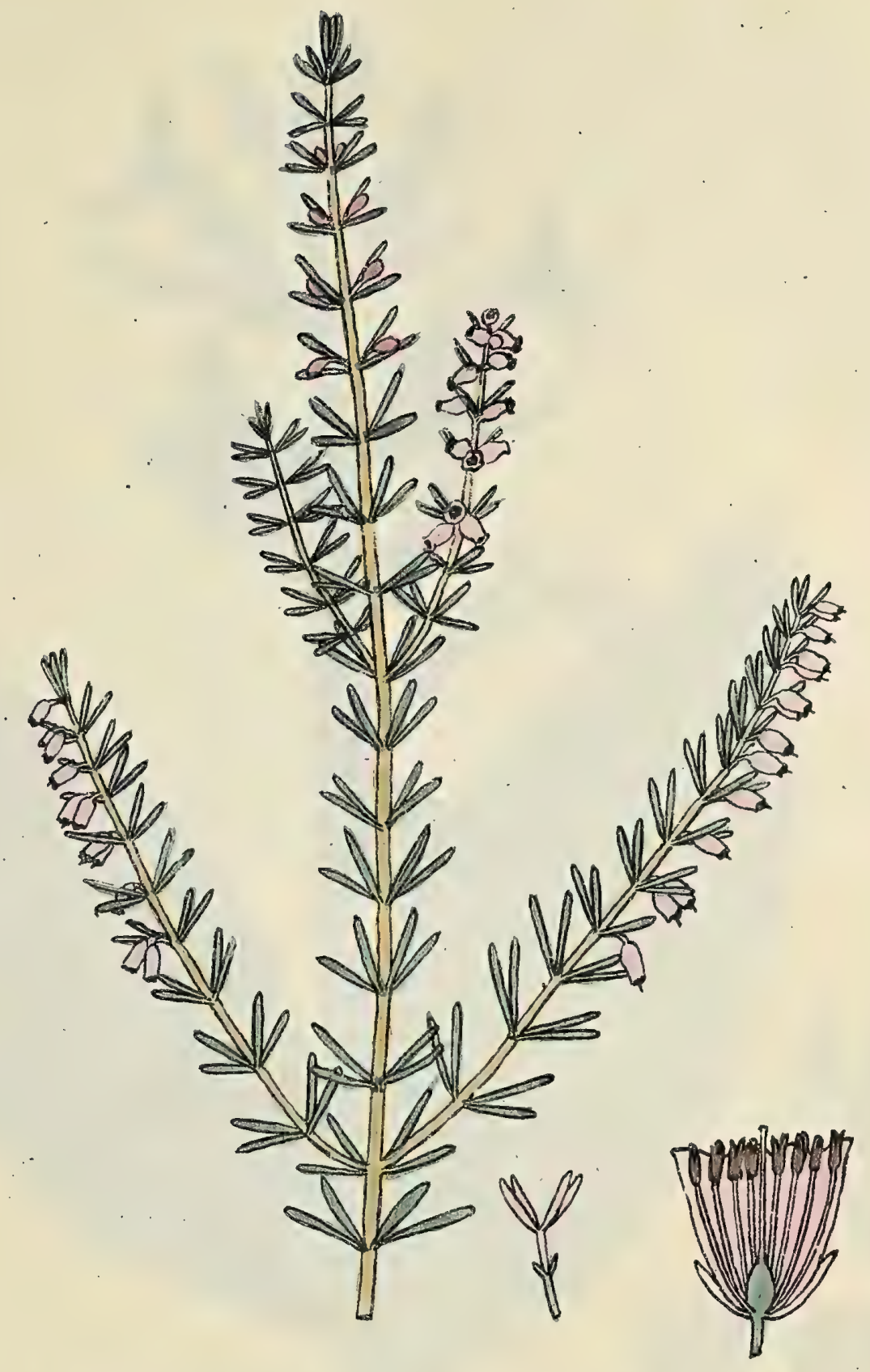

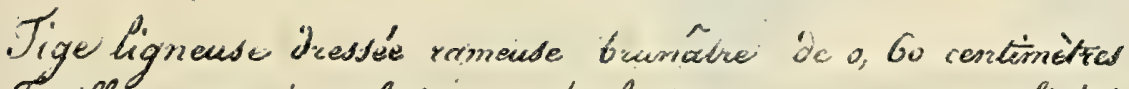
Fenilles ruaternées glabres, à pétiole très count, ouvertes, linéaires. T'Joncules axcillaires simprtes, formannt cornme un épi towene' Tun côté.

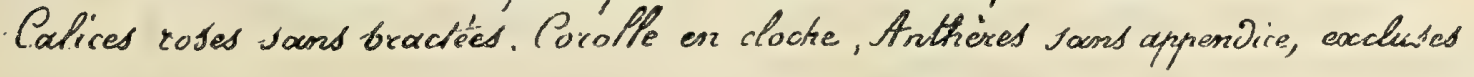

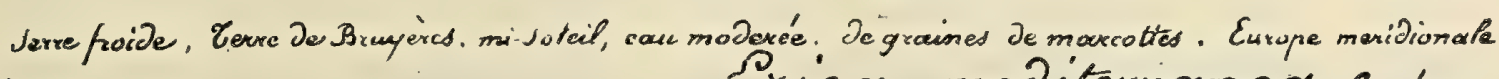
Prica mediterianea Sinné

Sith Jesailst $R$ des arcis if 


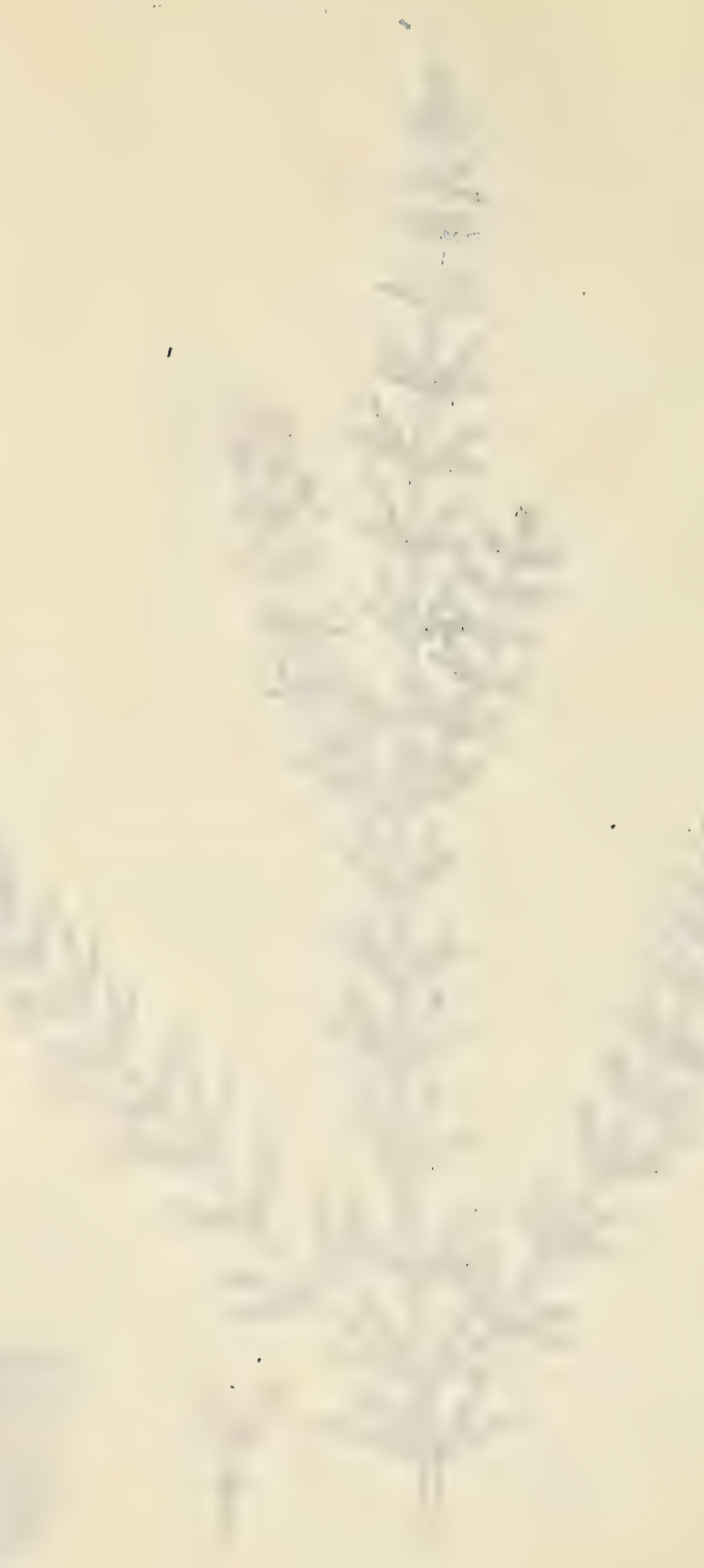

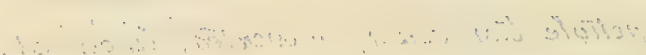

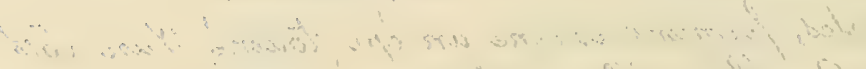

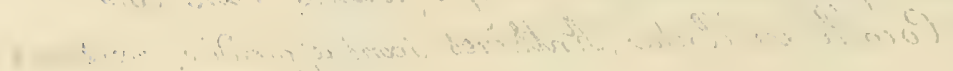




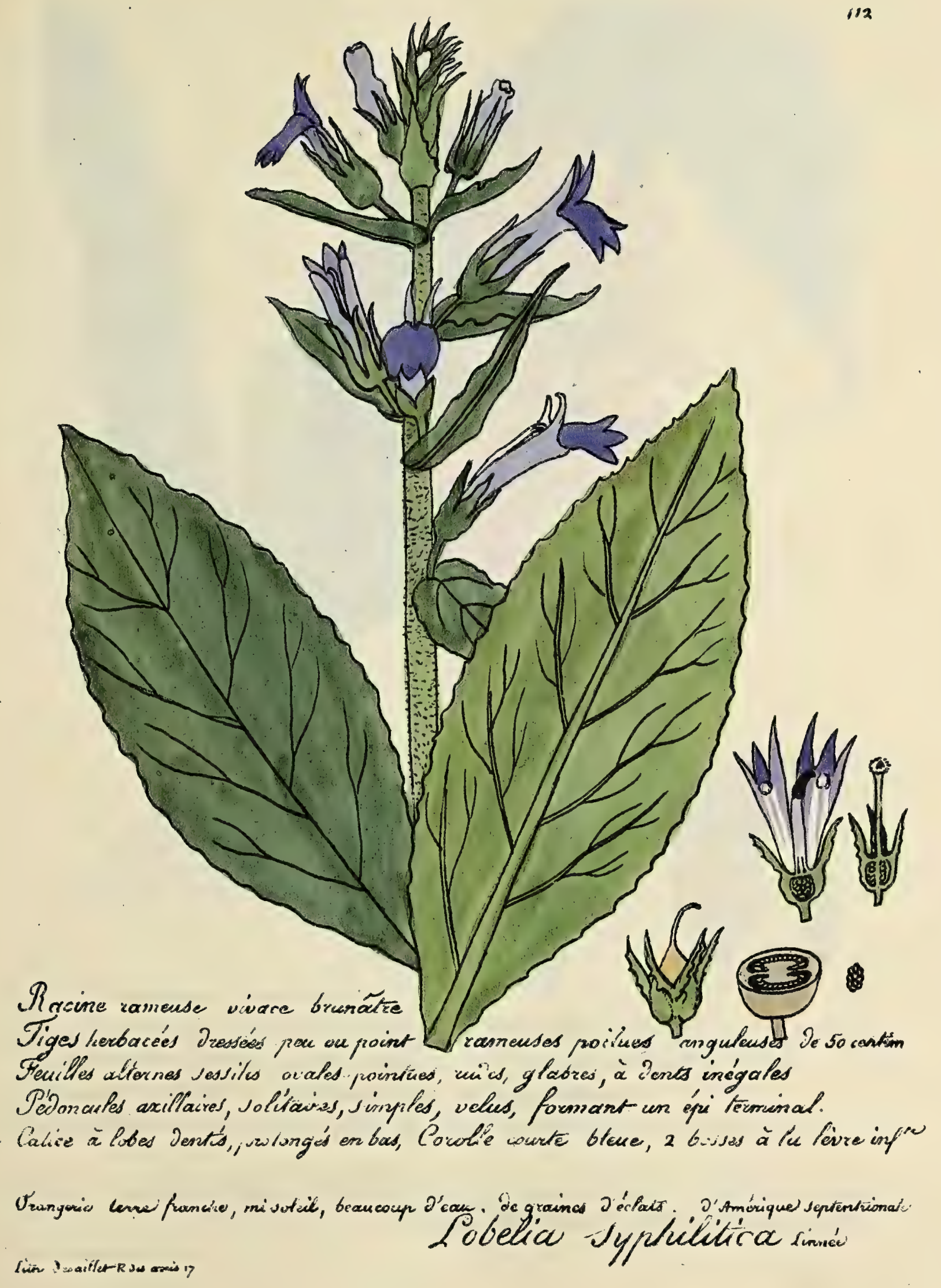




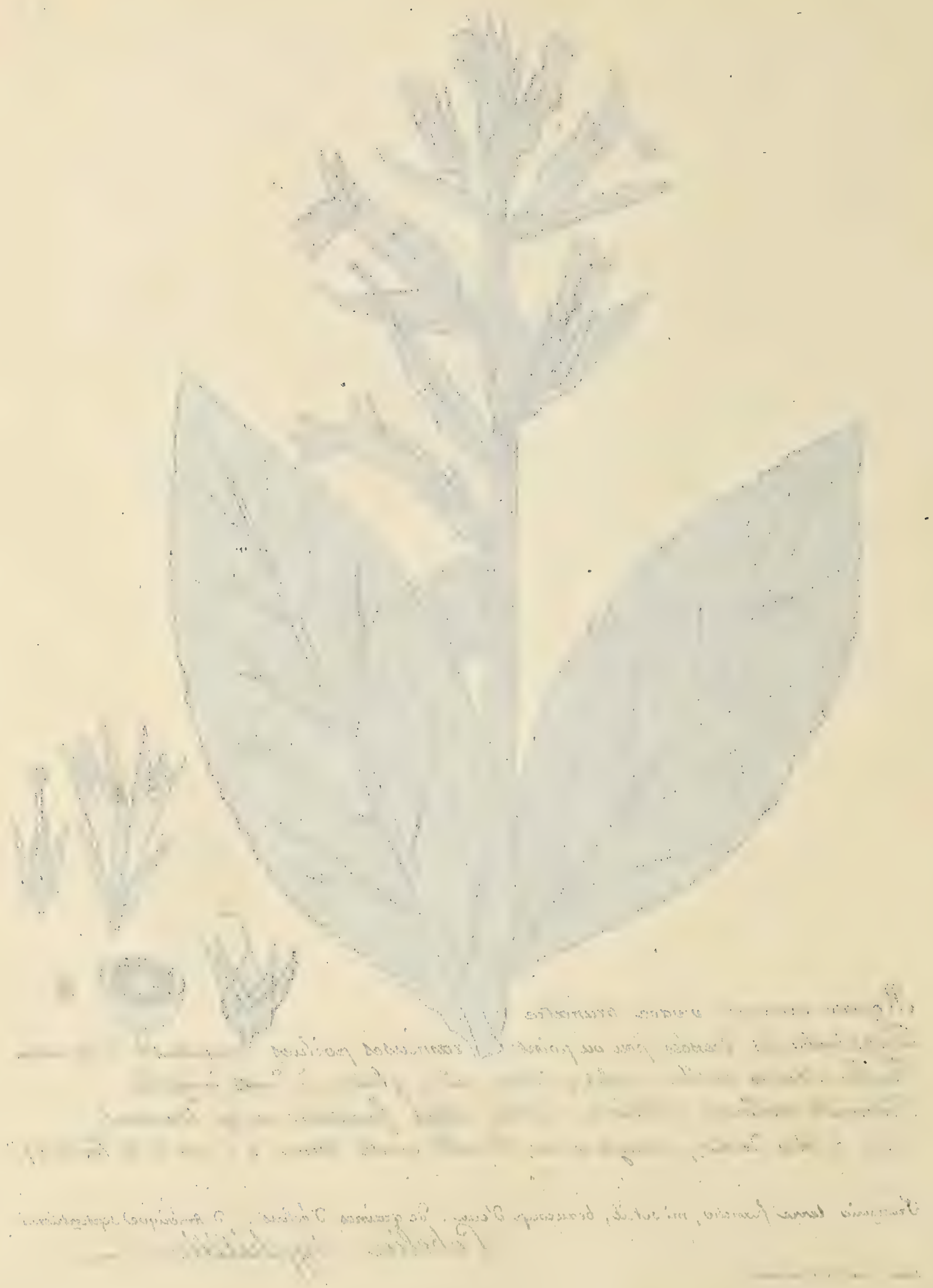




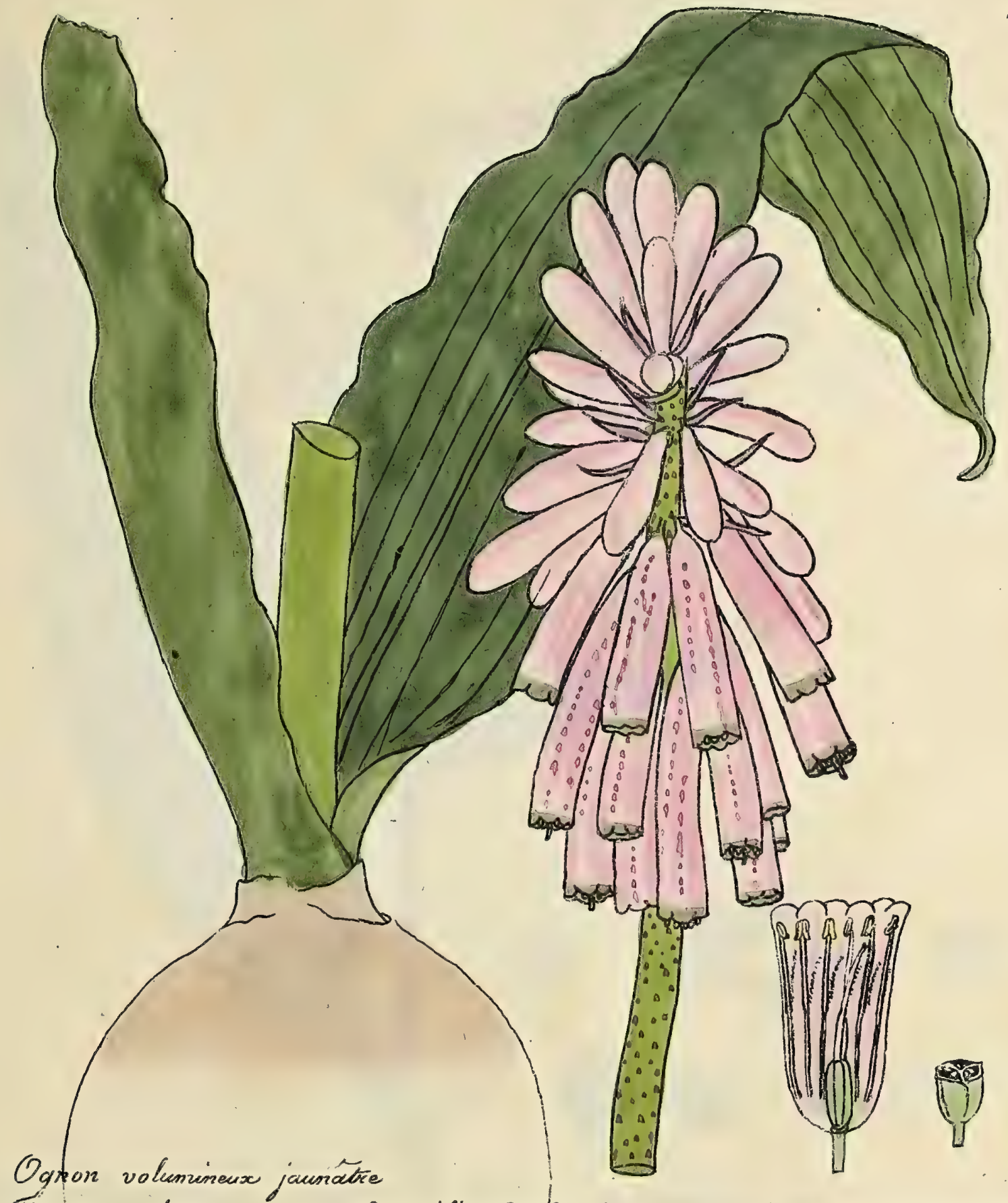

Jige nus, charnue, sortant Iu inilieu Des feuiltes, vertêtachée De buin, De 0,30 cention. veuvikes partant de l'ognion, J'envoitant, upules longues, ondulés, ipi ternpinal de fleurs nombreudes, rapsficochées, prendantes.

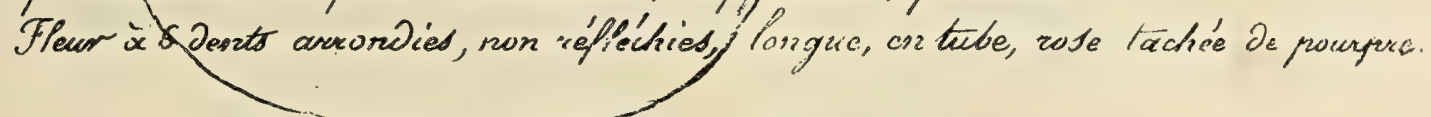

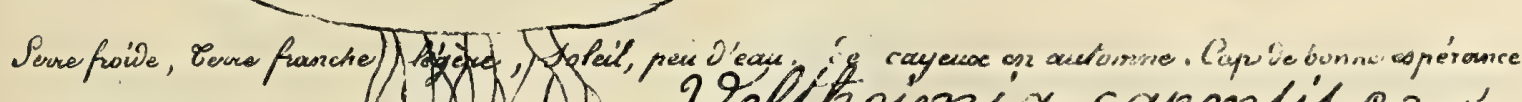

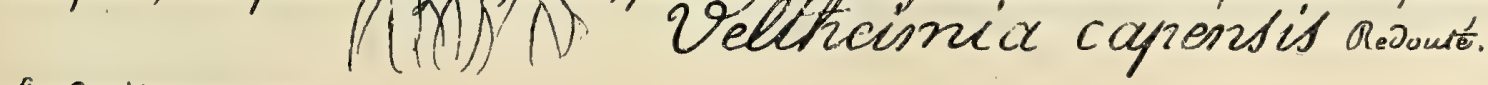

List Dosarillet $x$ Jes arcis $"$ ? 



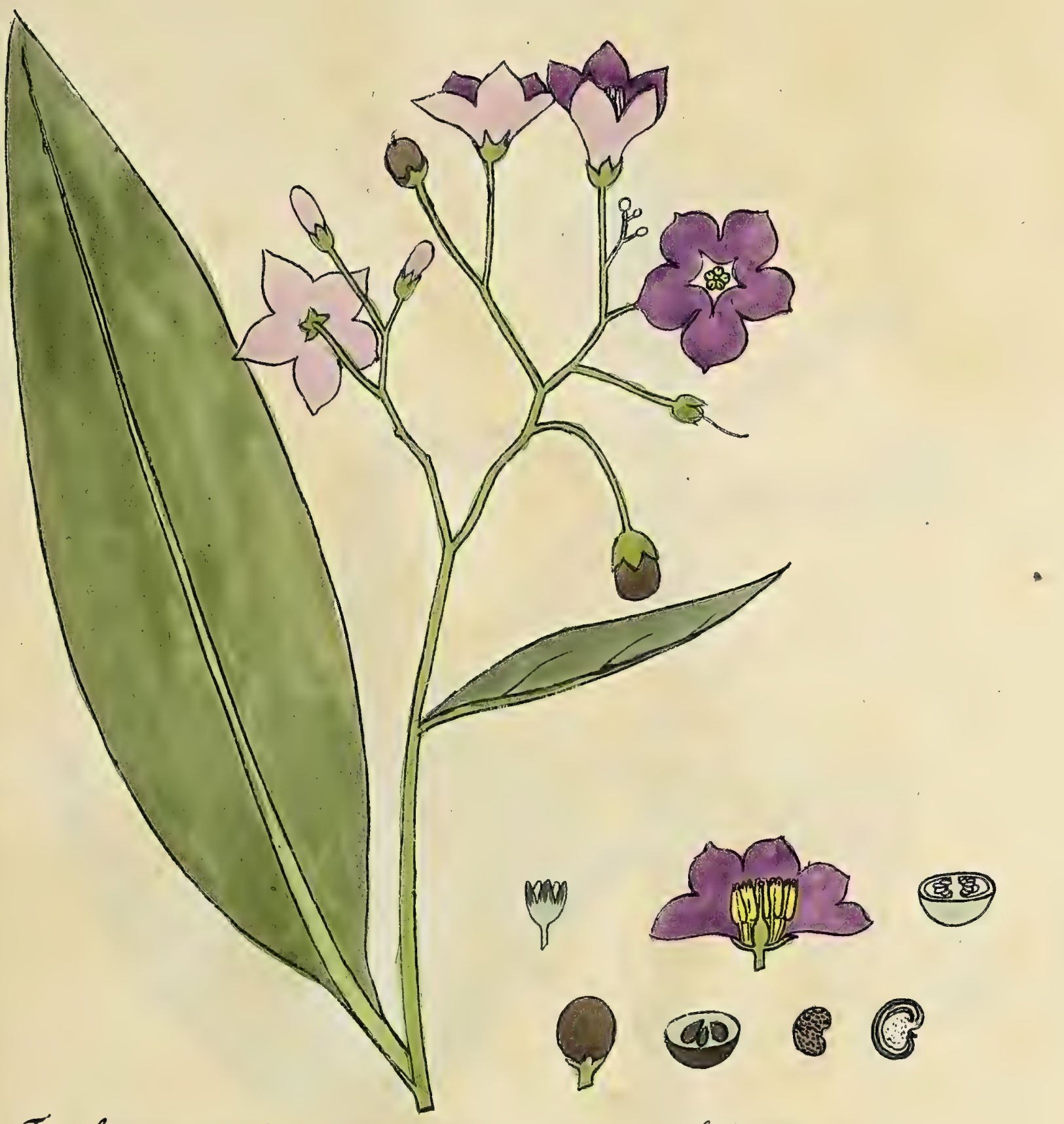

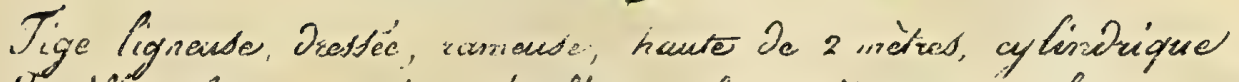

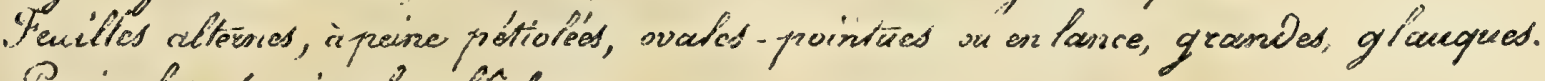
Tonciales terminales, faches

Porolles bleu-vioiacé moycrisias

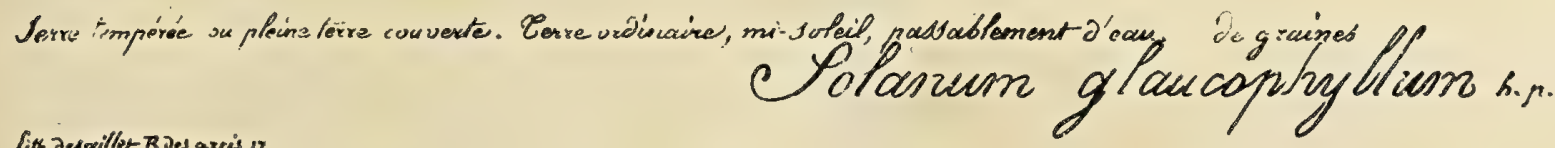





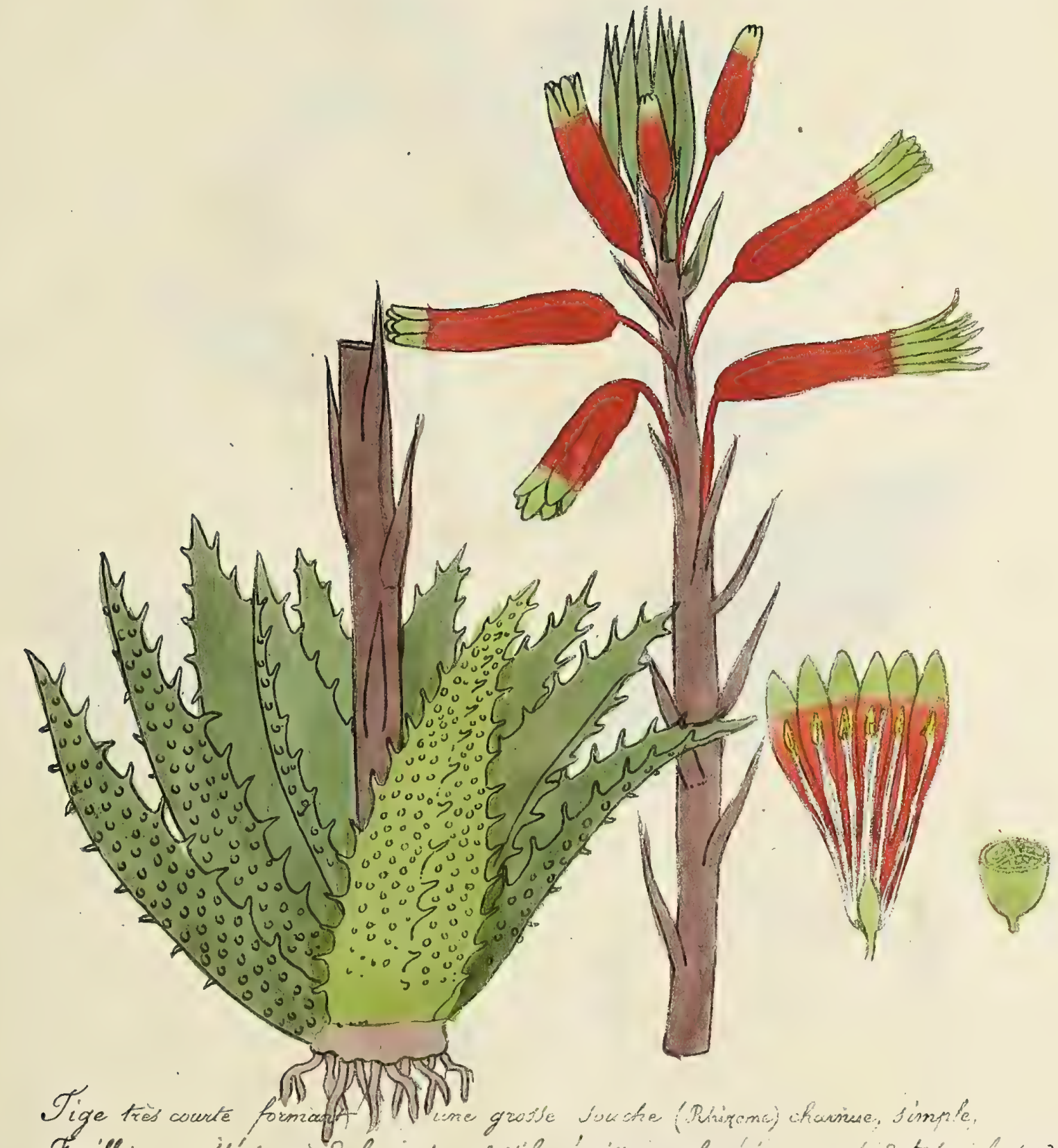

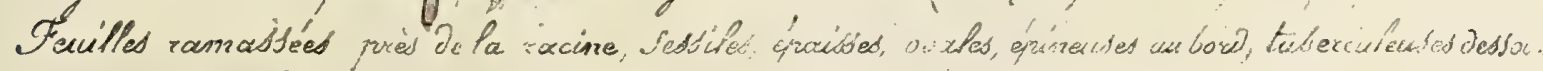

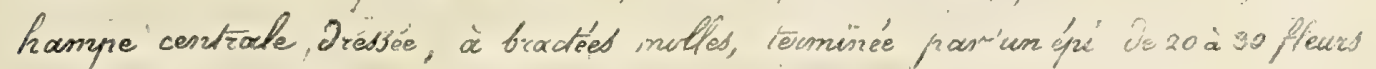
Corolle a lobes obtus, égaux, rouge, à trond vert

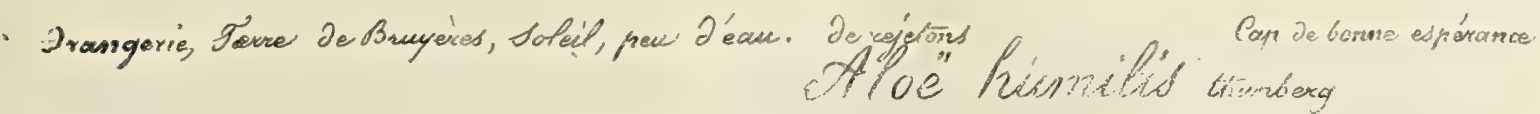
Sirt Desailler $R$ Dos areés $\%$ 


\section{-}




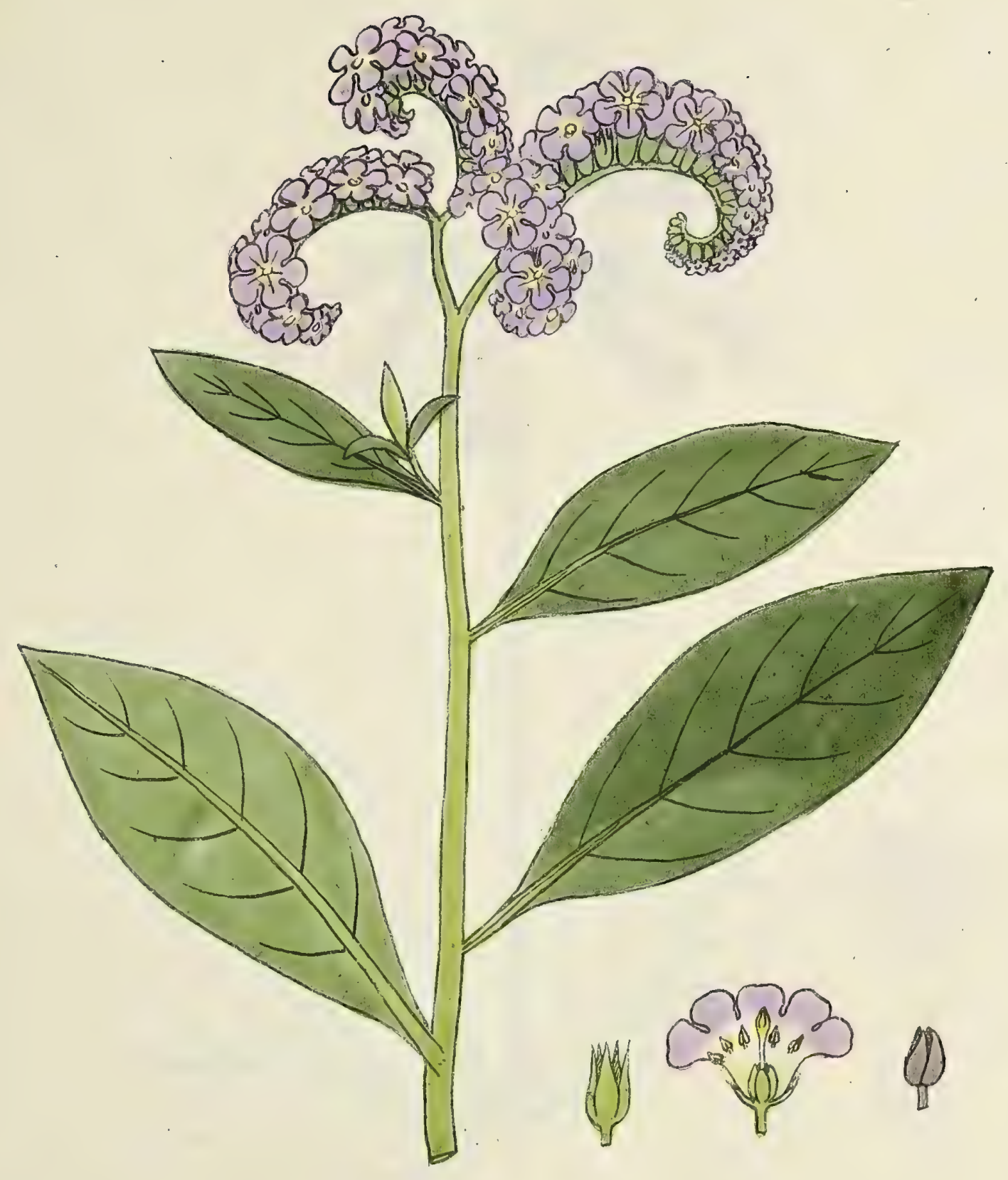

Tige ligneuse, rameube, un preu cuscheé, de 0,30 centicmeitred

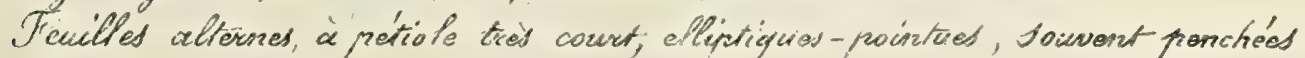

Gui terminat, rameux, roule' en crosse, "fourd attachées du mome coté, sand bractées Frulle à tube double Ju calice, aster grourio, odoraste

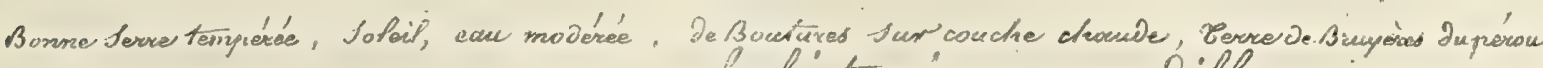
hevitropien grasidiforenz scirans 



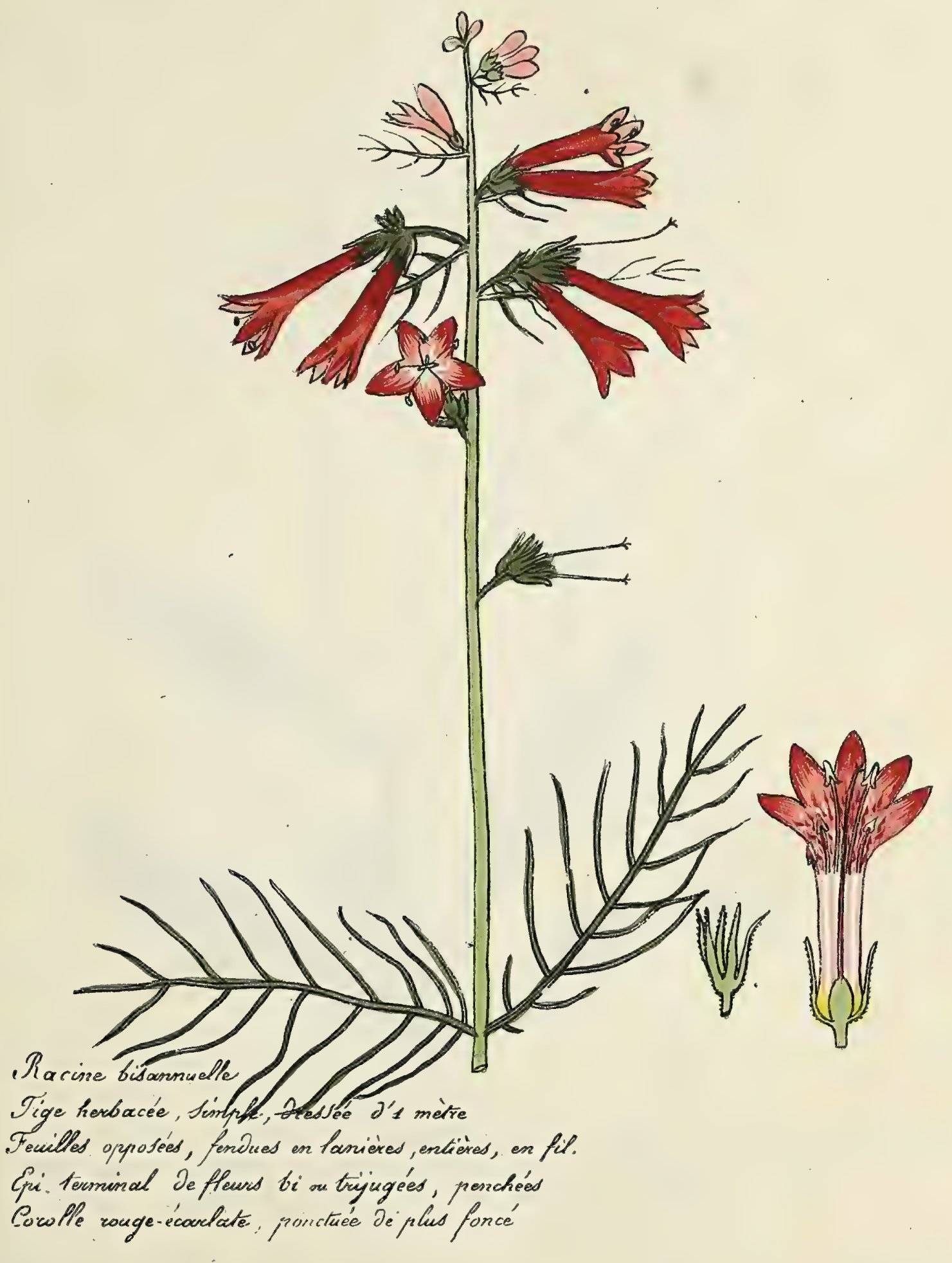

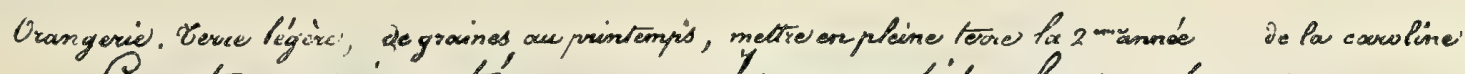
Cantua juguete' 'Jromopis is elegans michoun Sith Desailfer $R$ des arris if 



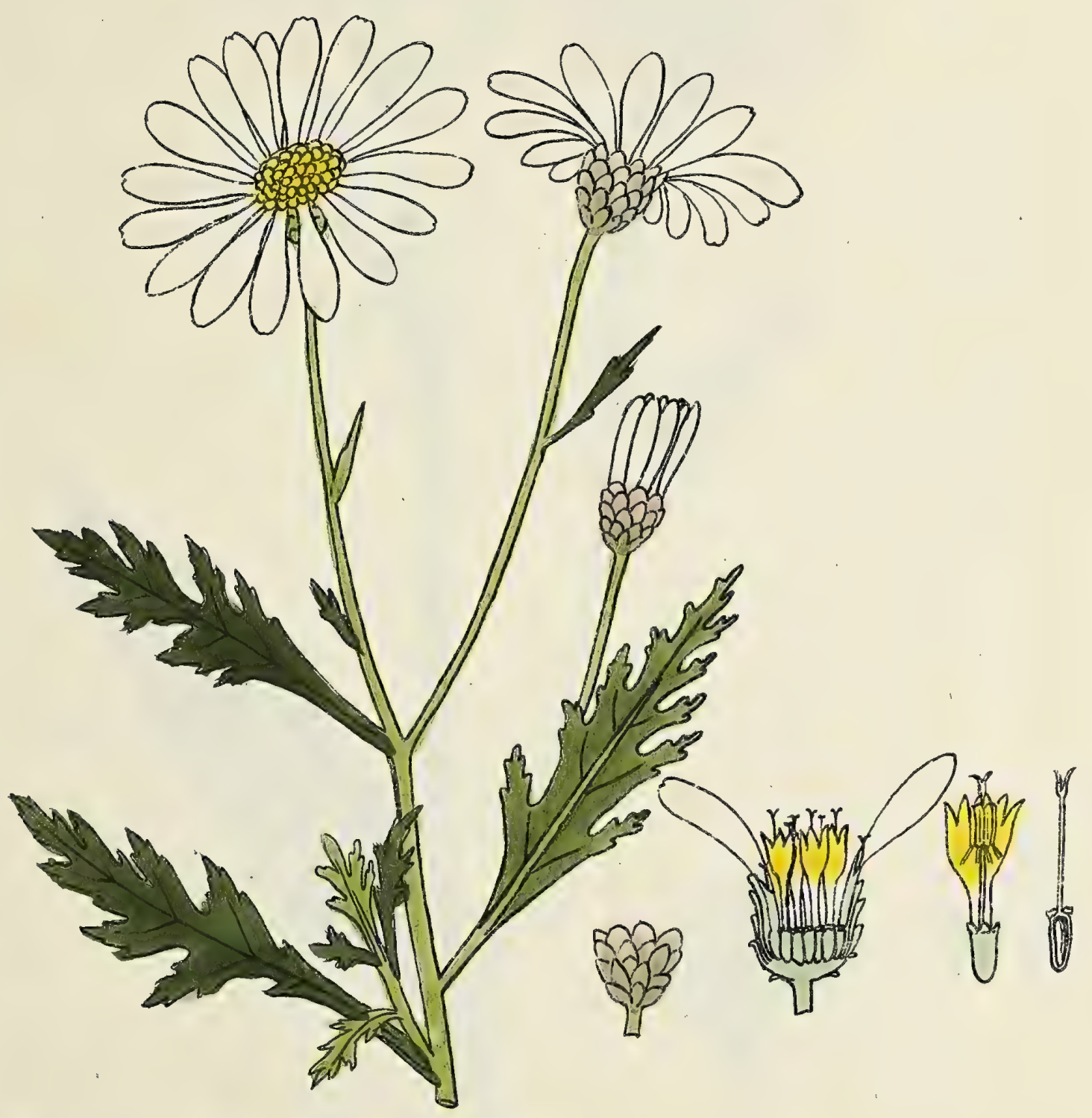

Tige lignexese, raincuse, Oressée, O't mêtre

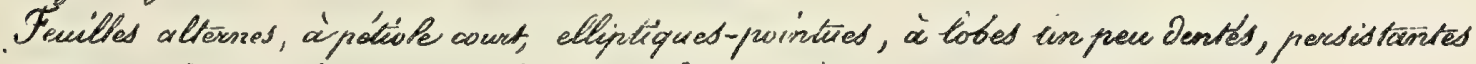
T'doncules axilliaires, simples, tres longs, formant souvent la rime Denri-pleurons blanes, fleurond joumed

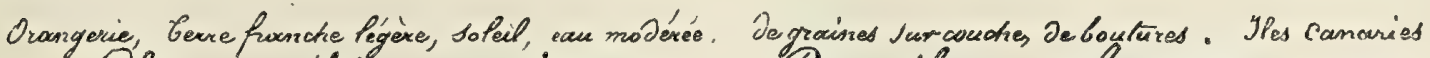

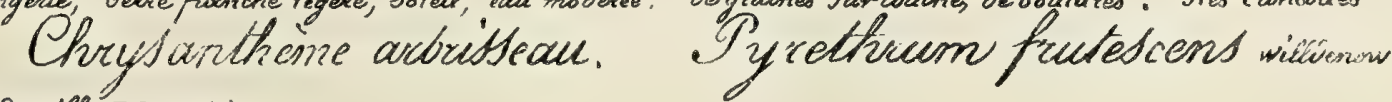
Sich Dascillet $R$ des aricis oy 



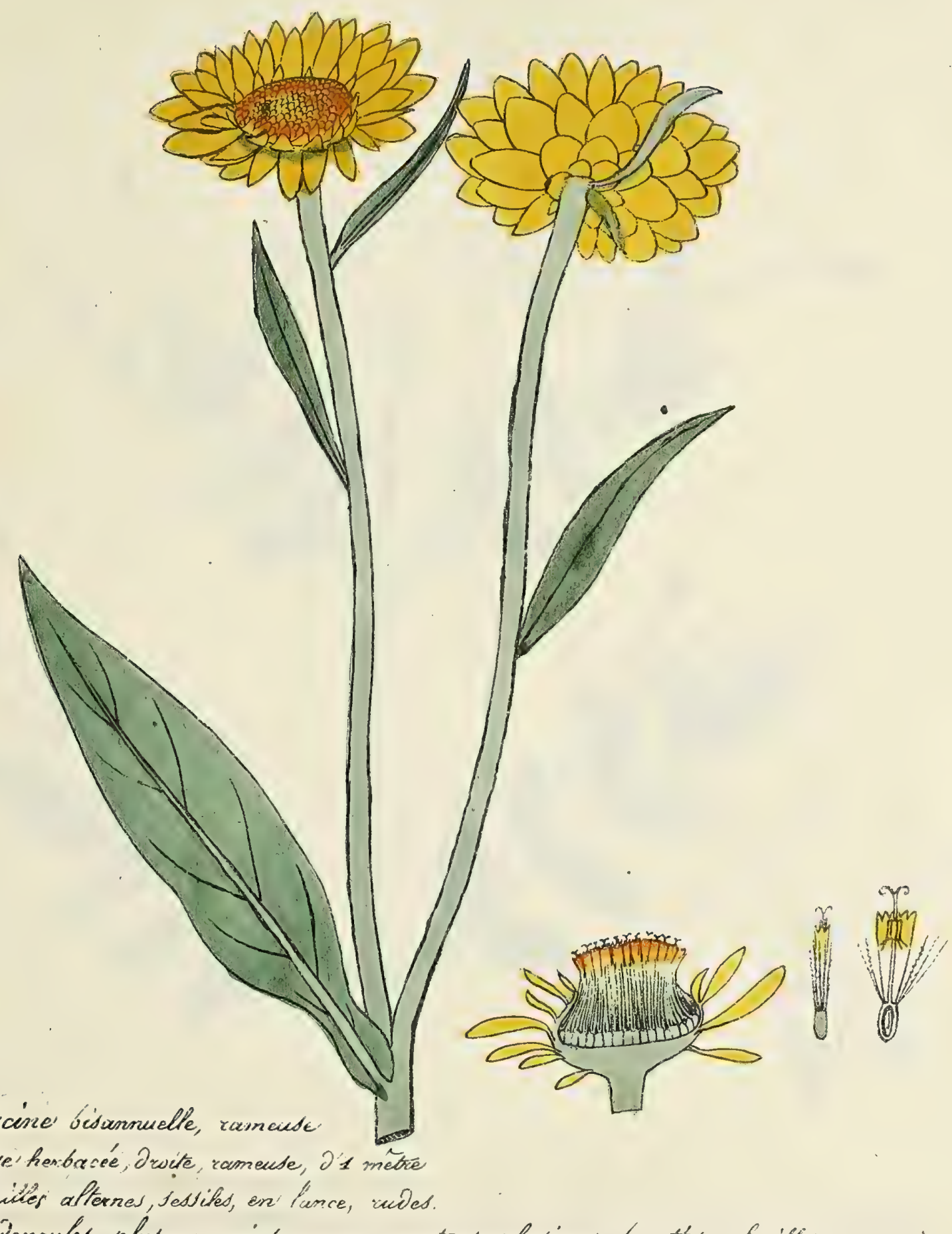

Racine bisunnuelle, raincuede.

Tige' hentracé, Jrwite, romeuse, $\partial 1$ mêtre

Senites afternes, sessites, en funce, wides.

Ievioncules plus ou moind romresex, portant plusieums bractées en ferciltes.

Palice J'écailles siches, dorées. flewrons orangés.

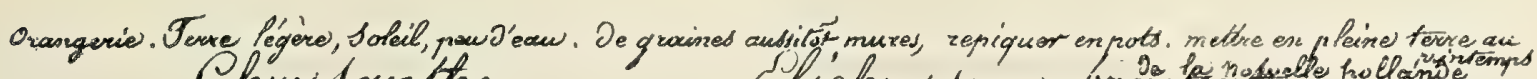

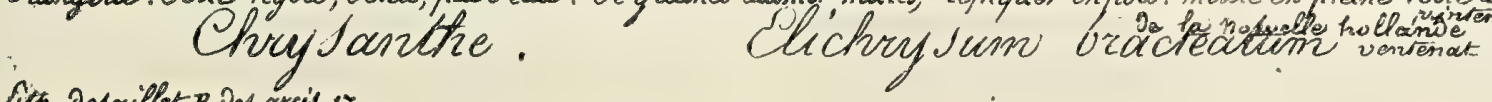

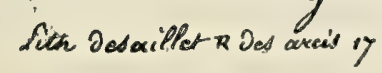





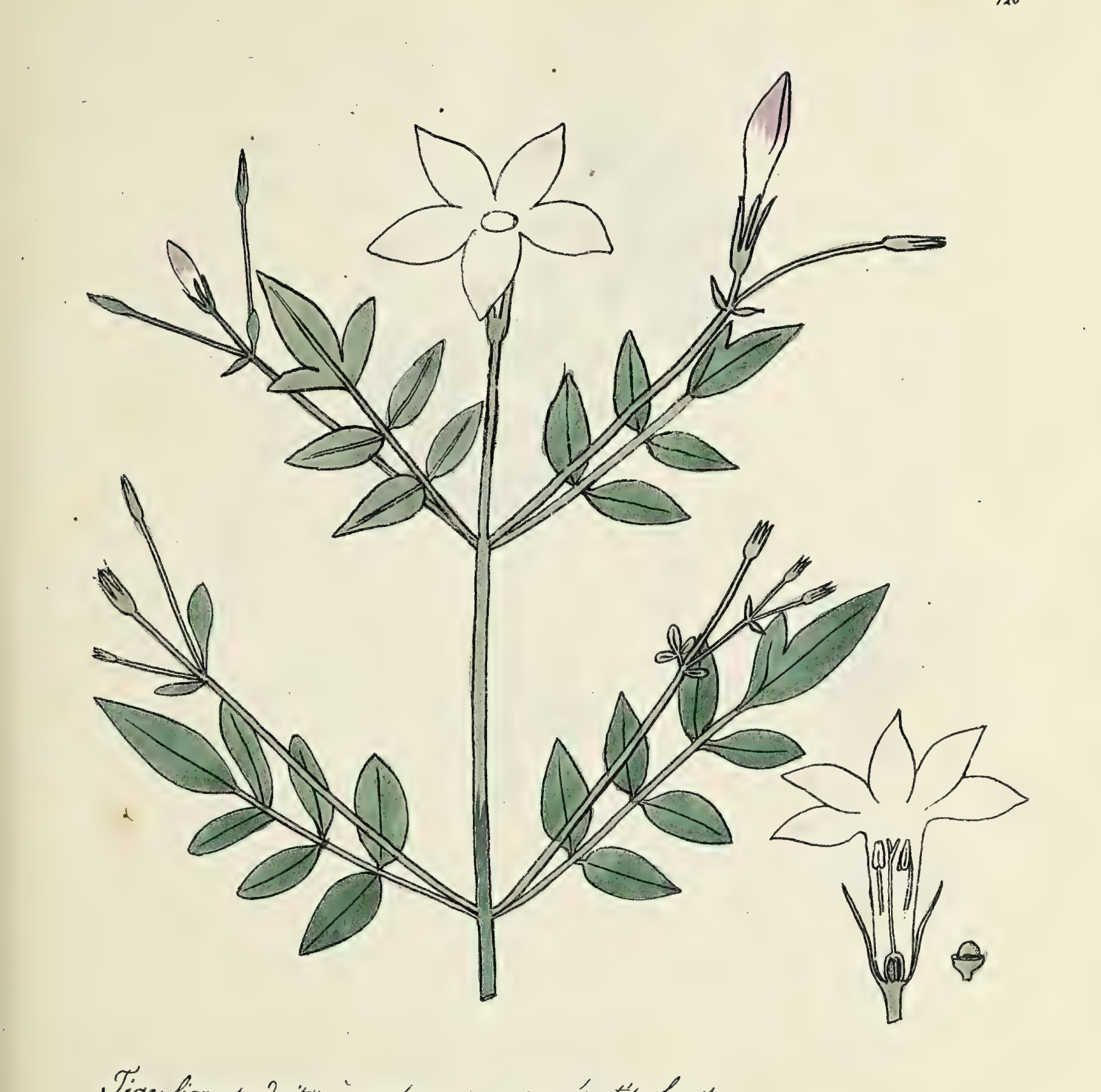


$-$ 


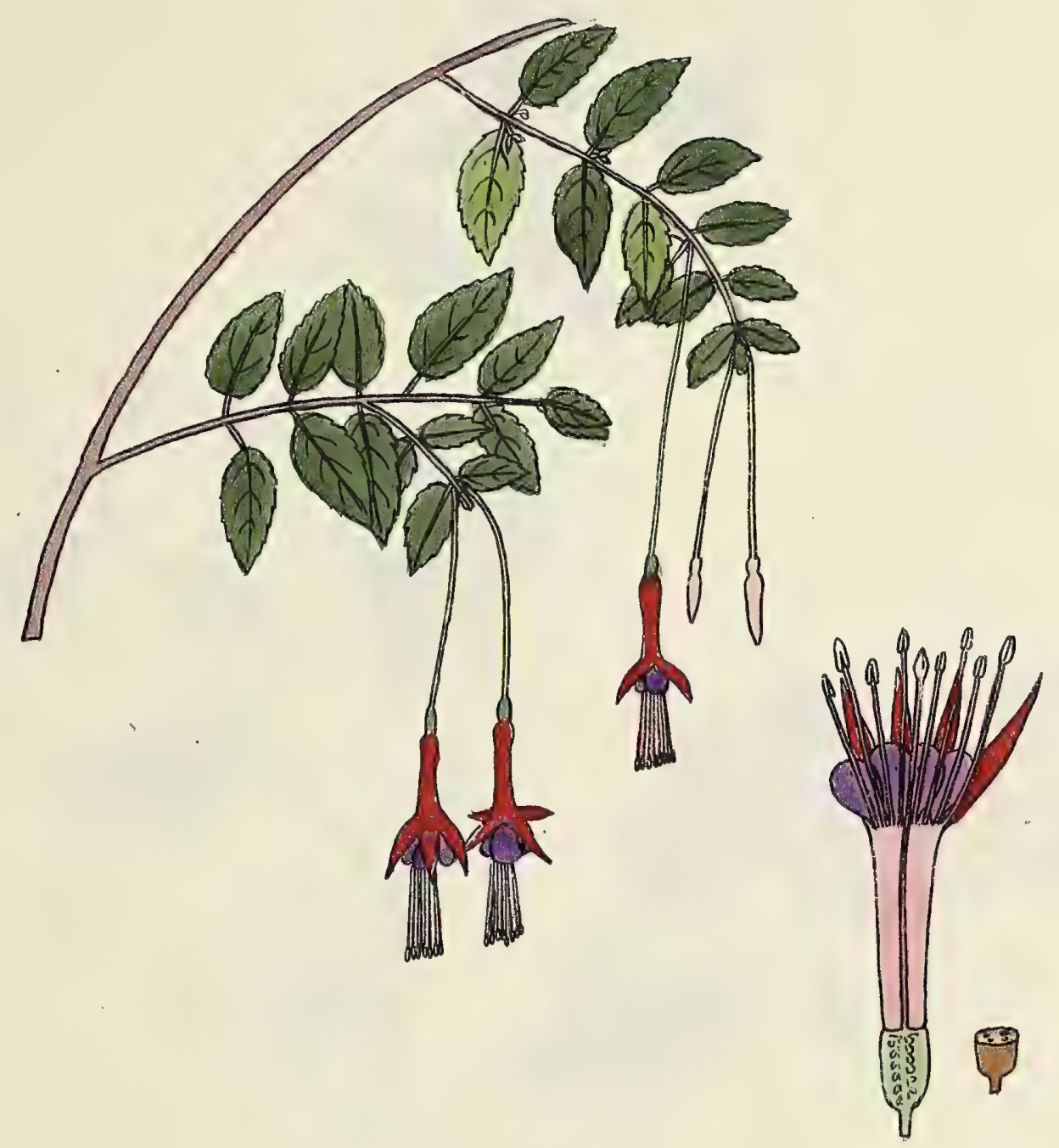

Tige ligneuse très ramense, à rameacise écartés Feviltes opposées, pétiolées, ovales, deartés, petites Pedoncules axcillacires simpilos, langs, pendants

Calices longs écouclates, Pétales avorondis, vichets

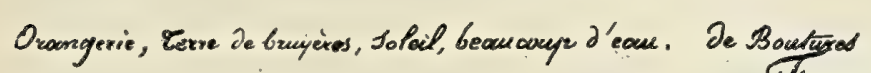
Fuchidid conica ravin Ju museum Sicx Derailler $R$ ales axreis y 



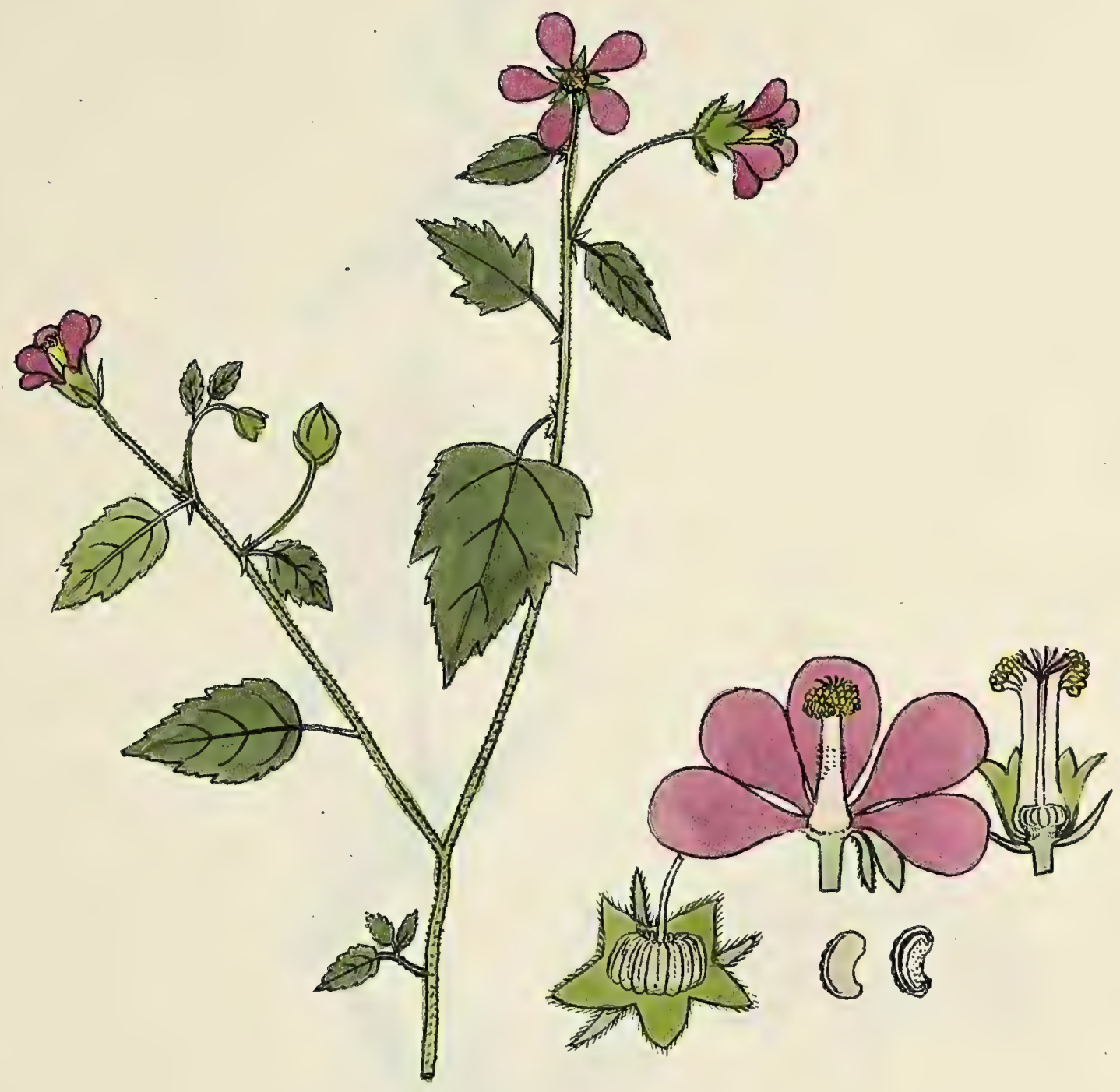

Tige ligneuse, drecsee, faible, couverte de poils rudes, J'1 à 2 métros

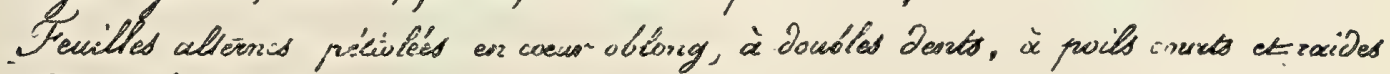

Pedoricules axillacires (portanzt 2 pleurs caw).

Teitales uses, calice valu

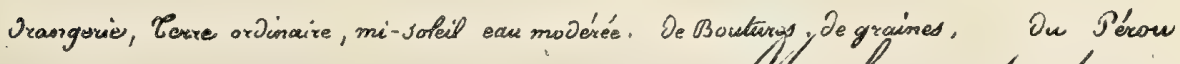

Mbaha Neabra cuvanilles.

Lith Dedaither $R$ aes areis 'y 



$$
\text { 致同 }
$$




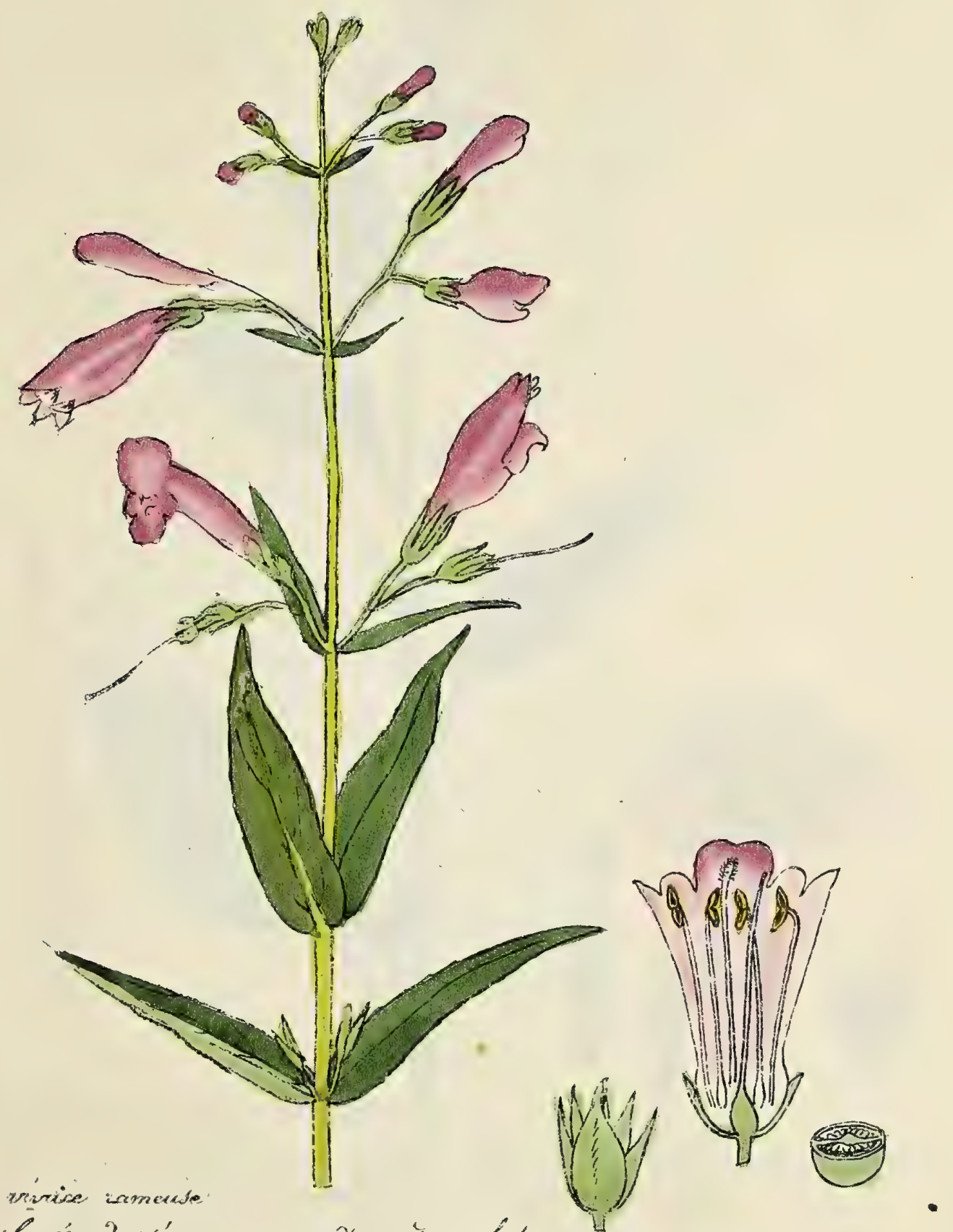

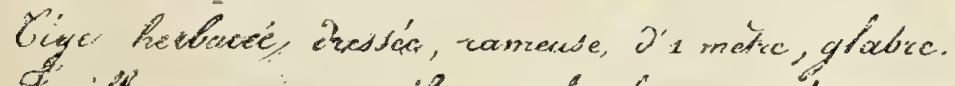

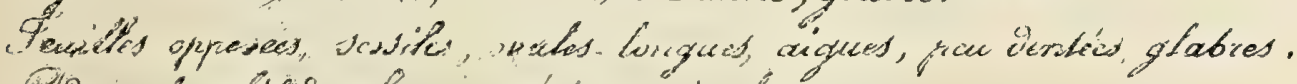

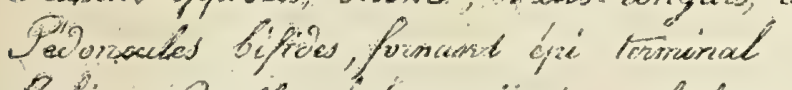

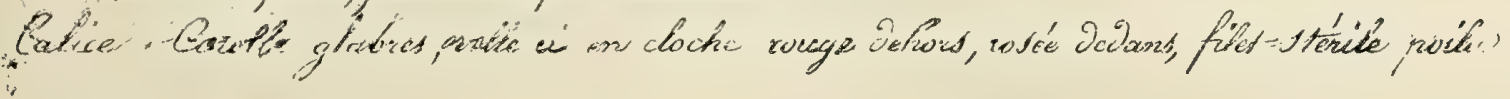

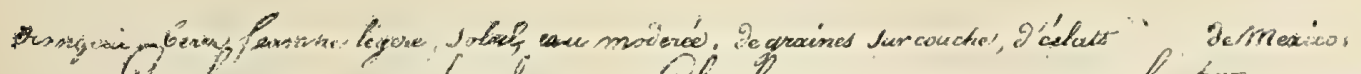

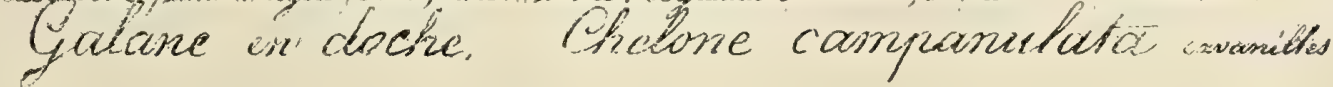

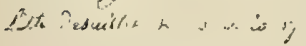





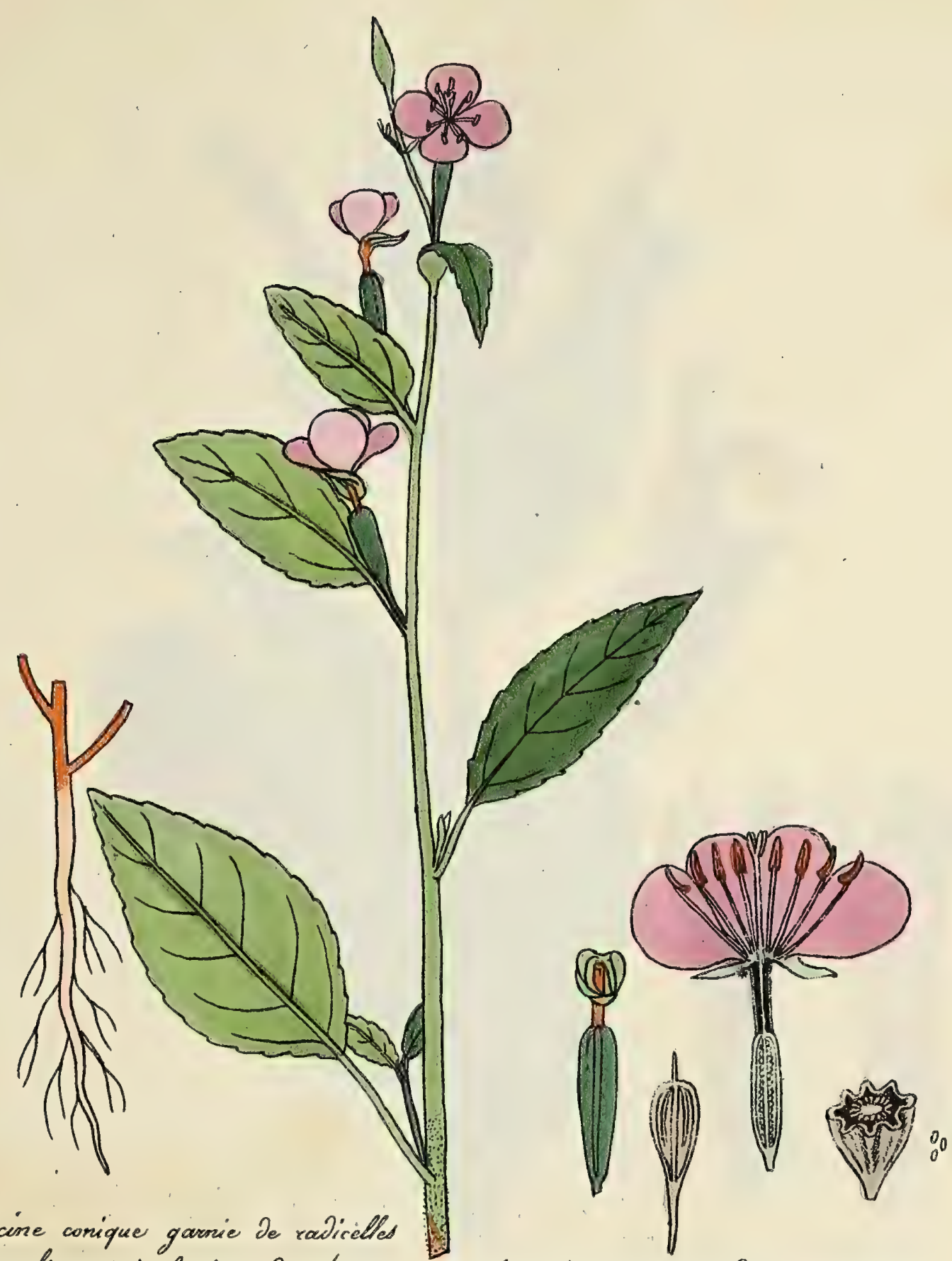

Ragine conique garnic de radiselles

Tiger ligneude à la bade, Dressée, un peu, roilue, tries ranncuse, De Go centionèties Heviltes alterones, pétiofées ellízíques pointues, dentiés, glabres

Fleius axillaires, solitaired formant ćid tonninawa

Petales rosed.

Papdule pésoncellée ob-ovale glabre à 4 anglas

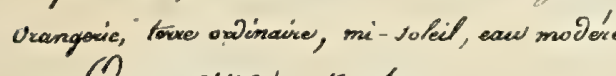
Onagre rose
lith Jasaitser as arcis $y$

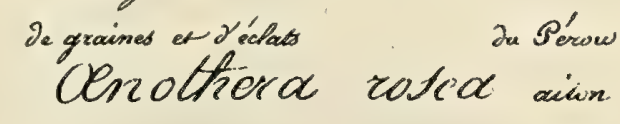





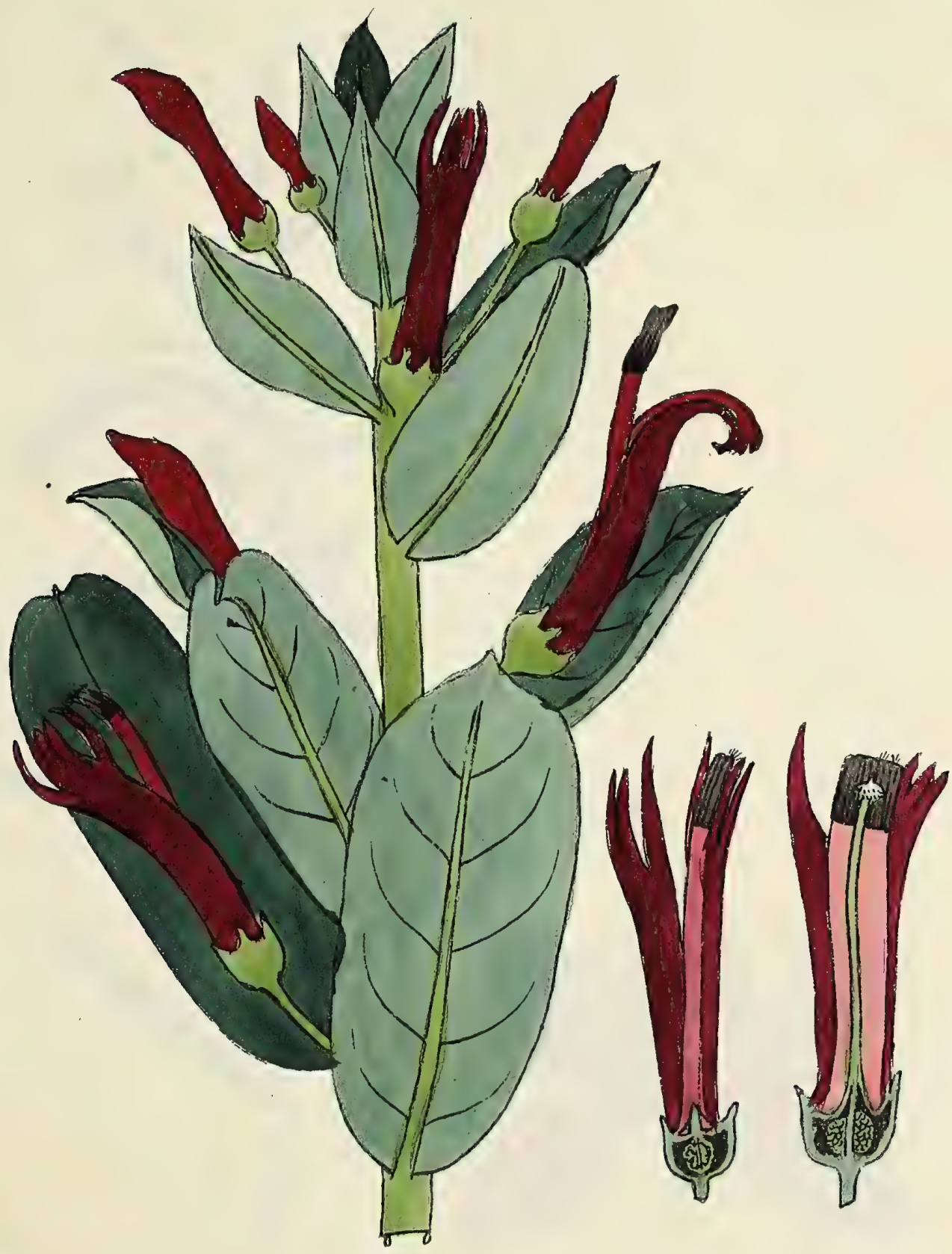

Racine vivare

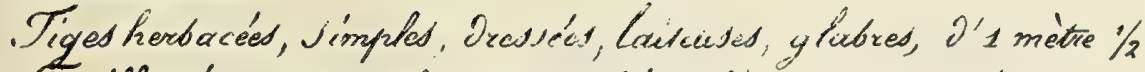

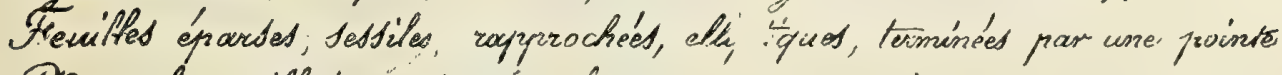
Pedoncules acillaires, jényiles, conges,

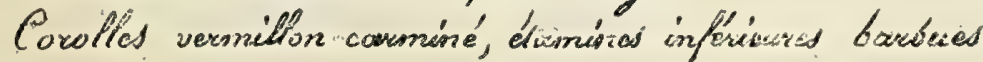

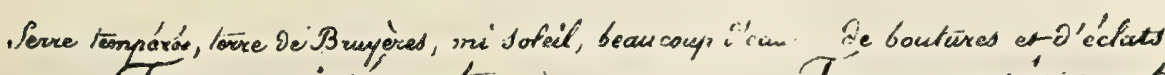

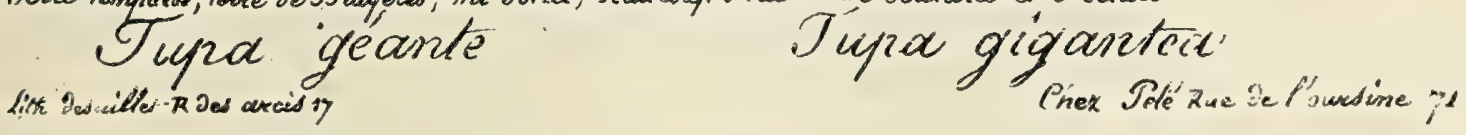


, 


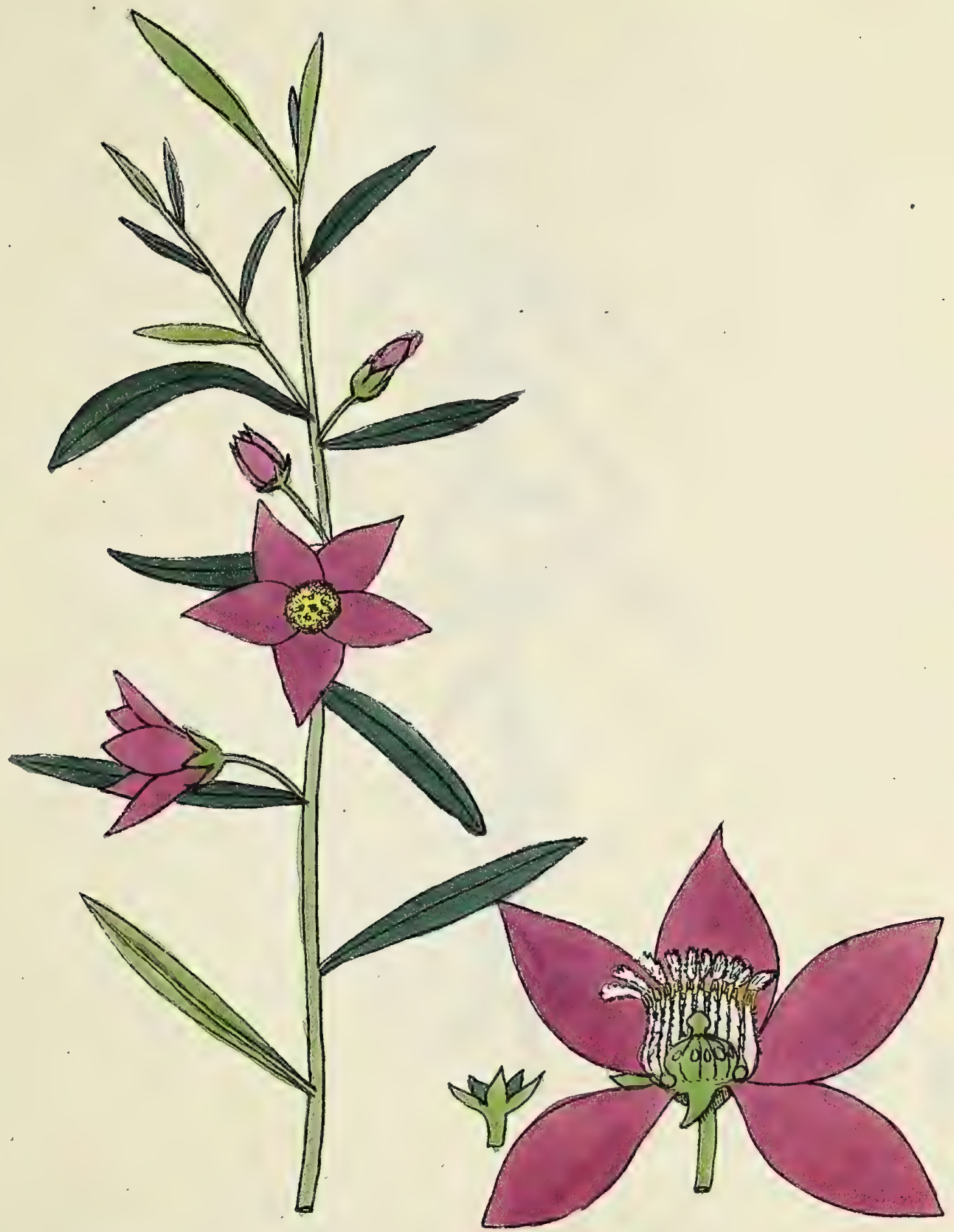

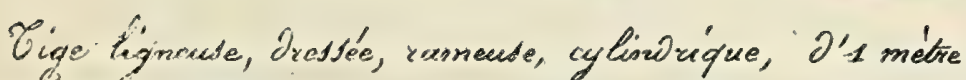

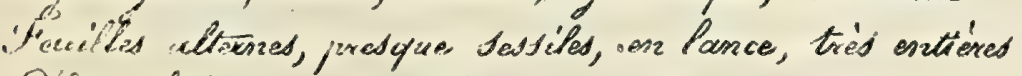
Iesonvalas moyens, axcillavires, simples, ponchiés

Ifexales graind, J'un rose-violacé

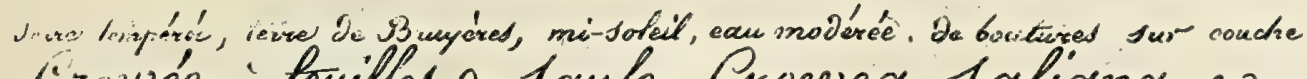
crowée à fewilles se Iaule. Oroved I aligna Antrews. fith Jesaifle- $R$ dos axcis 'y 



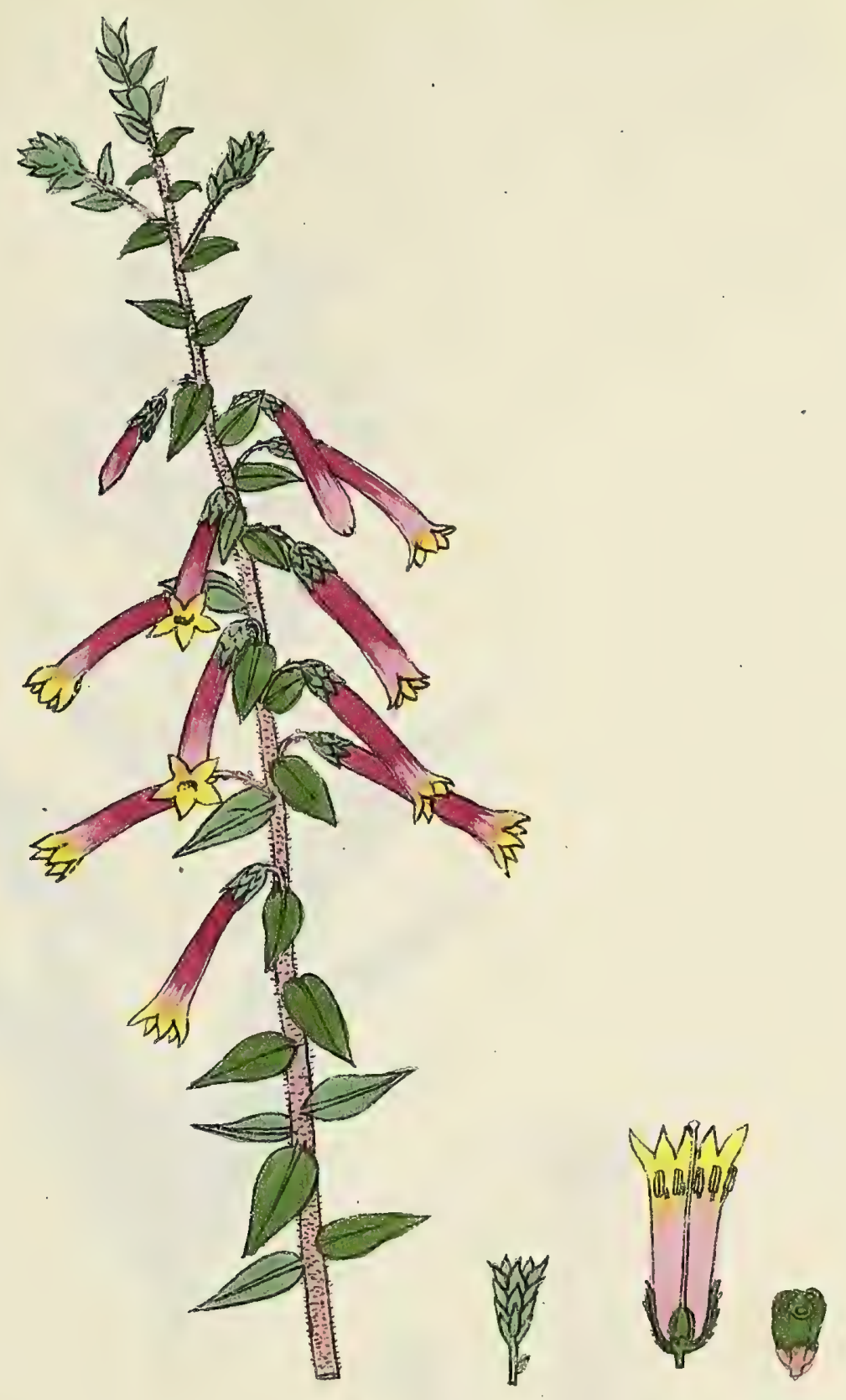

Tige ligneuse, Dressee, venneuse, grète, D's mêtre, gíabie, rougrâtic. Fevilles érandes, sessiles, soches-rointures, petites, ouvertes.

Peiloncules rowits axillaires. Sisryiles, peribarcts.

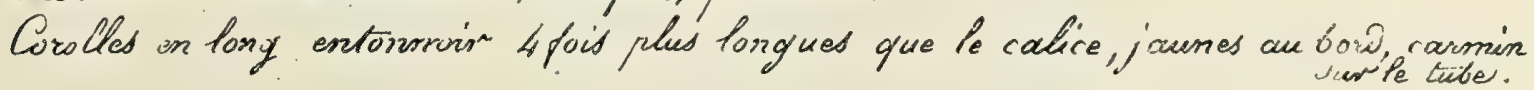

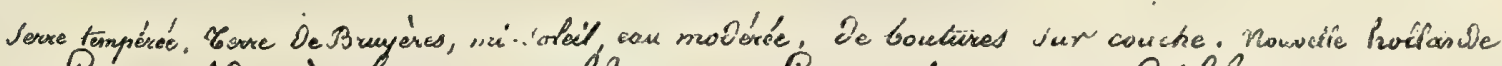
Gracride à longued flours. Gracieis granidiflora smists Sith Dosaifleor Ras arcis in. cher les freired Cels chaussée Du mainer yy 


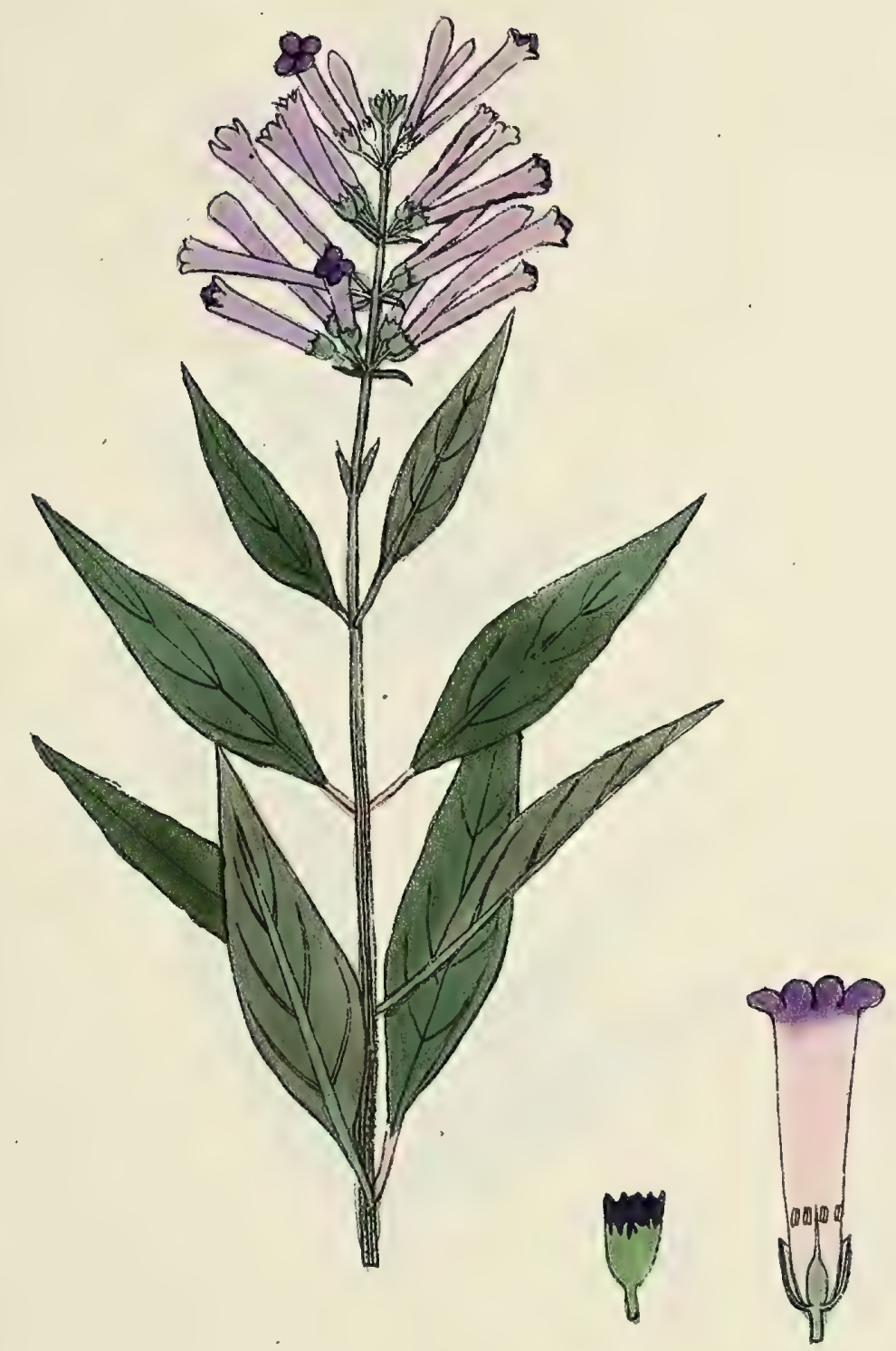

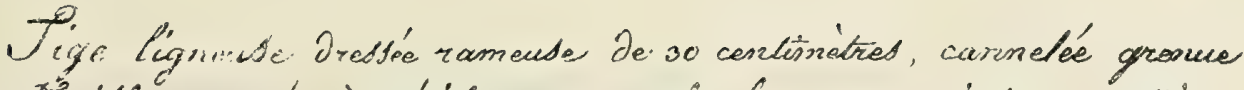

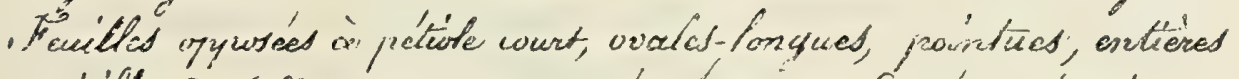

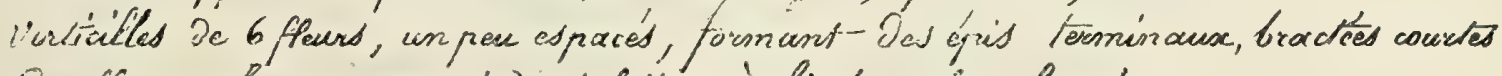
Corolle en fong entormoin violettes, à limbe, wius foncé.

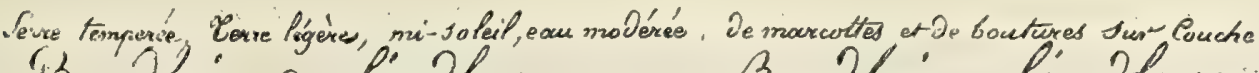

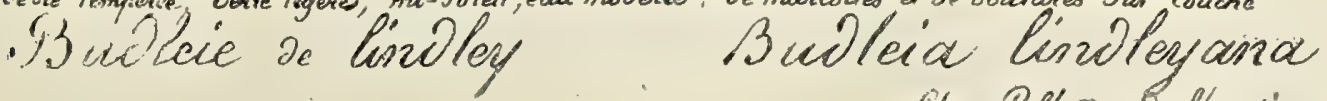




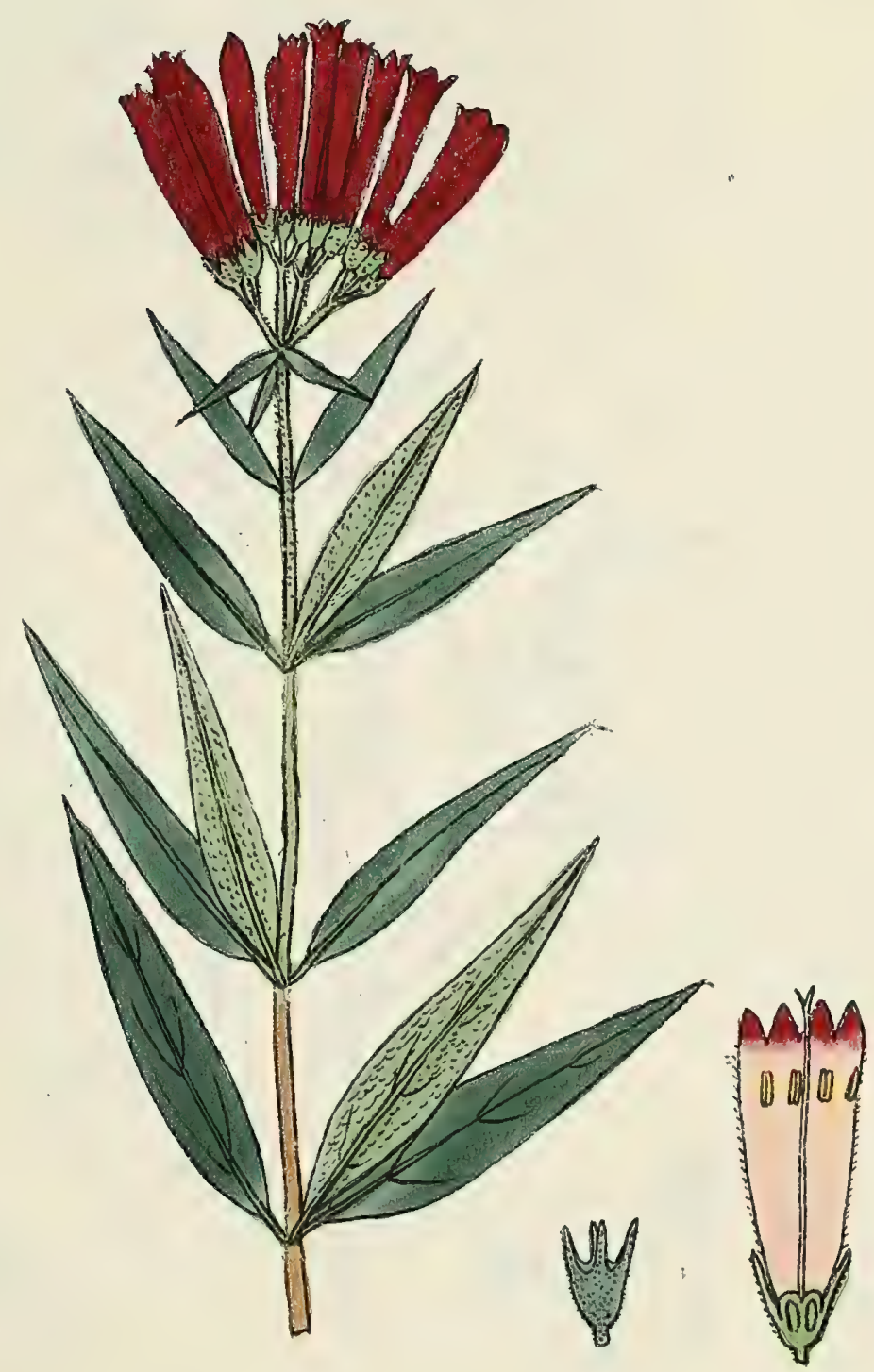

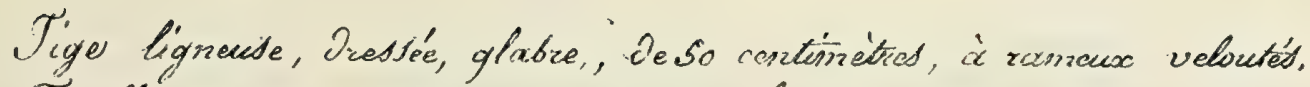

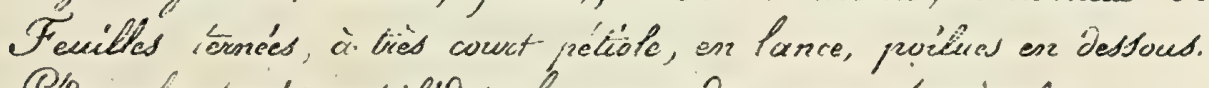
Pedonculas torriós at trifiedes, formant des cymes terminales.

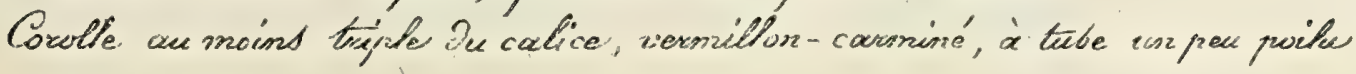

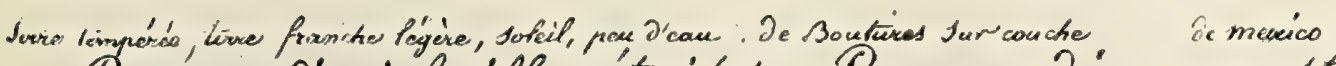

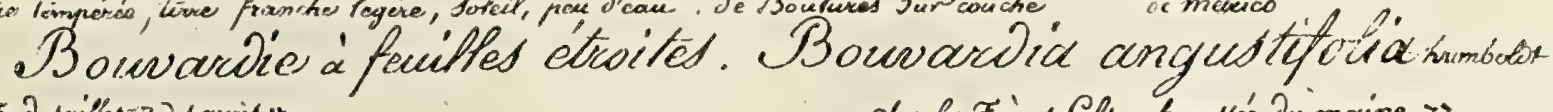

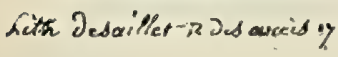
chea les Fievres Pels, chousseé Ju moine 》y 



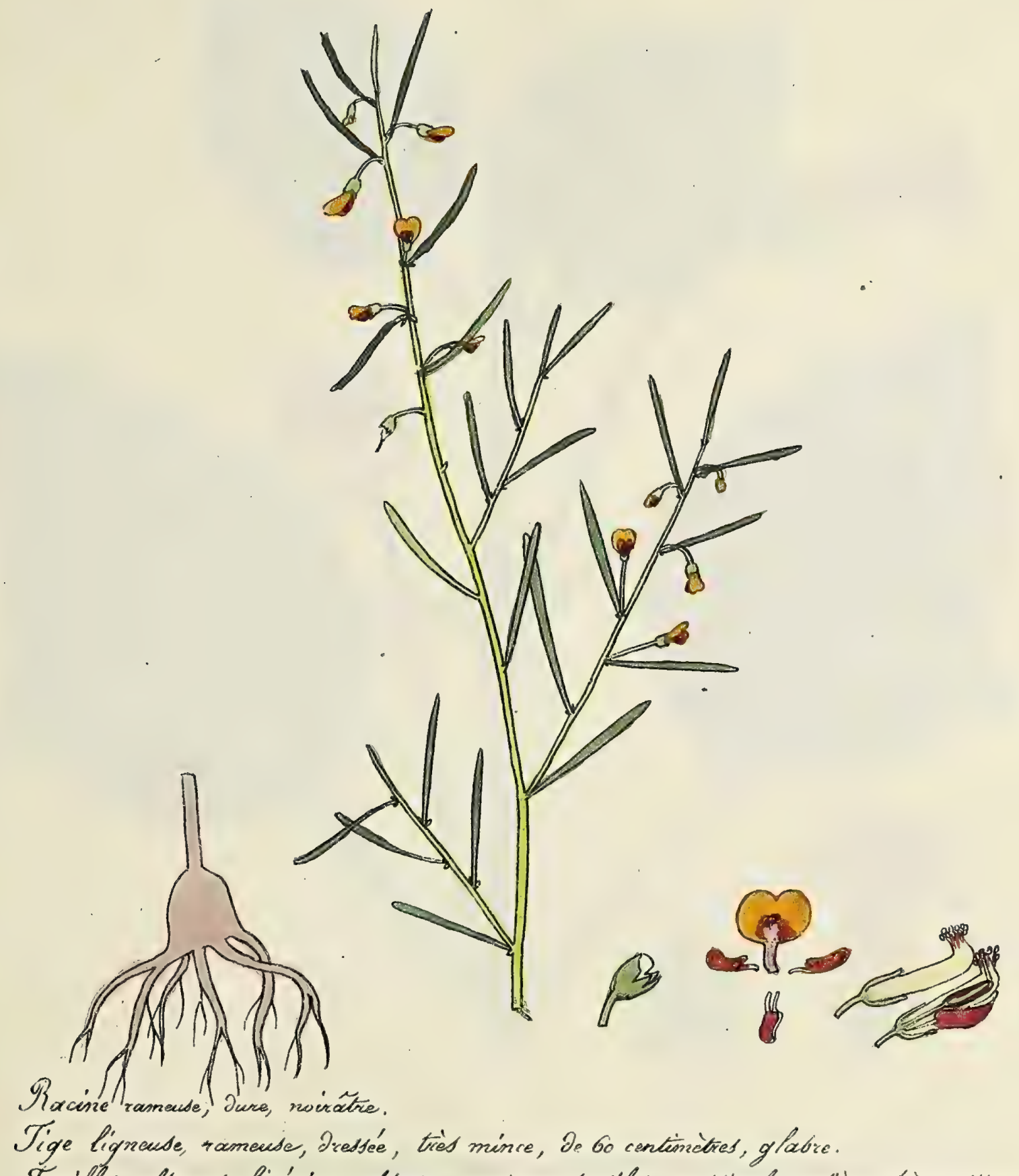

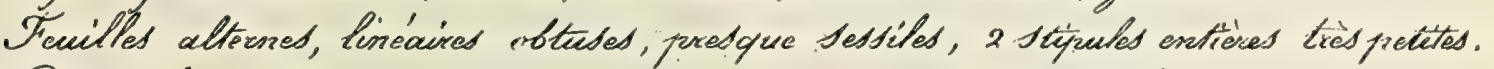

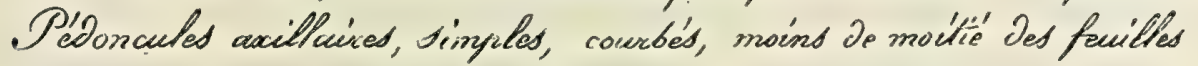

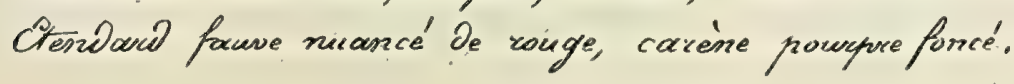

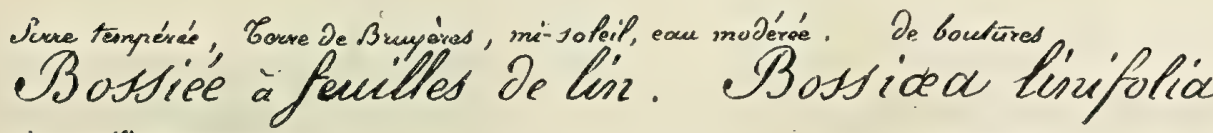
Lith deswills $R$ des arris
aujarion J'riven dos charmps Shisés. 



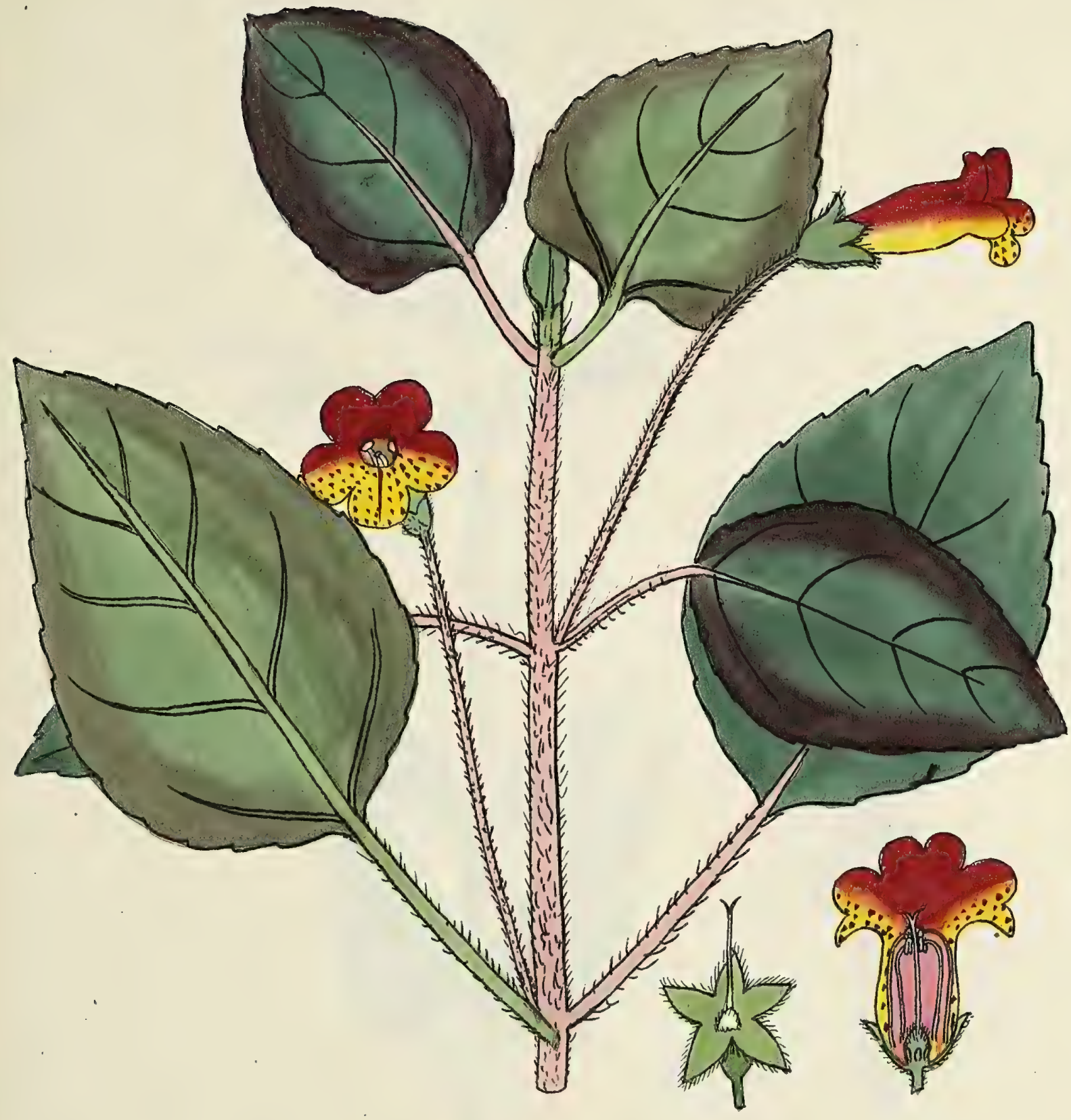

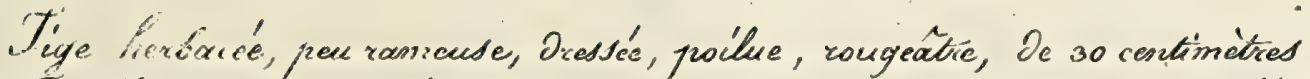

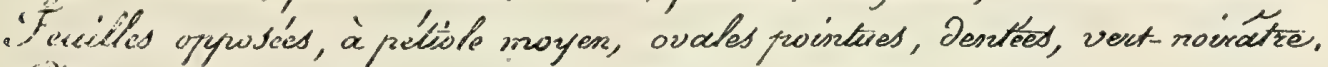

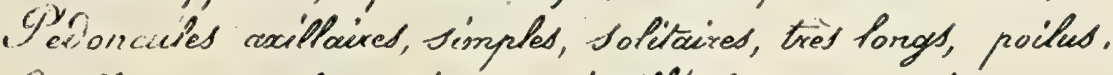

Arol'́c rouge en hout, jaune pointillé de wuge en bas.

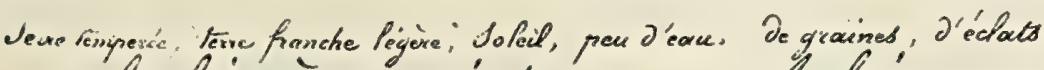
Atchinene peinzte. ctchimenes juicta vith Swosity a ine axcis'n 
i

, 


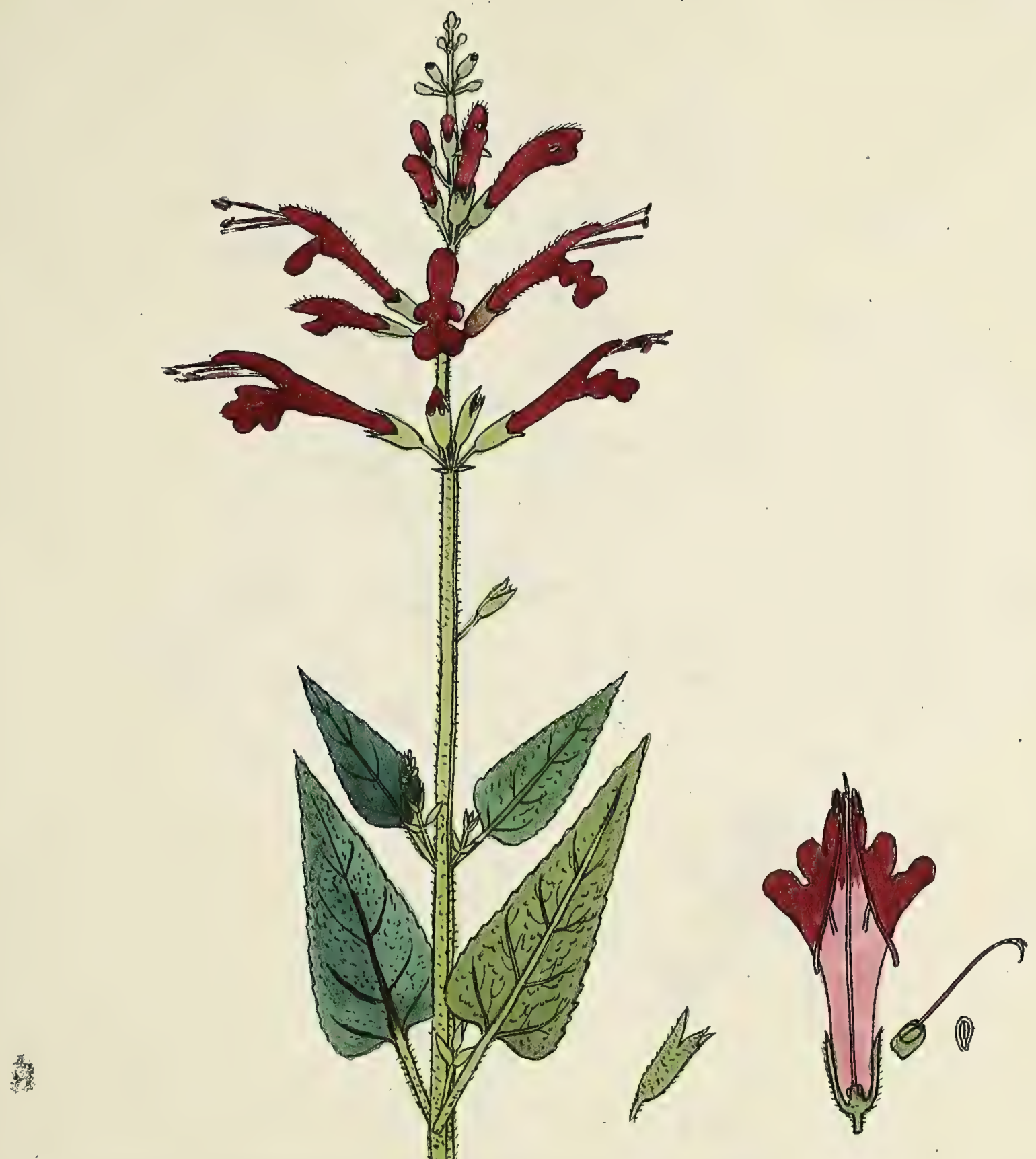

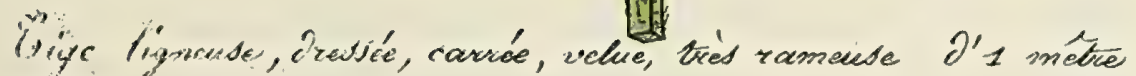

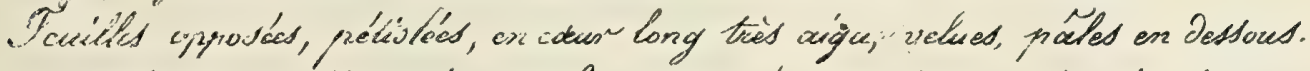

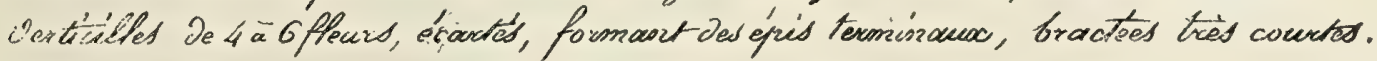

Crlice à s Dents, peu compruimé, Porolle vermillon-courminé, vilue.

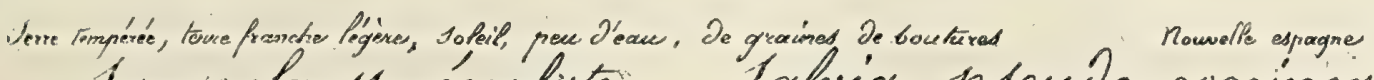

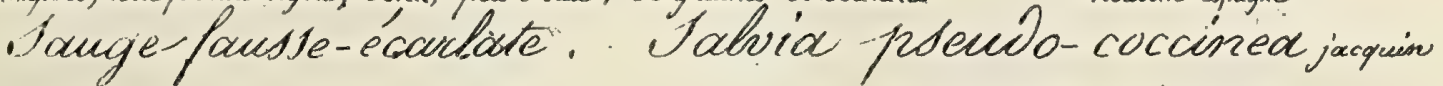
Sim desailler R as axcis $y$ Thes TPfé que de f'oursine y' 



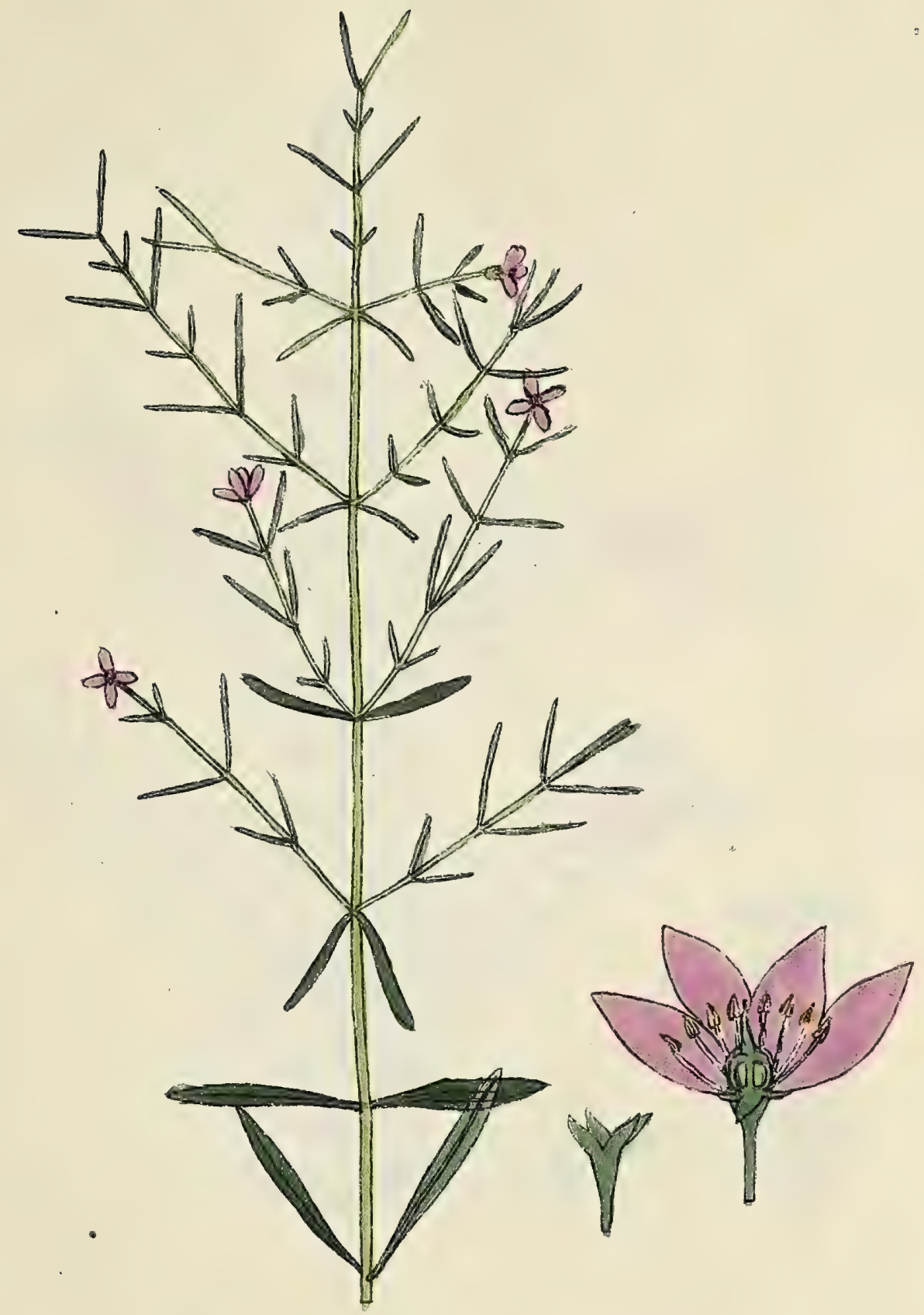

Gige lignense, mince, Jrevsé, trèd rameuse, Souple, de 30 centisnètres Frewilles opprosées, sessites, lincíres entiéres Fleurs terminales, solitaires it petites Petales roses étroits, aigus

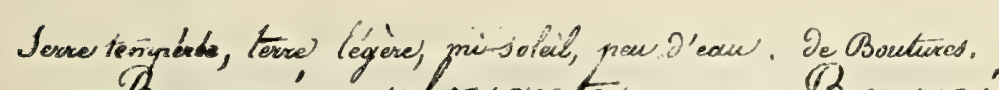
Boronie plogyante. SBoronia vininea Sith Jesaillet-a as cercisty 



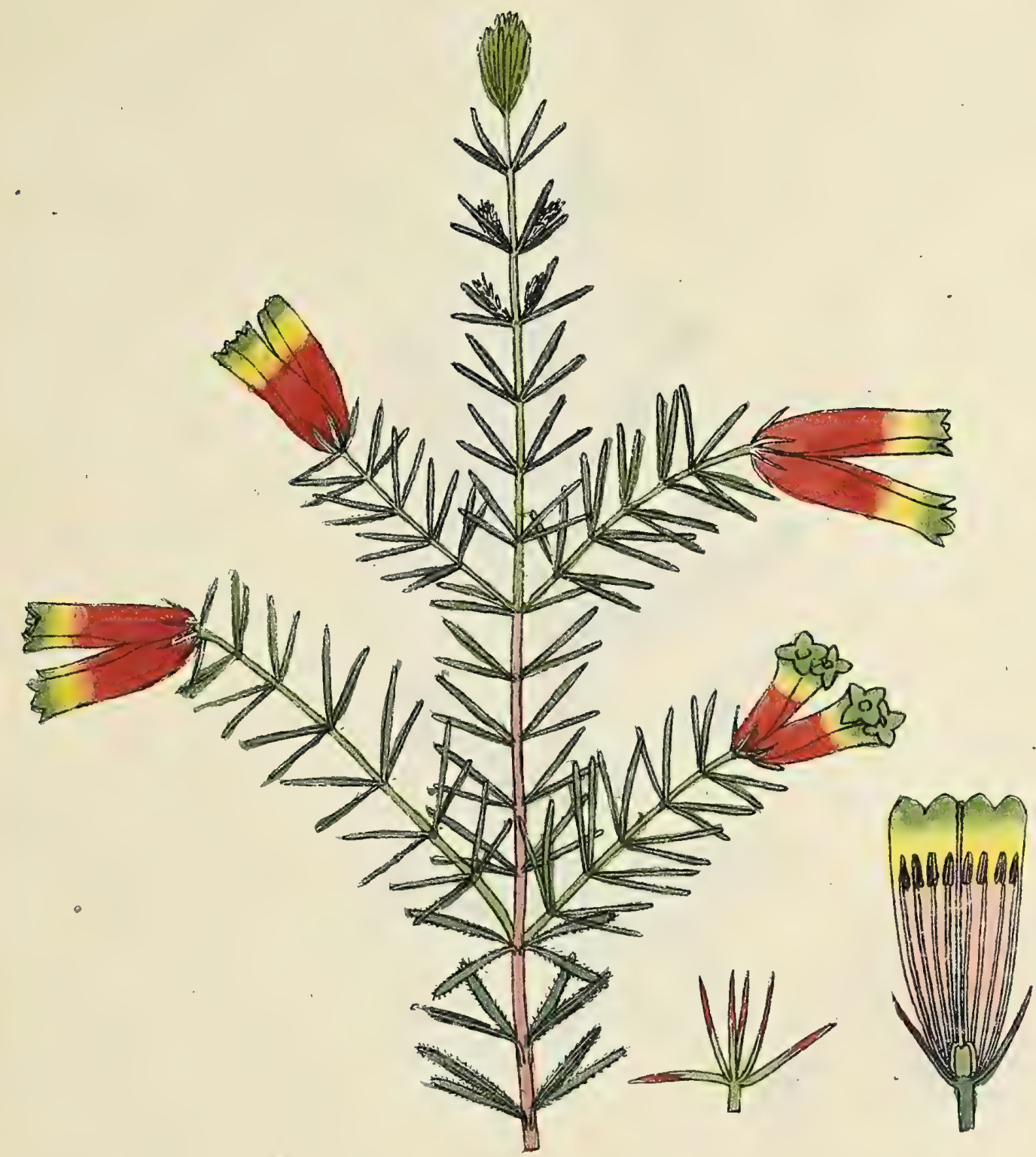

Tige lignousc, Jressé, rainuws.

Heuilles verticillés par 4, linéaires, forigued, ouvertes, (glabres!)

Fleurd teromienciles, par 4 , penchées.

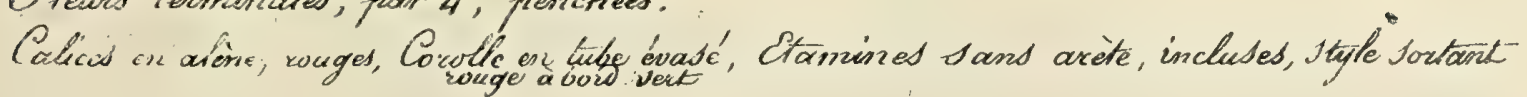

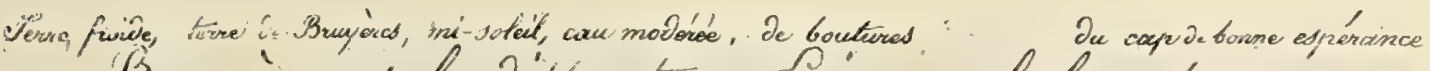
- Jisucie redplendistante cica refulgens. amirans

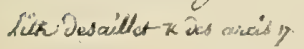




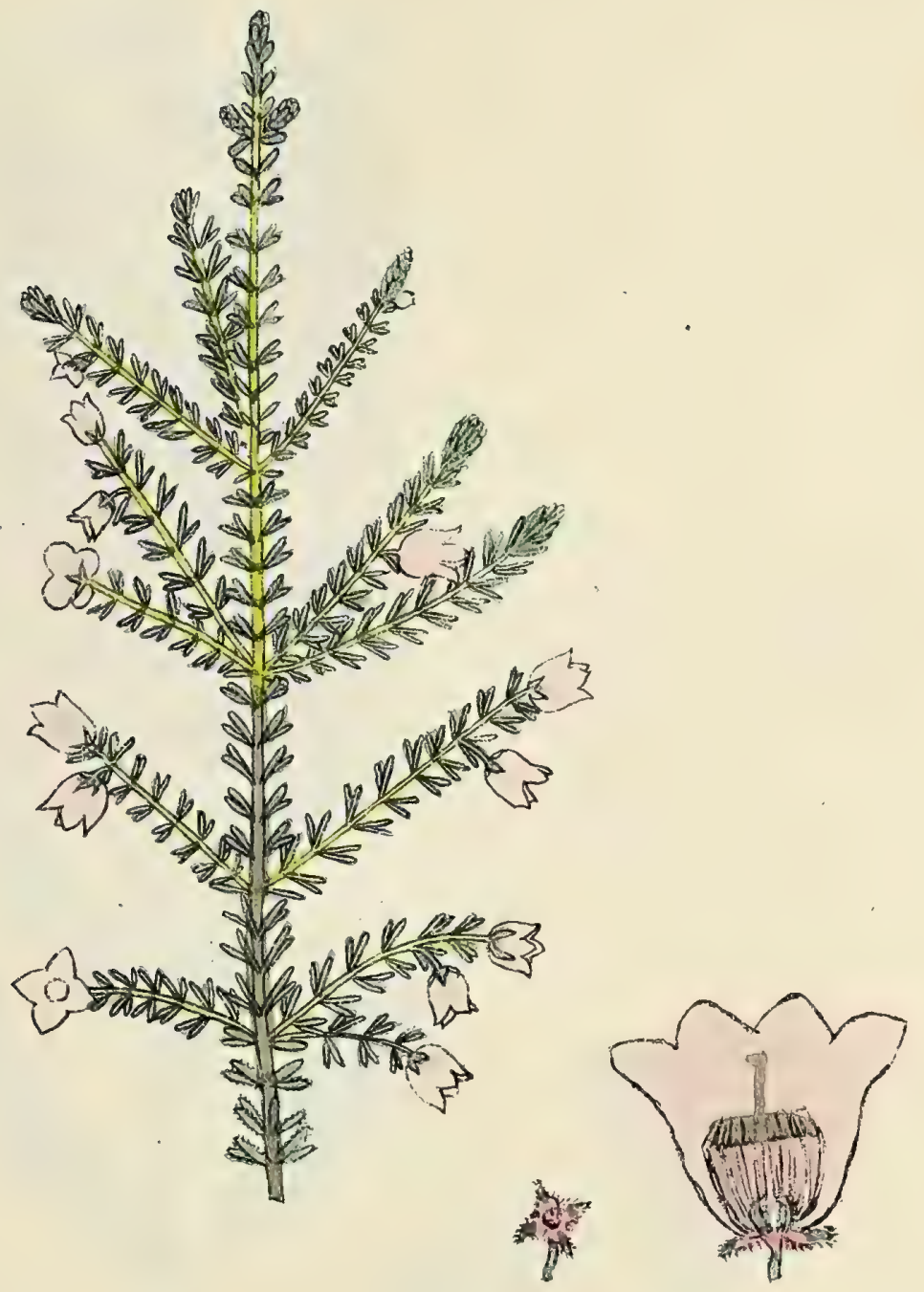

Iige lignouse, Dressée, triès rumonede,

Feuilles verticillees par 4 , conctes, triquidis, ciliés.

P'Soncules solitaires, ciscillacies et terminawe, virnyltes, couxes.

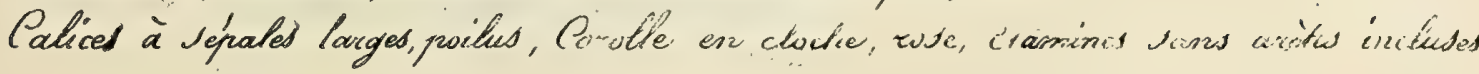

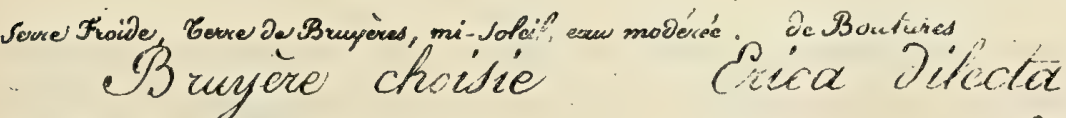

Lito desaitor $x$ Jos axais ny

Cher Lemicher Rue Jes 3 riurveures ils 



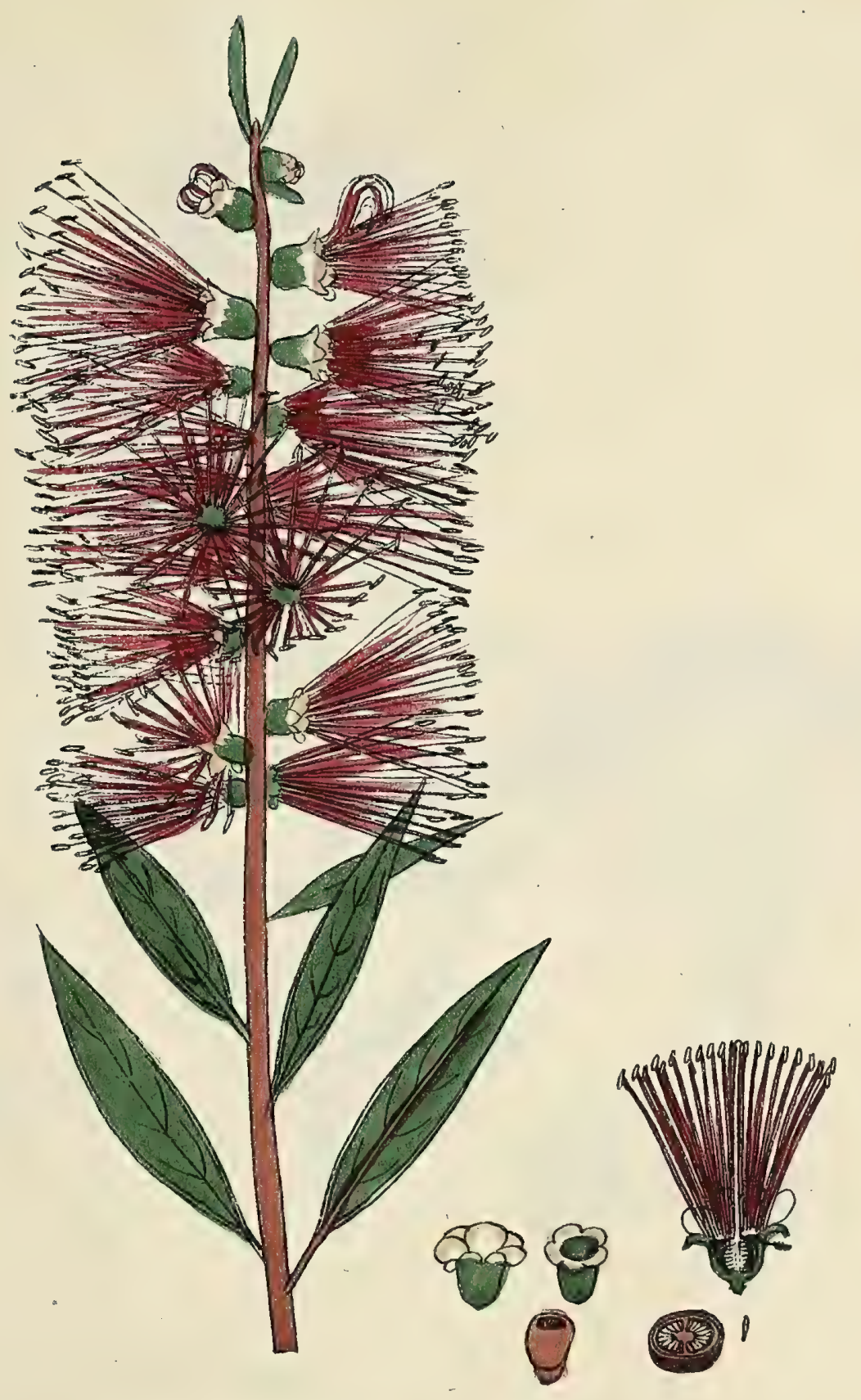

Tüe anboré, icessée, rameusen, de 2 à 3 mêtred

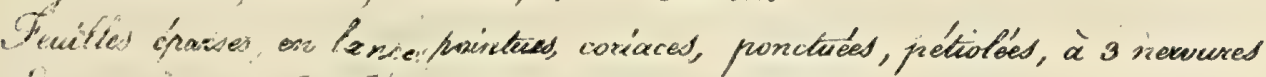

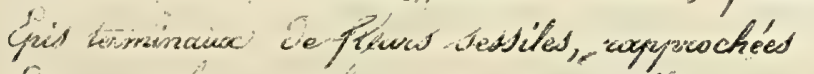

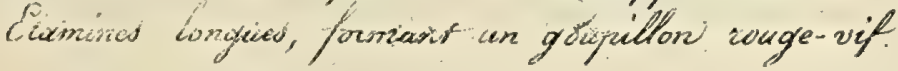

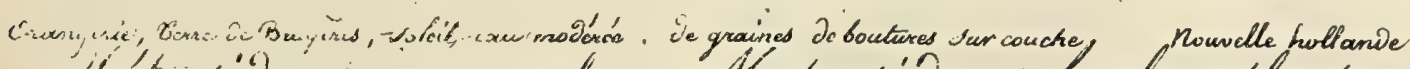

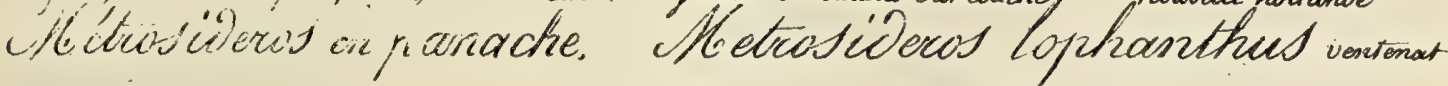
Chax Mbartione Ruo Des Bouryguignons 2y 


$$
\text { . }
$$




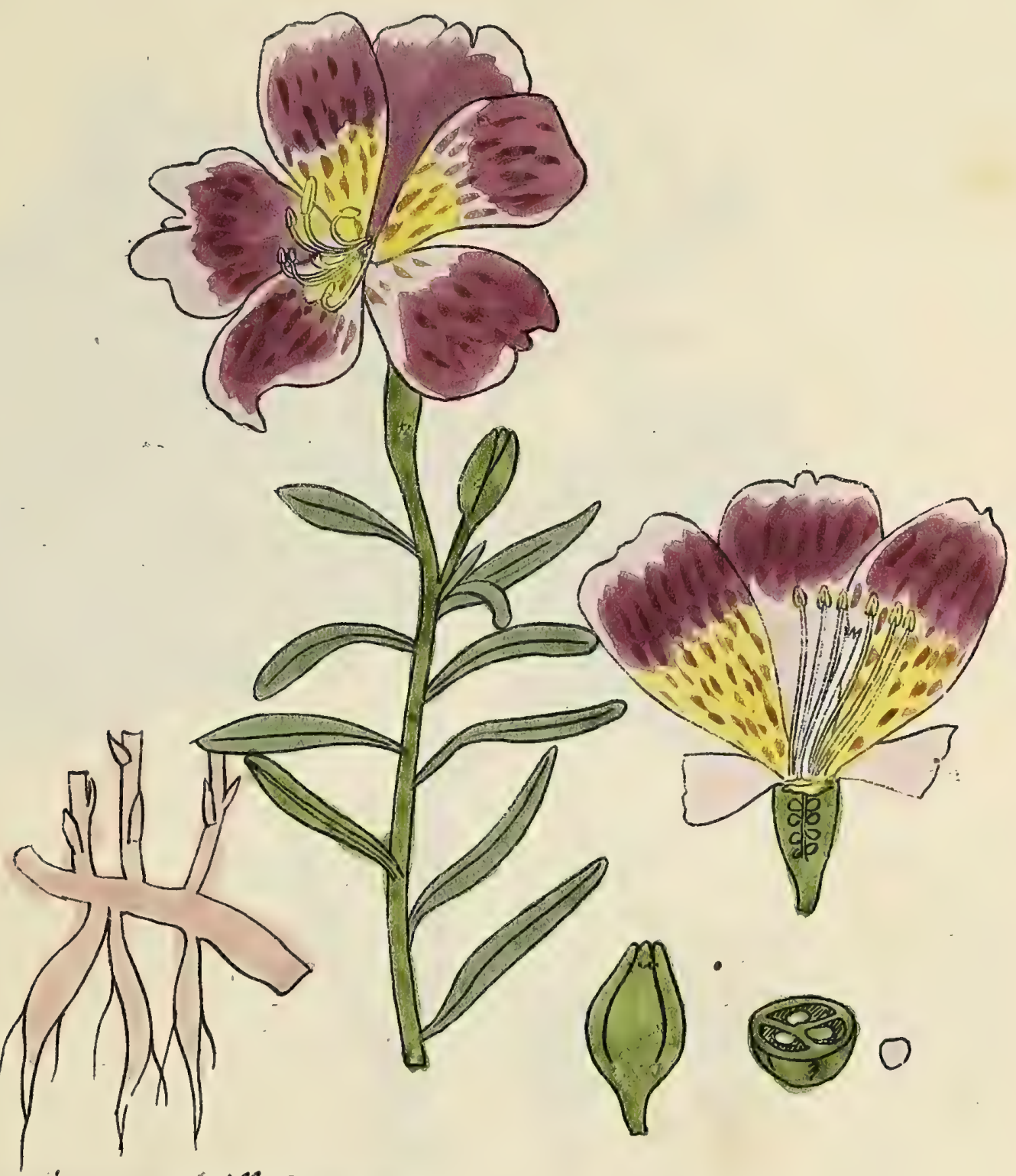

Racine vivace en griffe o'asperge.

Gige herbacee, Dressée, simple, faible, de 40 censtünétred

Fenilles éfouses, sossiles, on lances aigues, luisantes, contournées

3 à 4 Fleurs terminales

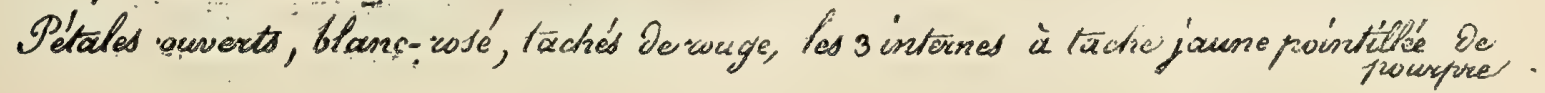

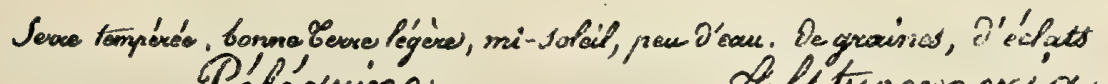

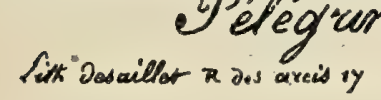
ofls troenizeria peleguina finnée 
- 


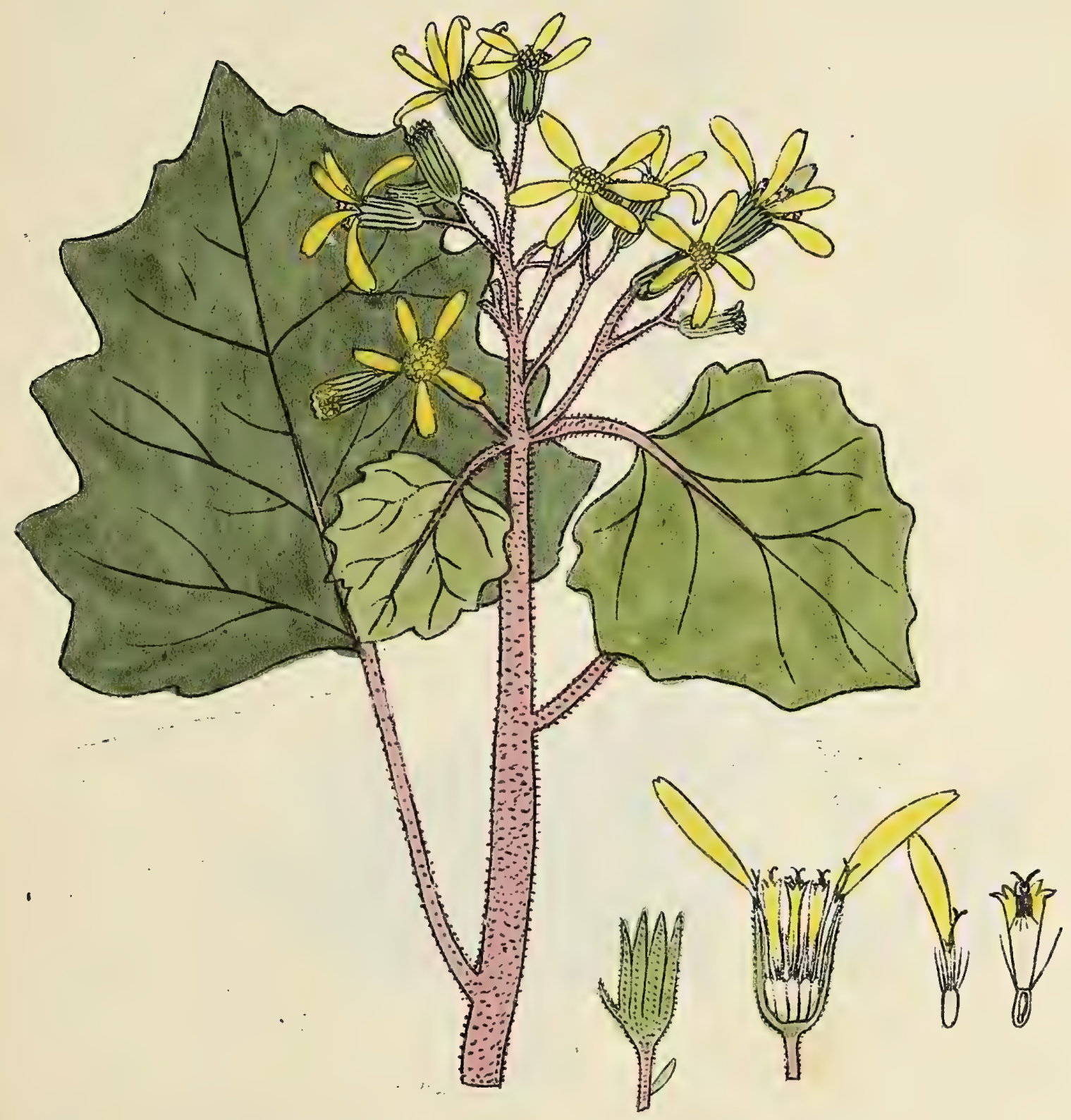

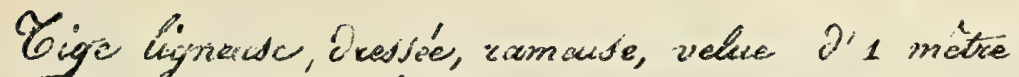

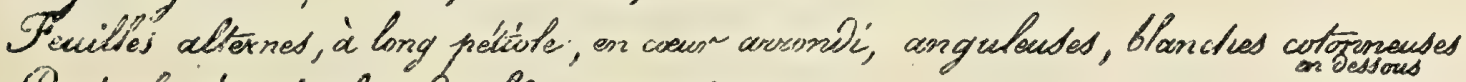
Panvicule torninale De flawes nombroudes Palice Scaviewar, Deoni-freurons ef flewrons jounses

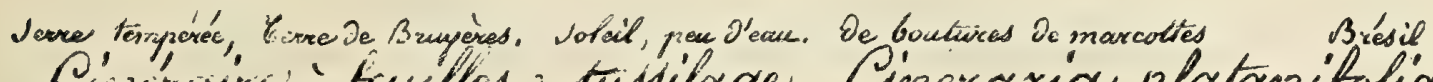

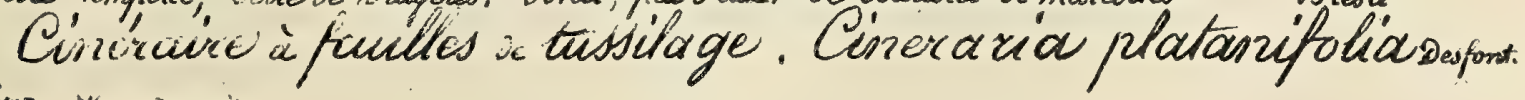
Som doctilles a dos areich 



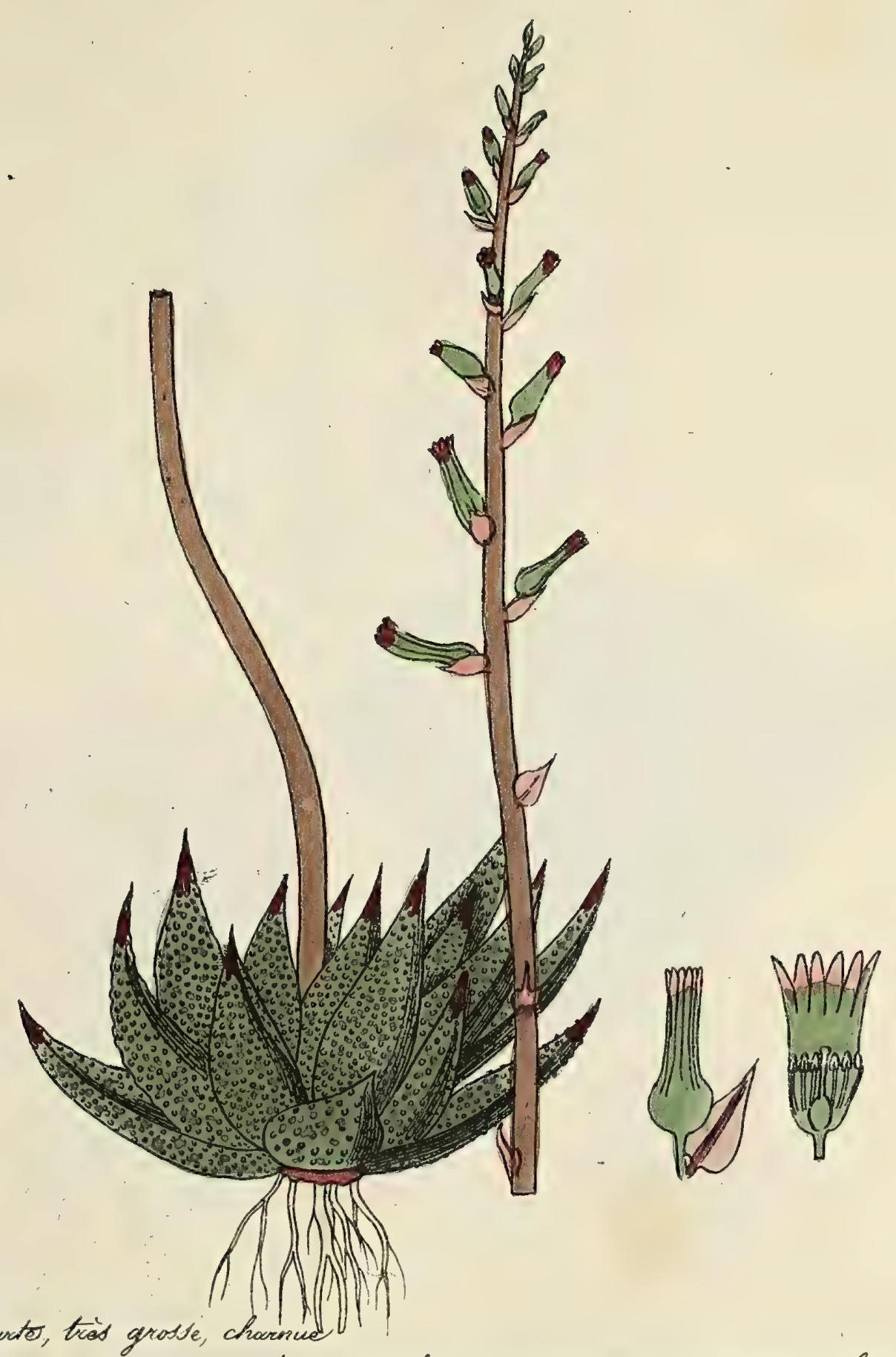

Tige tres counter, tios grosse, chocronue

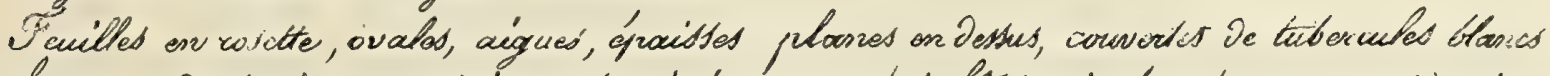

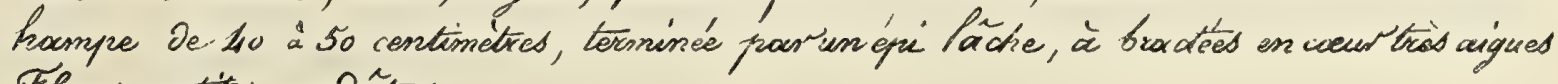
Fleurs petites, verdâtros

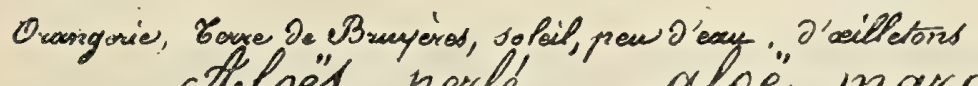

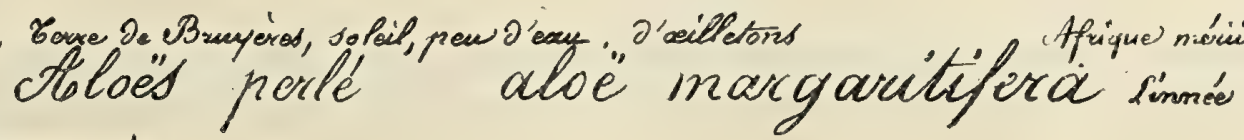

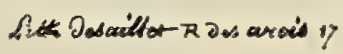




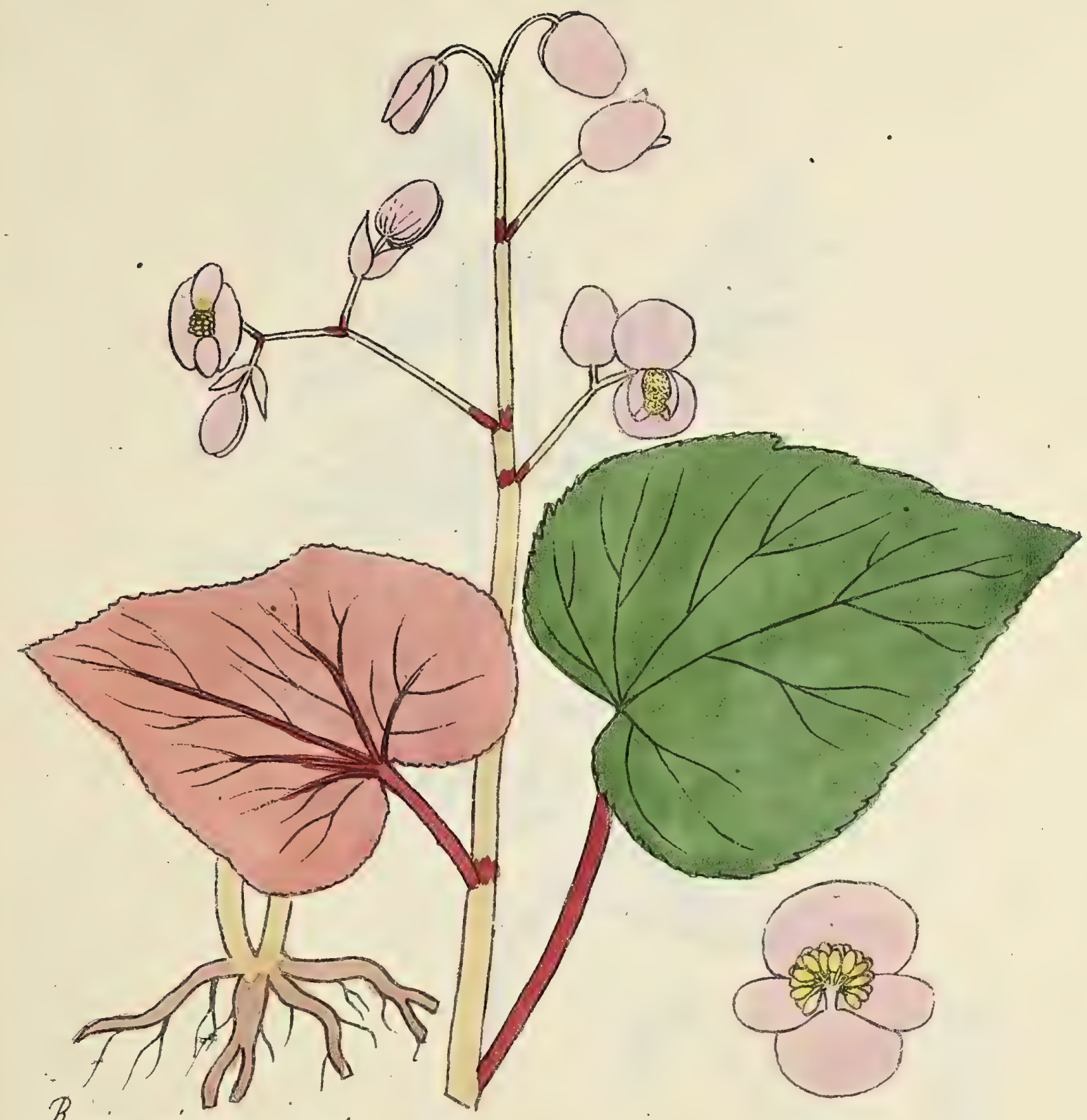

Racine vivace, rainente

Tiges herbarées, nuneuses, pen ramenses, wugged ausc articulations

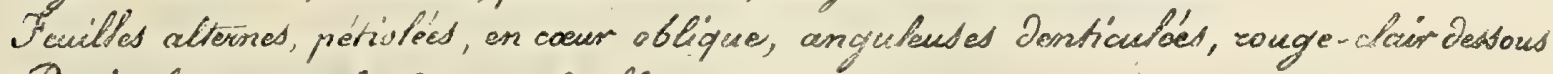
Panicule torminale, De prew De fleurs

Flewed rose terive

\%

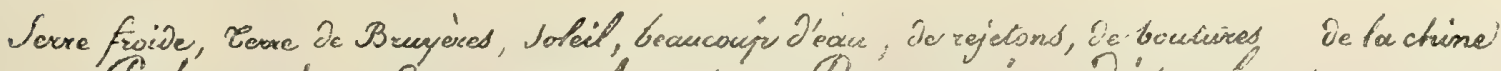

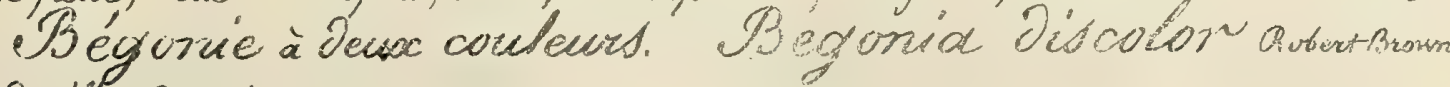

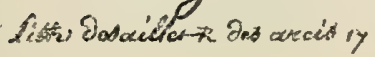





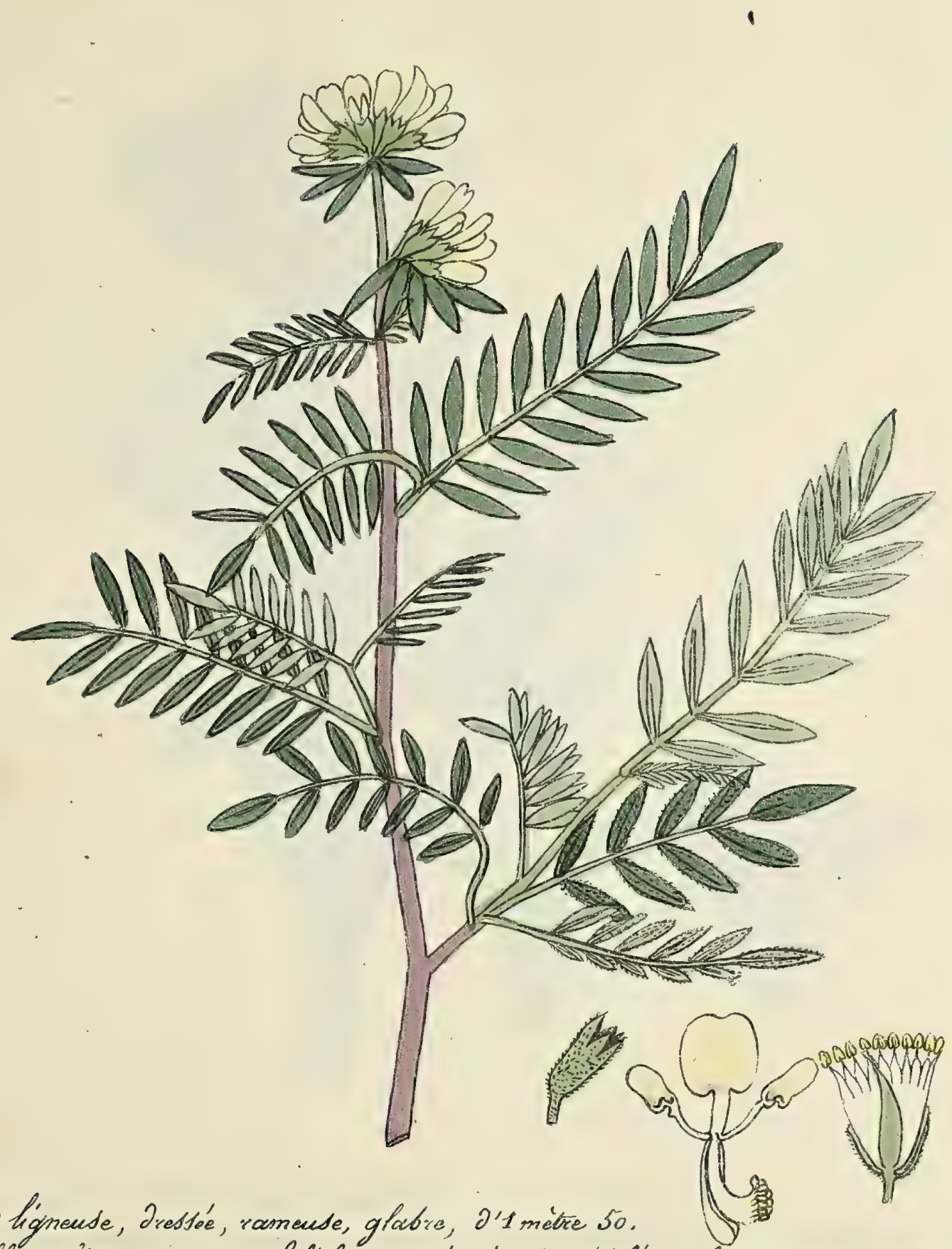

Tige Ligneuse, Jrestée, ramense, glabre, J'1 mètre So

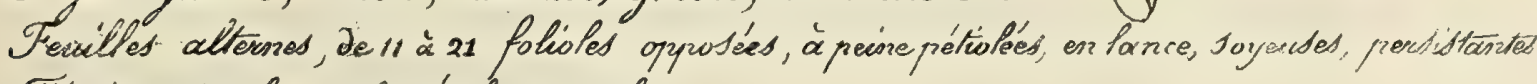
Tétes torminales et faterates, sessiles

Fleurs petites, jaunätres.

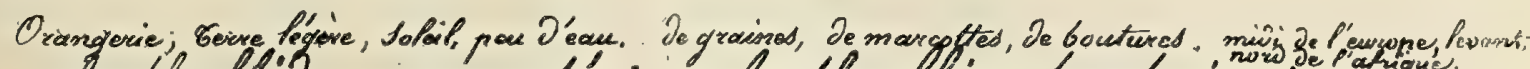
Hnthyflide ardenté. Anthyllis bacbajovis sinnic.

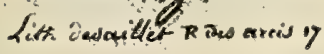


$$
\text { - }
$$ 


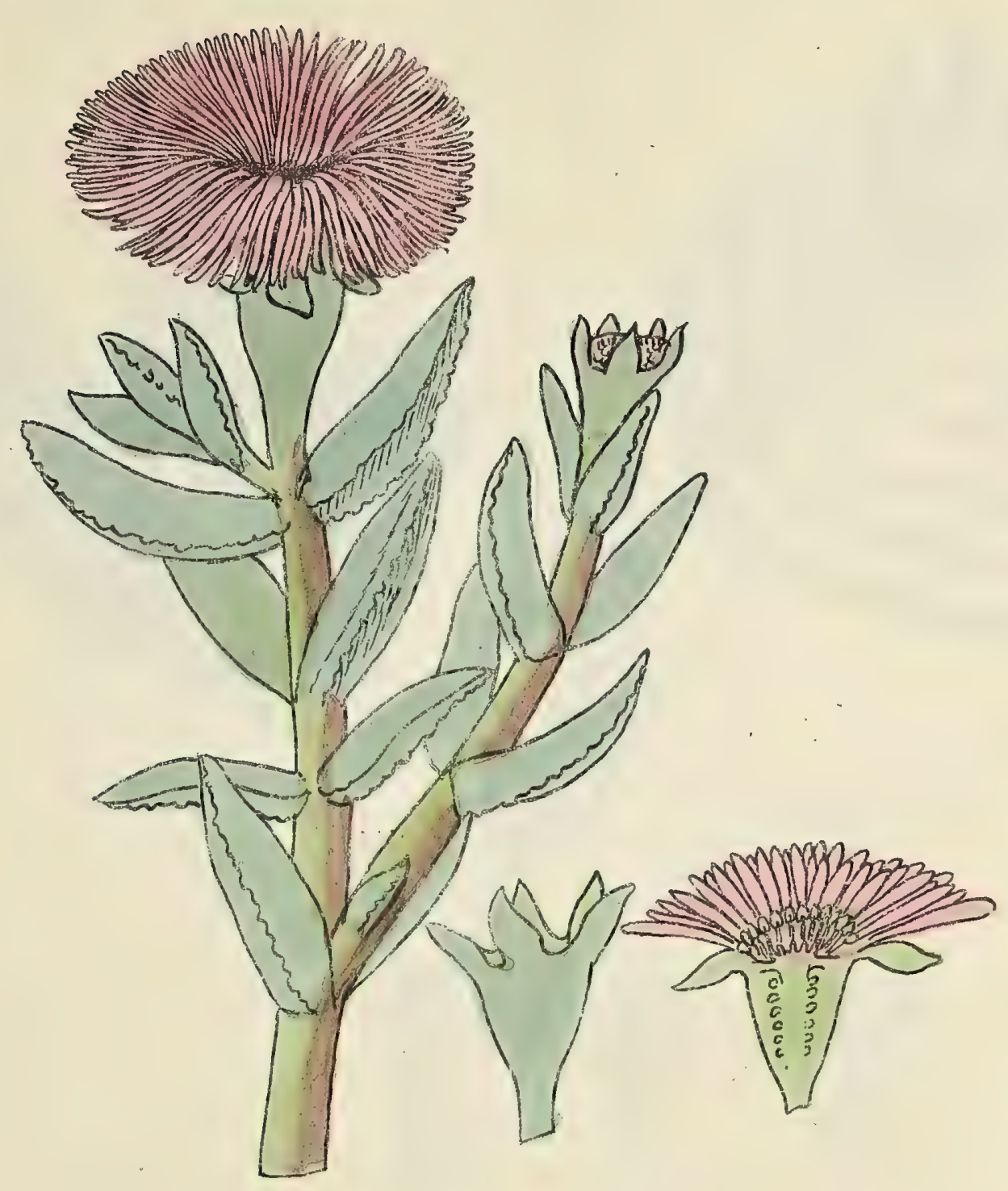

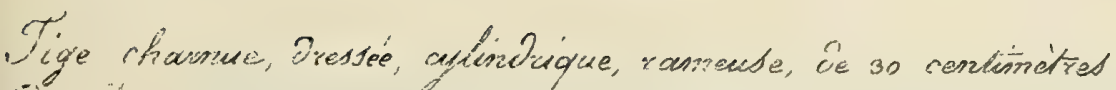

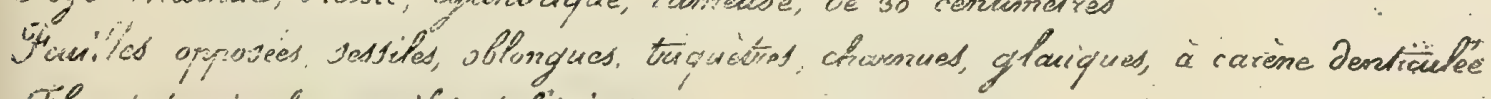
Theund, terminales, vessies, solitivires

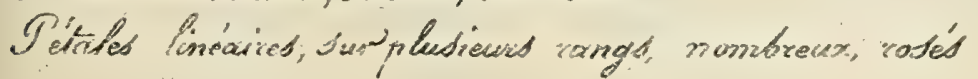

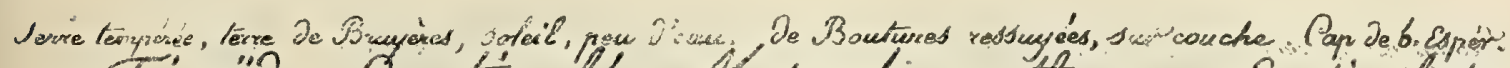

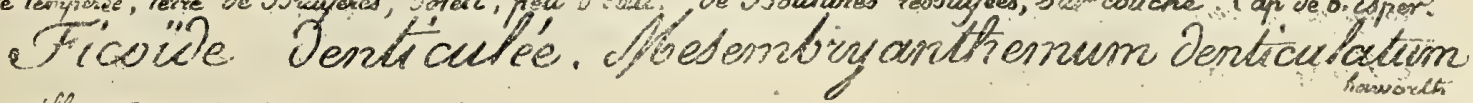

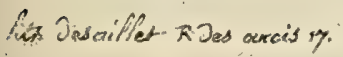




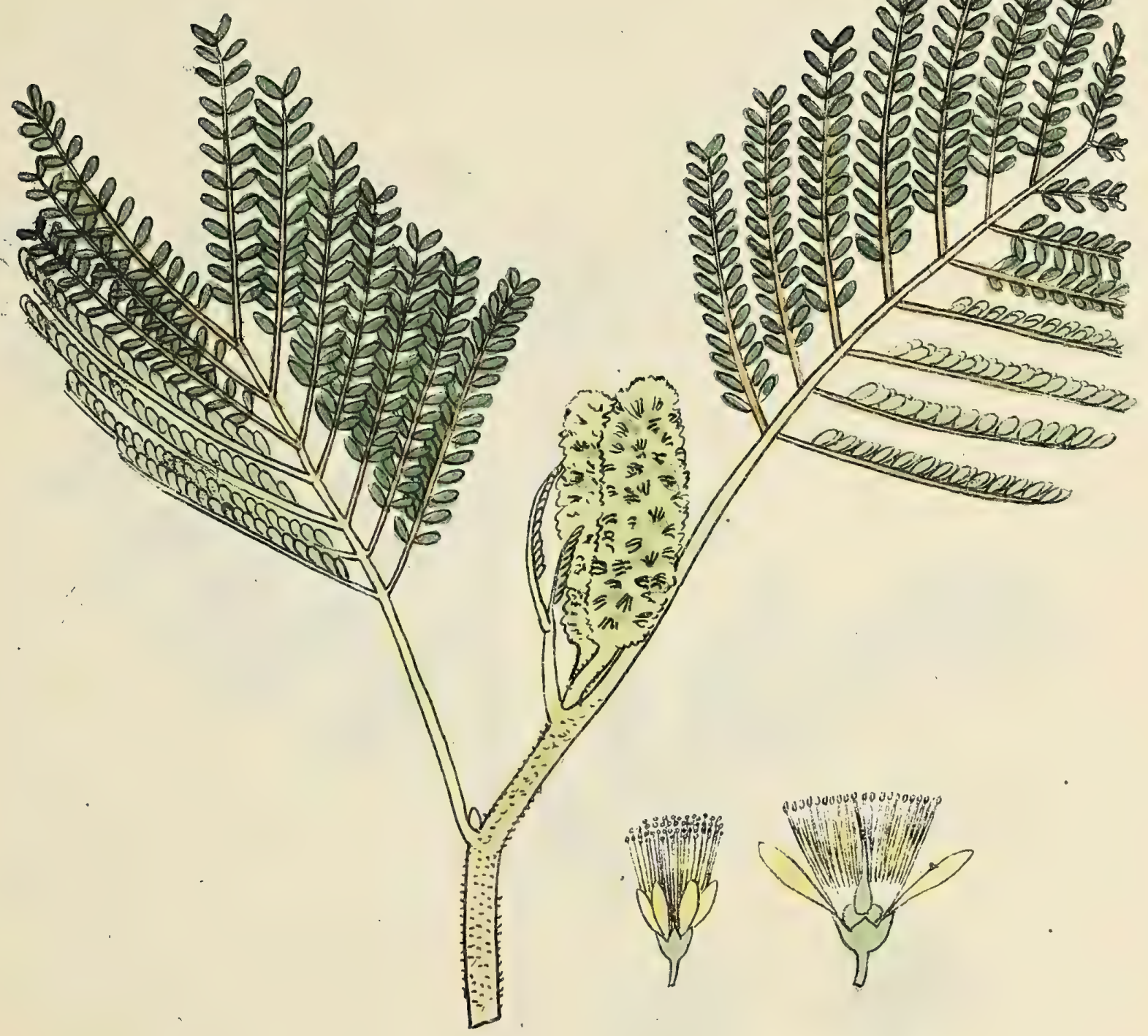

Tige ligneuse, Jrestée, ramouse, de 3 à 4 màtred

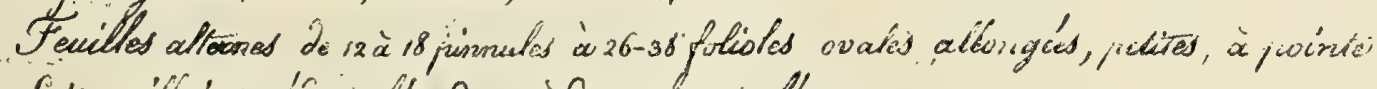

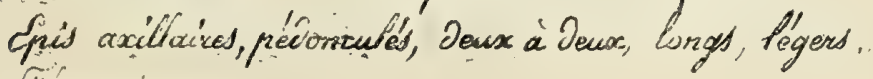

Hisurs jaunes. ..

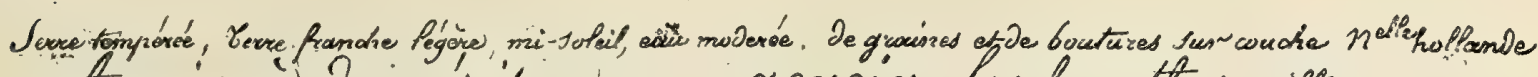

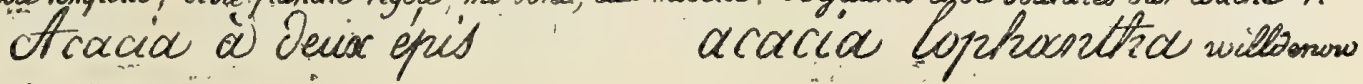
fibt Jesailler $R$ Jes arrers? 7 



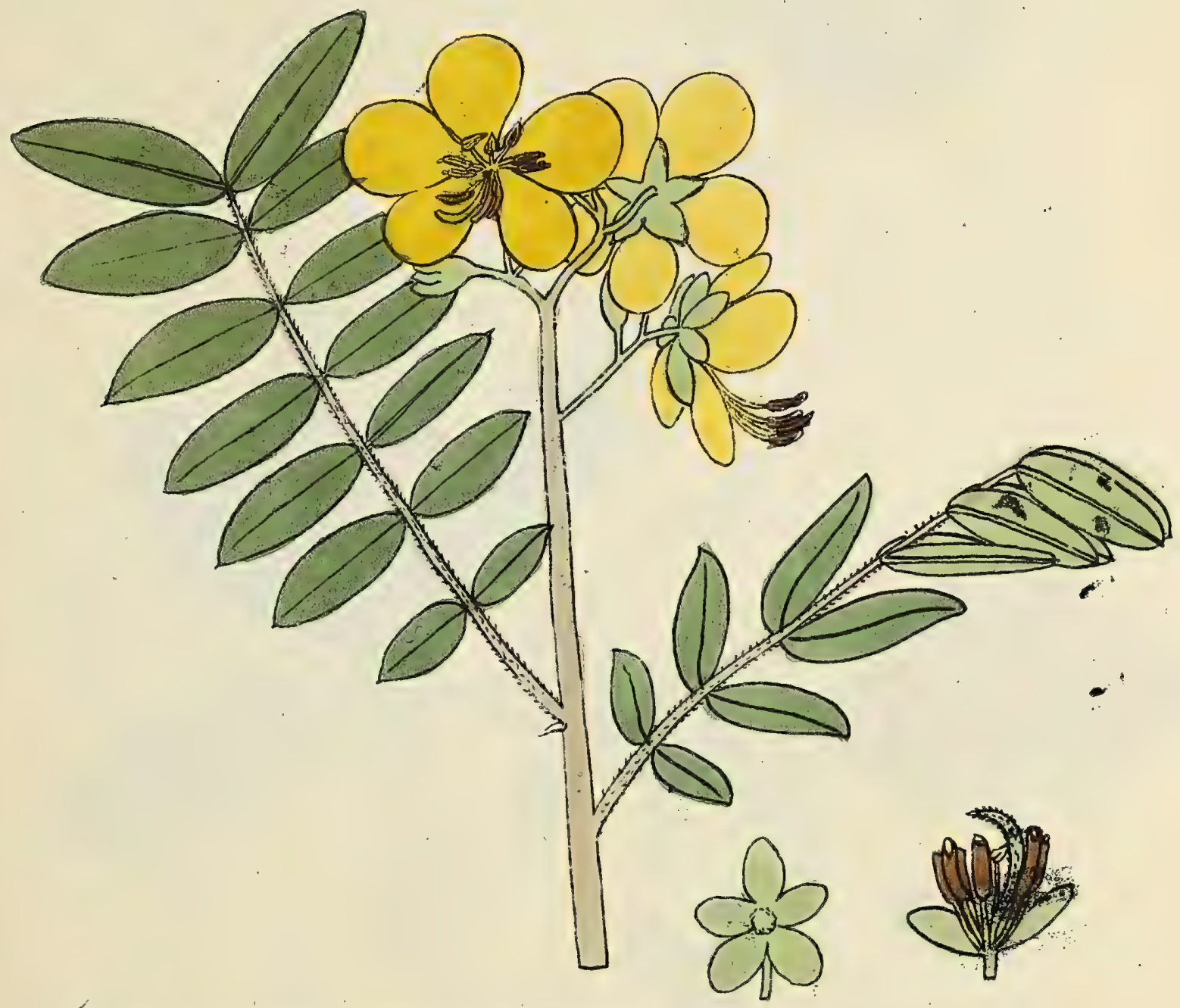

'Tiq: Pigricuse, iratsée, rameuse, J'1 mère 30.

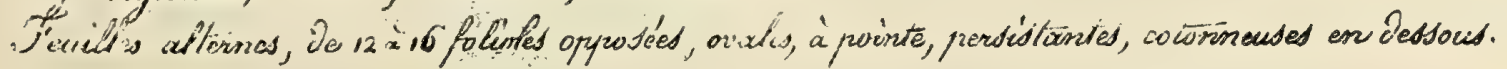

- Jinicules ierrninales, ramatsées

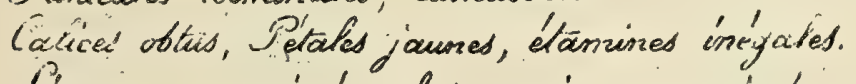

L'gurnes compricinés velus, groxines corrywionnés, Jans julpice.

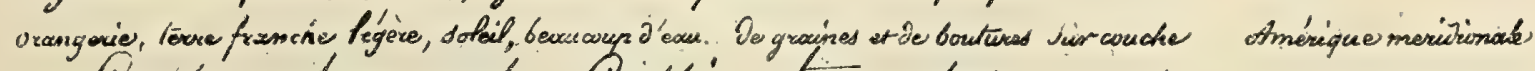
Cadse cotoriscude, Cassia tornentosa simnéc

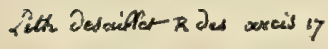



$146^{\circ}$

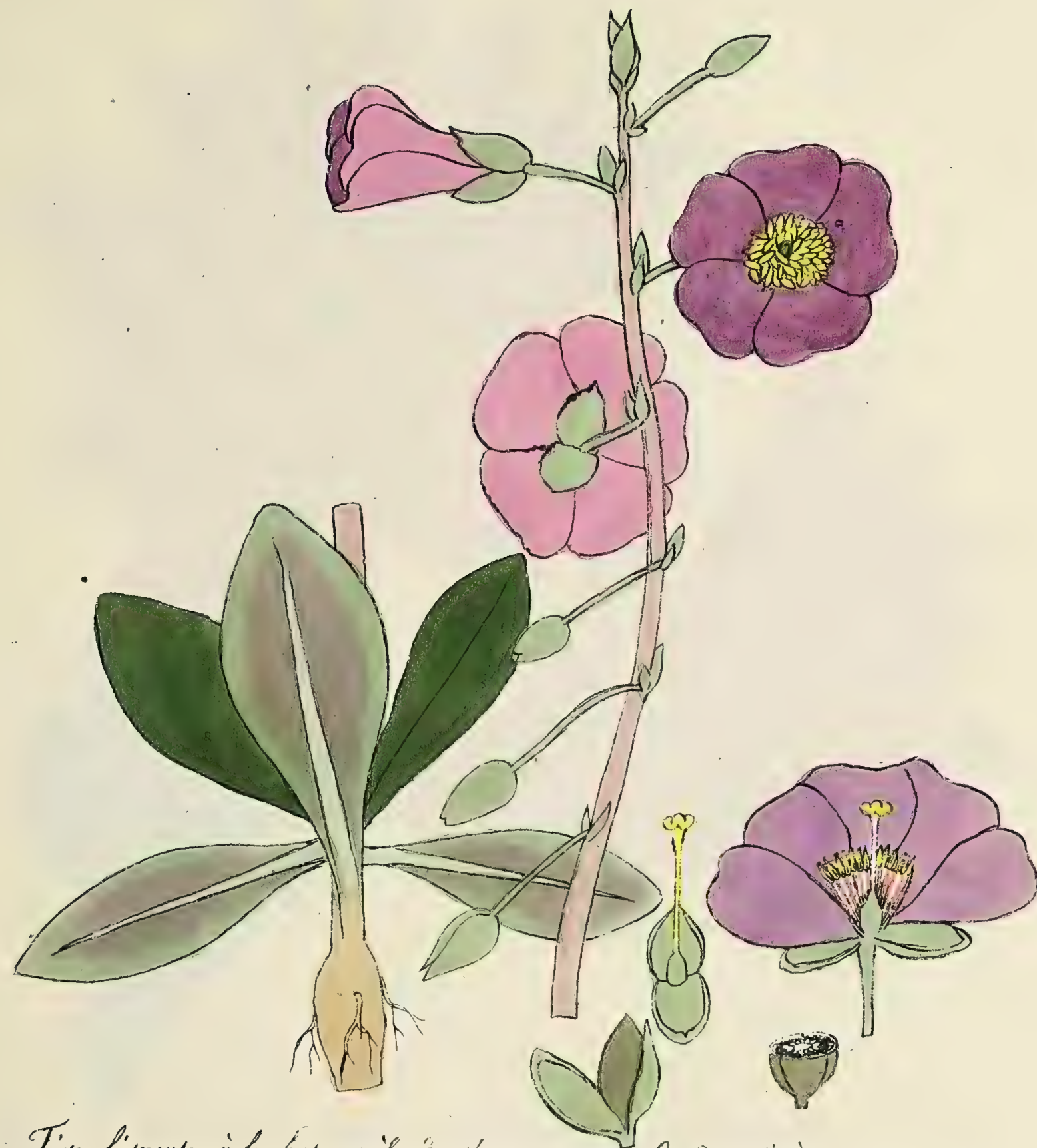

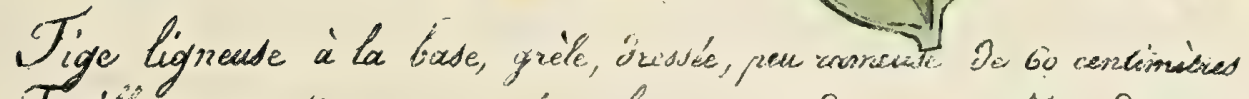

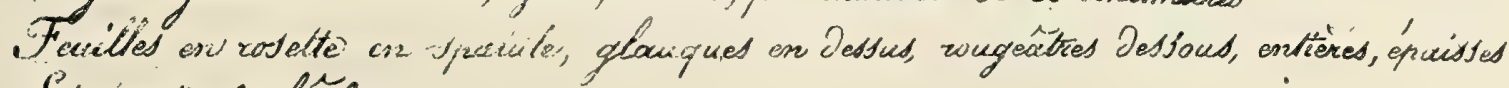
Give terminual lache

- Peíaies vislacéd

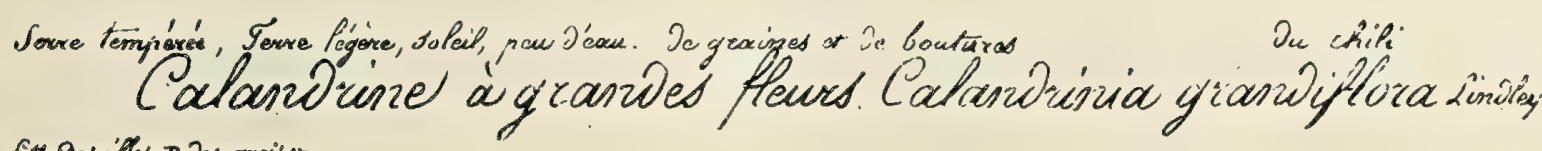

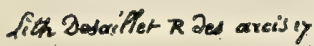





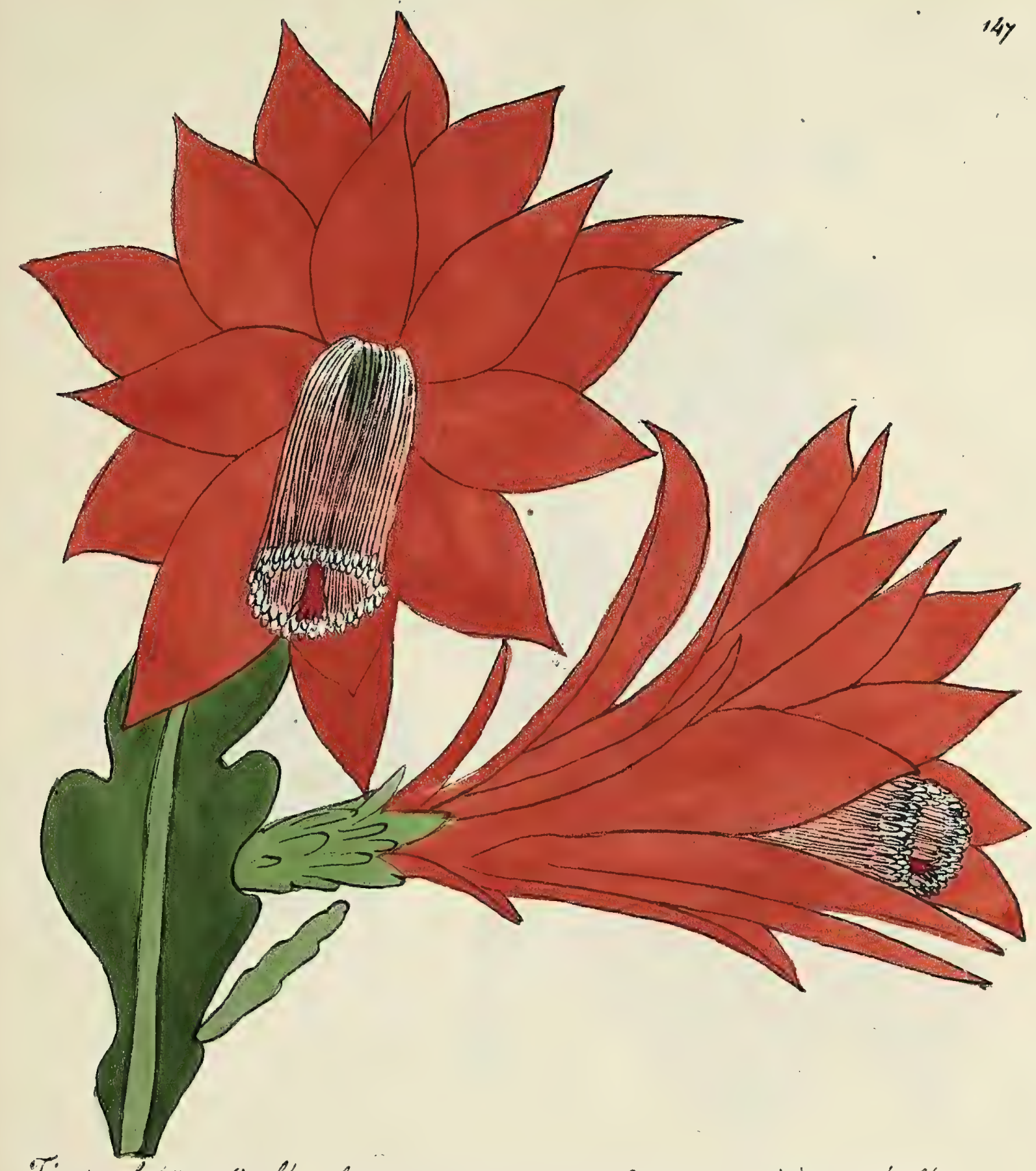

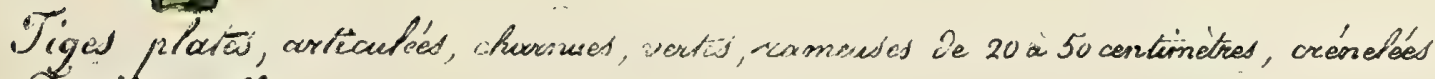
Fithes nulles

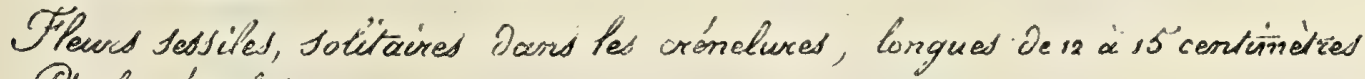
Pitales écartates

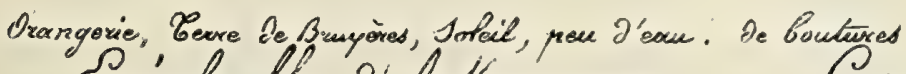

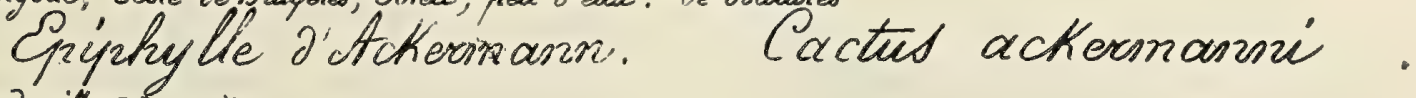
Lith Jesaitho-R ins axcis iy 


\section{•}

-

mata 


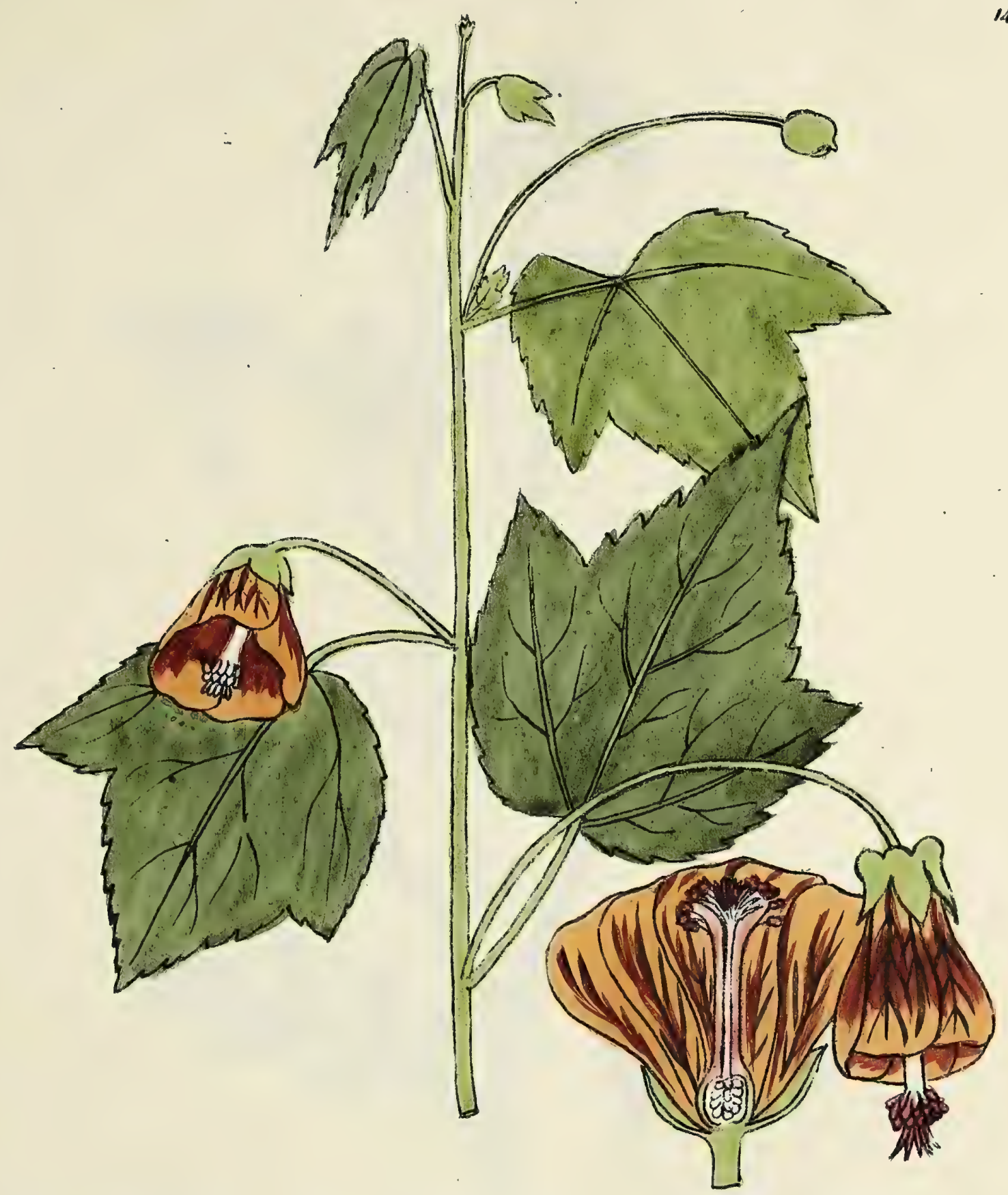

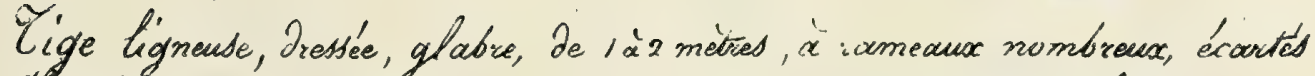

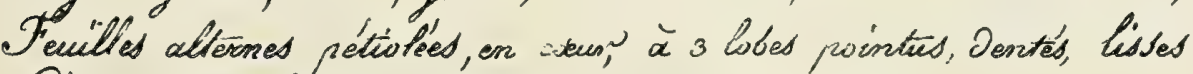
Peloncules acill aires, Solitaires, Simples, tries forgys,

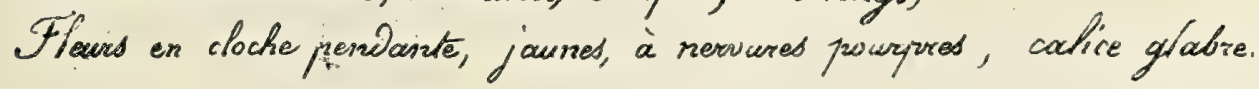

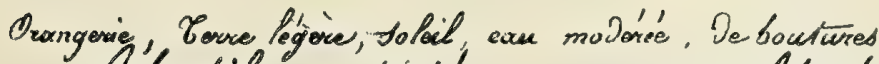
Afbutilon Strie, Abutilon Striatum Dickson

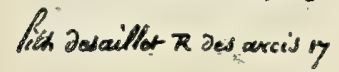


, 


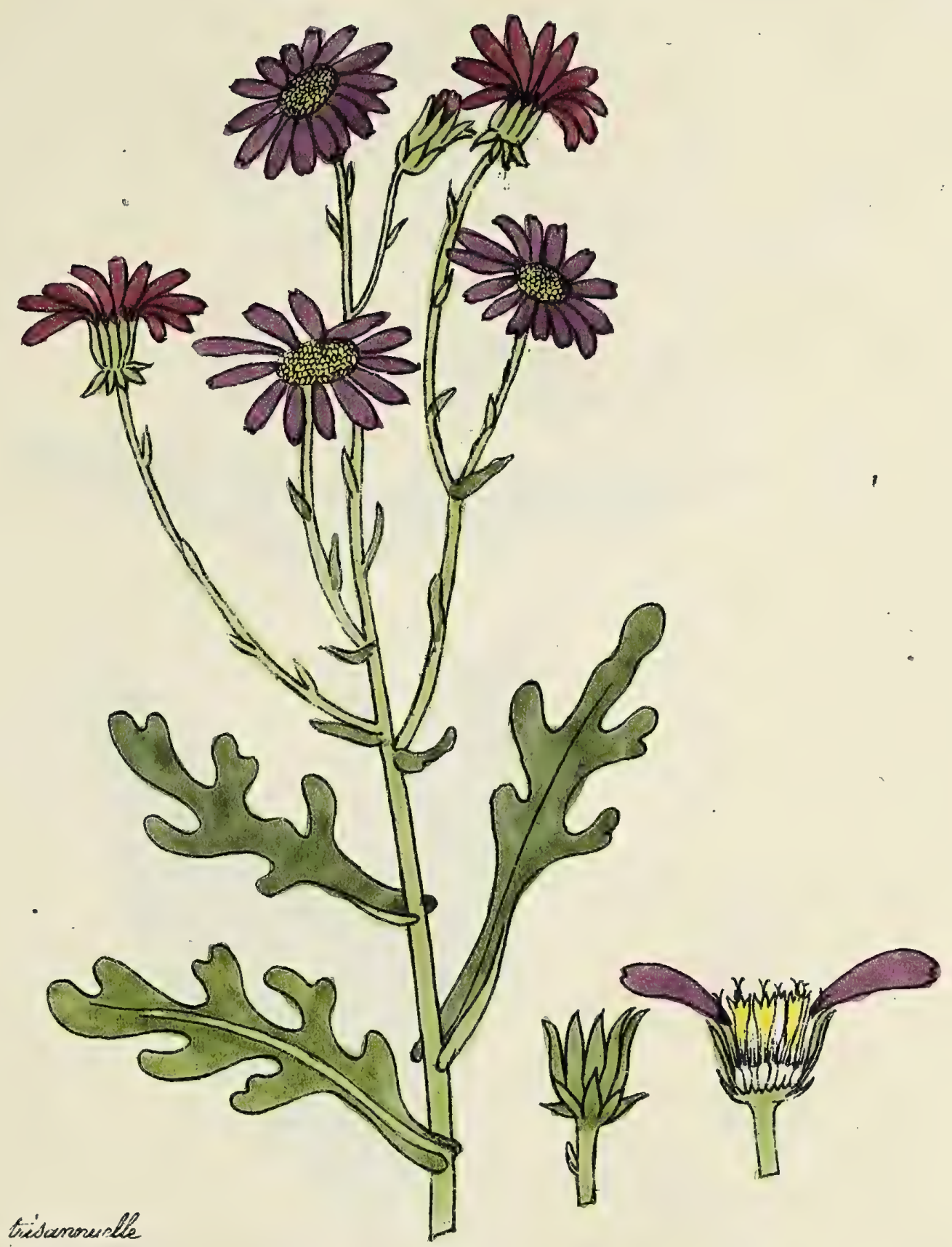

Racinc visionourlle

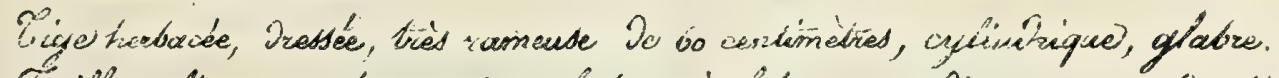

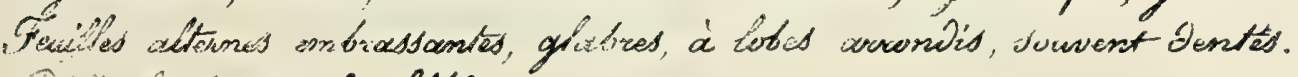

Trincule traminale lacke en cormonbe

Salicule ouverk. Demifleurons vistets, flewions jausros.

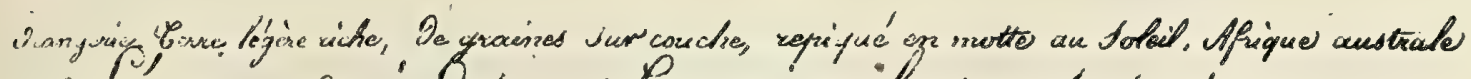

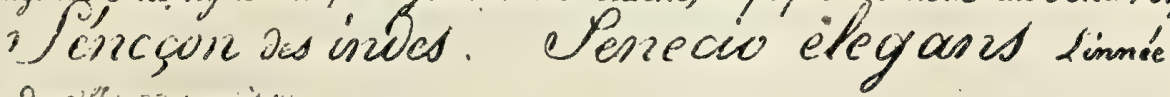

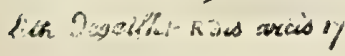




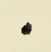




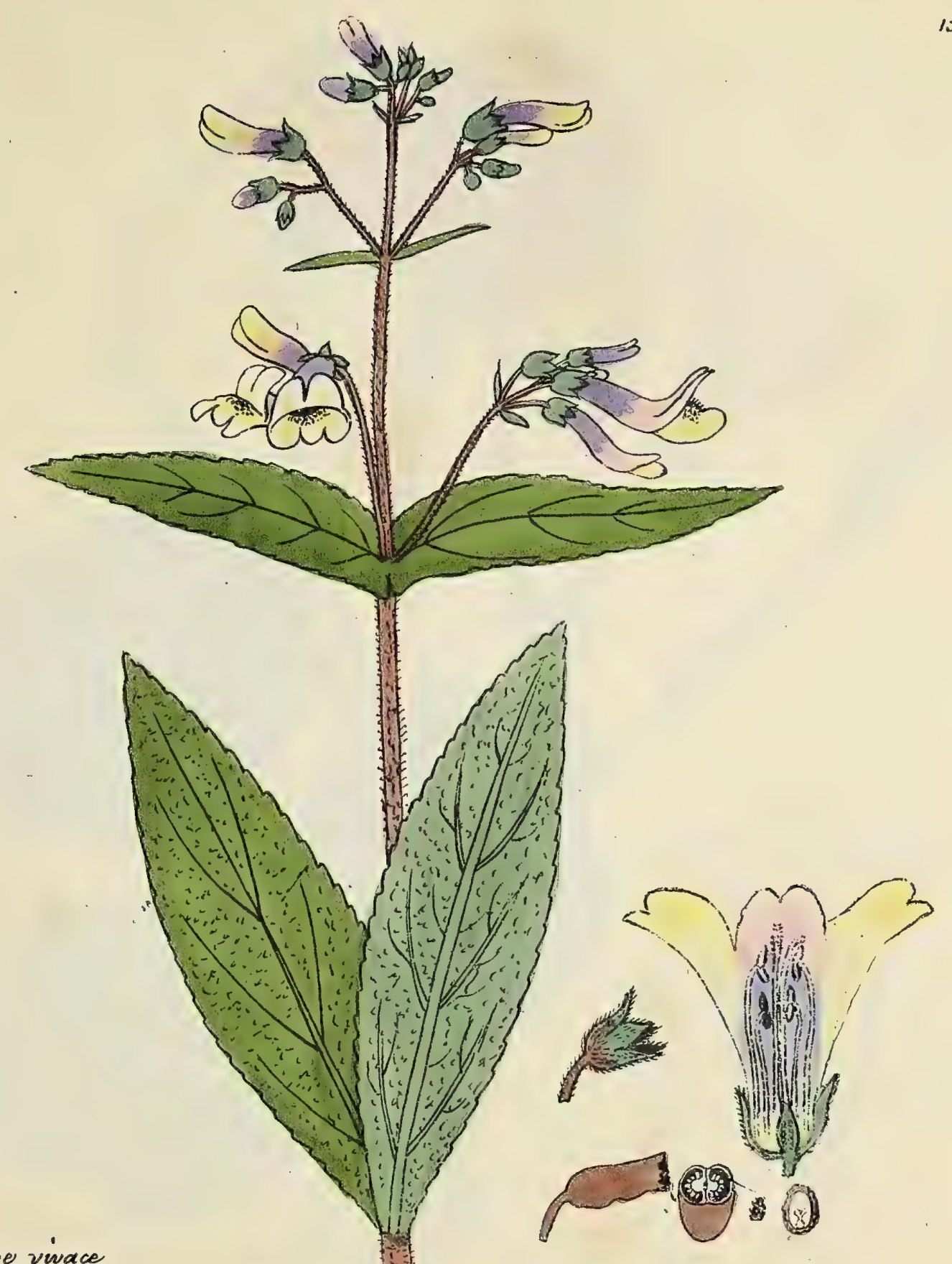

Racine vinace

Tige Gigneuse à la base; Oressée, ramuts, n'i mêtre, velue

Fewilled opyrosées, sedsiles, en lasrce, Denticulés, proilues.

Pancicule torminales

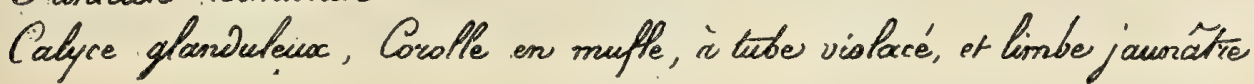

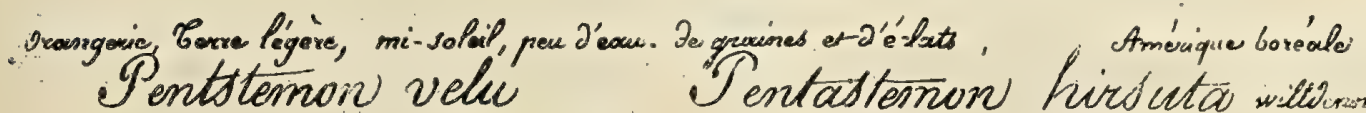

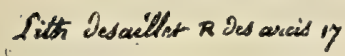





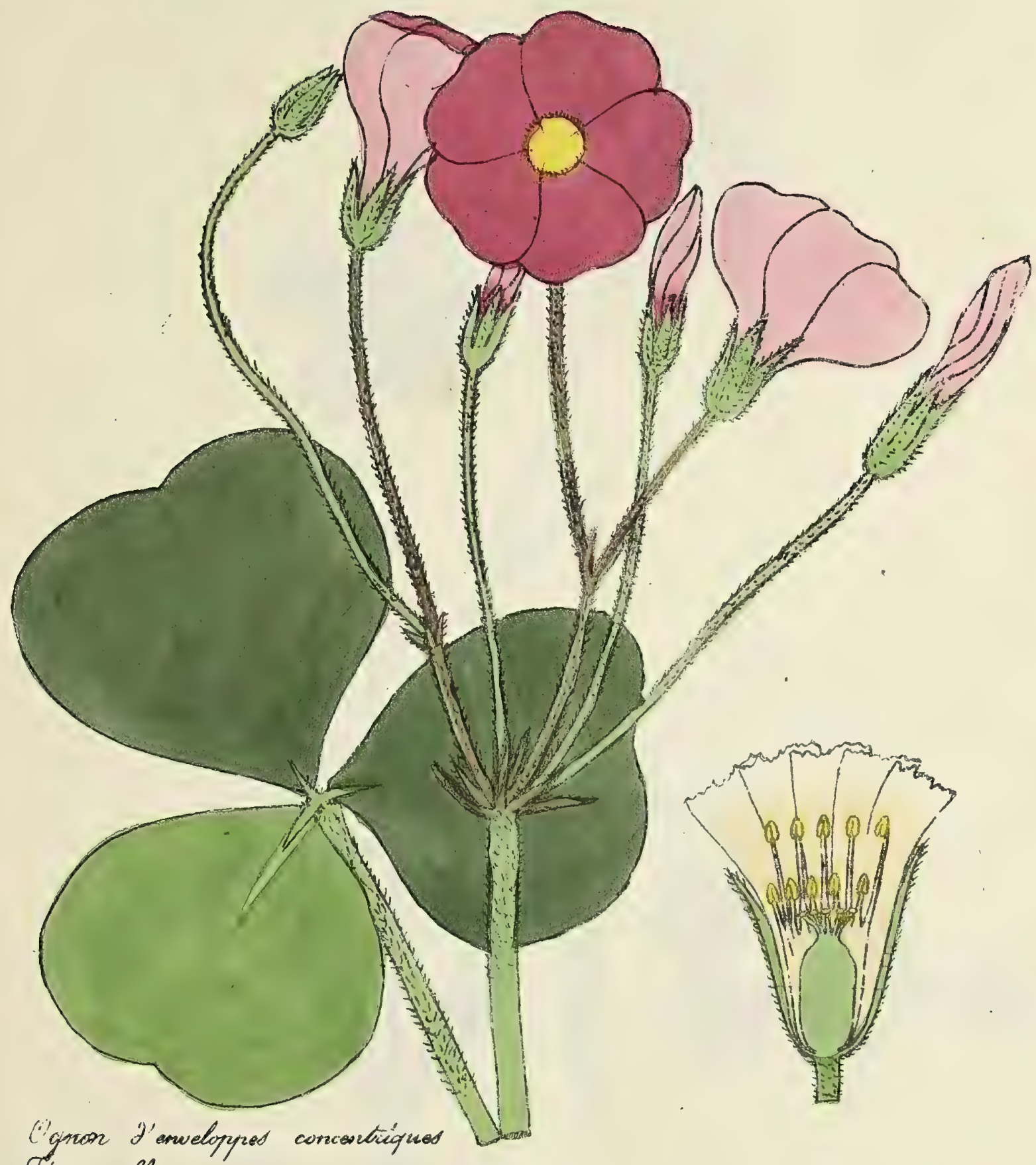
(igroan I'emelopyed concentrigues Tige nulle

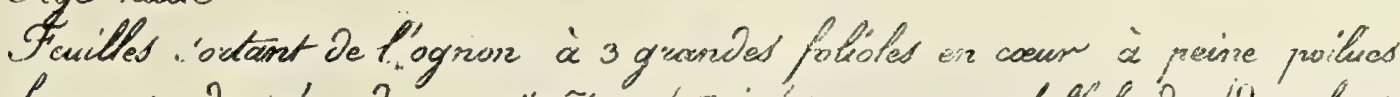

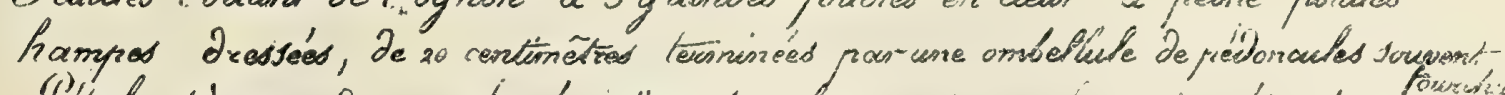

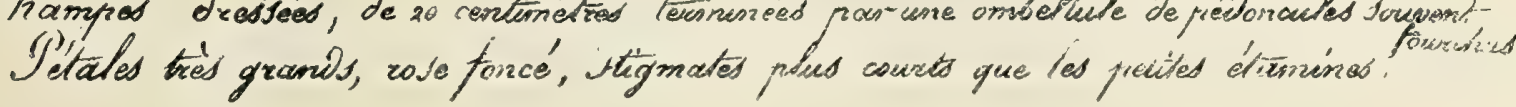

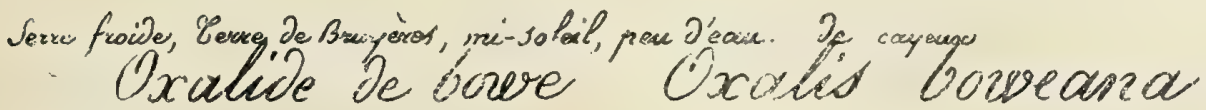

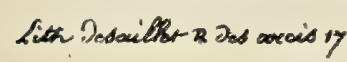
Chex Pelé ure de lourcaineyi 



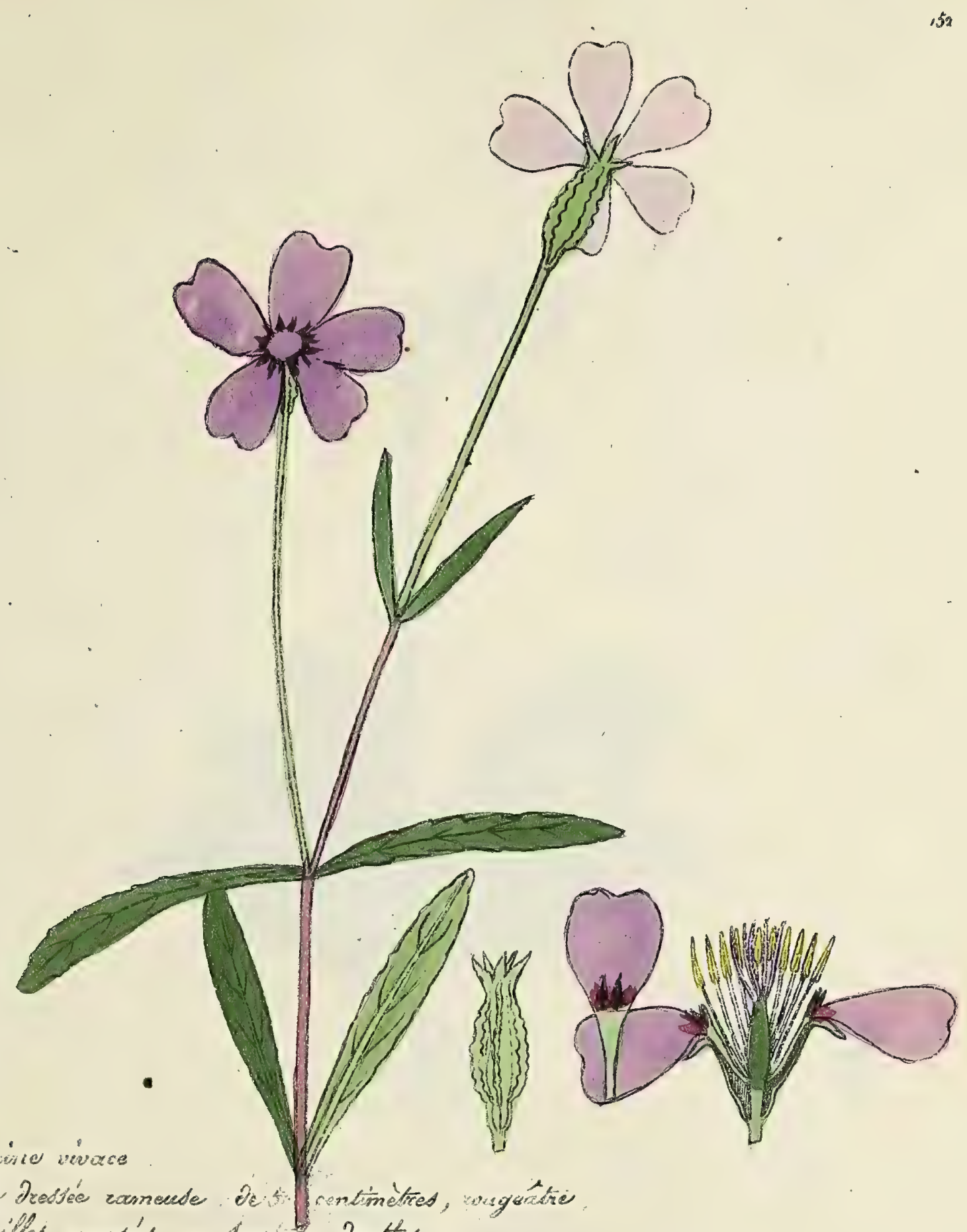

Hacizie veruce

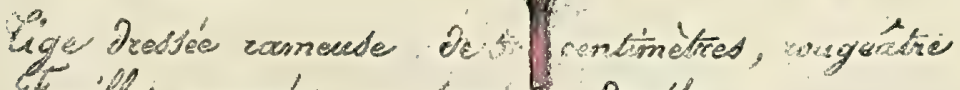

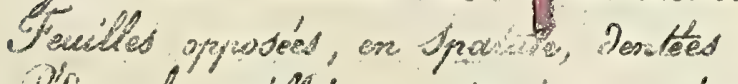

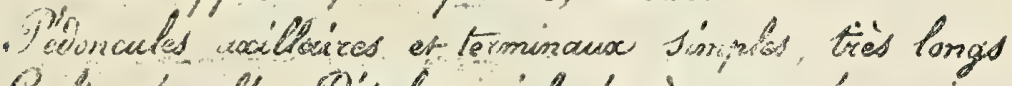

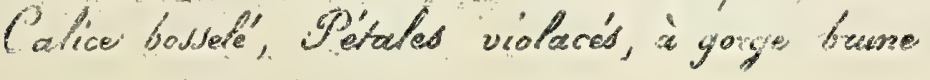

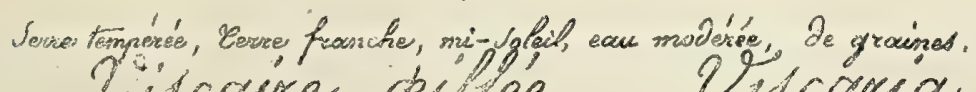

Viscaire ceilige Vidcania oculata.

Lien Descuiliter 2 Dos ouscis iy Chor Chawiere we de la rogueter 104 



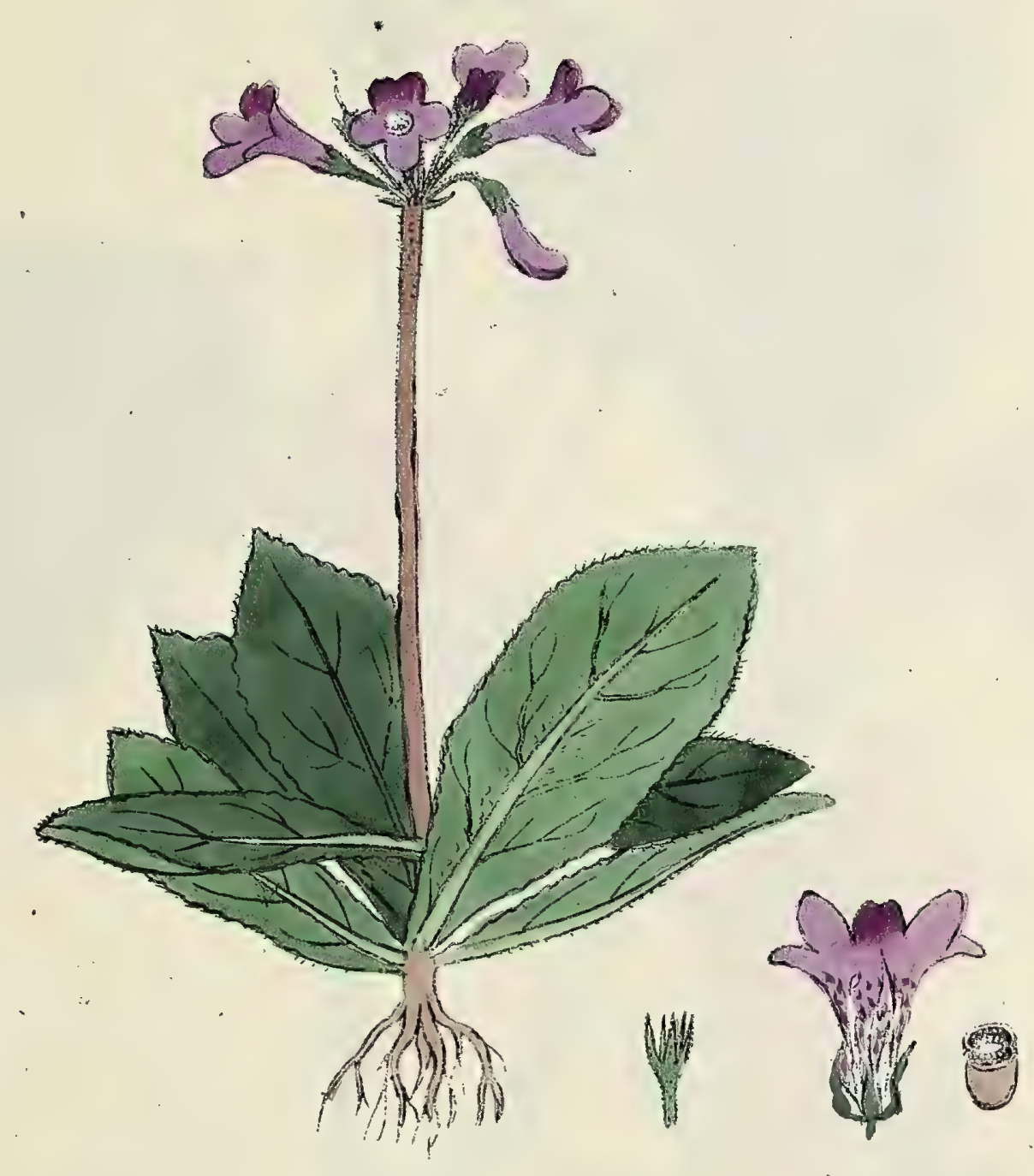

Tiyes trees courtes ligrnouses

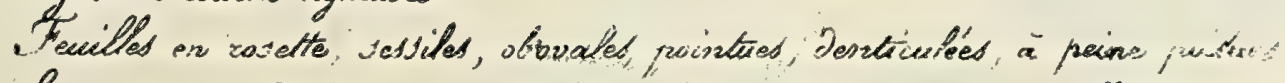

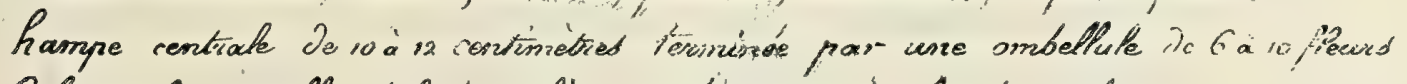

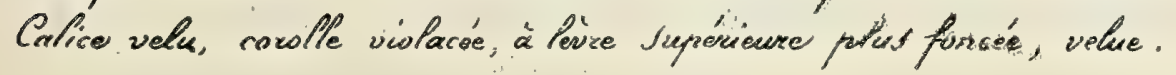

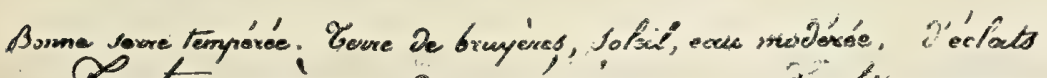

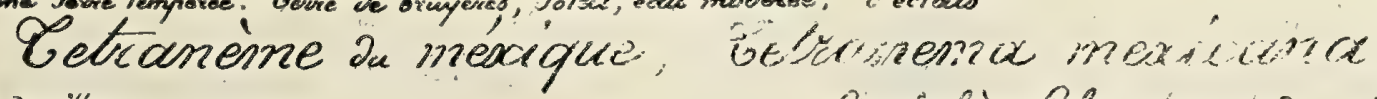
Lith iessillar Ros arcis ? ?

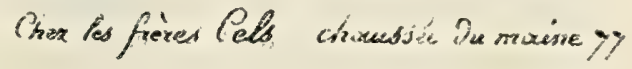




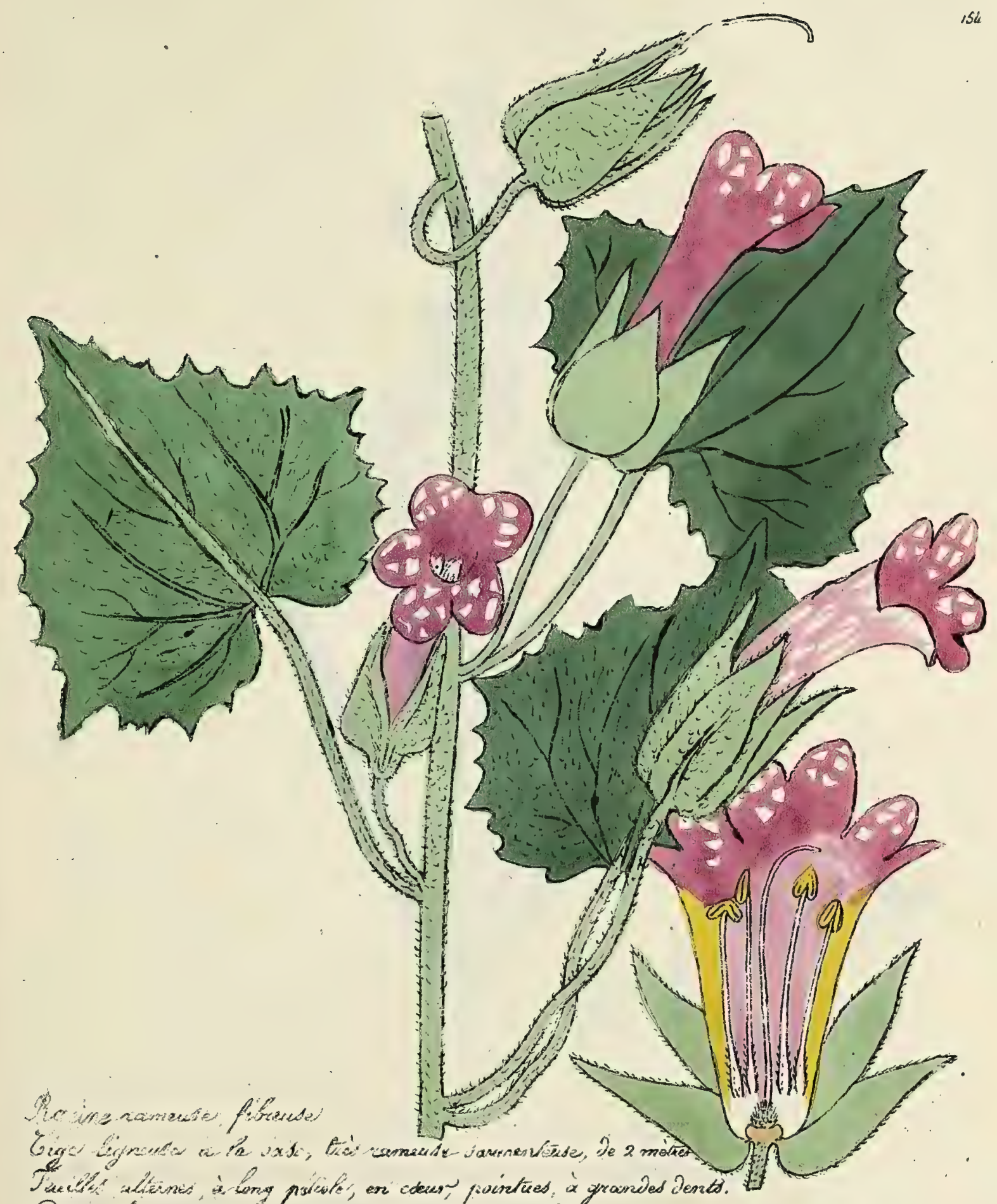

154 



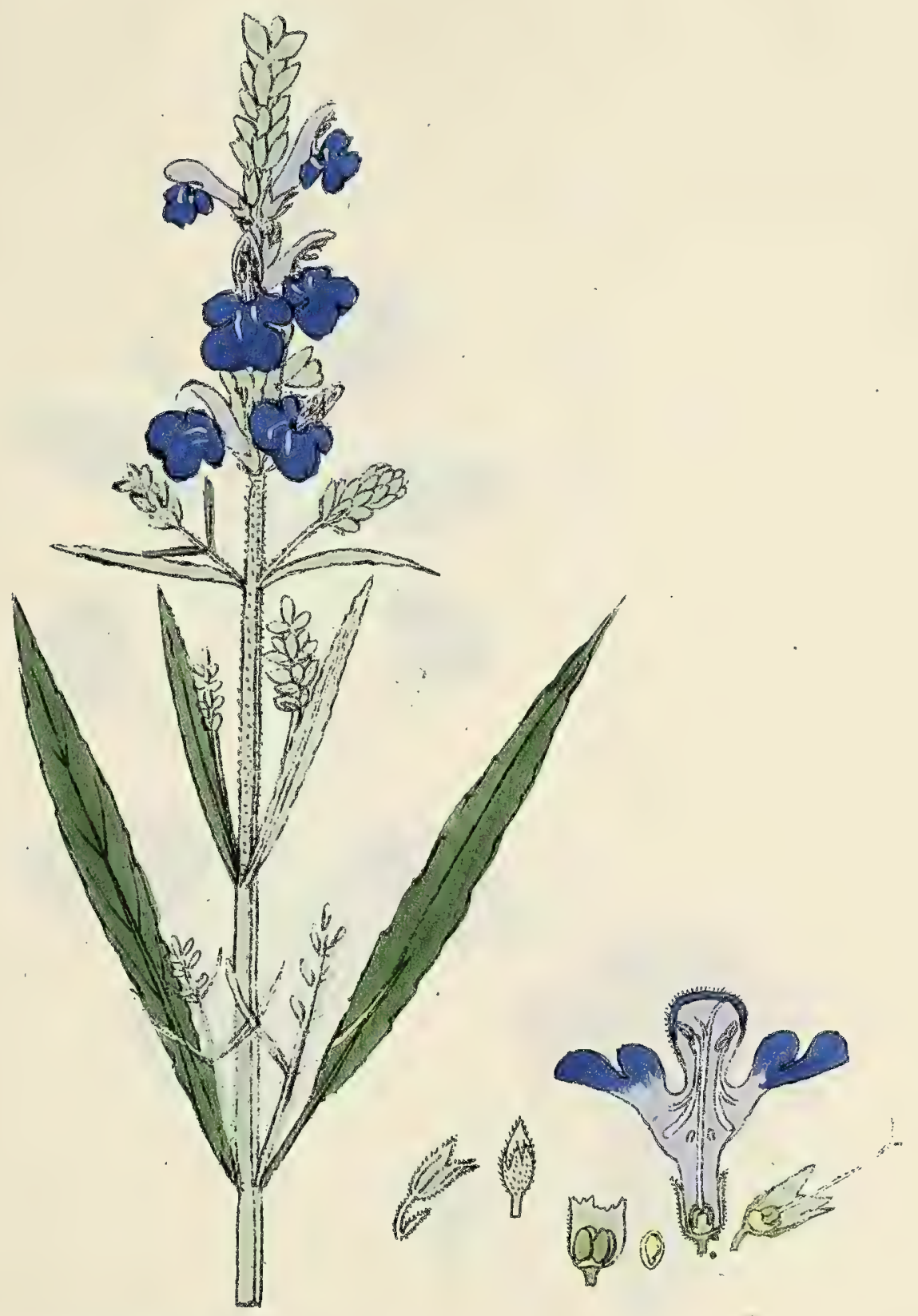

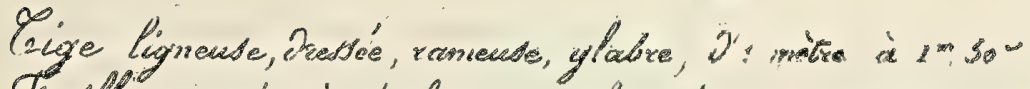

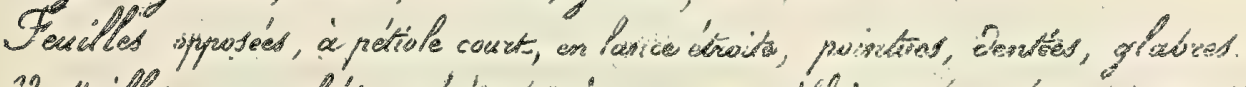

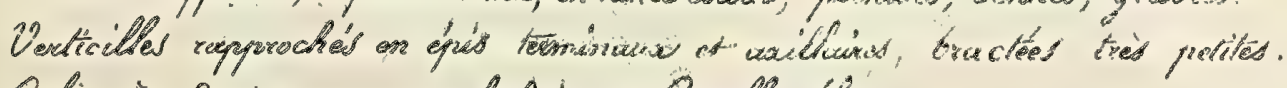

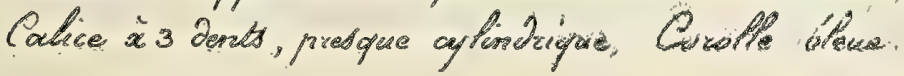

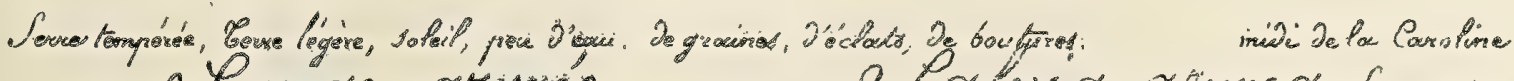

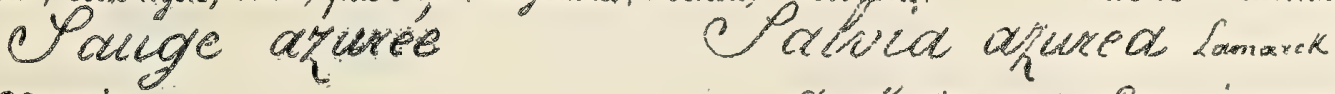
Lith beverilled $x$ ats areis of

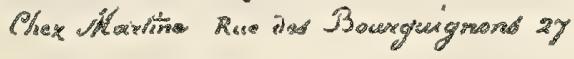



Recine uivace camsede

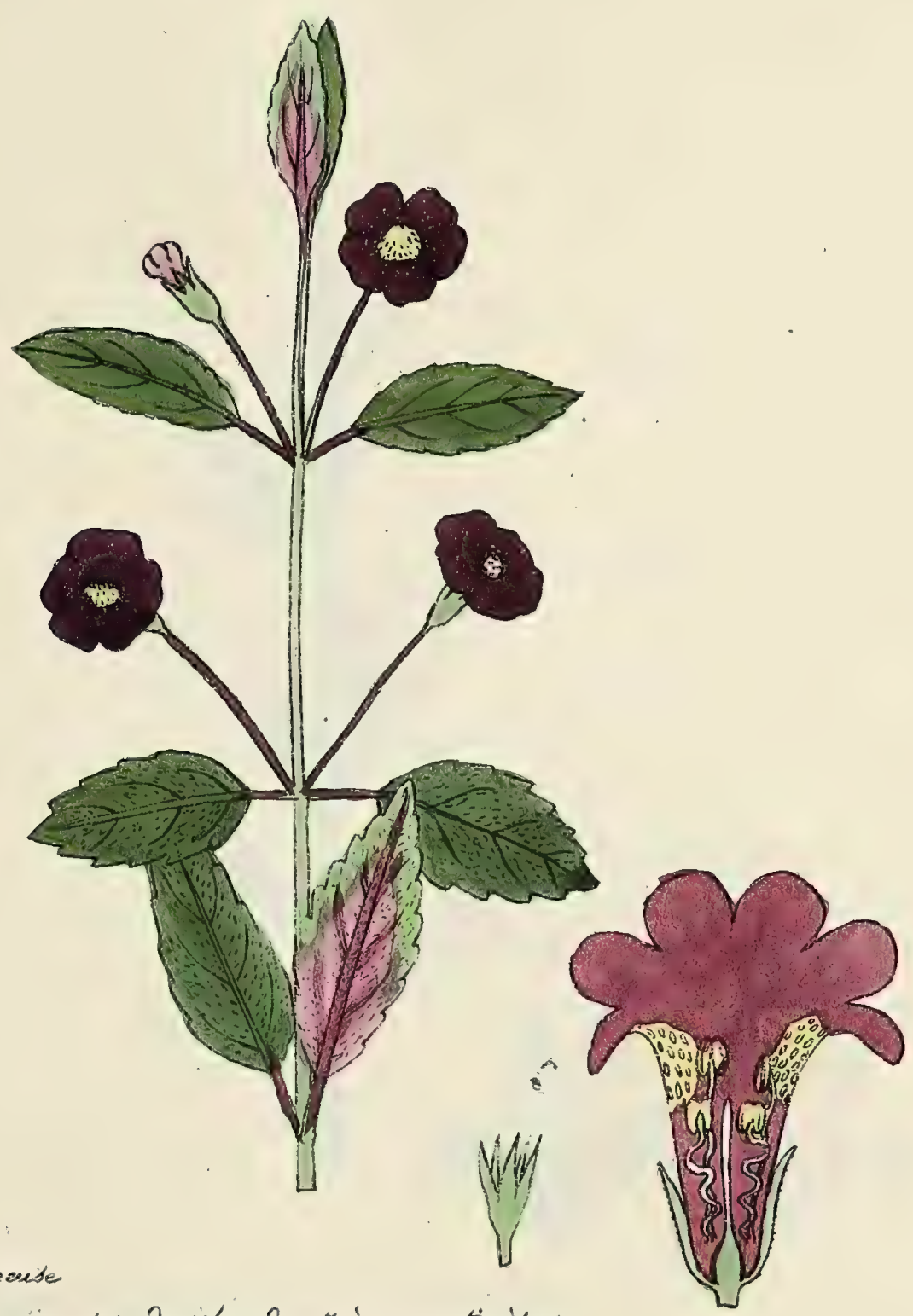

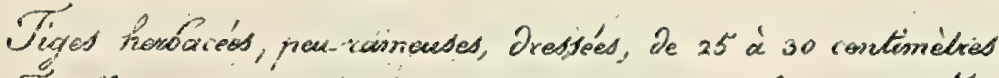

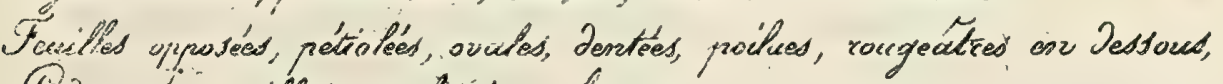

Tedoncutes axillaives, solitaires, longs

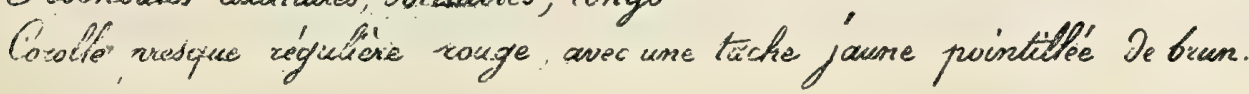

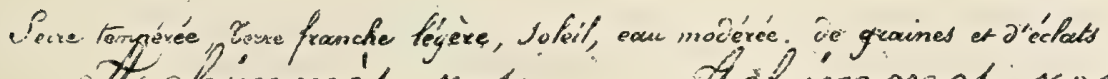

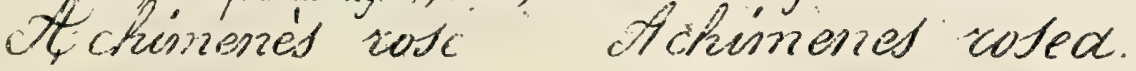

fitt iesasillar Ros axcis'?

Cher Chauviève Rue De Pa Roquatter 104 



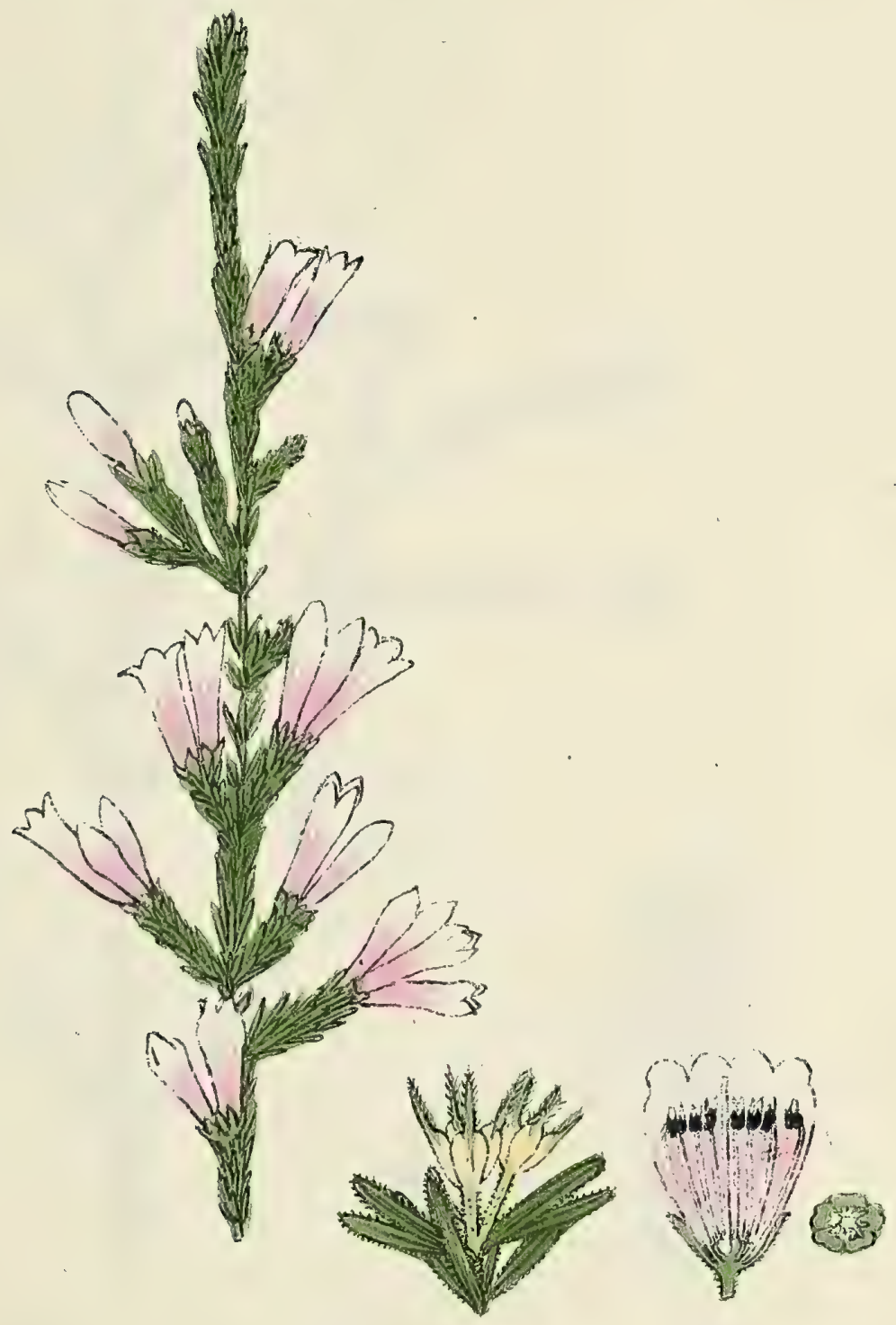

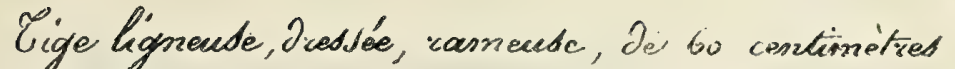

Fevilles 4 par.4, coyprwchées, limécirres, velies.

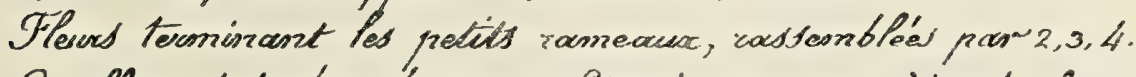

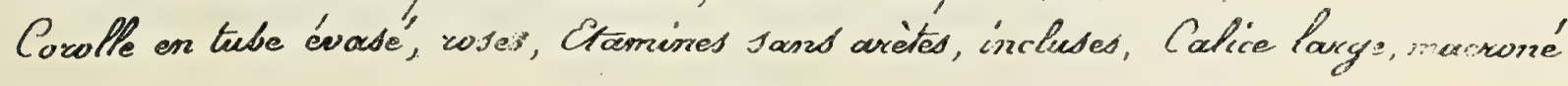

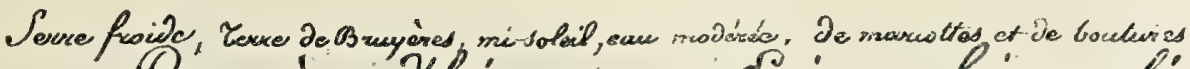
Sruyere Jhives". Bica hionalis

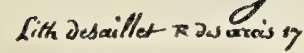

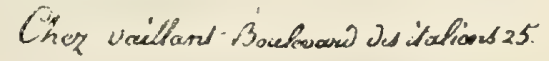


.

\section{•.}




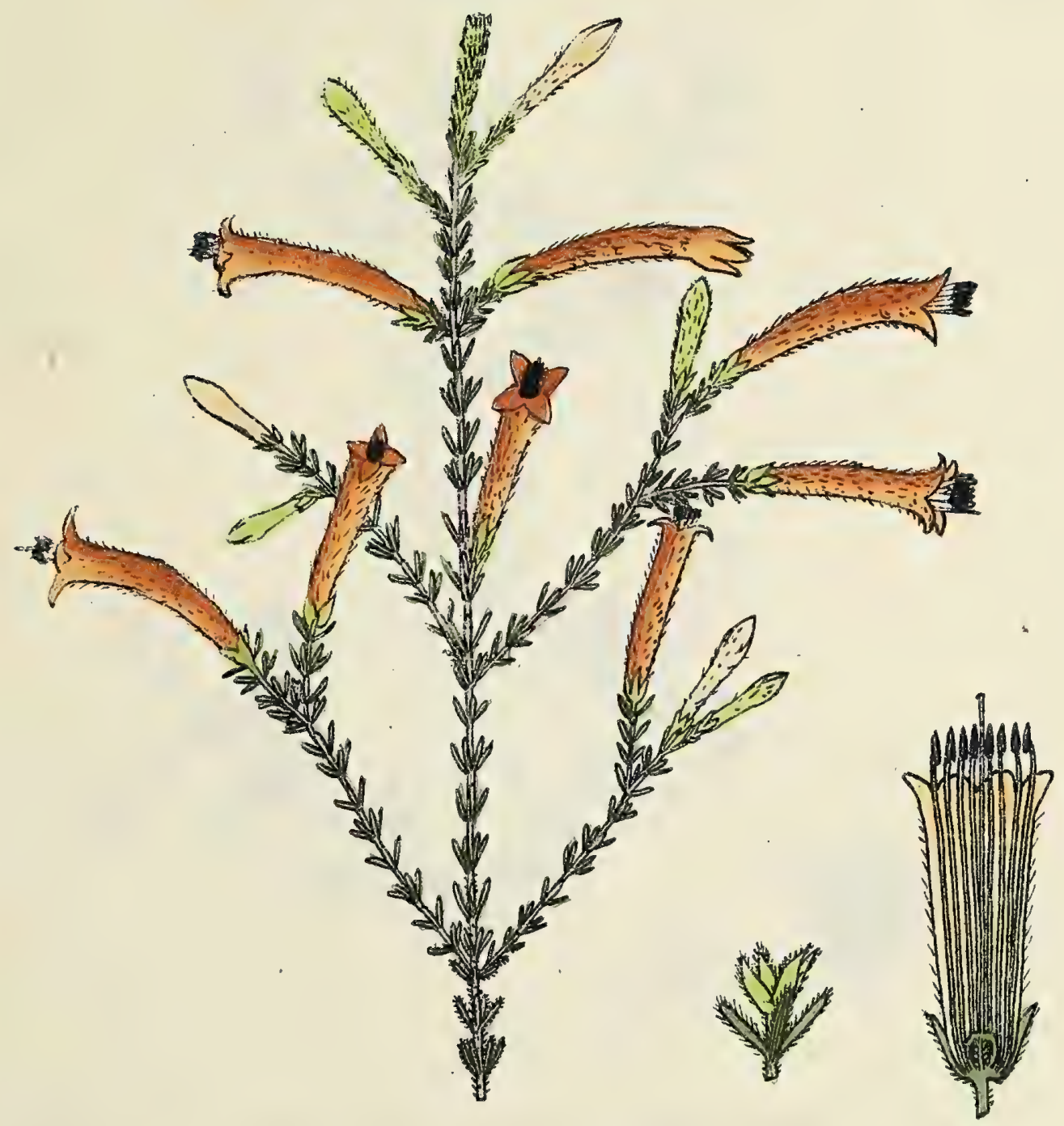

Tige lignense Jrestée ramende velue

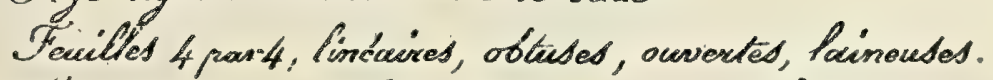

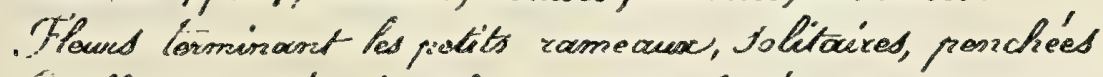

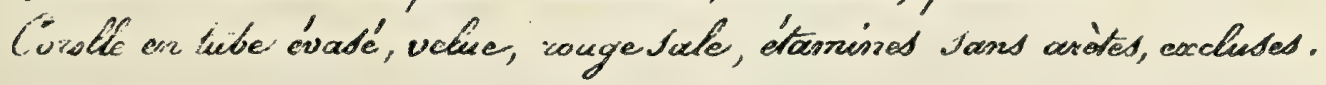

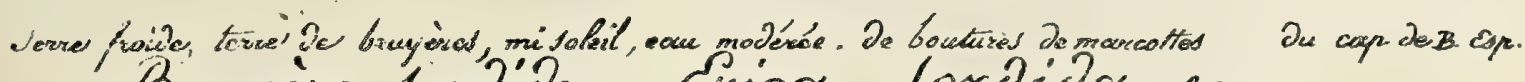
Bruyoure Jordide. Cuica Jordida indrens.

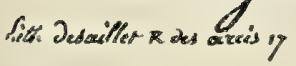
Cher martine Rue dis bourguighnoms 27 



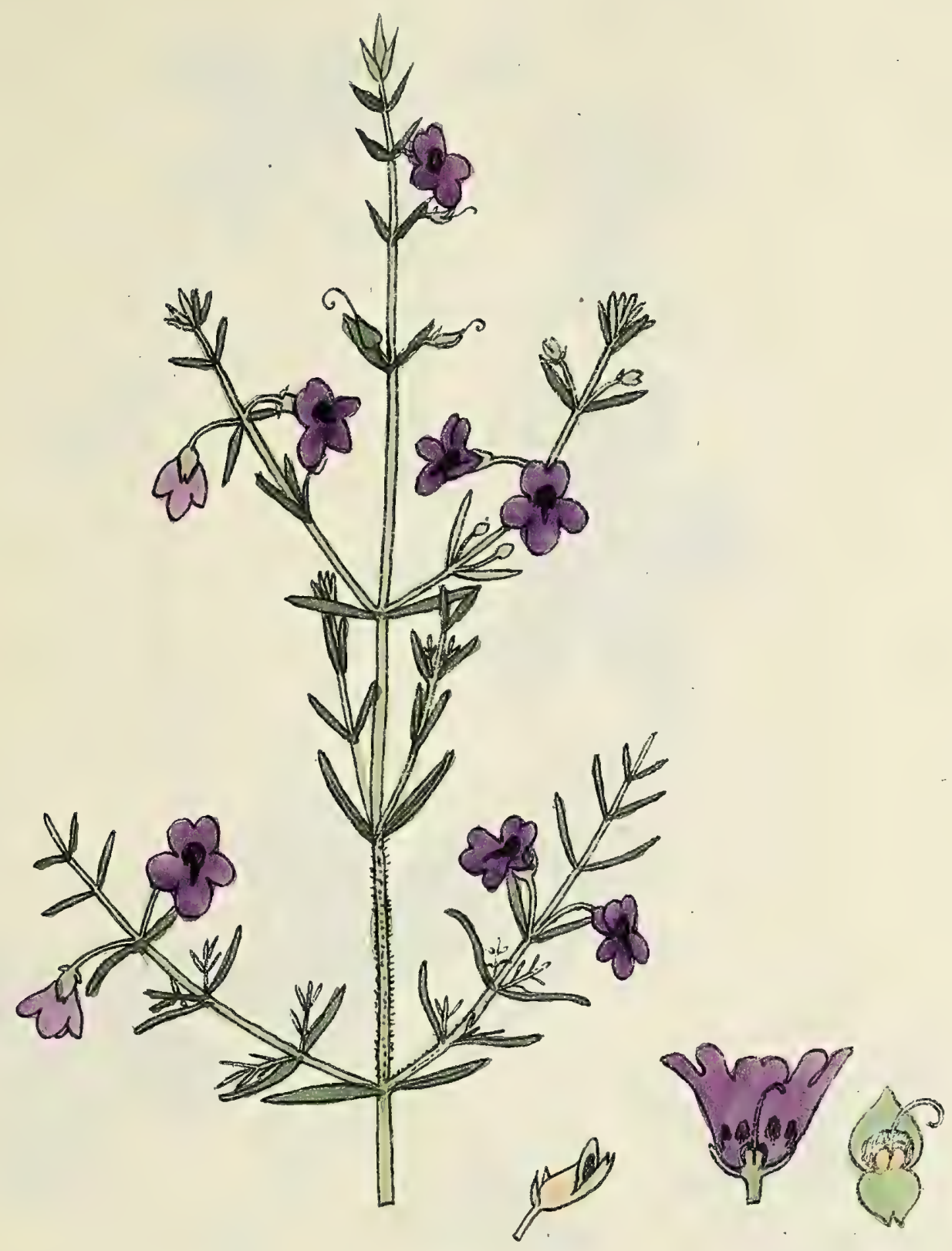

Gige lignente à la babe, Dredsée, ramente, s̀peine puiluer Feuilles opposées, Sossiles, linéaires, pwintues, glabres gedoncules axillaires, solitaires, simples, long's Flewes vislotes

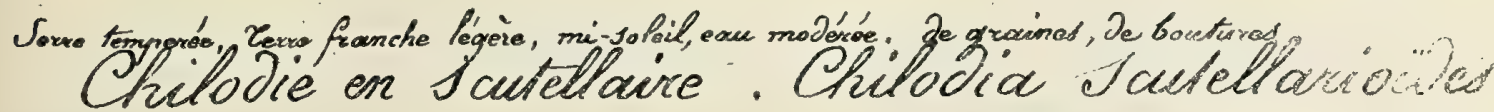

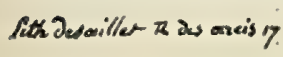
Chor les frères Sels cinususée an macize ? 

160

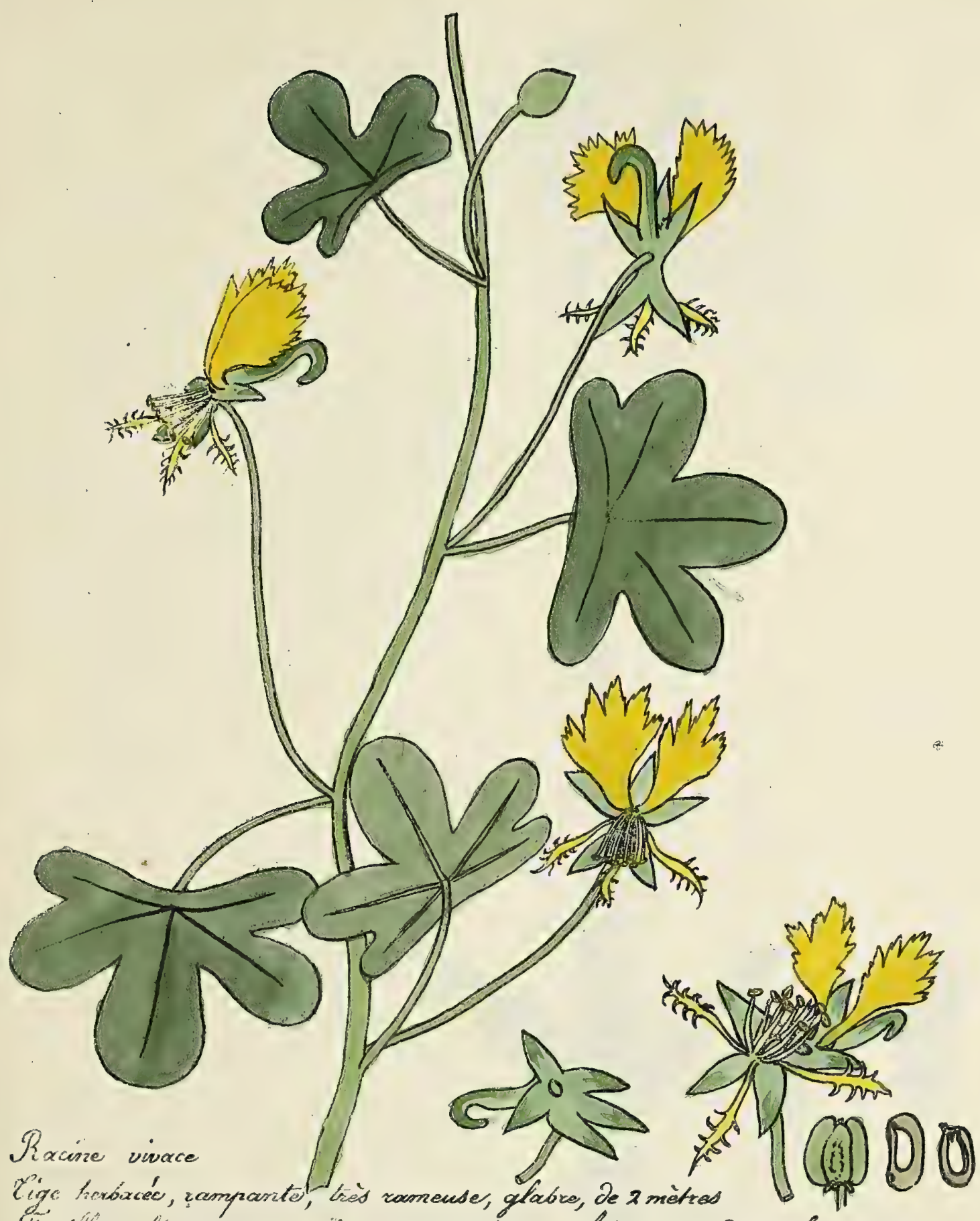

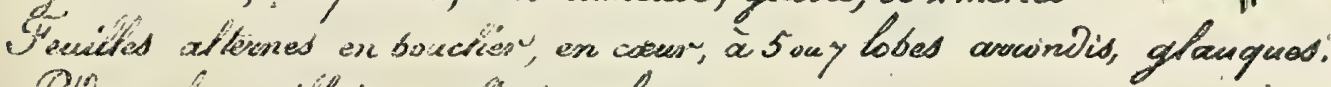

Pinoncules axillaizes, solitaires longs

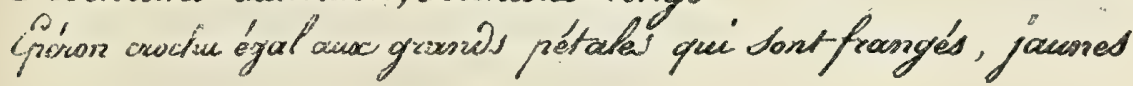

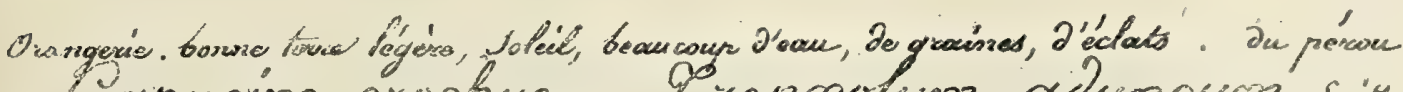

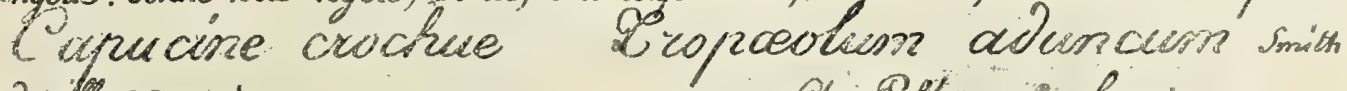

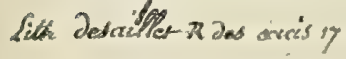

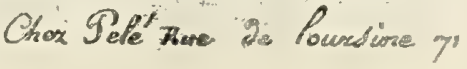



168

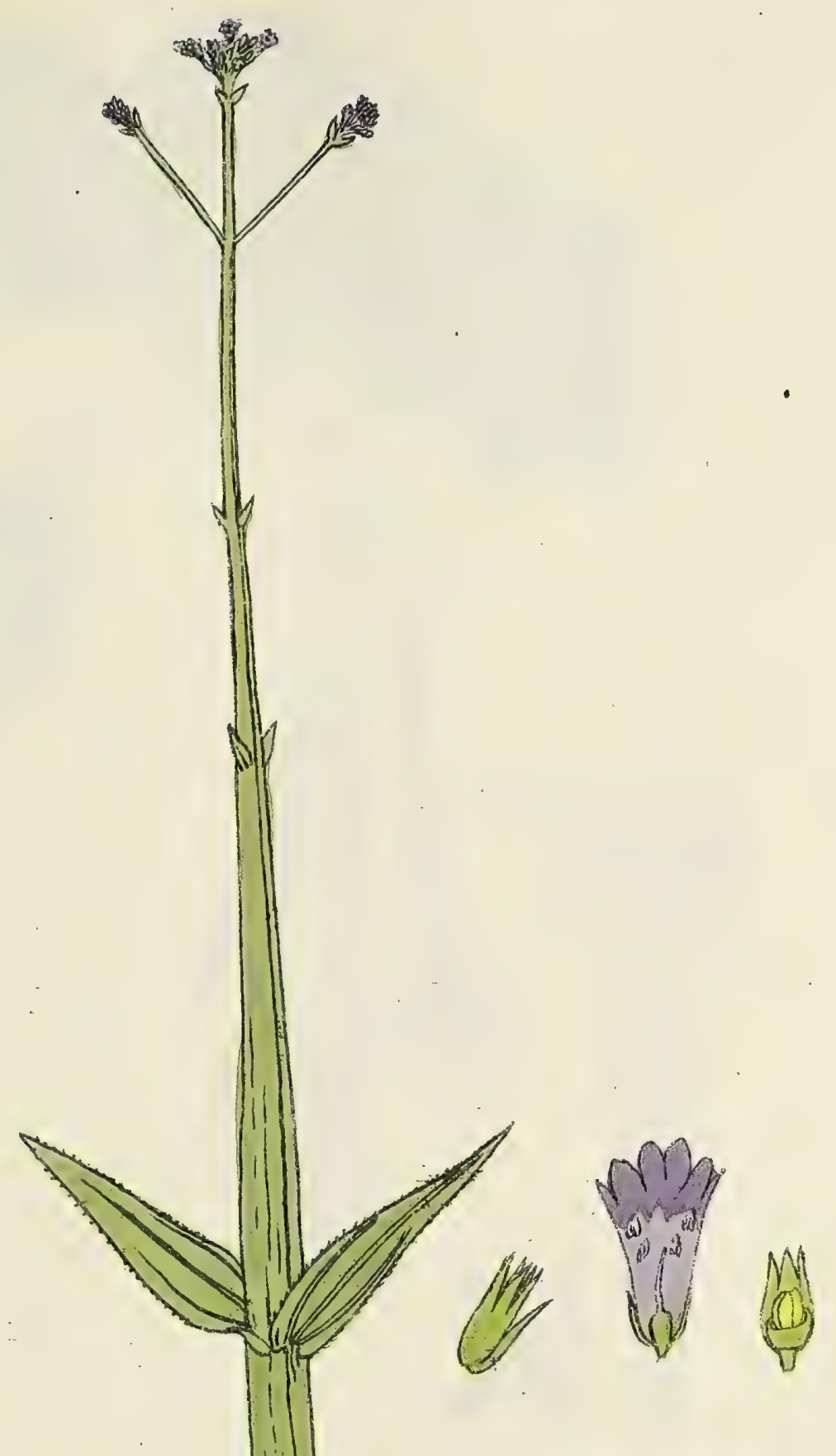

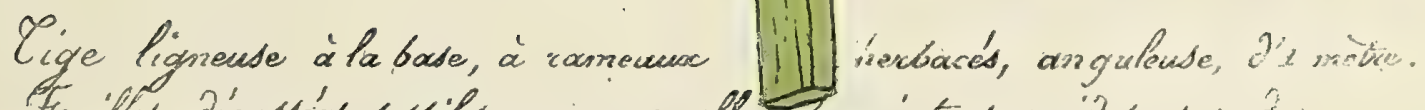

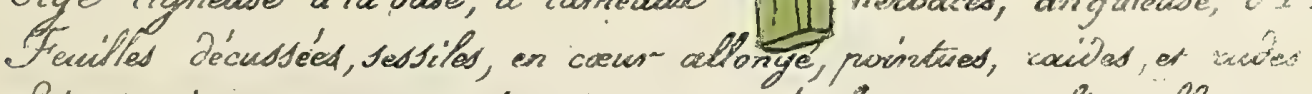

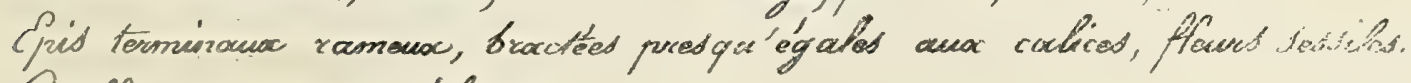
Porolles tres potites. viólettes

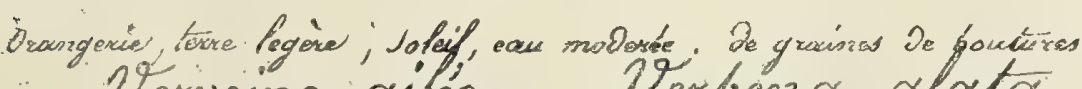

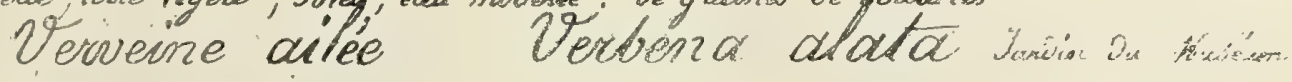
Lith Dedoittor $R$ as acreis 'y 


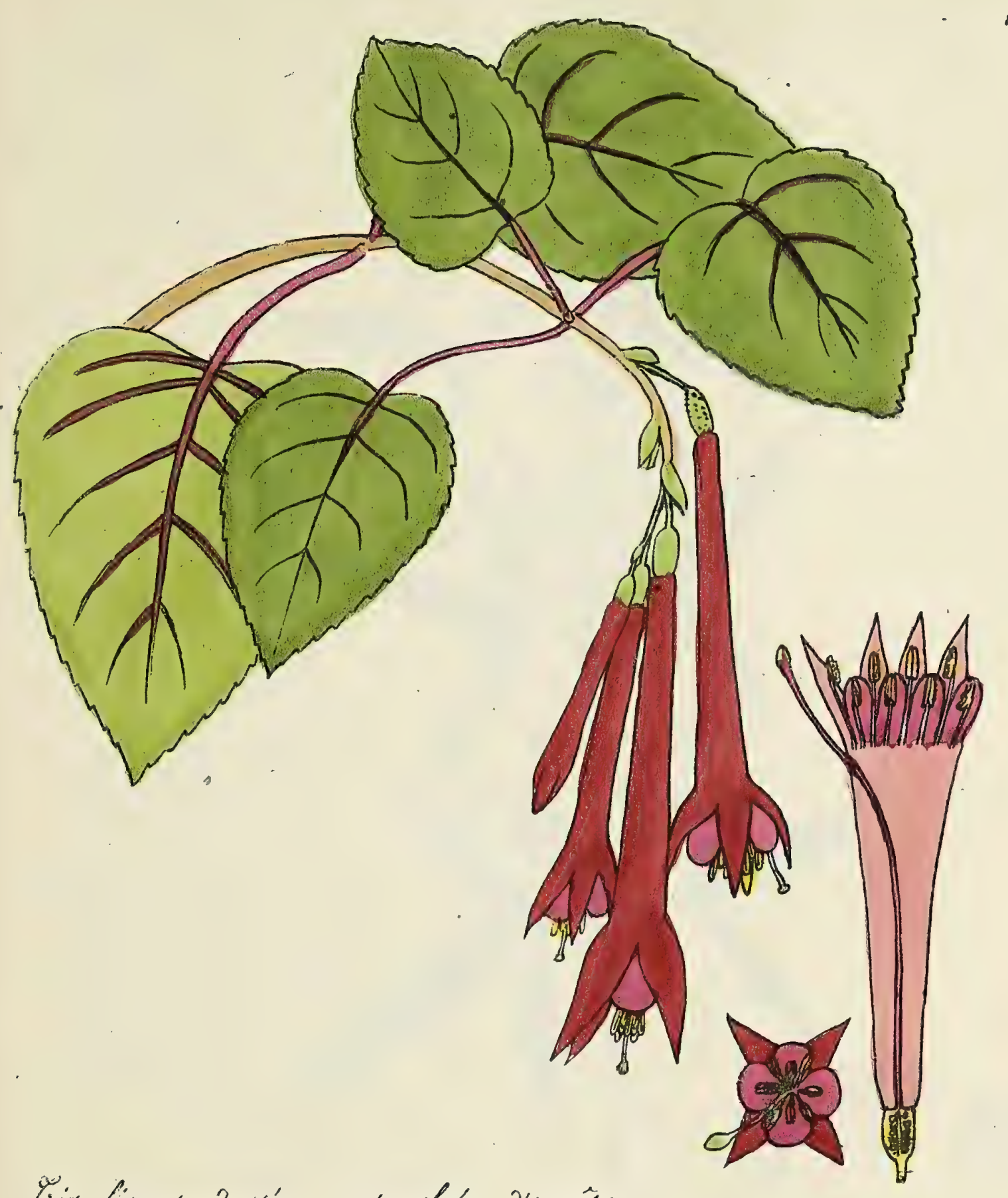

102

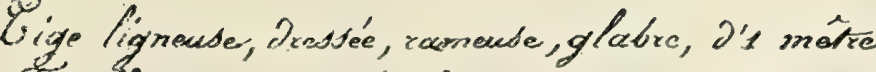

Feuilles 3 par.3, pétiolées, en coour, Dositéd, glabres.

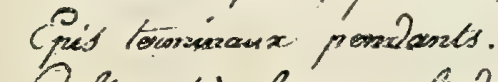

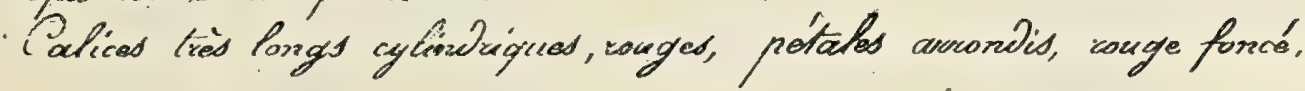

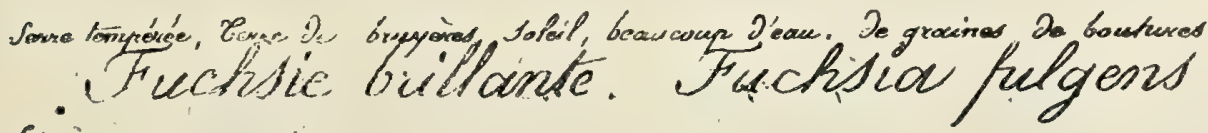





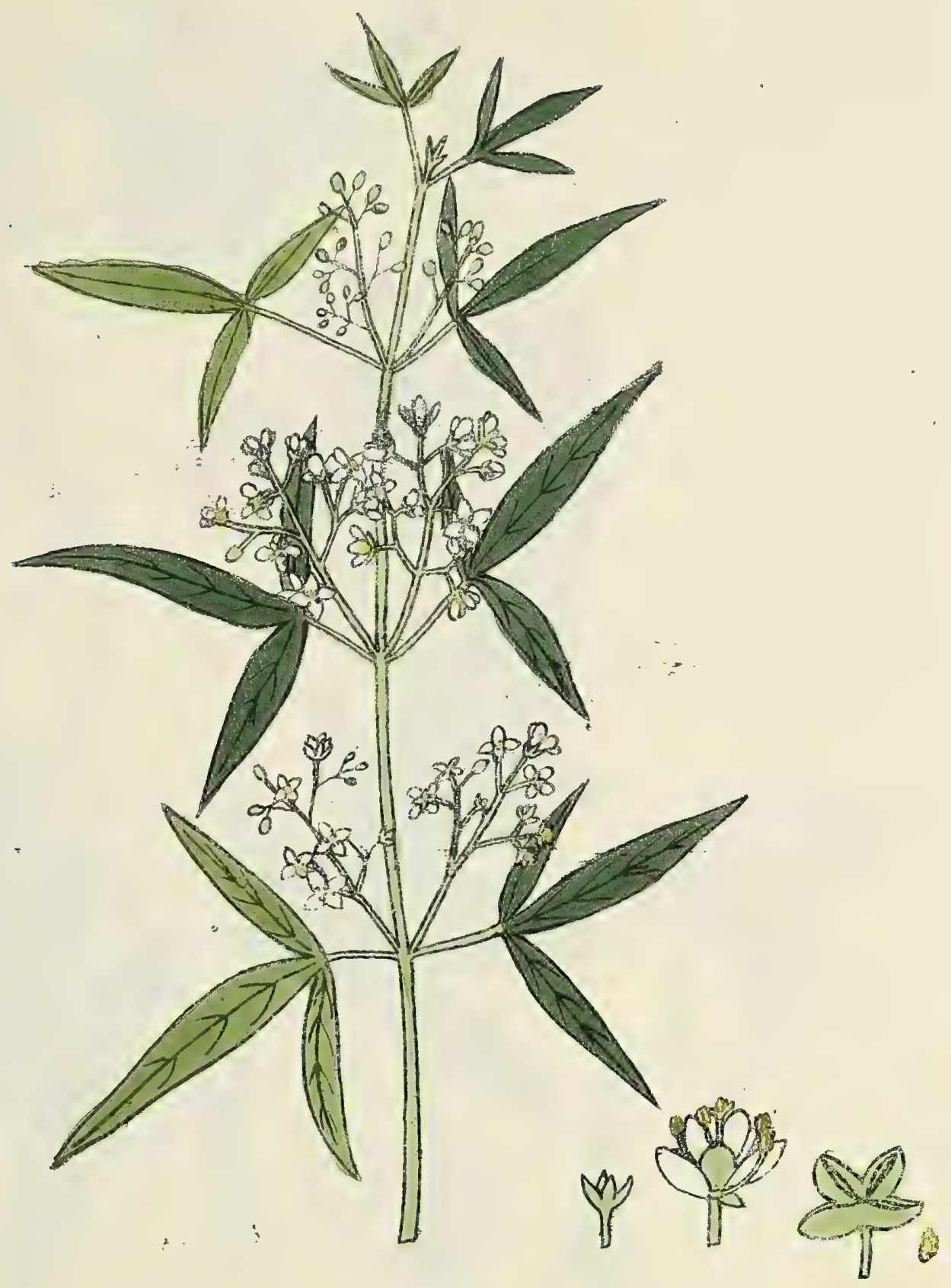

Gige lignouide, Jressee, cormende, J'1 metre

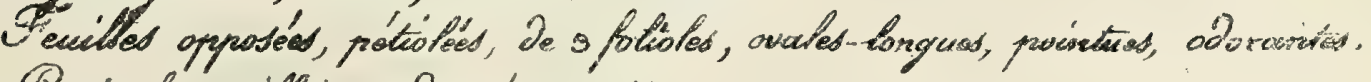
Pansicules axiltaired, Drestéed, pitites

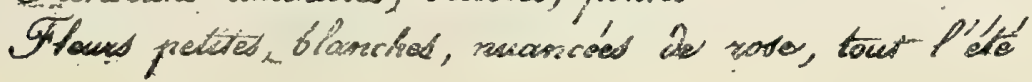

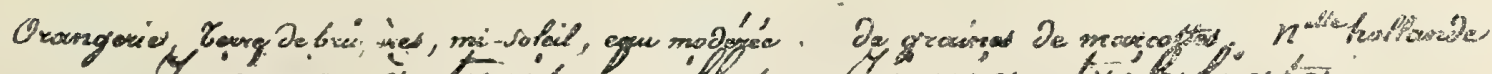

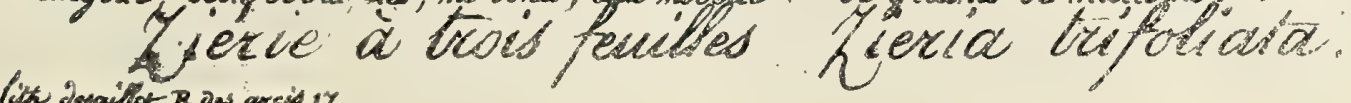





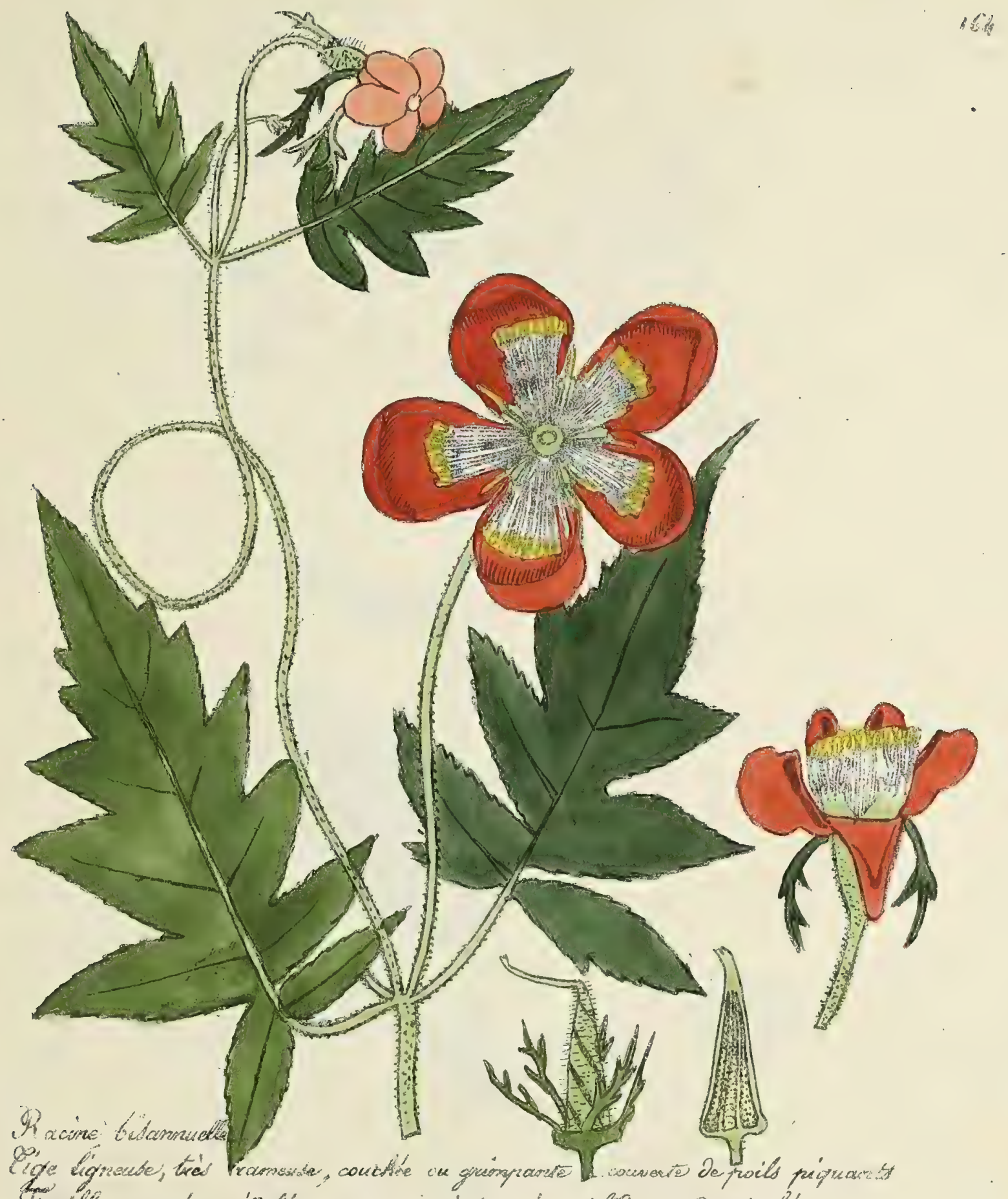

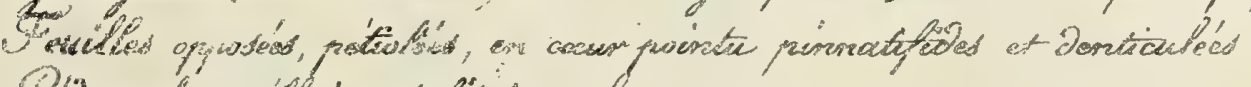

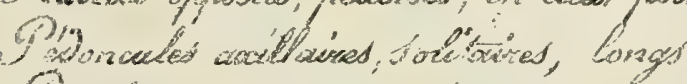

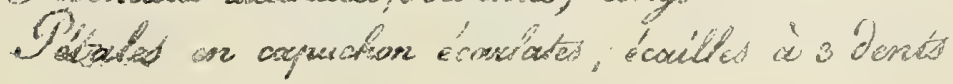

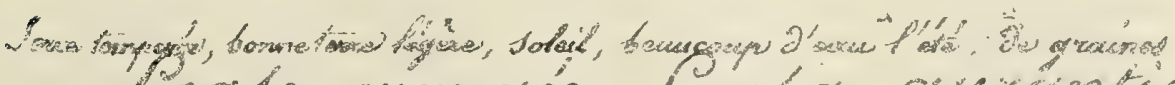

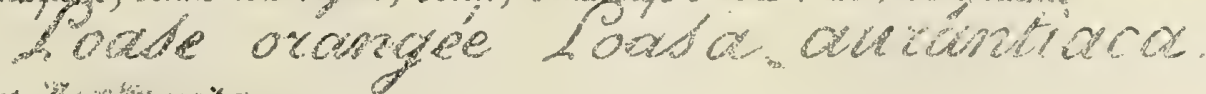

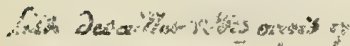





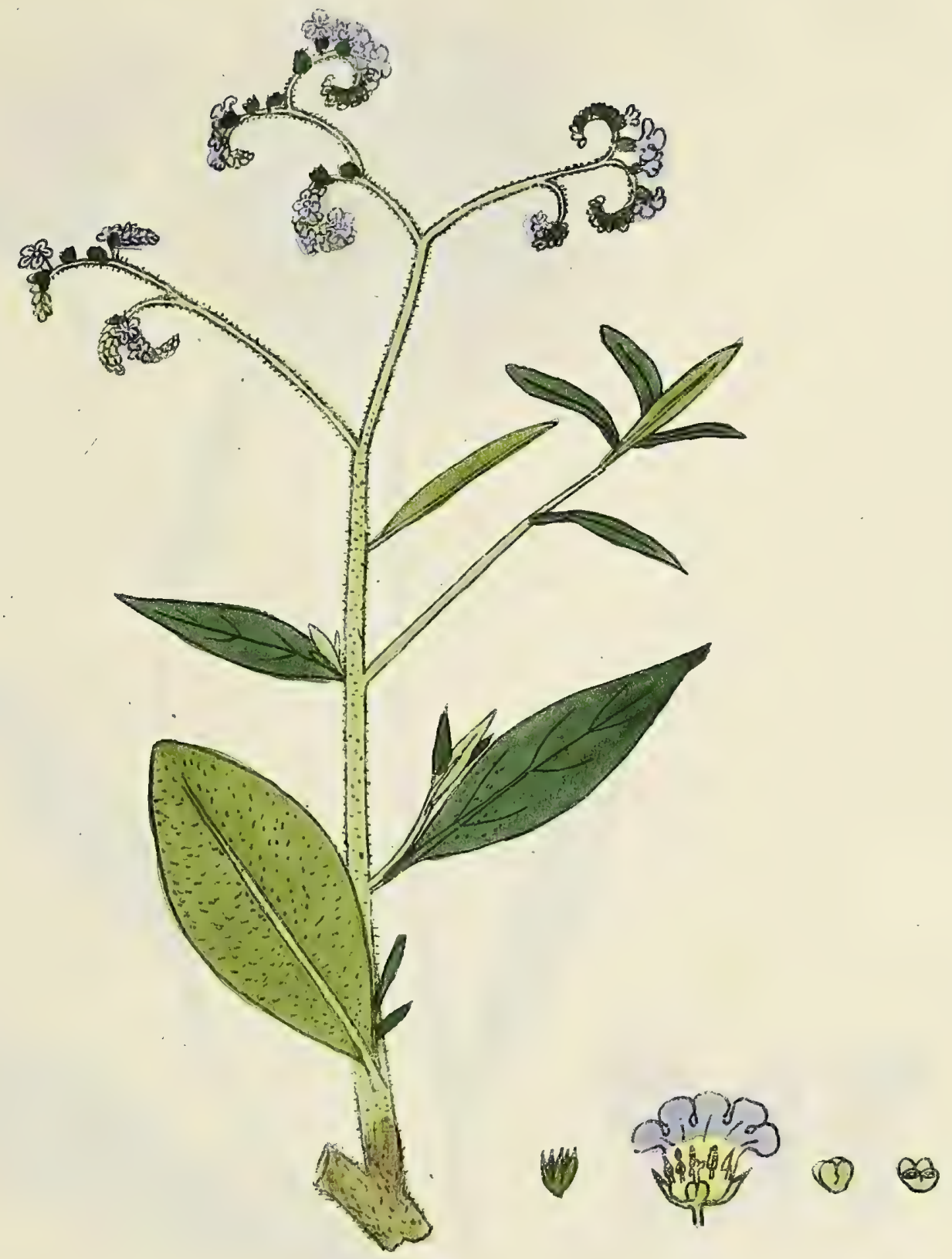

Tige ligneuse ramense uno prow Diffruse J't mètre, velue

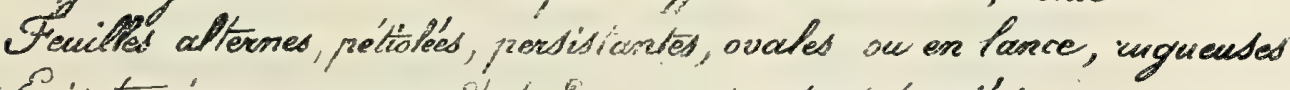

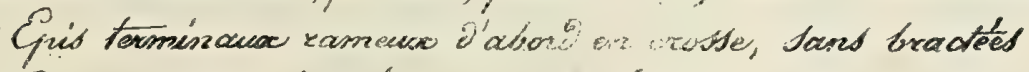

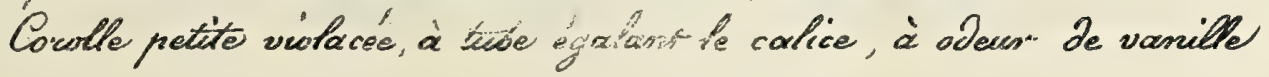

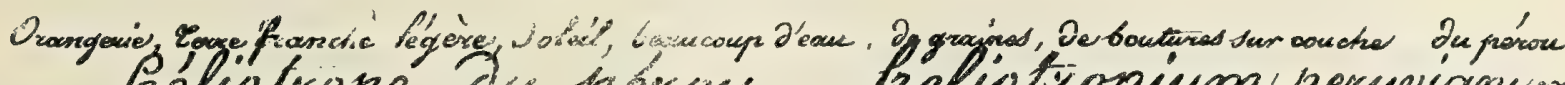
Réliobupe du pérver heliotíopium persuvianum Sith Desaifler a des arcis oy 


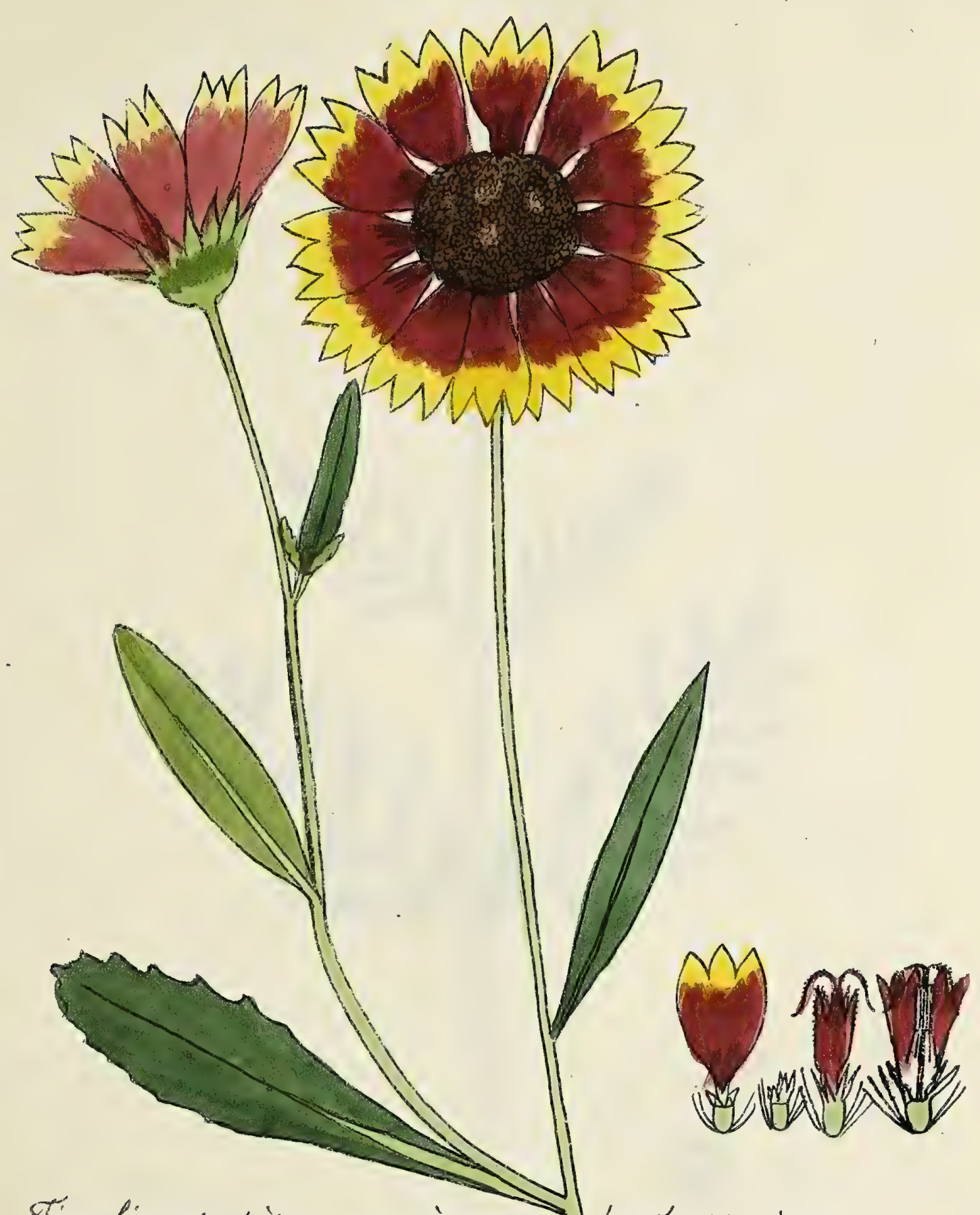

Tige fincude, très ramoude, à ramcaux écoutés, J's mètre

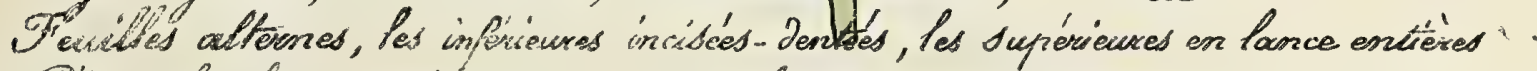

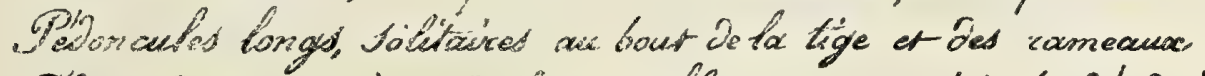

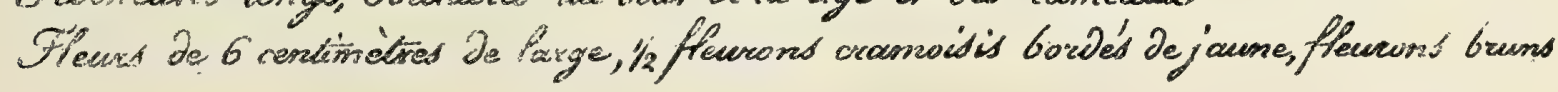

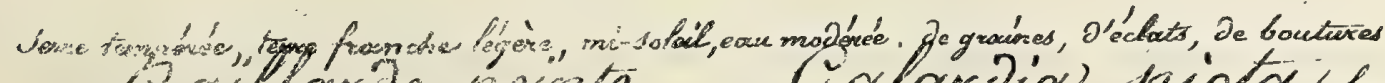

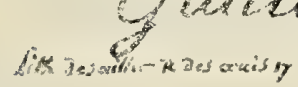
yolardial fuicta hortus promis. 



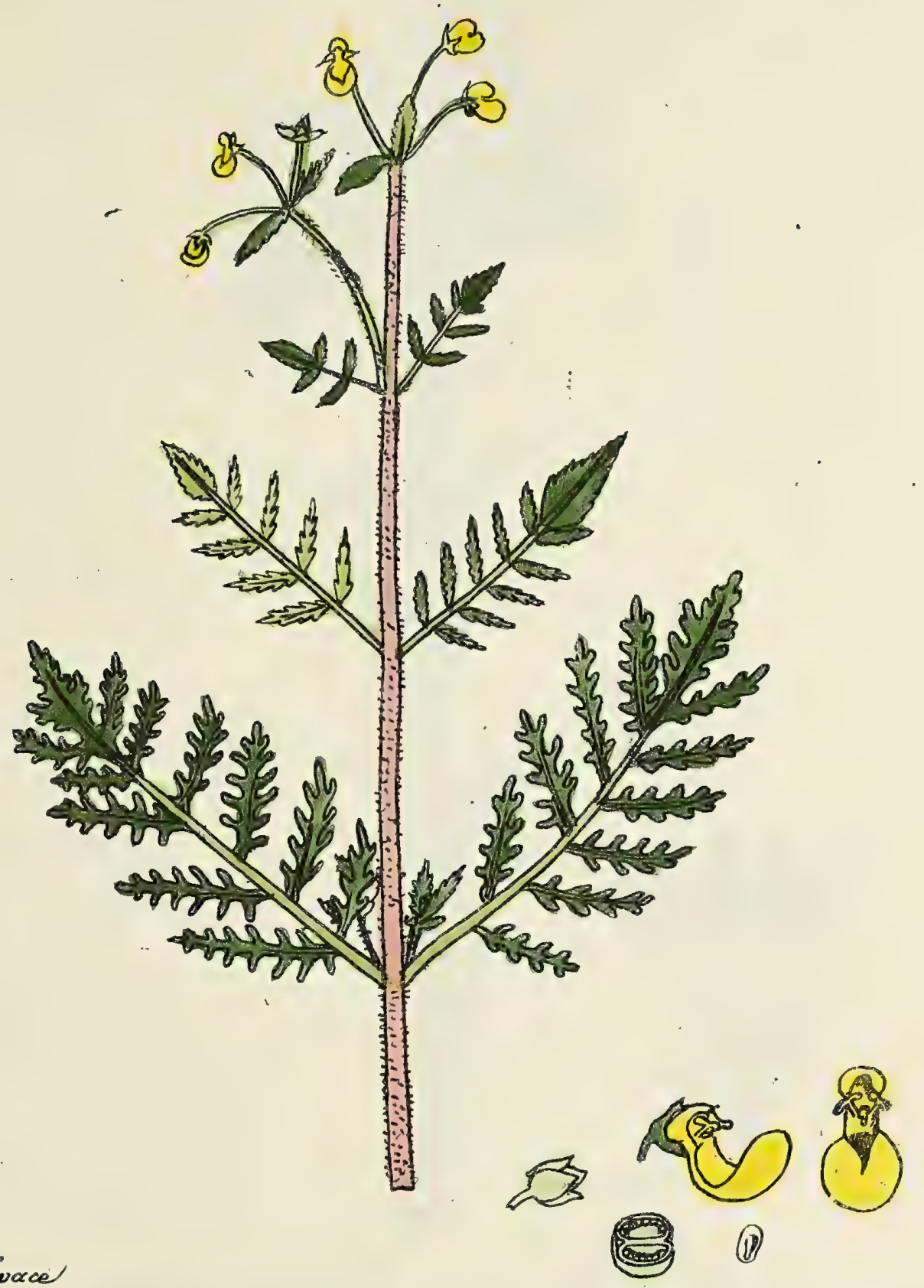

Racine viwace

Tiqe herbacié, Drestée, rameude, velwe, vidqueude

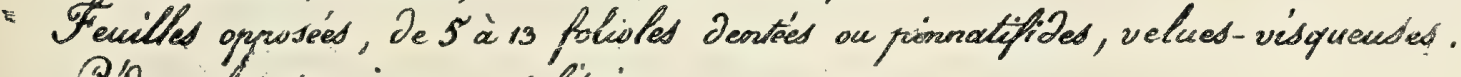
Pivonculed teminaux, Jolitaiced ou pror 2 on 3 Corolles petites à levire supórieure très pretite

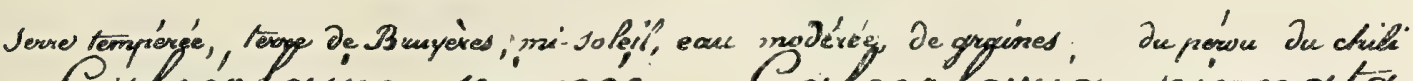

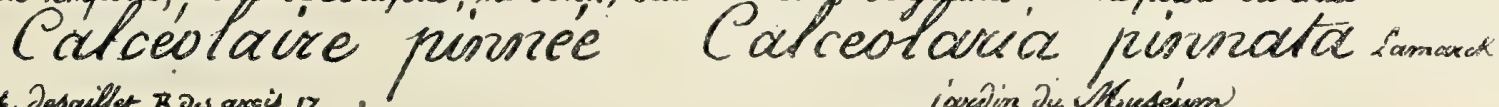

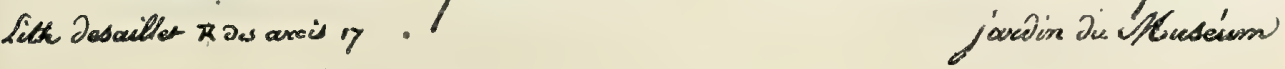



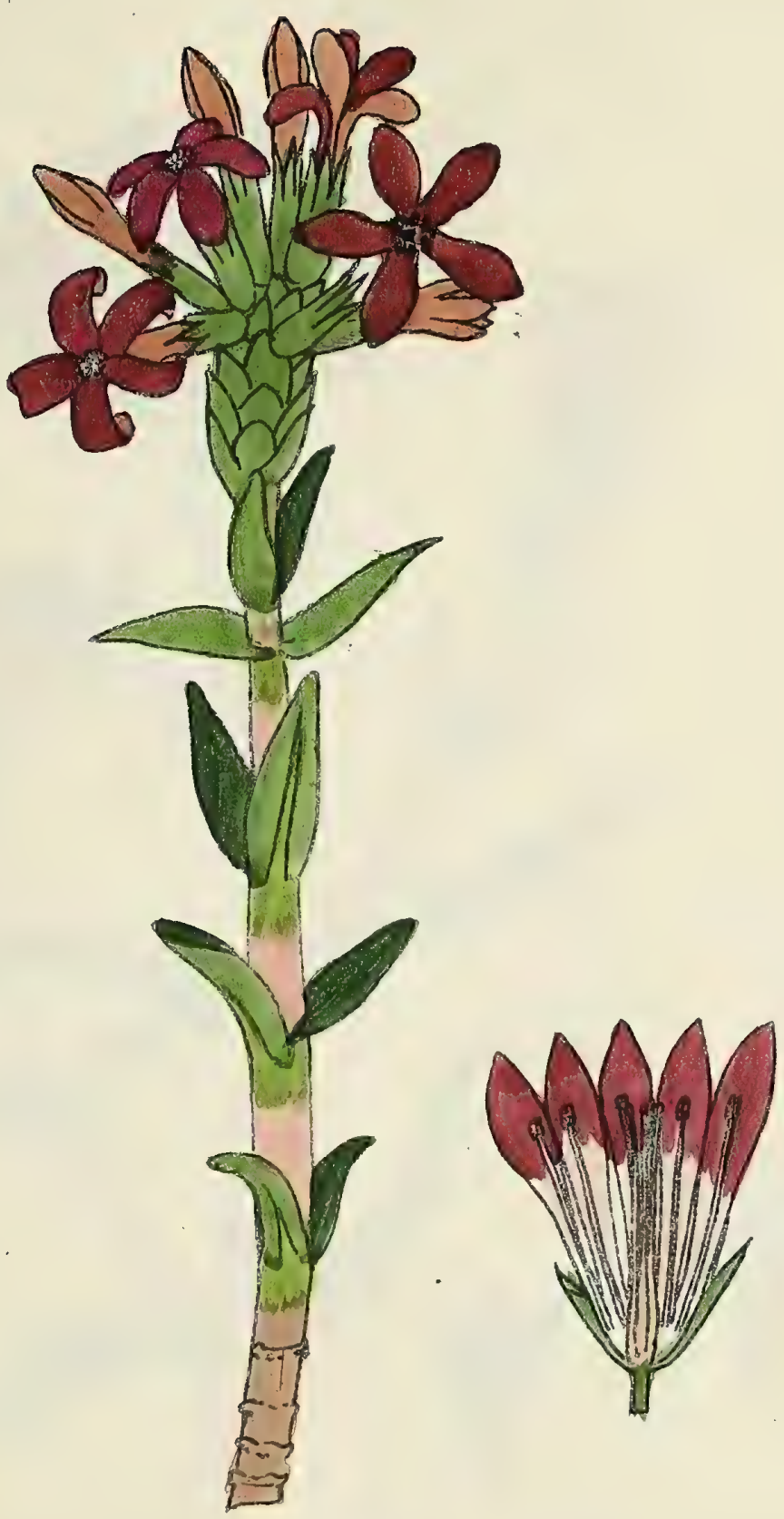

Ciges chansures Dressées vivaces ramented à la bade, 2'i mitre

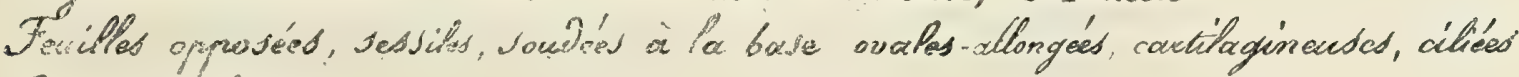

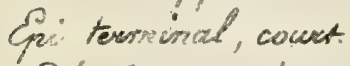

Peíates socidés ens tister écouclates

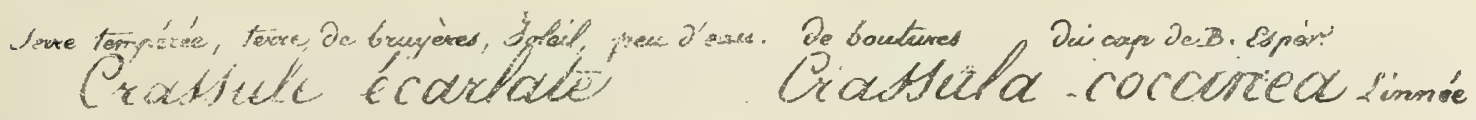
list Desciller 



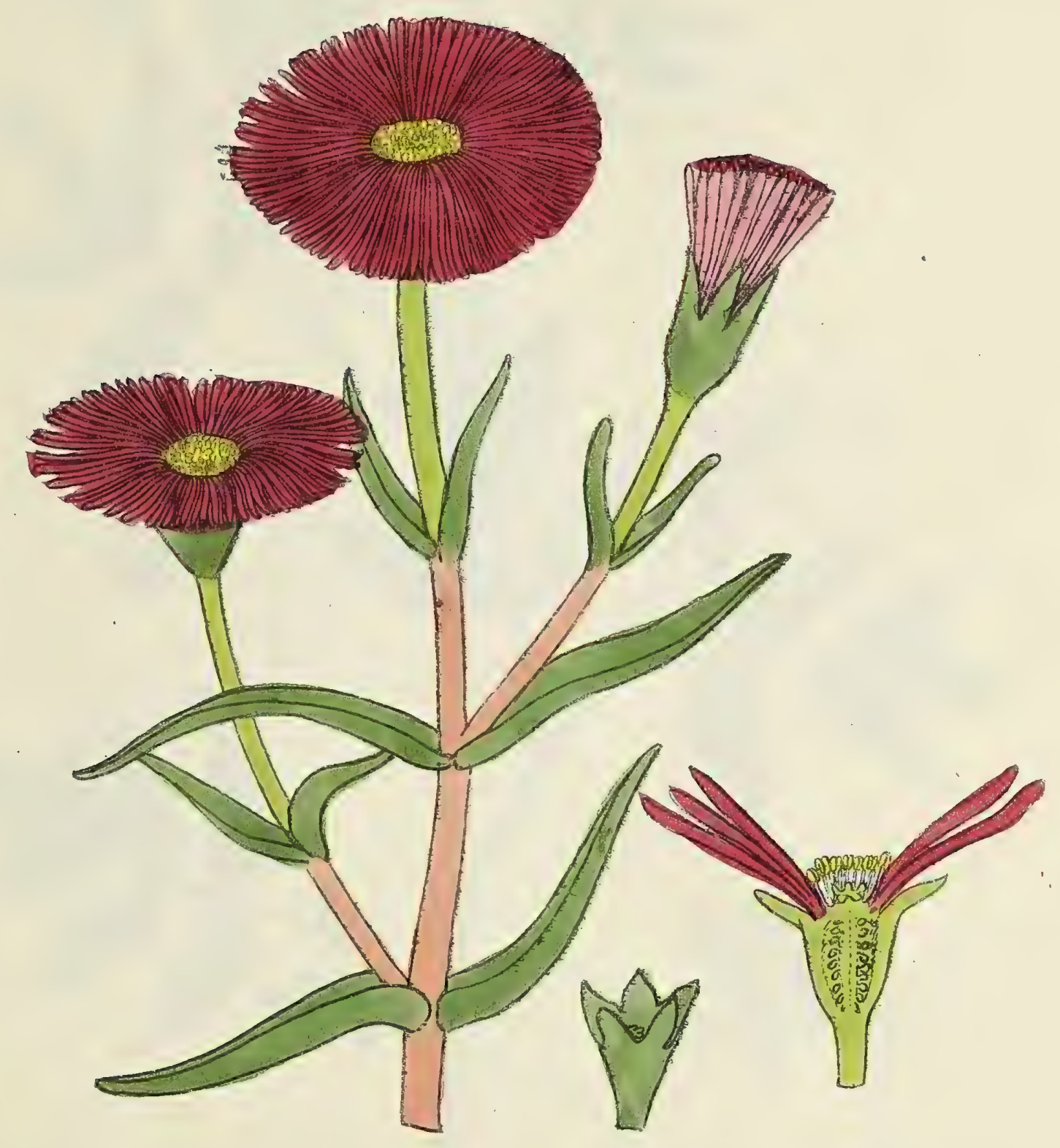

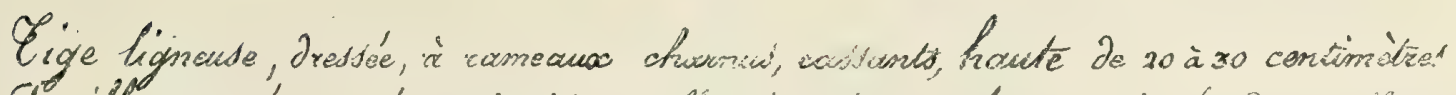

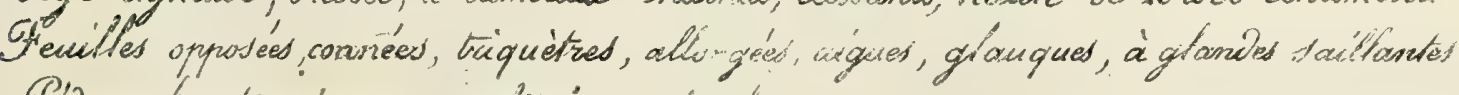
Sedoncules torminaciare, solitaiced, simples Flewed gramies, pétales prowyred.

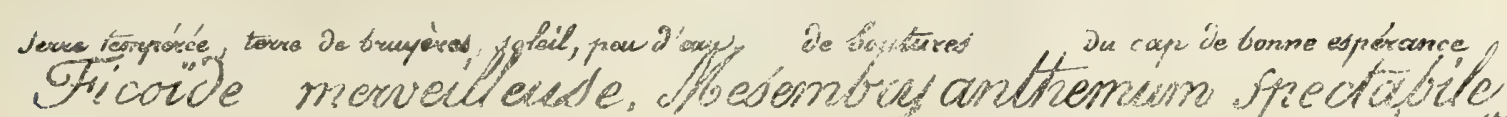

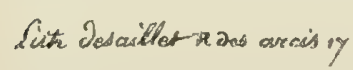




$$
\text { - }
$$




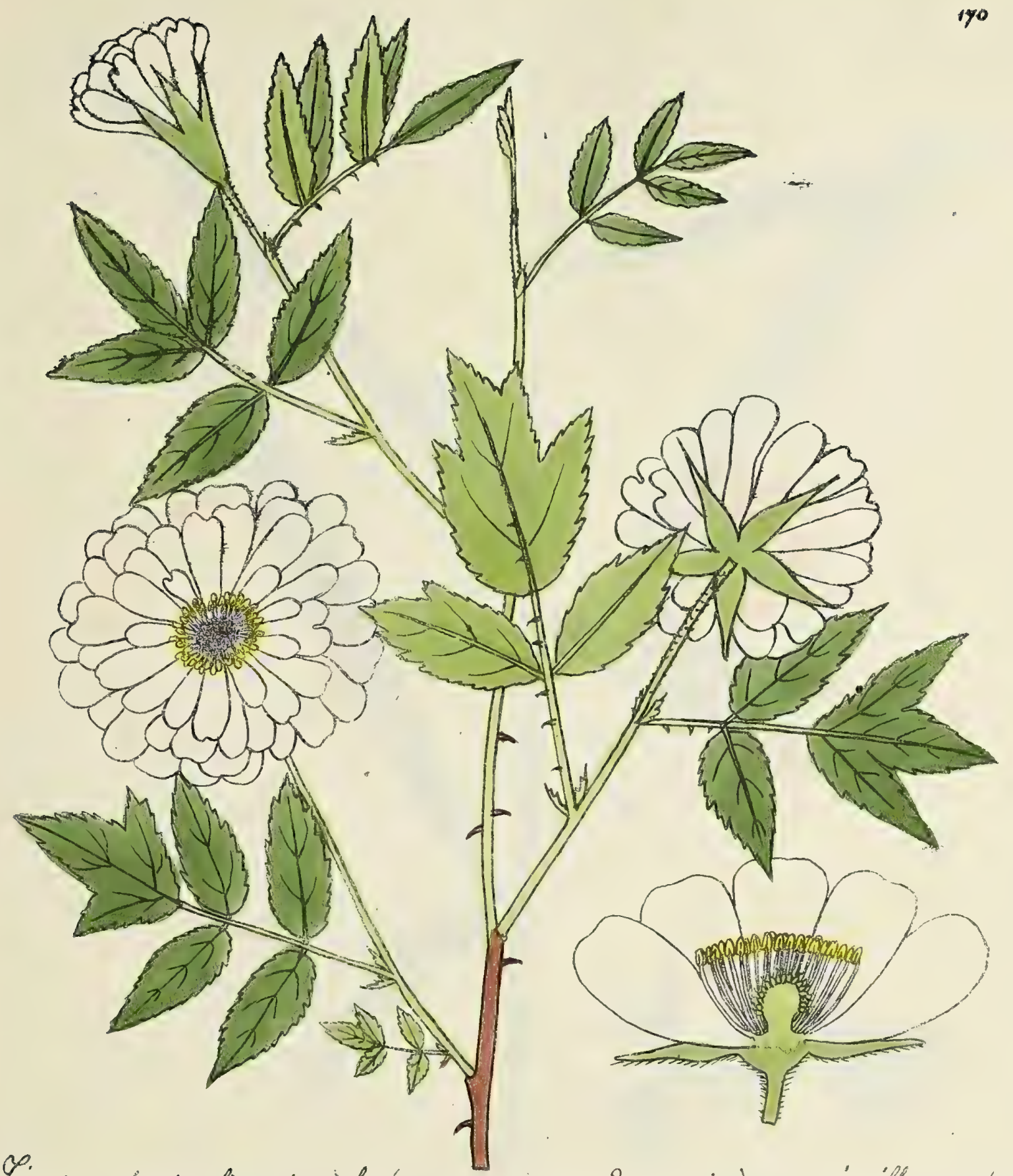

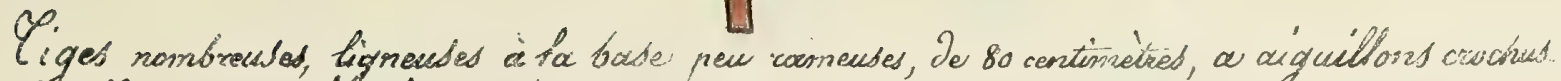

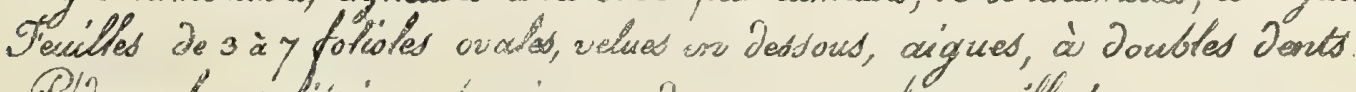
Sevonculer solitaires, ienmant des, ramsuscules ascillaires.

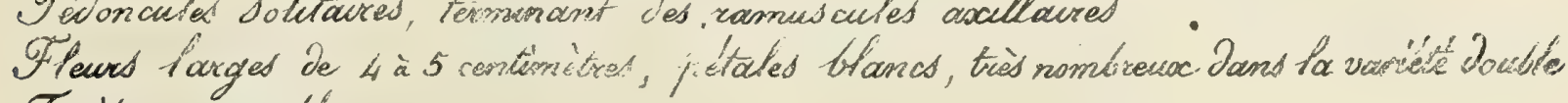
Fruits mangeabies.

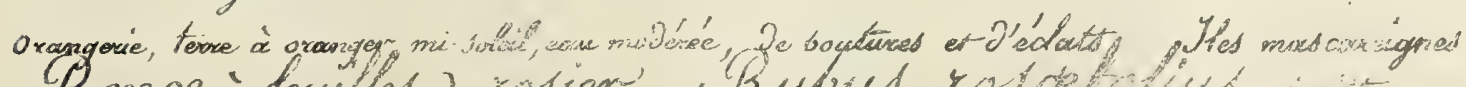

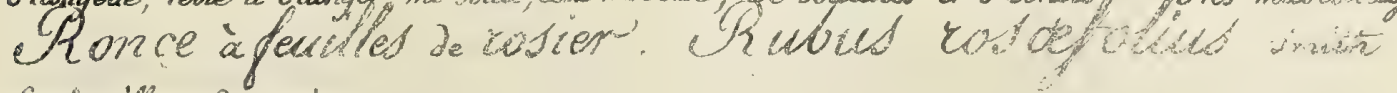
Lith jescisher $\mathrm{x}$ des axcis on 


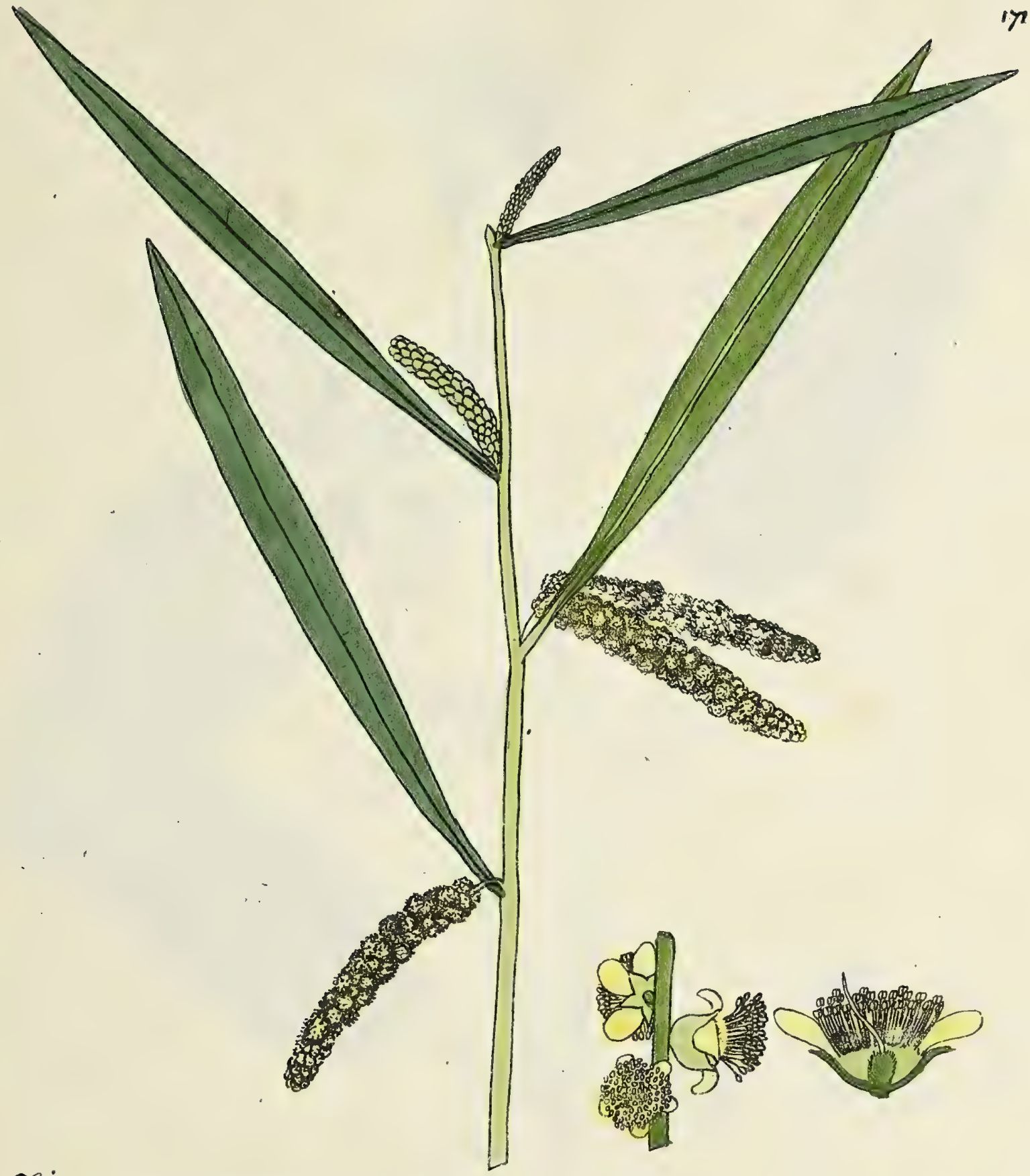

Eige ligneuse, Jressée, ramende, glabre de 4 à 5 mitres

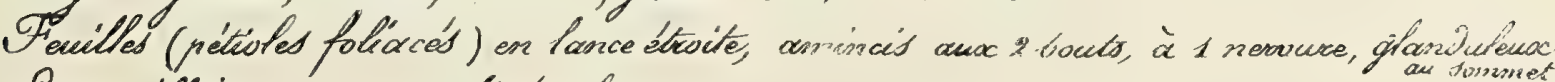
chis axillaires socwent binés, longs.

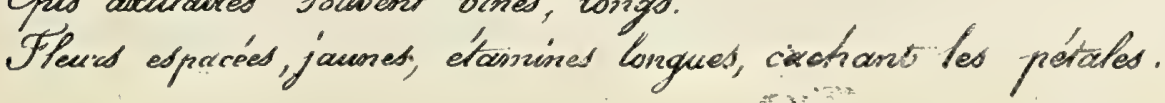

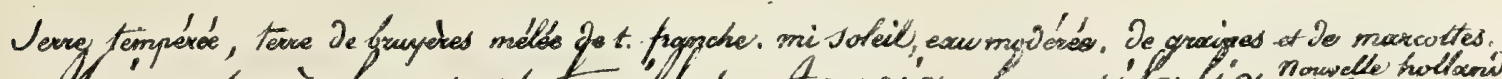

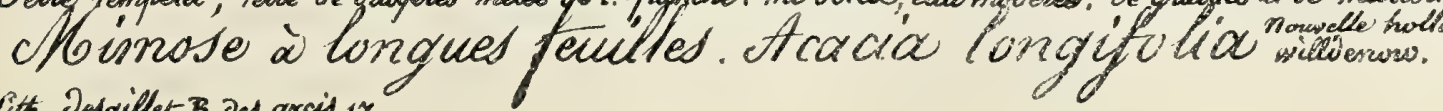
lith Duscilter-R aes axcis ry 



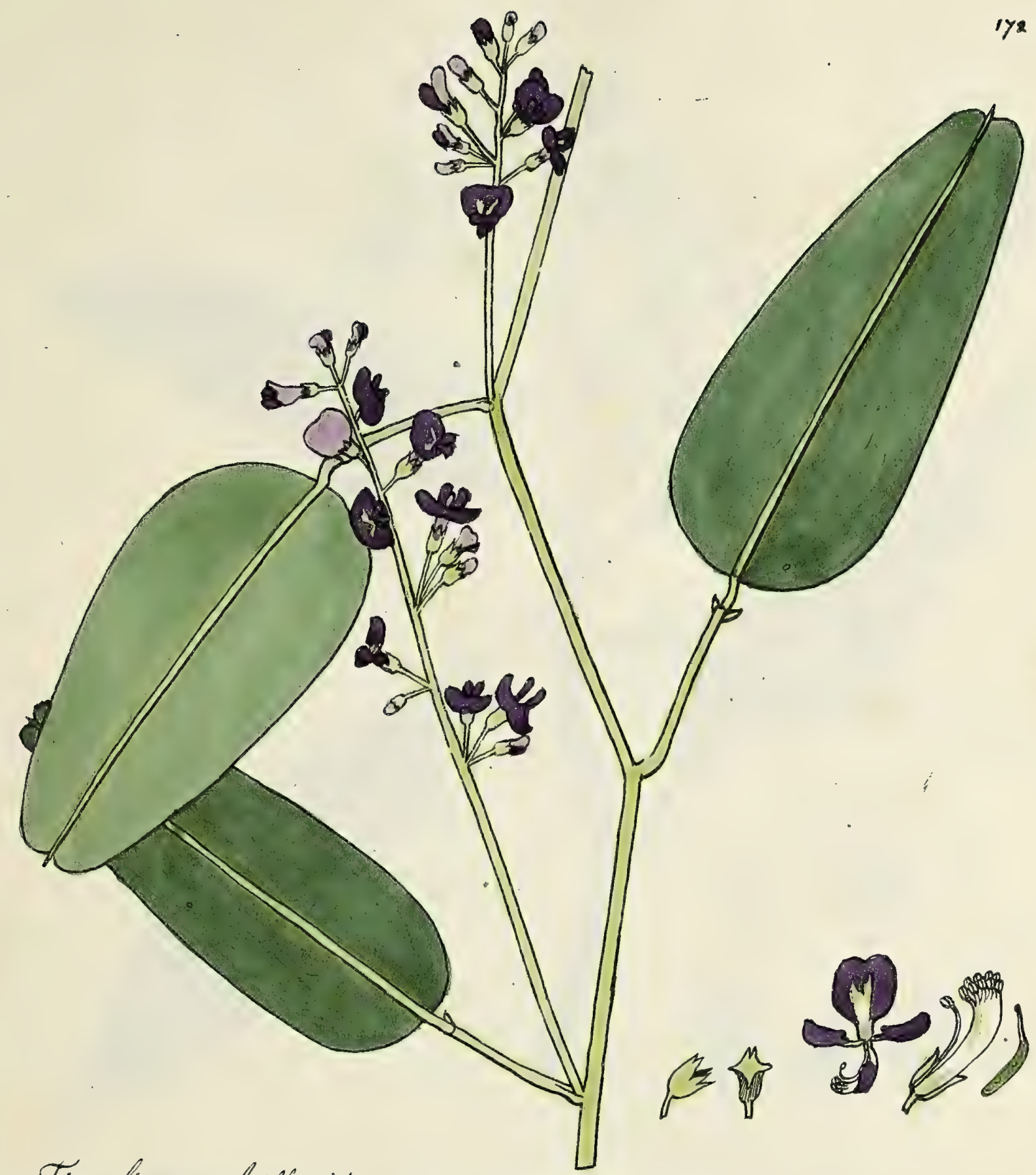

Tige lignease, faible, grimpunte, ramende, de 2 '̀ 3 métres.

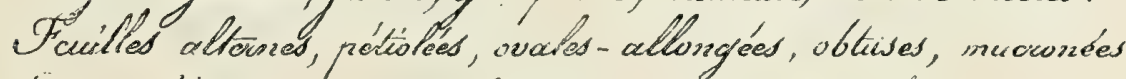

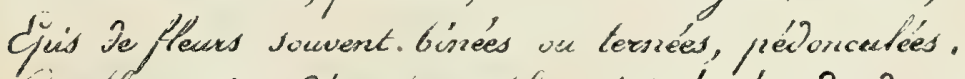

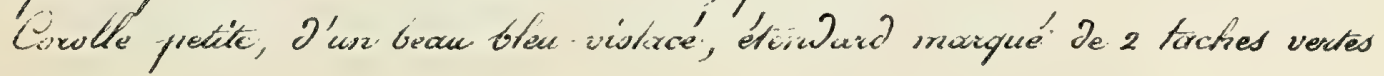

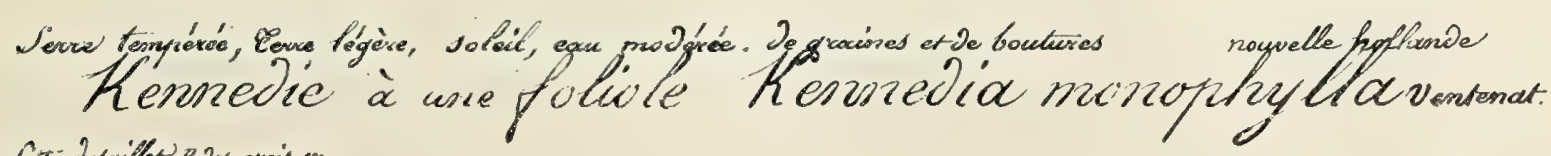
Sist- Jesociller $R$ des axcis $y$ 



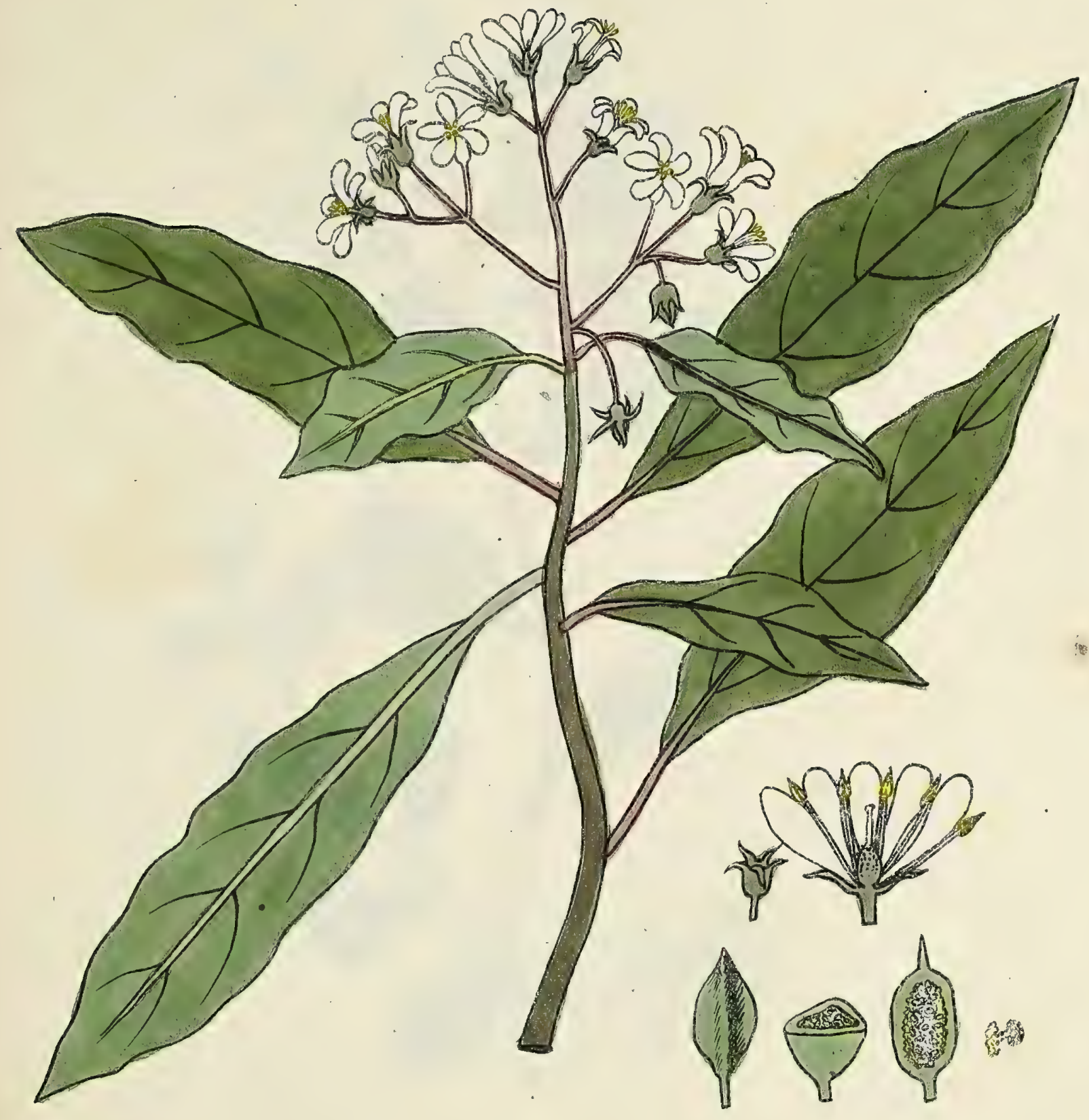

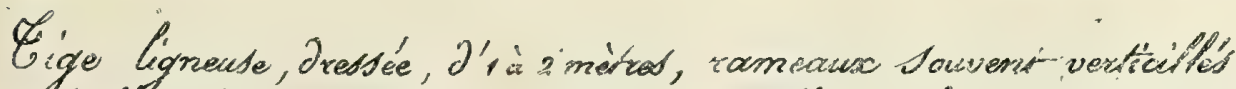

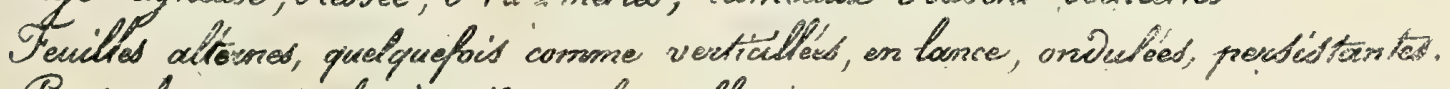

Tanicules torminales à pédoncules collarits Palices visqueus, Pitales blanos, odeun de jabmin.

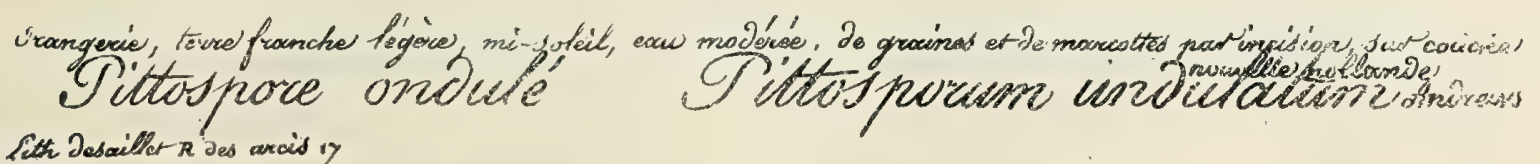





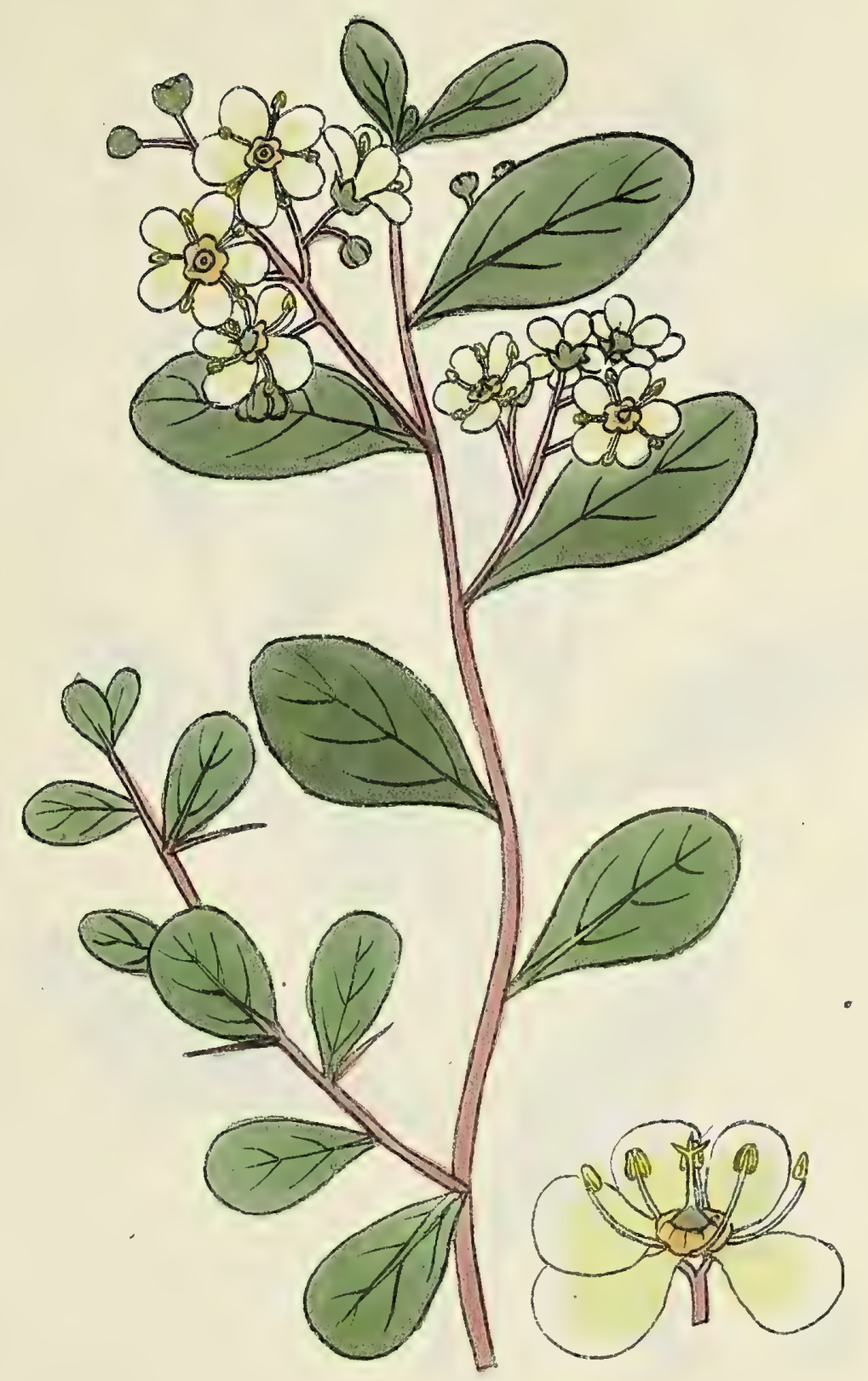

Eigre Ligneuse, Oressee, O'và a meitres, à corneaua éfrineux

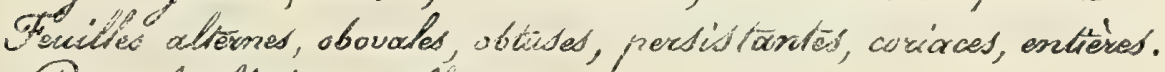
Tasnicules läches, axcillaciras.

Peitales blano-teone!

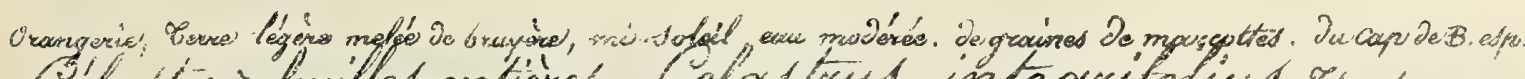

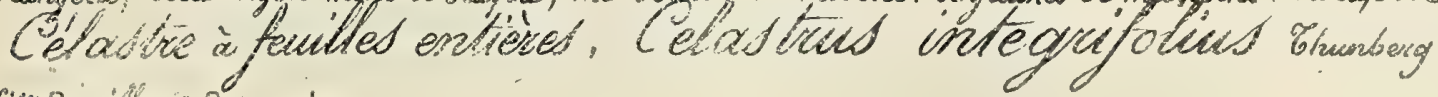

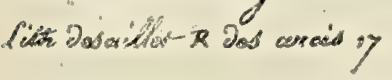





$$
\text { 婙. }
$$


. 


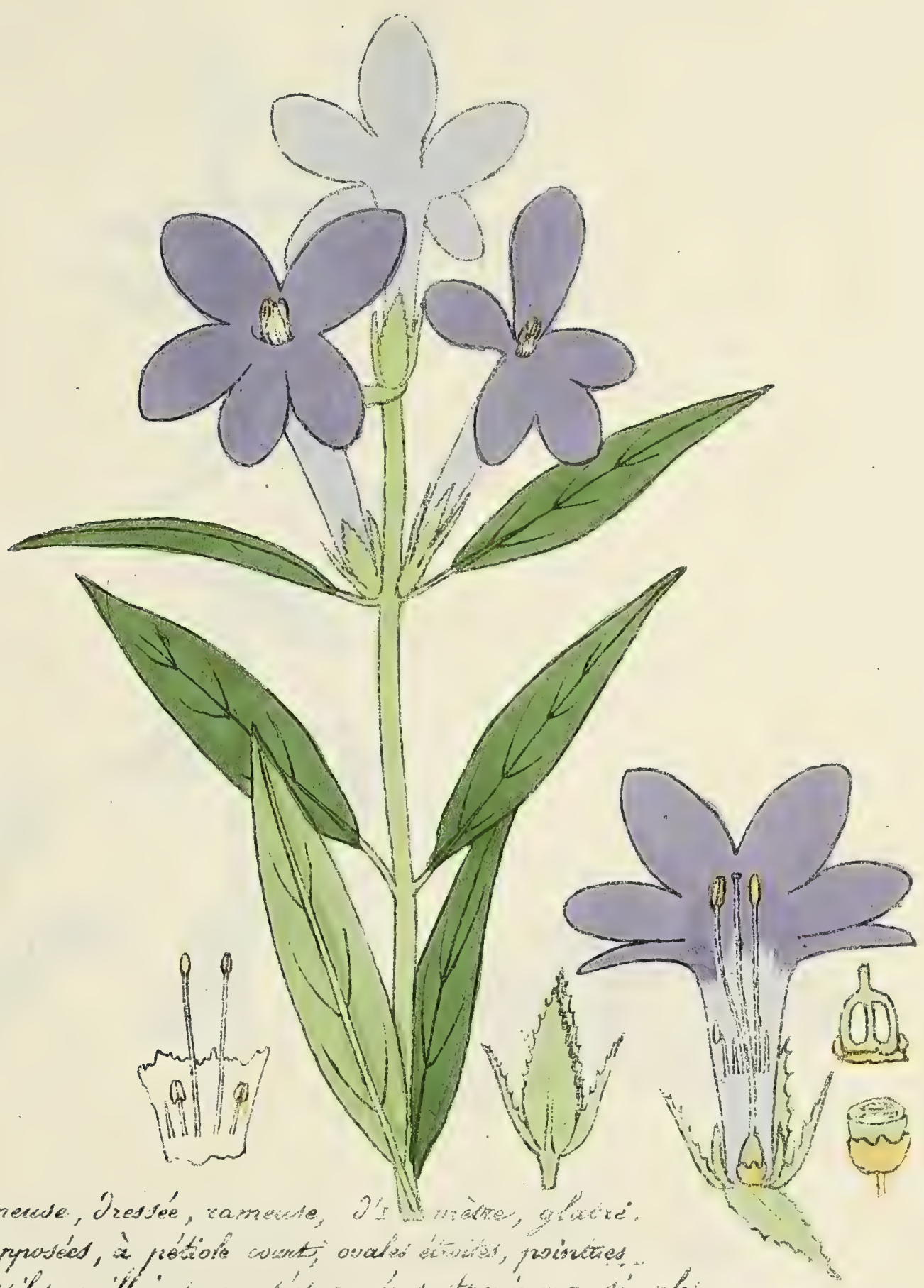

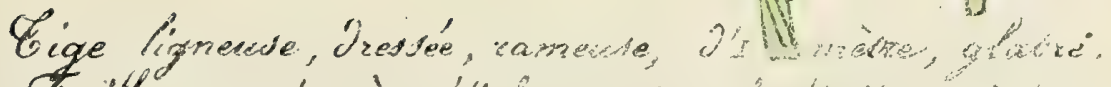

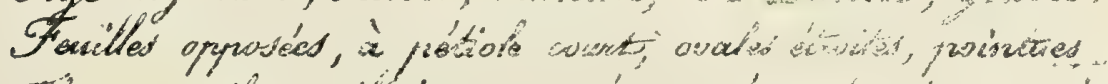

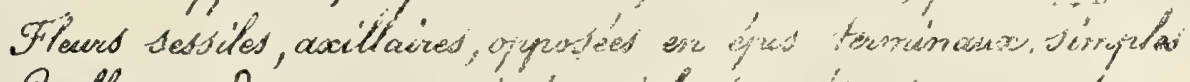

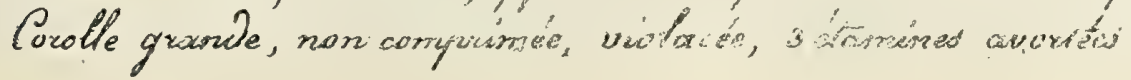

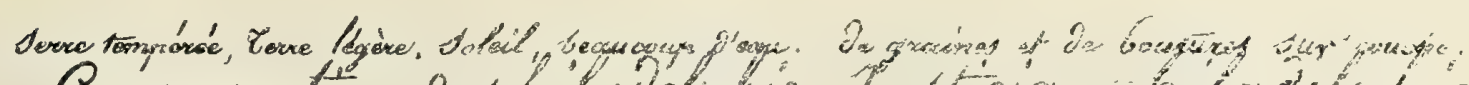

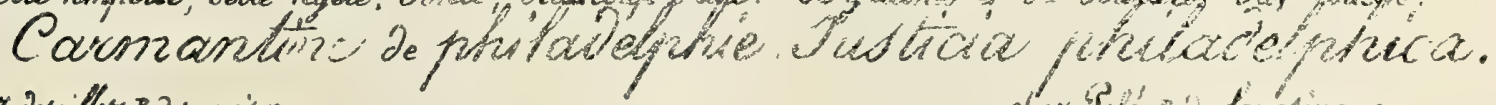

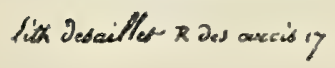





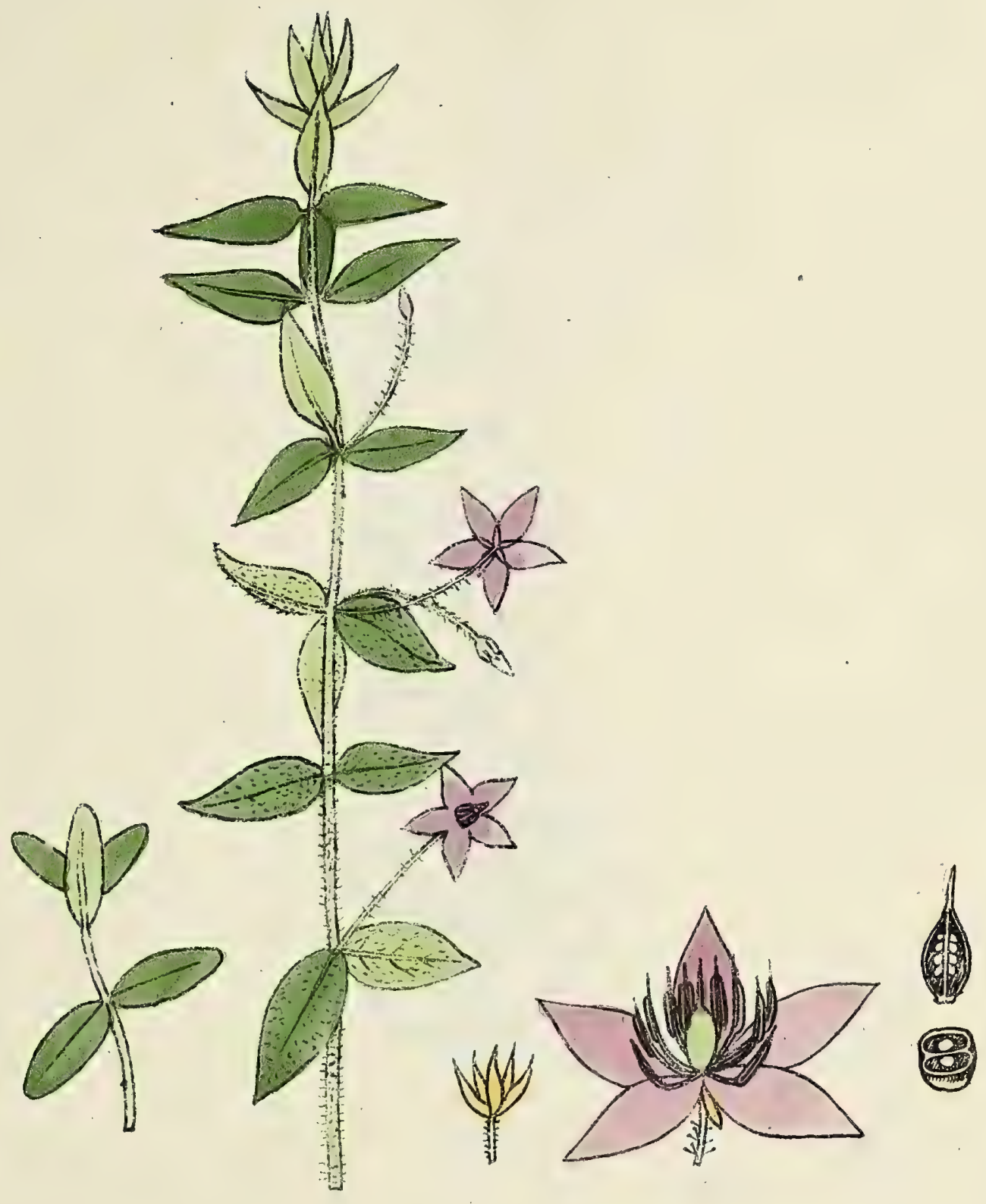

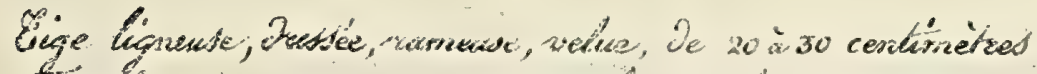

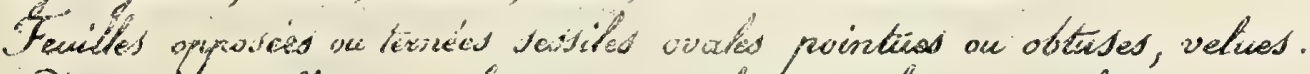

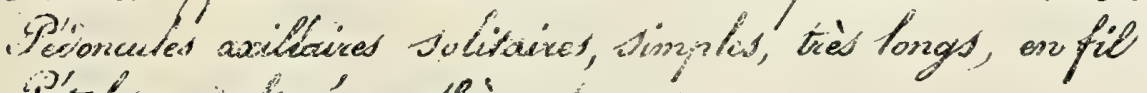

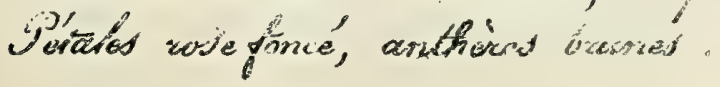

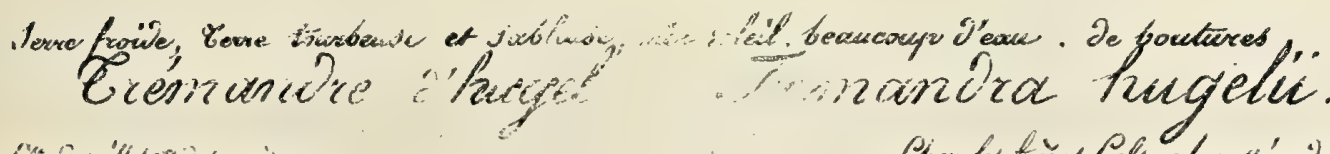

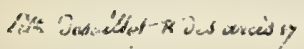

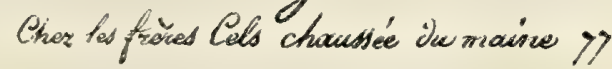




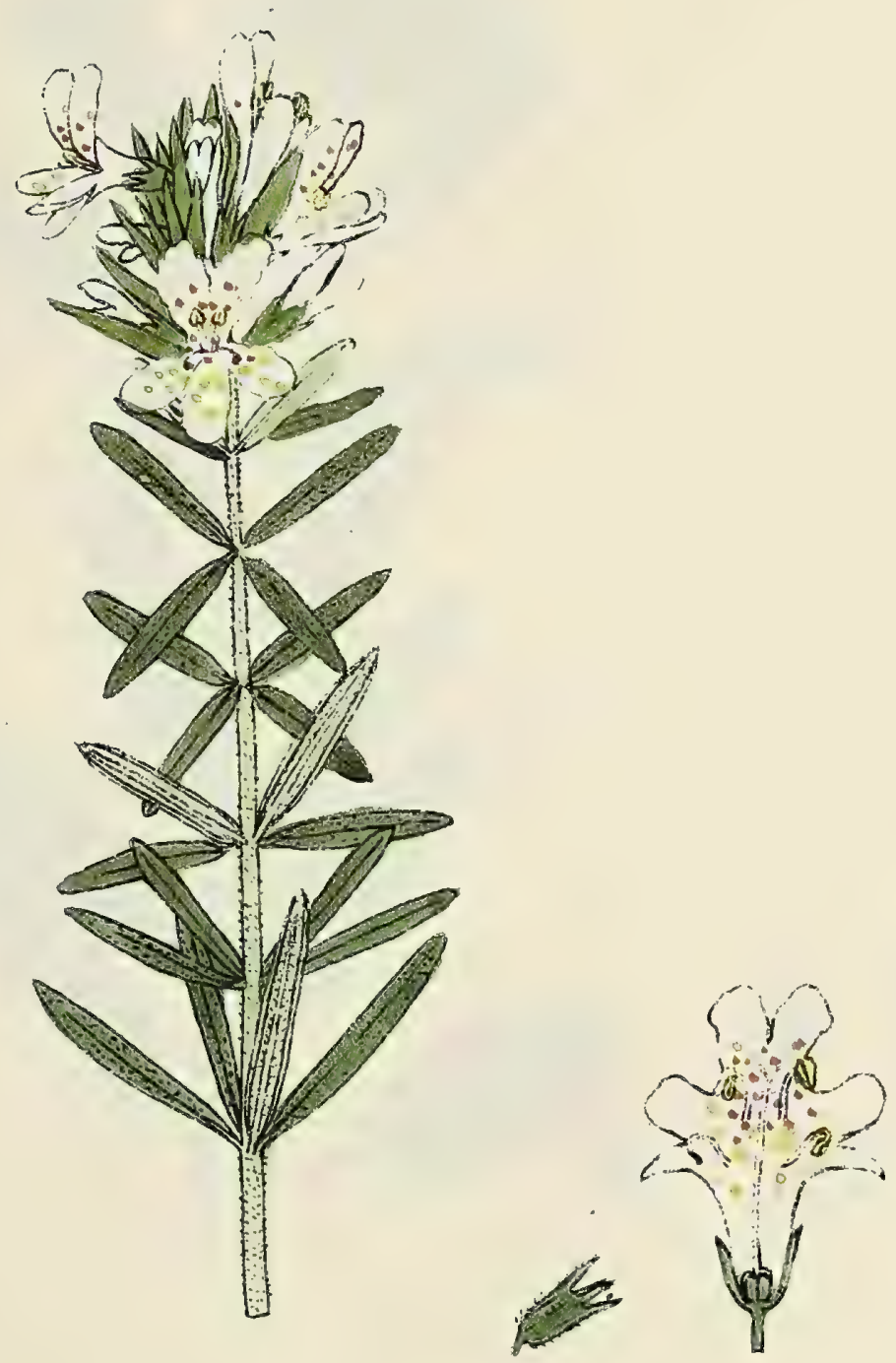

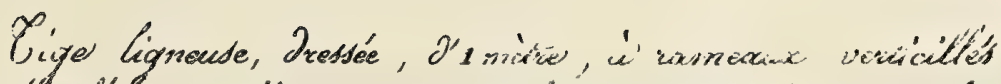

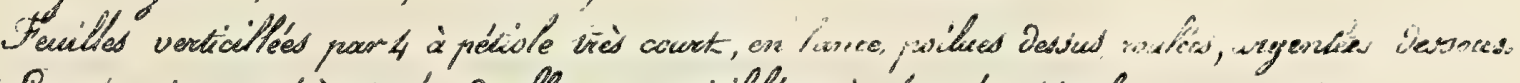

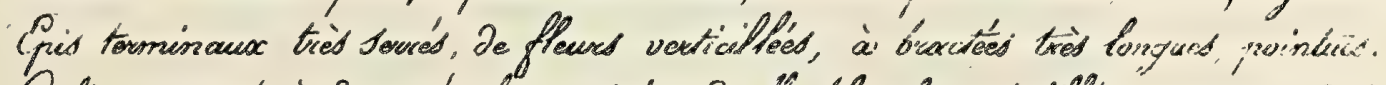

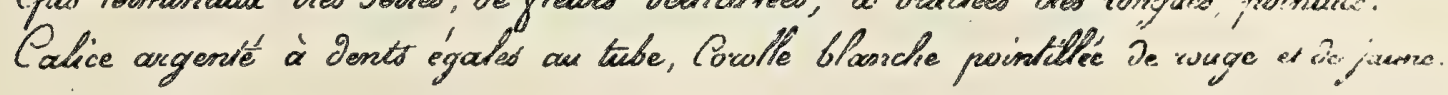

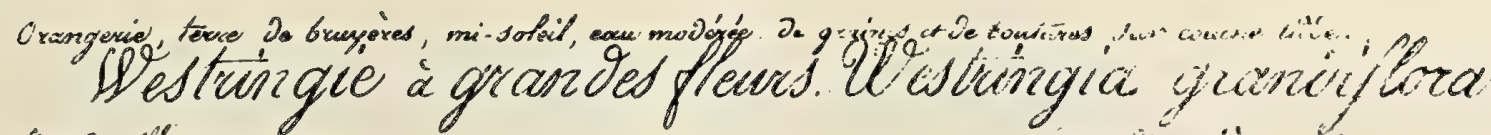
fin descullter $R$ aes axcis on 



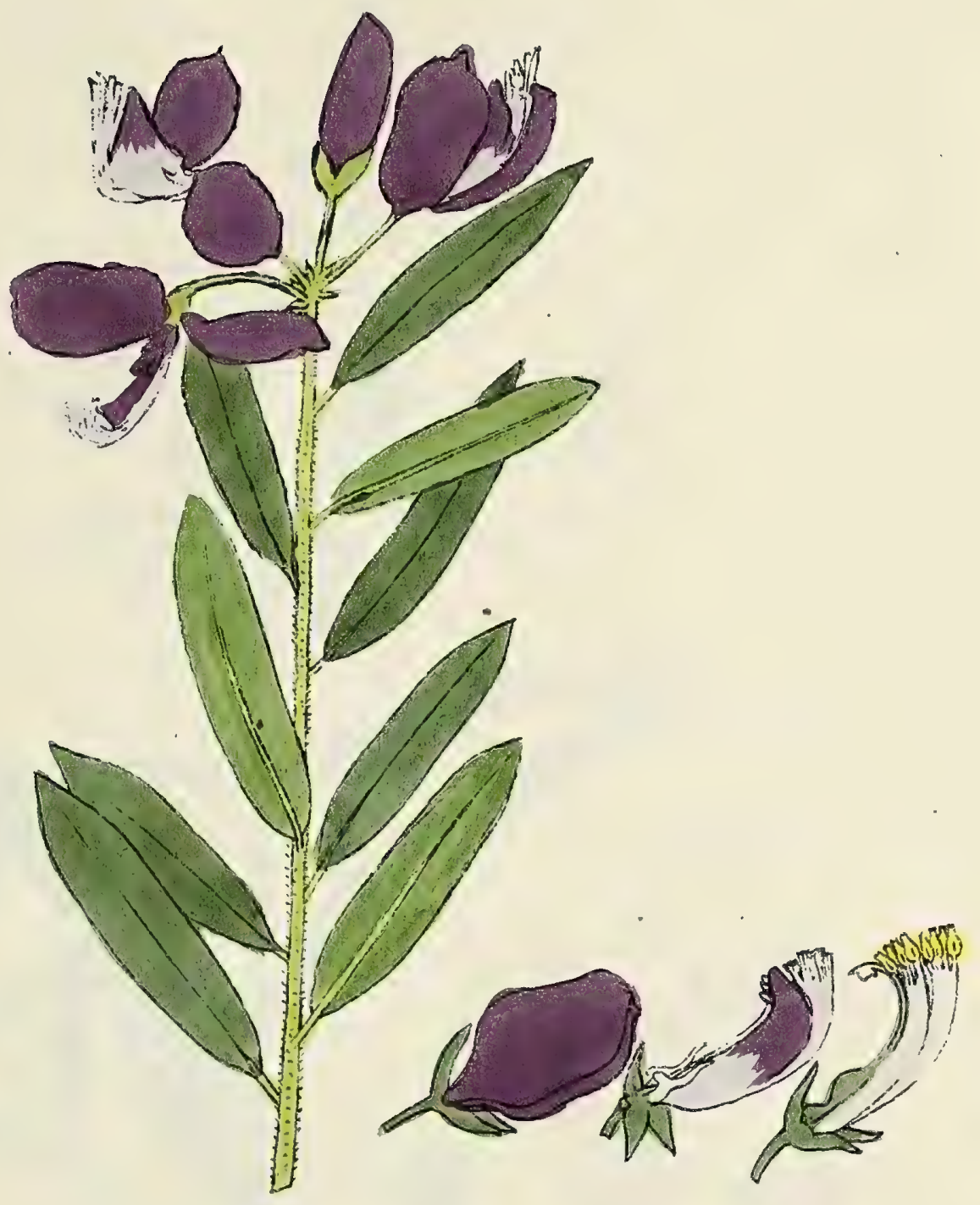

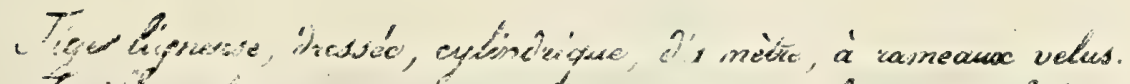

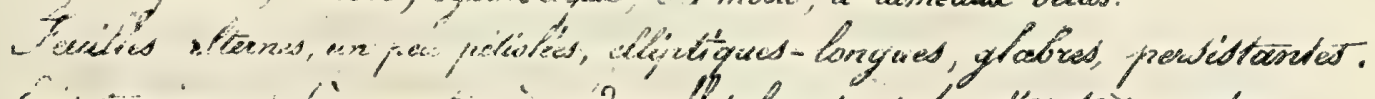

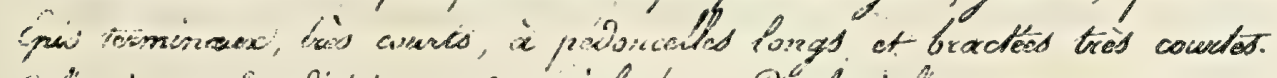

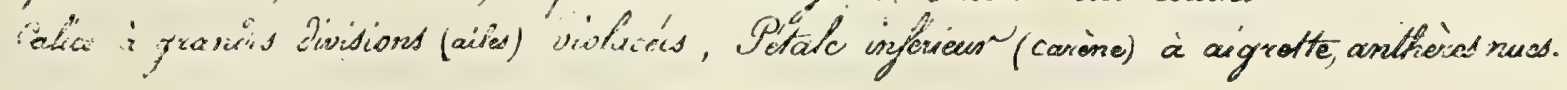

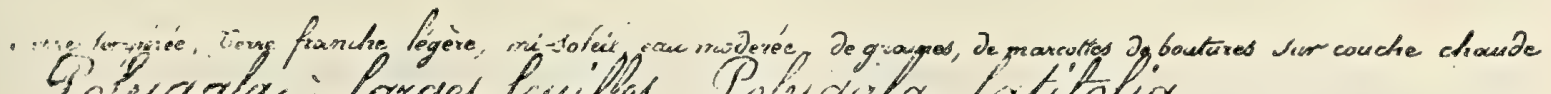

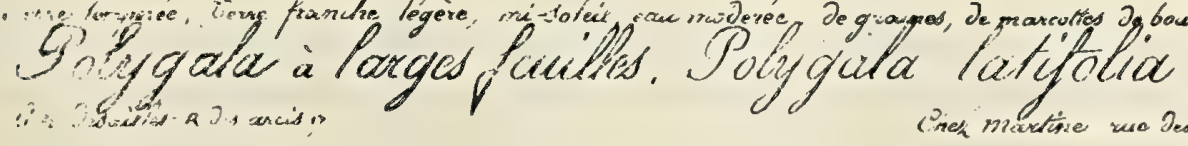

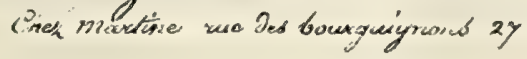




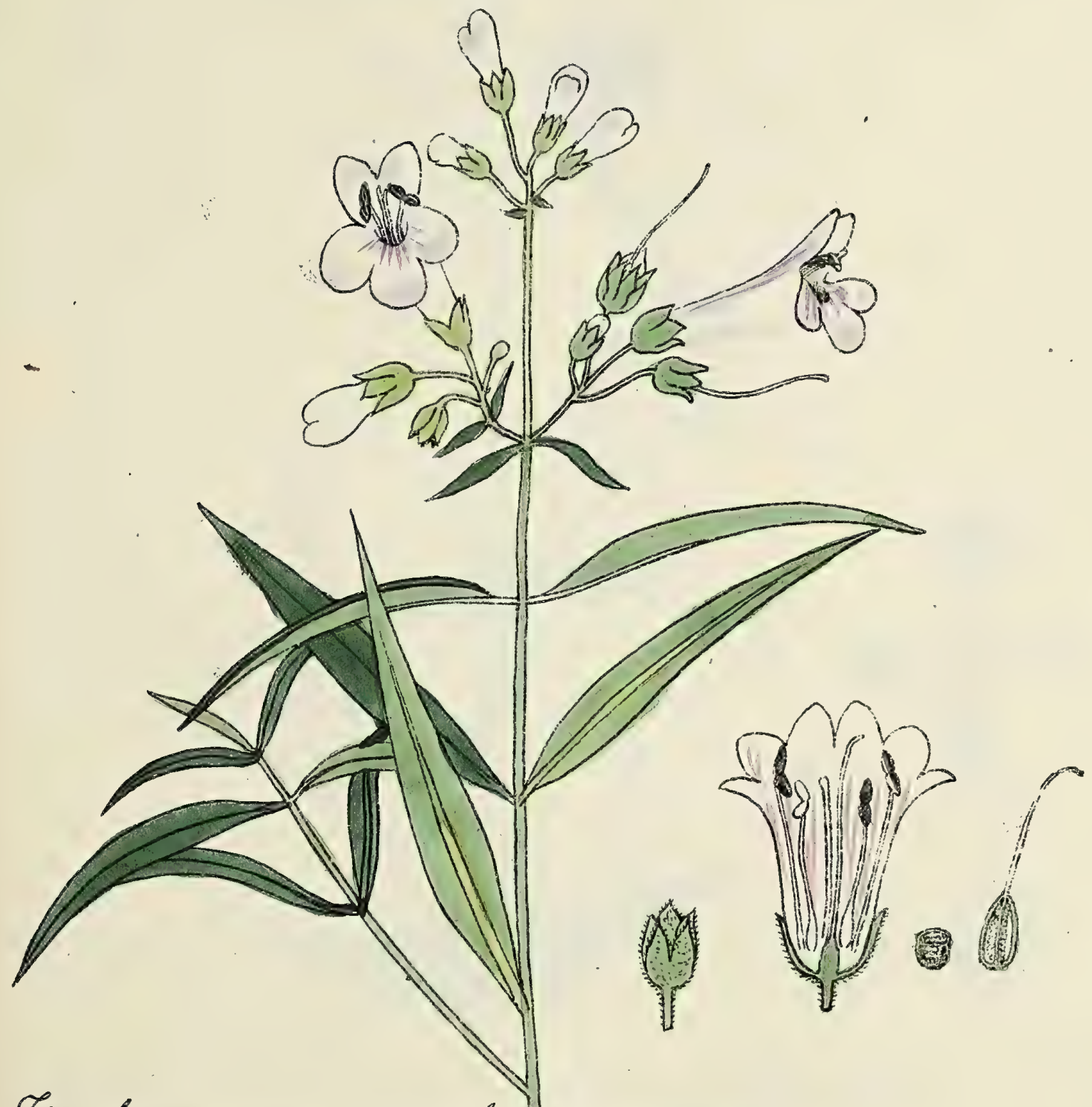

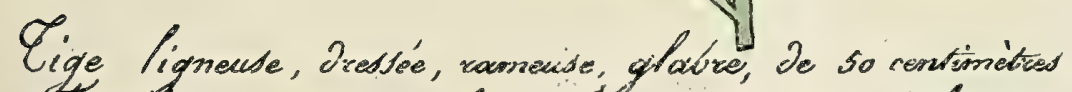

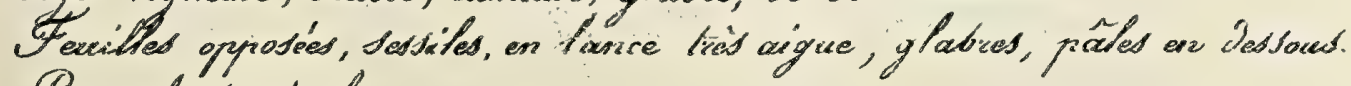

Panicule terminale

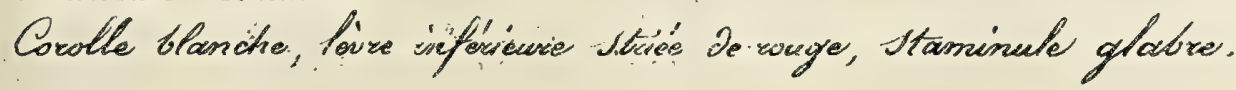

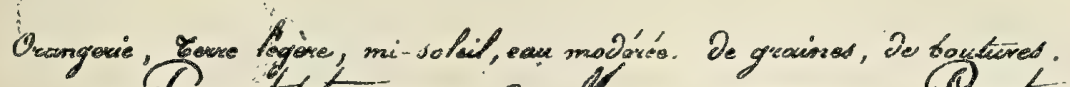

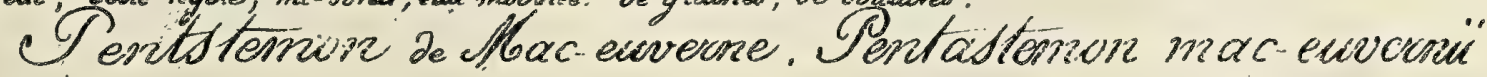

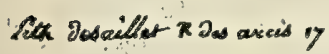

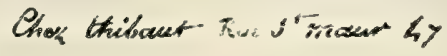




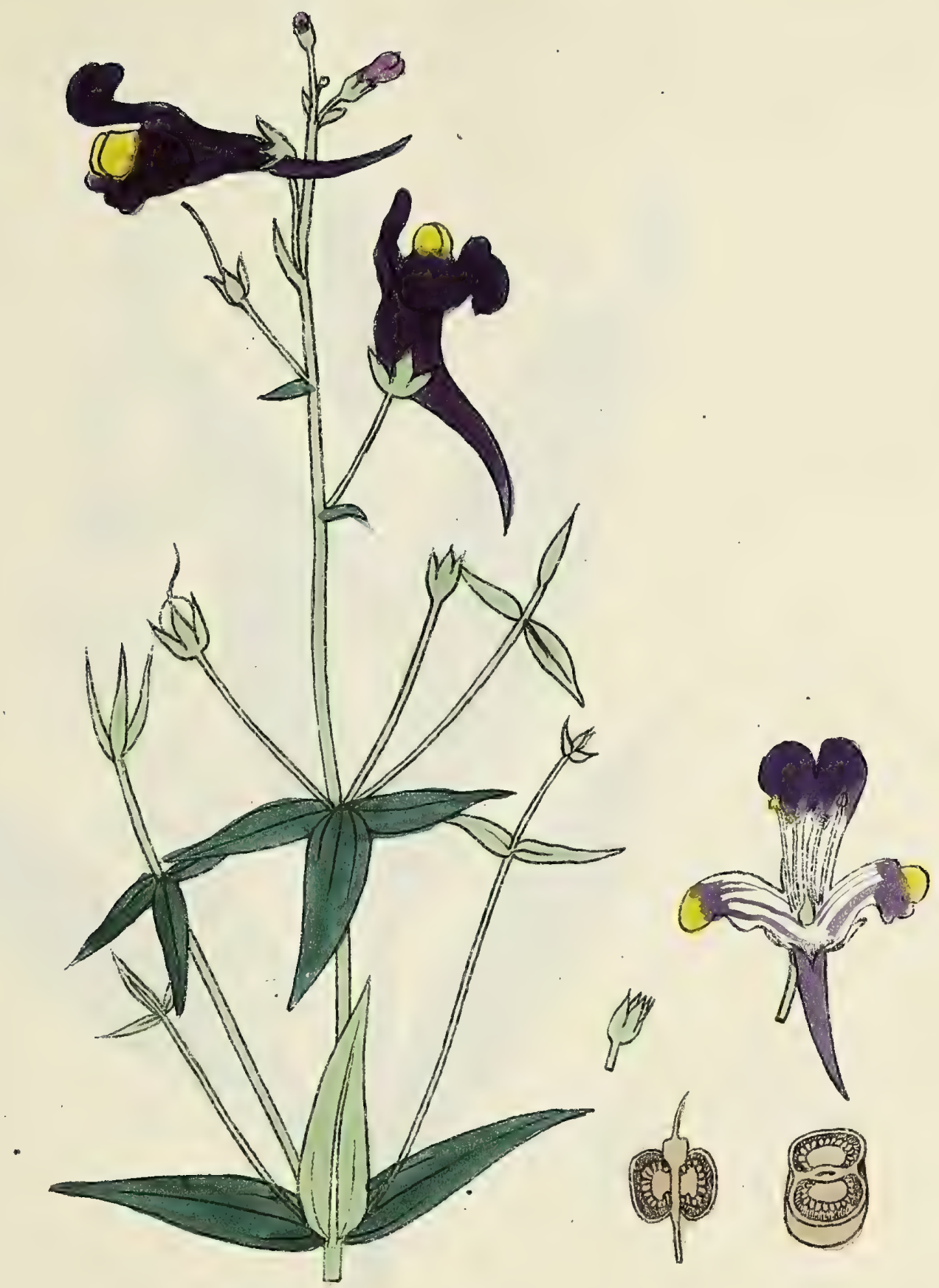

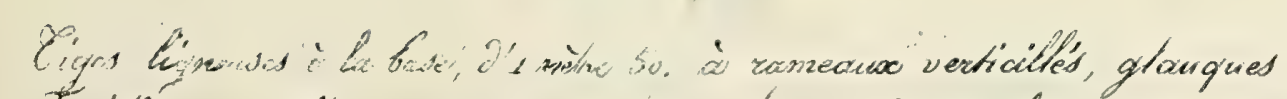

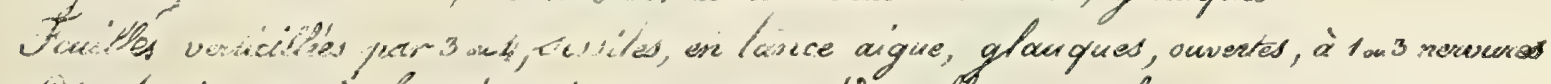

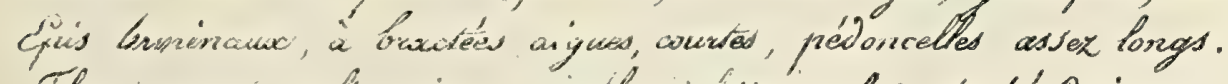

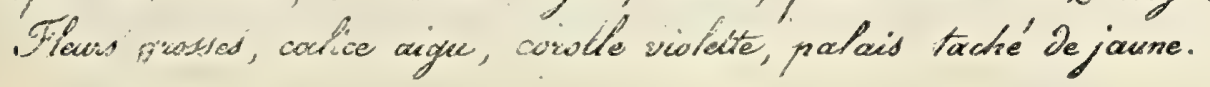

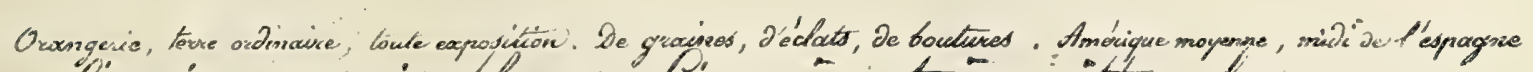

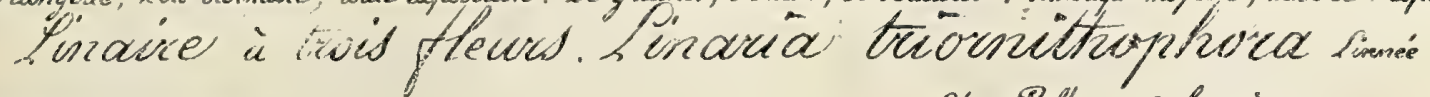
lith gedaition tas aris?

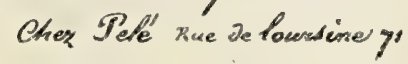




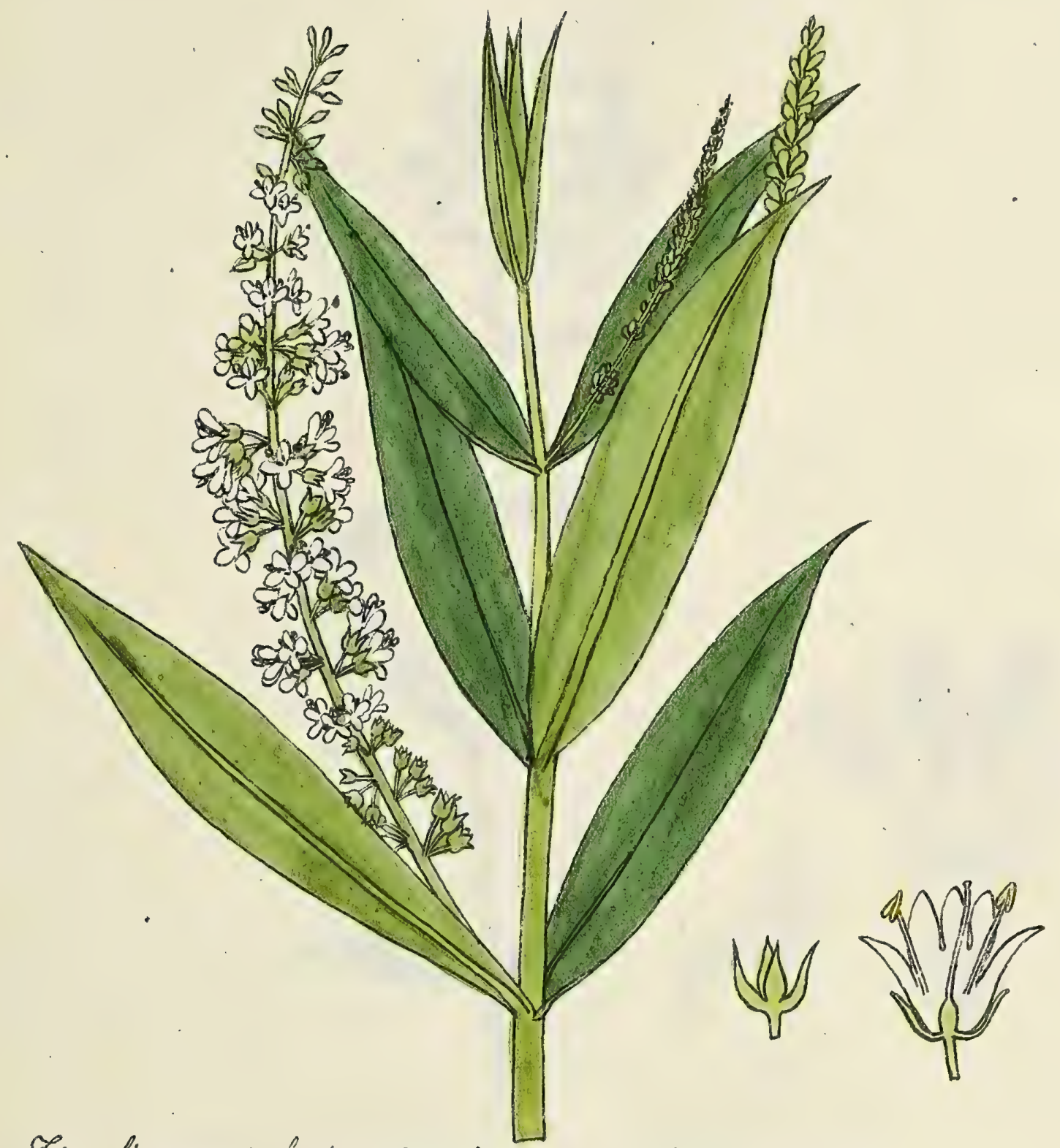

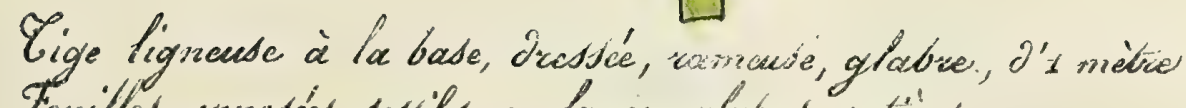

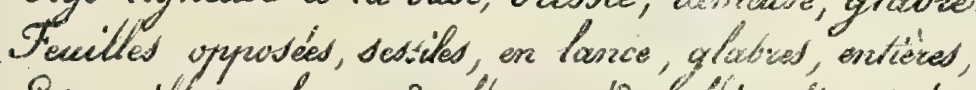

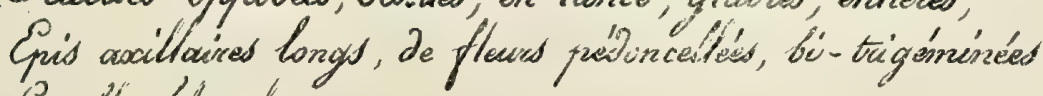

Cowtle bianche

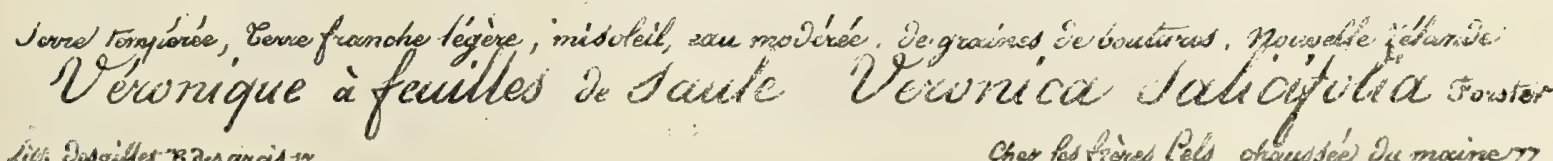

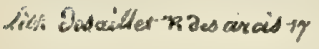



183

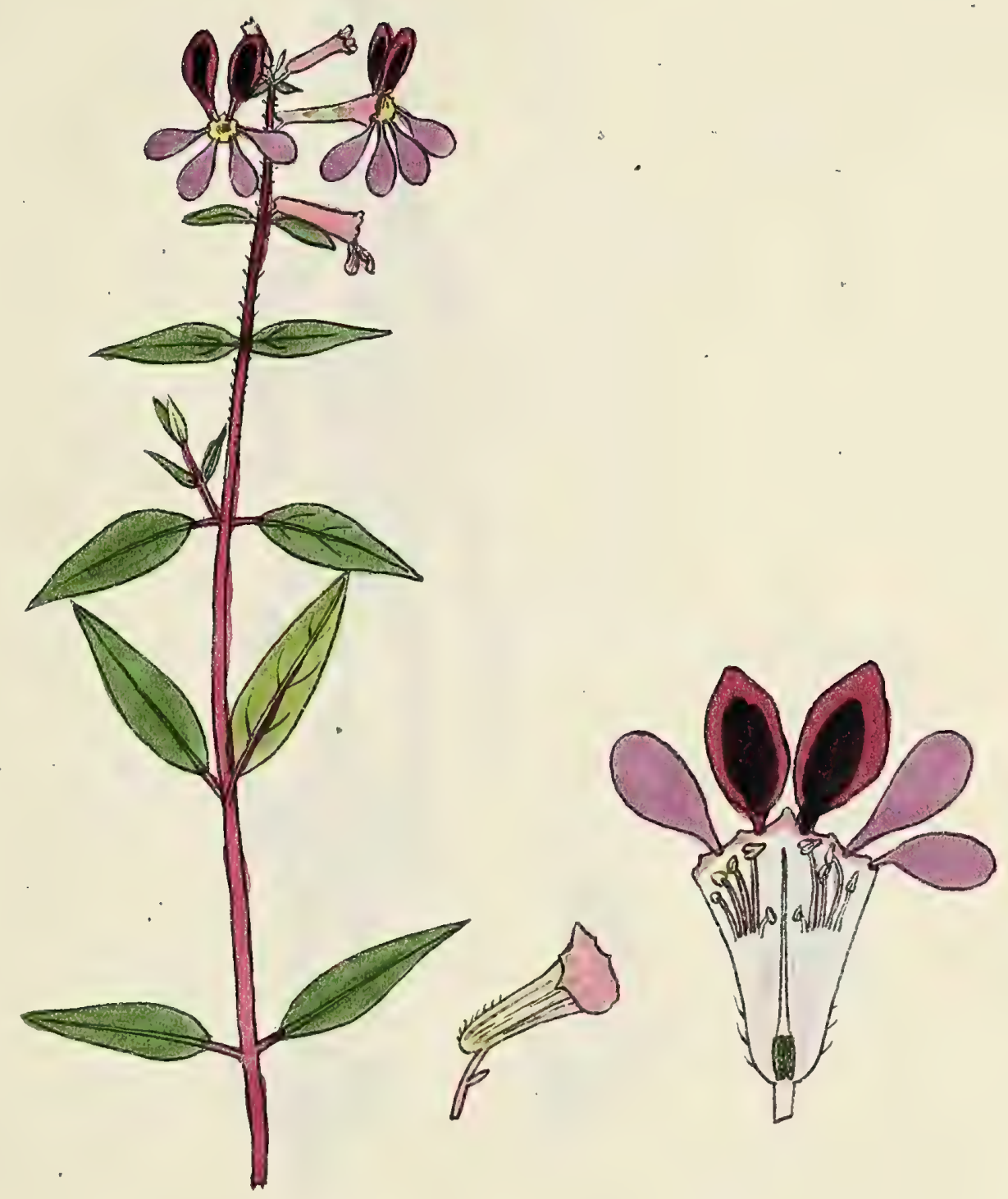

Gige ligneudes, Oressied, casnense, glabre, De so contionetres Teuiltes oppostés, prétiolées, ovales-étroites, pointres, entières, à paine cilives Heurs pédonculeies entie les feuilles, formant comme des éfis terminouac.

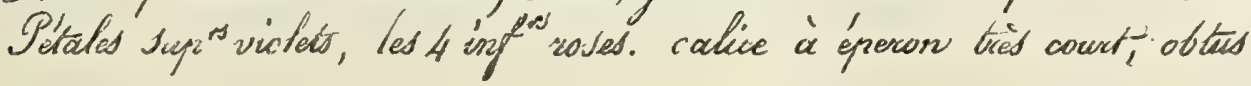

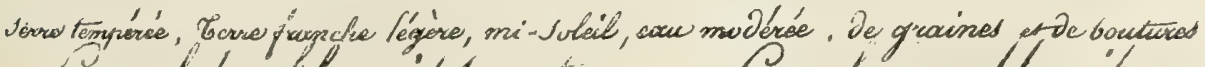

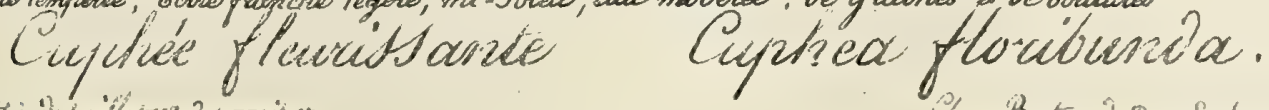

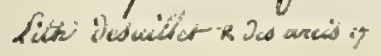

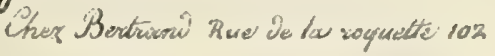




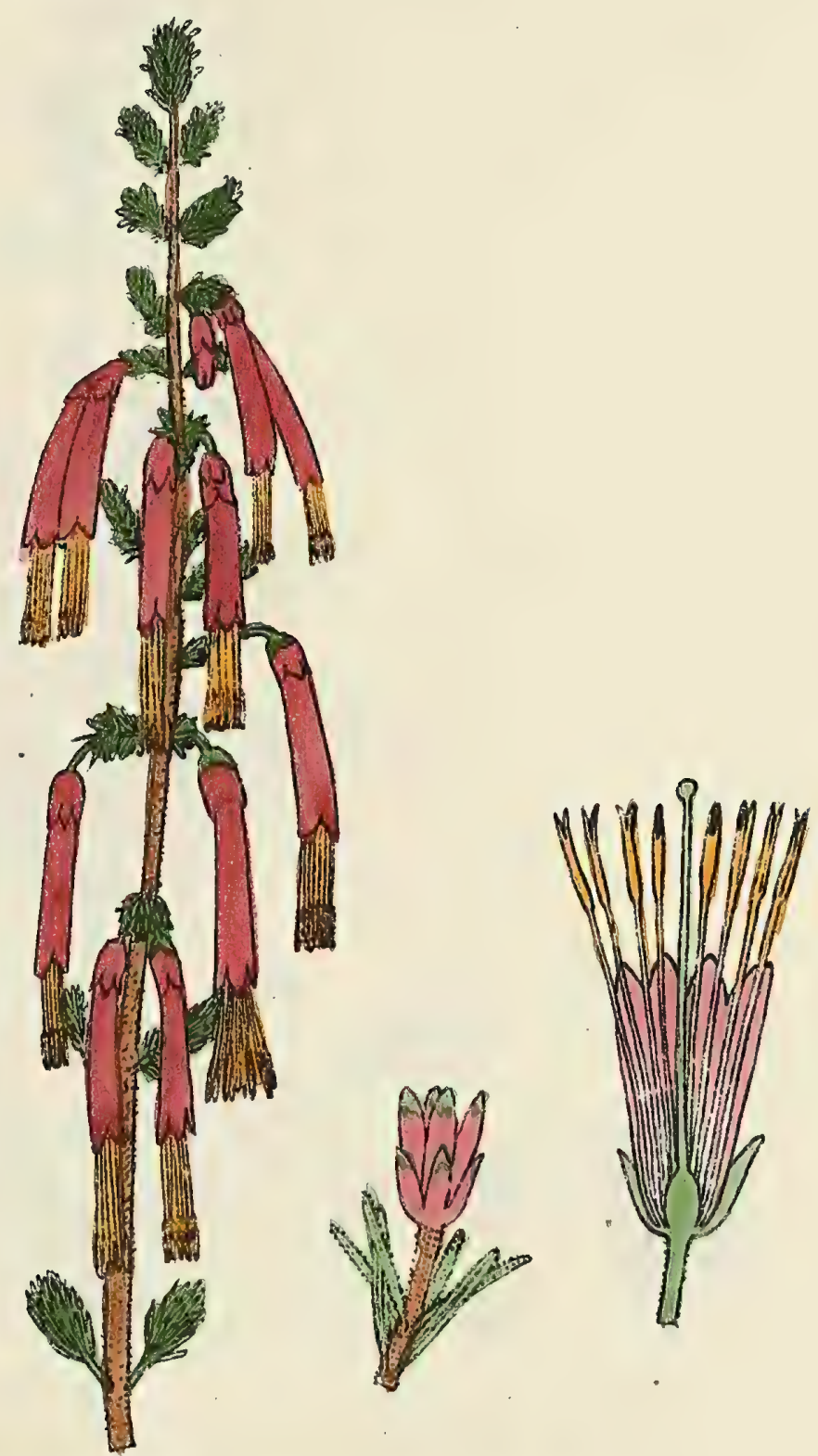

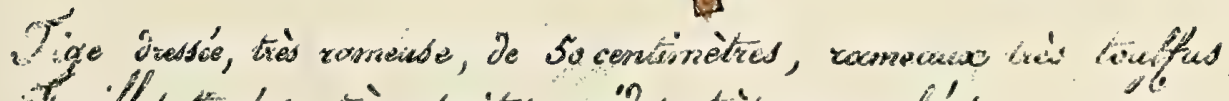
Ficilles torrées, vies etroites, raides, ties rapprocticís.

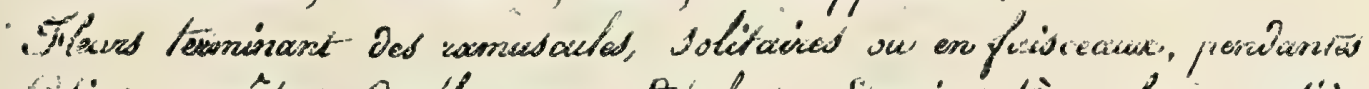

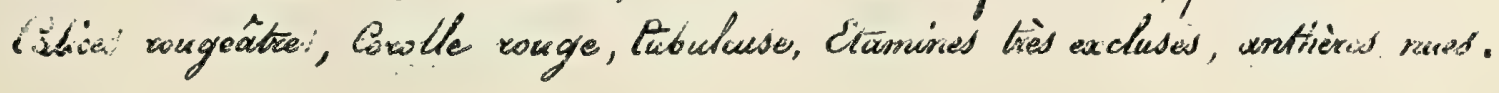

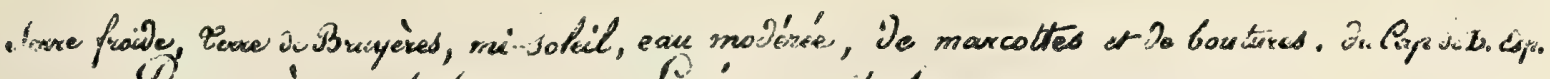

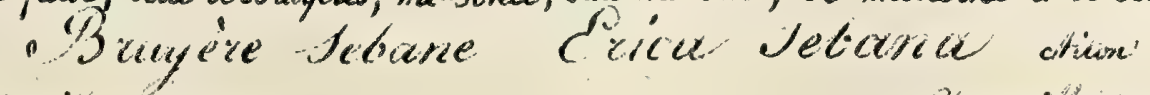

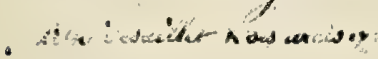

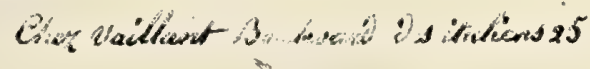




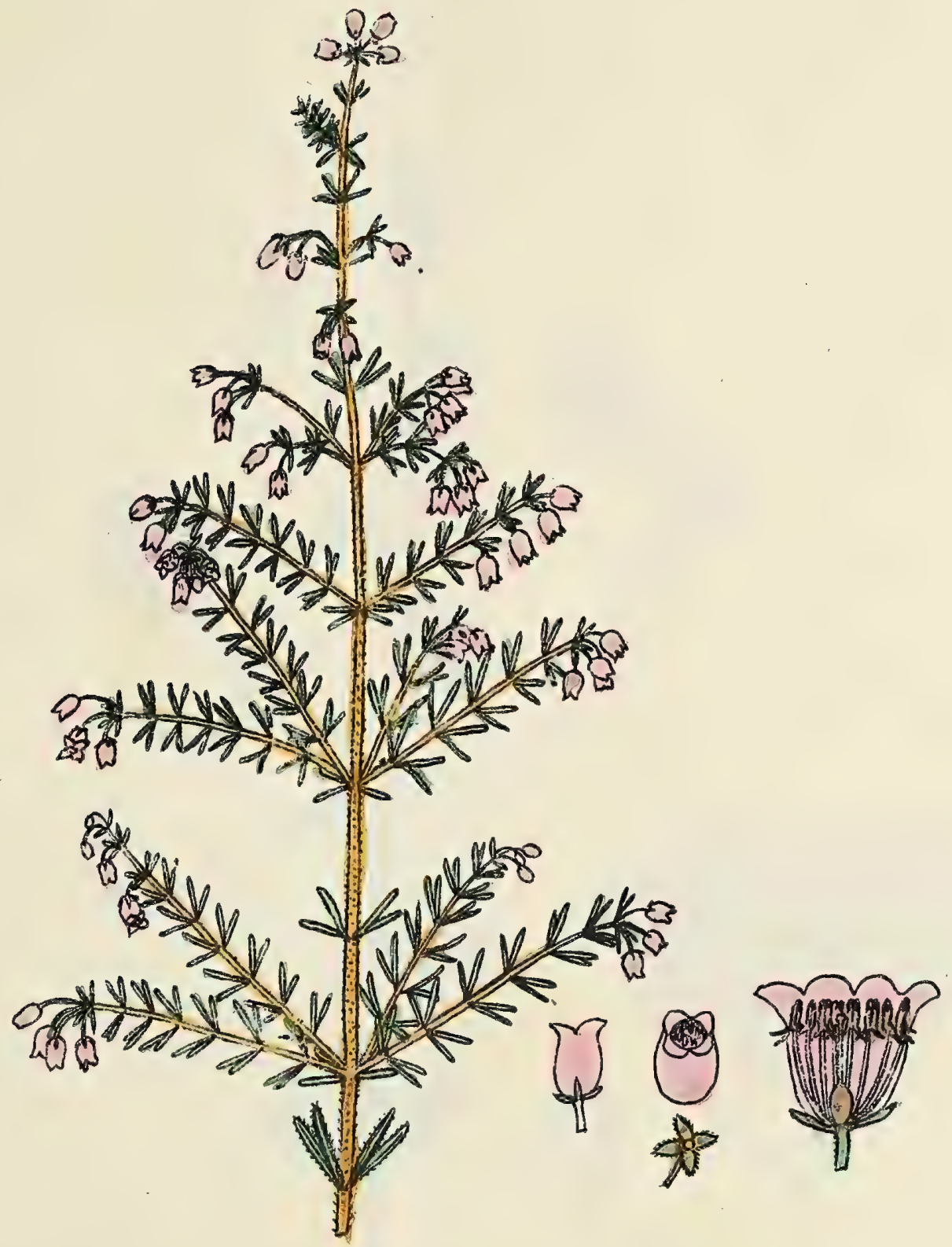

Tige lignecude, Drasséc, rameube, cilié, de so contionstras Feuilles quatomés, longues, ciliess, espaciés.

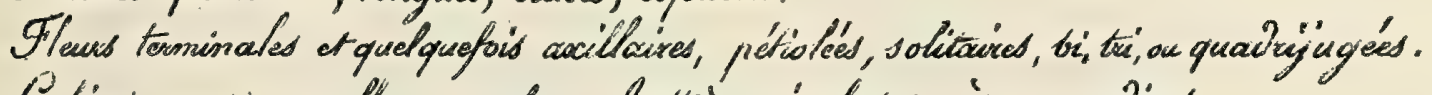

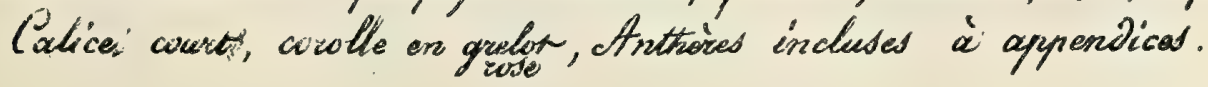

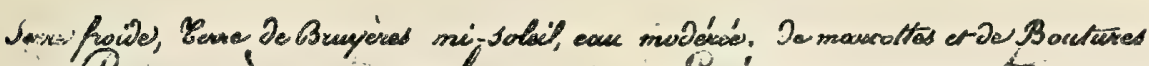
Buyere ovale dical rata

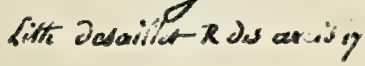

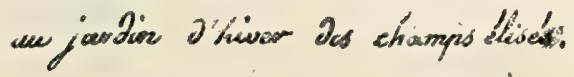





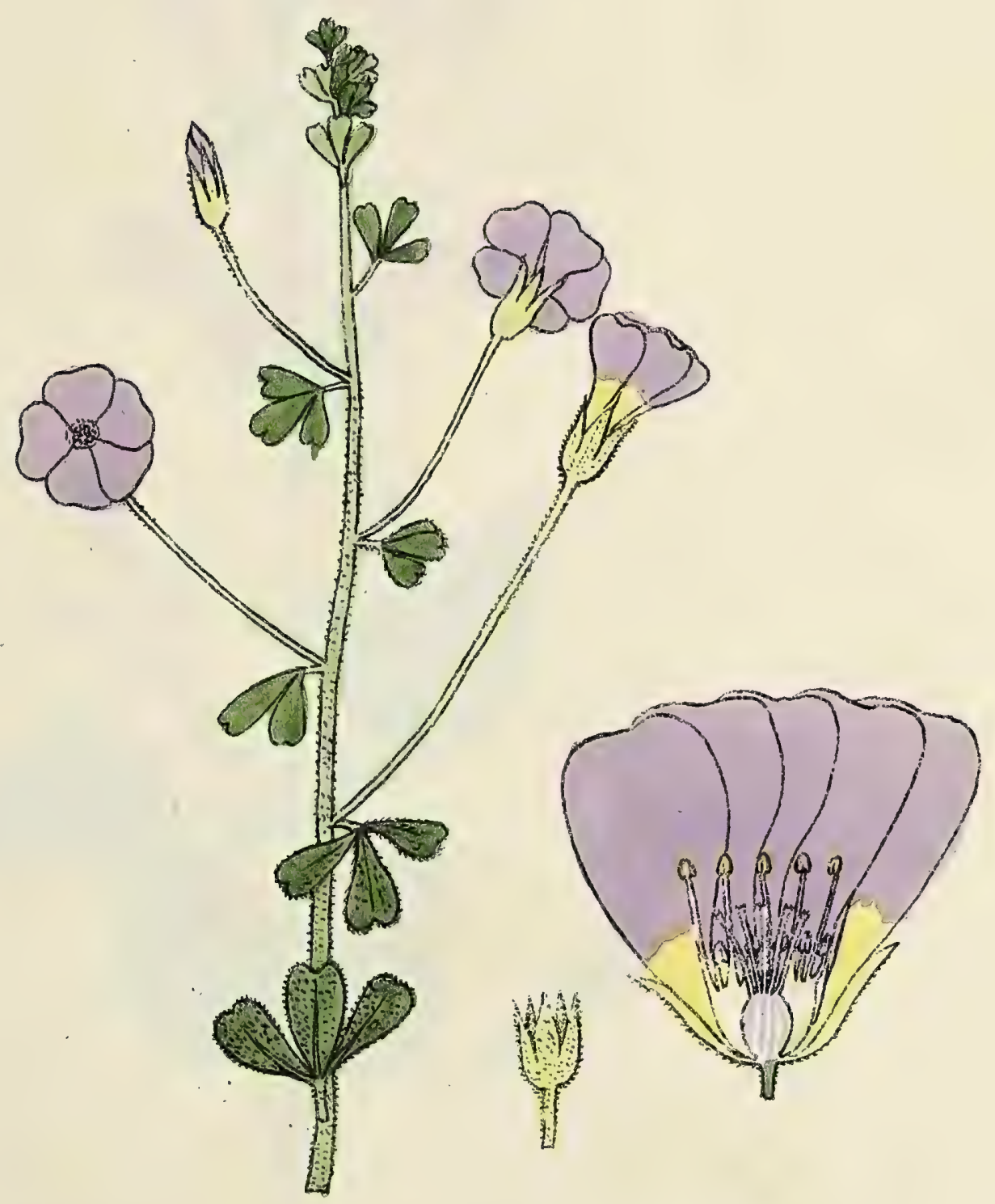

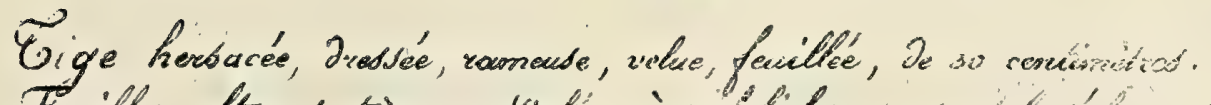

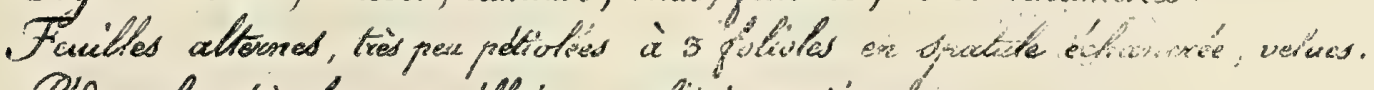

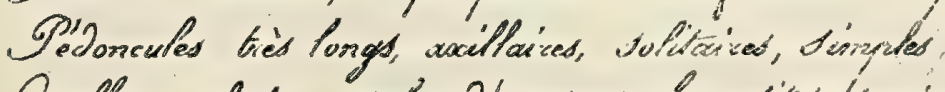

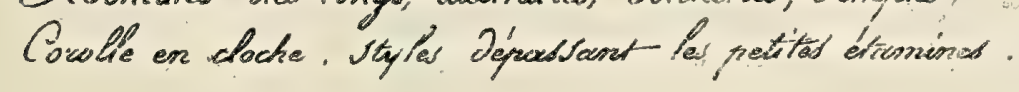

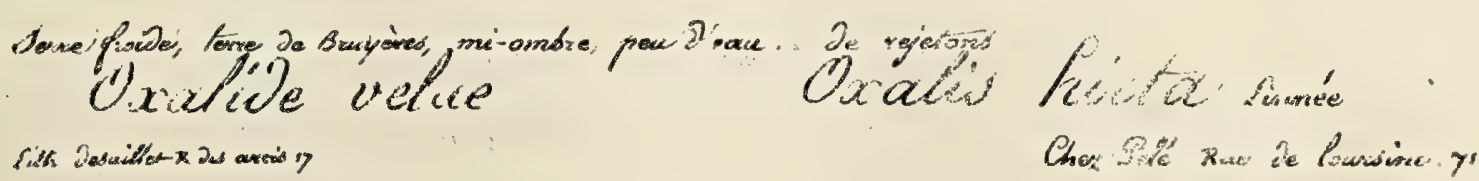





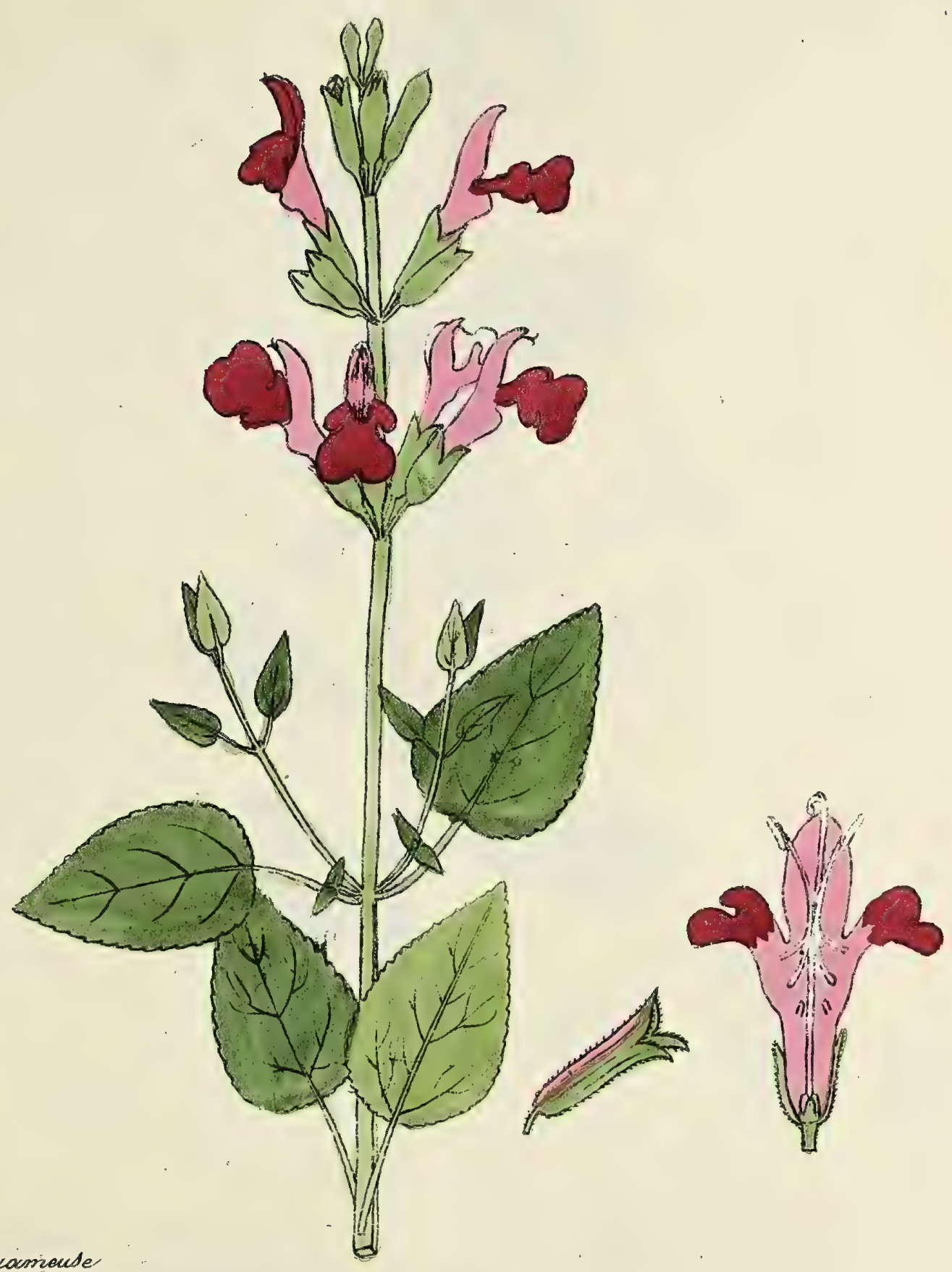

Rucine comoude

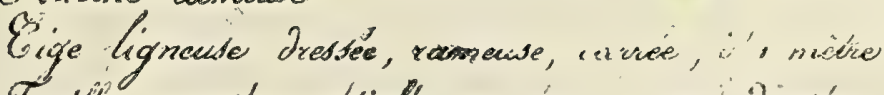

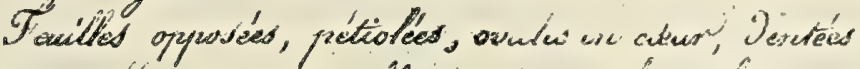

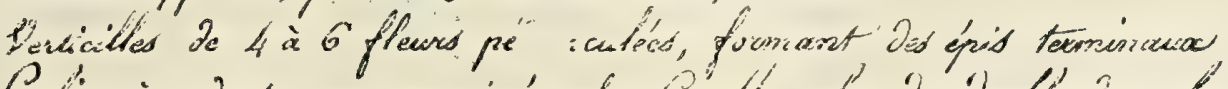

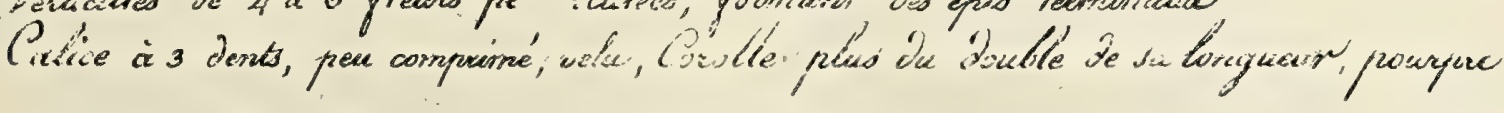

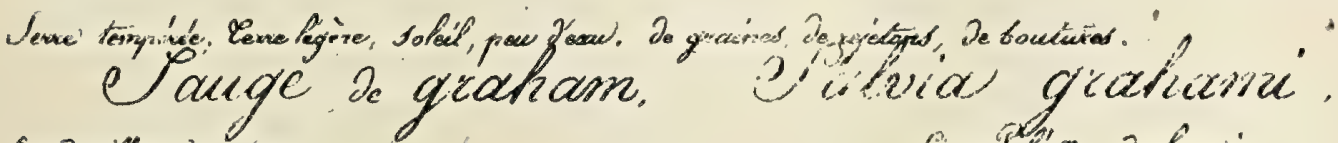

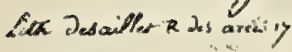

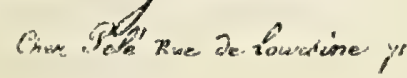




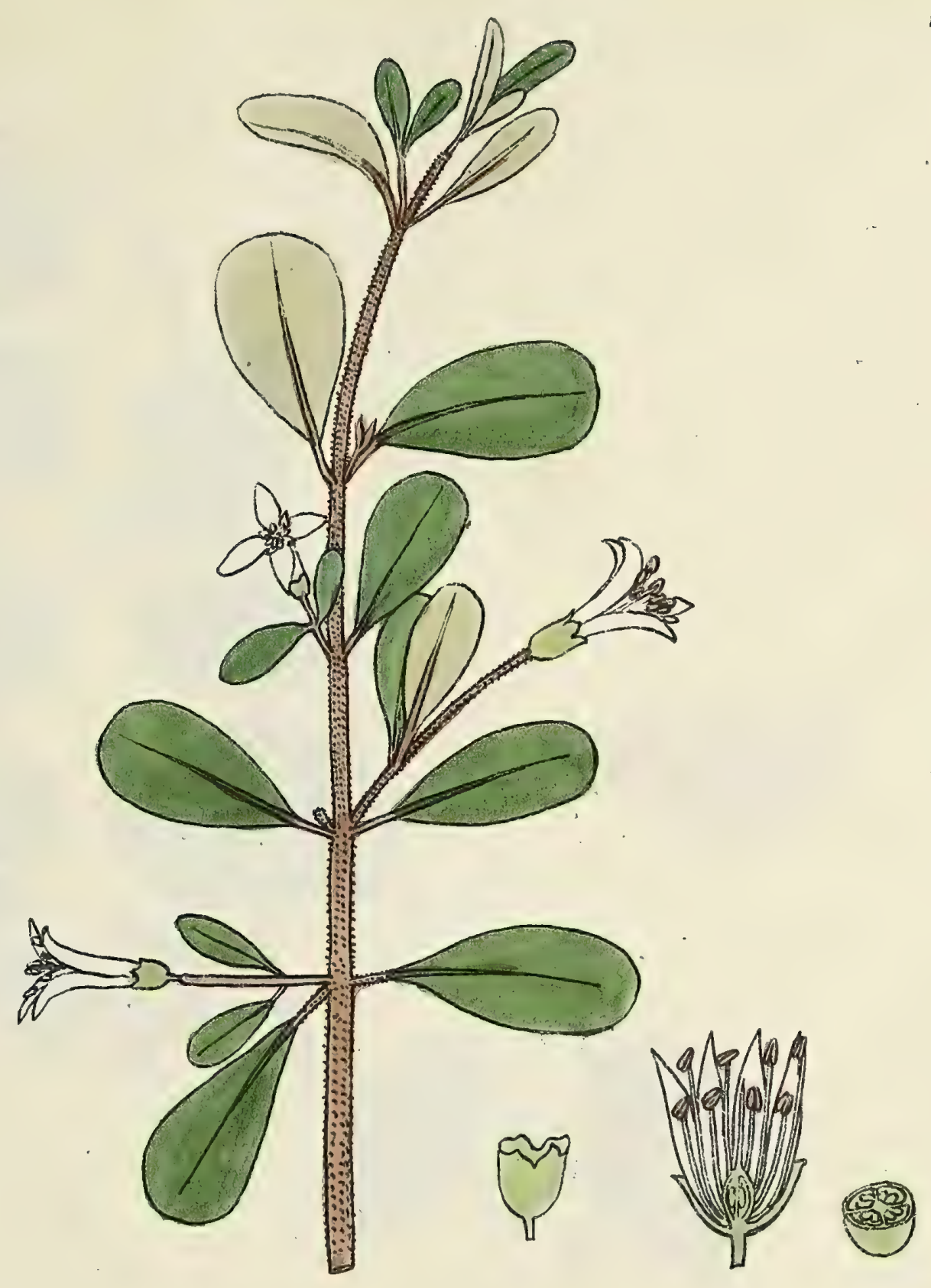

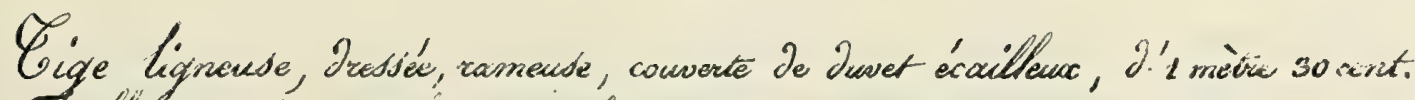

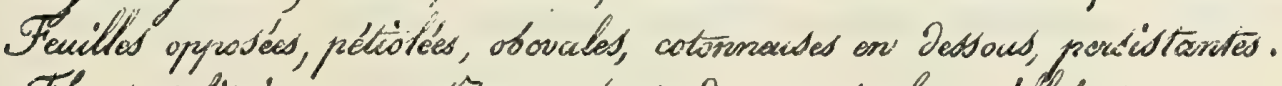
Fleurd solitaires ou on tete aw bout de romudoules ascillaived Calice à Dents aigues. Se'́lales distimats, blanc pien

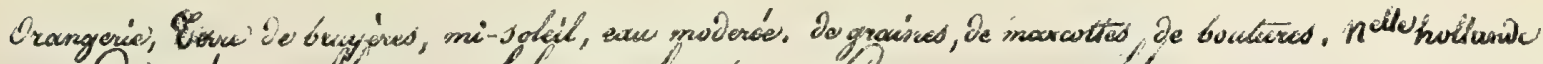

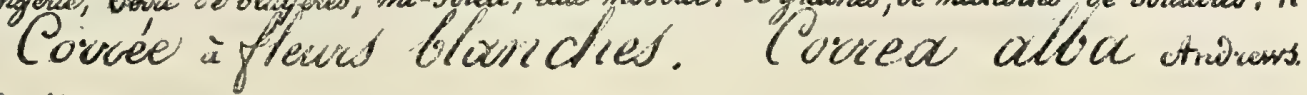

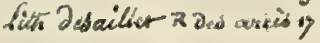




\section{.}




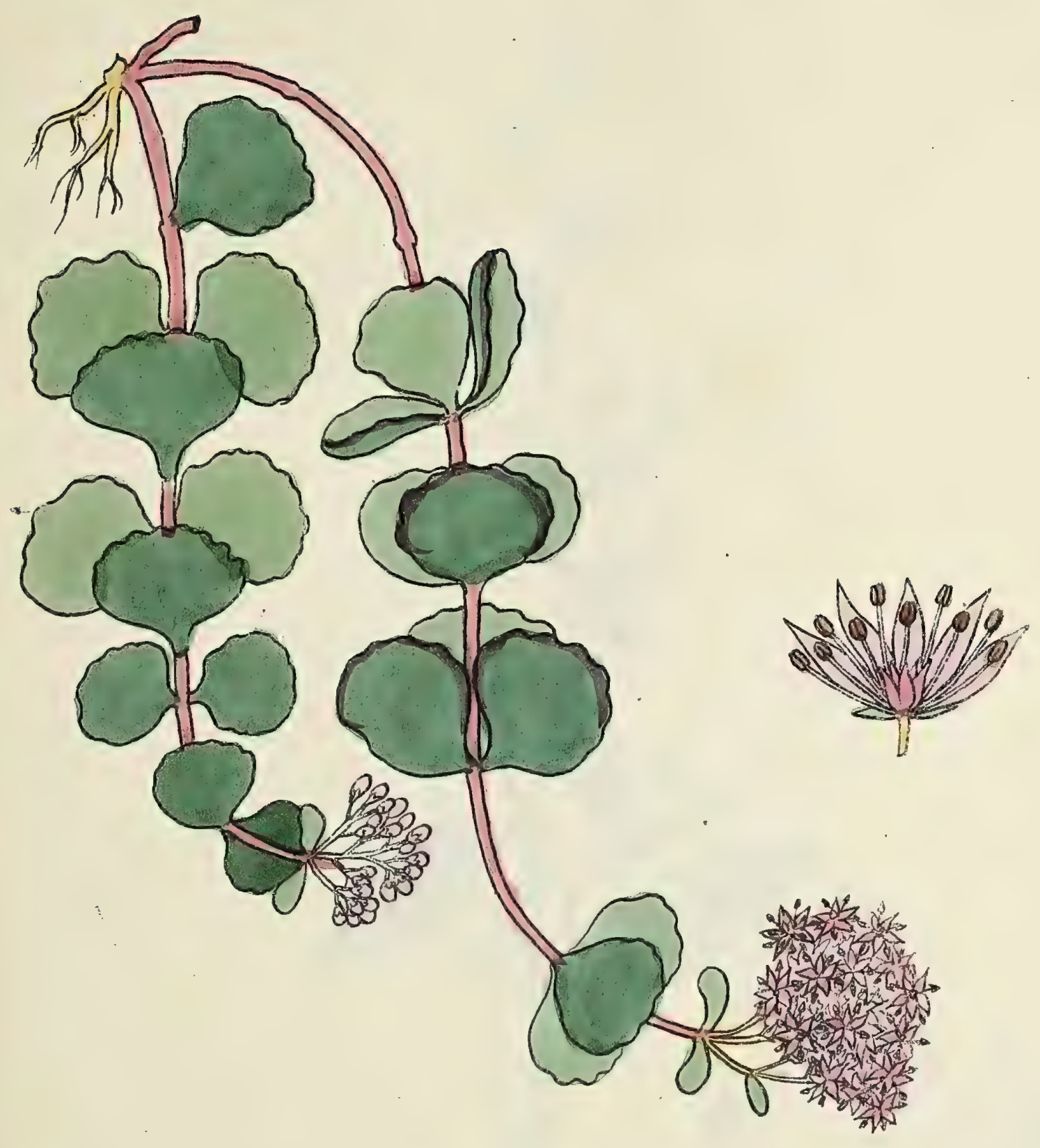

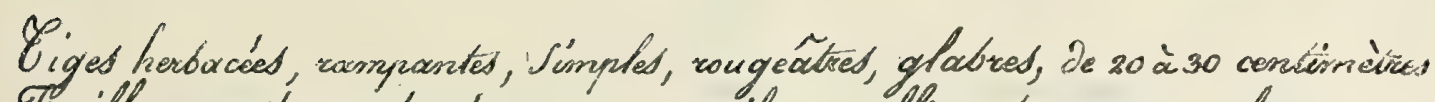

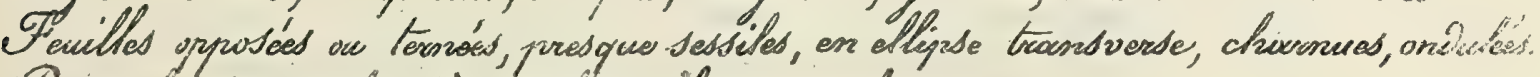
Panicule terminale, tries tougfue, formant la cyme Fleurd potites, pítales rases.

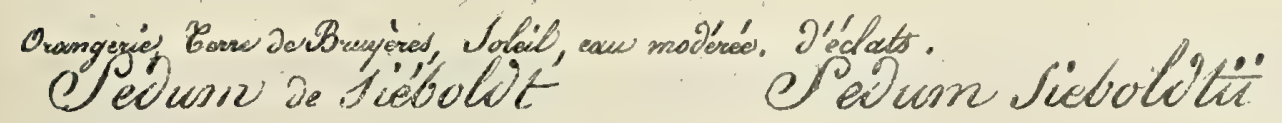
Lim Desaition $\mathrm{a}$ ins arrcis sy 


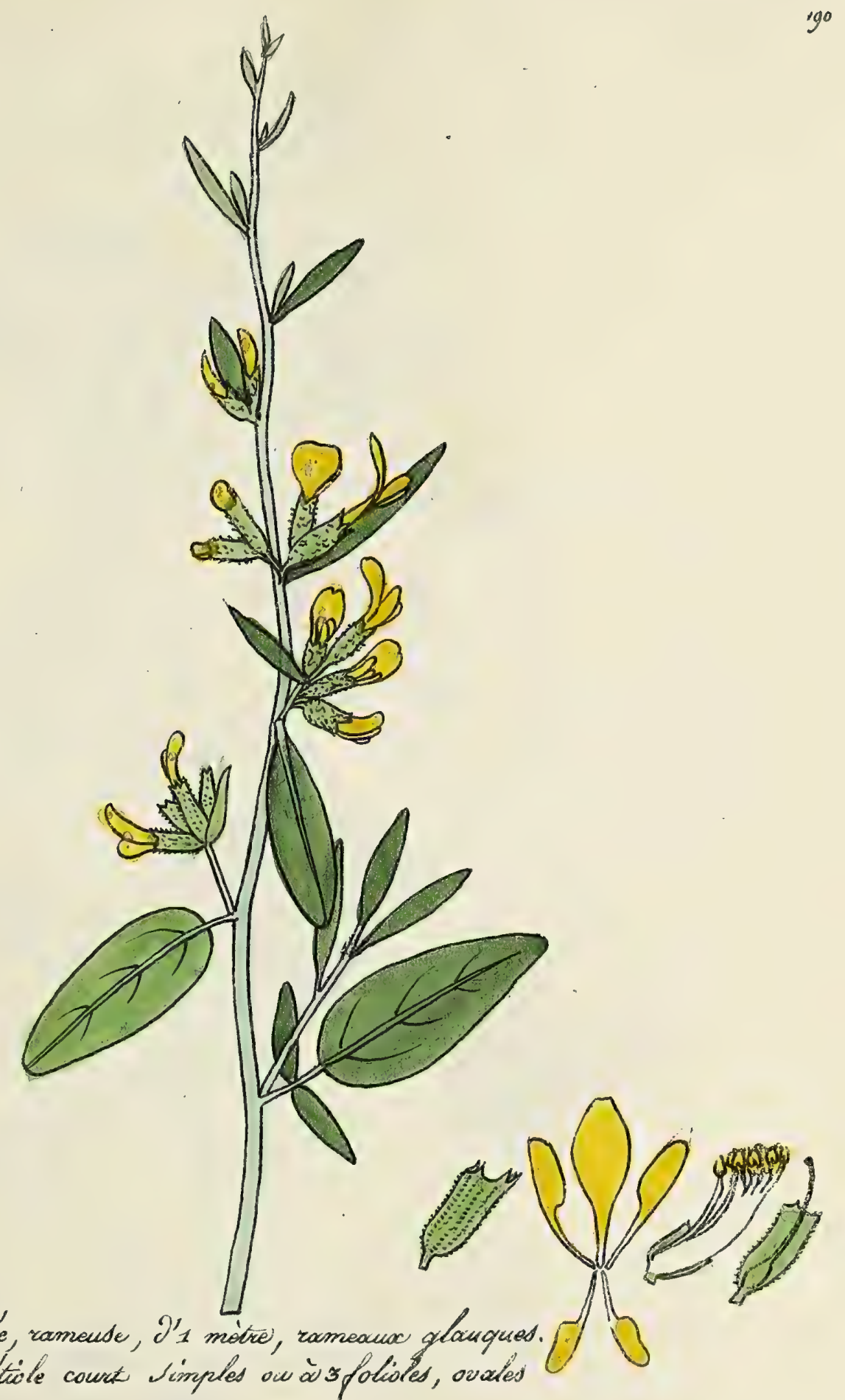

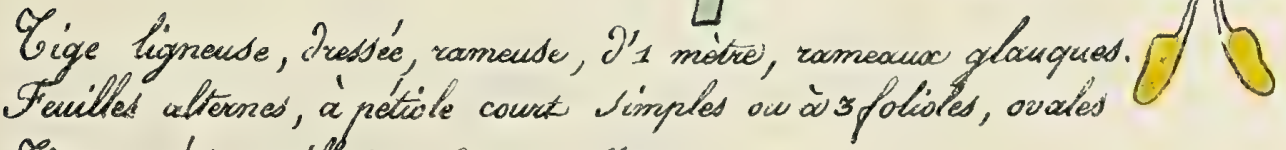
Eetes ou efins axcillacires de 3 à Gfleurd Palice tis velu, corrite jaune

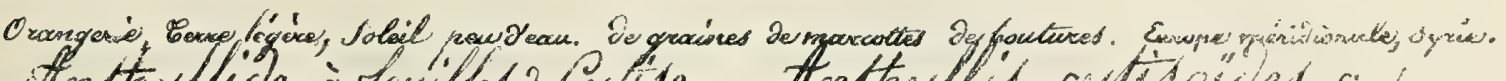

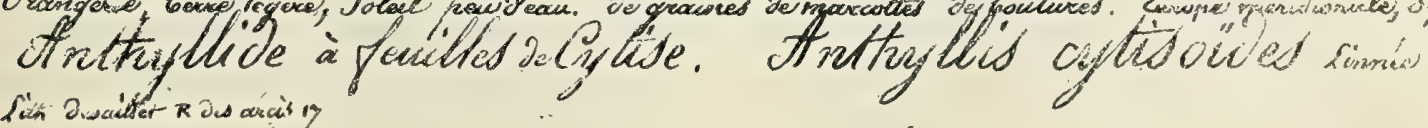





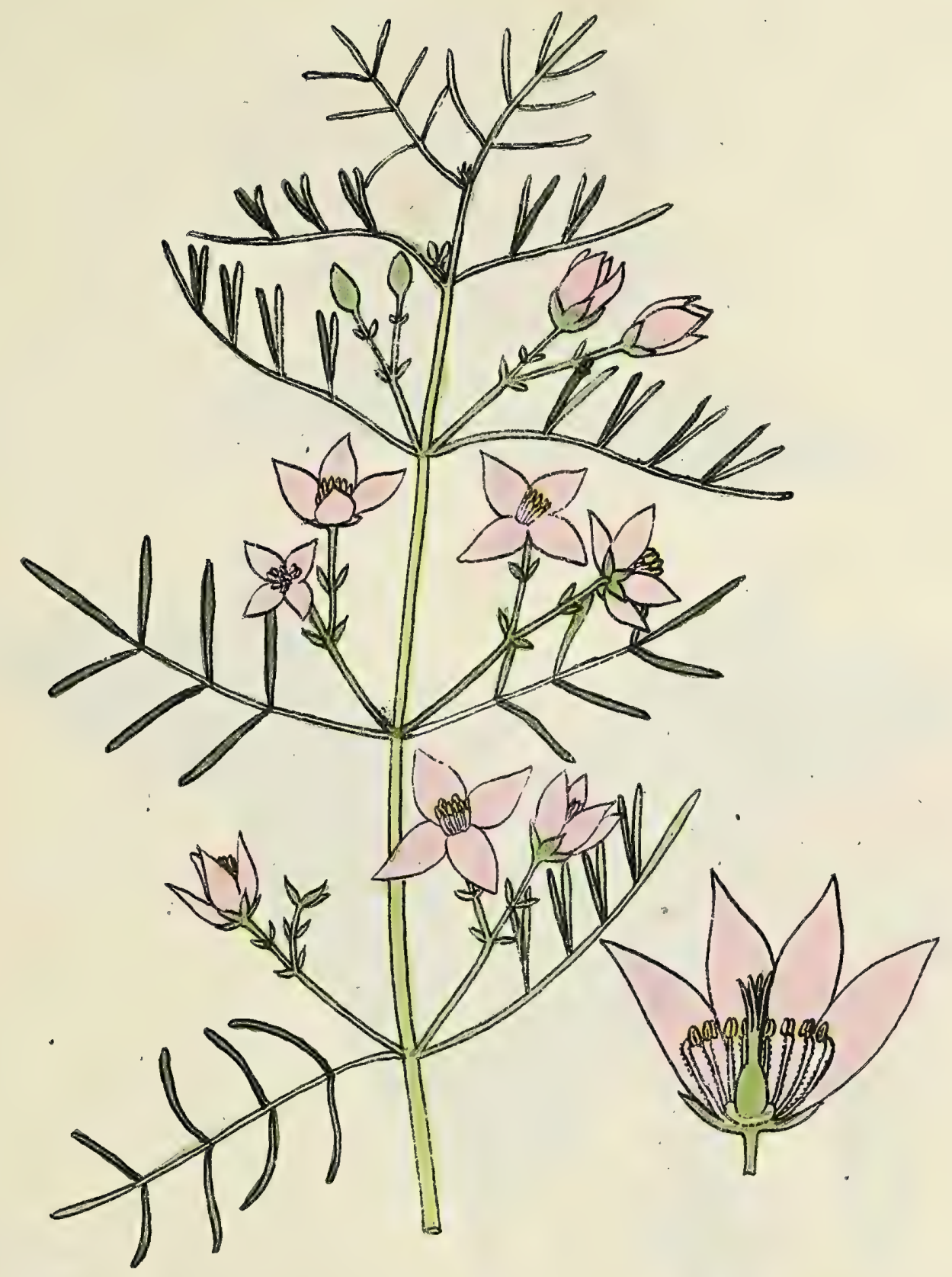

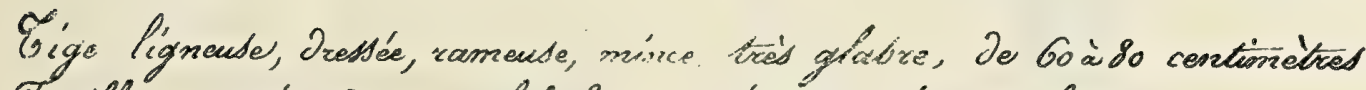
Femilles opposées de 5 à g plivies inis érioites, arigues, glabices.

Pedoncules axillacires, solitainas, byties.

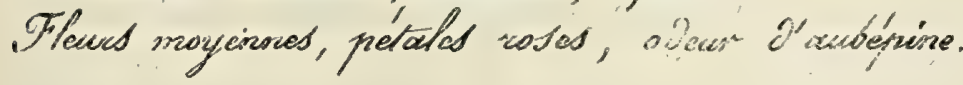

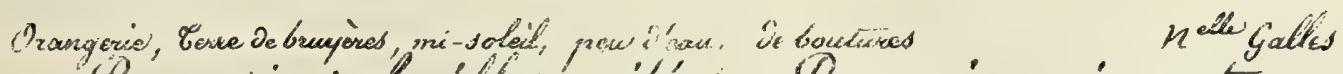

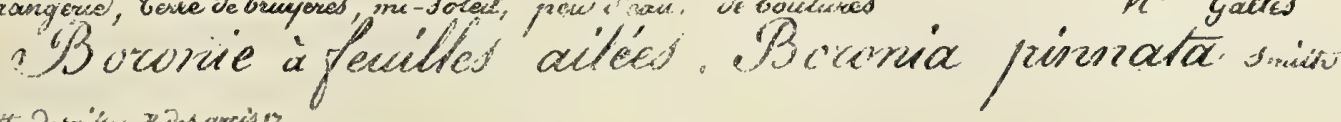





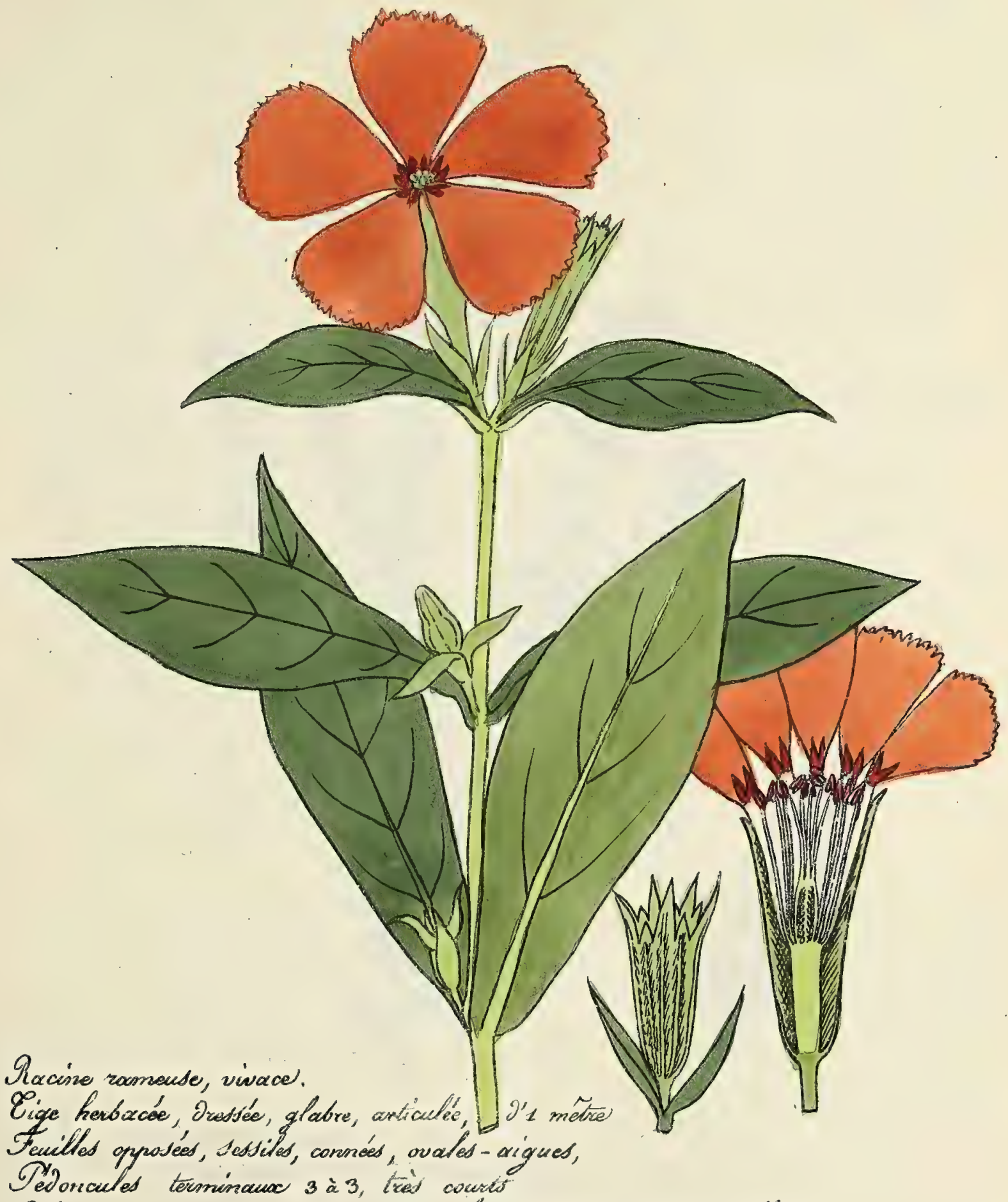
Calice orv masswe à 10 cotes, pótäles largres, Jéchiquetes, vermillons.

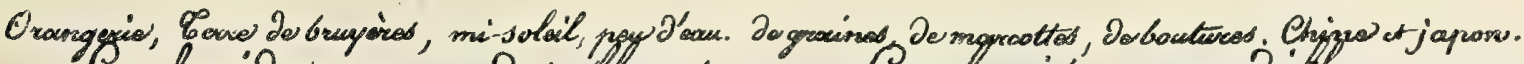

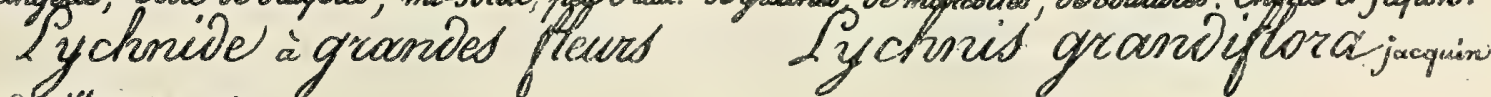

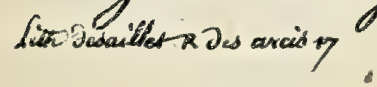





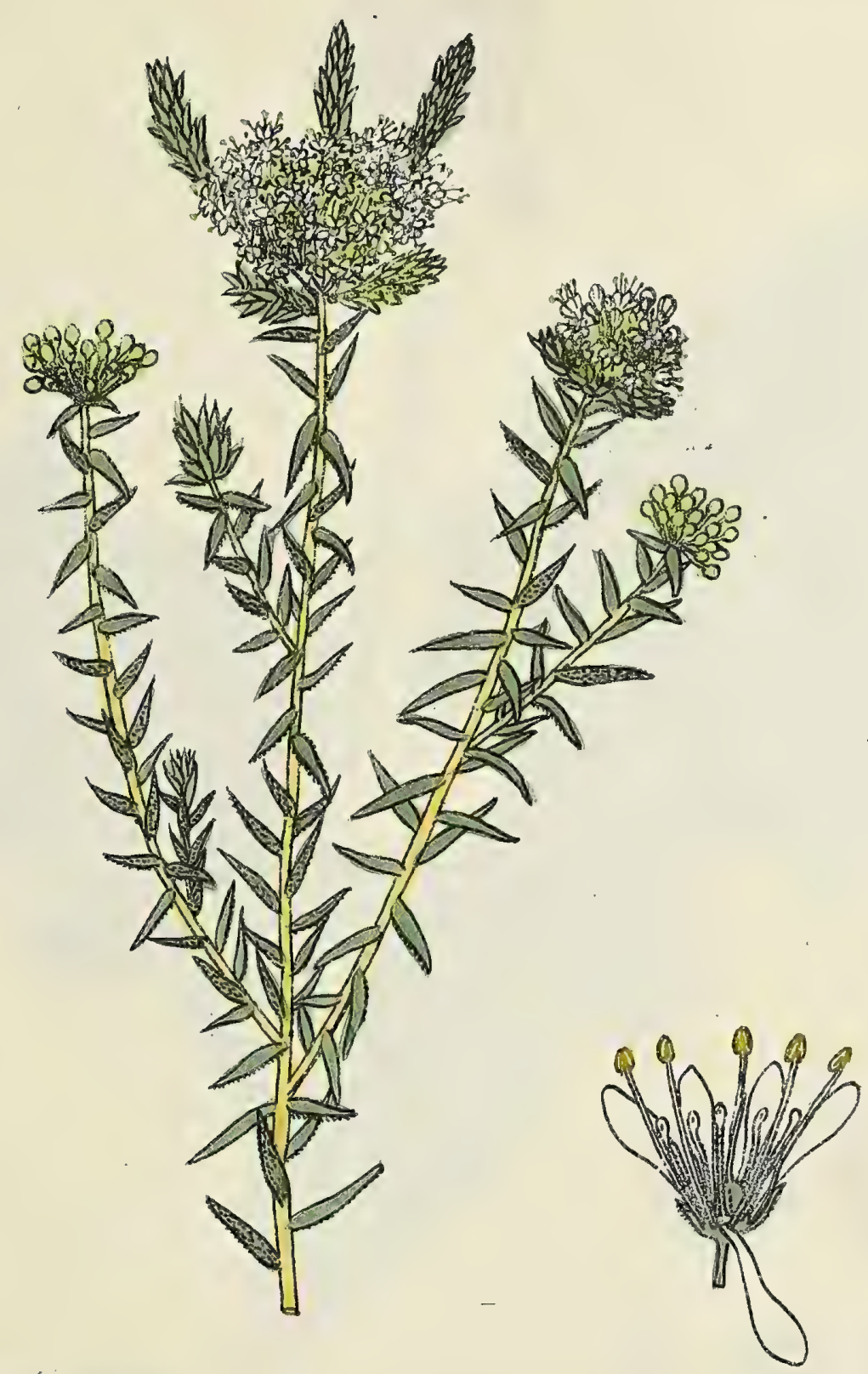

Sige Ligneuse, Itrestée, ramaude

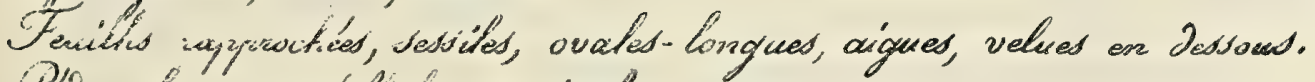

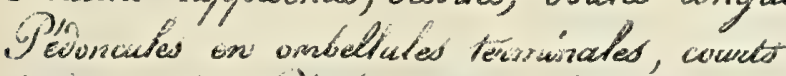

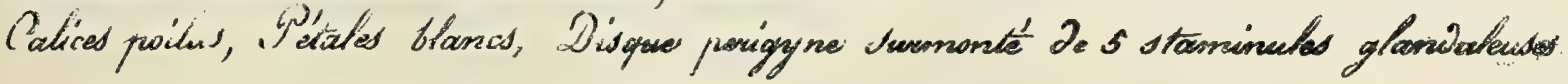

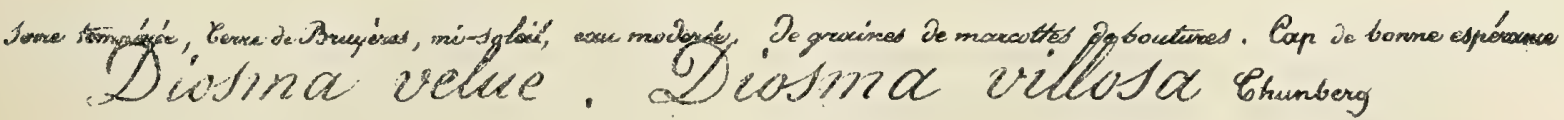





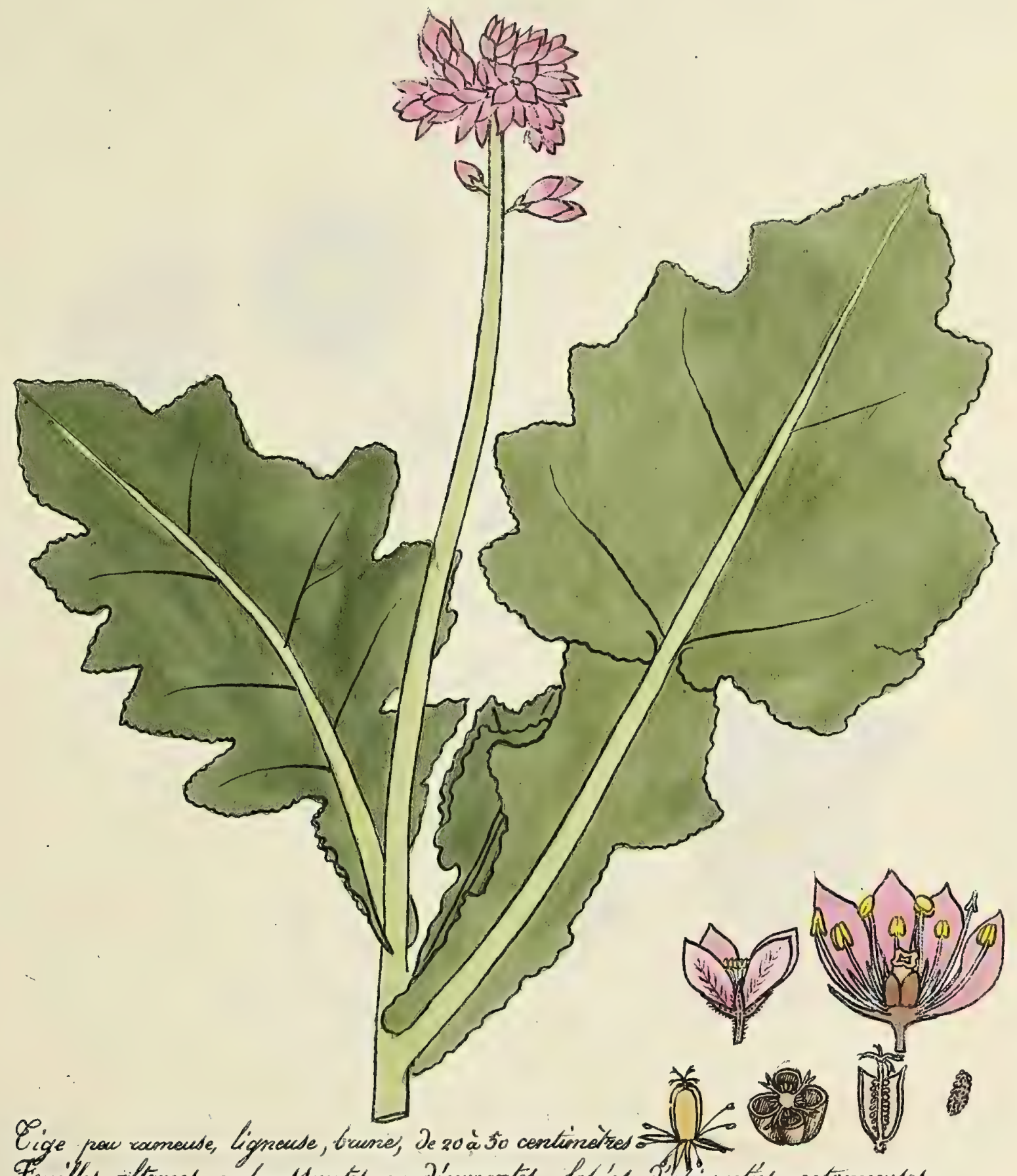

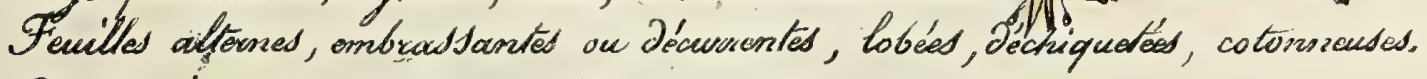

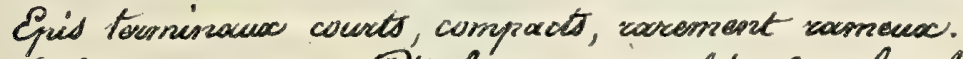

Calice cotornoux, Metales coses, tachés de plues foncé.

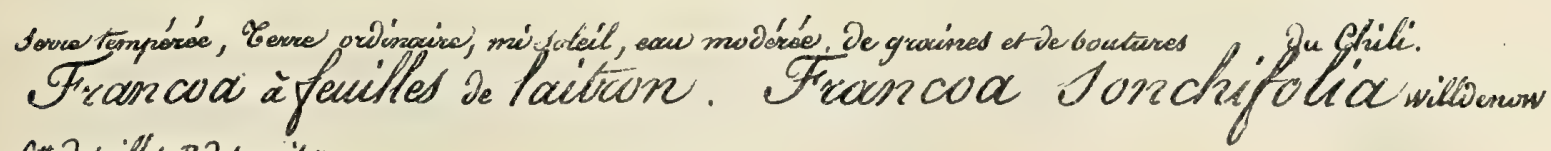
Sith Jedaillet $R$ Jas ancis iy 


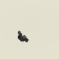




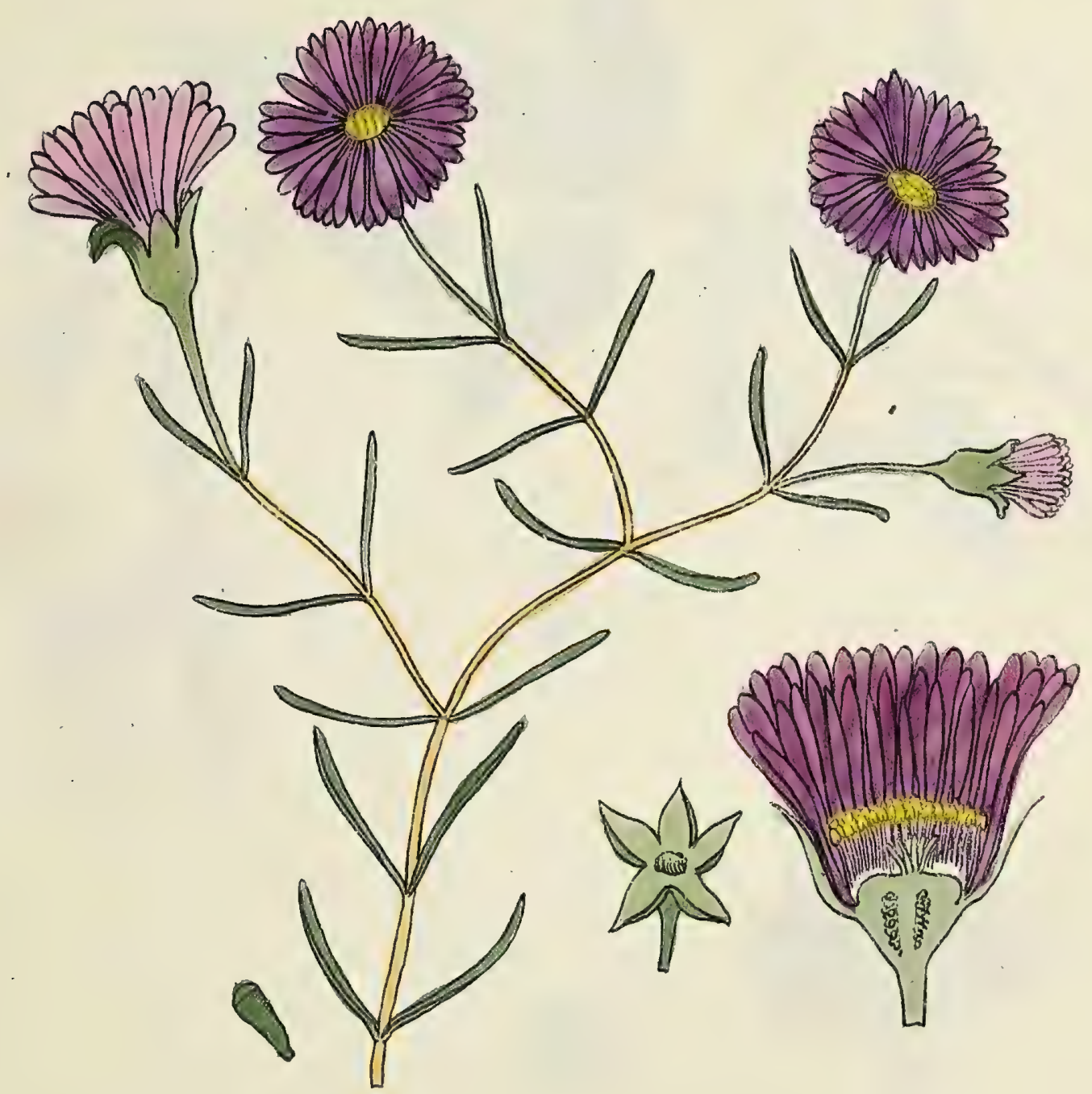

Eige ligneuse, faible, wougeâtre, à rocmeaux charnsus, glabres, ponidarts.

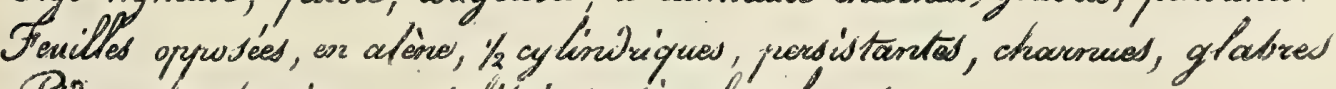
Pejonsules torminuma solitaices, simples, longs Petales viutets

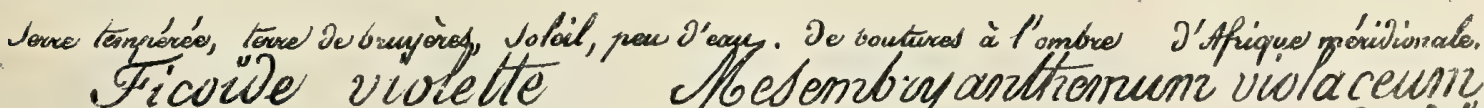

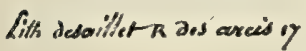




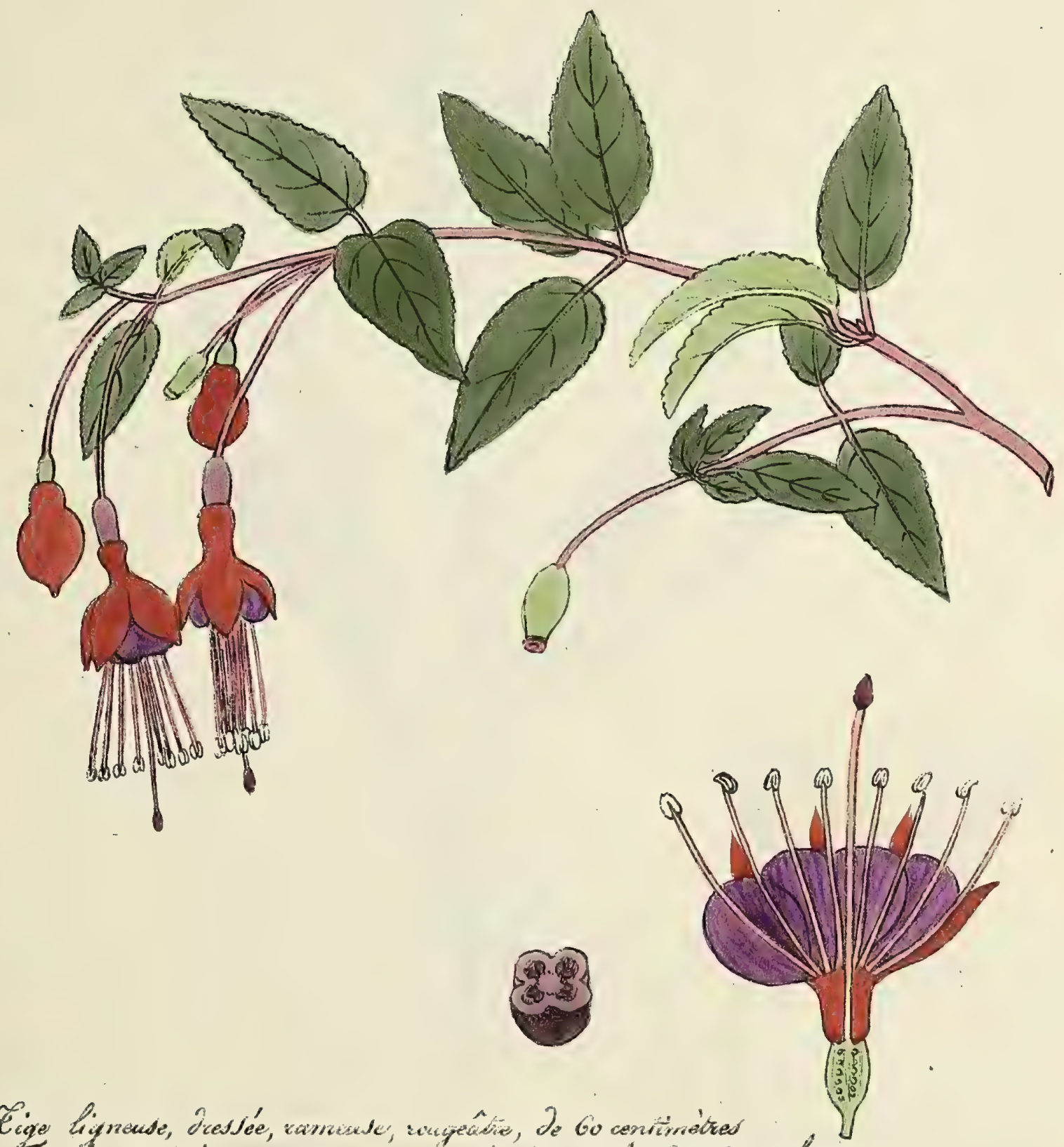

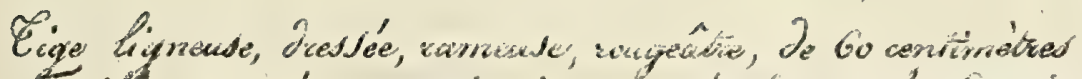

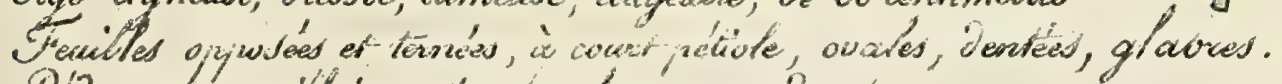

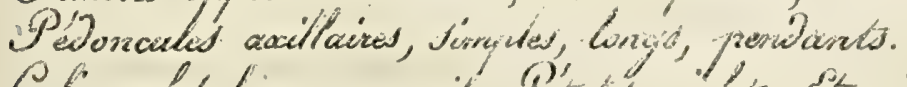

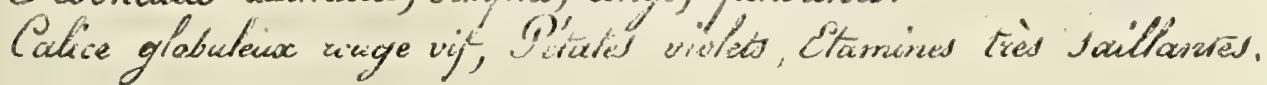

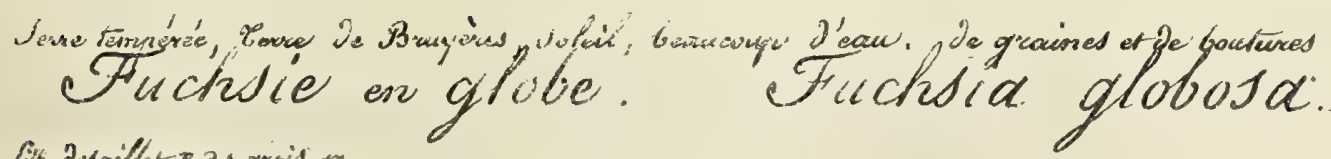

Sir Desaitler $x$ as arisis 17 


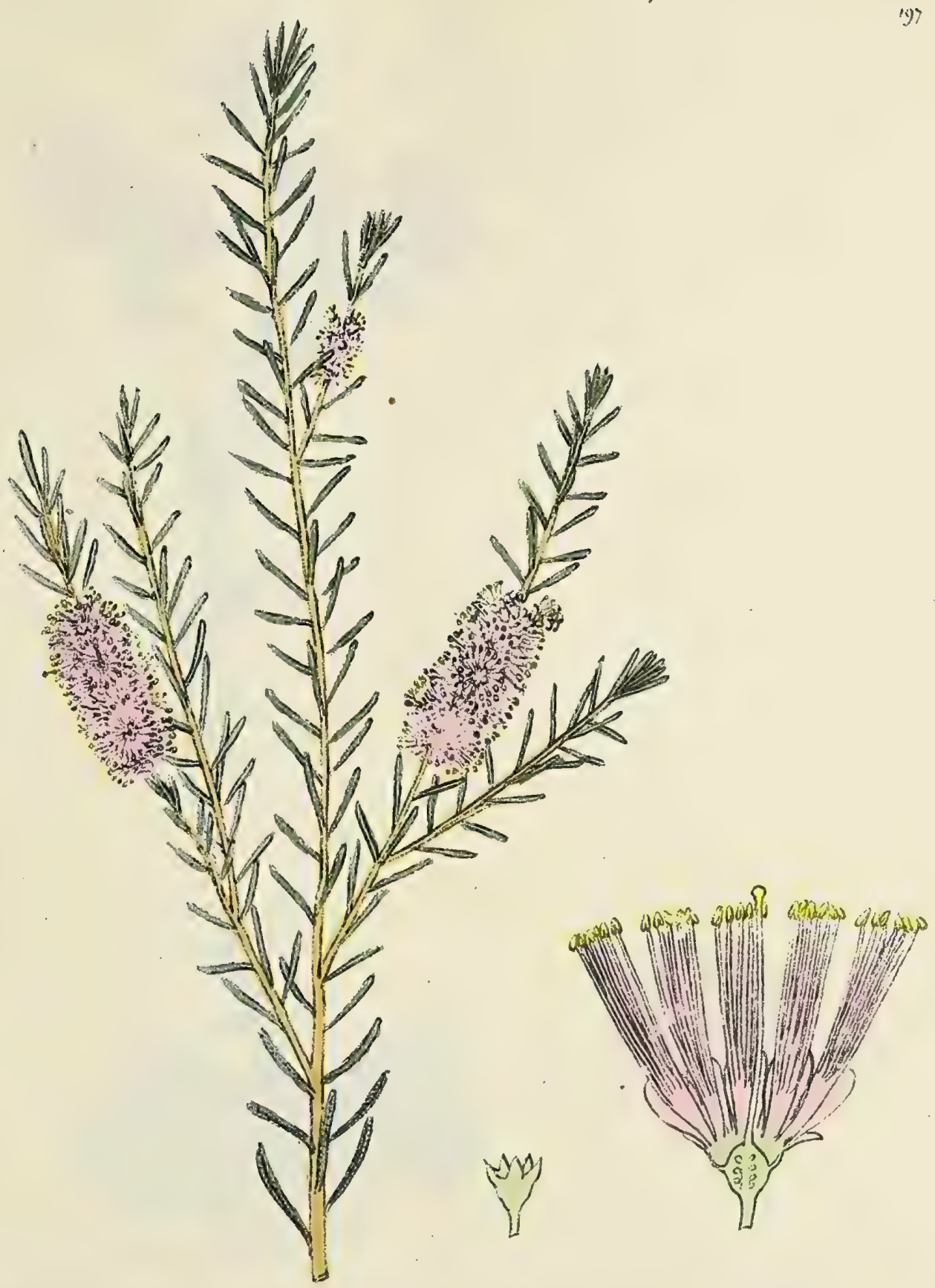

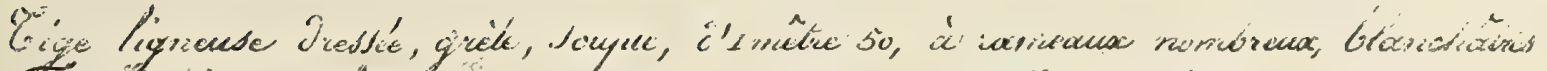

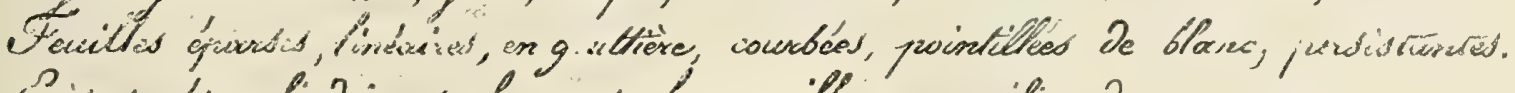

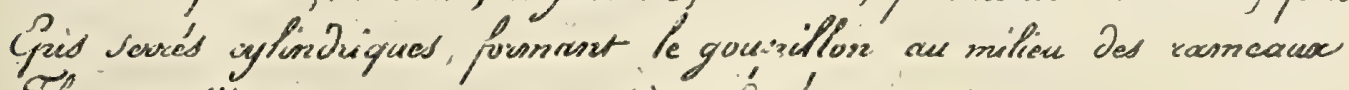
. Teund petites, rose-pourfuce, asuticies dovéd.

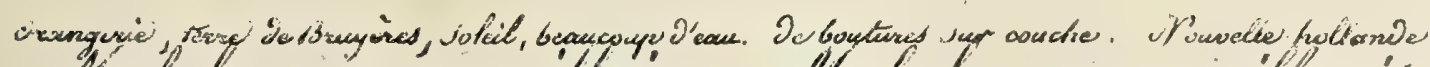

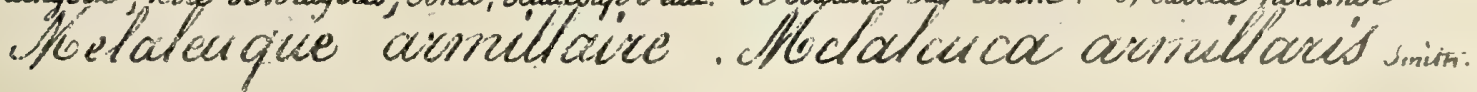




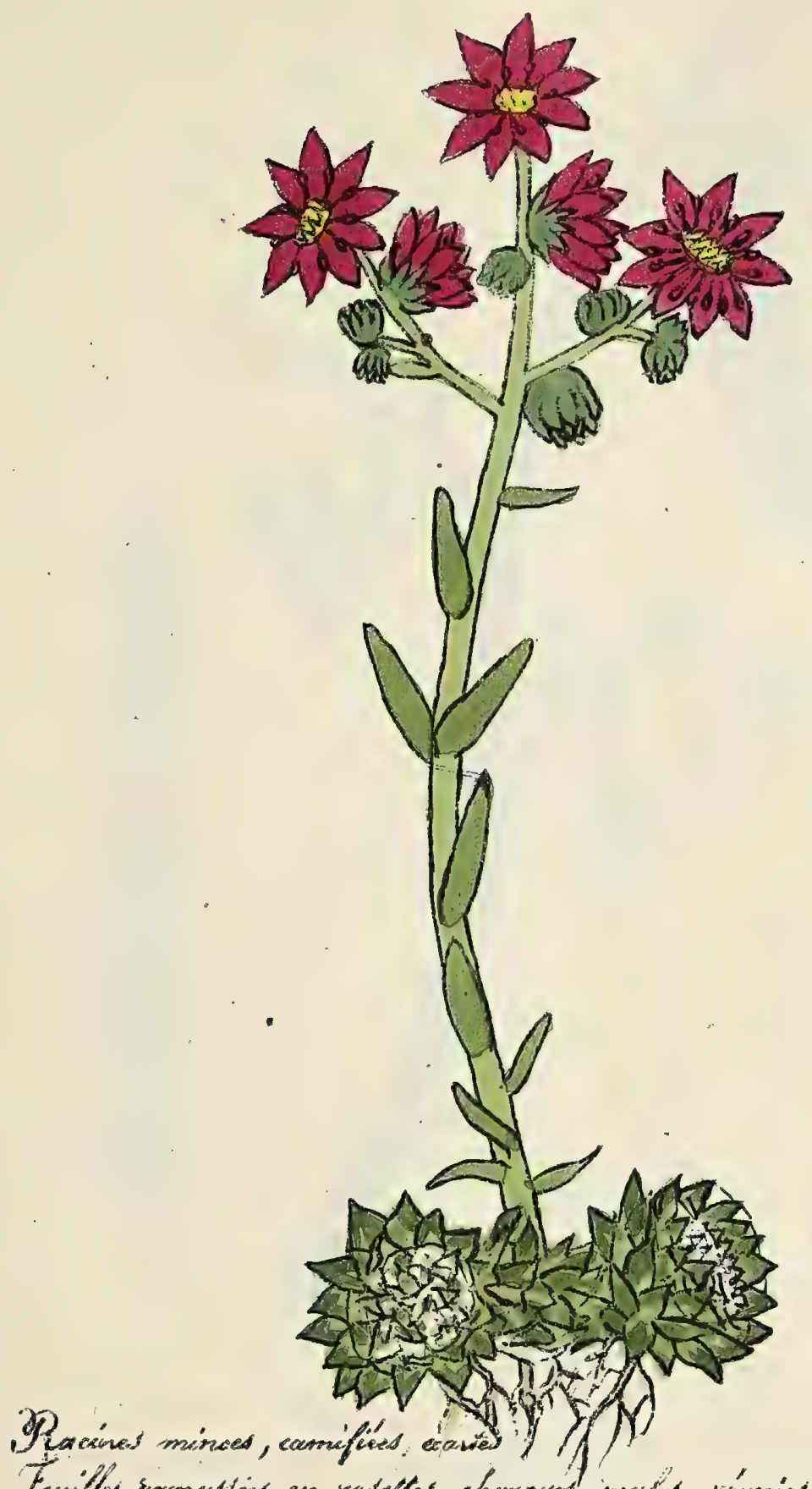

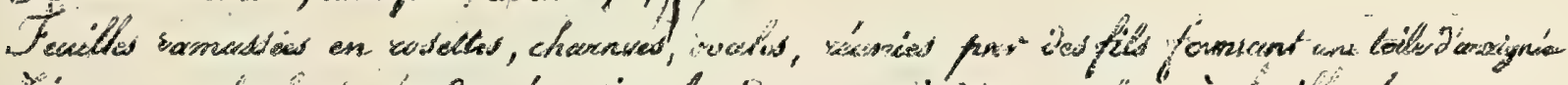

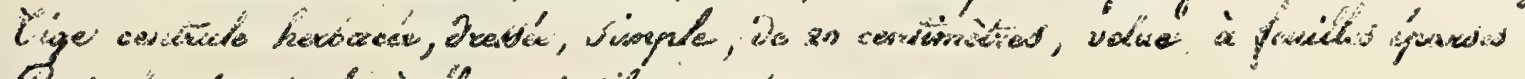

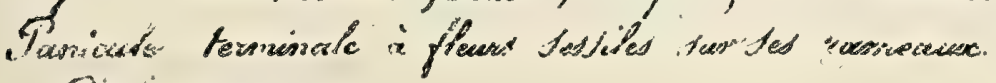

9 Fivices paroupred.

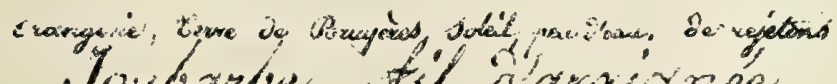
Joubrabe fil oraxiynee.

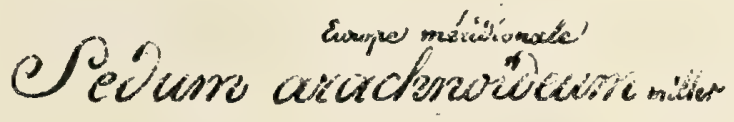

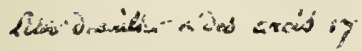

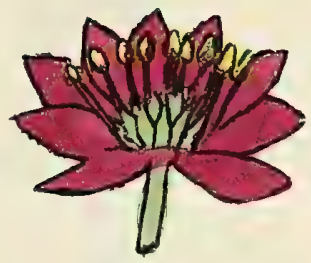





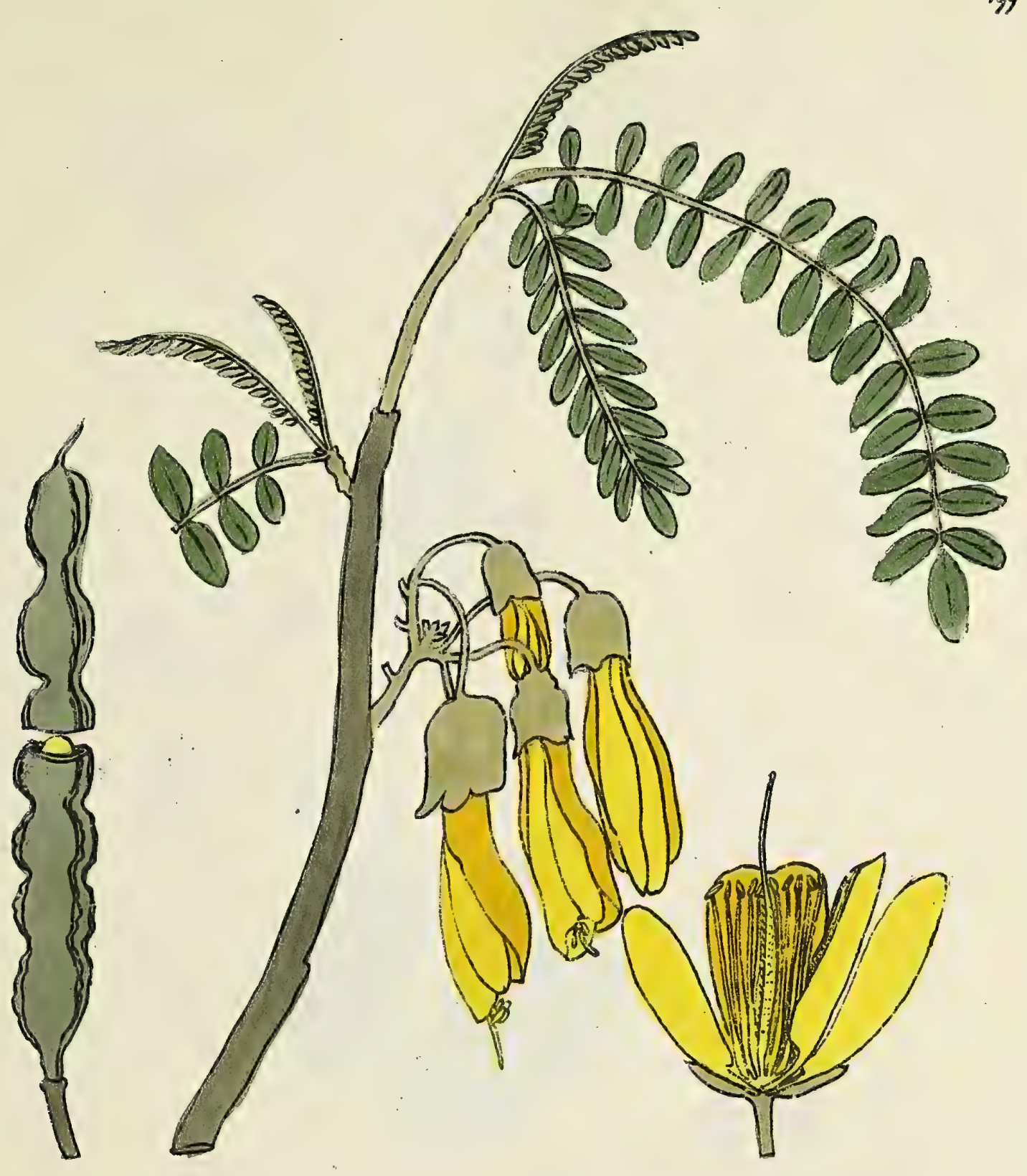

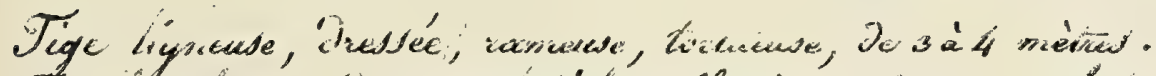

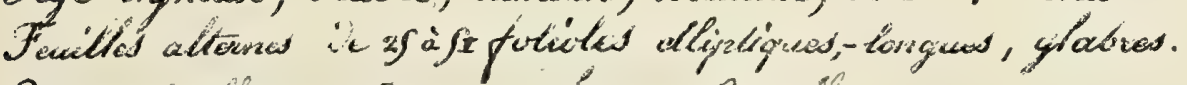

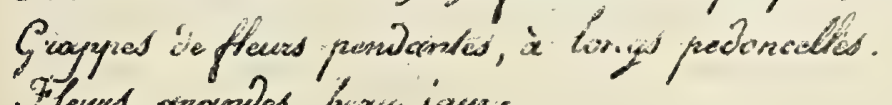

Fewed gramios, baxu jacuse.

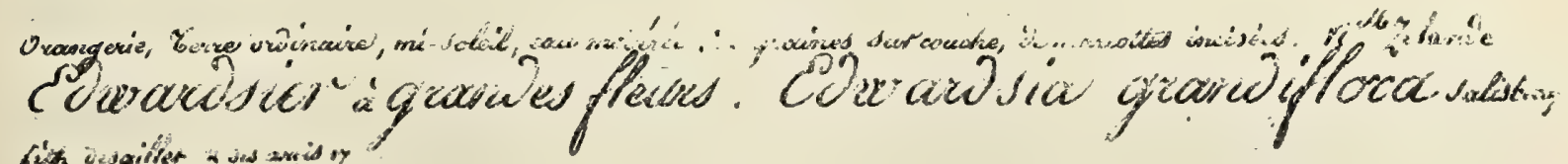




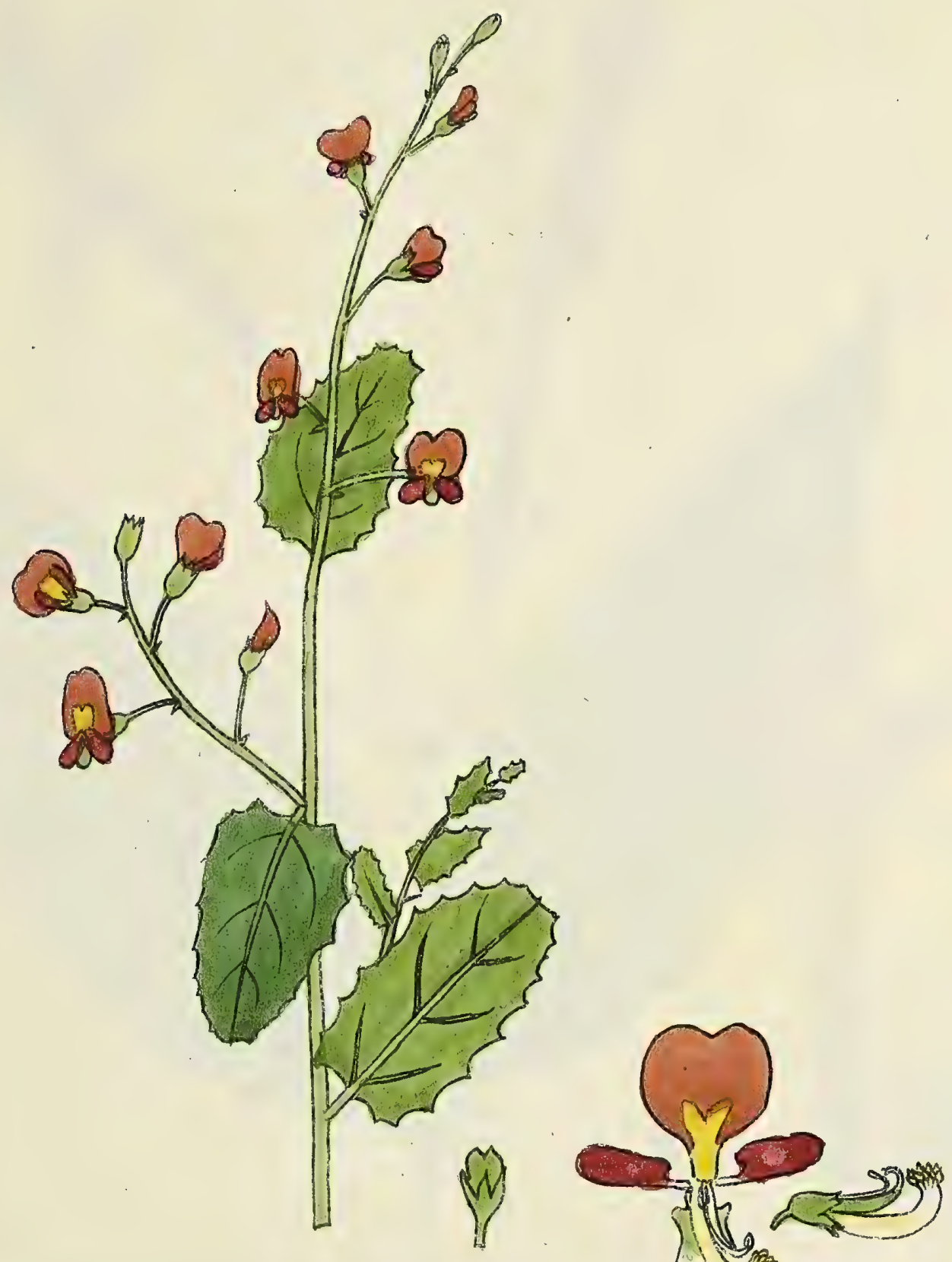

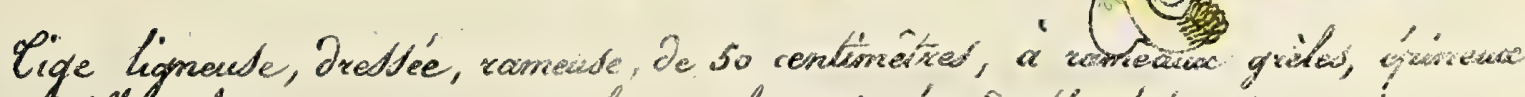

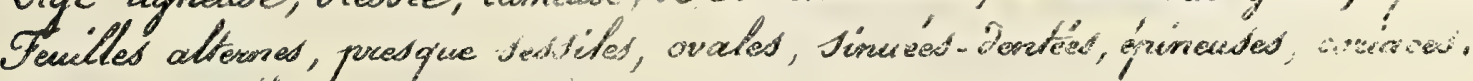

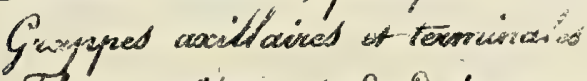

Fleurs petites, etondari jauser, lavé de vermillon vif

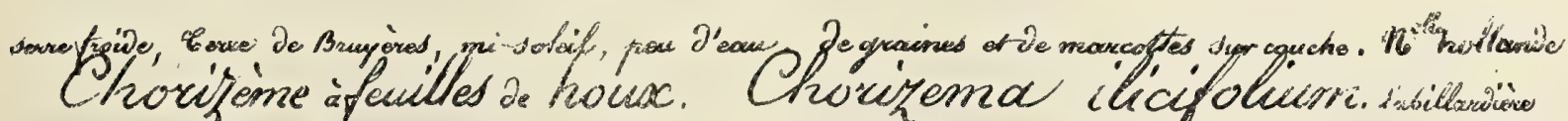

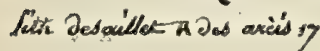





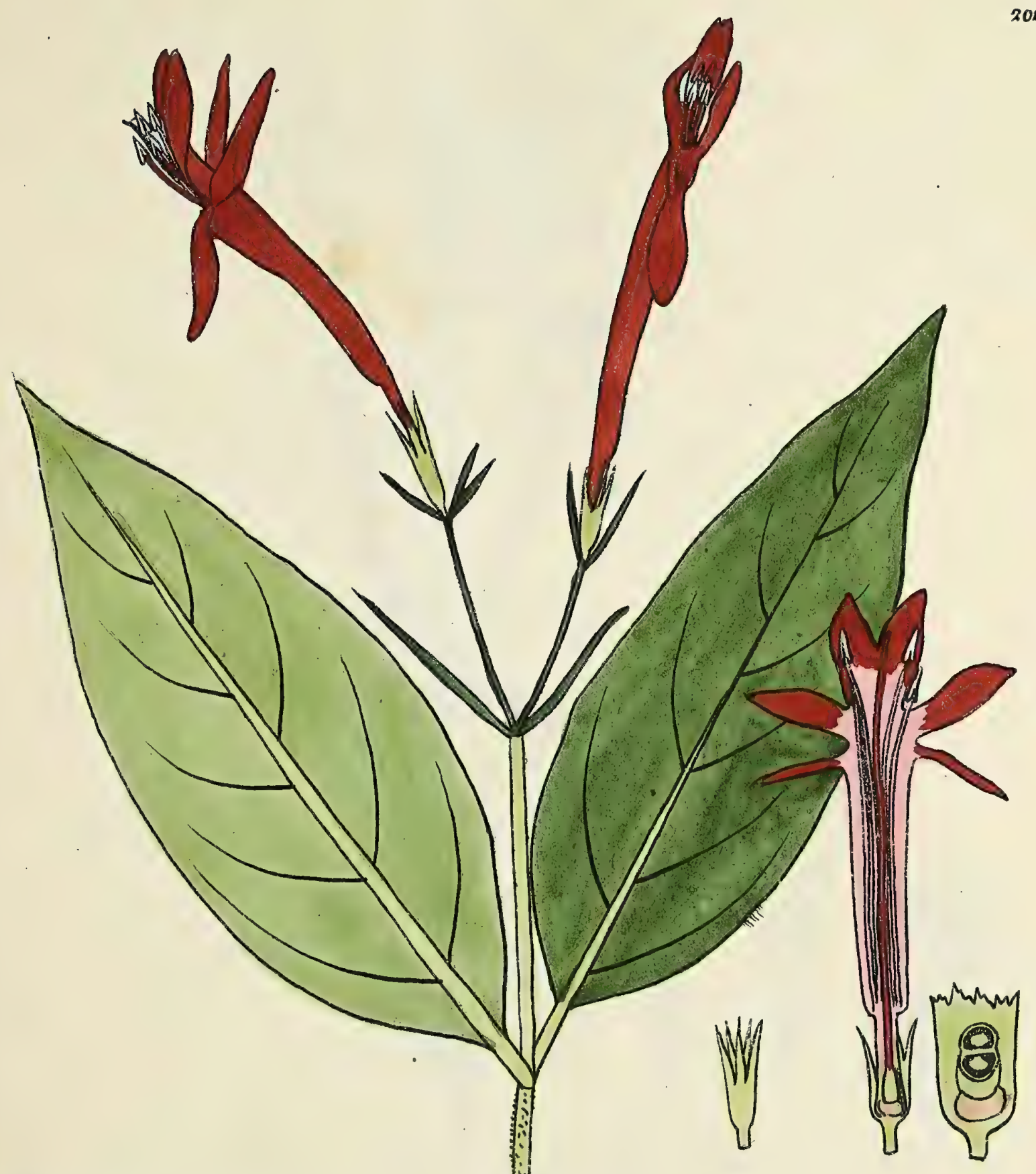

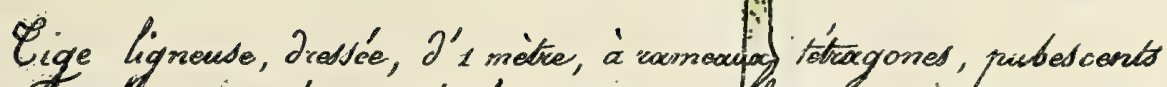

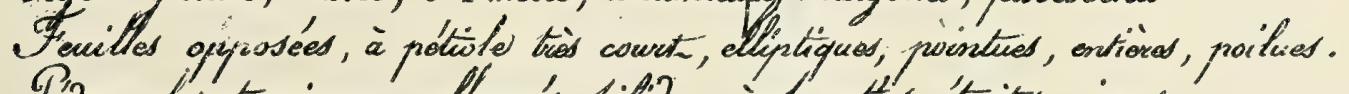

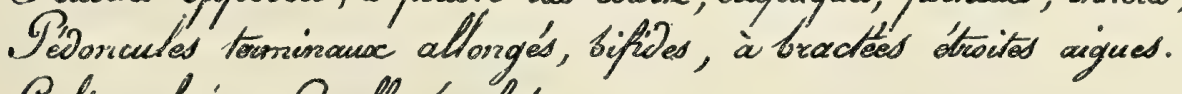
Calice glabre. Corolle écoulate.

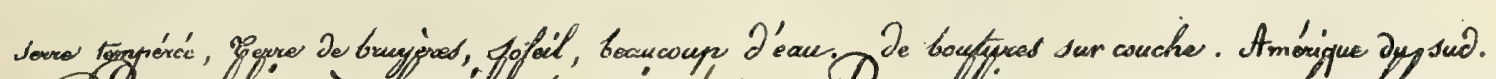

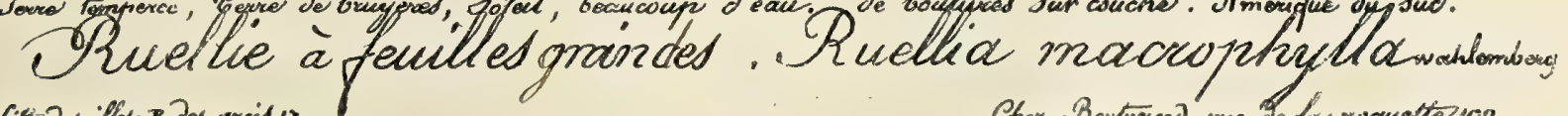

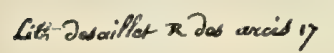

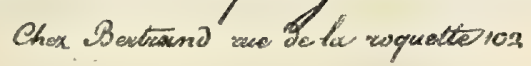




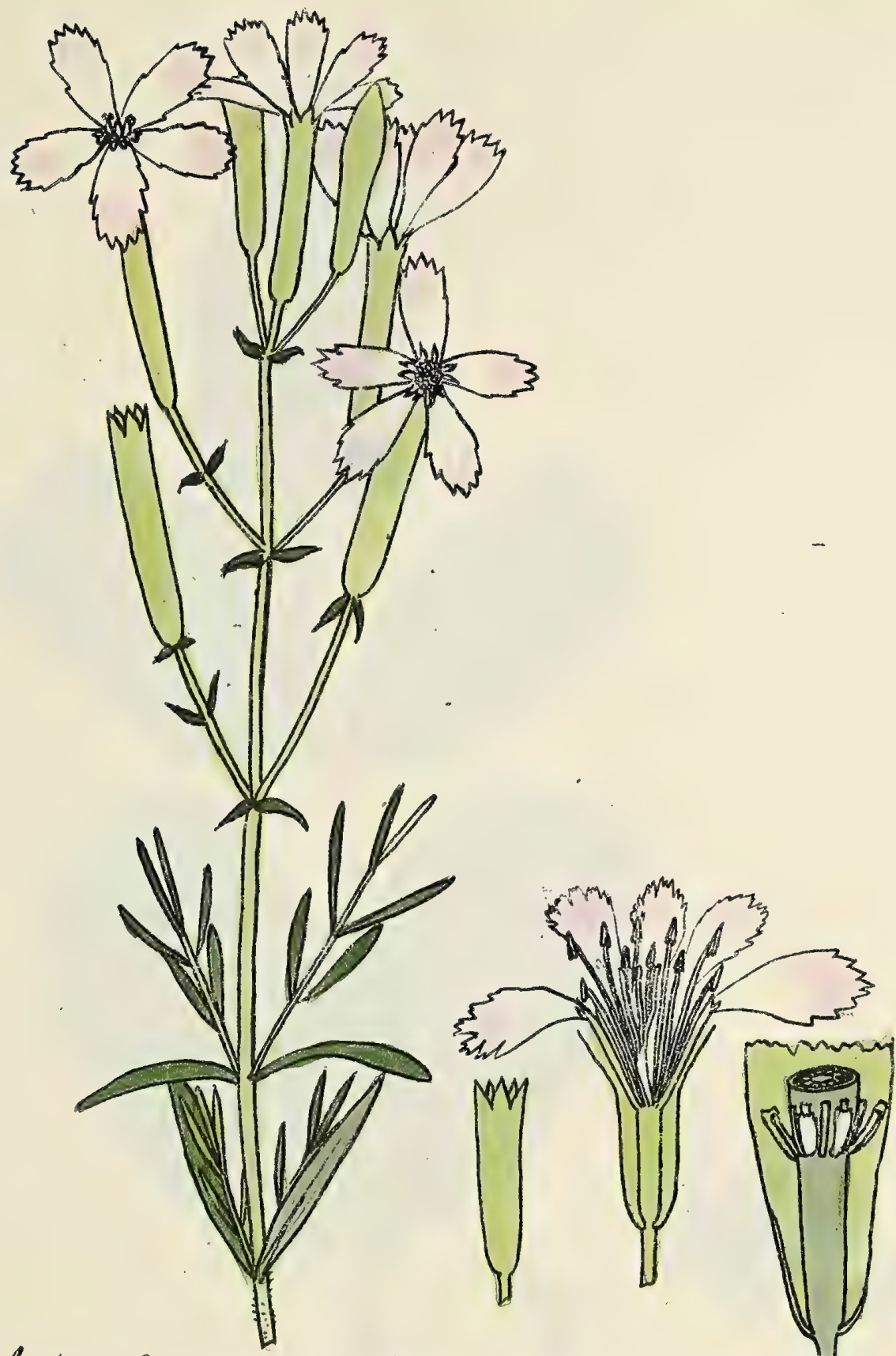

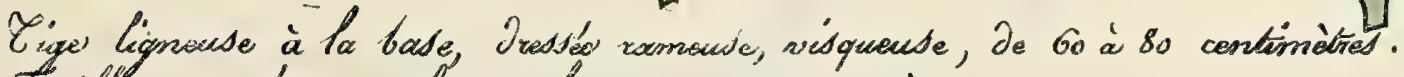

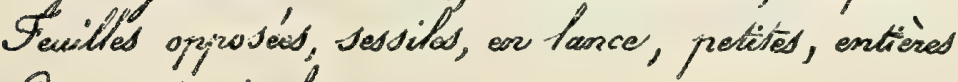
Croppes terminalas.

Calice à Dents aigues, Pettales Dechiquatés, rosed.

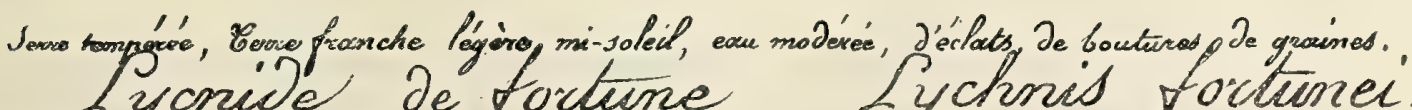
zyonide de fortune Lychnis porturec.

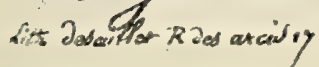
Cha Telé vue do Lubine y 



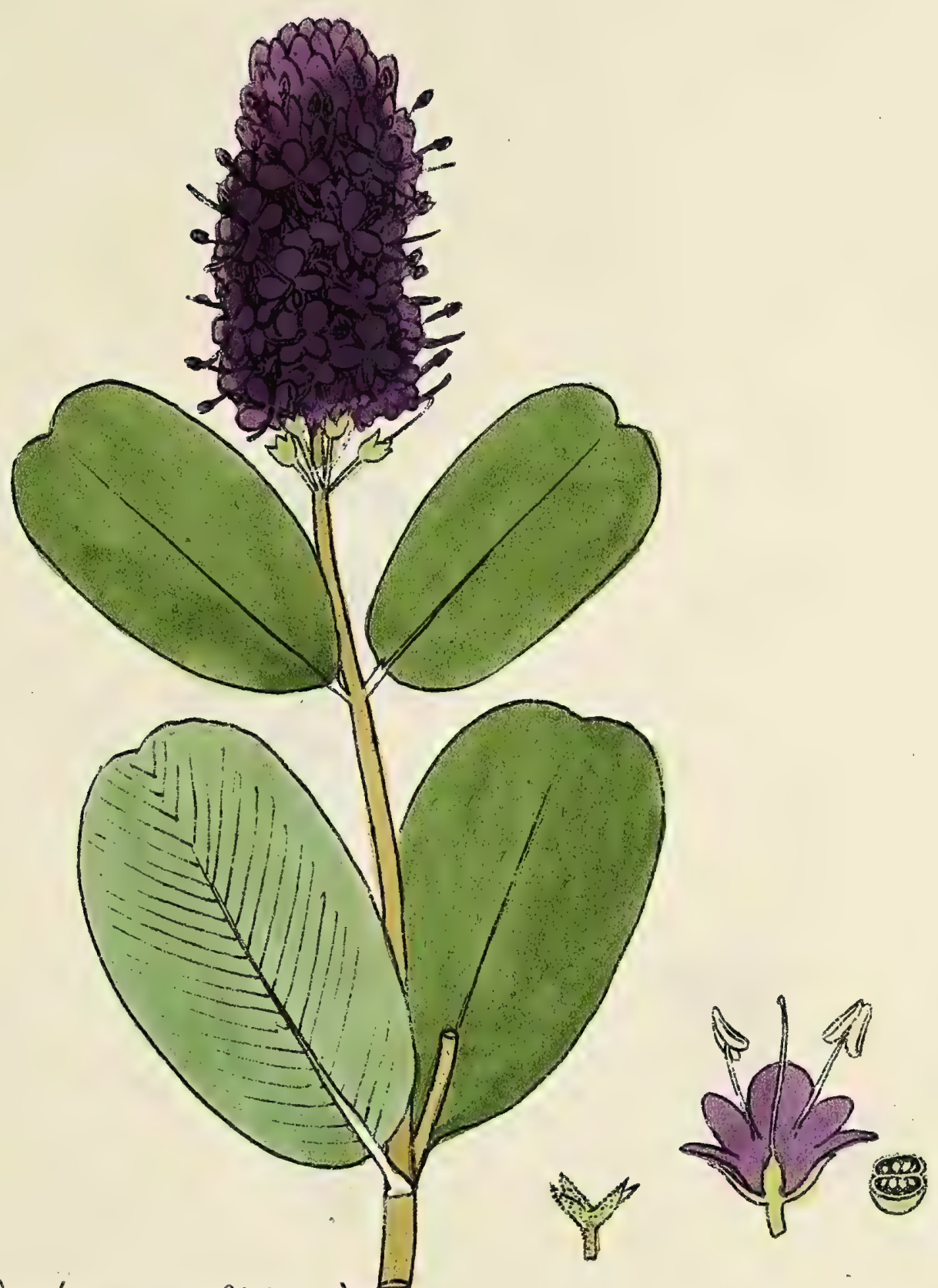

Eigre légneuse, Dresisé, vamouse, J's à 2 mivos

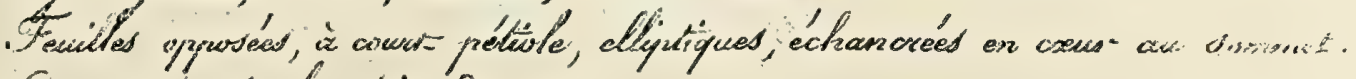

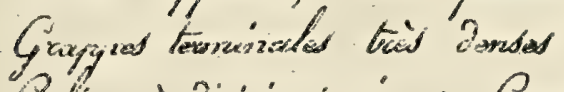

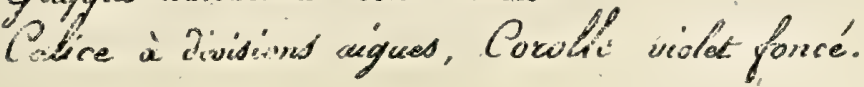

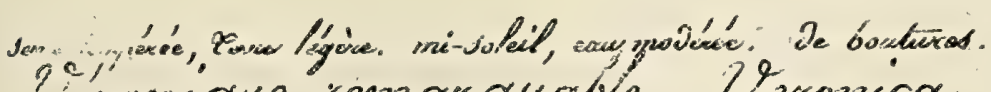

Zicuruque cenrarquable. Zexonica ufrecióla.

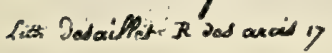




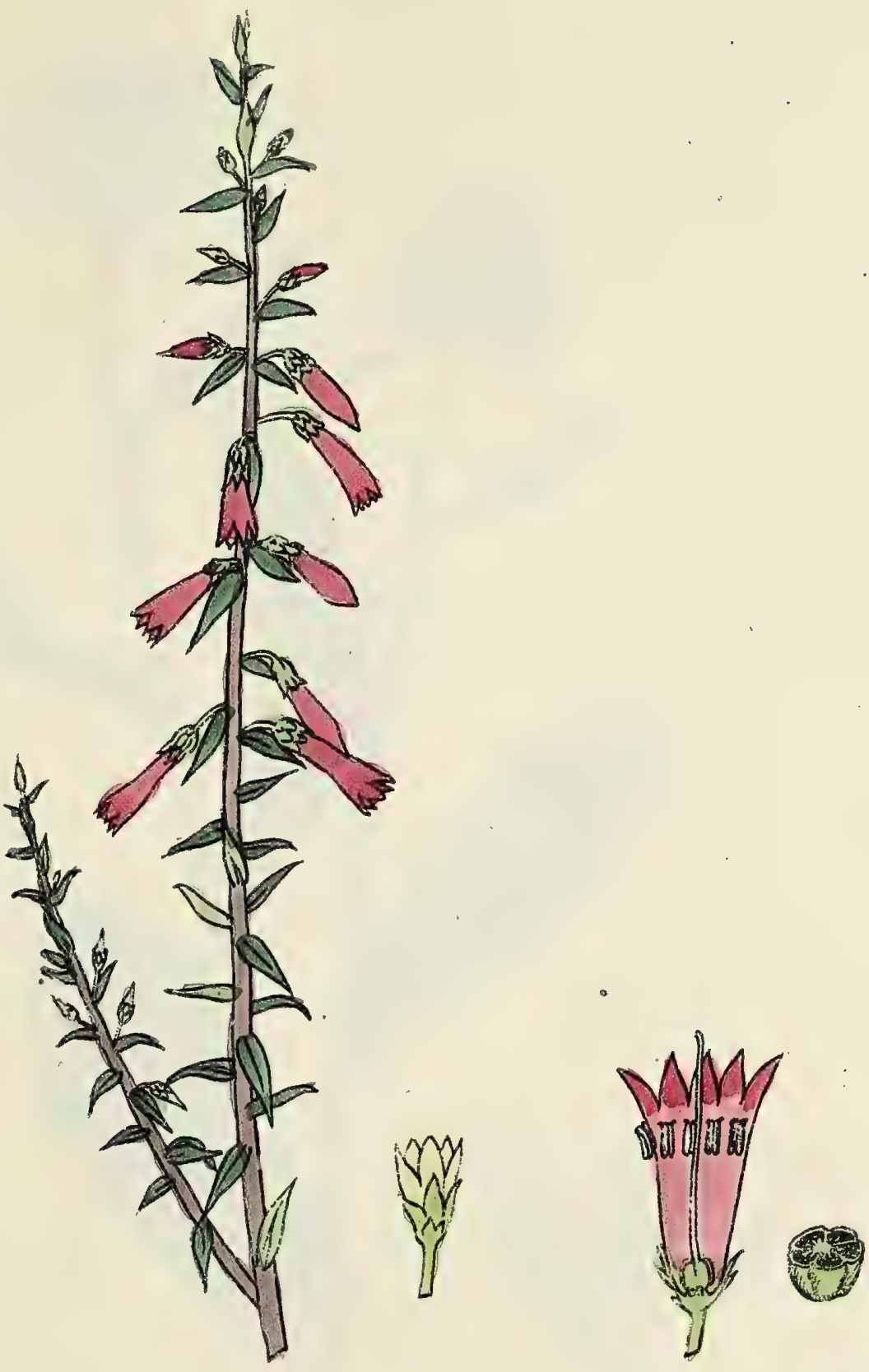

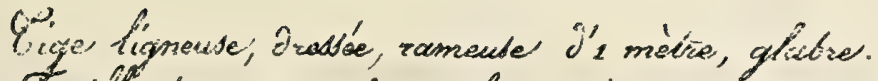

Fevilies époucbes, sessiles, en lance, trios aiguas, trais ouvertes.

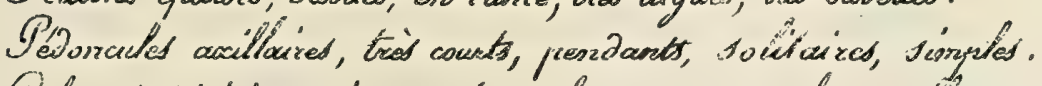

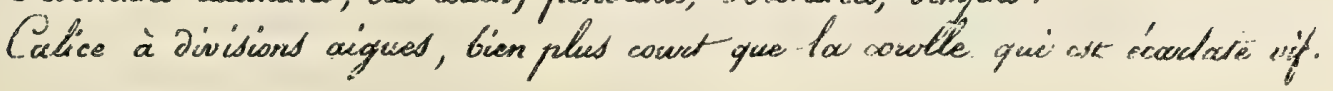

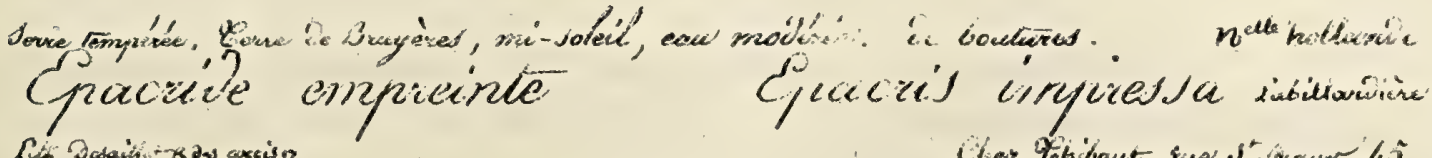


. 


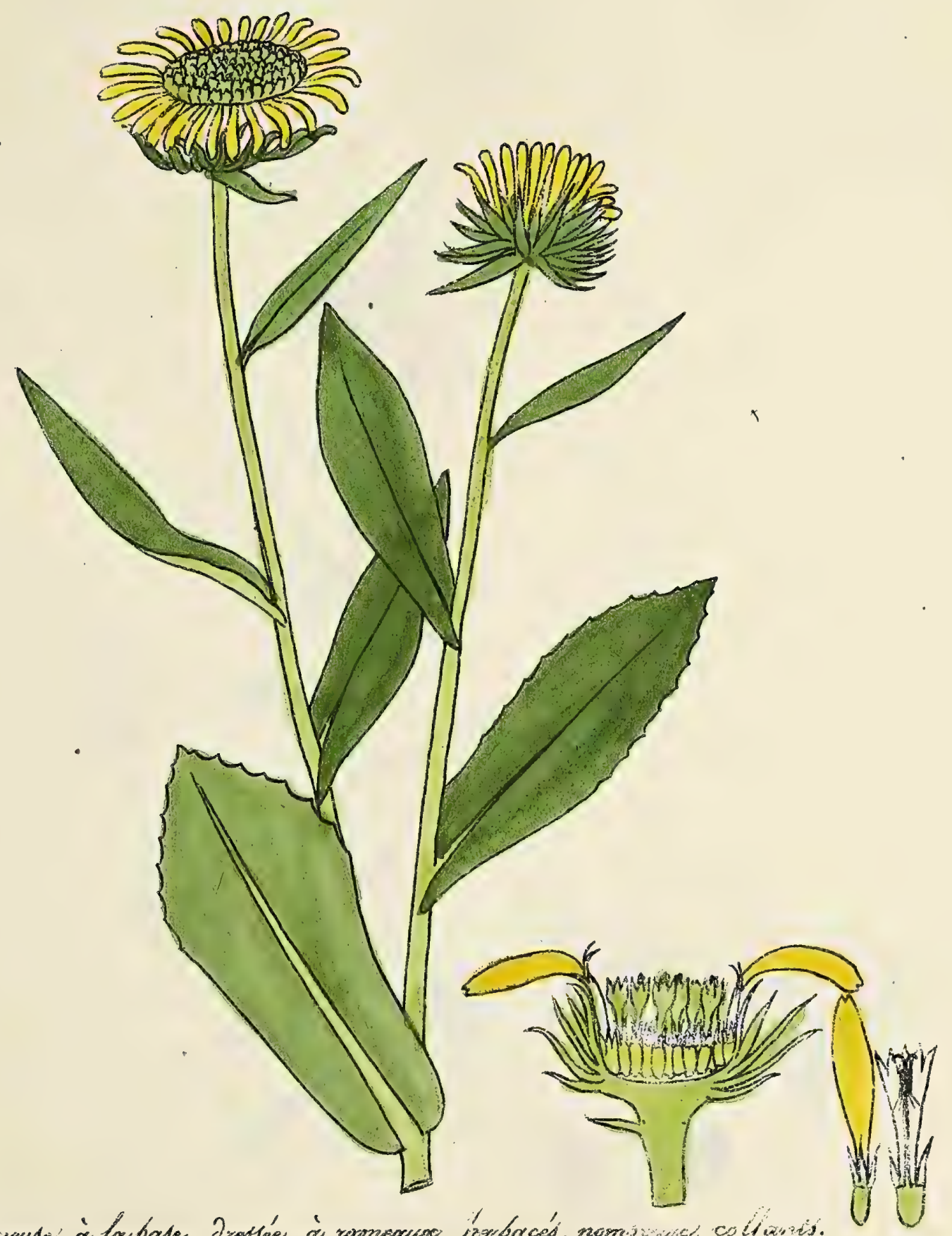

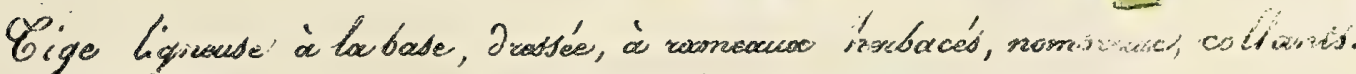

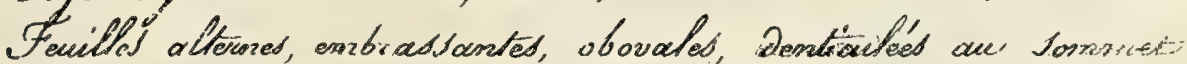

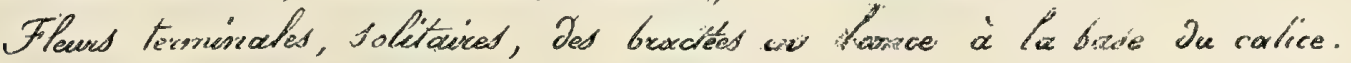
Deoniftewcons jauned, flevivons veritatred.

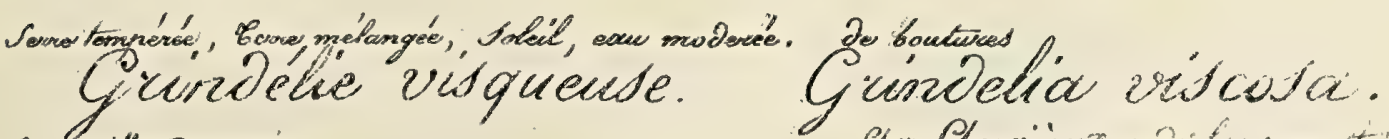
Sith beswither $R$ oes acreis?

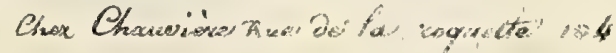




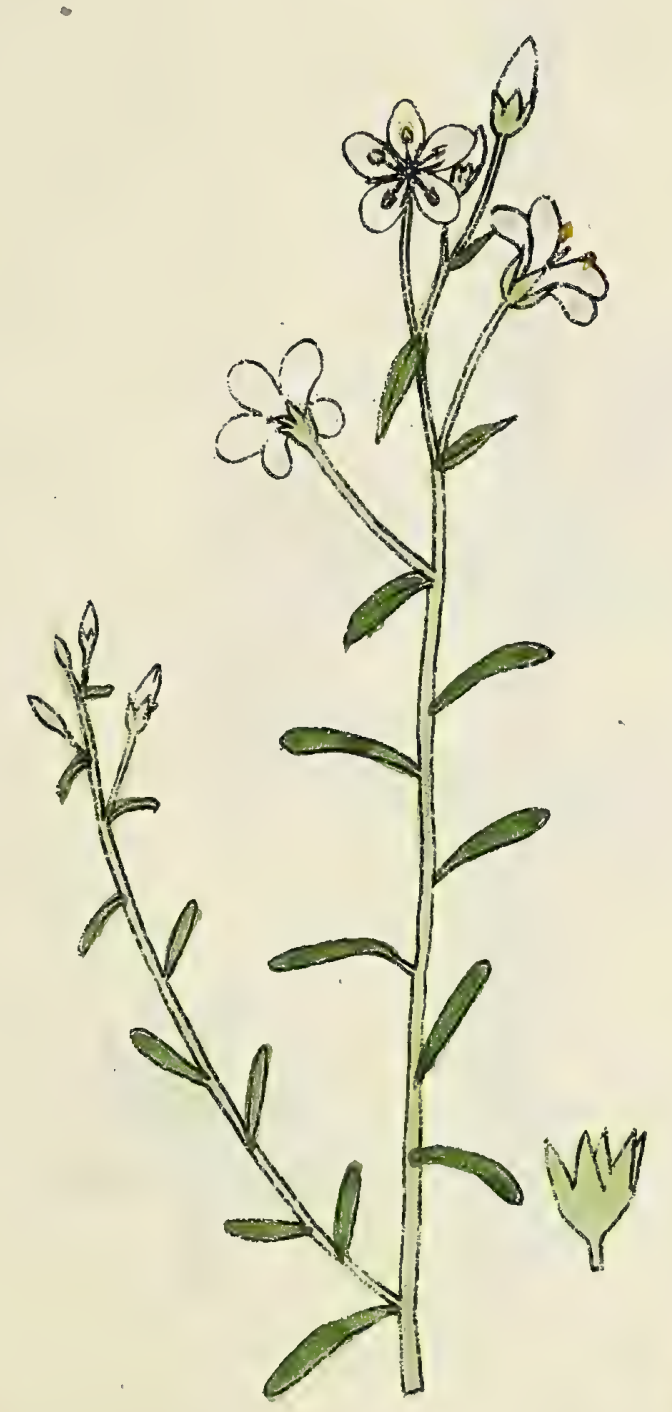

Siacirie inace

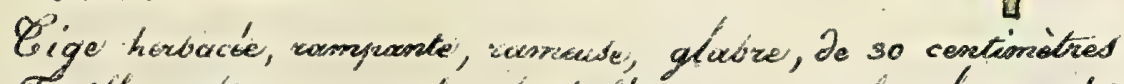

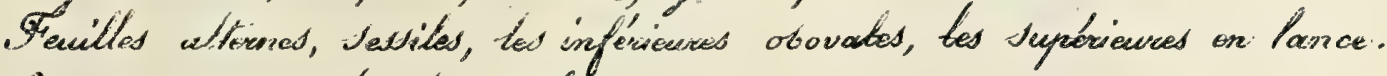

Grappes on pariculas torminates.

Calice à divistions aigues, Porslle Glanche.

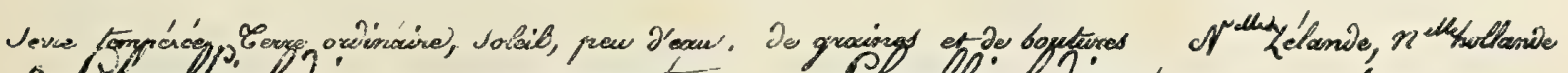

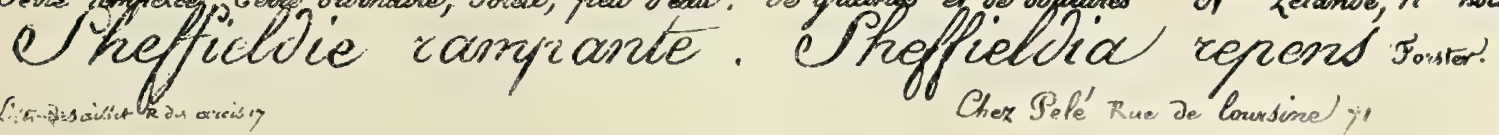





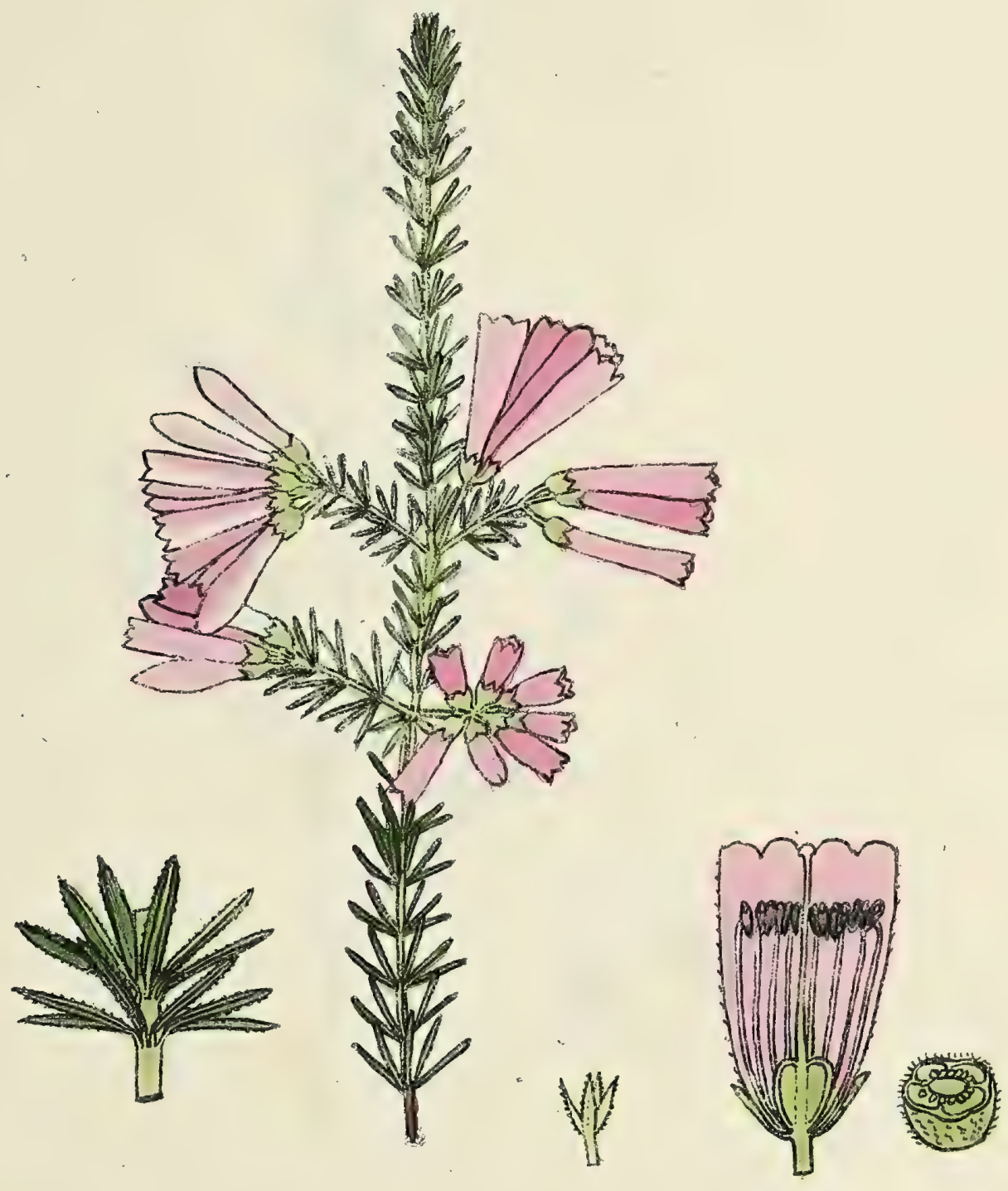

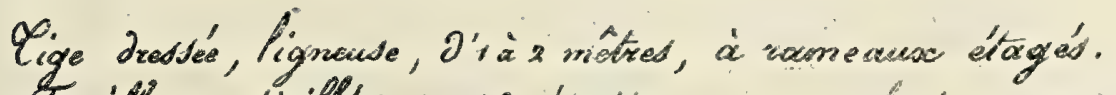

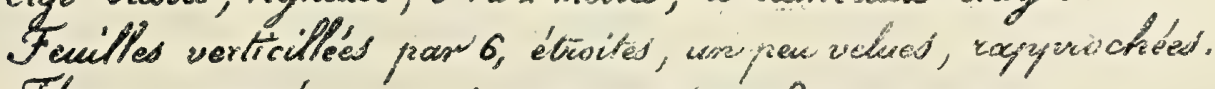

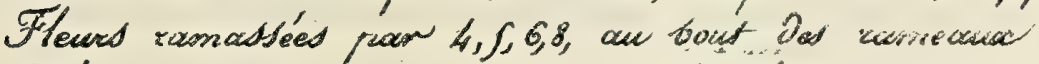

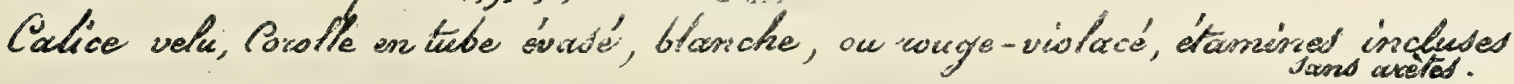

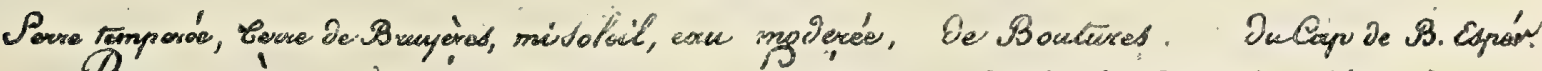
Bruyére migmwrone cicica concinana aiton. Sith Dosactist $R$ drs arcis oy

Ches Shourtiono rue Jes Bownguignonst 


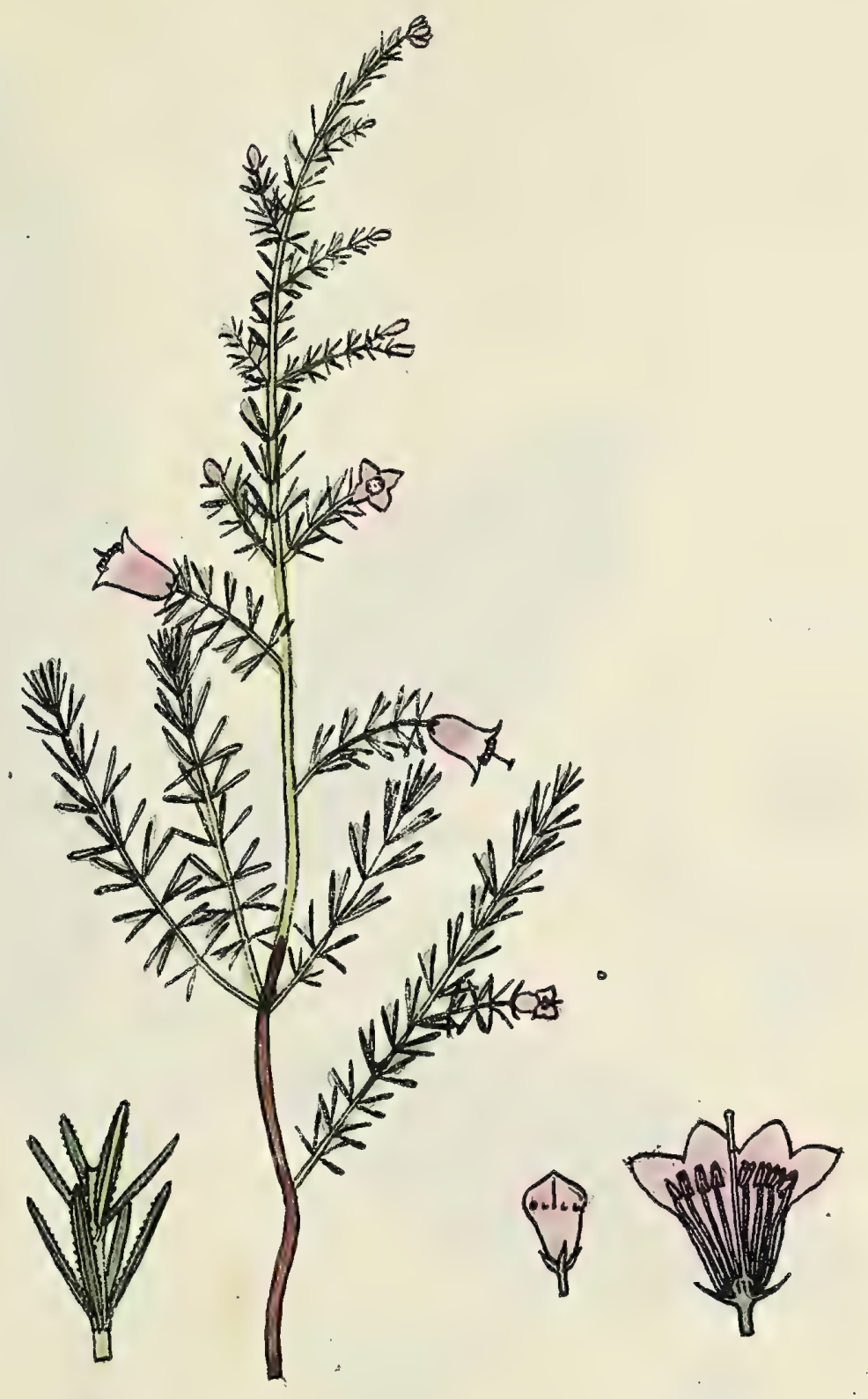

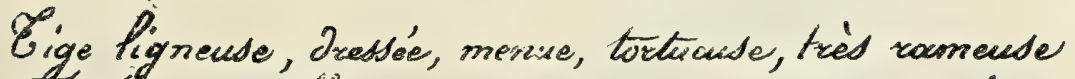
Teuittes venticilliés parr4, ties étroites, ouvertes, ciliées. Tieued solitaires, torminales, pencheied Palice glabre, Corolle doche, wose, Fonthèred inclused dans arietes,

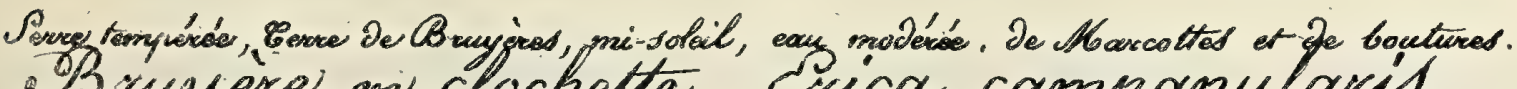
Bruyere en clockette. Cica campanulais fitr descillat $\mathrm{R}$ Ded arcis Cher Lemicher rue Des 3 couromses 14 
.

.

- 


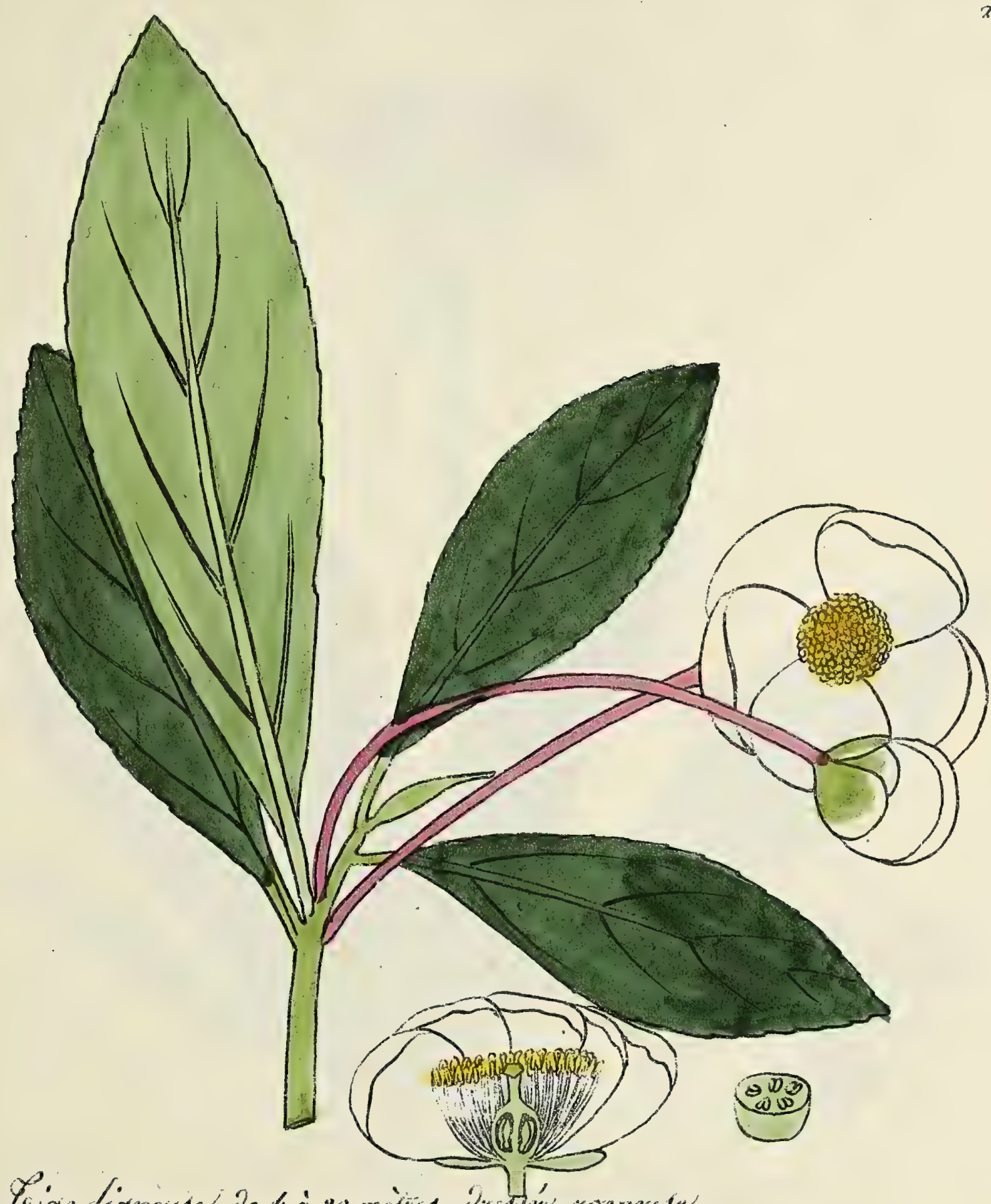

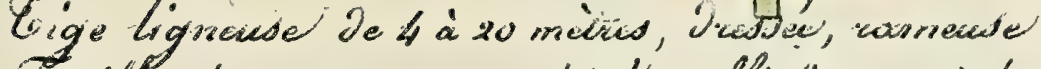

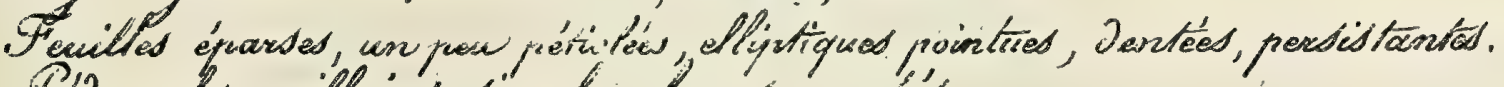
- Poncules acillawed, singrles, Pongit, courós

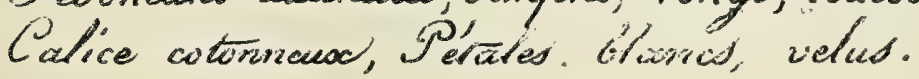

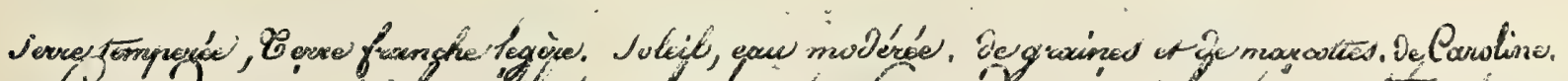

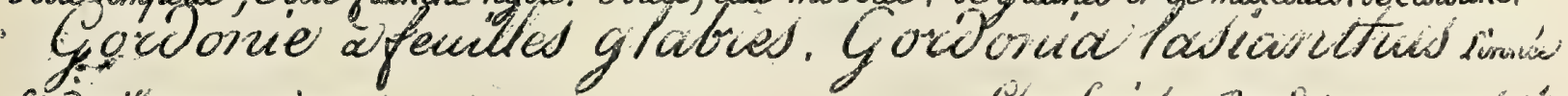
fike Jasailier $R$ aw axcis y Uhas Romicher Rued Des 3 cowroriones 14 


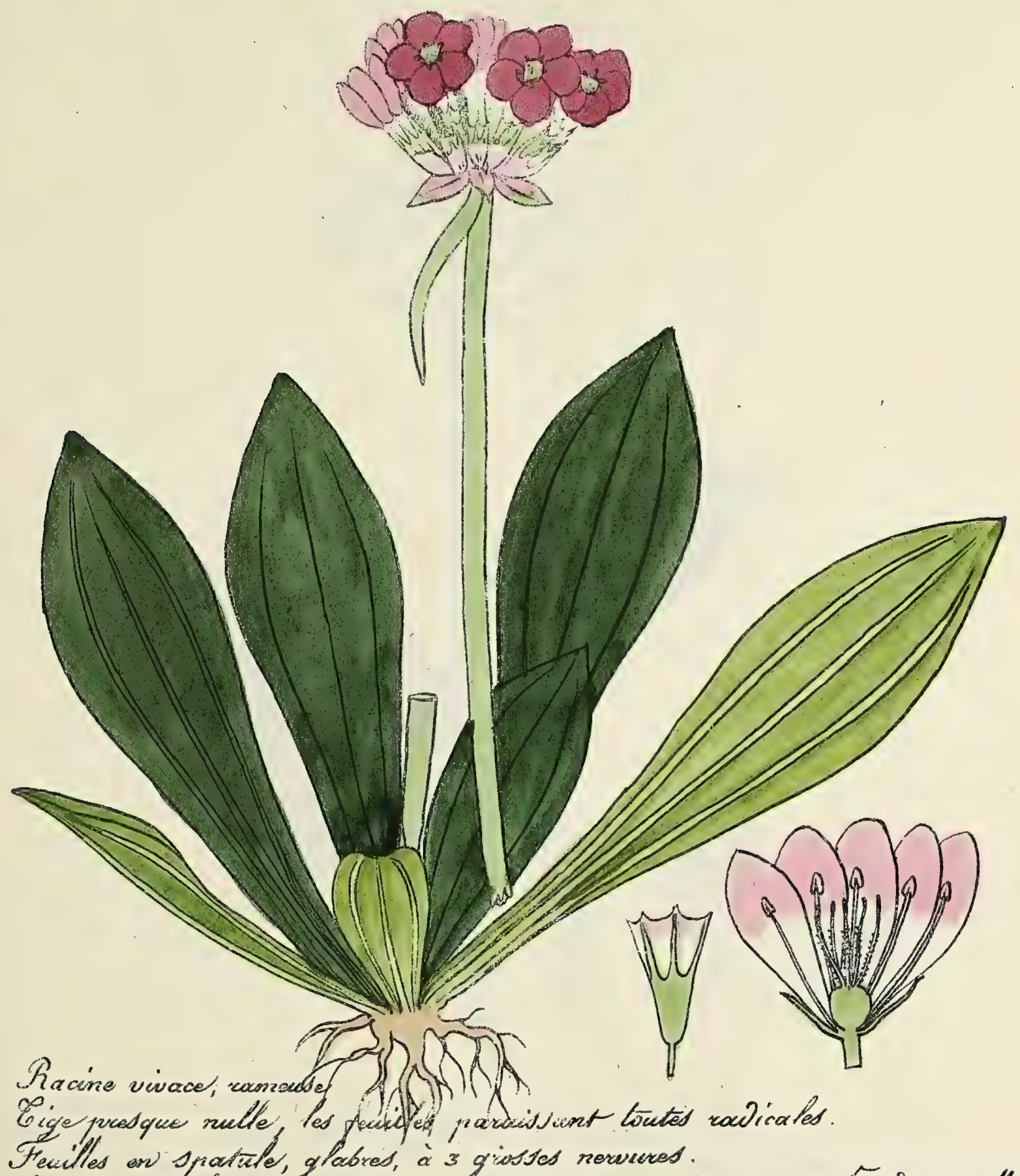

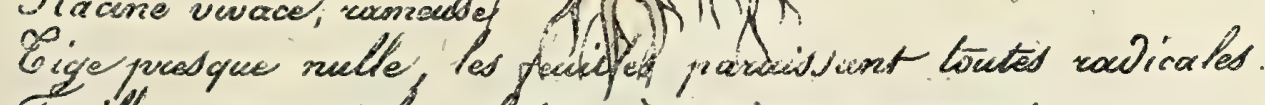
Fewilles av spatshe, glabres, à 3 giosses nerwives. hampre contrale, nue, de 20 à 30 censioncitres, ternimée par unie tote de ro àzofleurs. Palice gilabre, rasé, Ietales obovales, werfoncé.

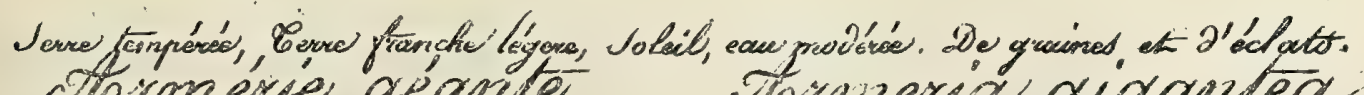

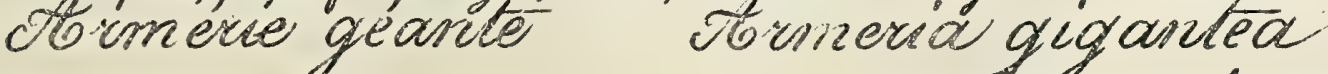
Lich Jasicilior 2 ar axcis cher Sele we de lowasiond $y$. 



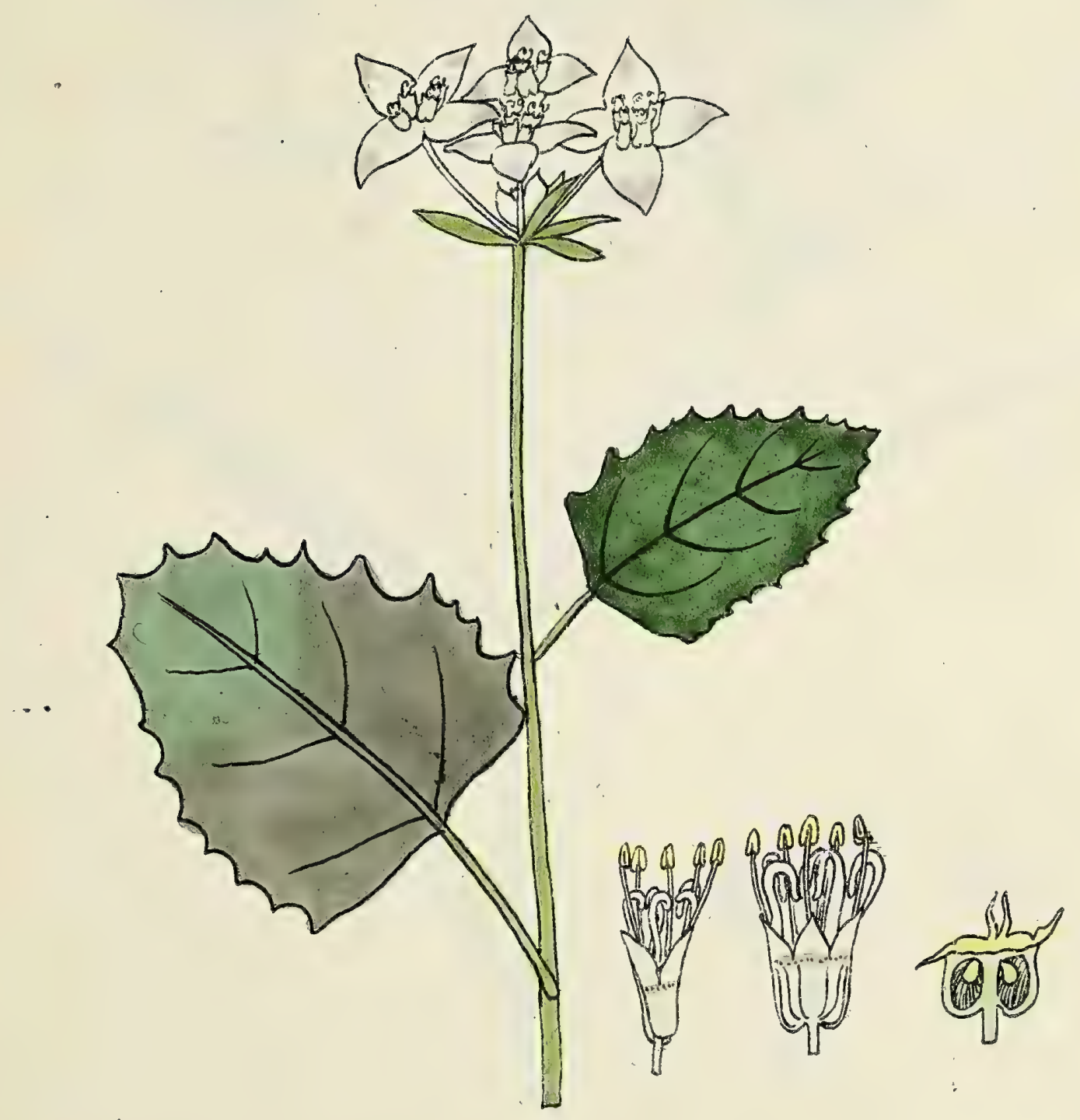

Tige lignente, Dreblée, comrense, glabive.

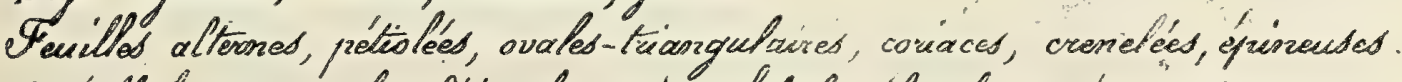

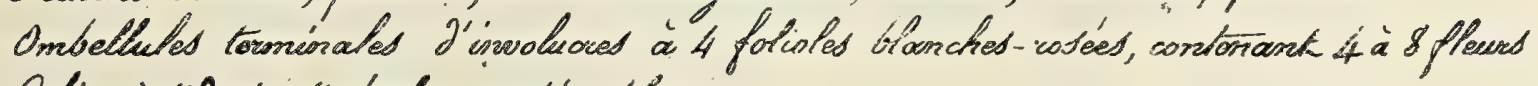
Calice à 5 donts, 5 pétatas courbés, blownes.

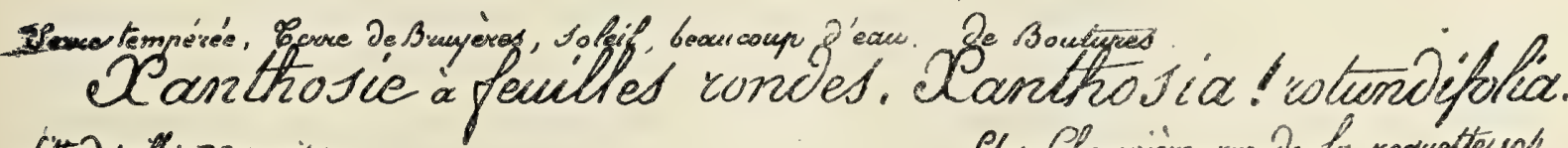

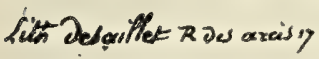
Char Chousnience rue de la roquetio rou 


$$
-
$$




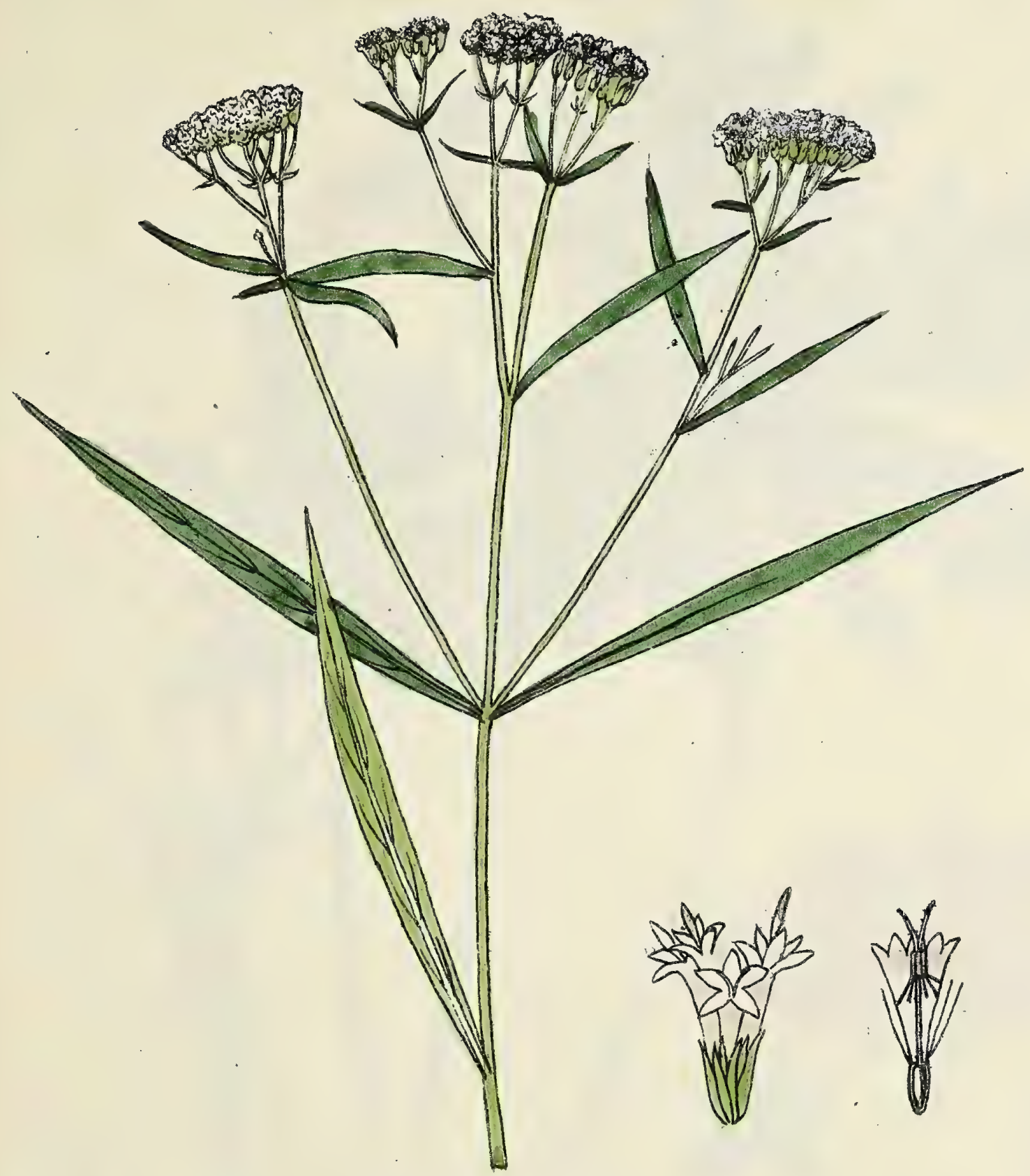

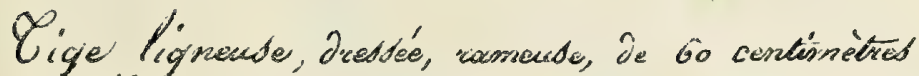

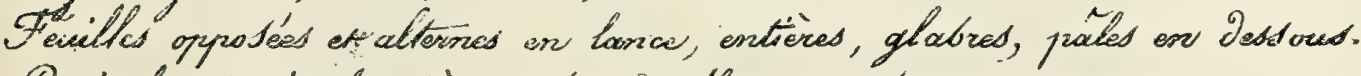

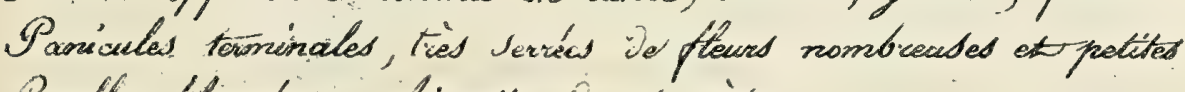
Corolles blanches. Atiguete de st aretes

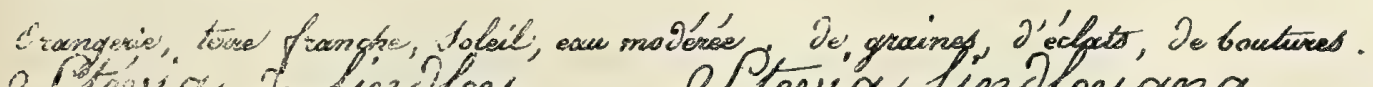
eriviar de linstey. OPteria lindey ana

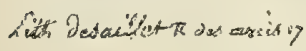

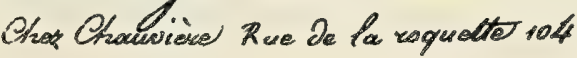




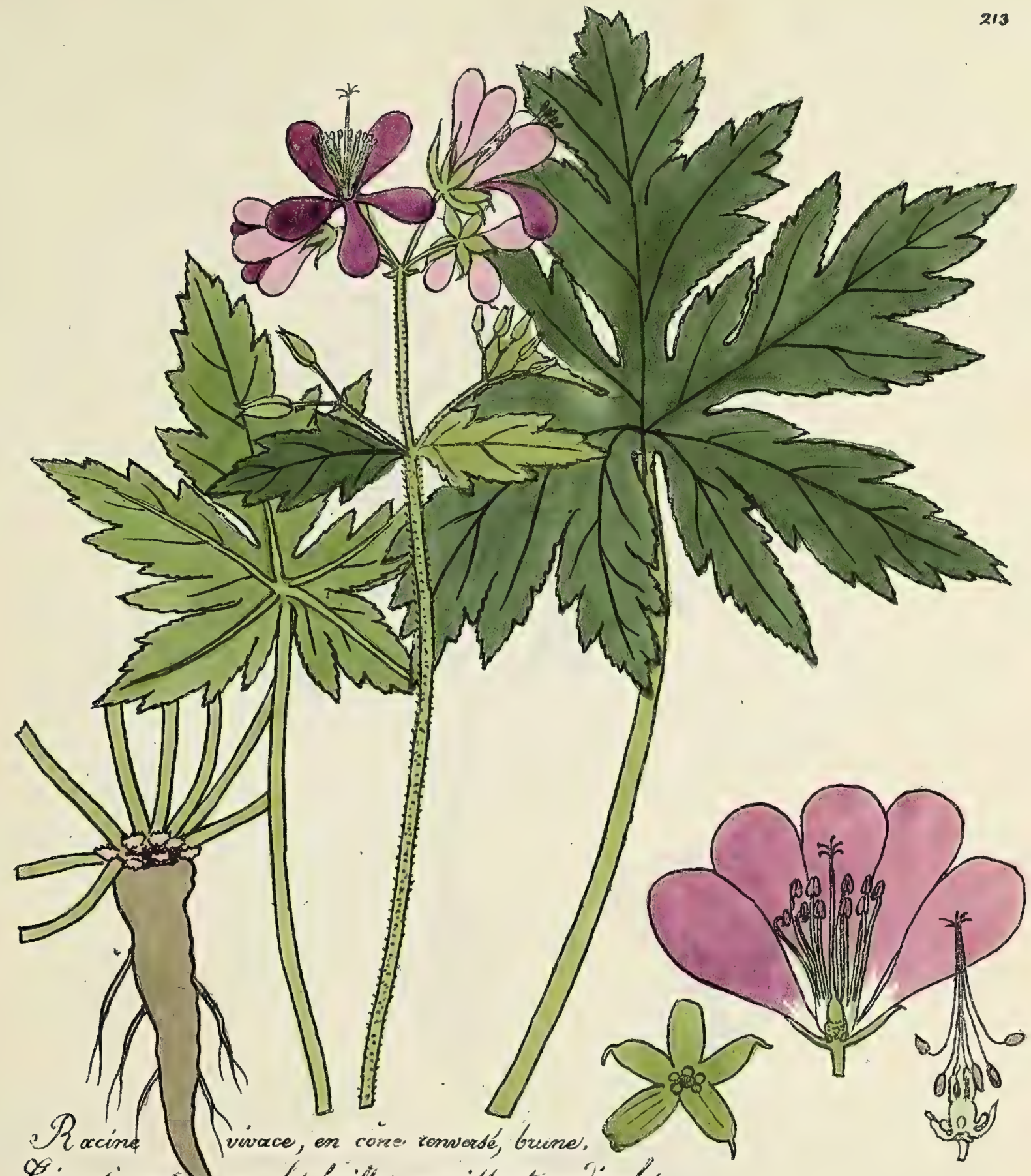

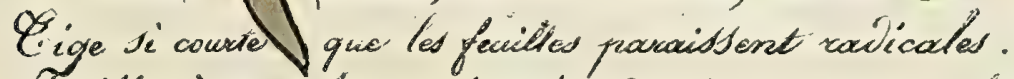

Feviltad à 5 purmuses incisées-Denstéed, poinstived, glabred.

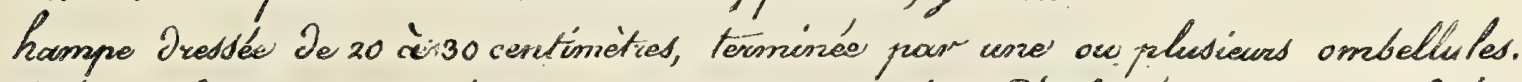

Calice à dividwont terminées par une prointe (mucronsés) P'etales égaux cose-violacé.

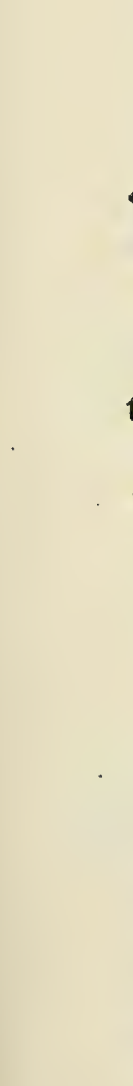

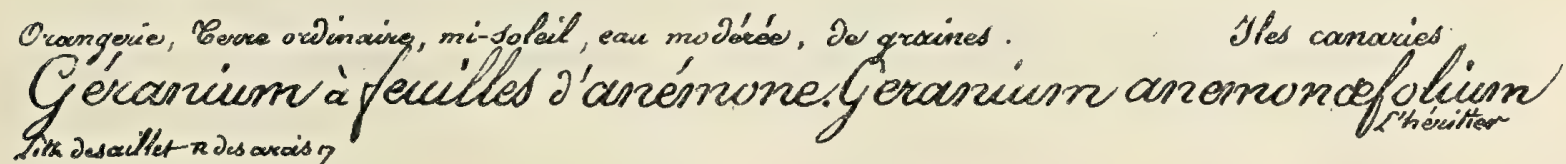





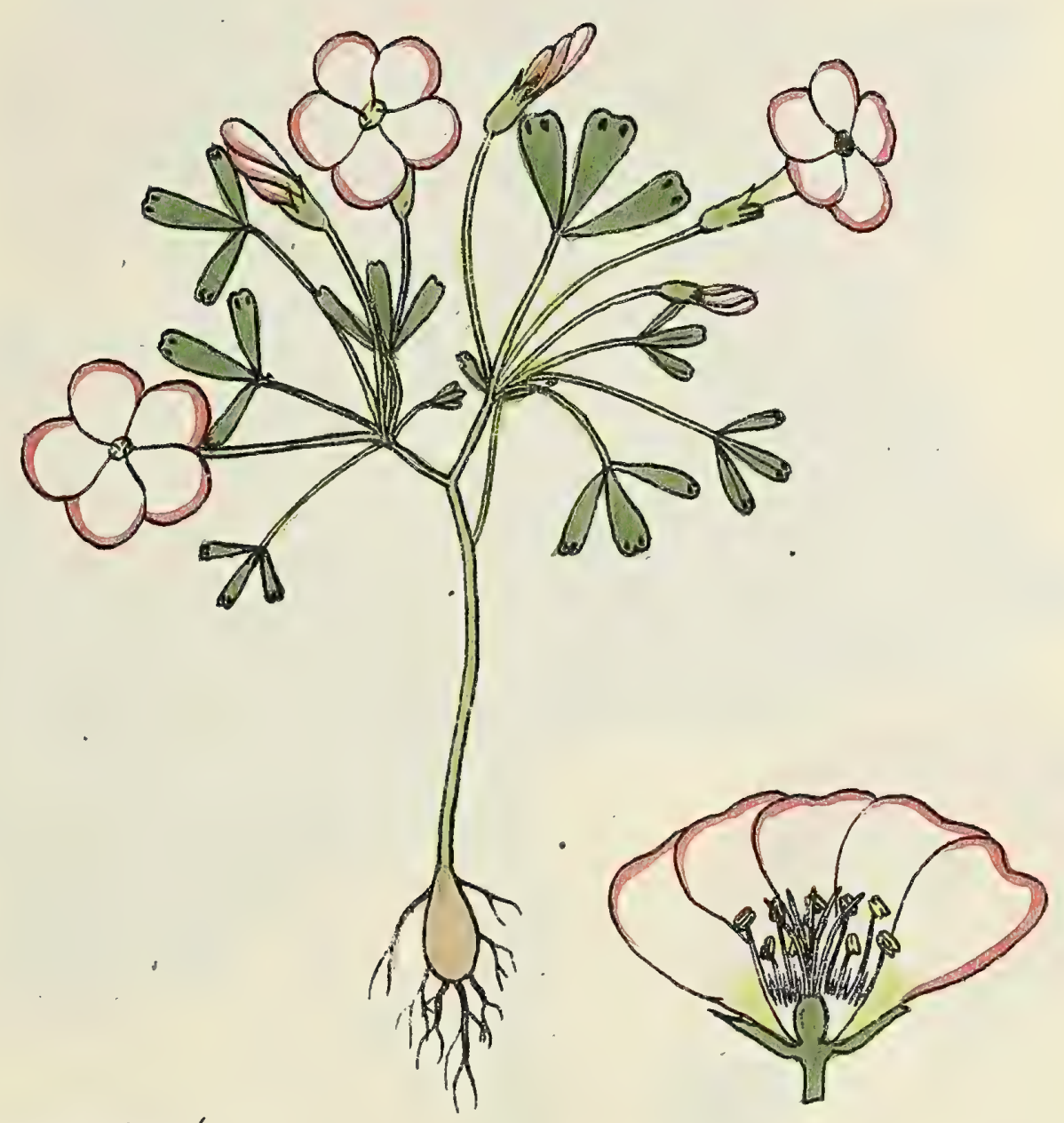

Oonor petit, allonge', buen

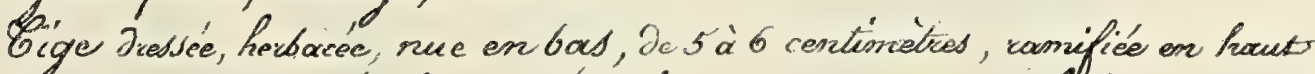

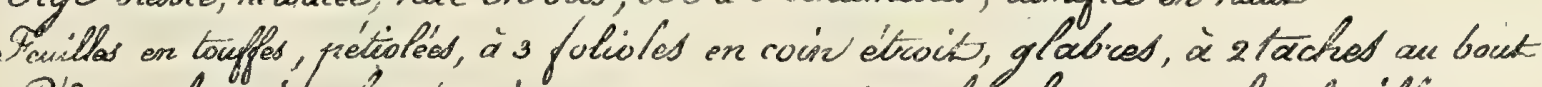
Pejoncules simples, tominaux, on paquets, plus longs que ples feuiliss. Corwlle blanche burdée de rouge, Styples Jépassant les étäminus.

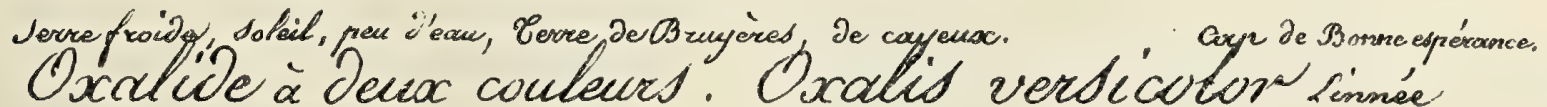
istrossaller-r as arcis or 



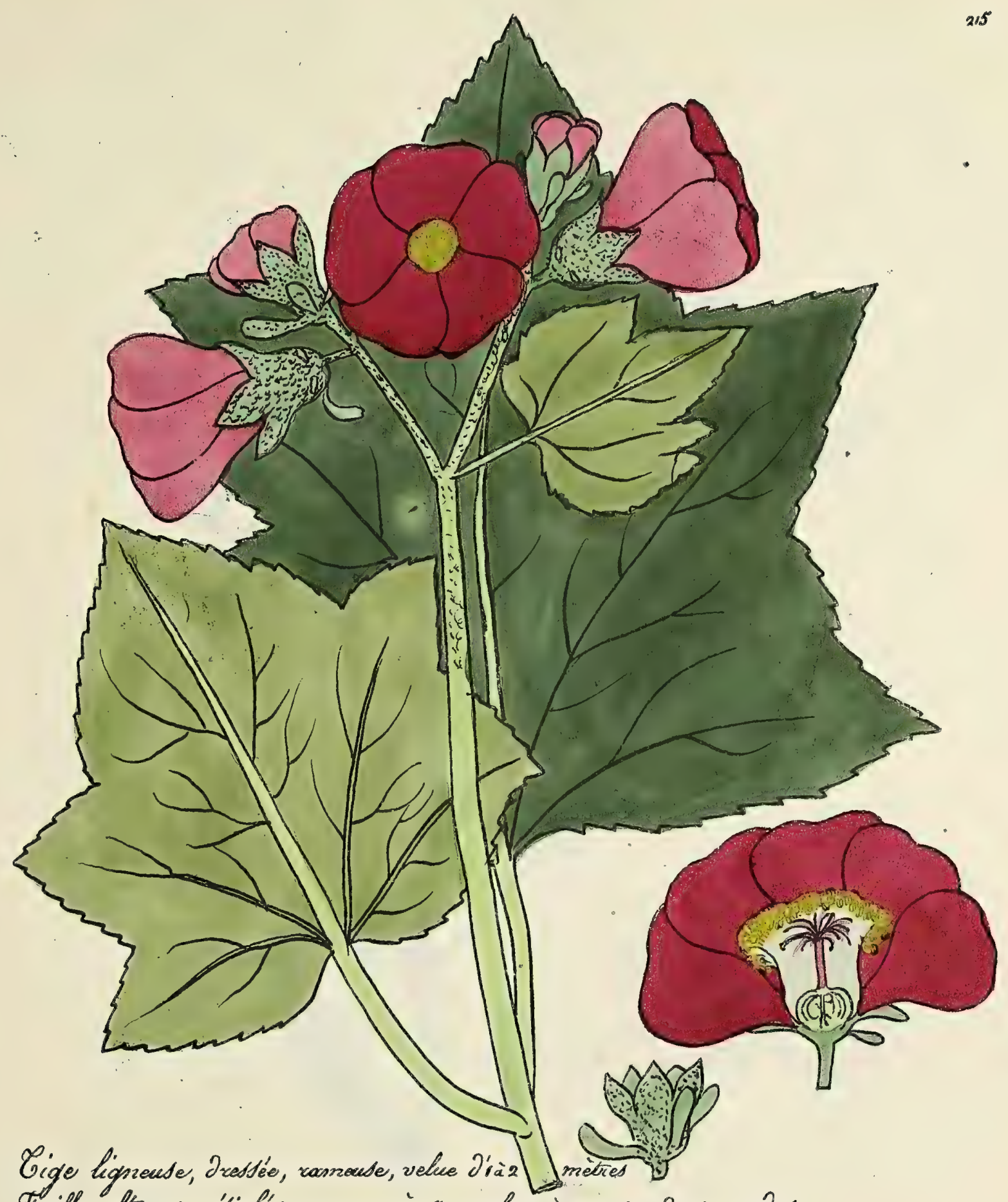

Fivilles altornes, pétiolés, en cobur, à 5 angles, à giostes dents, rueded.

- Panicules terminales

Palice exterieur coctuc. Petales en cueur ocamoidis.

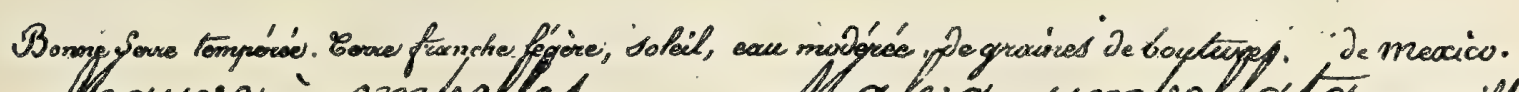

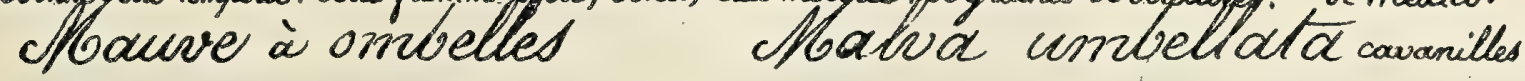
iith Desailler-R Jes arcis '7 


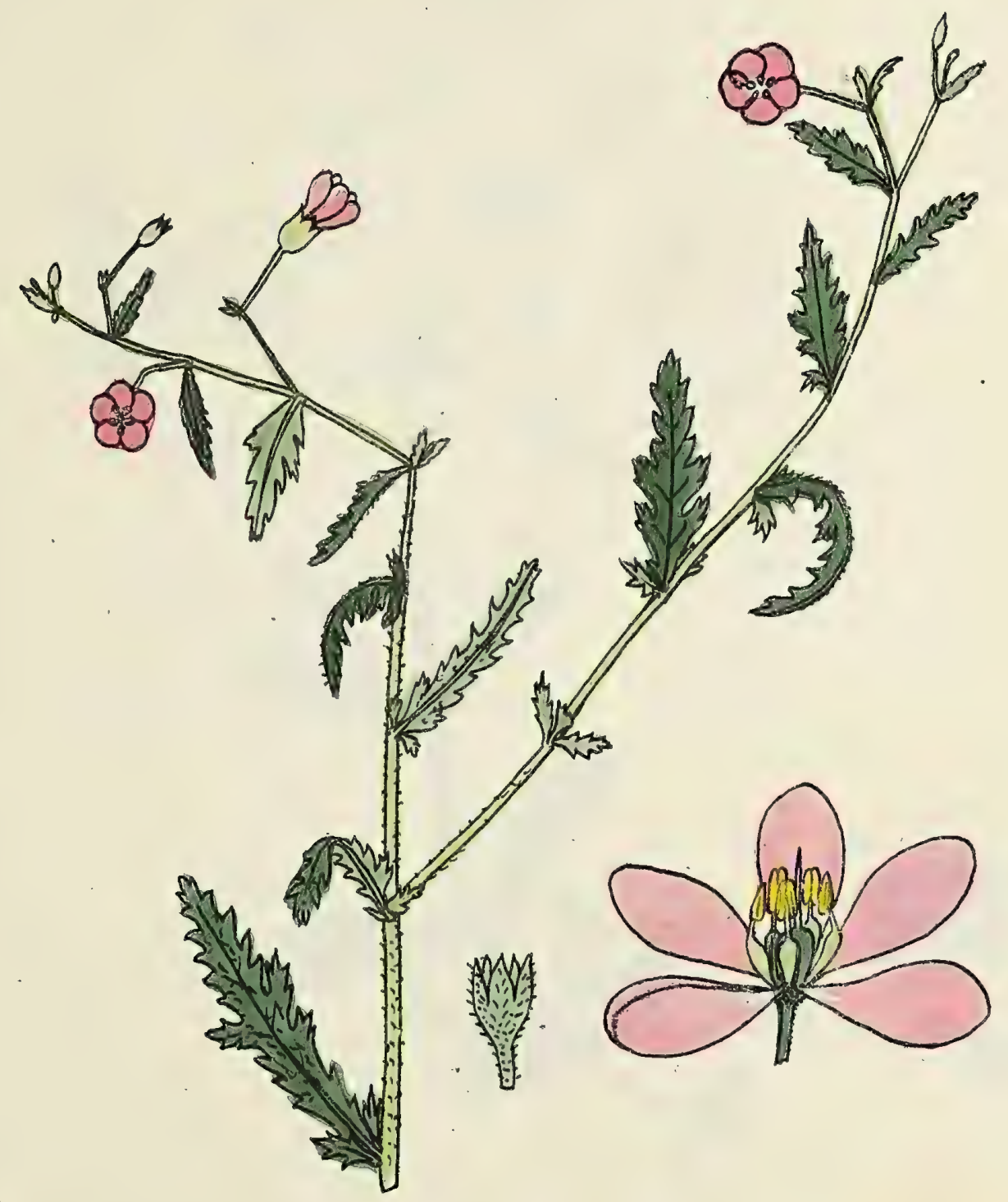

Gige ligrowse, couchée, conneuse, Jowvent coivée, poilue.

Feuiltes alternes sessiles, en Lancespinnatifides, velued. Stipueled cilices. Pedoncules accillaicet simples, formant comme des grappies teraminales Calice proilew, Pétales rougeâtres.

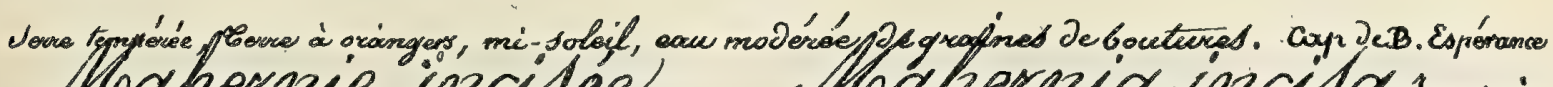
Modhernie inciseel. Mbahernia incisa sacquin.

Lith Desailletr Des axcis 


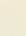




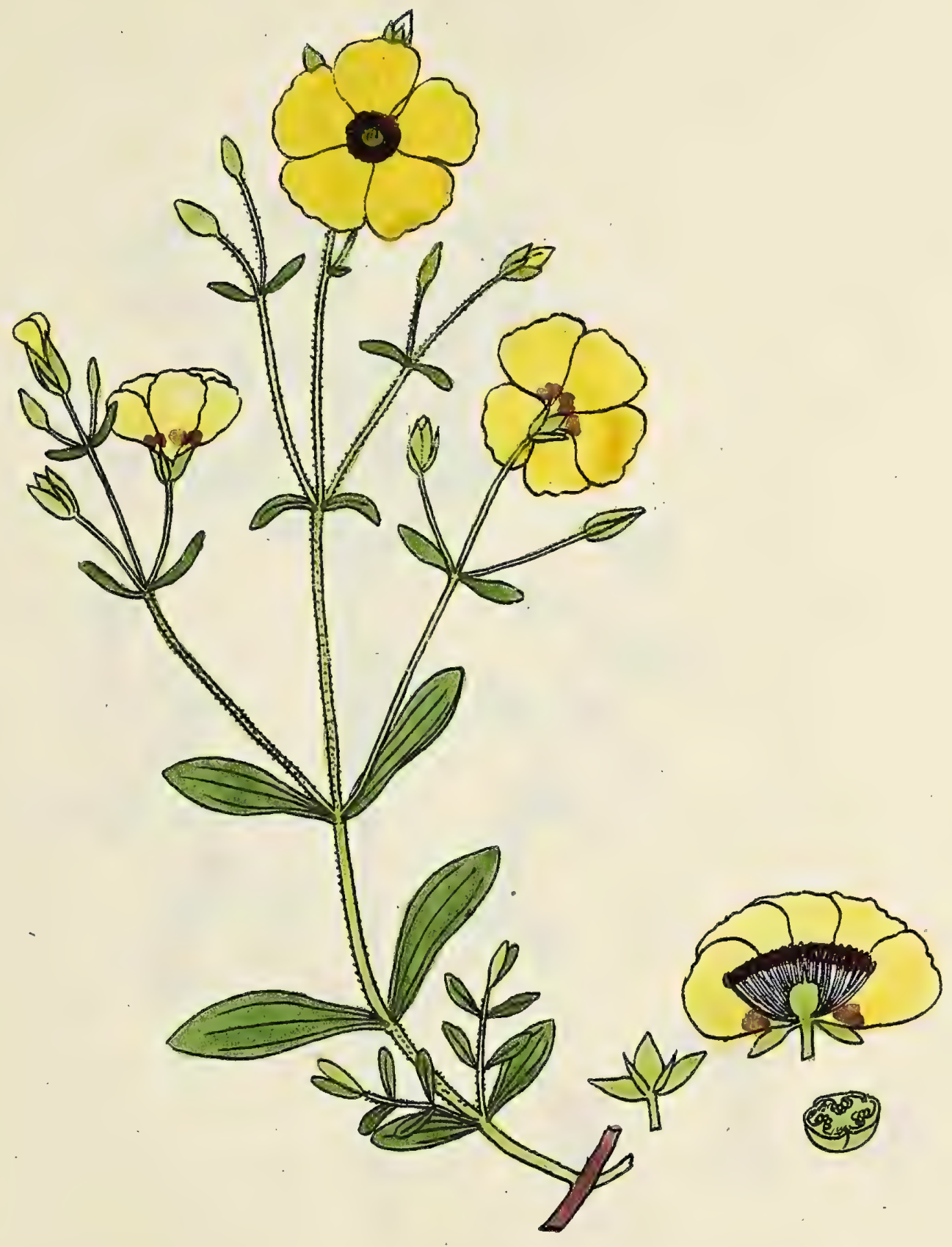

Gigel ligneuse, wu pew couché, tred roxmender

Teuilles opposés, sedtiles, obovales, giabred, à 3 newures, blanchabred. Paricule à forgs péDoncules veruiguenoc.

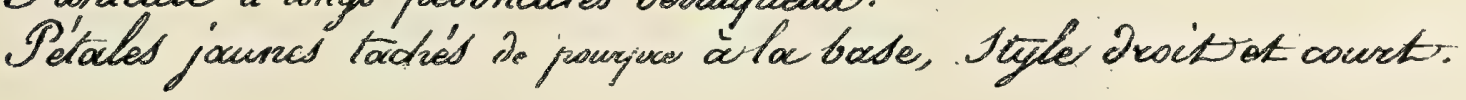

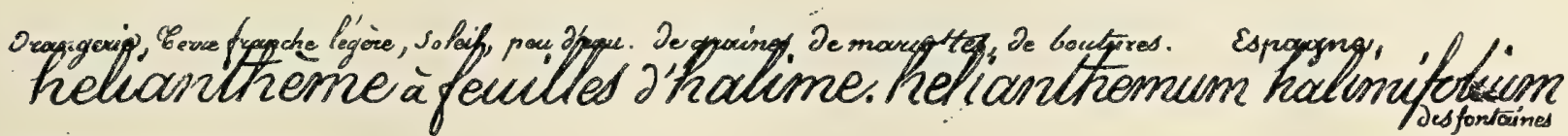
Sith Jed aillew oes areis "y 



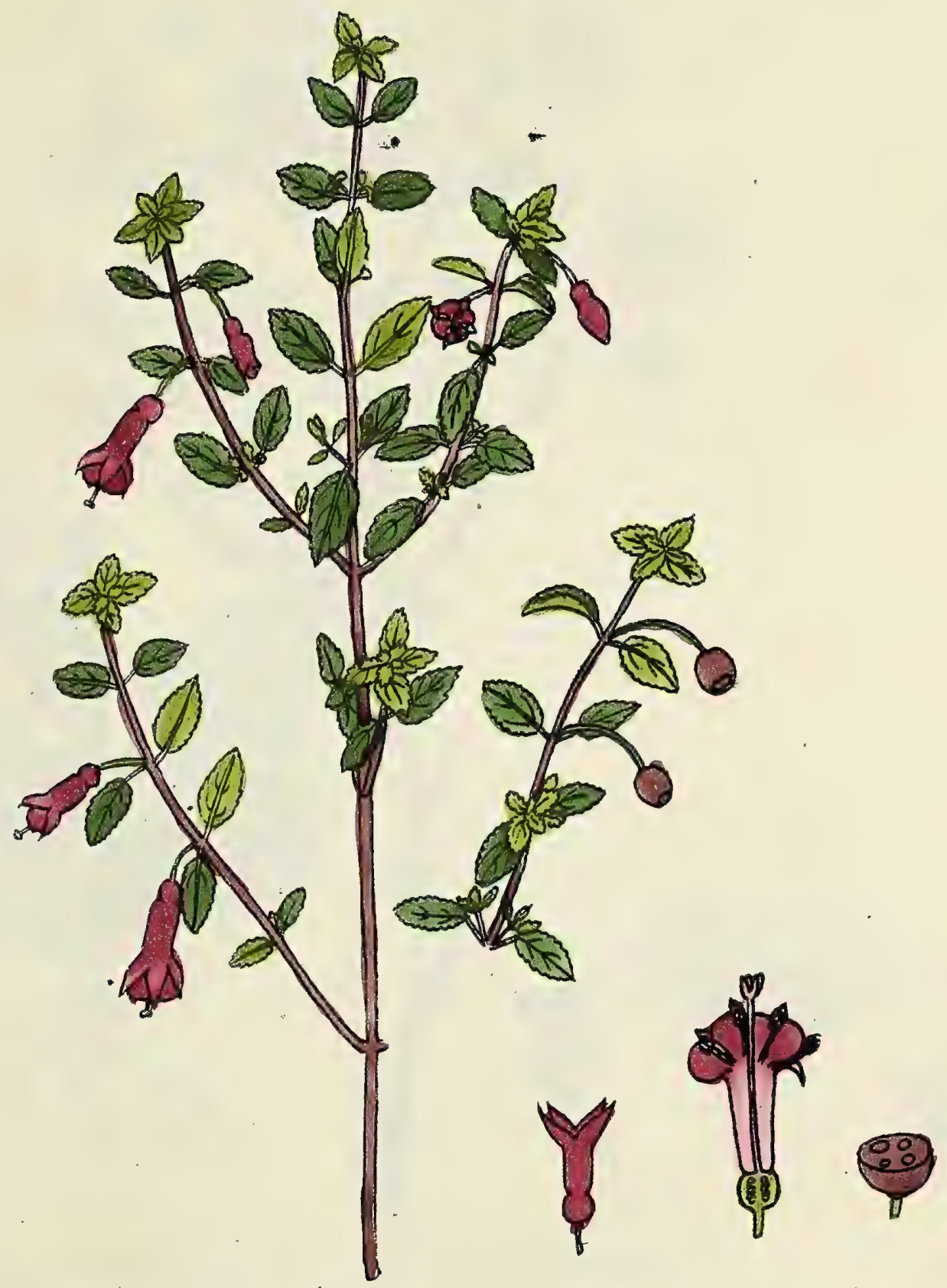

Eigles ligneubes, Dressés, rameudes, Gucurres, de 20 à 30 centionètres Feuilles opposées, pretrolees, ovalhs, dentiès, triès potites.

Pedoncules axilfaived solitacices, Sinryles, peniants.

Fleurs petites, cowries. calices' proverpuce, Petales arrondis pourpre foncé.

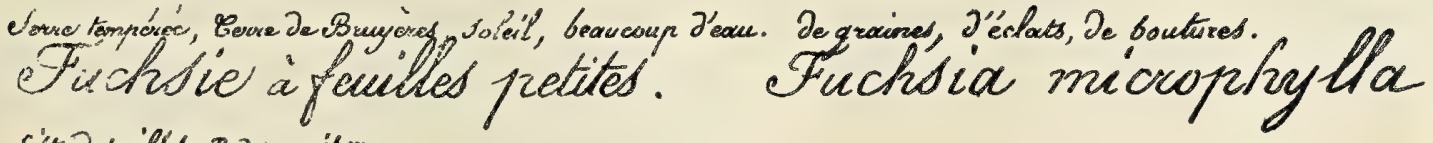
sikes Jeiailict $\pi$ jes ancis oy 



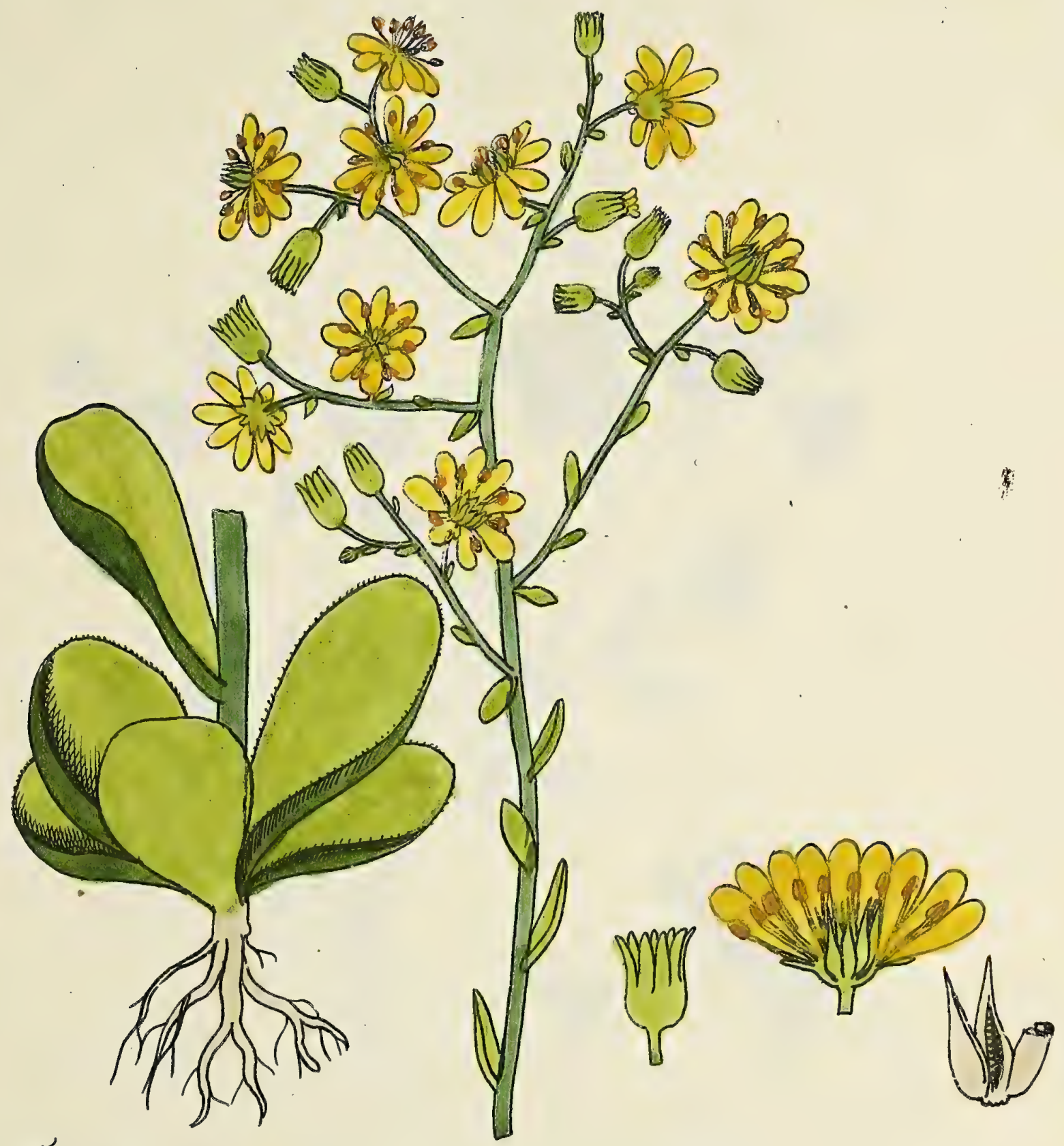

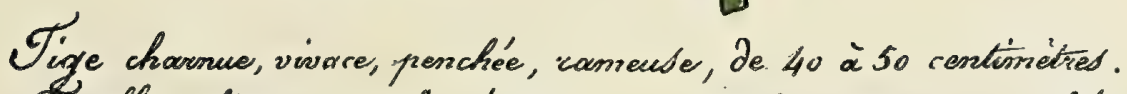
Heuilles altriones, sessibs, áraisses, env spactule, visquouses, cilises

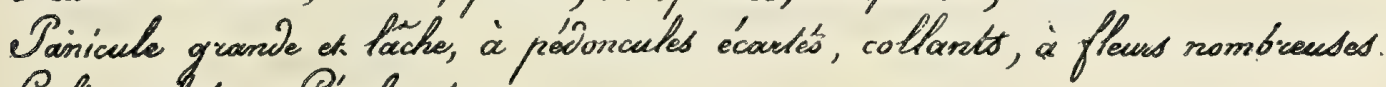
Calice glabre, Pitales jausres.

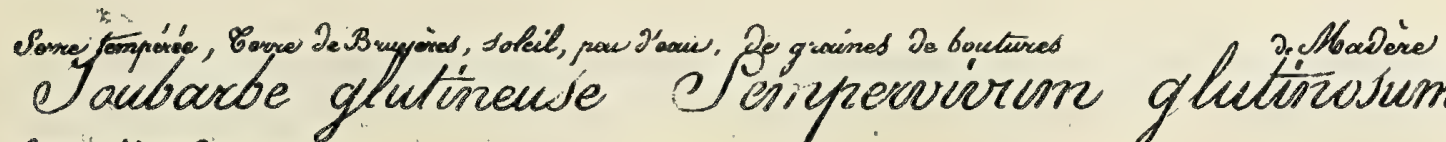

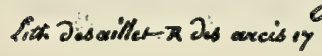





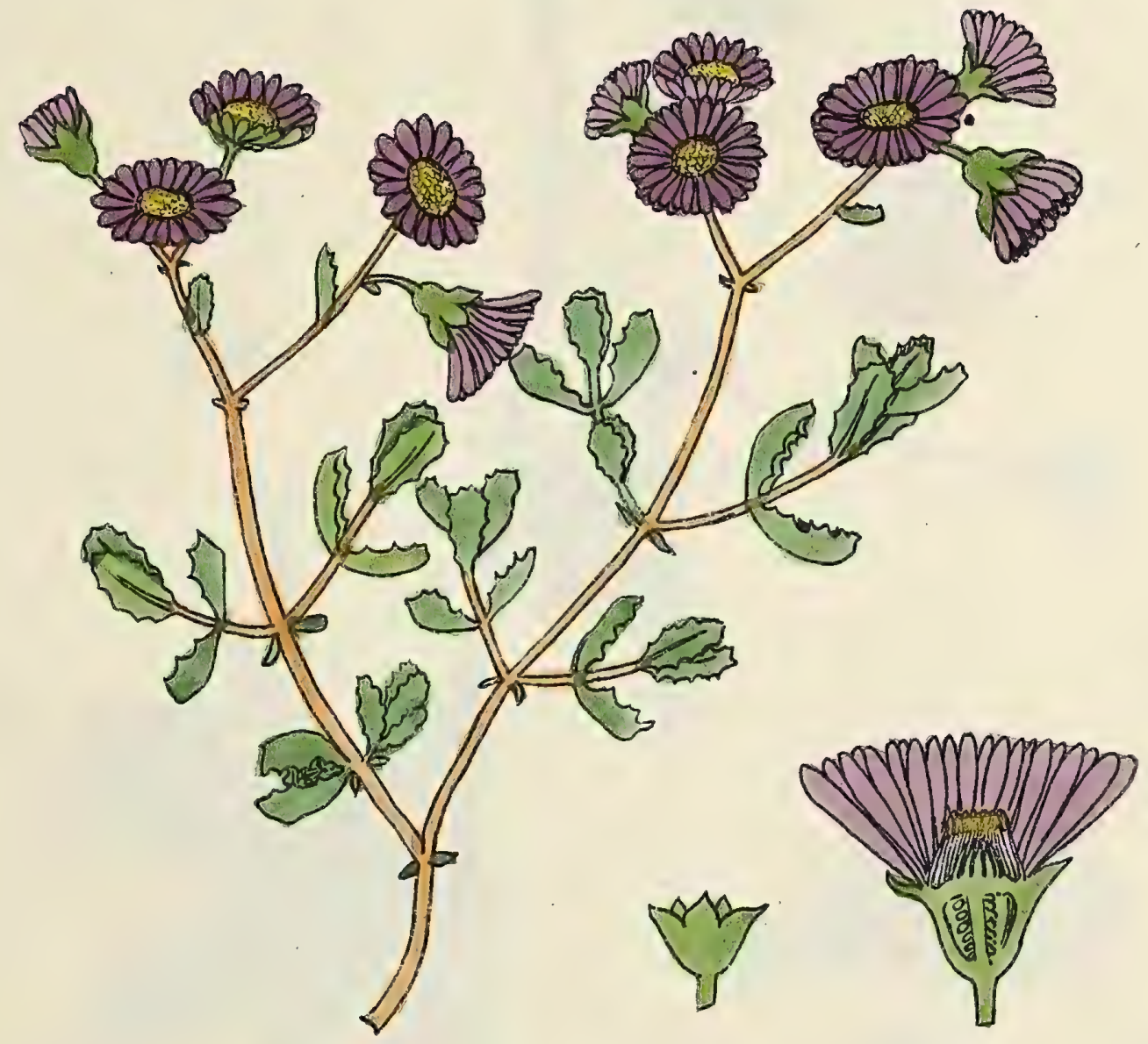

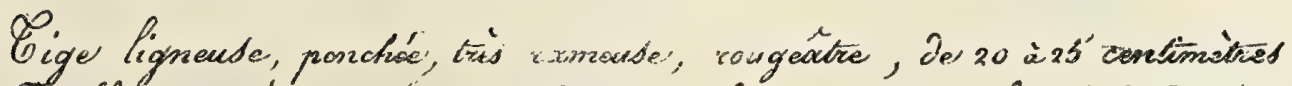

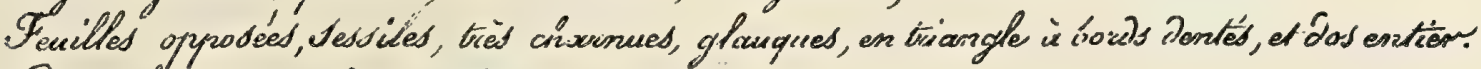
Panicules terminales, à Pleurs nombieuses.

Pétales étroits, vislets

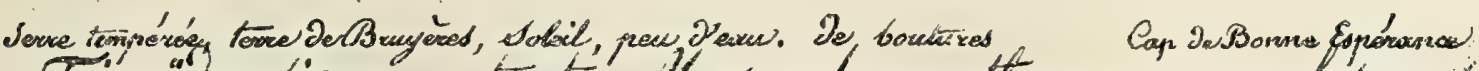

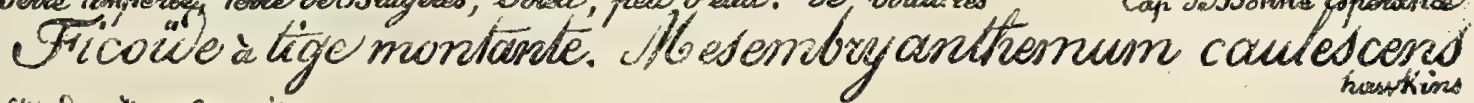
fint Desaction Ras axis iy 


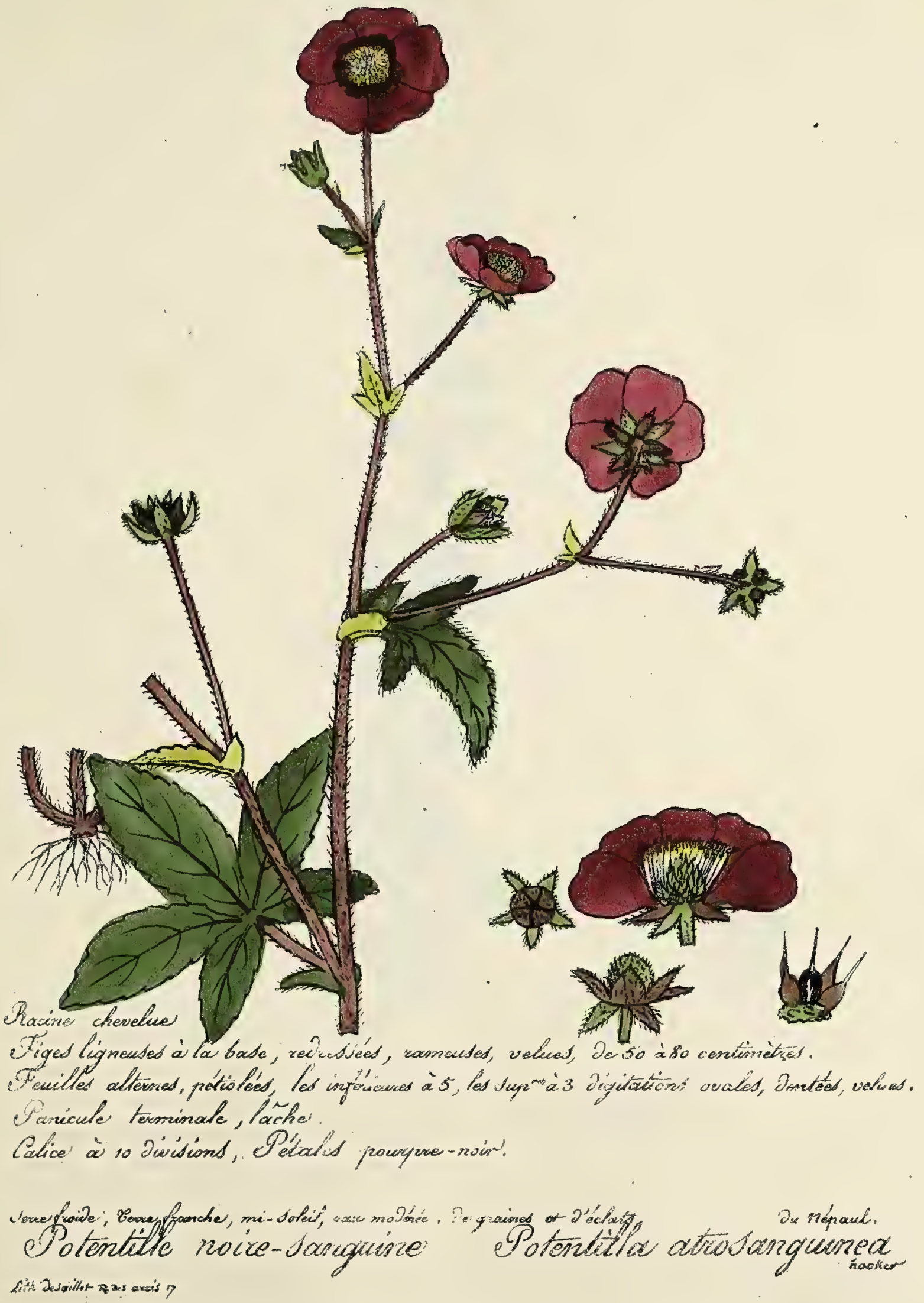


4 

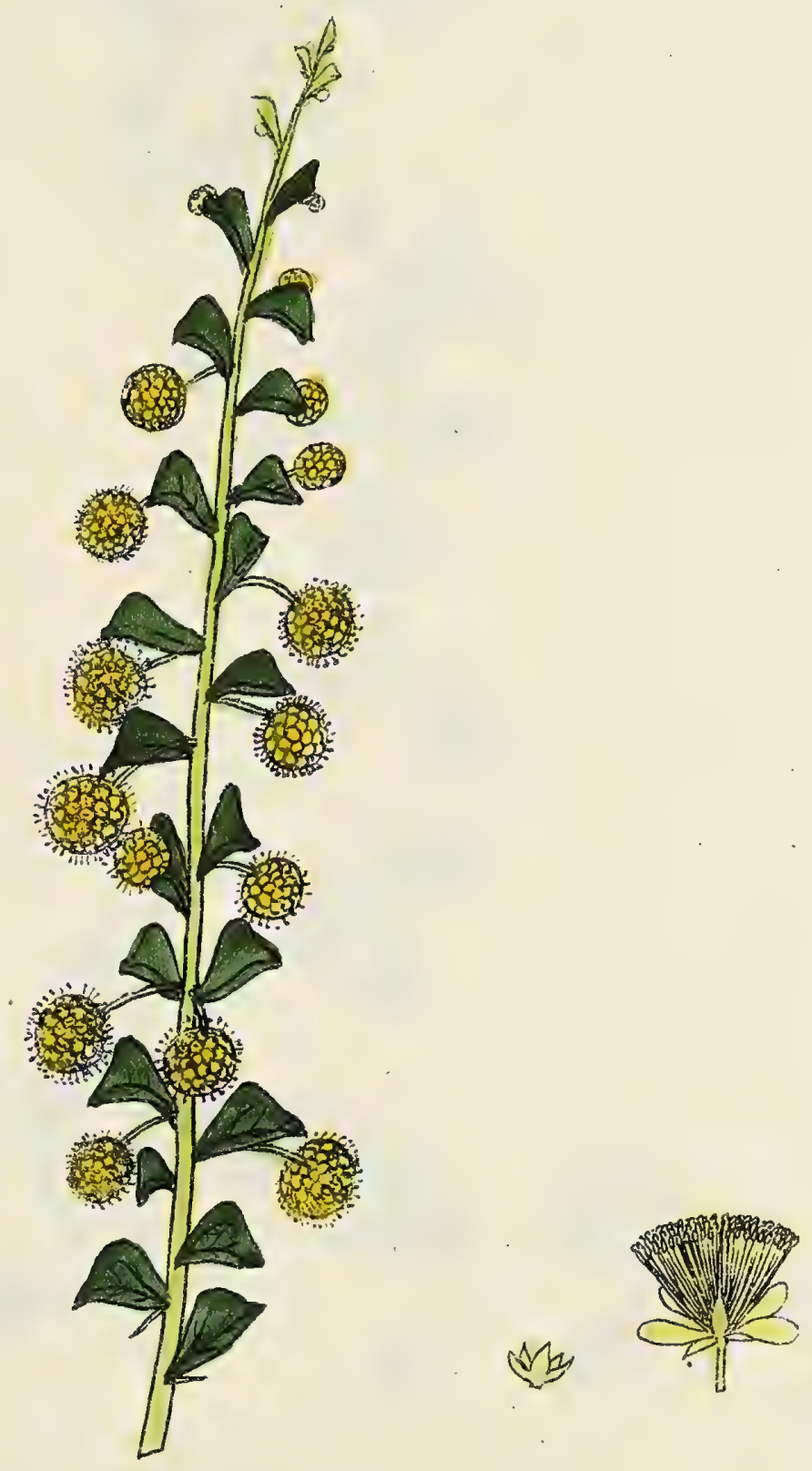

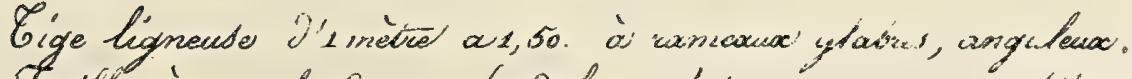

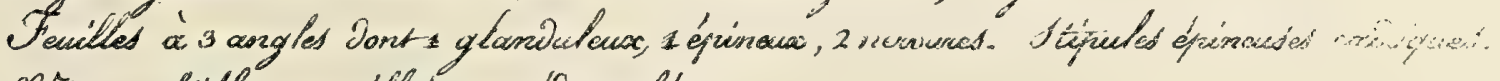
Eetes multiflores, acillavied, pesiunculeed.

Hlours, petites, joume piate.

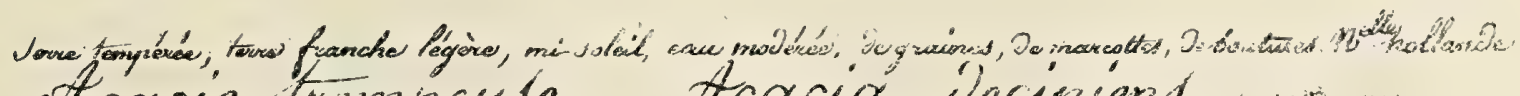

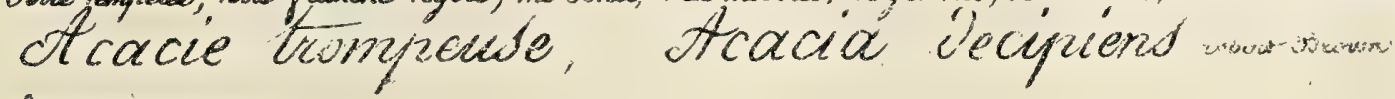

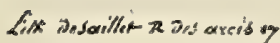





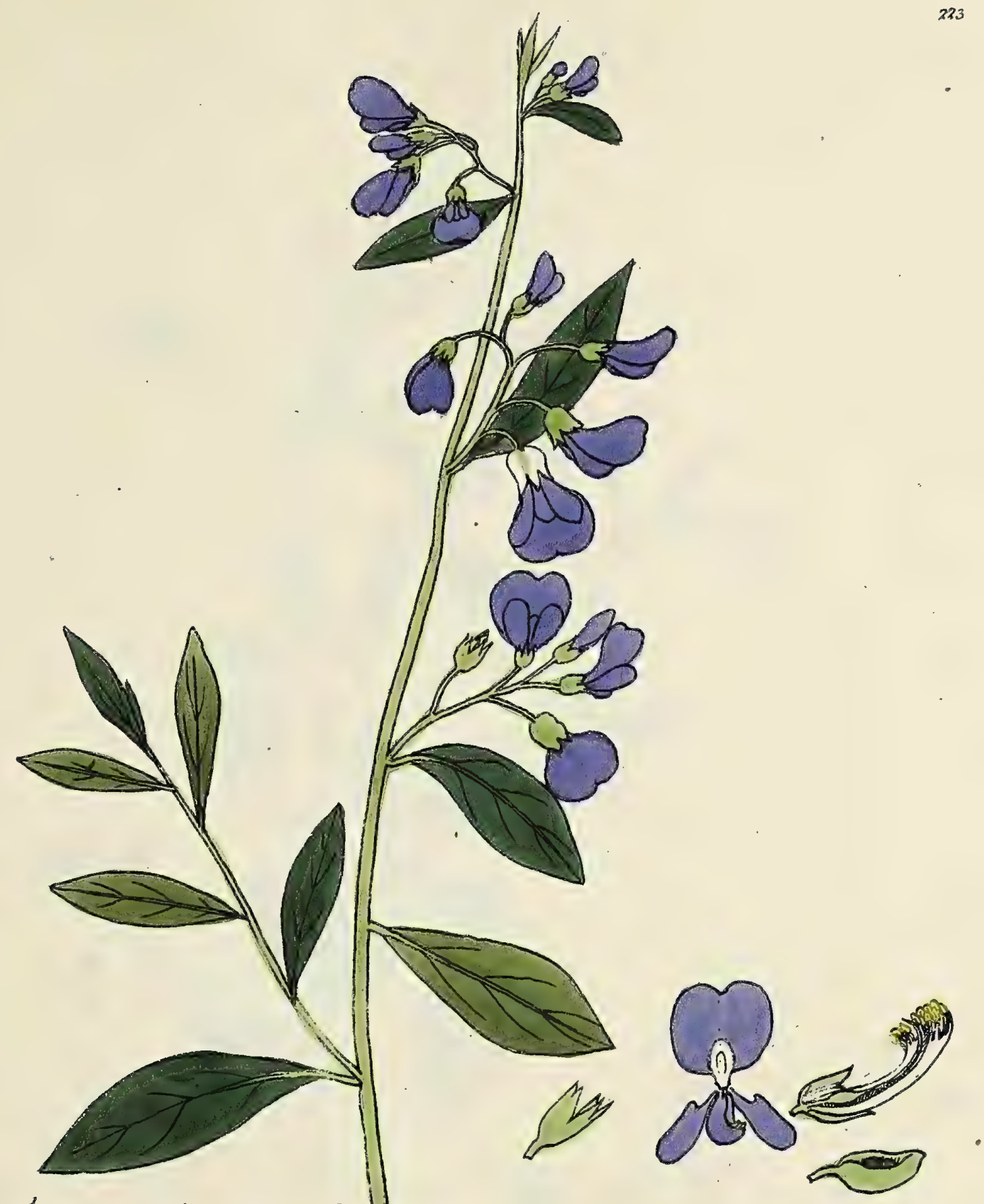

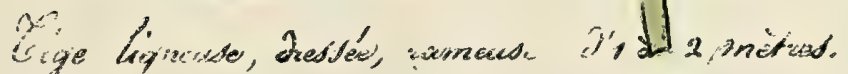

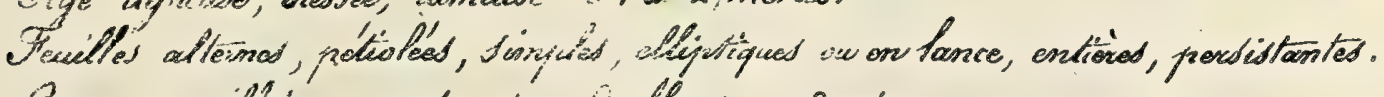

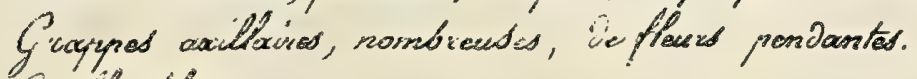
Corvite bluew

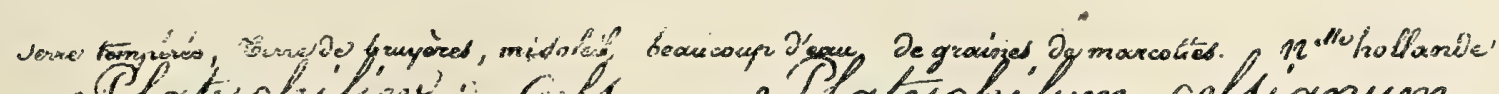

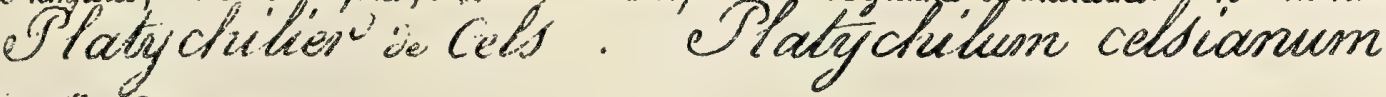

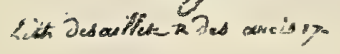





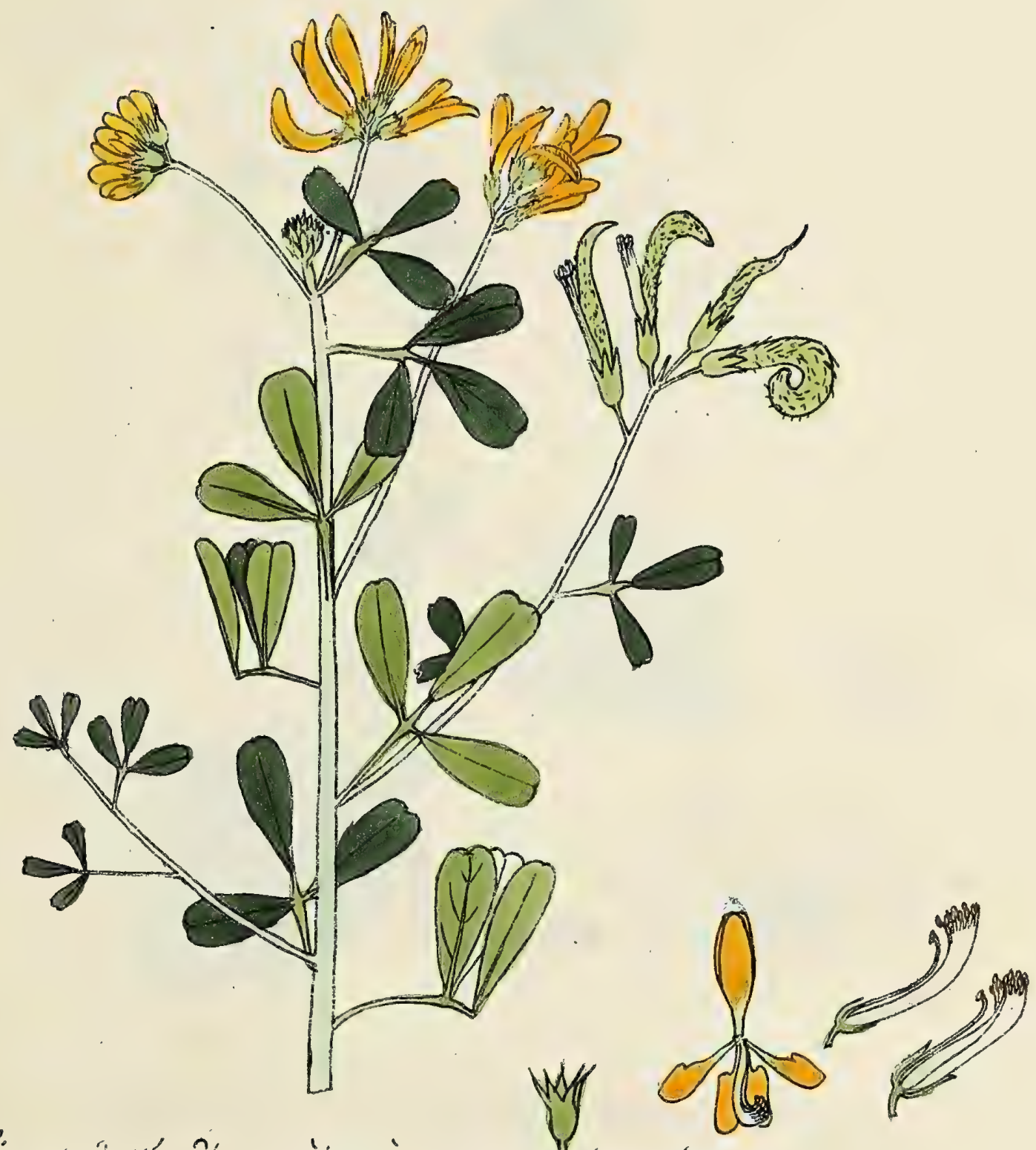

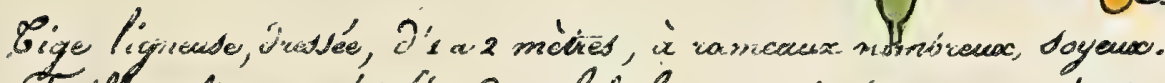

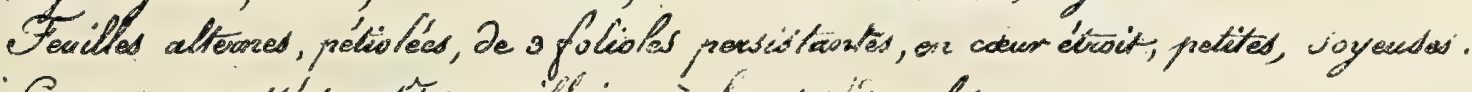

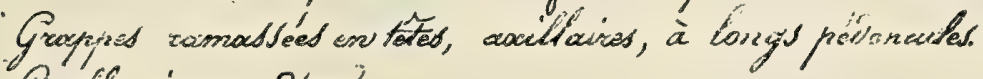

Porolles jaurc D'og"

Leguene en croistant Sugueco

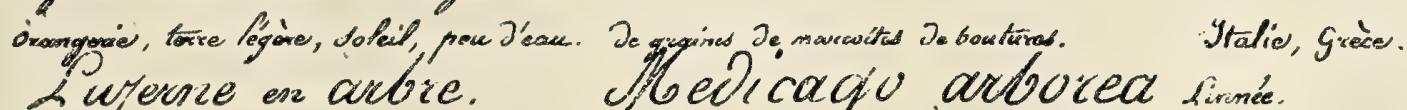

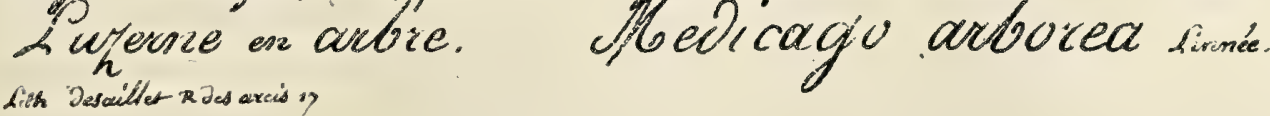




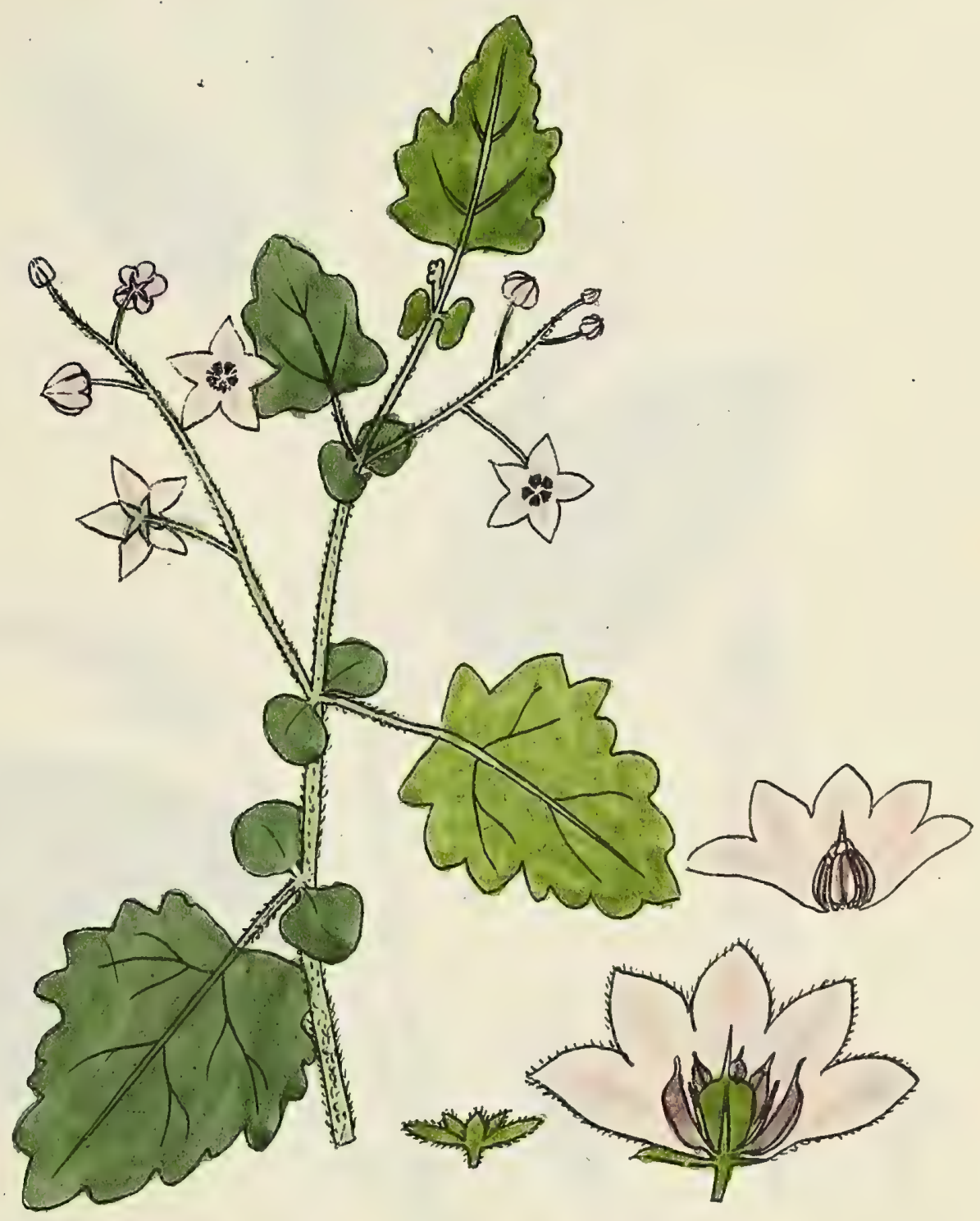

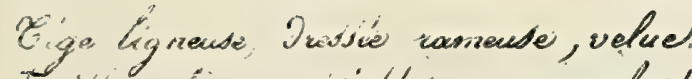

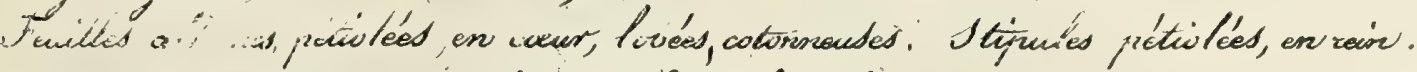

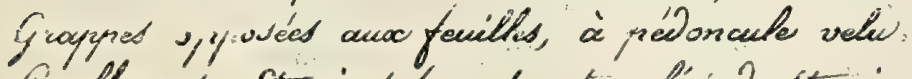

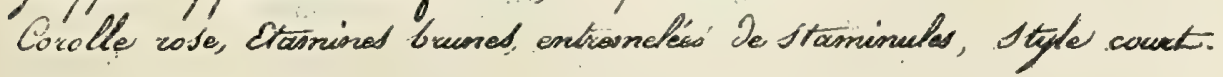

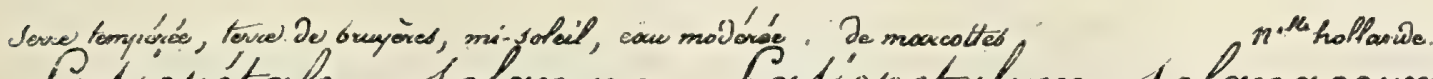
Pas iopétale en Solanunn Pabiopetalum Solanaceunn?

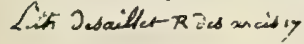


$\circ$ 


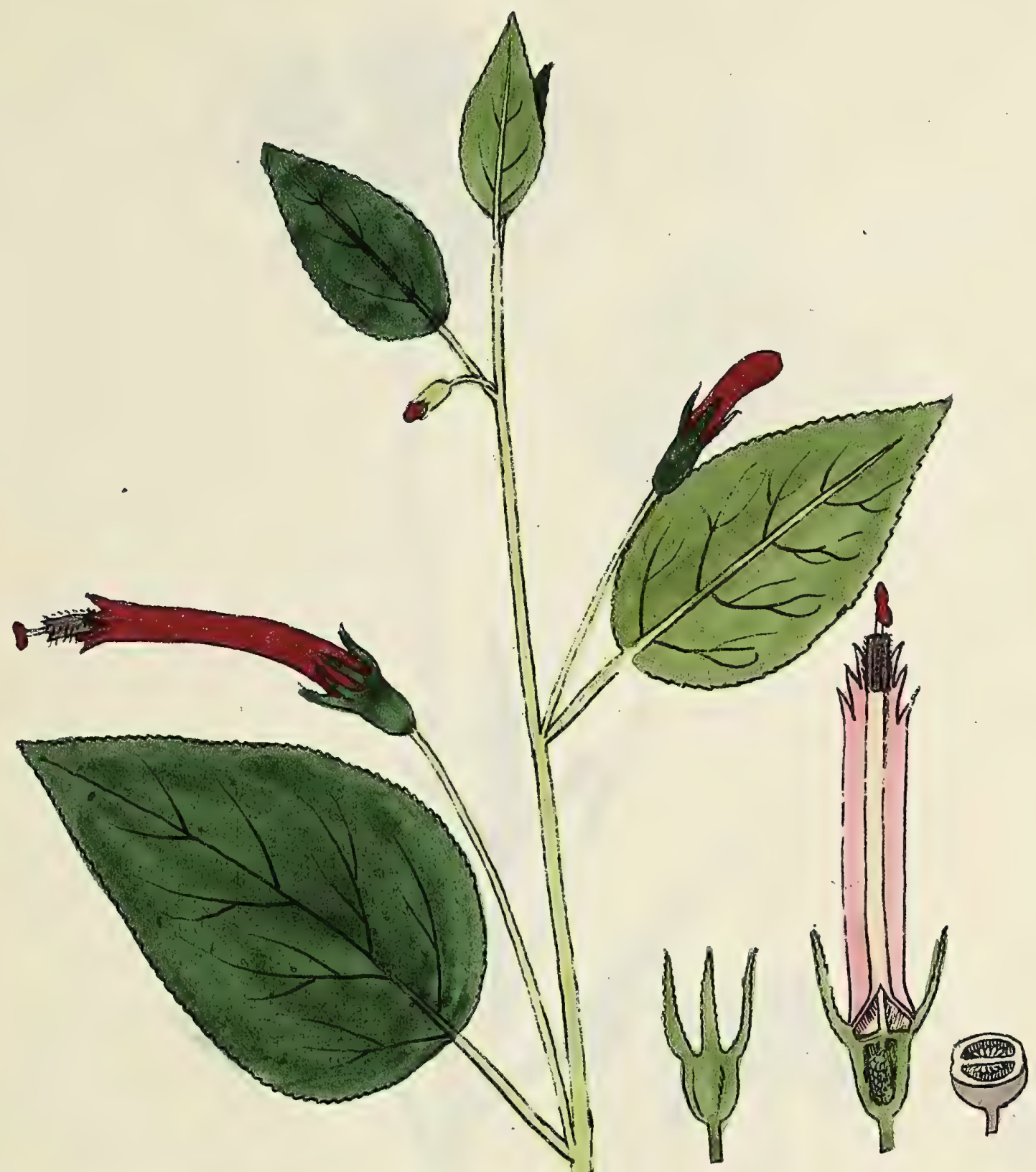

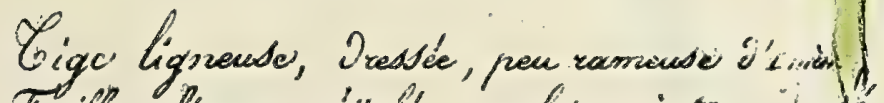

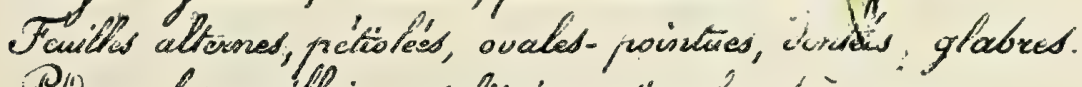

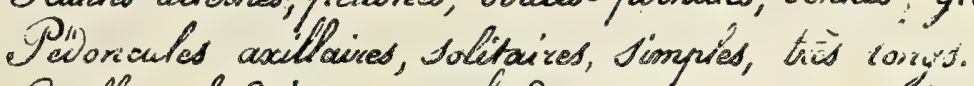

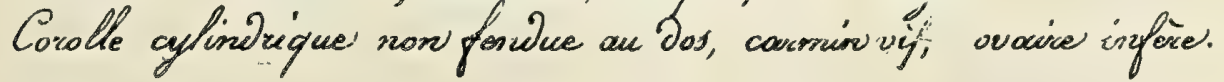

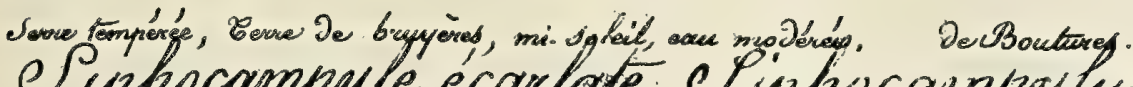

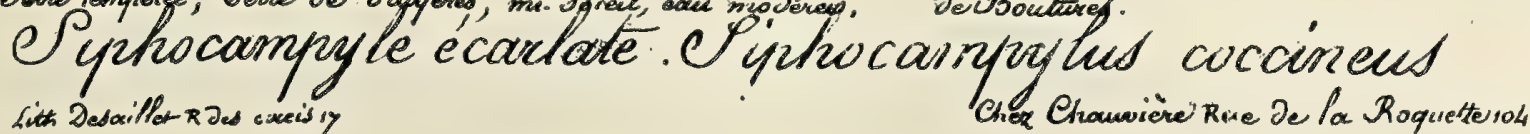





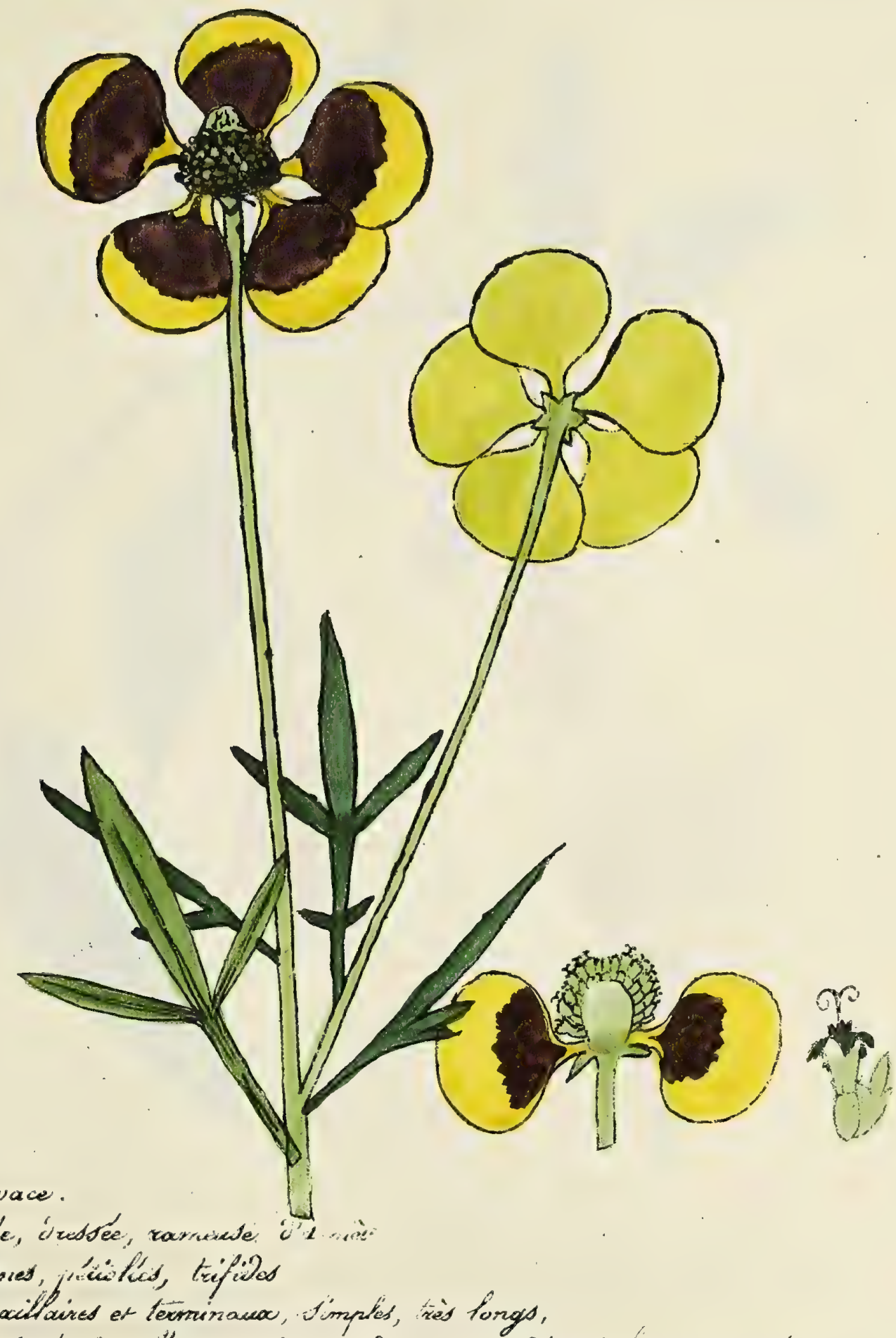

Ravize vivace.

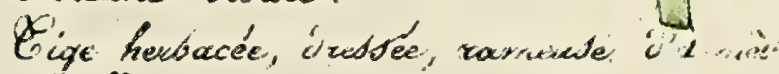

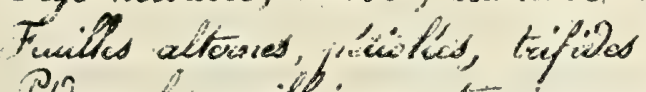

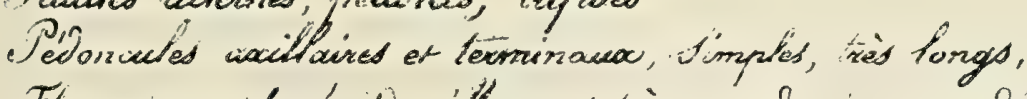

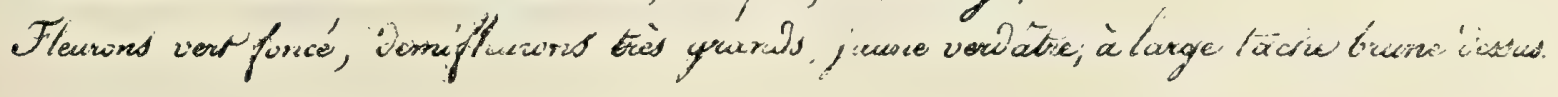

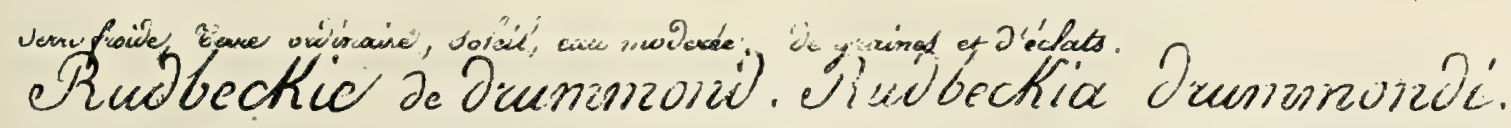

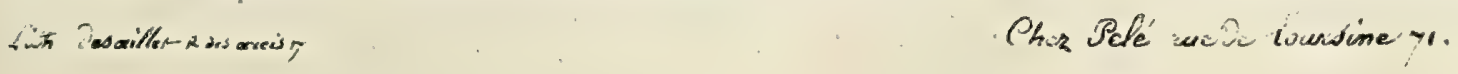





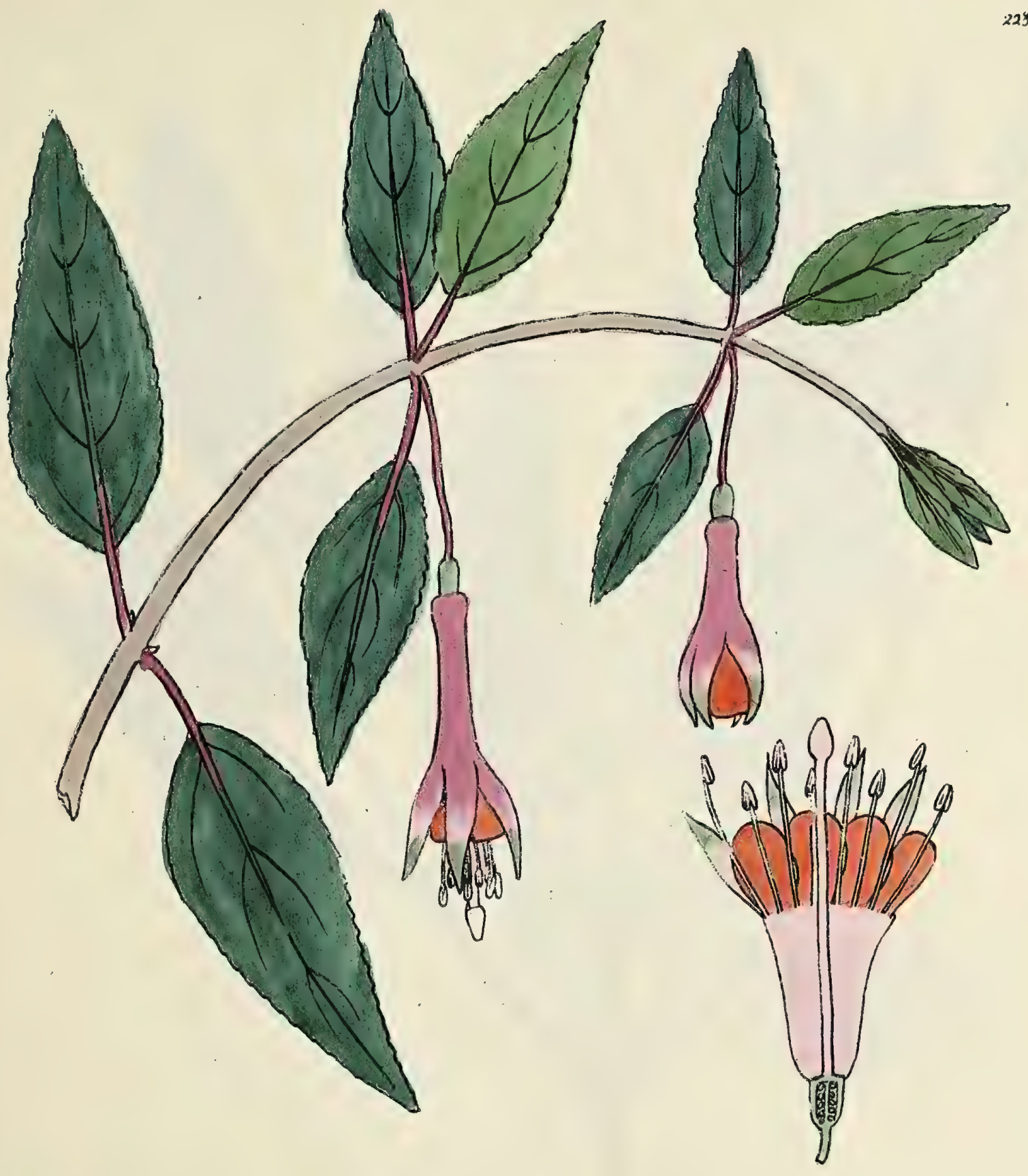

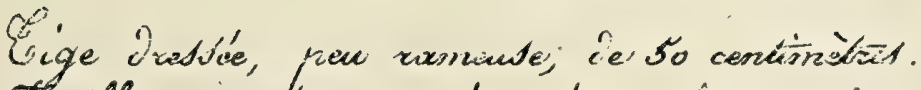

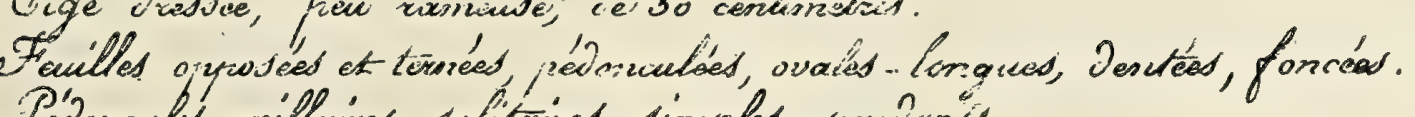

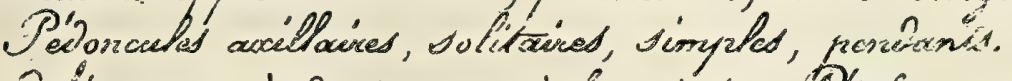
Calice ruse à cents veries à la pwirte, etocted vermillon-foncé.

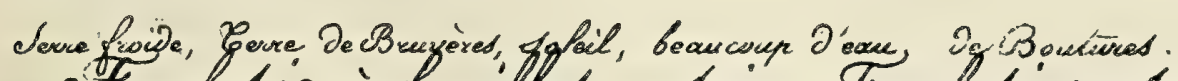

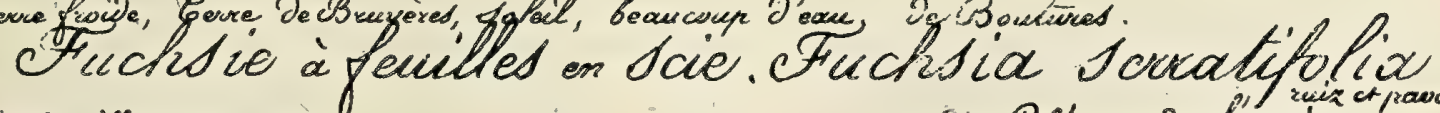

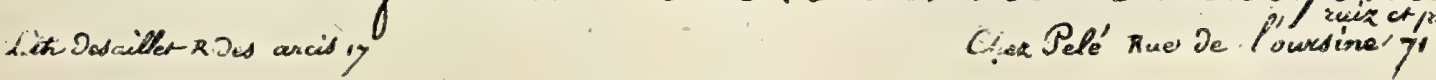





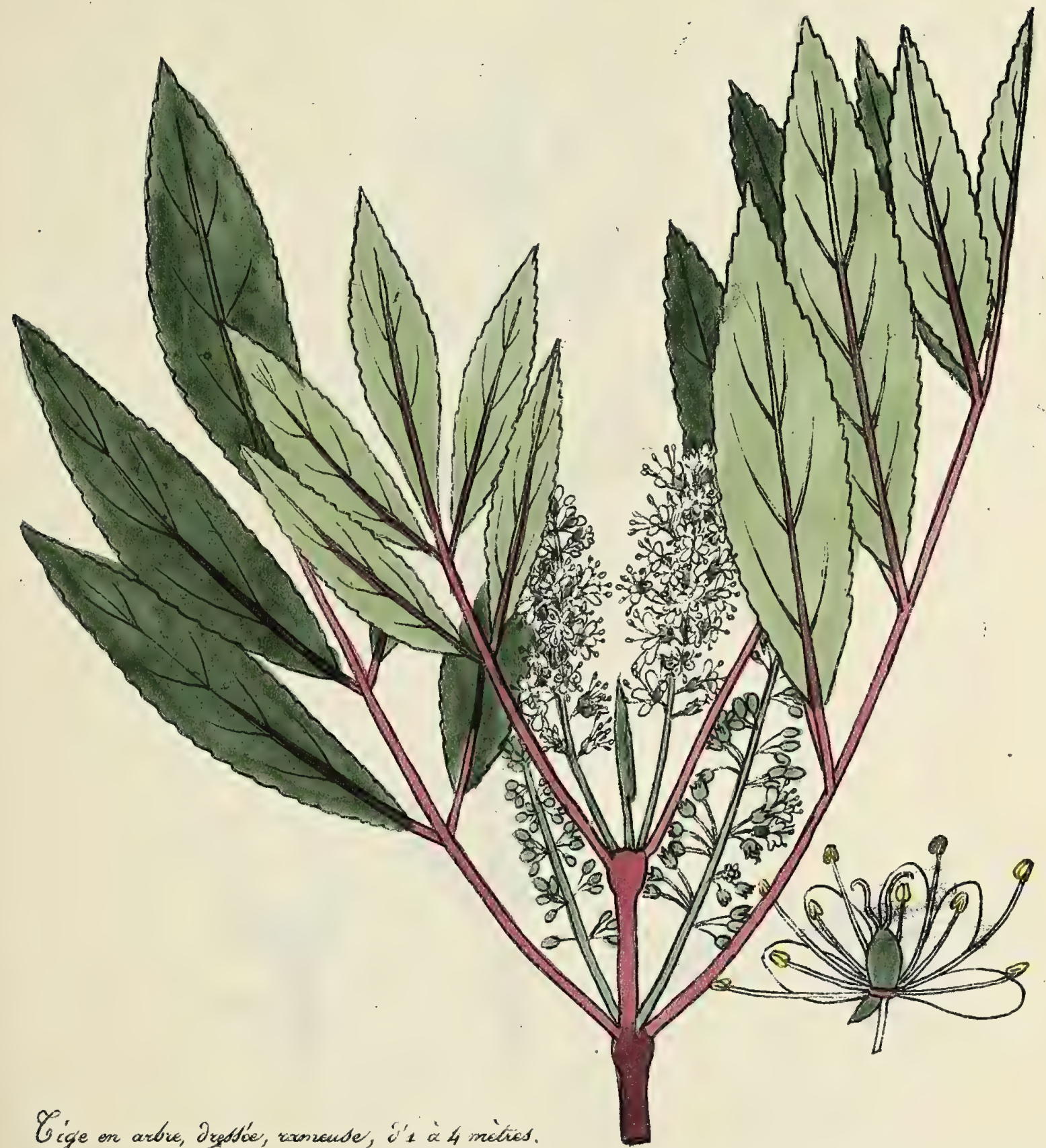

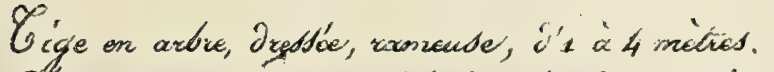

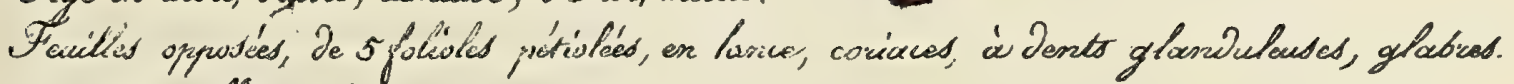
Groypred axillacired imitiont un ápie.

Flewes petites, blanchas.

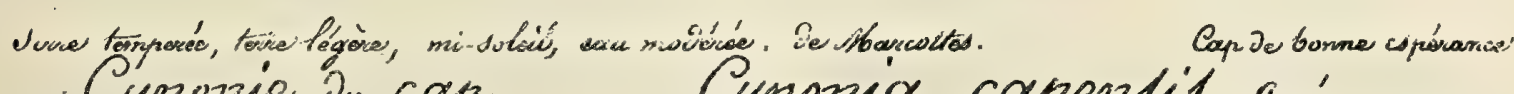

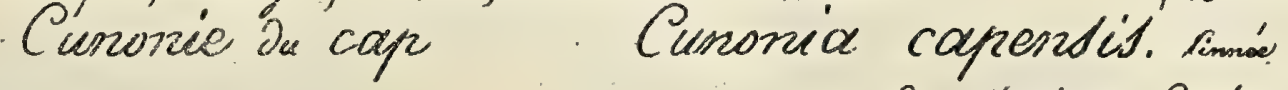

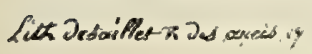

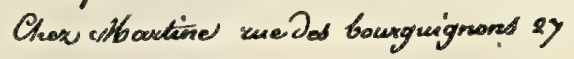





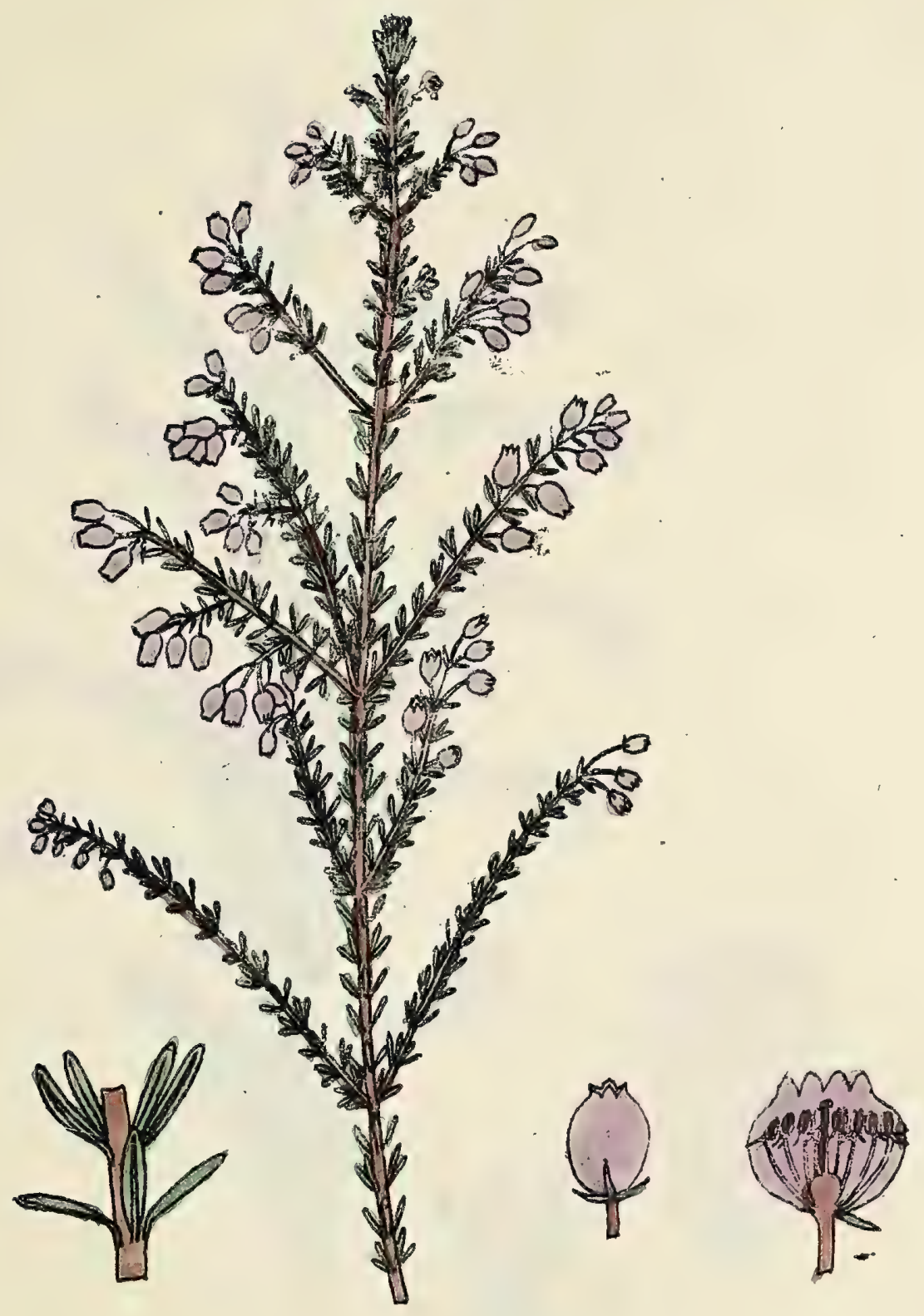

Gige ligneude, Dressió, ramoude, de 60 contionetres.

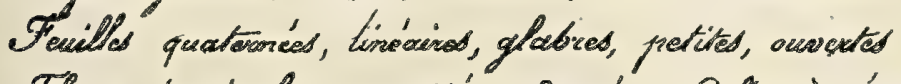

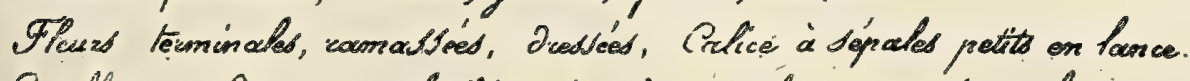

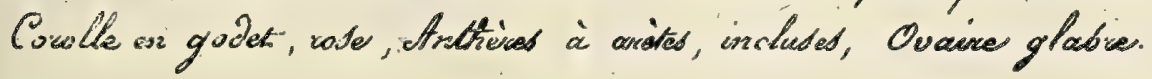

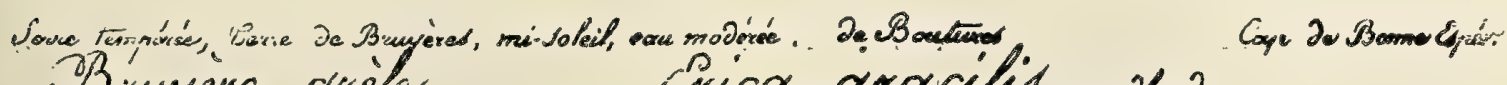
OBnyere gicele crica gracilis wordand.

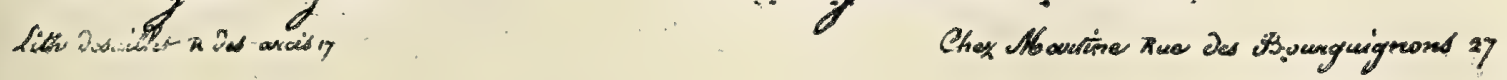




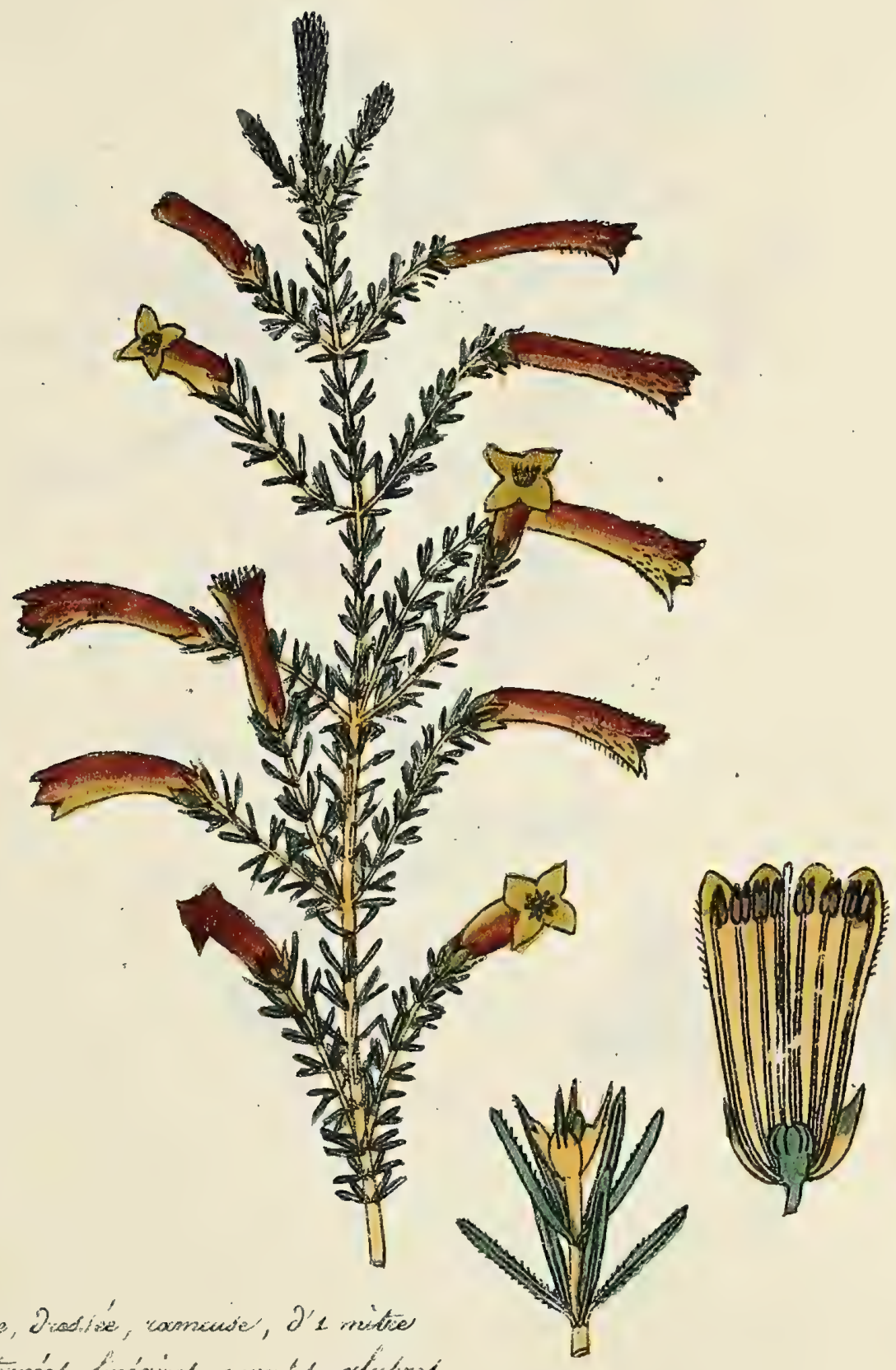

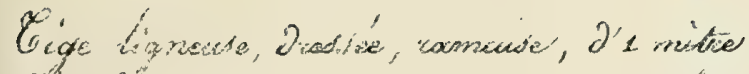

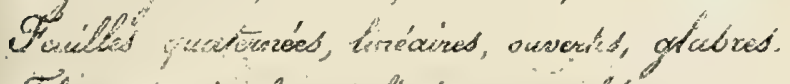

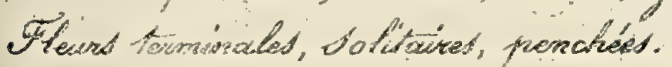

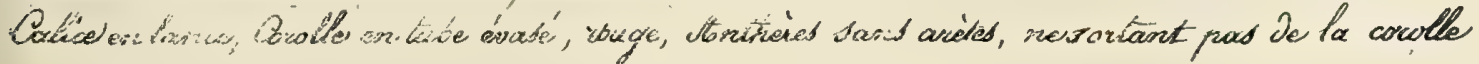

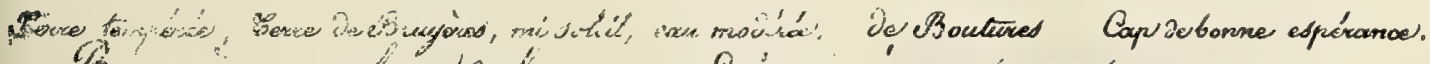

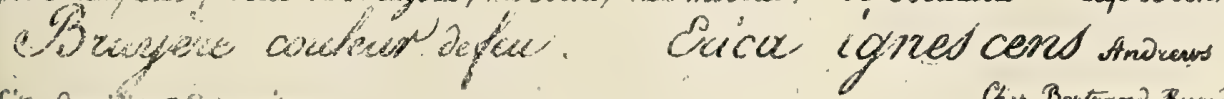

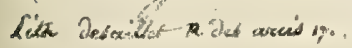
Chis Bertrand Rue de la ruquetto 102 


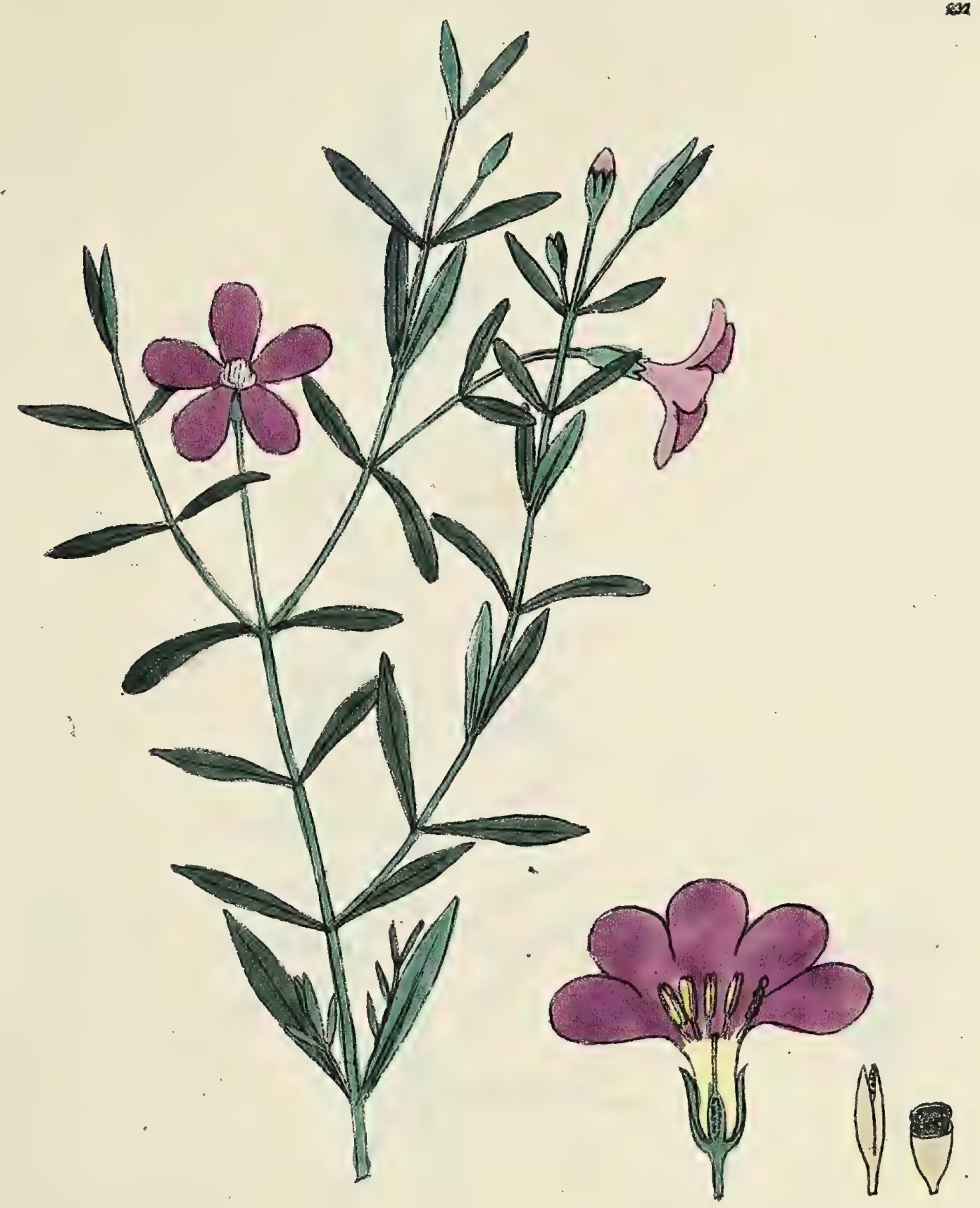

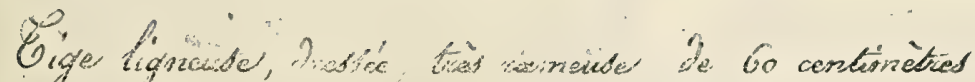

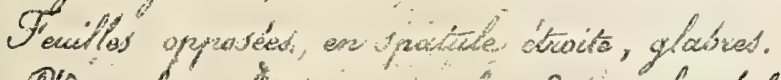

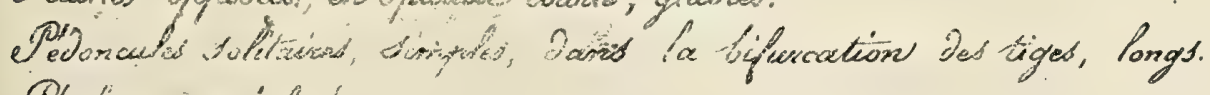

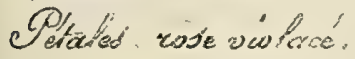

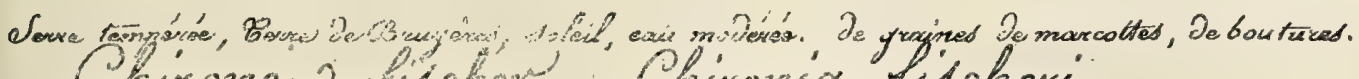

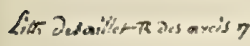
Cher Selé rue de Poursine 'y' 



$$
\text { 鵕 }
$$





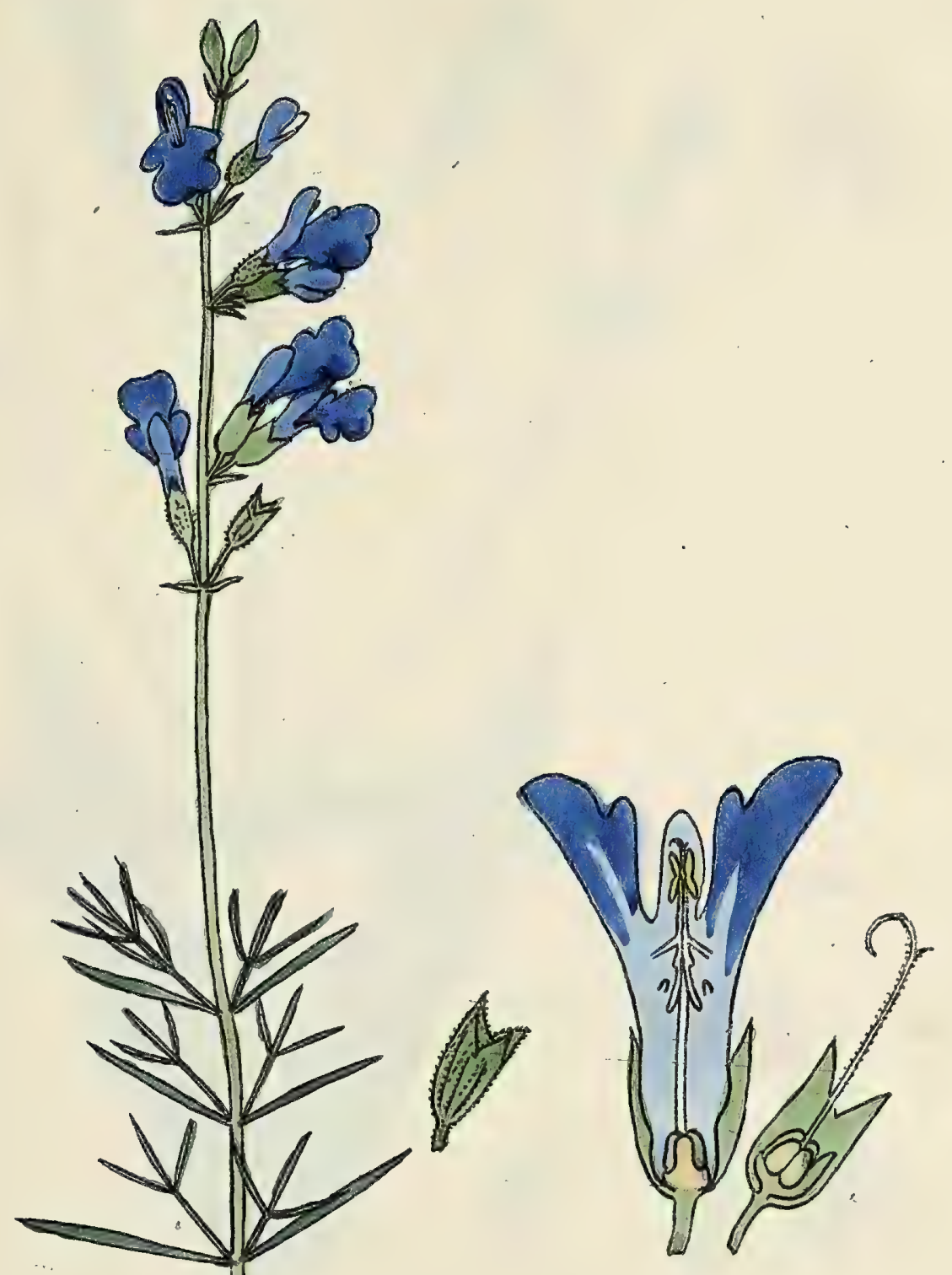

Fige ligneude, womeuse,

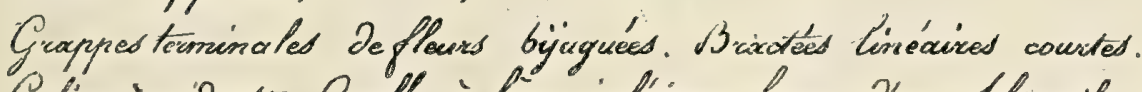

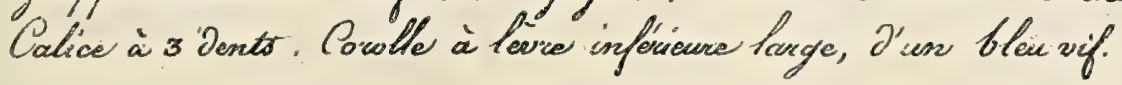

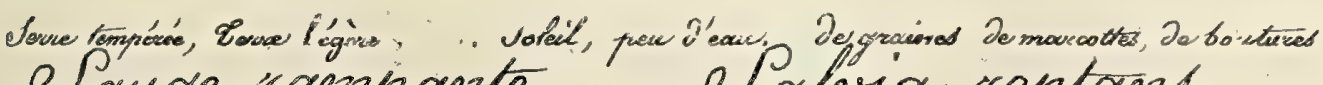
Cauge 'camparite efabria replaszs 



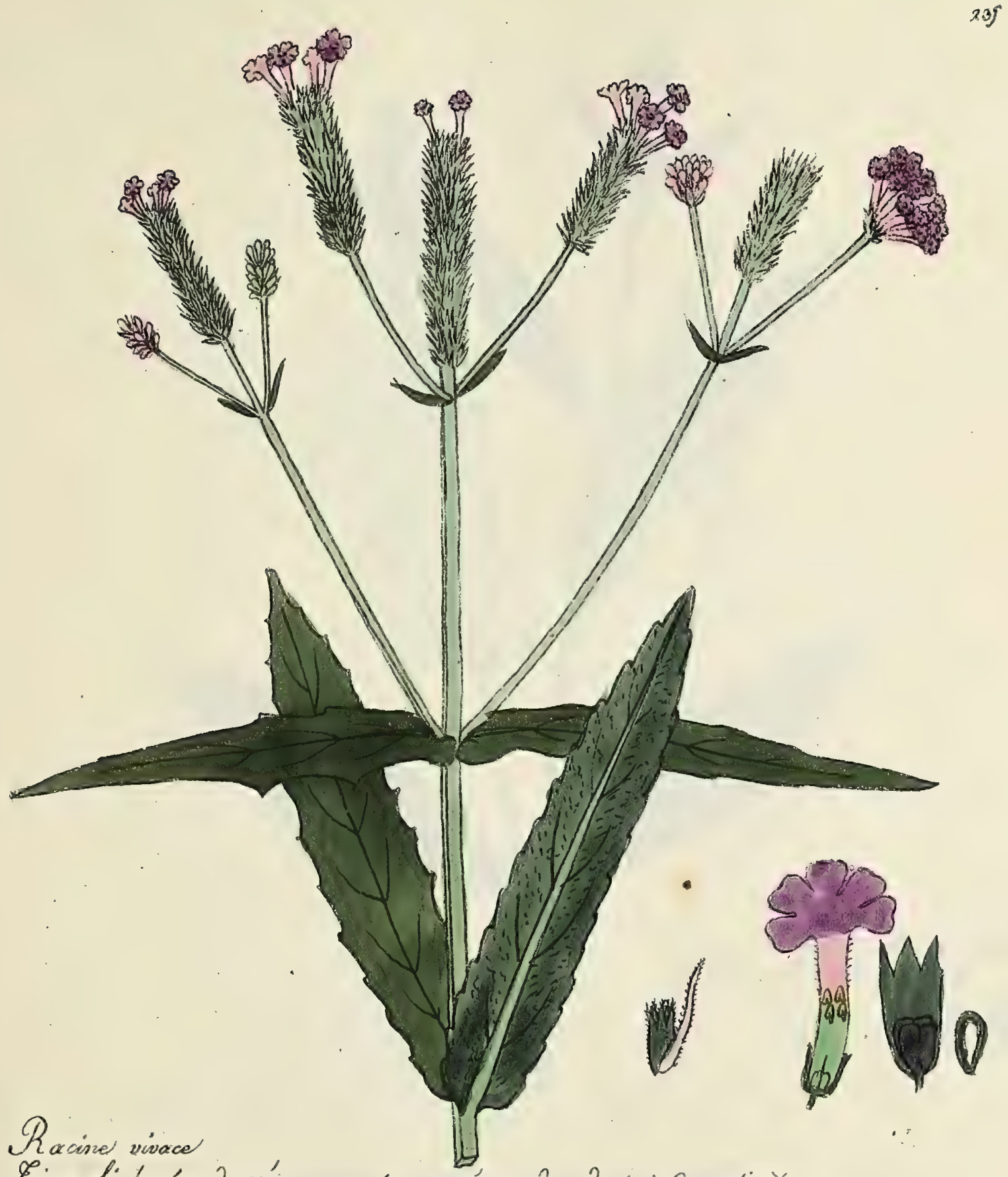

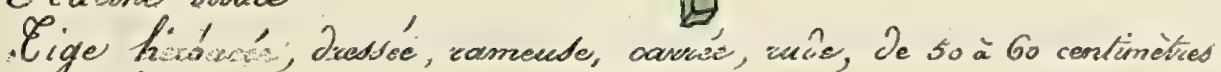

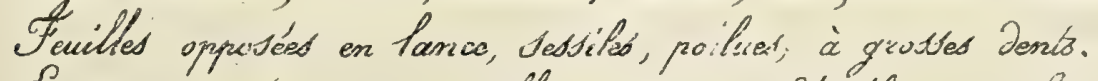

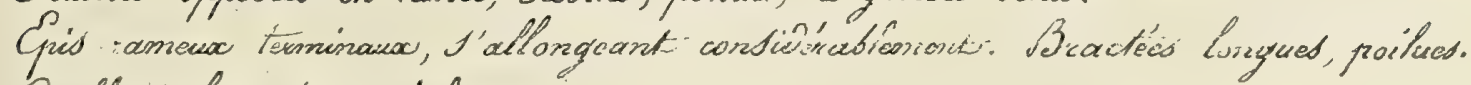
Corclle à long tube, violette:

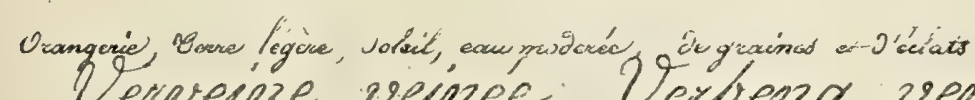
Verveine veincé Verbena venosa Simb Jesarllet-x and arciss ny Chow Sile' Rue de Poursine 'y' 



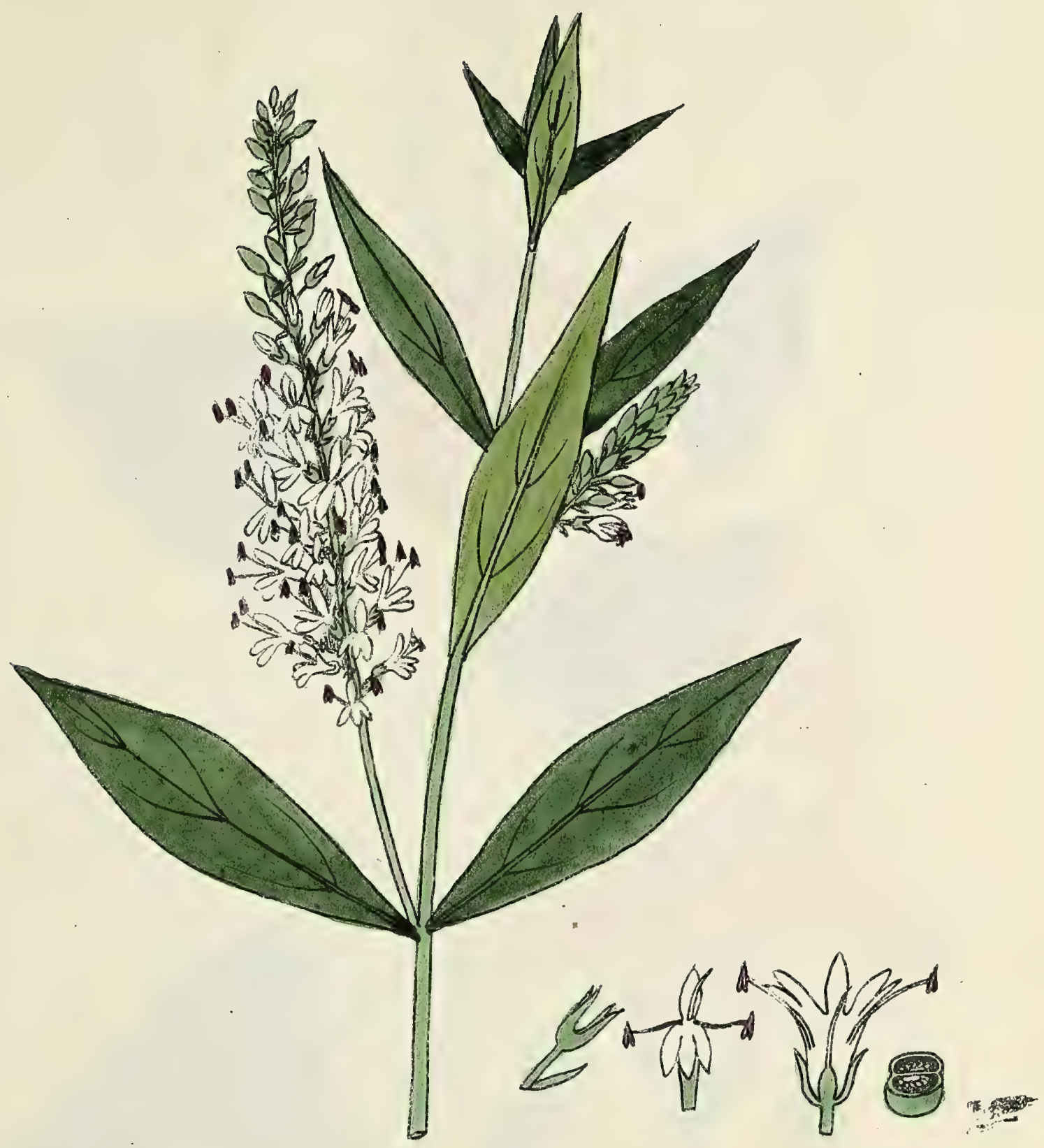

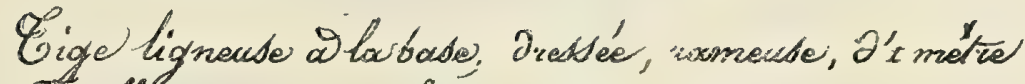

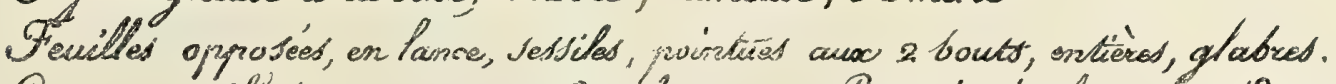

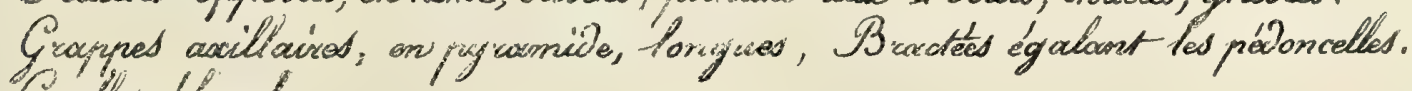
Coratie blancho

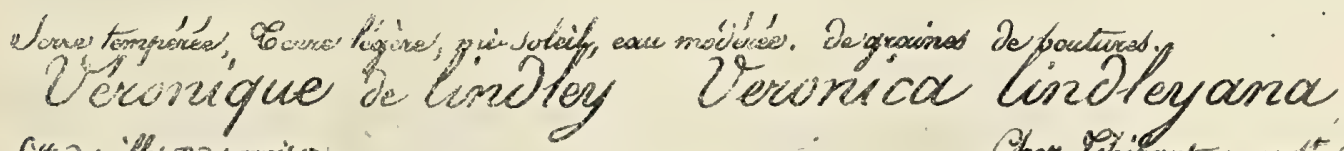

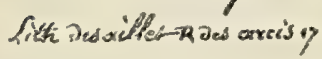





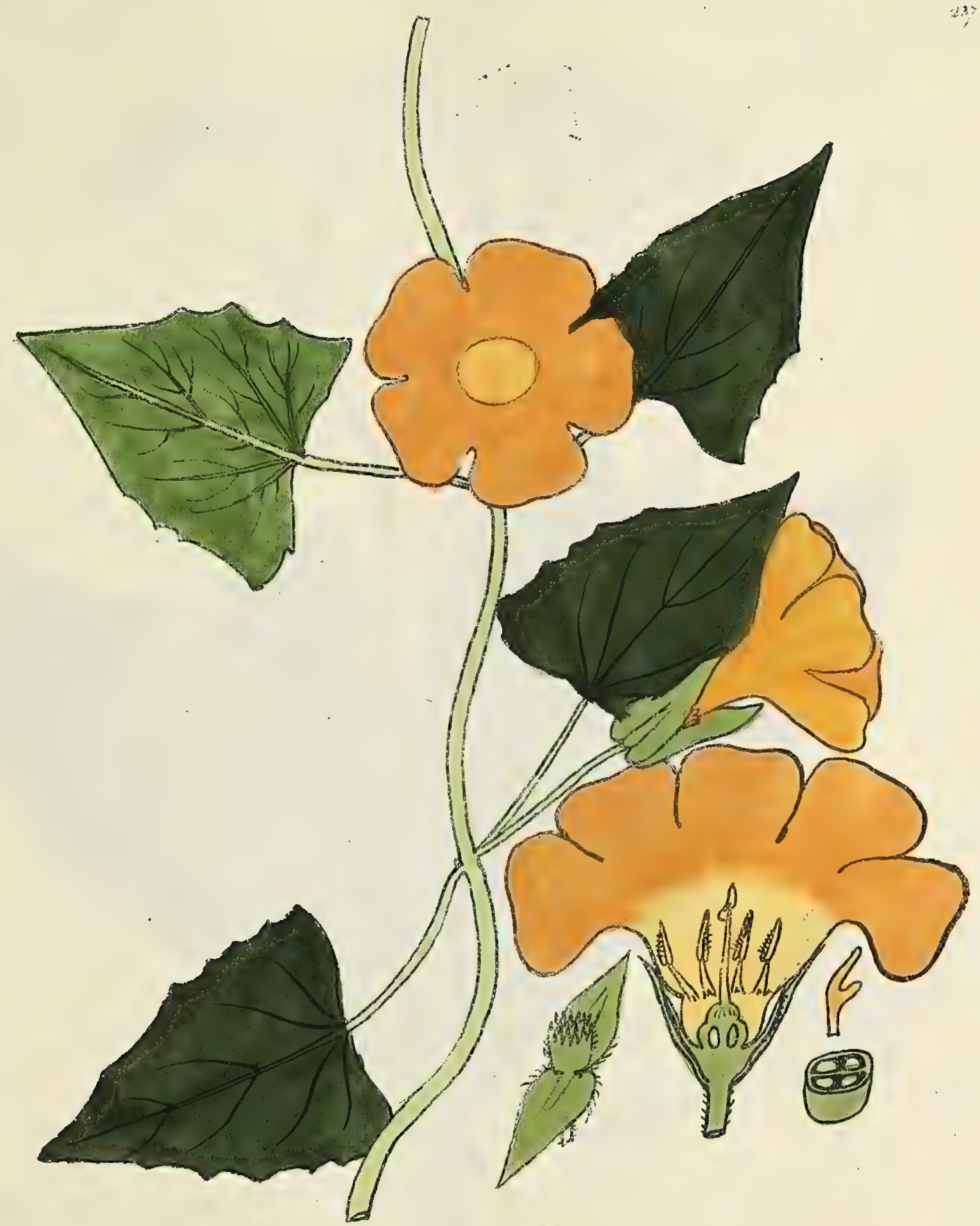

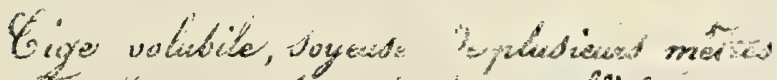

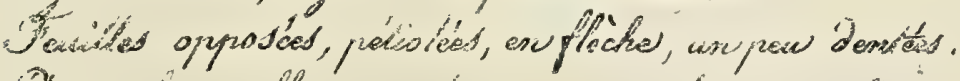

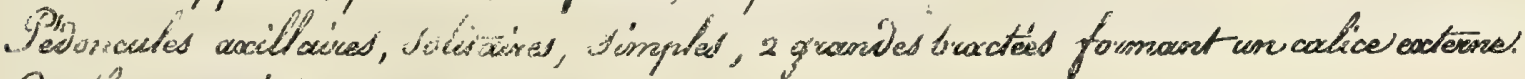

Corolle orargáe, à yorge jourser

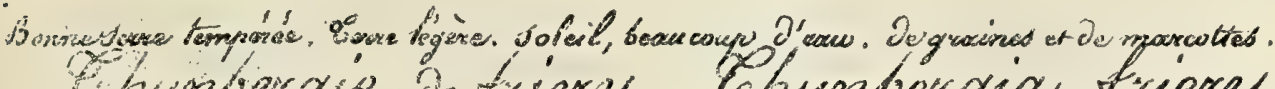

Enwbergie Defiery Ehembergia Priery.

Cha Chamine ravedeforiconuttersar 



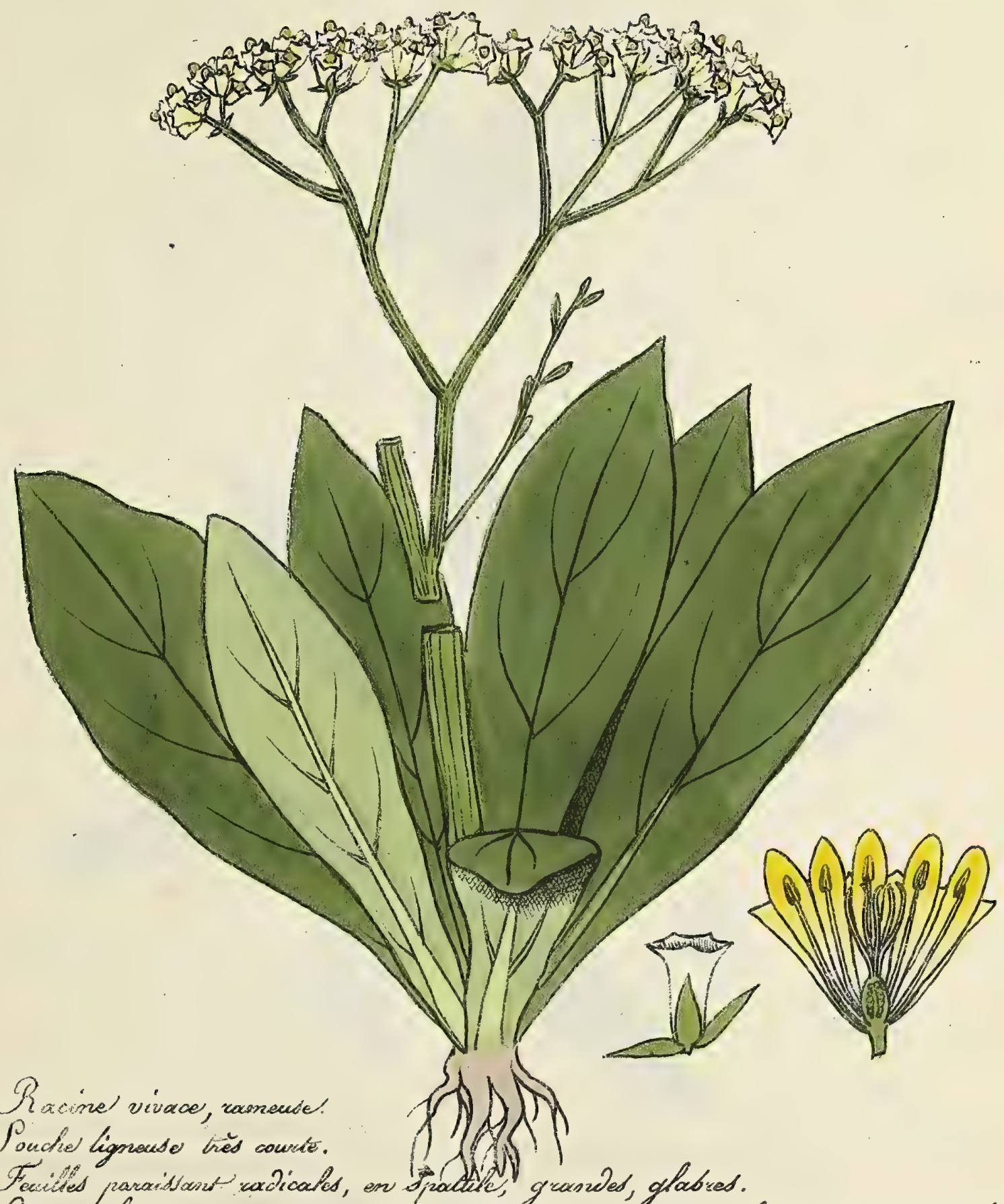

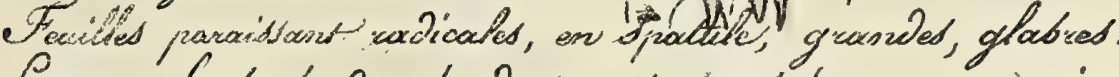

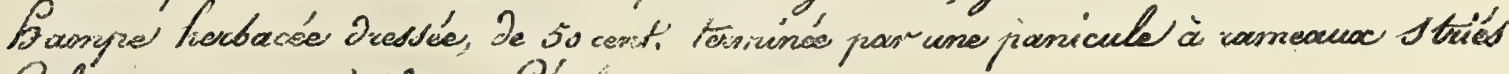
(alice en entorinoin, blanc, Perated gizunst.

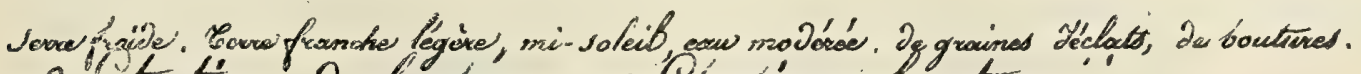

Clatice de forture ePtatice focturie fith Debirillet $x$ des caresis iy. 


$$
\text { 䒚 }
$$





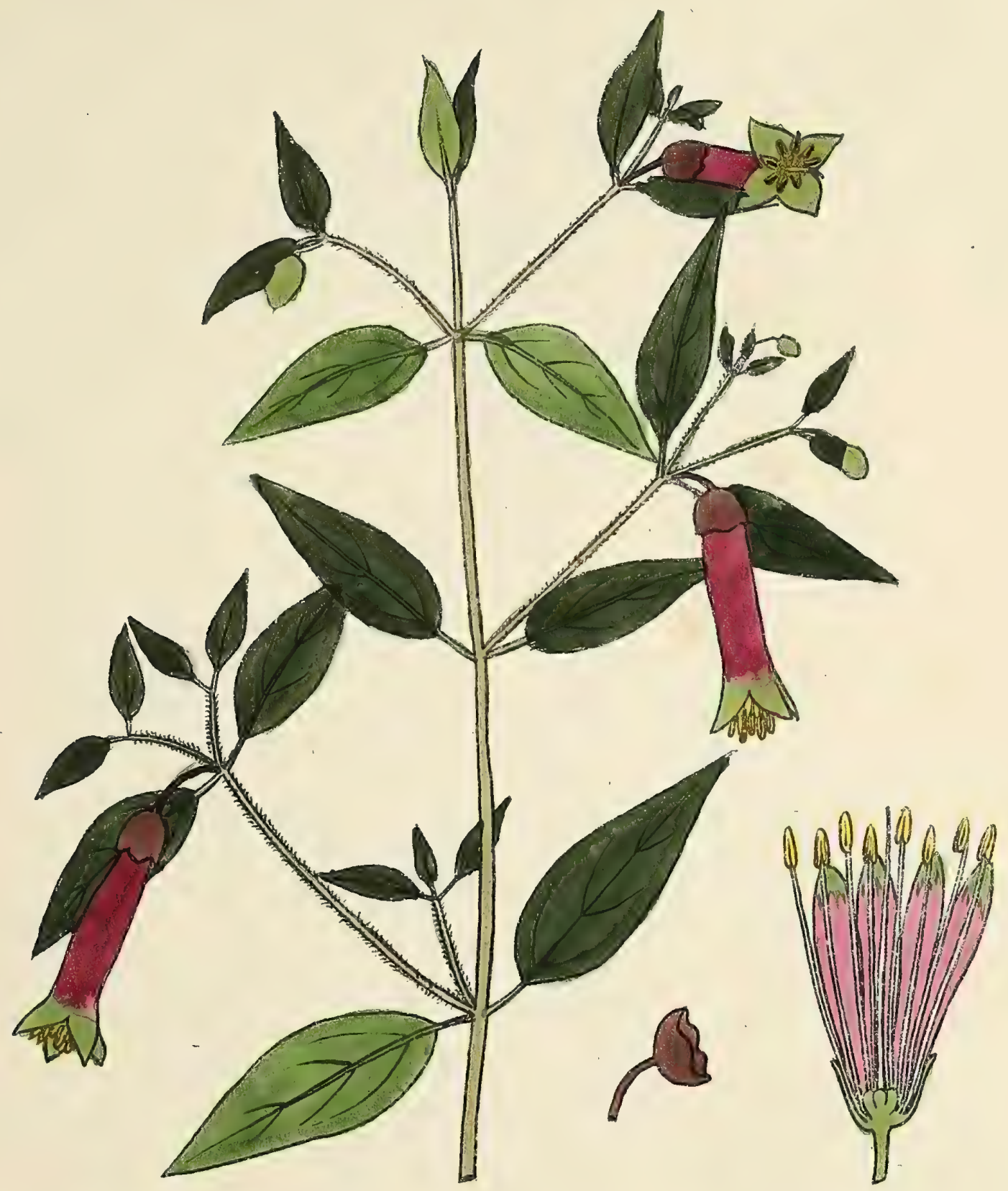

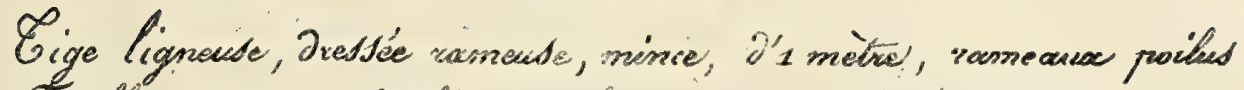

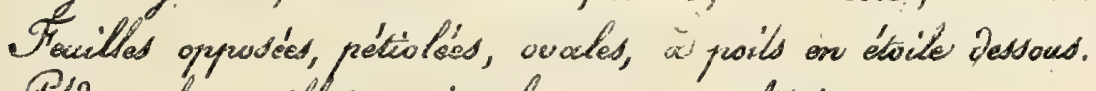
Pedoncules acciltairas, sinzotes, courts, solitaired.

Calice trongué, pétailes soudés, cougre vif, à boud vers

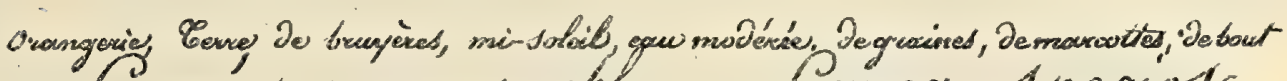
Coviee, remoucquable Coviea Ipeciost

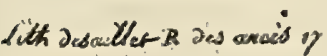


.

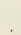

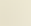




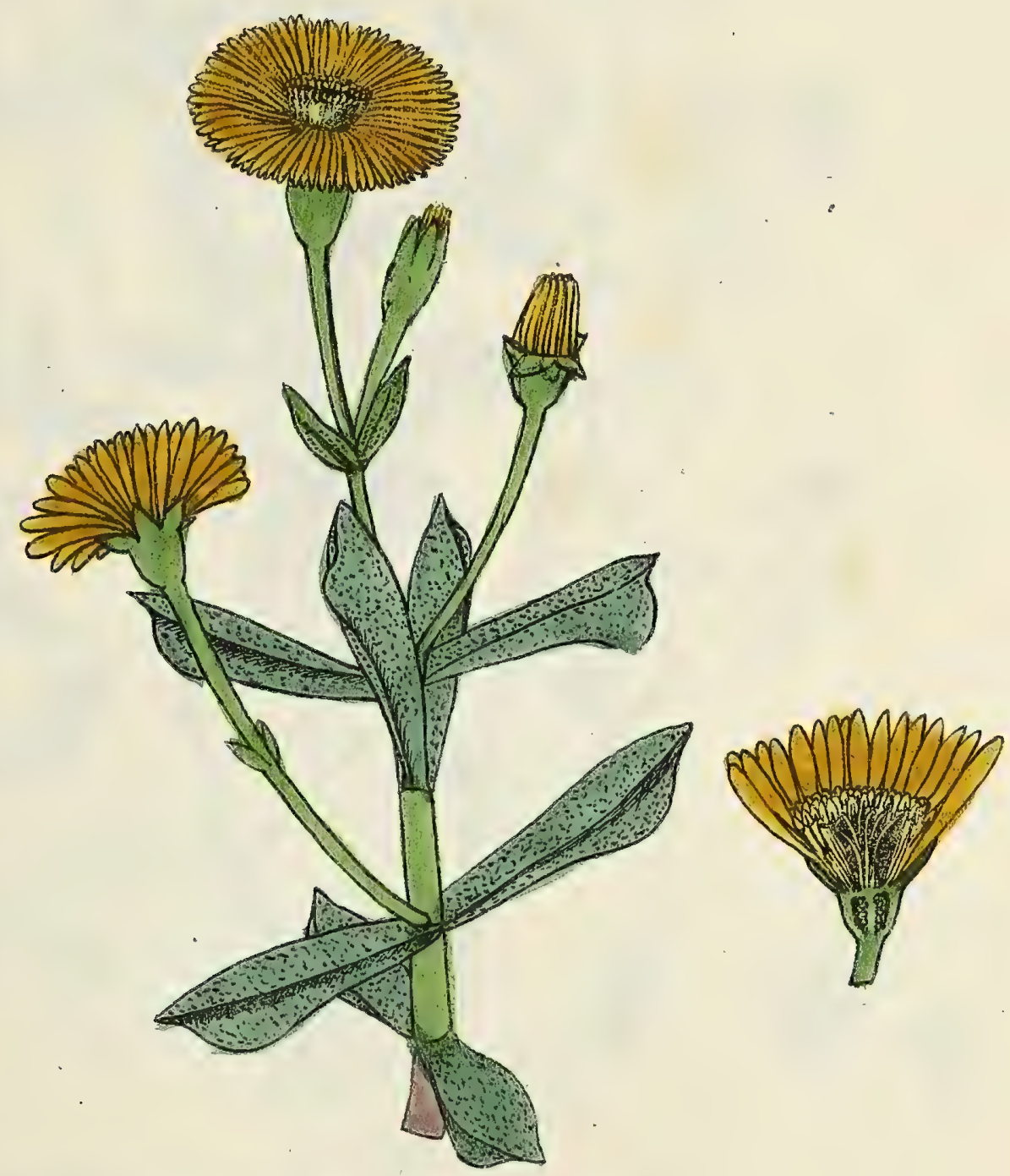

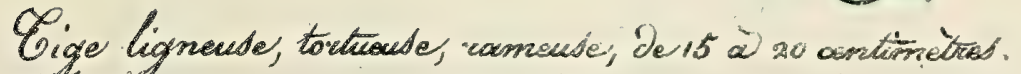

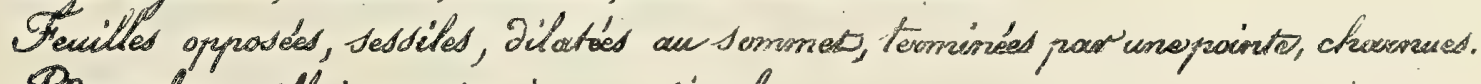

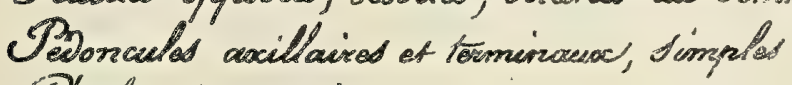

Sotales jaure o'or.

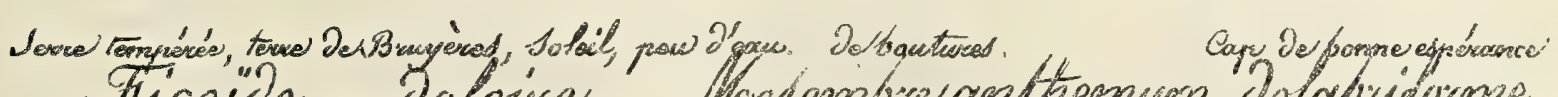

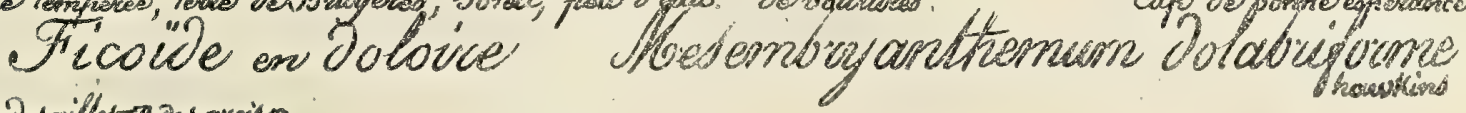

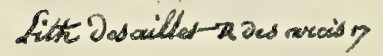





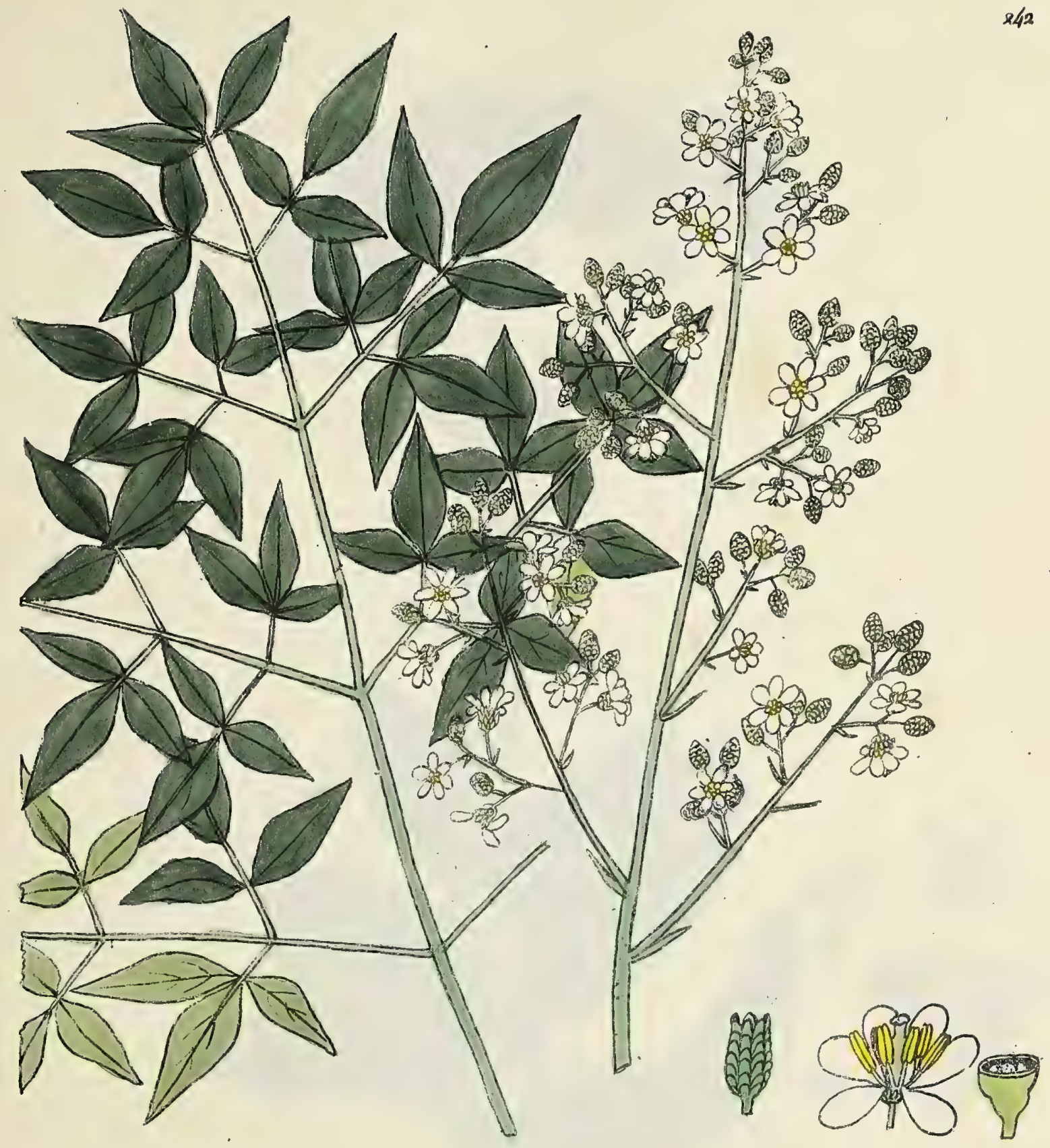

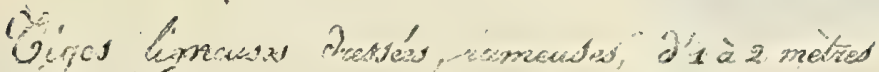

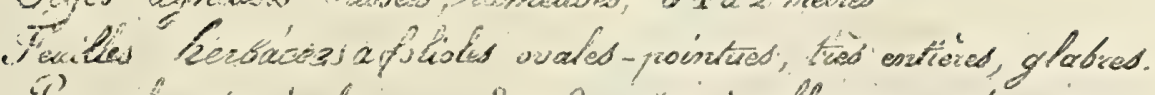

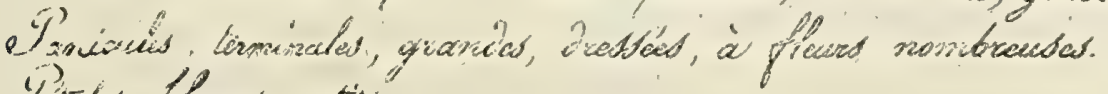

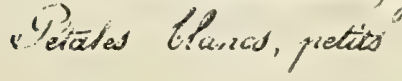

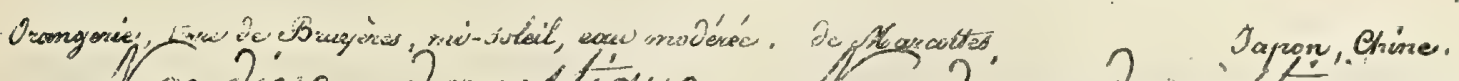
ilandive Jomedlique If andina domedlica Ghunderg.

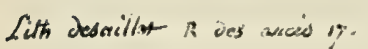





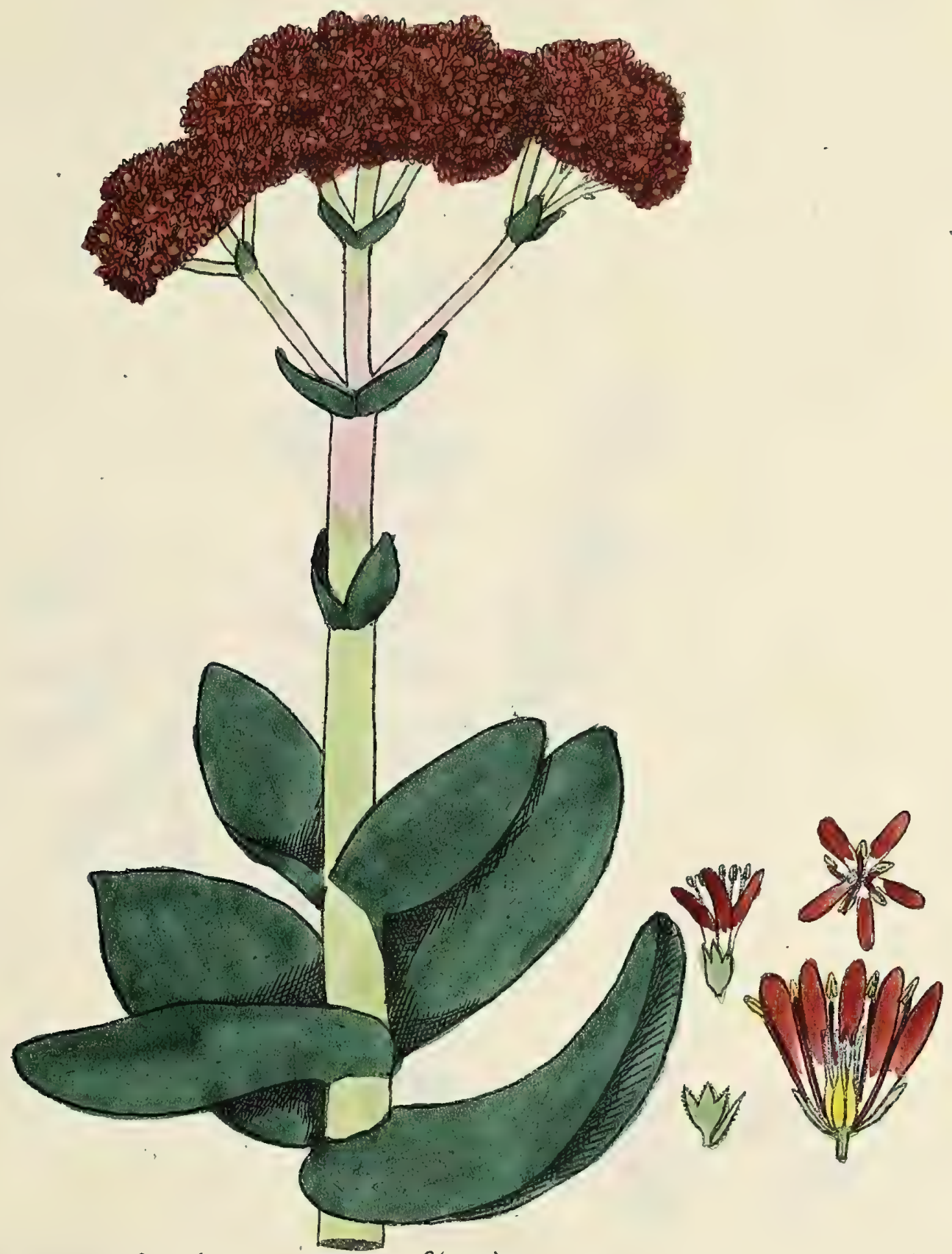

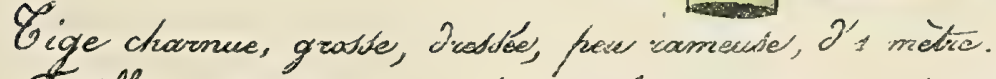

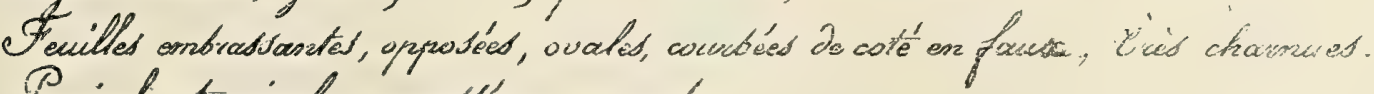
Panicule toumiorale, ramadice on conymbe.

- Flecus écrarlates, poldited, Z'odour agréable

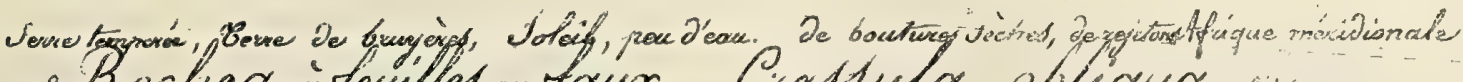

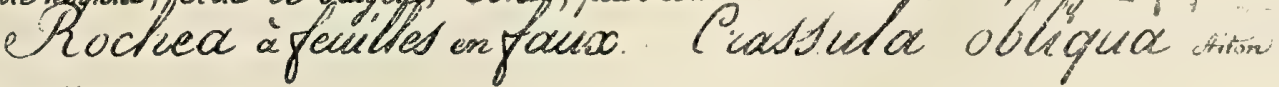

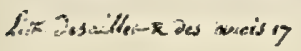





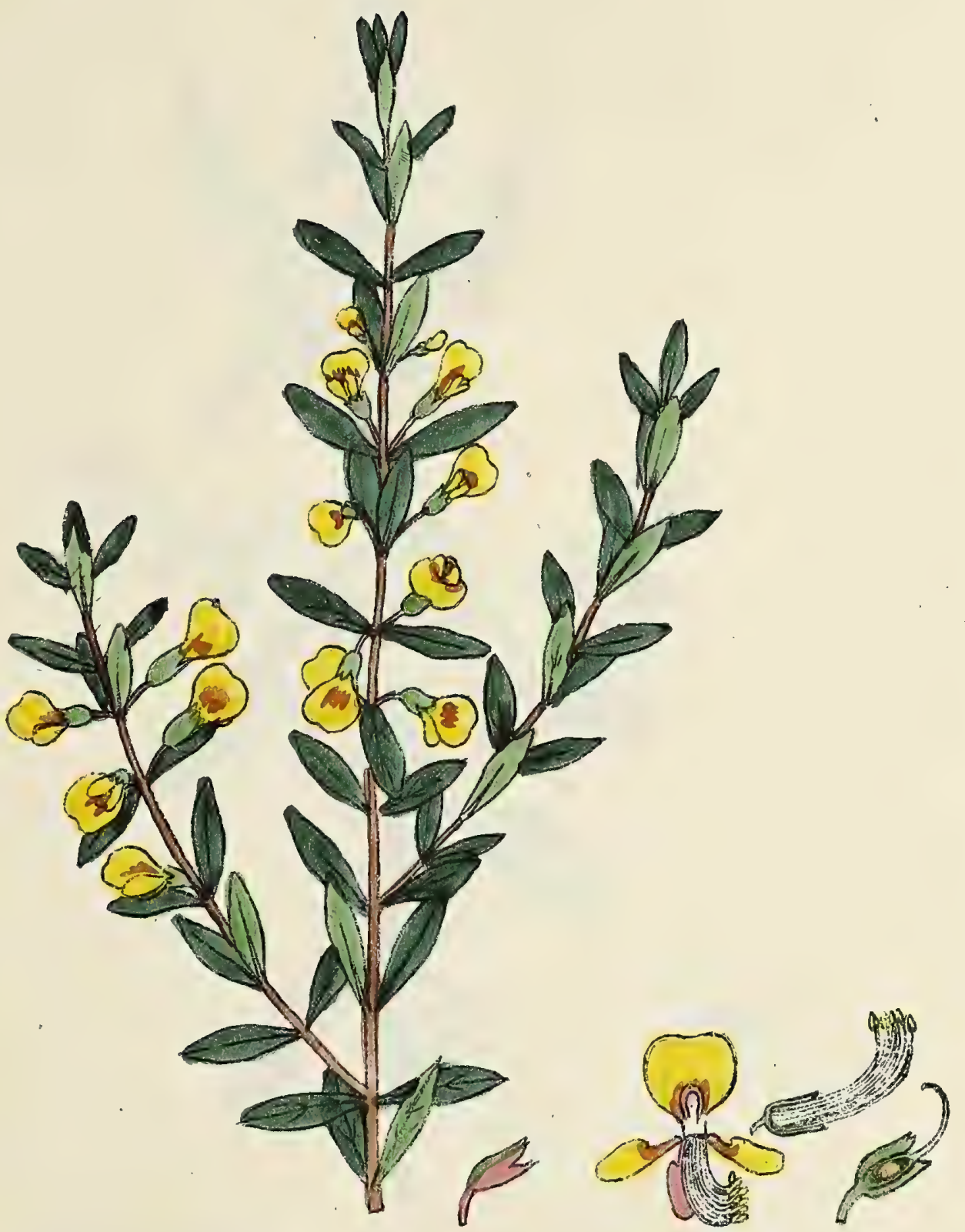

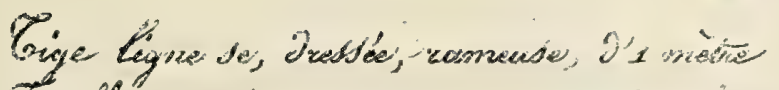

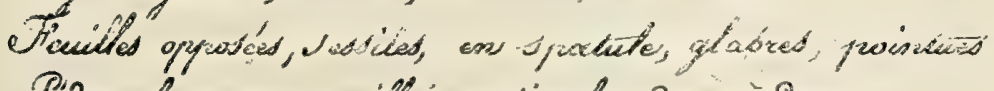

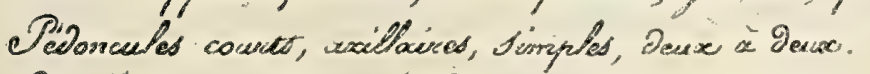

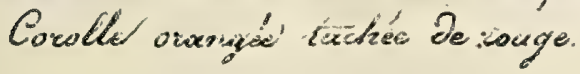

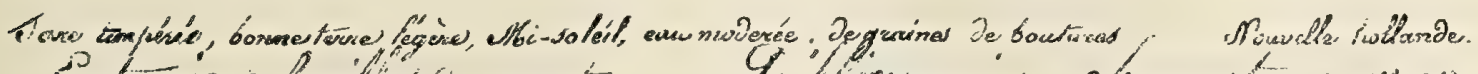

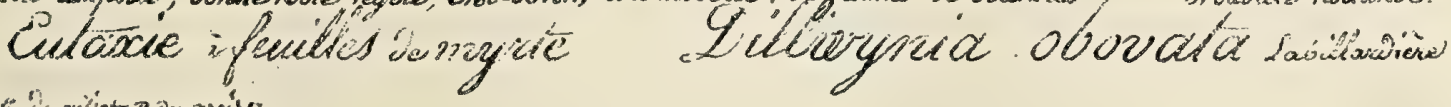

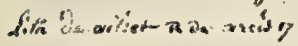


a s $>+\infty$ a... 


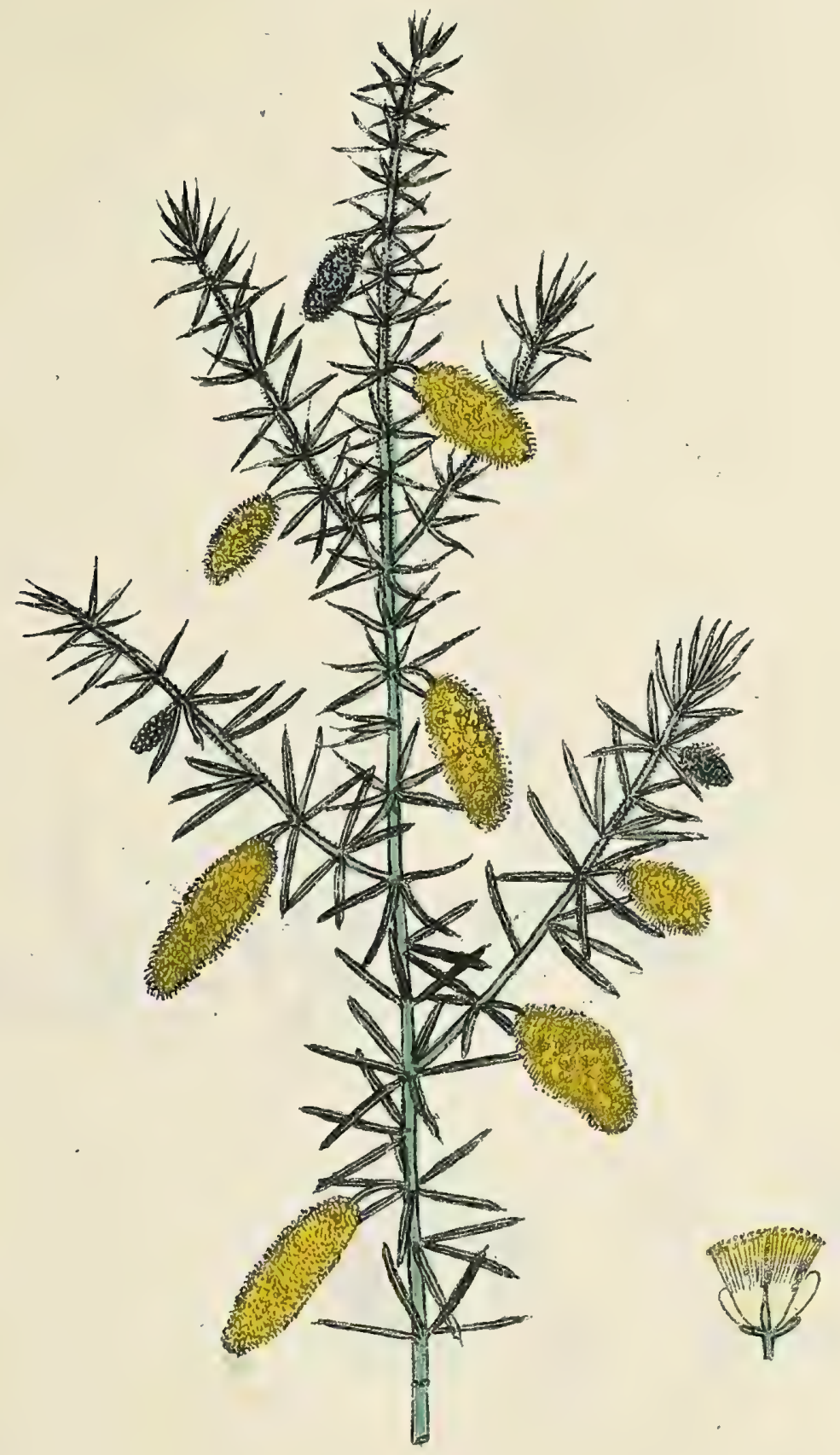

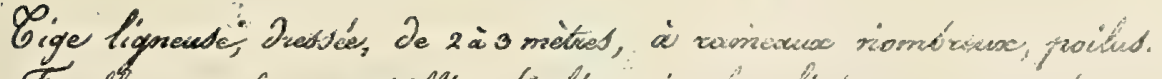

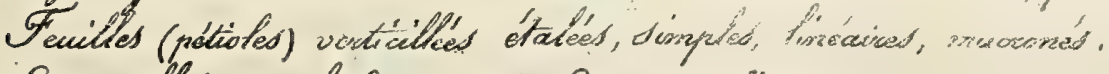

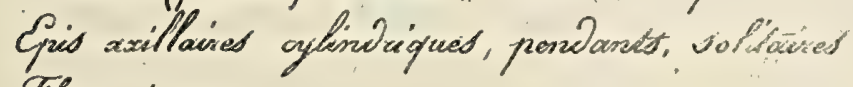
Fleures jaunes:

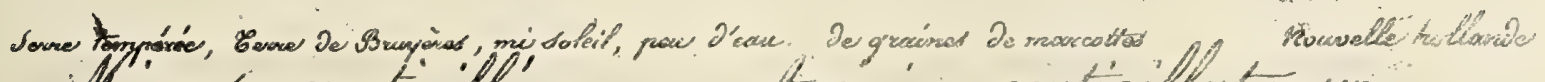
chumose verticillee Hcacia verticillicía willowion.

Sith Jesailles $x$ Jes aucis ? 


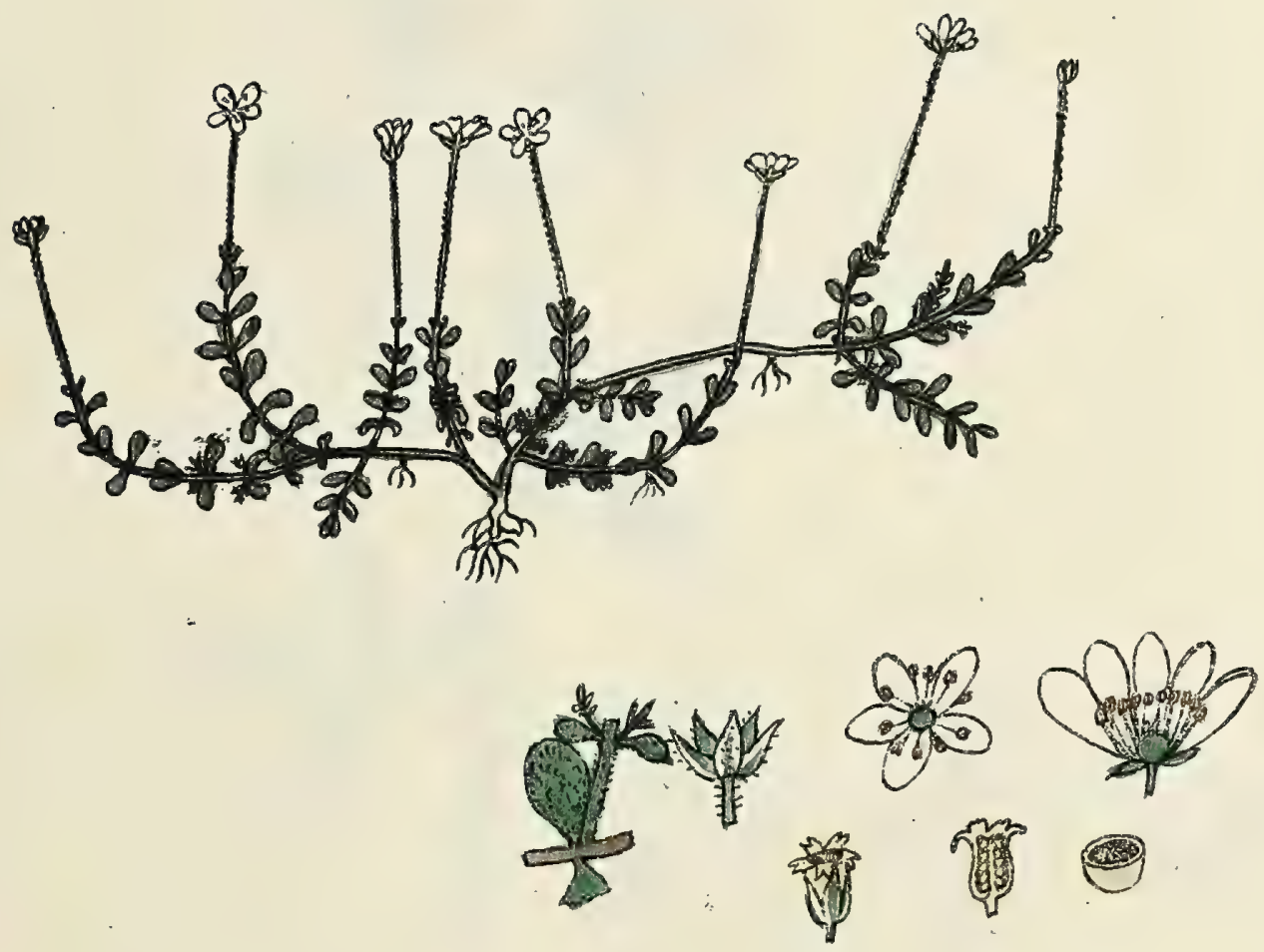

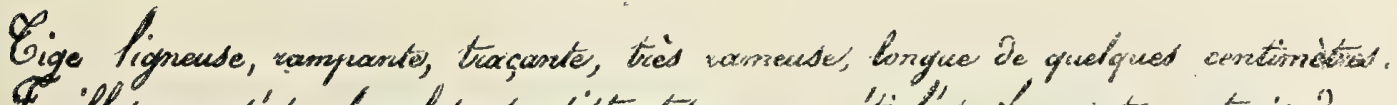

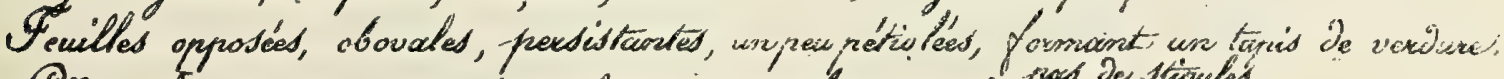
Sevoncules terminawar dimples, solitaired, tries Lonqs, velud. Tetales plus longs que le calice, blanas, fleuns nombreudes, tres petites

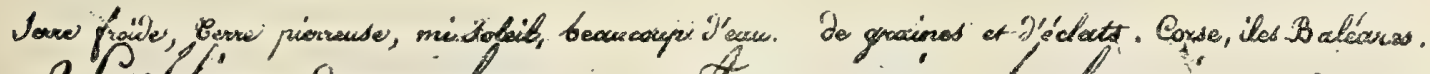

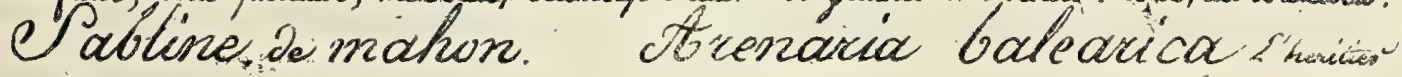

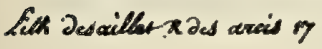




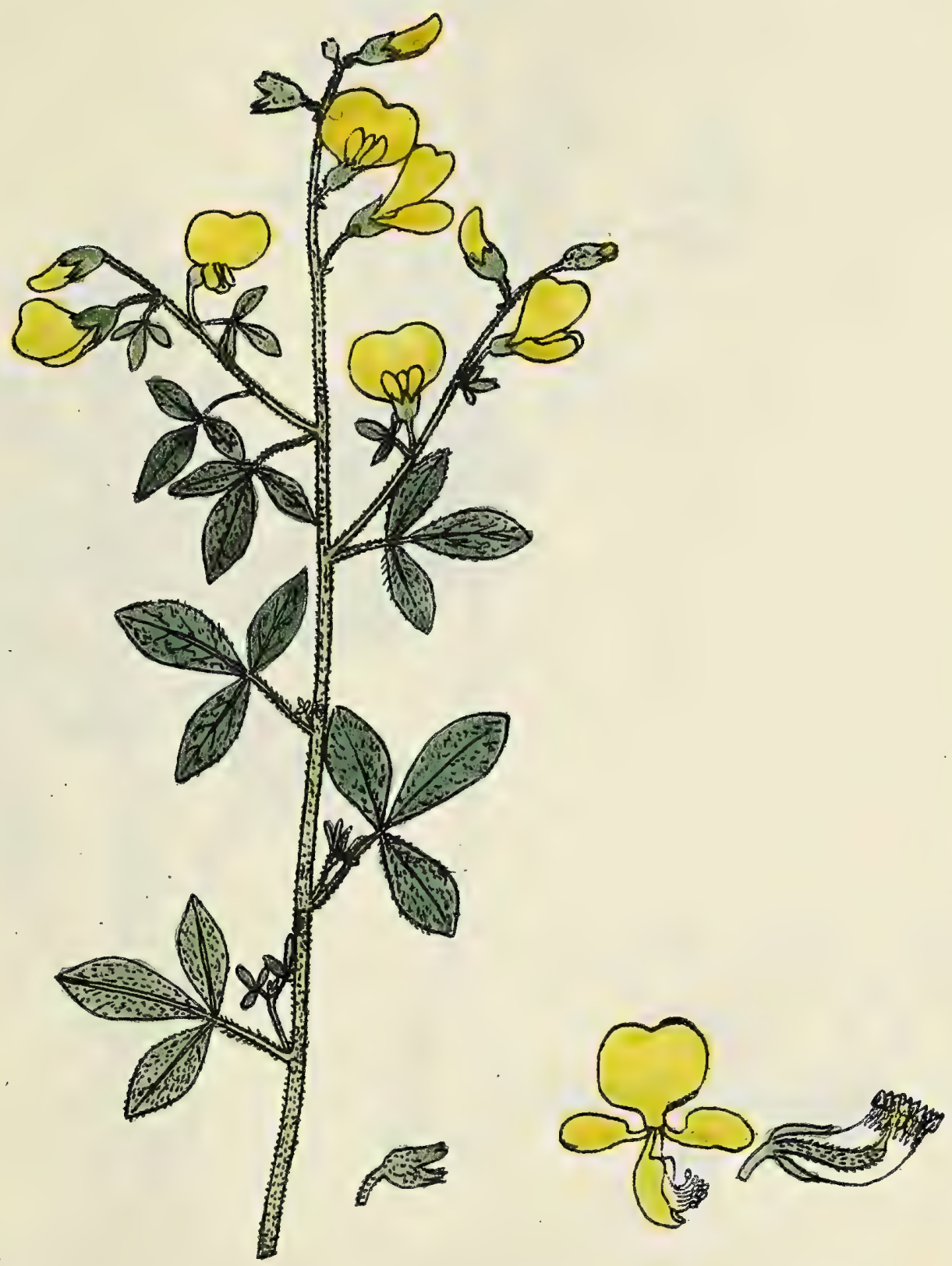

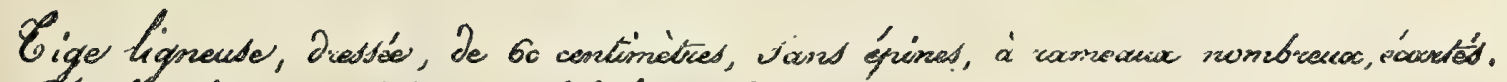

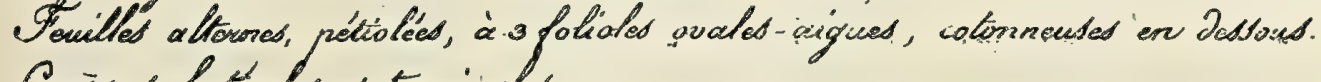
Groinged lateraled et toroninalad.

Corolls jaures, ovaire velw.

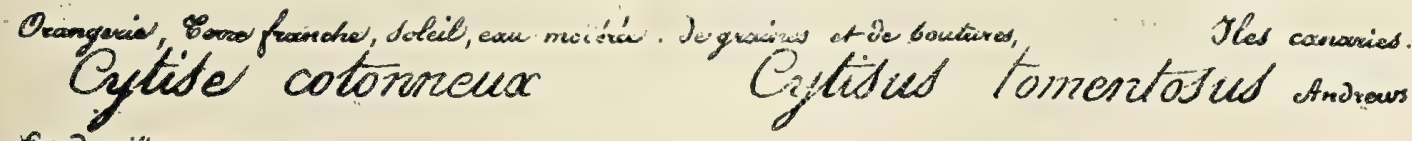
fin Jesailler $x$ ous areis $y$ 


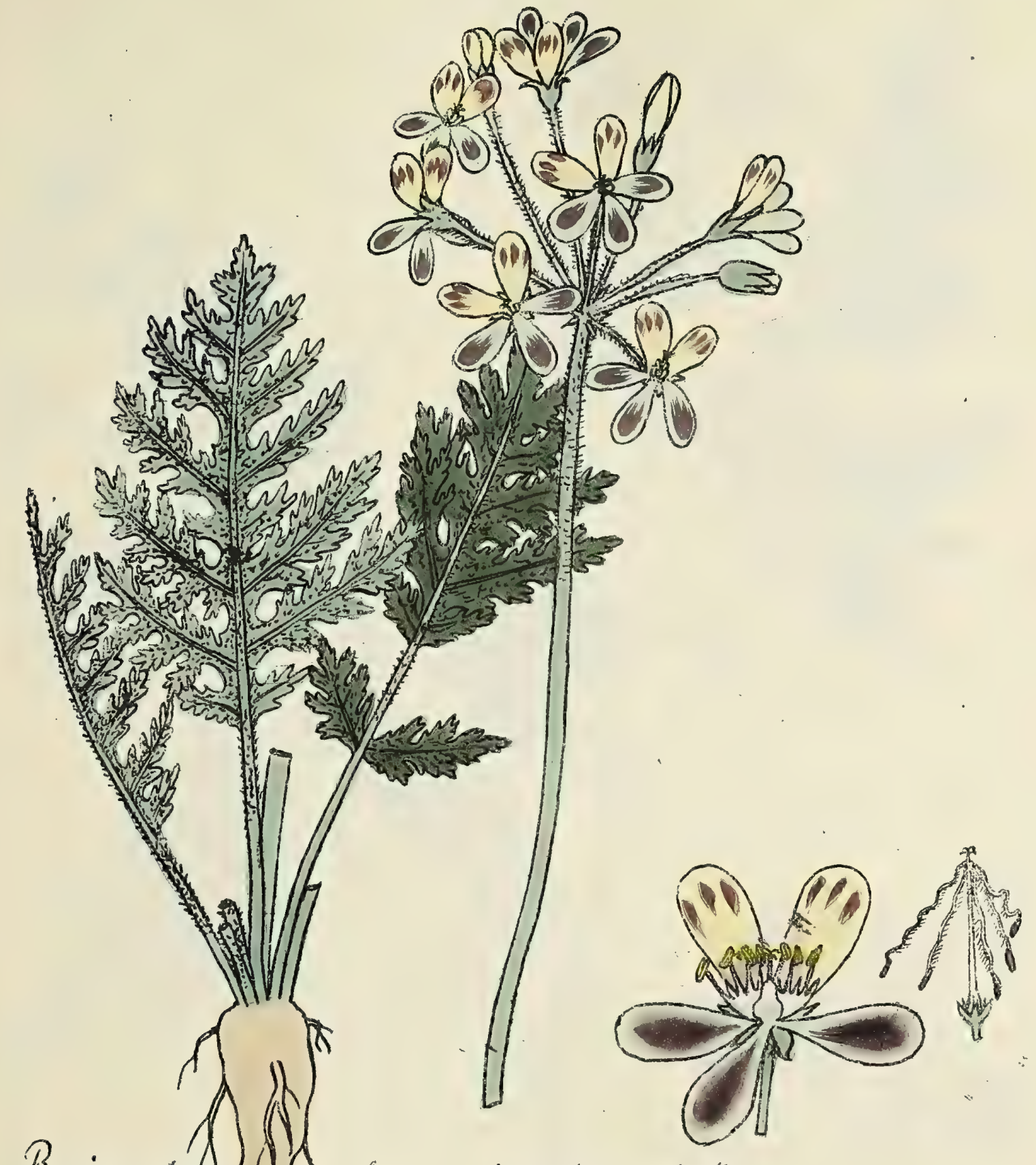

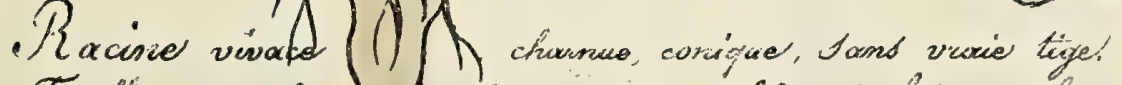

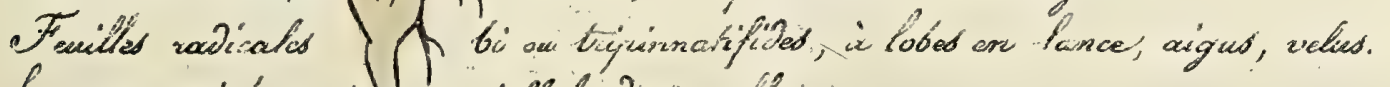

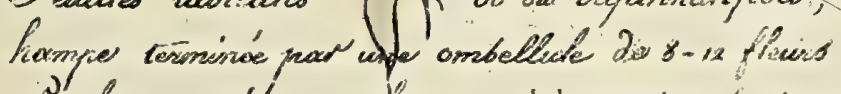

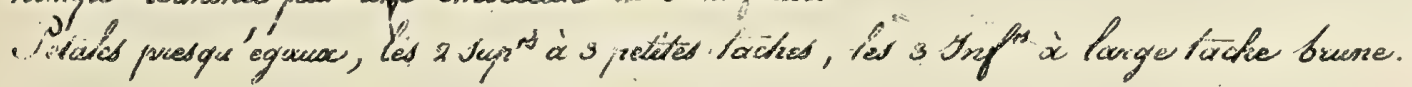

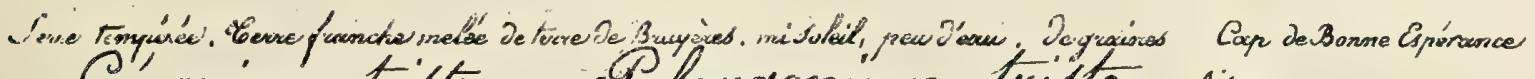

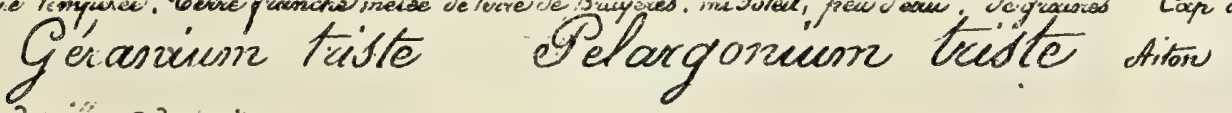

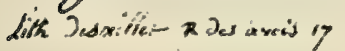




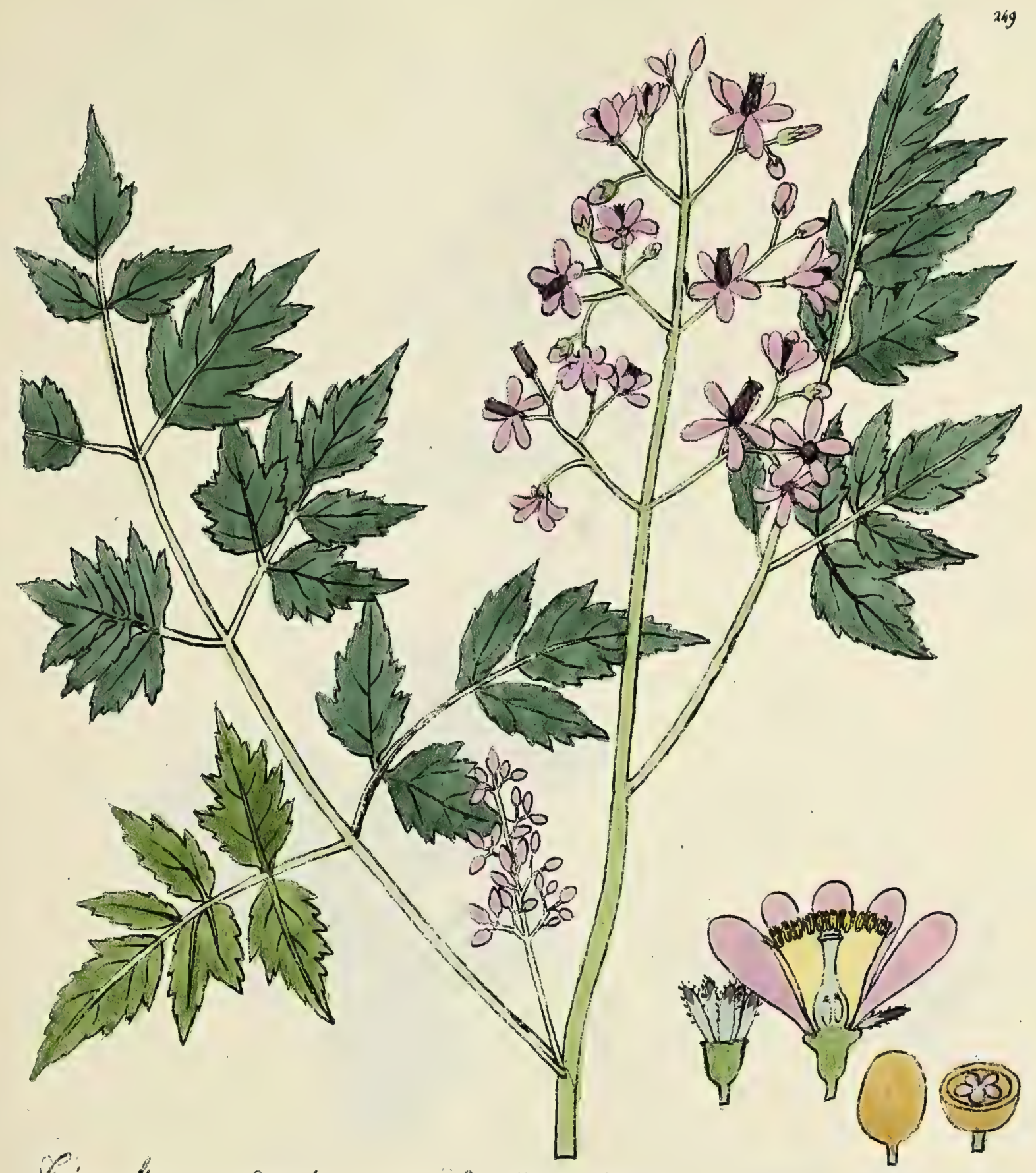

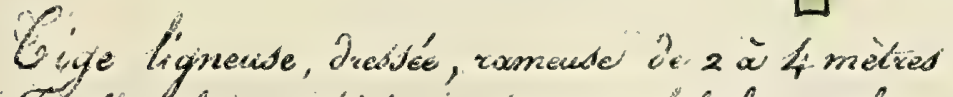

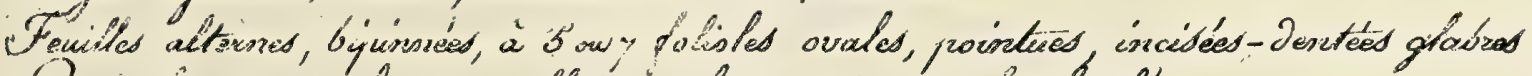

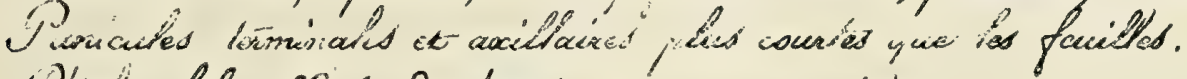

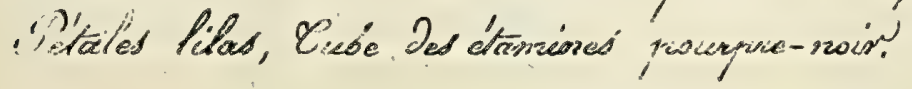

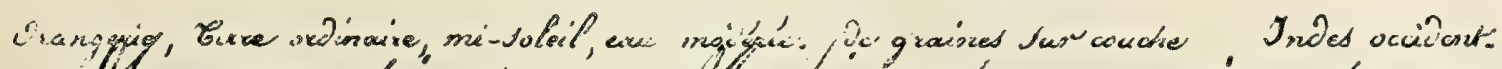

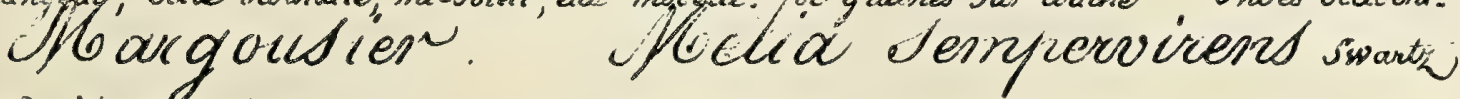
ritatisurition $\mathbf{x}$ as ancis'? 


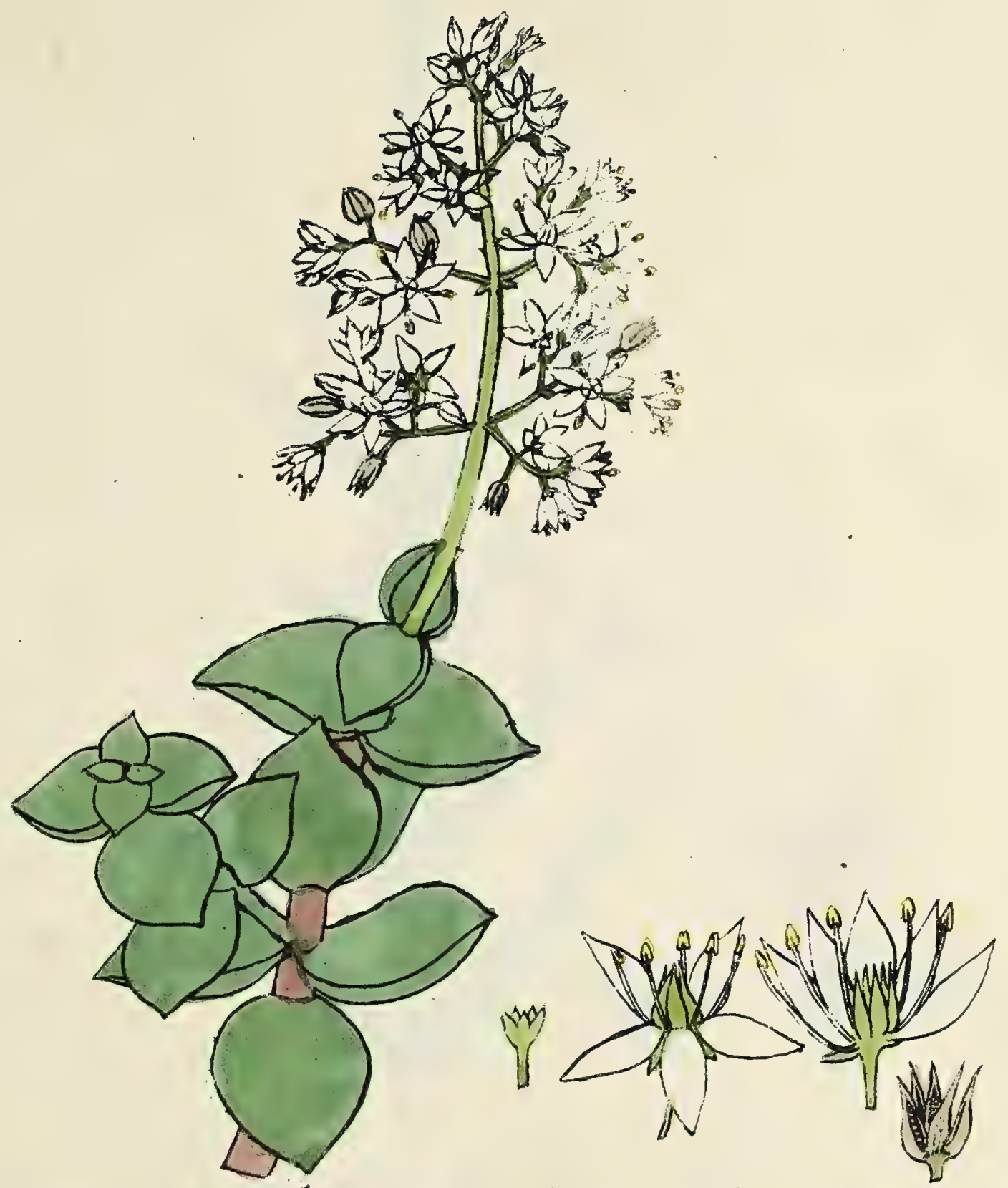

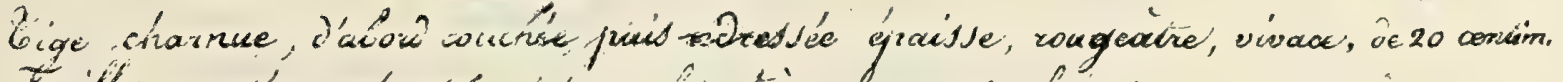

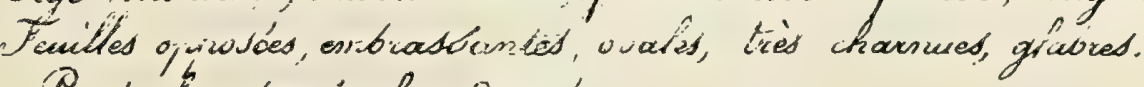

e anicules teñrionales, inestiós.

Flas on éroite, sfanc de tuifo.

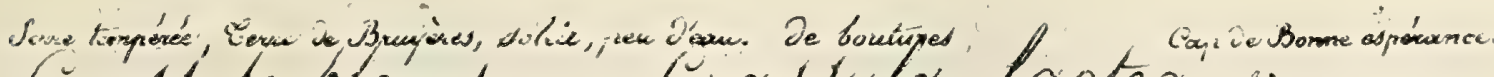

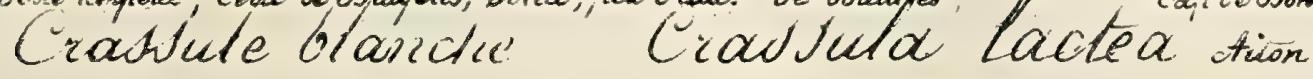

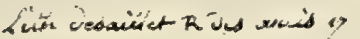





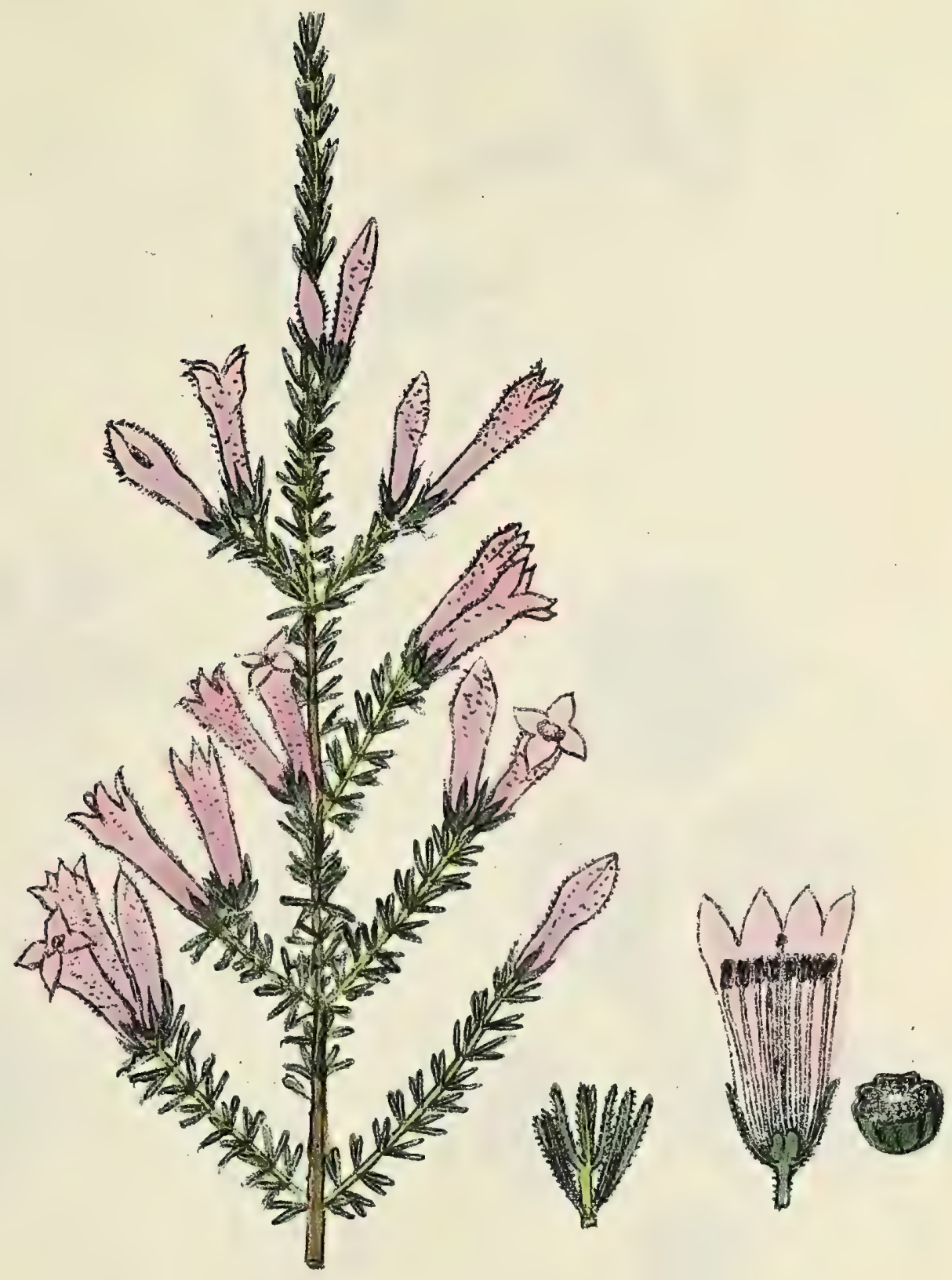

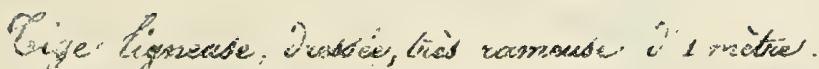

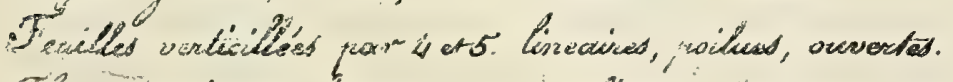

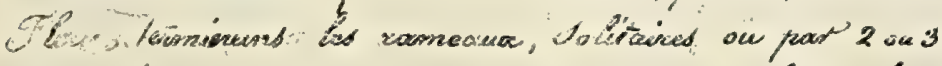

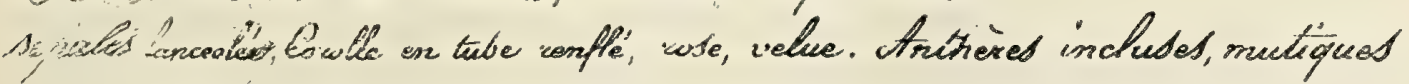

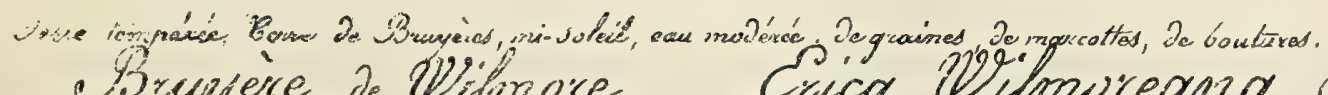

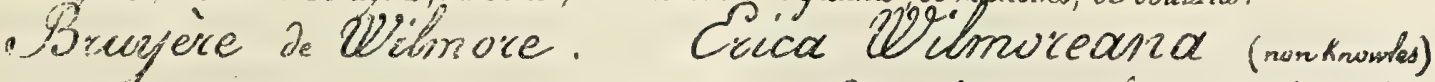

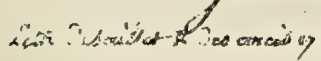
Cher vaillown Bouter. dus italiens 25 



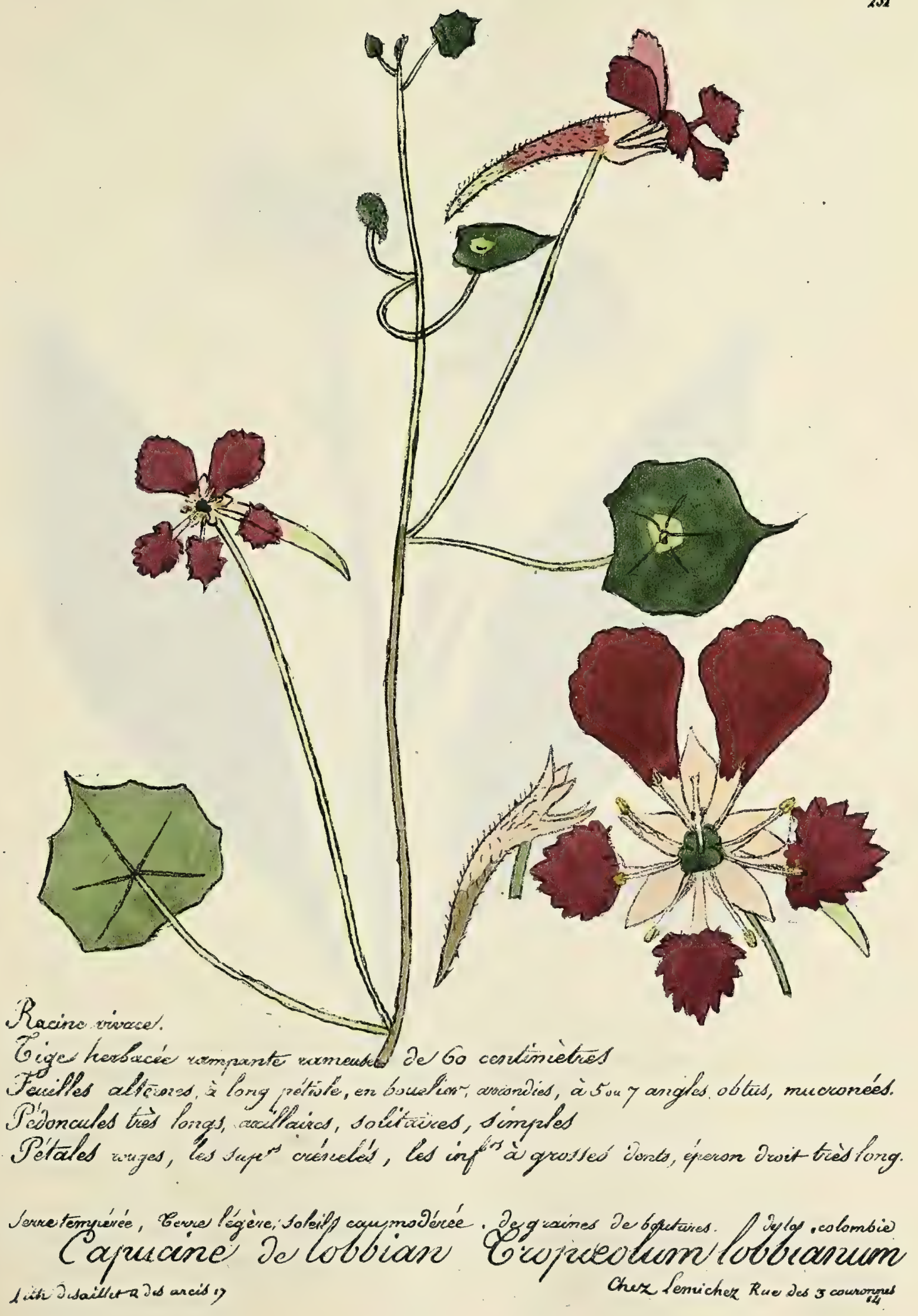





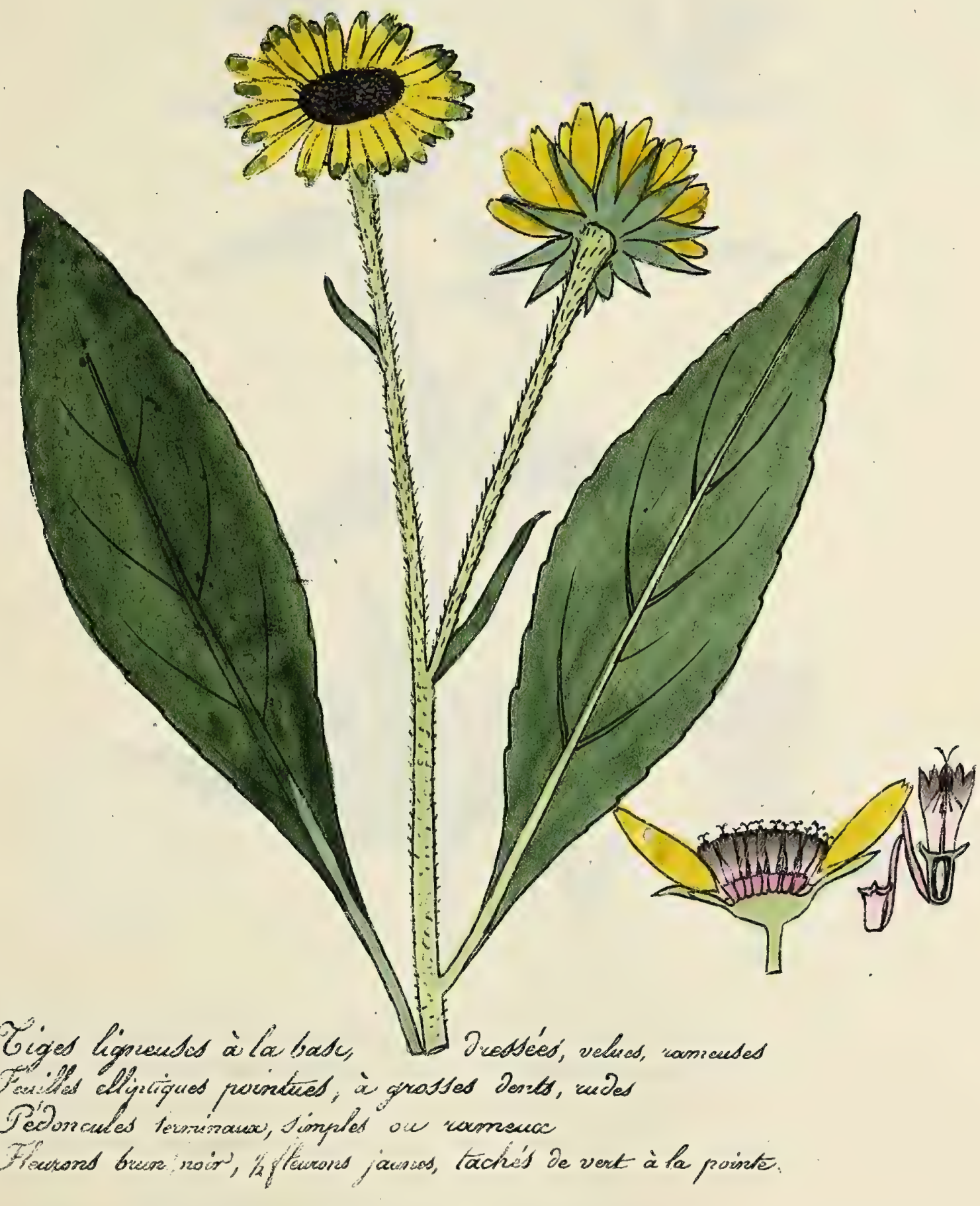

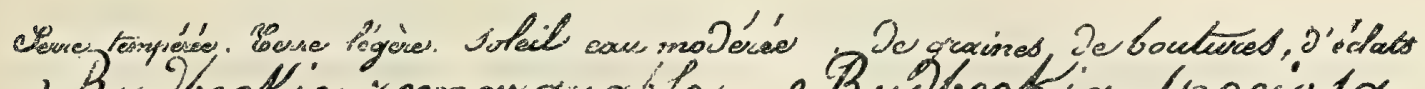
- Rubeckic iemarquable Mubbeckia d/reciusa Lith Jebaillek R iw arces'

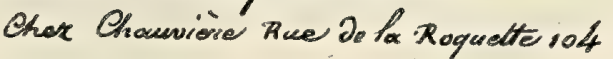




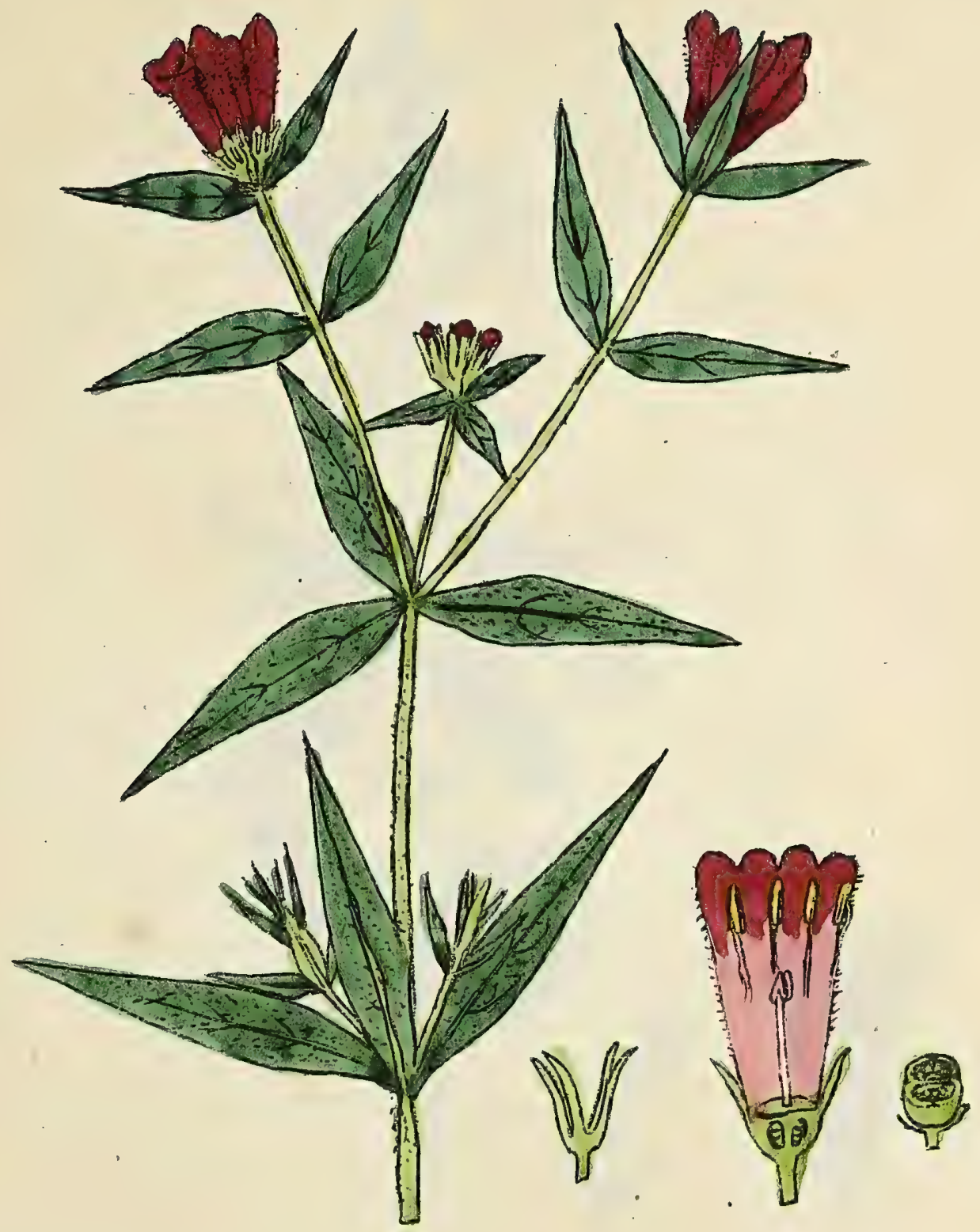

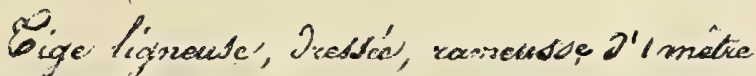

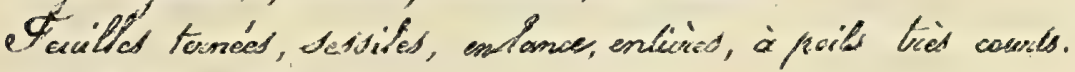

Onbellutes romeninates

Covolts velues, écariates

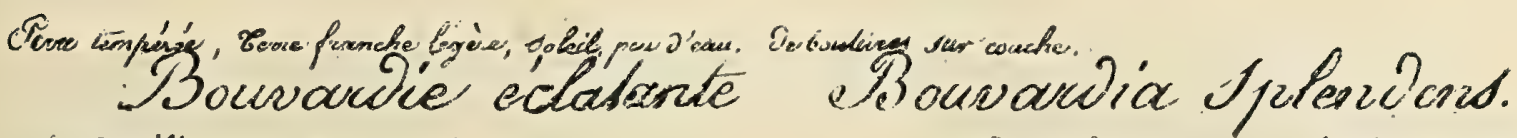

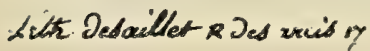

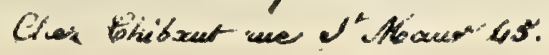




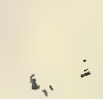

, 


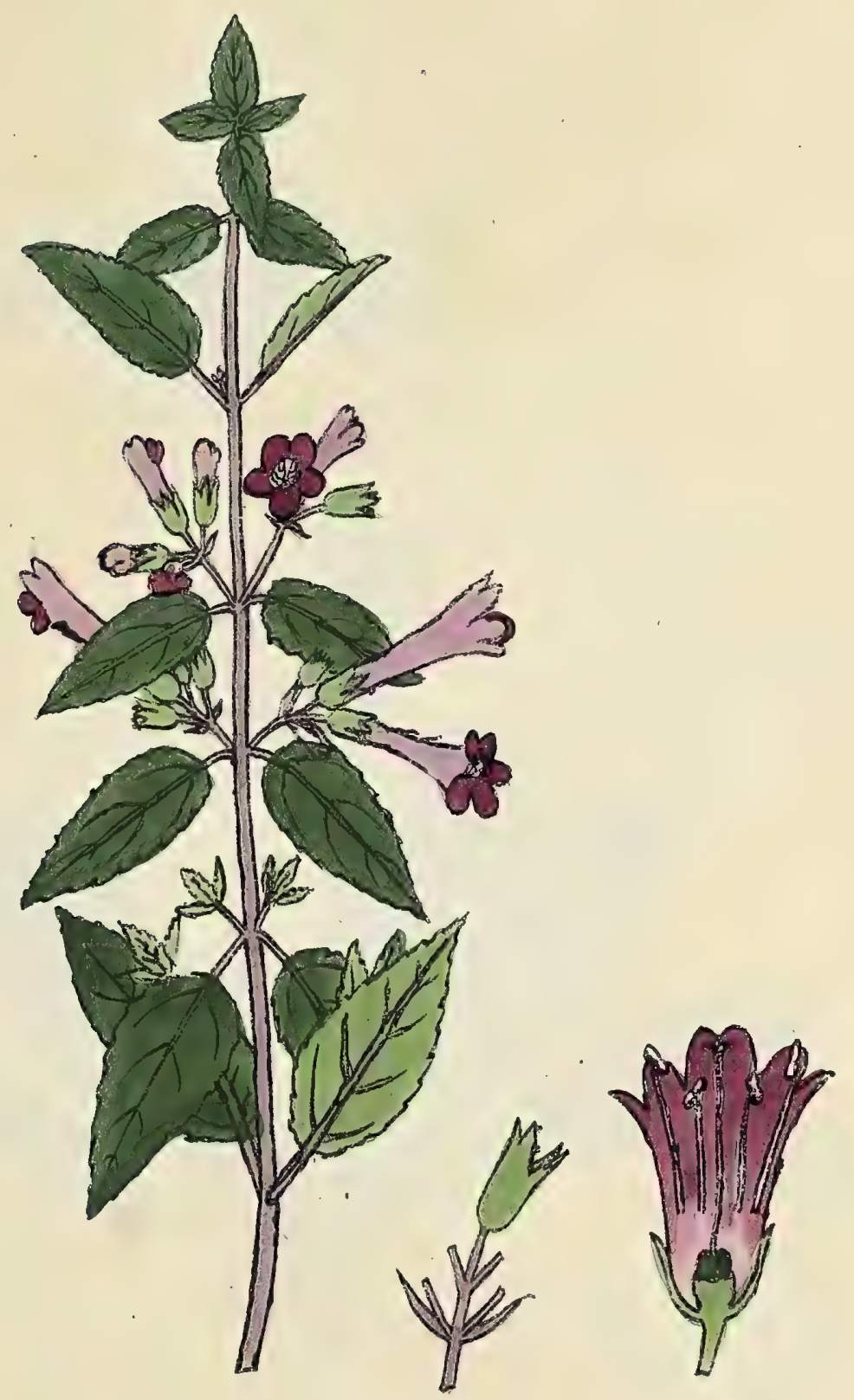

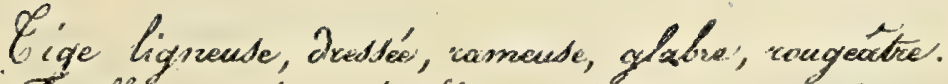

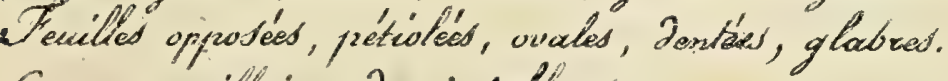

Grappized axillacies de a a 5 flews
Cocolles violectes.

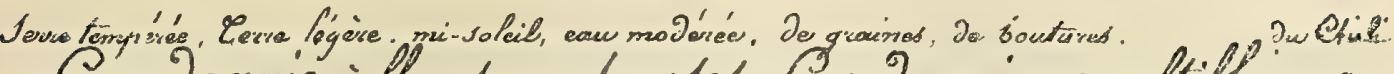

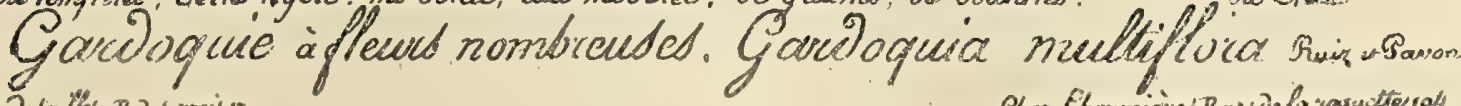

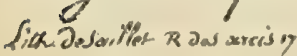

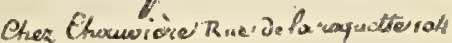



256

Racine vivace Pouche tred courte presque Lignoude.

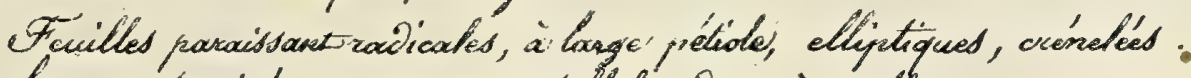

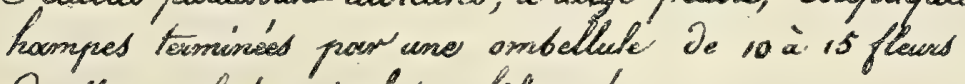
Corolles vislacress, ì Lobes bigunuyués.

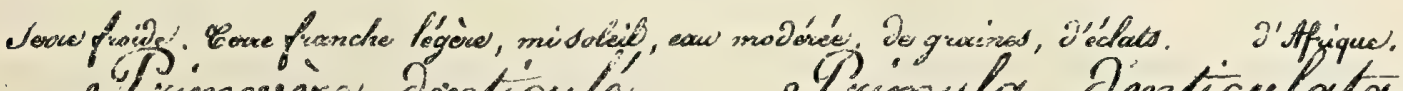
éfirzevere dernticulé of cirrula Denticulata smis

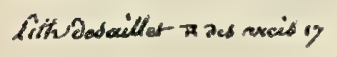

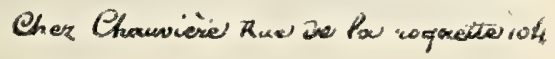





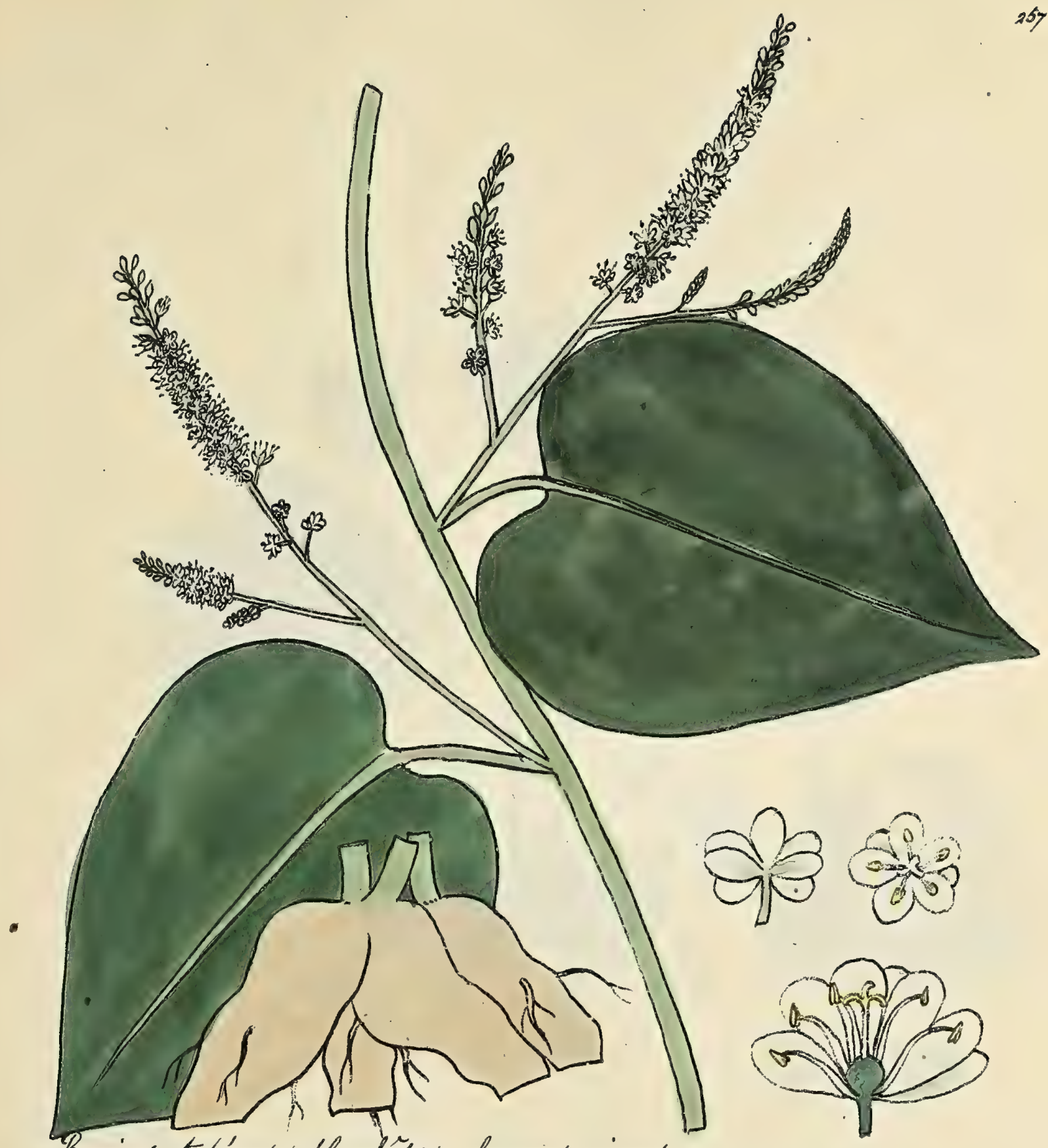

Tacines tubereused blanchatres, chavnies, vivaced.

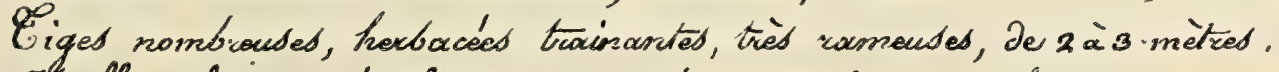

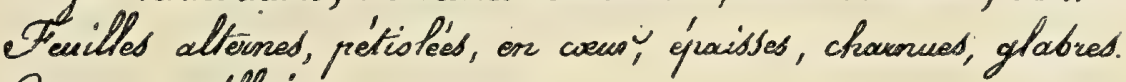

Grappred acill aived, cormeuded

Flewns nombreuses, petites, Glanches, à oveur Douse.

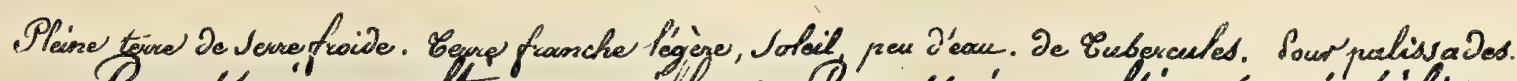
Couss ainzgautre meweilleuse Boussaingaultia Spectabilis. Lith Jesaillet $\pi$ aes acriss 'y cher Bertinand we de la woquarteive 


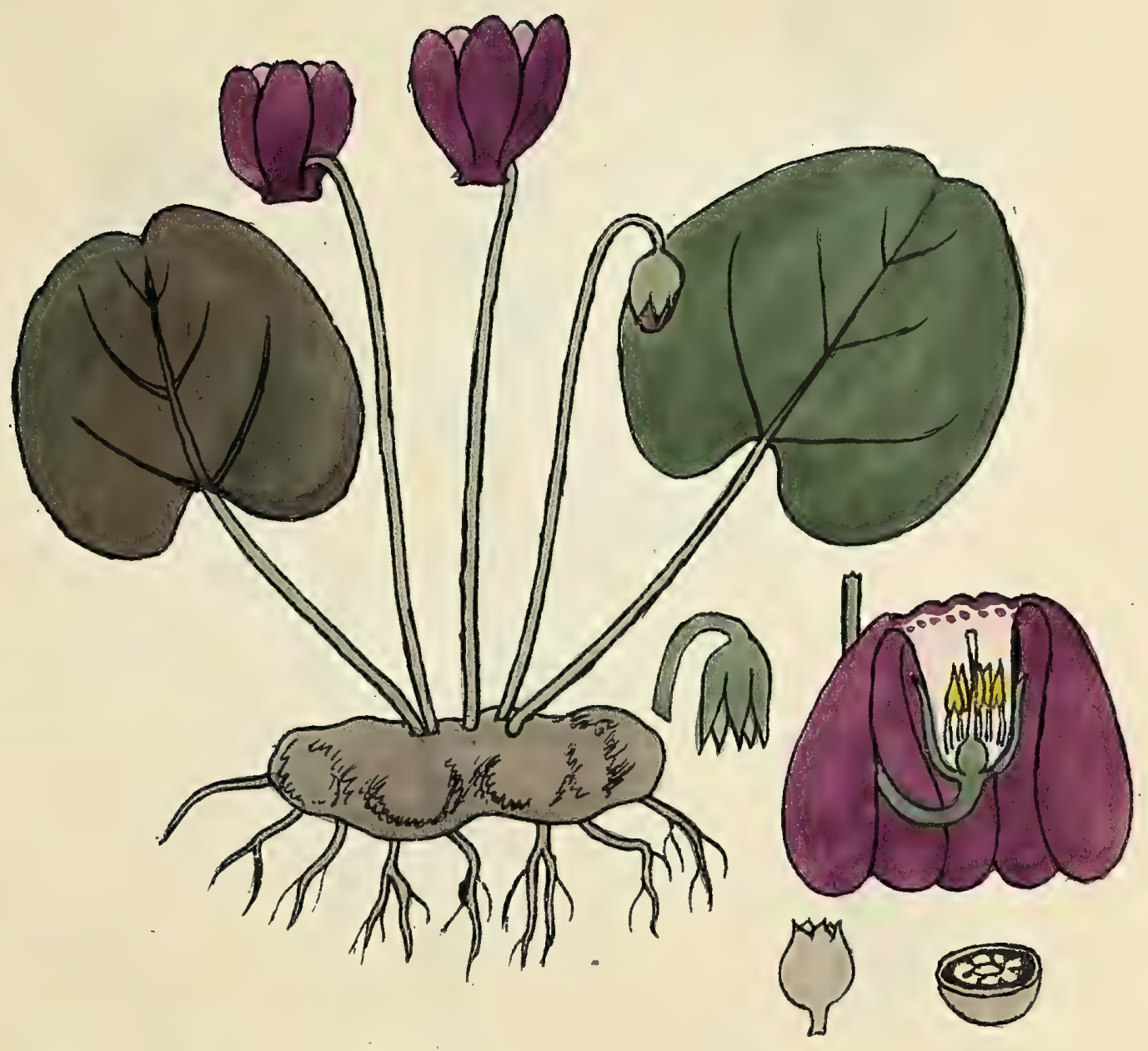

eRacine tickéreuse, Jénuimée, brumather:

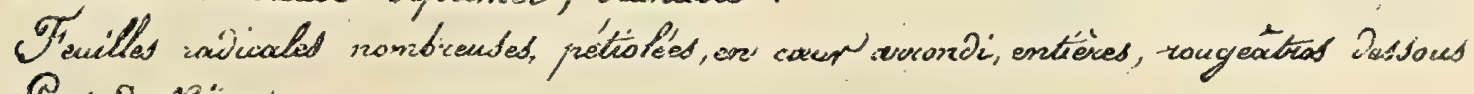
Pas De Biger

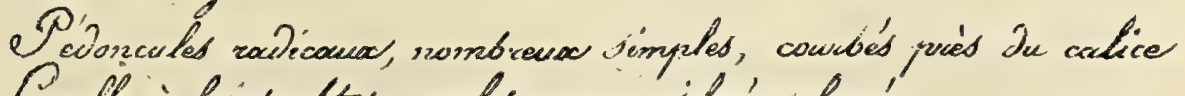

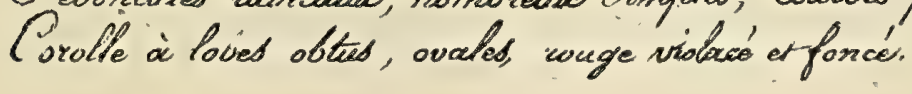

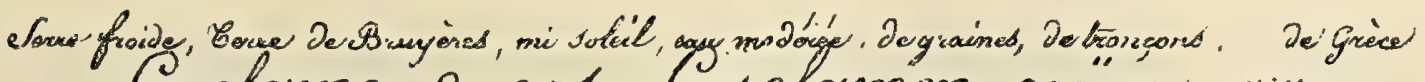
Yyclanne de cos Cyclamenz coüm Hither

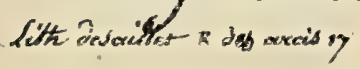
Cher (haminice) Rue de Ro Rogueite 104 



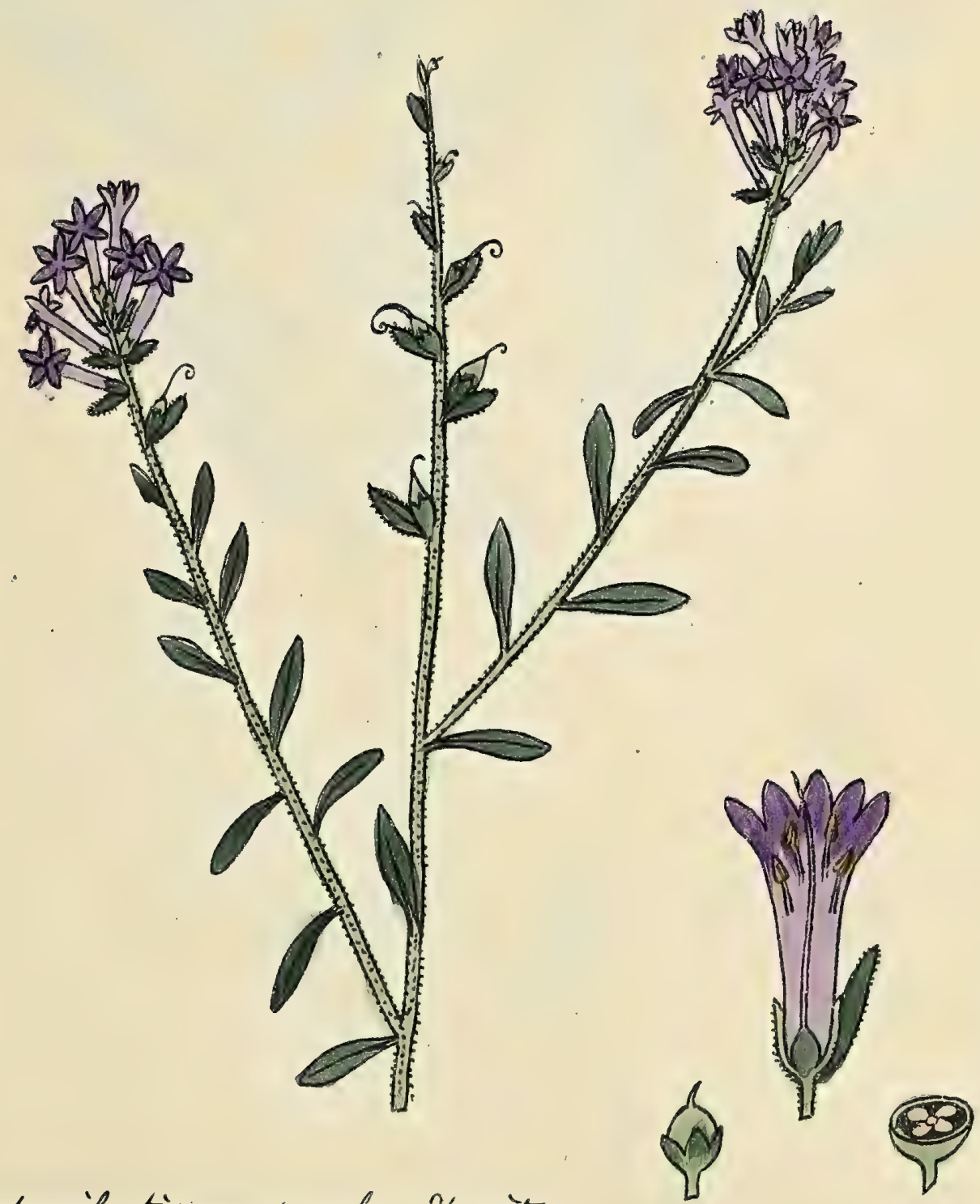

Ciges ligneuder griele, tives ramoude, veluse, D'x mètres. Frevilles alternos, en spaticle, entières, petites, wriares.

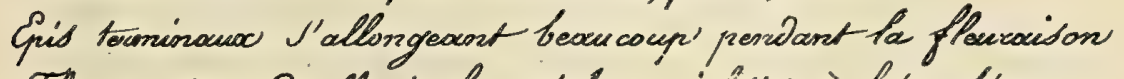
Flavis pretites, Corolle à long tube, vioisttes, à lobes obtus.

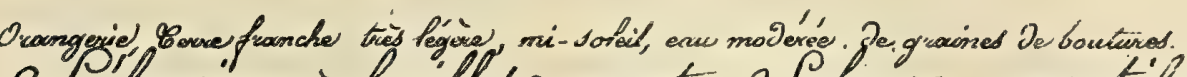
Celaginze à feuilles de myite. Pelago manctifolide. 



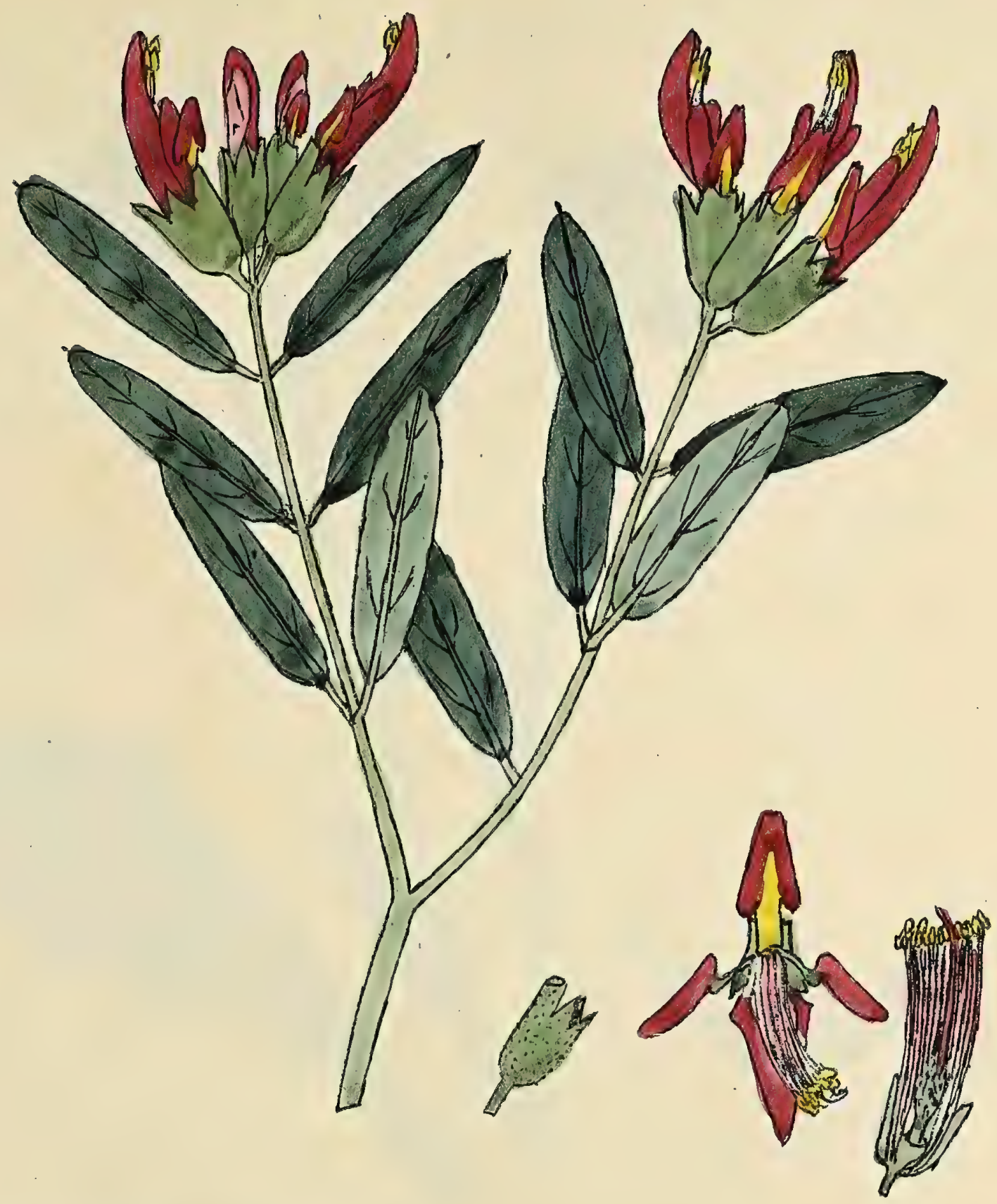

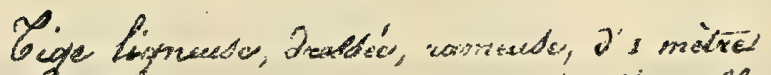

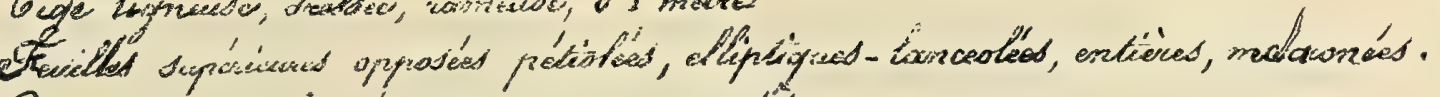

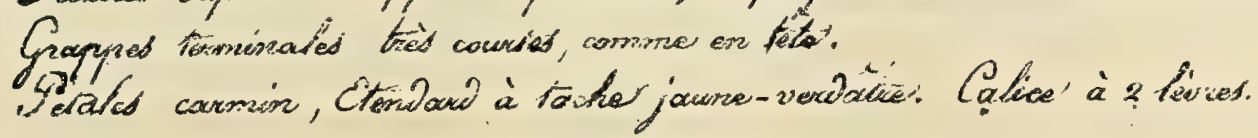

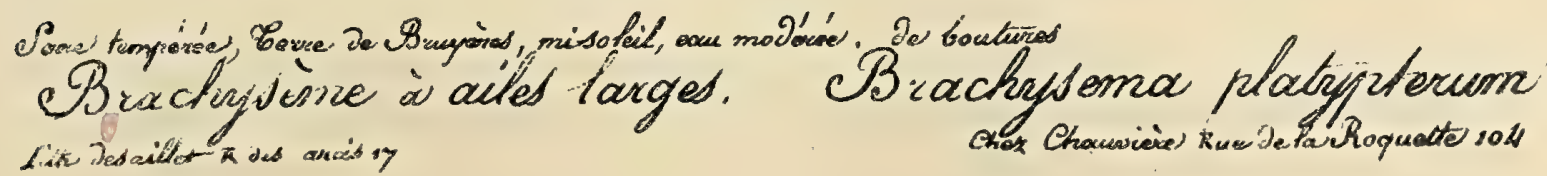




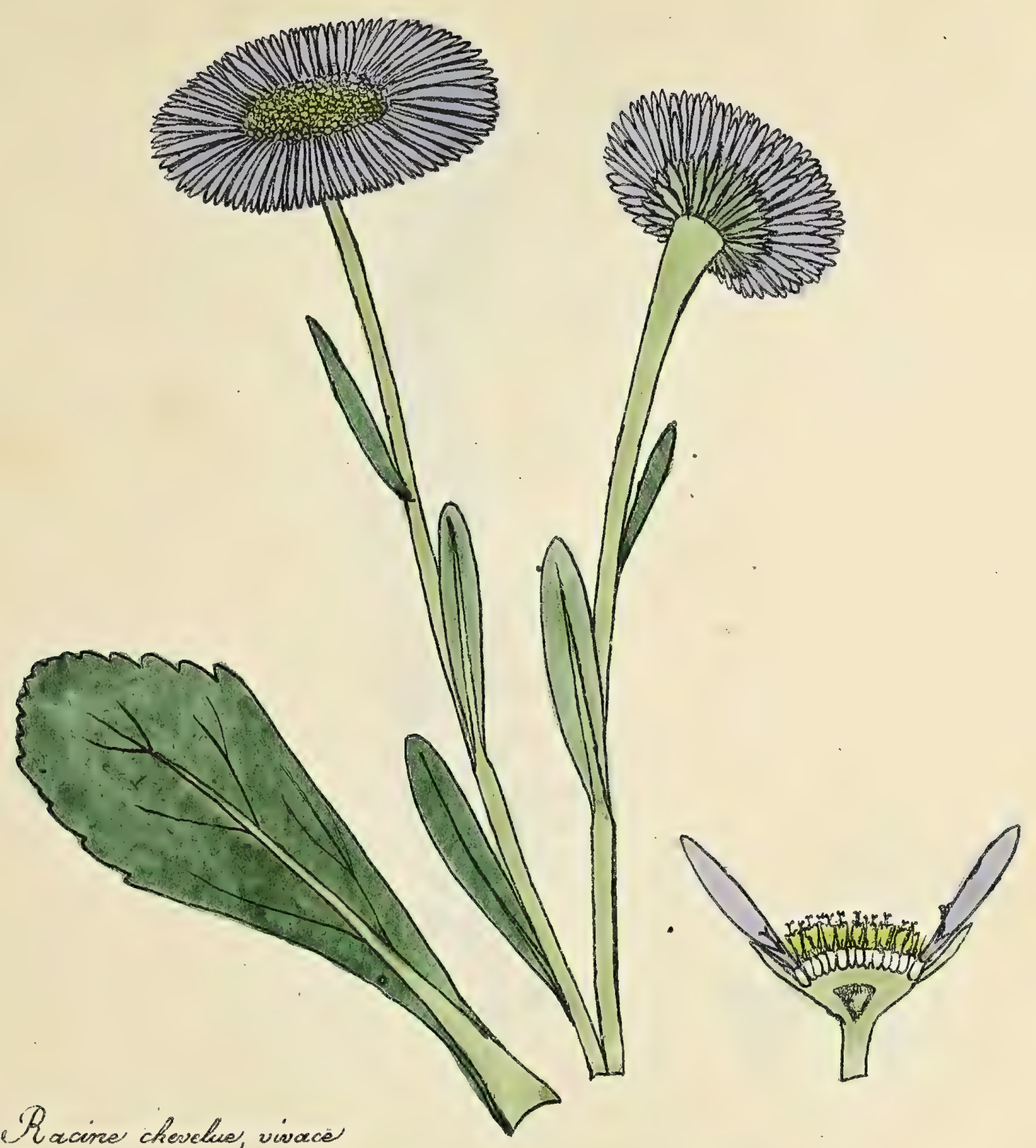

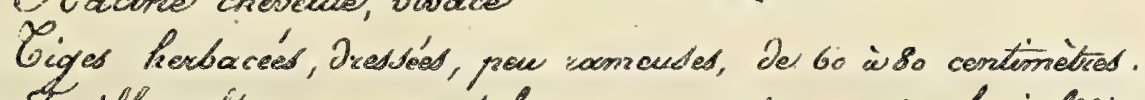

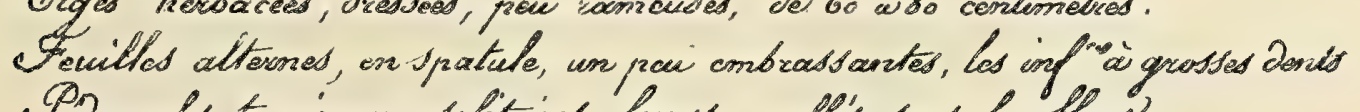
PPoncules torminaux, dolitaires, Pongs, rengle's sous la flous?

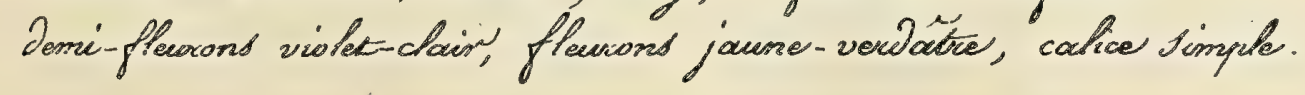

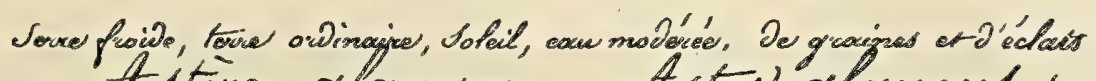

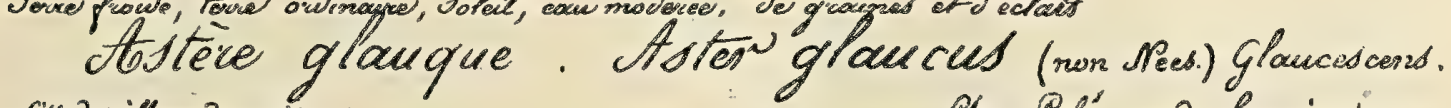

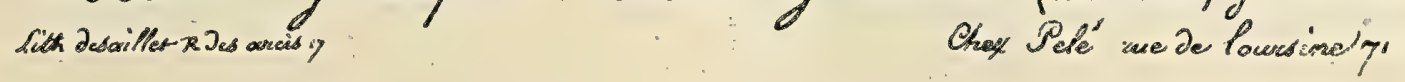


-

- 

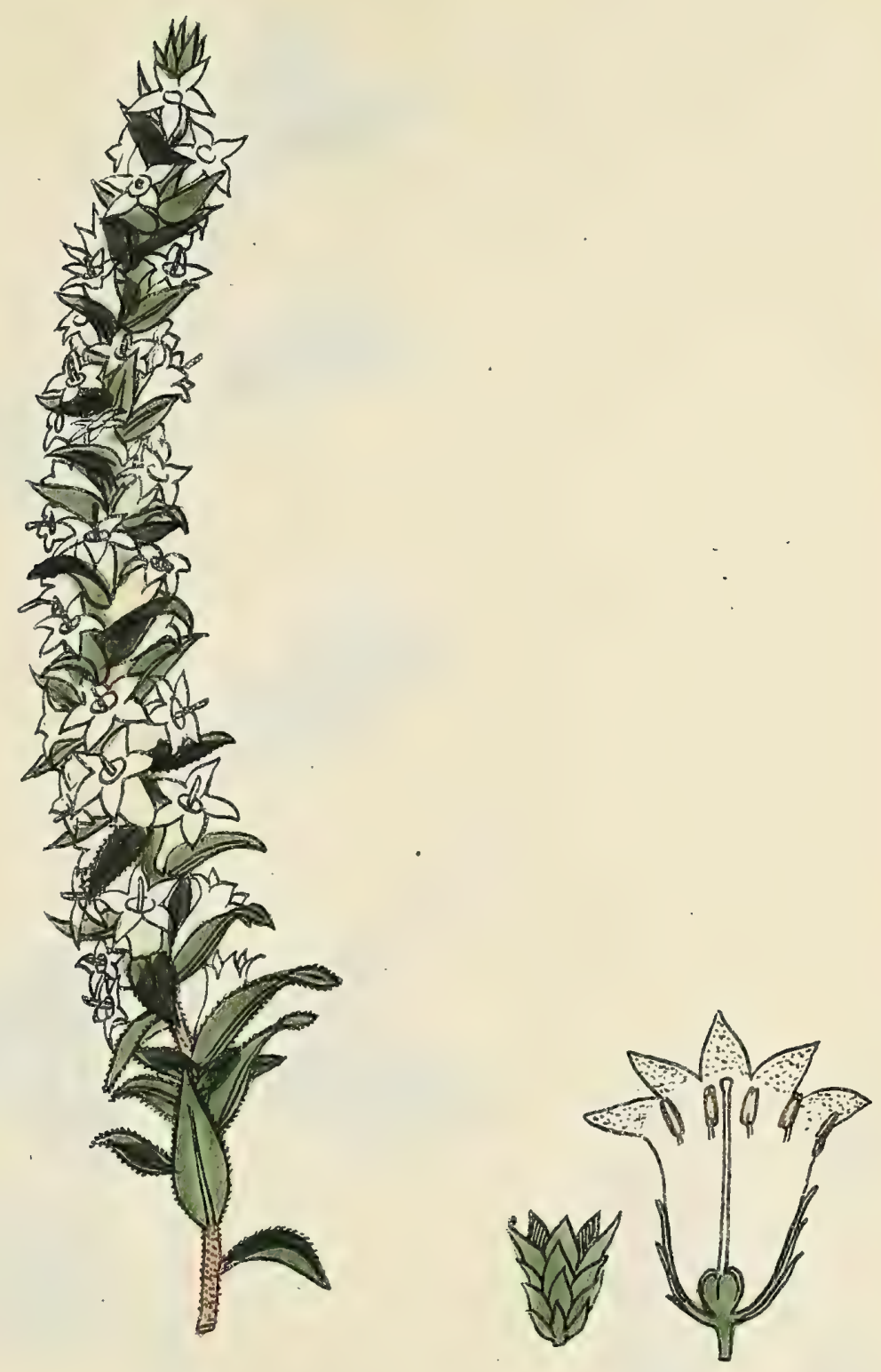

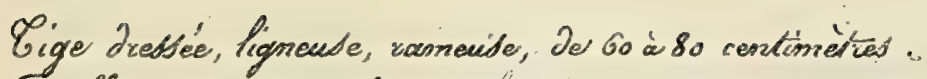

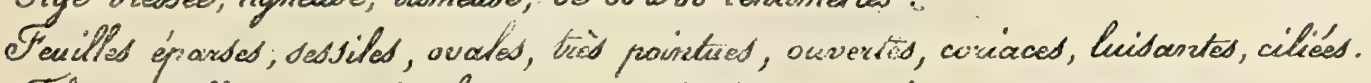

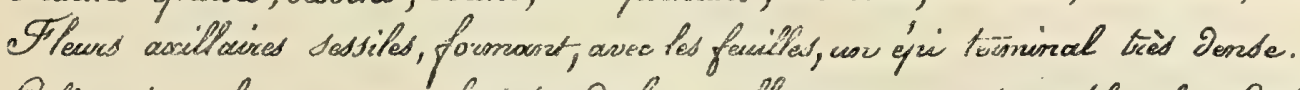

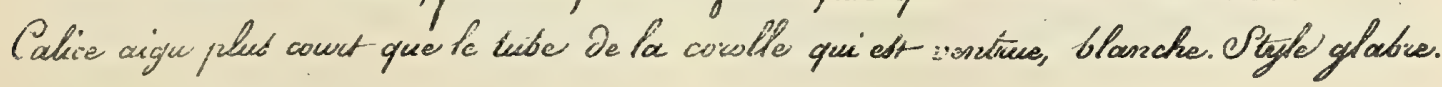

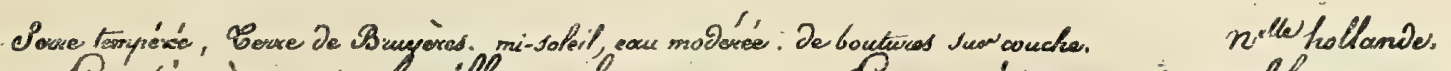

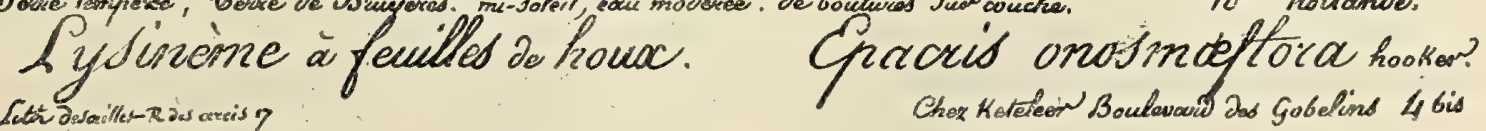




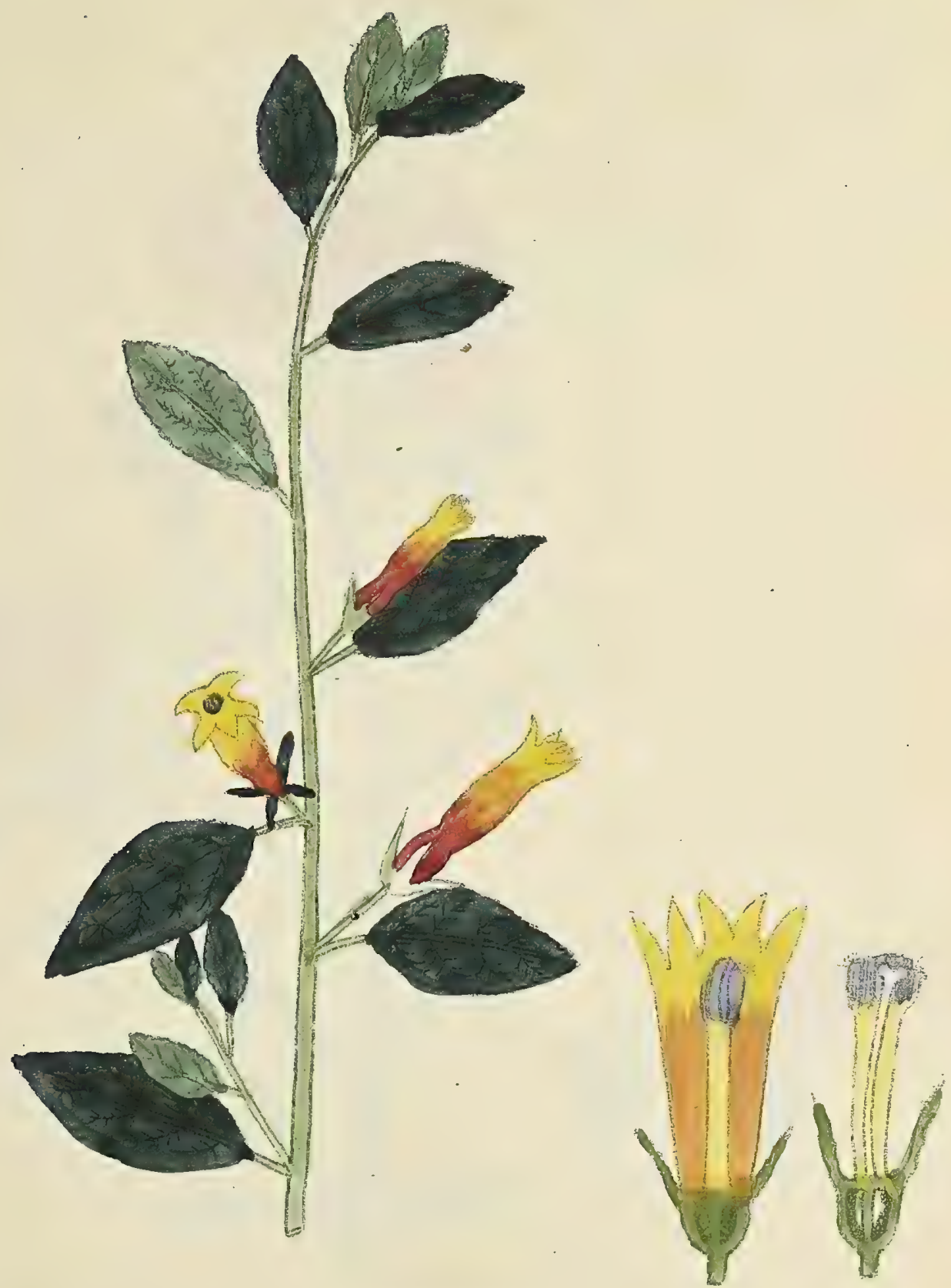

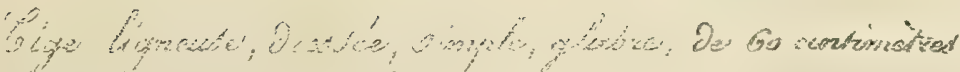

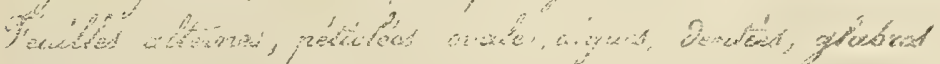

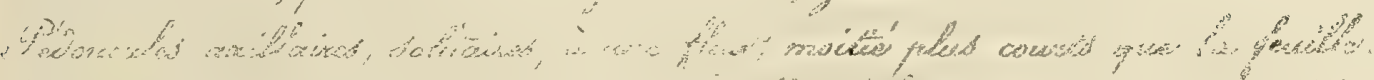

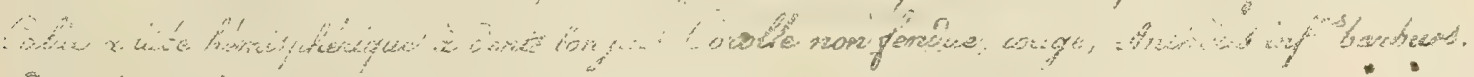

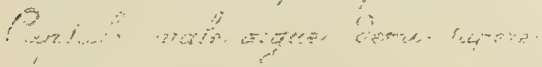

$\therefore$.

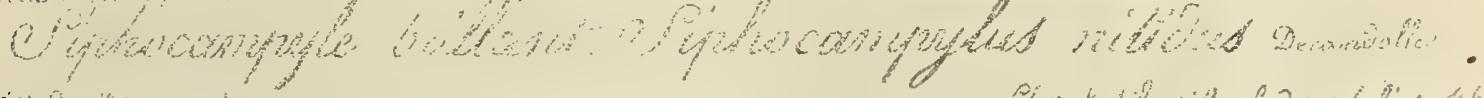

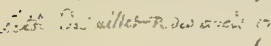

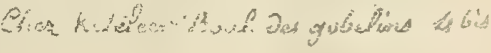


$a$ 


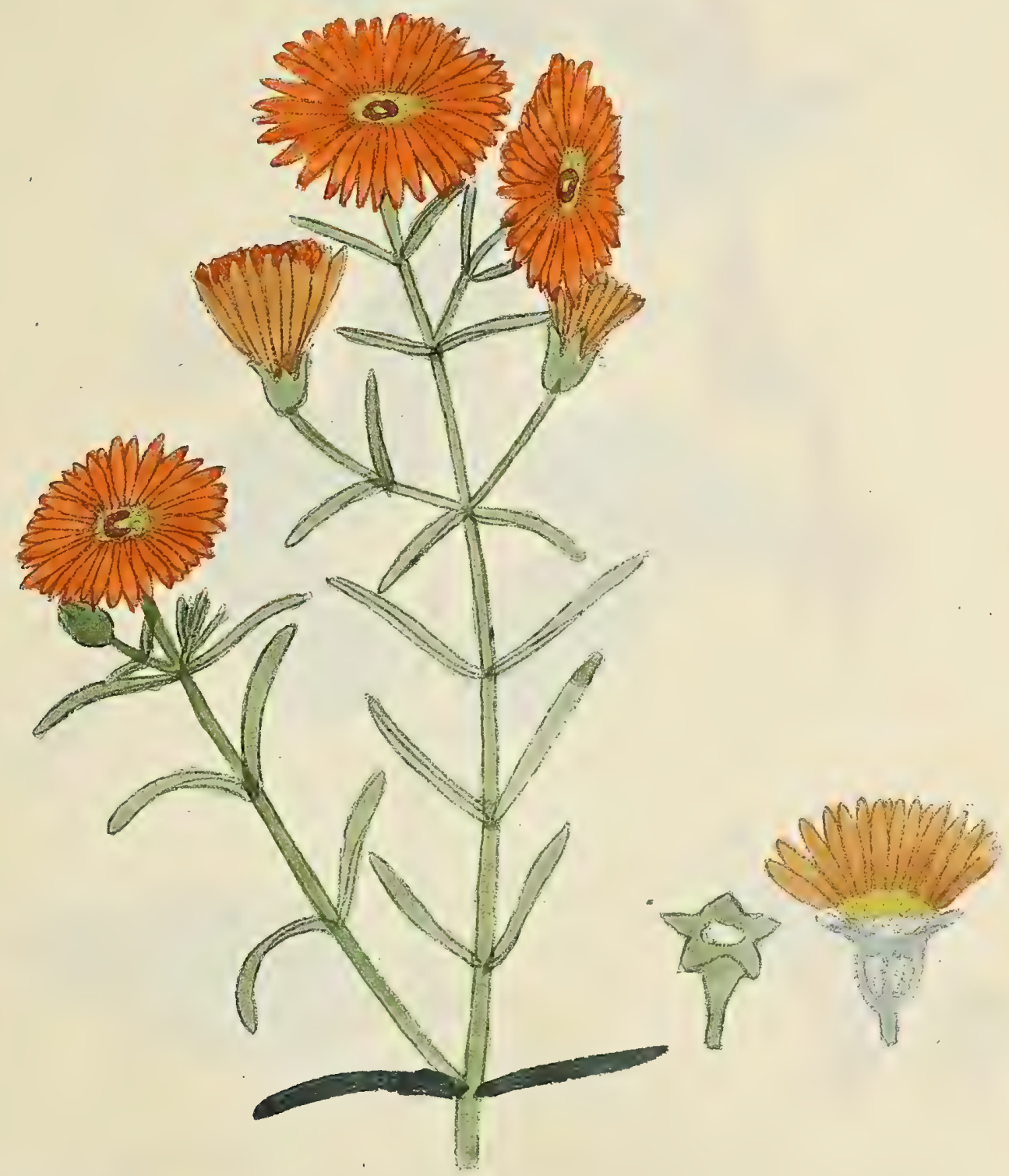

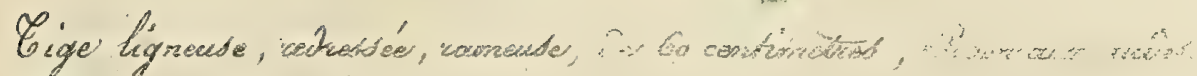

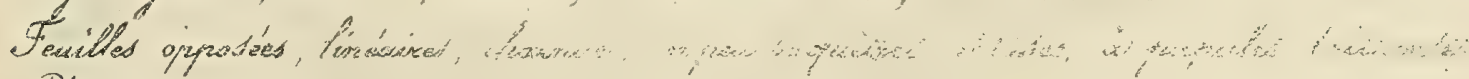

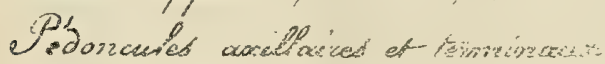

Petailes safwersés, flumb moyournat

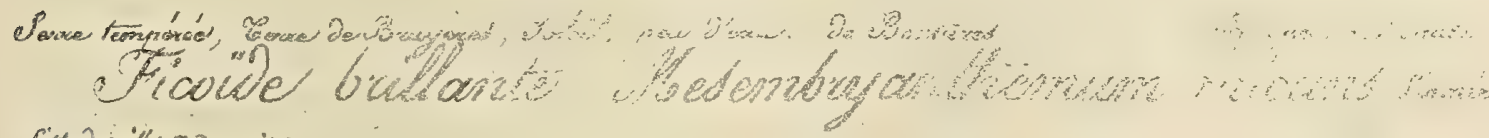

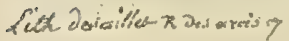




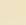




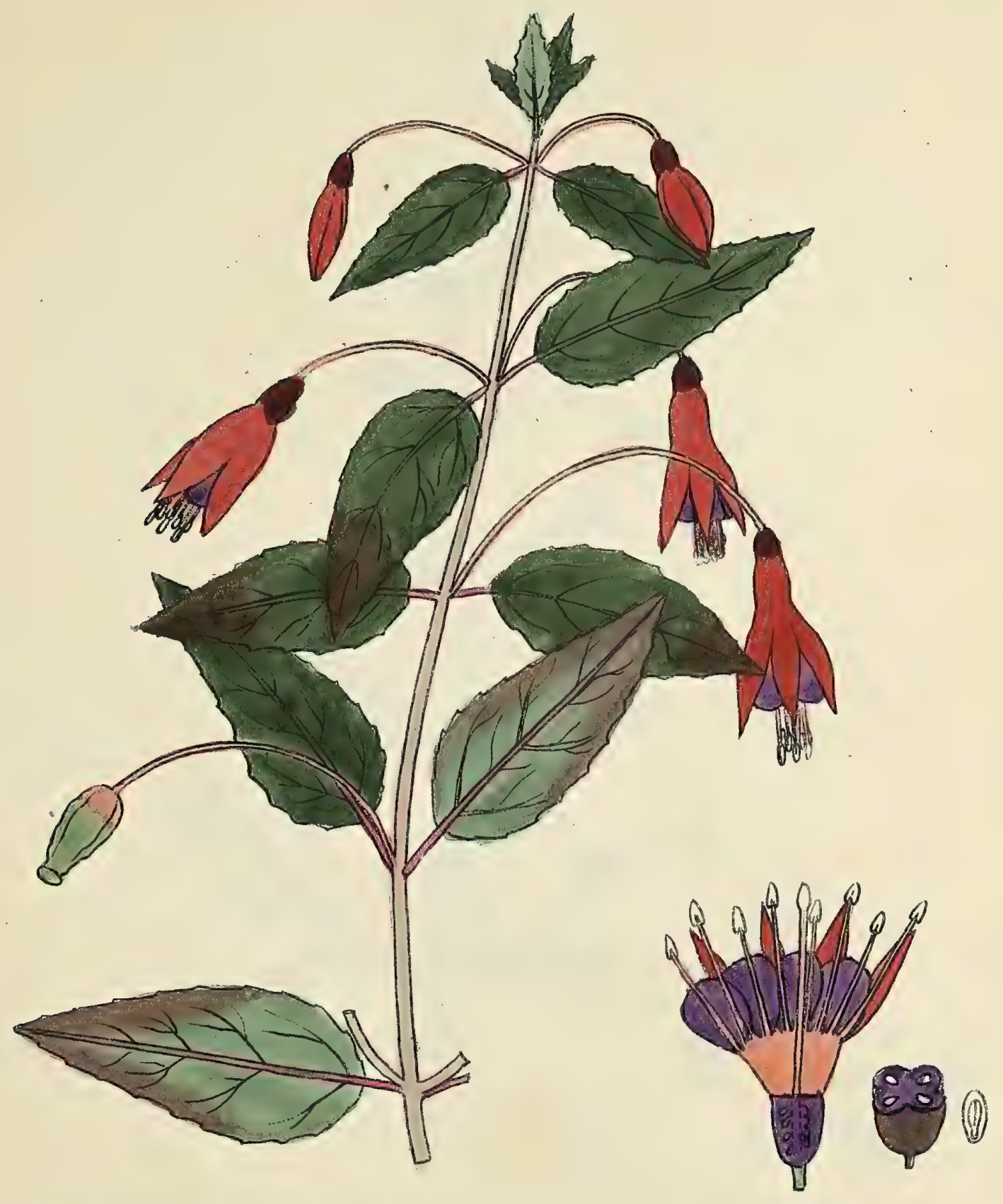

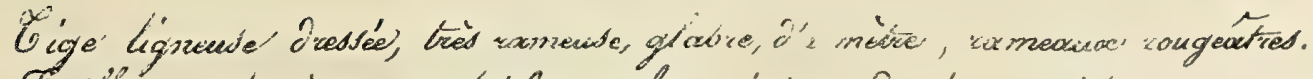

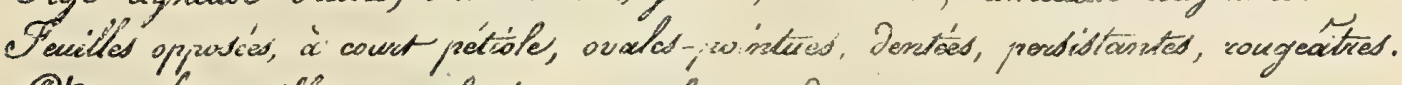

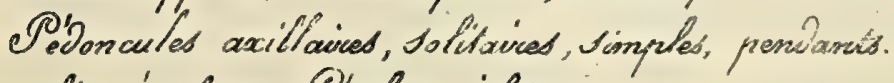

calice ecauchate, Sitales viofets courts Baie ovale noirâtre, à chair viofelte.

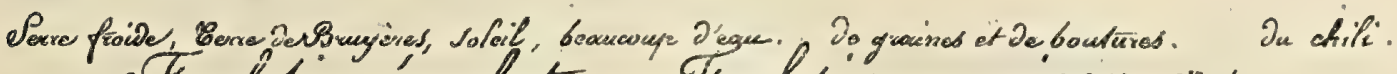
Ciuchidie écarlate efuchsia coccinea sinnce

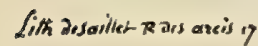





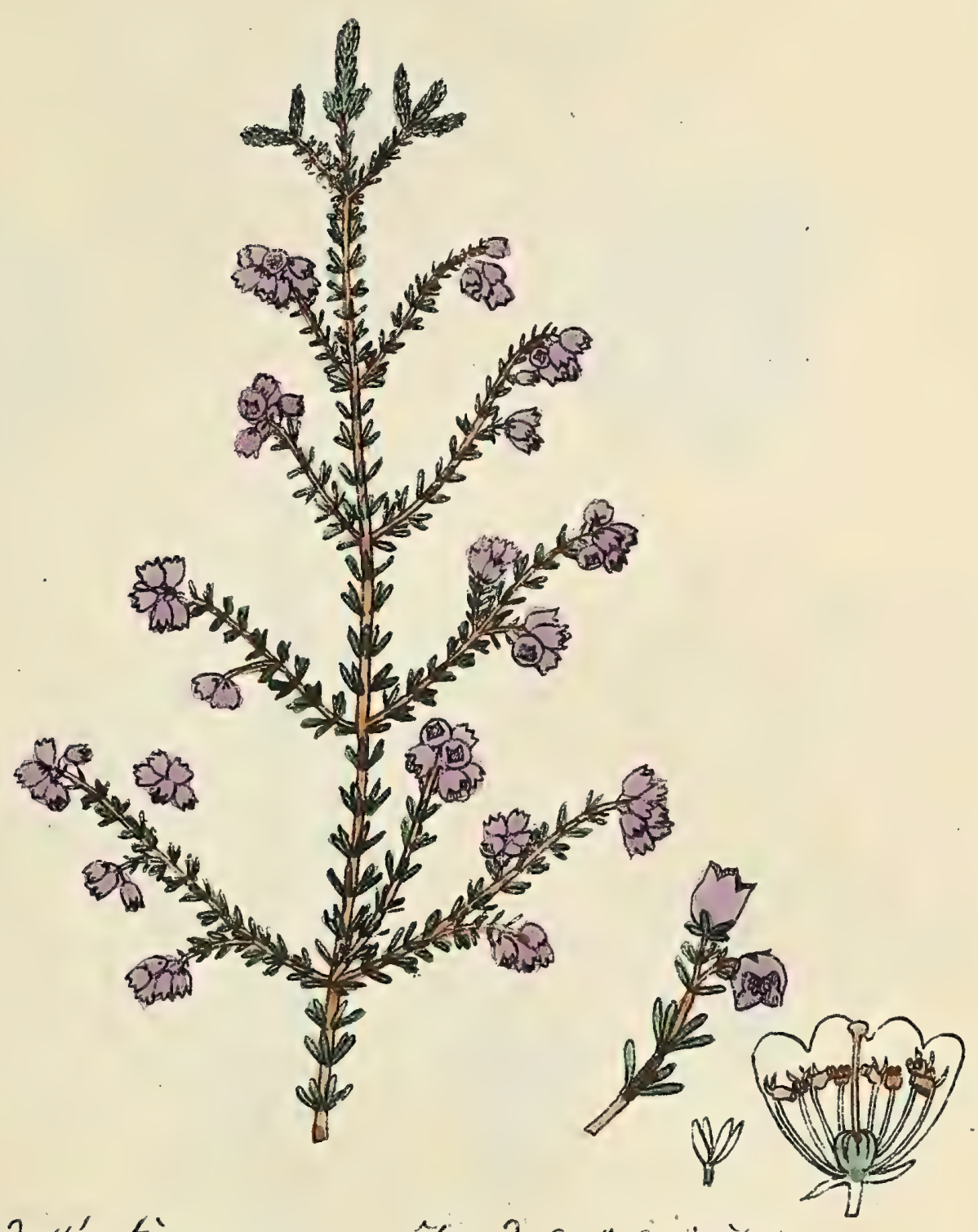

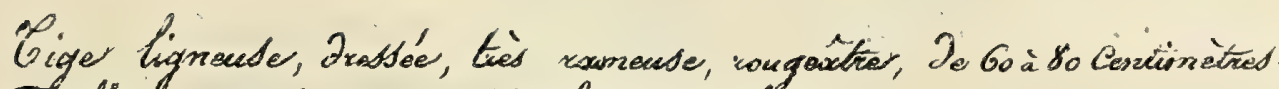
Fenilies quateinves, rapprochées, liséacies; glabred.

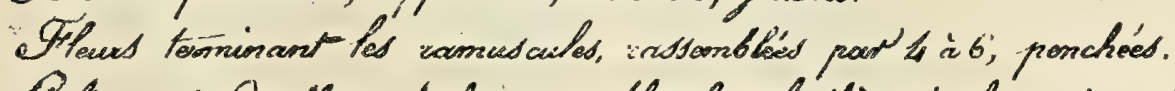

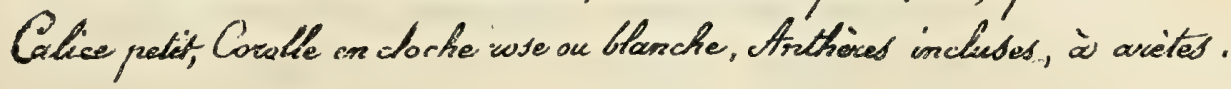

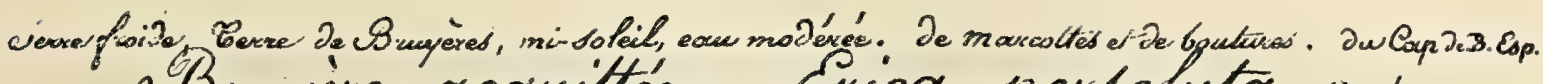

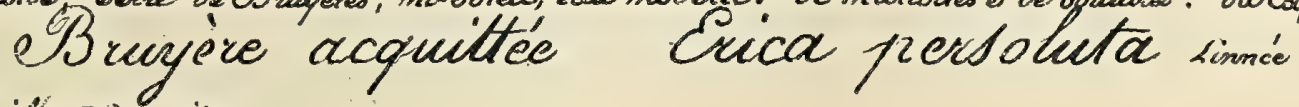

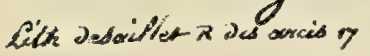




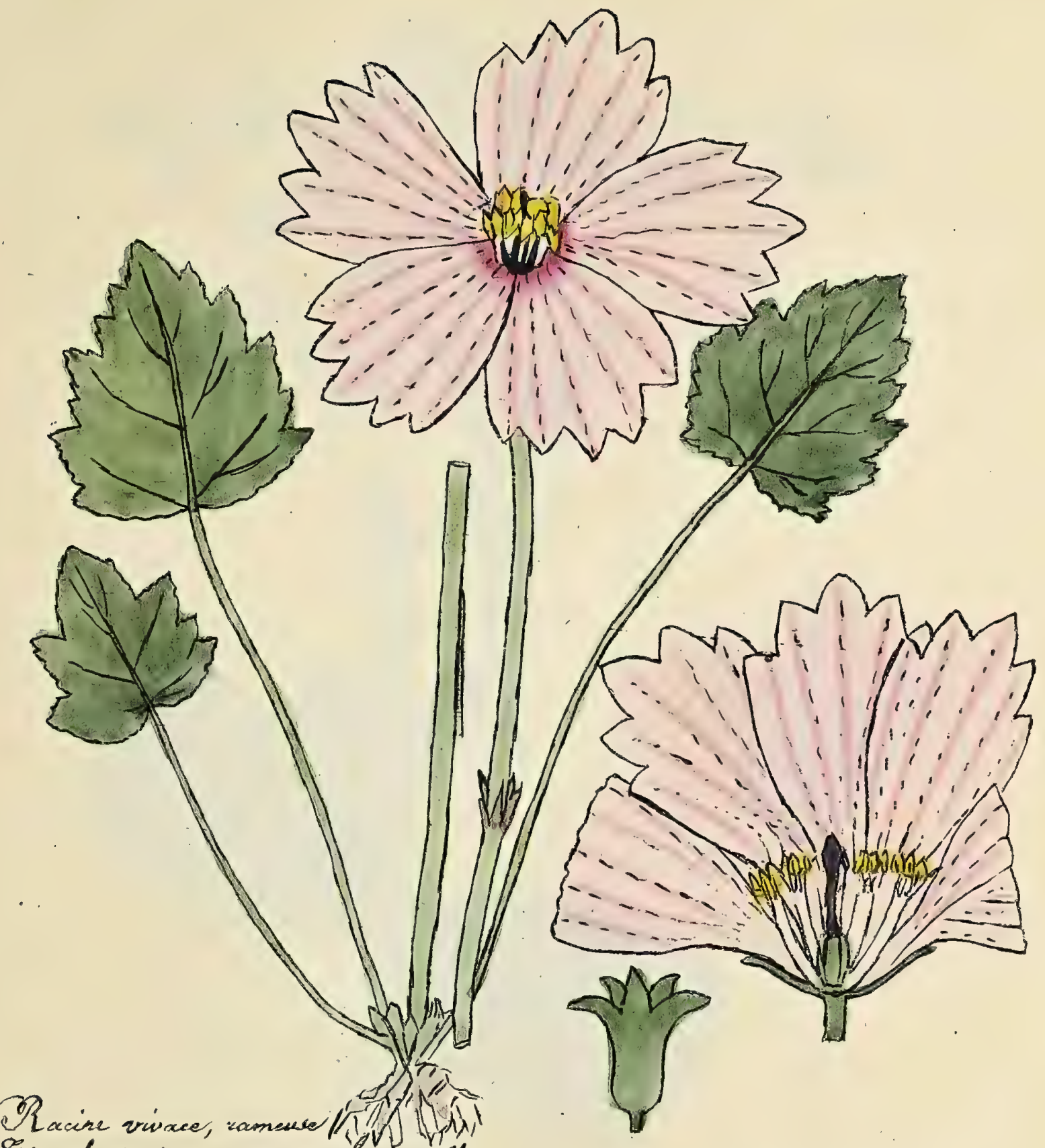

Eiqe herbacie, eamente pued que nuble

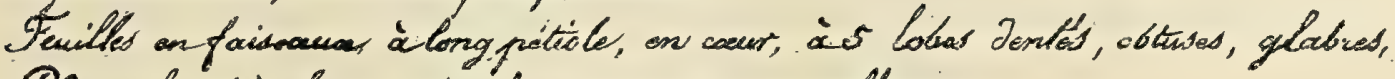
Pedcrecules thes Longs, dincples, provtant une collecette.

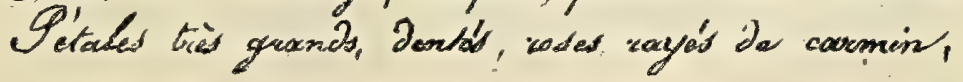

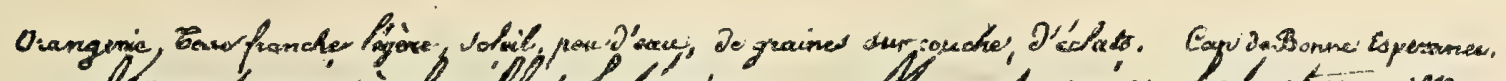

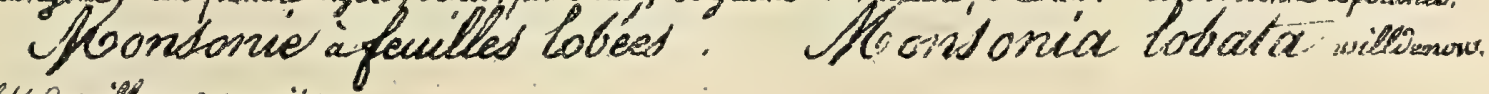
Cuth: Desailler a dew arais of 



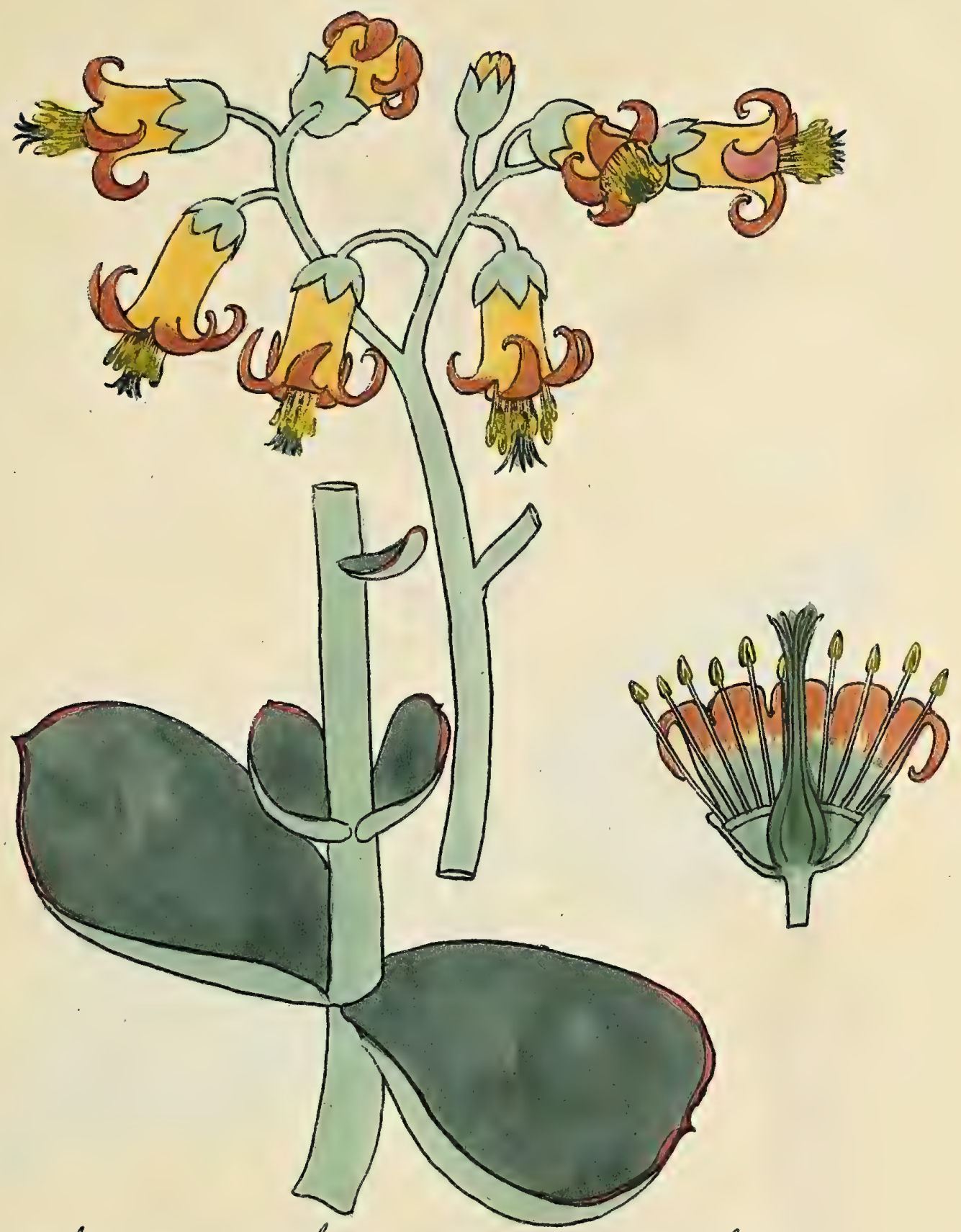

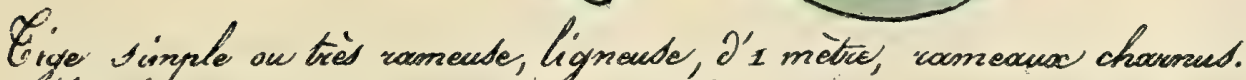

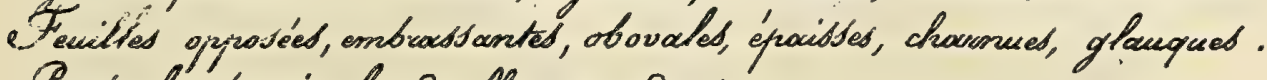

Panicule terminate de flewes pondanies

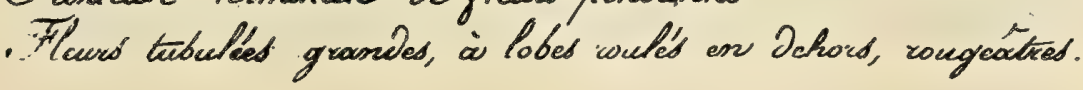

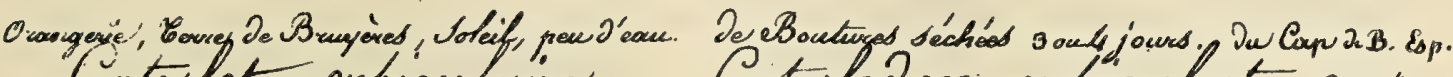
(rotylet ocbiculrives. Cotyledon orbiculata sinné. Lit: Desailfet $x$ tes arcis "y 



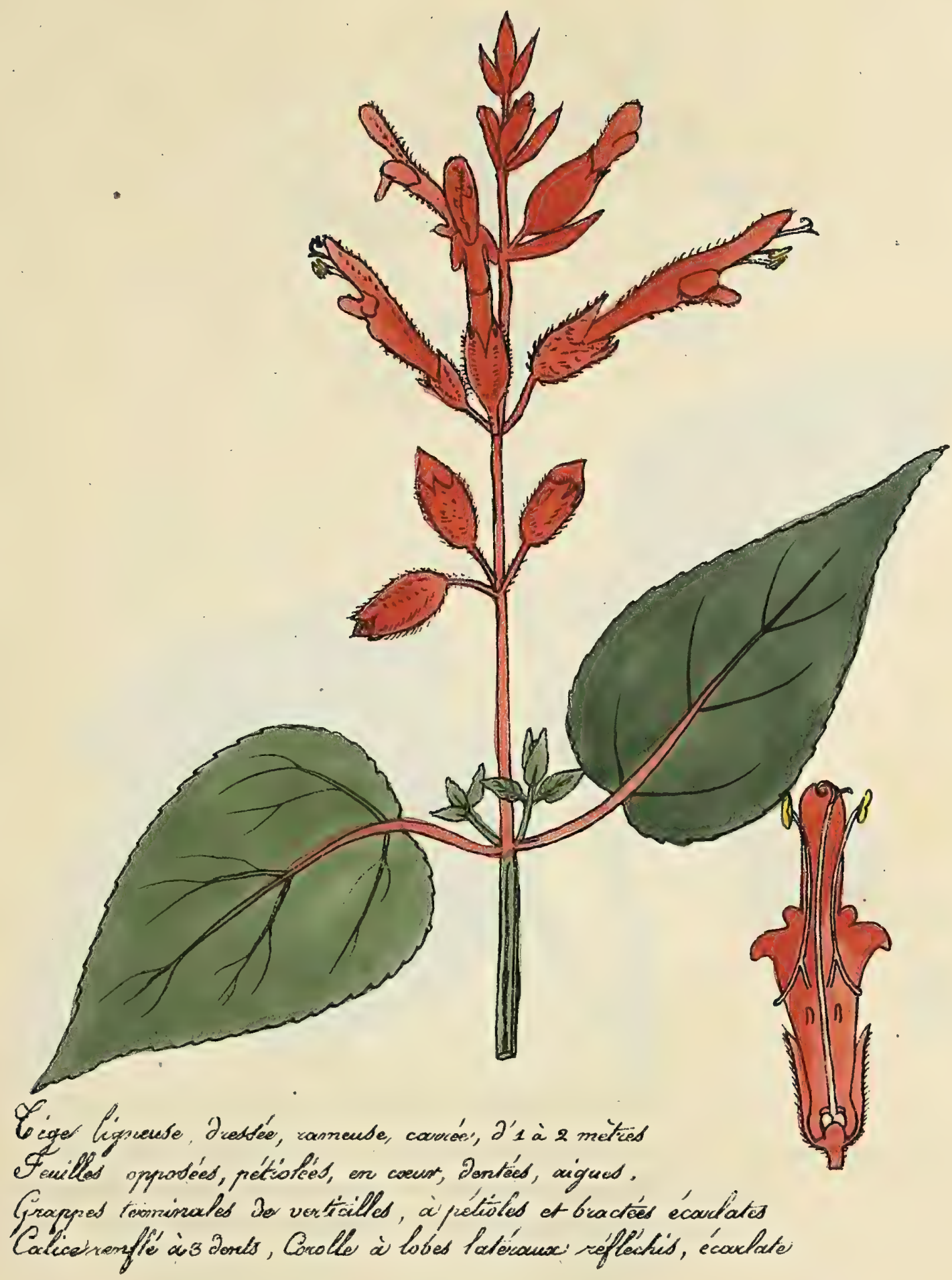

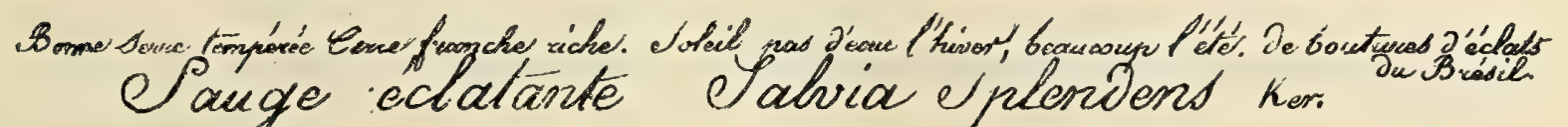

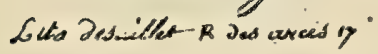





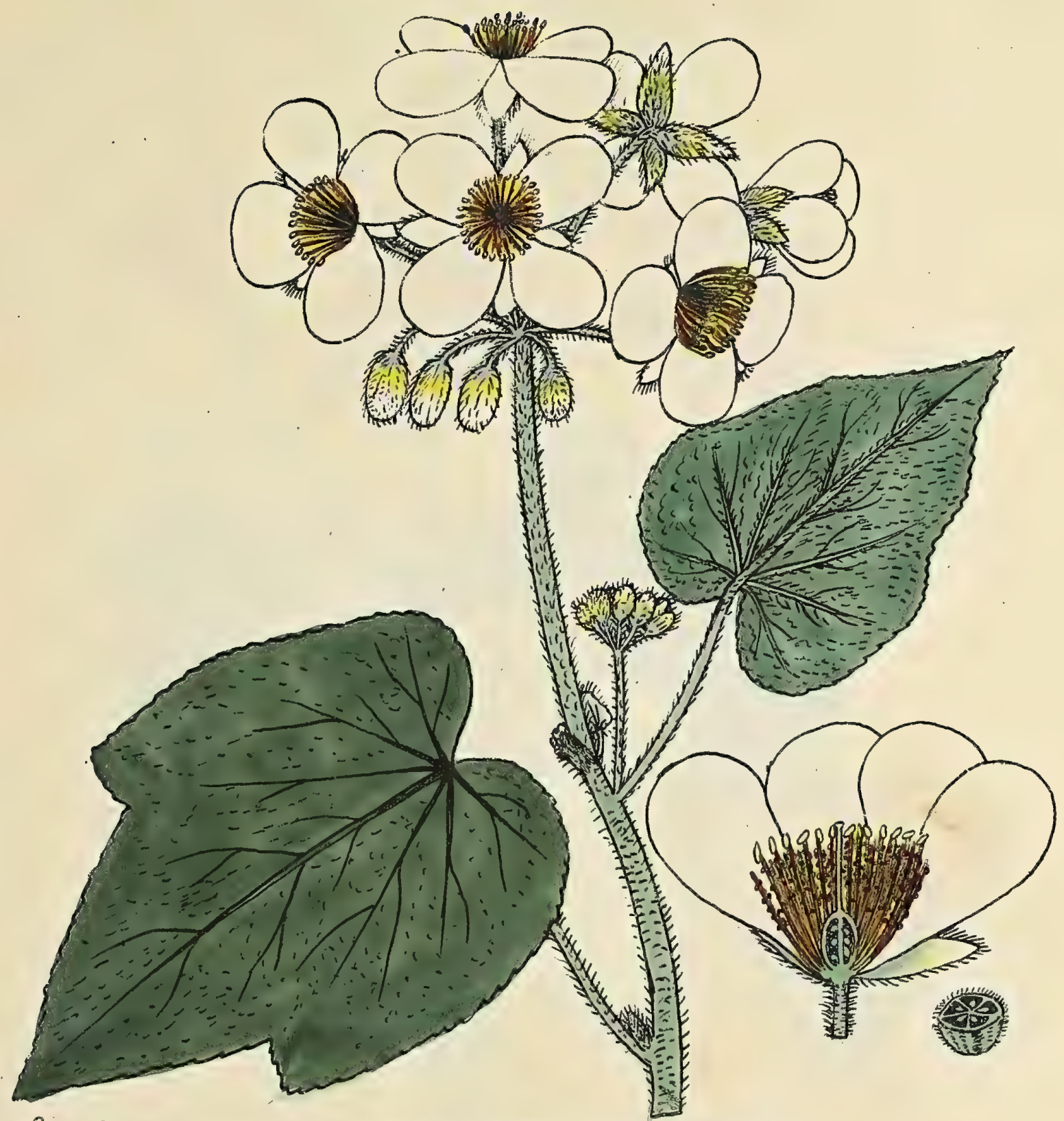

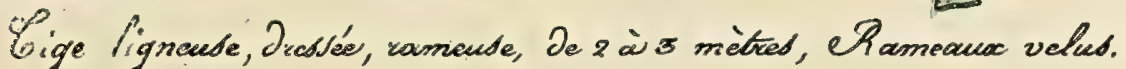

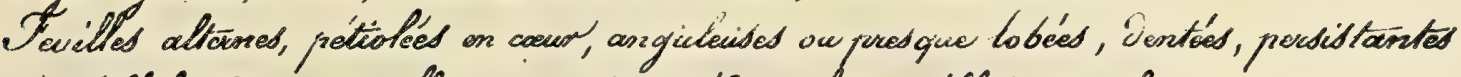
-(')mbollutes de 30 à so flewes sur des pédoncules axillaires, velus.

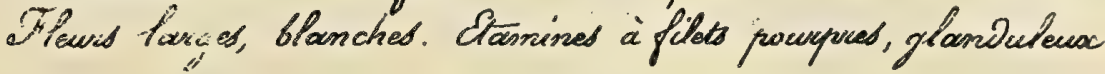

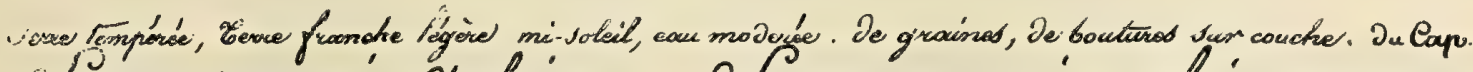

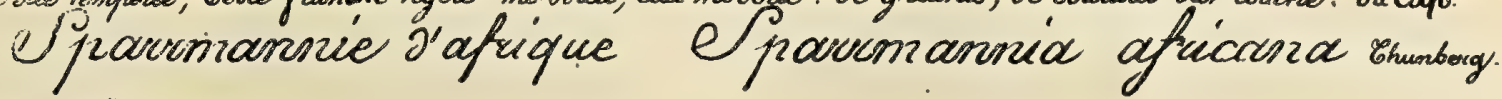

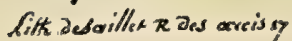





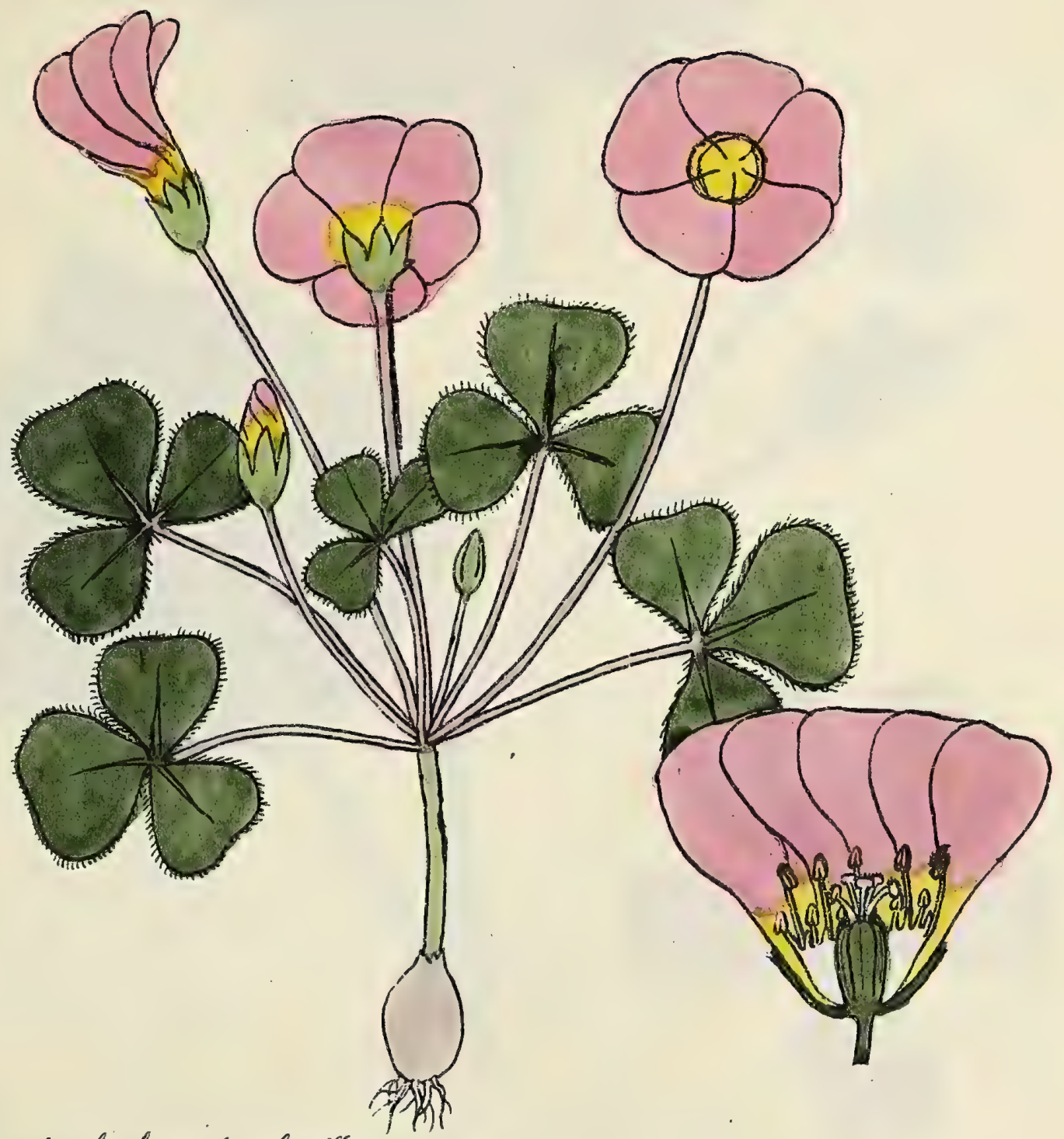

Eige simple herbacées, fecullee.

- Fevilies à Cong pétiole, à a potioles obovales, ciliées Peinonated simples, plus fonges que les fouilles.

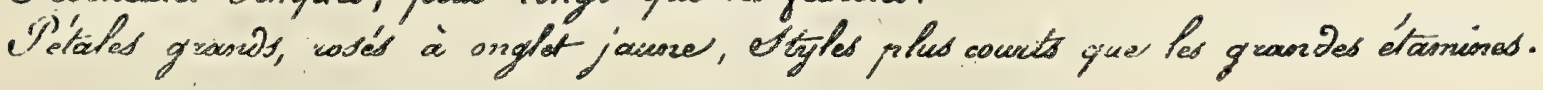

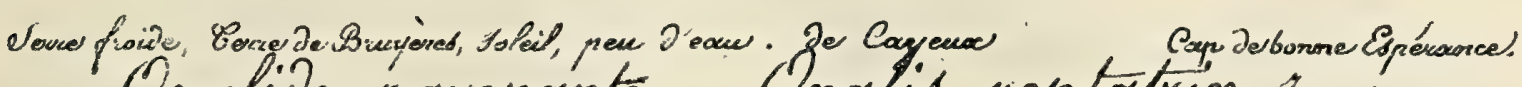
Oralive rampante Oxatis reptativa Jocyuin.

Ras Dowaille $x$ Das werrity 



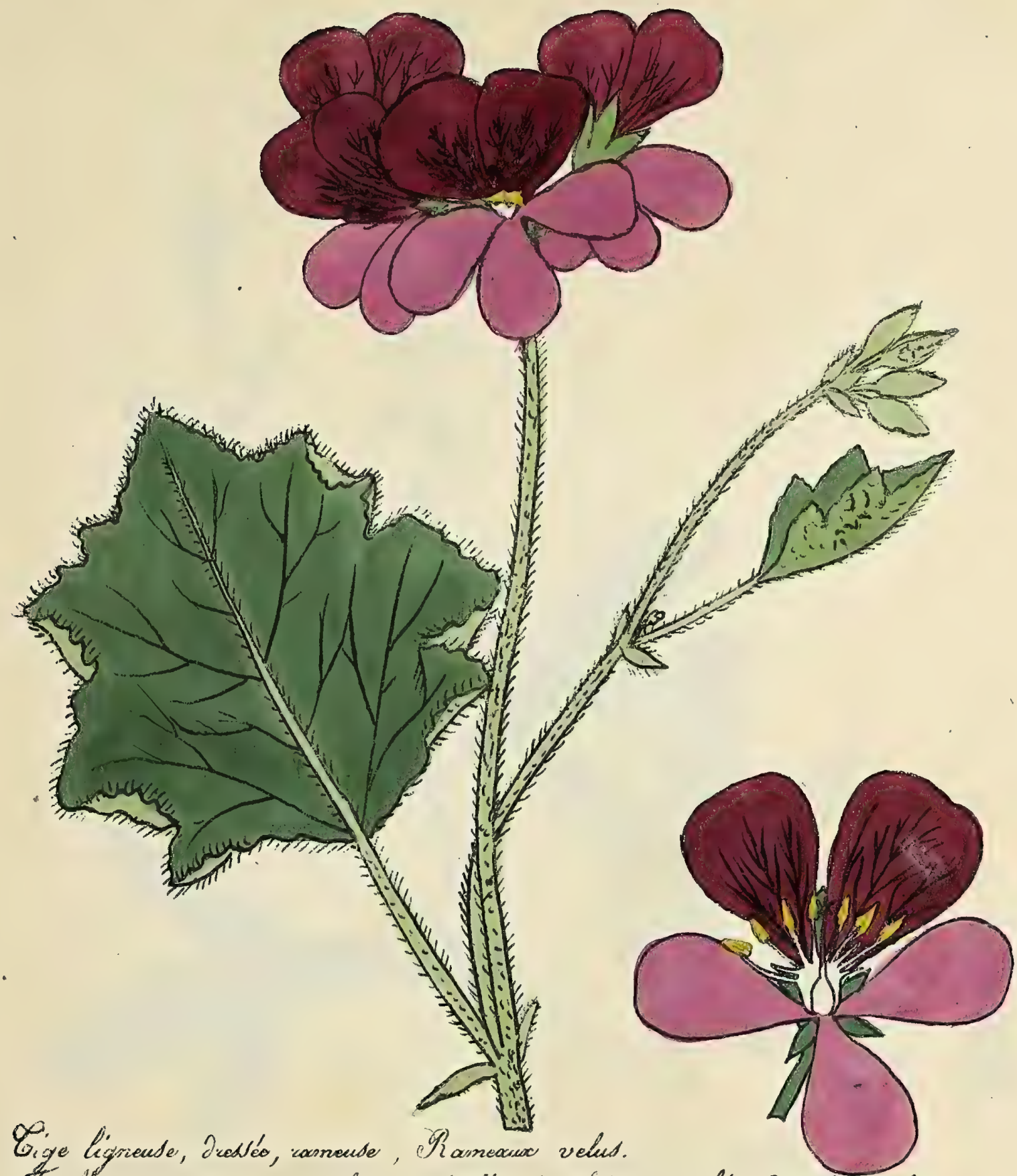

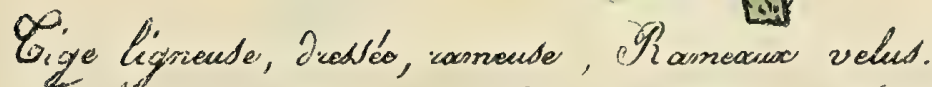

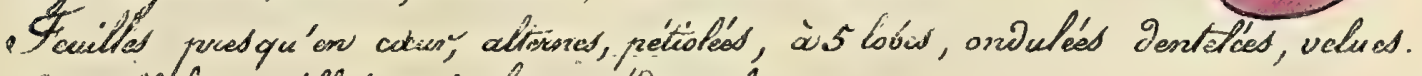

Orrbellietes axiliavis à long pei oncule

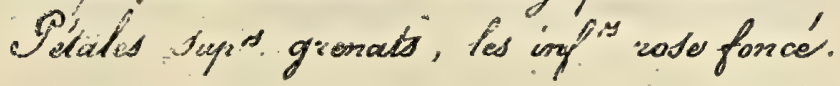

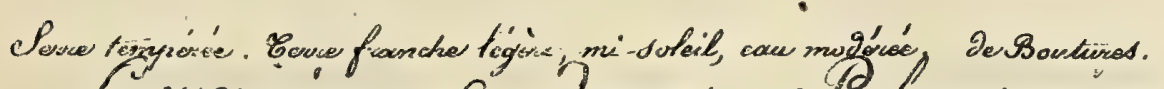

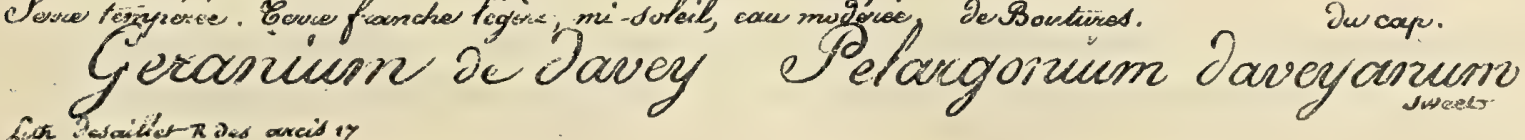





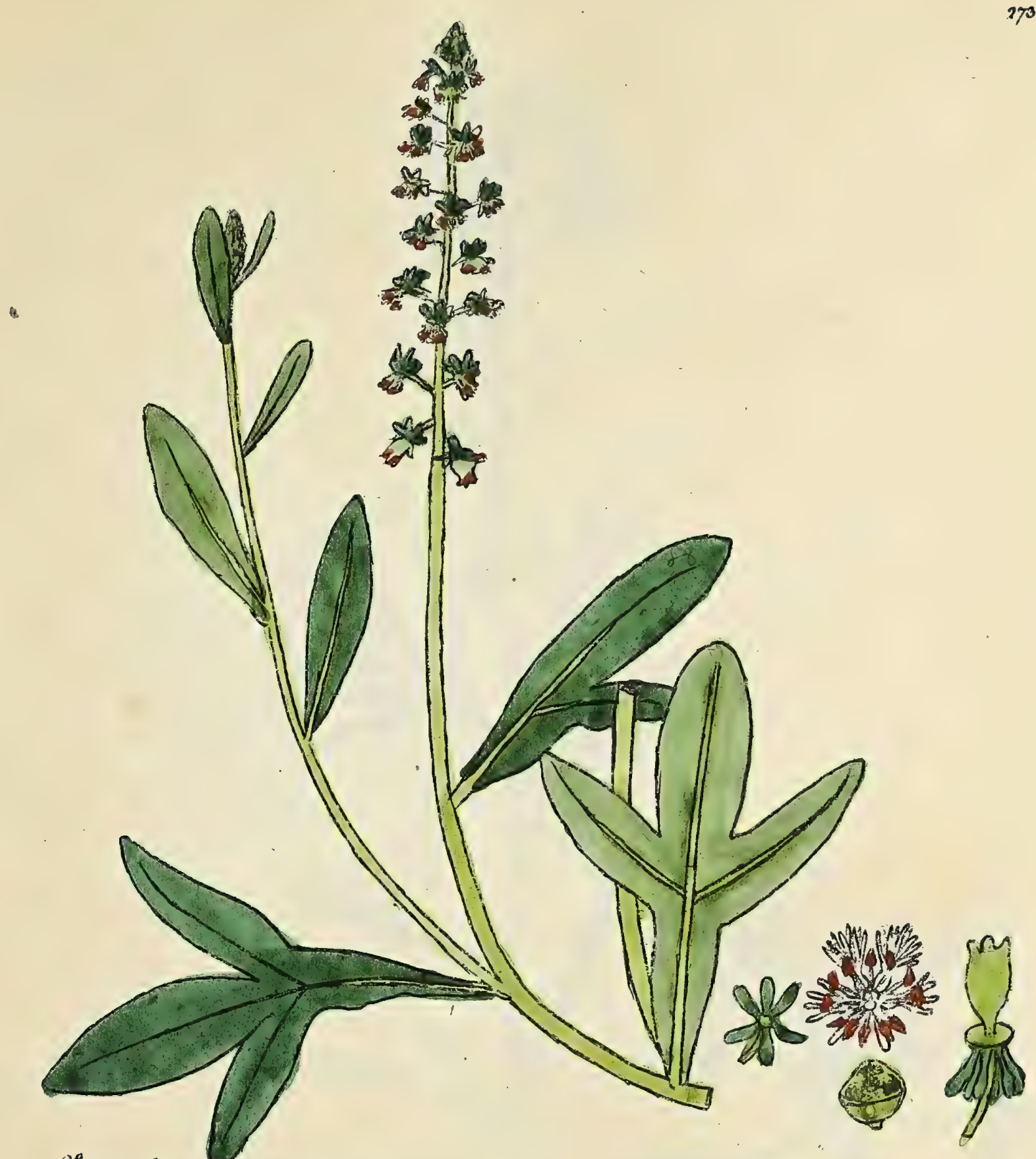

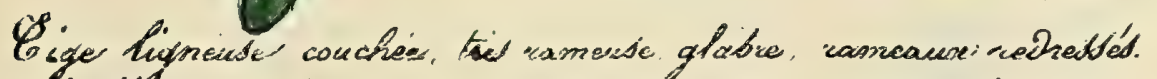

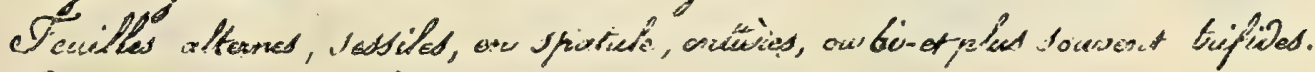

Croxpres teiminales Conzunt, Drestées, Droited.

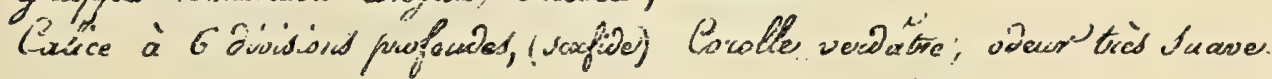

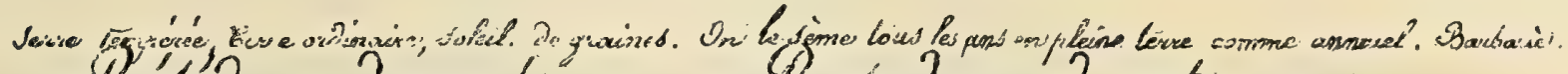

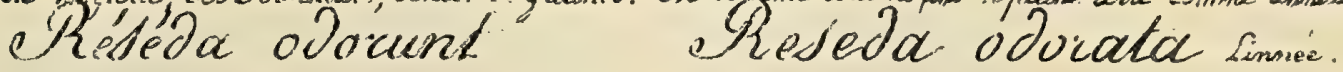

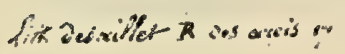




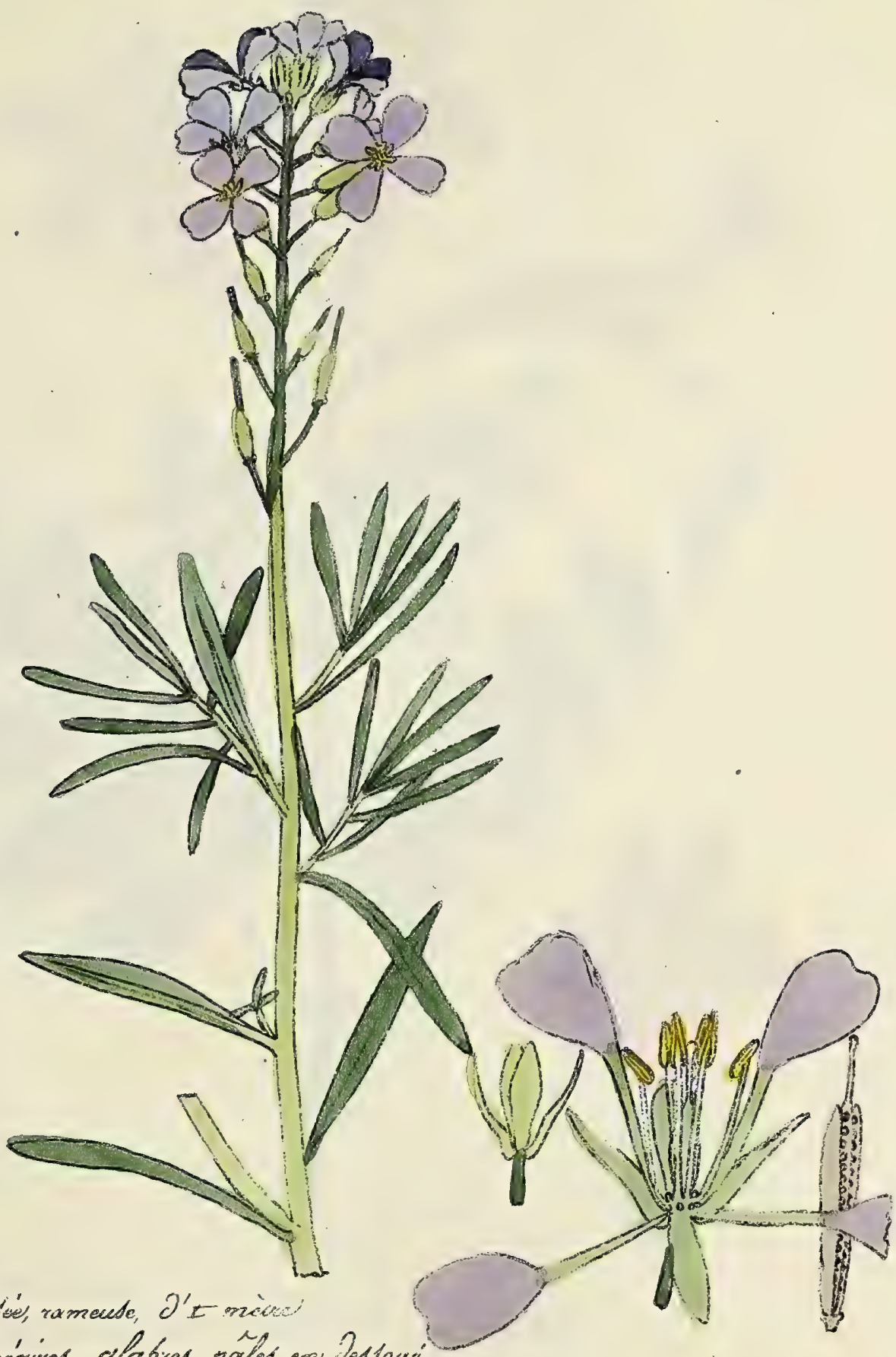

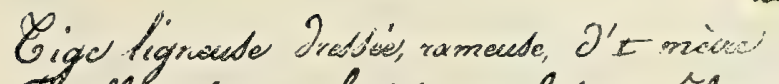
Feuilles alternes, lincicuries, glabies, pates en 20 sous Grappras lonigues, teuminiales

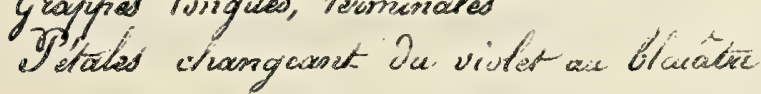

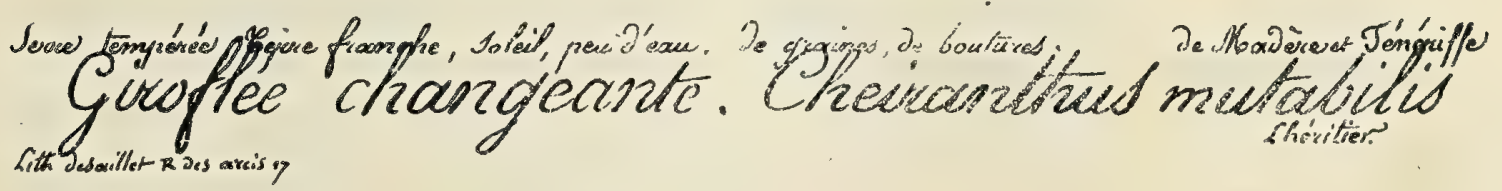




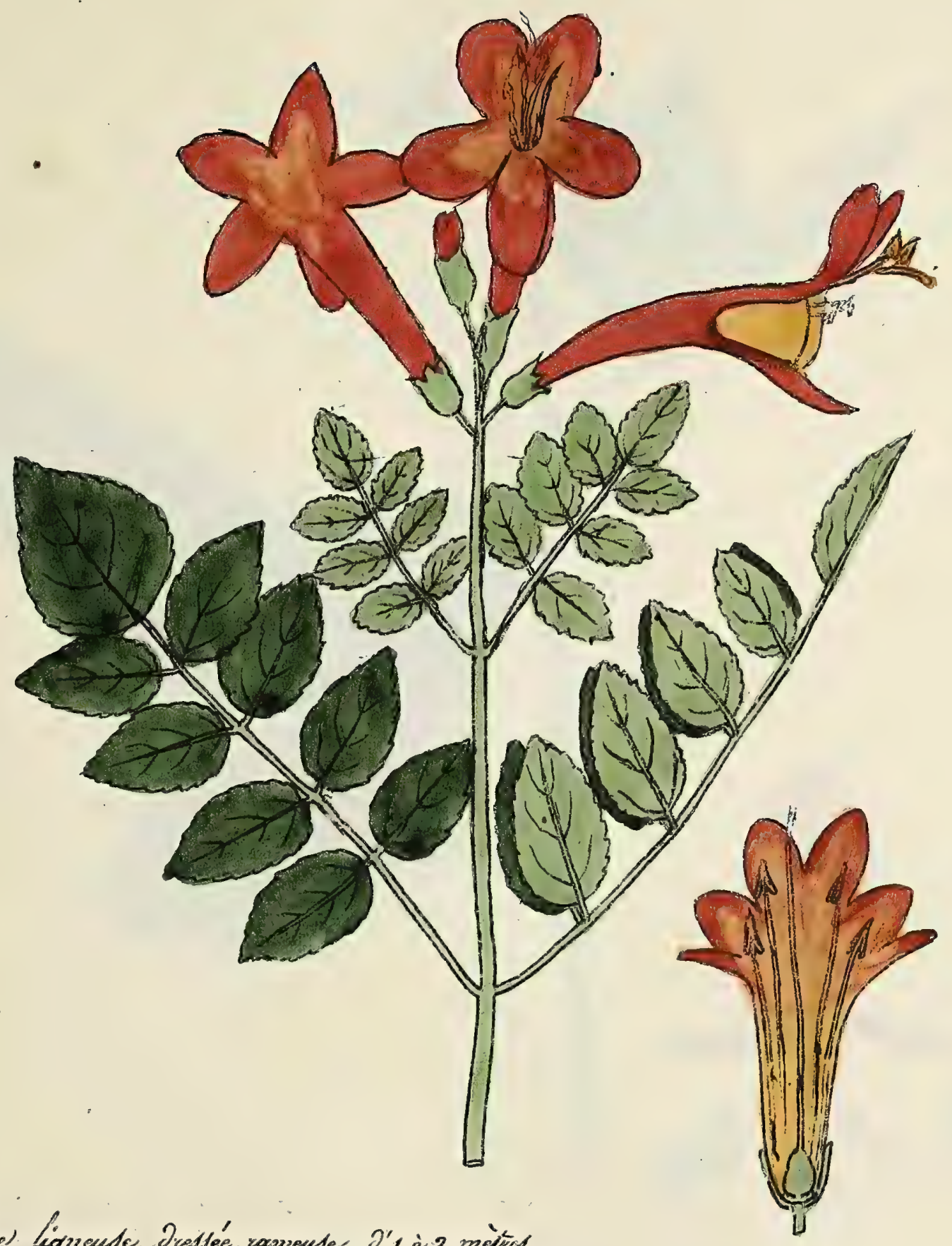

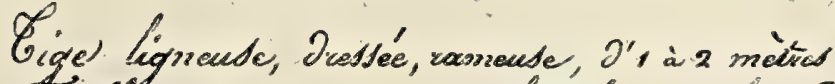

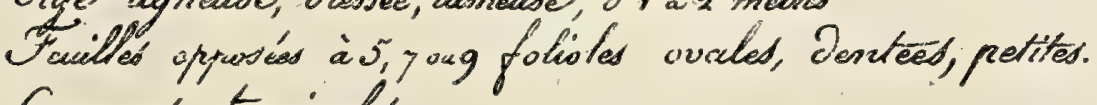

Groxpized terominales

Coralle gramde rouge veronillosio vif.

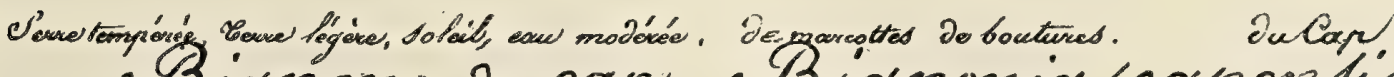
CBiginone du cap CBignonid caprenzlid.

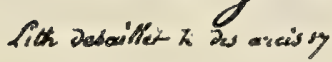





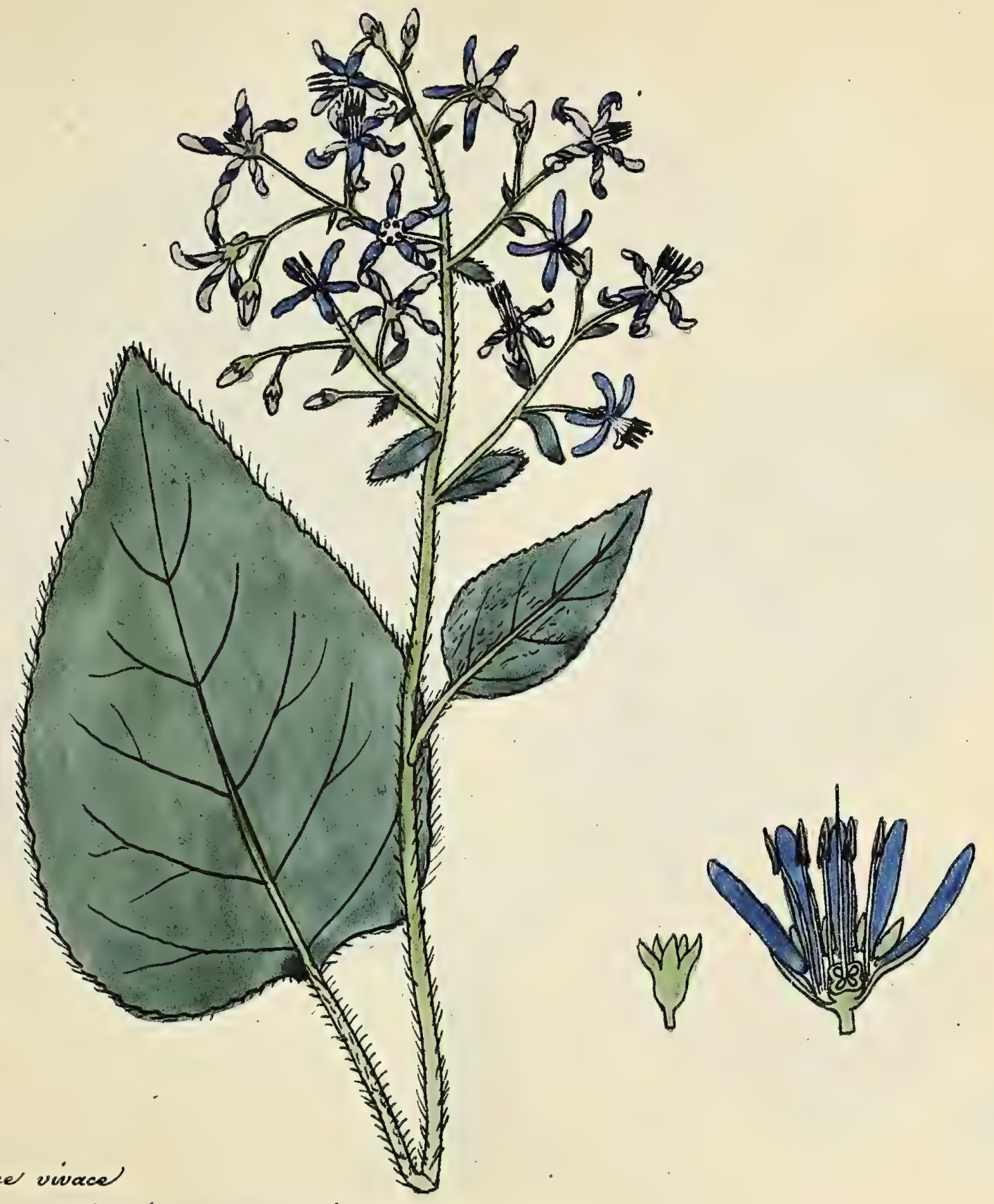

Racine vivacel

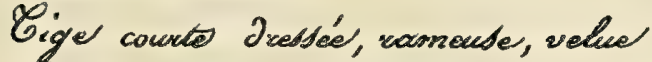

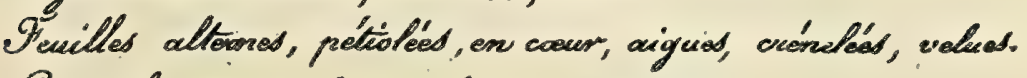

Pasicule touminale de flaens nombreudes.

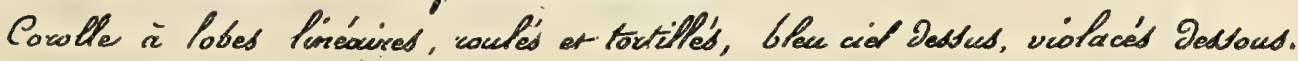

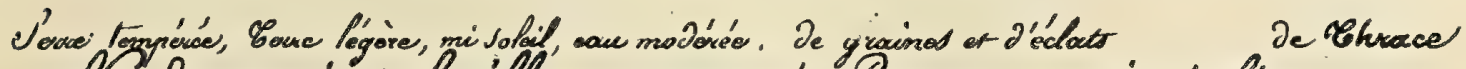

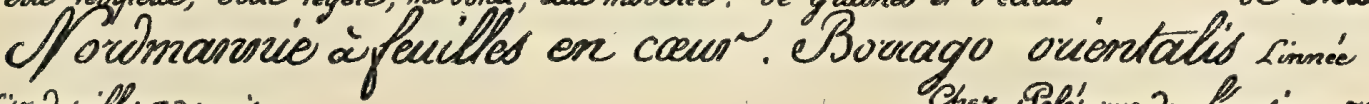

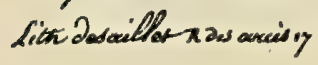
Cher PRf'́ mede Poursione $7 t$ 



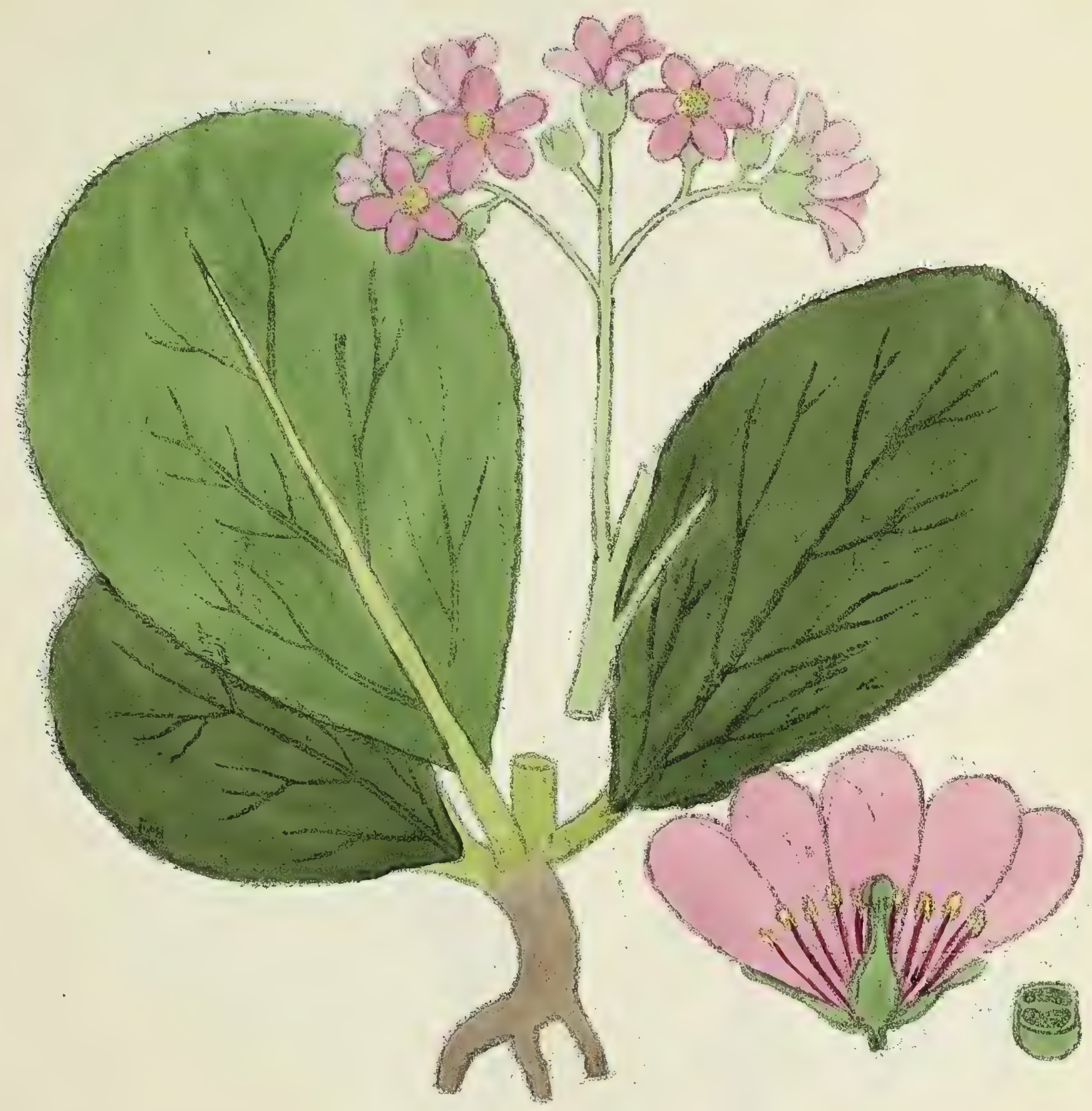

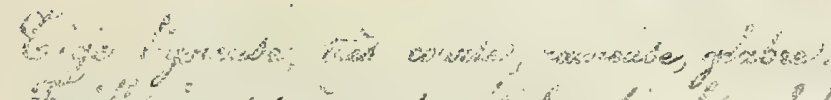

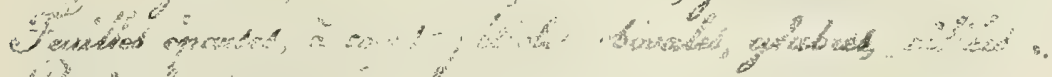

i.

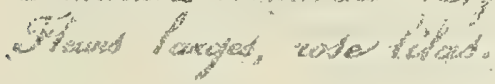

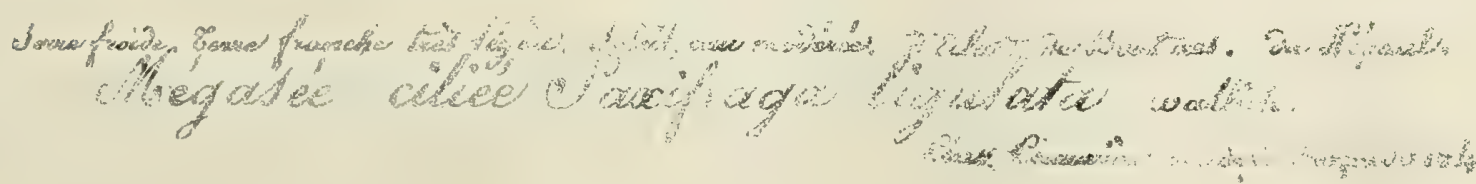




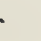






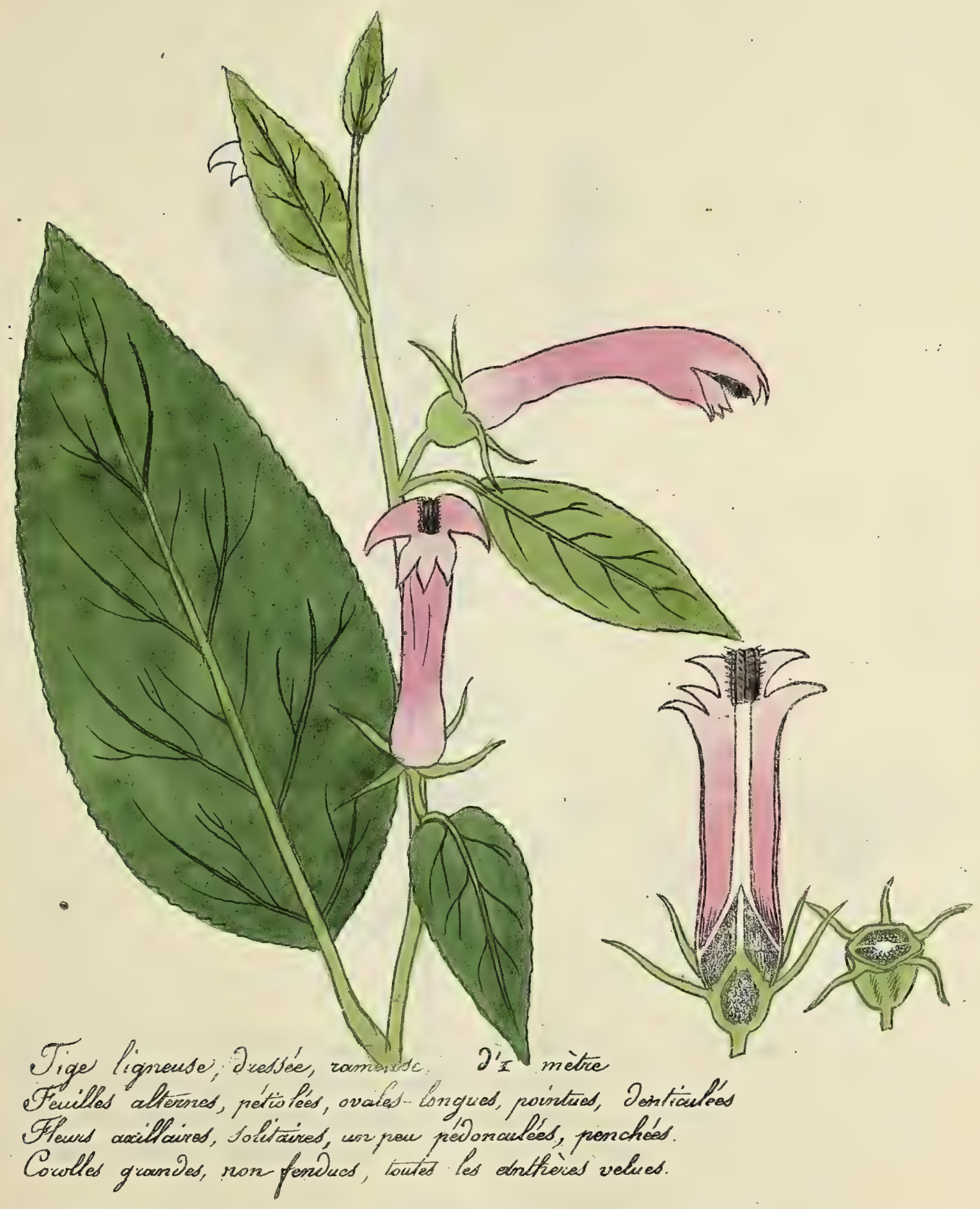

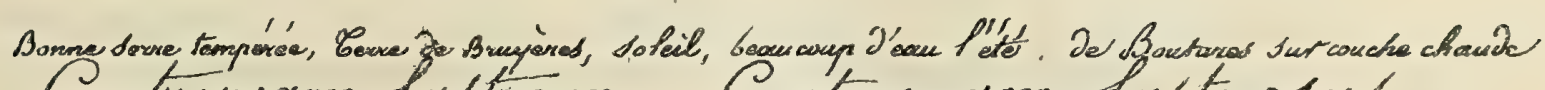
Centioprogon fastuewa Centuopogon fastuosud.

firt dwailler $x$ Jus arris'

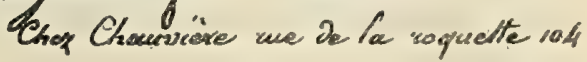





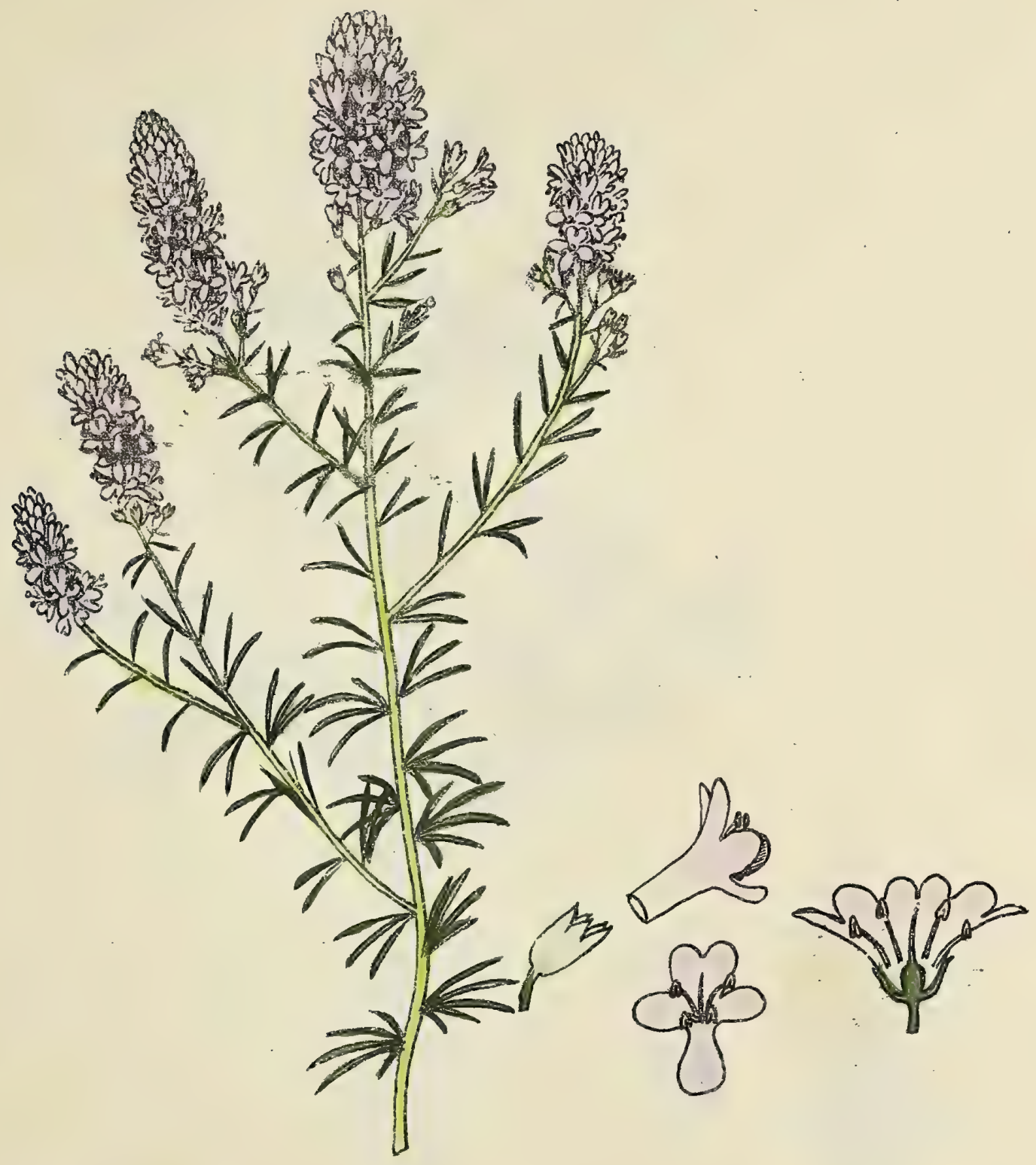

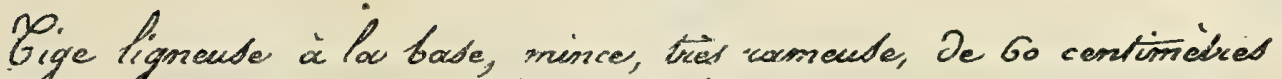

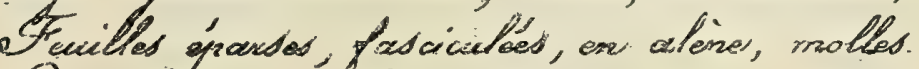

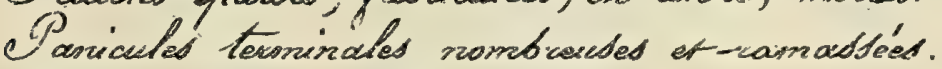

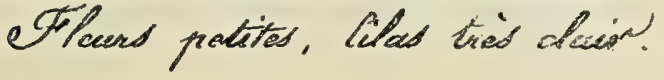

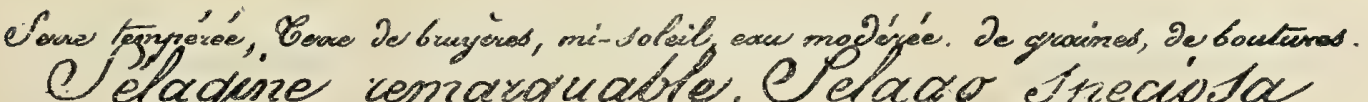
Celagine cenrayuabre. Selago éfiecióla

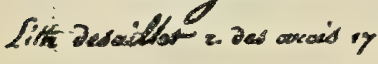
Chen Korteon boulev. Jas gobelind 4 bis. 



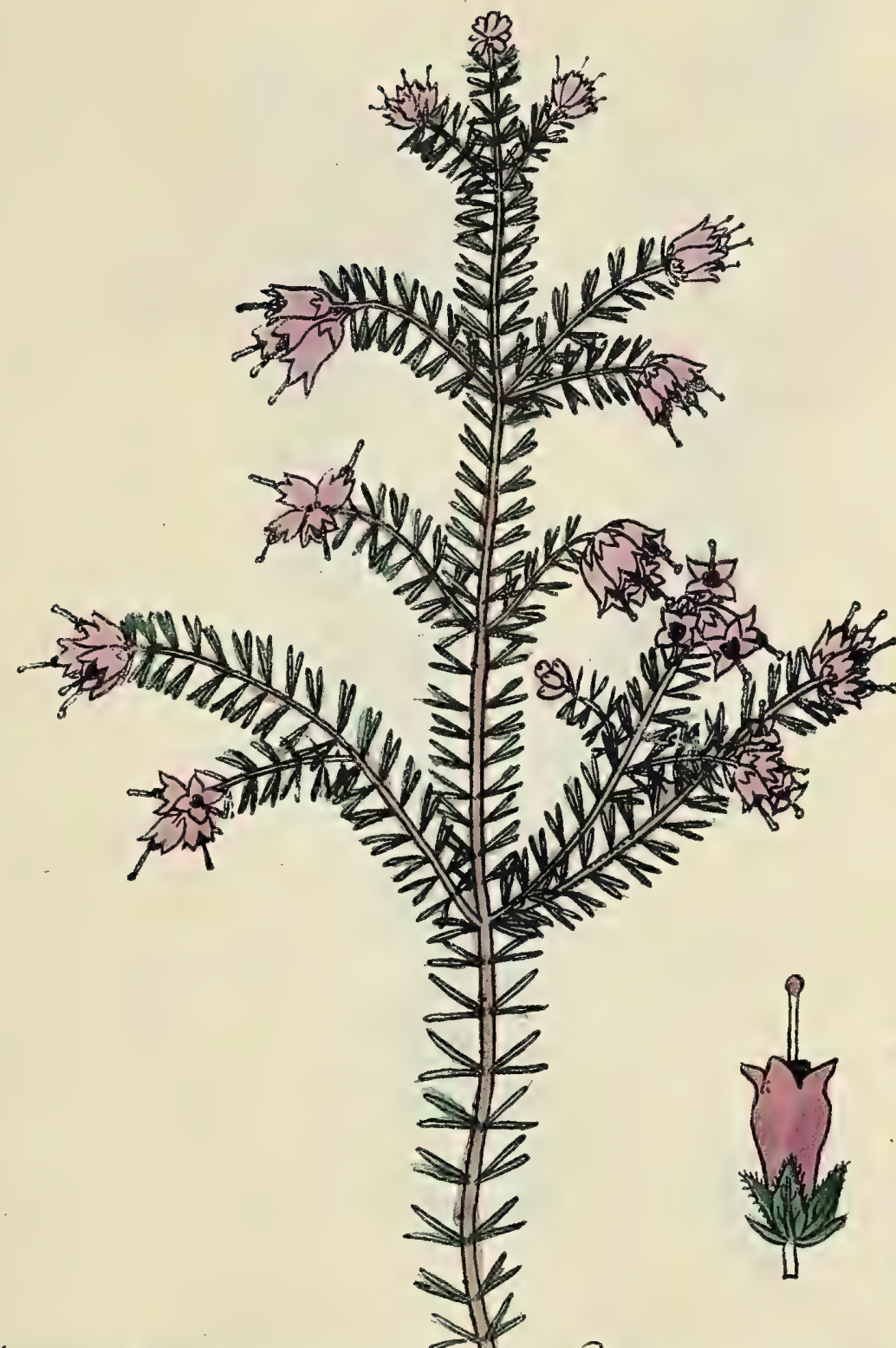

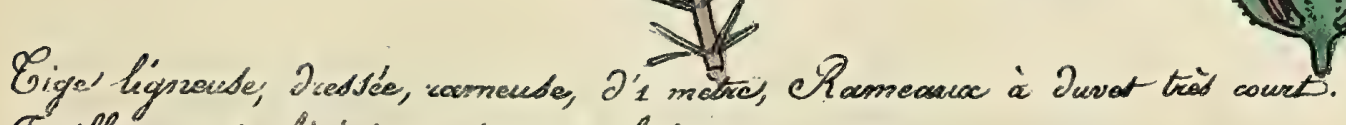

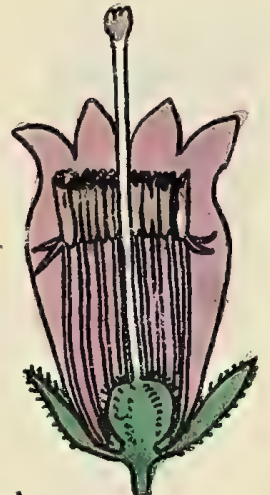
Feuillas pan 4. Linéxired, obtuided, glabres, ouvertes.

Freund terminacies, Sessiles, pour' 3 an 4.

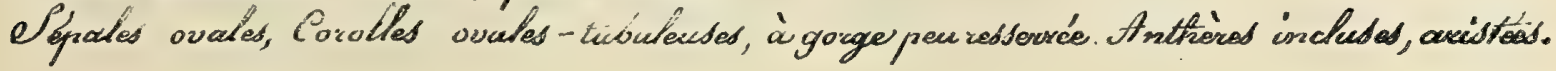

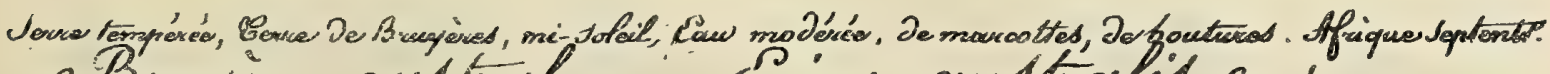

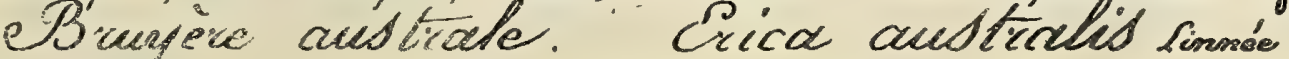

Sist Desailler it in arcis?

Chan ketteerr Boul Des gobdired 4 bis 



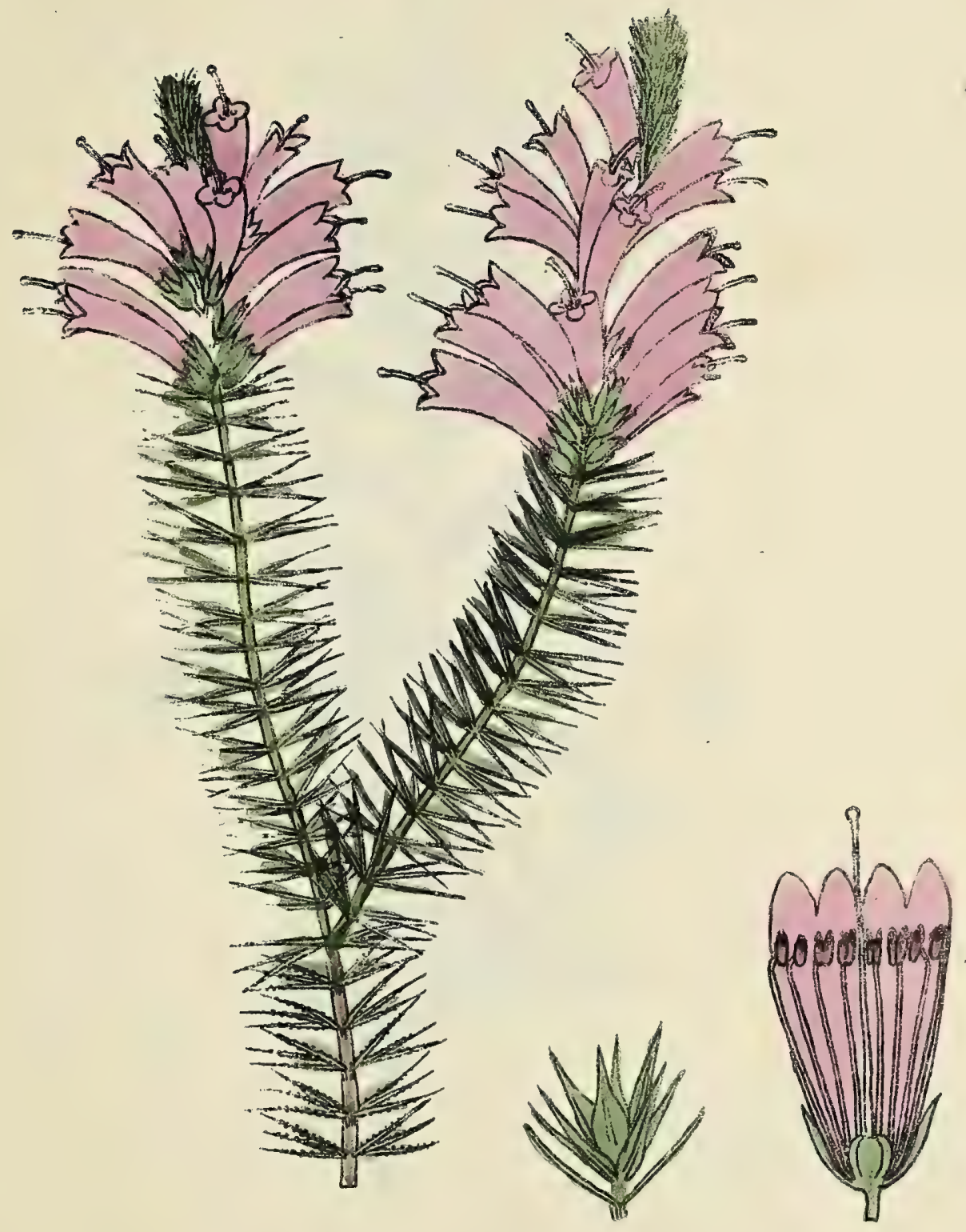

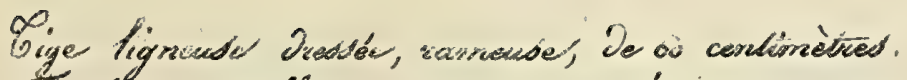

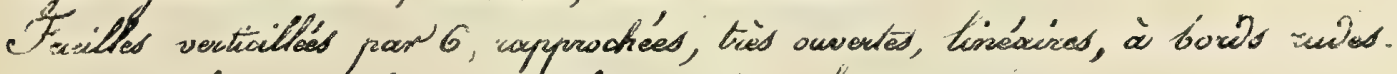

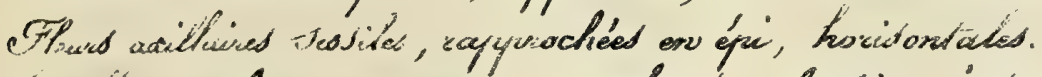

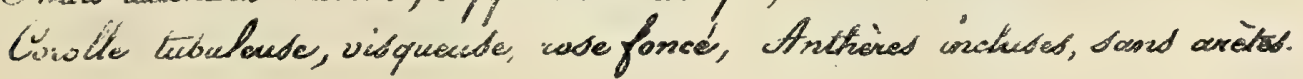

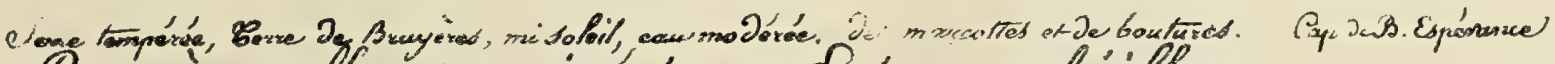

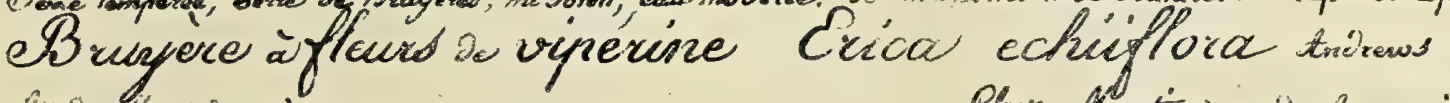

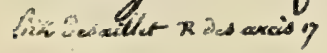

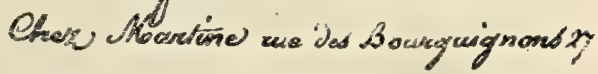





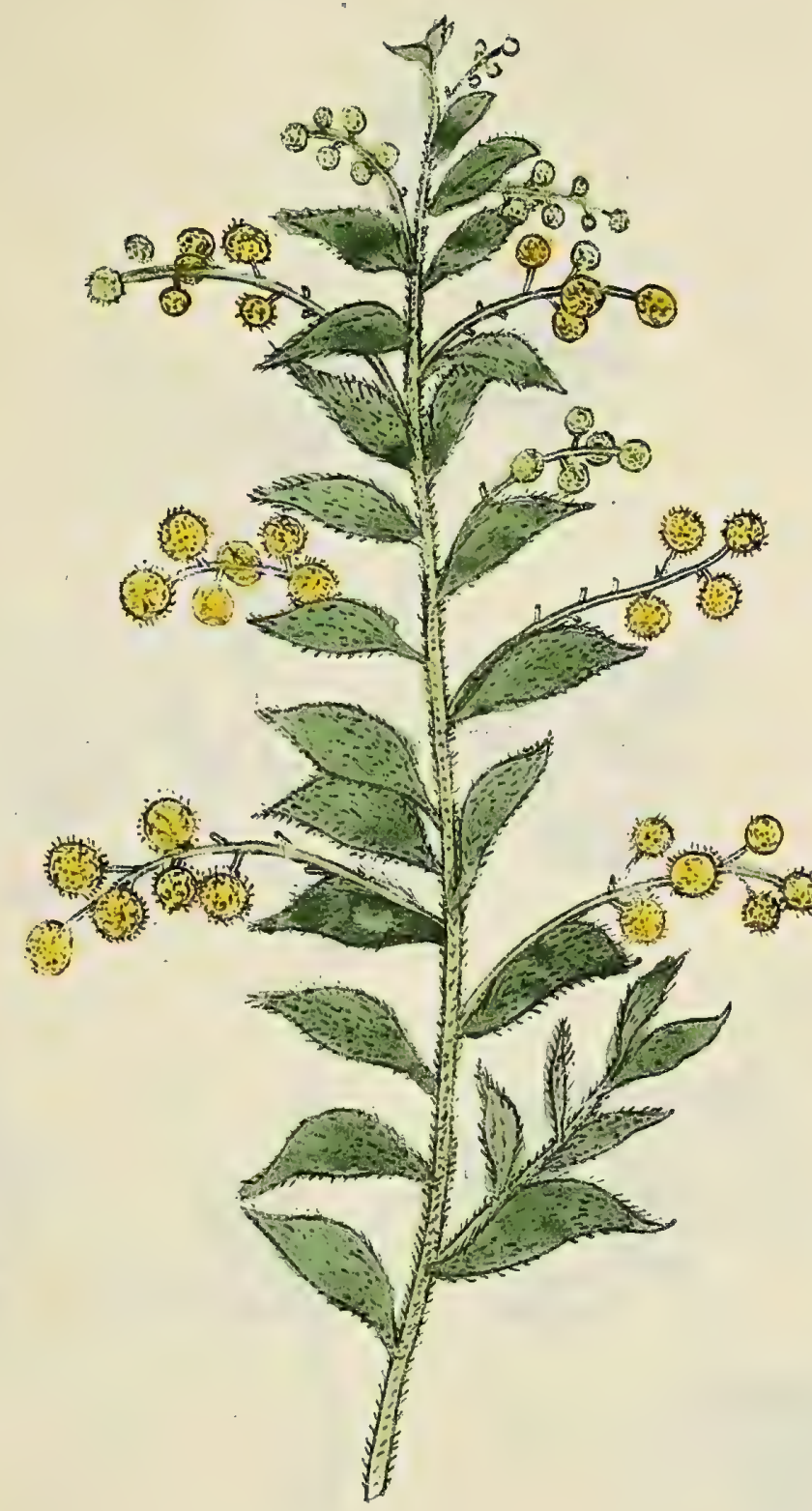

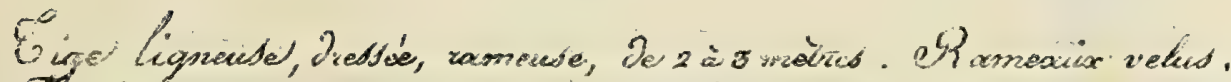

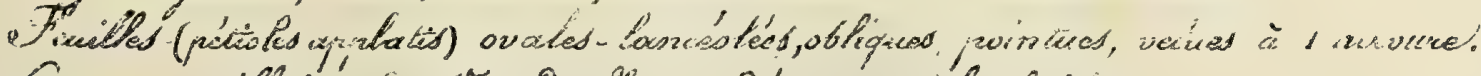

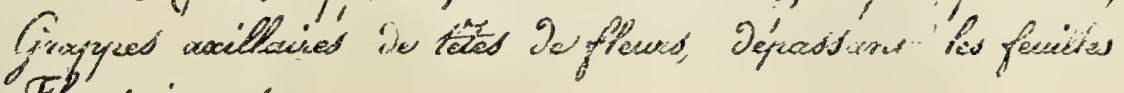
Flecus jouned.

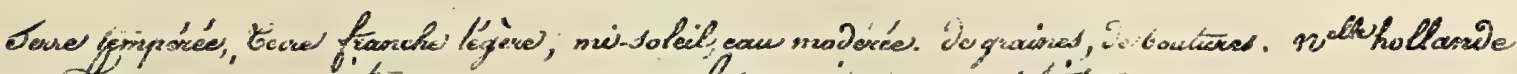
Heacie vilue ifcacia vedtita nar 



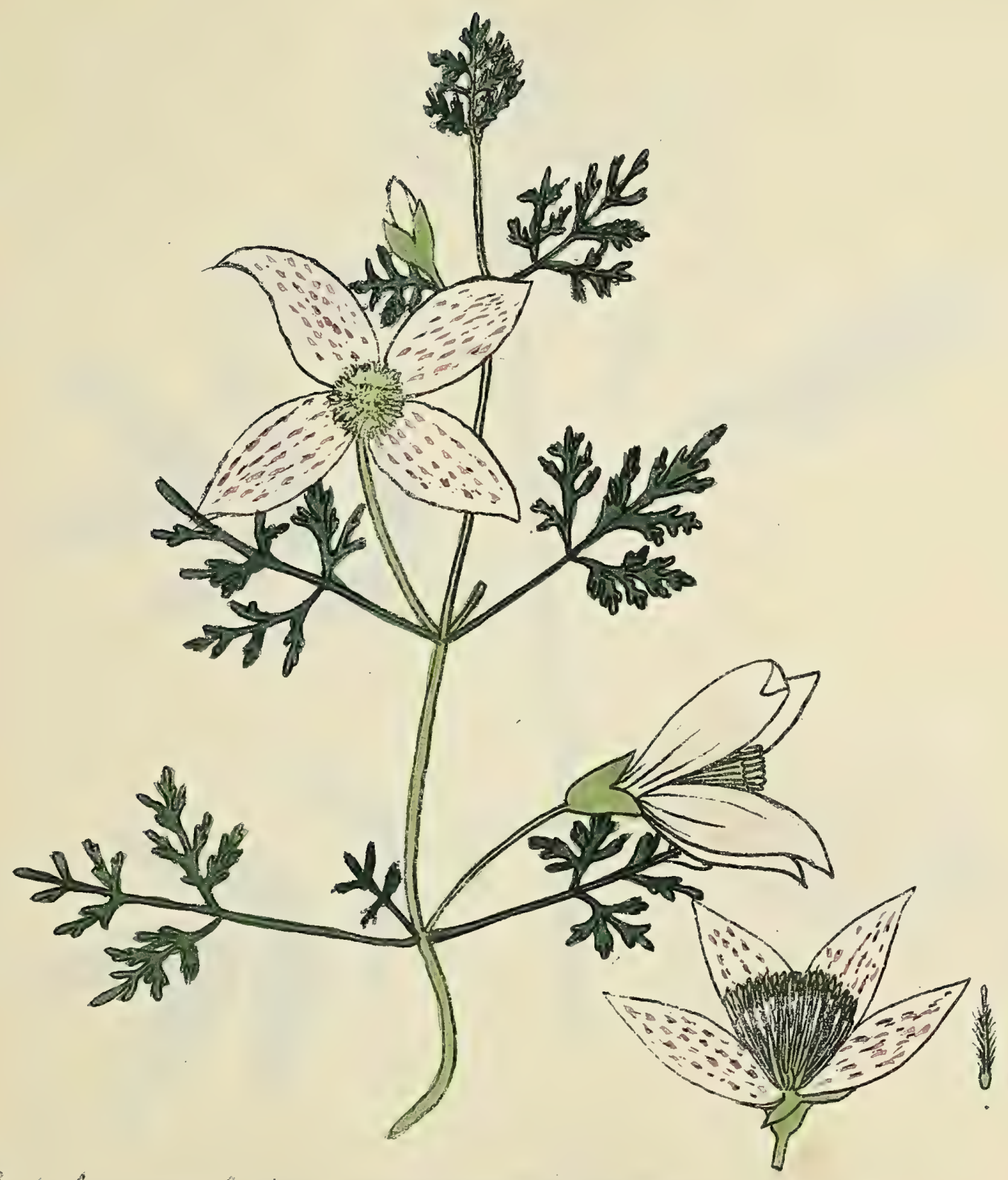

Cigej uignroude à la bade, à camanuad minces, nombrewa:

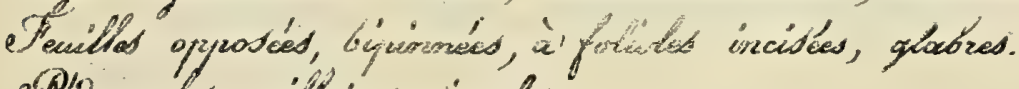

(Pidoncules axillinives, vimples

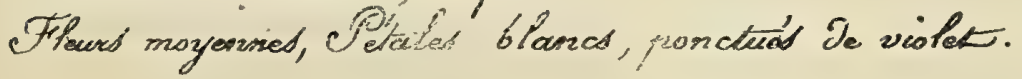

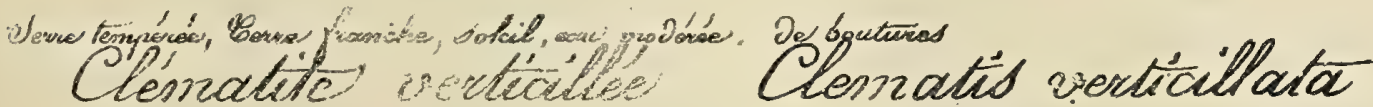

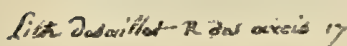

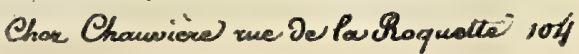





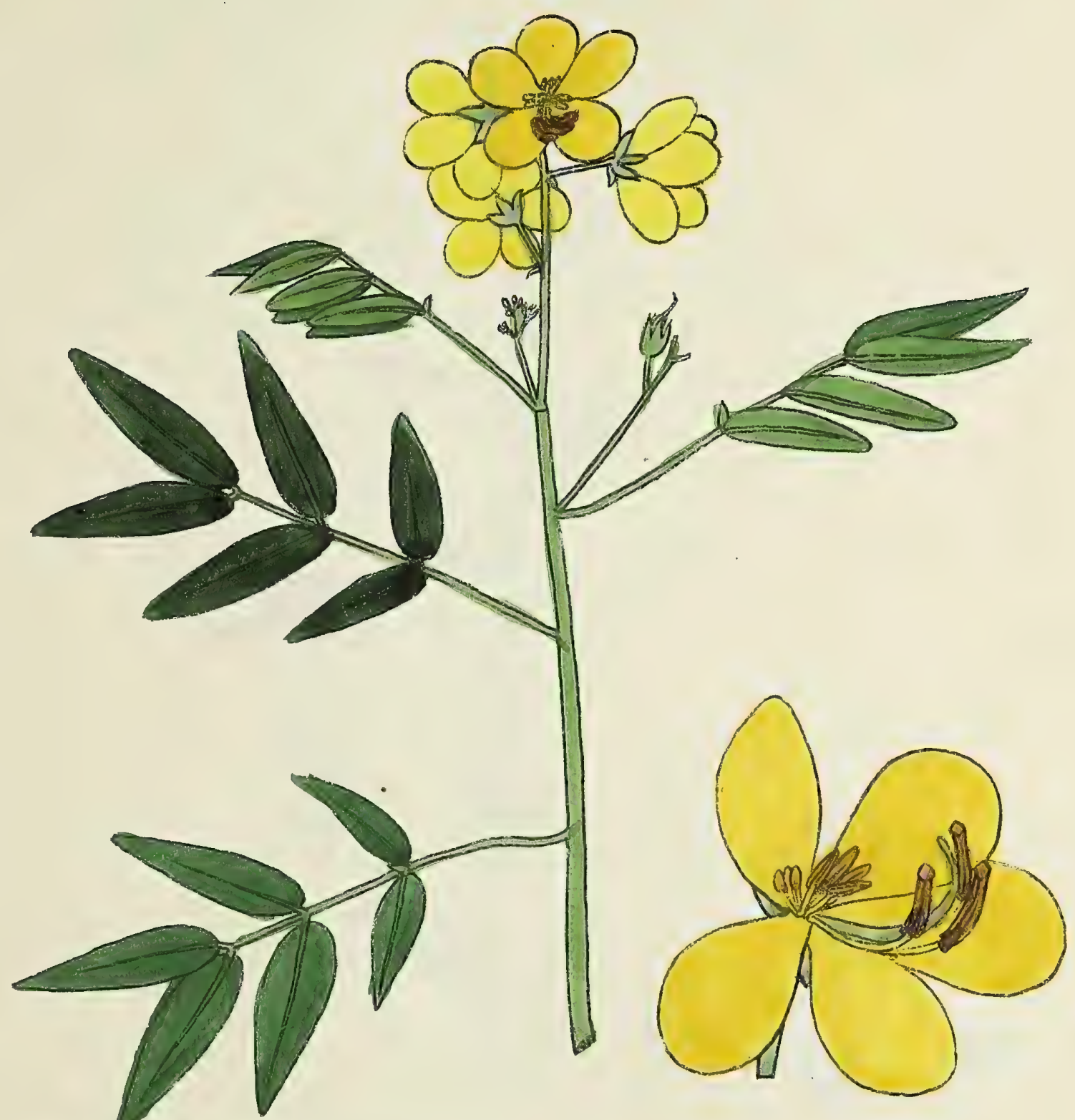

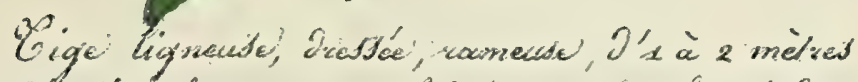

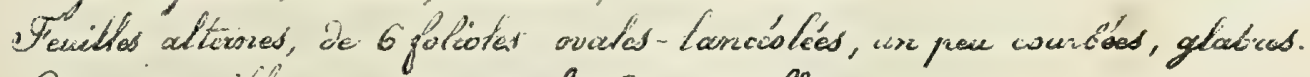

Grapizas axiliaine of terminales de 3 is 5 fleurs.

ivitules jaunes

Légumes cyifindicígued.

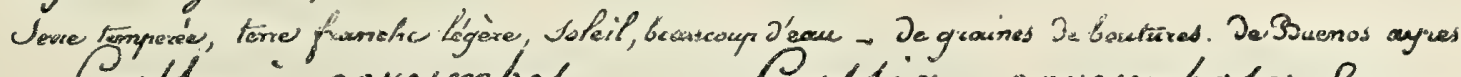
lable is corymbes.

Litt 2rsaillet $\pi$ 2es axw is $y$

Pabjici conymbola Pamaxek 



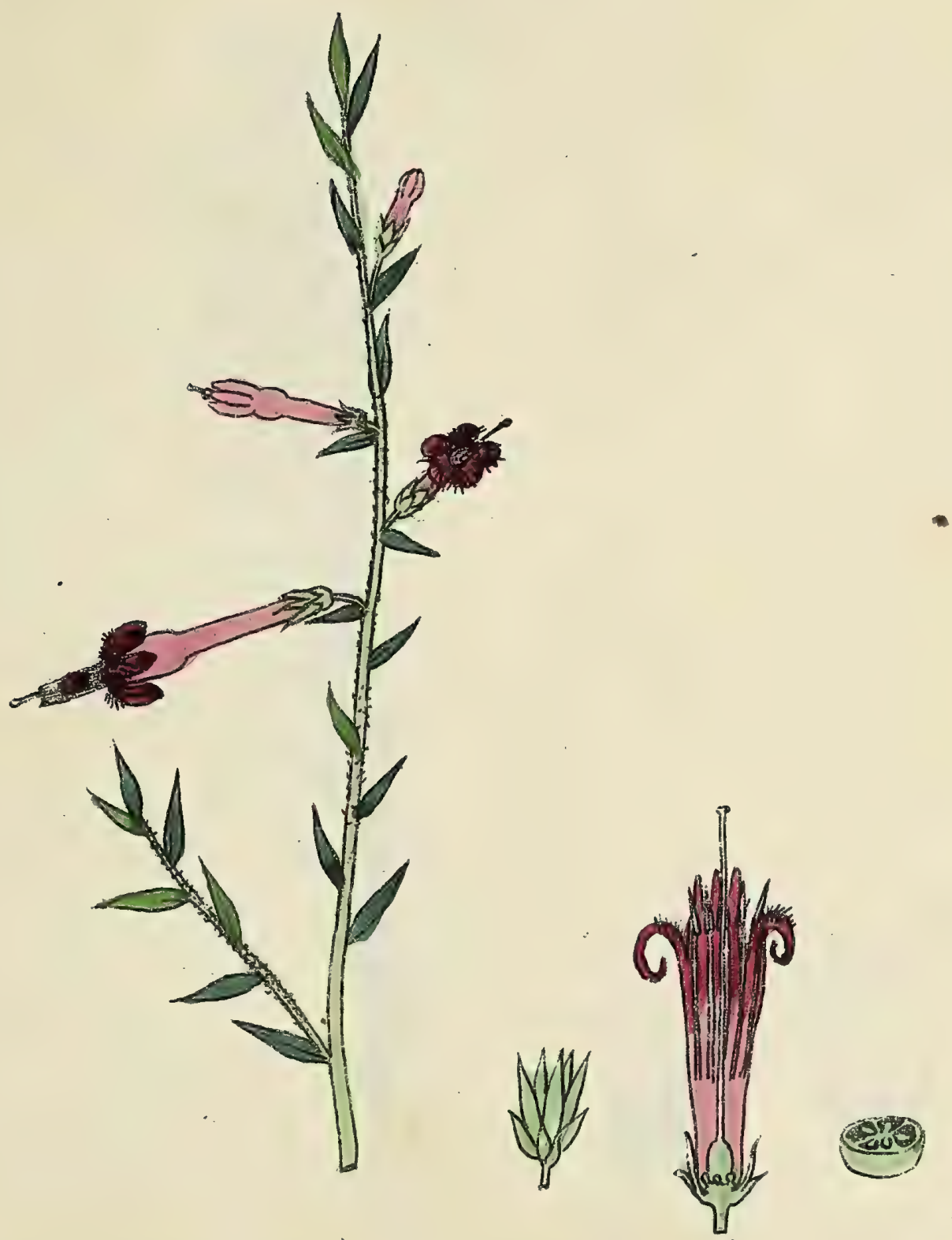

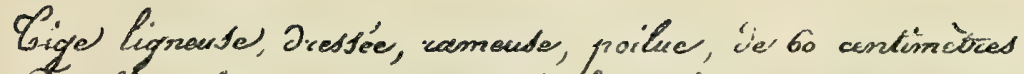

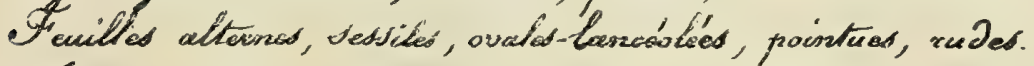
Tleures arillaives, solitaires, penchiés, à pédoncule cownt.

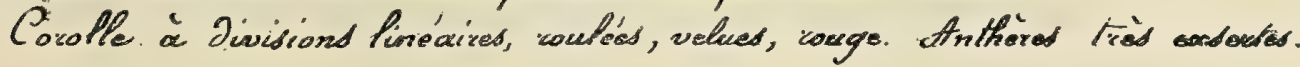

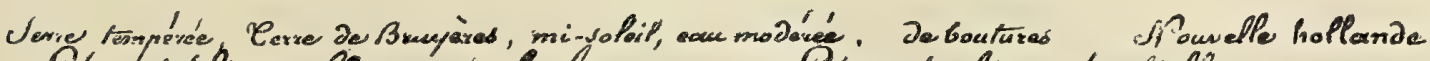

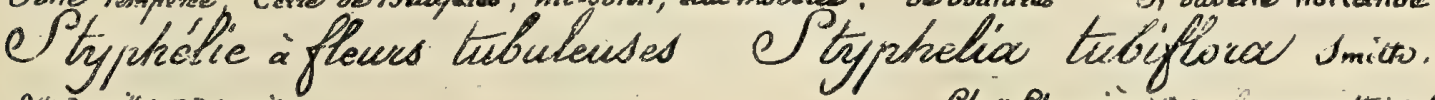
fitt Jes arillew th as arcis sy

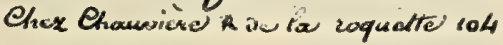



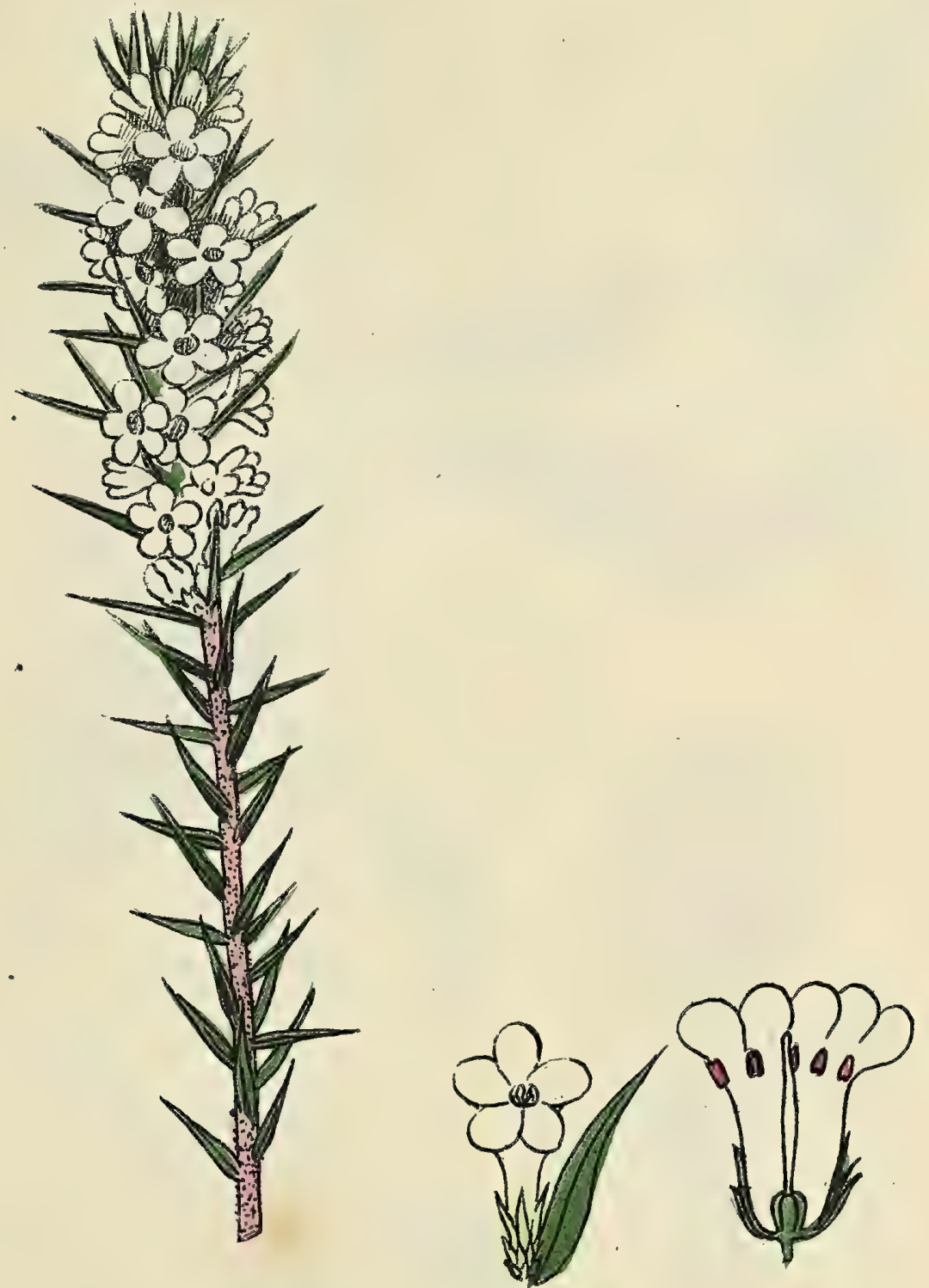

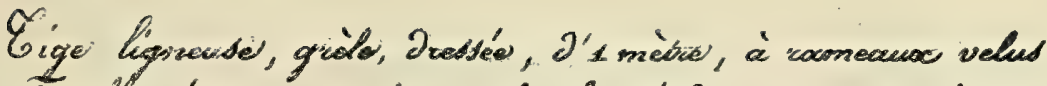

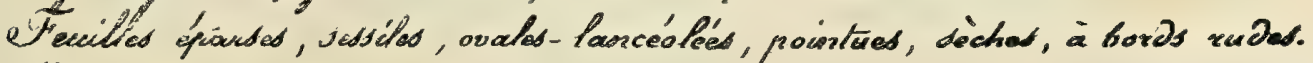

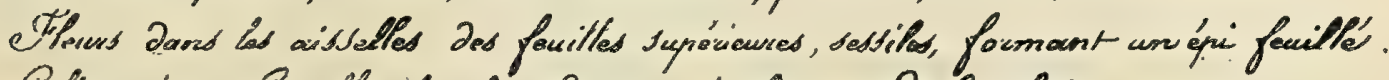

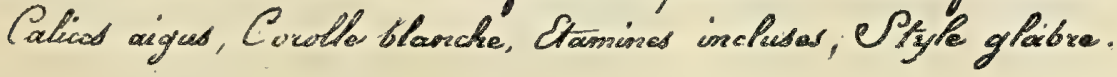

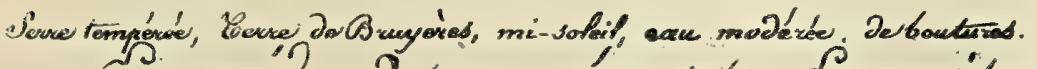

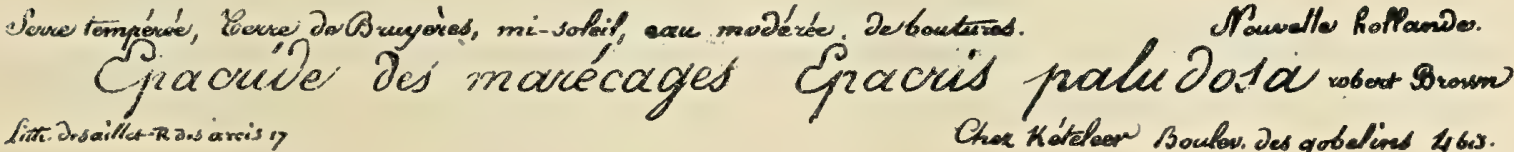

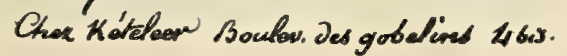





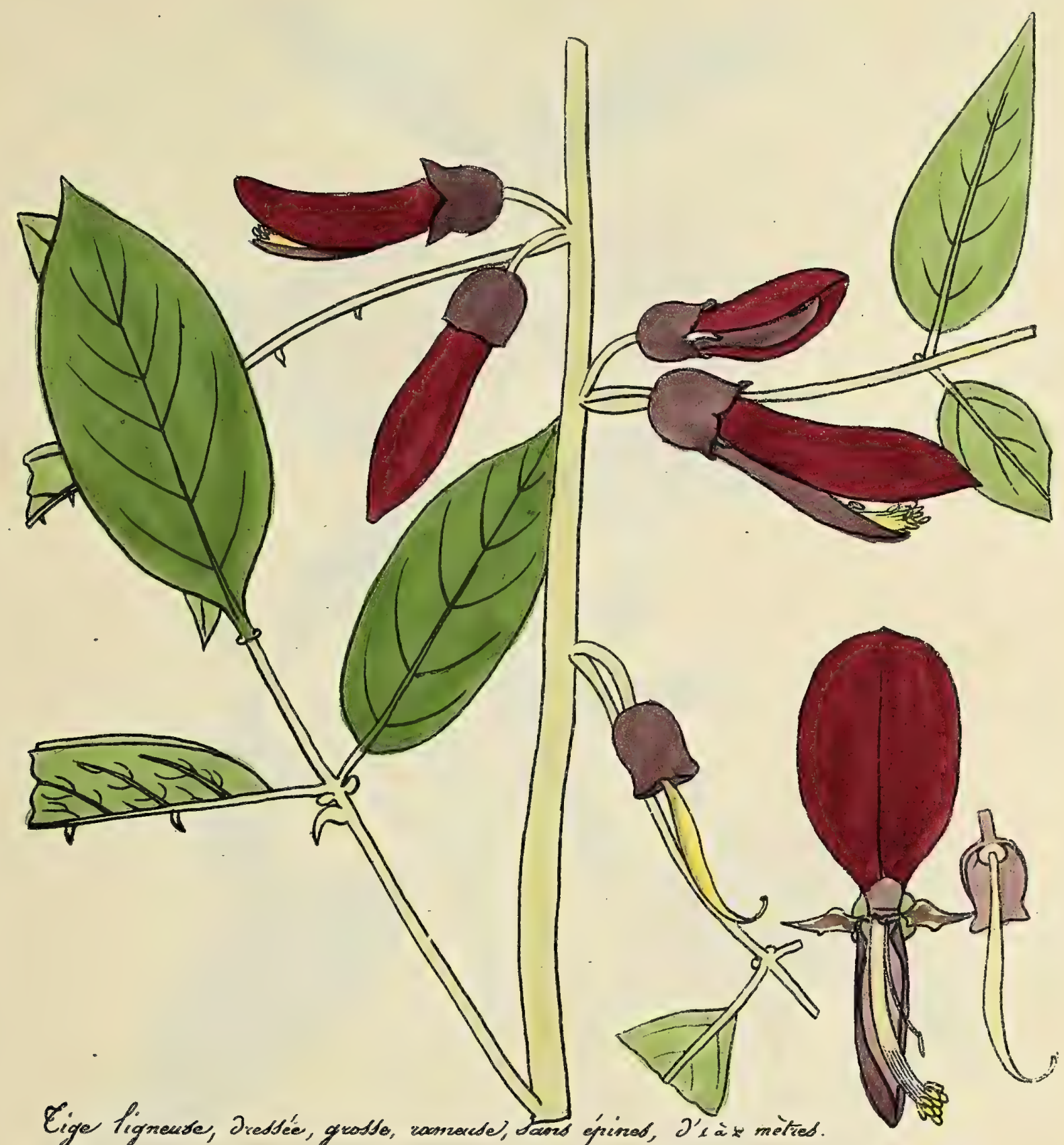

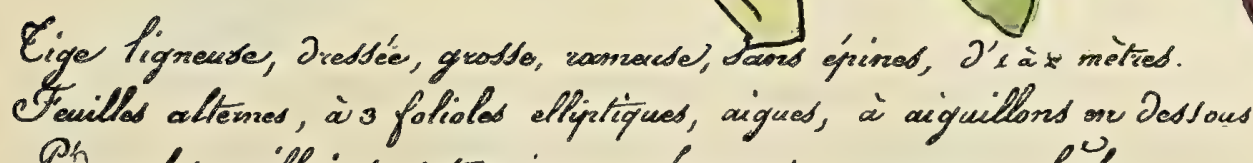

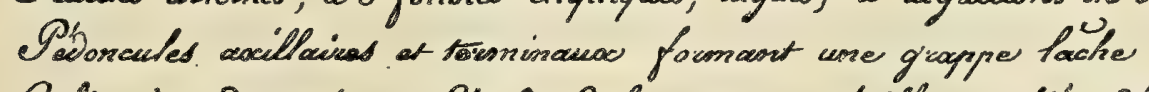

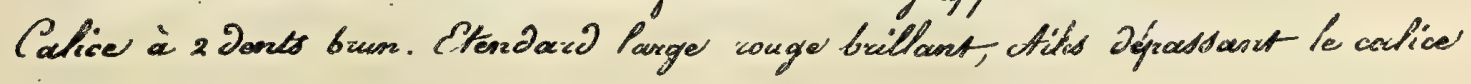

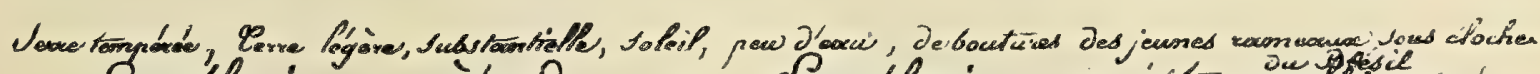
Crythrine ciète de cog Coythriona cuista gallis Limmé

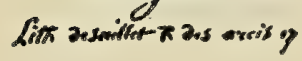





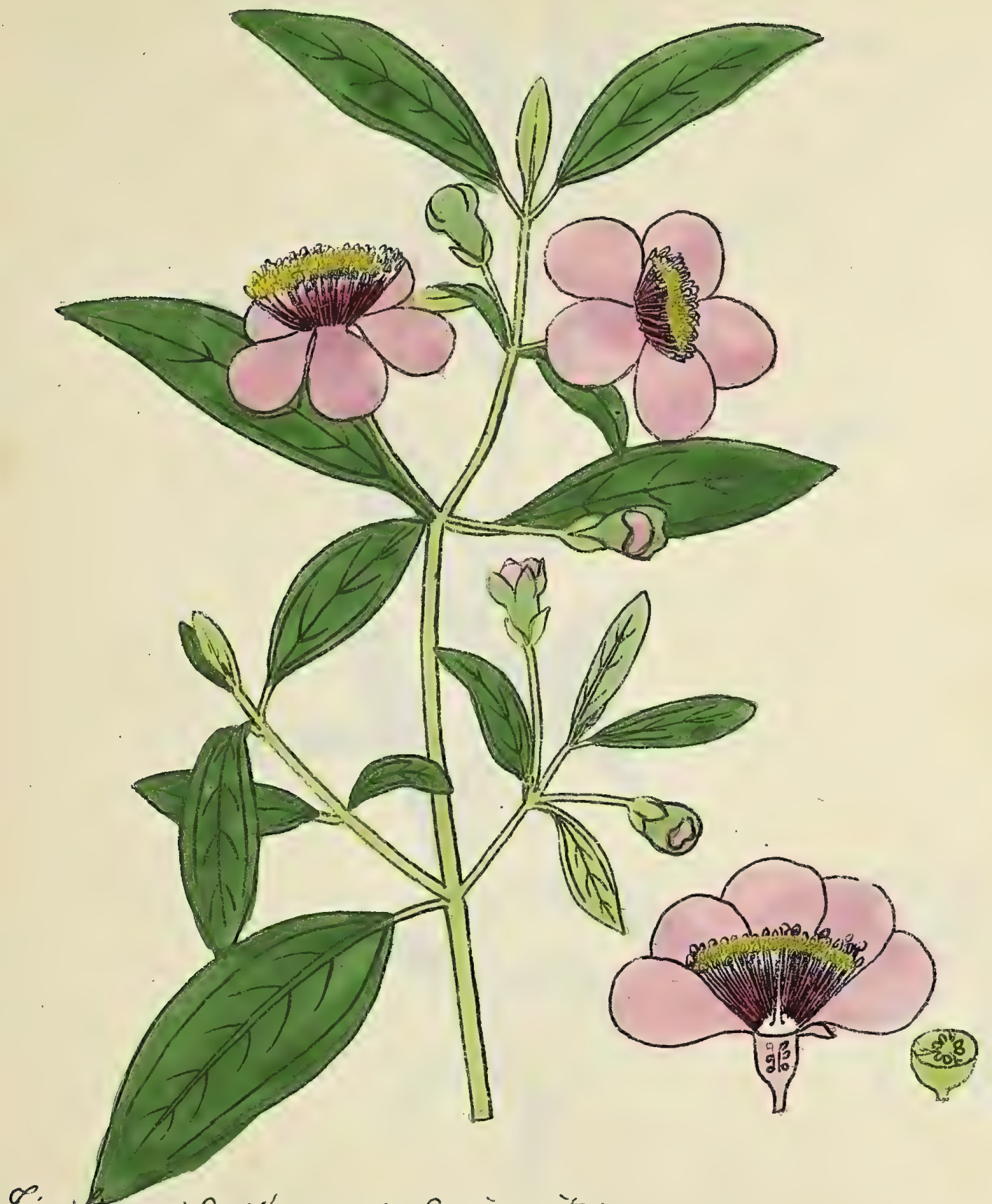

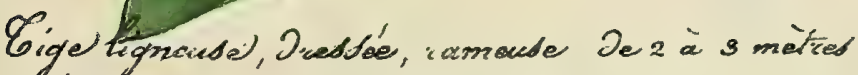

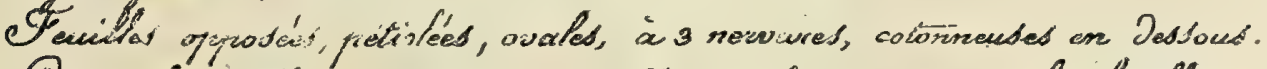

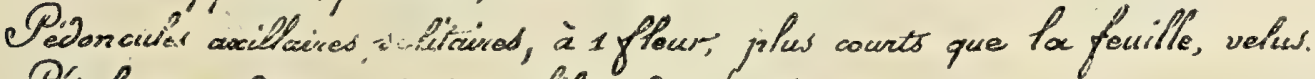

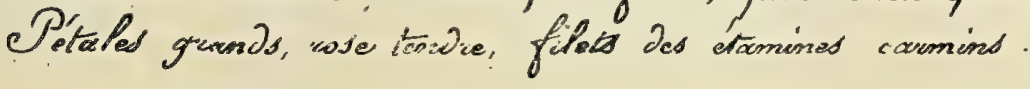

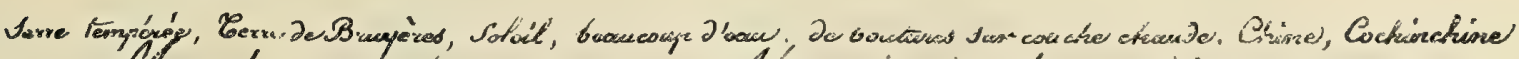
Mbycte cotonnewa Hoyrtied torresisosa Aiton.

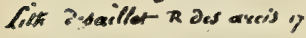





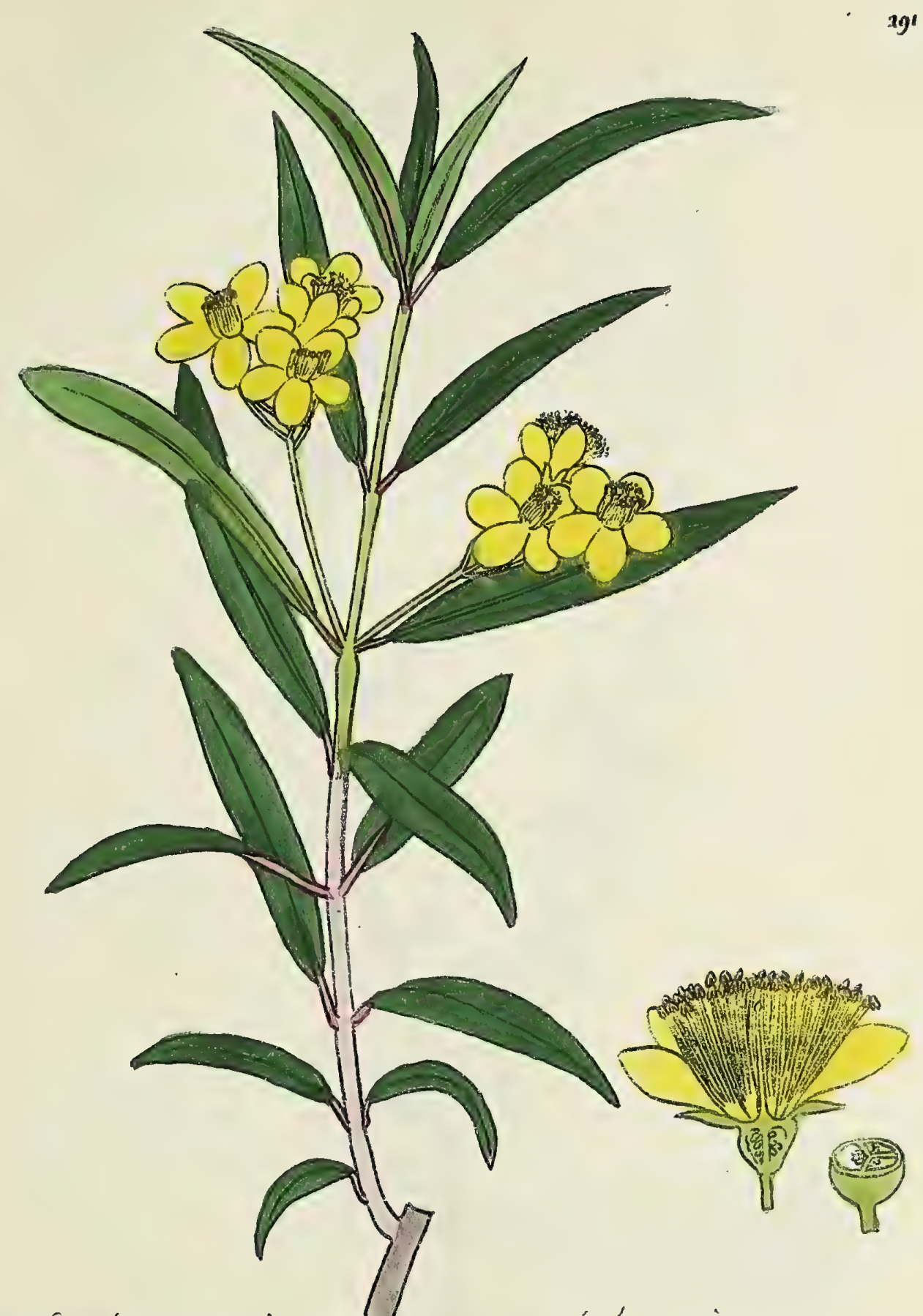

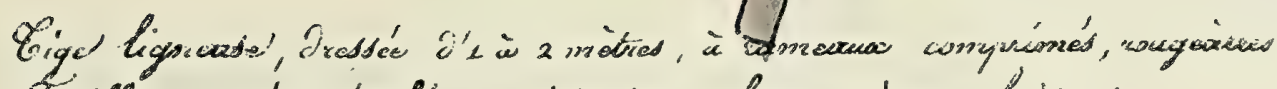

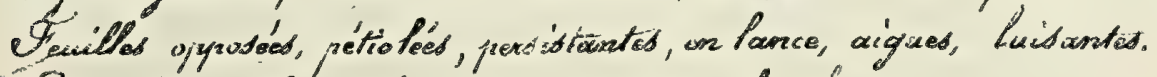

ePaniculas waillaines, trichotomos, à péboriculos Longd.

Potales jaure-chasis

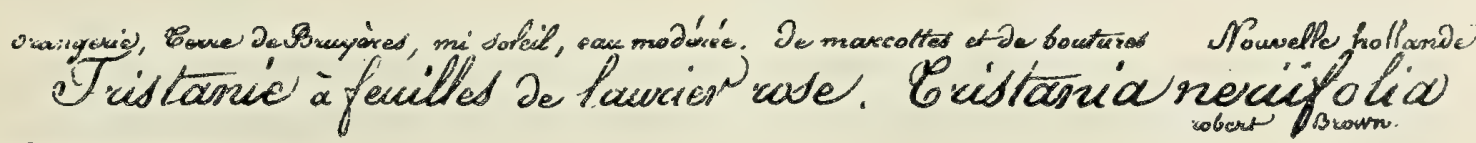
fito Dosicition $x$ as arsis $y$ 


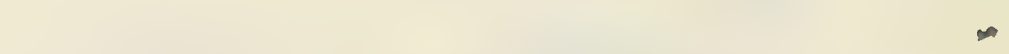




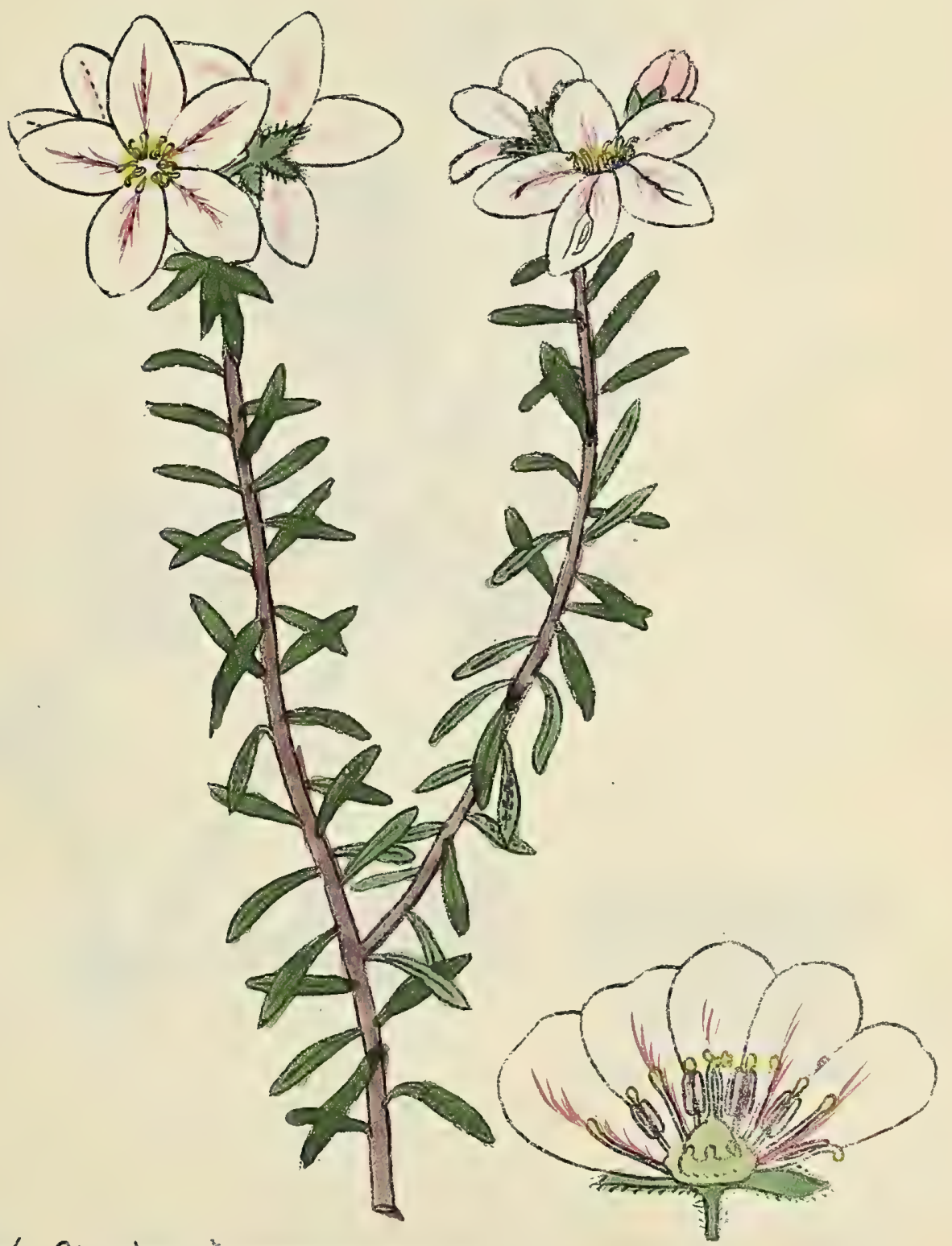

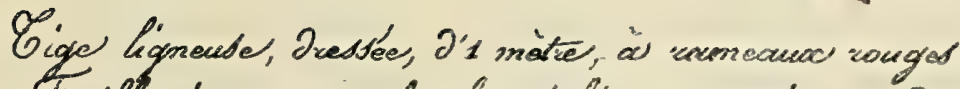

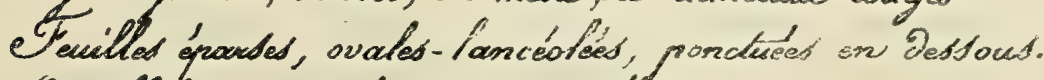
Ombellutes terminatas de' 3 à 5 flewes.

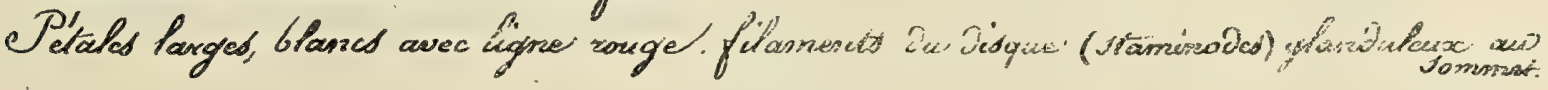

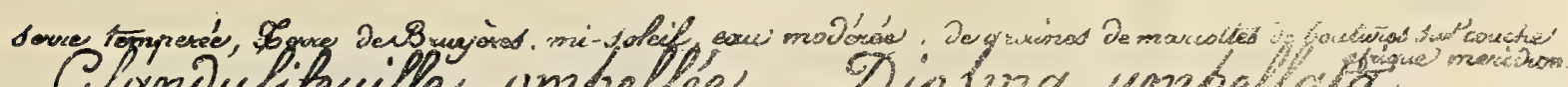

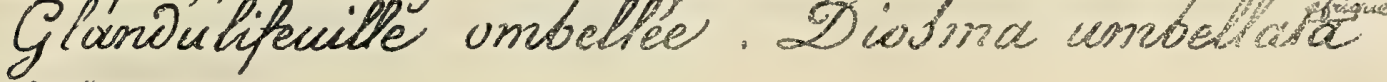

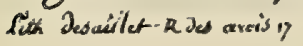





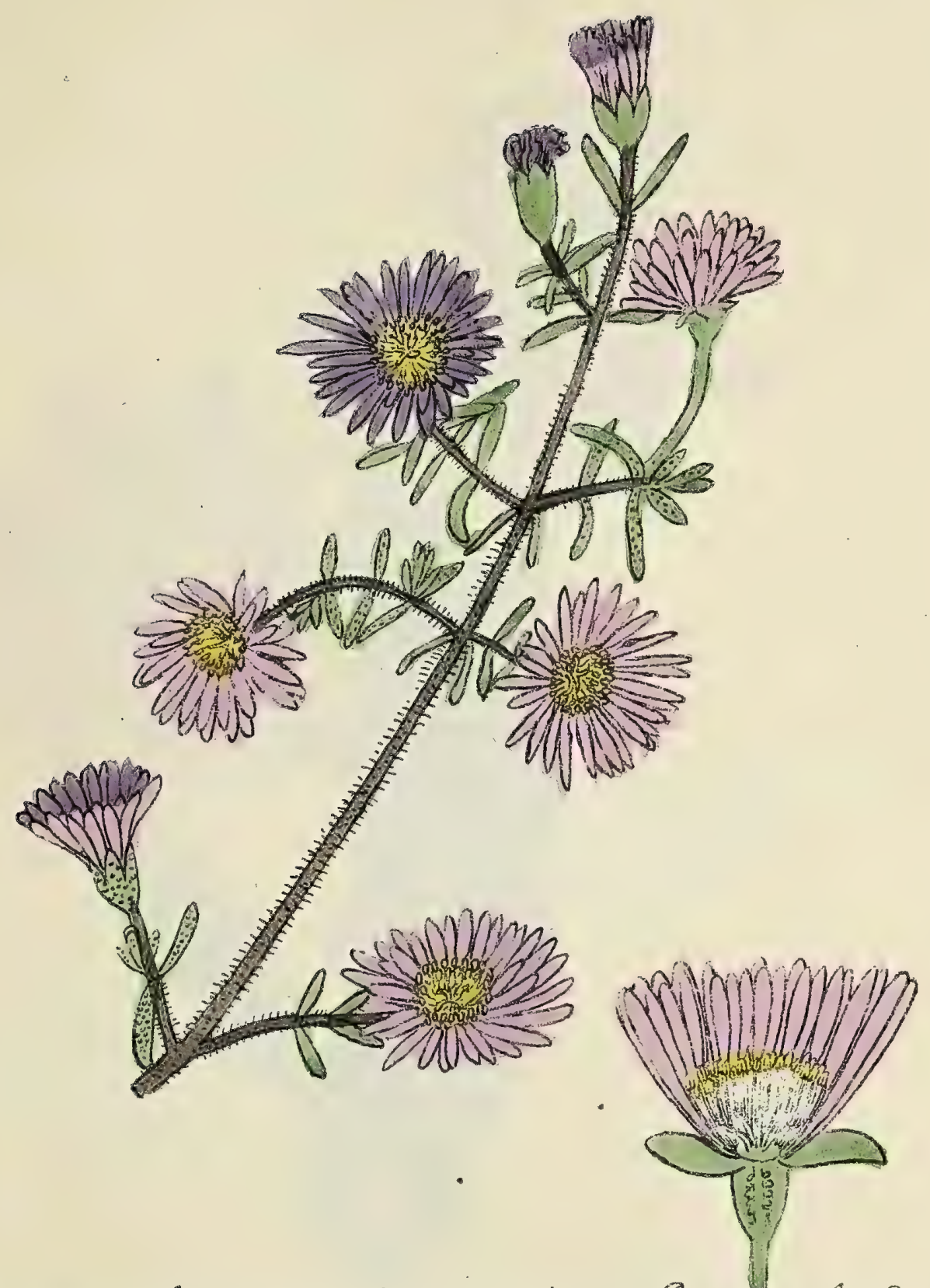

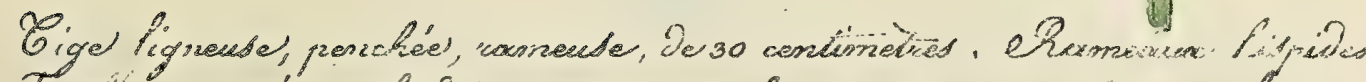

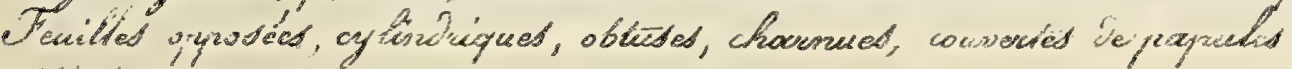

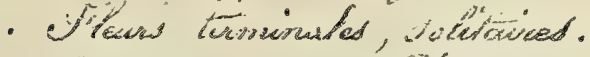

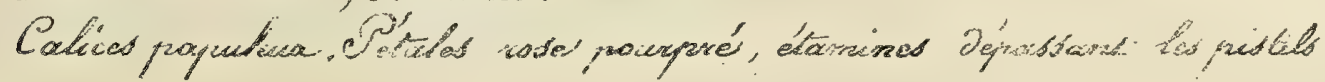

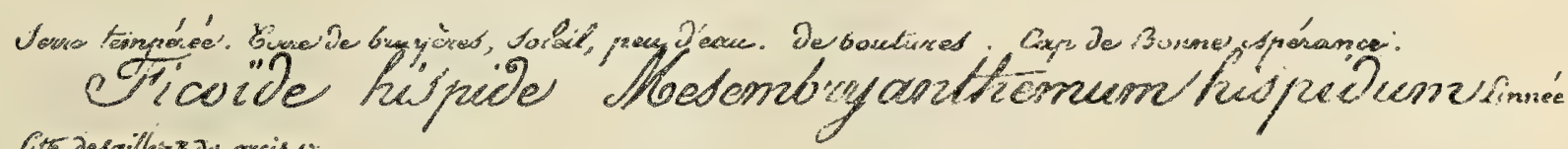
fith descillers des arreis ny 



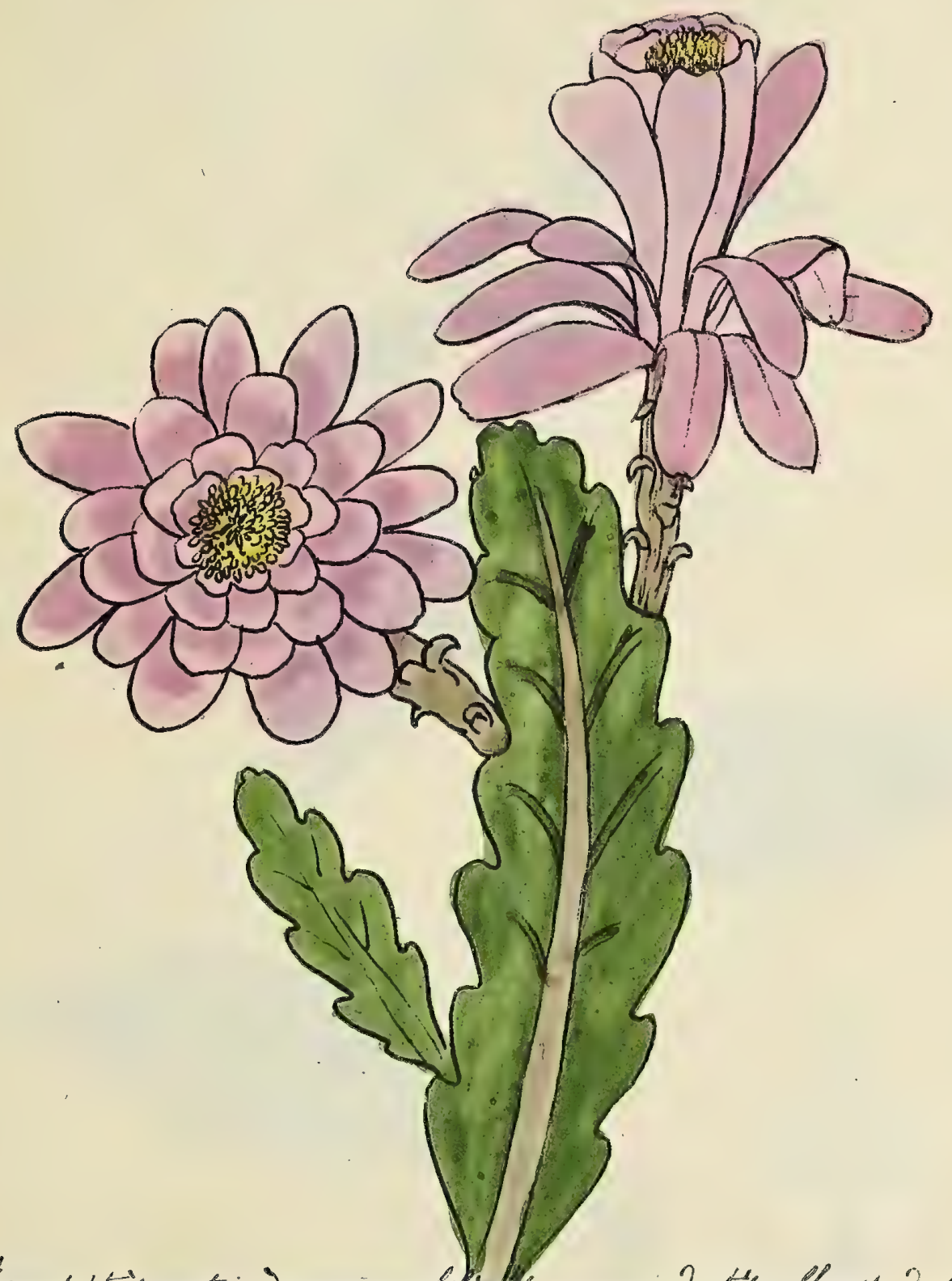

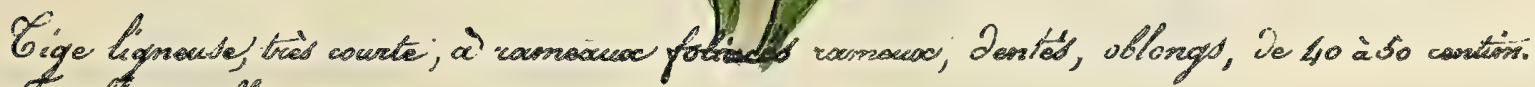
tracitad nuets.

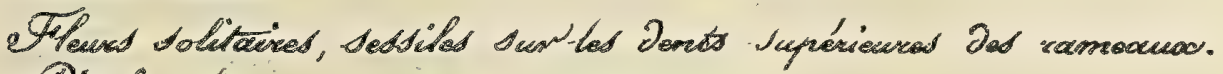

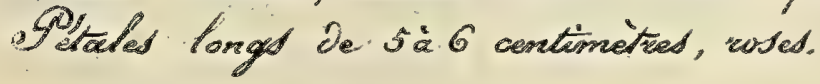

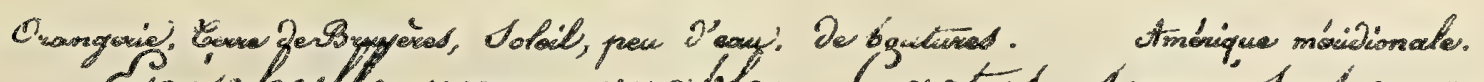

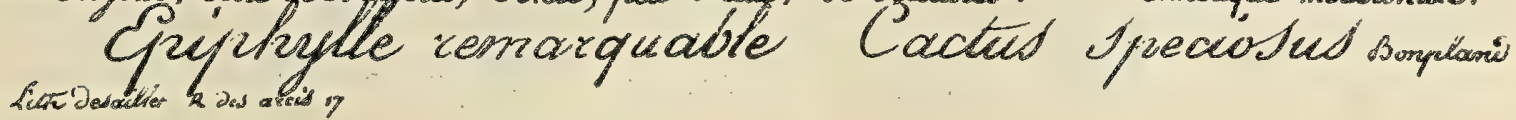




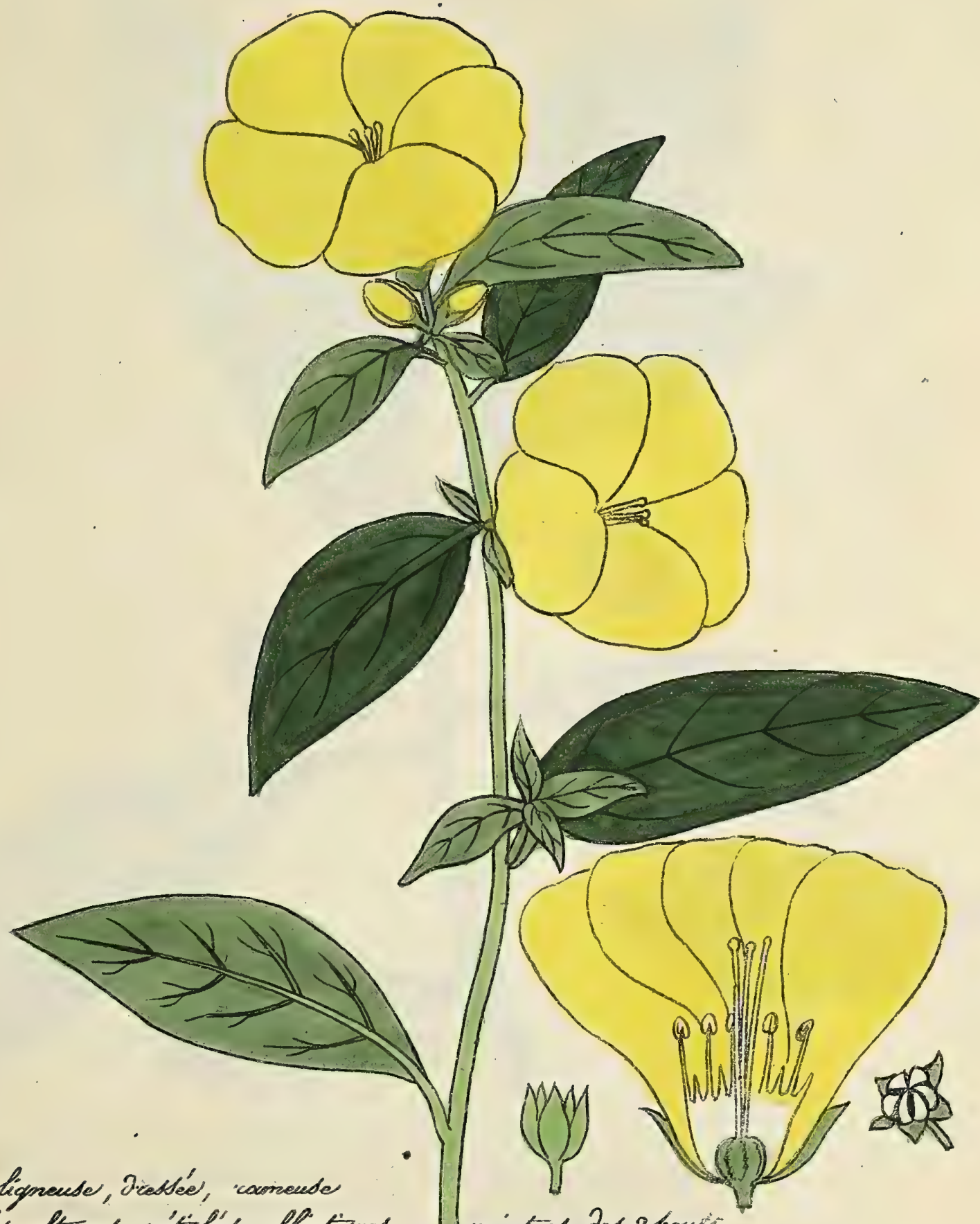

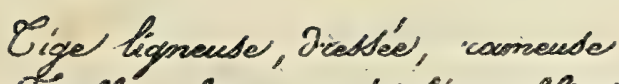

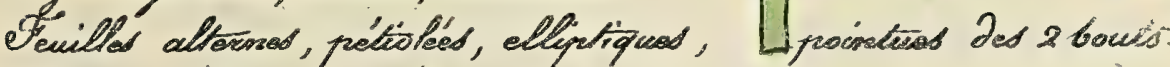

Treurs axillaines, à piodoncule tiés court Sotalas jousced, o styplad.

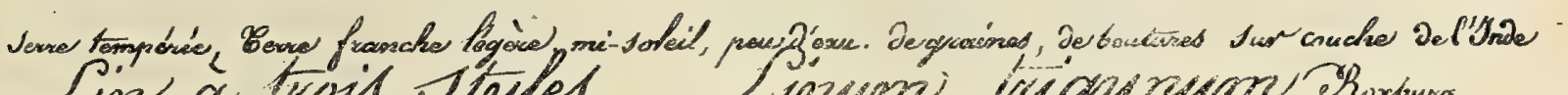

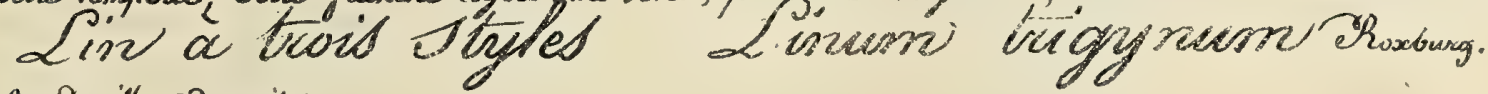

fas Desacillet, 2 Jas arcis 7 


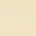




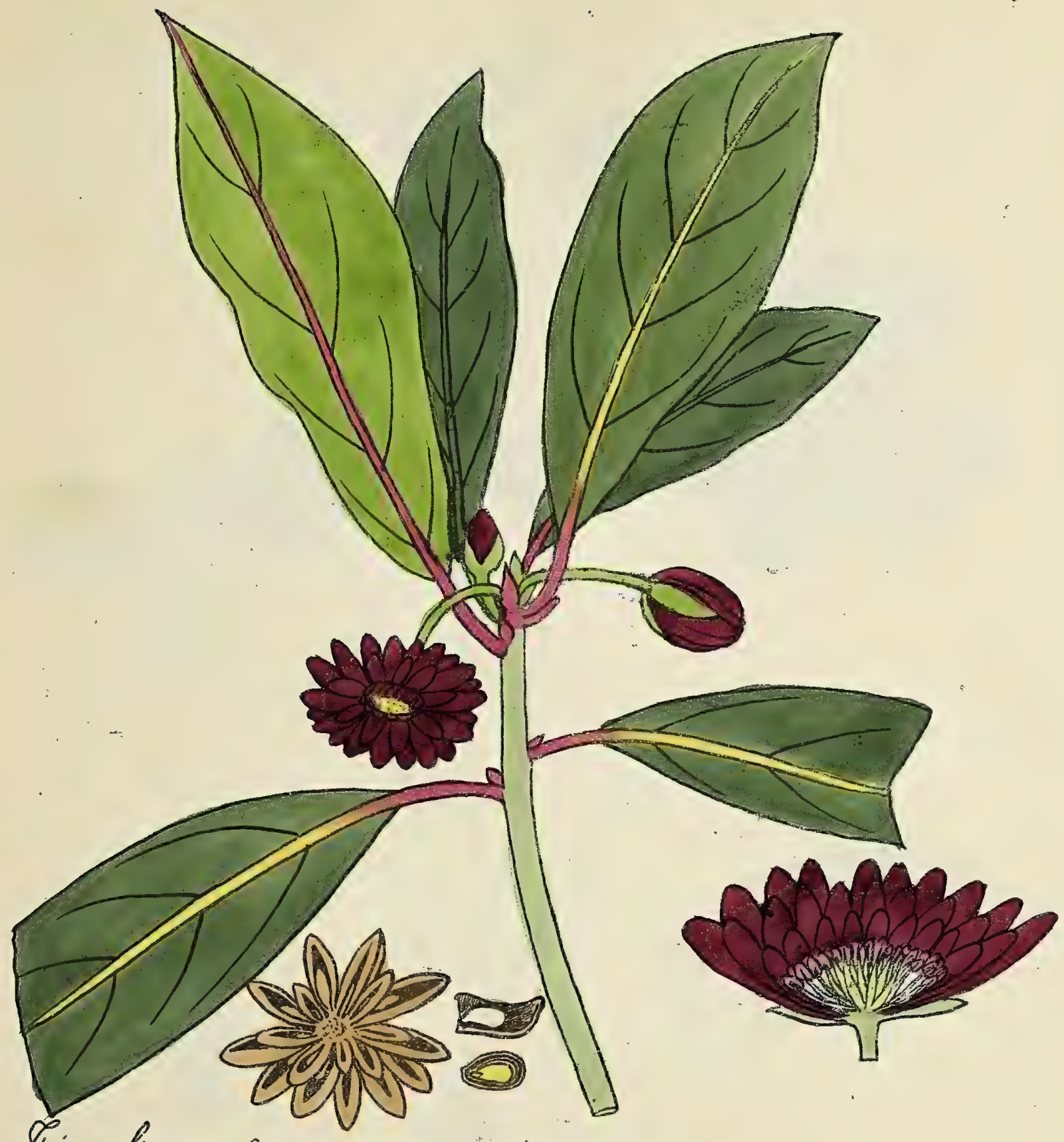

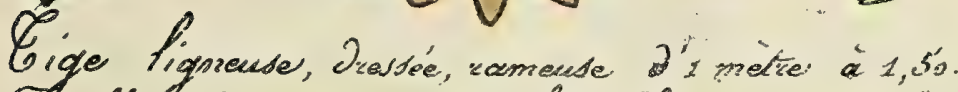

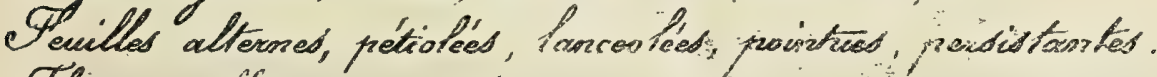

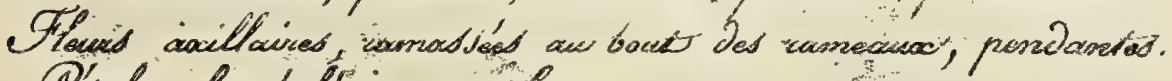
Petales lancéotes, cougeintruen.

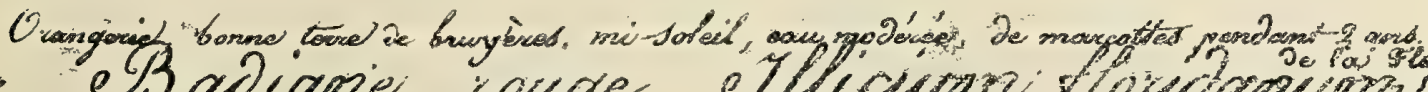

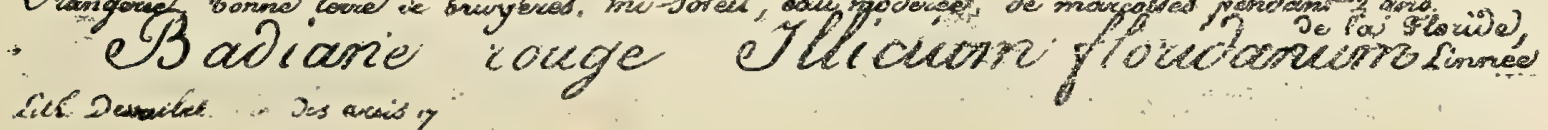




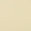




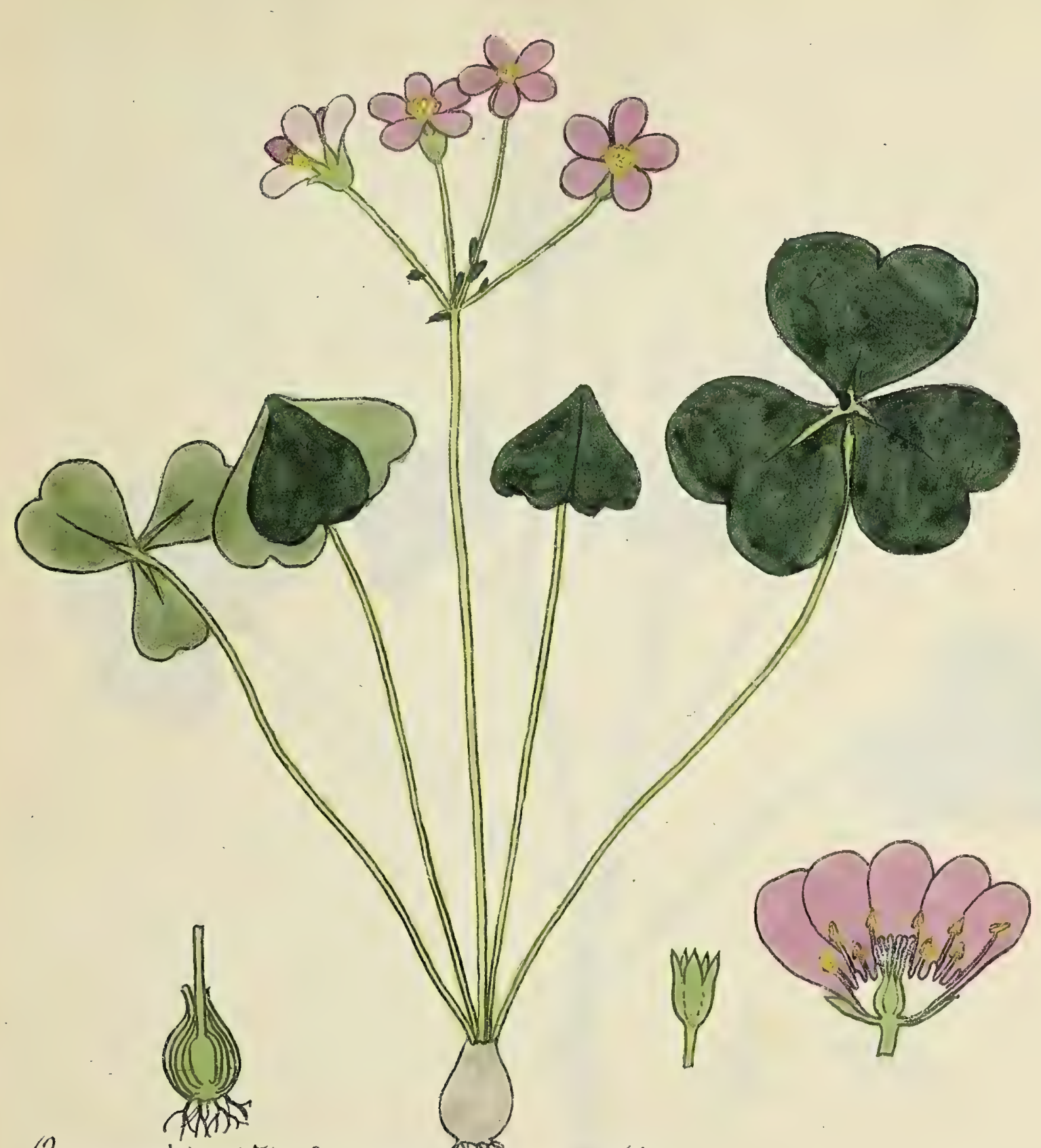

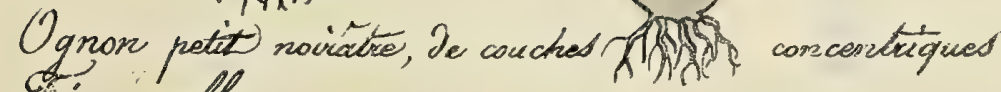
Cige nulle

Teuithes radicades, à lorg pétiole, à zjolived obcowiés, glabued. hampe dépassant les gaulles, terminne par une ombellute

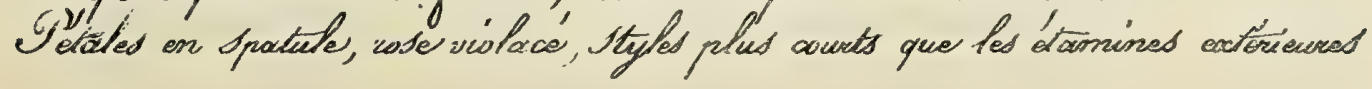

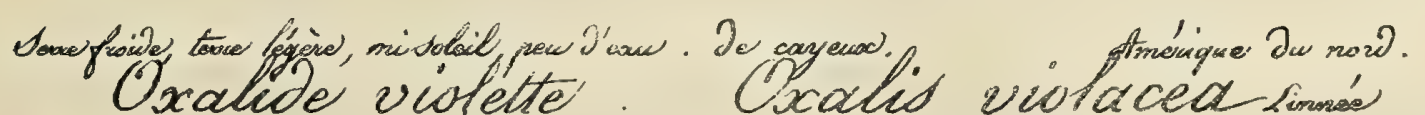

Sitt Jesciffer R Das oureis y 


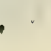




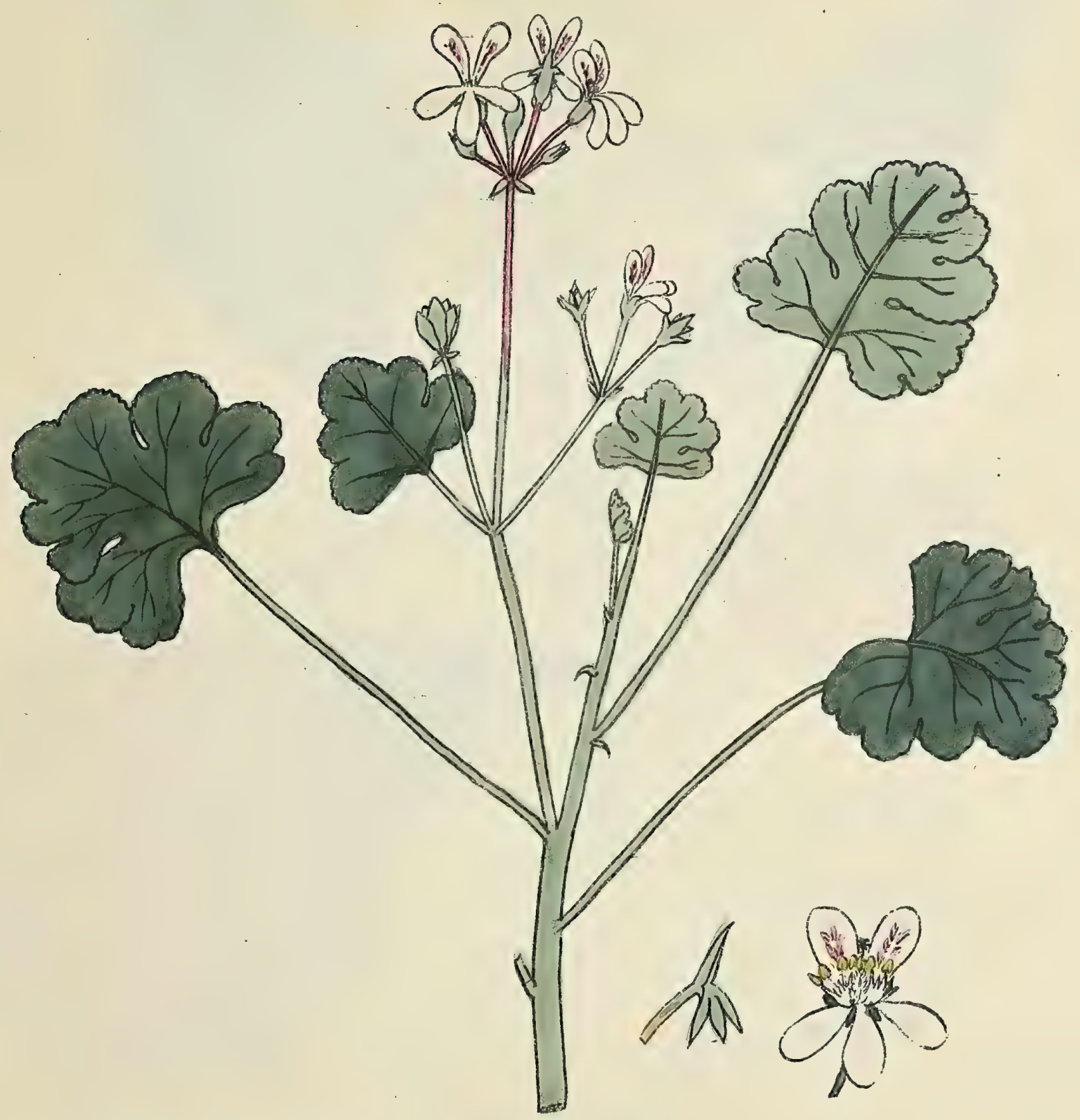

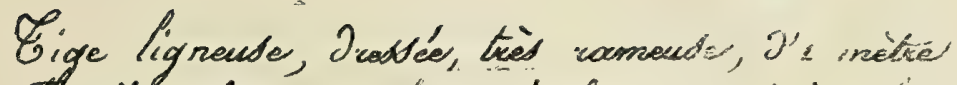

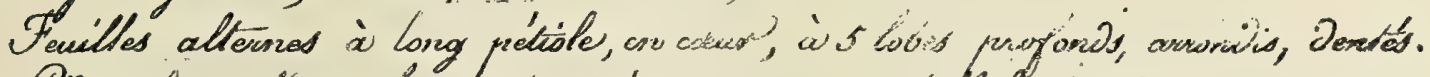

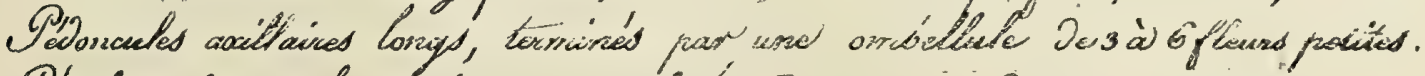

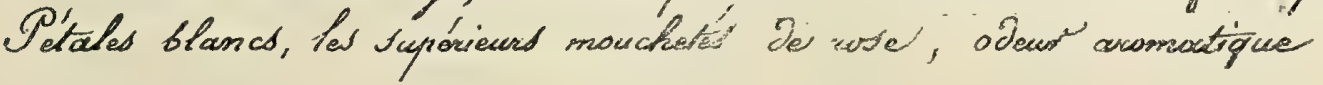

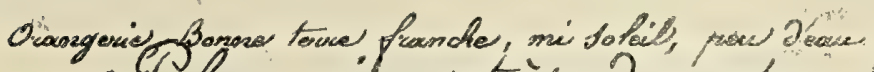

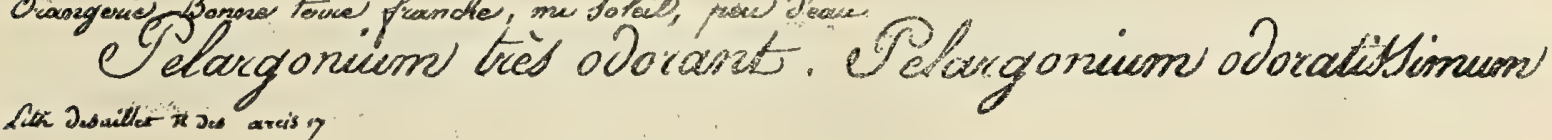




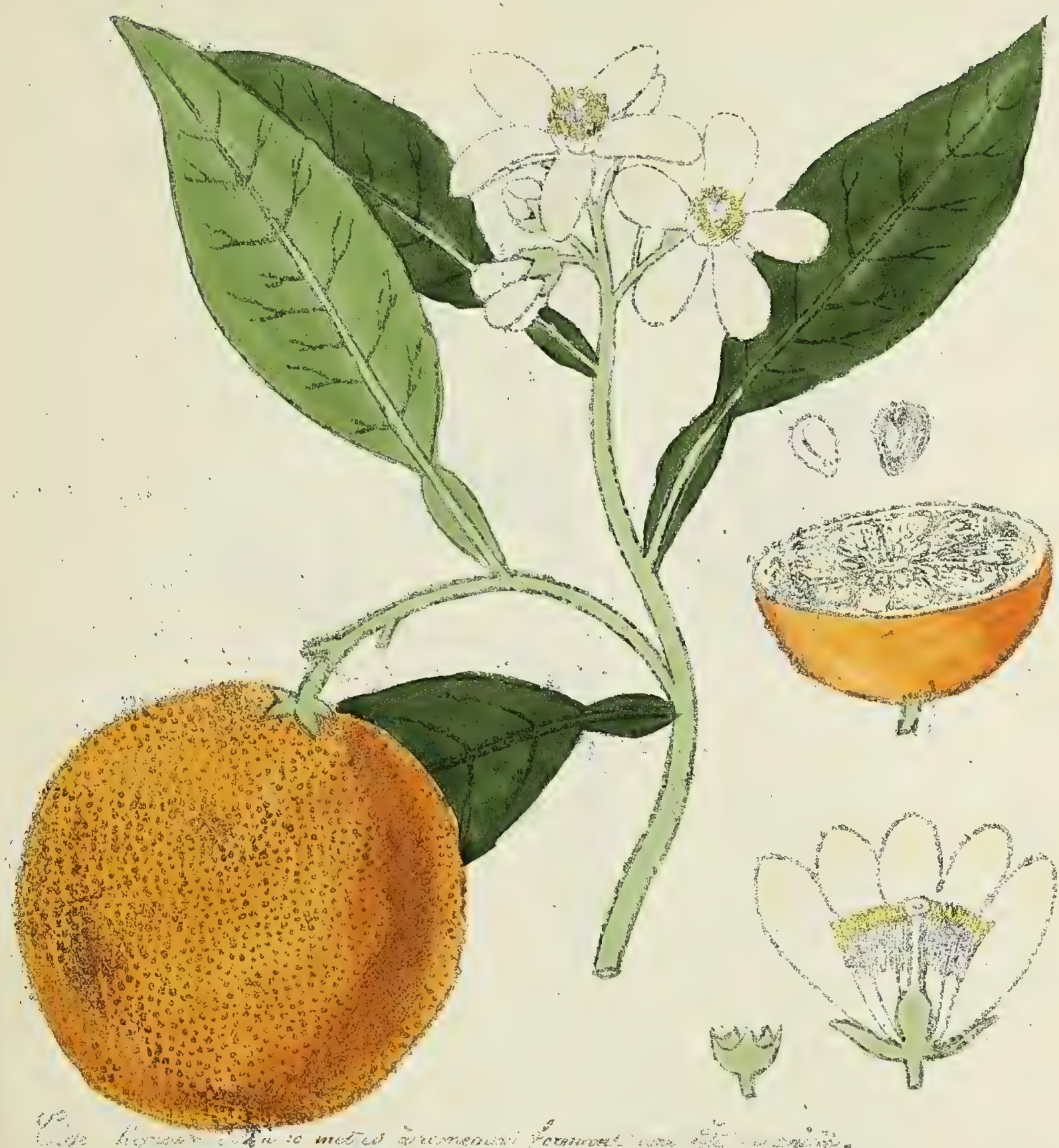

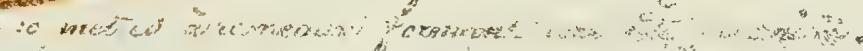

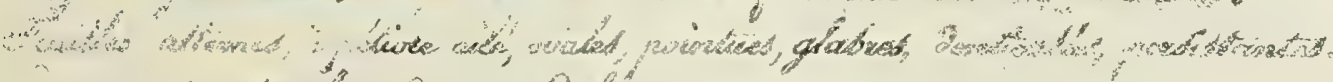

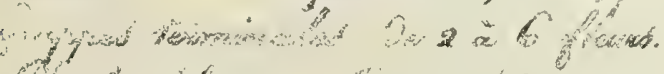

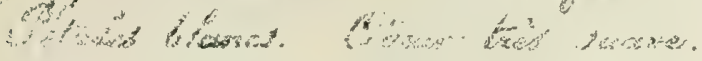

4.

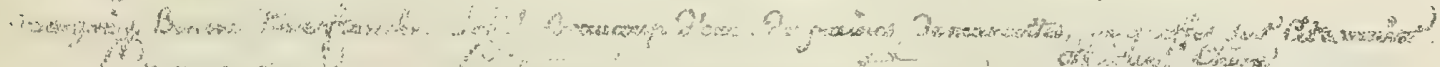

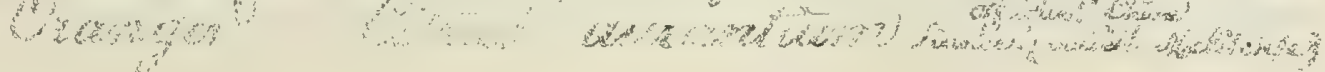





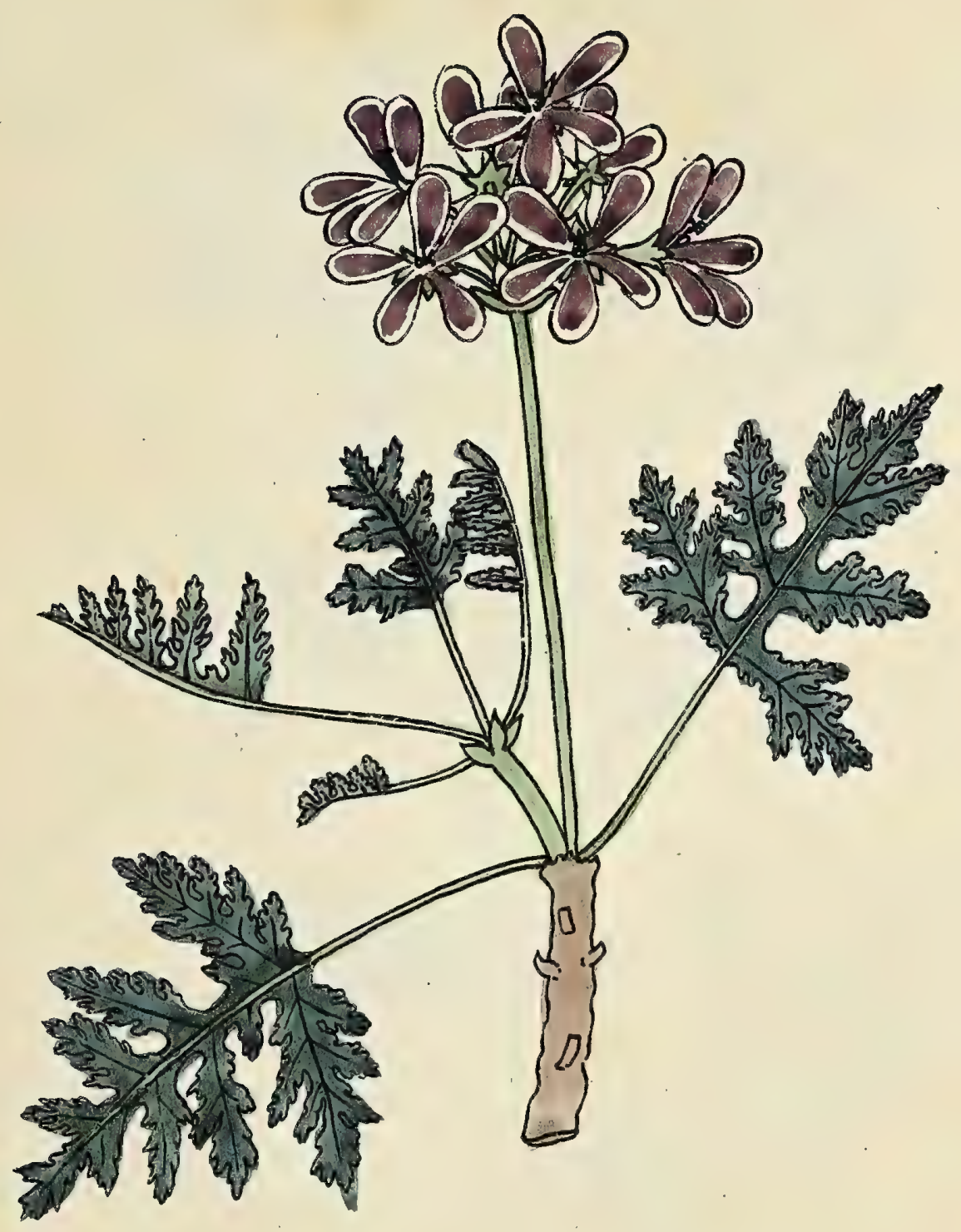

Gige ligrecusc, baste, Drestie, camende:

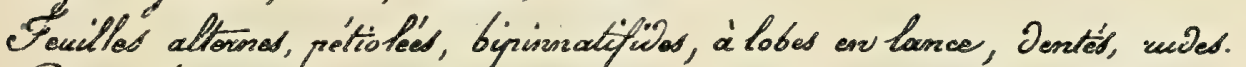

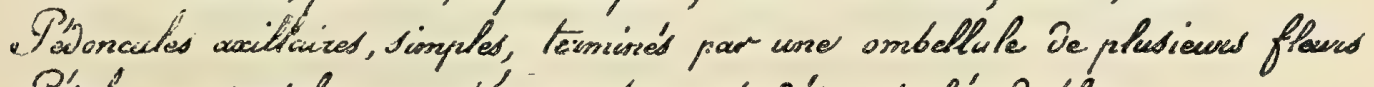

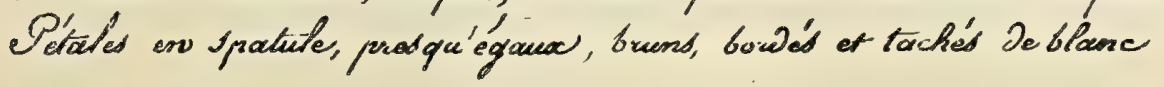

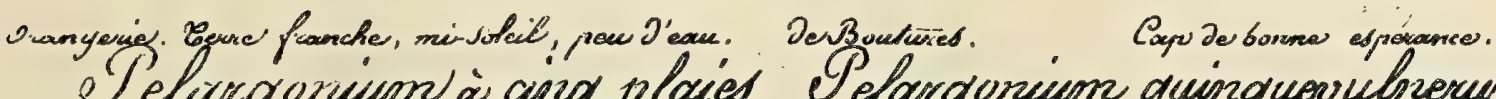
Selivgorium à airg plaies Pelargoniem quinquevulizenon

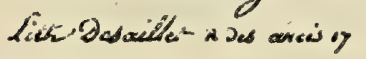





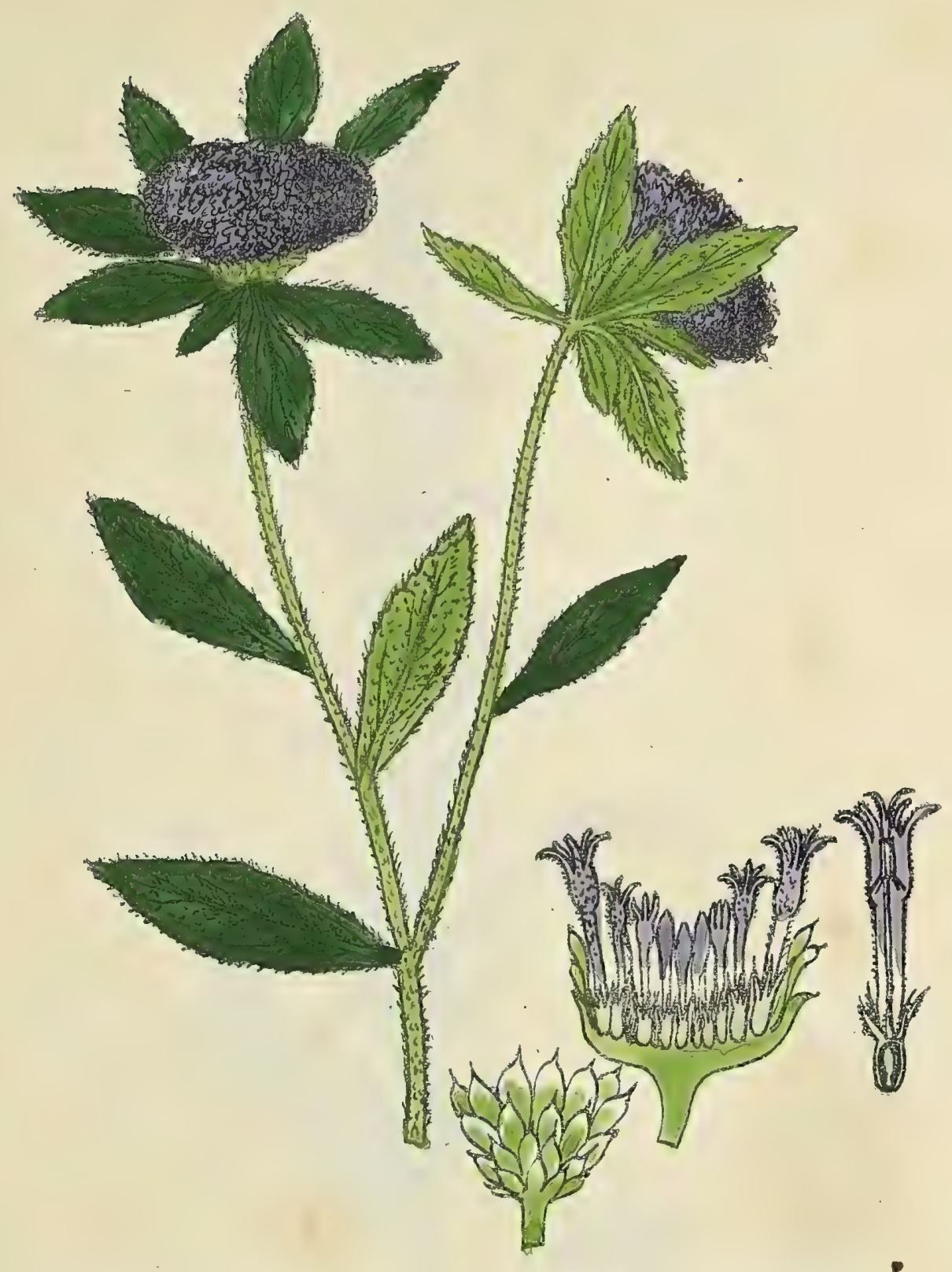

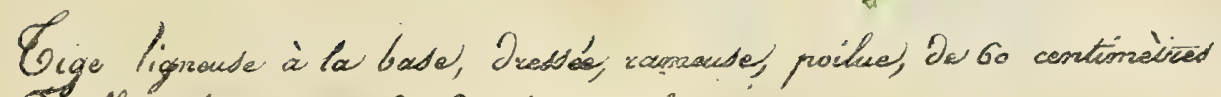

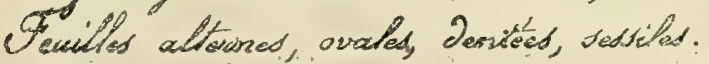

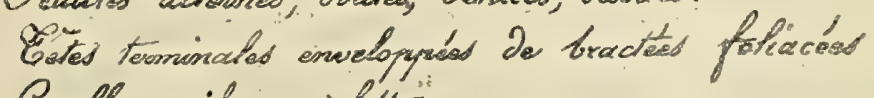
Coroflas poilusas vislatises

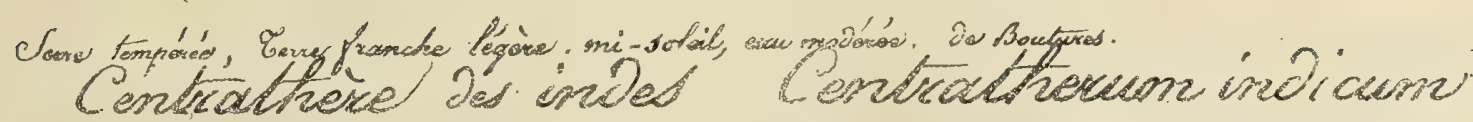

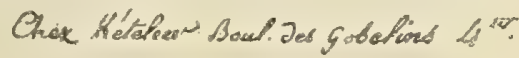


- 


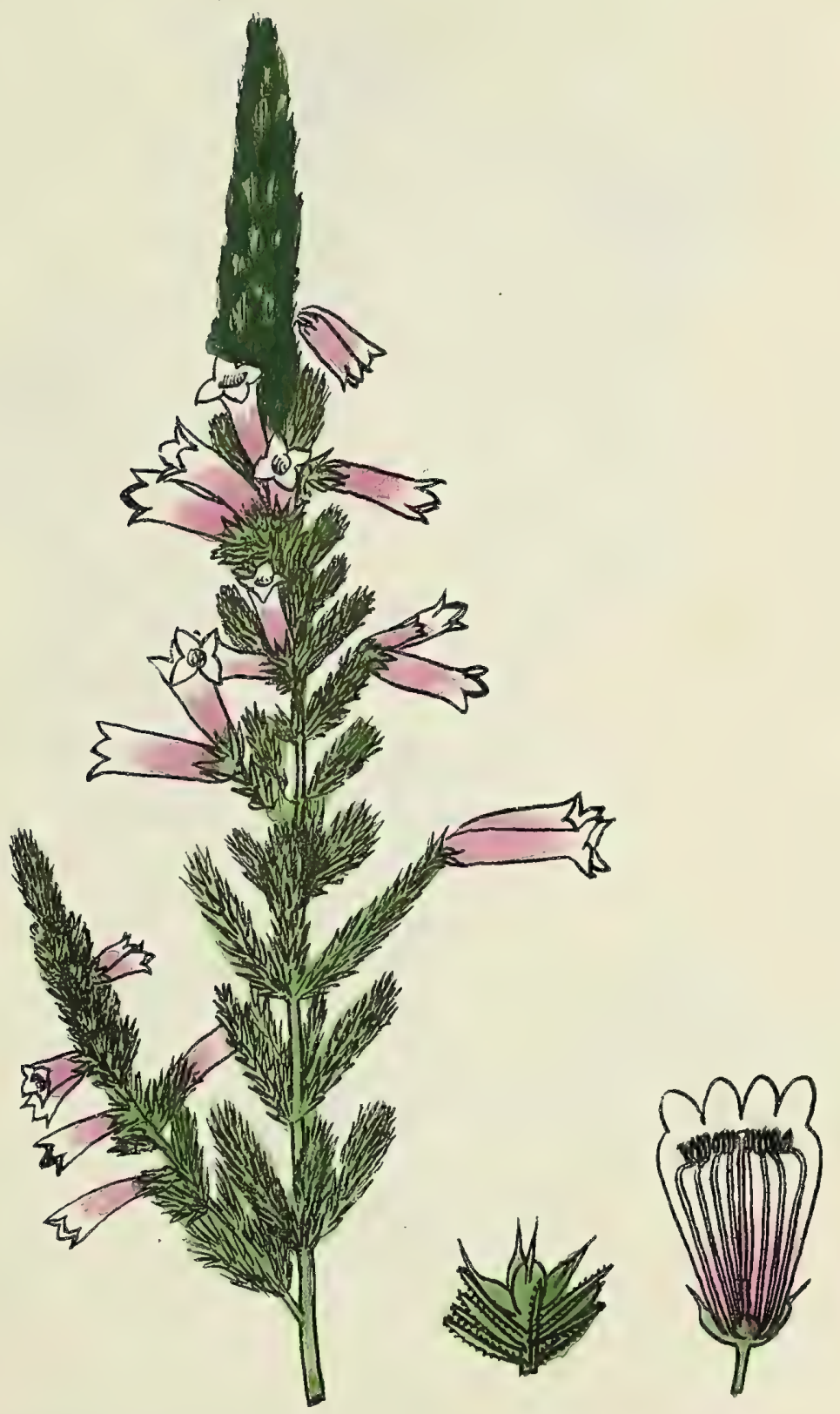

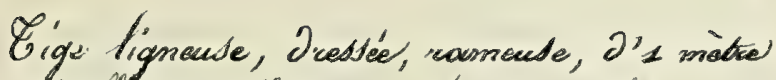

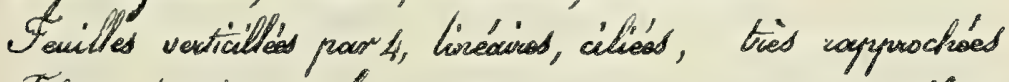

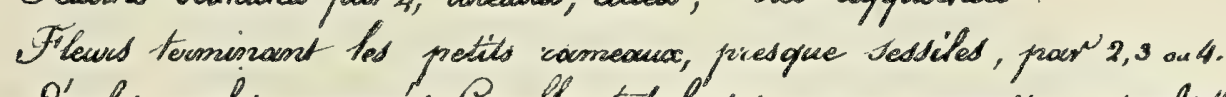

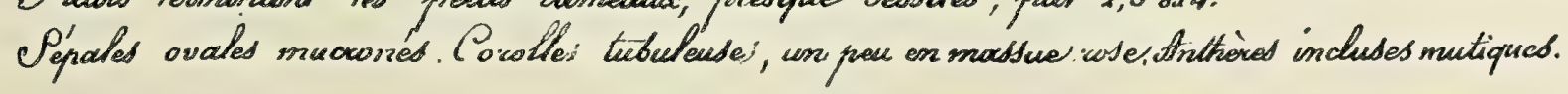

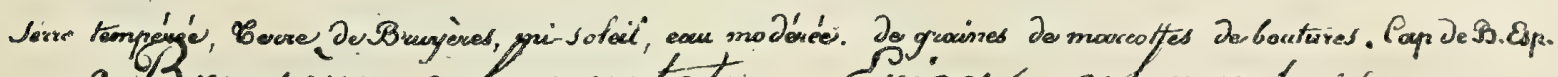

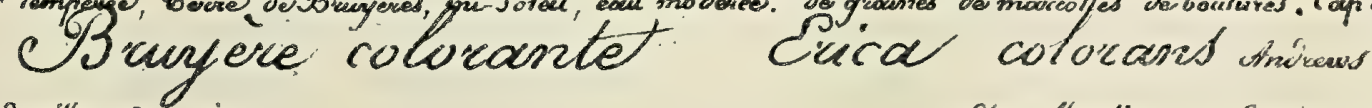

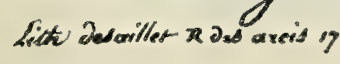
Cher Aboertine kue Jas bourguigrondsy 
. 


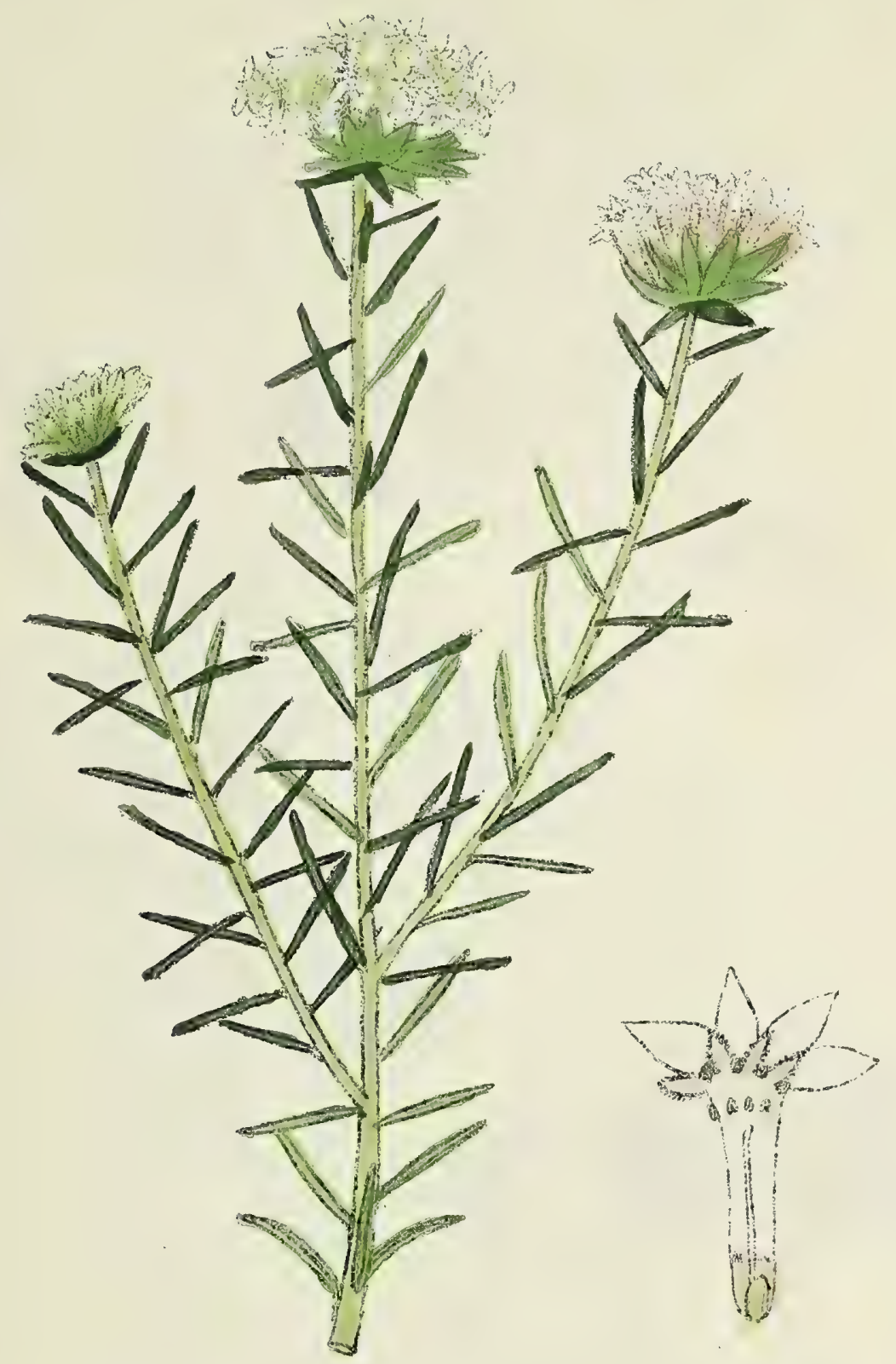

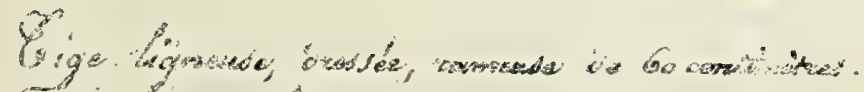

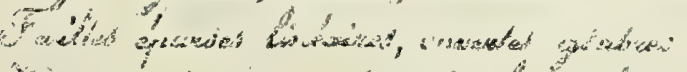

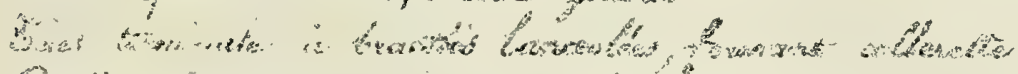

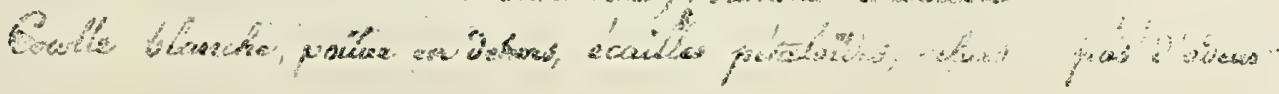

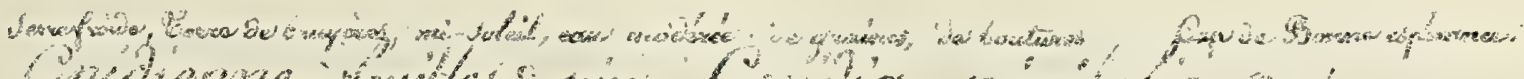

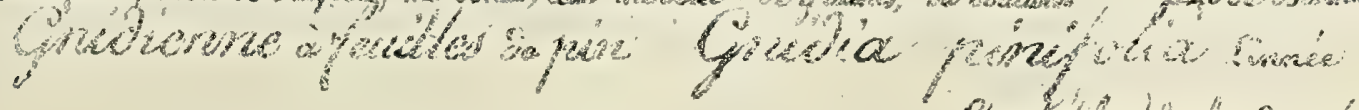

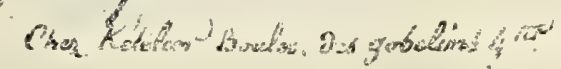





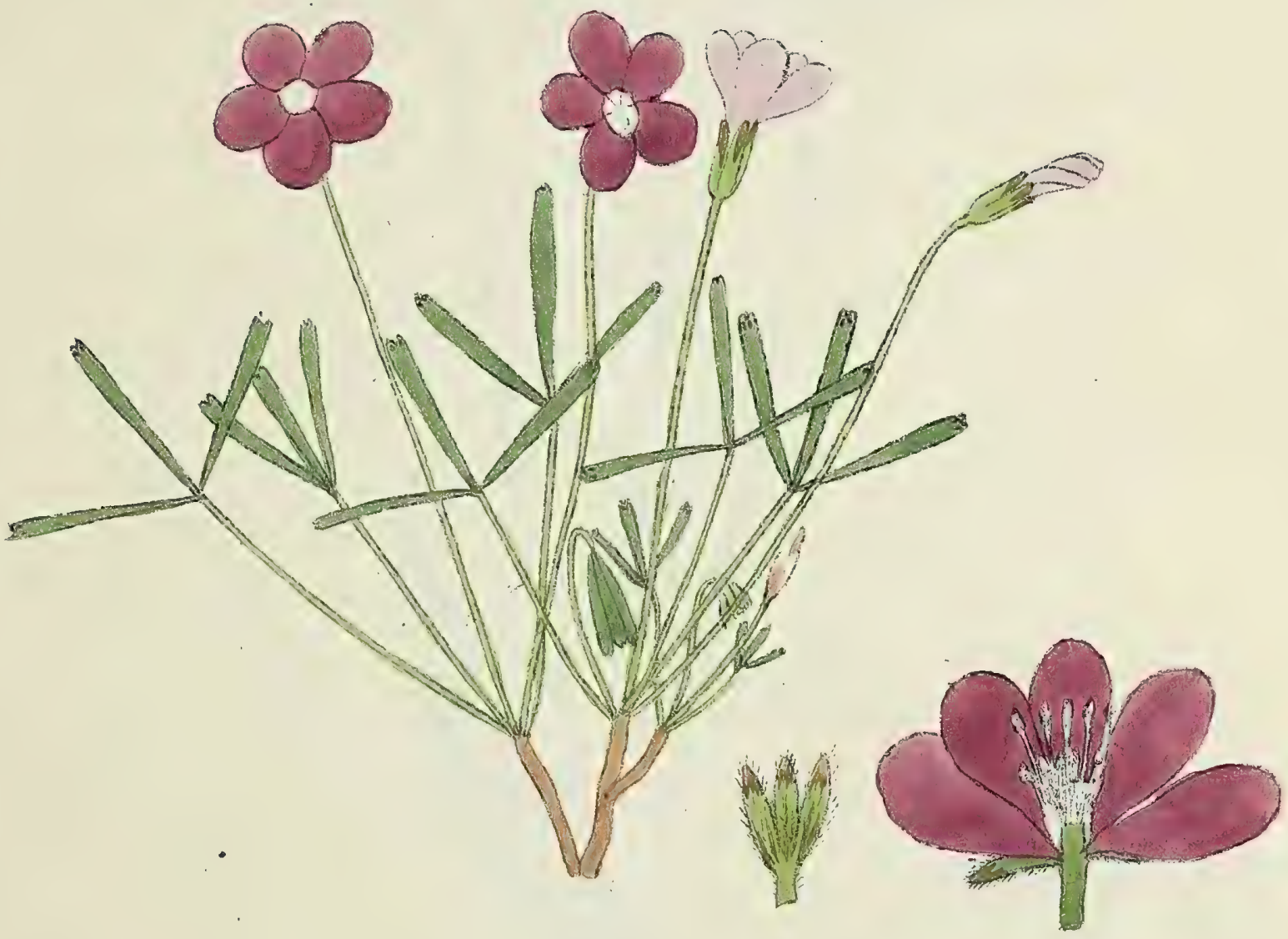

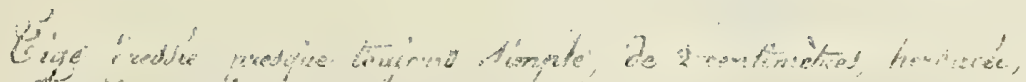

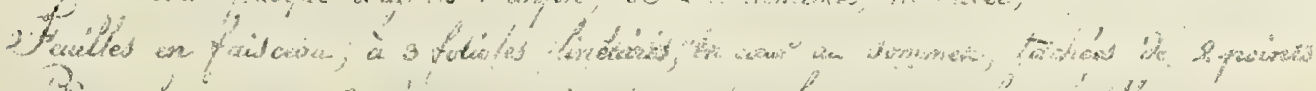

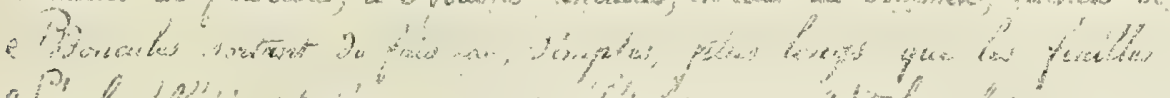

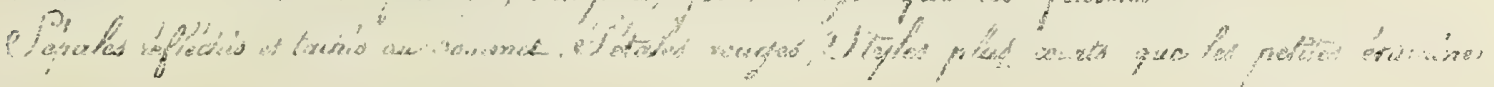

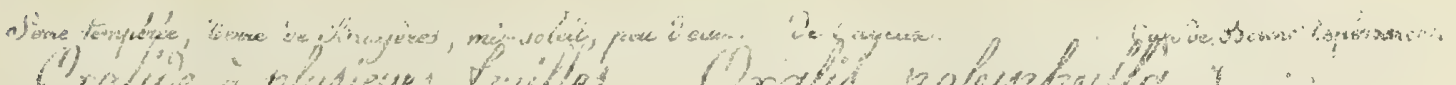

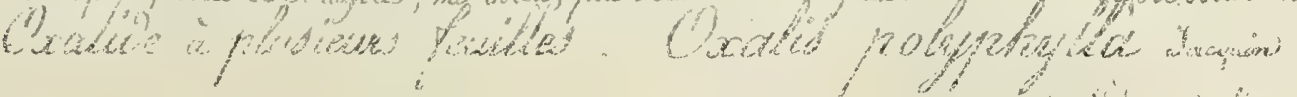





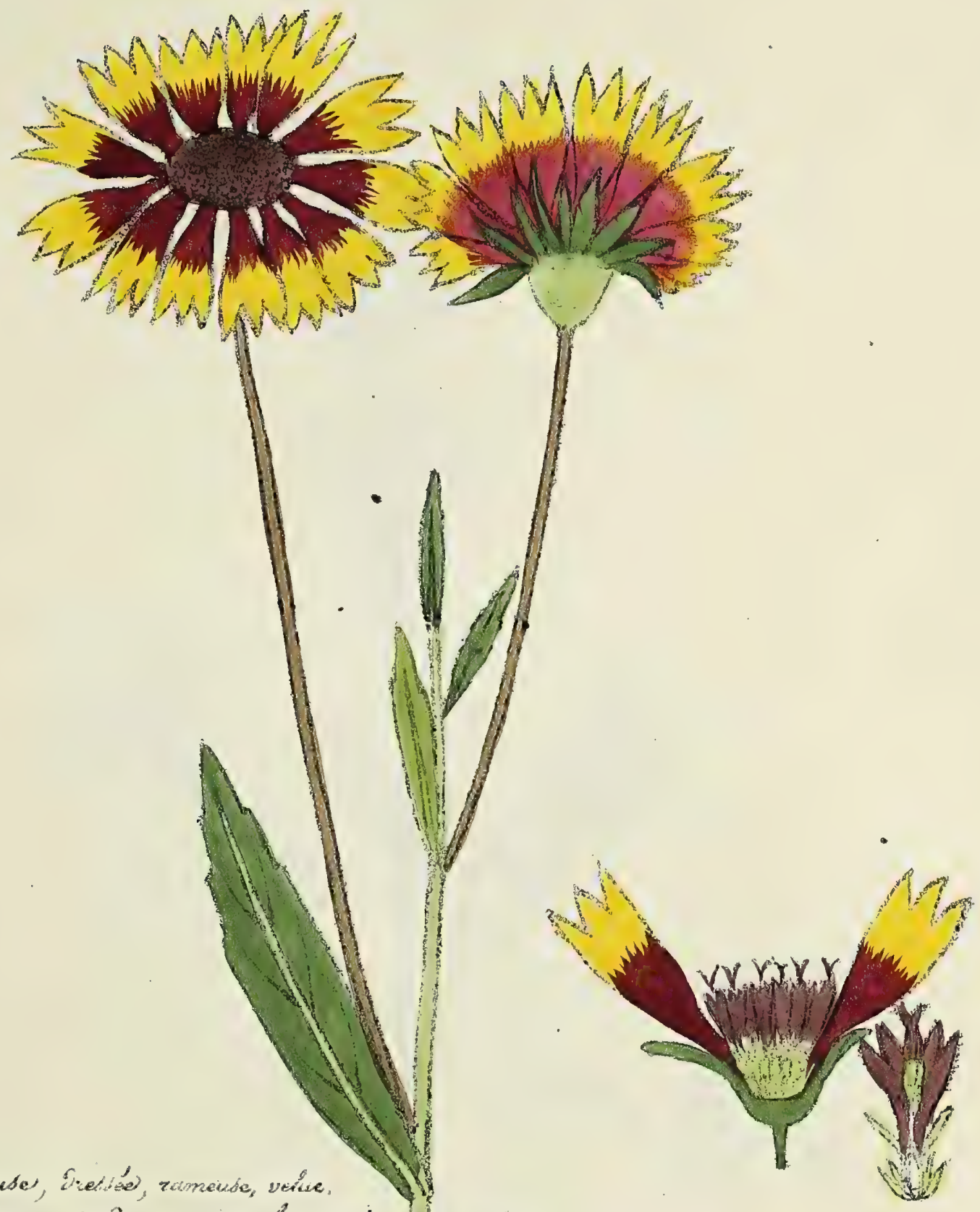

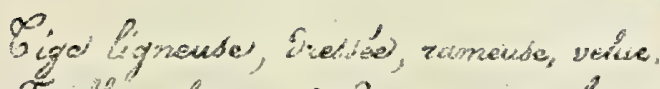

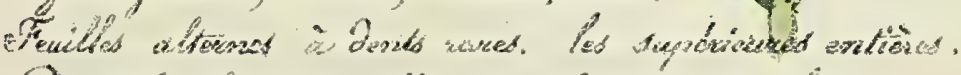

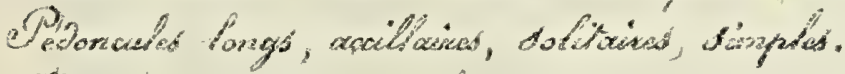

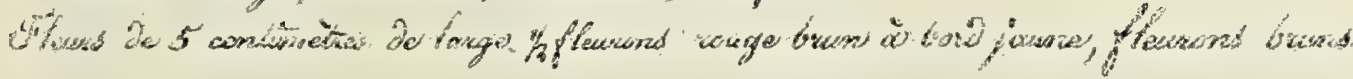

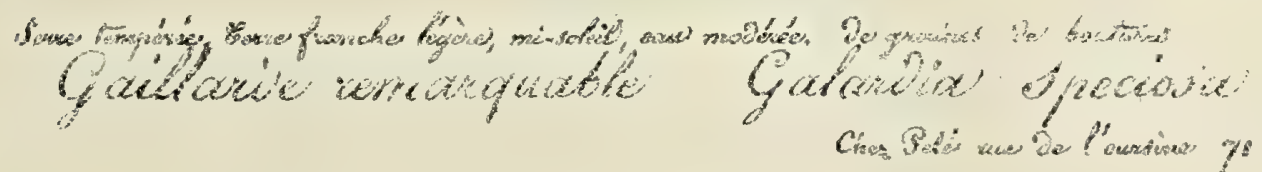





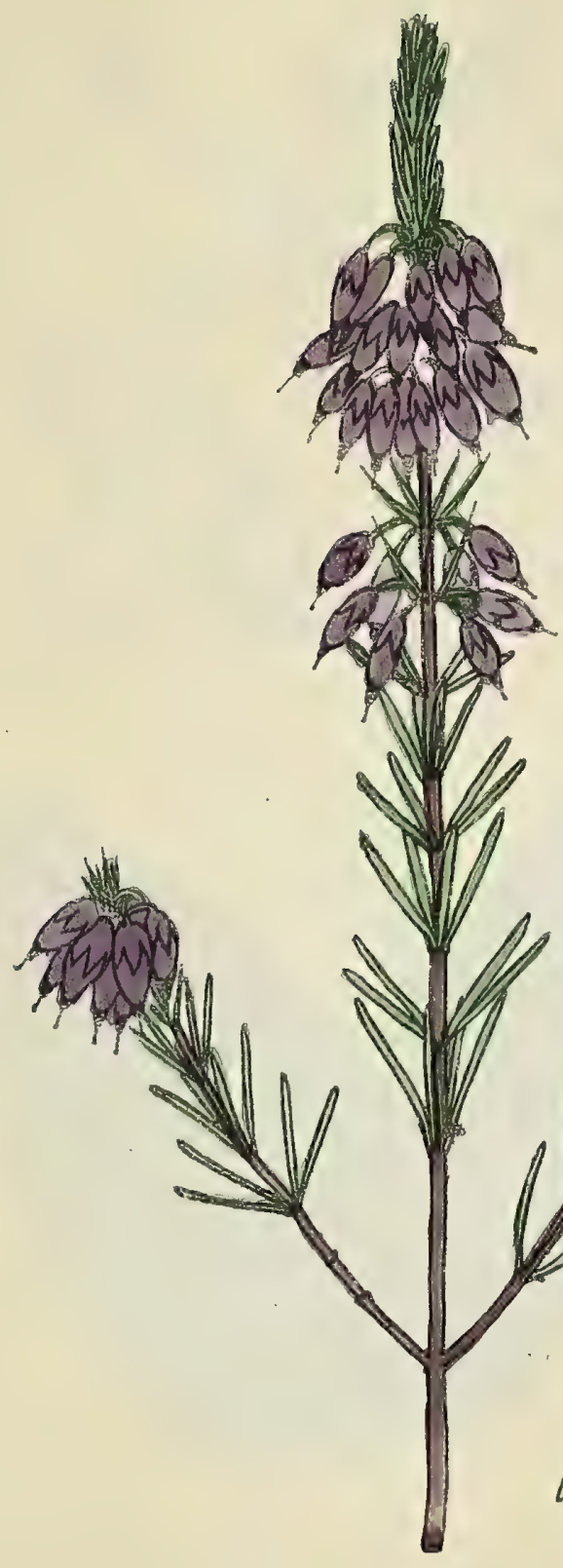

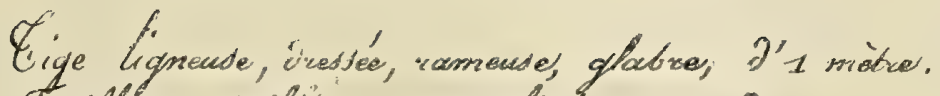

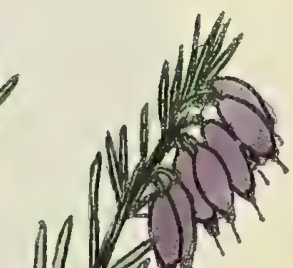

Fevilled verticiltés parly, fineaires, racides.

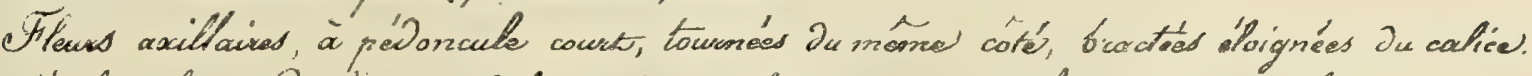

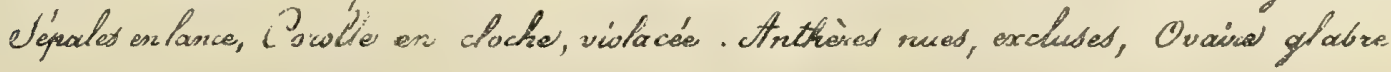

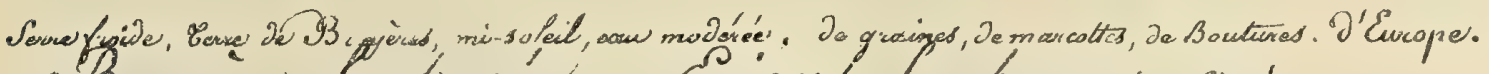

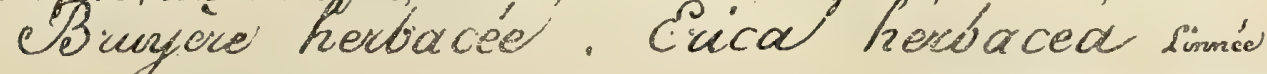

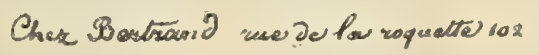




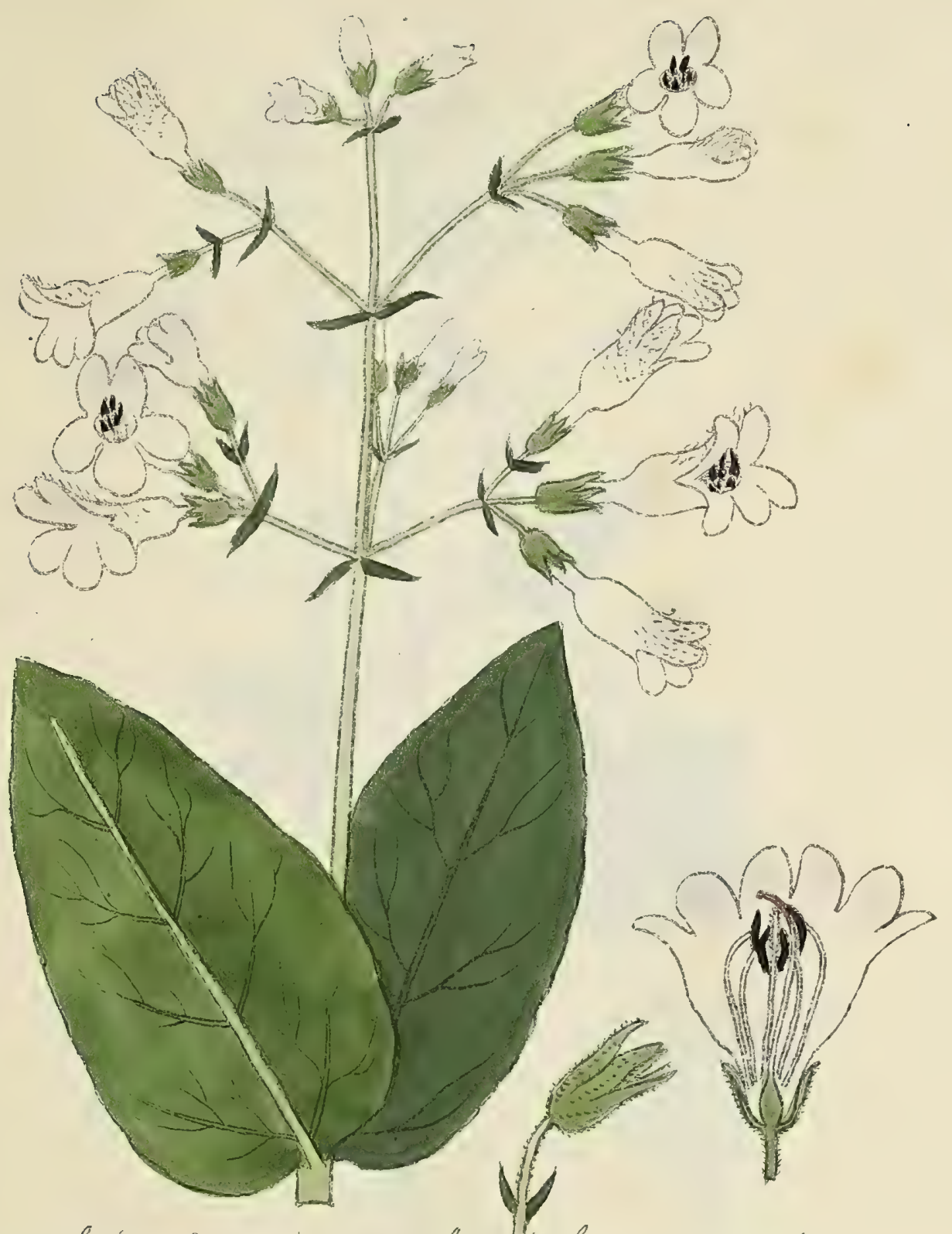

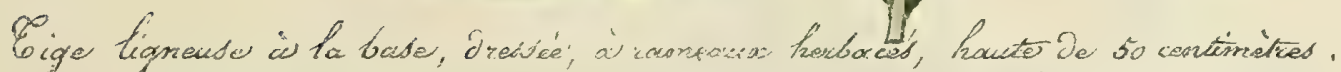

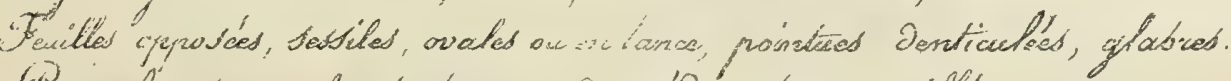

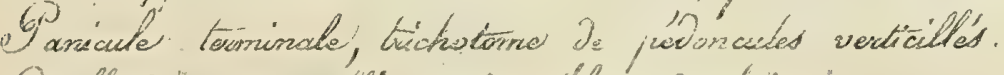

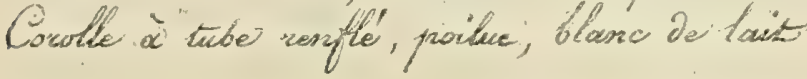

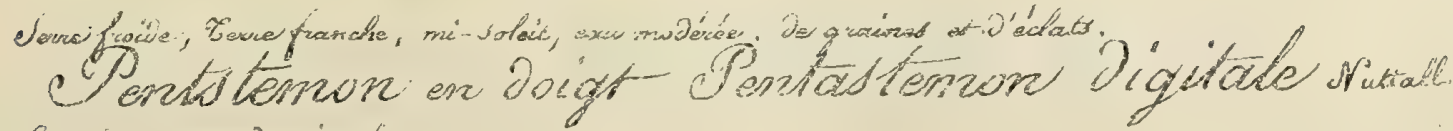
Sibs. 


$$
\text { w }
$$




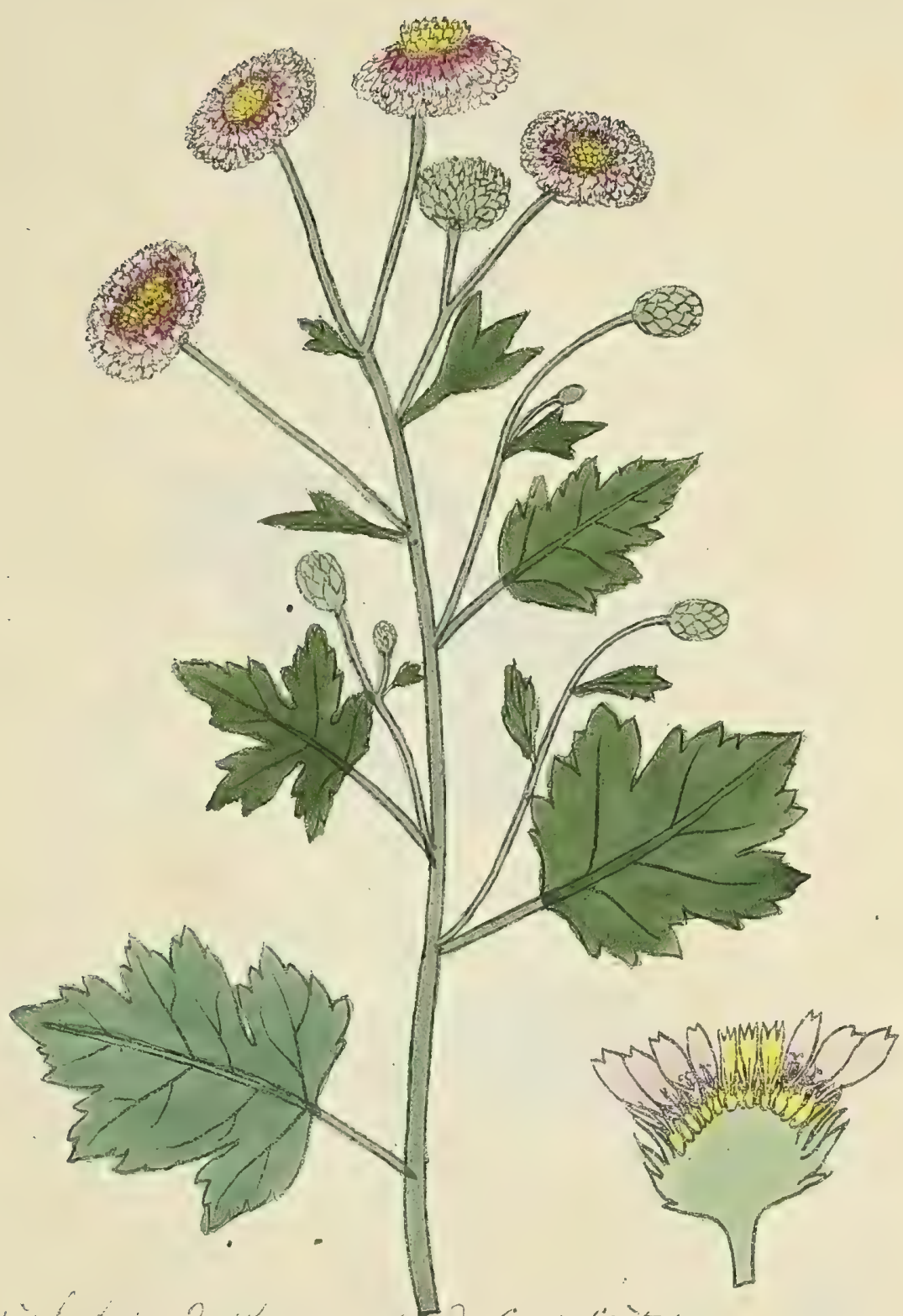

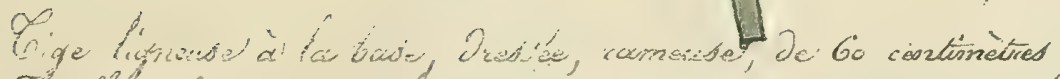

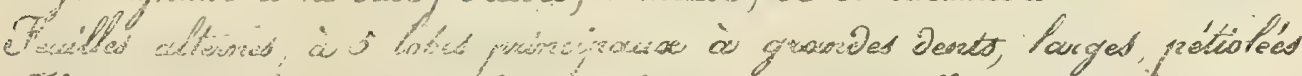

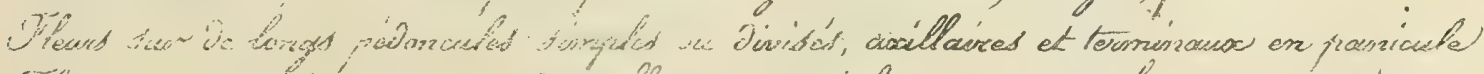

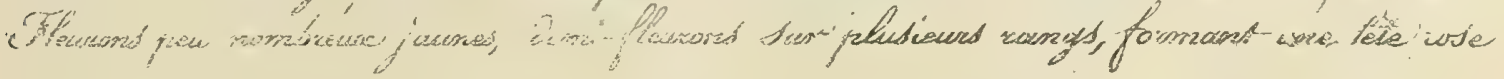

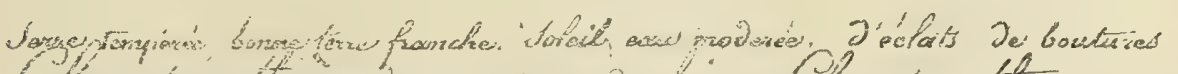

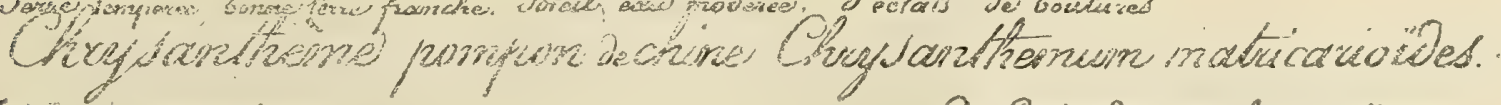

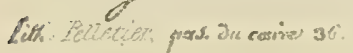

Ohez Berticand Rusdel fa roquattes rox. 
$-$ 


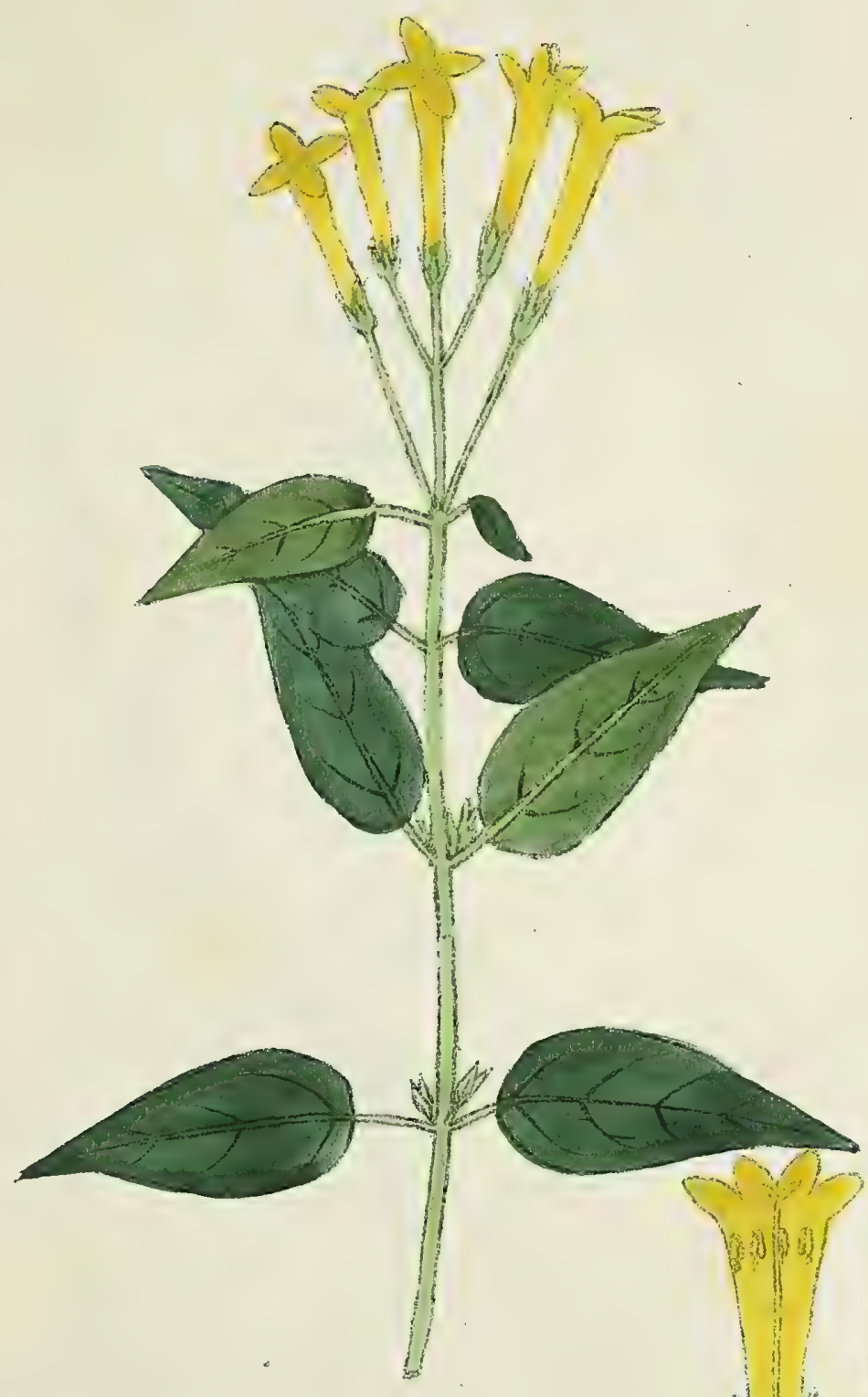

(3) A

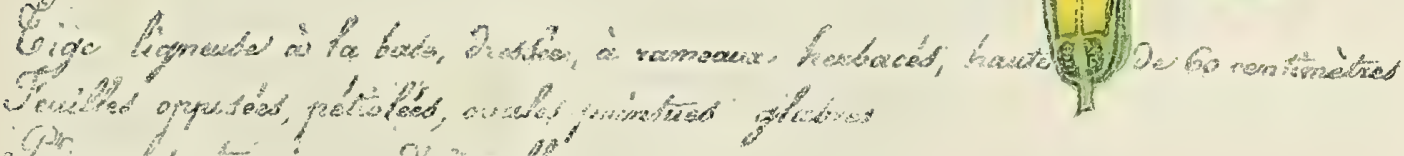

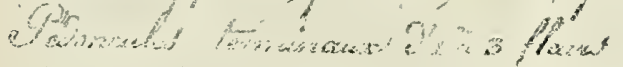

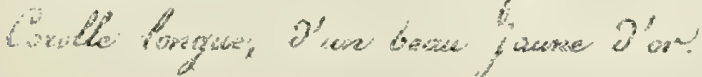

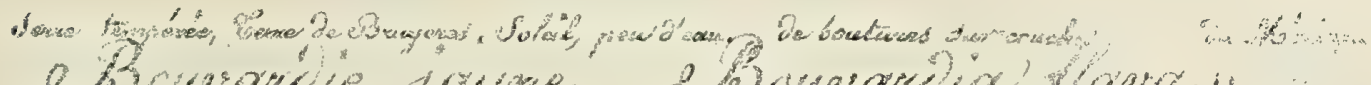

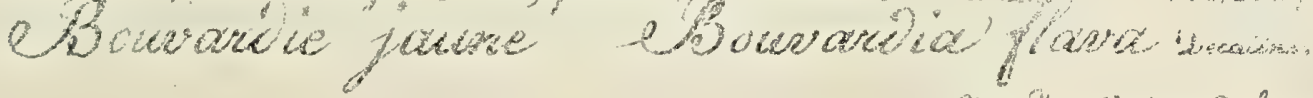

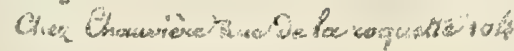




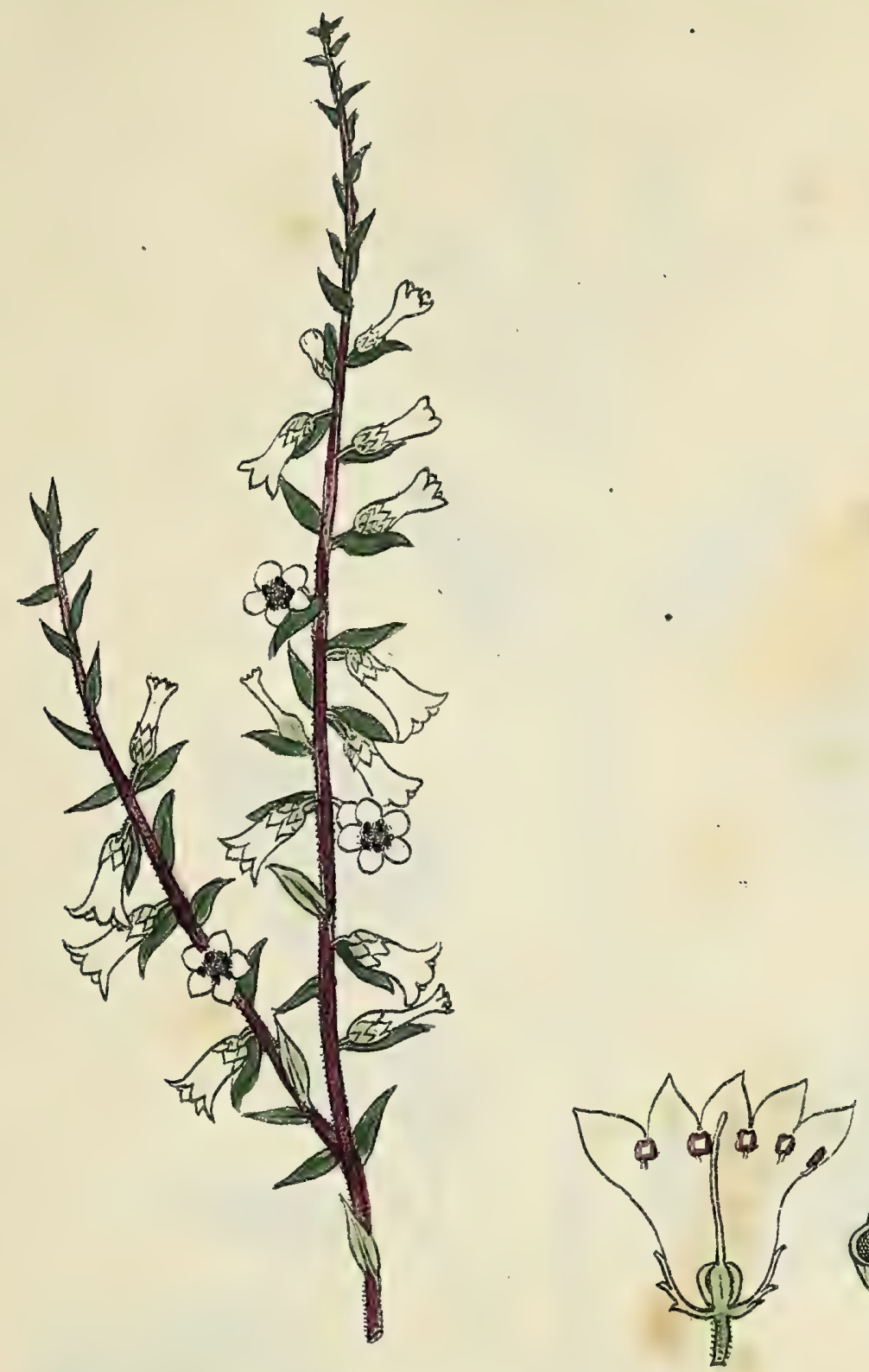

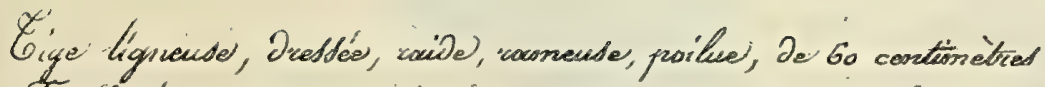

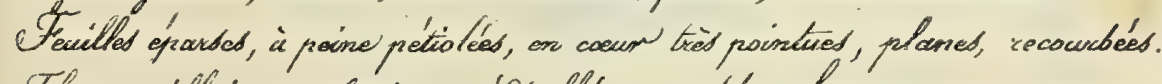

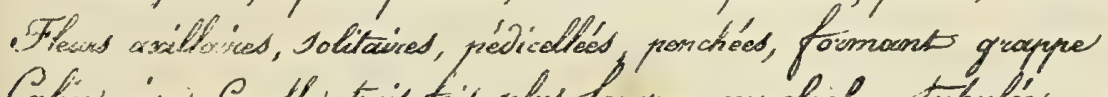

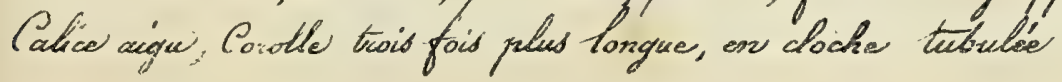

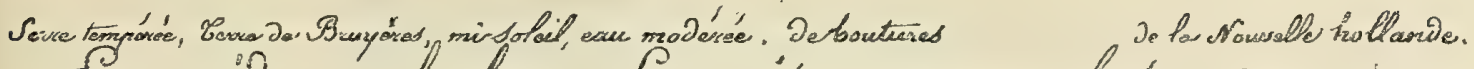
Gracuive on cloche. Facuid camparmulata Losiges.

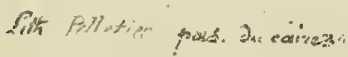





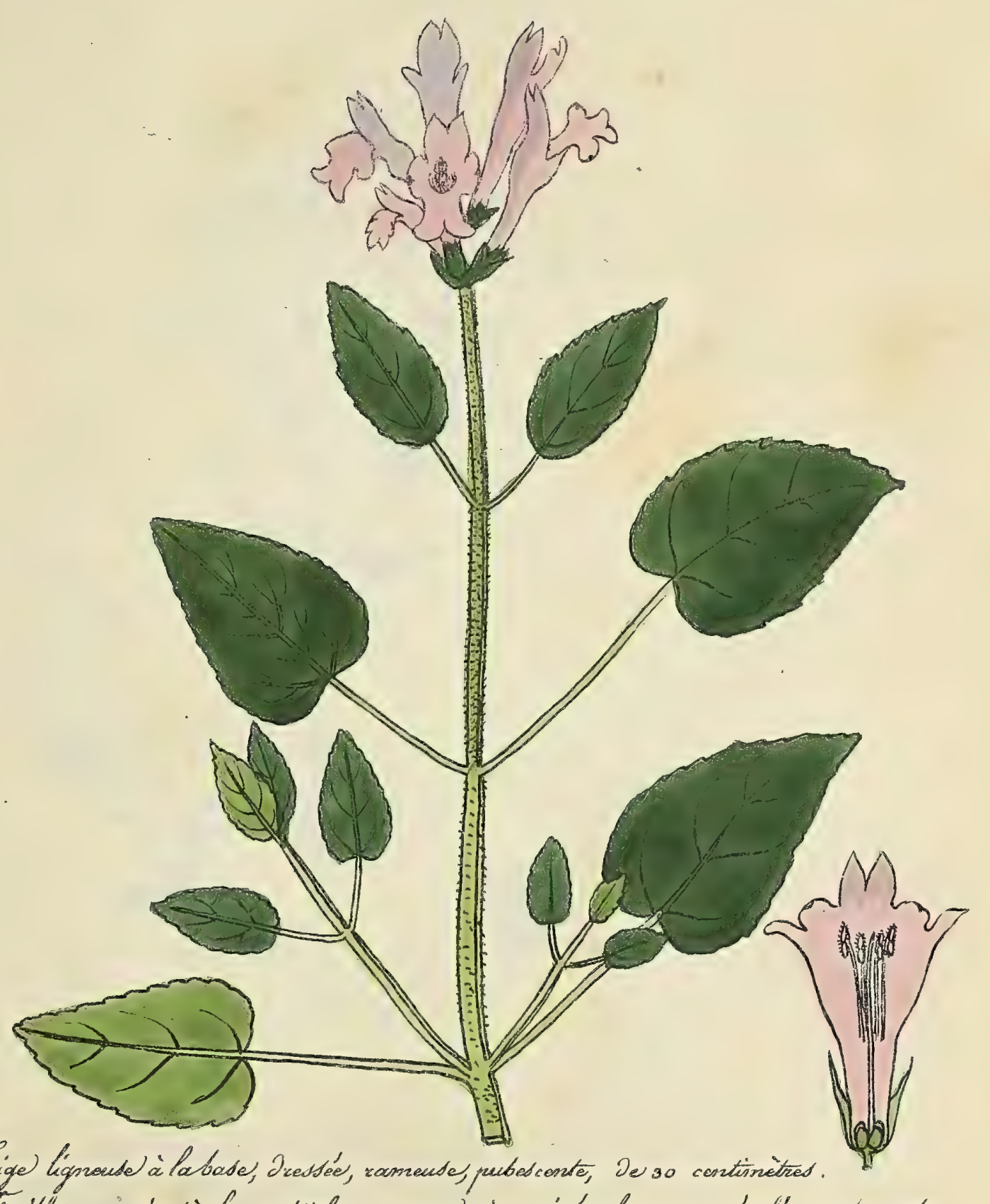

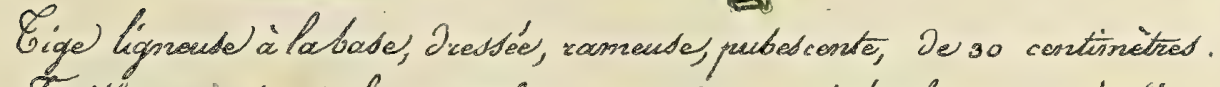

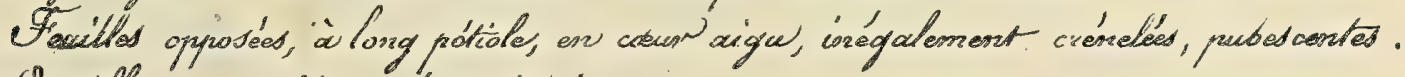

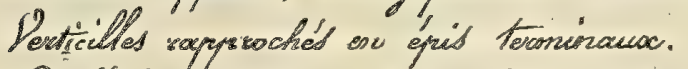

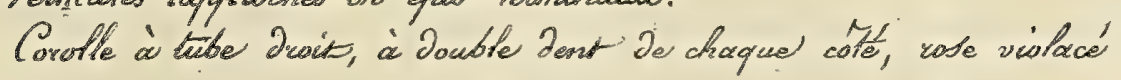

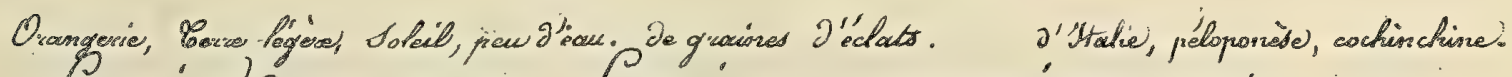
Lamions ju gargans. Samuim garganicums Simóé Sim.

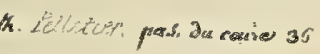




\section{.}




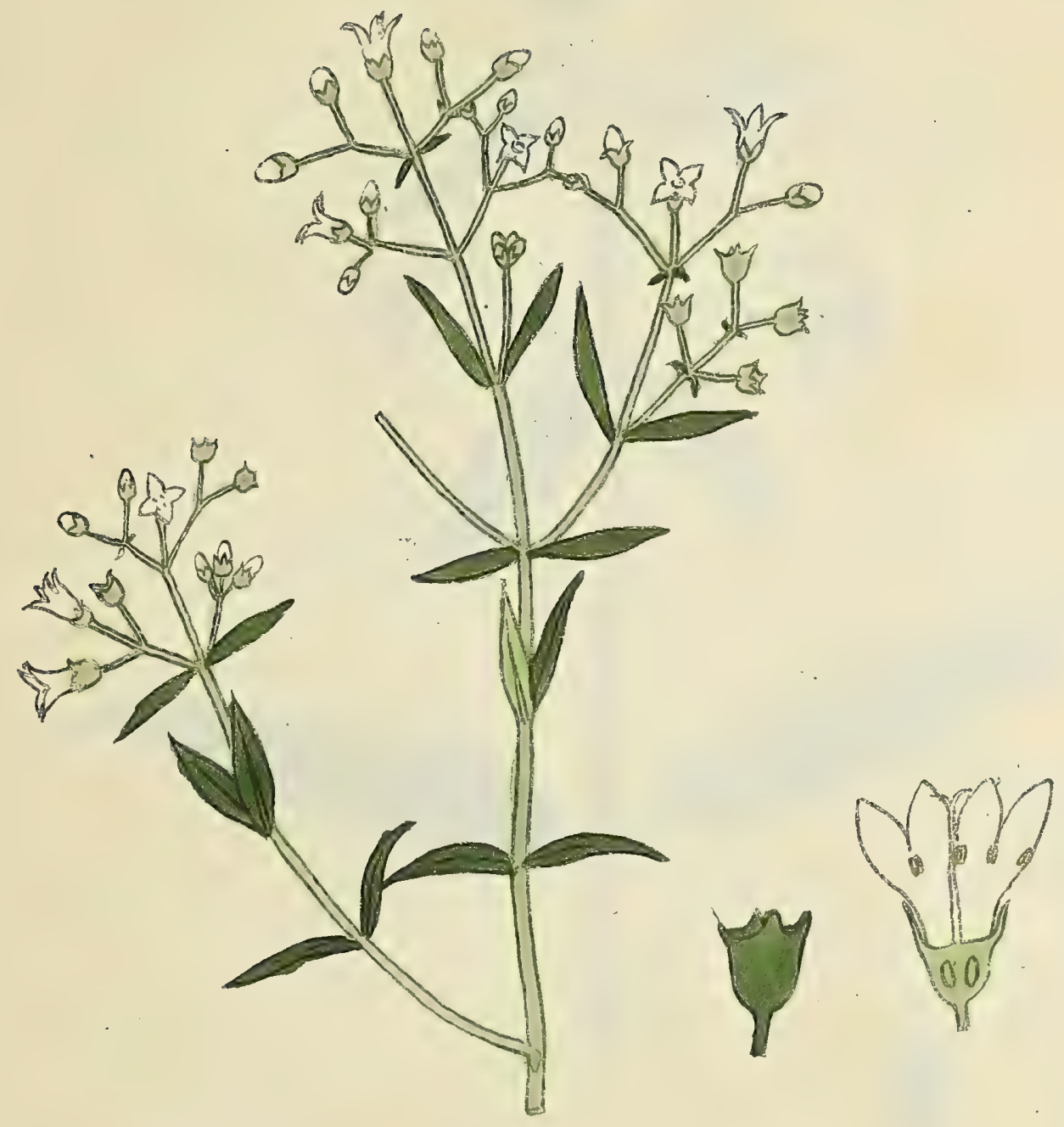

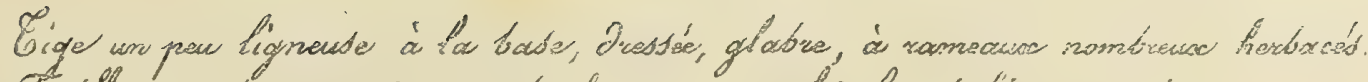

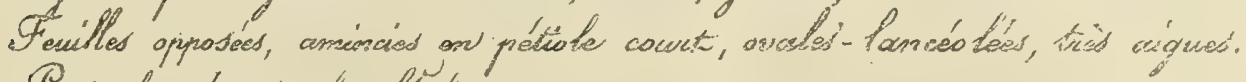
Panicula torminate facho.

Corolle btanche

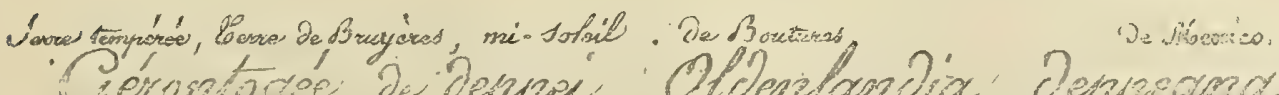

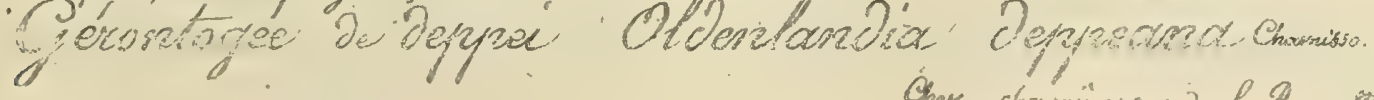

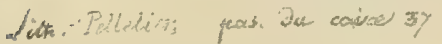





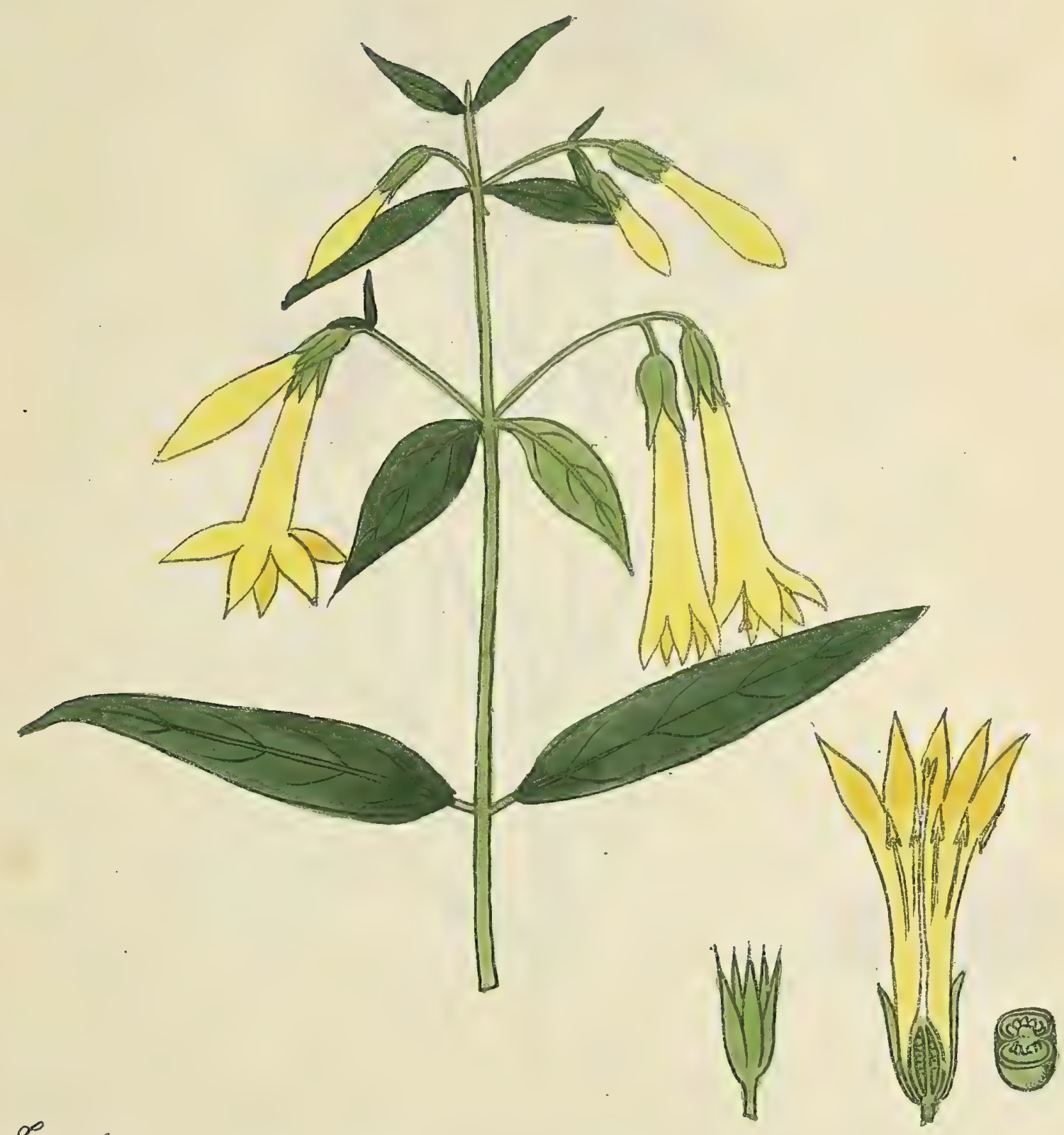

- Eige figneuse à la babe, Dredsce, vamense, D's màtre

Feuilles opprosiés, à sourct pétiole, en fance

Flawes axcillavises sur des pédoncules simples on bifives.

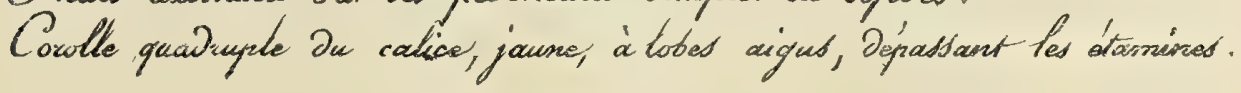

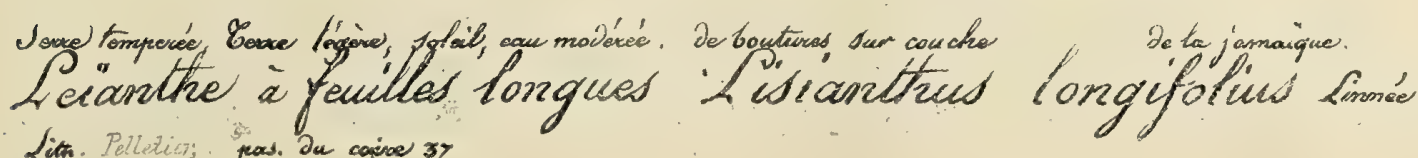

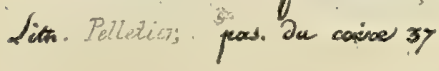





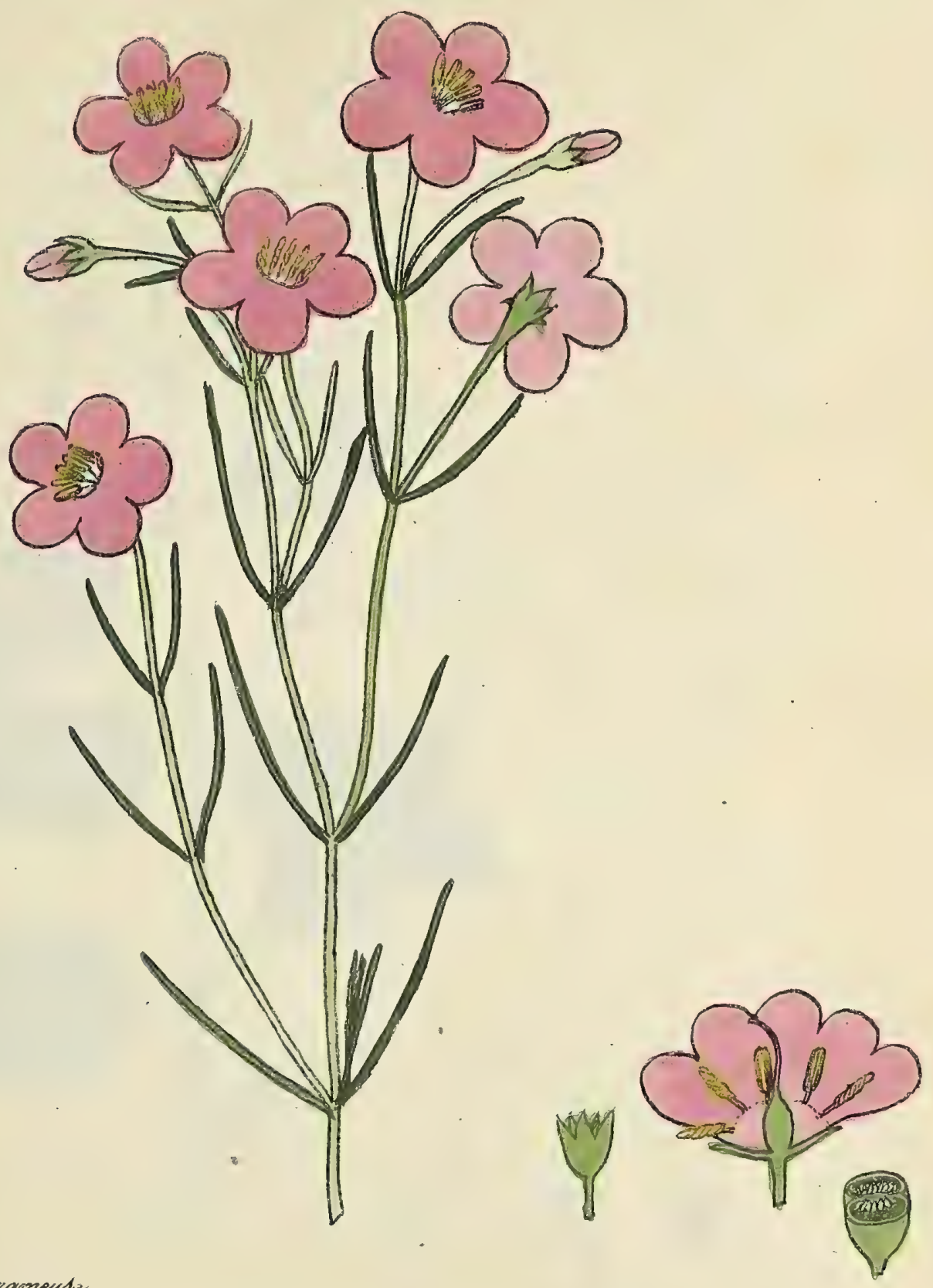

Rasione viwace, rameude

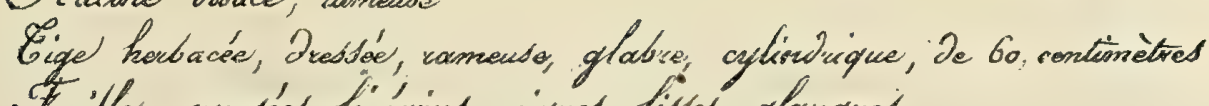

Fenilles opposées, linécices, aiques, lisses, glanqued.

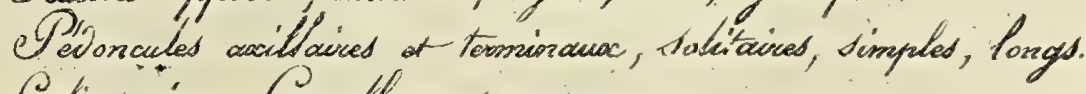

Calice águ, Corolle wos prouryme

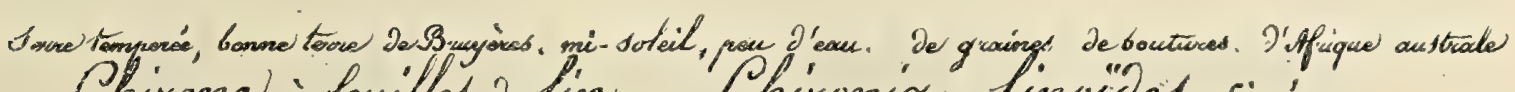

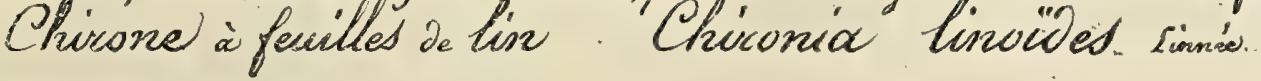

Sict. Pellizier, pros. Dis caive sy 


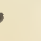

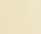




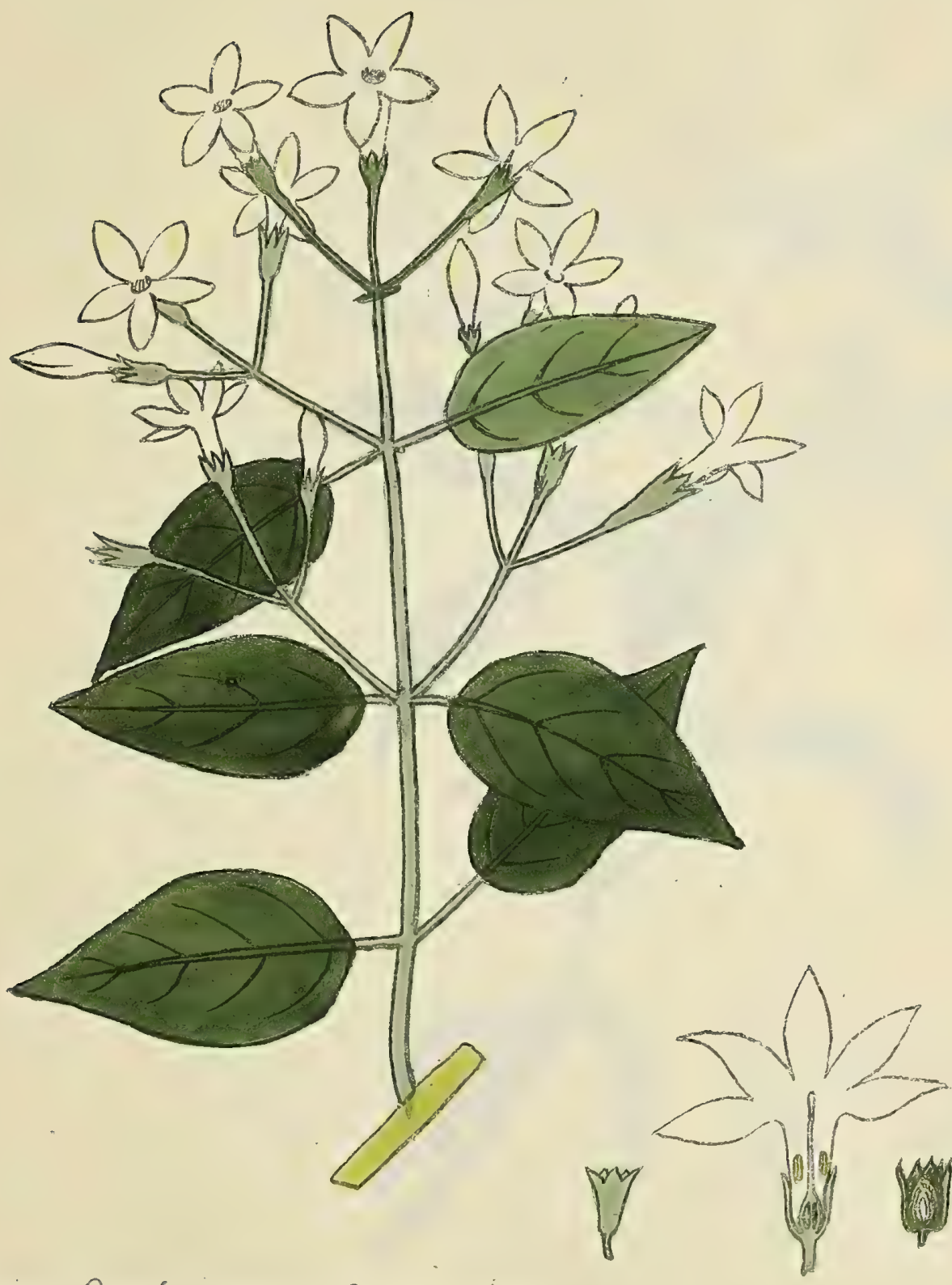

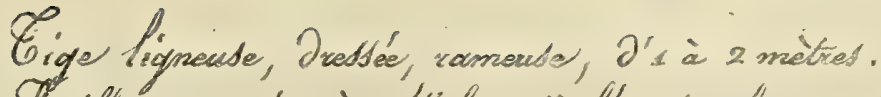

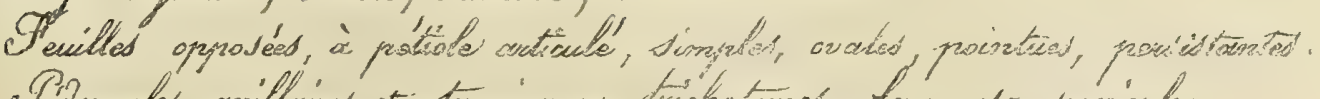

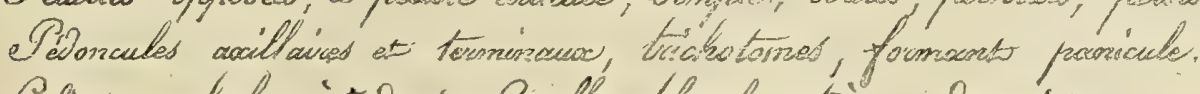
Salice on clschen, is donts, Porolle blasnche ties odorante.

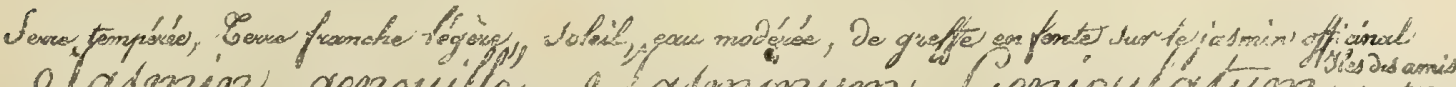

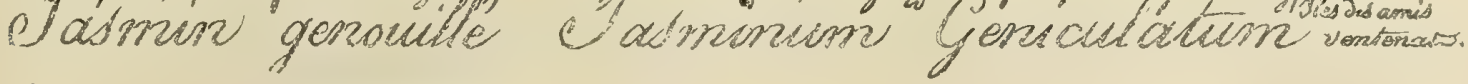

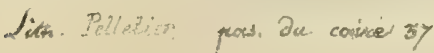




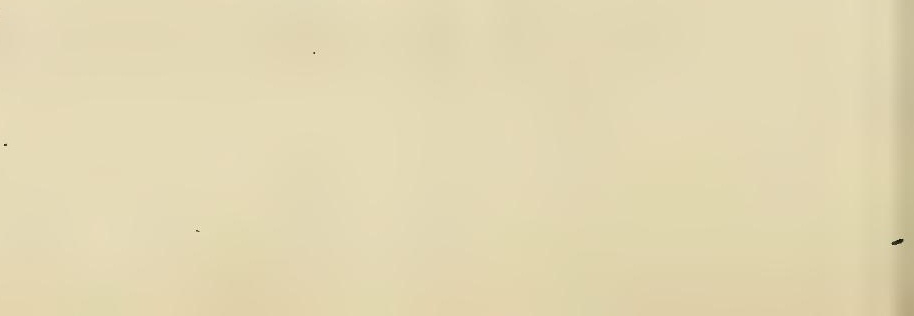




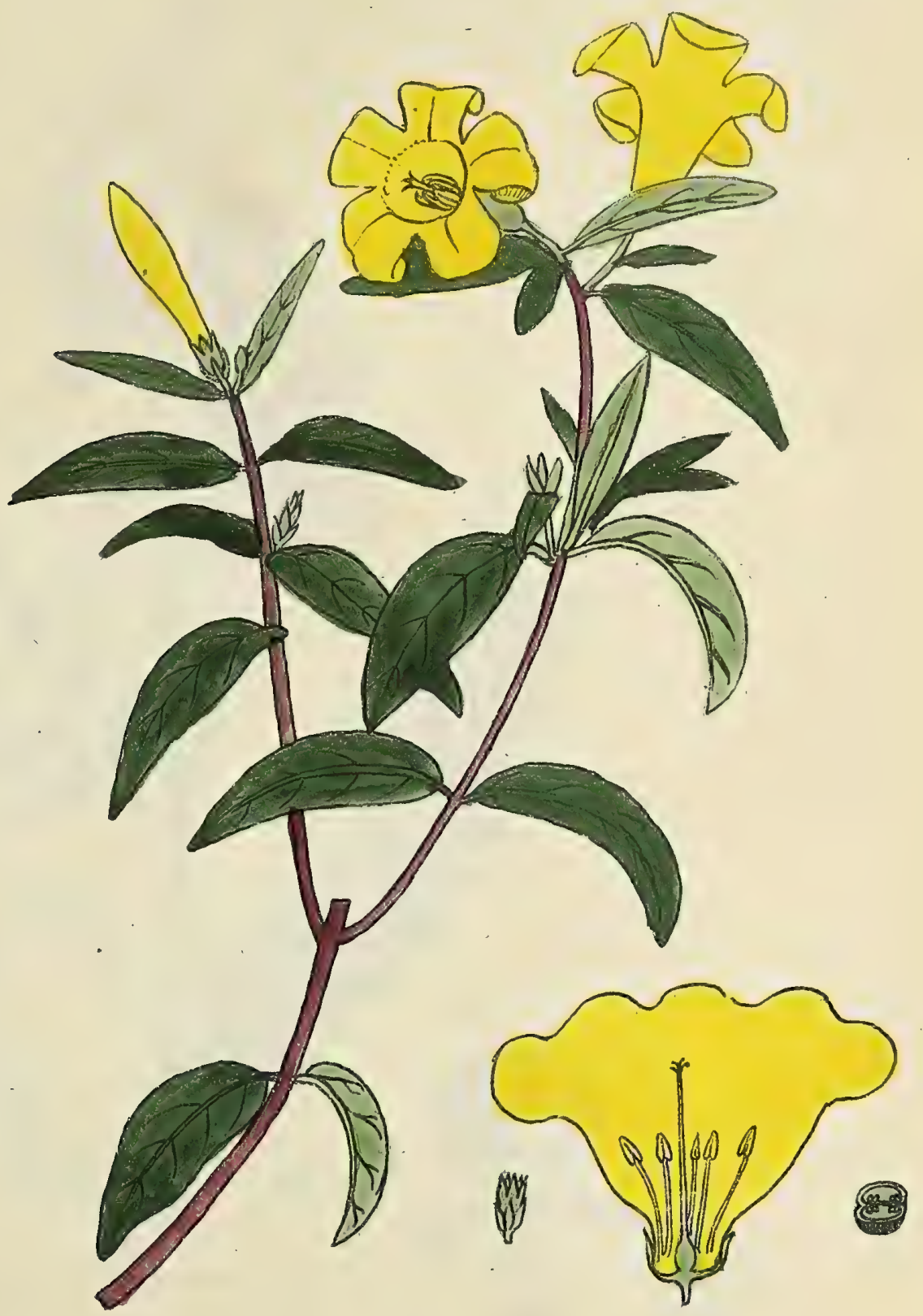

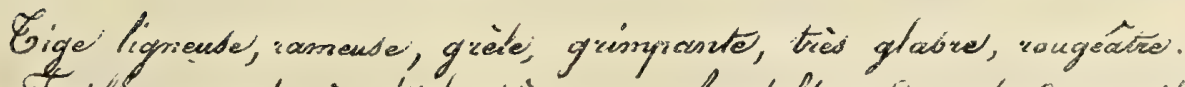

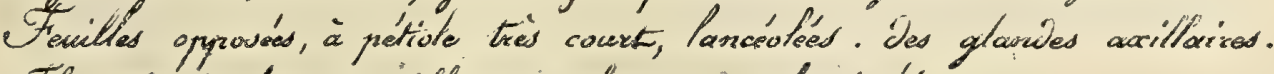
Fleurs terminatas of axillaines, solisaives on fasciautés.

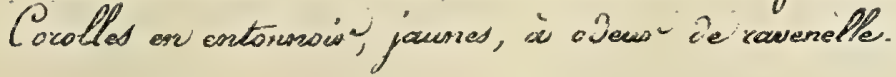

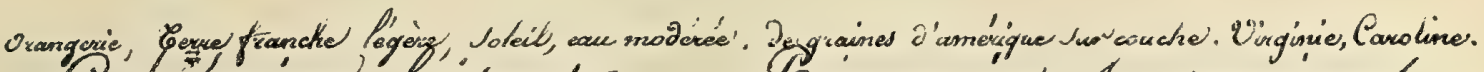

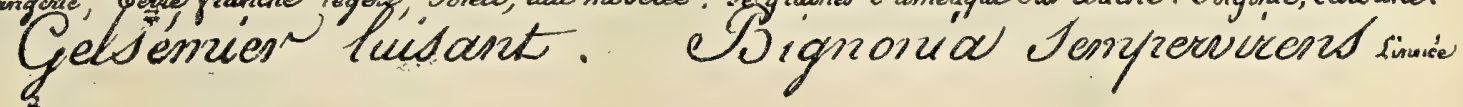
Lith. Pellictior, pass au cerier $3^{5}$ 



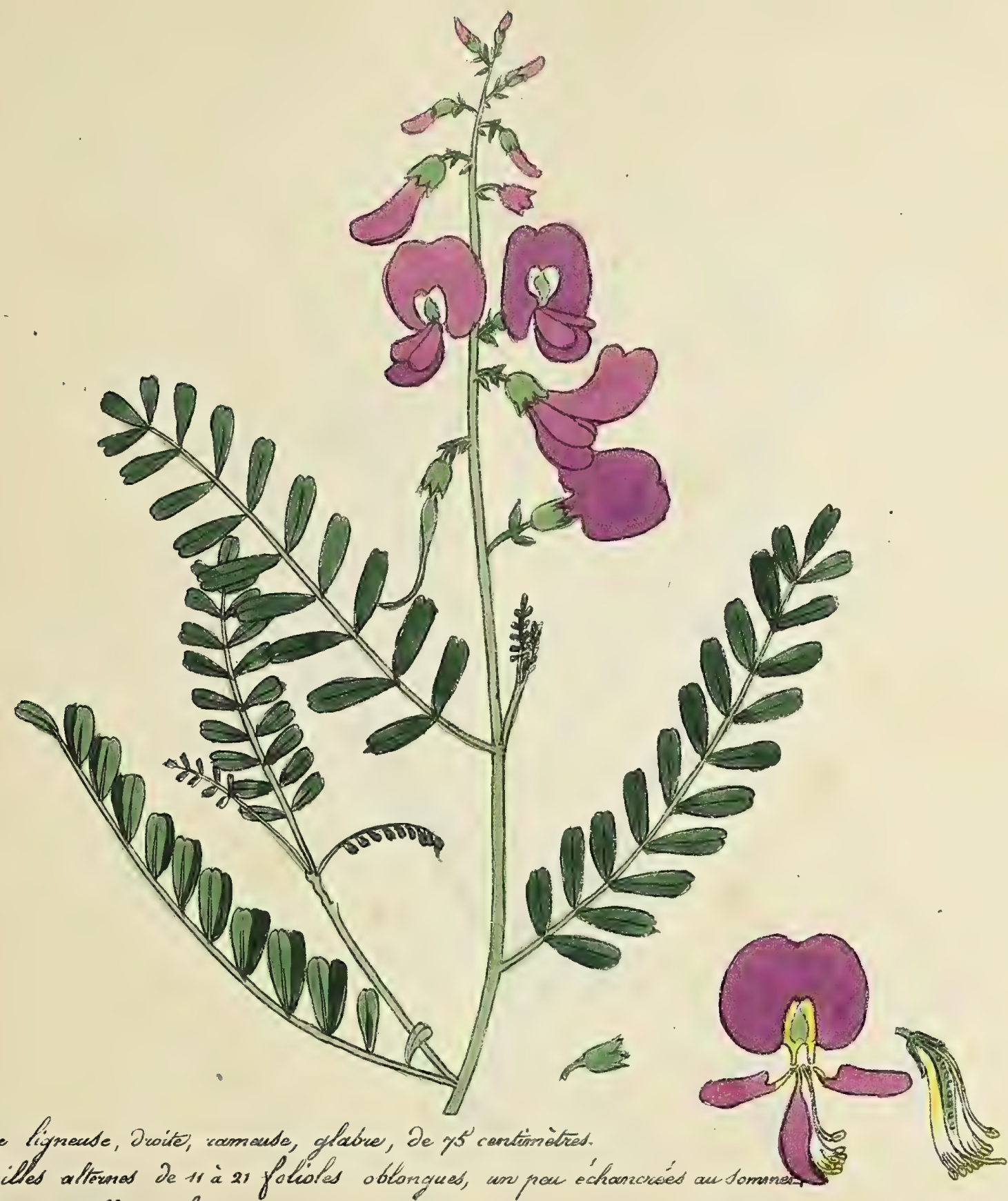

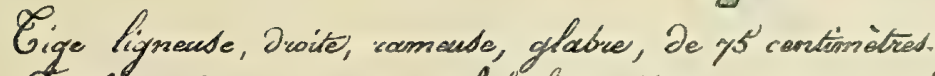

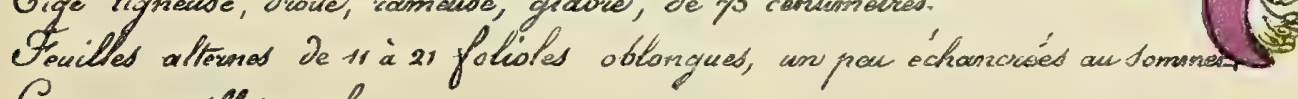
Grappes axitlaired, fongued.

Corolle rose tendue prowyzé.

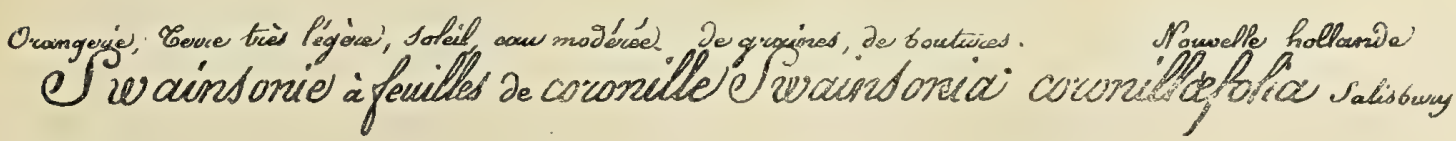

fith. Pelletier. poes. 2us cairess. 



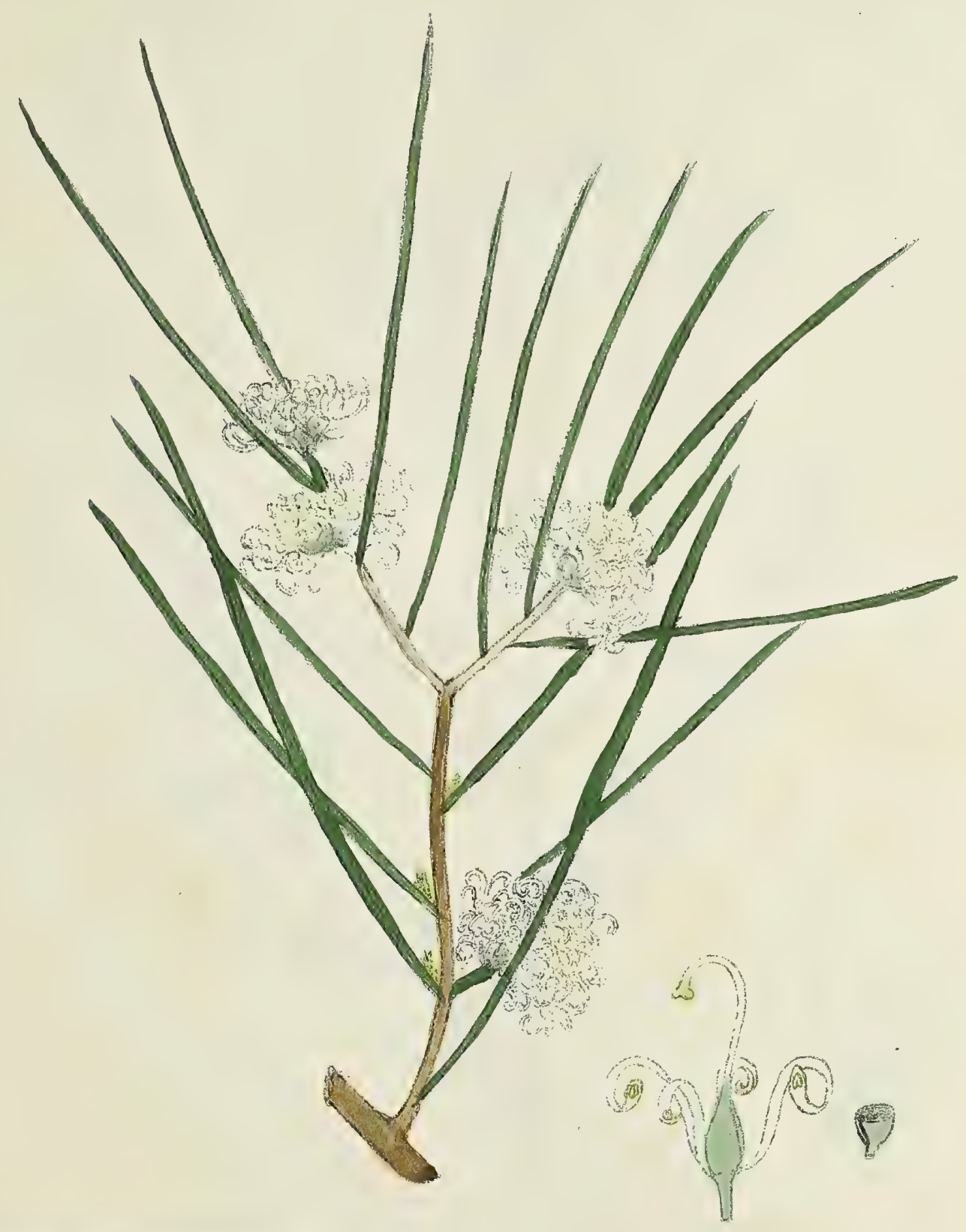

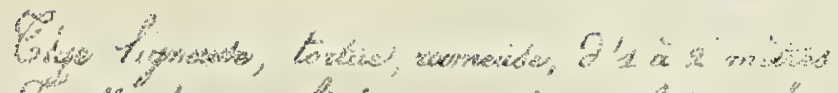

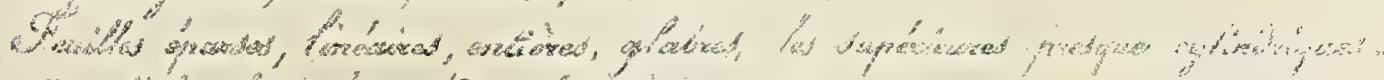

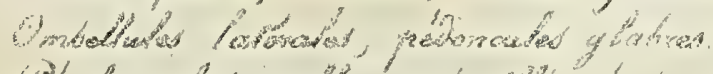

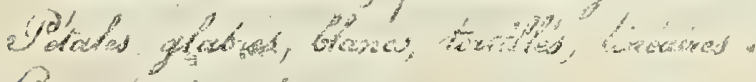

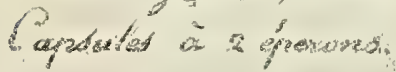

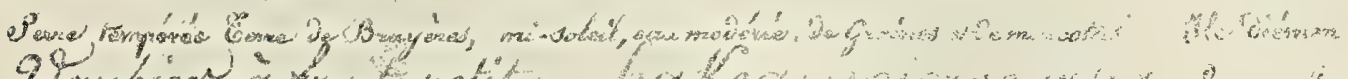

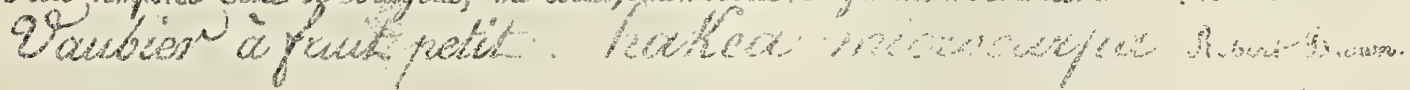





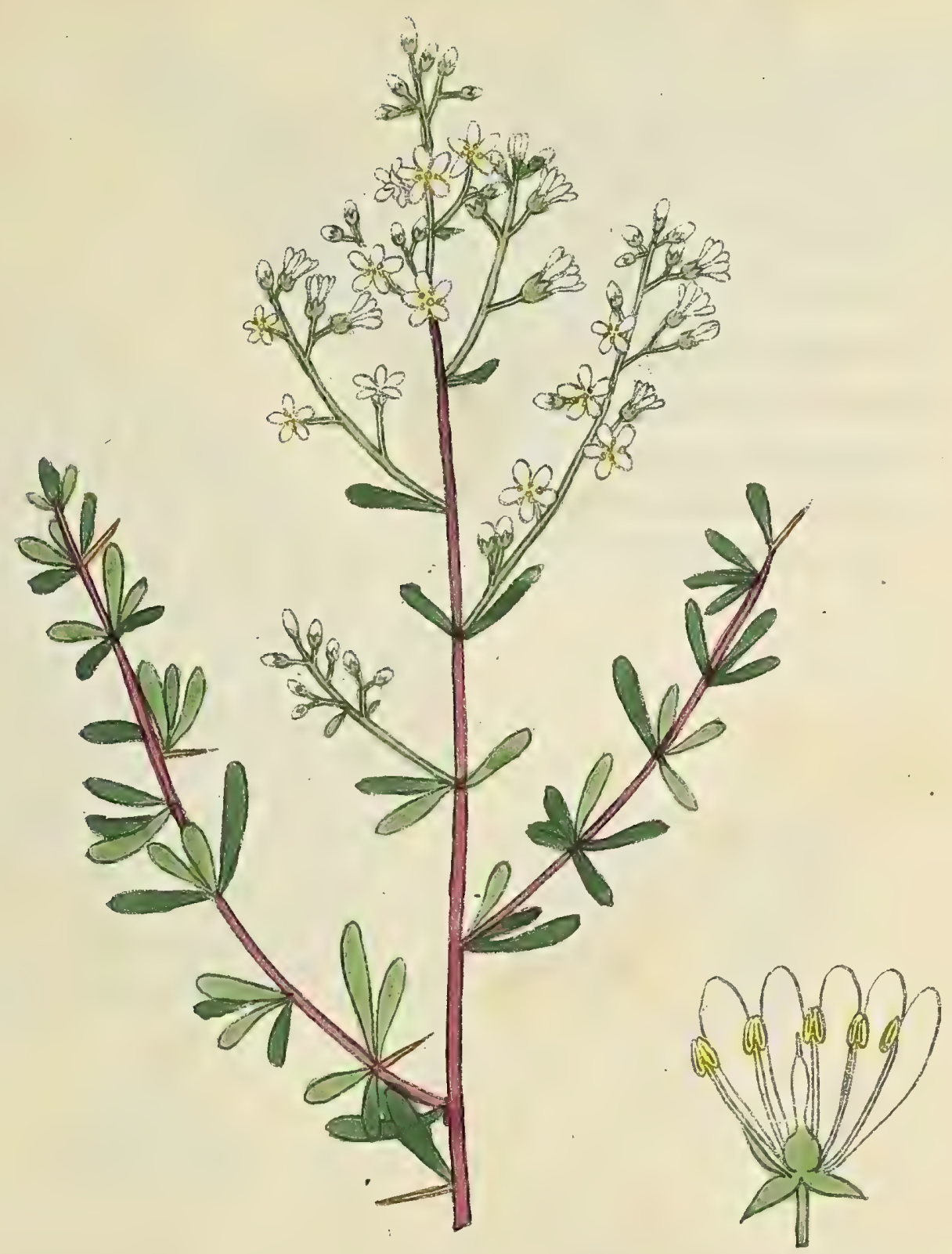

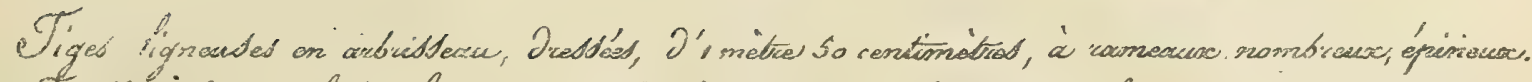

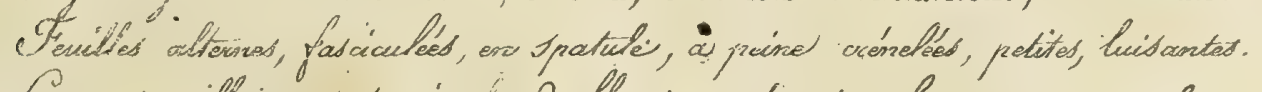
Guapped axiliavied et teimninates de flewed nombirsuded, formant provicula.

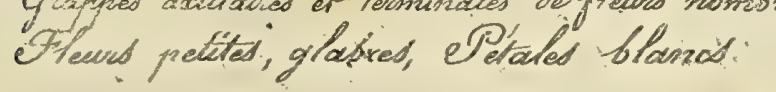

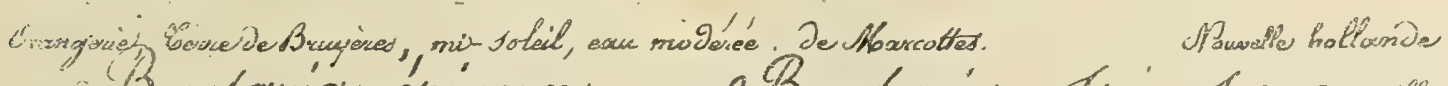

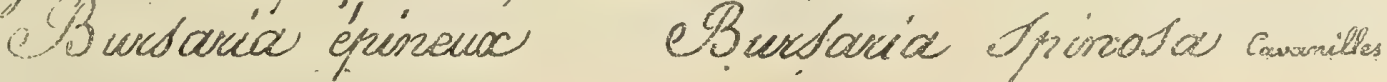
Sith thet pas dovairex 


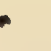




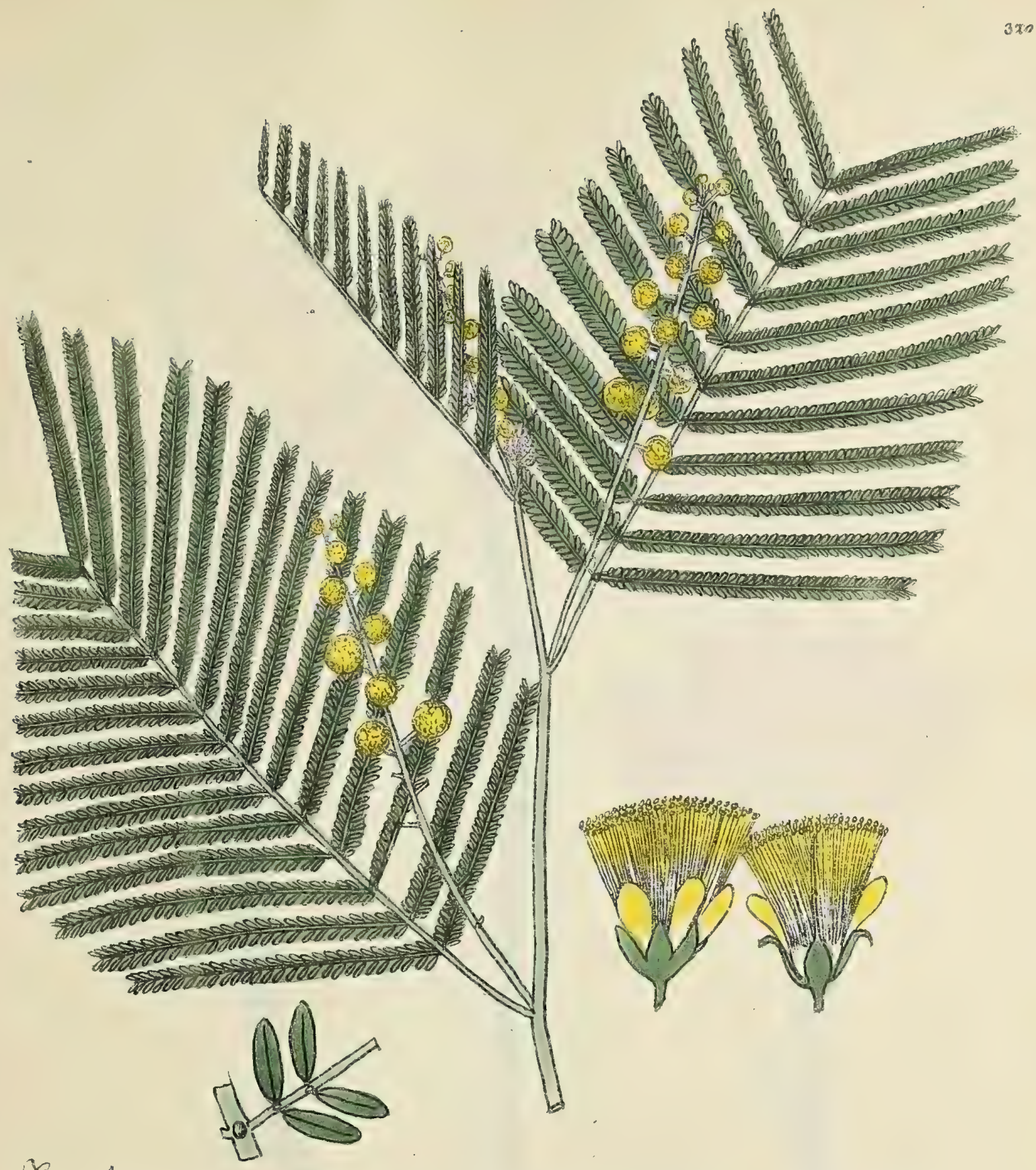

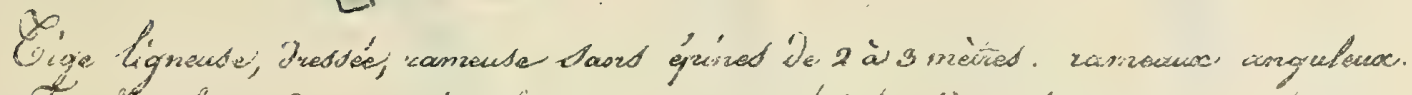

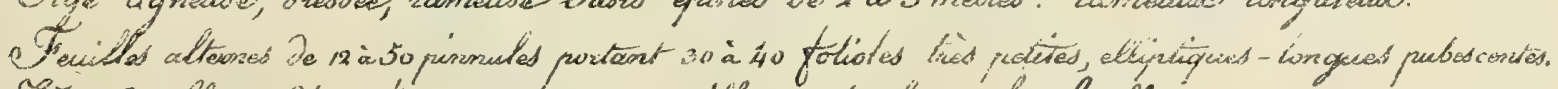

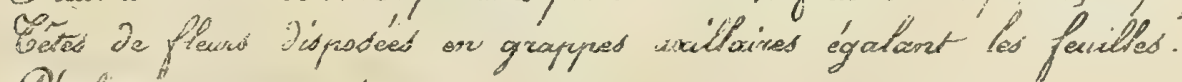

Cetales et atamioned jauned.

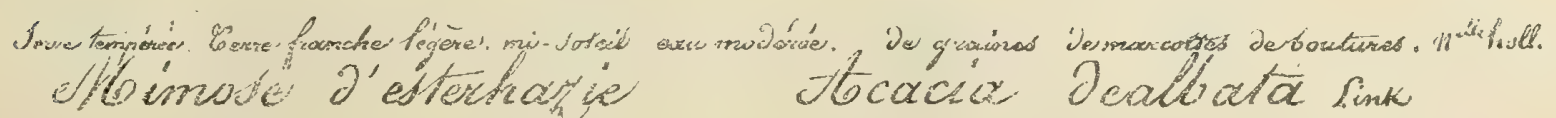
Sisto 



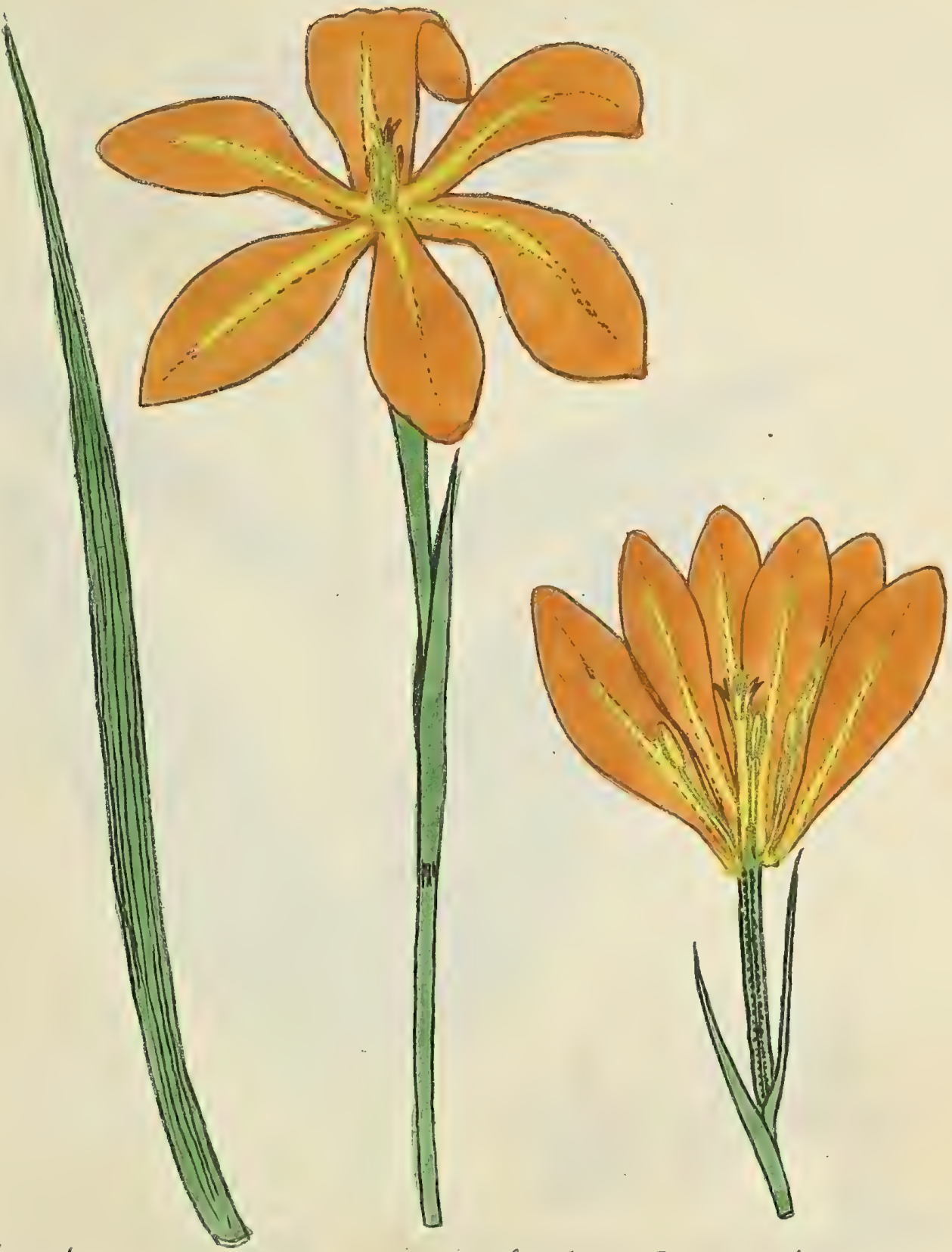

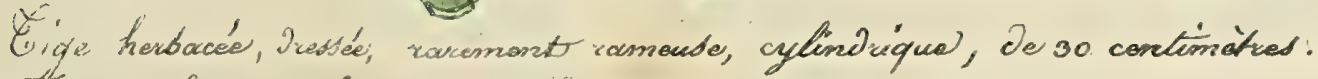
Tewitted finéaired, longued, inotles.

Flewnat terminates à spatted foliacées, pwiontued.

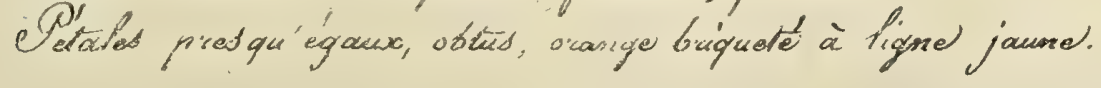

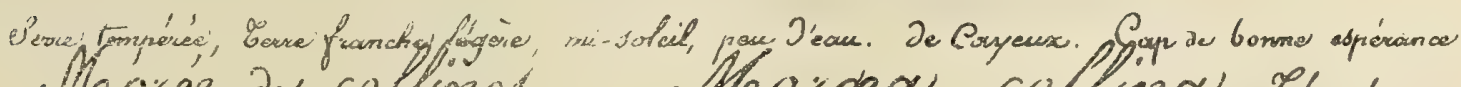
Moorée des collimes Mborded collinal Chumberg. 



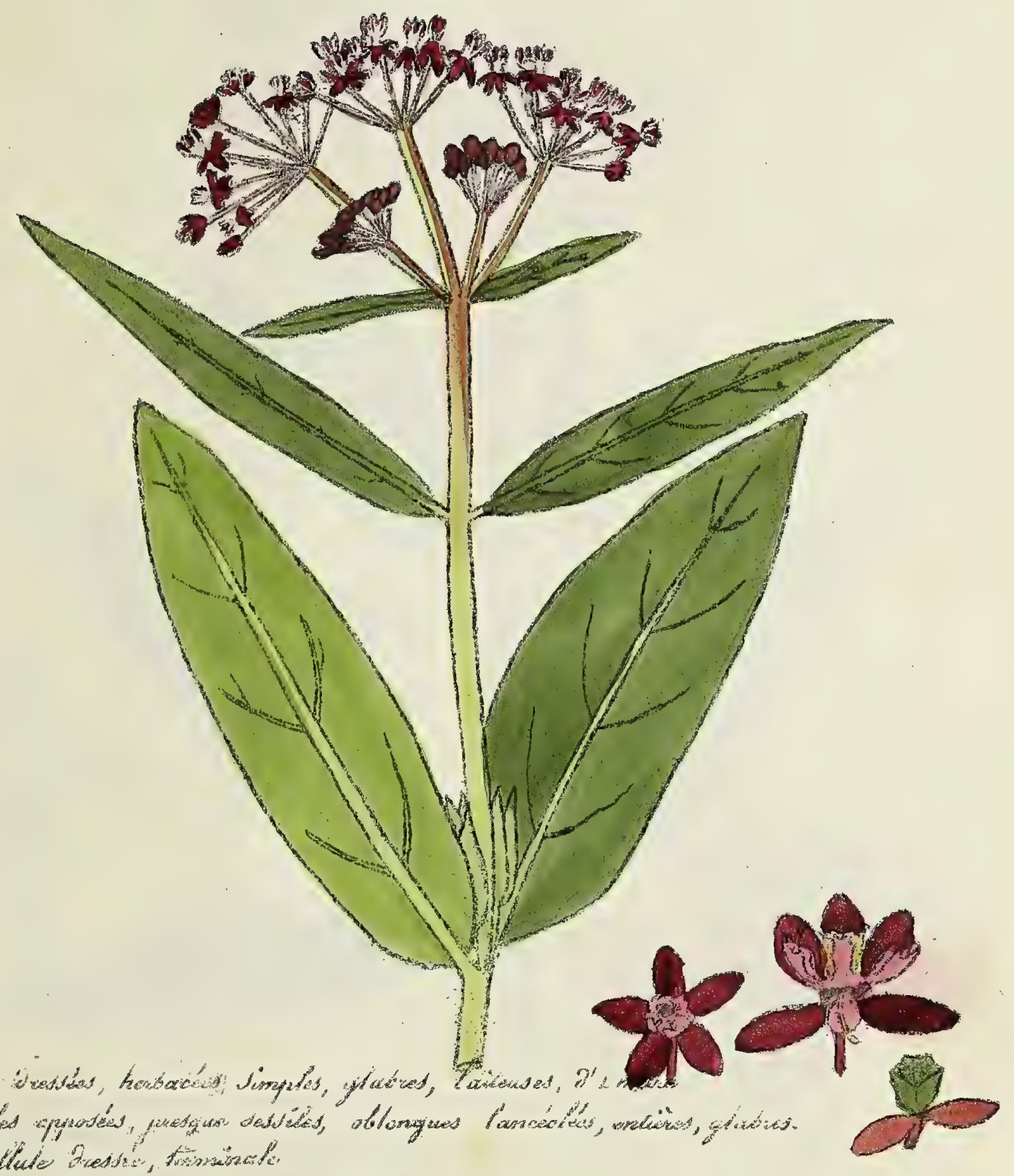

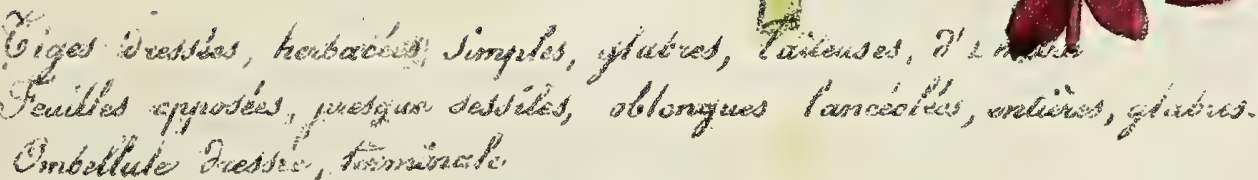

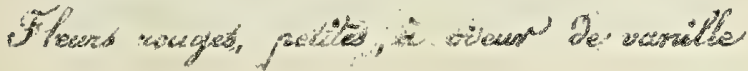

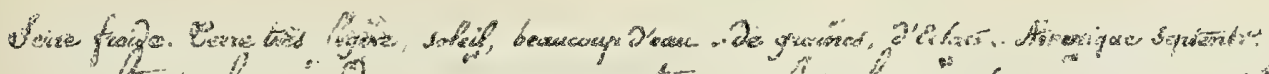

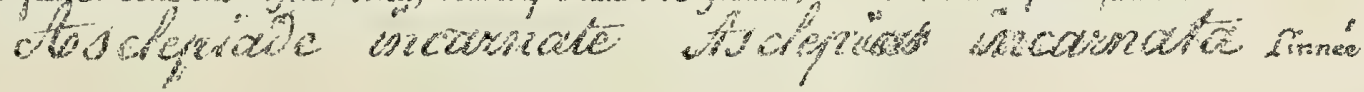





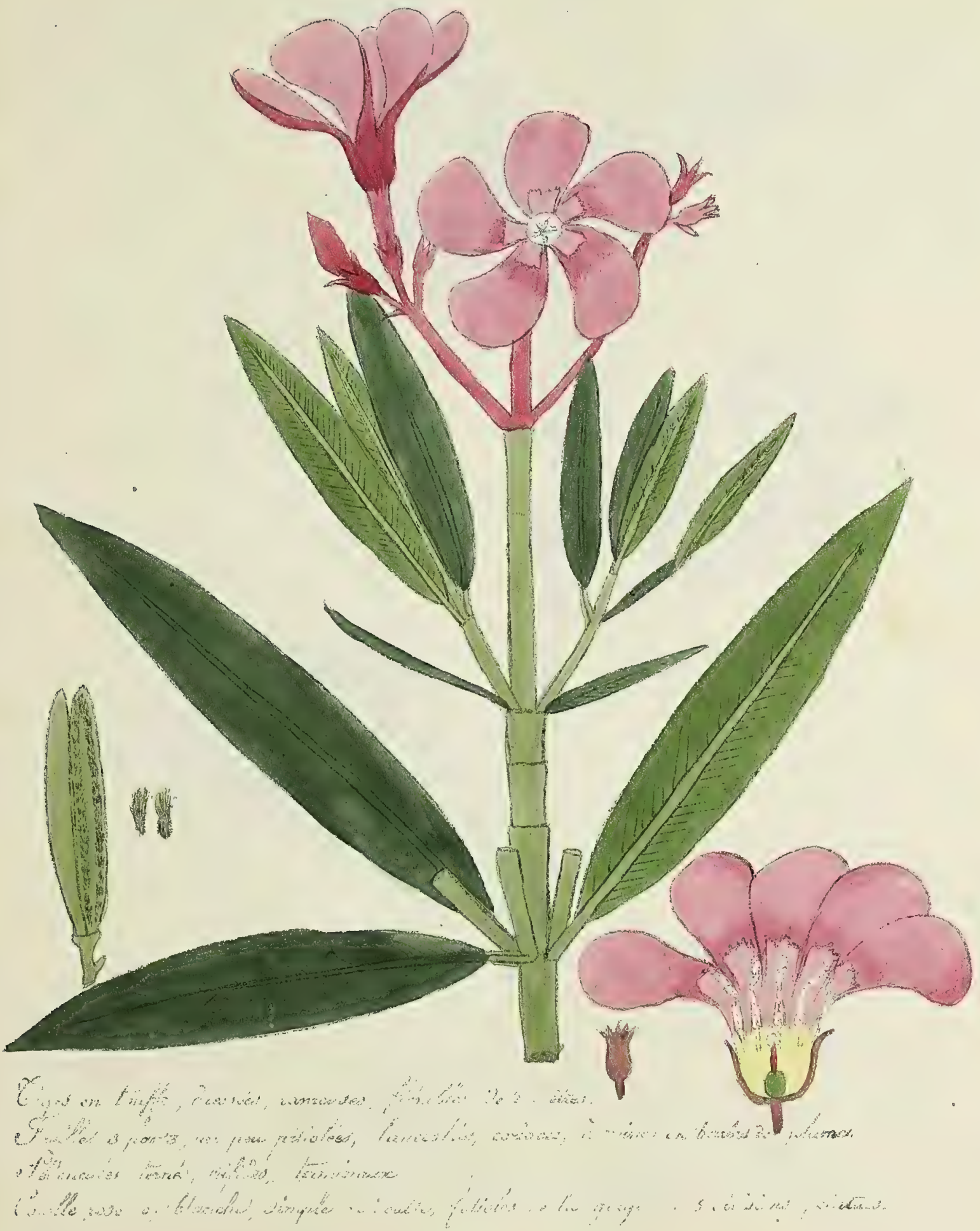

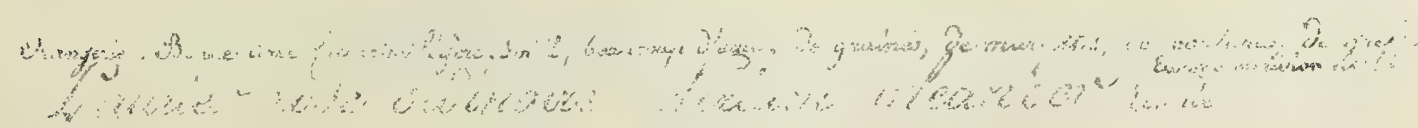





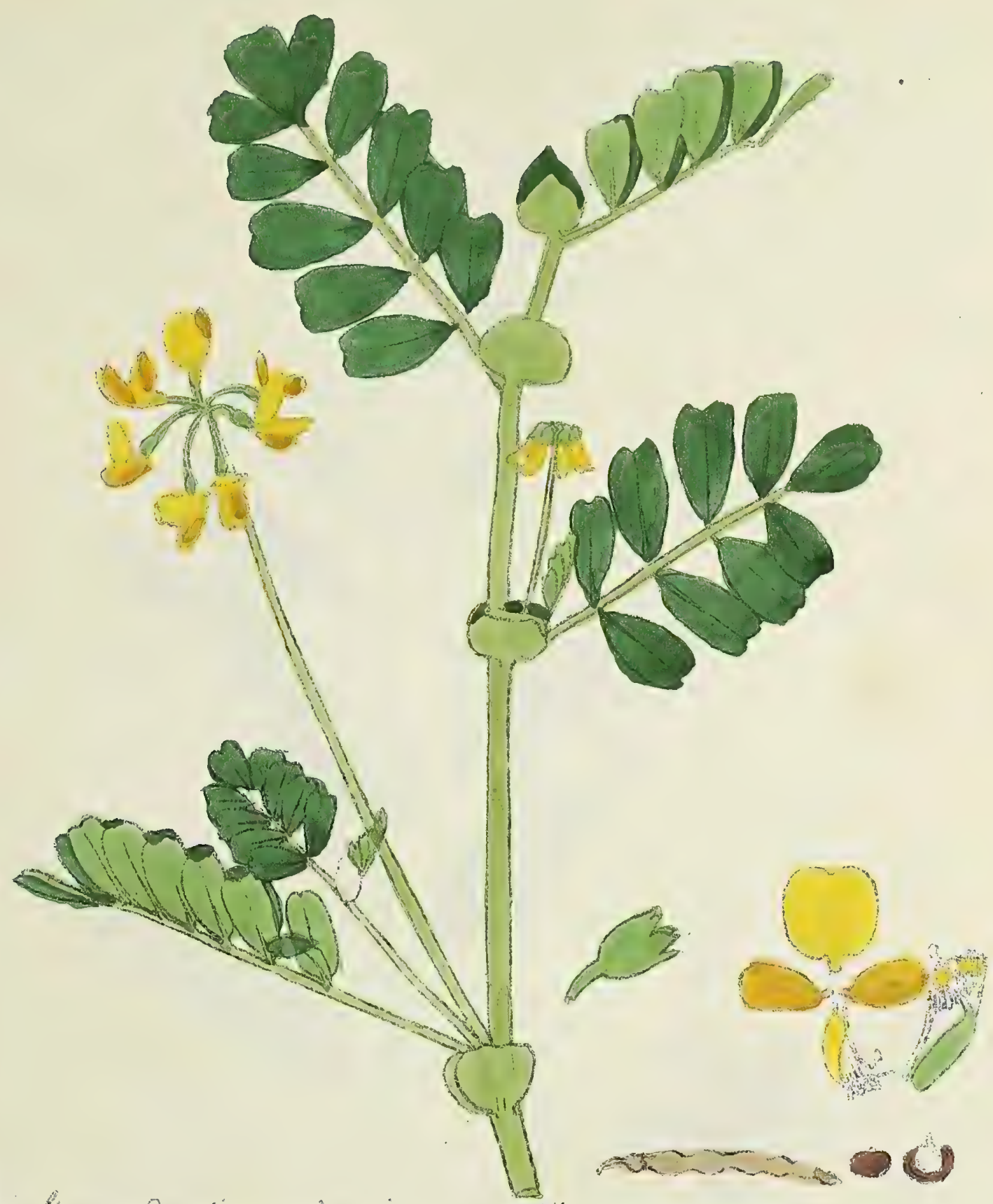

Wige ty

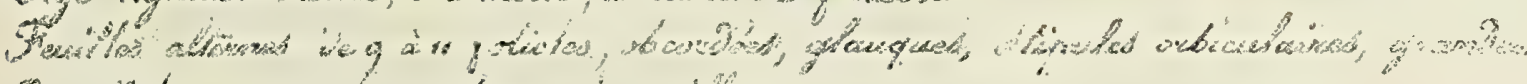

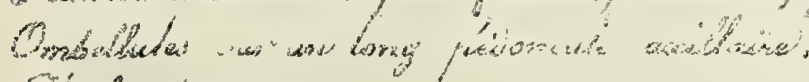

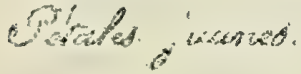

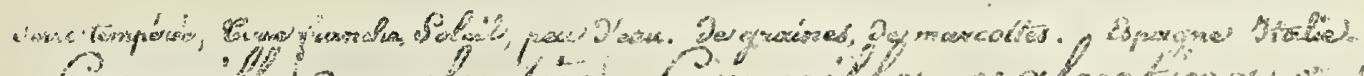

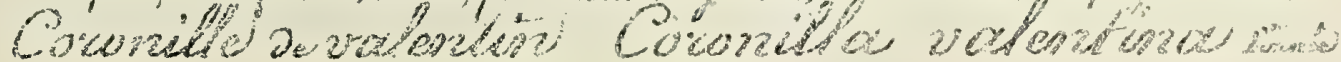




\section{.}




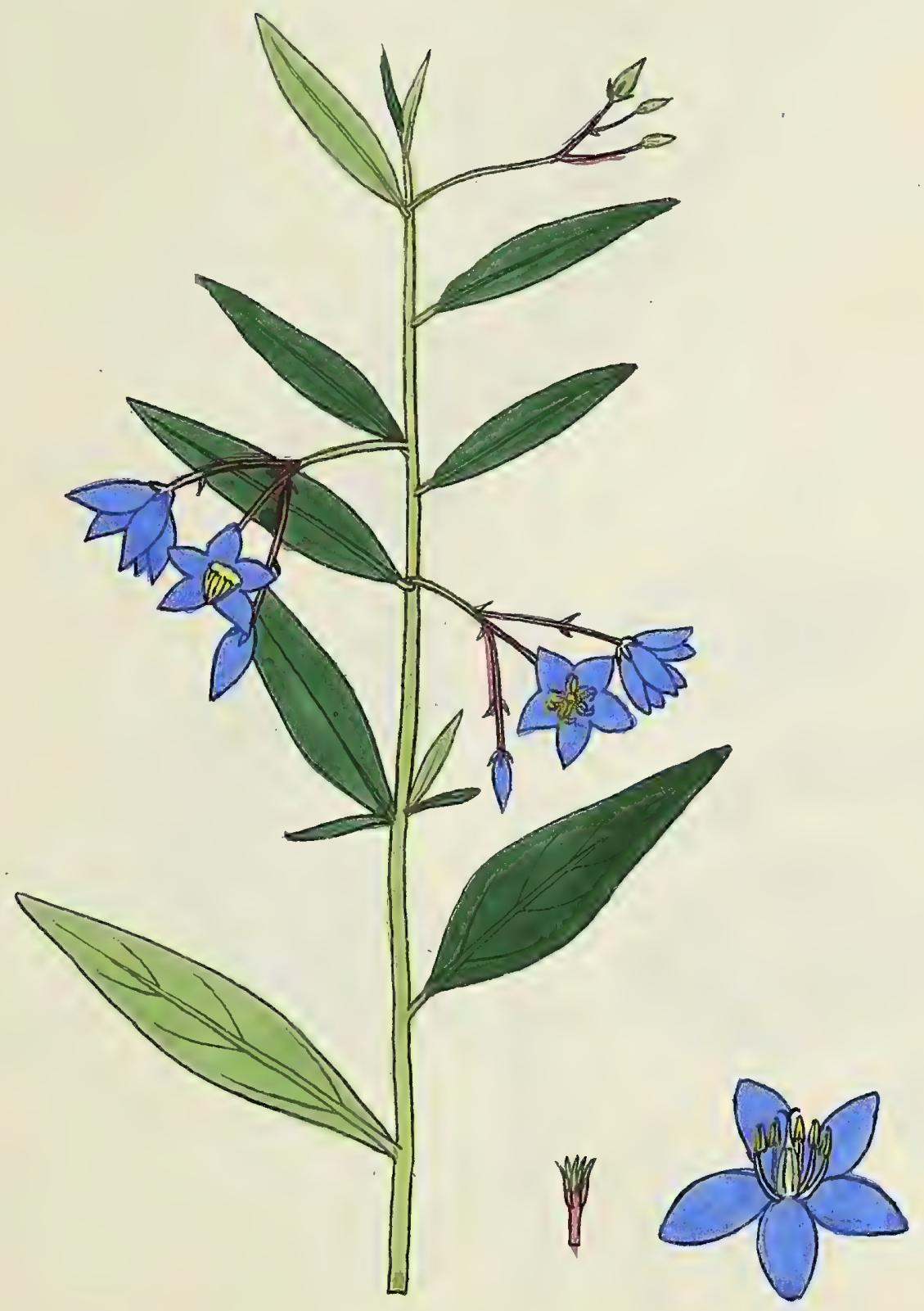

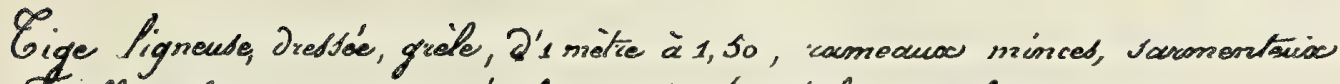
Feuittes altornos, à court pétiole, vuales-lancóolées, proilued,

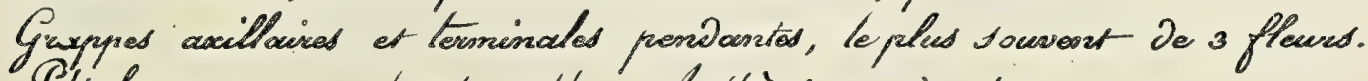
Petales ouvints ovales, beaw blew, Arntieired conninentes.

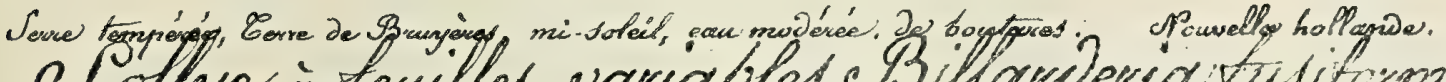
C) ollye à fecilles variables. Billowiderid âsifornis.

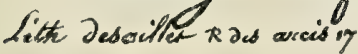




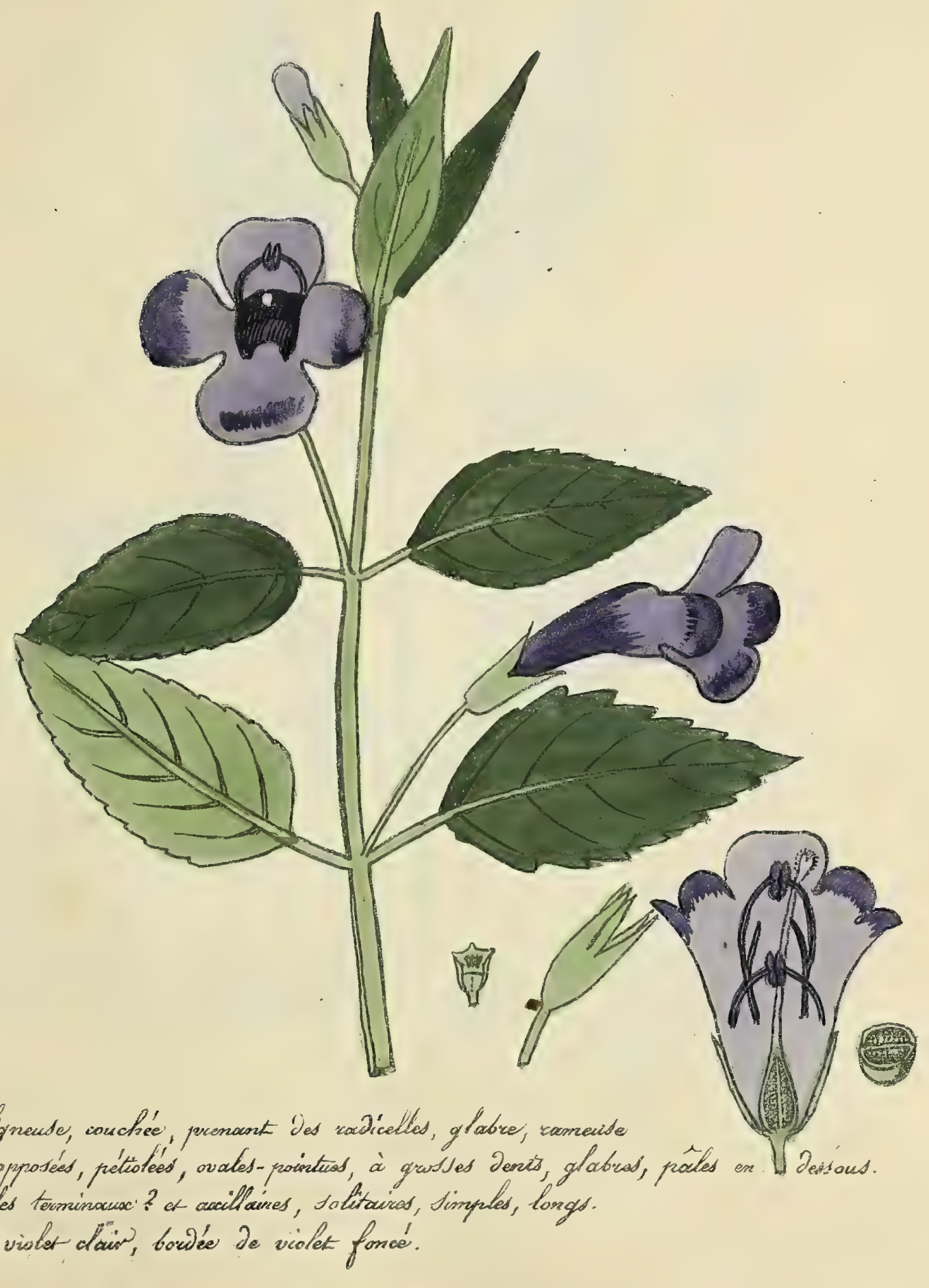

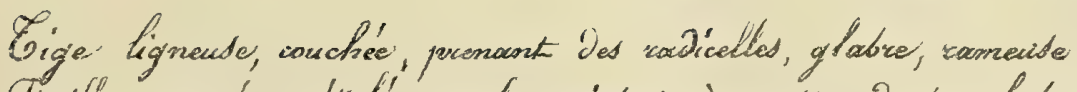

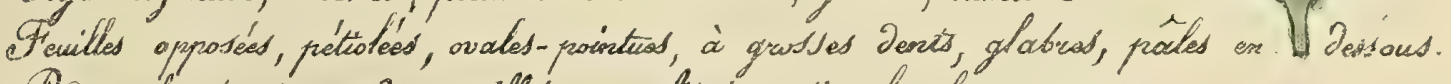

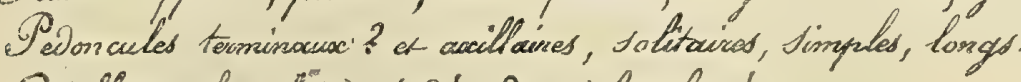
Corolle vishat claior, boweé de violet forcé.

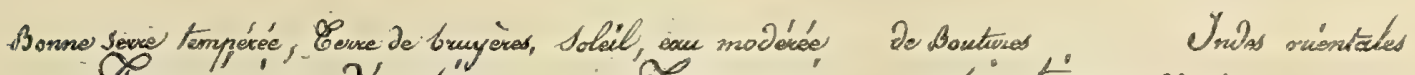
Eovenie J'adie. 'Cocenia abiatica Simés

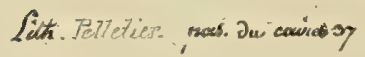

Cher Bentranes ruederial Raquelts 102 


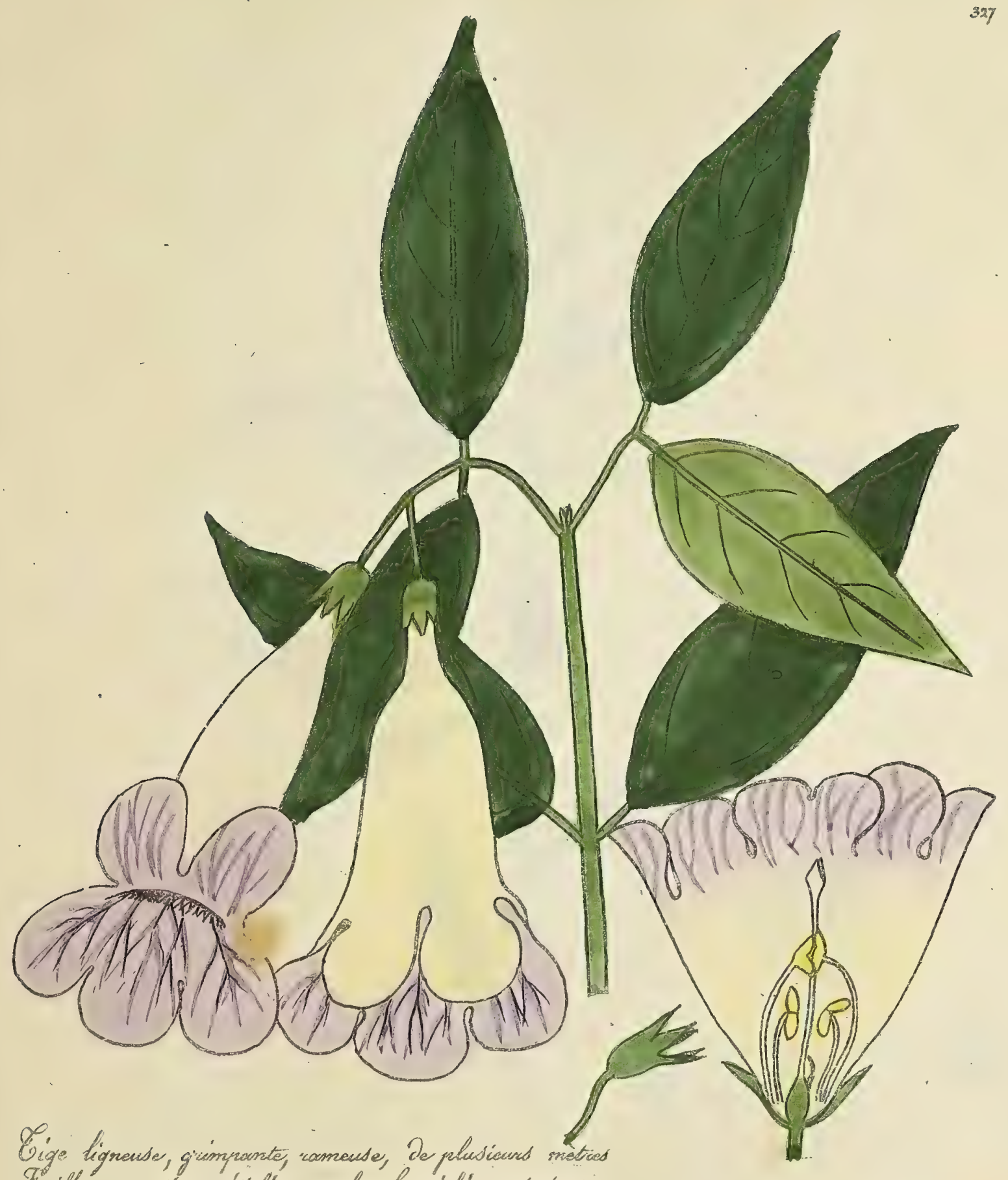

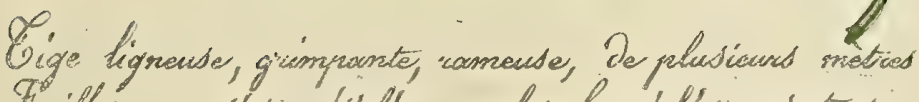

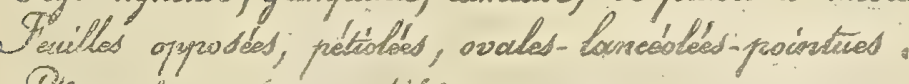

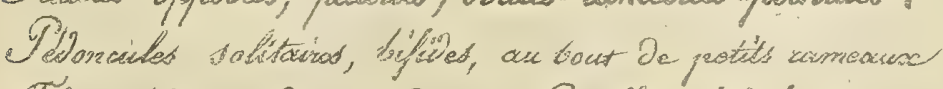

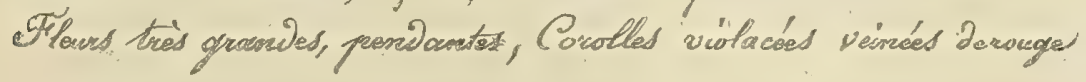

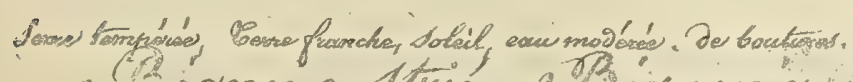

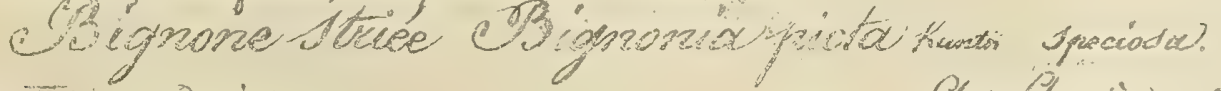

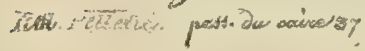





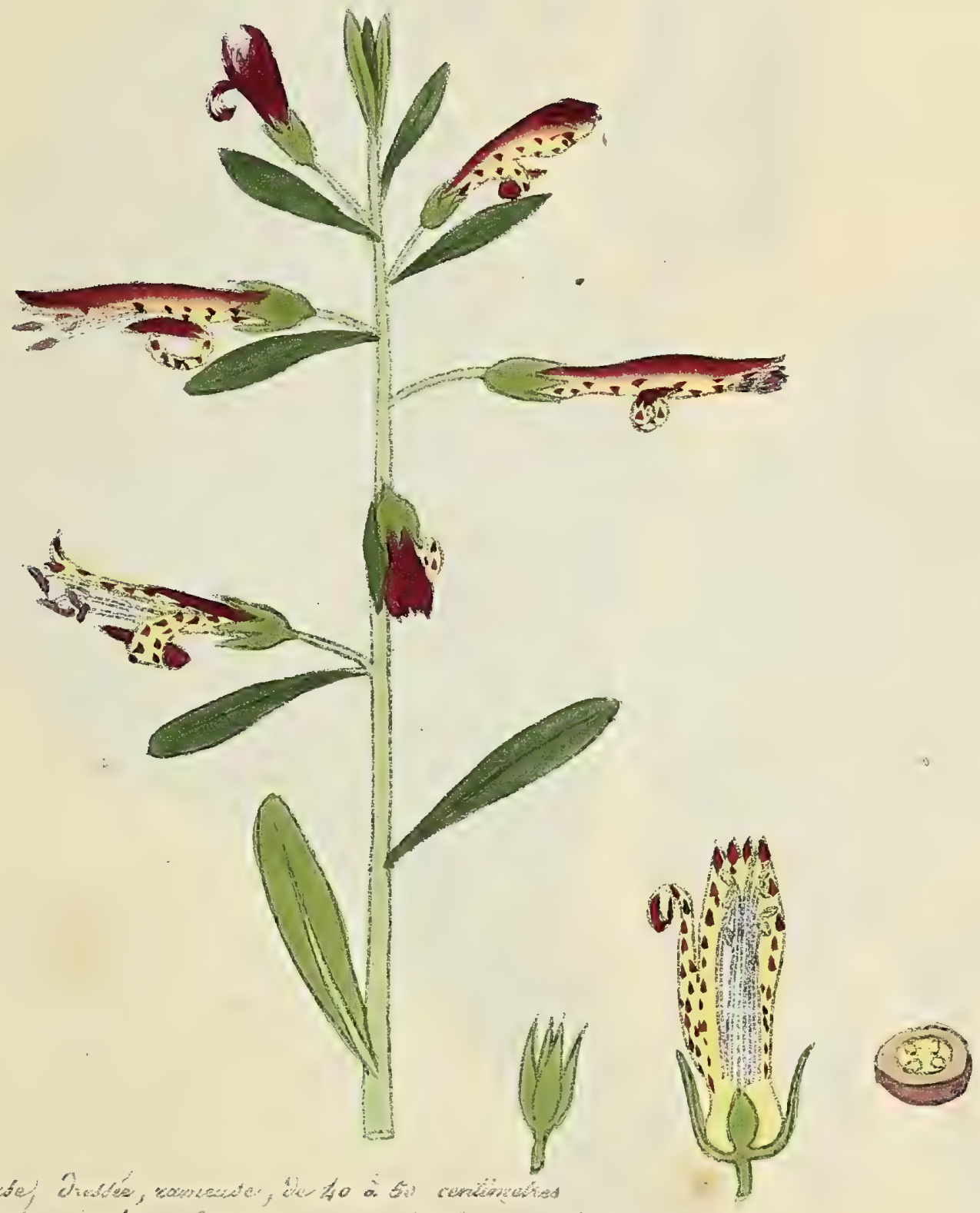

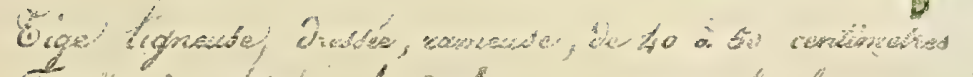

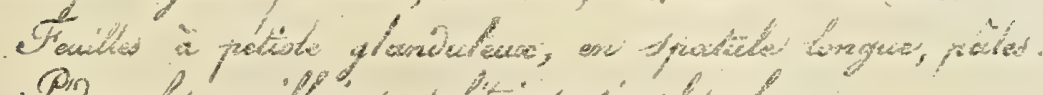

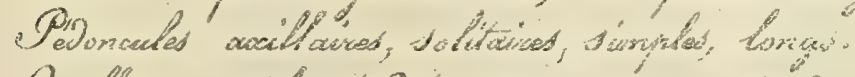

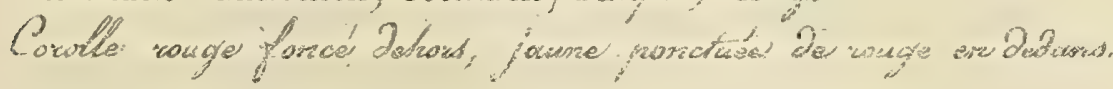

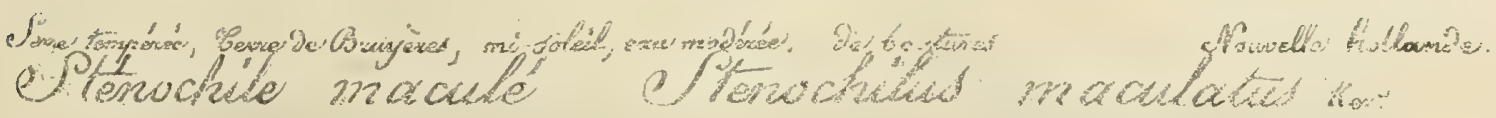

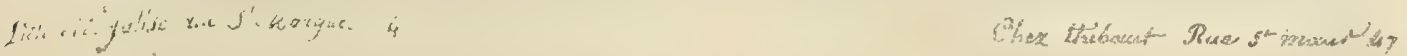





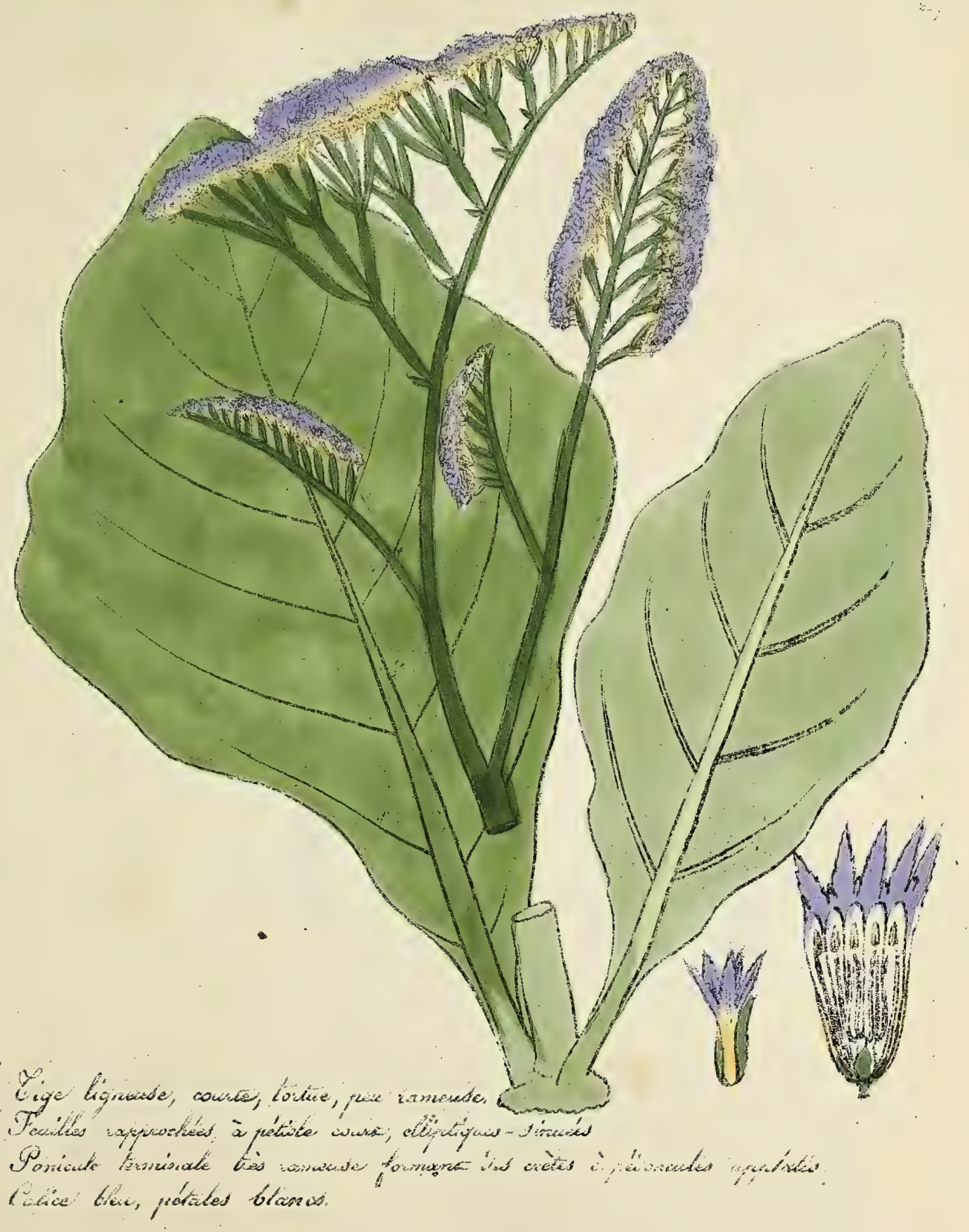

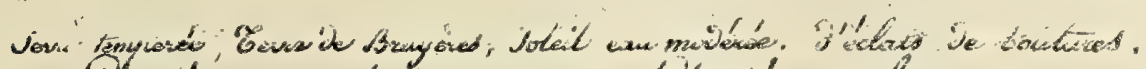

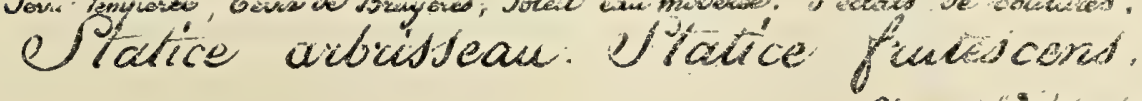

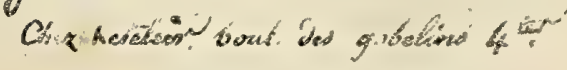



उद्ध

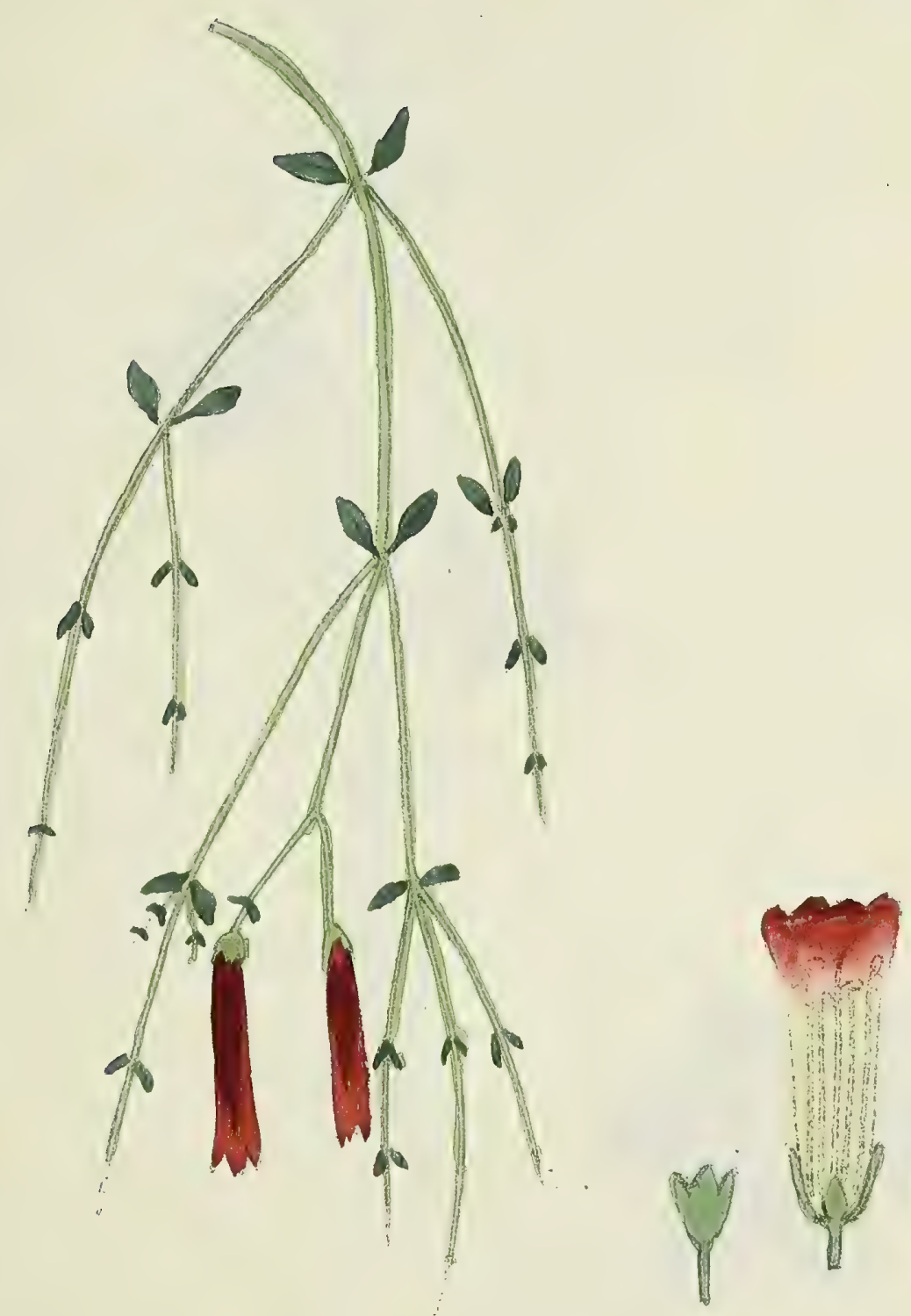

ton

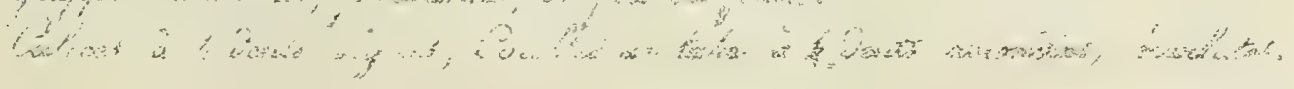

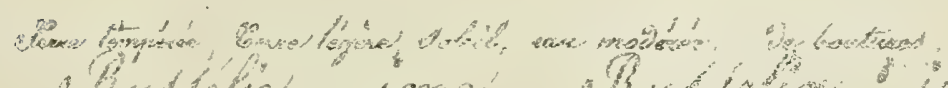

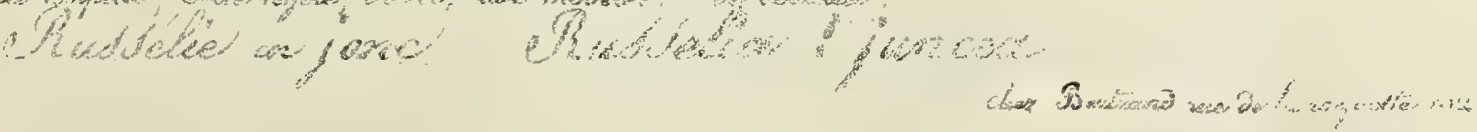




$$
\text { - }
$$




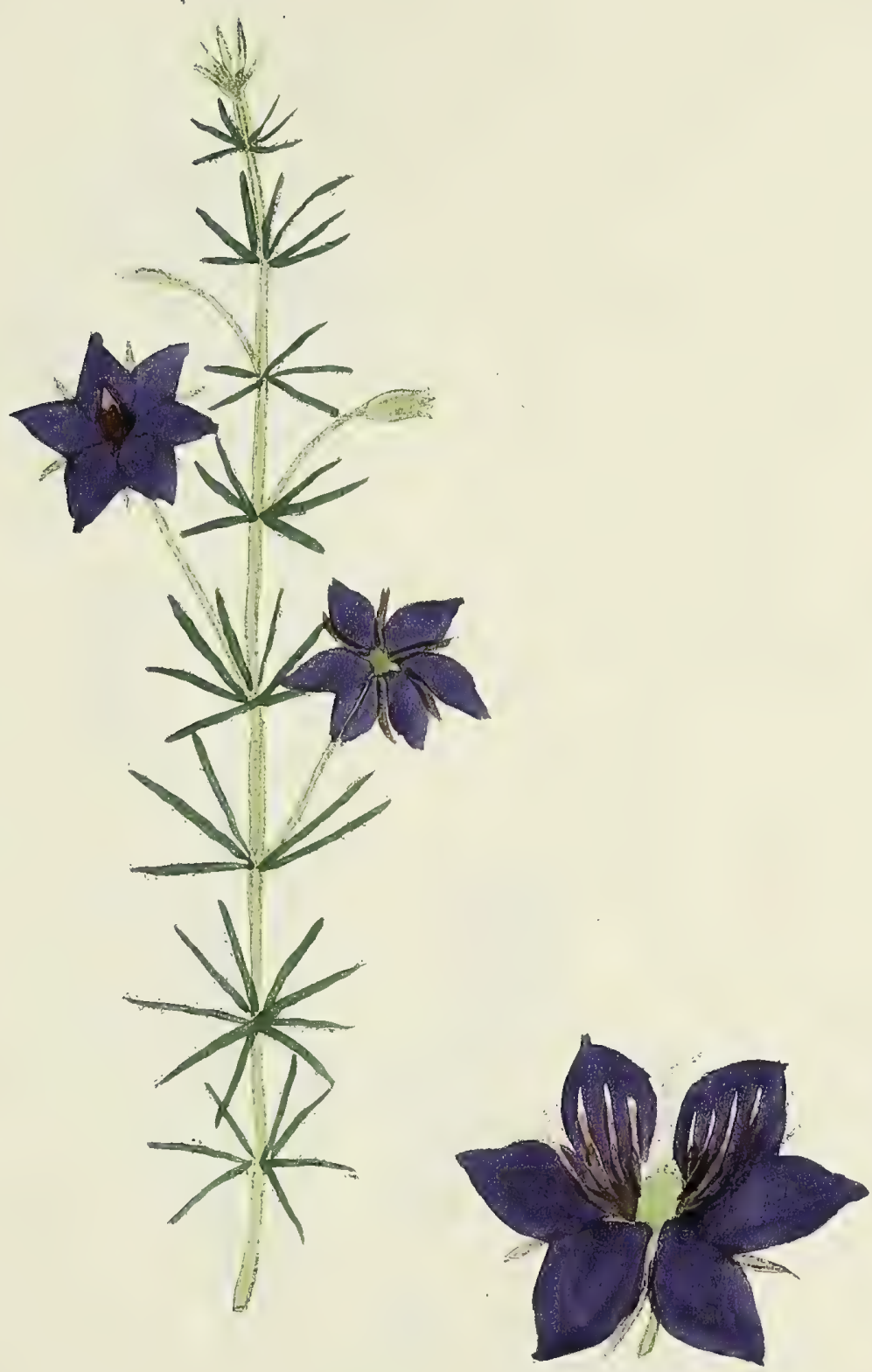

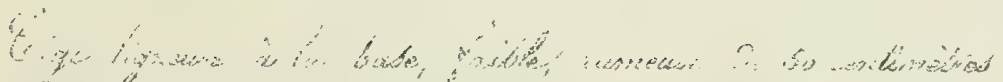

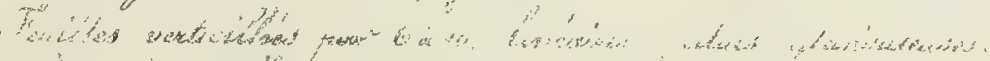

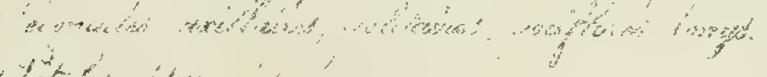

y

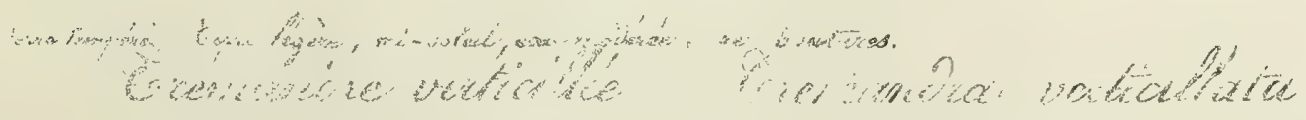





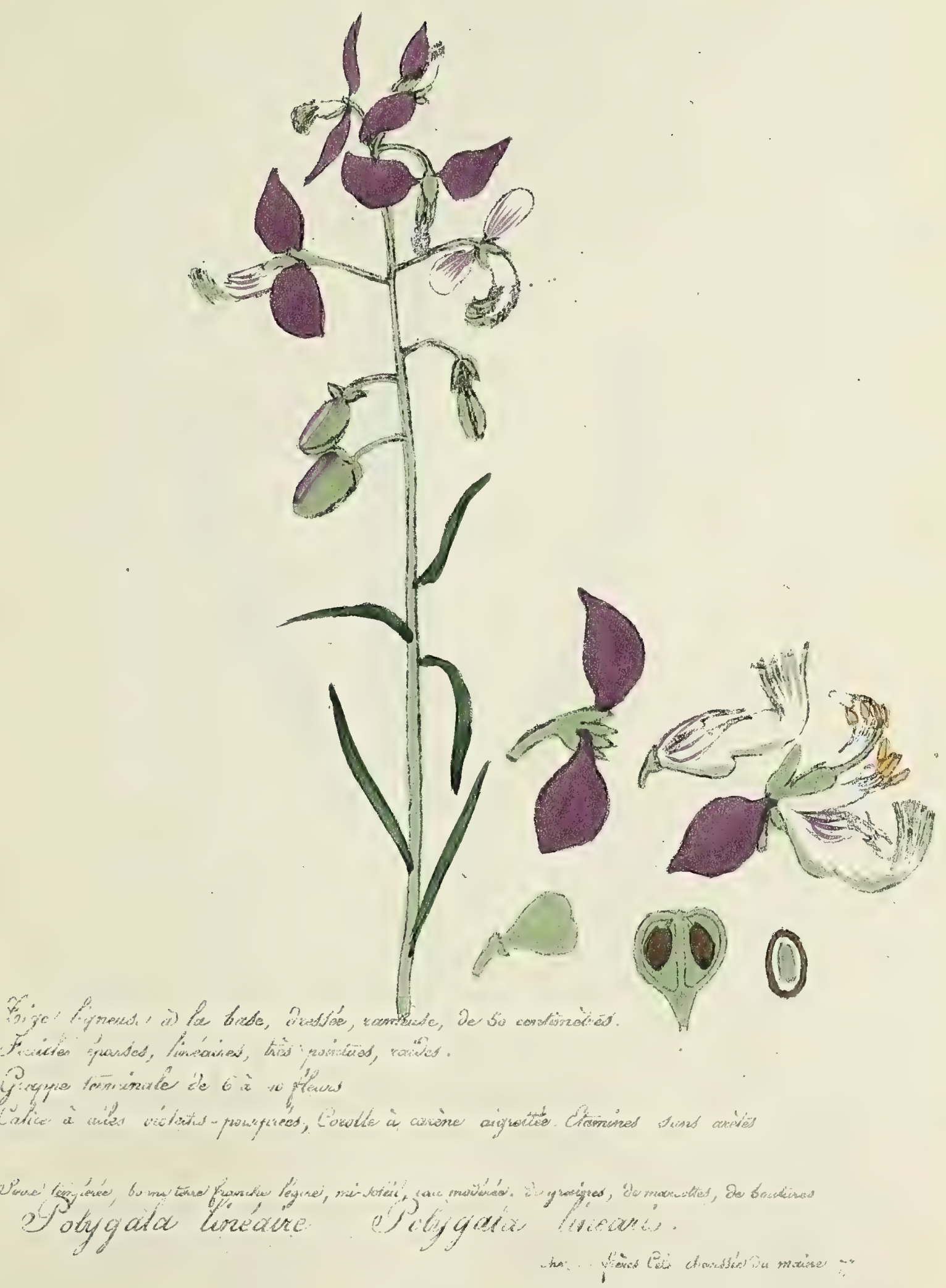

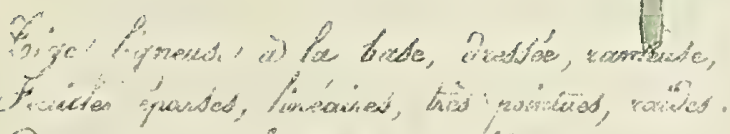


. 


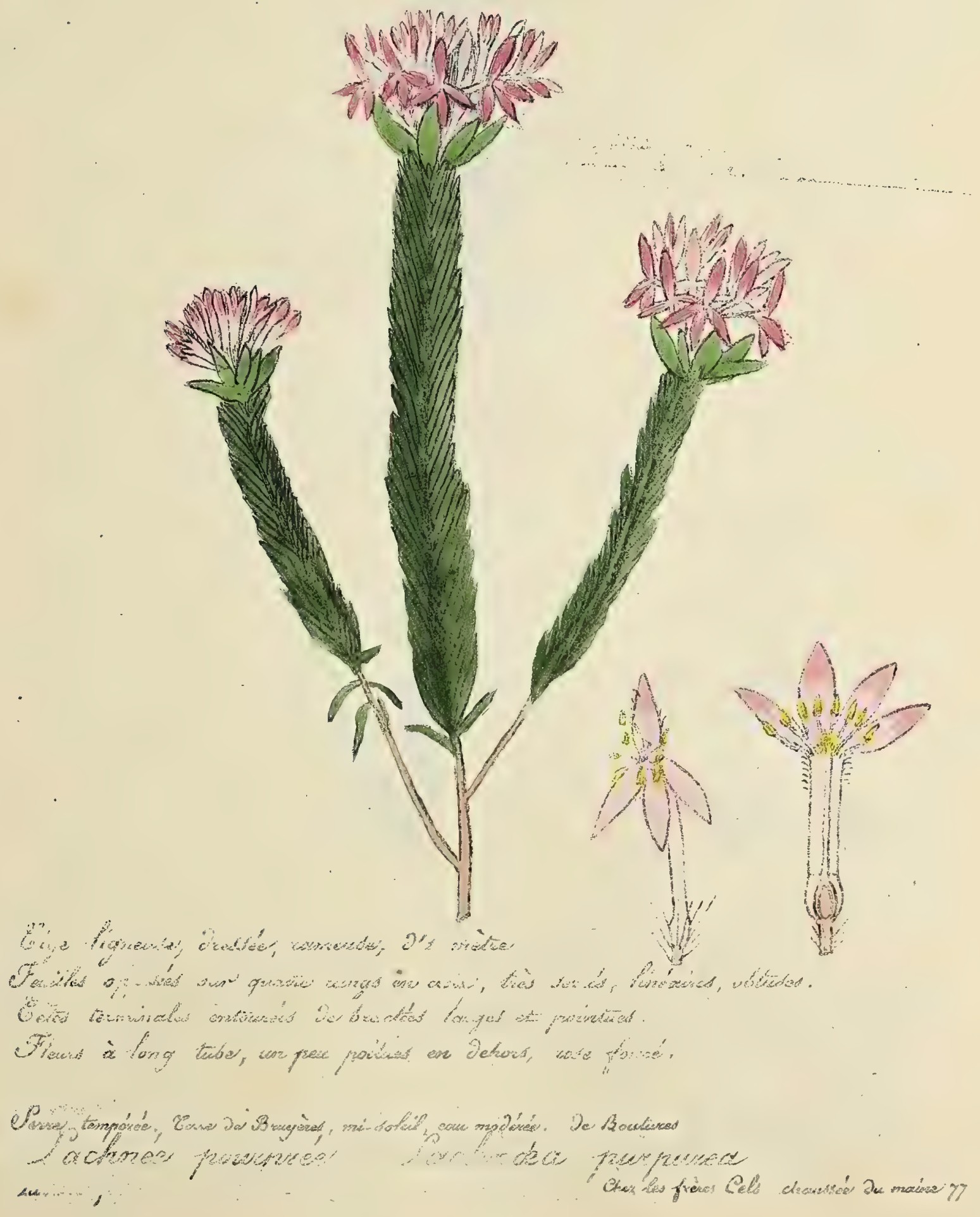


- 

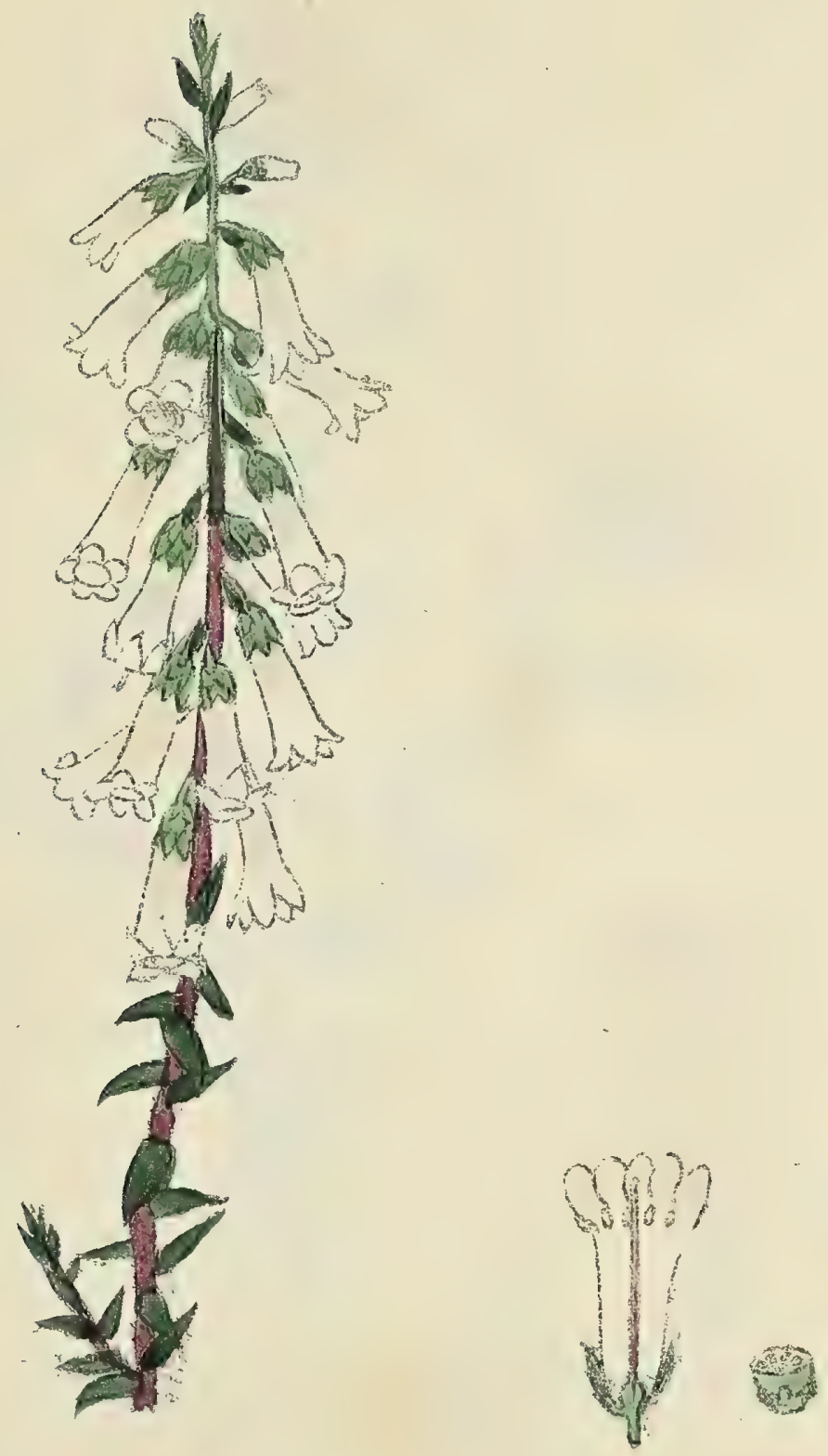

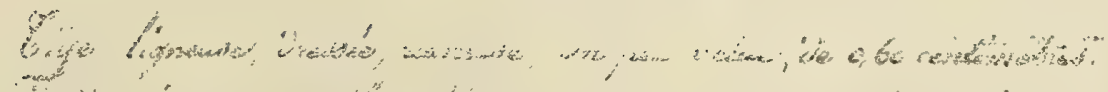

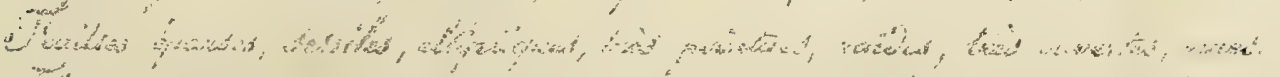

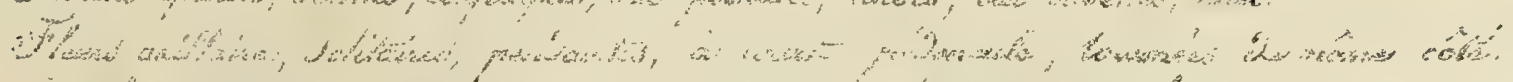

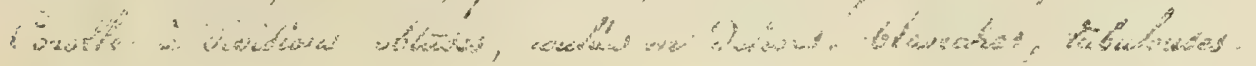

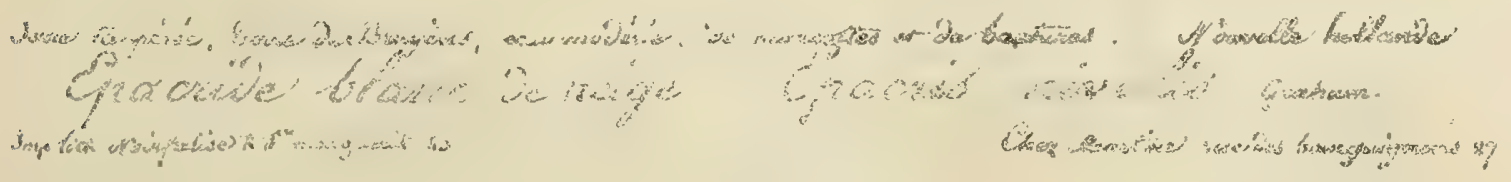




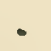




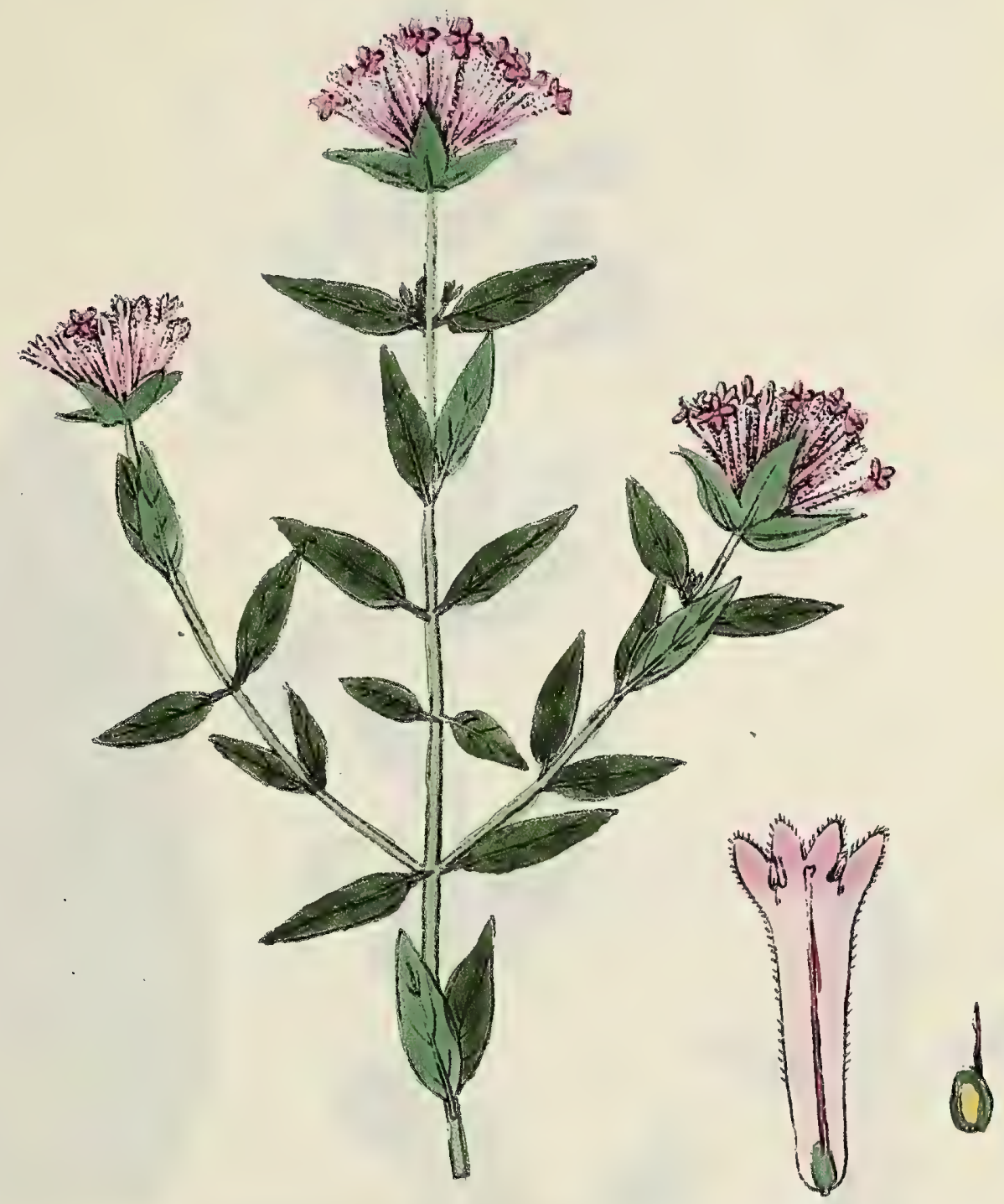

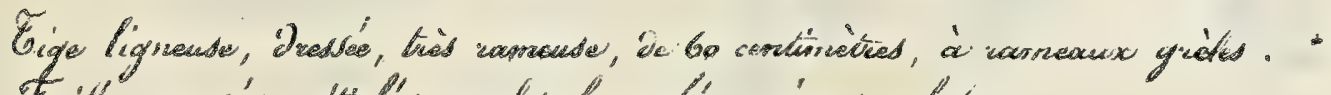

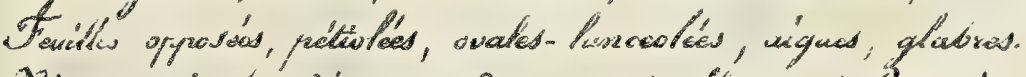

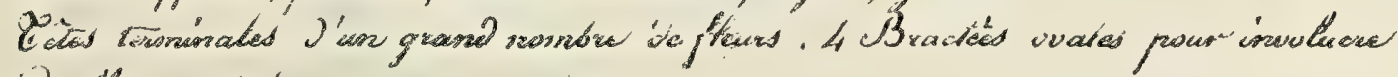

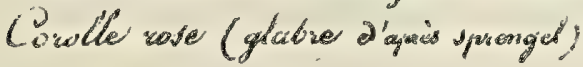

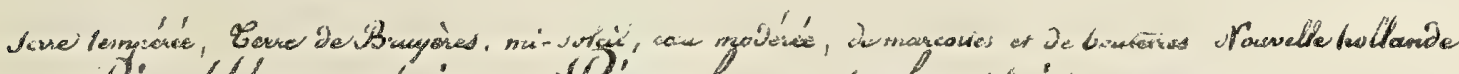

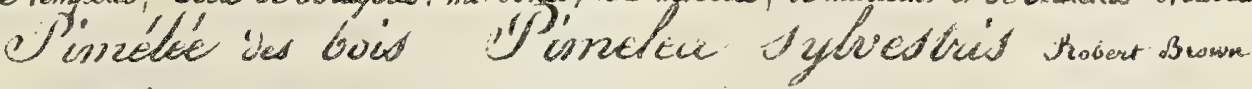

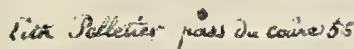

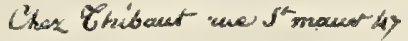





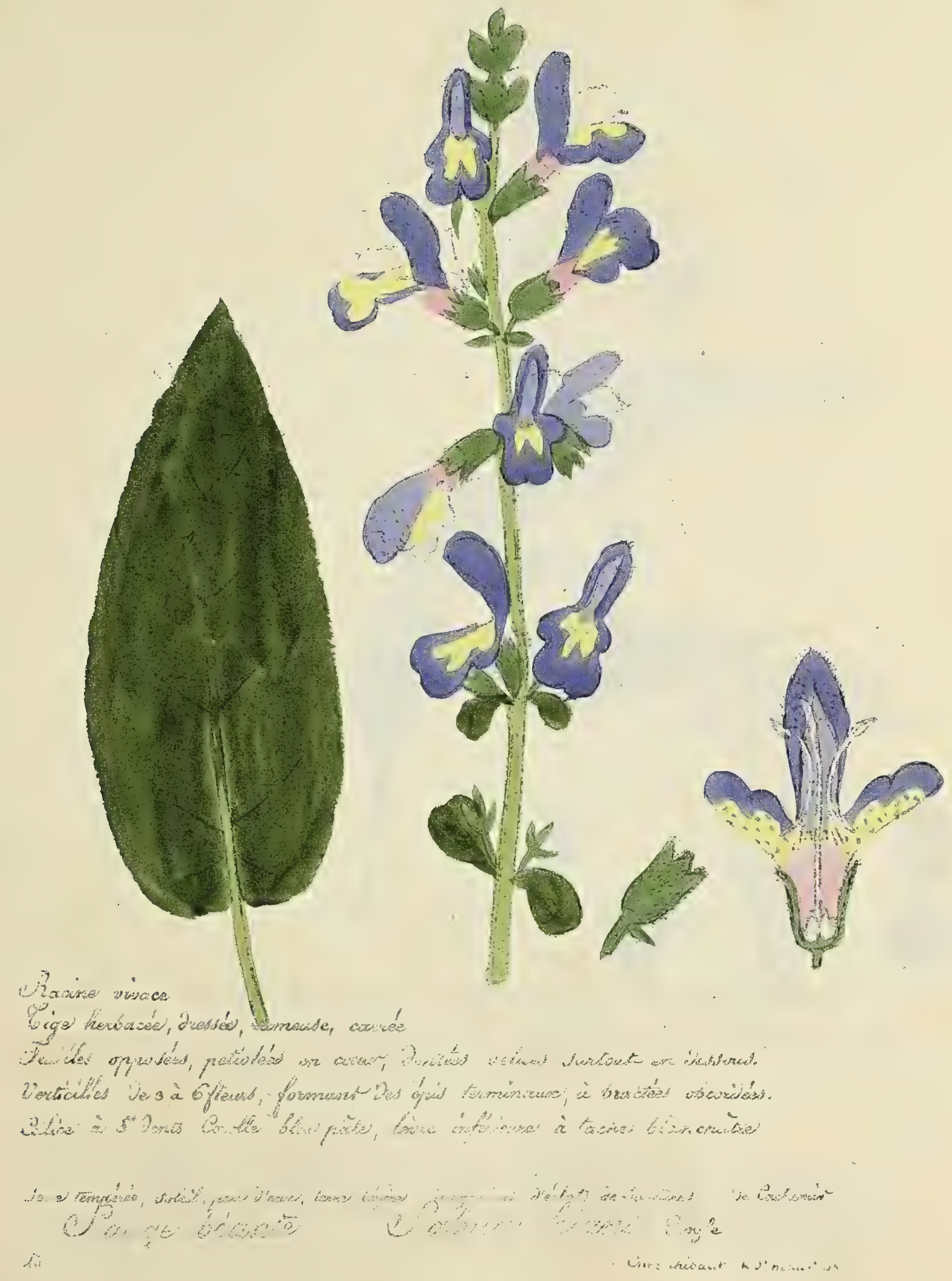





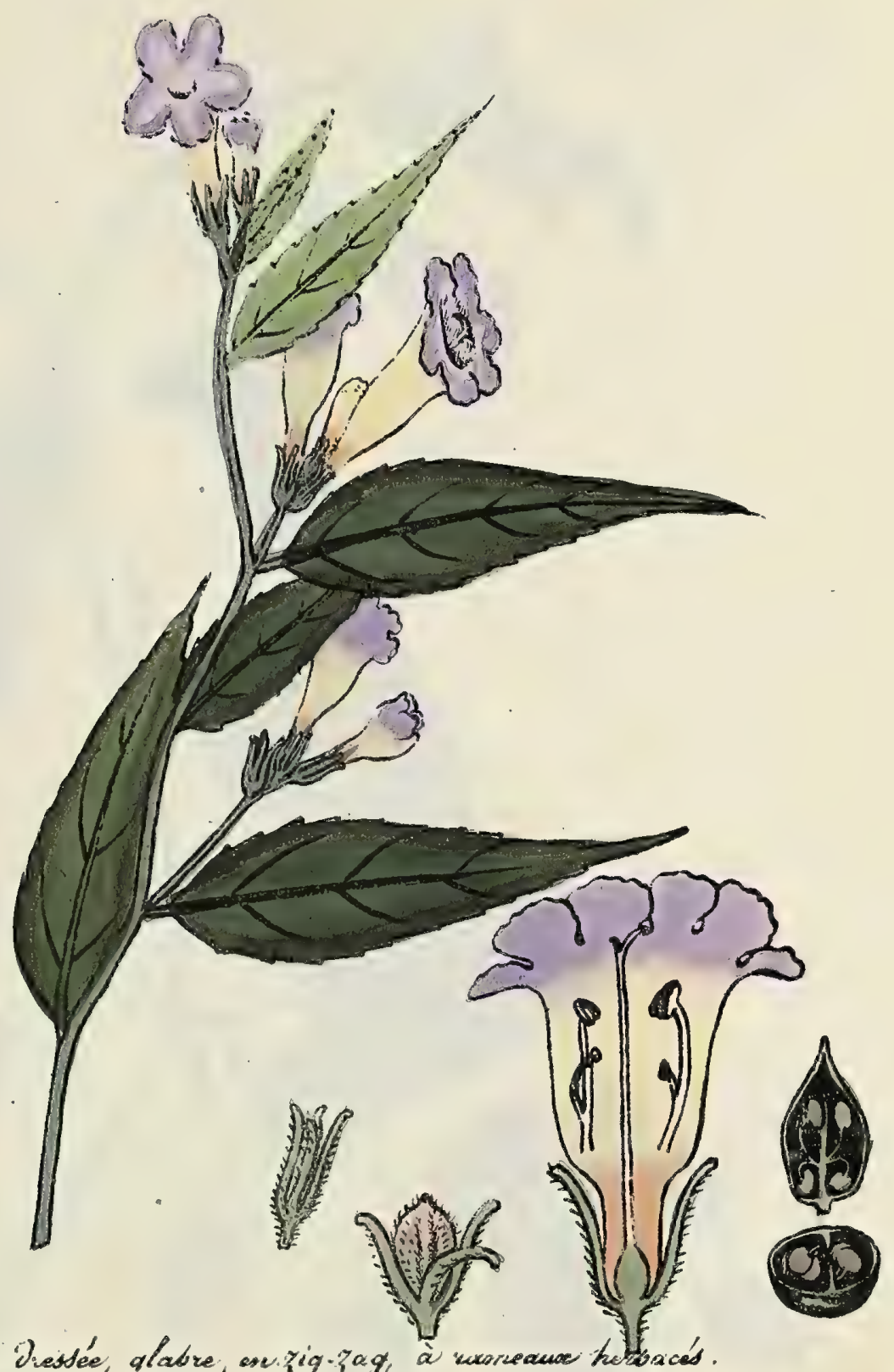

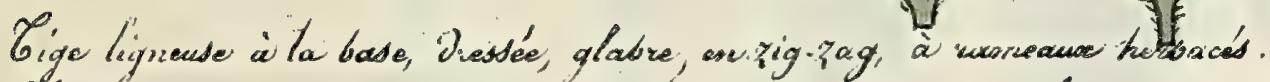

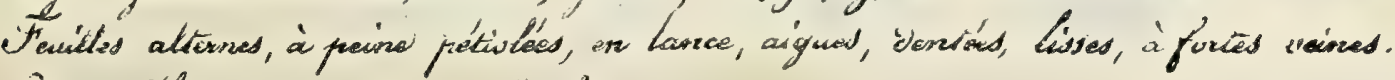

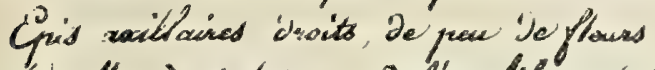

Cowtle is tobes onisules, hilas chair.

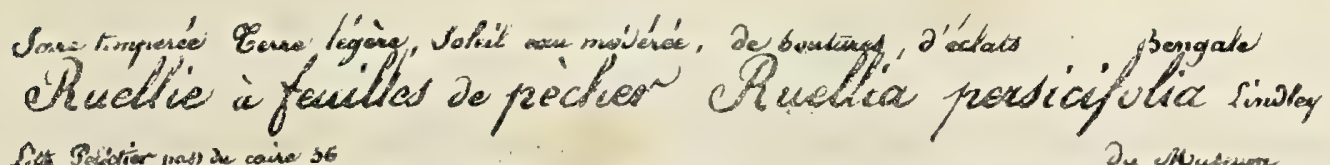

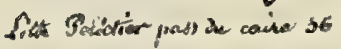





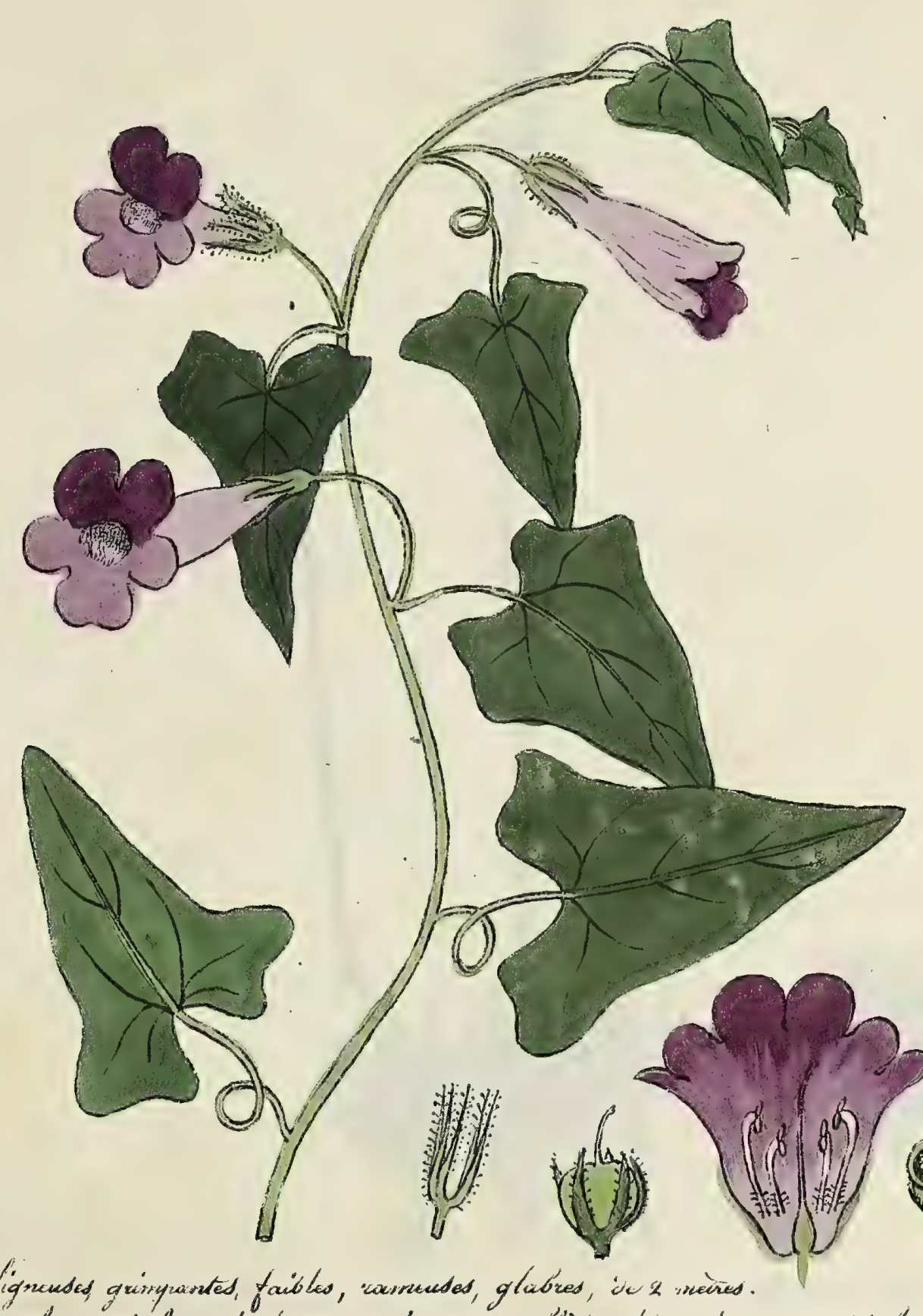

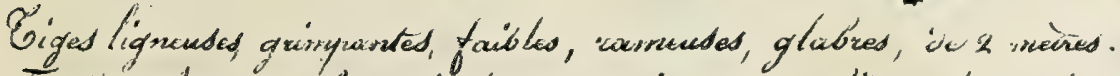

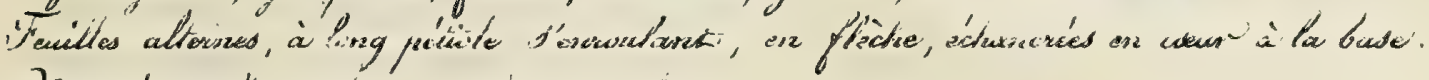

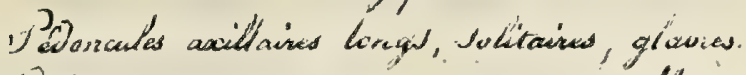

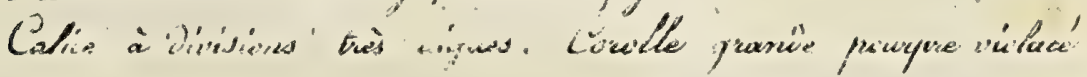

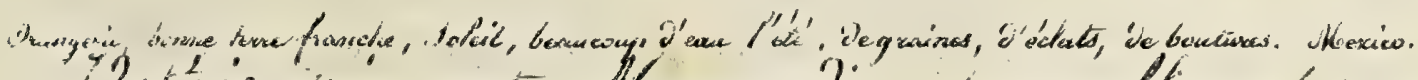

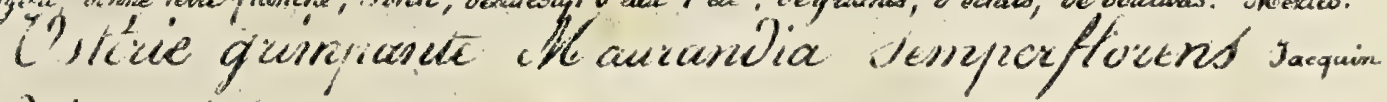

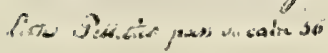





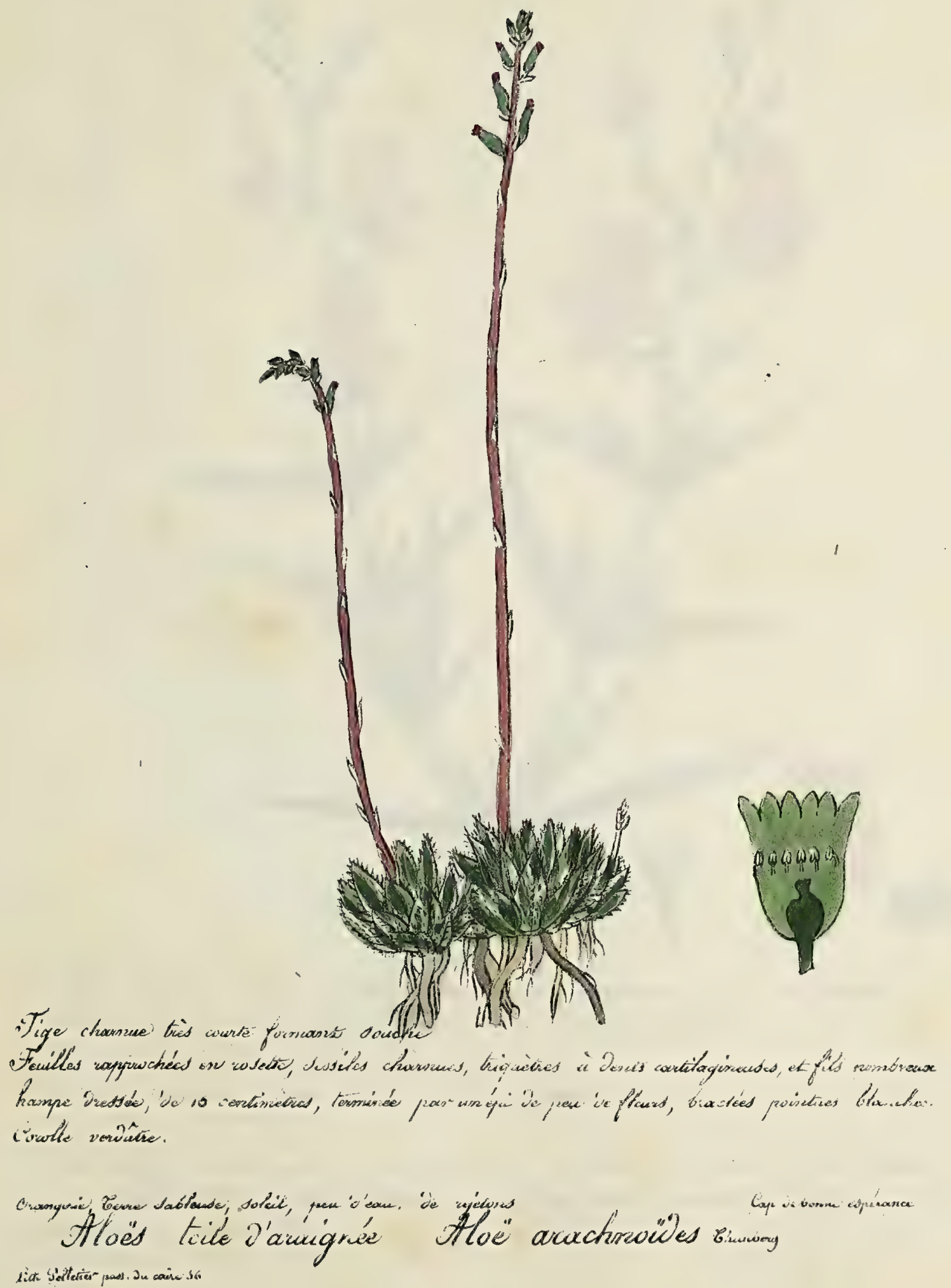

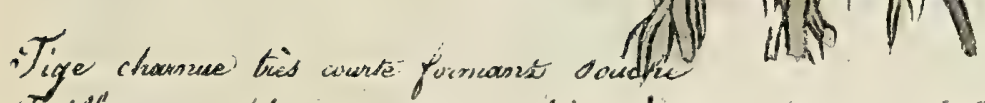





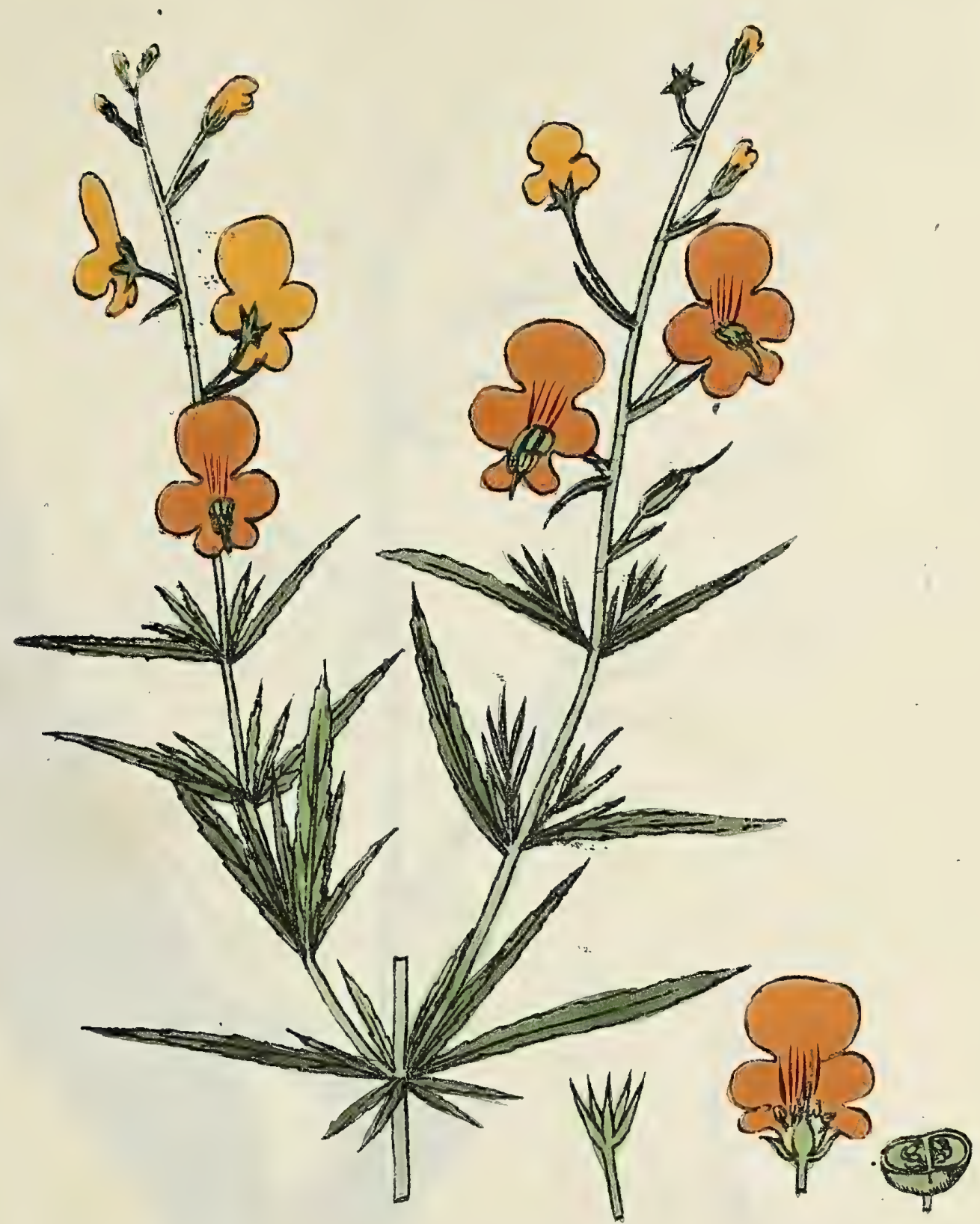

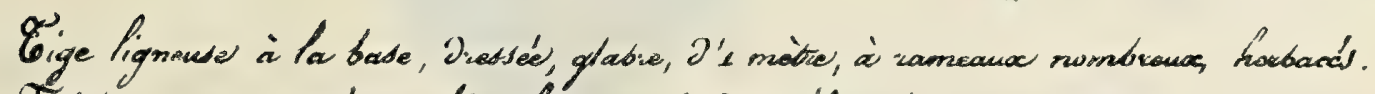

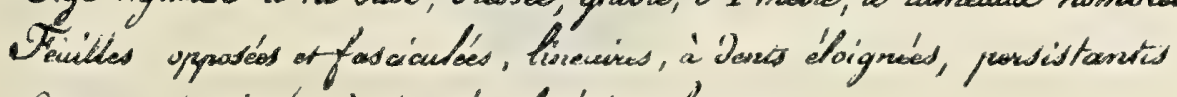

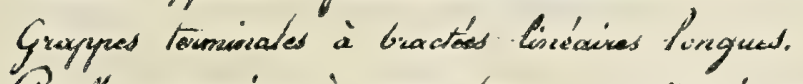

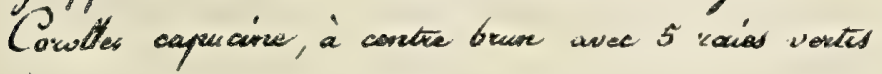

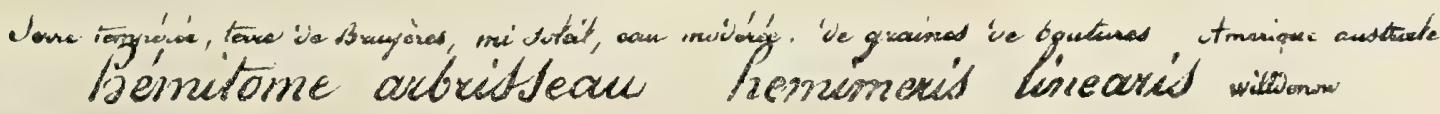

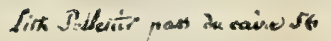





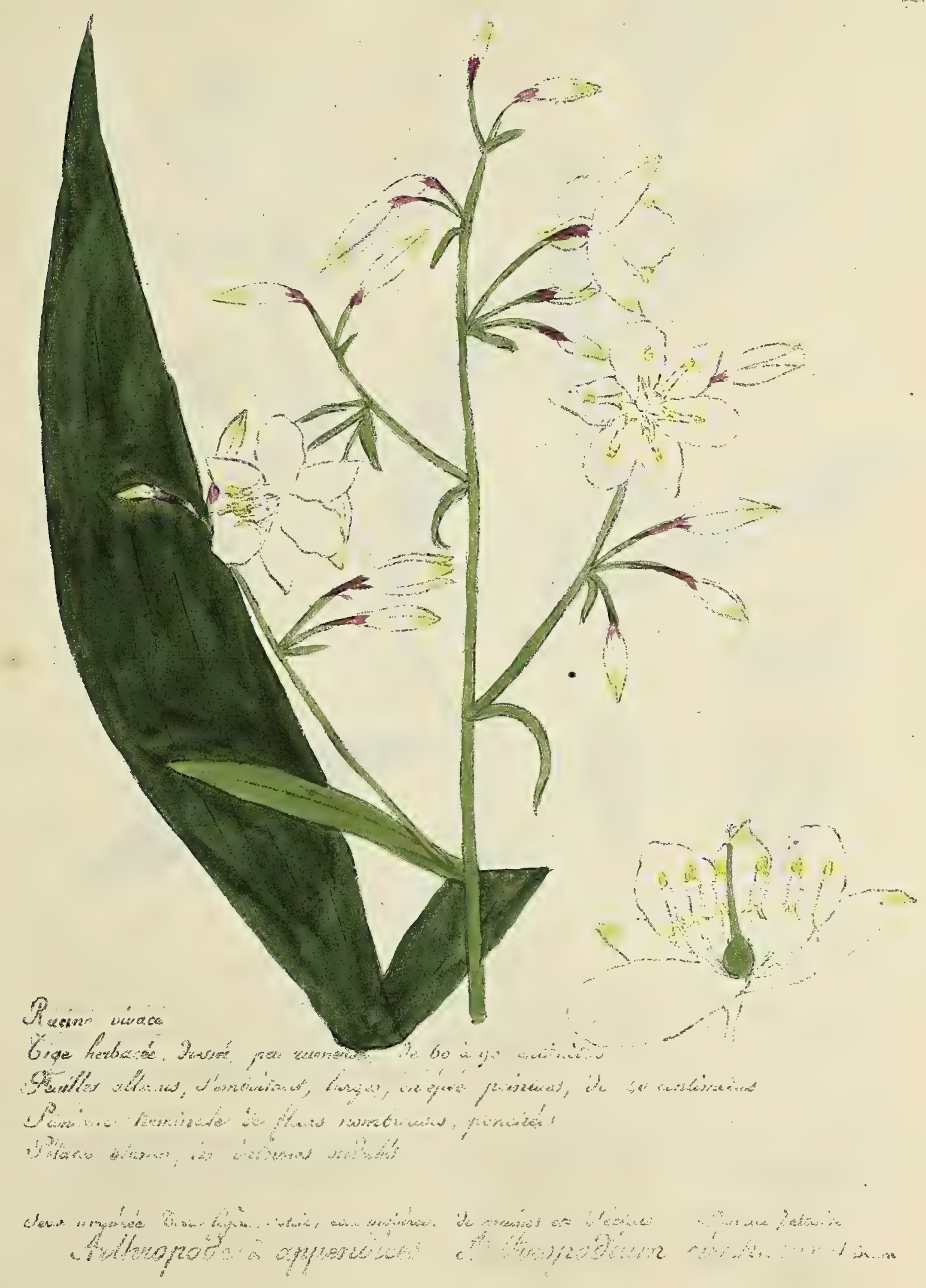




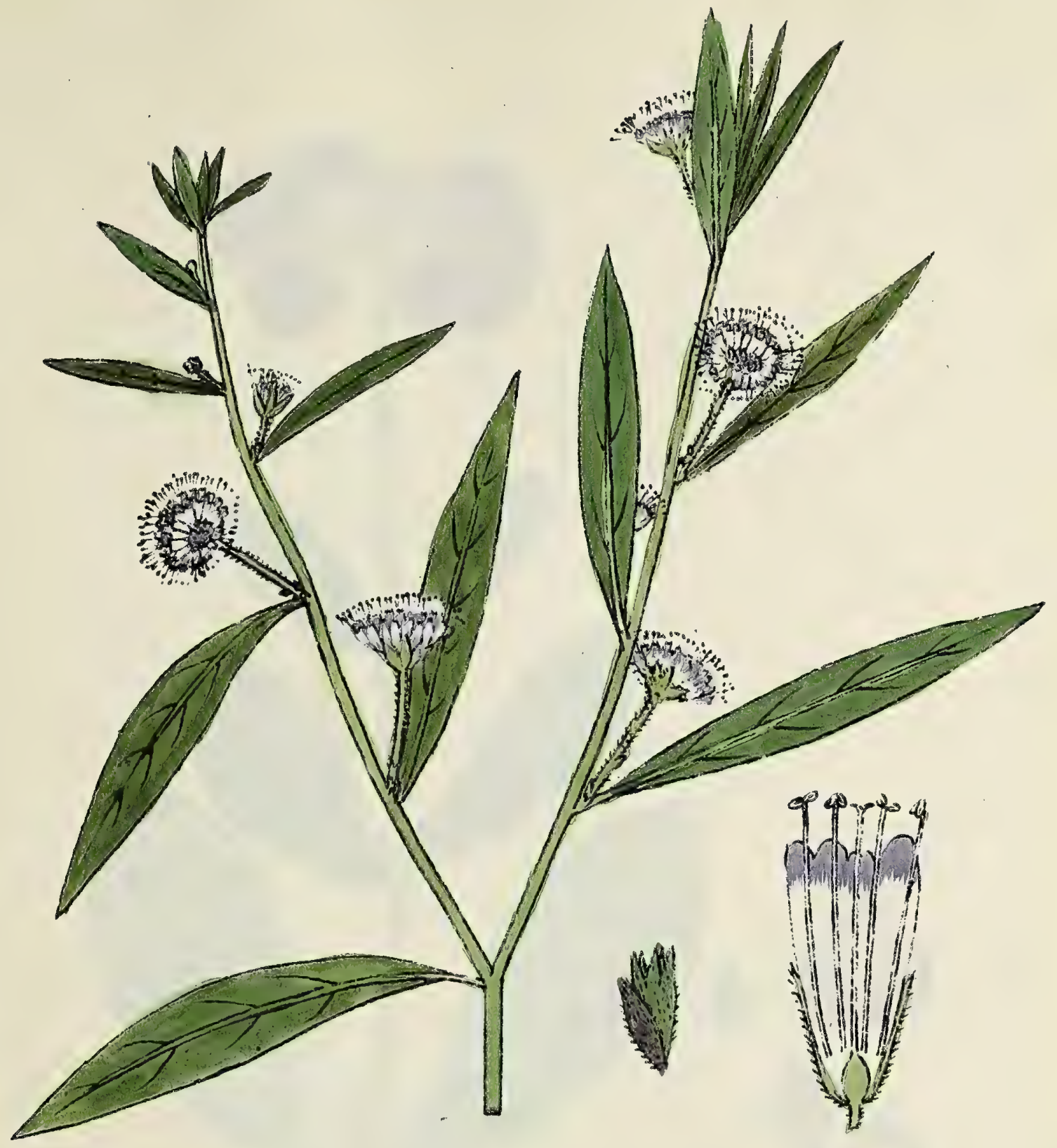

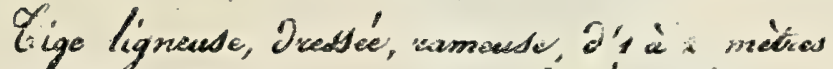

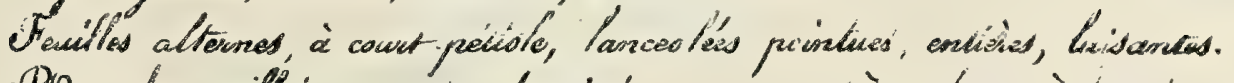

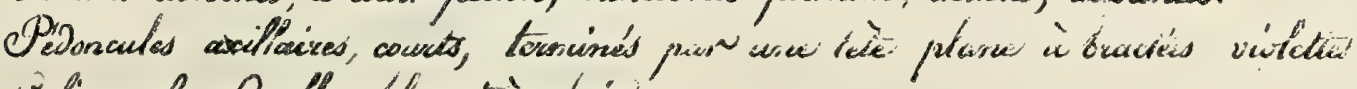
ialia velue, Porolle blow tius dain

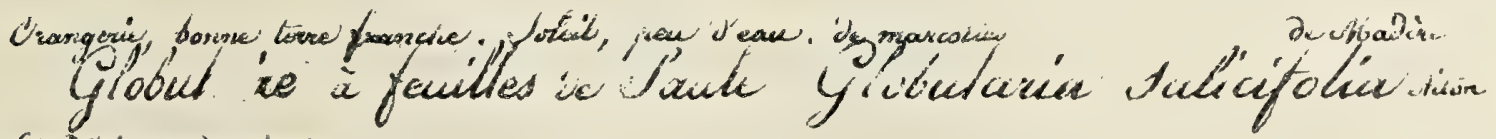

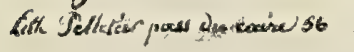





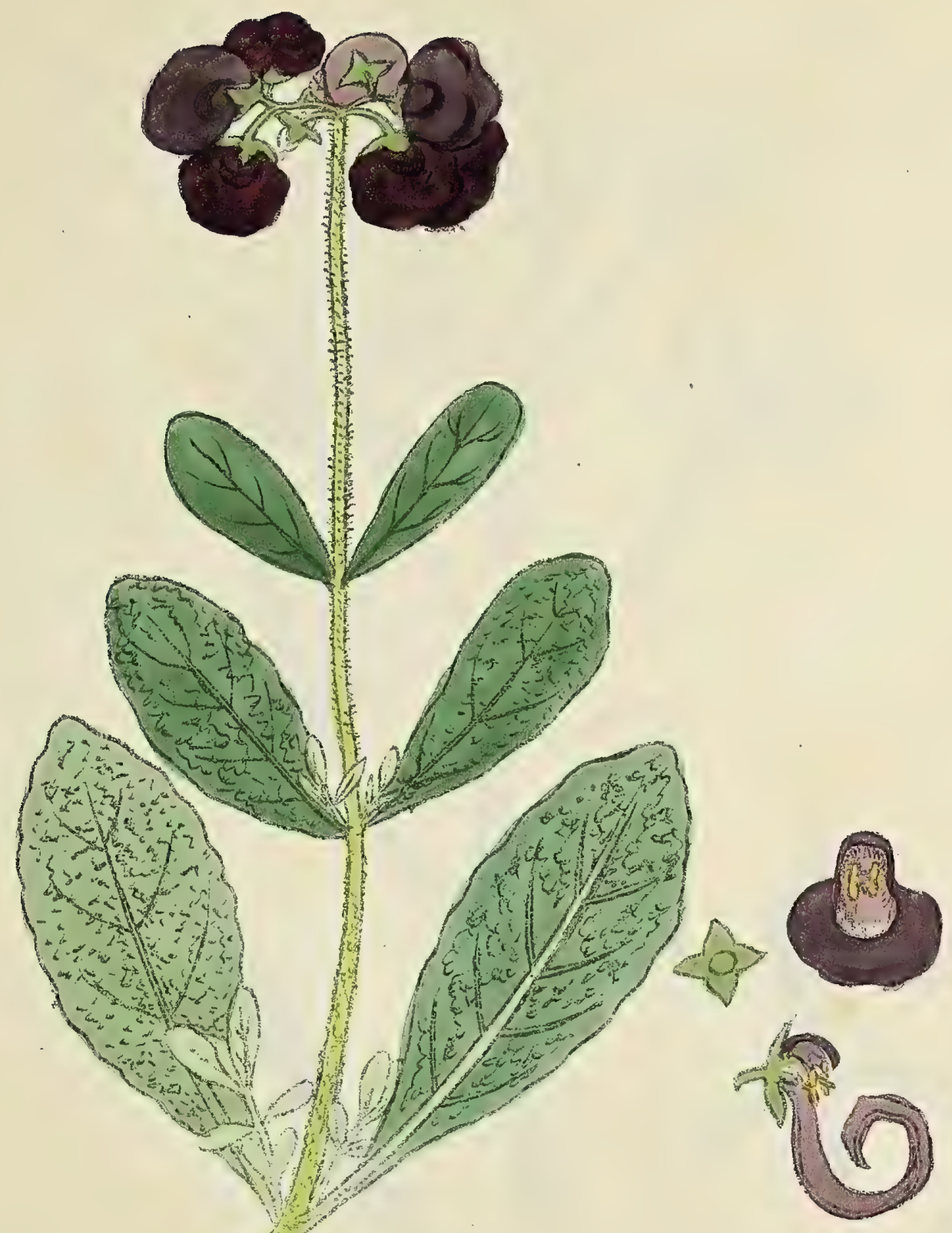

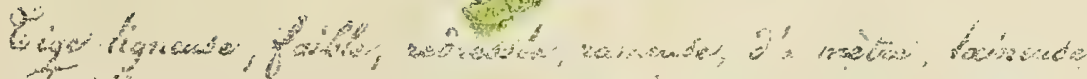

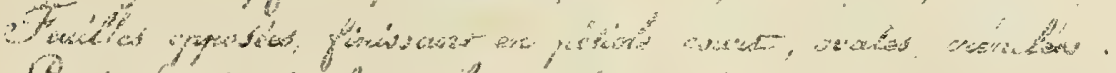

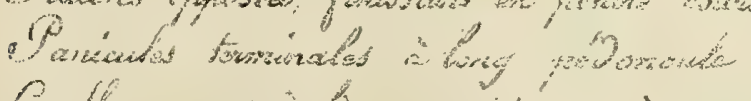

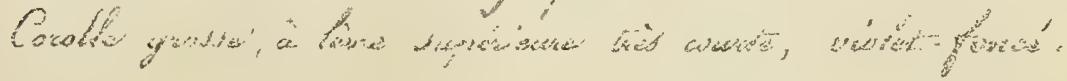

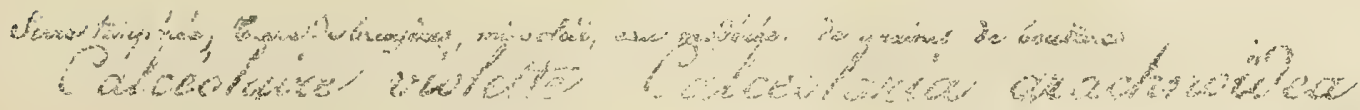


$\therefore \quad 36$ 


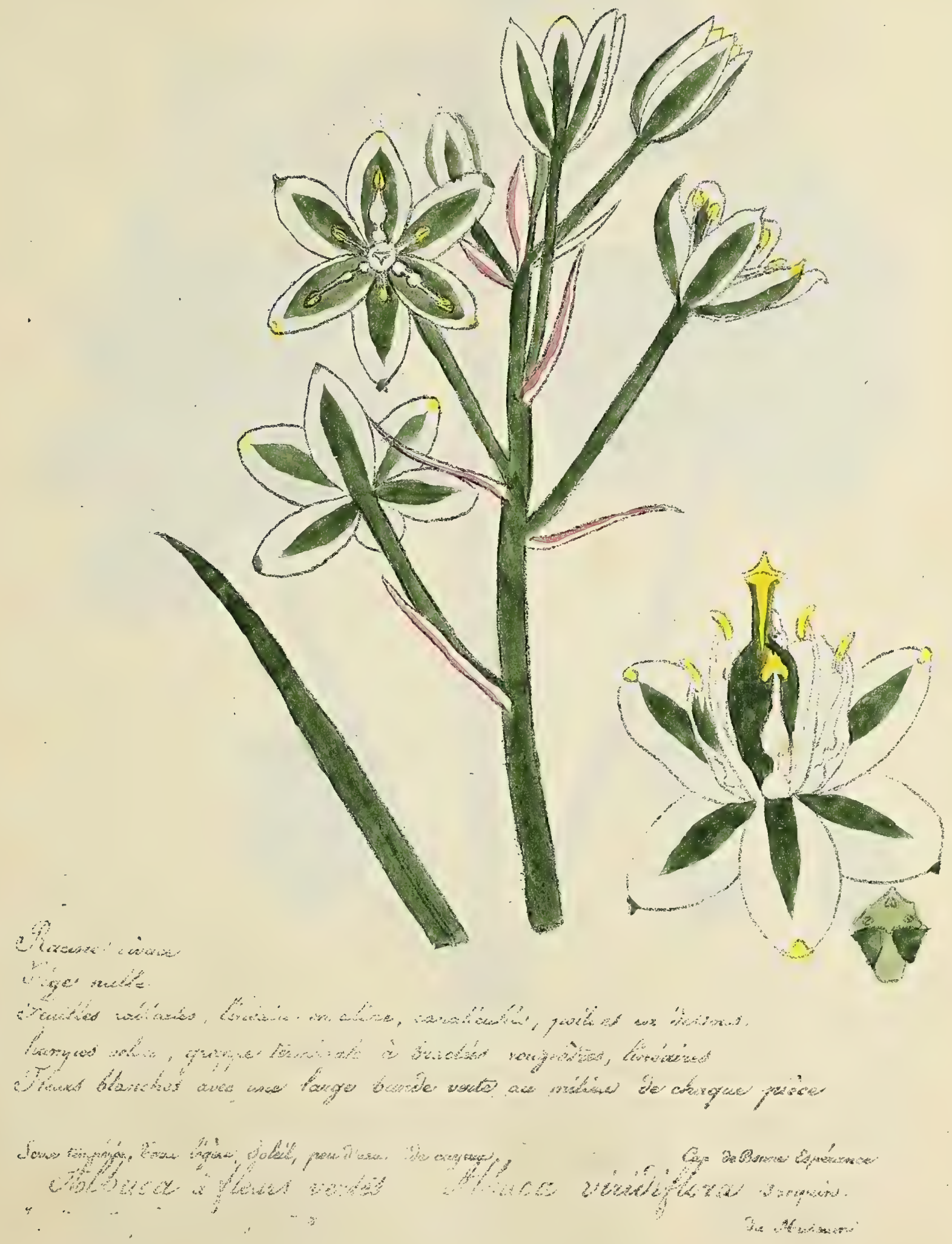





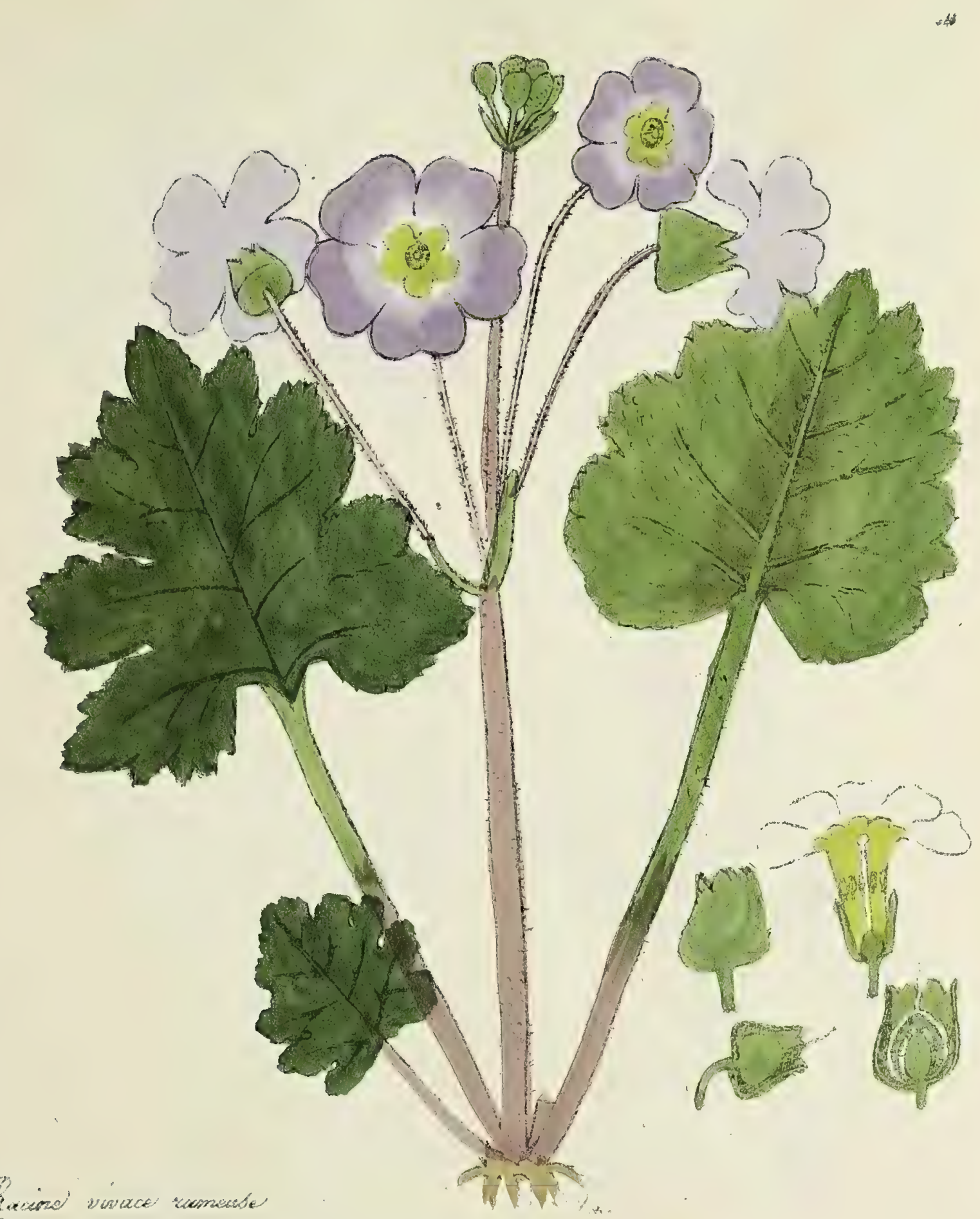

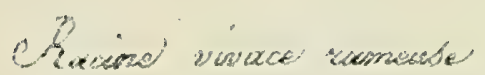

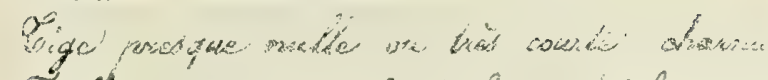

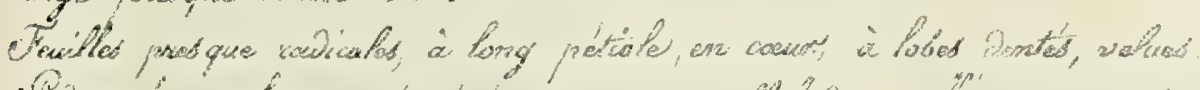
1. Pu

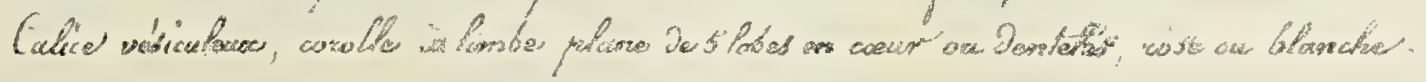

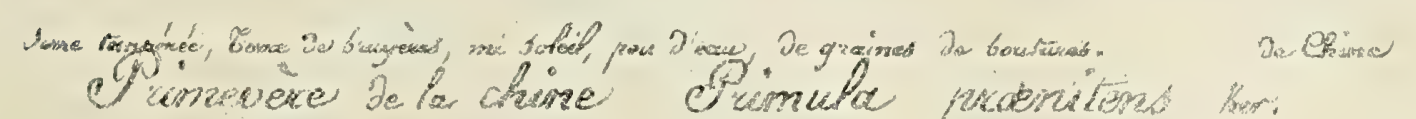


,

- 


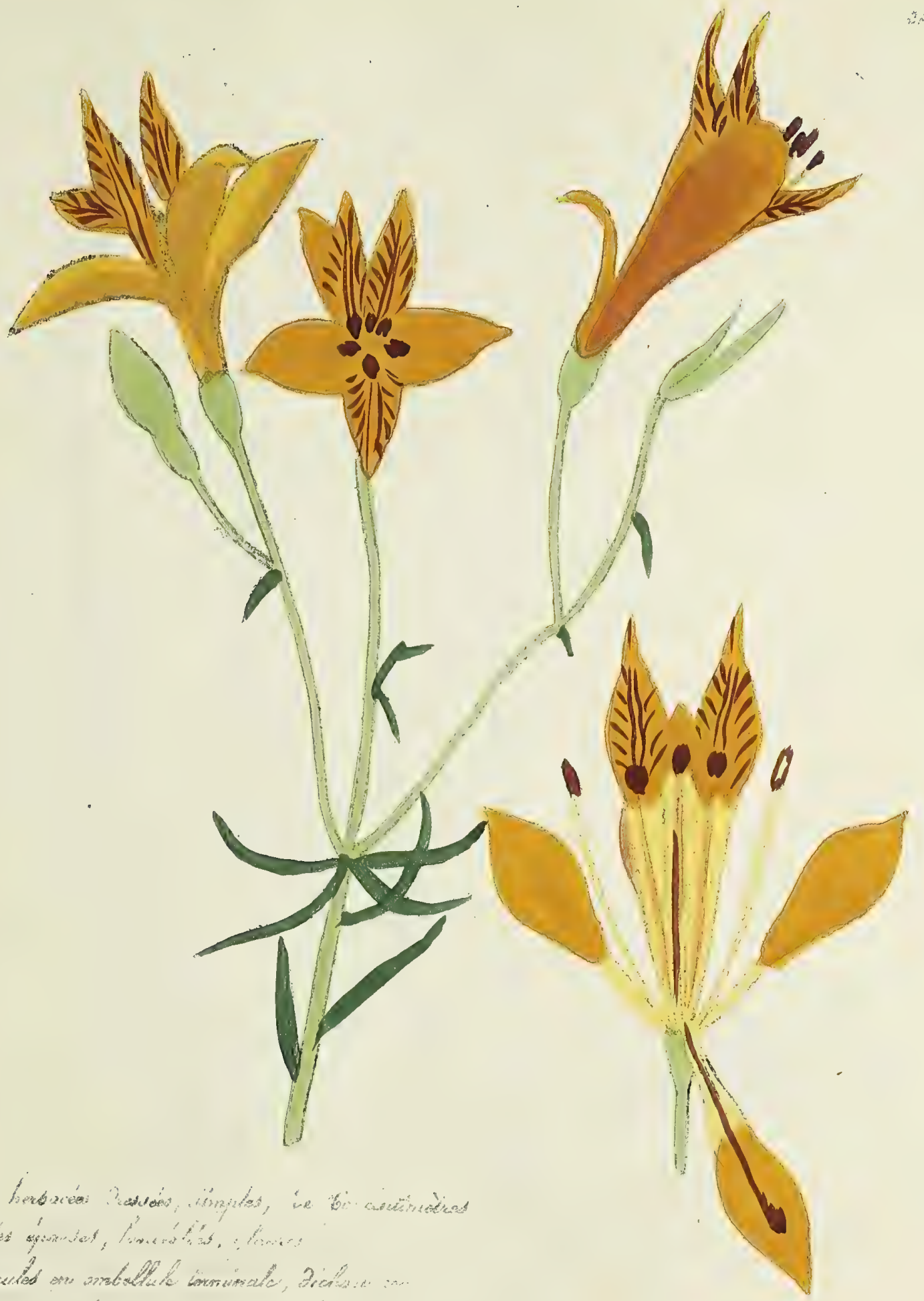

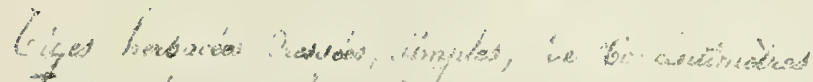

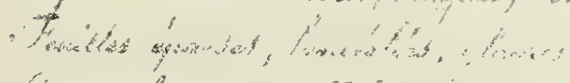

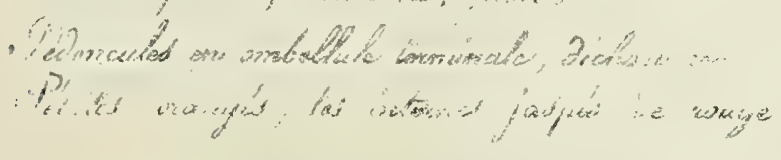

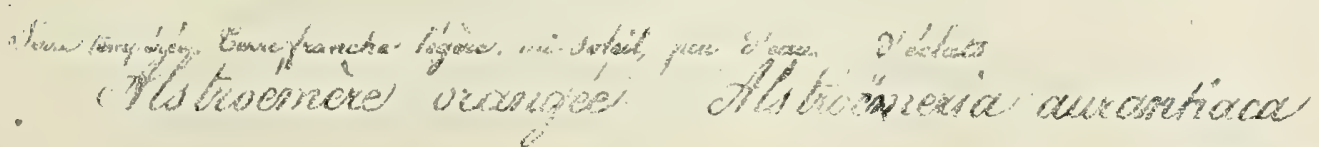
Du. Mestums:. 


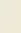


26
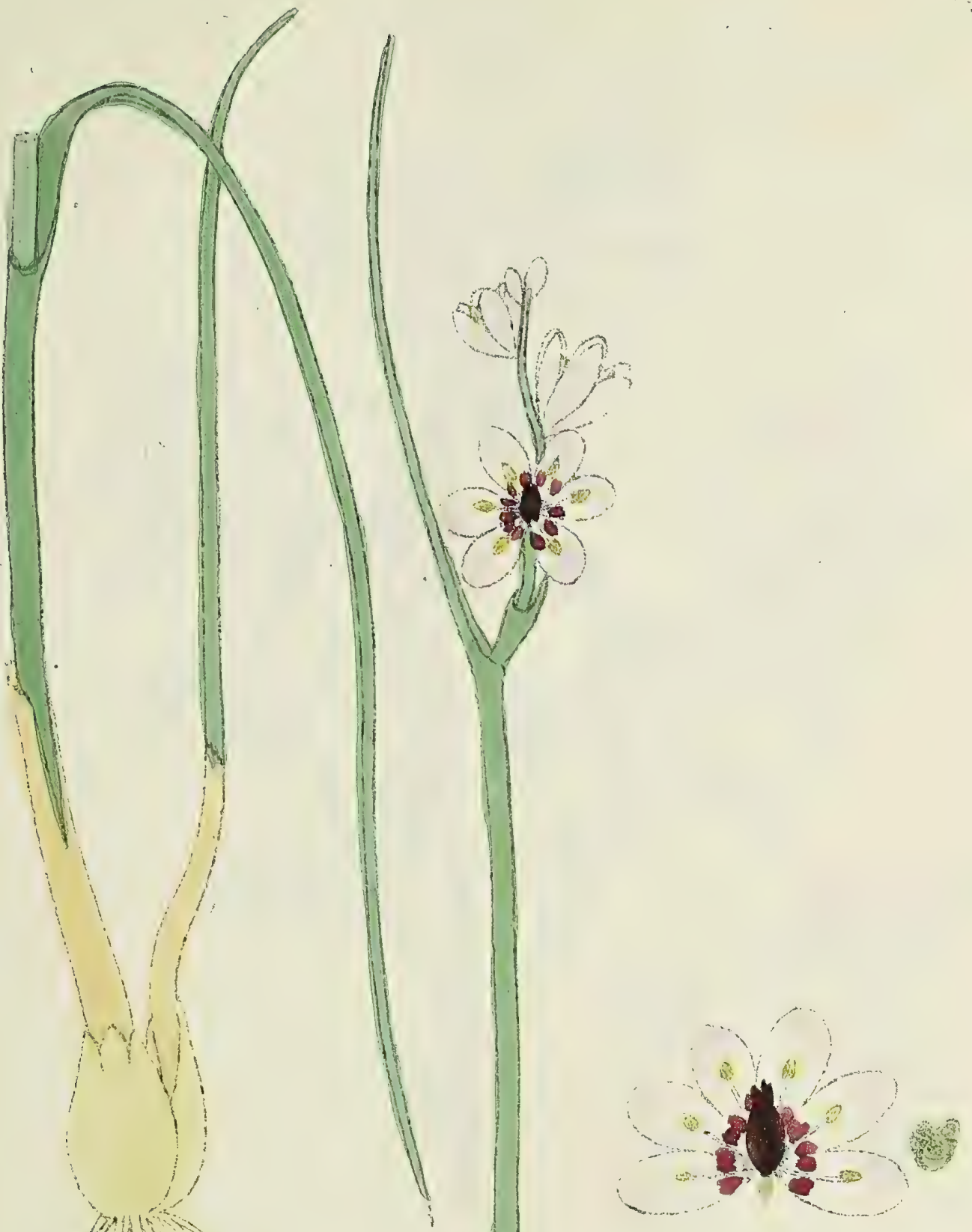

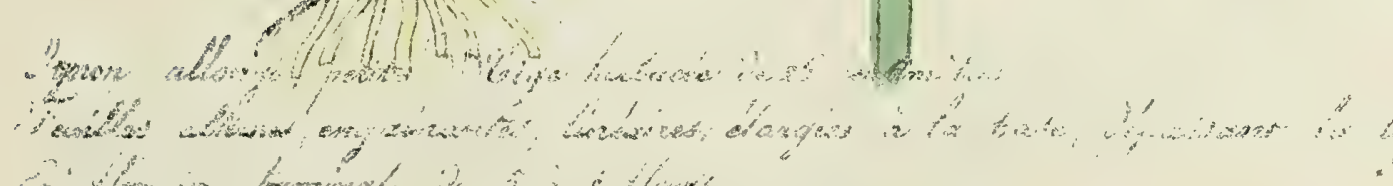

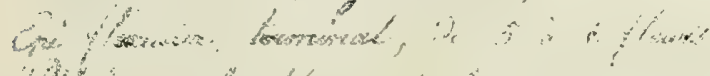

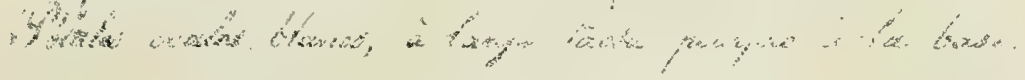

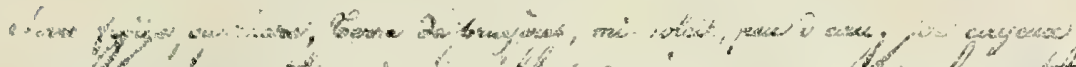

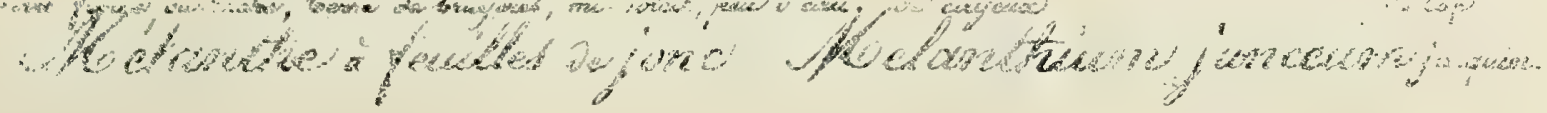




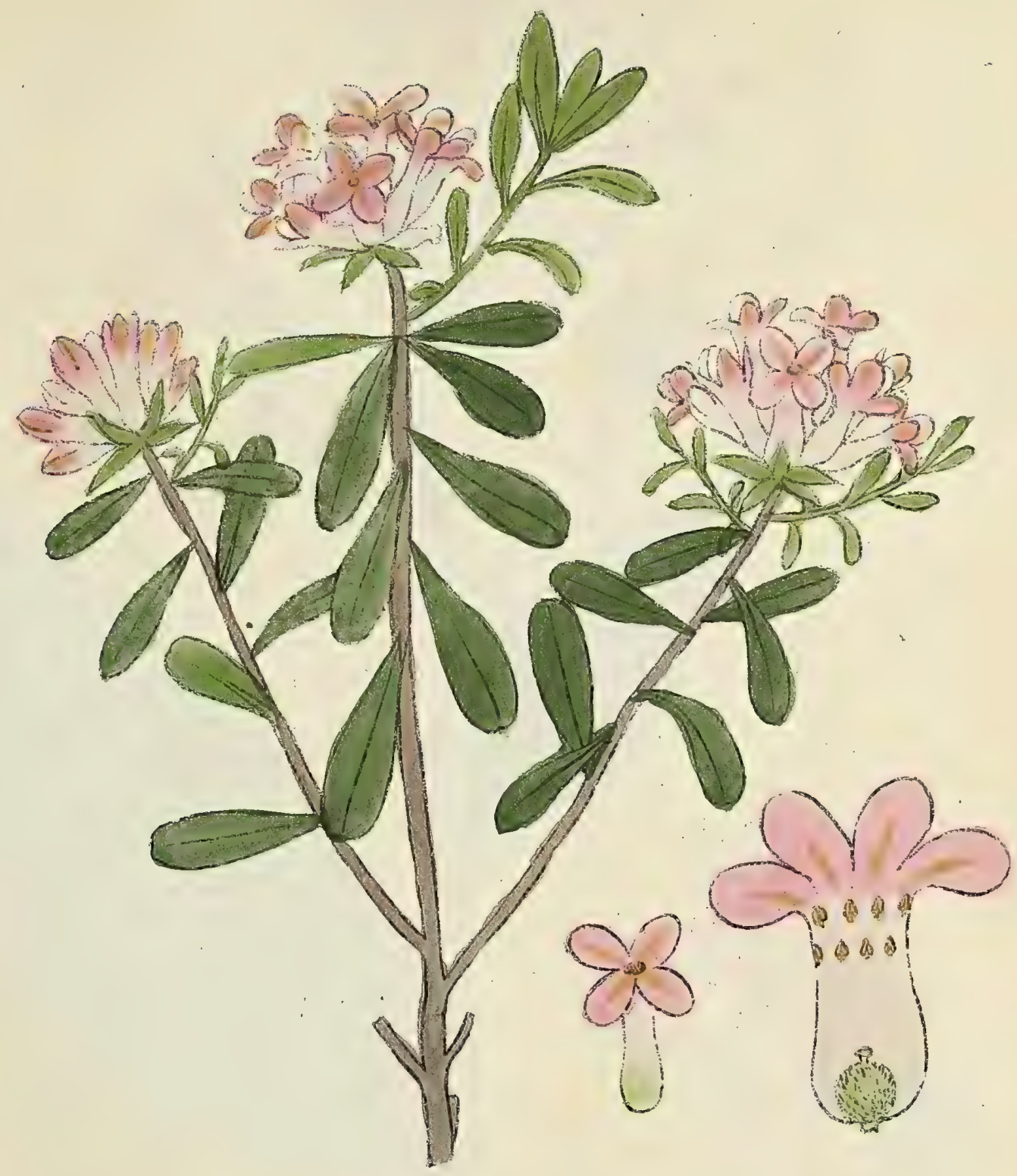

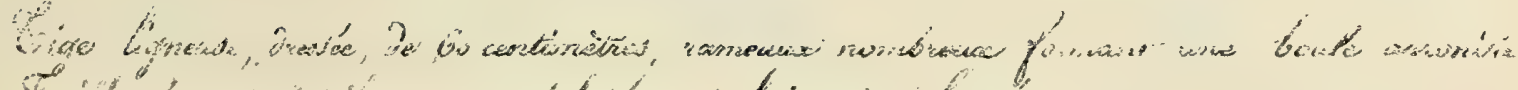

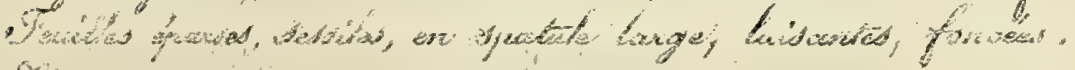

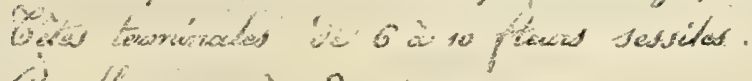

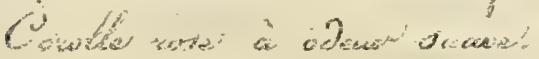

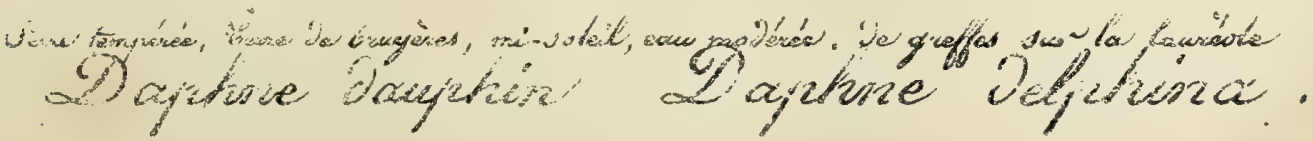





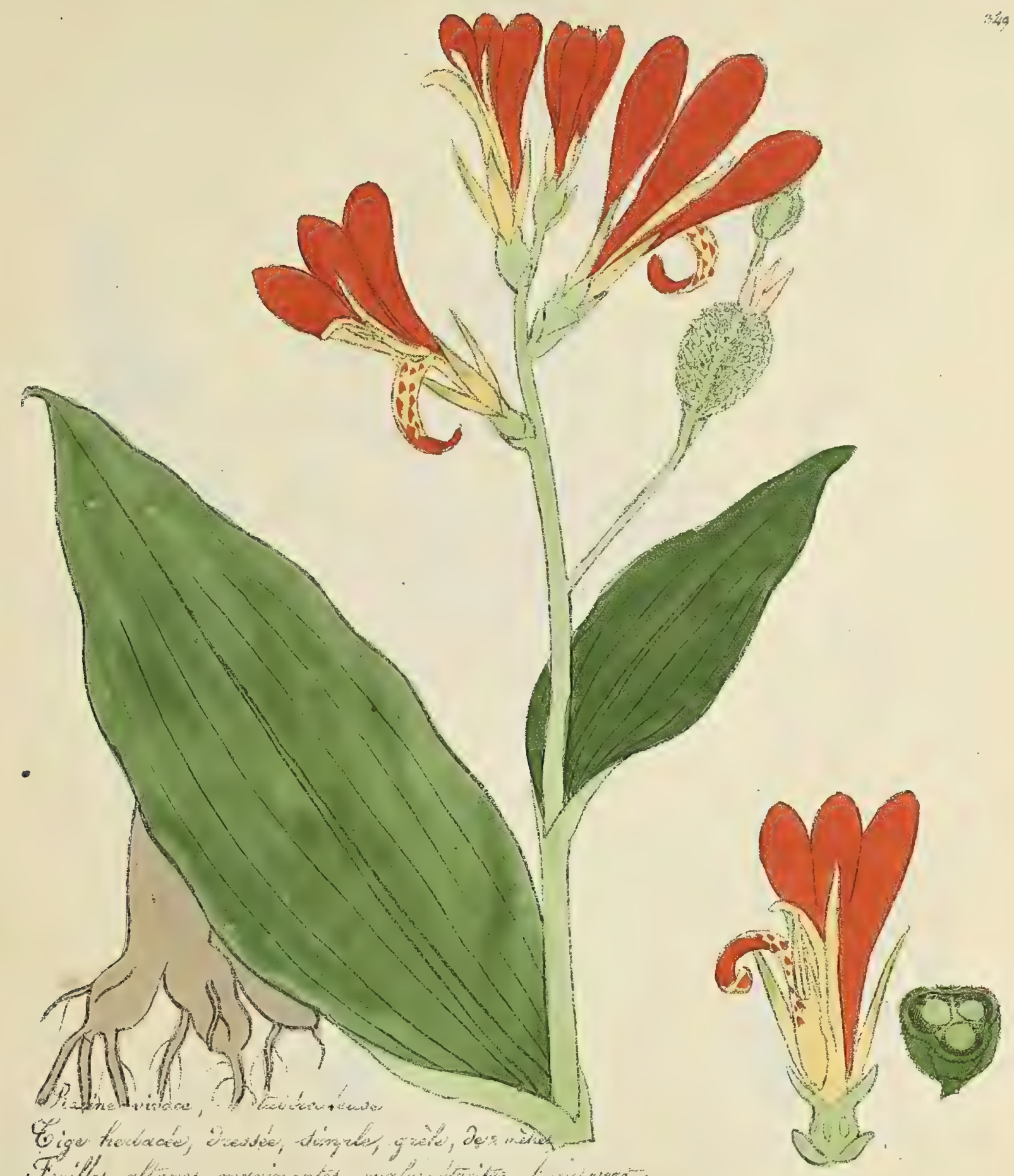

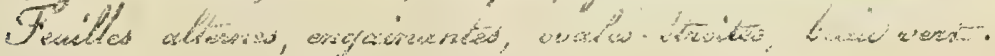

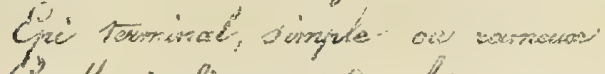

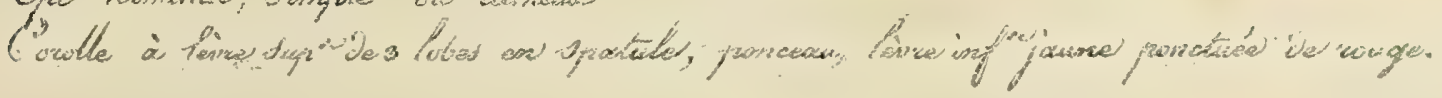

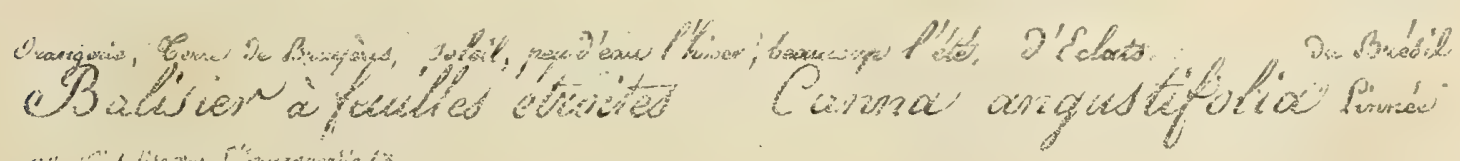

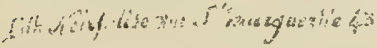




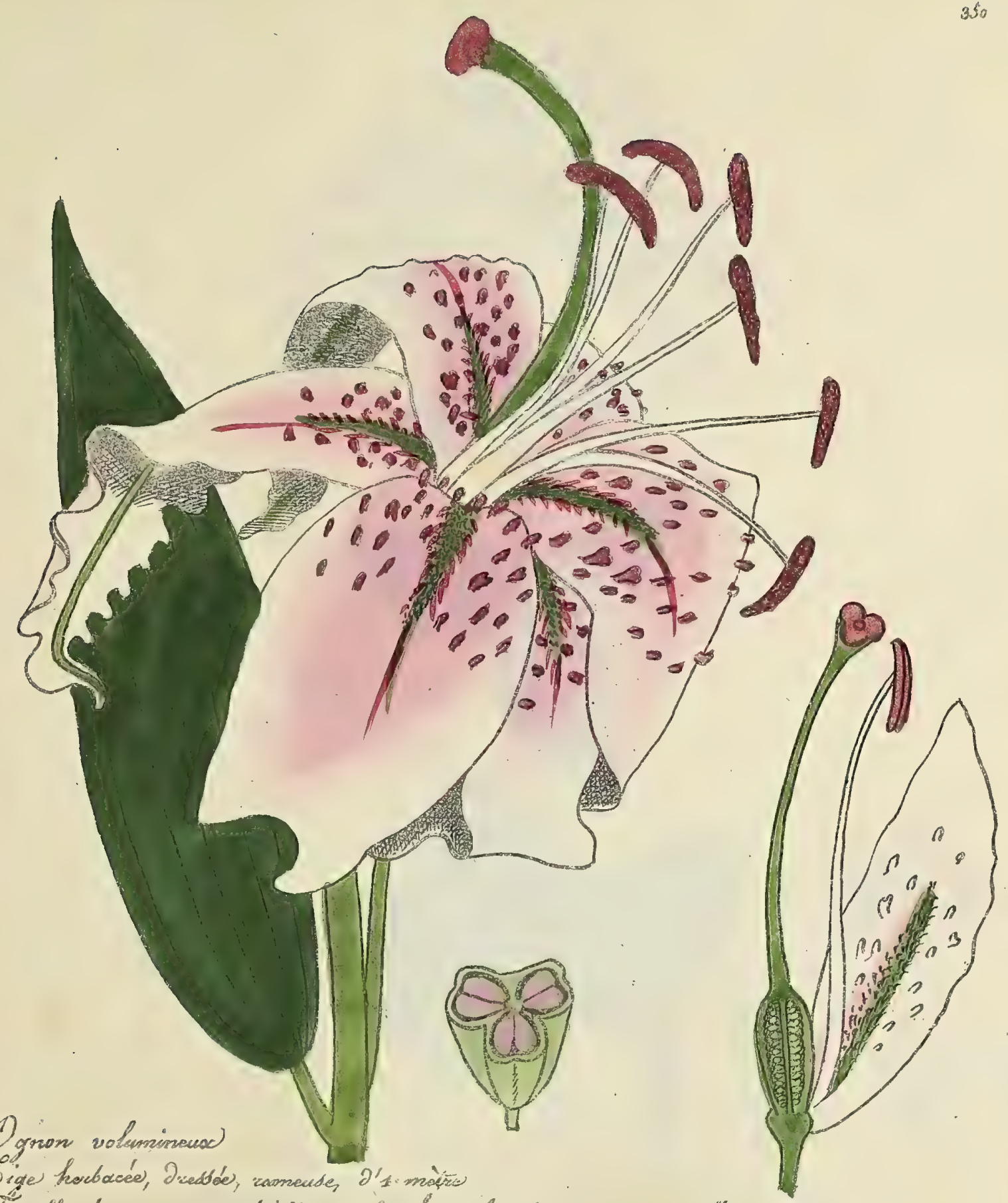

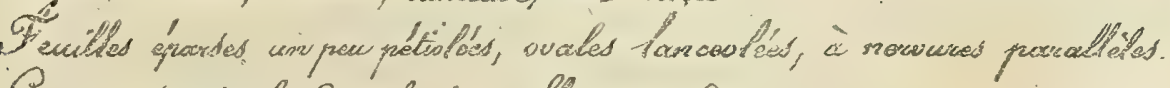

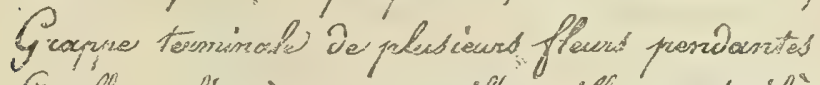

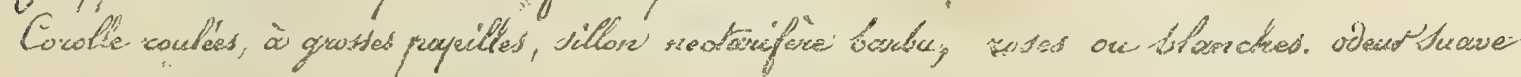

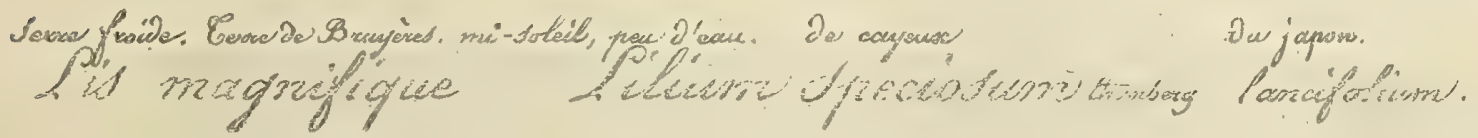

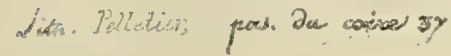



3
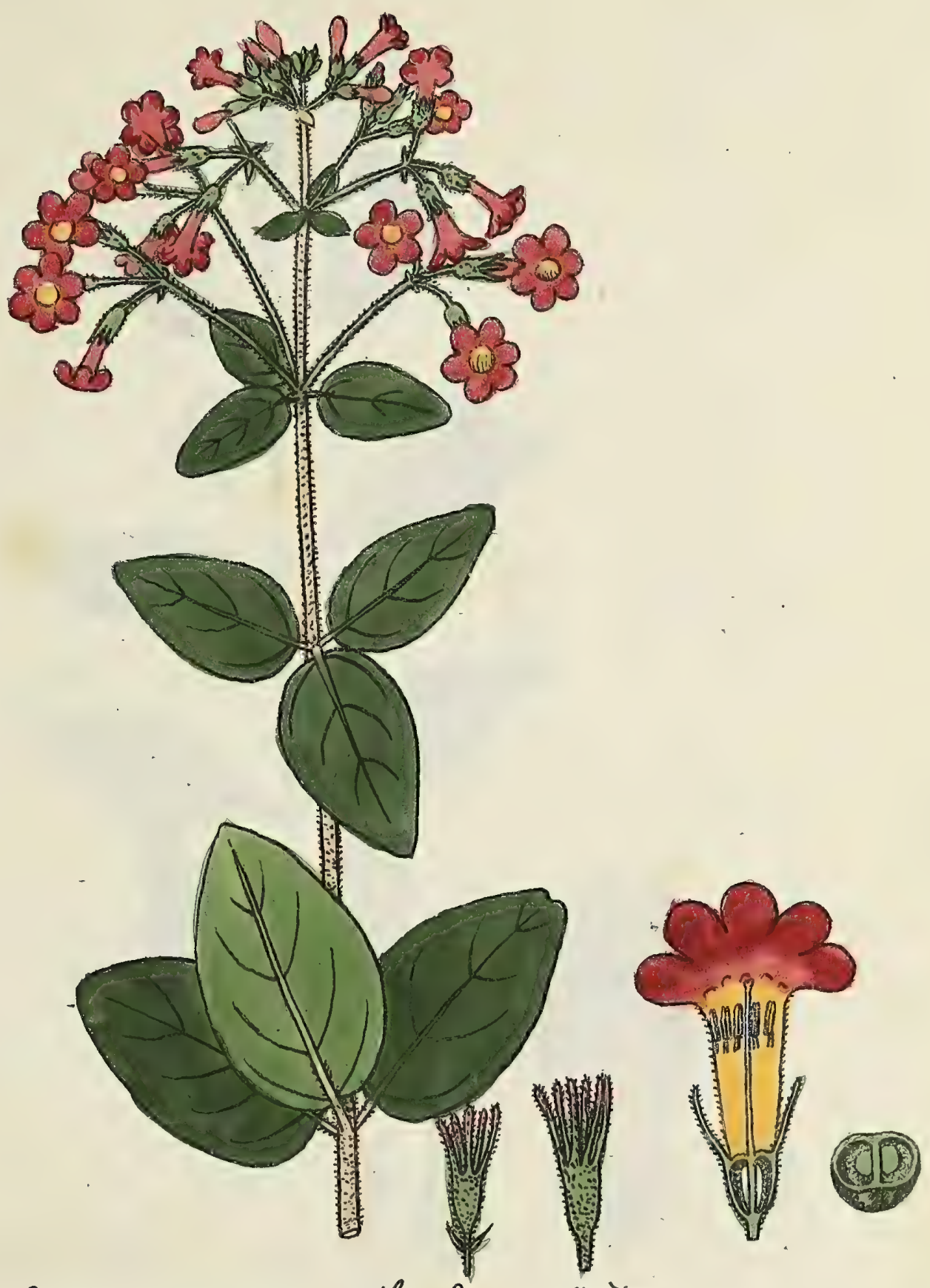

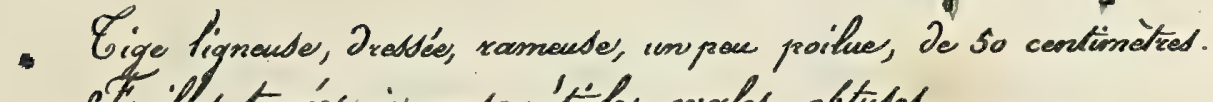
Temilles tovinées; à count pétiole, ovocles, obtuded.

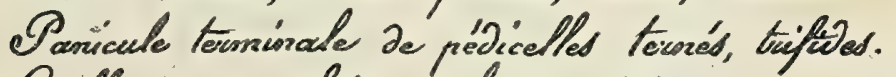

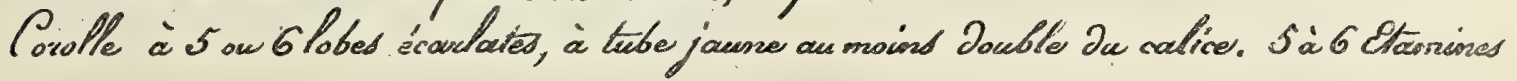

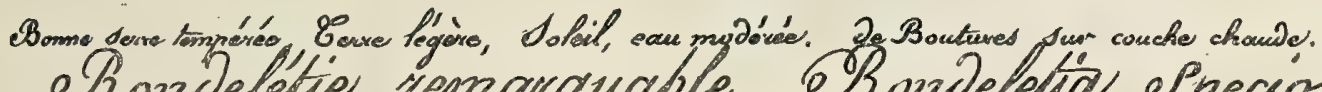

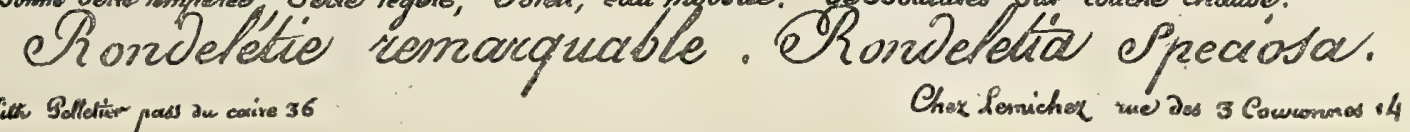
Silt Bolldition pass ar caive 36 


.




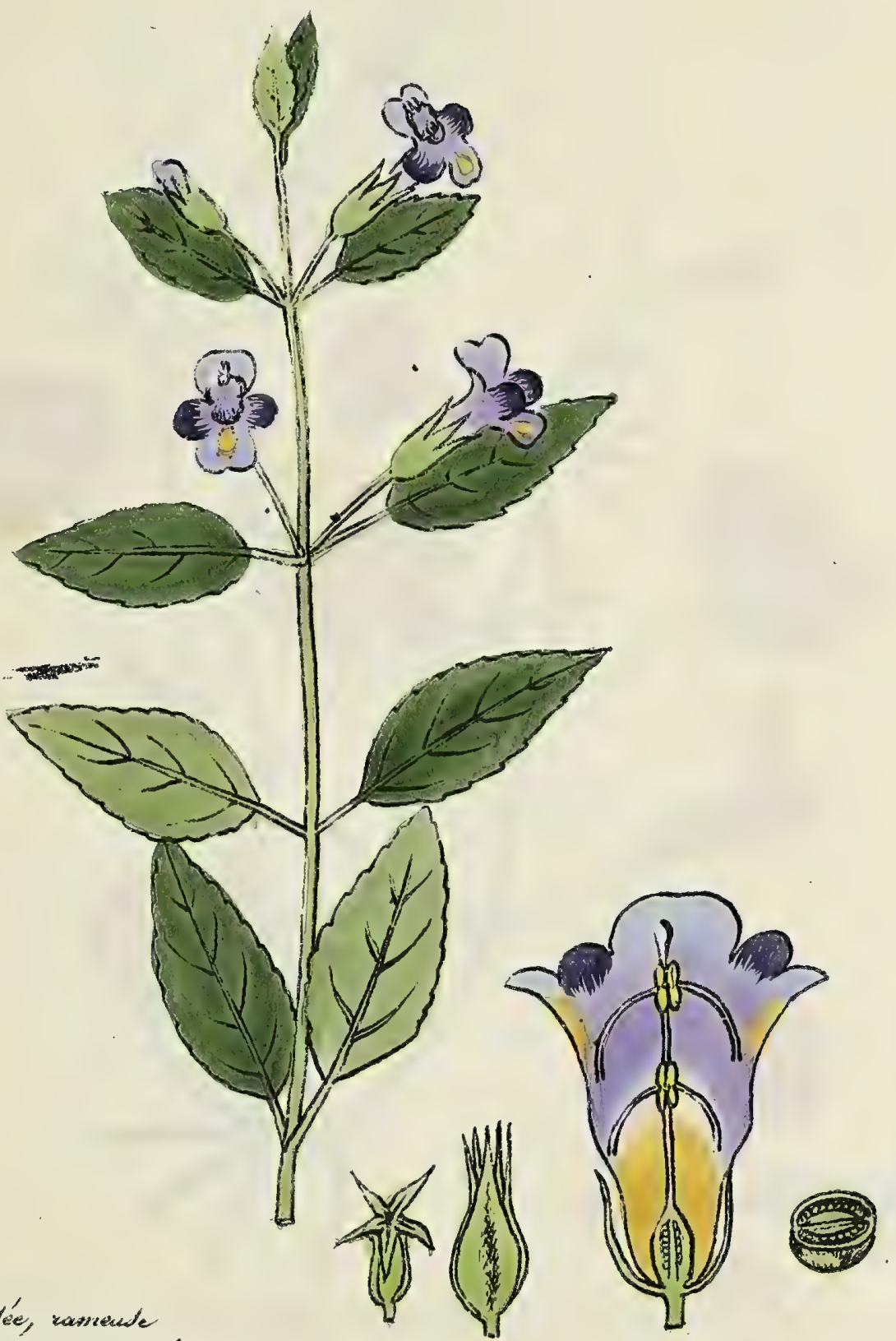

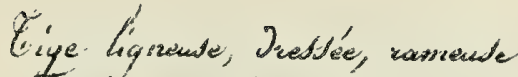

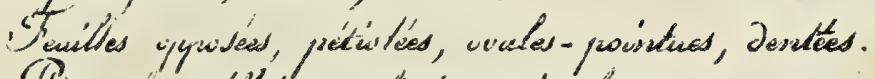

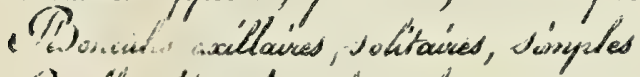

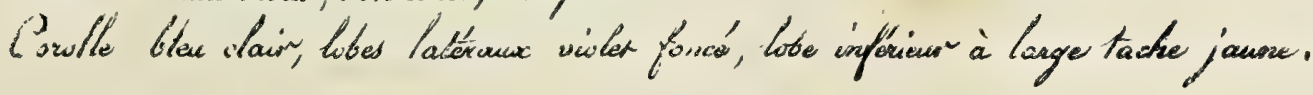

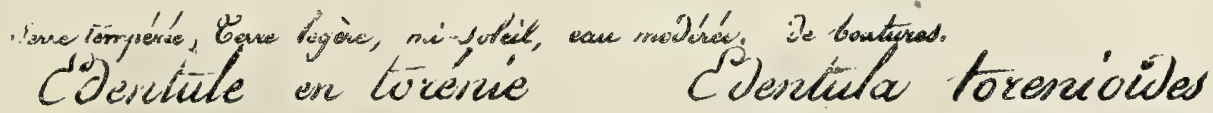

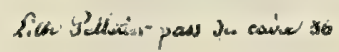

Chas Bontrand we Jela iaquelie tor 



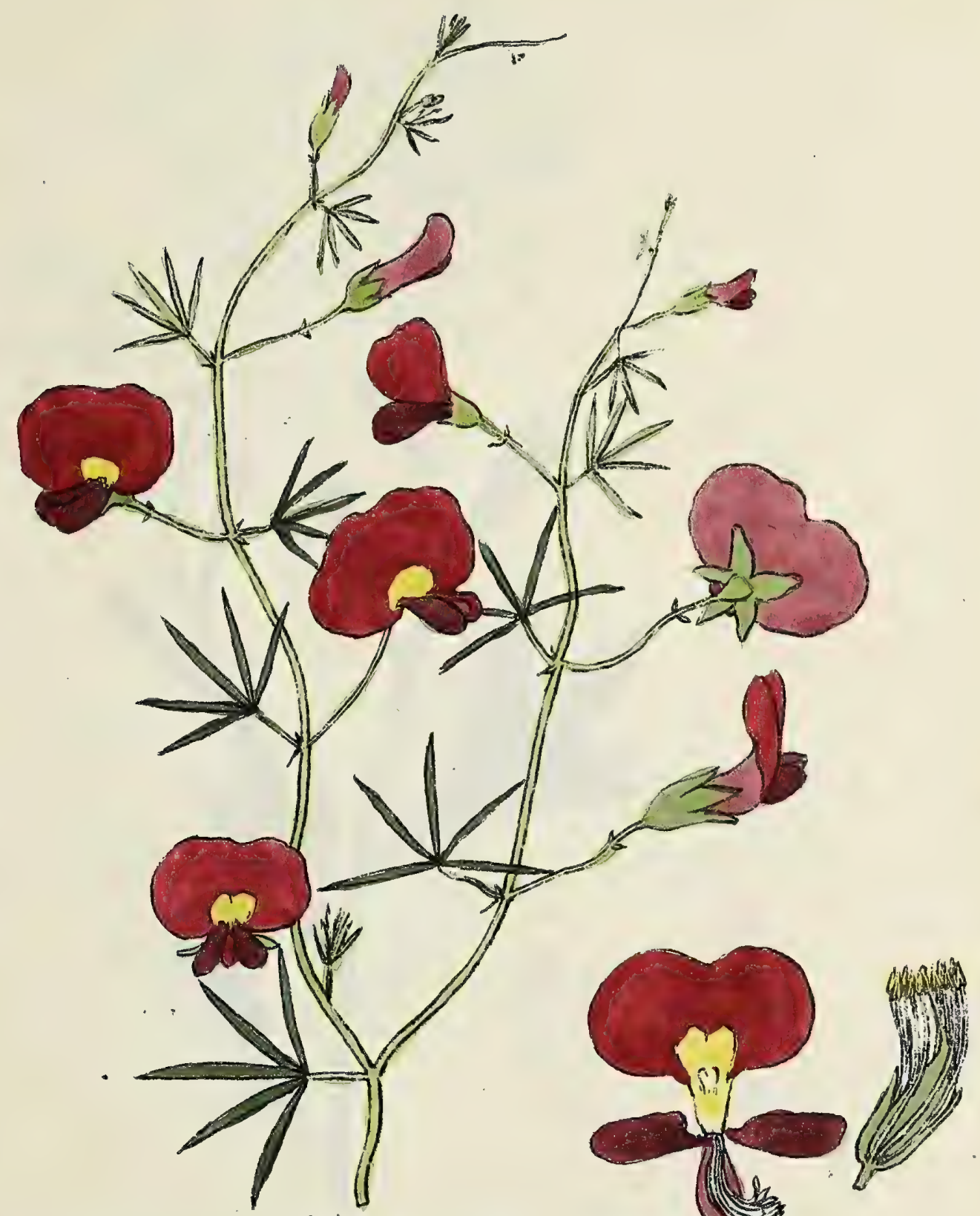

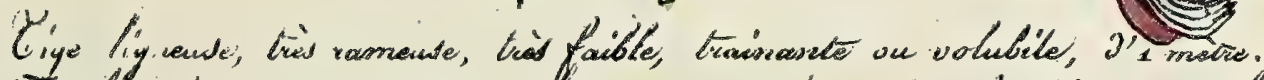

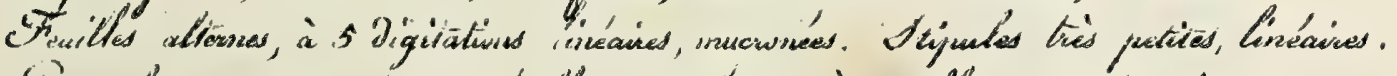

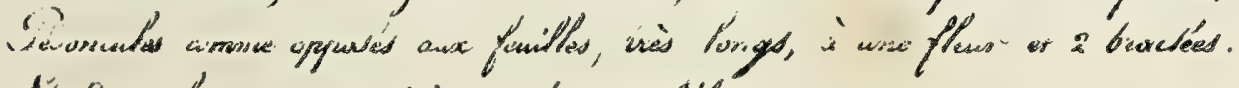

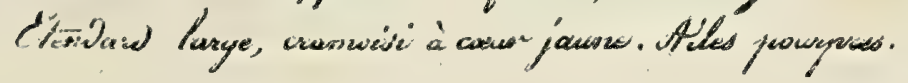

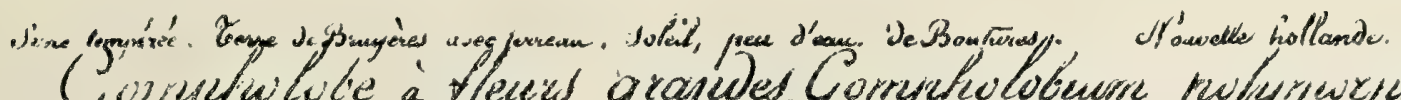

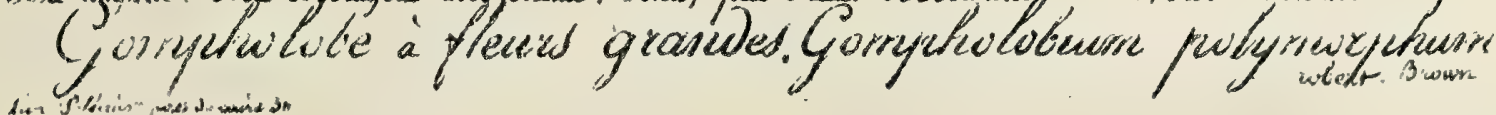





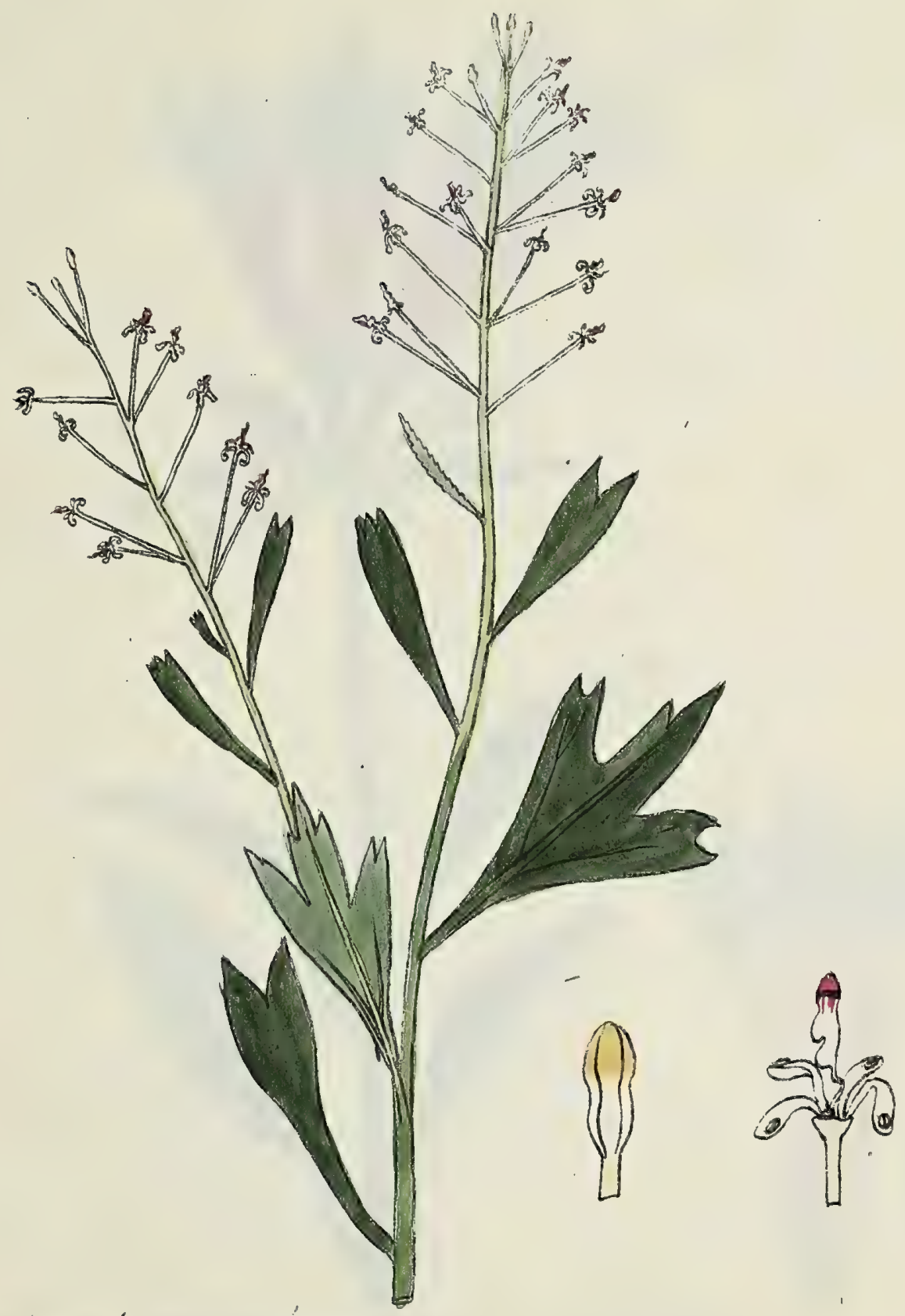

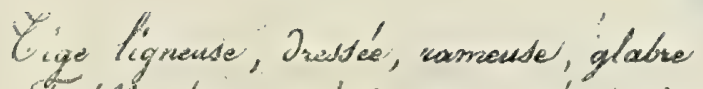

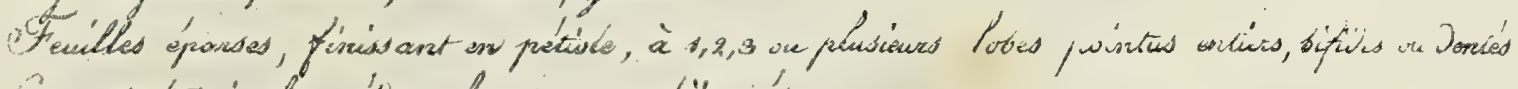

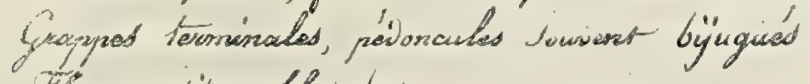

STlows perites, blasiches.

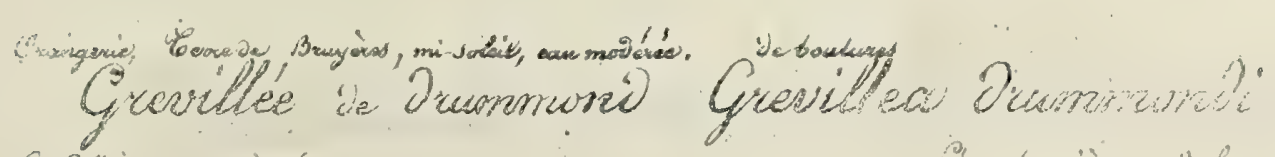

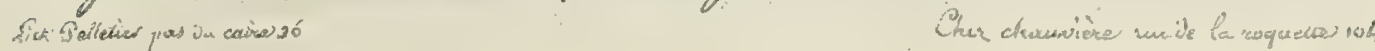





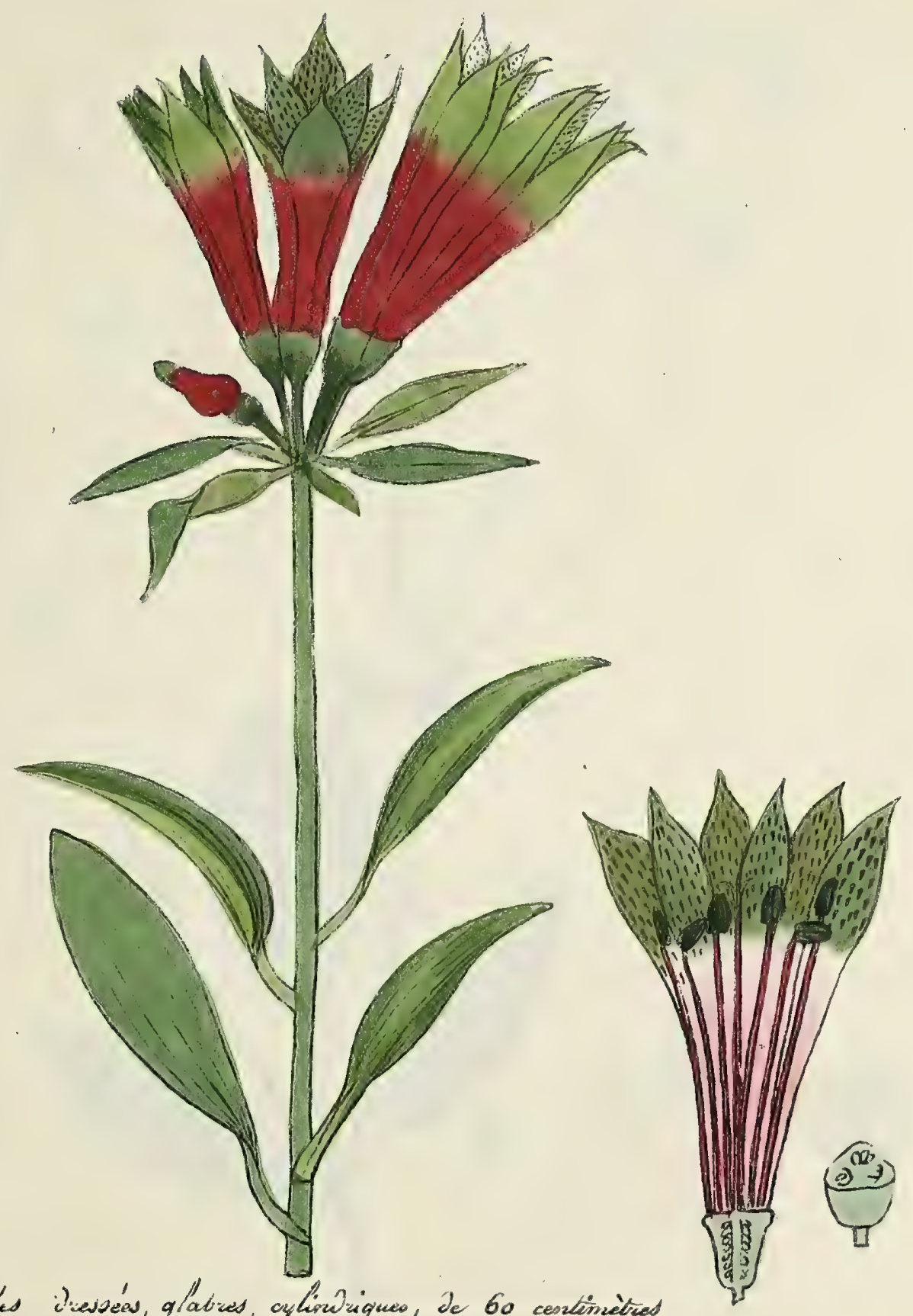

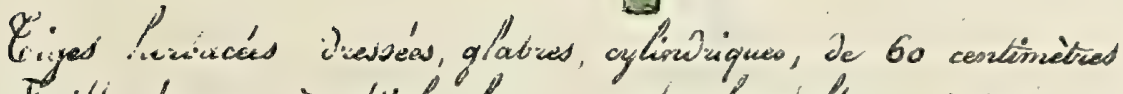

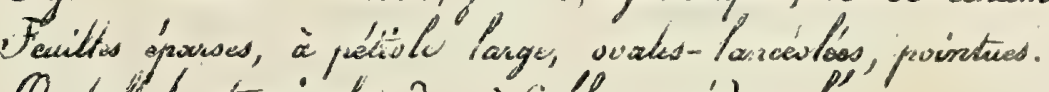

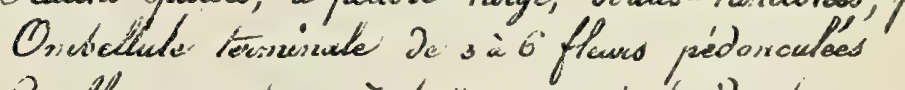

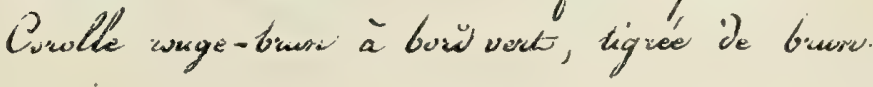

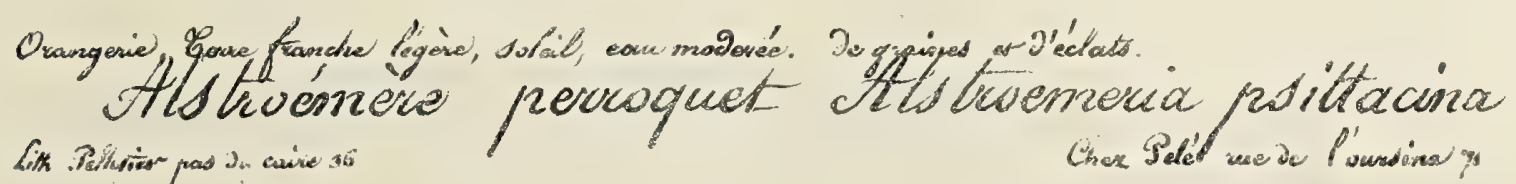

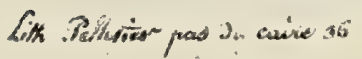





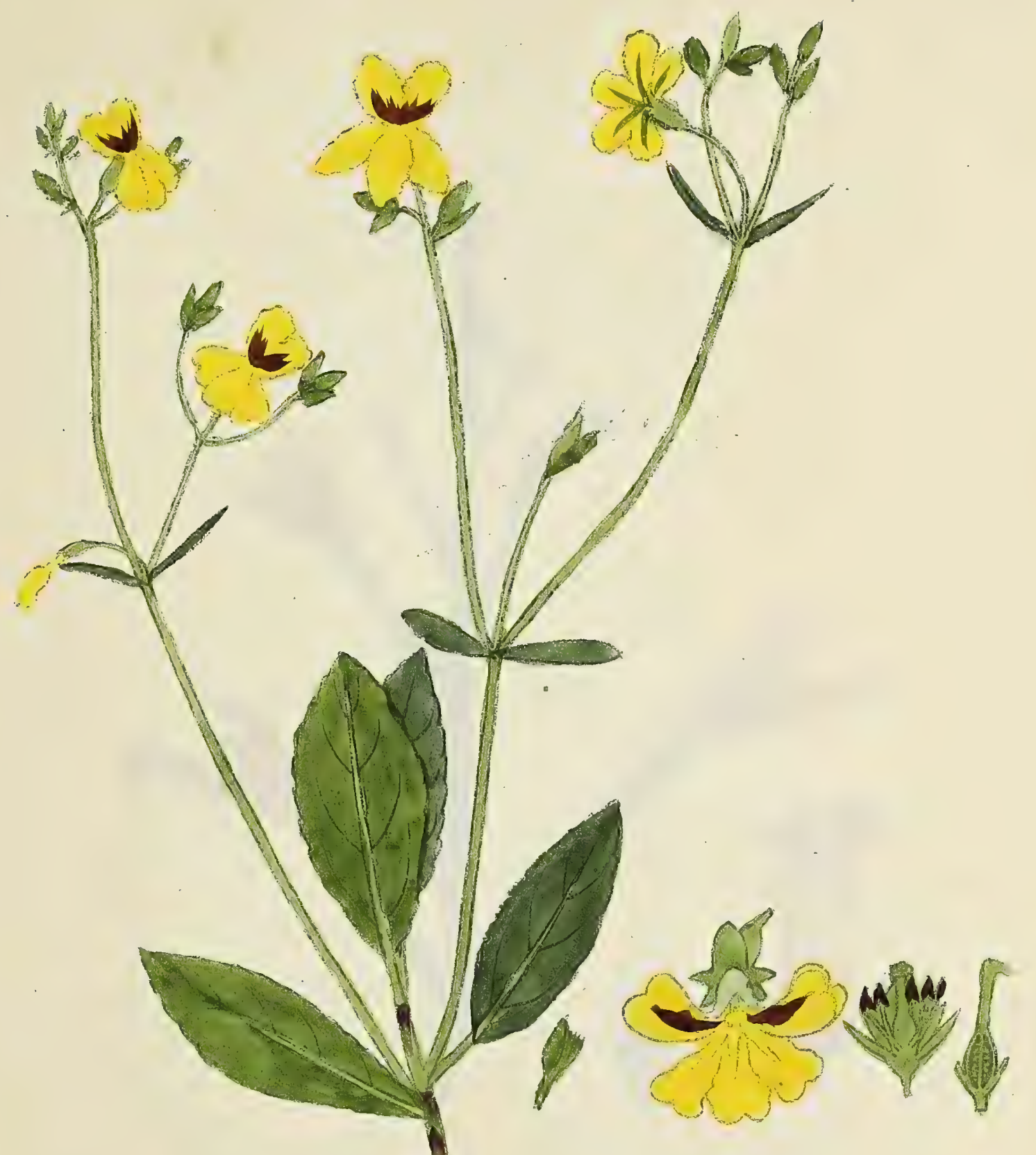

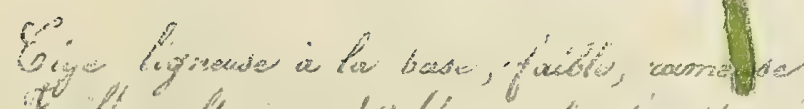

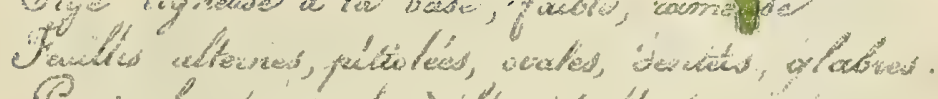

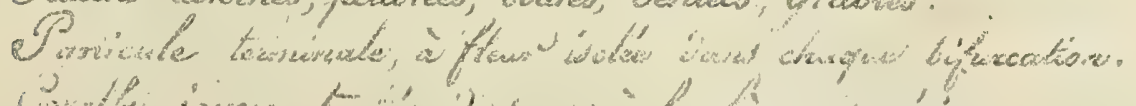

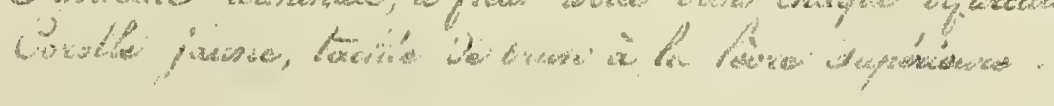

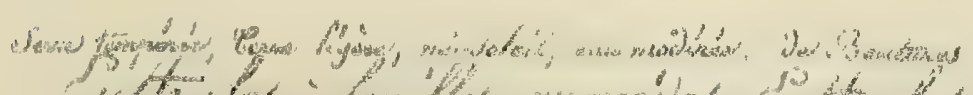

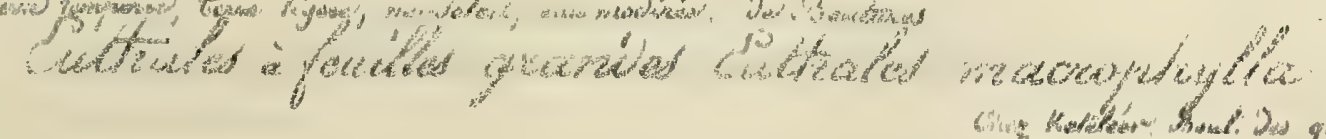

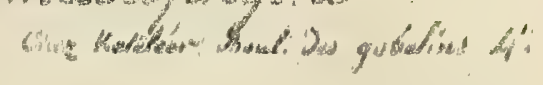




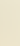

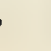




$$
\sqrt{* \pi}
$$





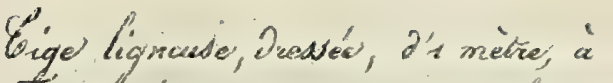
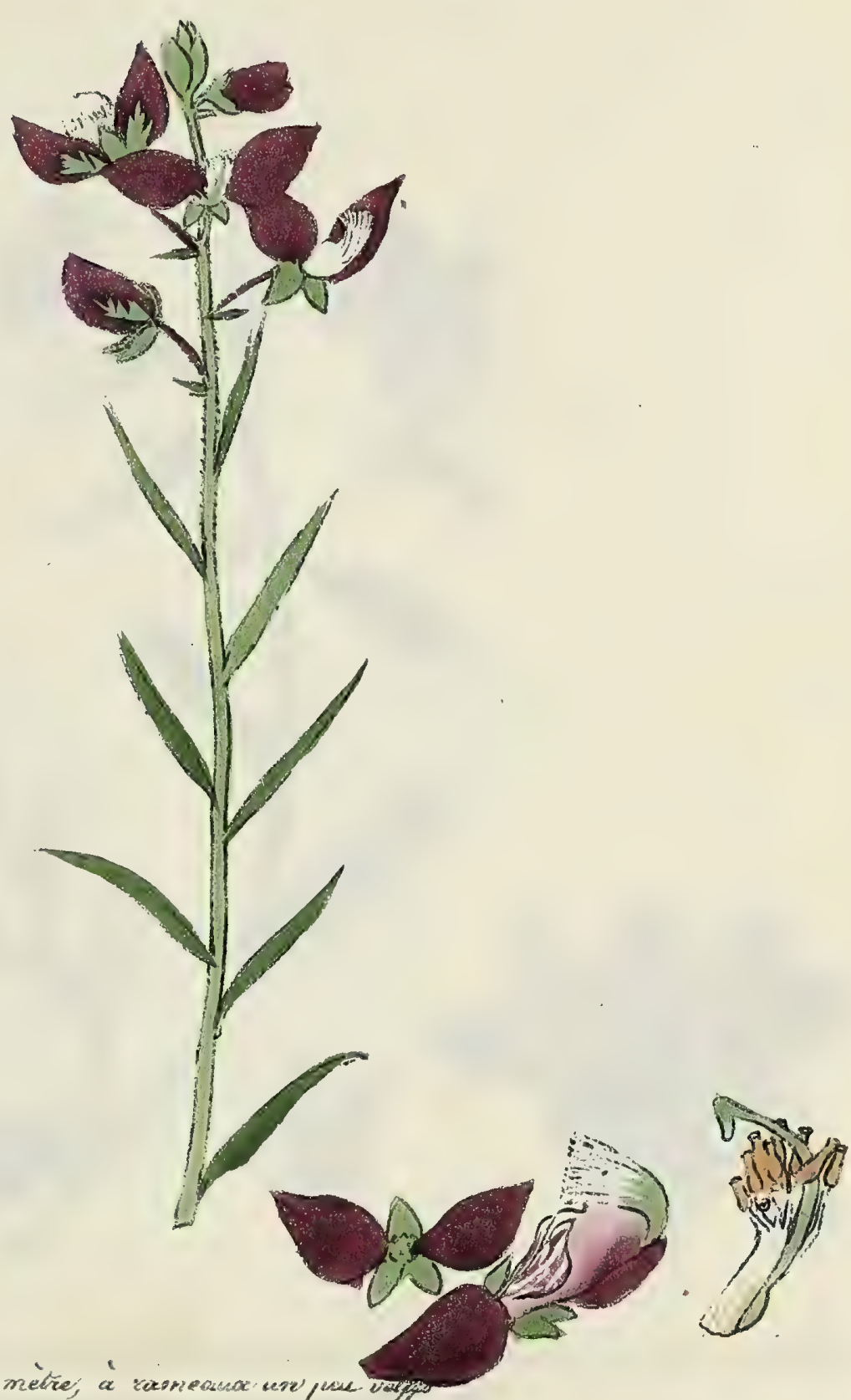

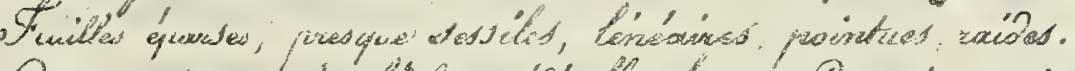

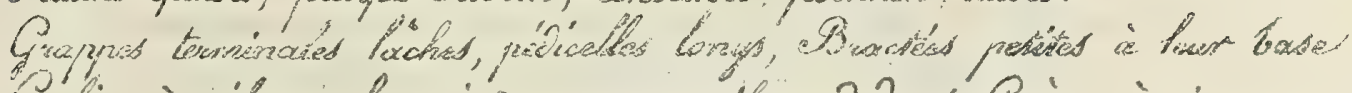

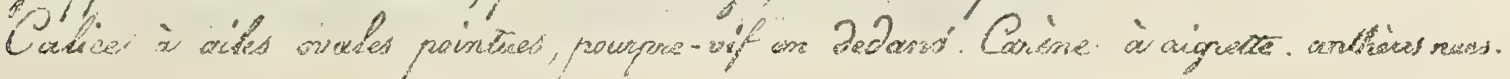

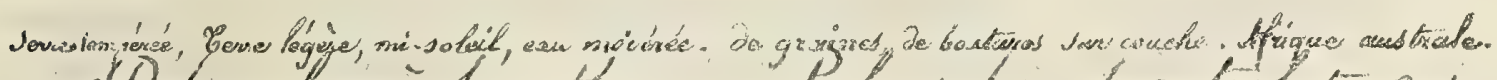

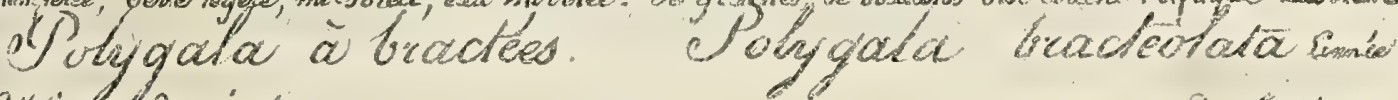

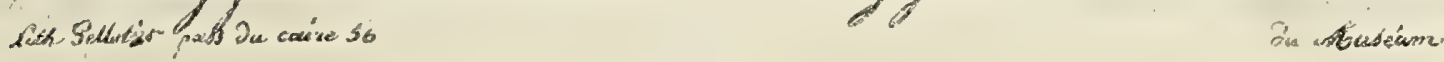





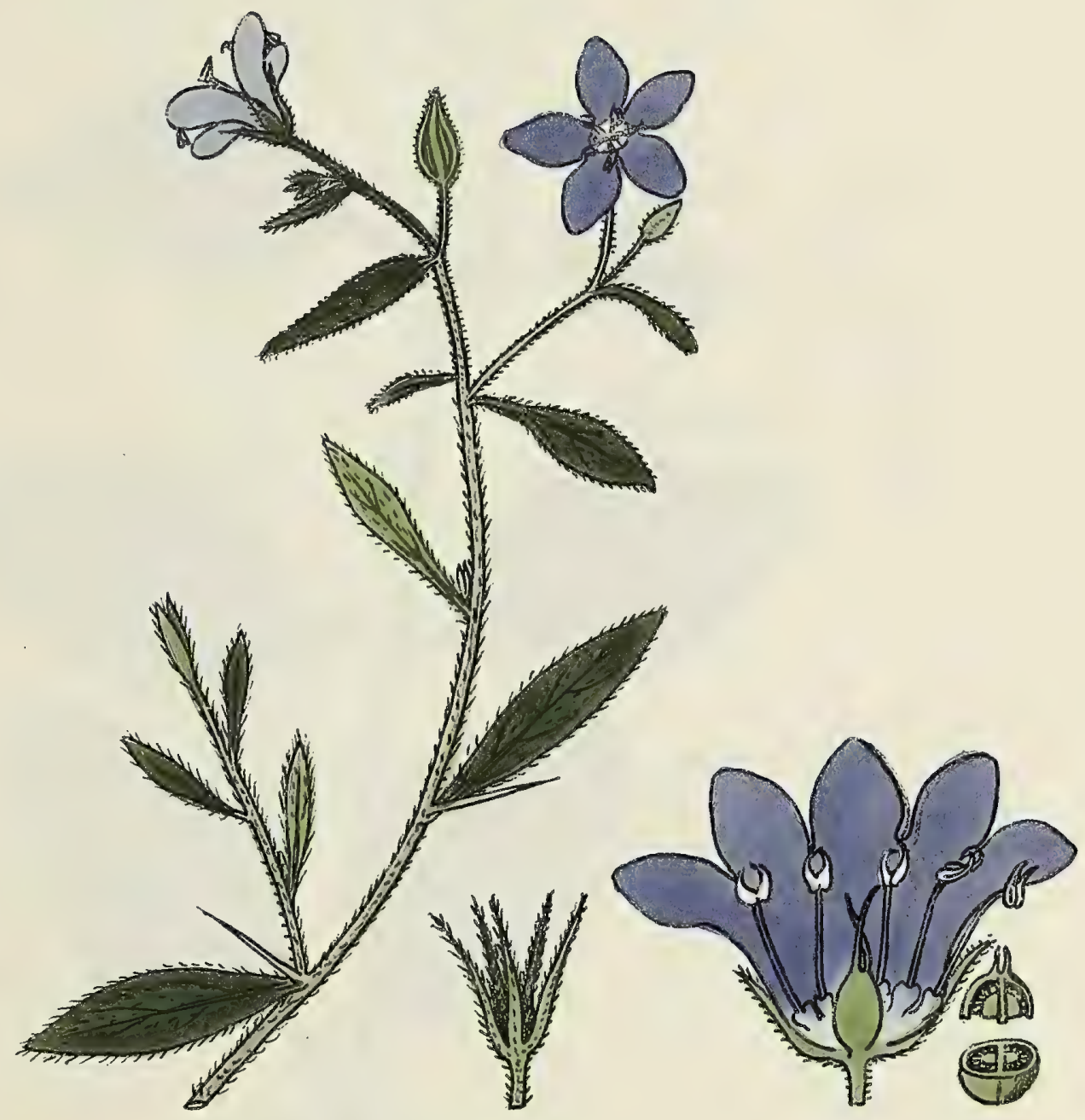

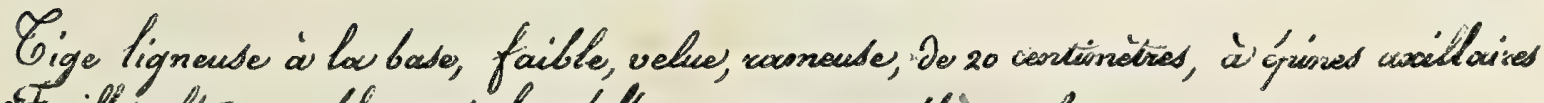
Femillis alterins, oblongues lancéolés, presque sesdilas, veluar.

Flewrs en grappos ramoudes formianst une petis paoniaule teiminale: Calice à Jividions lioneavies velues, Porolle blewe, à lobes obtus.

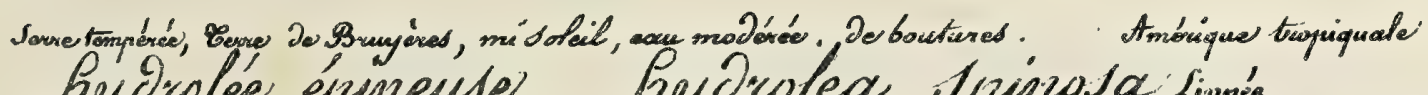

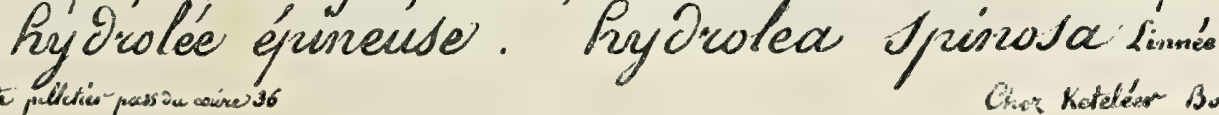

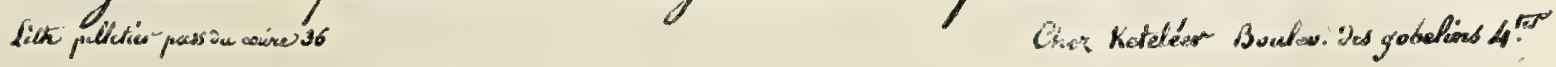





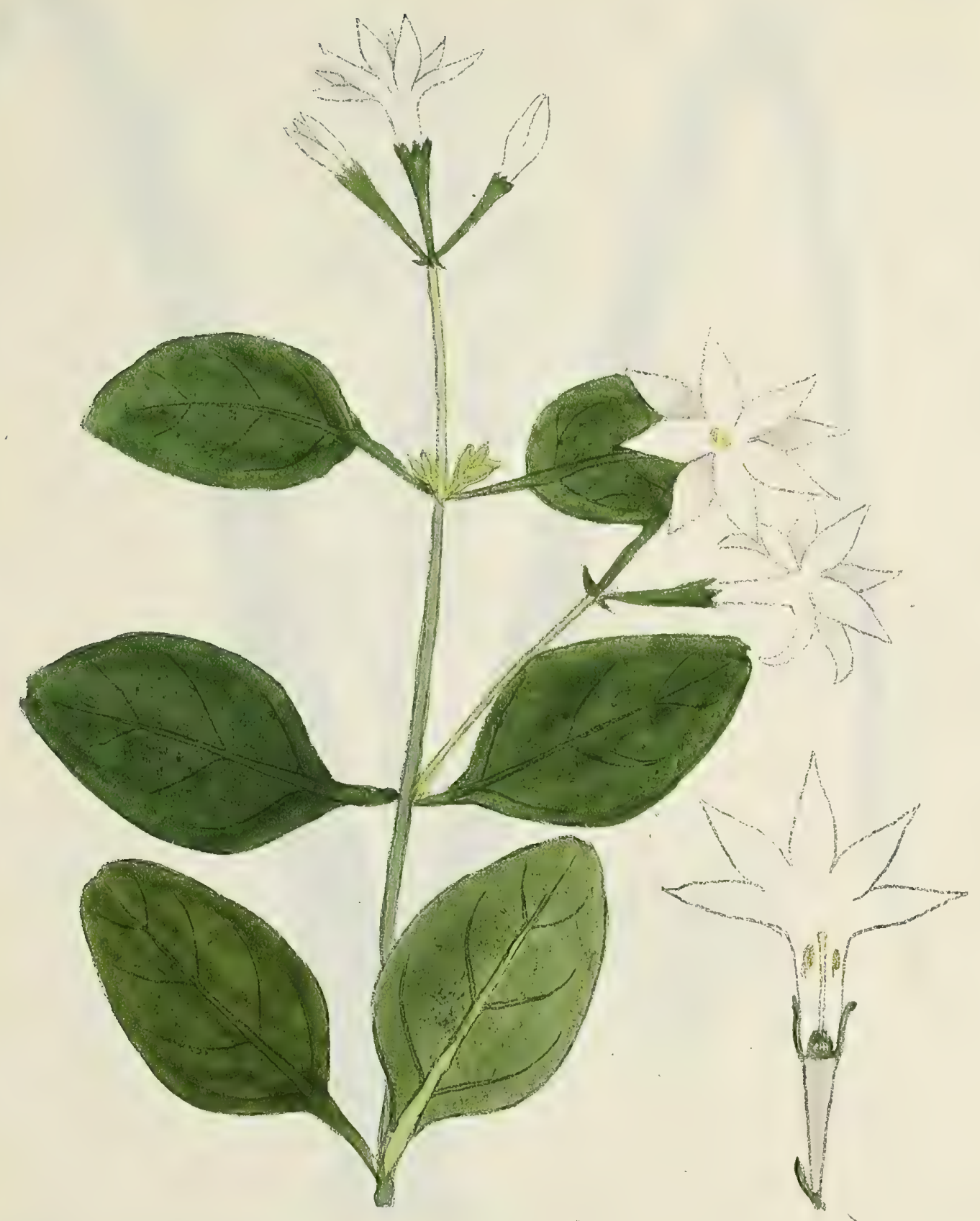

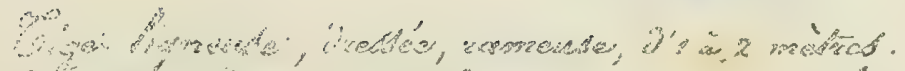

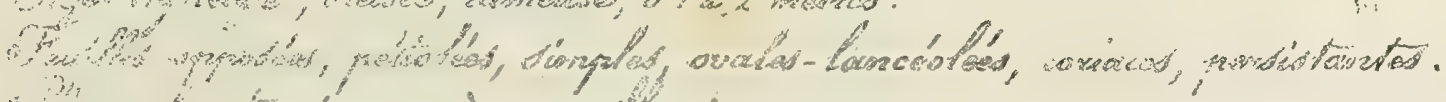

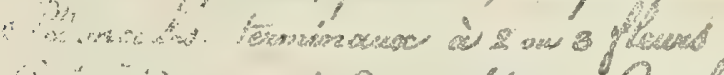

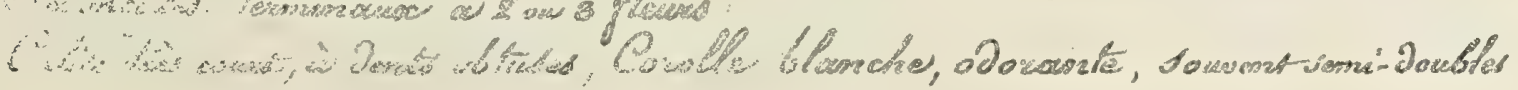

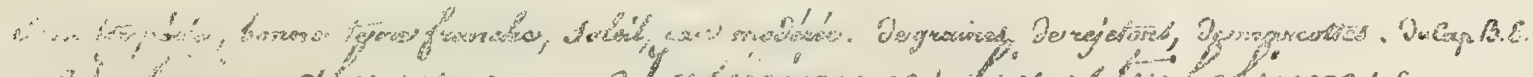

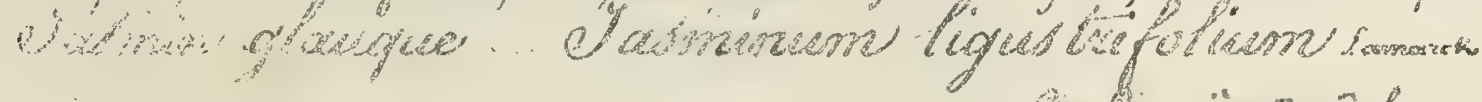

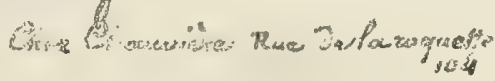





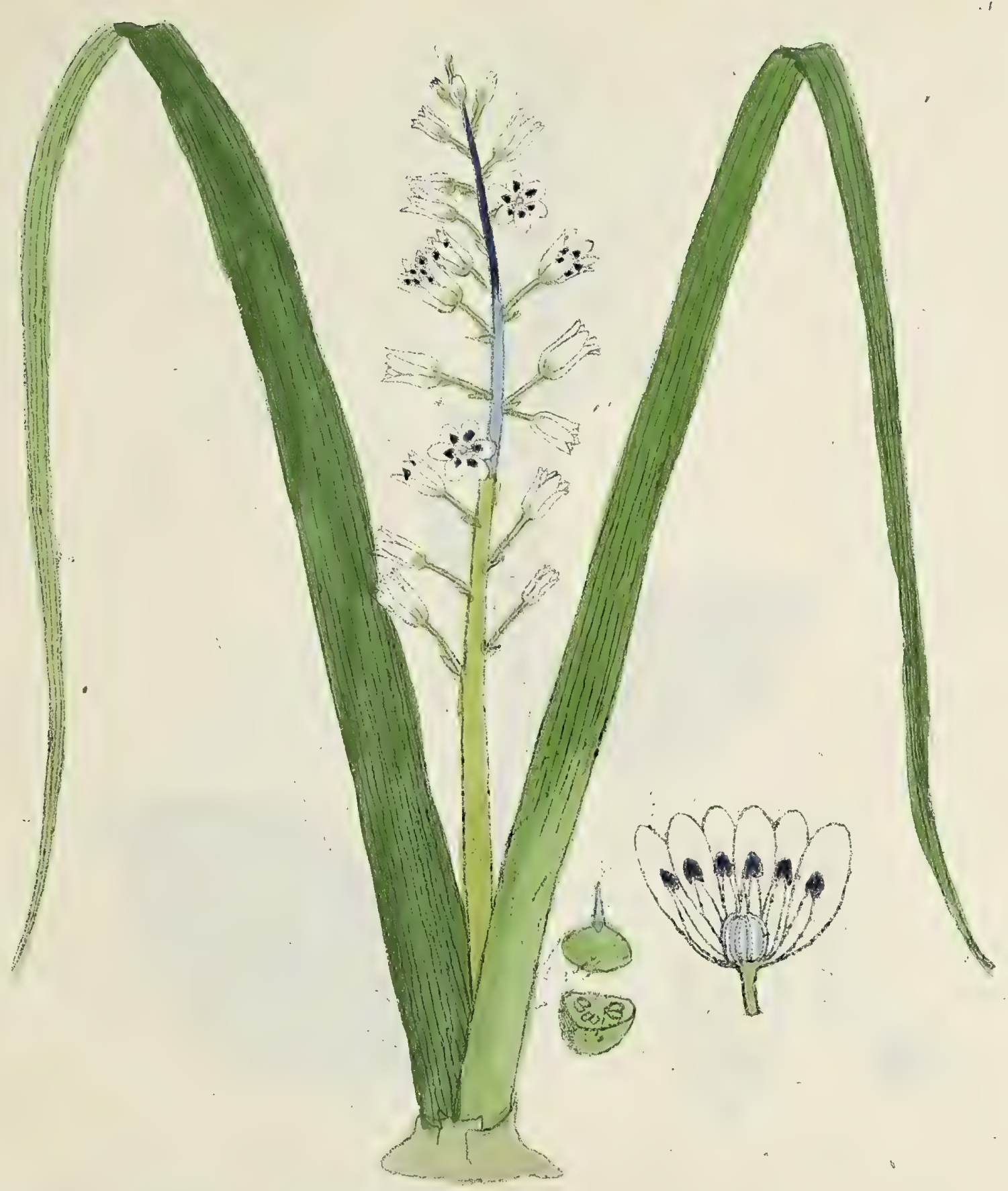

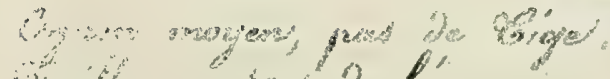

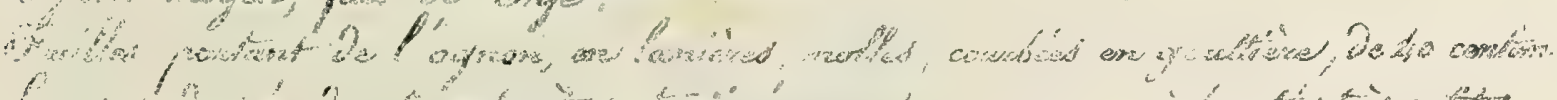

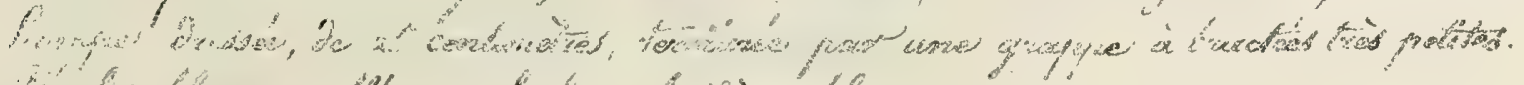

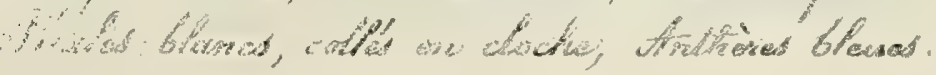

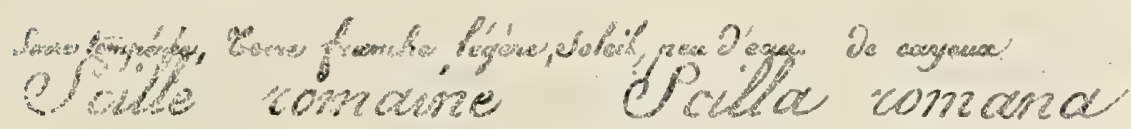

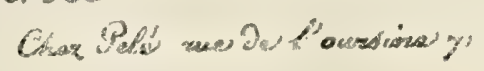


• 


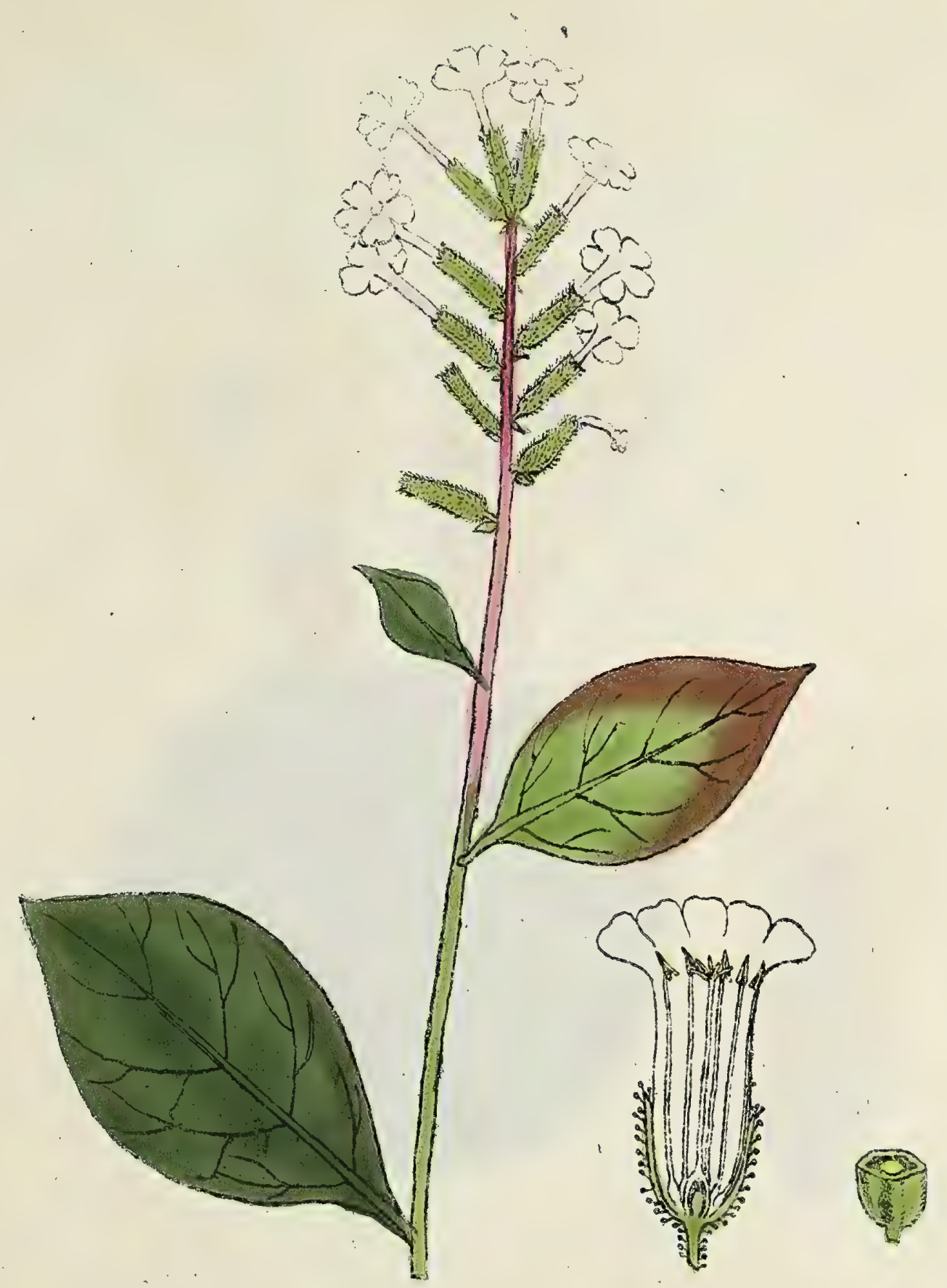

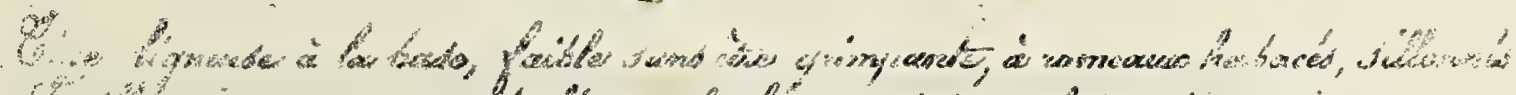

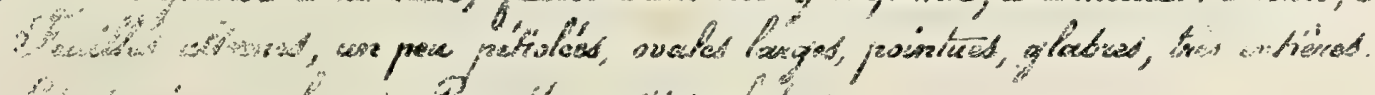

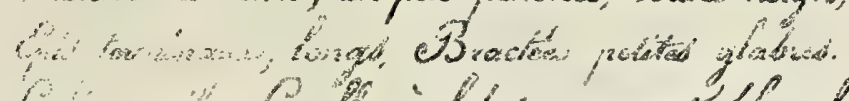

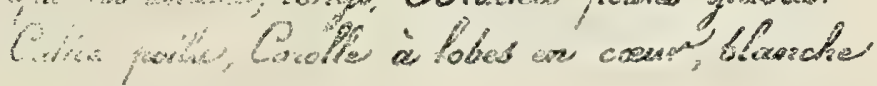

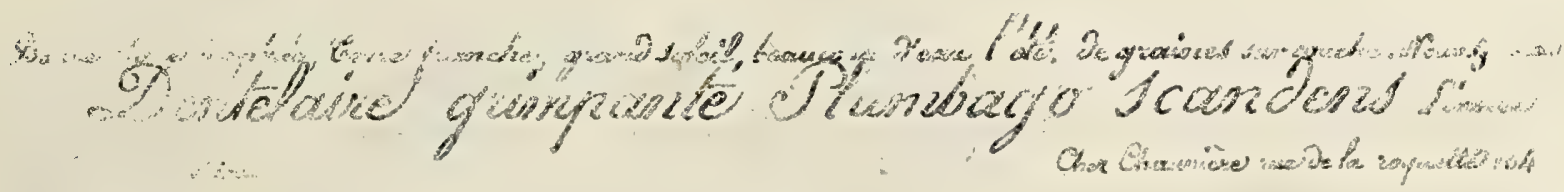




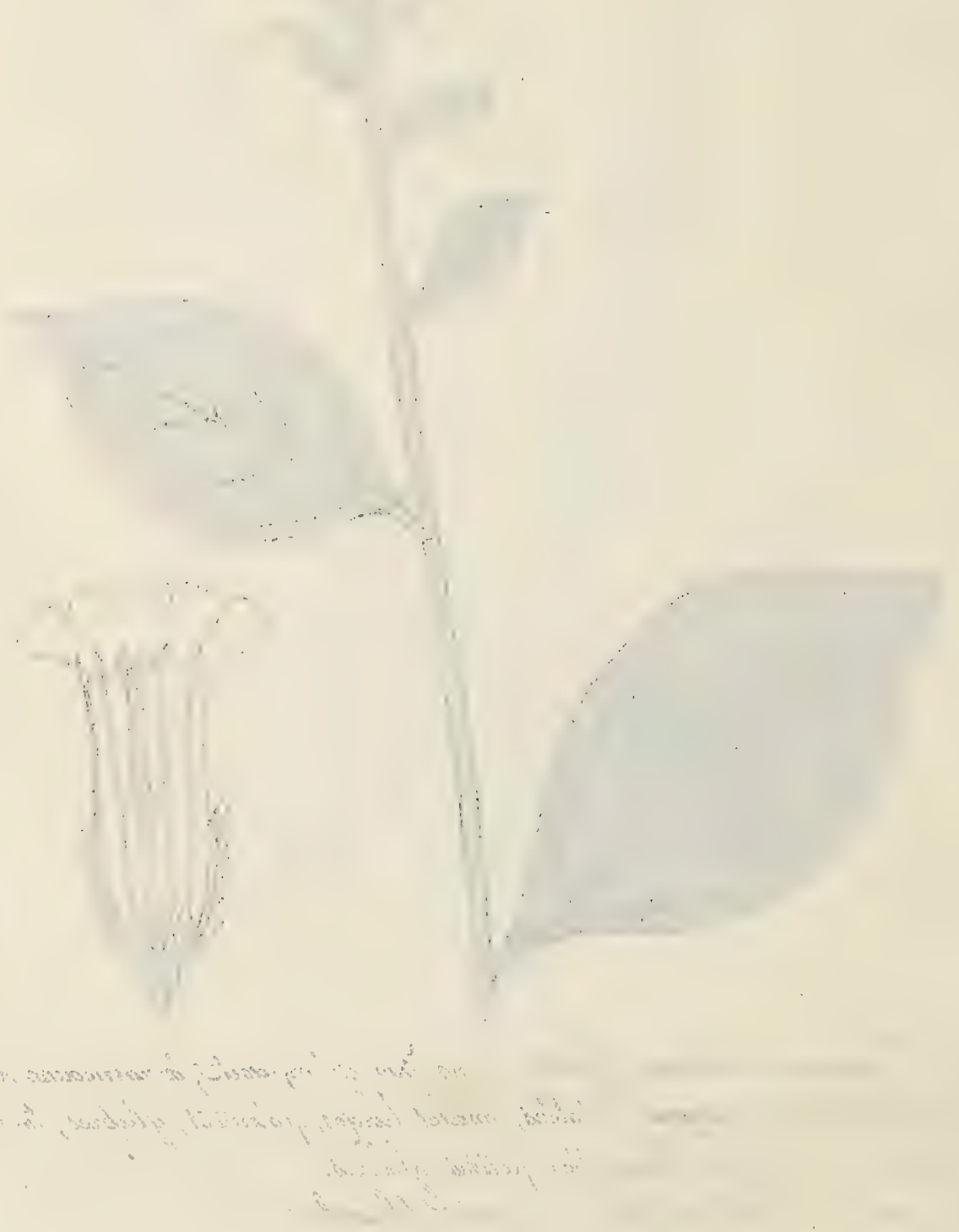




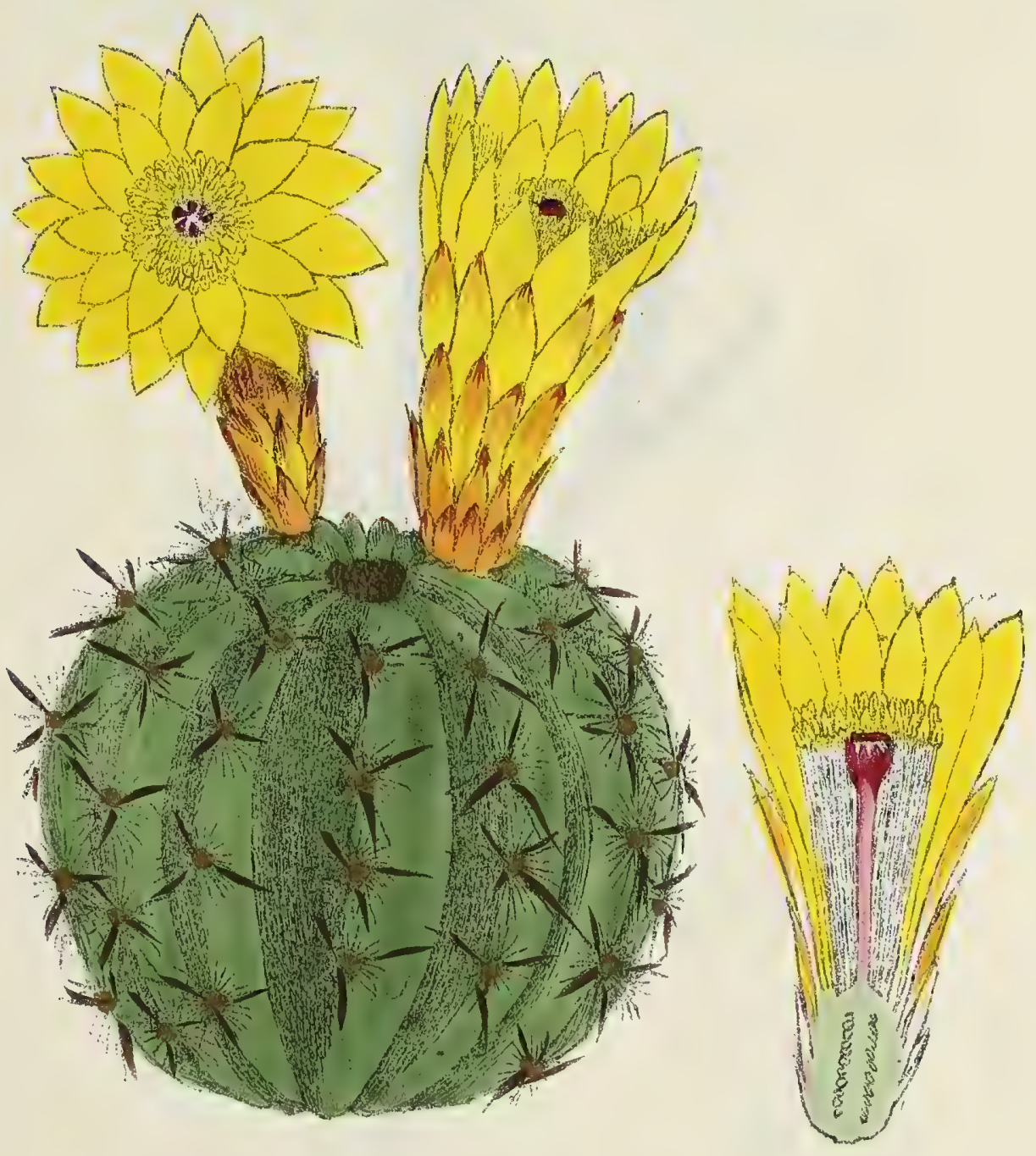

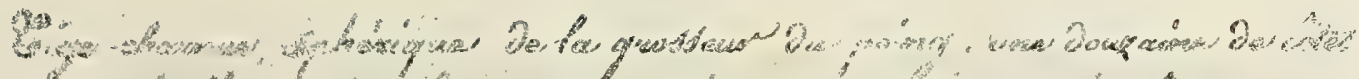

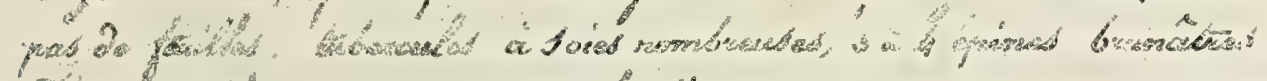

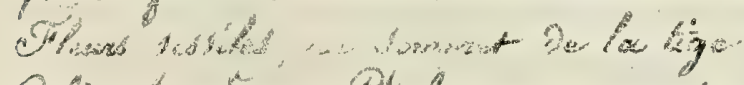

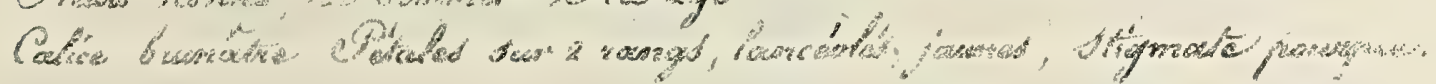

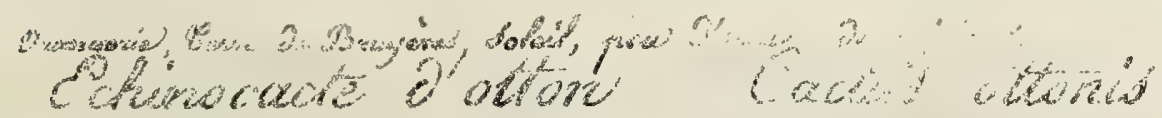

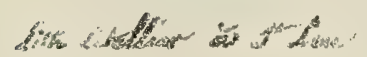





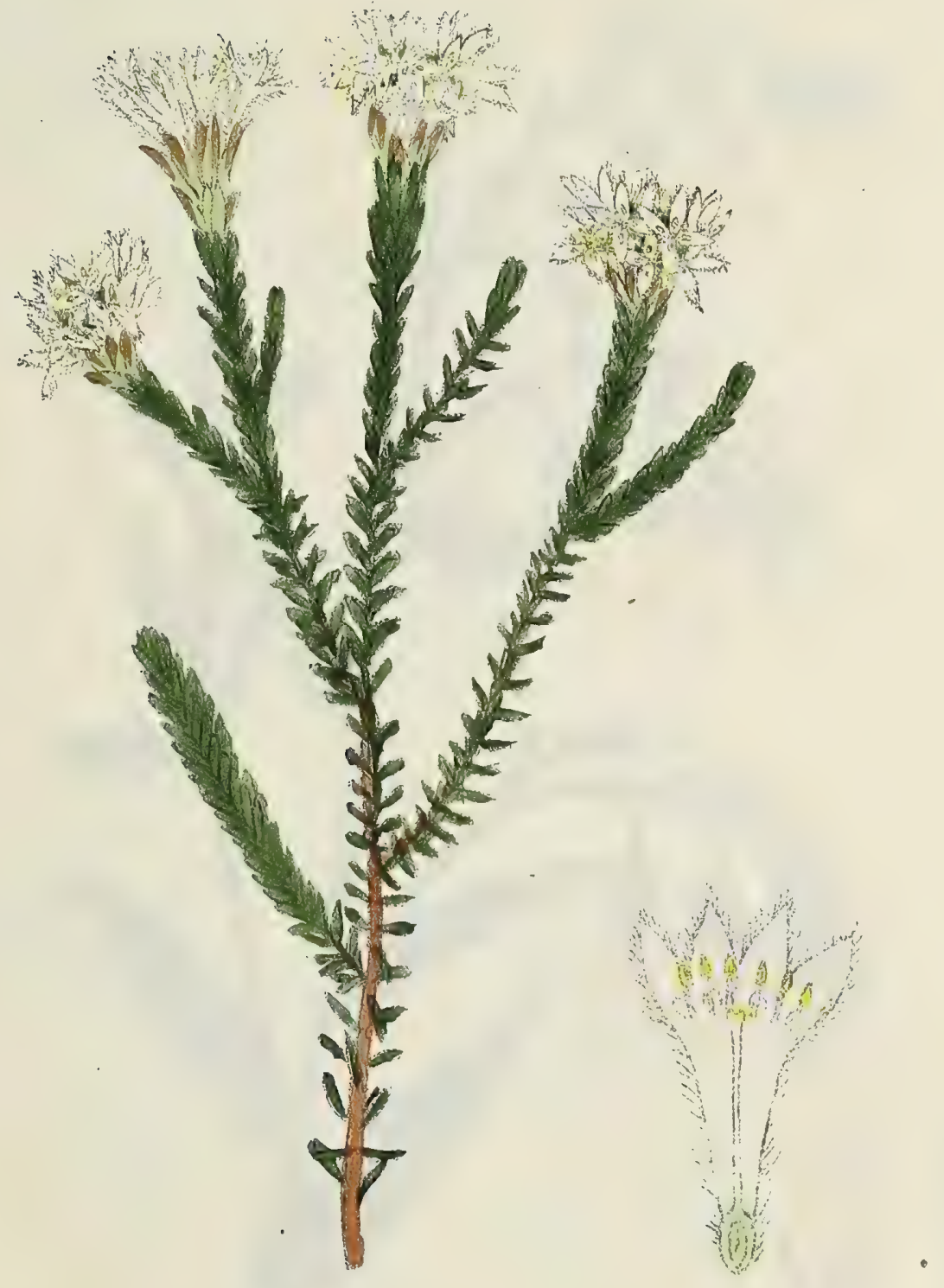

अ.

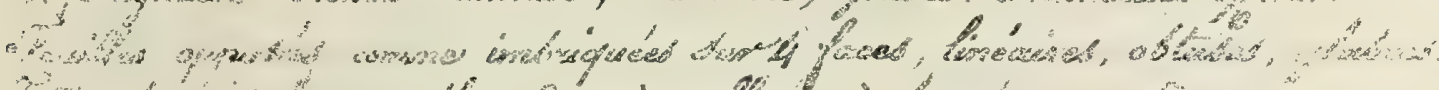

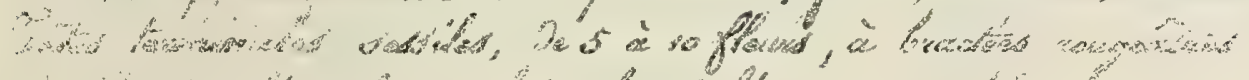

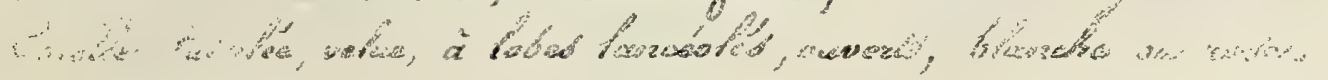

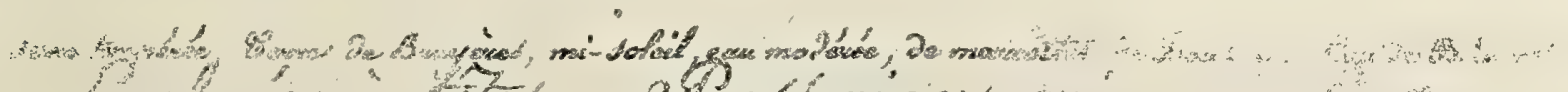

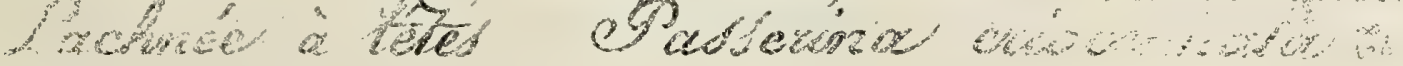

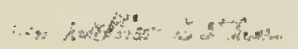





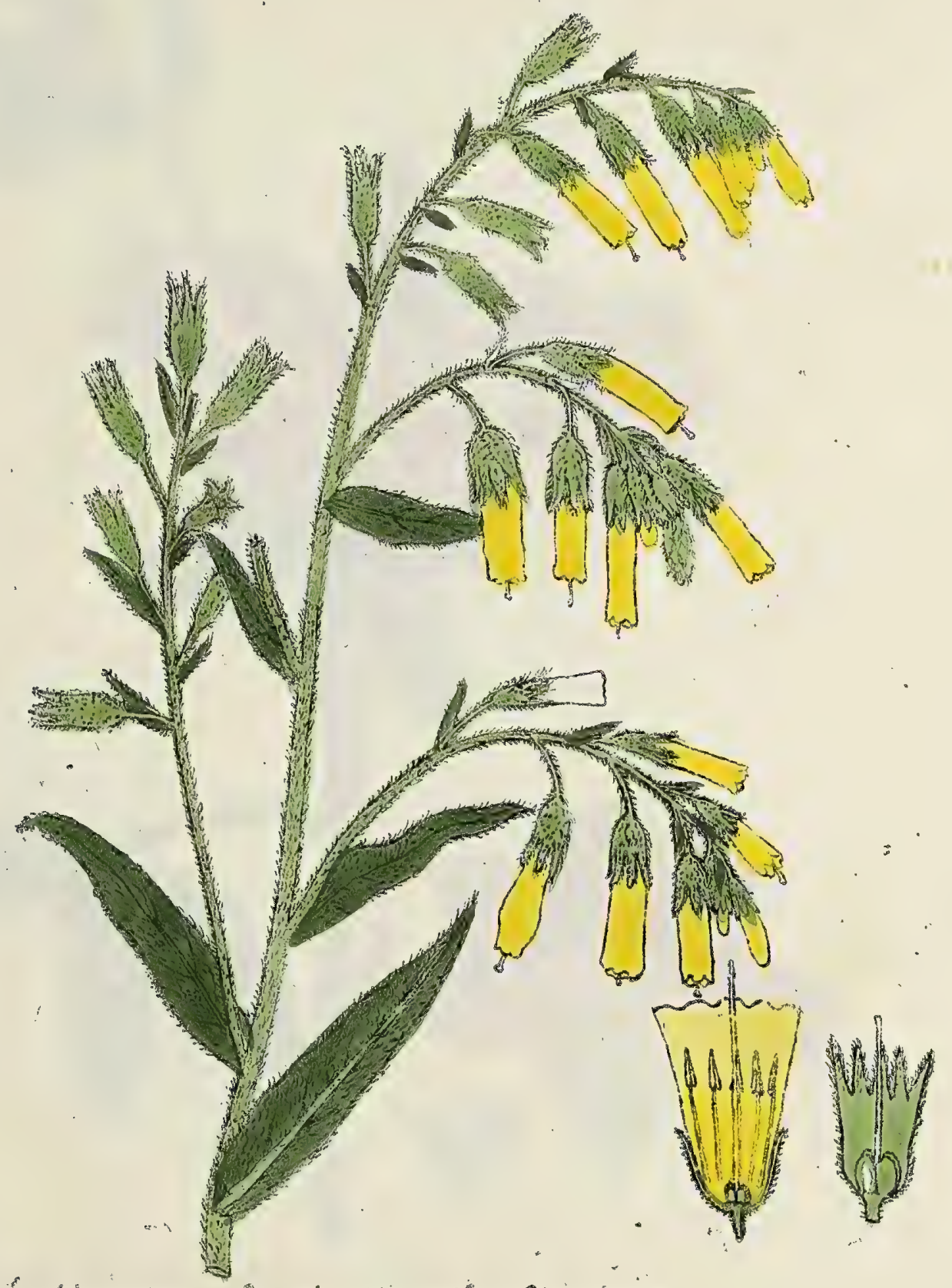

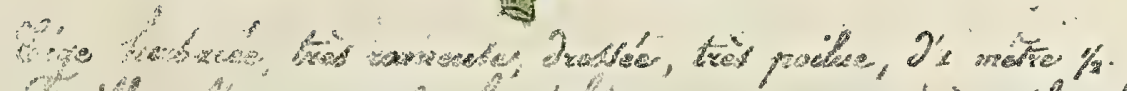

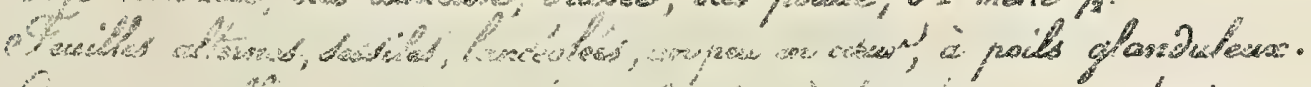

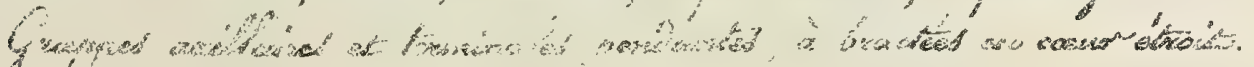

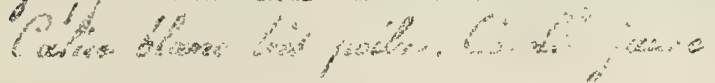

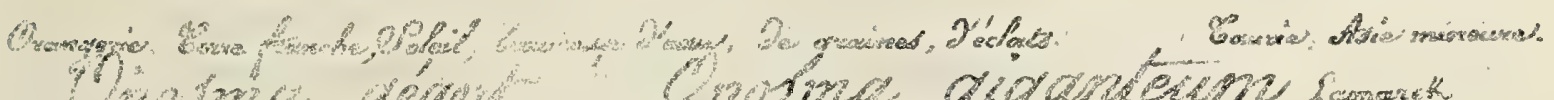

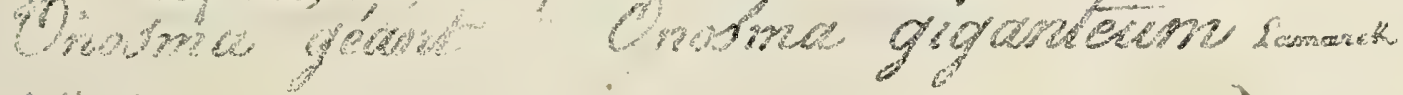

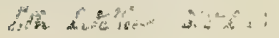





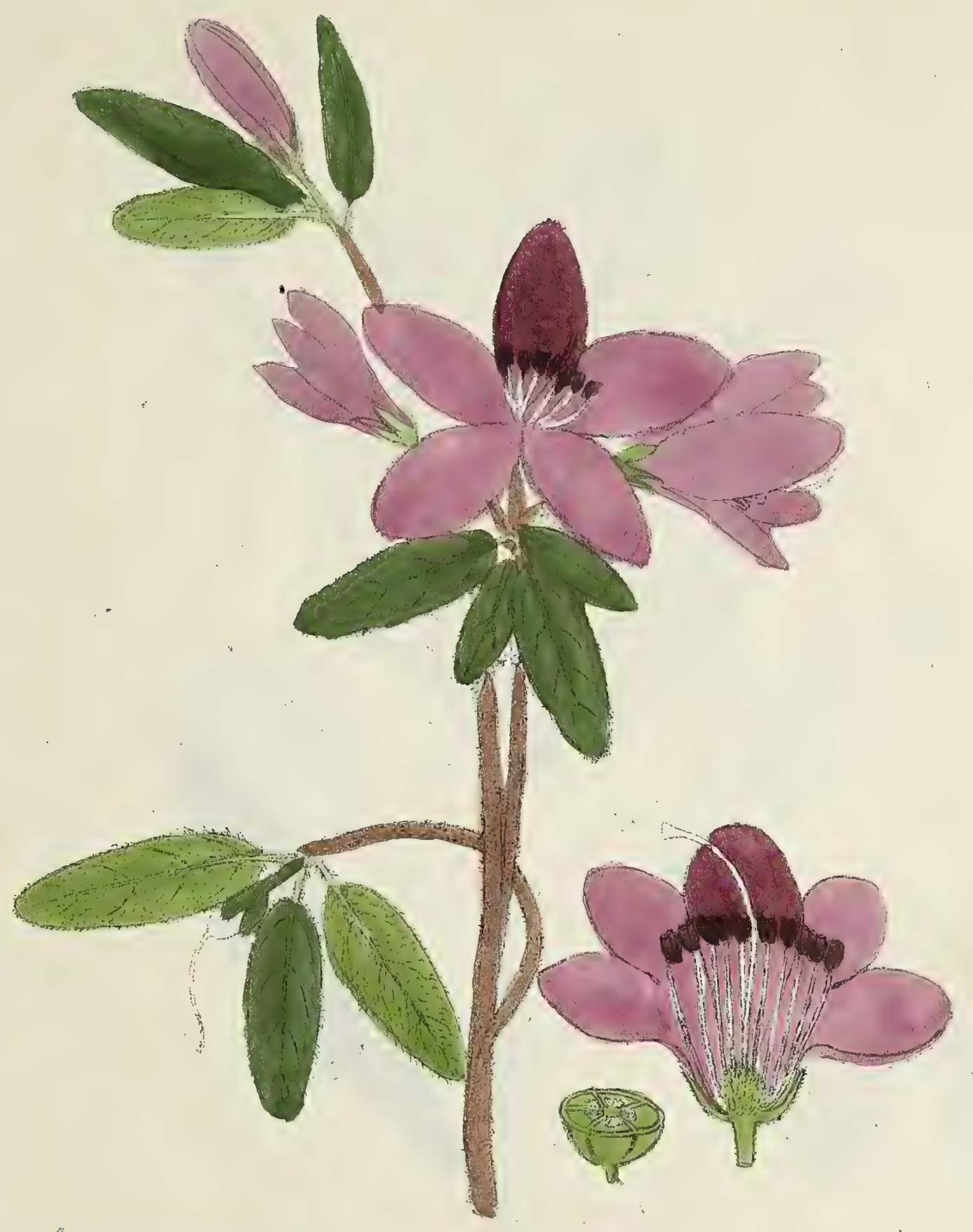

$6, x_{1}$

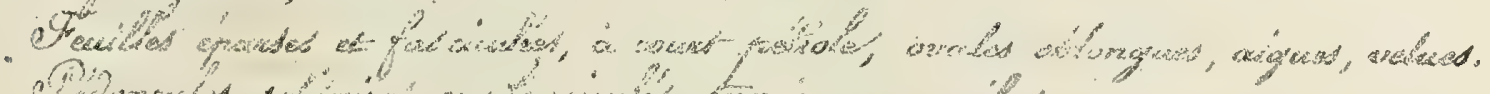

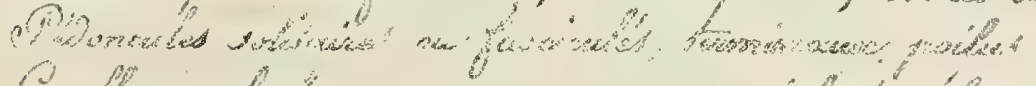

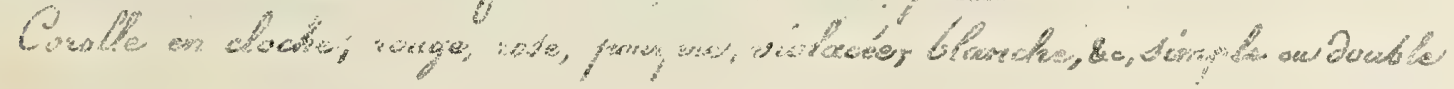

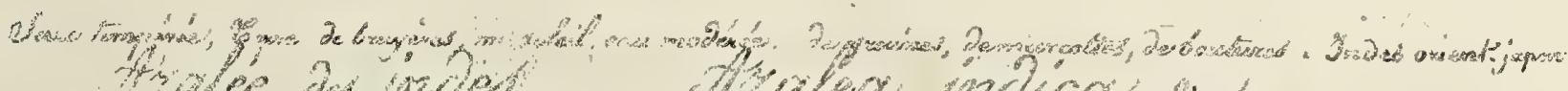

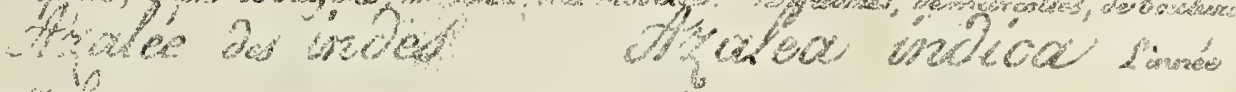

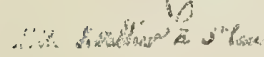




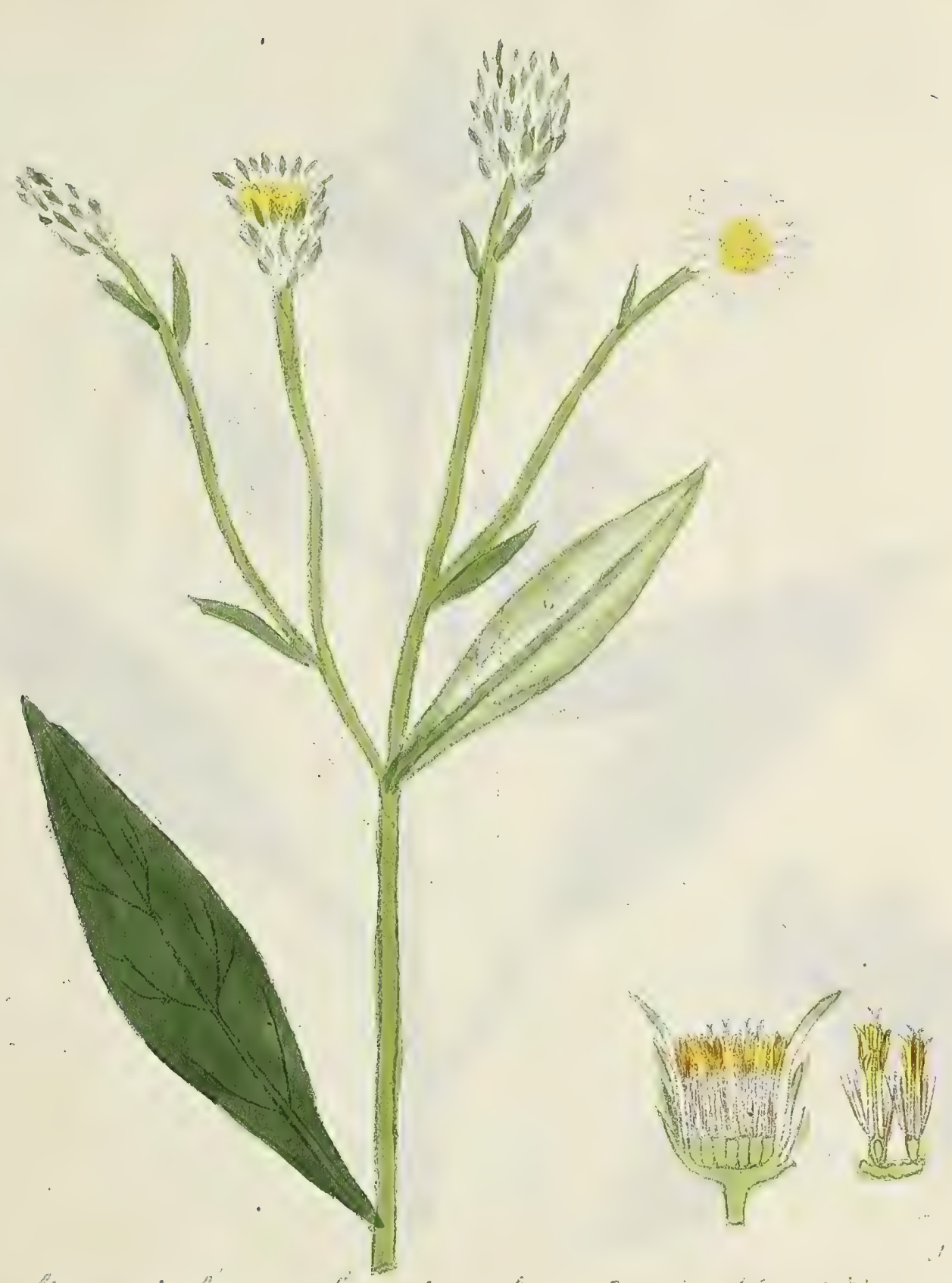


1 


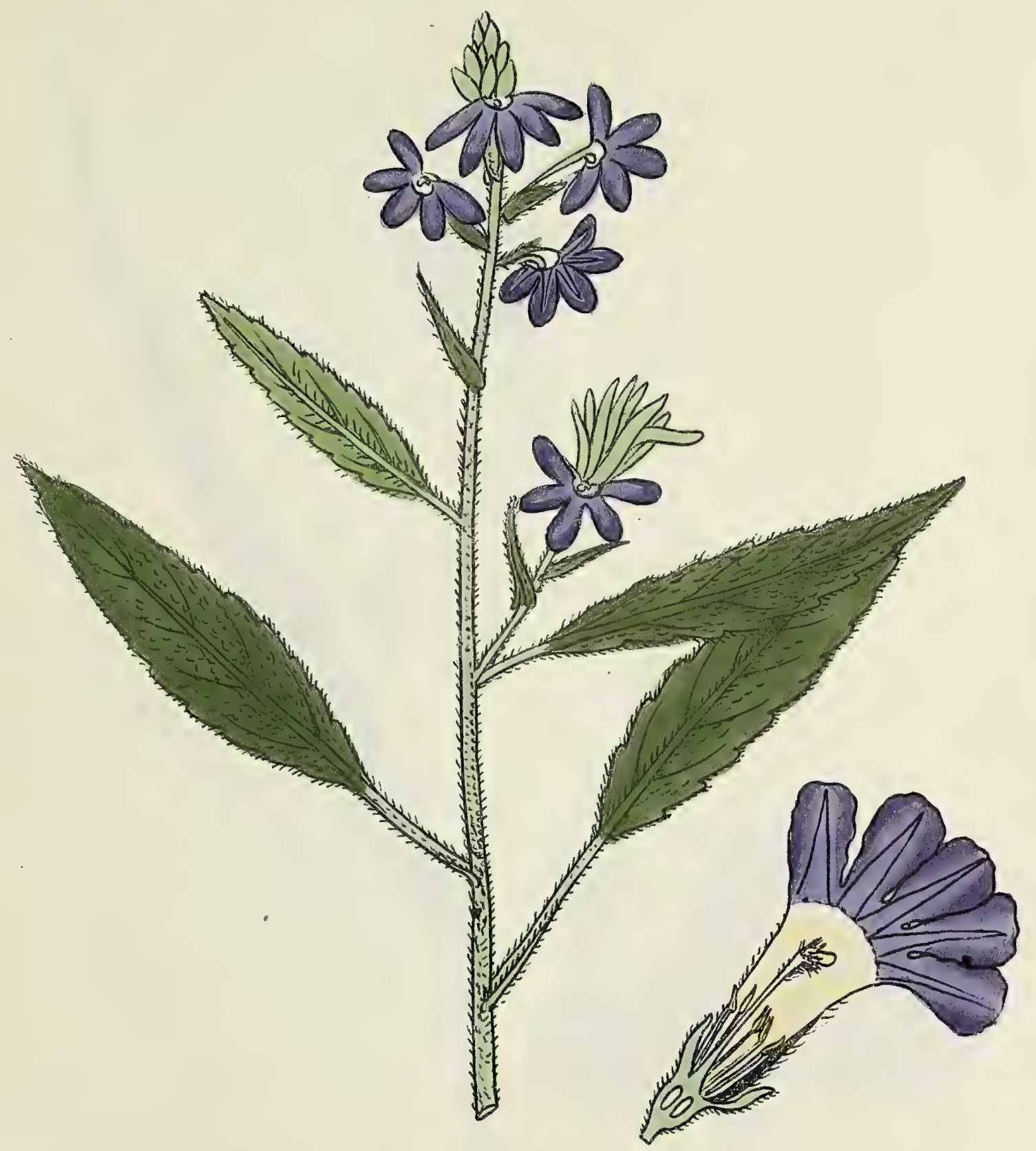

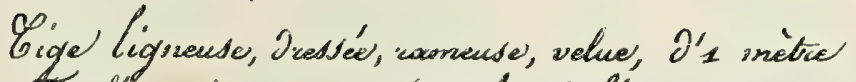

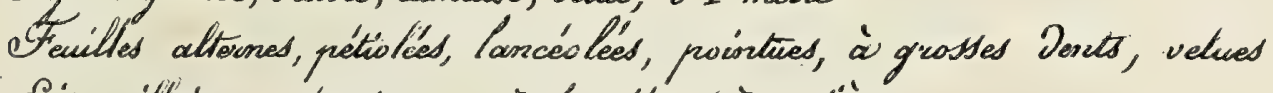

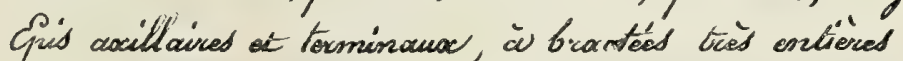
Corolle à tube velu, à linzbe blew vislacé glabue, styles très velw.

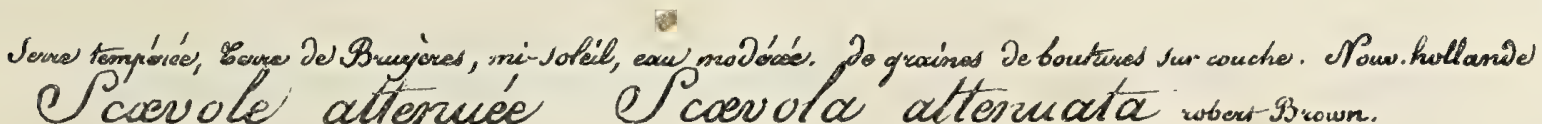





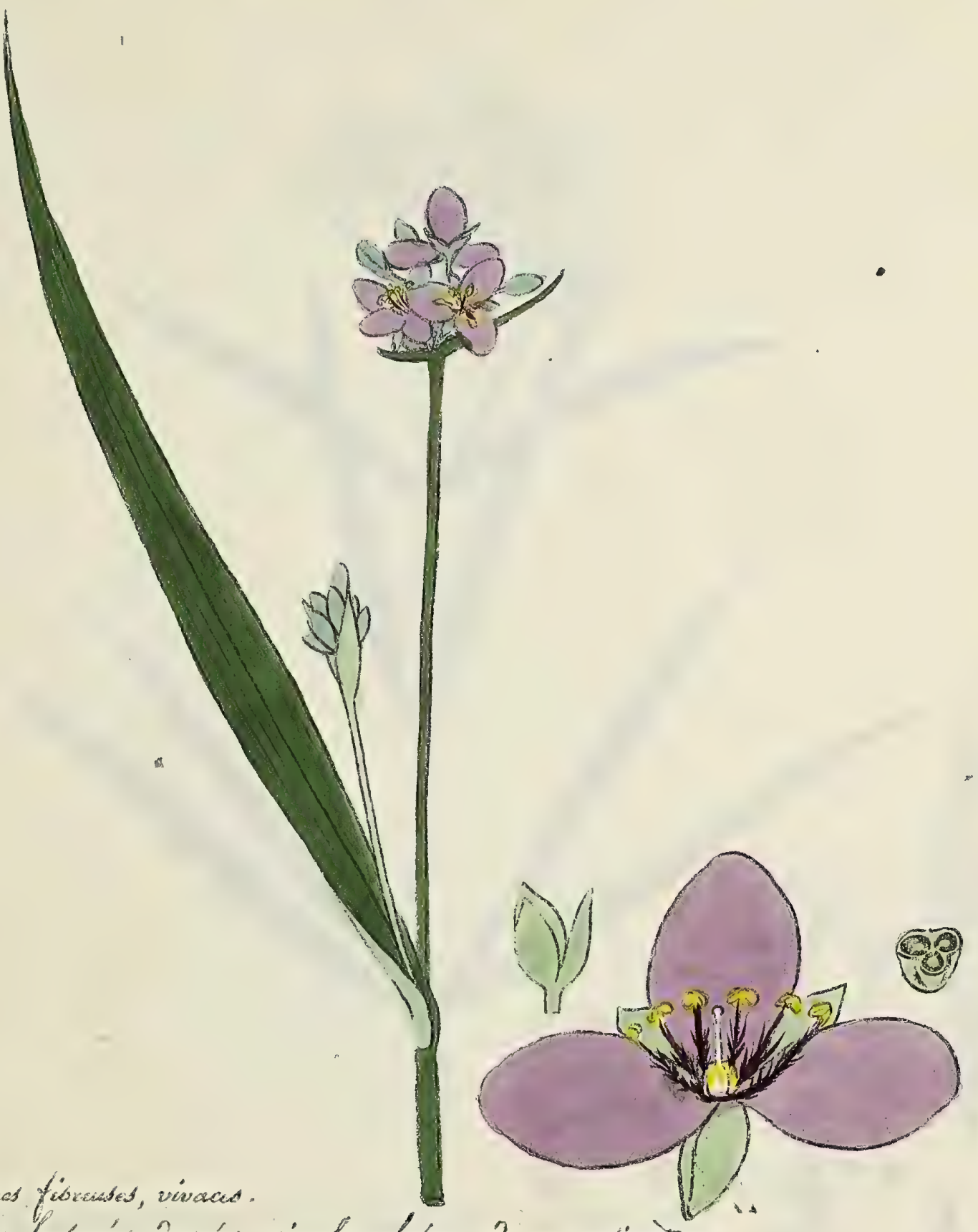

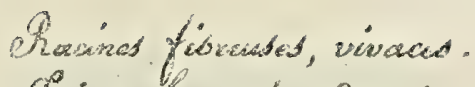

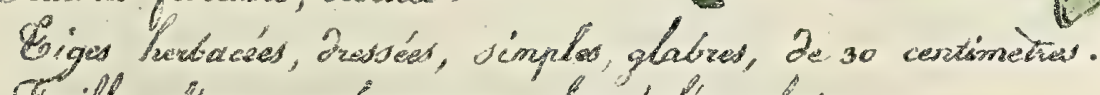

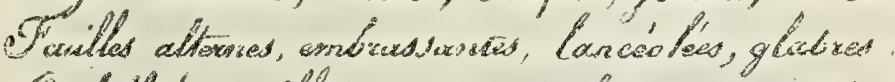

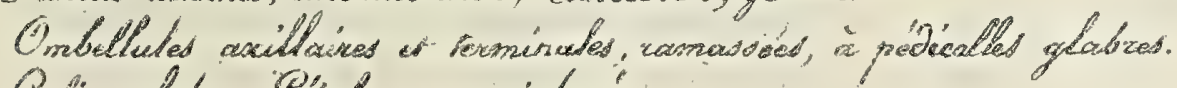

Palice glabre, TPraled wase visklace".

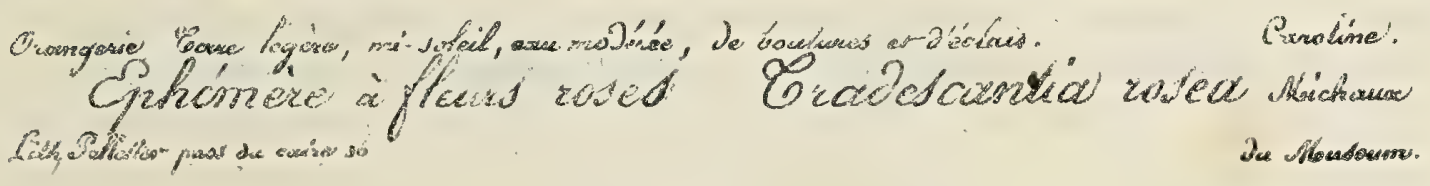





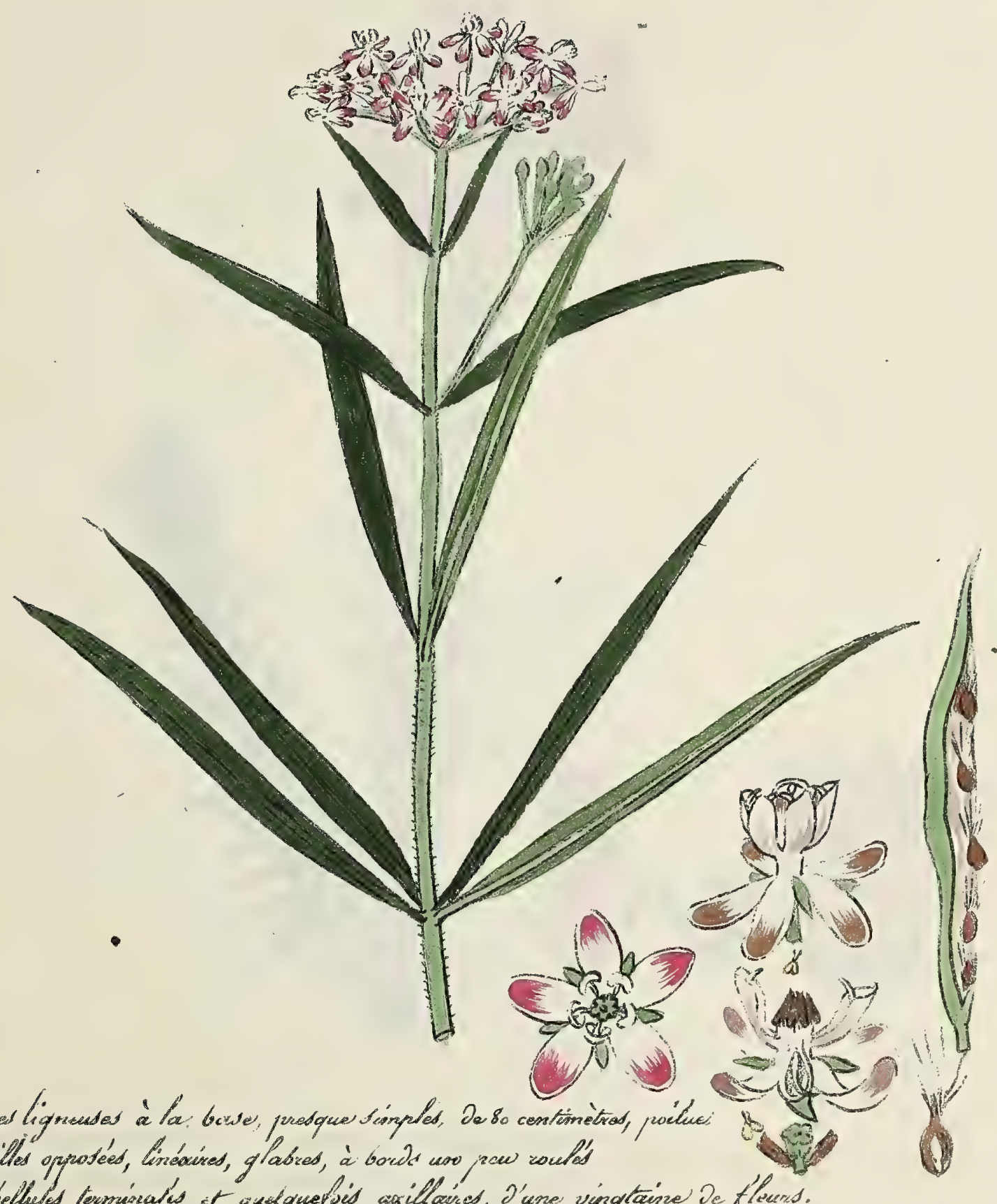

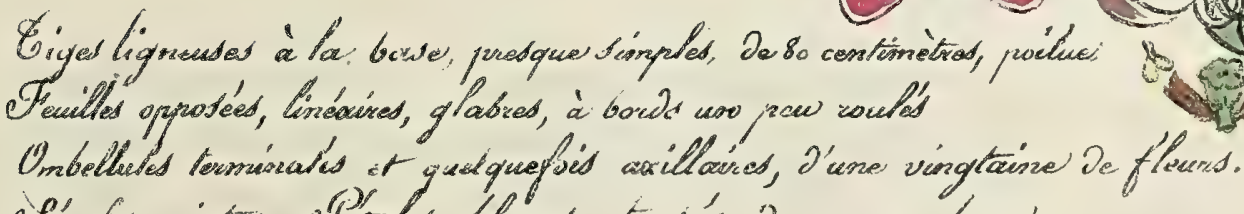

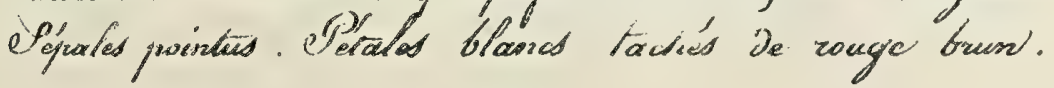

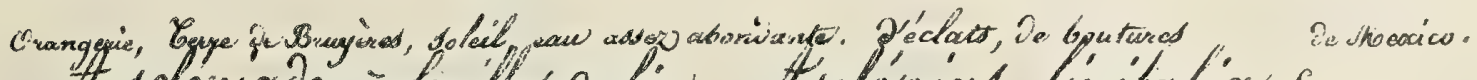

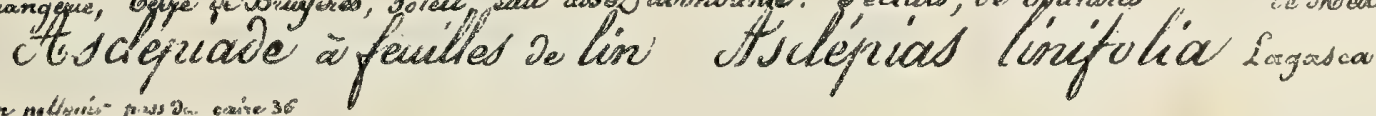

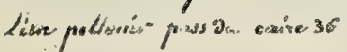





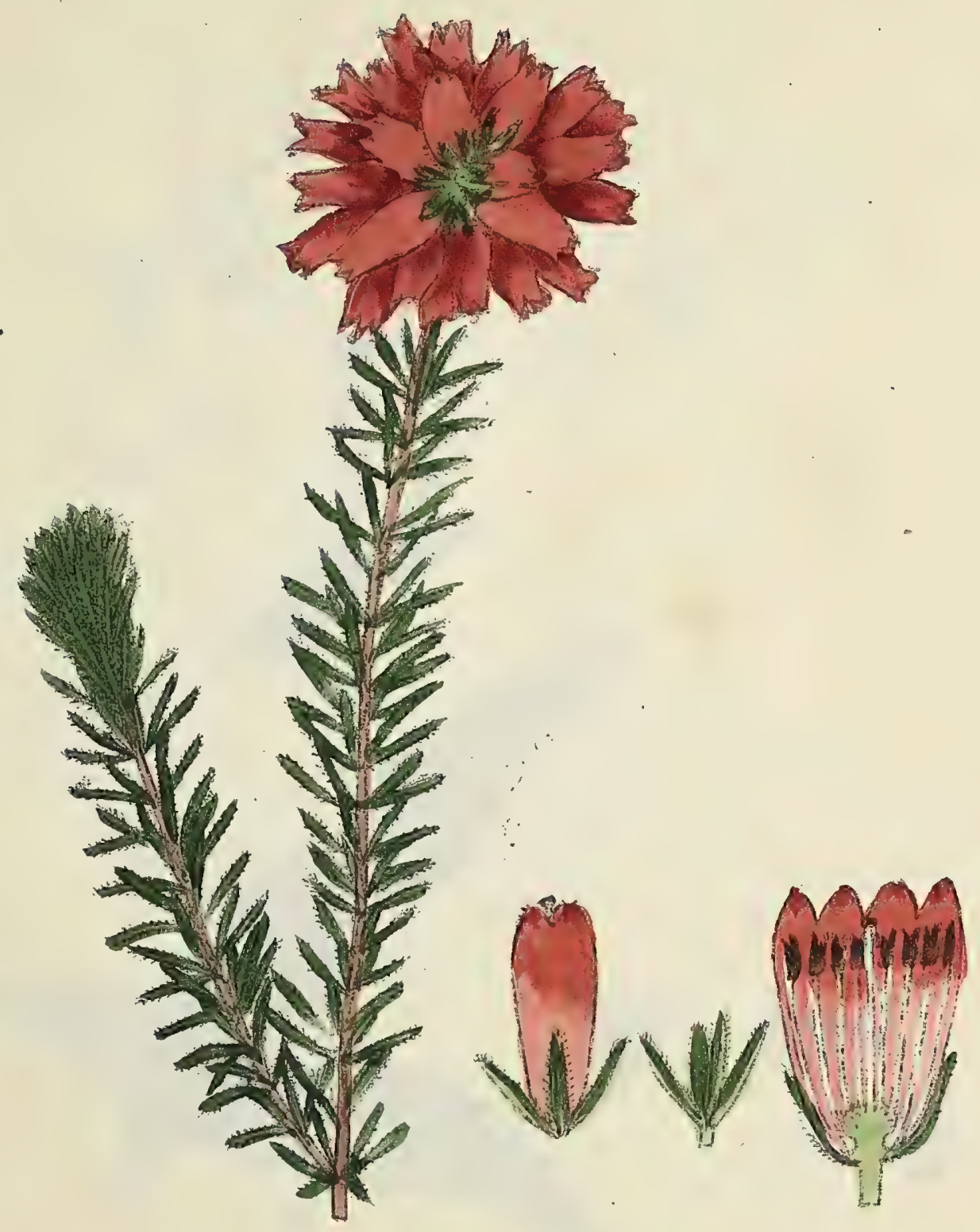

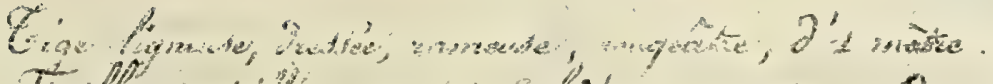

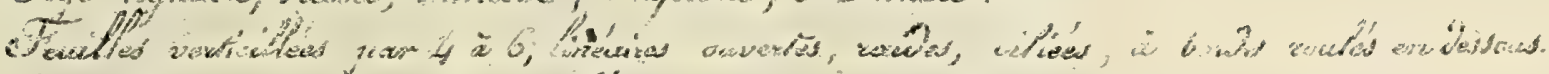

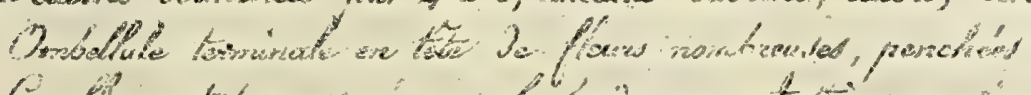

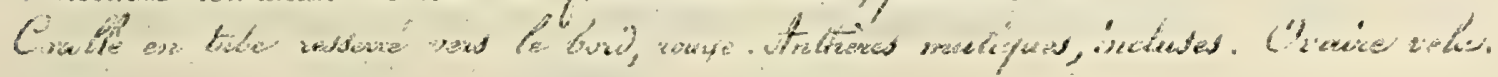

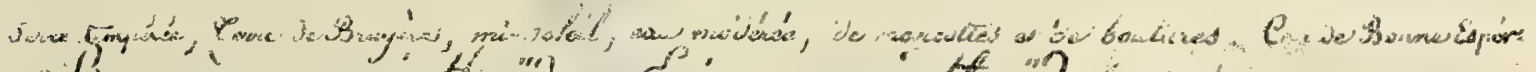

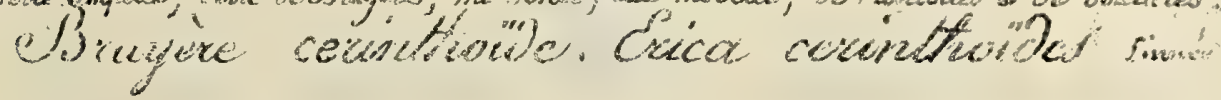





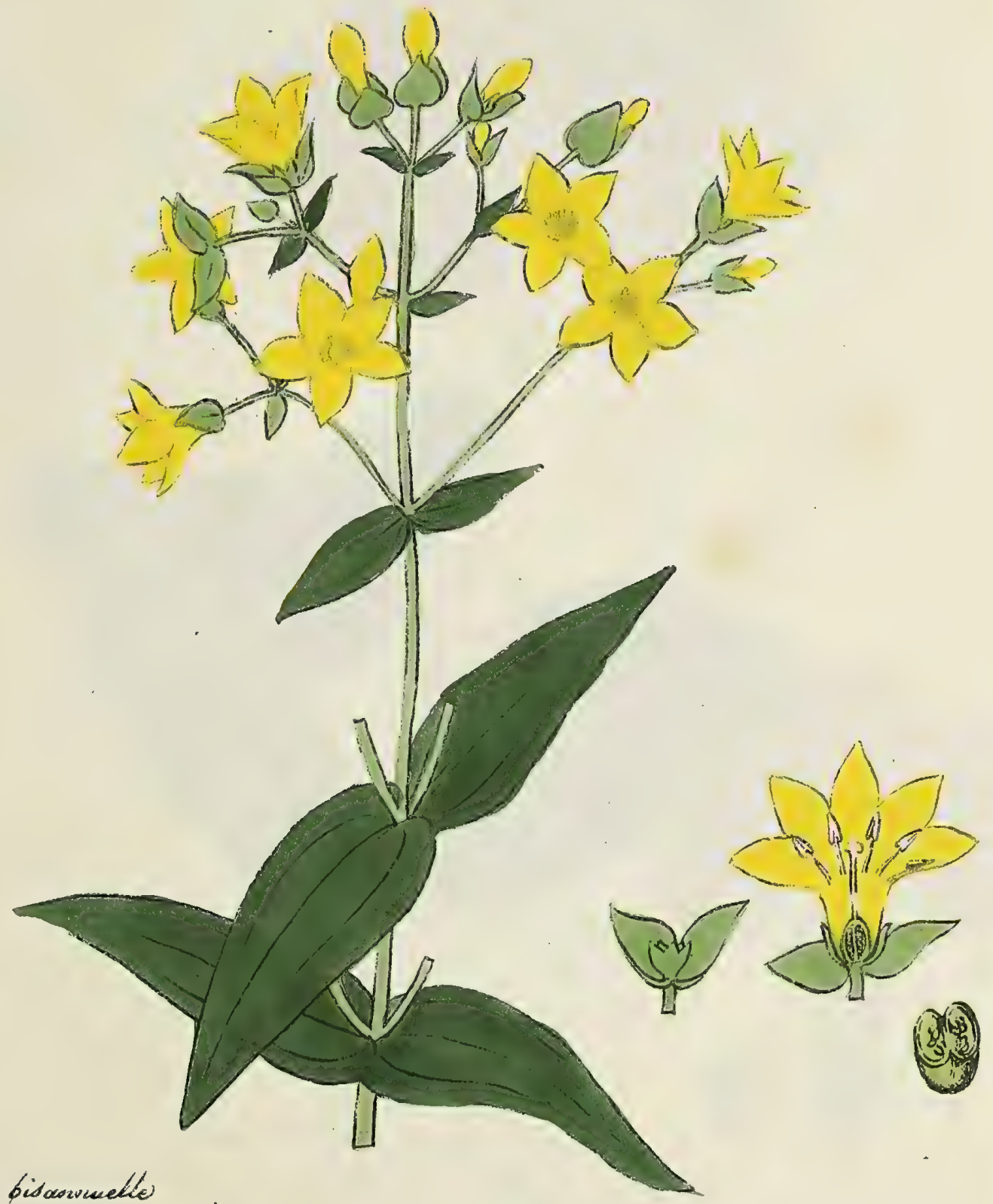

elacives biscorvectio

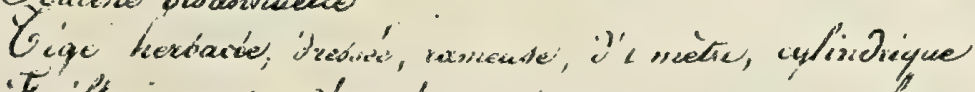

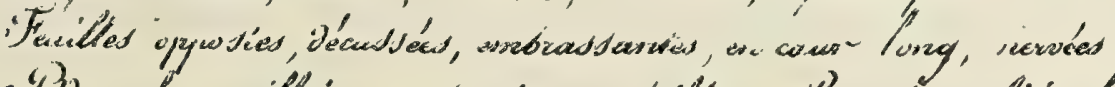

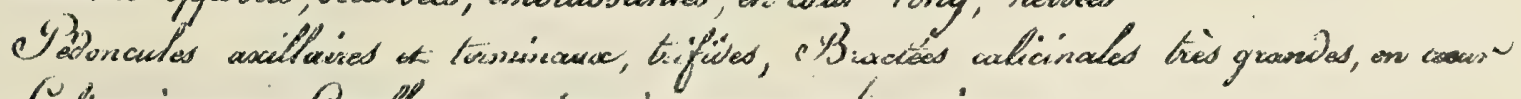

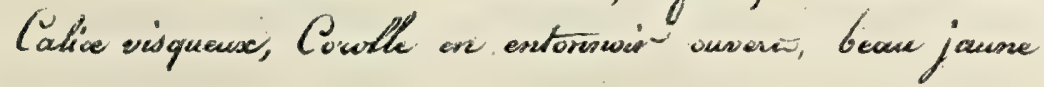

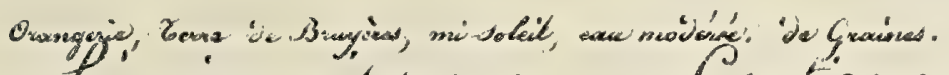

Yles Cas ravinat.

Fupion visquena. Gerctianca viscosa tion

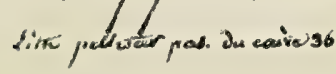




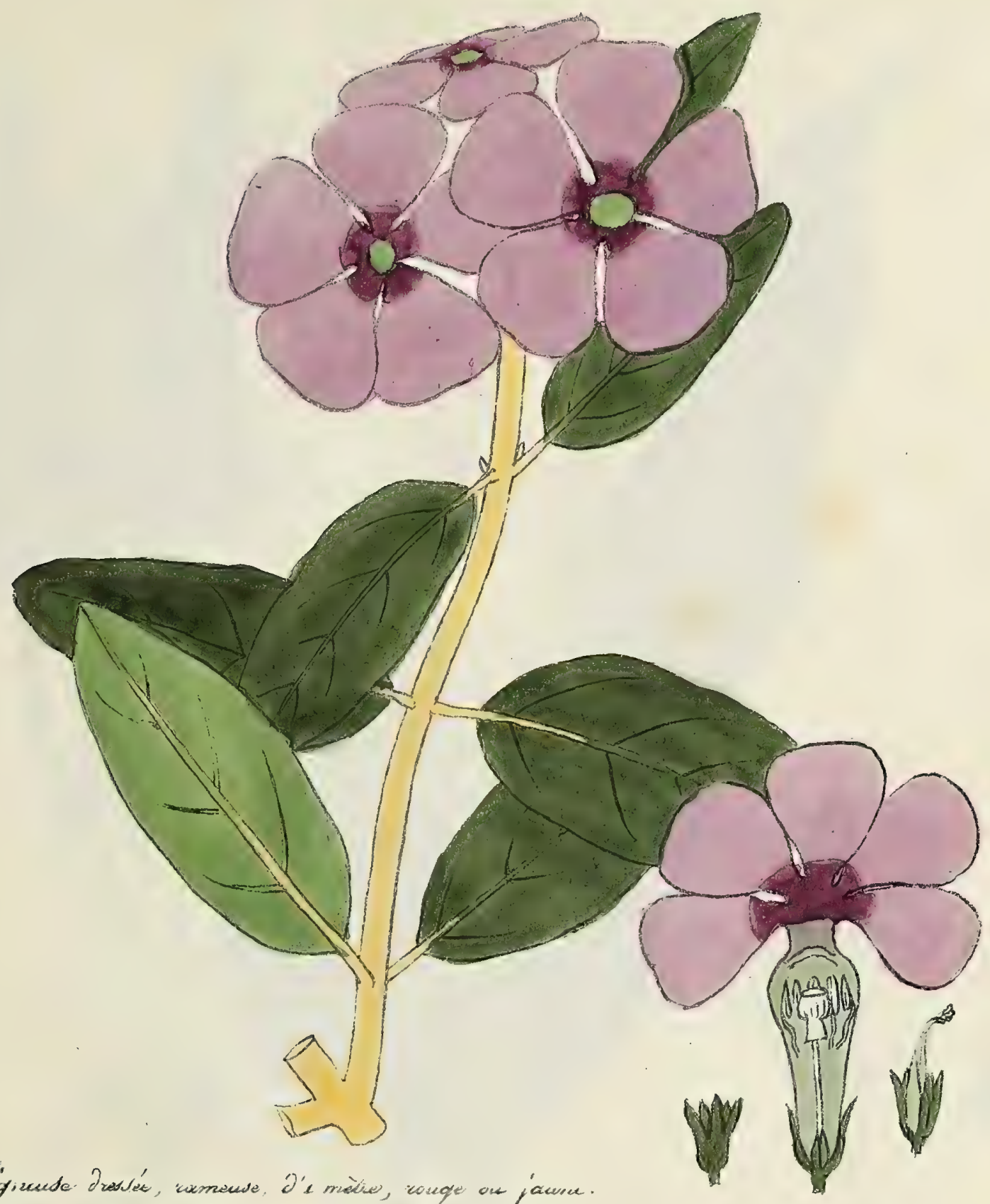

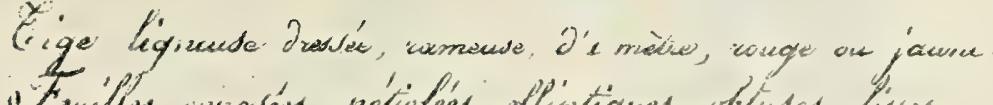

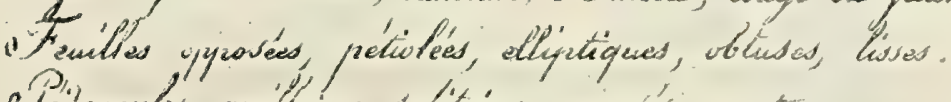

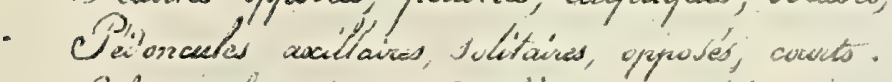

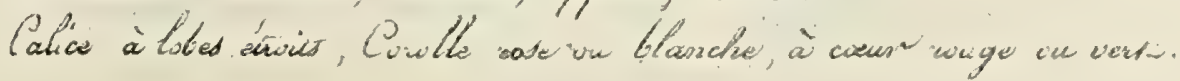

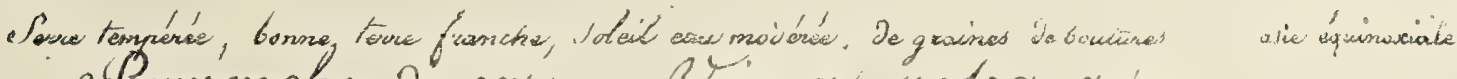

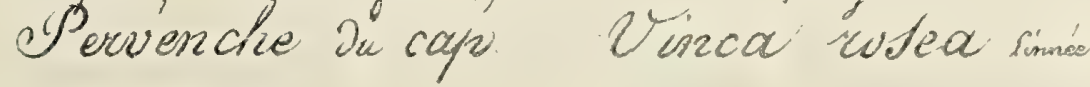

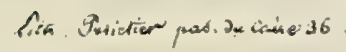





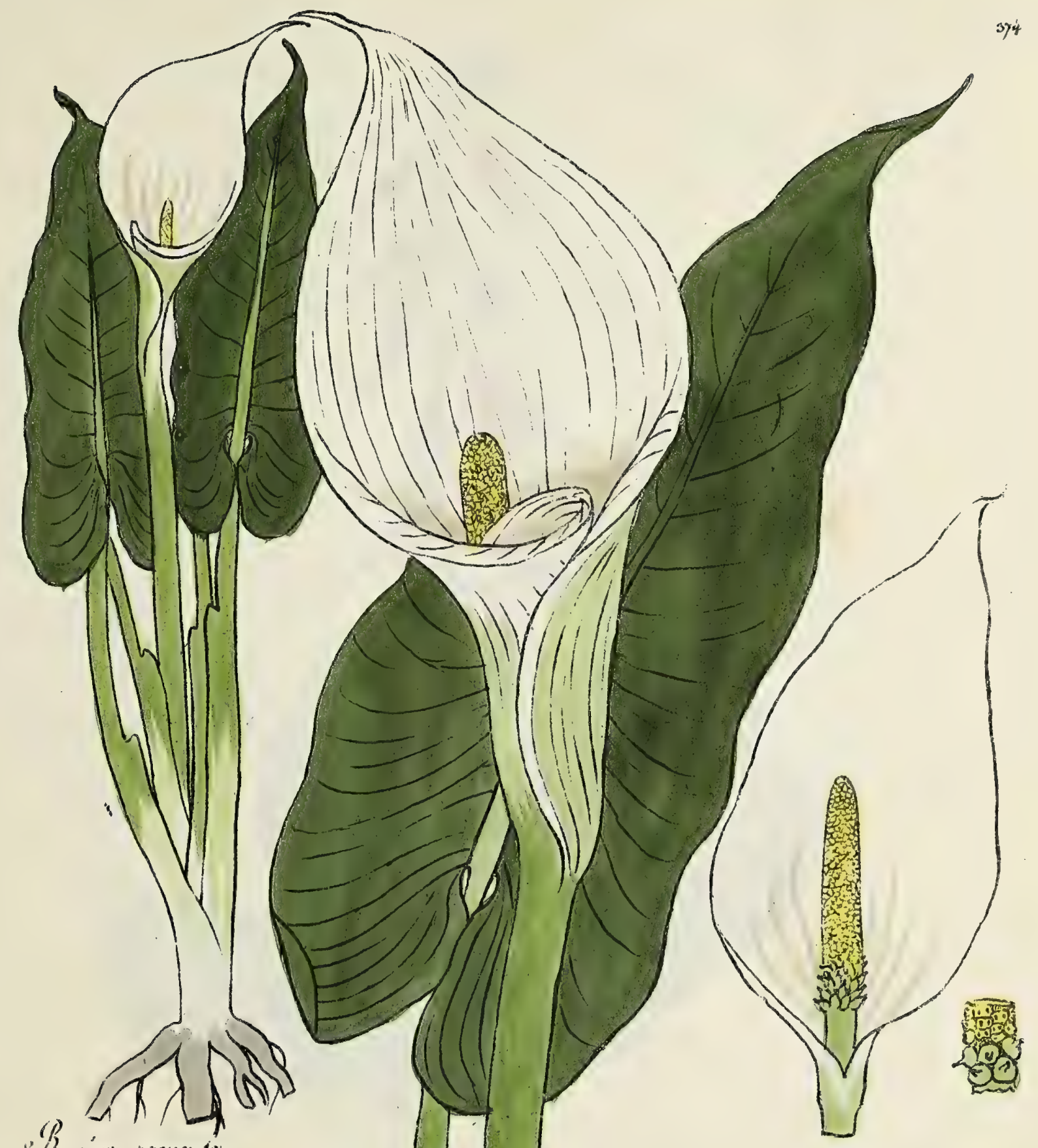

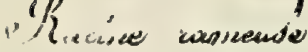

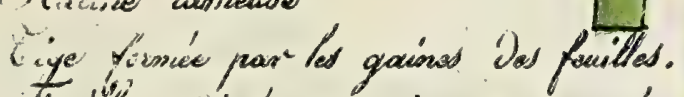

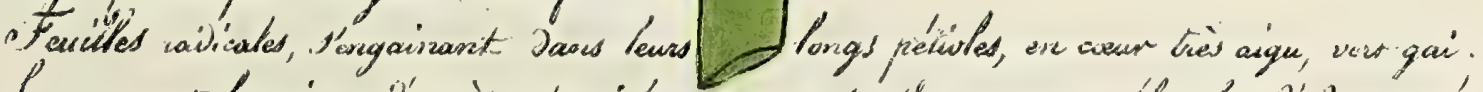

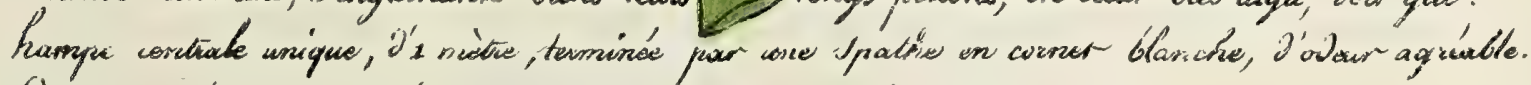

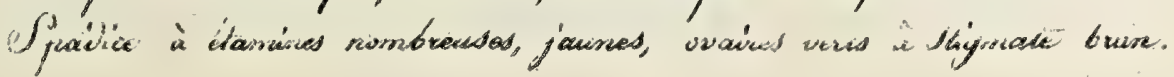

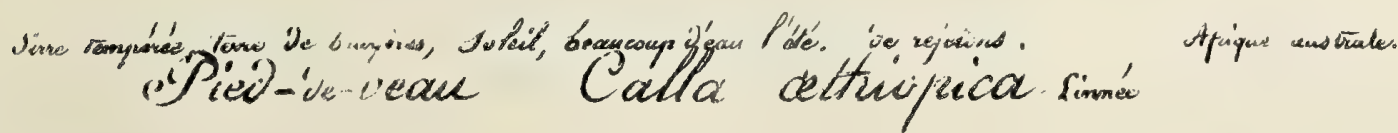

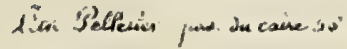





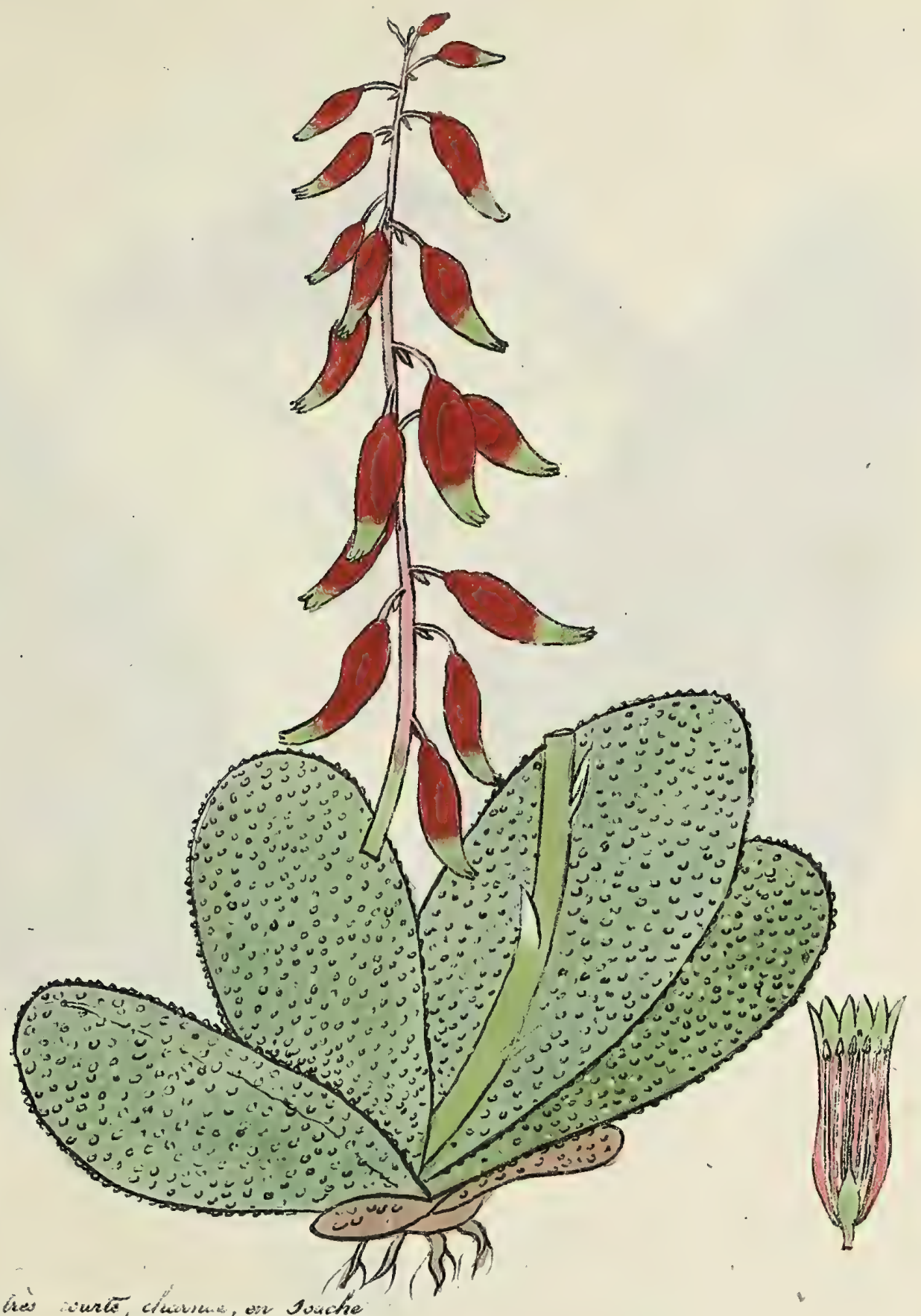

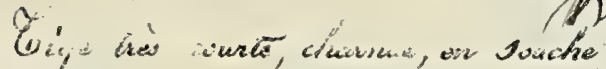

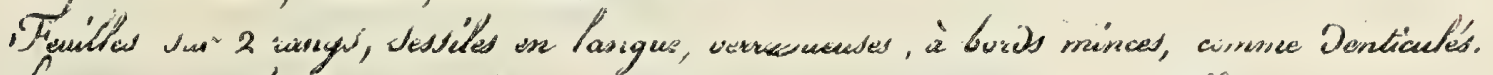

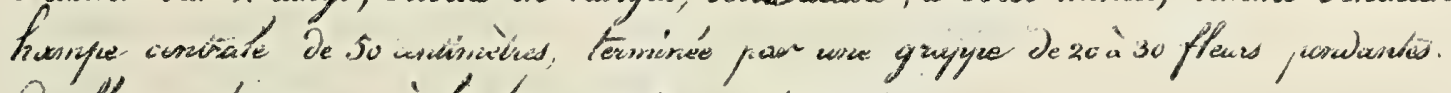

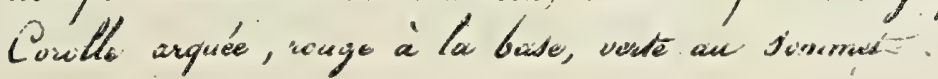

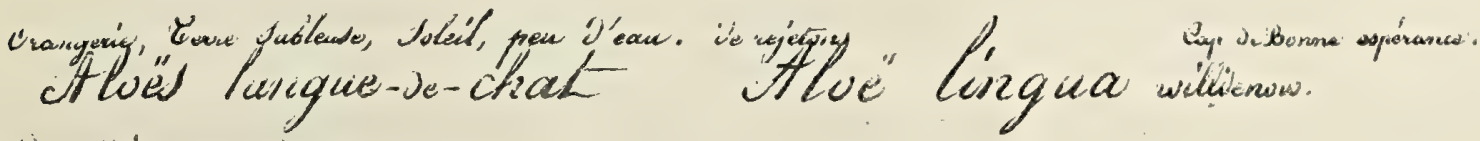

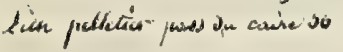





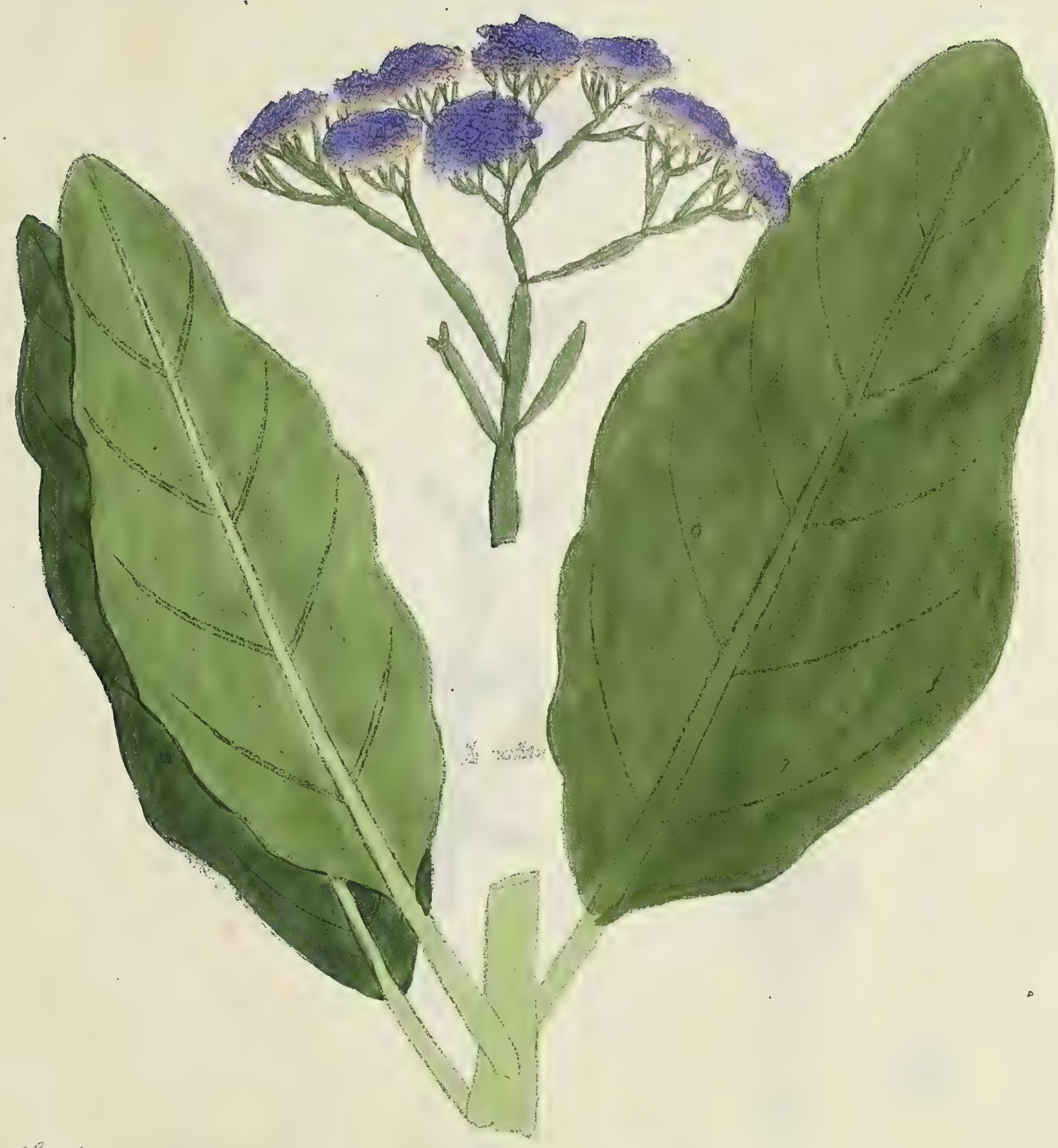

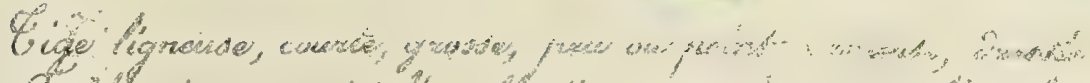

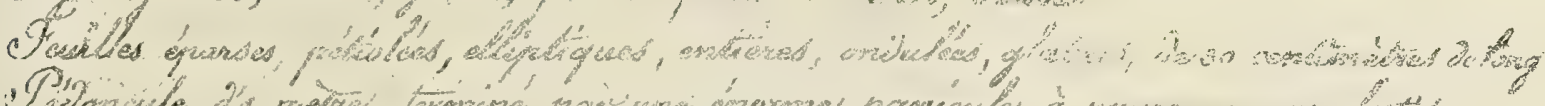

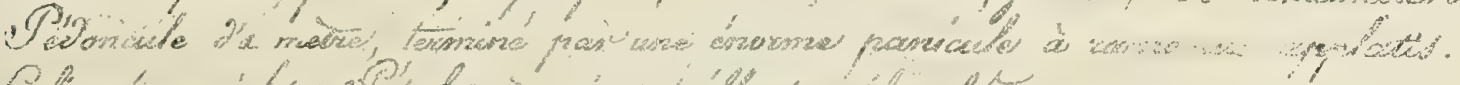

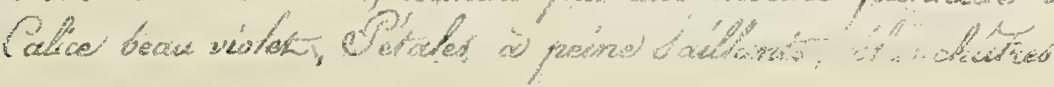

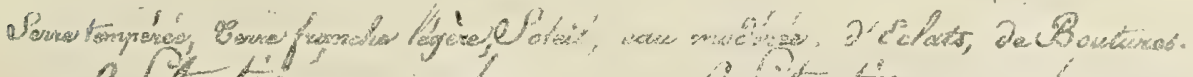

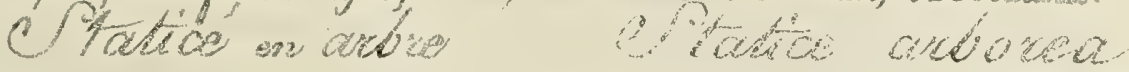





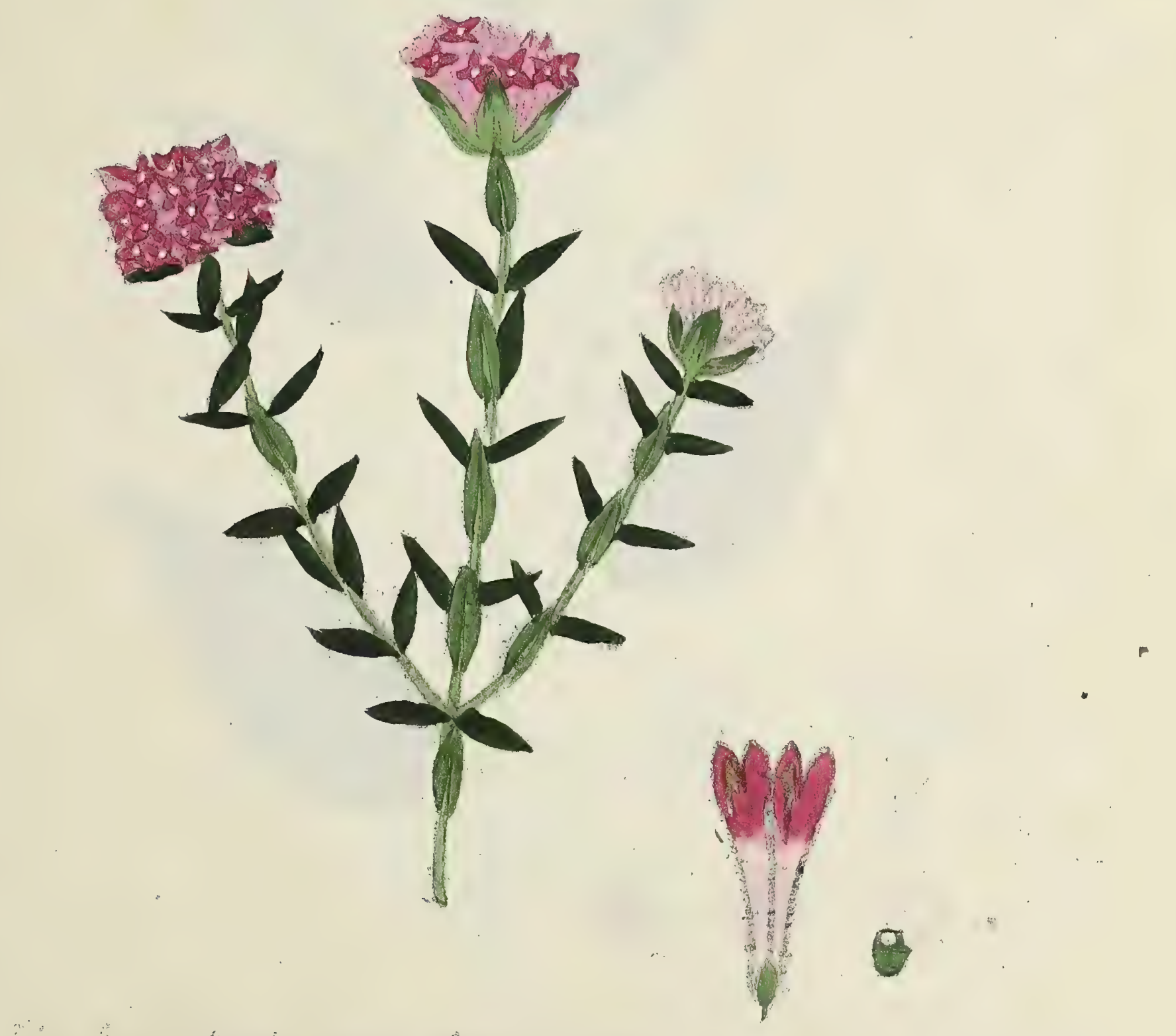

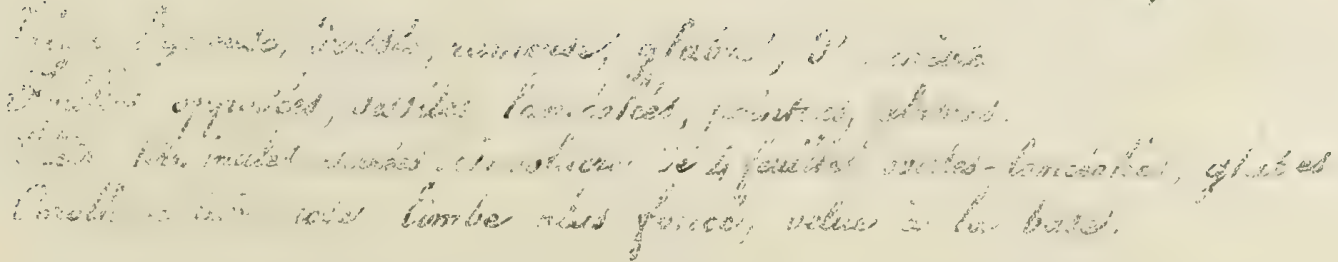

$$
\begin{aligned}
& \text { 2: }
\end{aligned}
$$

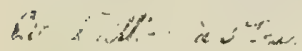

$$
\begin{aligned}
& \text { ens }
\end{aligned}
$$





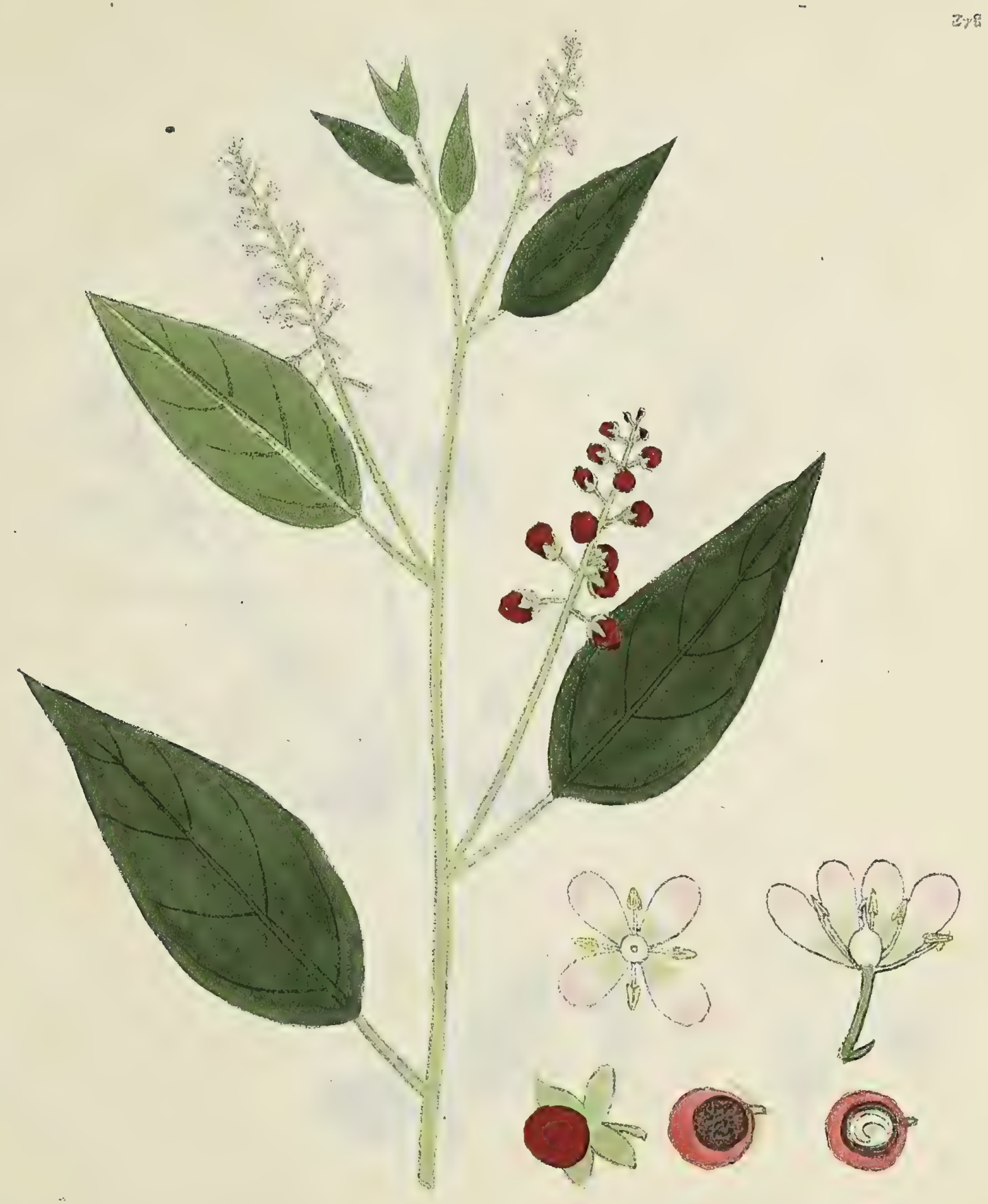

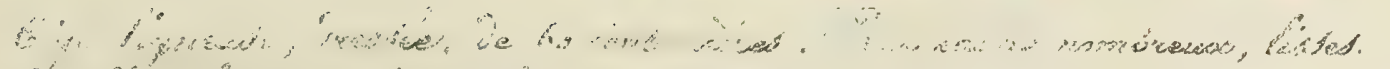

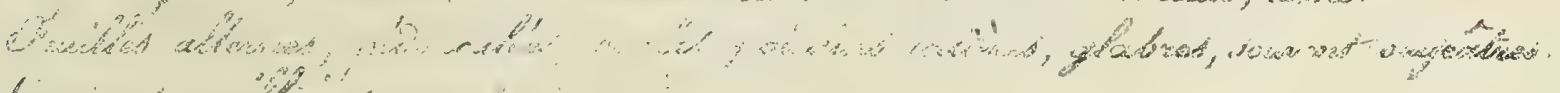

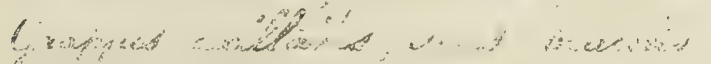

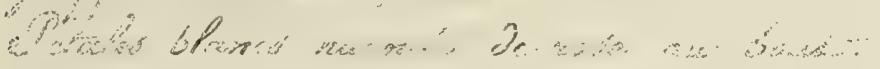

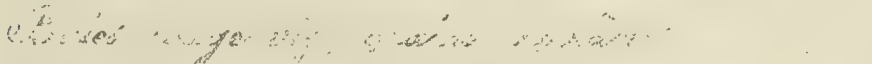

S.

1. 


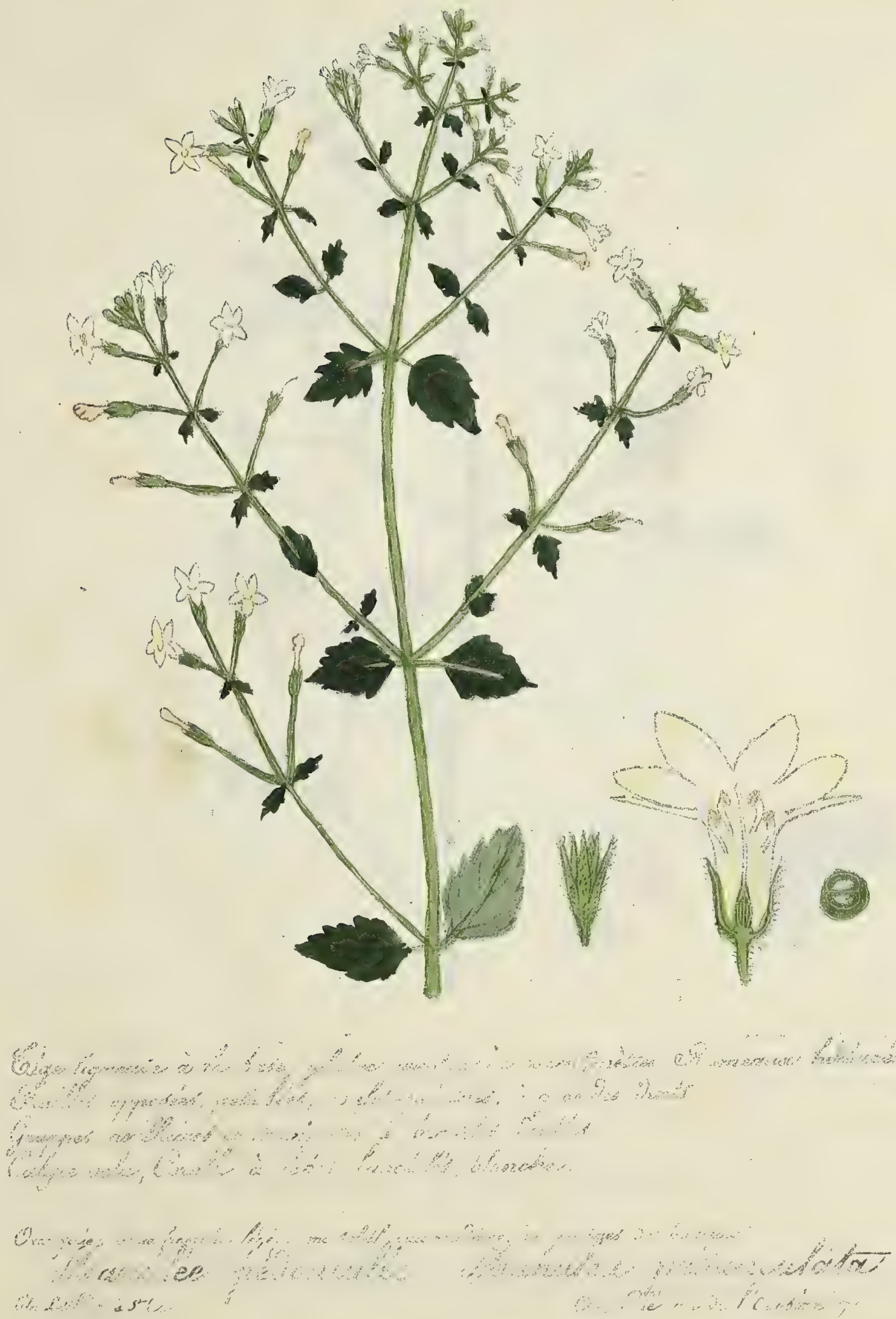



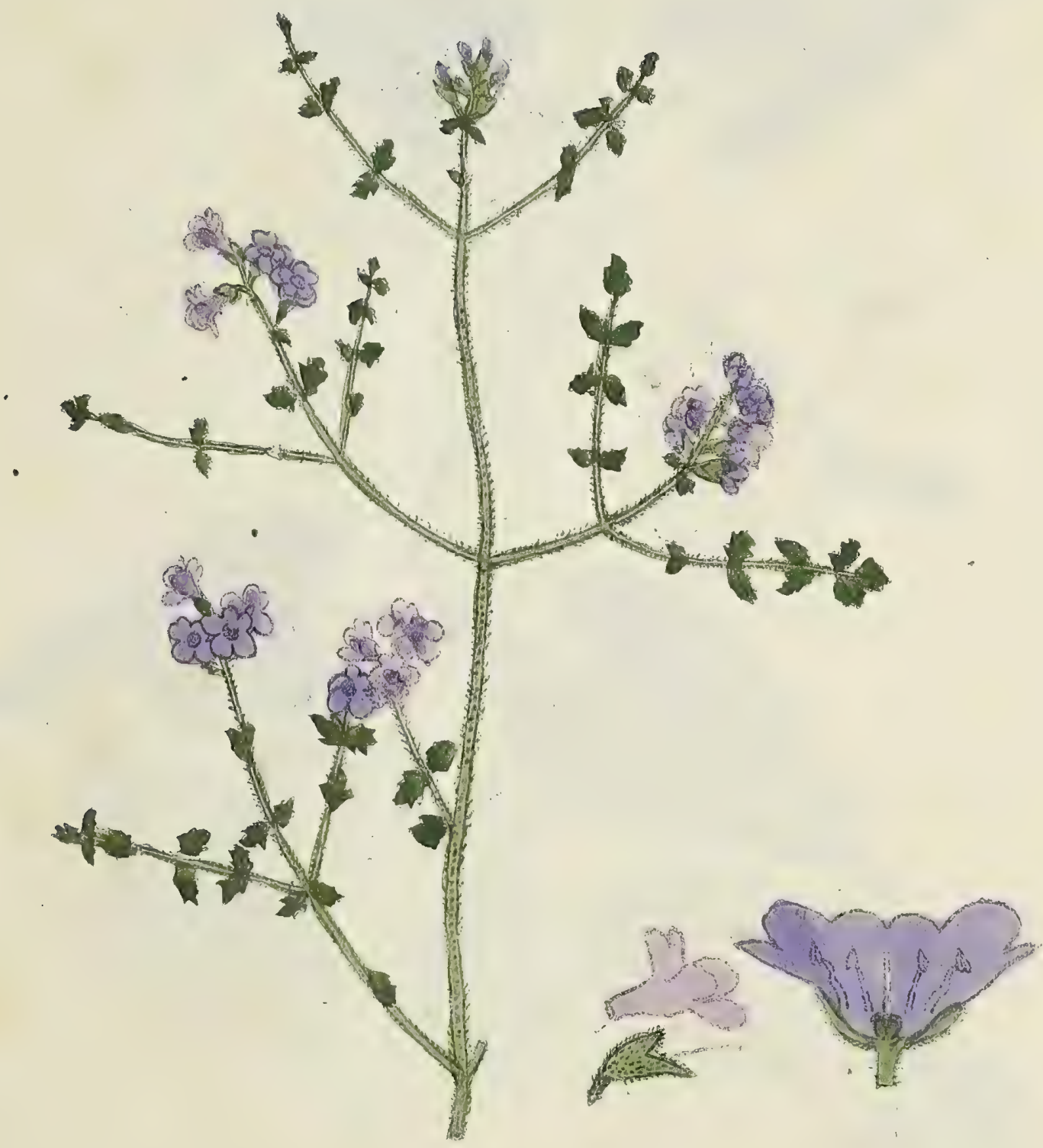

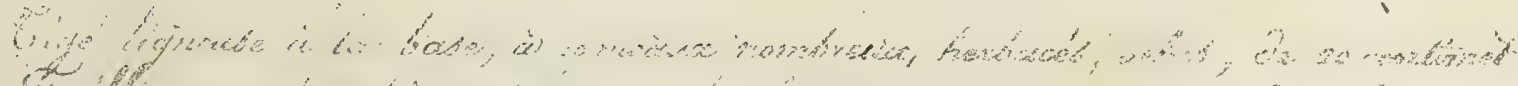

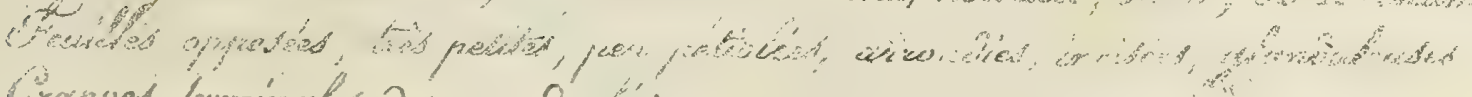

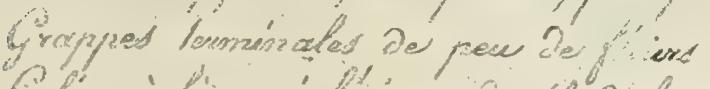

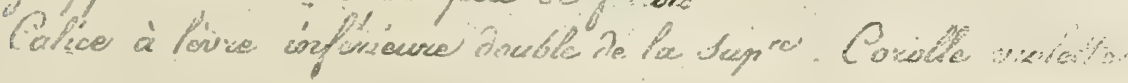

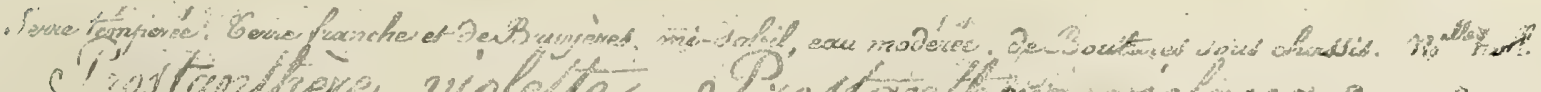

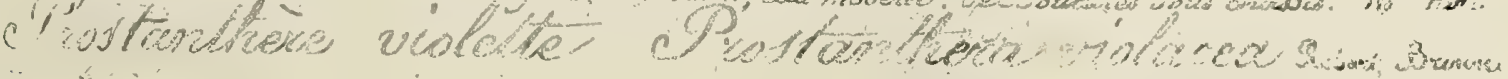

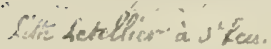

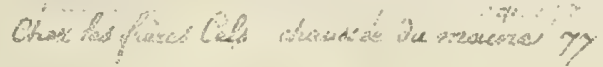


1 


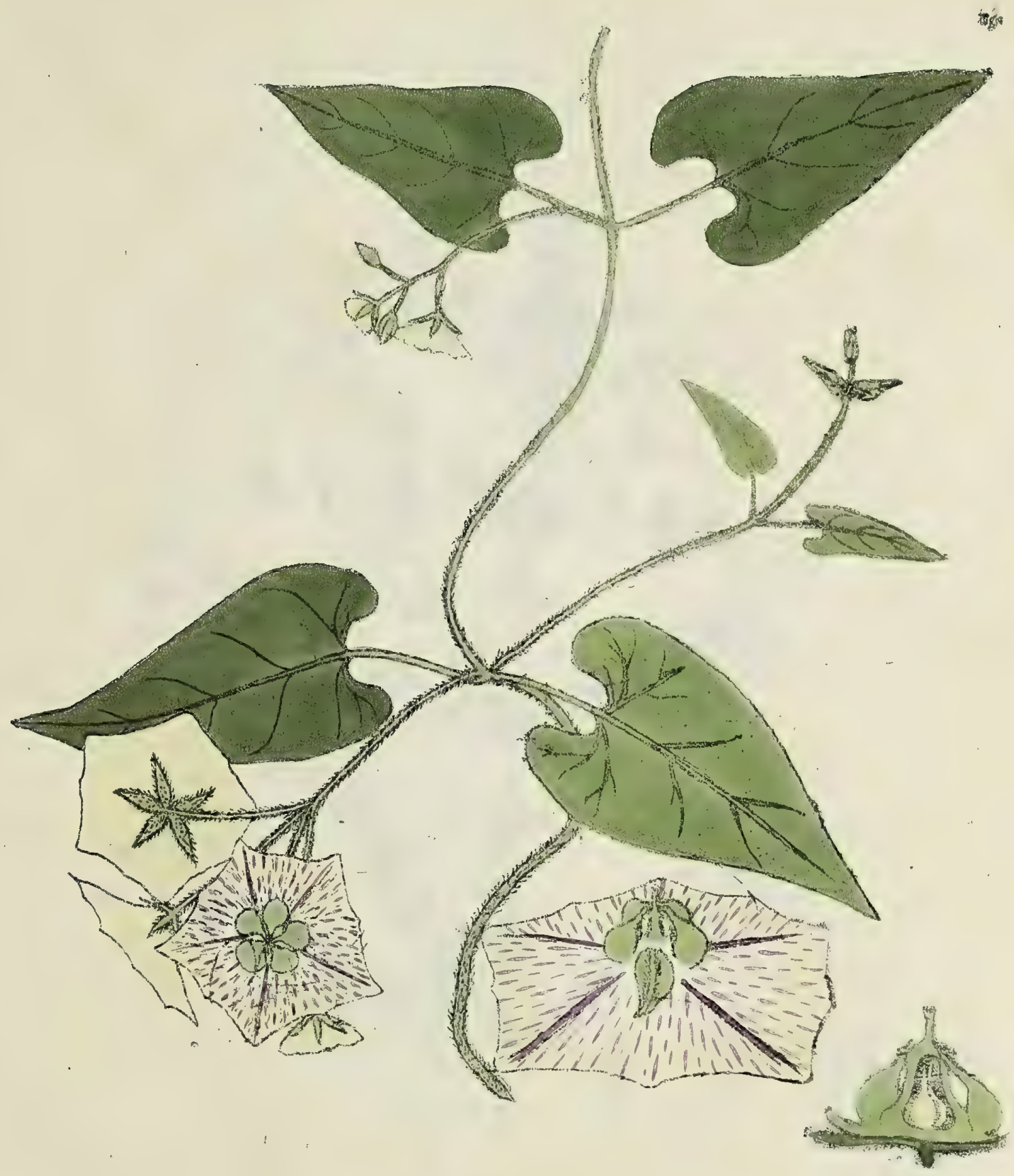

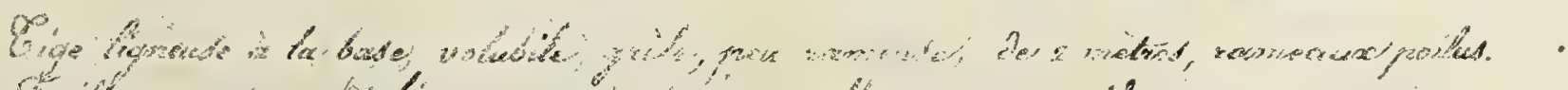

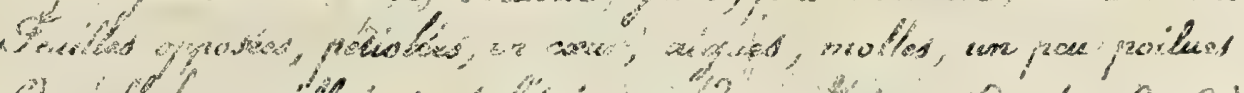

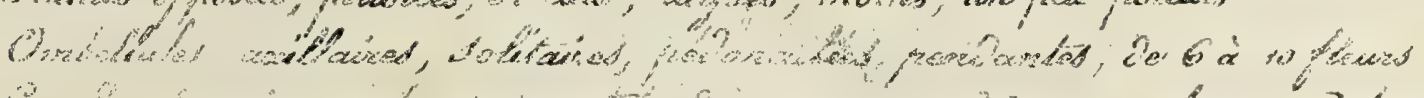

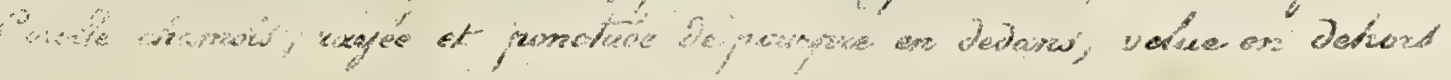

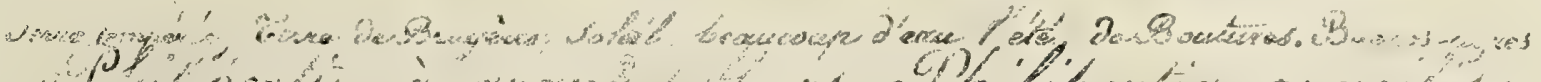

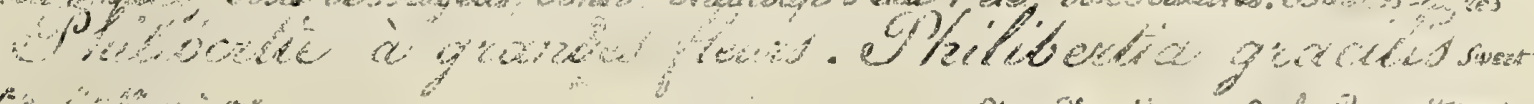

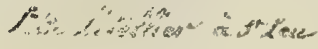

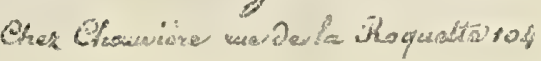





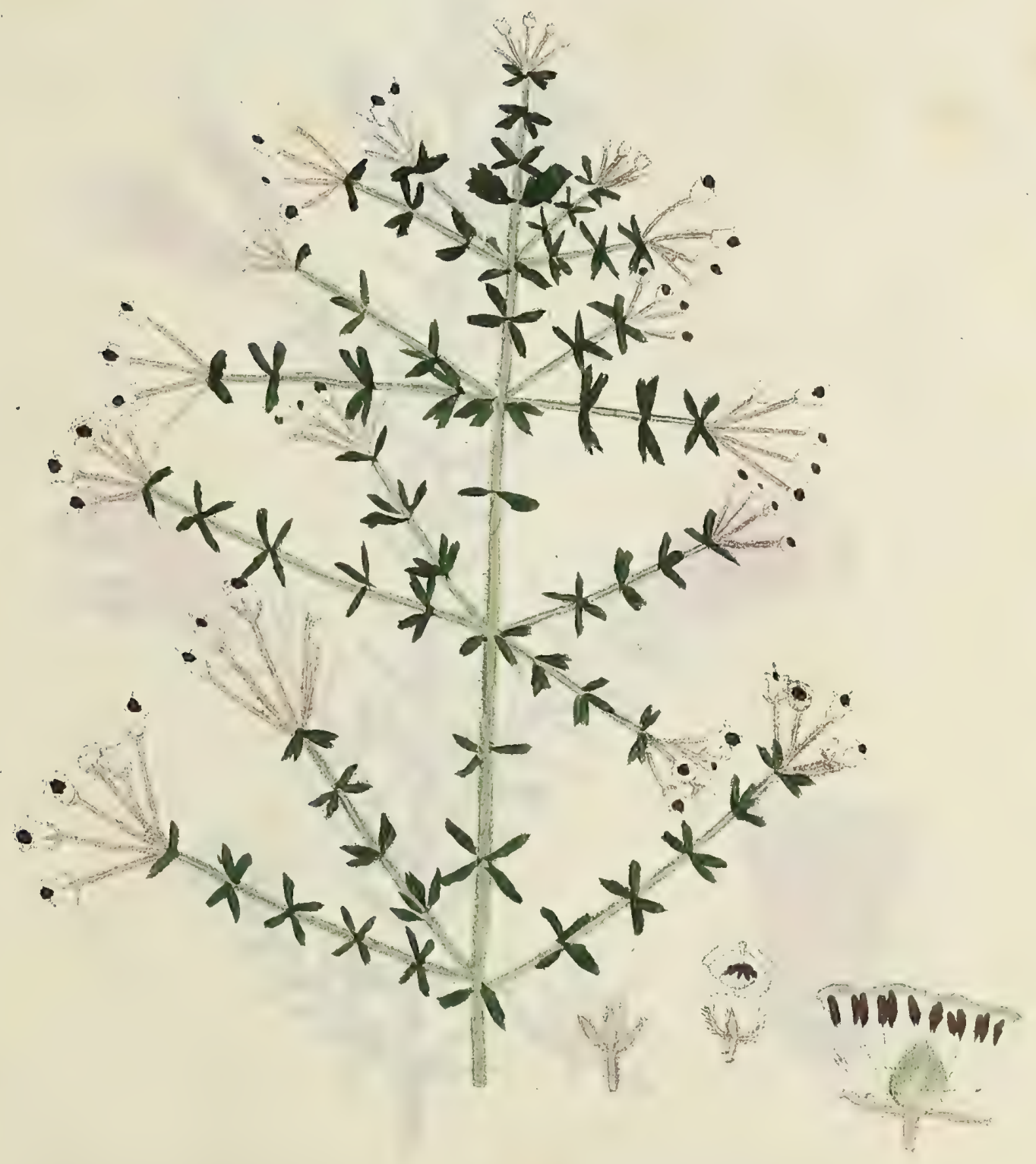

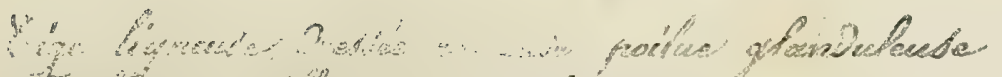

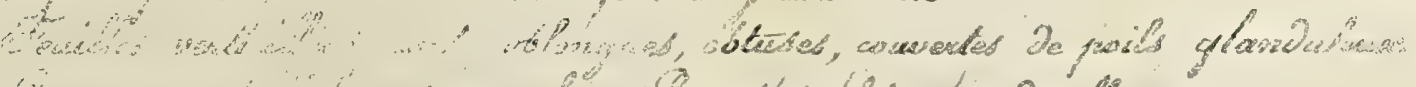

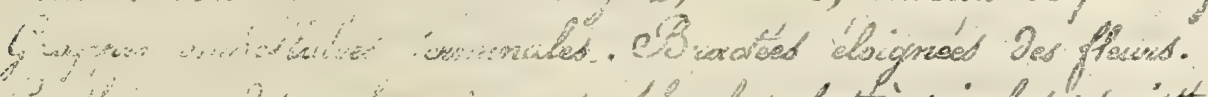

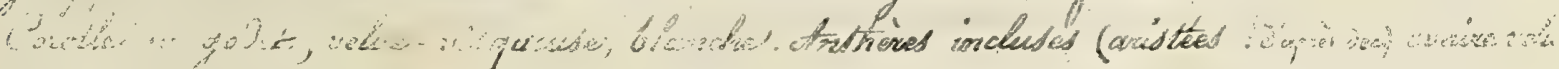

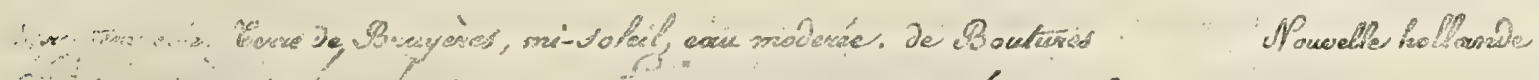

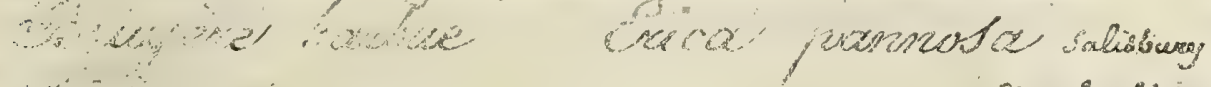

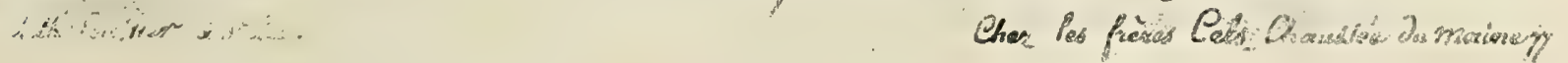





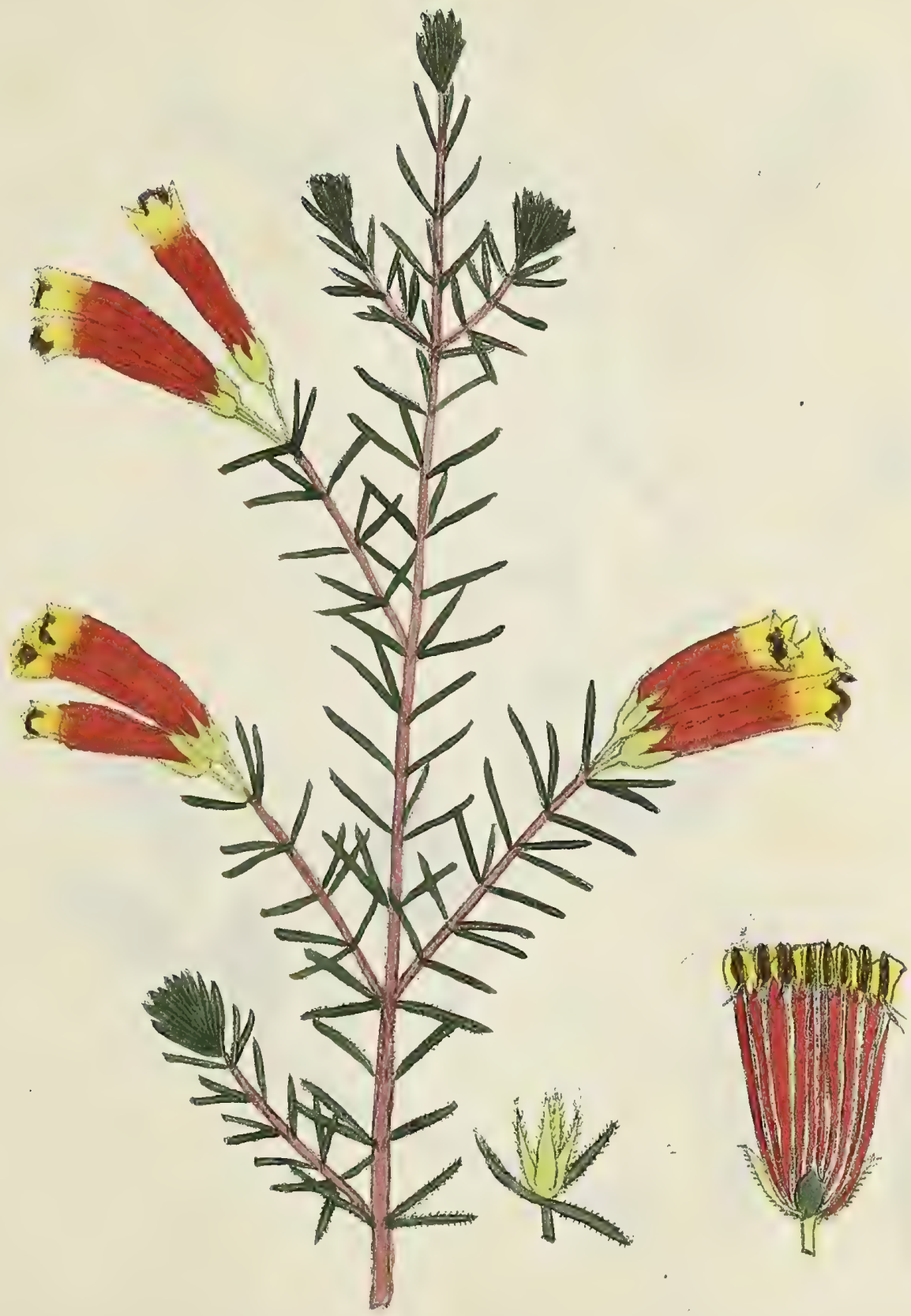

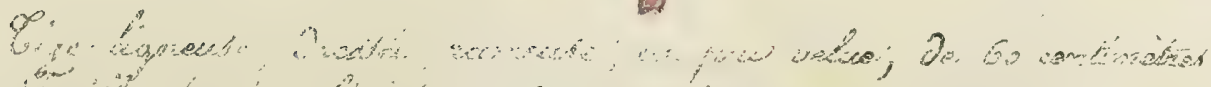

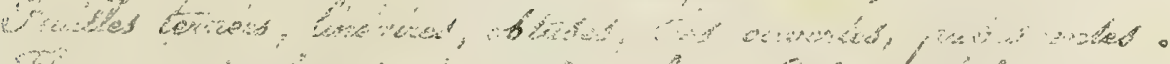

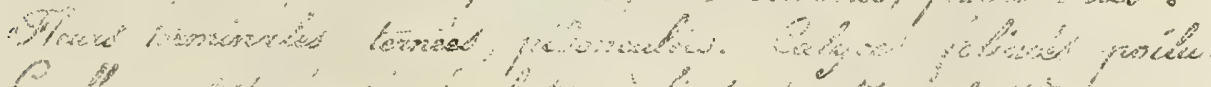

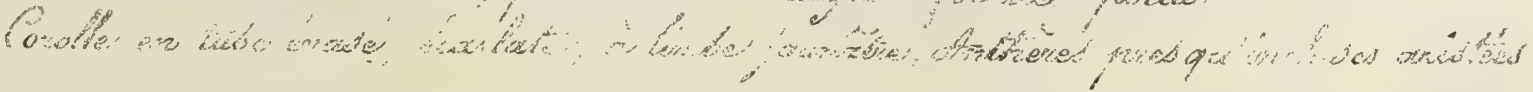

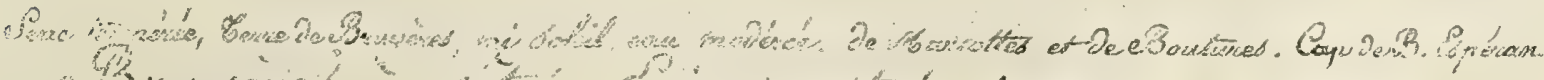

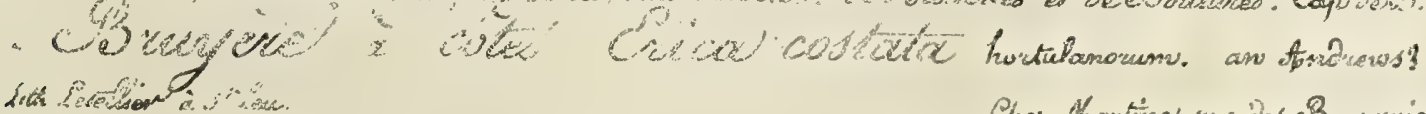
Phex thas thes rus Bes Bourguignon's ay 



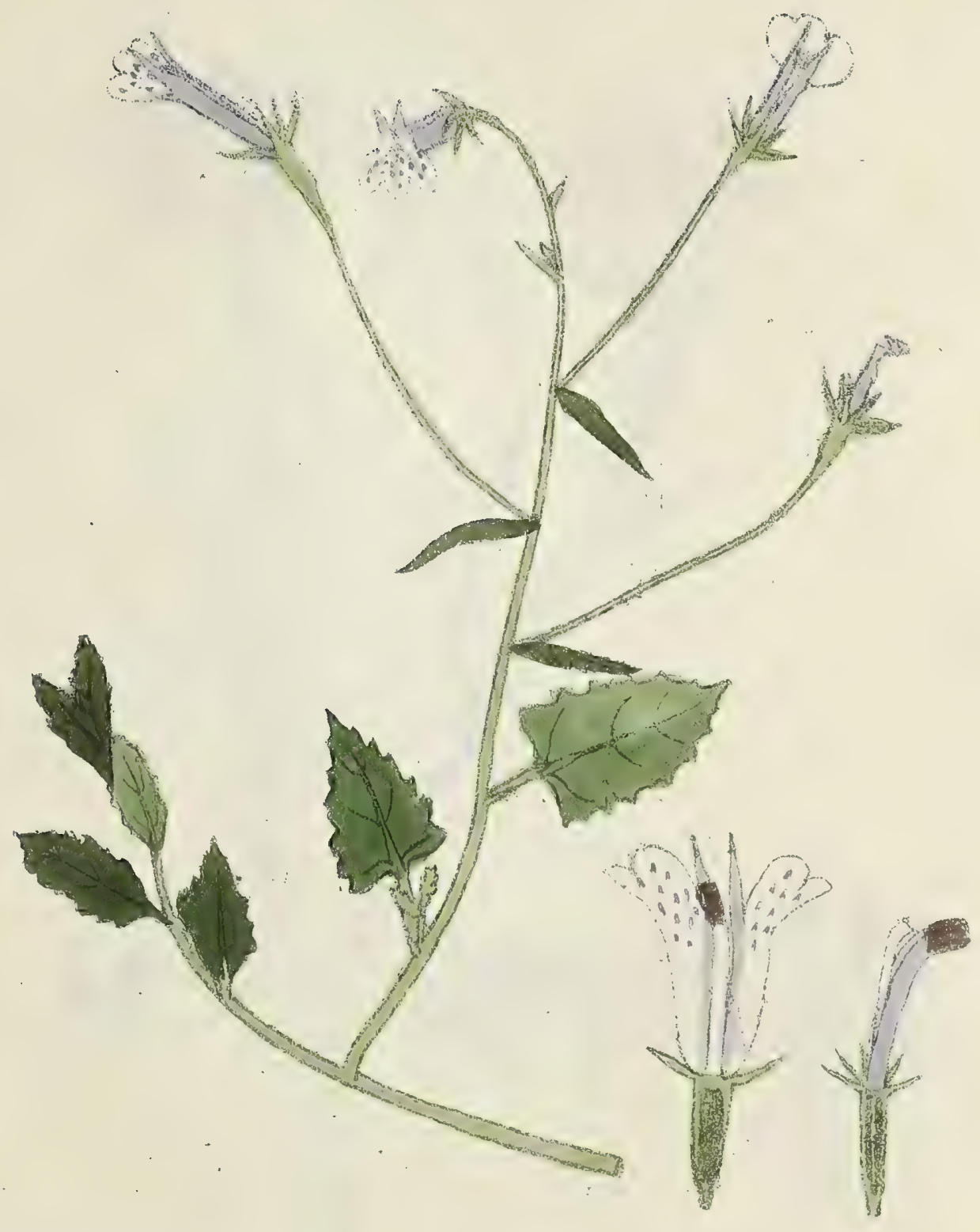

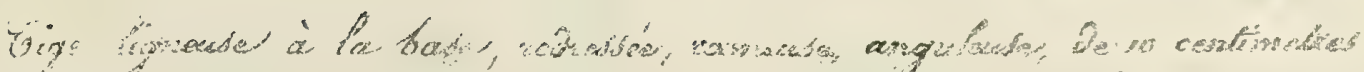

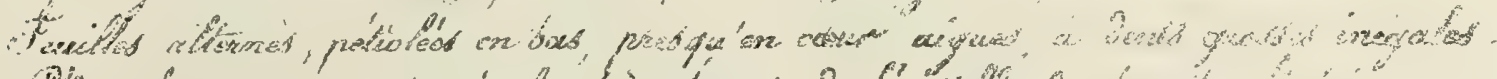

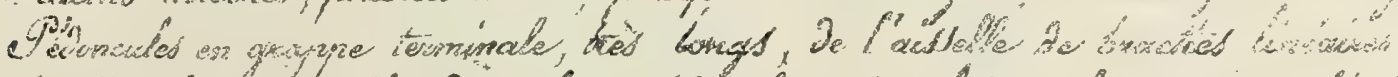

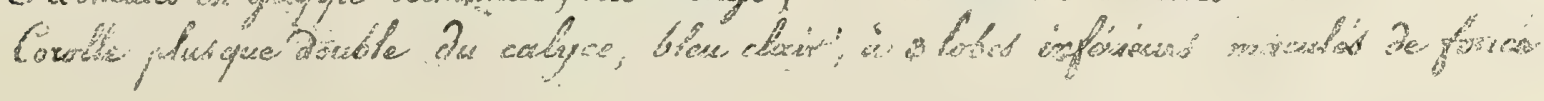

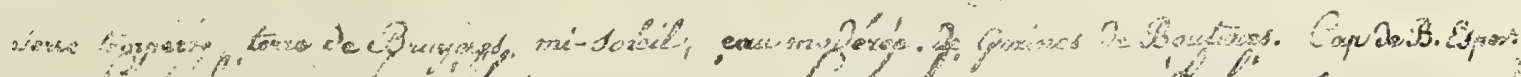

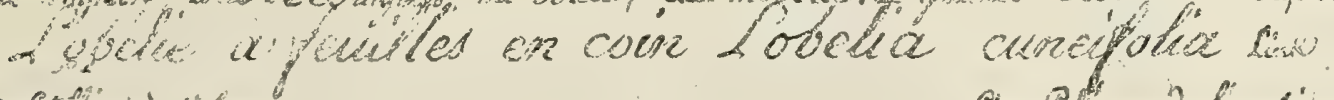

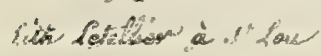

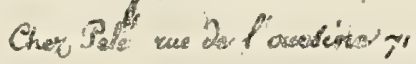





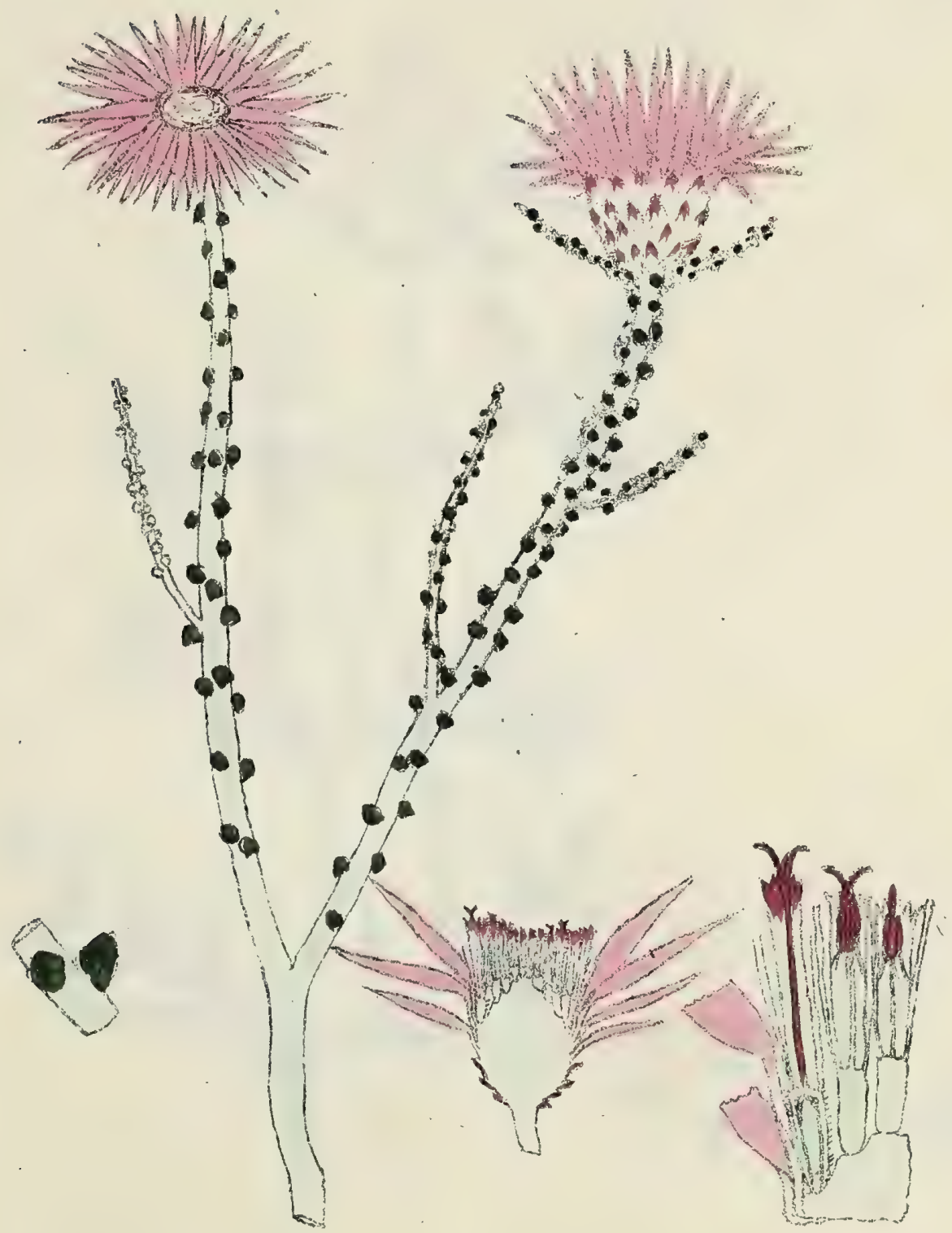

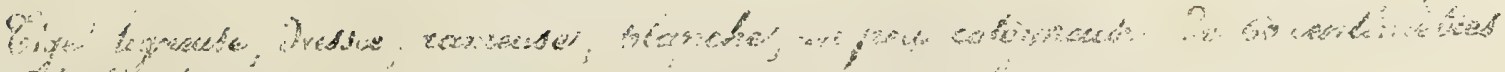

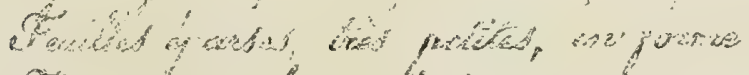

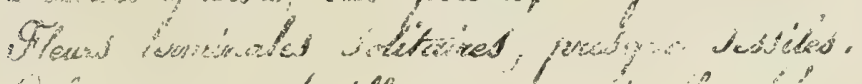

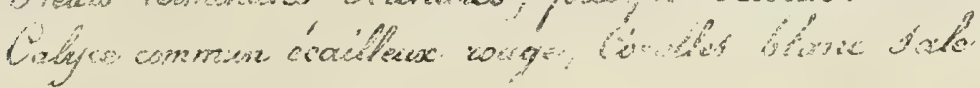

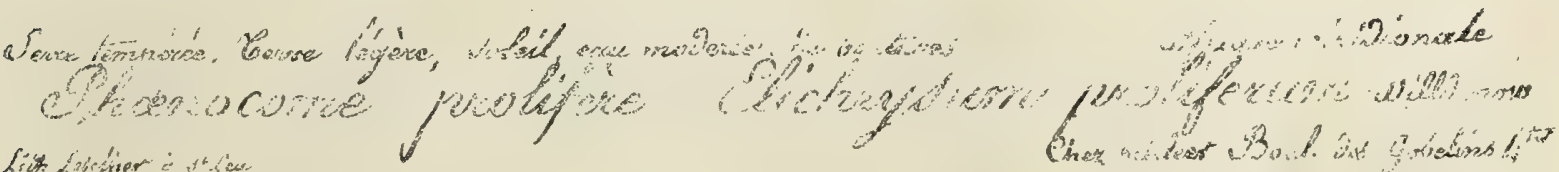





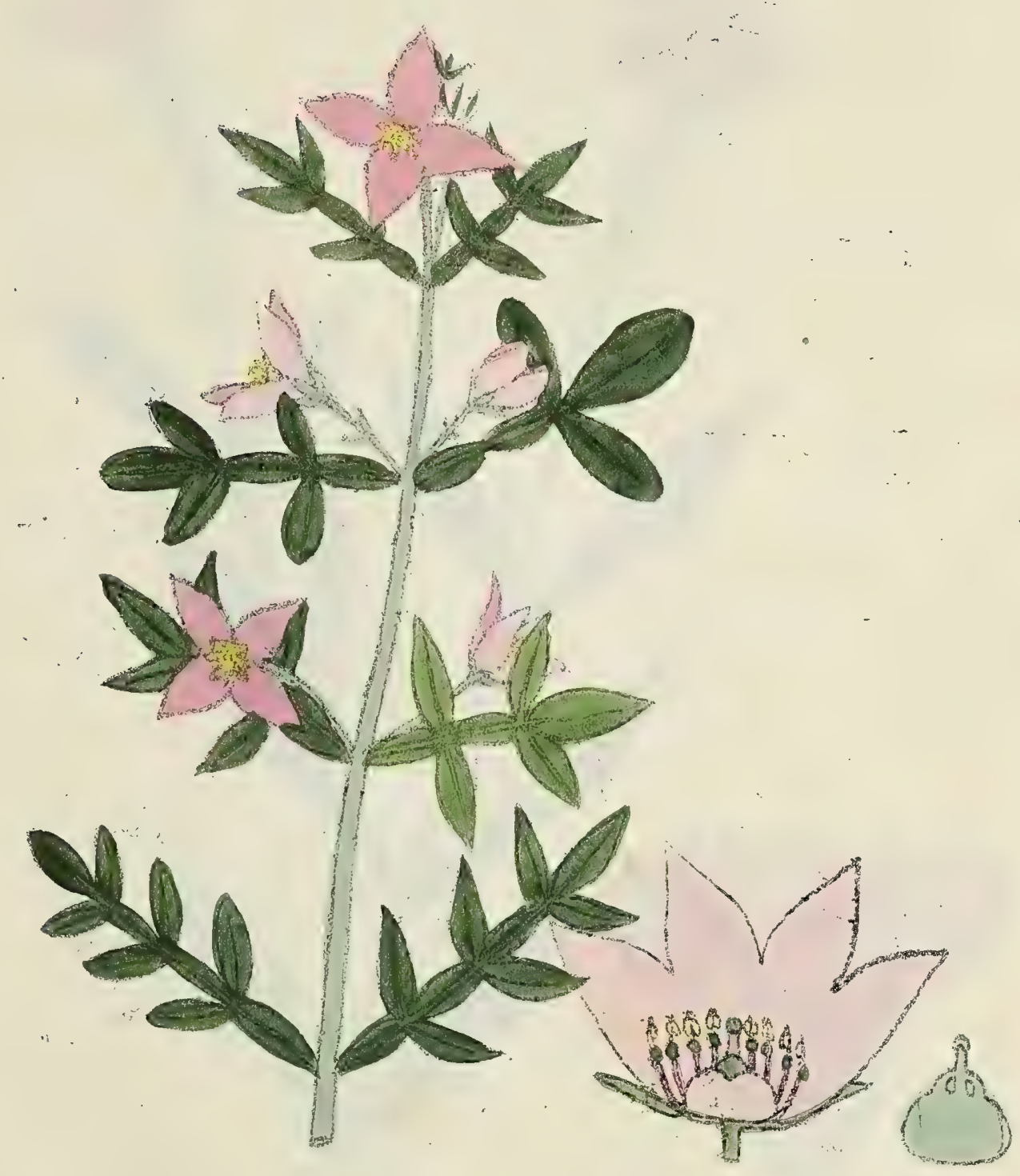

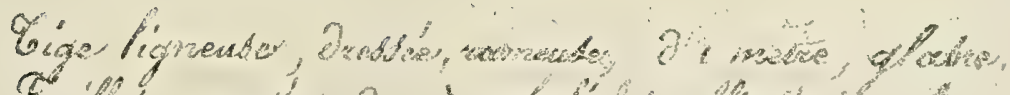

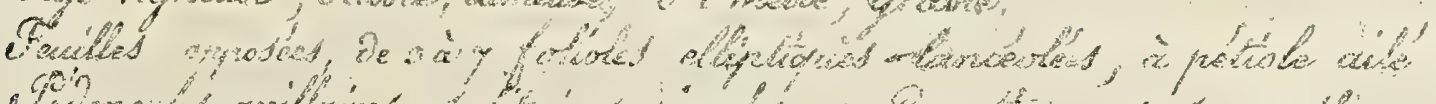

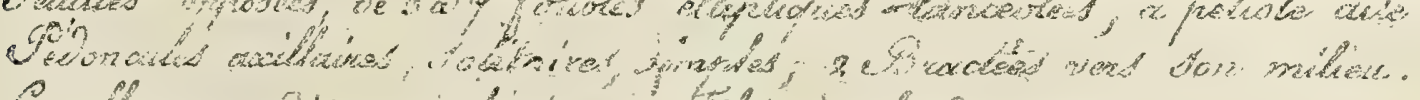

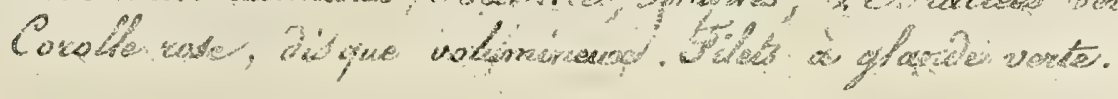

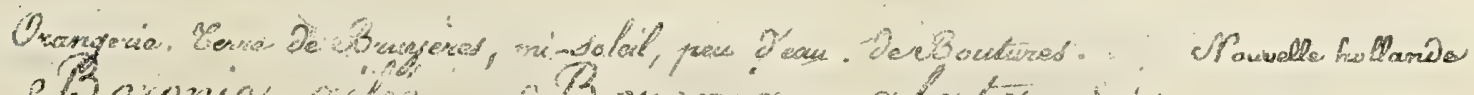

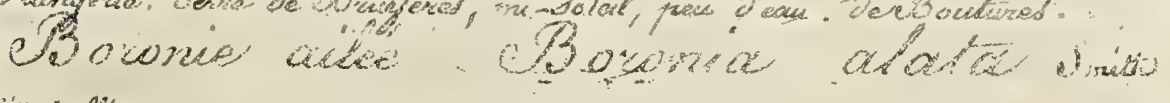

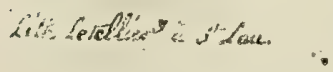

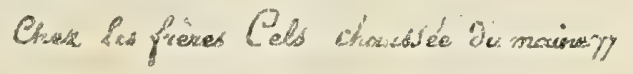





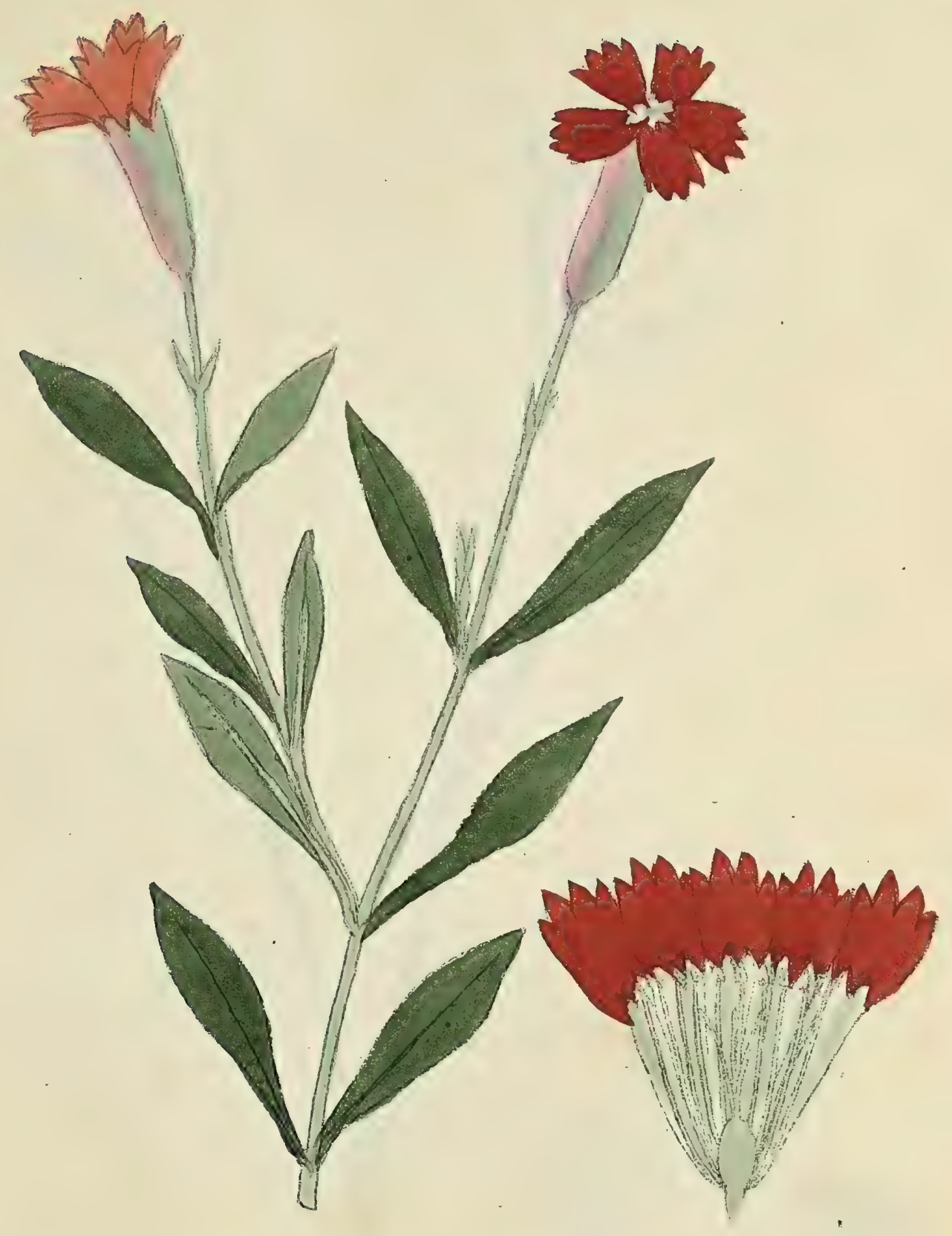

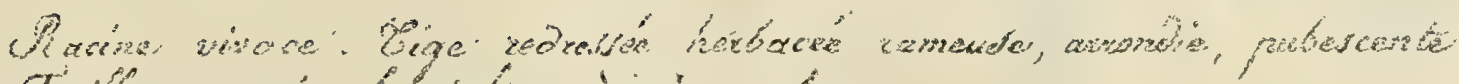

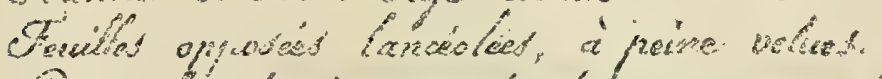

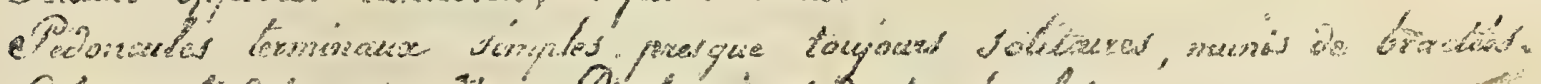

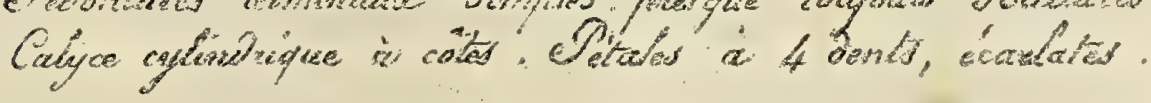

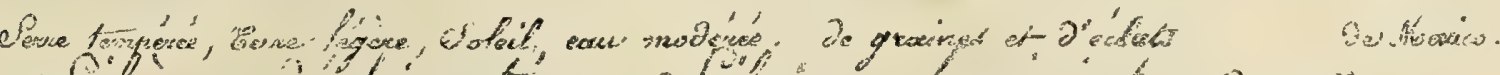

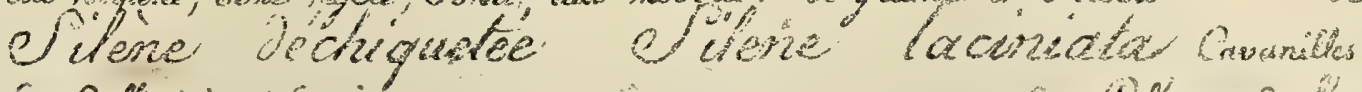

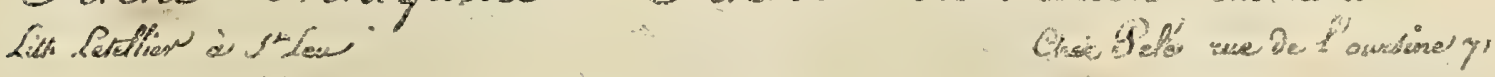





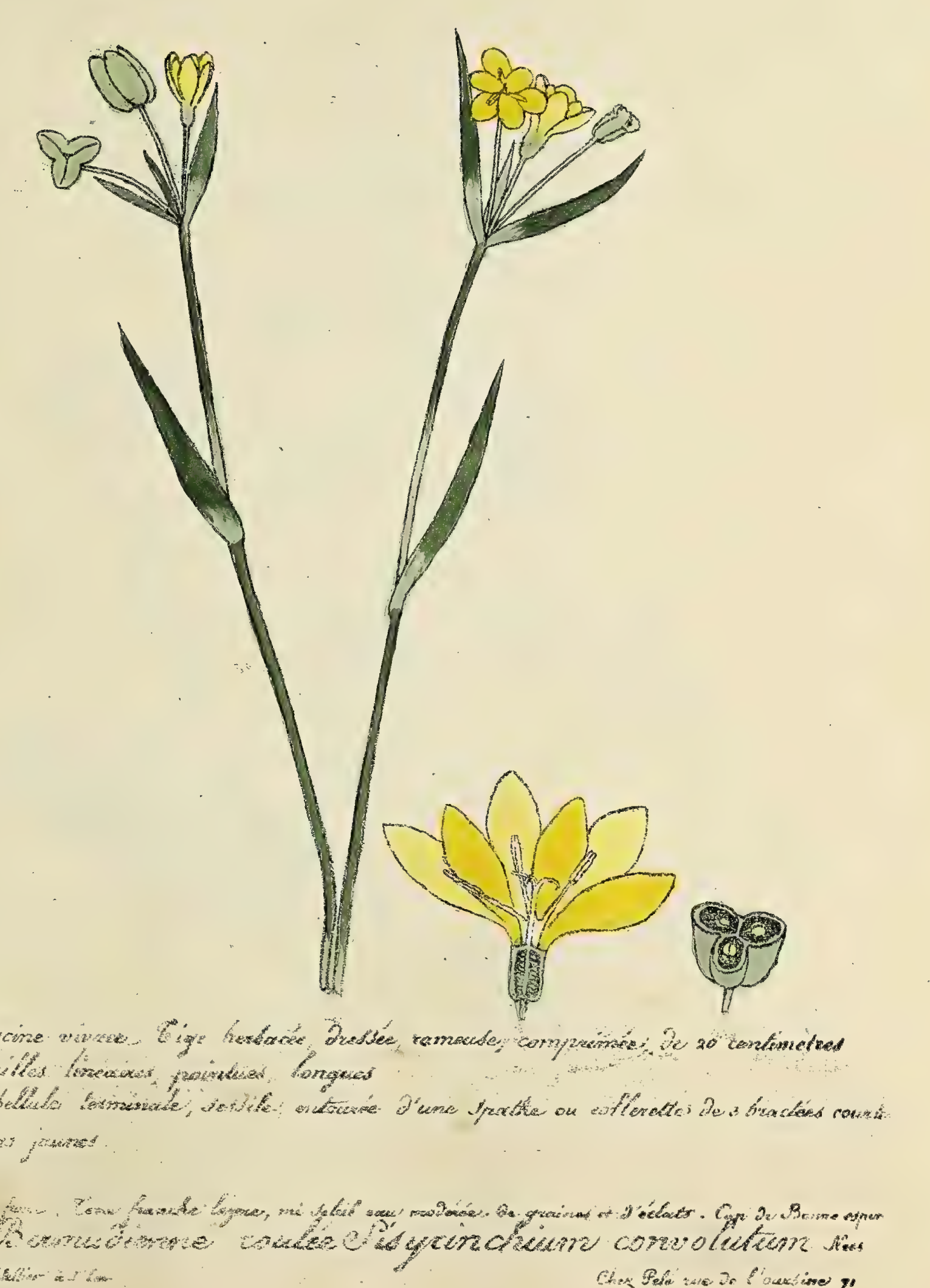





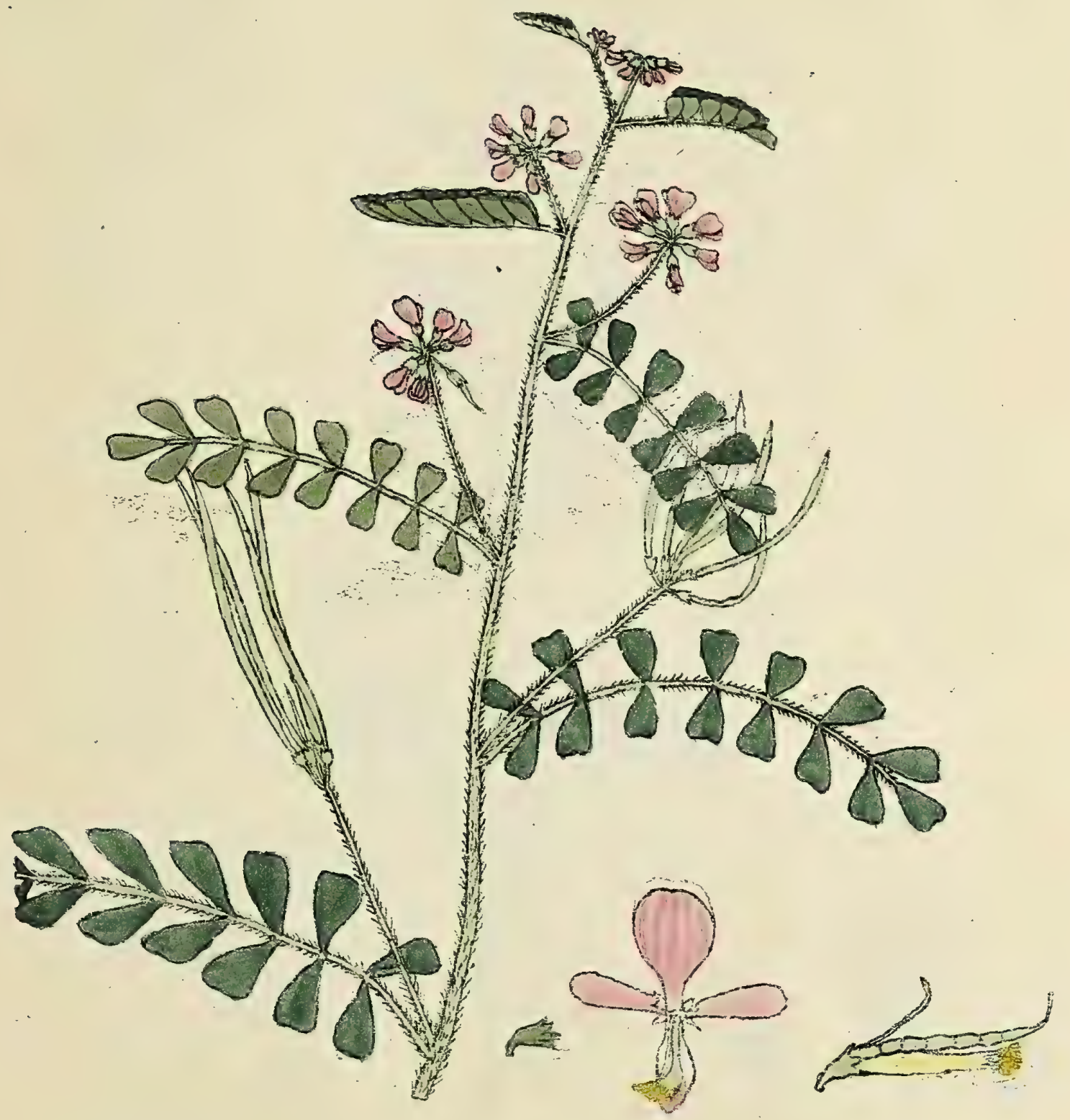

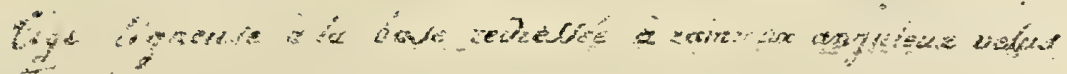

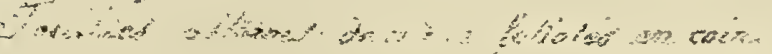

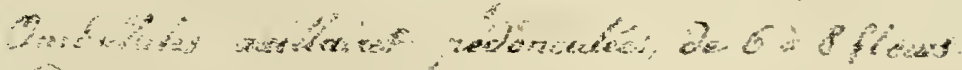

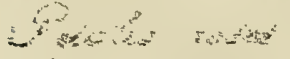

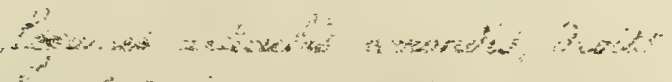

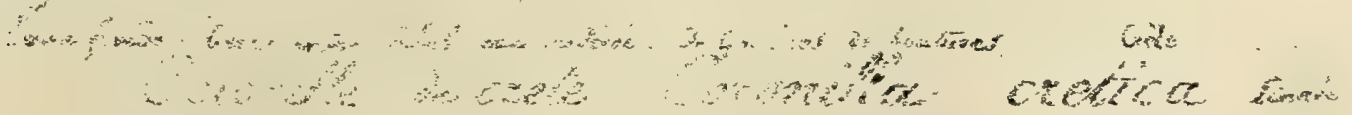





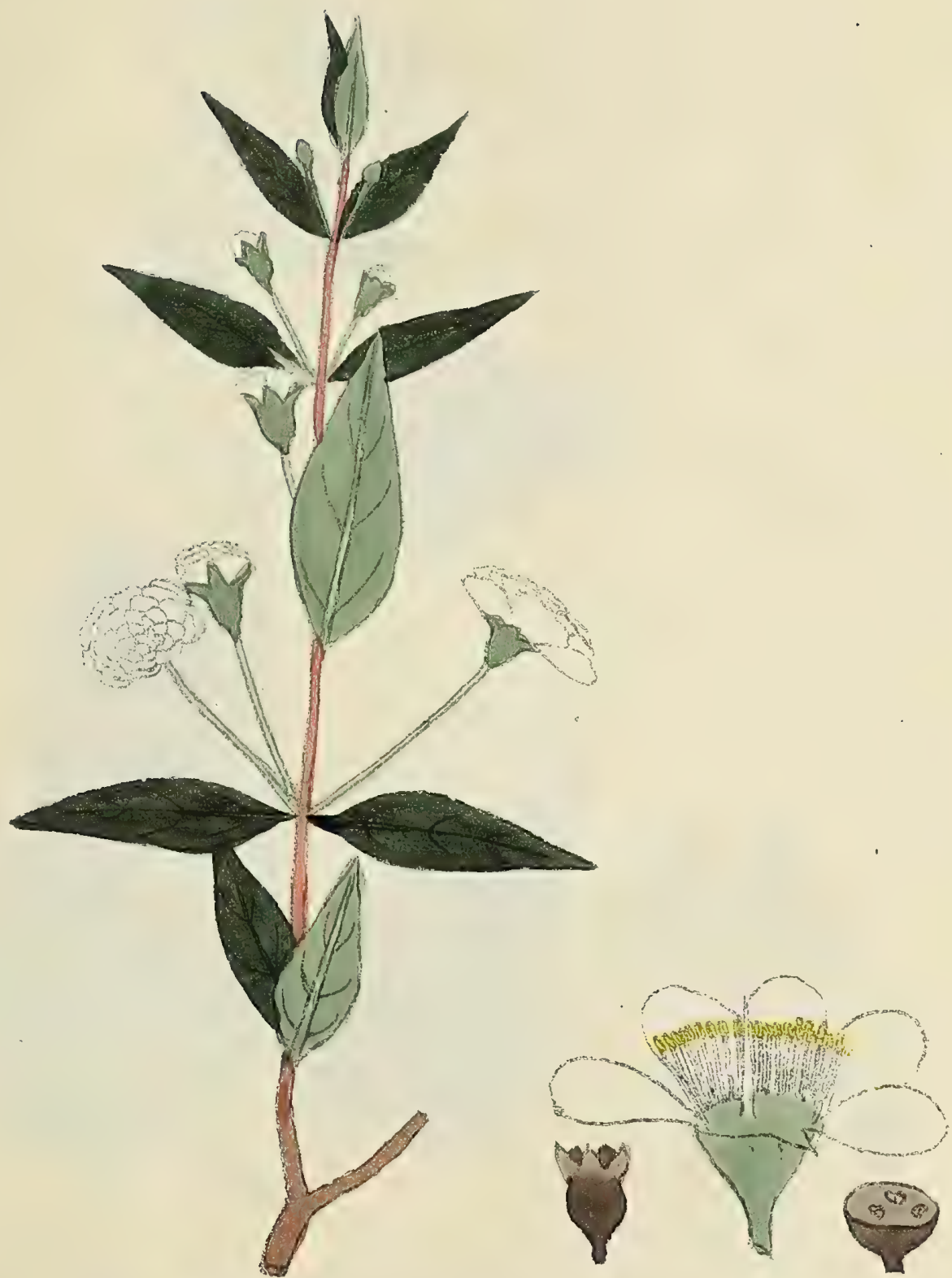

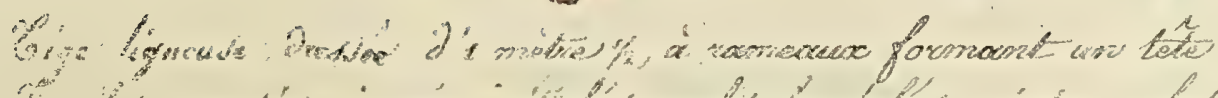

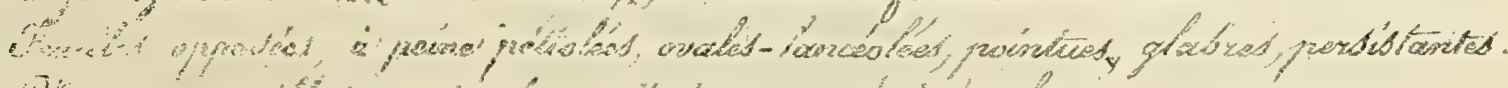

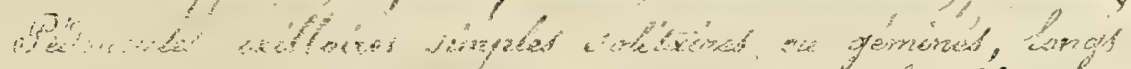

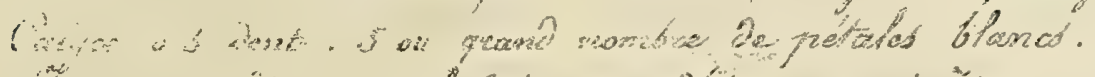

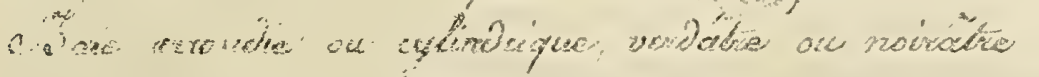

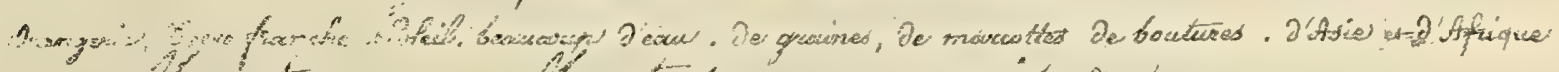

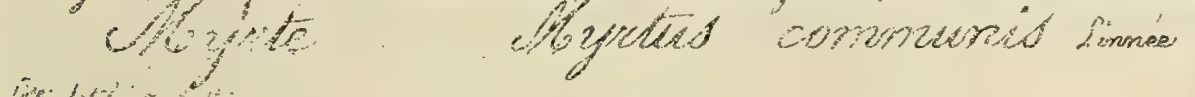

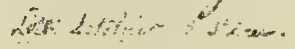



3.

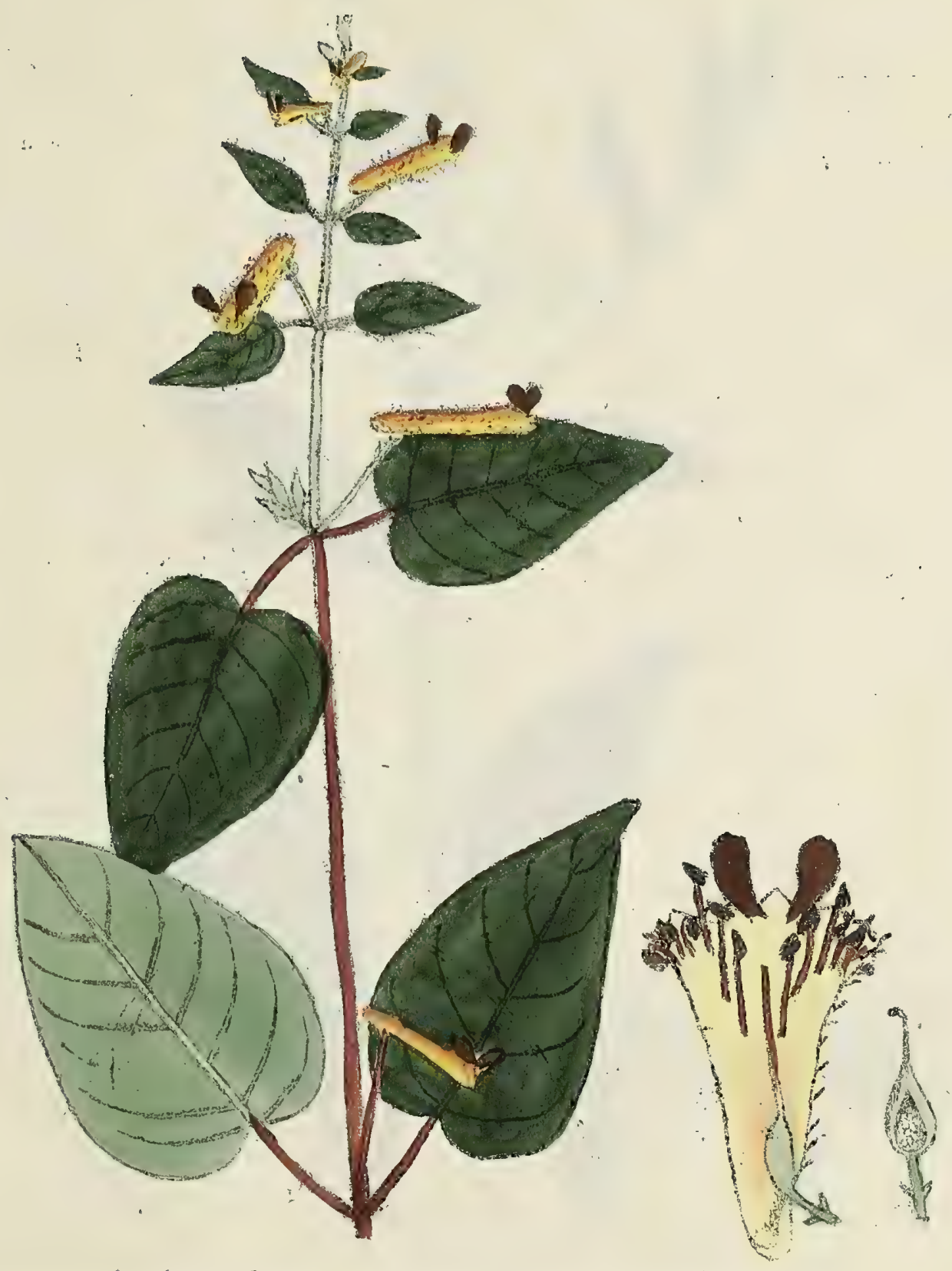

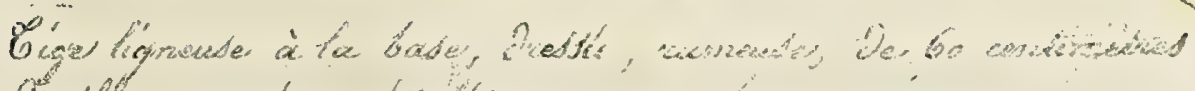

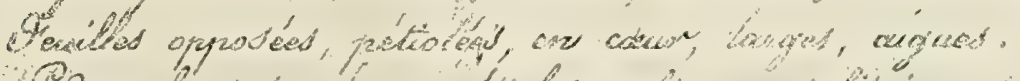

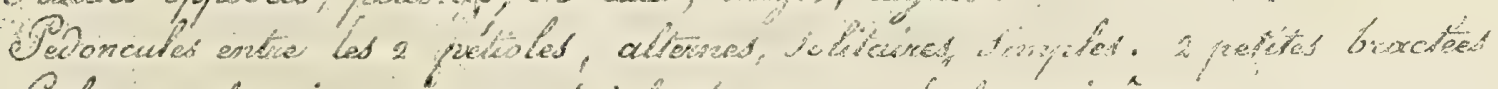

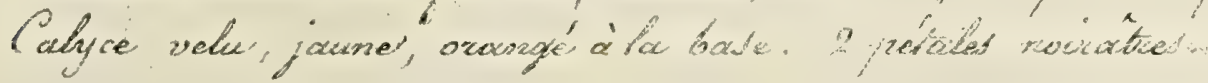

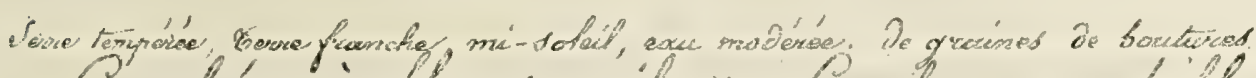

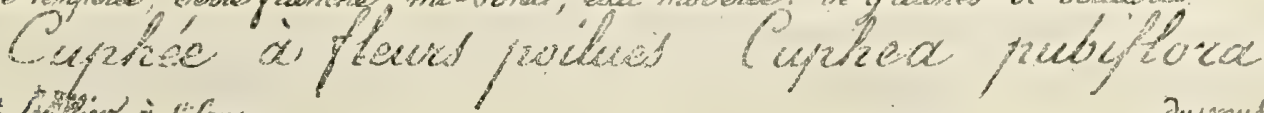

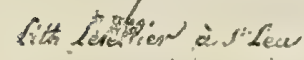

ow 1nuderm 



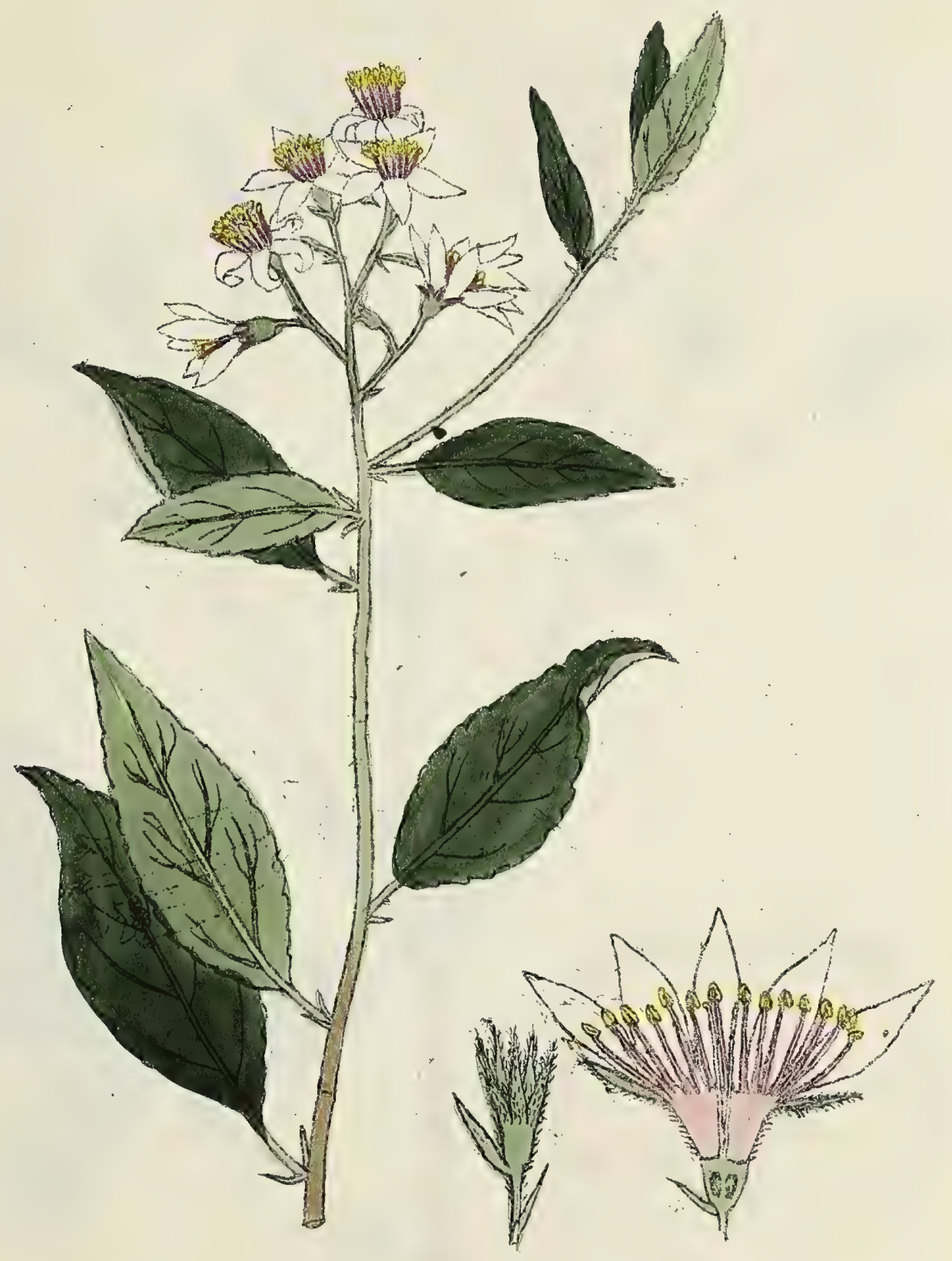

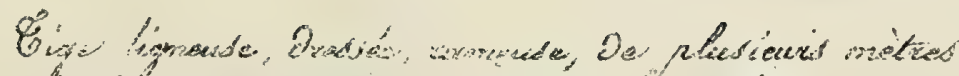

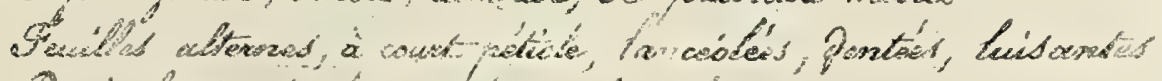

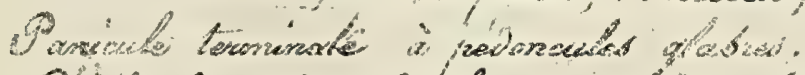

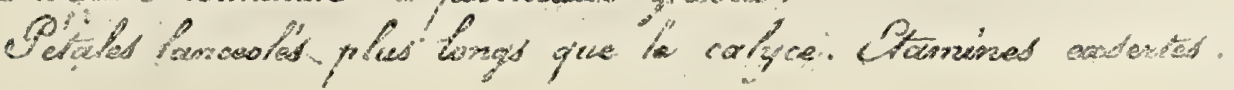

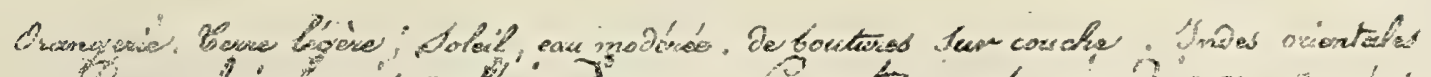

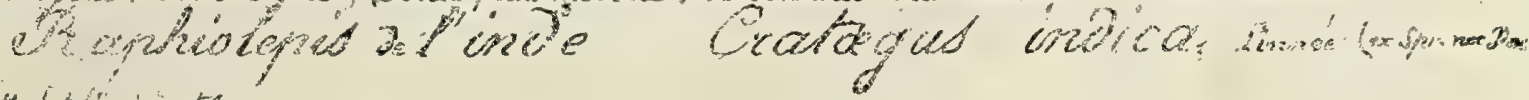

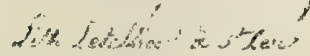





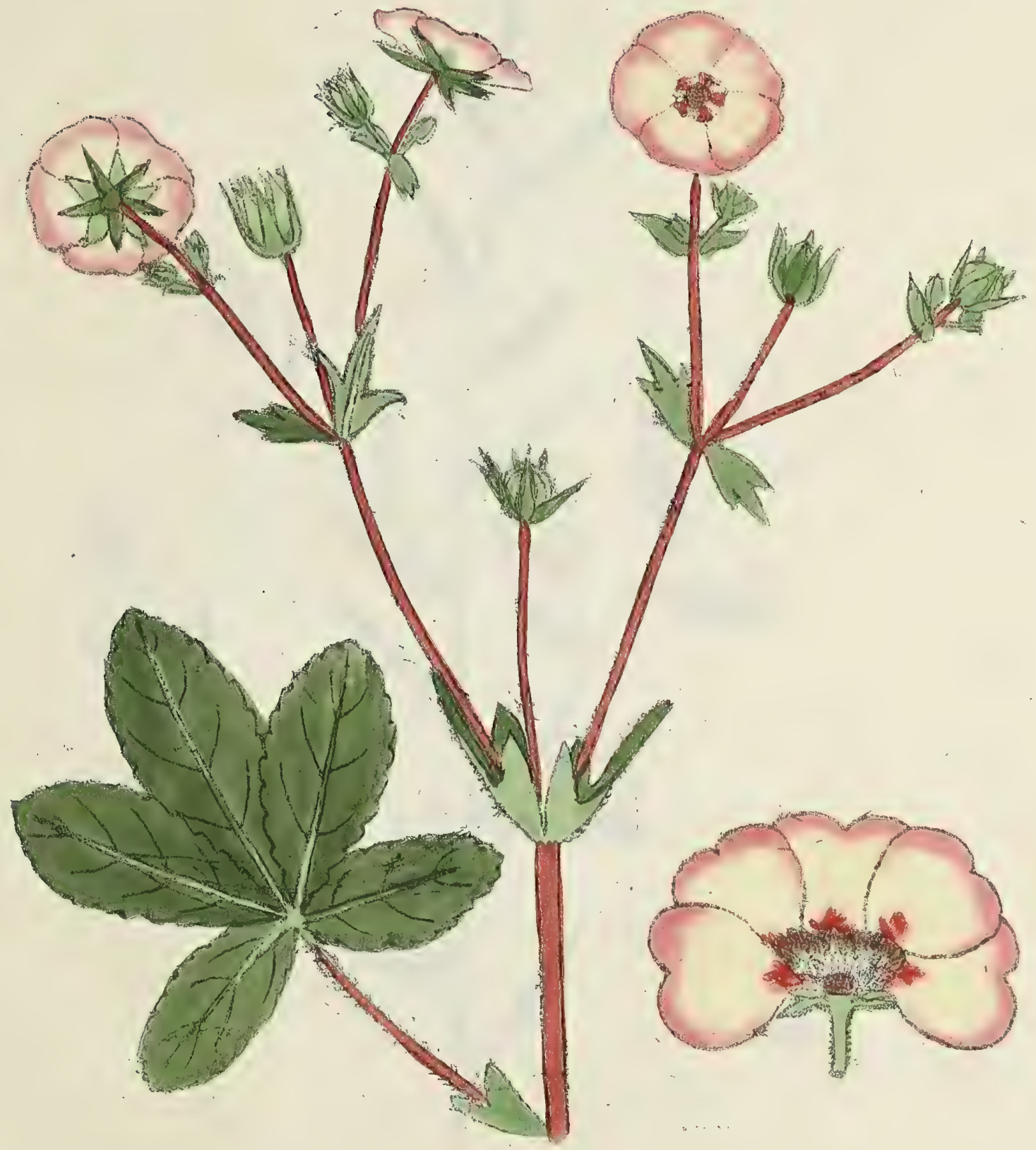

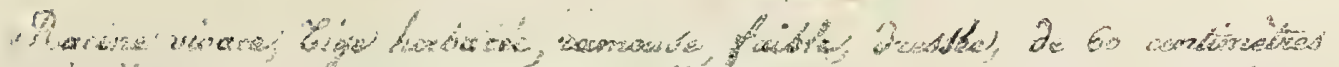

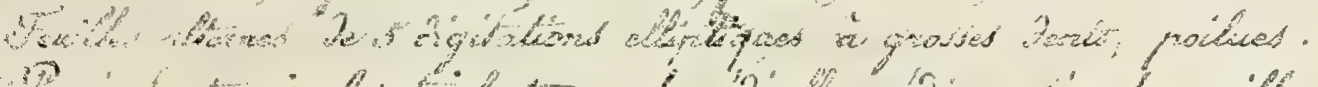

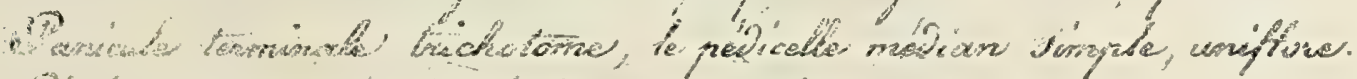

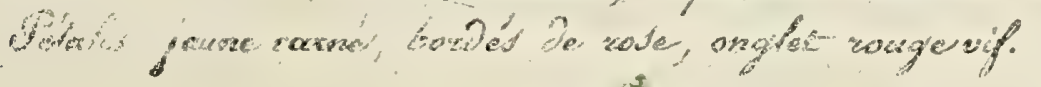

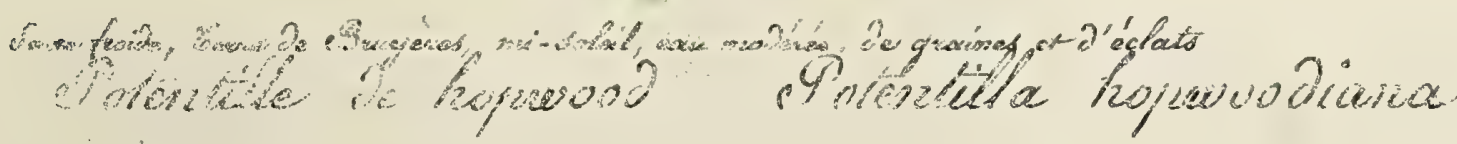





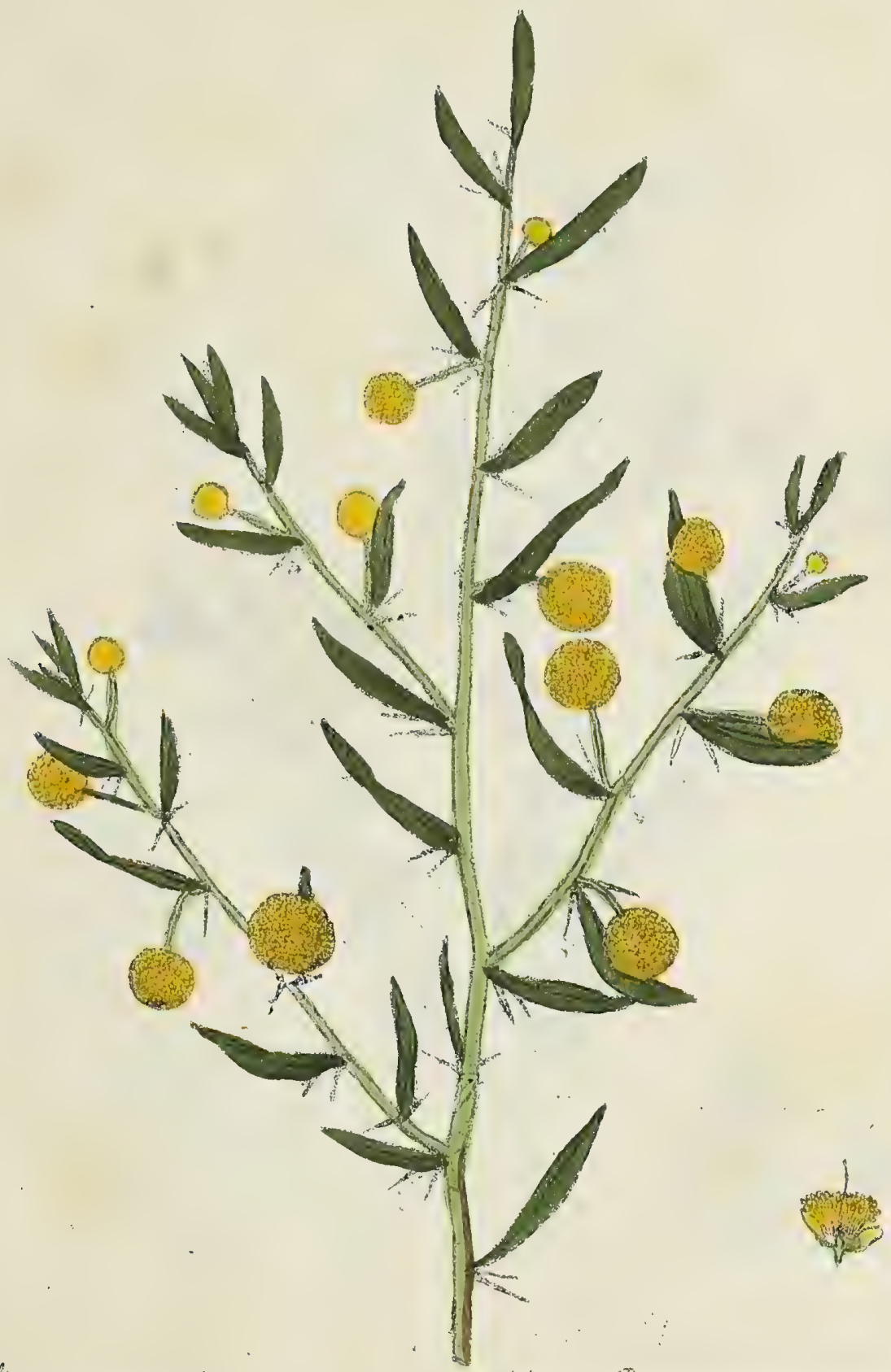

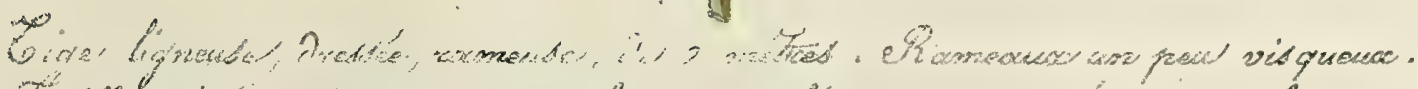

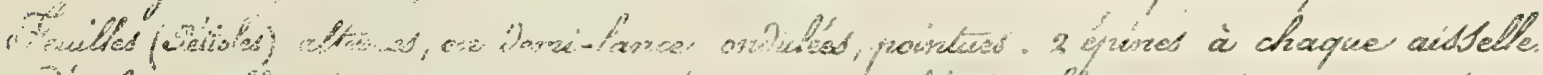

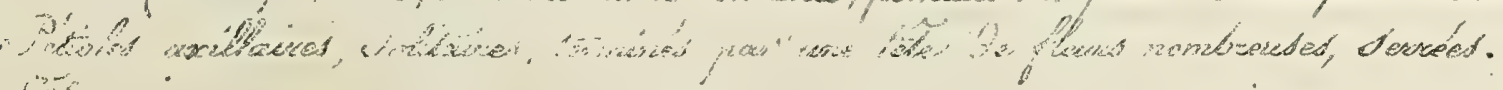
Cuivis

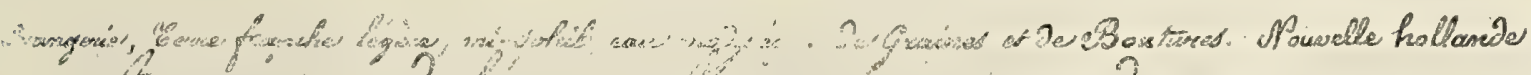

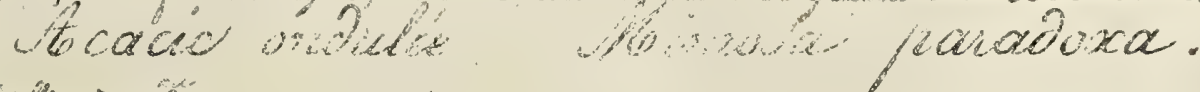

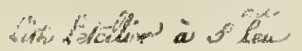





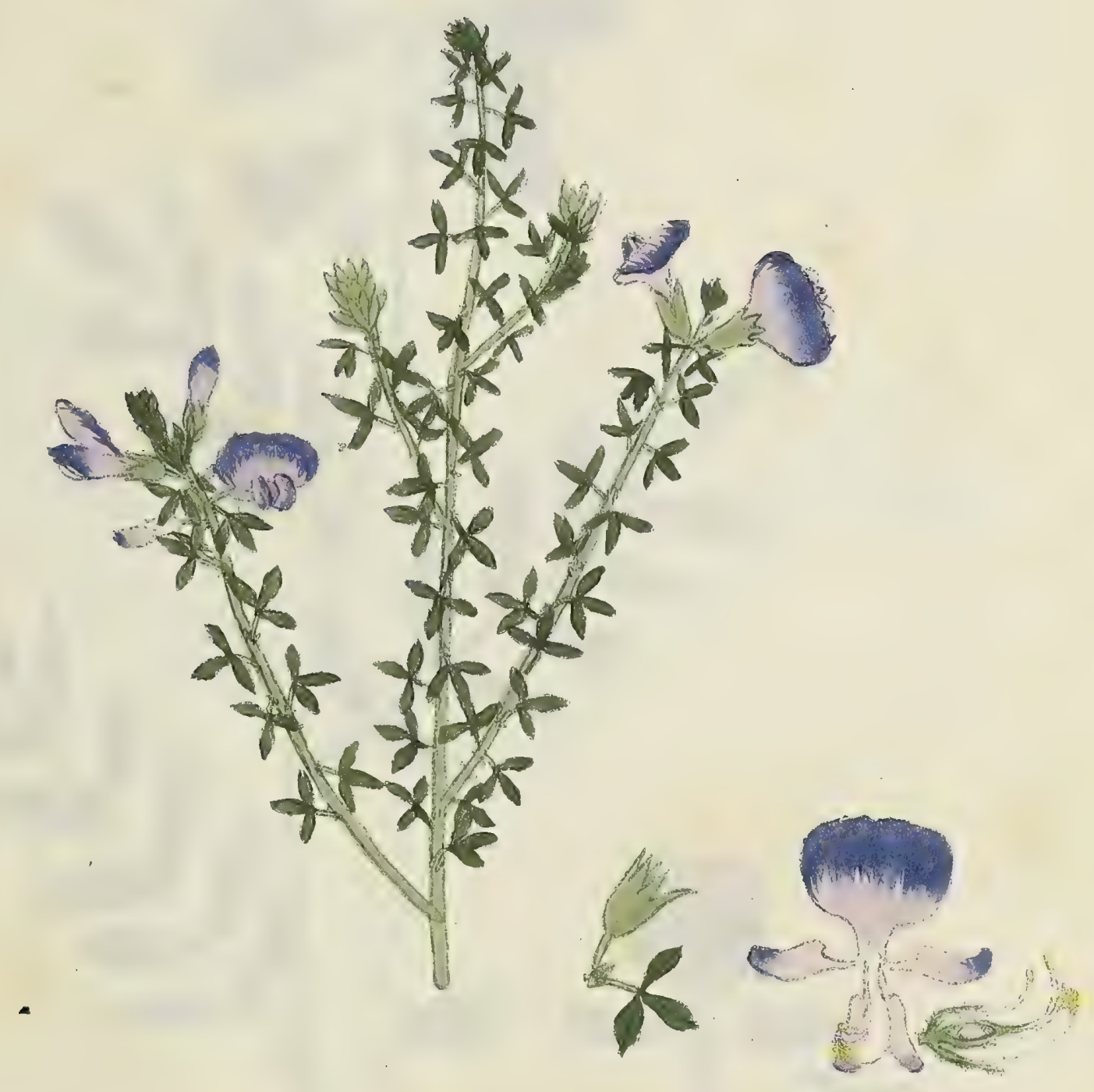

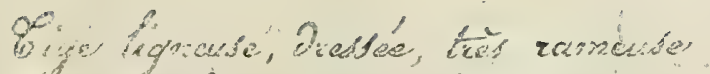

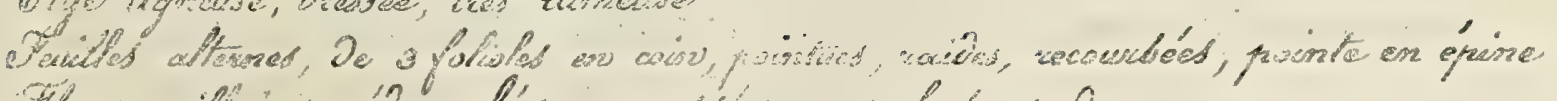

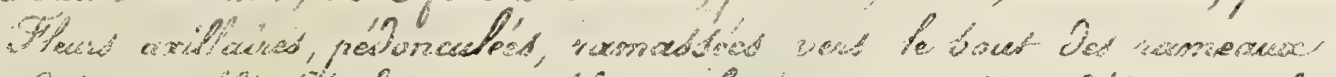

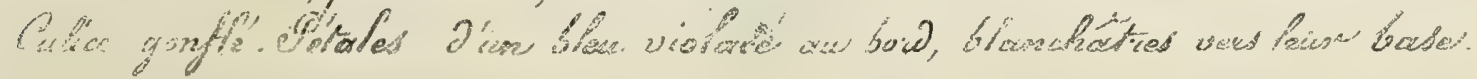

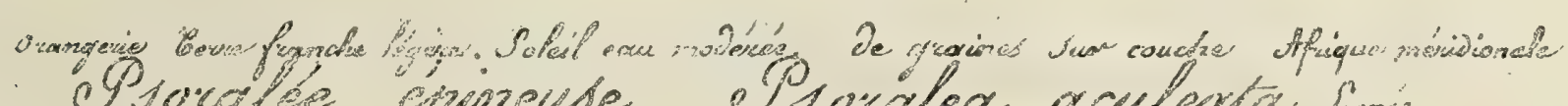
lith Selatlier a $g^{2}$ lives. 



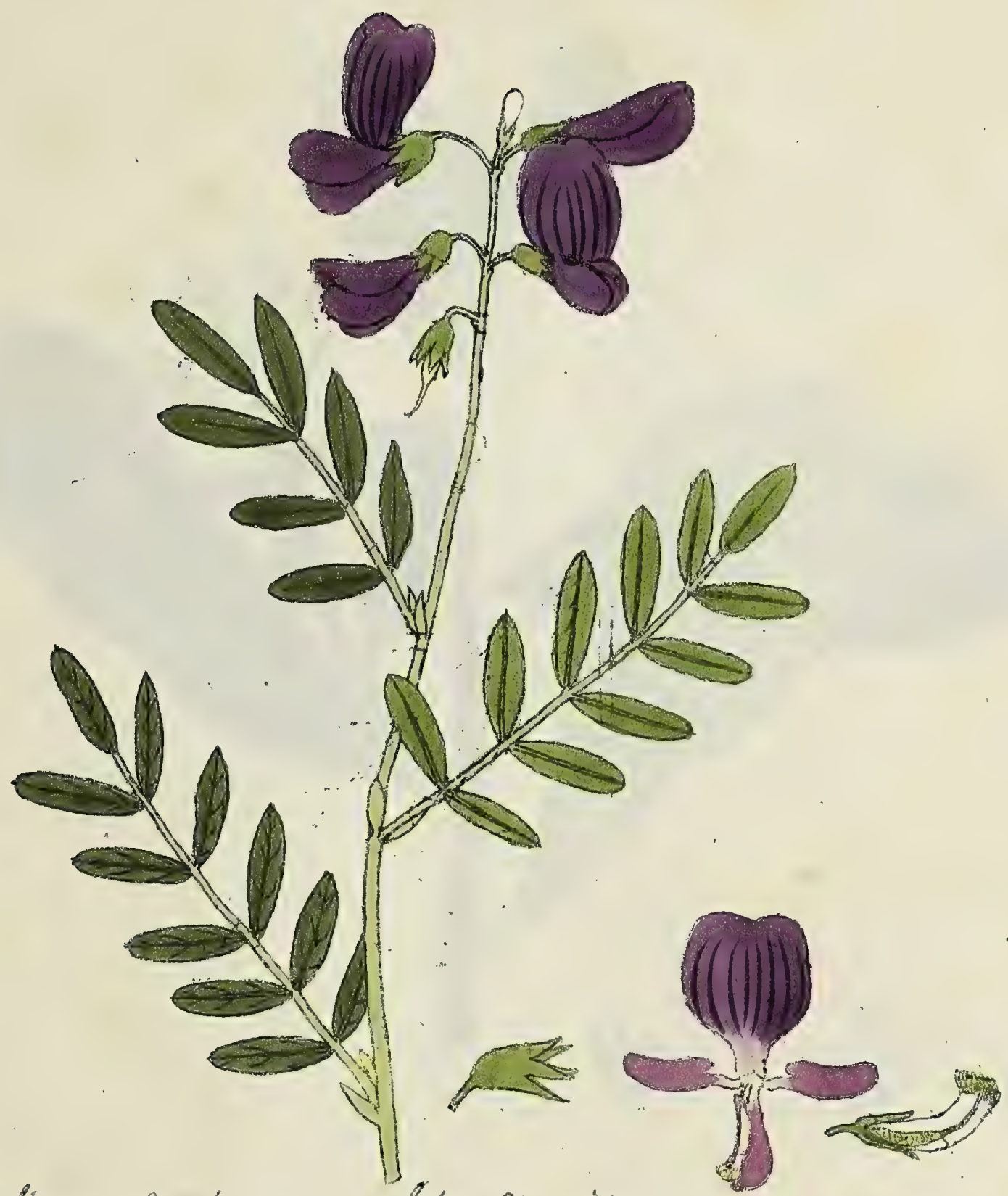

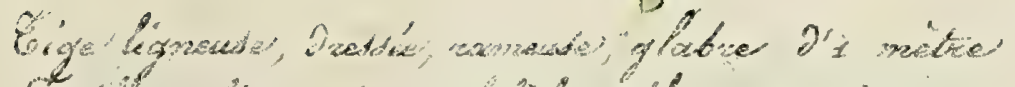

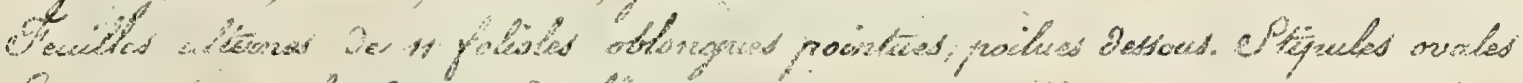

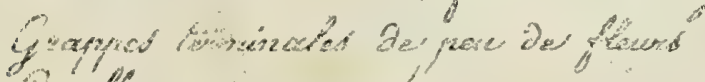

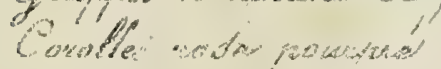

fistersis

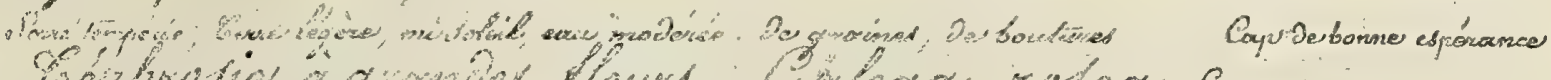

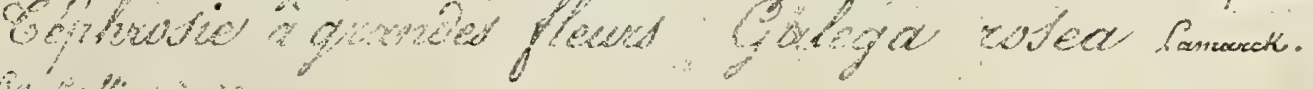

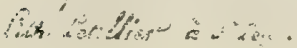




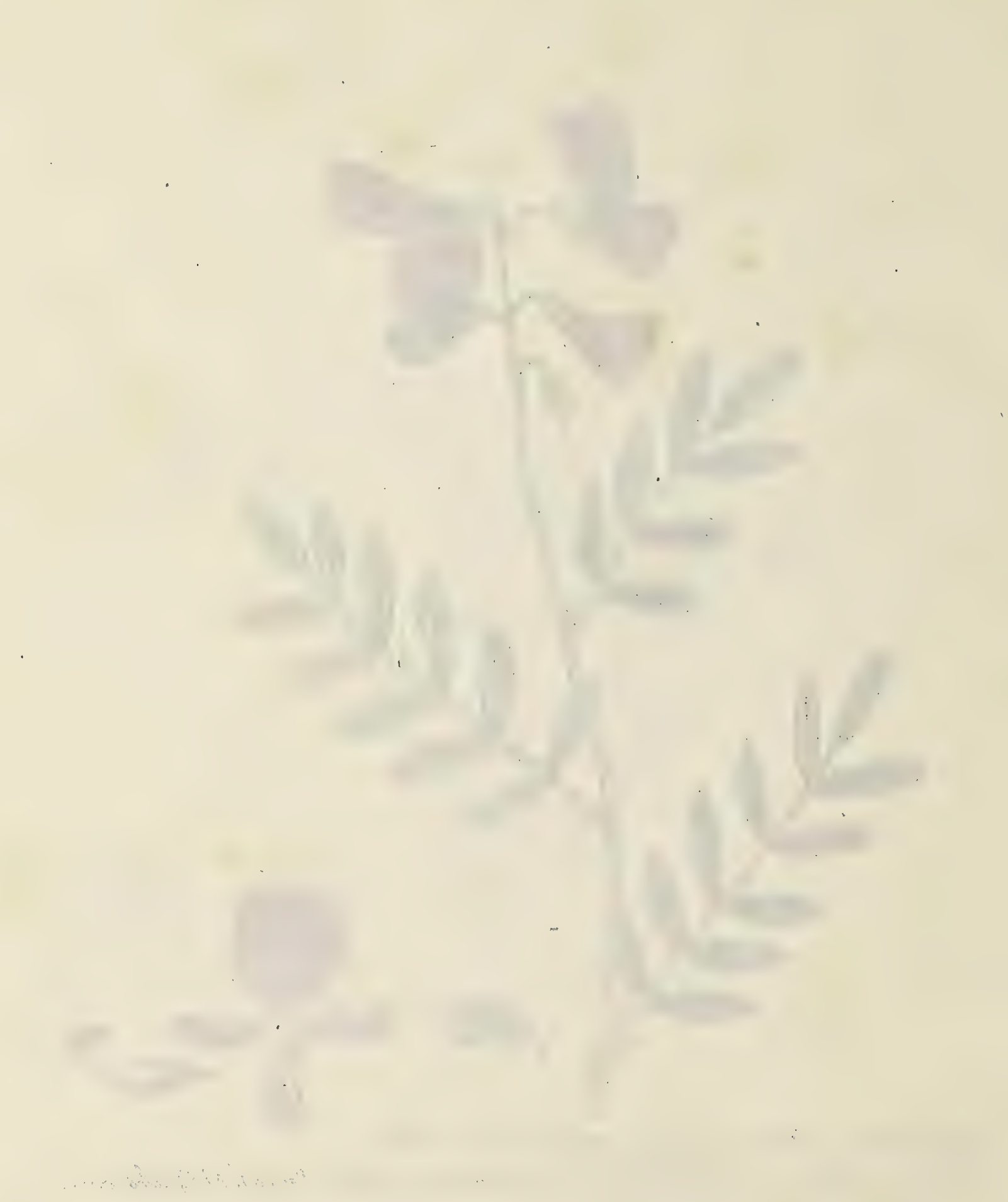




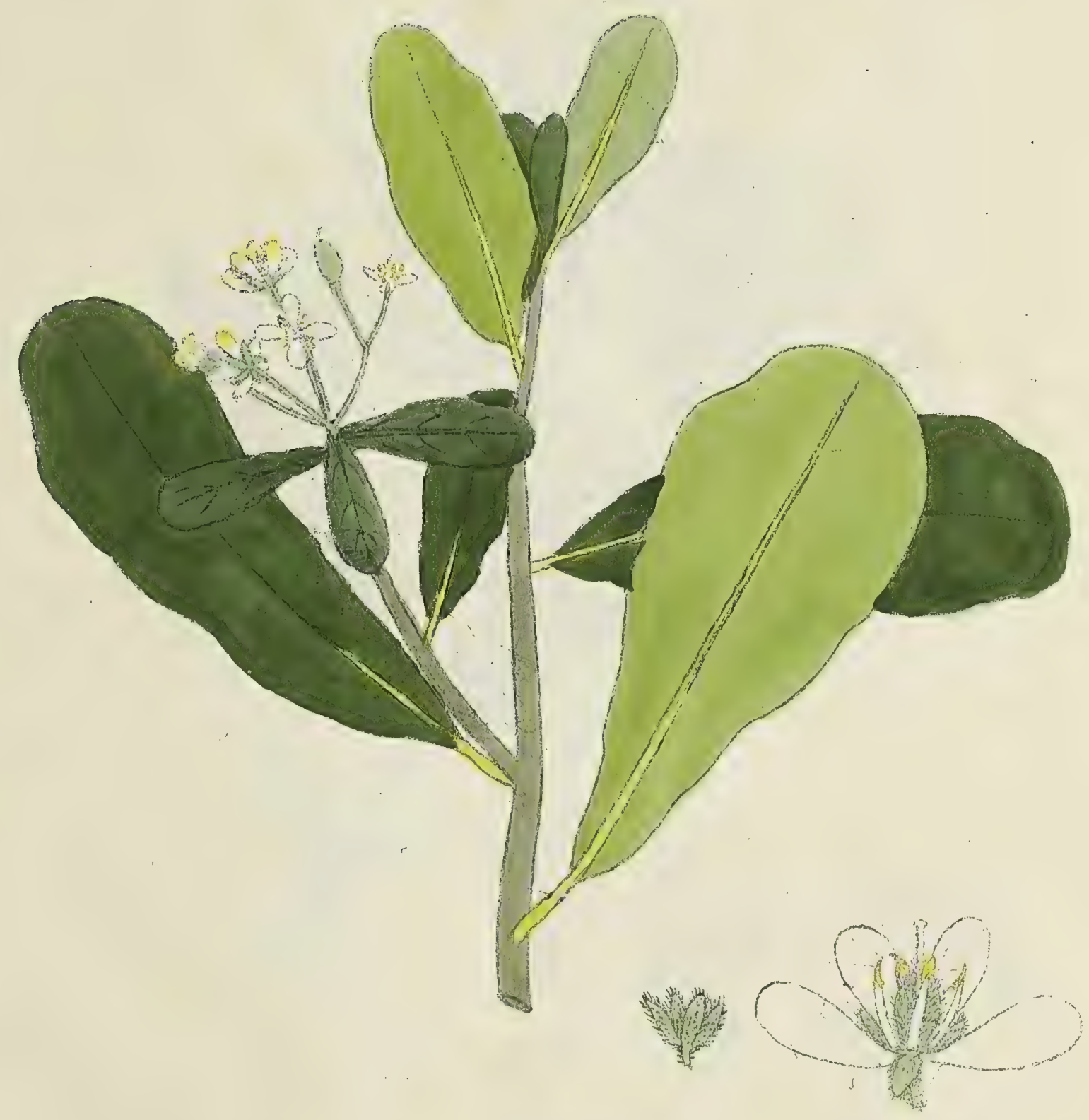

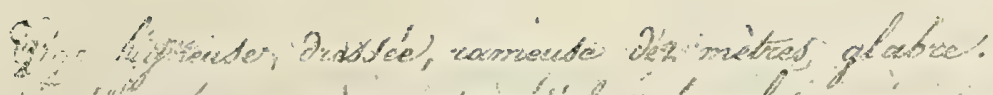

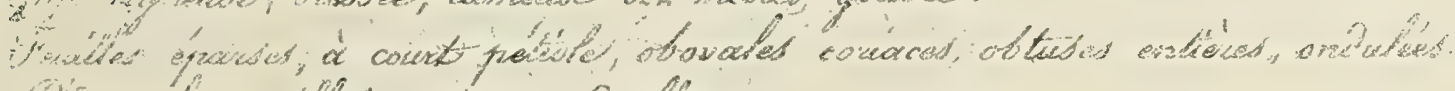

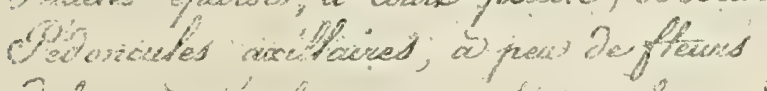

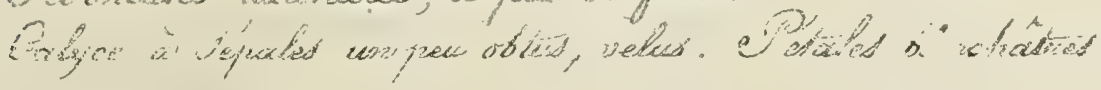

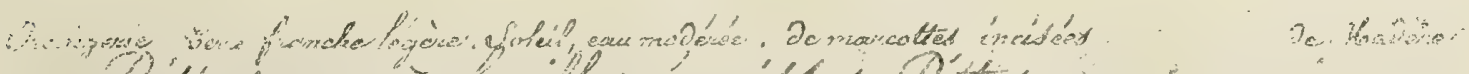

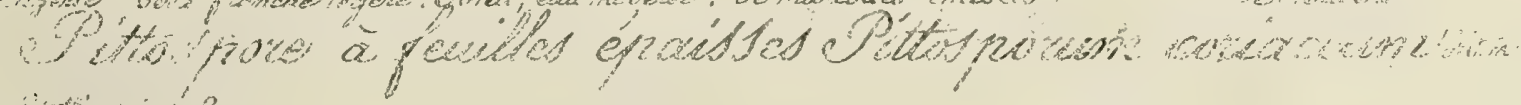
ㄱ. 



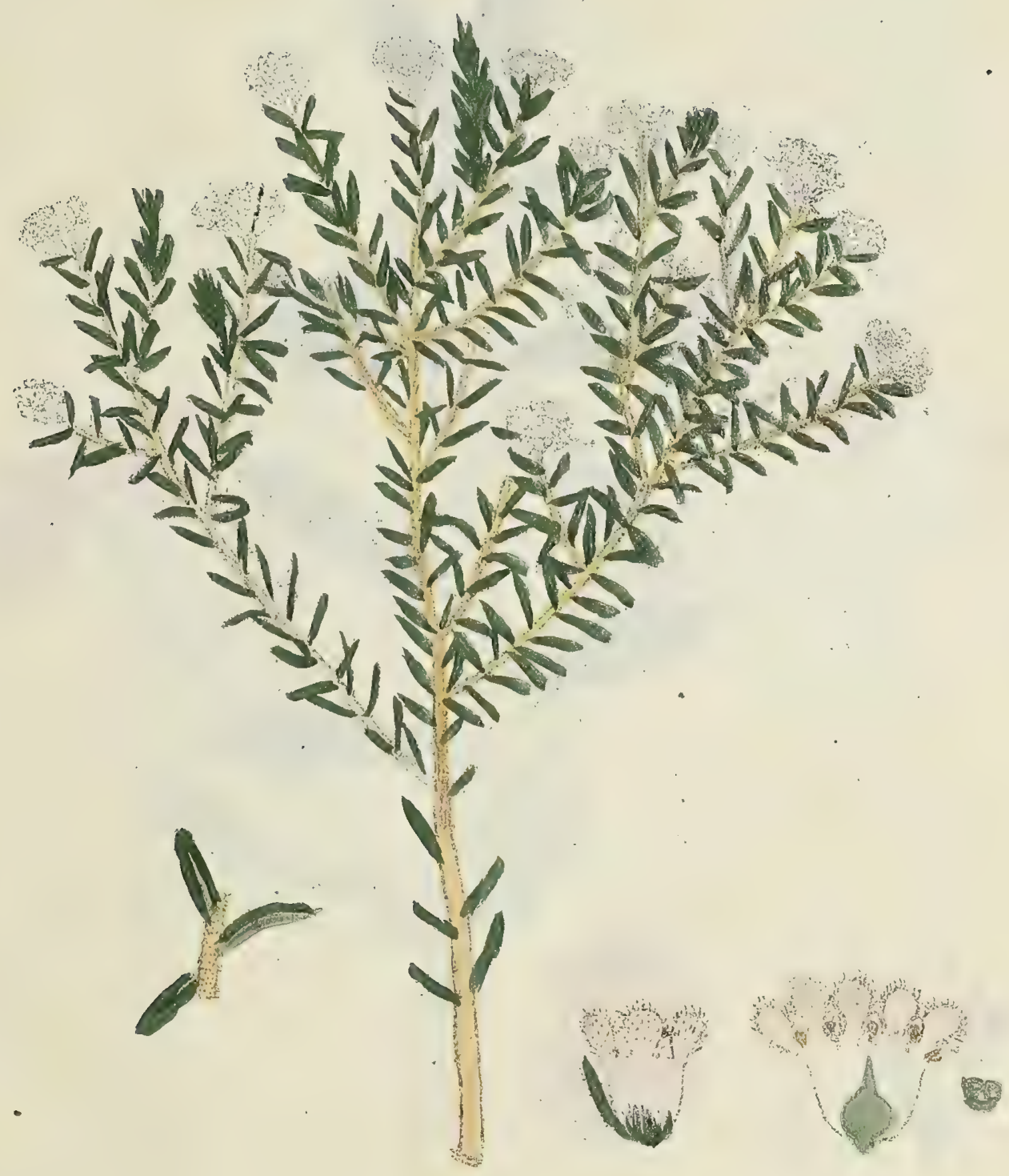

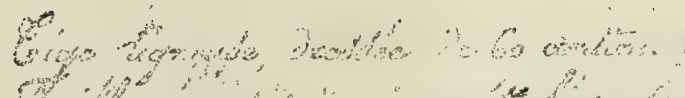

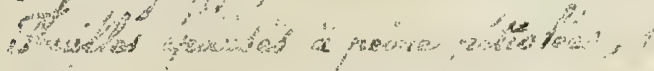

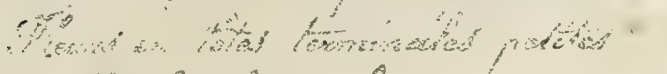

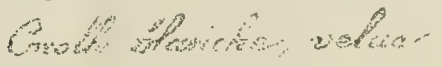

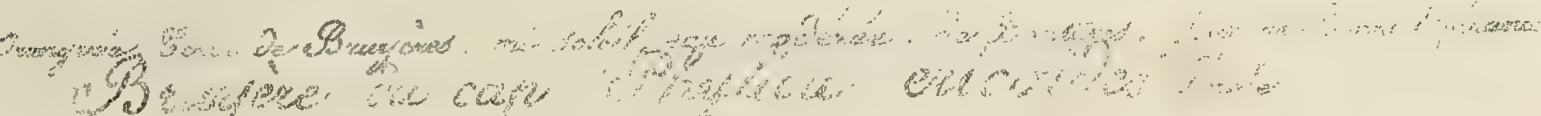

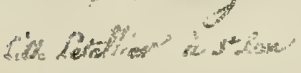





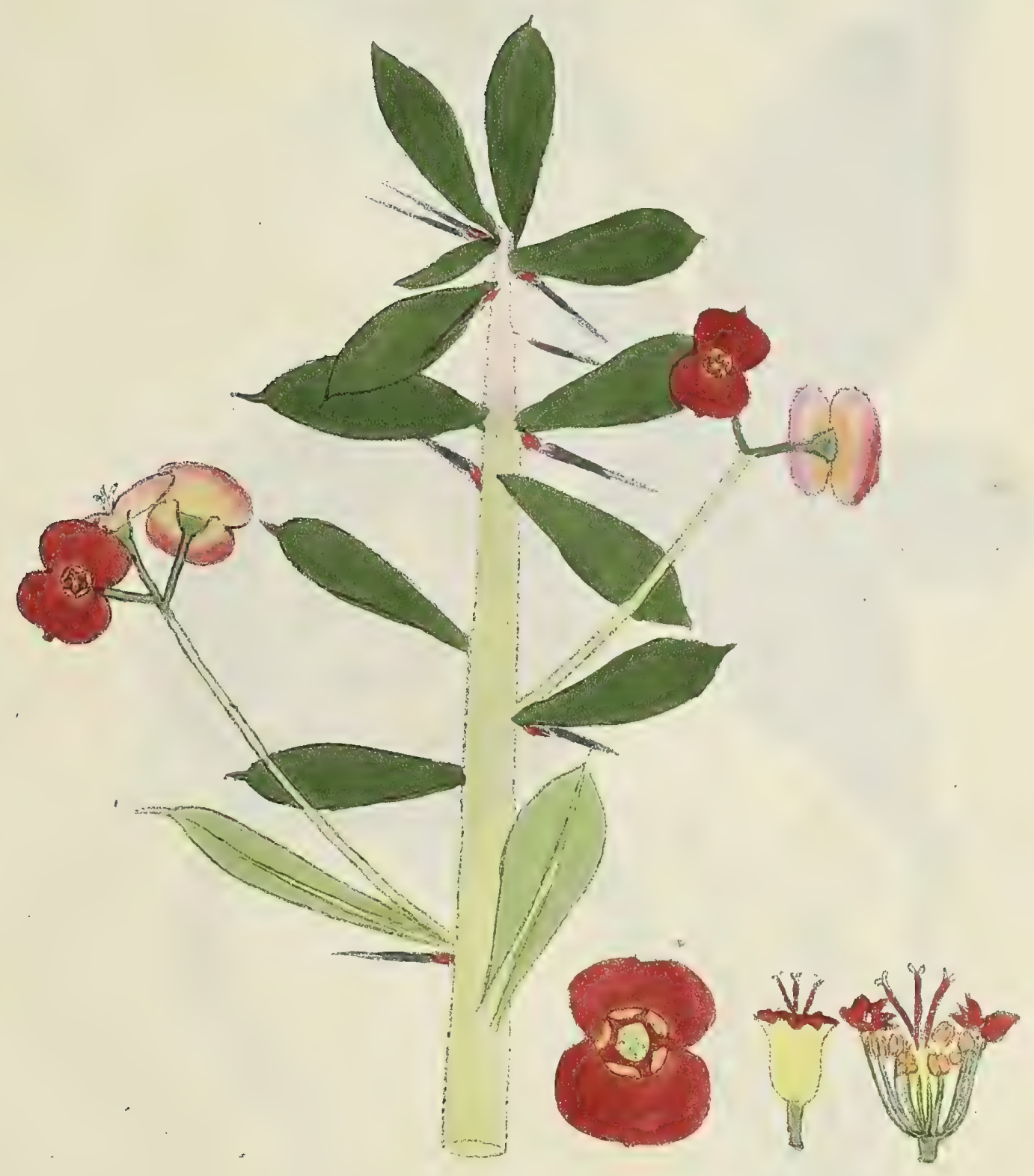

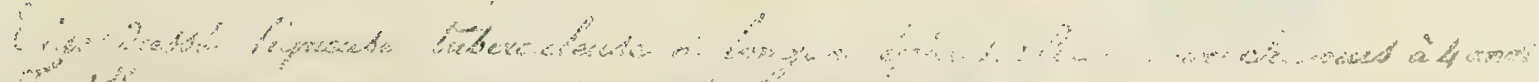
2)

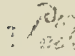

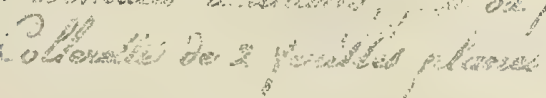

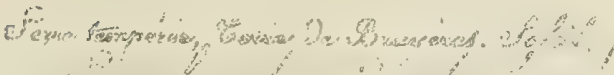

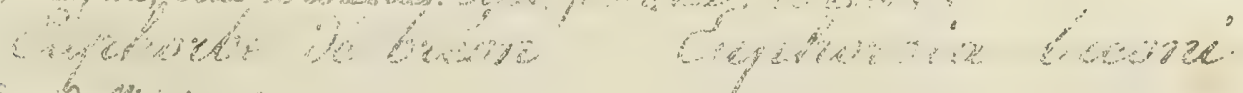

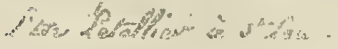





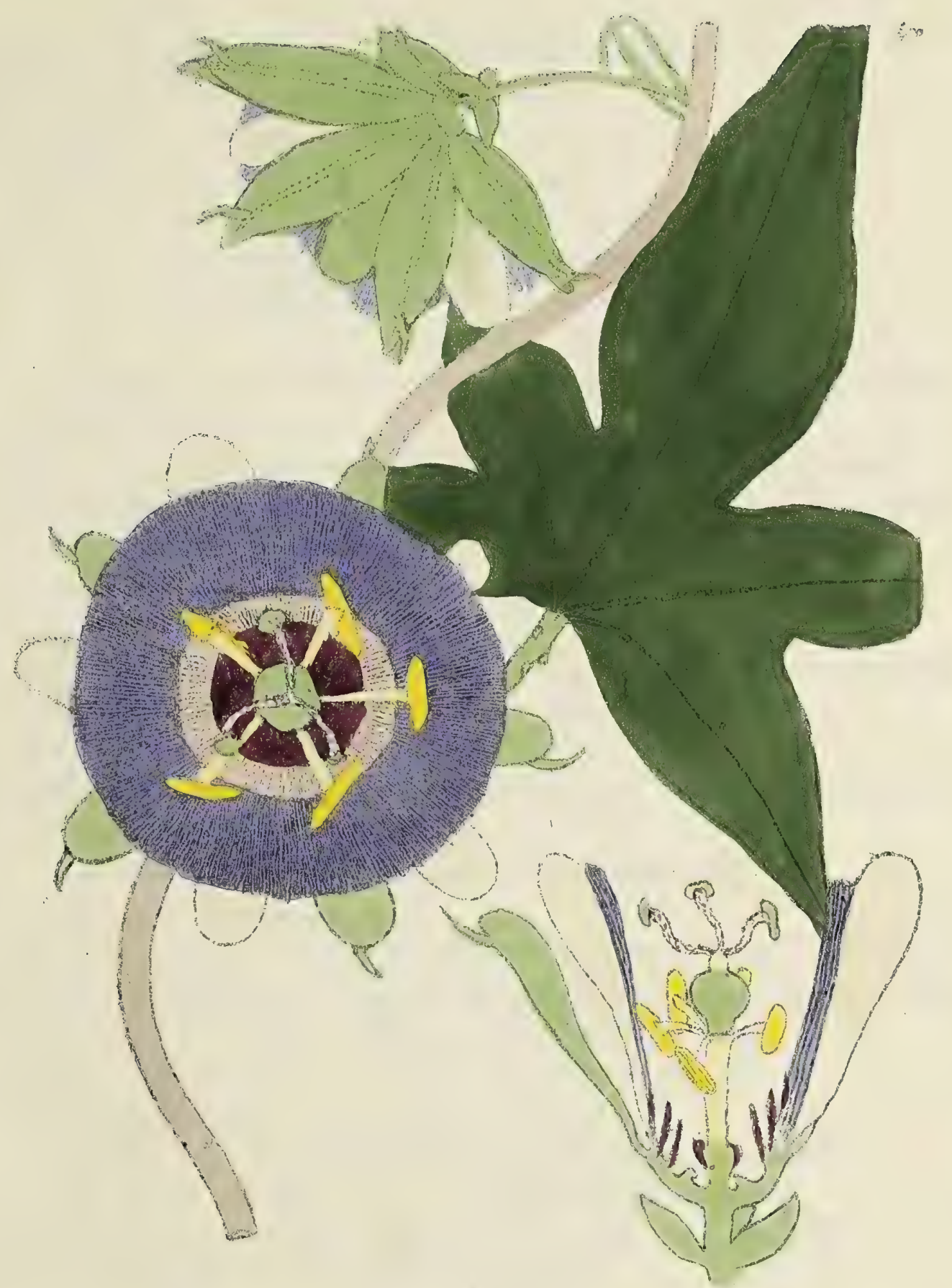

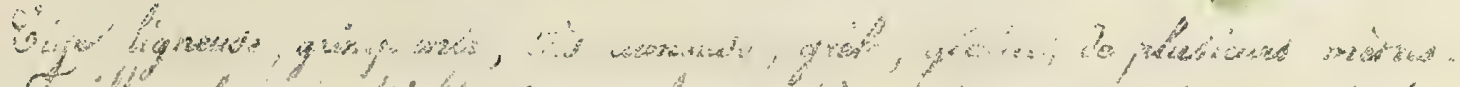

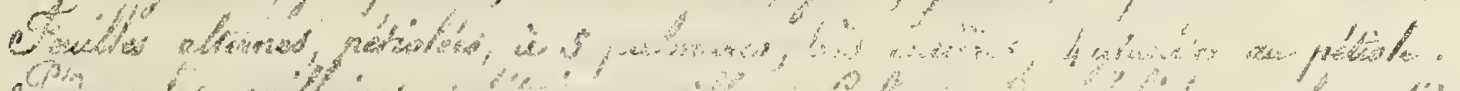

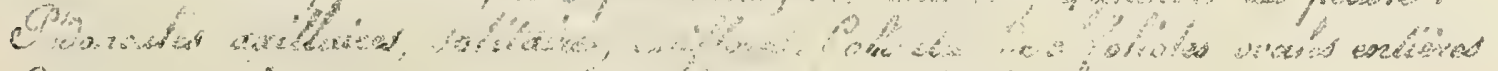

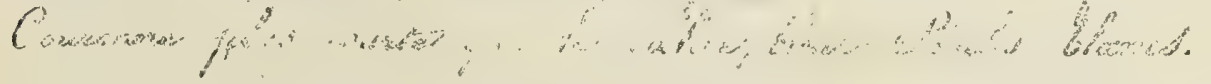

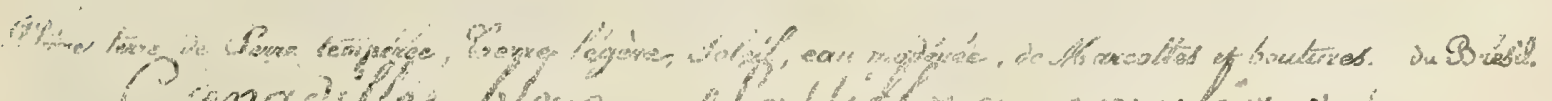

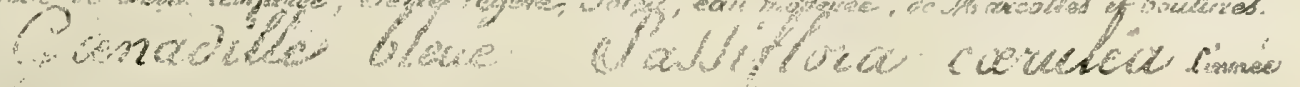
- then 



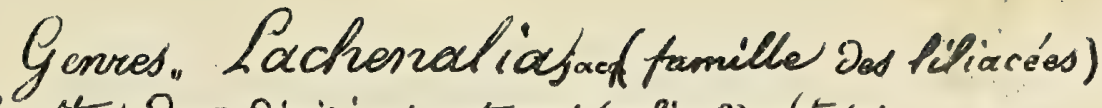

Percanthe De 3 divisions excierned (calice?) obtuses

ct 3 divisions internes (corotie i) plust-longires

6 Ciamines à filess droit, anthères ovales à 2 loges

1 ovaire supère à 3 arères, style en alène, Jtigmate Jimple

Cayisule ovate is 3 areites sailes 3 loges, placentia central

Peclienautía r. Brown (tamitle Jes Lobéliées)

Palice is s Dents

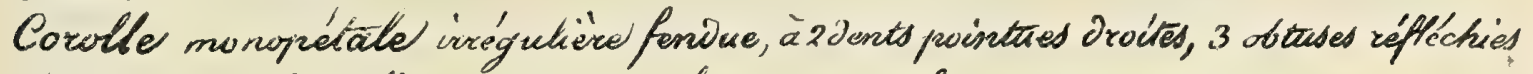

5 datamines à files libres antières longues à 2 loges et conniventes

1 ovaice infére, 1 style, Jigmate au fond D'un entomwir à 2 fevired

caprat ule in prisme, à 4 valwed, Dont 2 opyuséed pivient ta cloidon aumilieu grasined nombreused tres petived

Calicelà śdents

$$
\text { Mo innulled sinnéc (famille sed scrofulaciées) }
$$

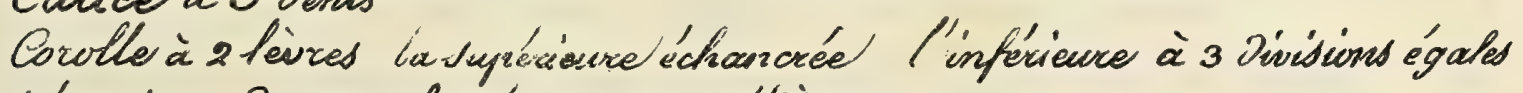
4 d́amines Dont 2 plus longues, contheries en rein

i ovaine supire, 1 Jtyle, stigmate bifide

Copndule ovale ì a Ioges, 2 valves, clois on placentaire perpendiculaine ause valus Graines nornbrengy peties

Mour ranzia ortigal familte des Nowfulariées)

Palice às Jegments en quincurcel

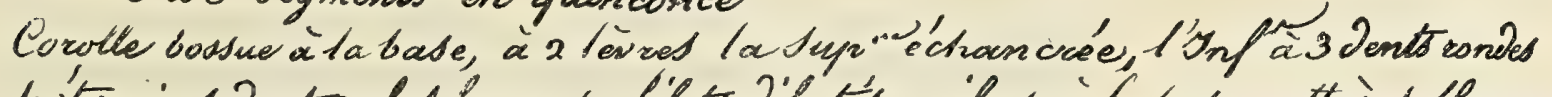

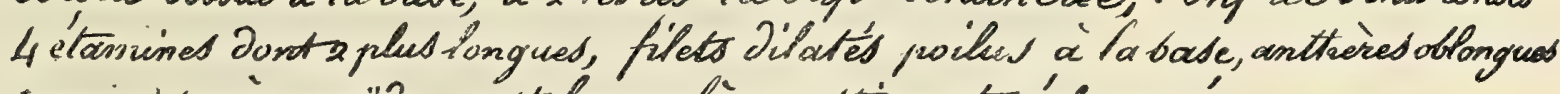

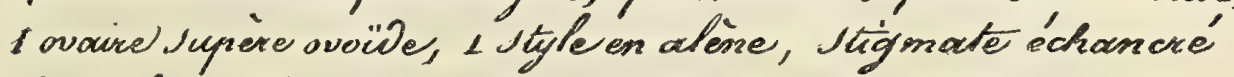

Poprdule à 2 loges s'ouviant par 10 Dents au sommet

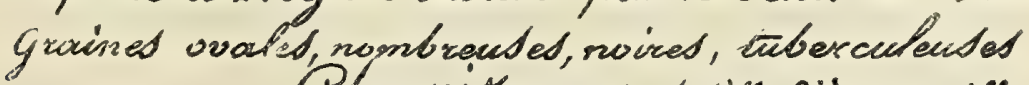

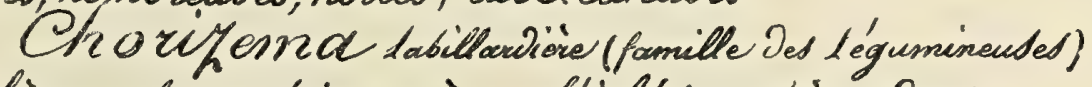

Calice à 2 livres, la Jugínievere ì 2, P'infórieure à 3 dents

Corolle papilliunacée à cariene ventrue plued courte que ted ailes 10 ctamines à filets libres untiered à 2 loges

- ovaire supiere, Styte crochu, Sligmate oblique obtus

'egume ventru ox plusiourd grained

Grained réniforned, Lans peridperme.

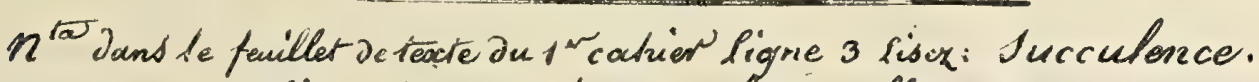

phig lidex: calice irès velu égaiant fa corolle pubes center en cloche

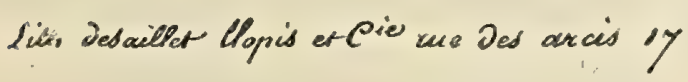





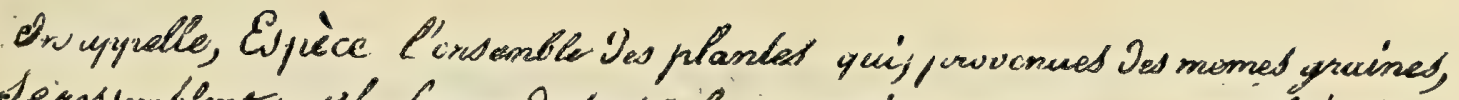

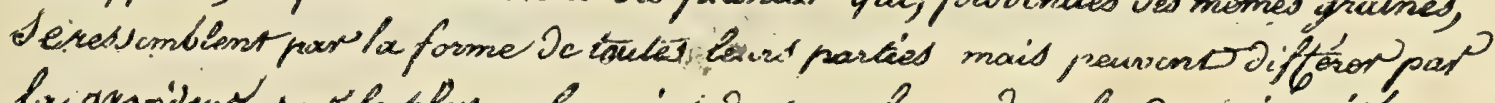

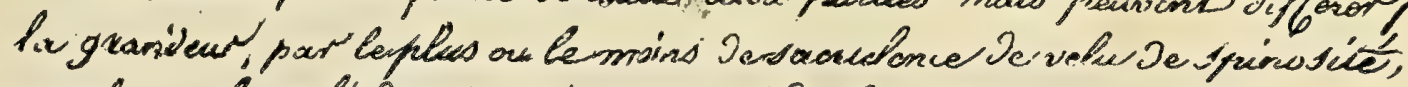

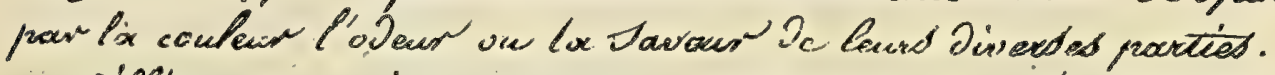

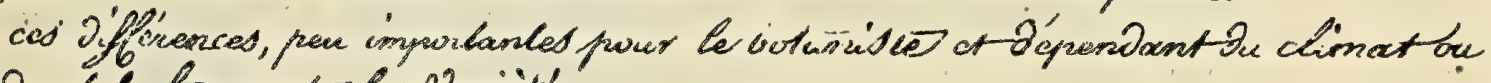
Du, Sol, fornent les Varièt's

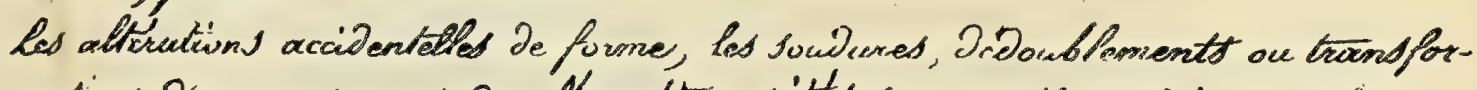

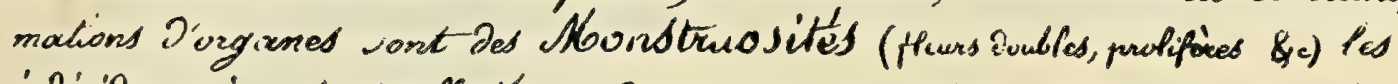

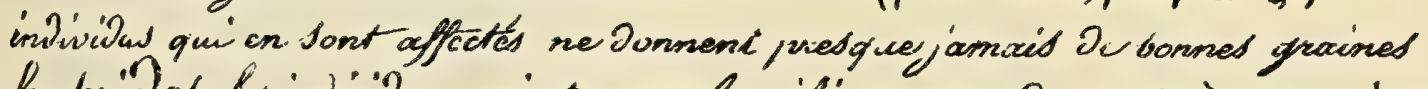

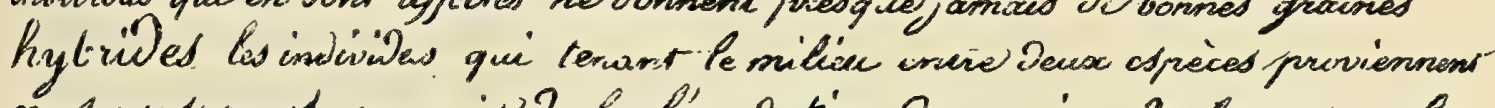

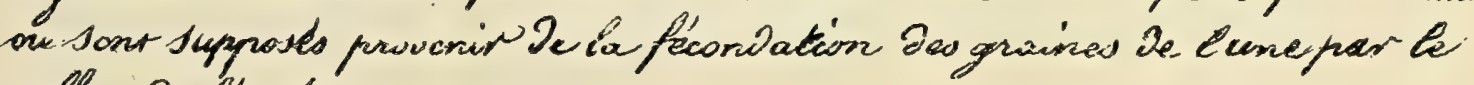
pollen De P'autré

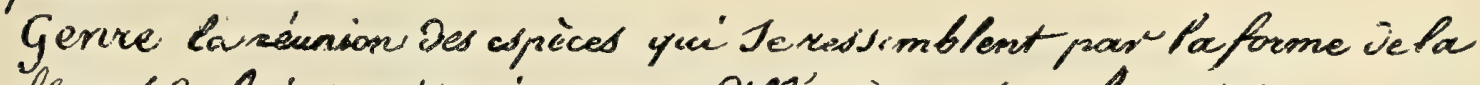

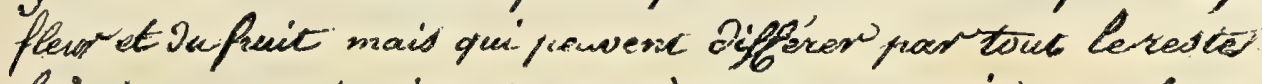

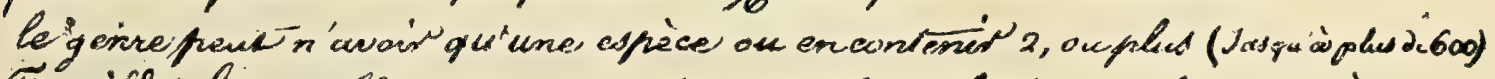

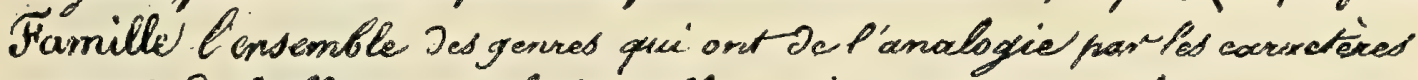

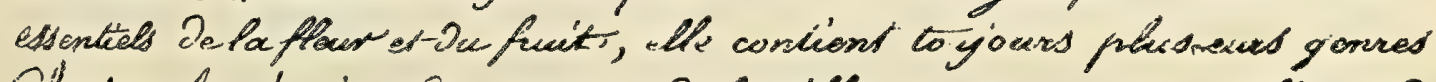

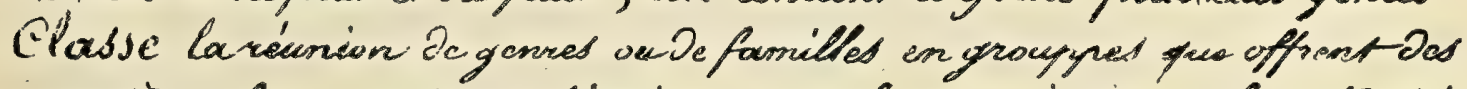

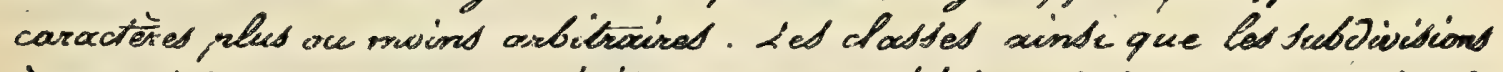

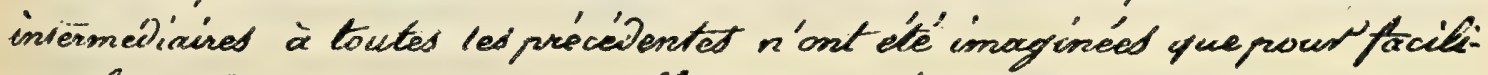

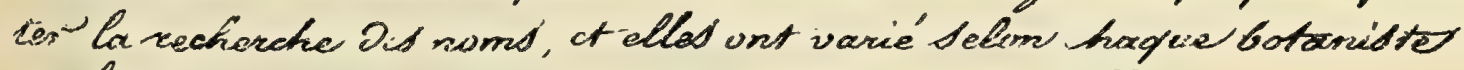
Les botanistet Systematistes n'admettent jras De familles

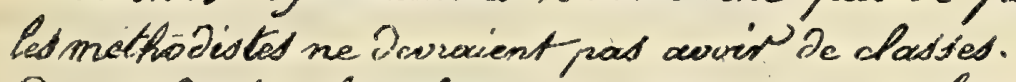

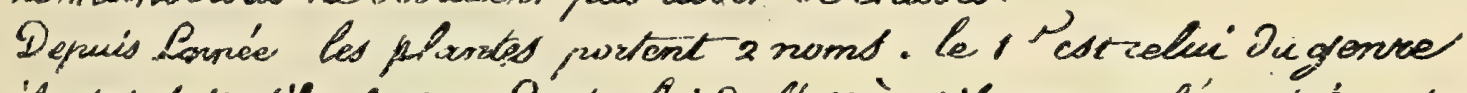

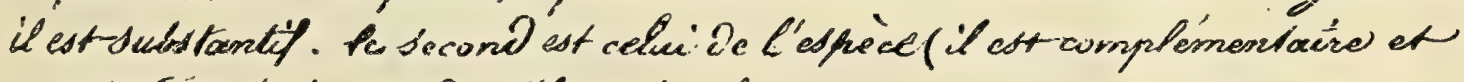

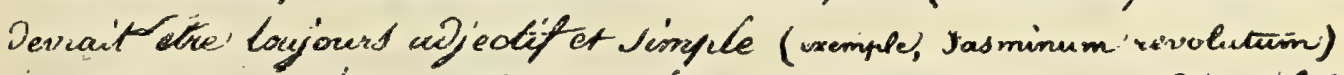

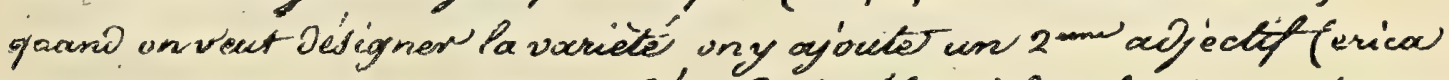

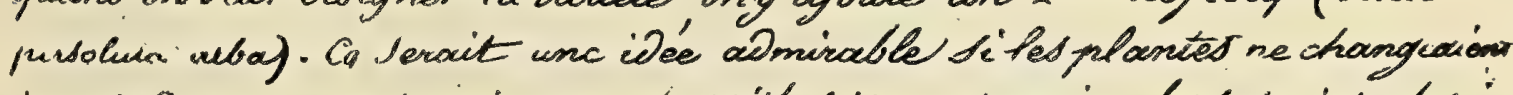

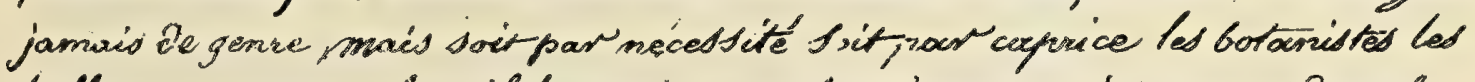

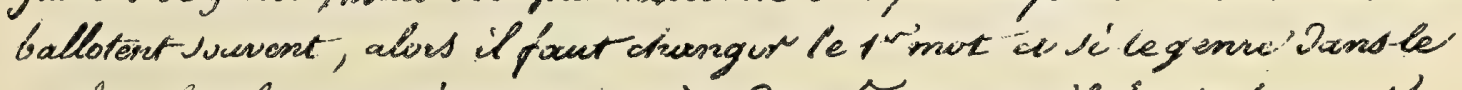
quel or las place conlient une espece ow même nom il faut choonger

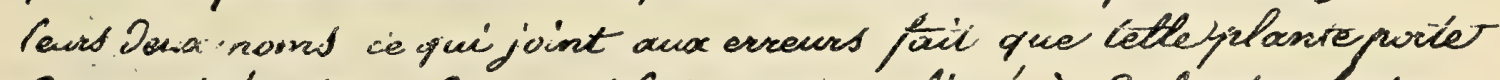

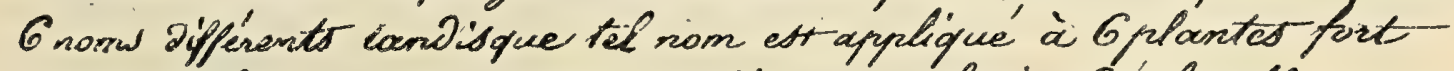

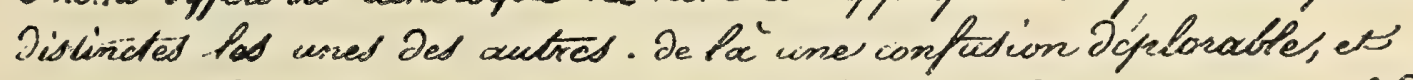

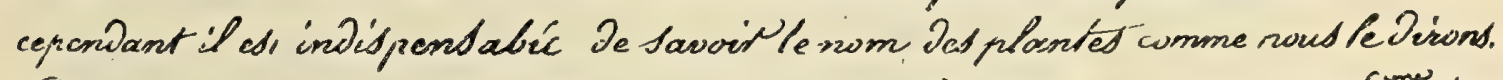

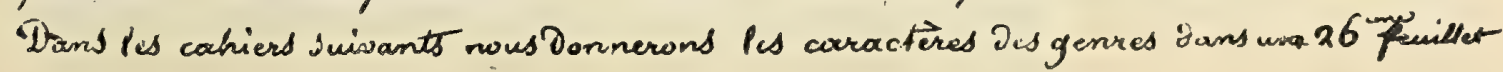
itti J. Desaillet llupis et cid me Jes arcis if 

Calice is 5 divisions

\section{Angelonia humbolor (Jamille des scrofurlariées)}

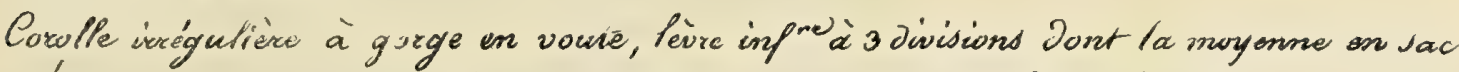
4 étamiszes Dont 2 pluw fongues, (DiWynames) anthères à loges écarries 1 Ovaire supière; "siyle, Jtigmate simple 1 Capsute ovate à 2 values fensues, 2 loges, plusieurs graines Palice is 5 divisions colvie' Billaciovia smitre (famille des pittospurées)

5 Petrales concowes rapprockés

s'etamines hypogynes

1 ovaice supière 1 siyle, stigmate à 2 fobes Baie à 2 loges polys permes

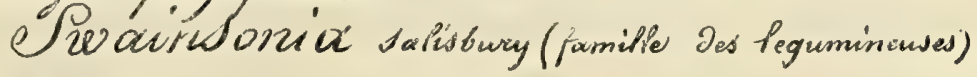

Palice à 5 denis

Powlle payillonaceé, dien dawd à 2 callosites à fa bave

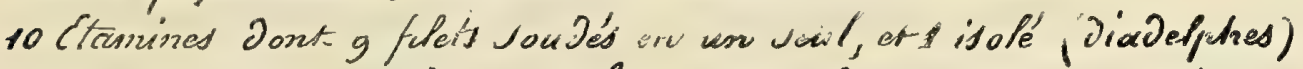

1 Ovaive -Jupière, Jyle barbu Pongitu Jinalement, Stigmats terminal

Legume gonfié mois pas boursoufle' a I loge et plusieurs grained

$$
\text { heycesteria wallich (fannille Des Rubiccées) }
$$

\section{Calice à 5 donts inégales}

Corolle monopétate en entomnoin, bossue priès la base, à 5 lobes

5 ctamines égales, anthères à 2 loges

1Ovaire SouDé au calice (infère) I style, Jigmate on tete

Baie à 5 loges polyspermos

Cccrem ocaypus zwizer Pavon (famille des Bignoniés)

Palice à 4 ouf lobed, grand lacke.

Porolle on tube, bord renverse' en dehrors 'à $s$ divisions

4 Etamines Dont 2 plus longues, un 5 'mu fifet saris anthìre

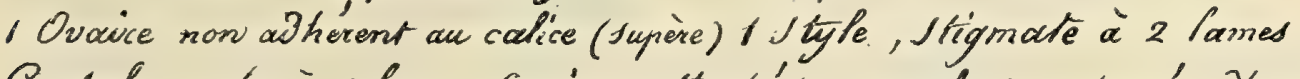

Caysule ovale à I loge, Graines altachées aux valves, entourés d'une aile. Davies ic r. Brown (furnille des teguminauses)

Calice à 5 gents, jains bractiés

Corolle papillonacée, à carène très peltite

10 Cramines à filets fibres

P'egume corrypuimé angulewso, s'auvrant avec élasticite', à 1 graine 



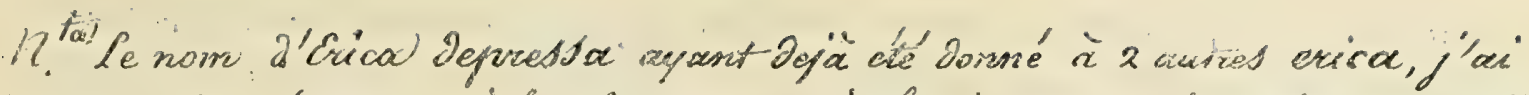

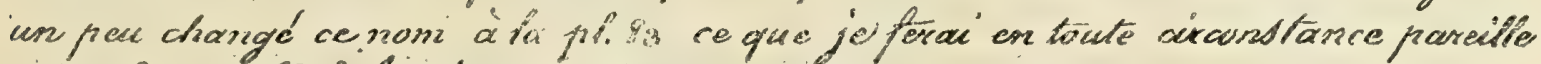

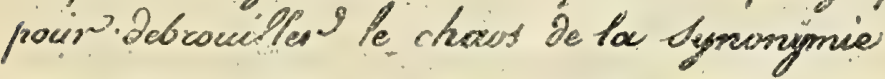

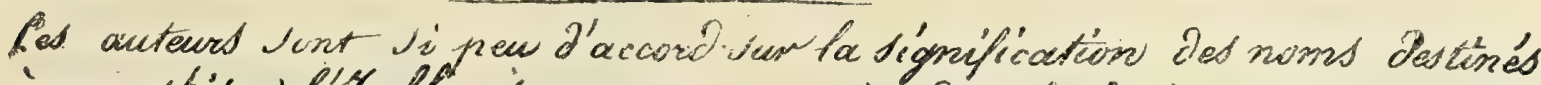

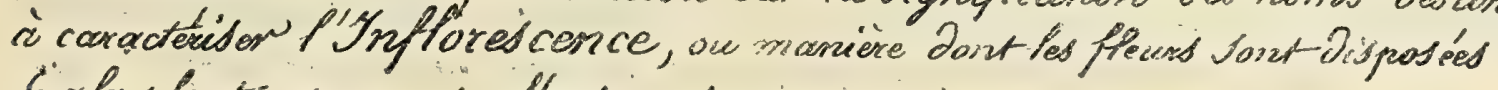
Sun-laplante qive nous allons nous en occuypor

Les fleurs sont altachés go ou à ine lige bion visible et on pes dis caulinaires $2^{\circ}$ ou à une tige $J^{\prime}$ courte (Ahixome) qu'on. les croiraitsortied de la racine ou Radicales.

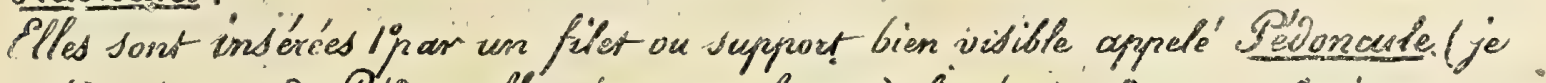

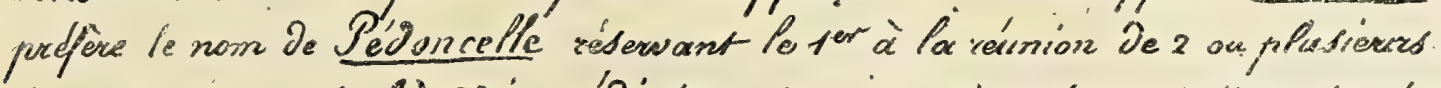
supports en un Joul) $2^{\circ}$ immédiatement ow par un suppout ji couct qu' on ne fe

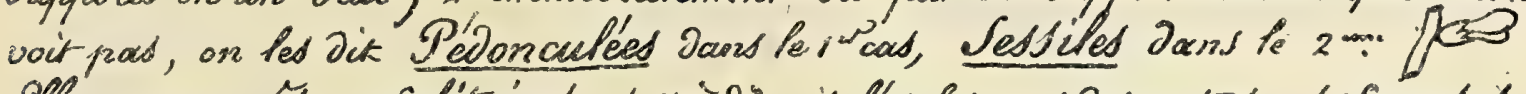
clles pewent être Solitaired c'estàdire isolées les uned Des auries, of frardes

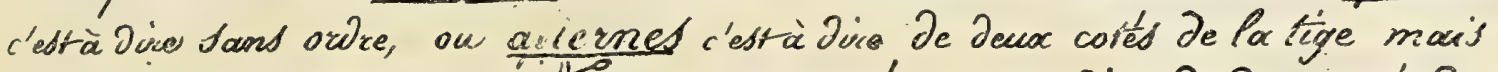
pas à la mêre hauterer afto ou opposés c'està dive de deux colés dela tige of à la mène houseur anto ow décustées quand les flesxs sont

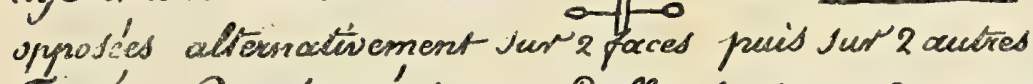

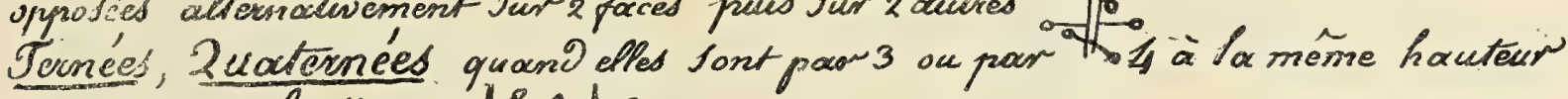
et ausurus de la tige ofo of

vecticilfes quand elfes Sont en plus grand nombre et on anseaue auntour de la tige

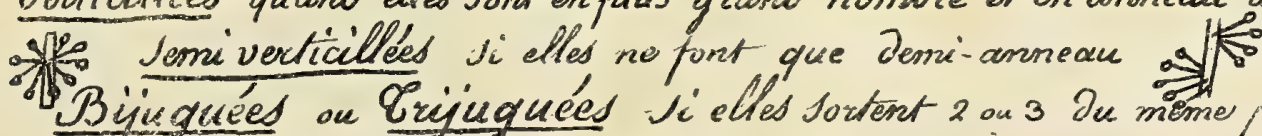

$L^{\prime}$ insemble de pluticurs flours I'appelle

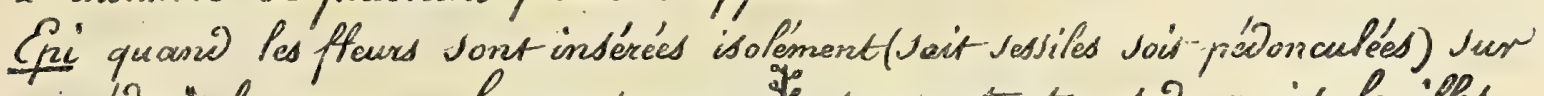

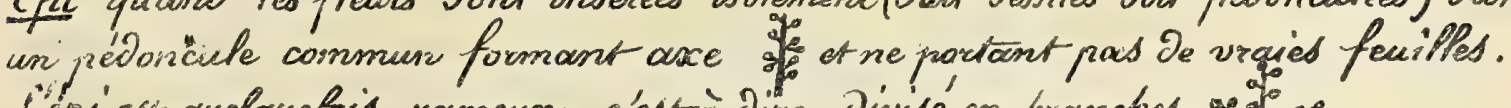

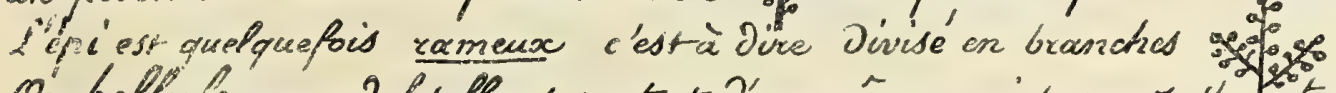

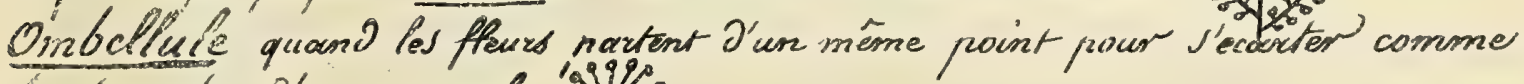
los branches D'un paras of. Sives

Ombelle si le point de départ de phusieuns ombellules est-le sommet De pejoncules

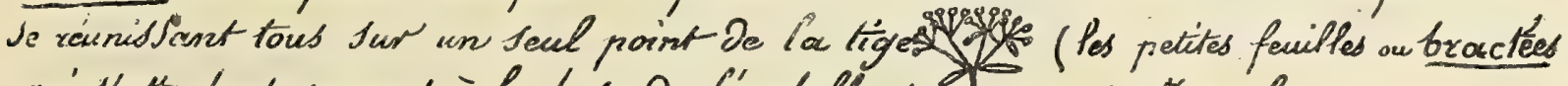
qui s'attachent souvent à la base de l'ombelle se nomment Hrovolucke, celles de l'ombelfule inwolucelle)

Tête quand les flewss sessiles sont Disposées tout autour J'uri ronffemens formé par f'extrésnité du pédoncule (une tête de fleurs peioncellées n'est-qu'ume ombalupe trop étalée)

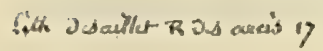





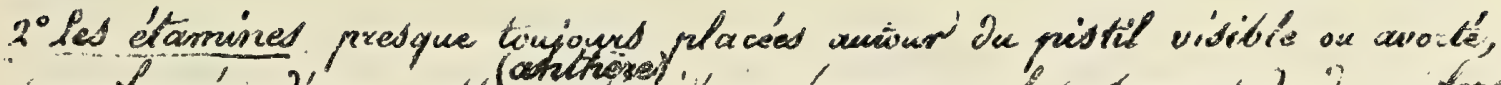

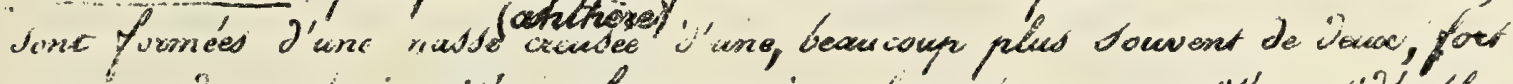

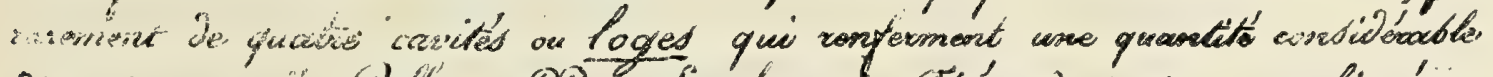

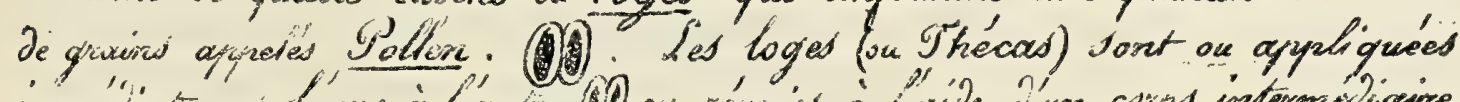

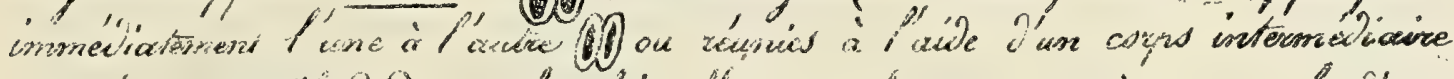

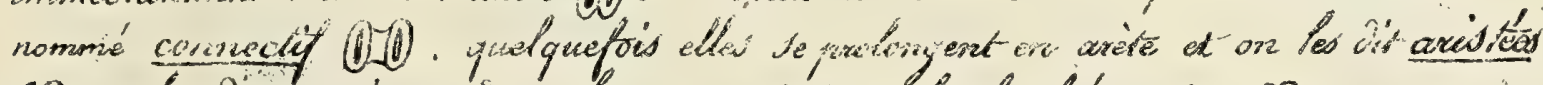

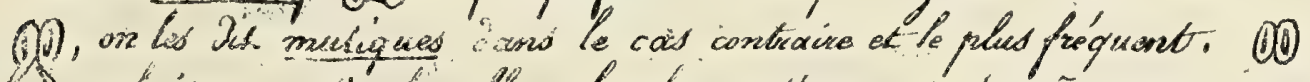

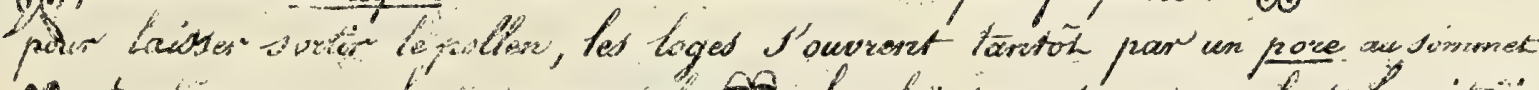

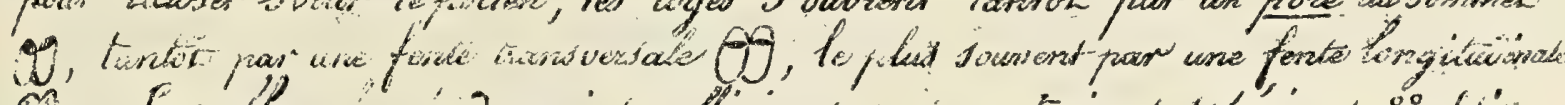

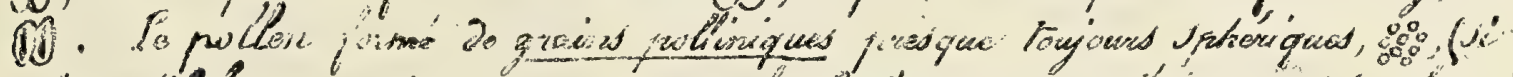

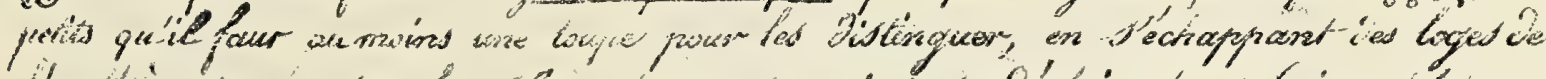

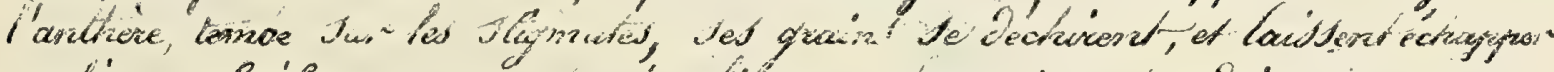

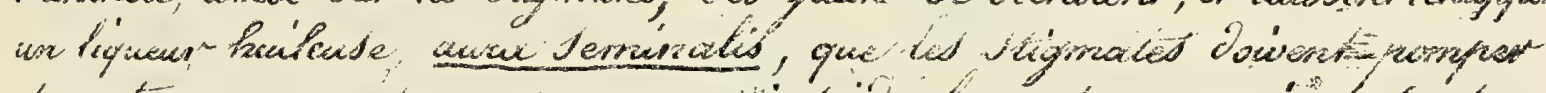

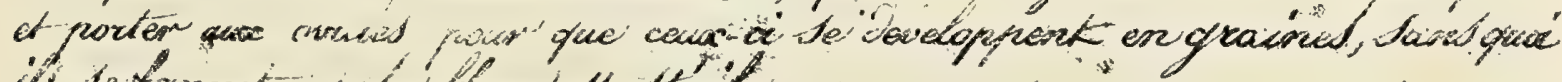

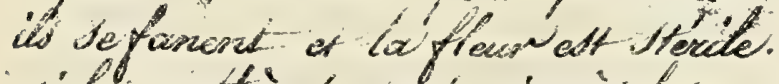

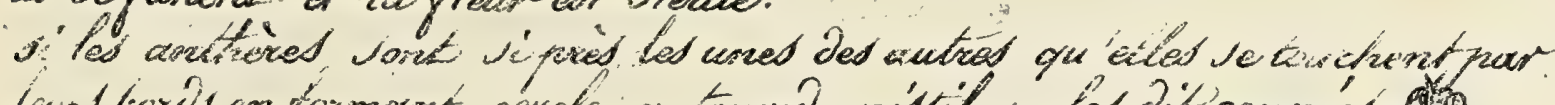

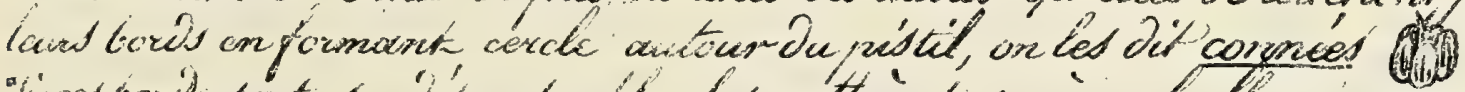

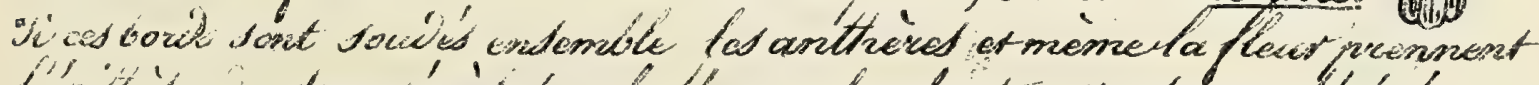

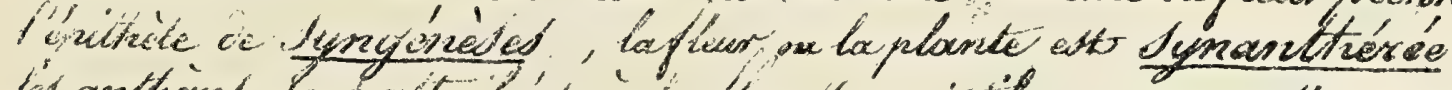

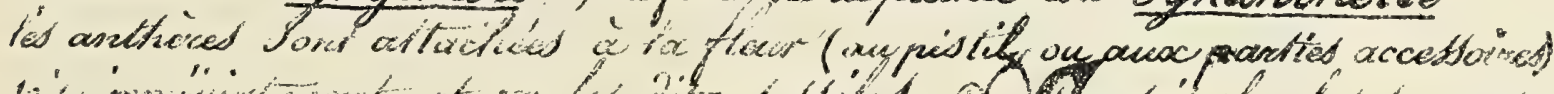

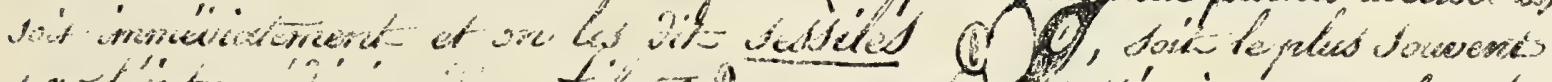

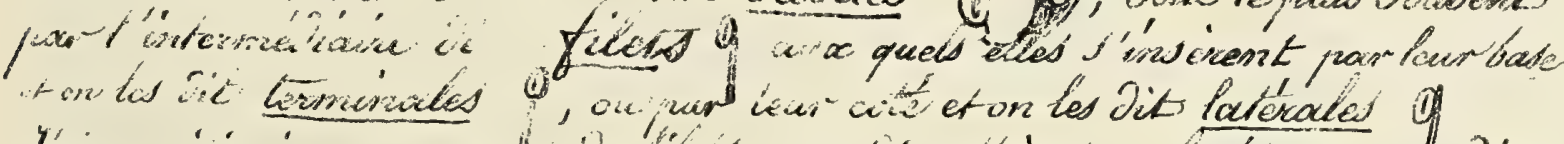

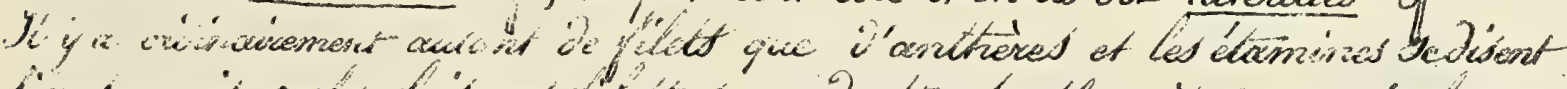

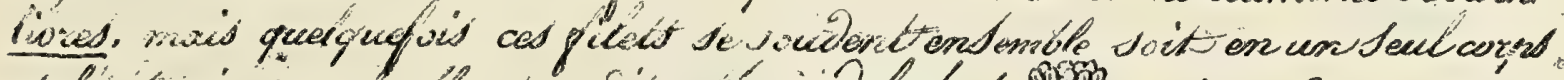

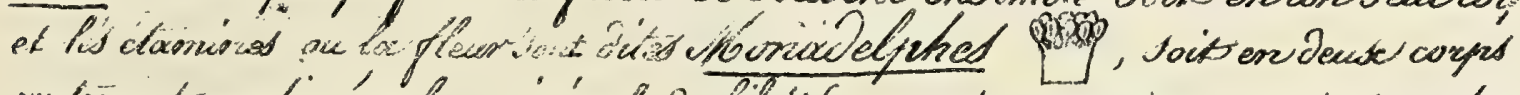

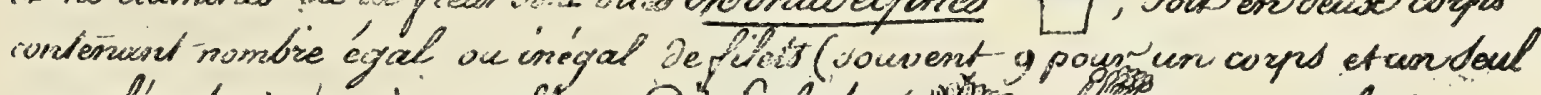

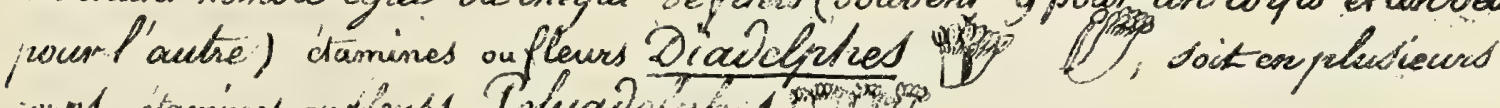

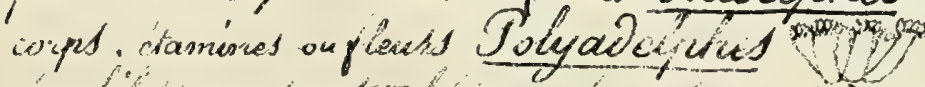

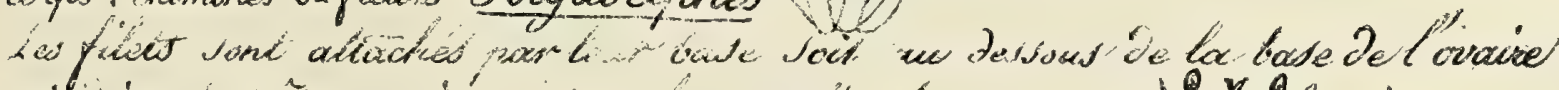

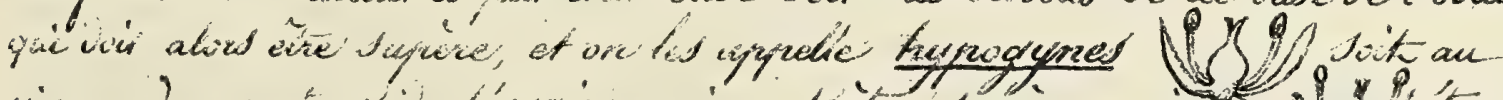

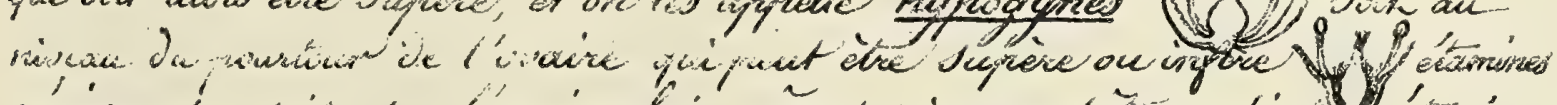

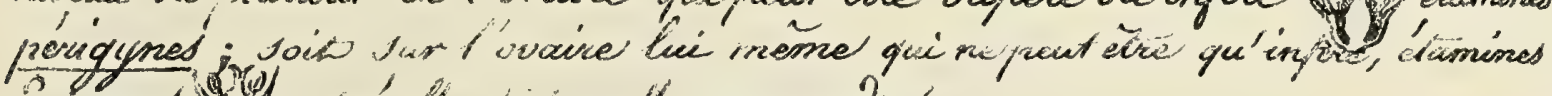

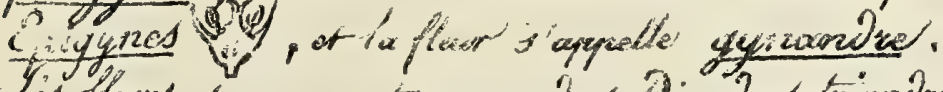

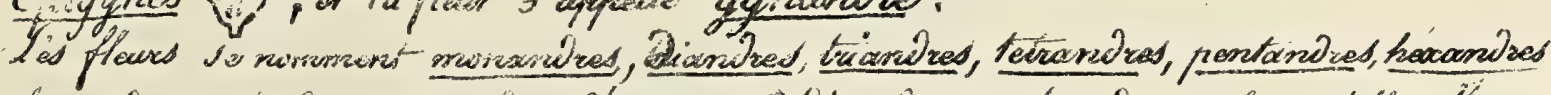

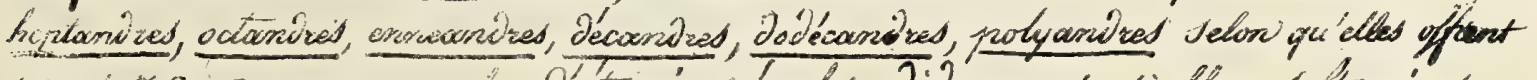

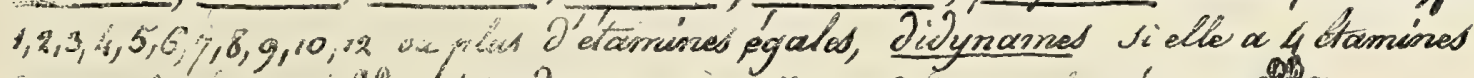

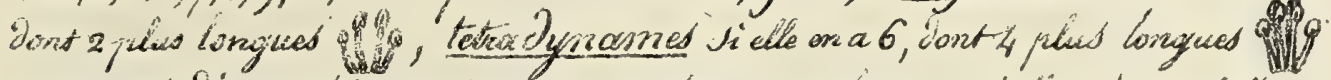

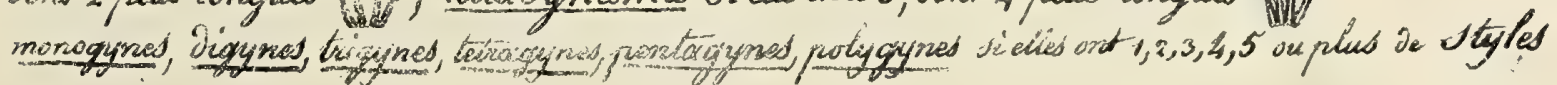





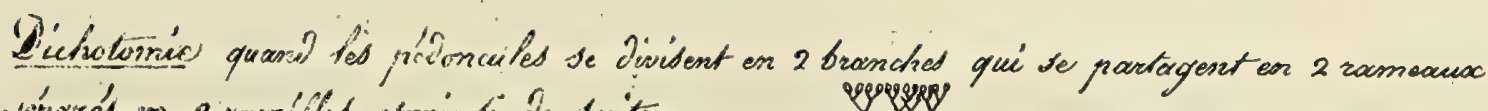

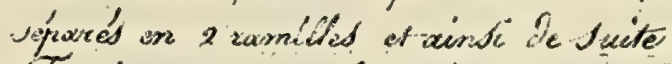

Trichotomie "i les memes divisions ont liew

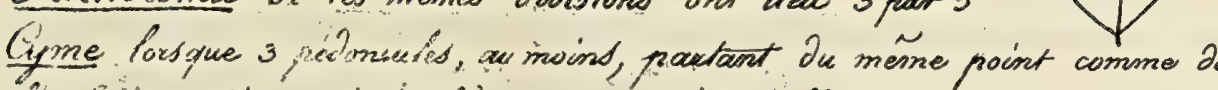

Ejmbeile, divient inrégulièremont en pédoncelles

Iasucule ji les nédoncuites partant De Divers points o'un

inréguliviessent

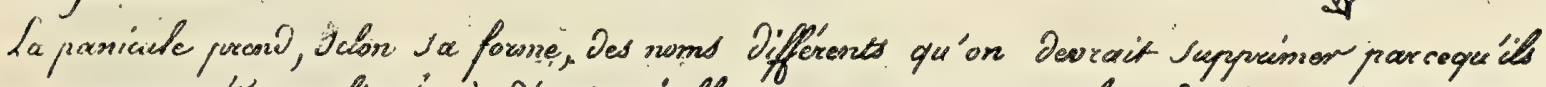

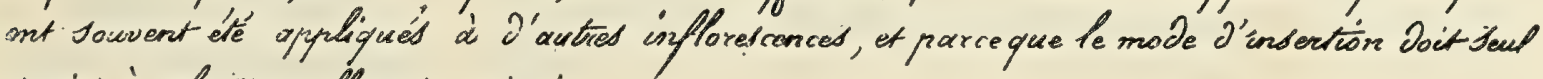

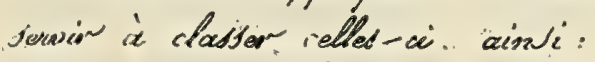

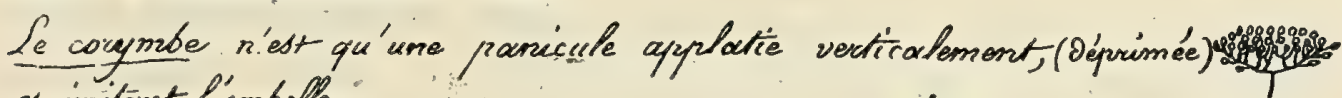

et insitasst lombelte

Le Chyrse est une panisule conique et Dressée

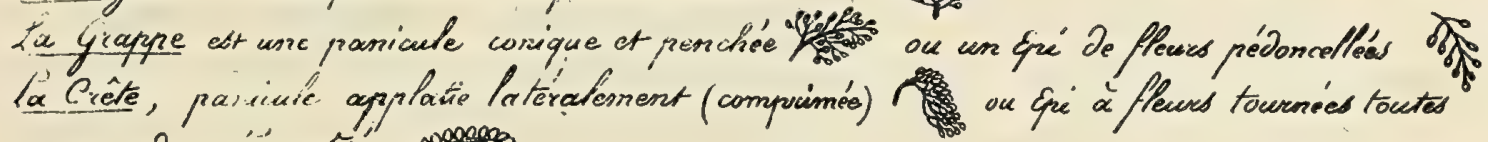

$$
\text { Ju mäne ôte }
$$

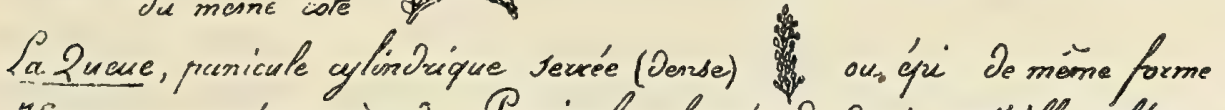

"Yy a une autre espice de Panicule formée de demi-vorticilles alterned

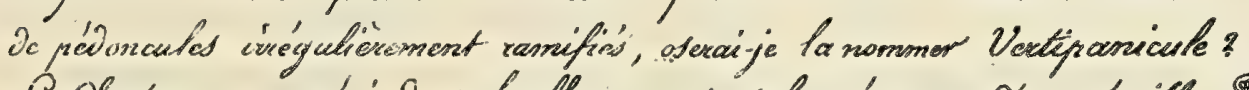

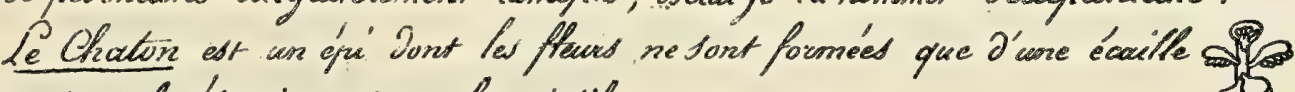
poutant les étamines et ou les pistits

Pe Cone est te menne épe' Jont les ćcailles J'encististent aw somonet pour

pormer une madte coniquie

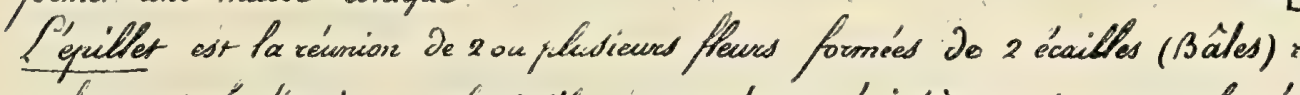

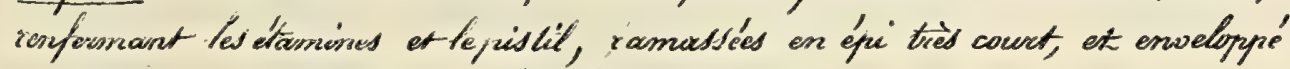
ì la base pas 2 (qualquefois 1) écailles (Glumes)

Le Receptacle astun epaisissement Du sommet Du pedoncule, sur fe quel

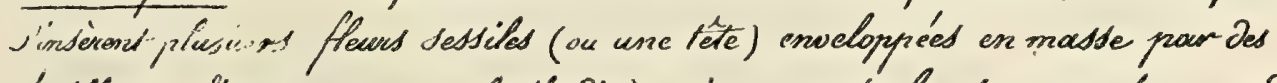
écuilles (calice conmun su Anthiodie). Si ce receptacte se recourbe pres Dessud les flewes pour Pes cenfermer cornme Dans une puche Sons ouverturce c'est une figue.

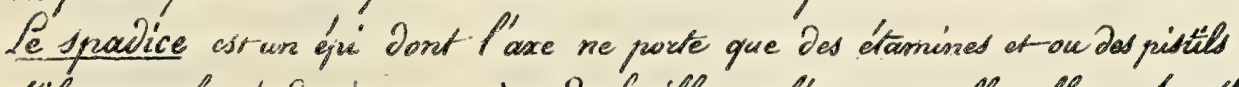
Sill est enveloppé Jans' une espice de fouille roulee, on appelle celle ci Jpathe Onv voit que louted ces expressions Depuis corymbo pourzaient etre Suppicimées ii les freurs sont toutes inserées Ju merme coté De feus support commuen on les

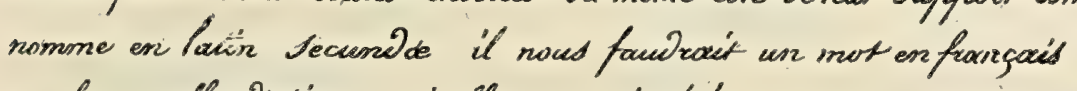
un les appelle distigues si elles Sort insérées Sur 2 rangs oppusés

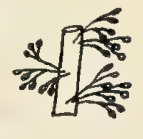





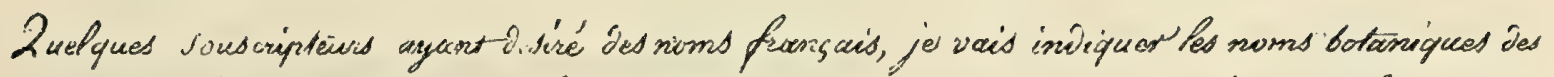

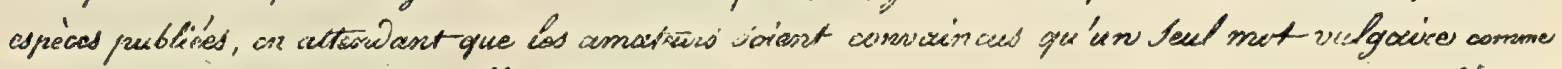

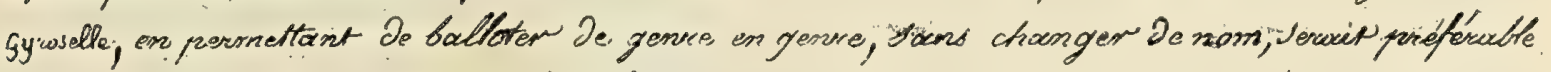
à vingt syronines pour la mêne plante

- Pernulite as usé

2. Pimélée reninarquable

3 Caruaine tricolore

4 Cestreacu rose

5 Labichée punctué, 6habrothamme élegiast $\gamma$ Phorizeme varie" 'Pobyala de Jalmaid g. Breyeres bruniade 10 Lové de ceés

11 Fimule cowdinate 1: Ciste créu

13. Puaderithe

15 Stisaurandie de bauchoy 16. Yasmin des acores is Ang'íne comaryuable

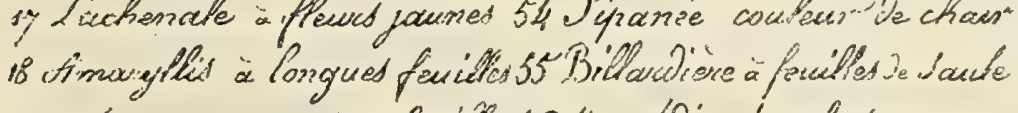

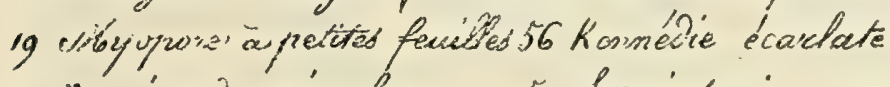
20 Berweine te miquelon

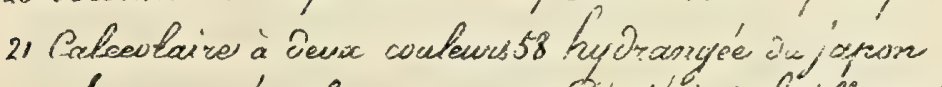
22 Tauge écouflate 23 biachis 24 Sotwira Janguin 25 chorelle poilue 26 Secherioultie offerte 2y Compraxule. grelle

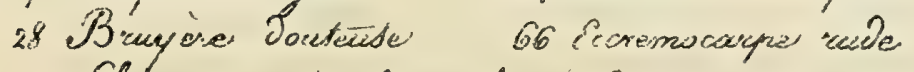

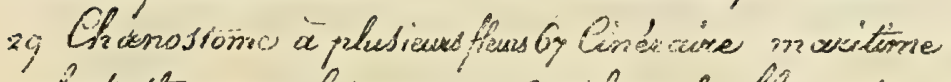

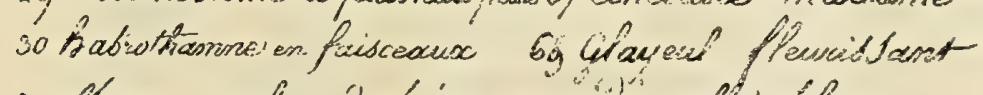

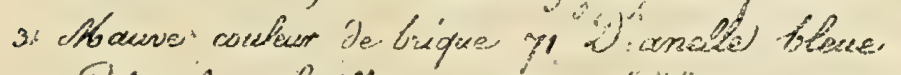

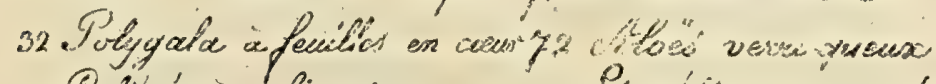

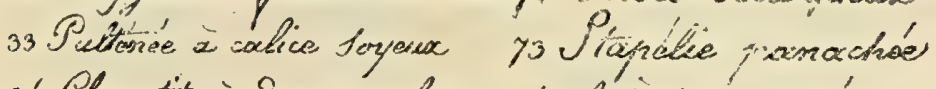

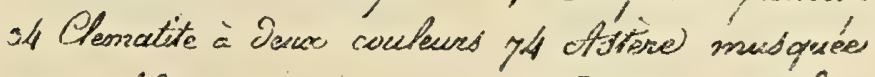
ir ixclite ic Seppai.

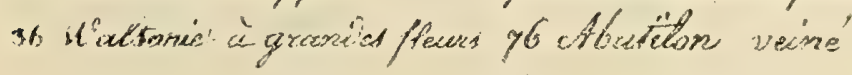

5 y haindonie, prowyrue.

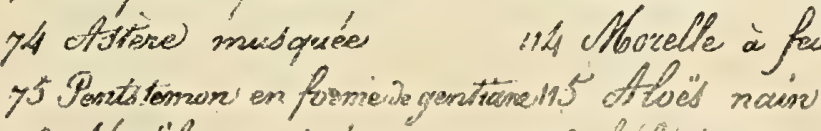

7) Yotome à fleurs axillavies ys Solygala à perilted de lawion yoclatice Juveteude 40 hémiwive ufailies D'orie 80 Carmantinze carnée 41 Critome mayer 8 Mitteportivis Ou nópaul

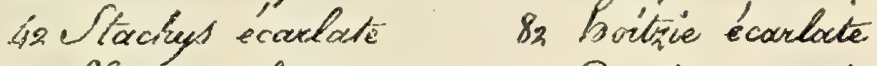
43 Gaba glauque 83 Bruncie abaibté 45 . Thinocample a's couleurs 84 Arnphicorne Odlicate 46 Grachélie Ófeus 4y Cieitra de madeice

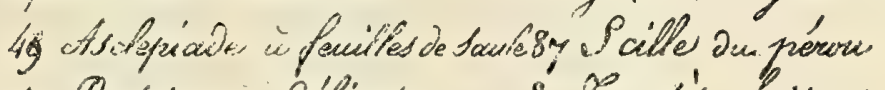
5o Penticnnon Dilicat. \&g Gagetes tuidant

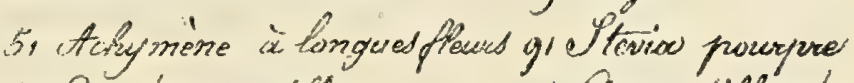
So Cuphée varmillors 'i gh Pierge Jillonnié $9^{5}$ Lecherantive betie $9 y$ Phlox tout flami ys Lobelie brillantos 99 Gralanes barbue 100 Cupatoire ruguaube 101 'Yadenie trangé

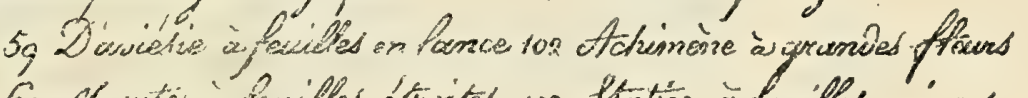

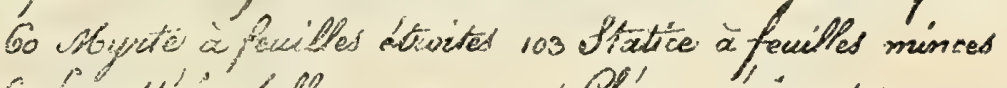
Gi sucelterice belse 104 Preome éfinade

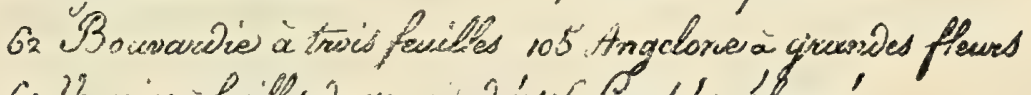

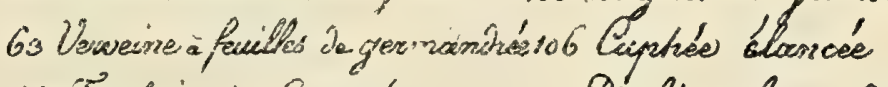
64 Tuchide a Congmbes 'o) Divchée en forme de glyaine 108 Niexemtergic intermédiaire rog Lourncloutie en hilioboupe" 110 e Pelagine ae gilles in Buyyere mésiteranés 112 obelie sy.

113 Velthemie de cap "Mal Morelle à fruiltes grauques

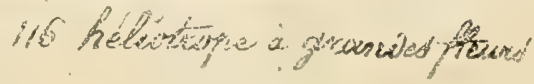





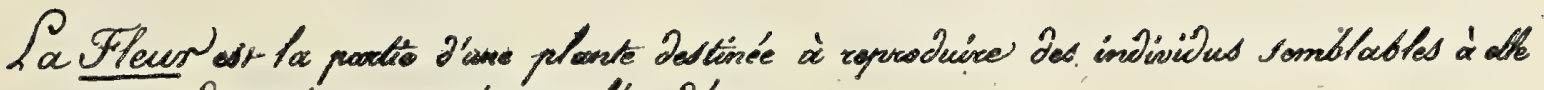
aw moyen de grainas aic unbryons fécondés.

Clle se comprose de parties assentielles, (Pistils stétamines) at de parties acressoures (Corclle, Calice, Tectaires, Strominules \&- \&

'Le Pistil est-formé de' P'Ovaire, organe pilacé presque toujours aw centre de la

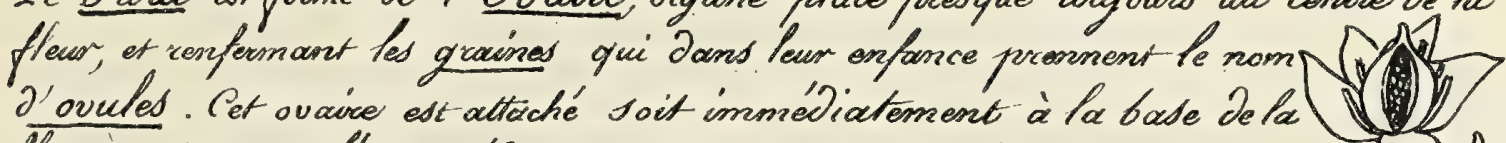

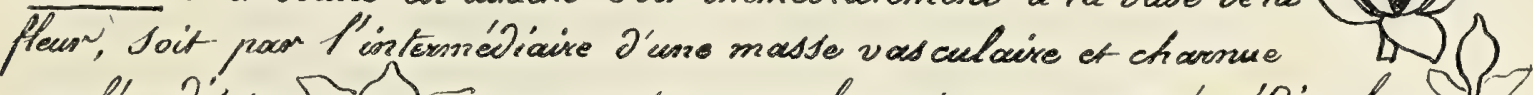

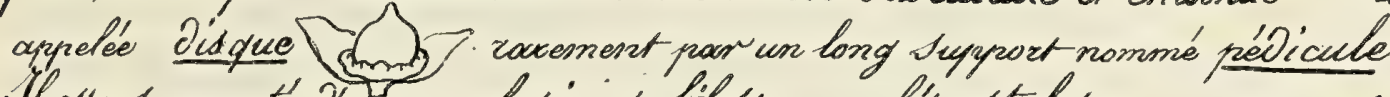

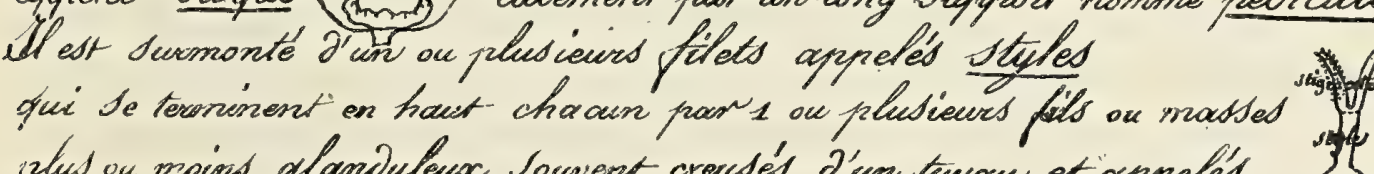

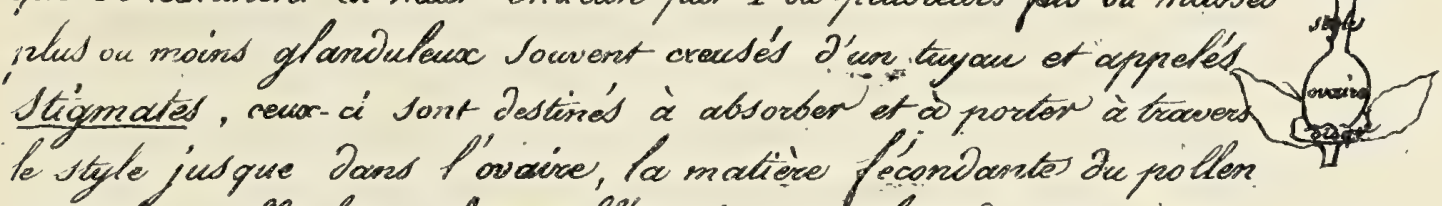
sans la quelte les ovules se fletriciciont an liow do muxis quelque fois les Sigymates s'insèvent Jirectement à f'ovaive Sans staile, et on les ait dessiles.

lecon forme varie beaucoup. Conutón comme Des fils filiformes cositot comme une tête If quelquefois applatis on crête ou en pétale pét alliformes outsurs creusés en entornoir

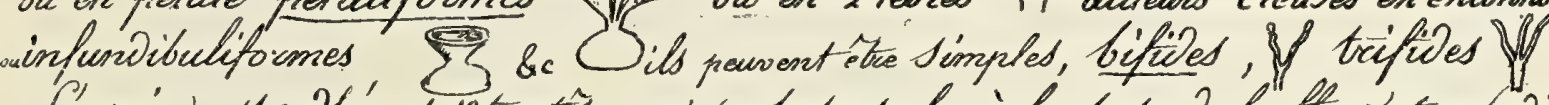

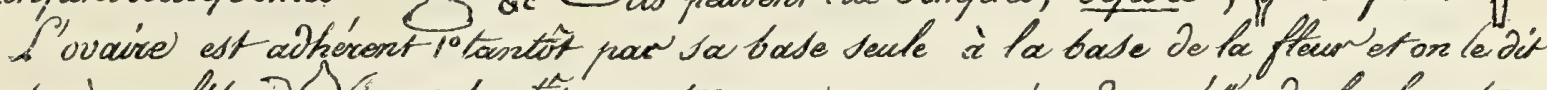

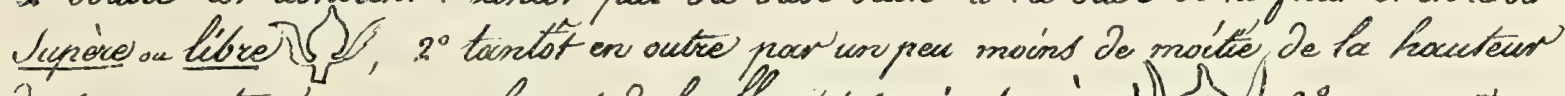

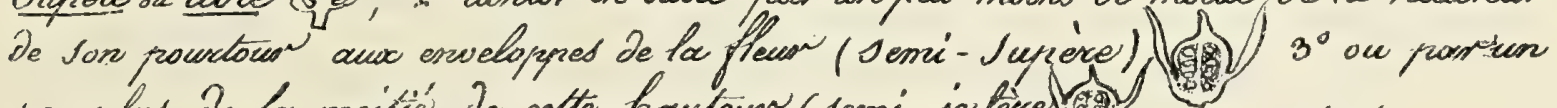

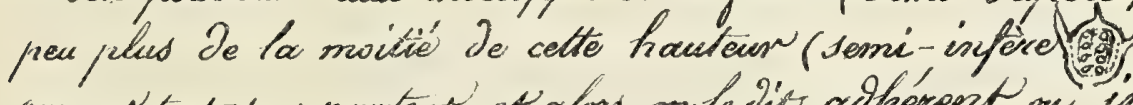

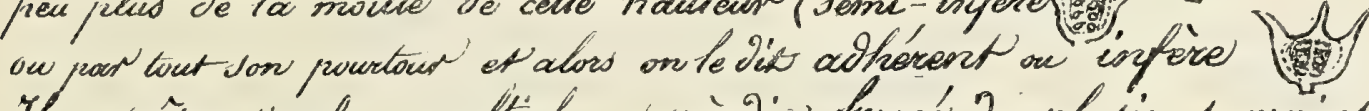

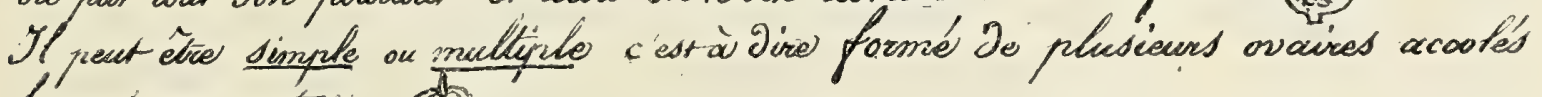
les uns acua acutres dy

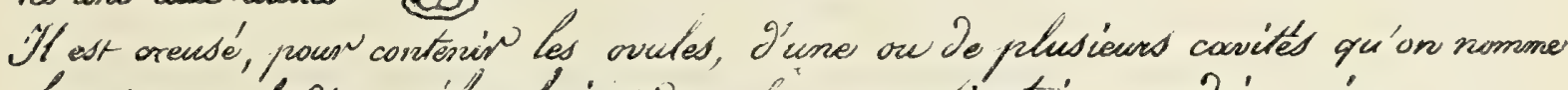

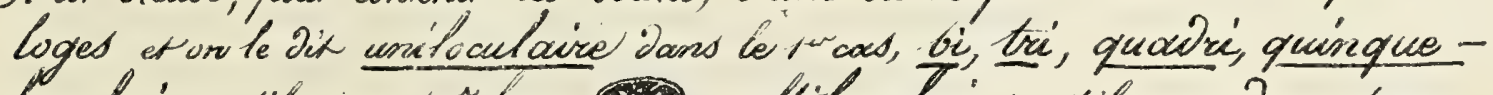
loculaive s'il a 2,3,4,5 loges mulibulaulare s'il en a davantage Tes lames membraneuses ow chavonues qui séparont les loges J'appellent

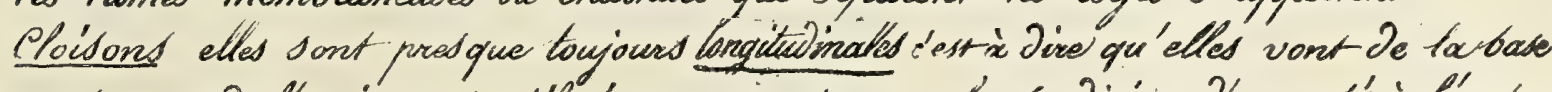

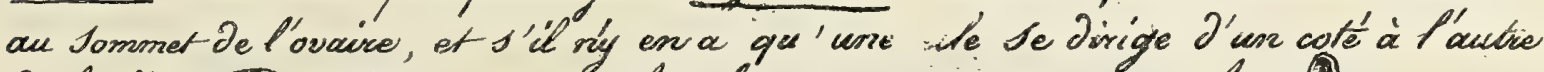

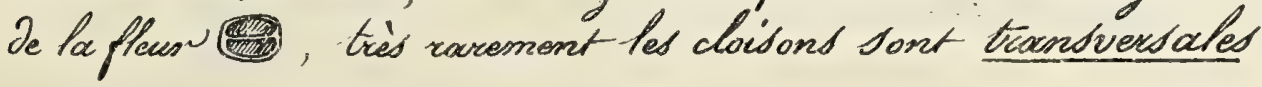





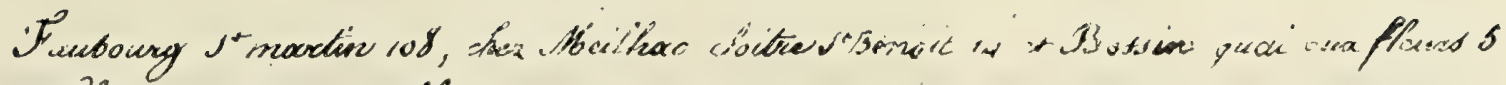

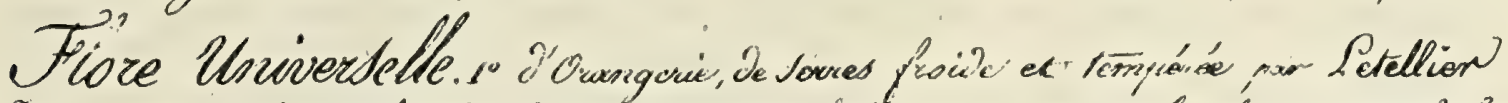

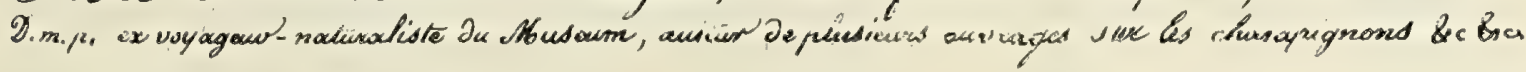

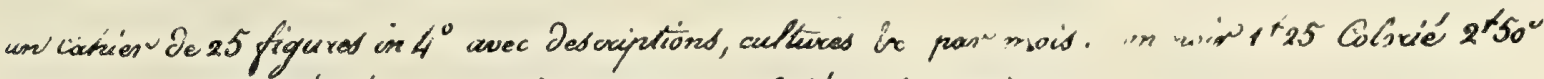

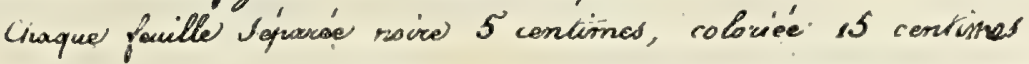

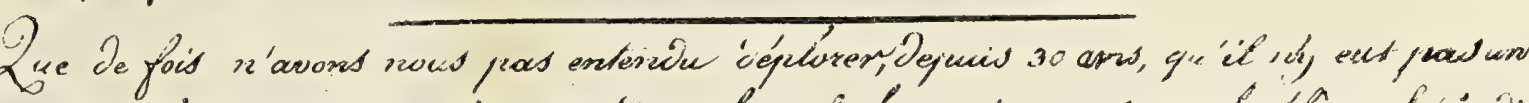

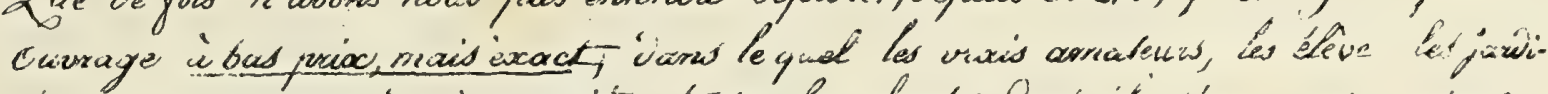

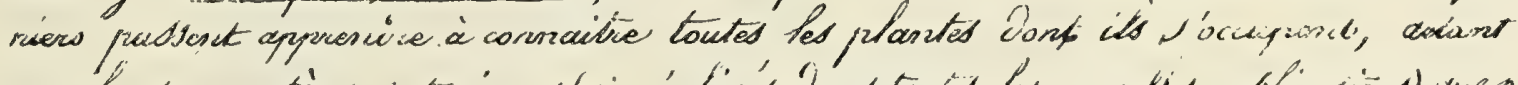

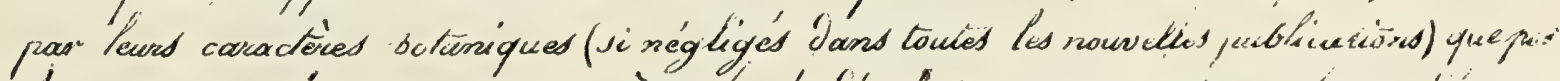

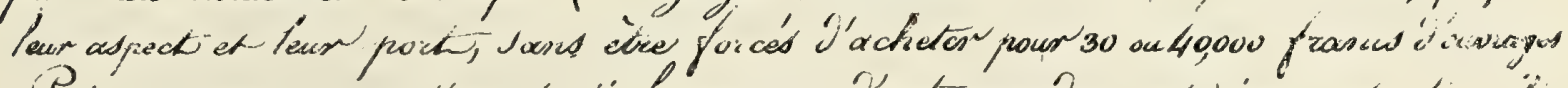

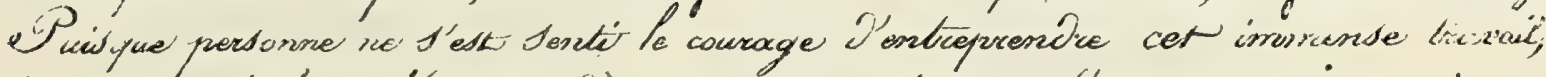

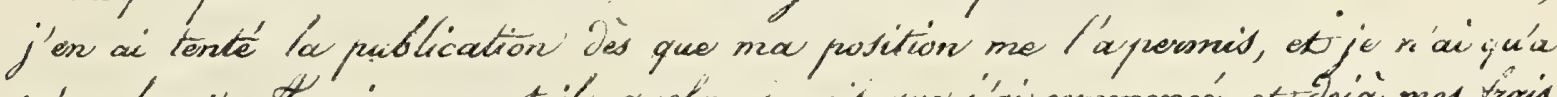
m'en lowor. Tt peine y a til quelques mois que ' ai comnencé, et dejai mes frais sout couverts (c'etait ma seule ambition) graxce a f apyini biesweillant que m' uns

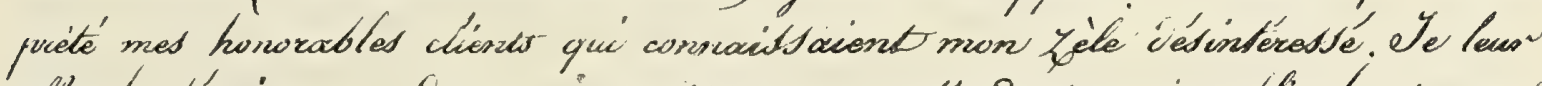

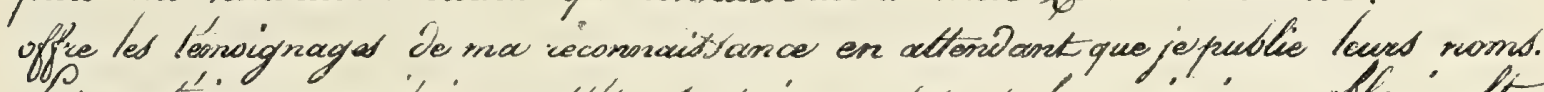

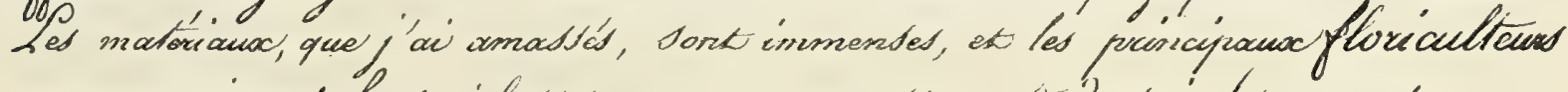
me communiquont leurd cicheded avec un snyuces sement iuntje les reonorcie:

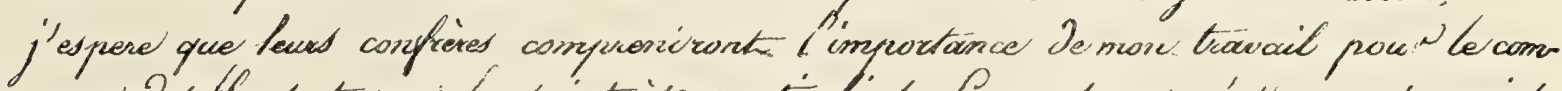

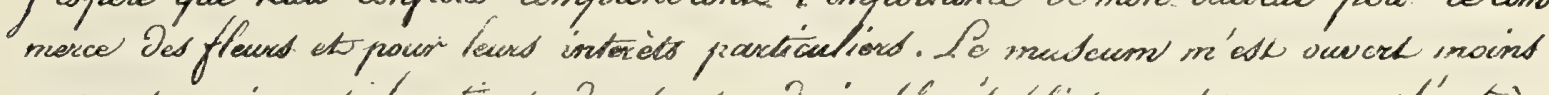

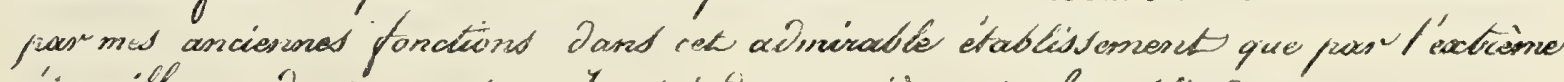

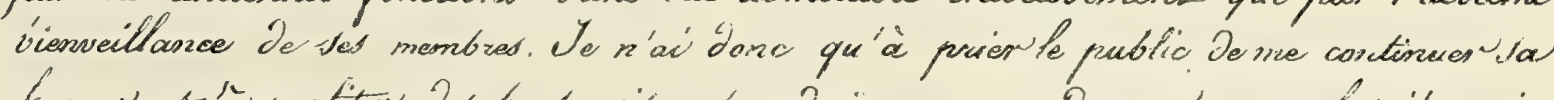

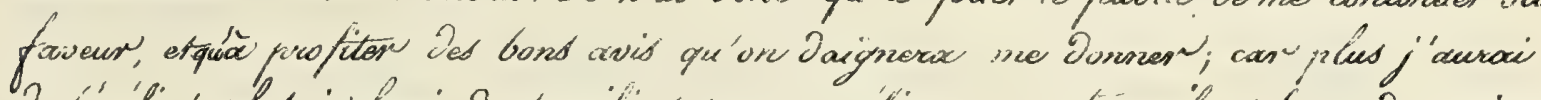

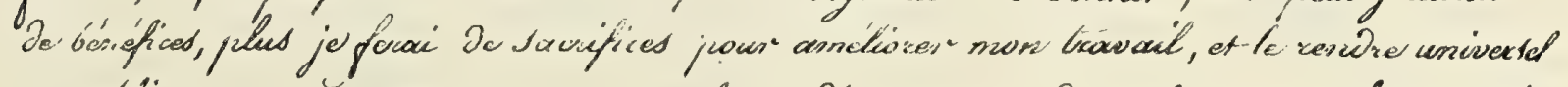

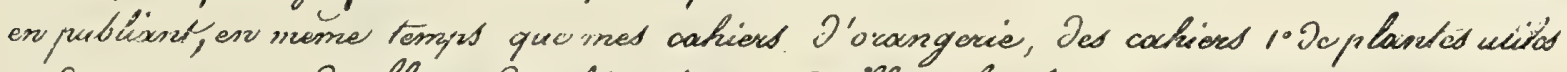

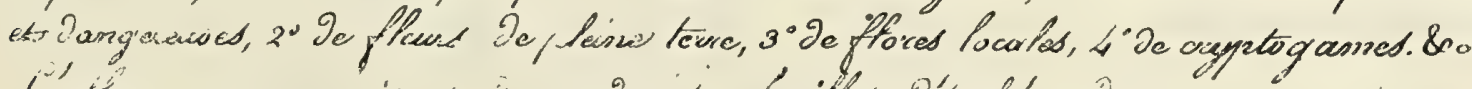

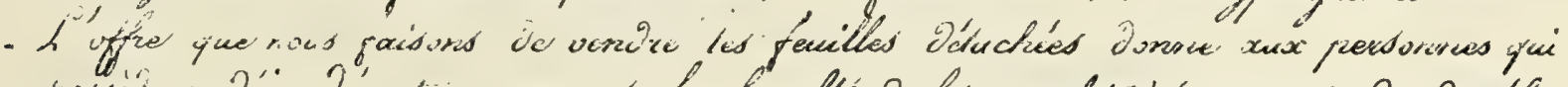

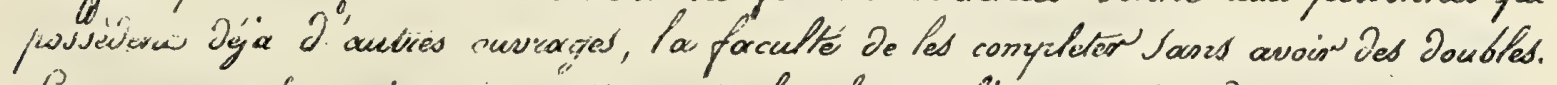

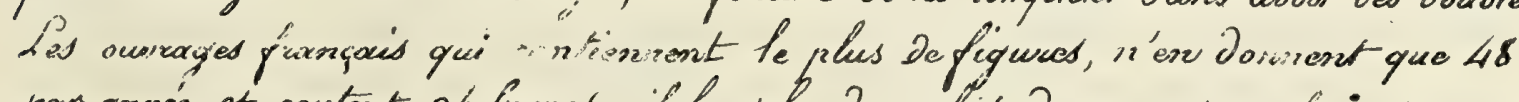

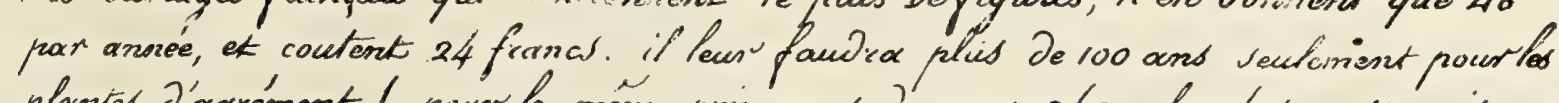
planites J'agrément.! pour le morne prix nous Jonnons 240 plonsties on 10 mois ow

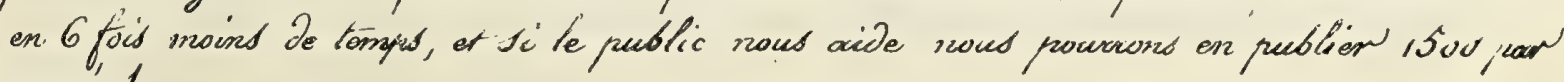
anmee!

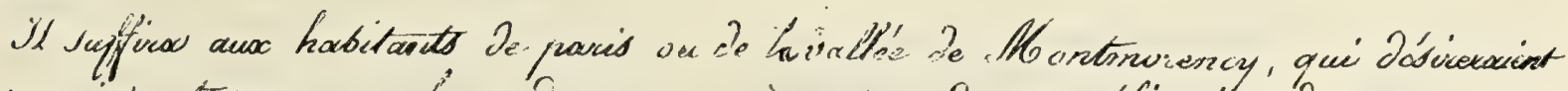

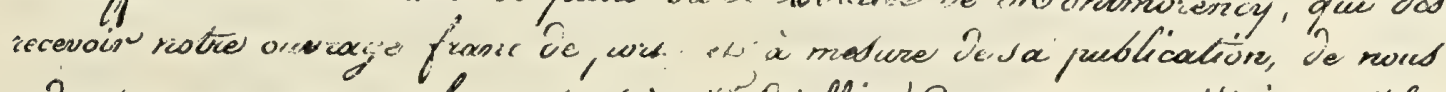

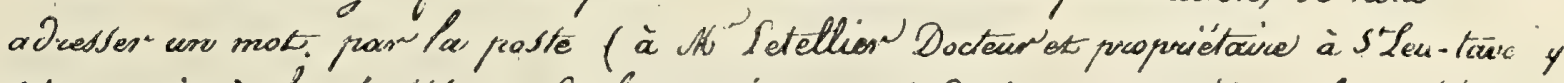

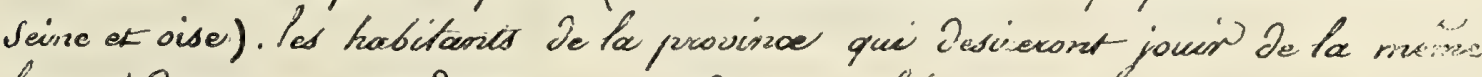

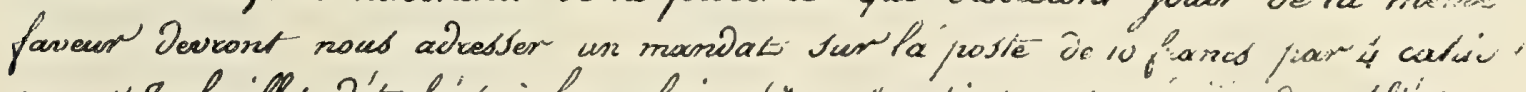

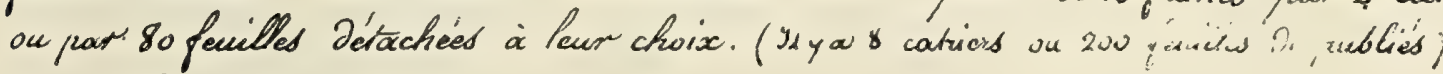





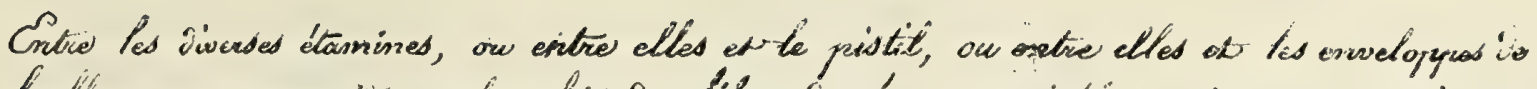

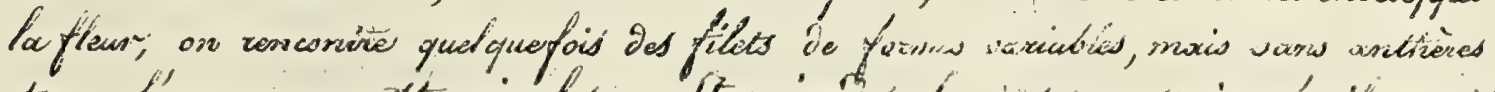

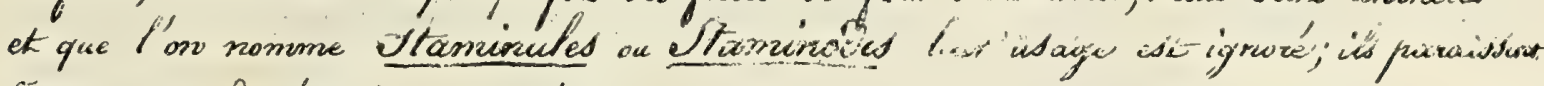
âte sounent des étaminas derortées.

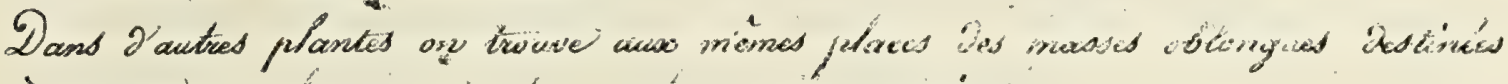

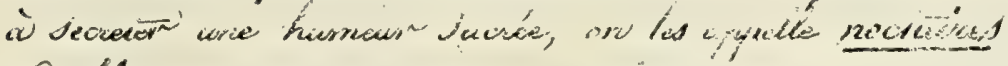

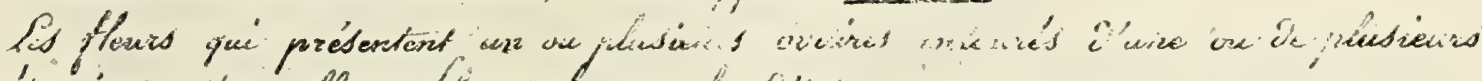

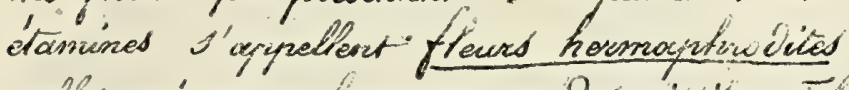

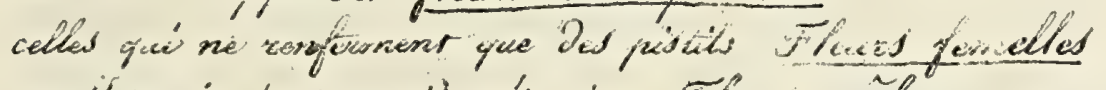

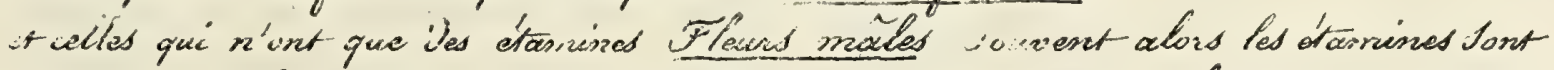

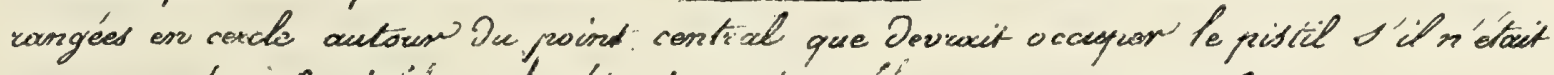

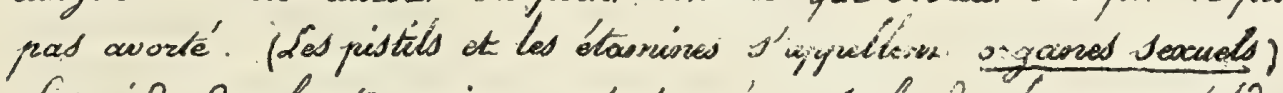

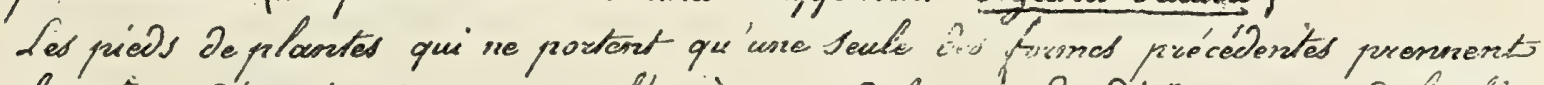

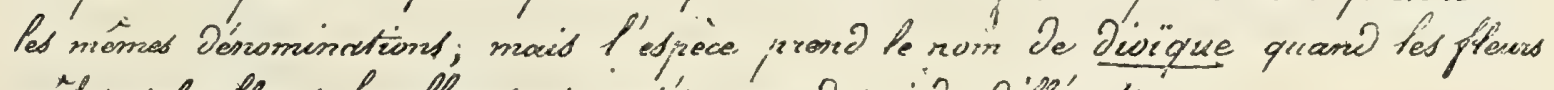

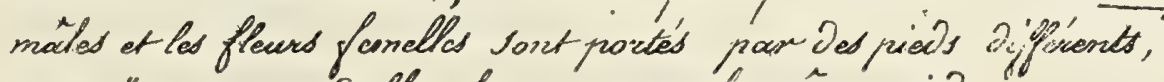

monsigues quand elles lo junt par te menne pied,

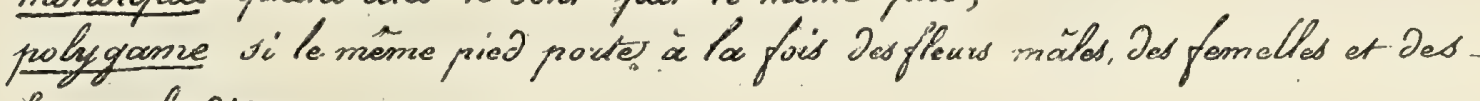

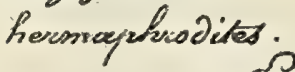

Cnucloppes flocales.

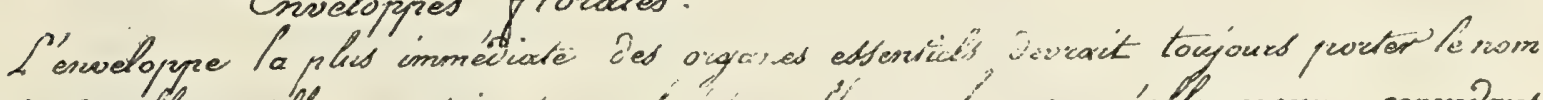

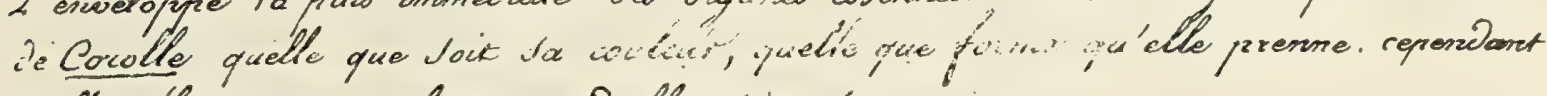

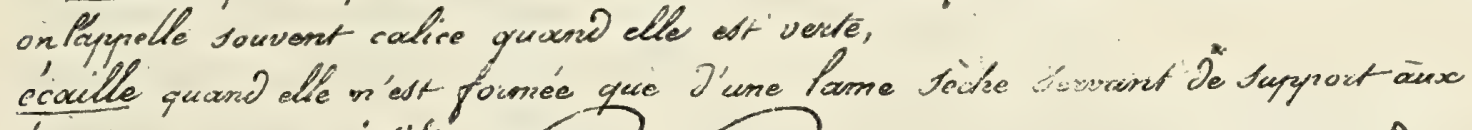
étanimed ou aus pistits

batle quand elle est formée de 2 écailles opposés Piens ì autre

et chacque écaille prorte le rom de voulve

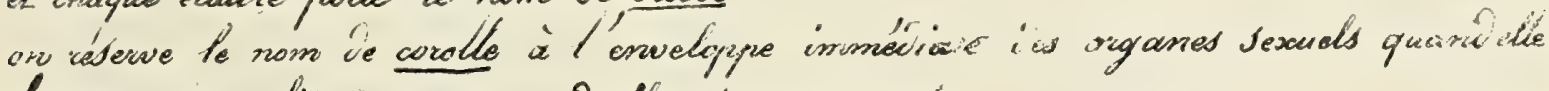
fes entowne complitoment quand elie n'est pass verle:

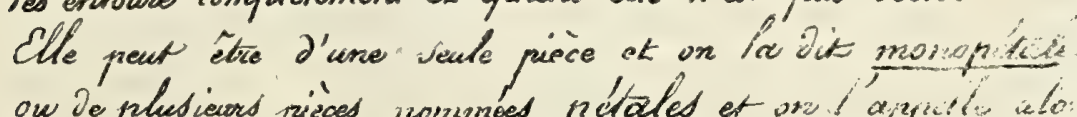

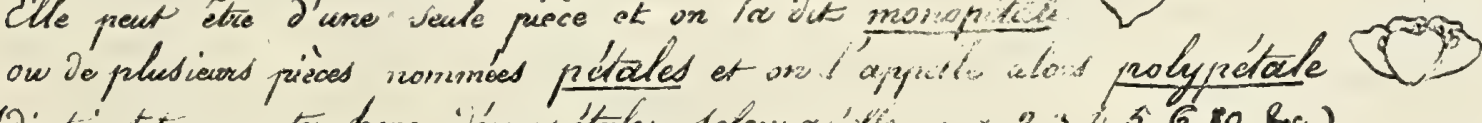

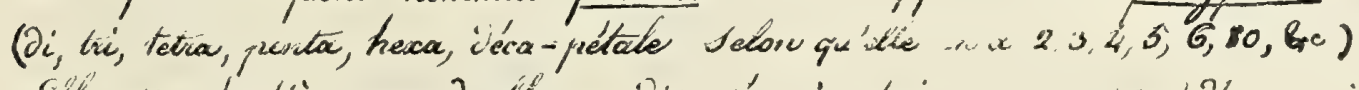

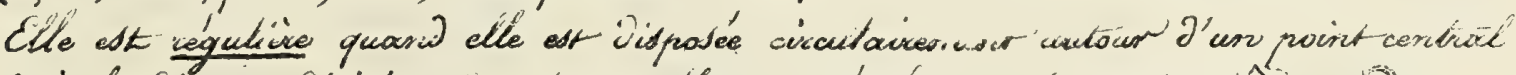

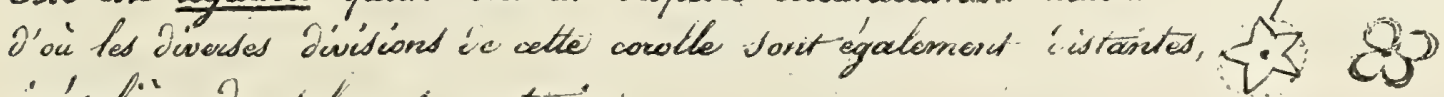
inréguliever dand-le cas contraive

On a donné Des noms particutiers awa puincipales formed De cowtle ainsi la corolle mongrêtale régulioic paut étre.

en rous quand etie est pucesque piate

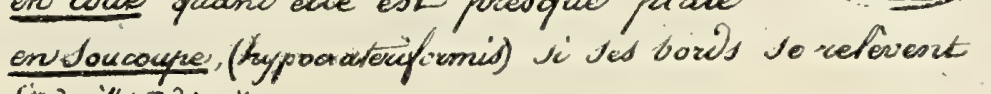
Sitt decaider-R as ancisy 



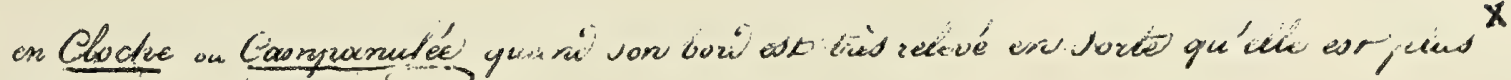

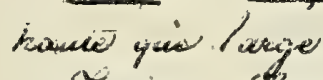

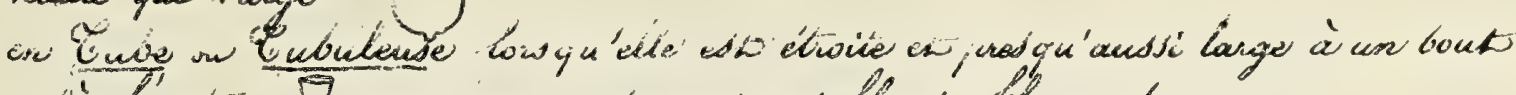

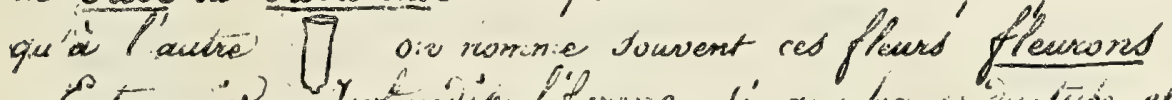

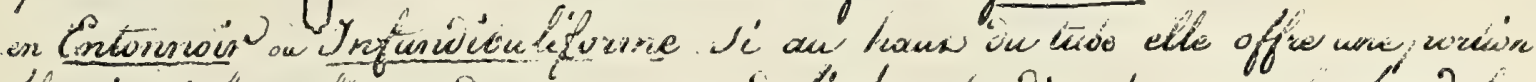

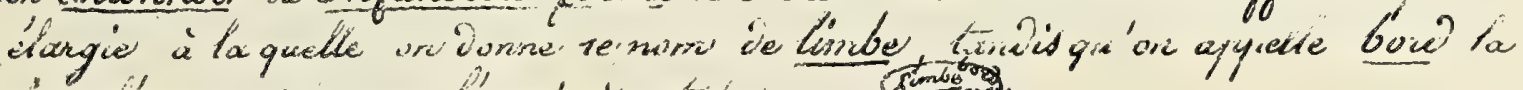

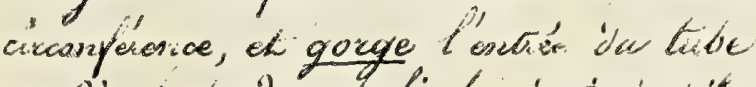

simbor

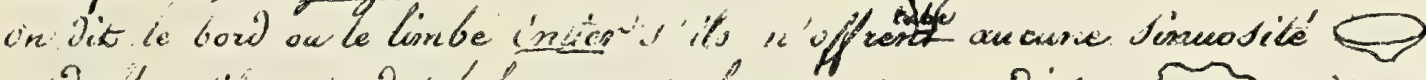

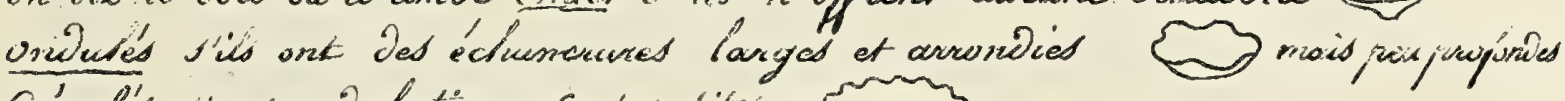

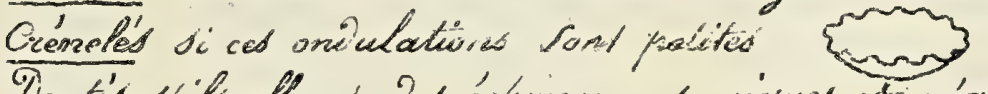

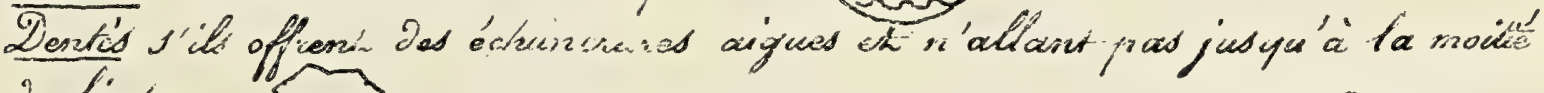
ia limbe $\rightarrow$

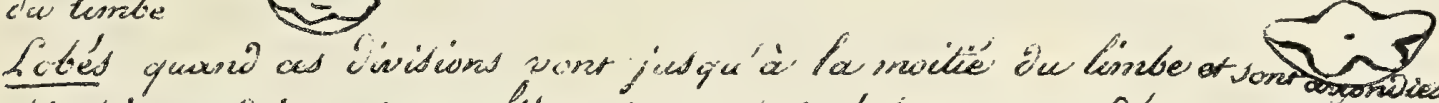

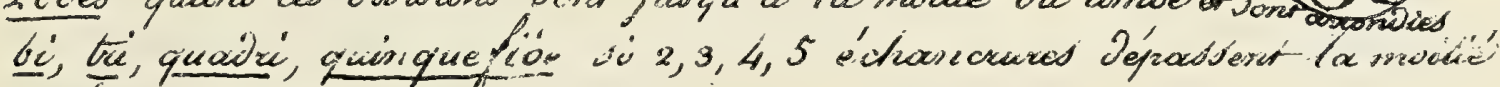

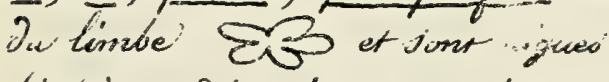

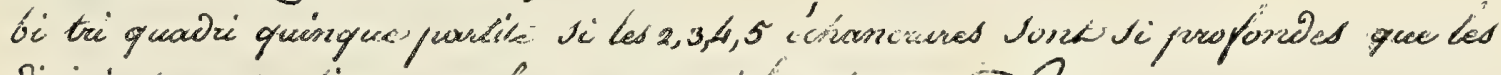

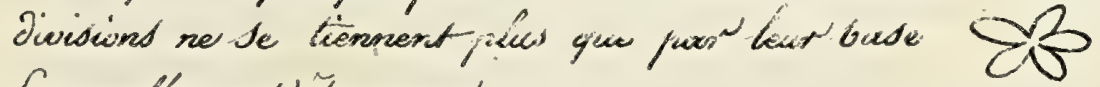
La corolle peut etre on cor

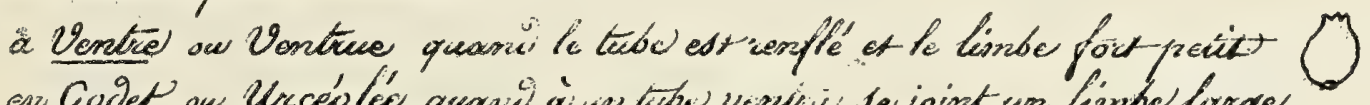

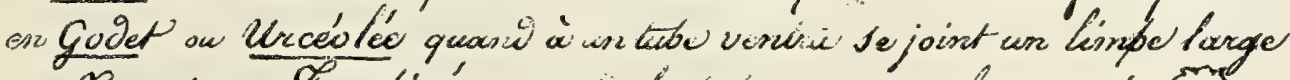

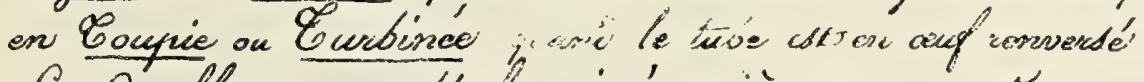

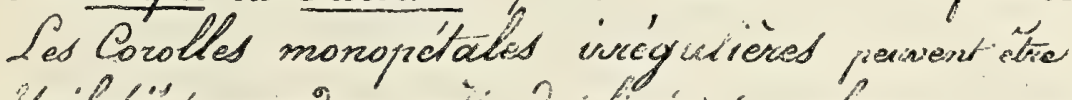

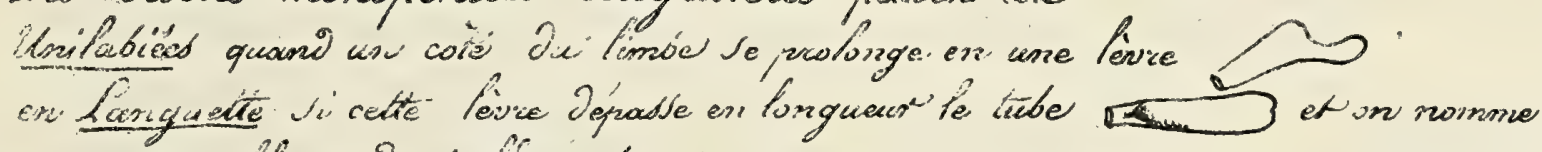

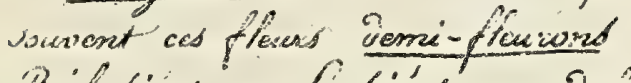

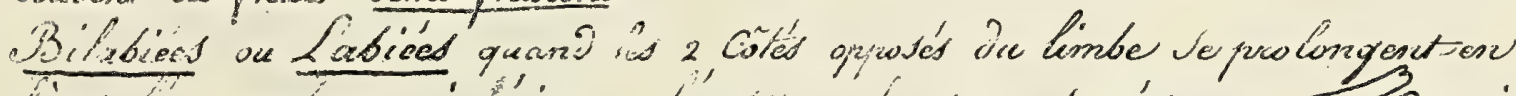

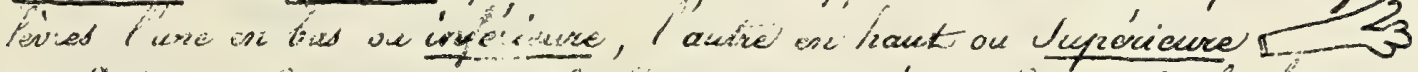

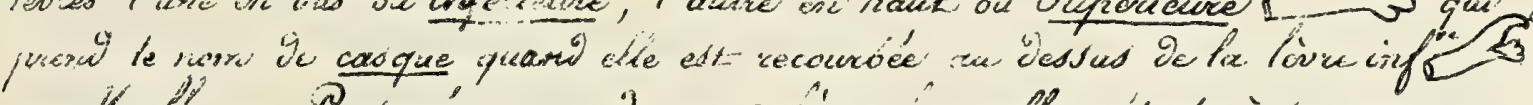

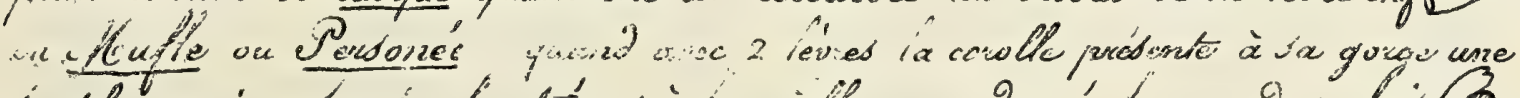

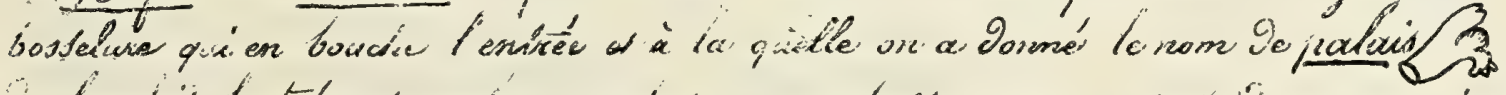

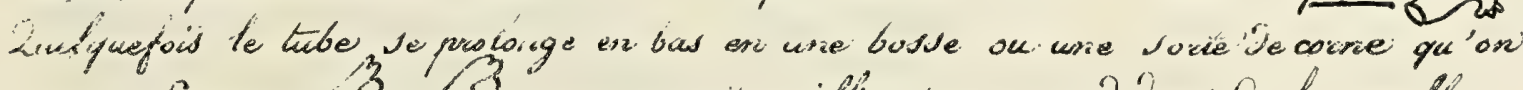

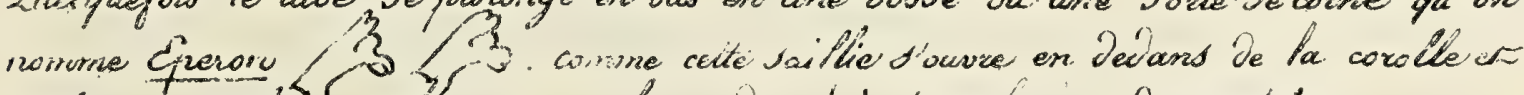

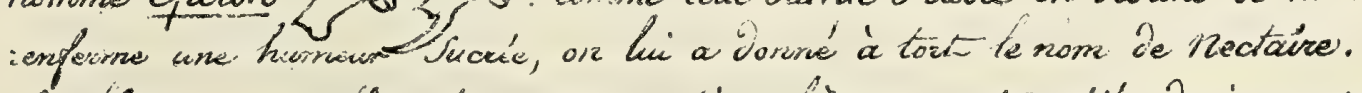

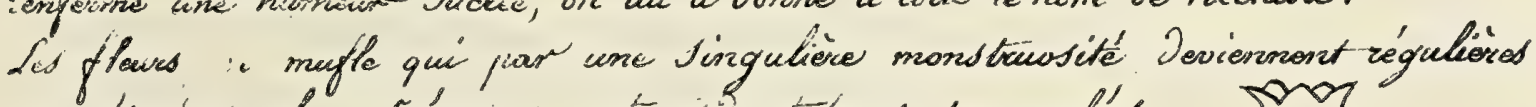

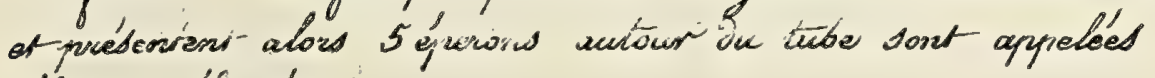
fleurs péforiées

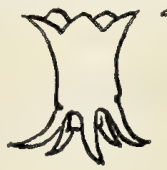

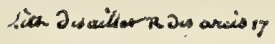





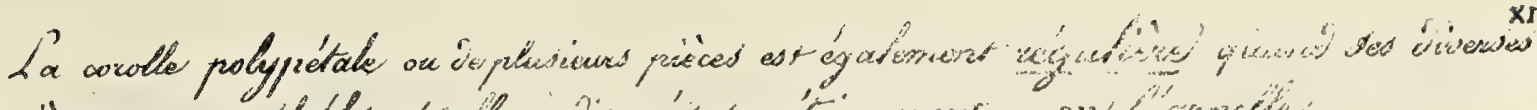

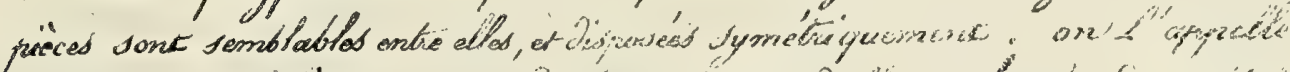

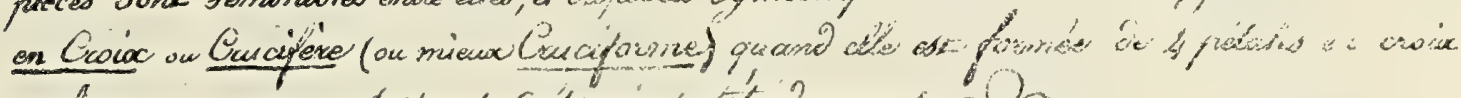

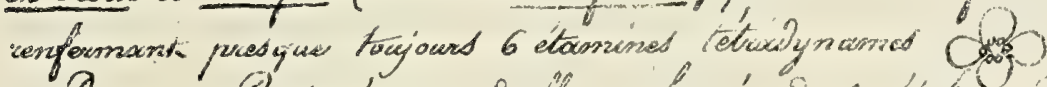

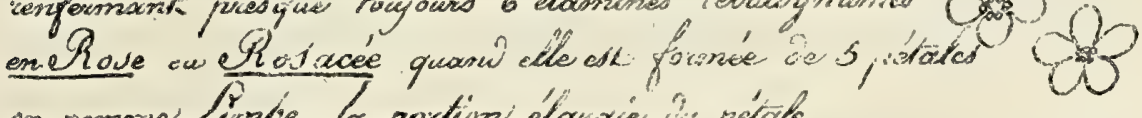

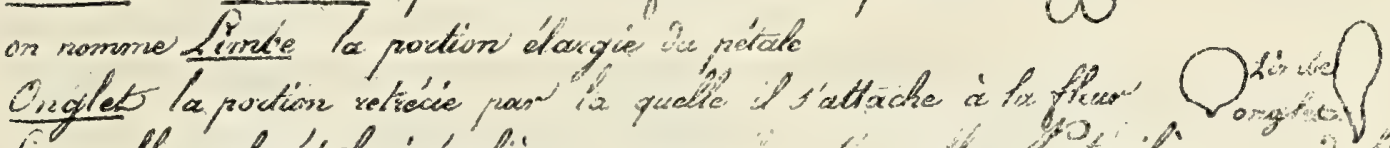

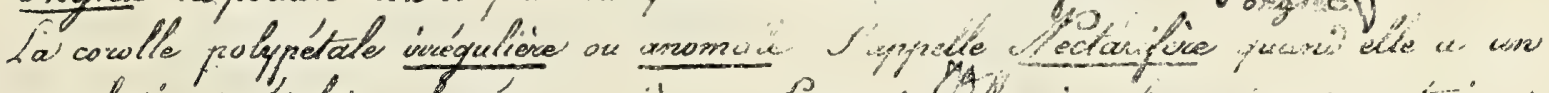

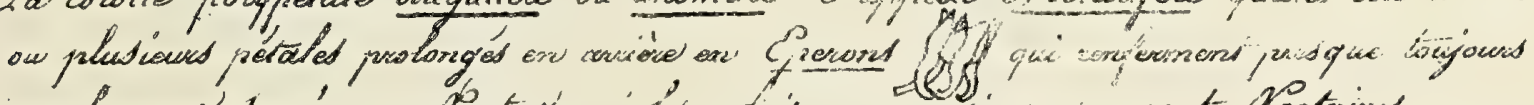

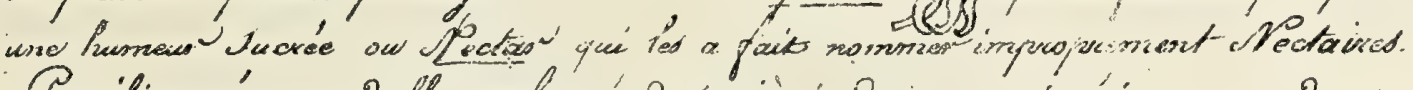

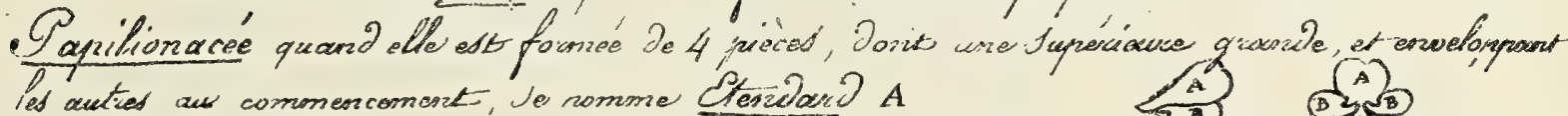

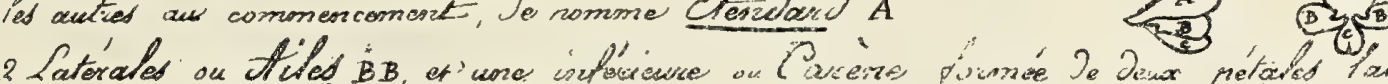

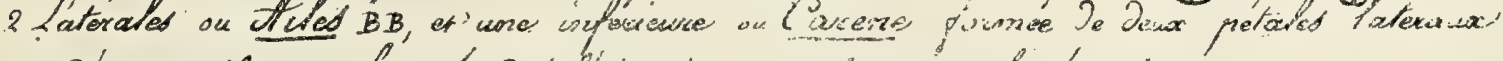

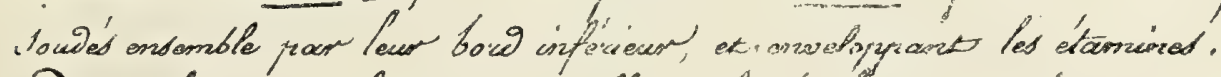

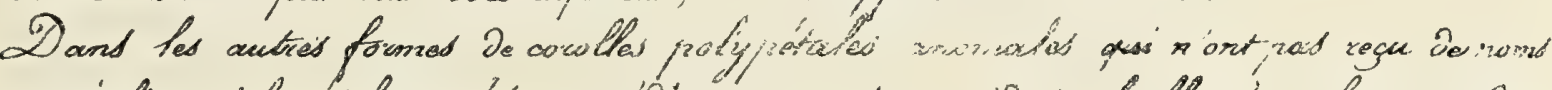

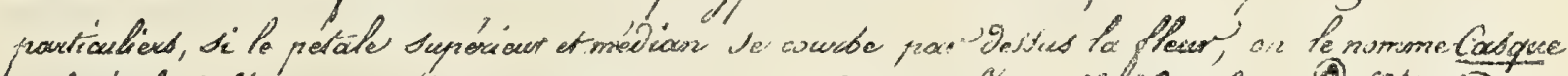

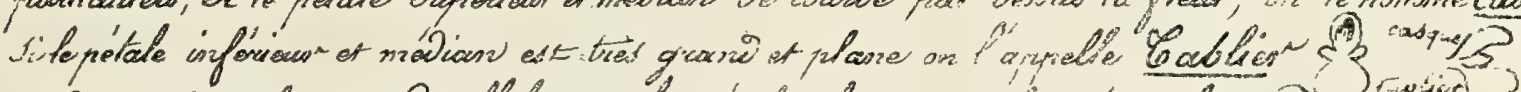

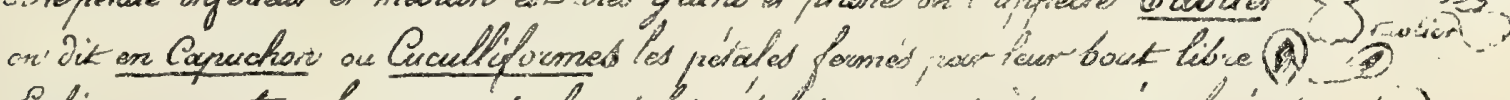

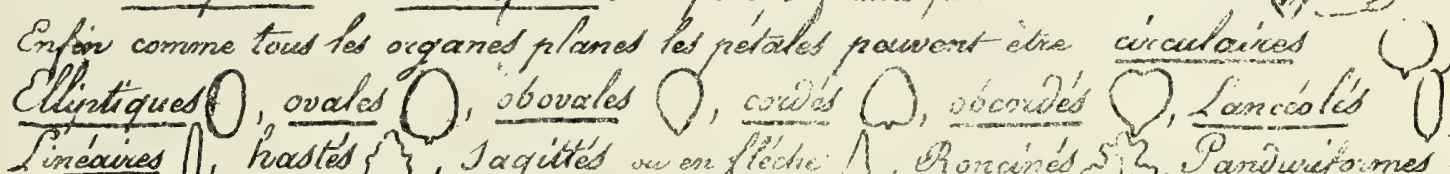

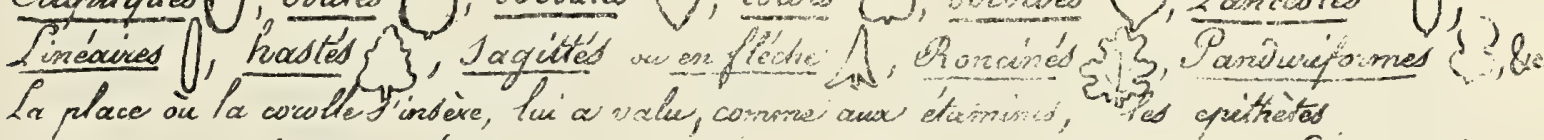

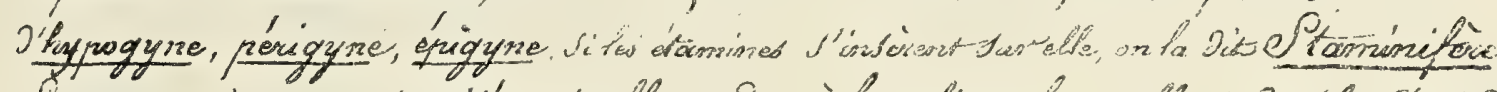

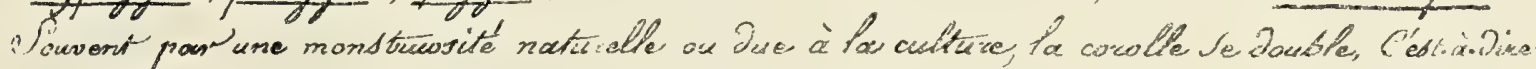

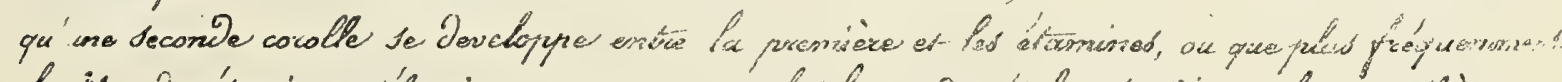

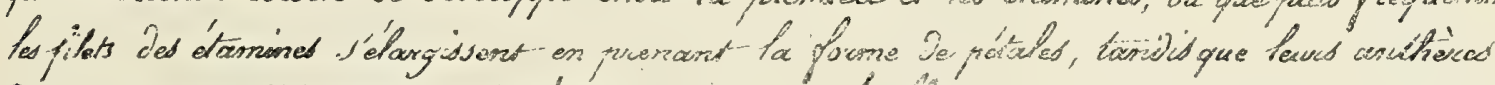

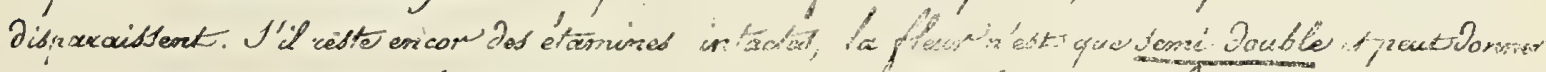

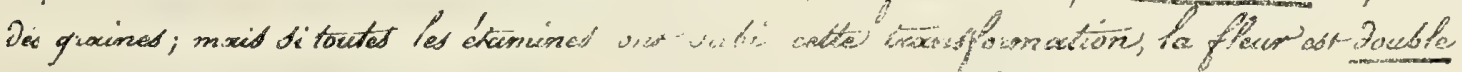

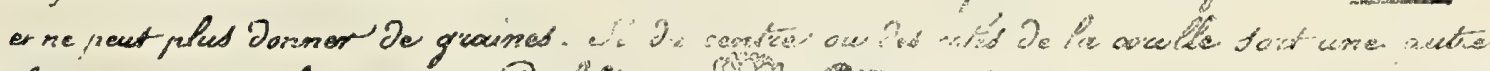

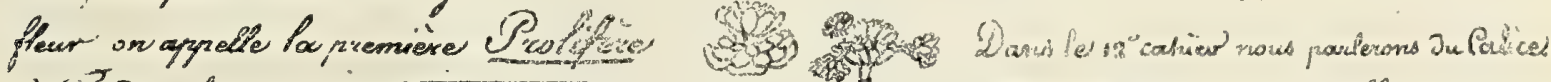

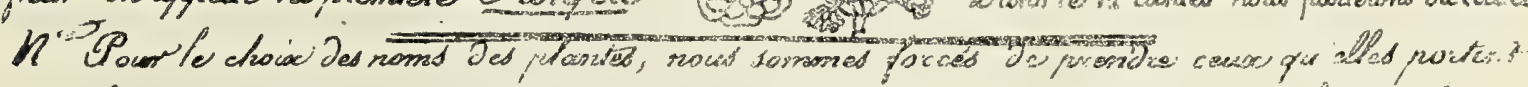

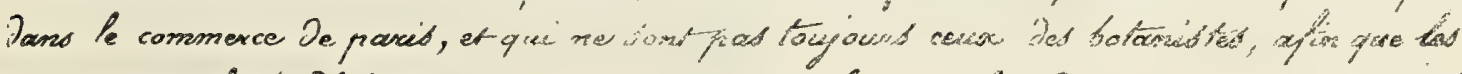

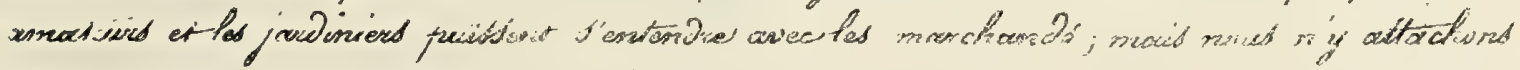

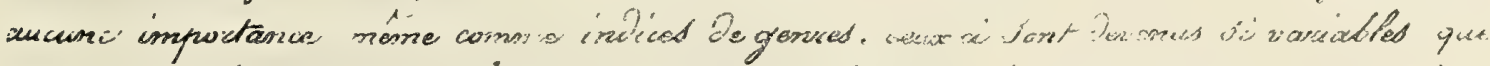

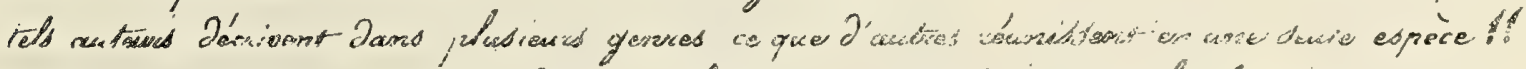

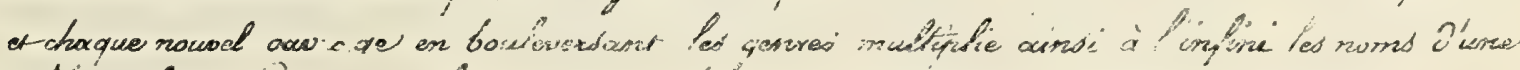

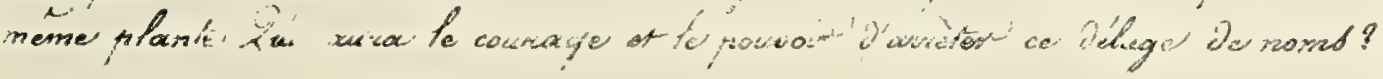

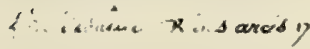




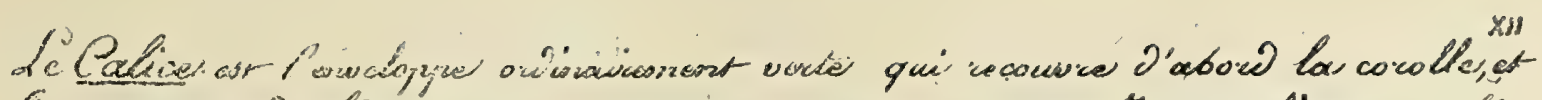

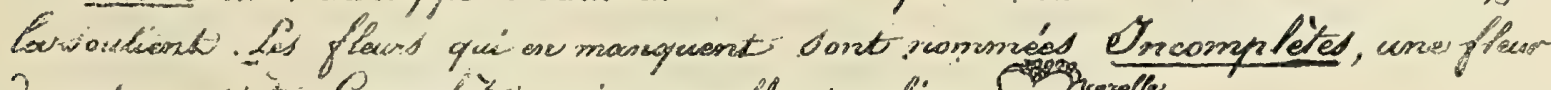

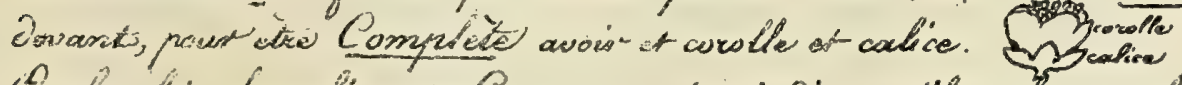

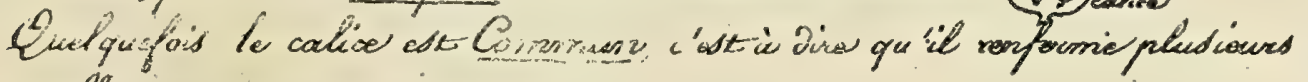
corolles.

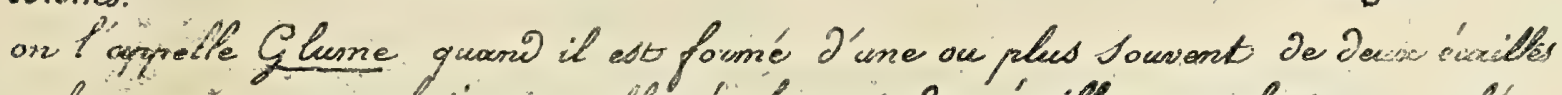

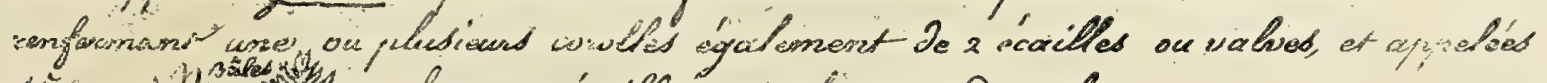

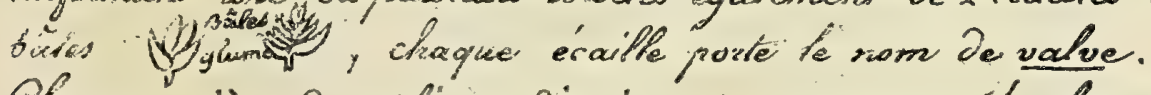

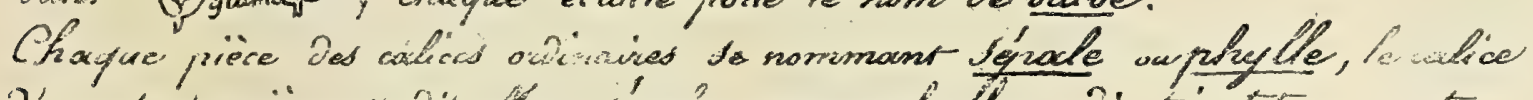

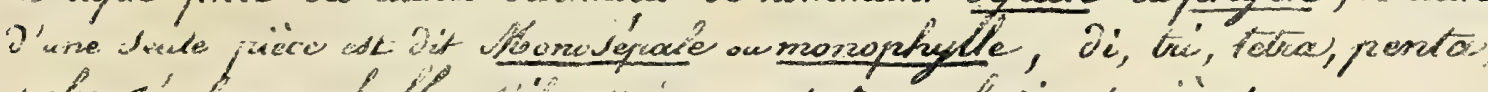

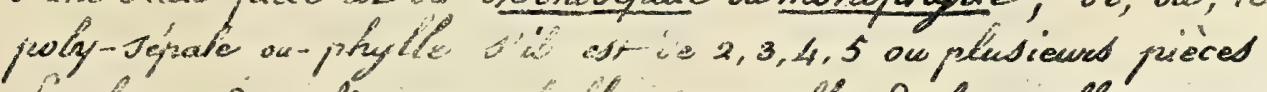

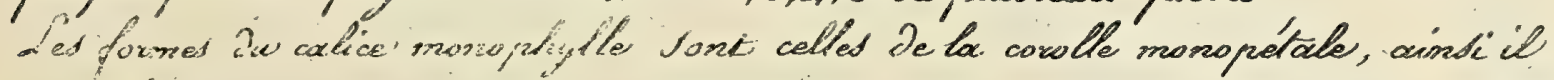

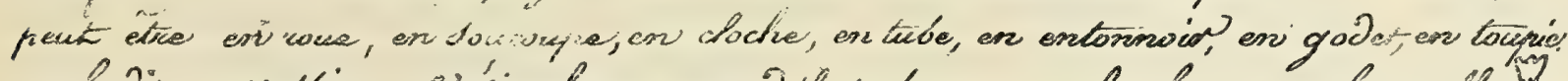

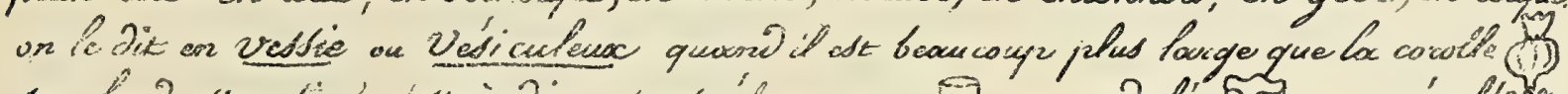

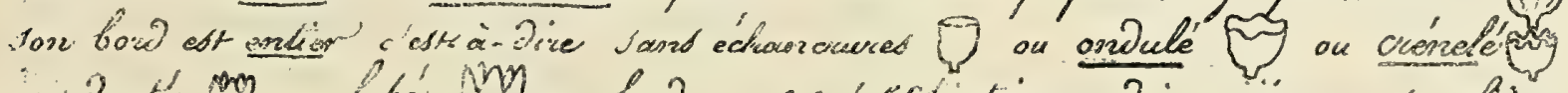

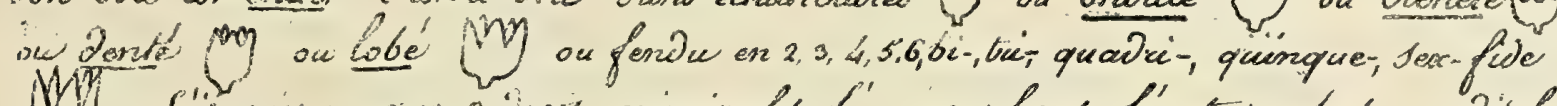

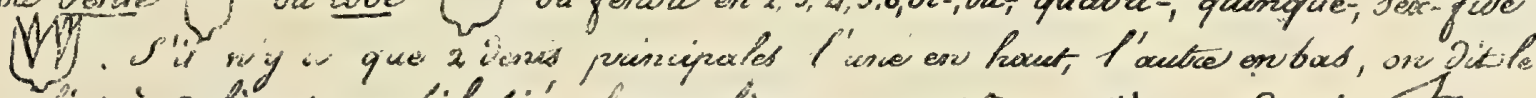

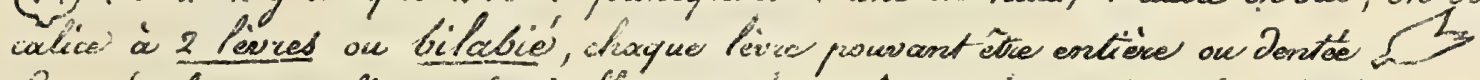

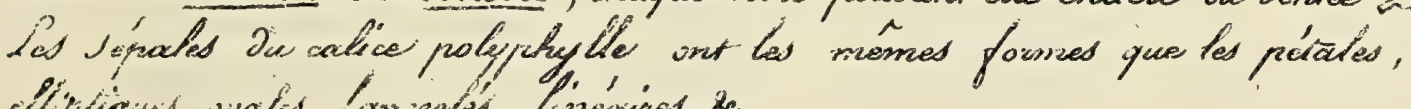

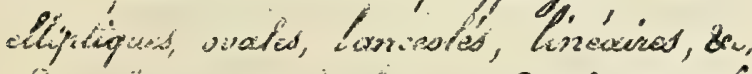

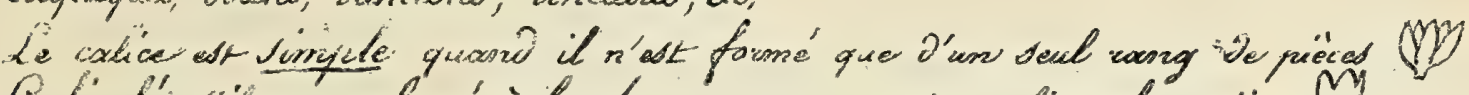

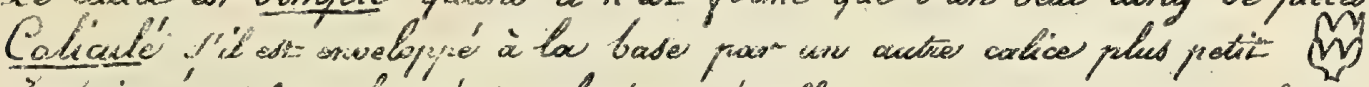

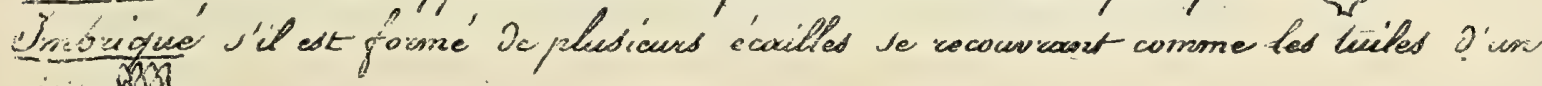
ant

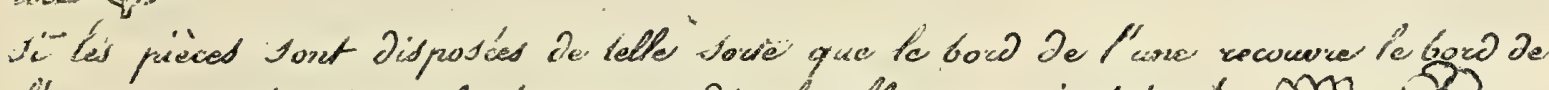

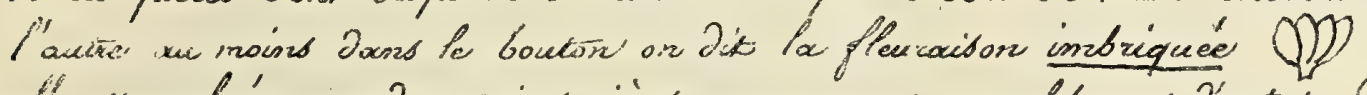

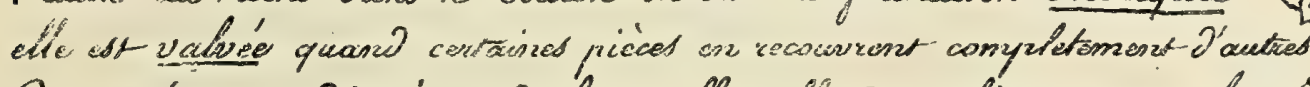

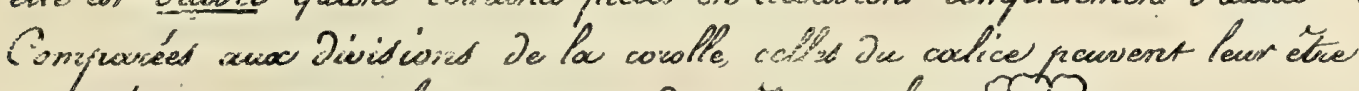

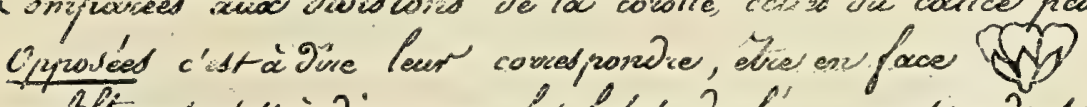

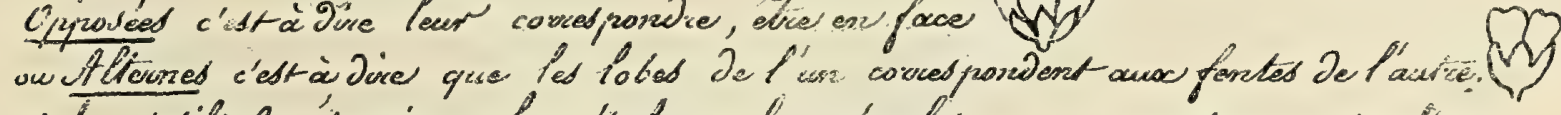

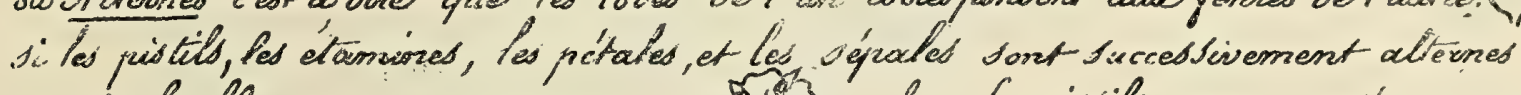

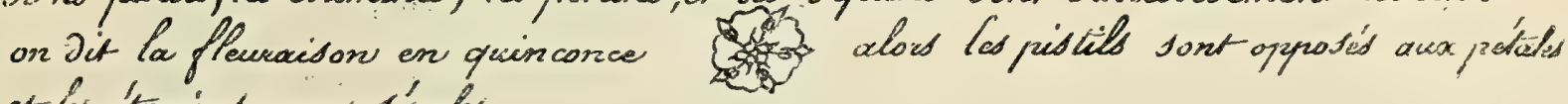
ot les étanioned acuoc déparles.

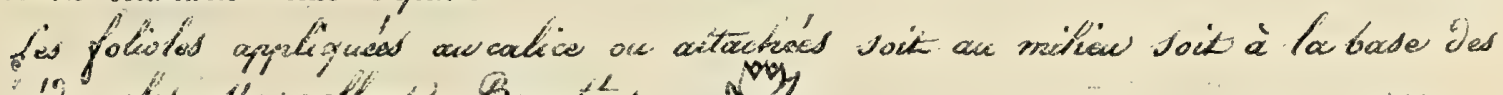

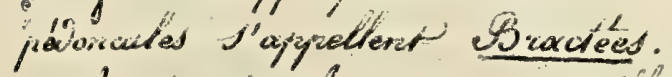
ii ies braisies formont wo verticilie Lollexté 



\section{2) $w$ Fruic}

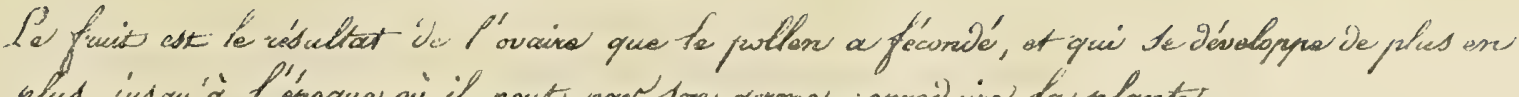

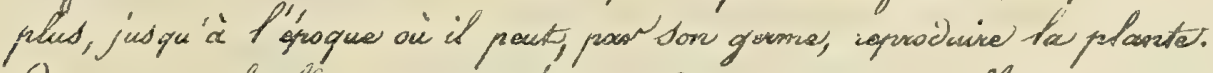

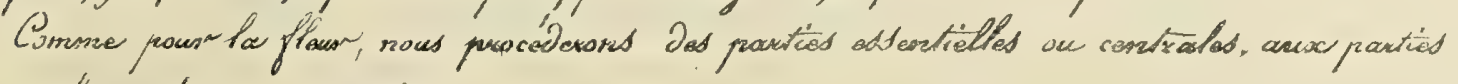
coneloppunated ow accedsoired.

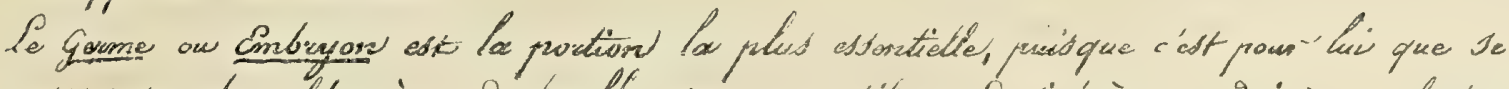

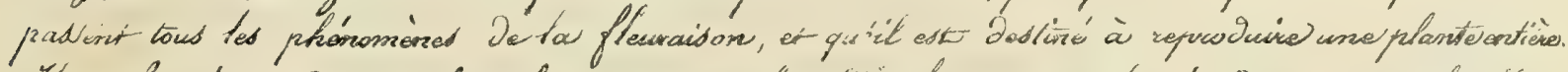

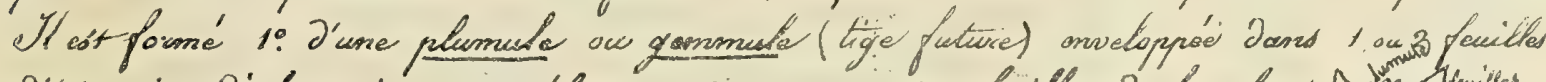

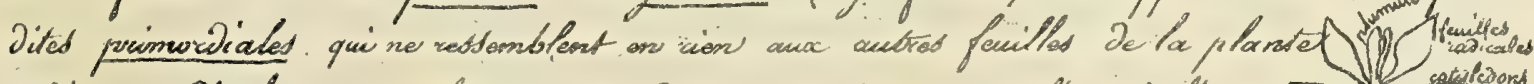

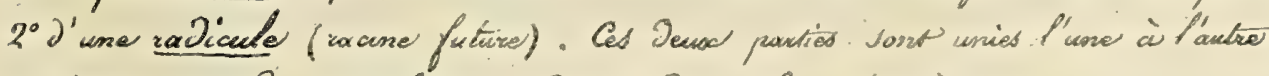
prot $3^{\circ}$ un notued ow colles, aw Dessud Dw qual I'inderents

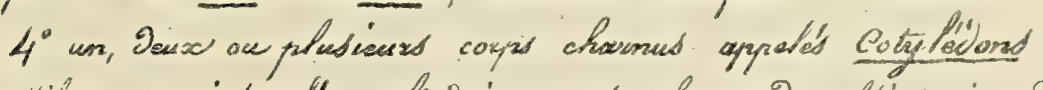

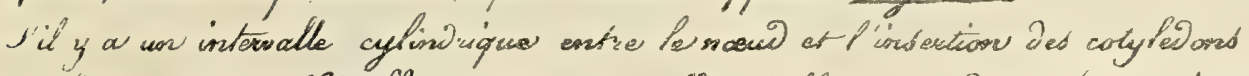

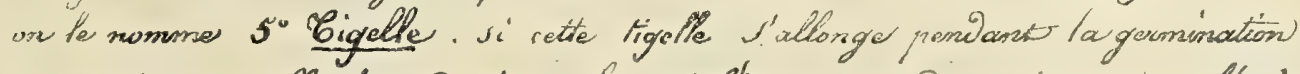

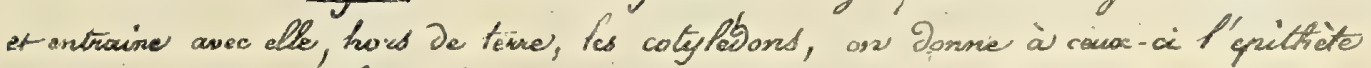

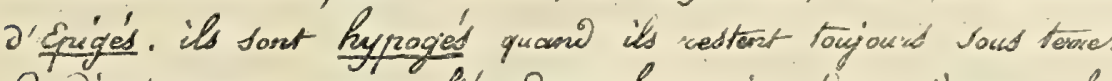

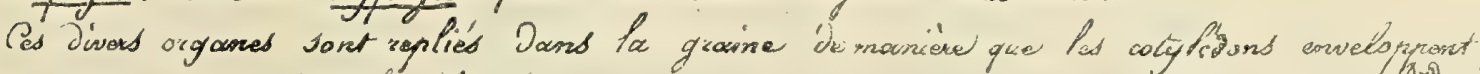

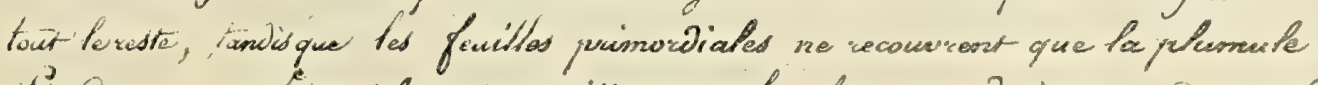

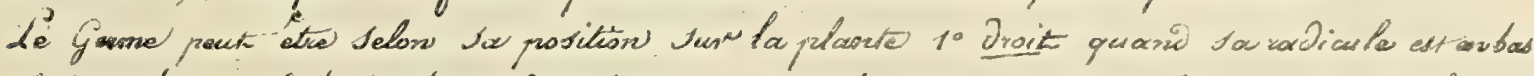

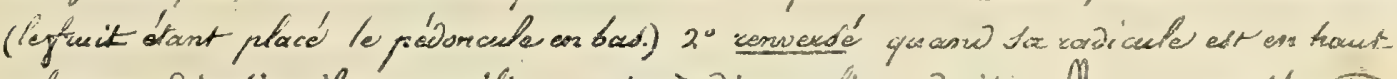

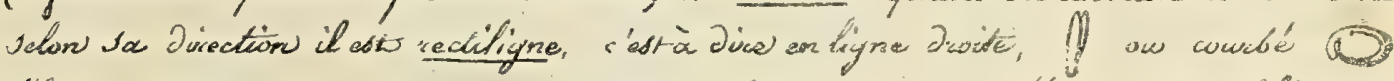

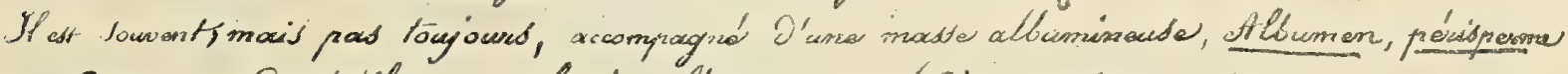

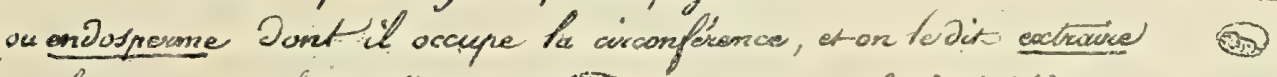

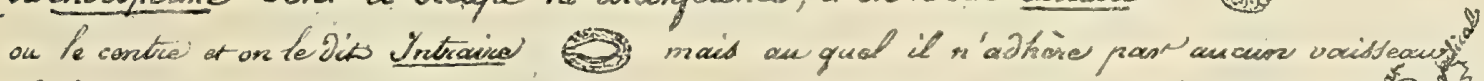

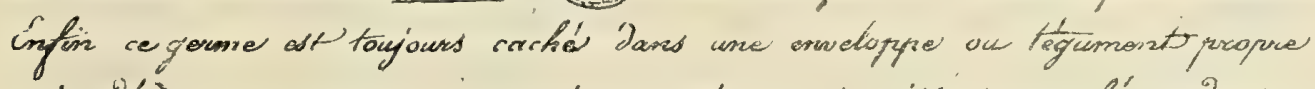

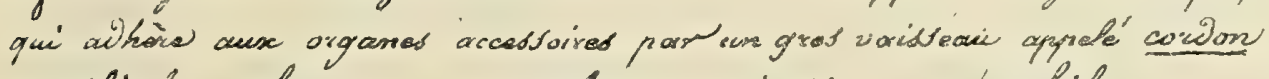
Ombilisel qui faiste Jur Sa Jurfare une cicatuscel nommée hile

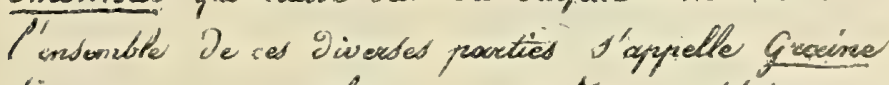

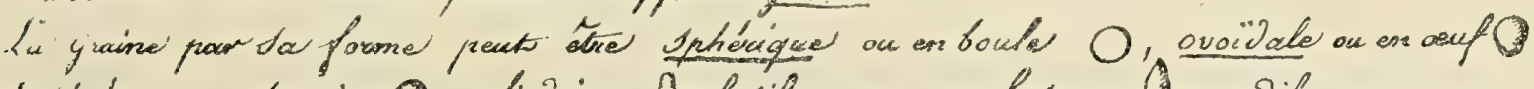

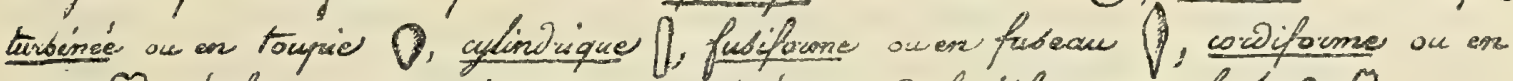

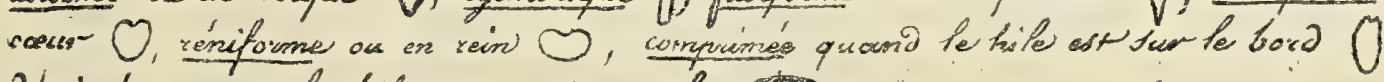

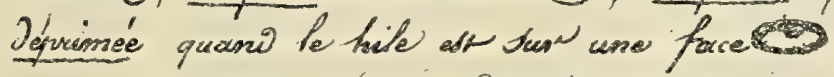

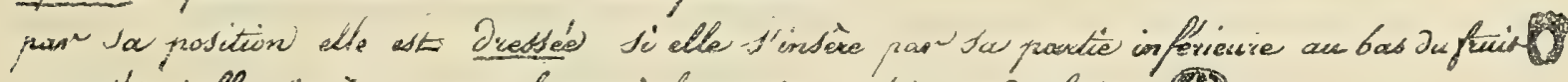

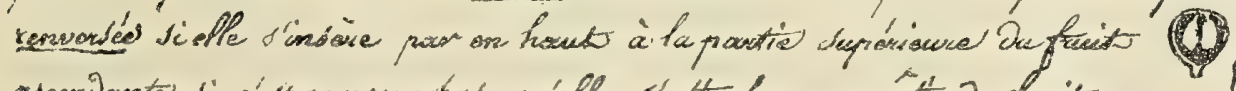

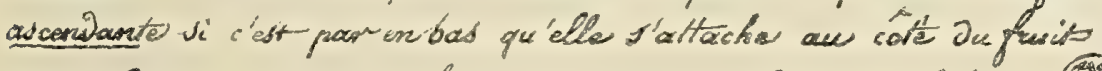

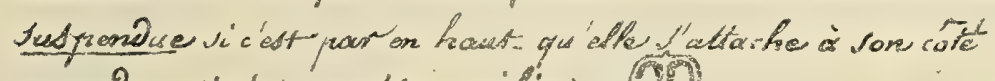

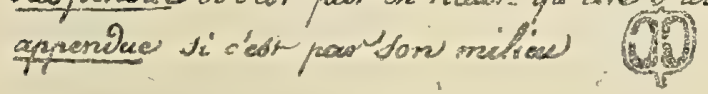





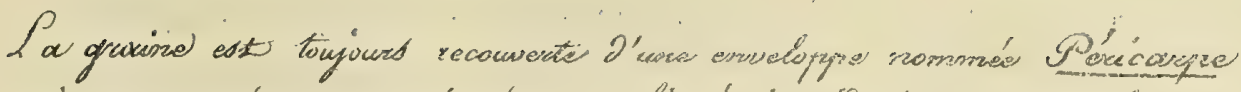

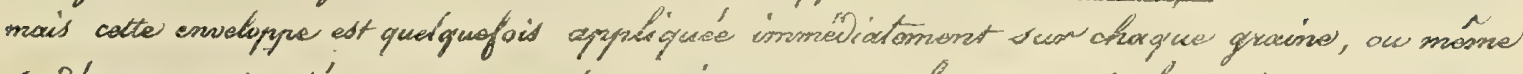

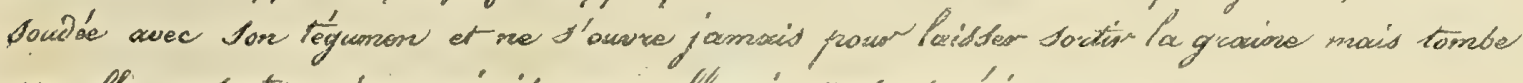

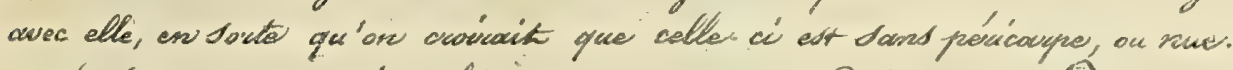

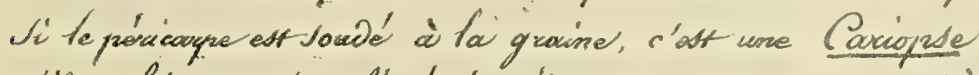

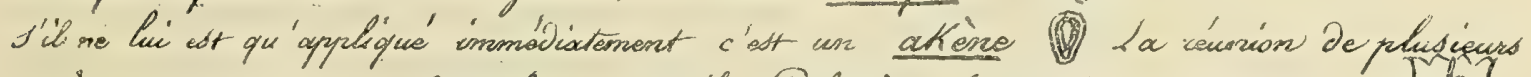

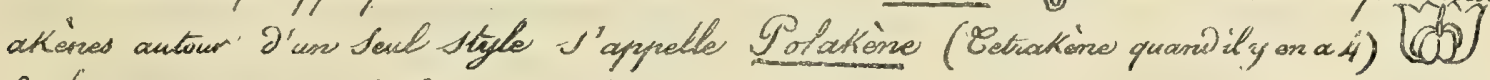

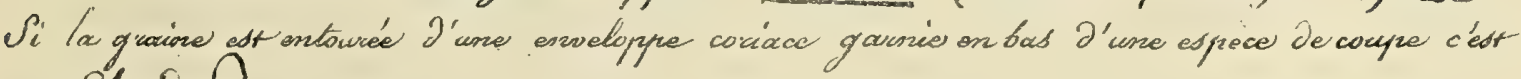
une glanid

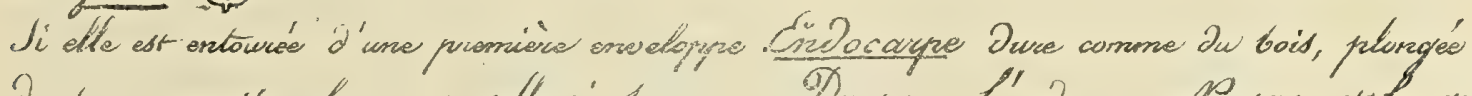

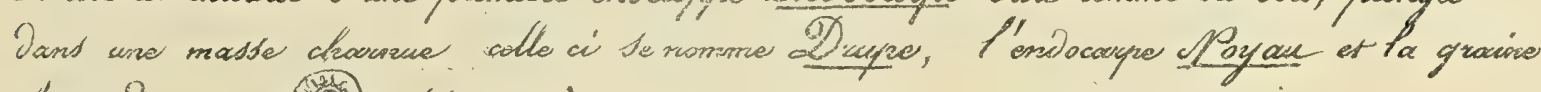
trmaride (Carises, preches.)

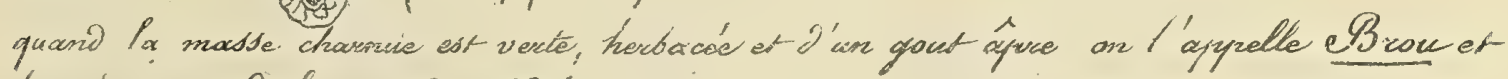
te noyou pucerid te num de Moí.

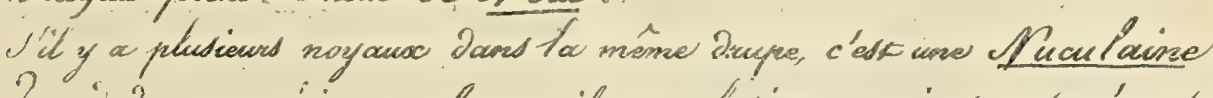

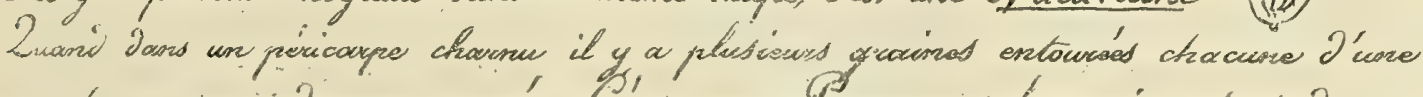

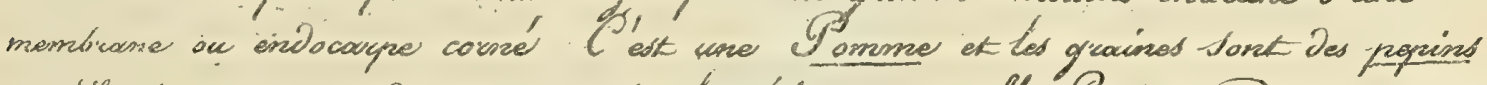

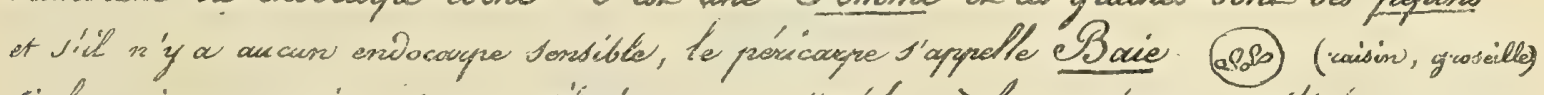

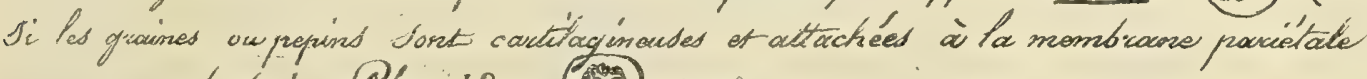
on nomone te fruit Syronide (Nabon)

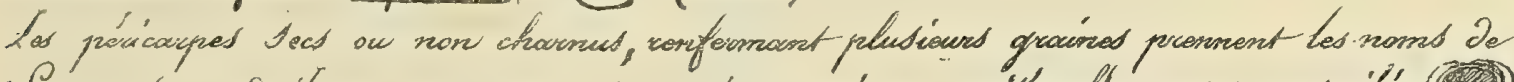

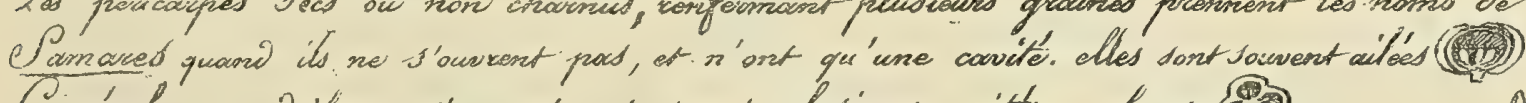

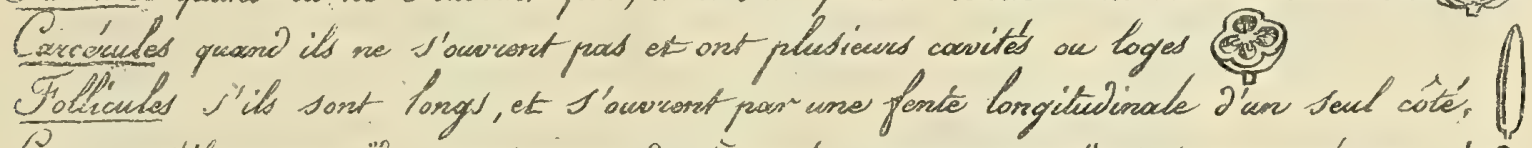

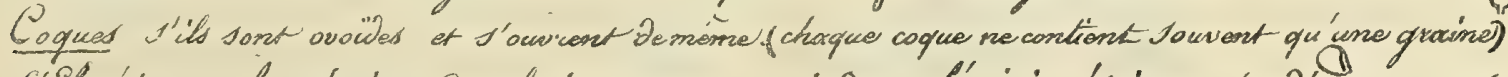

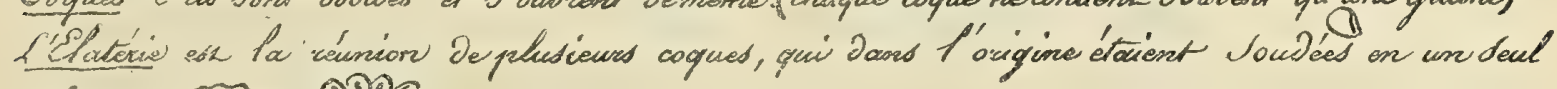
puit (1) NOP

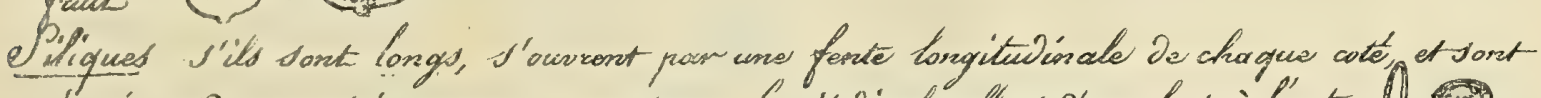

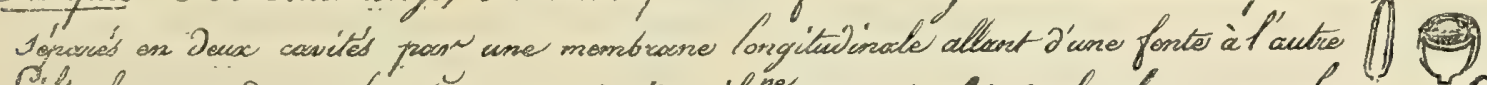

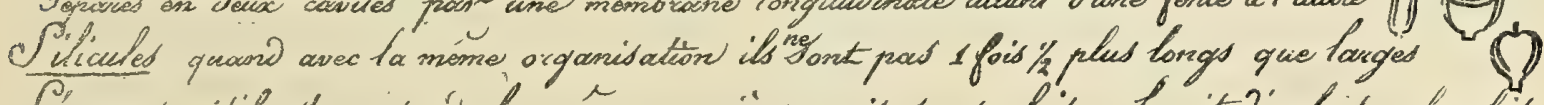

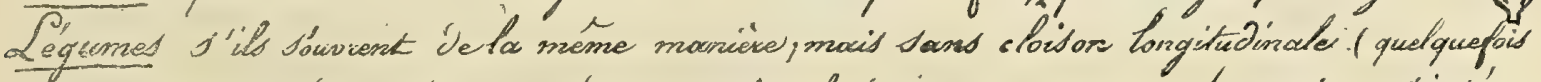

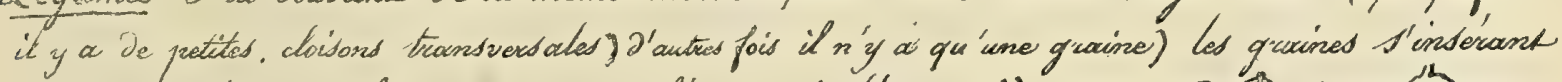

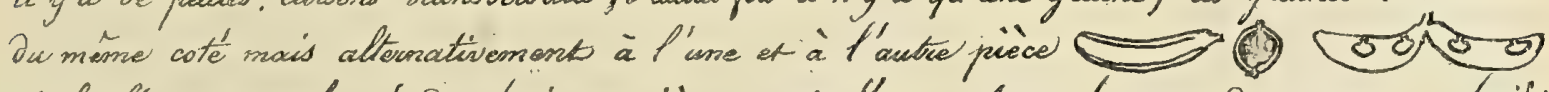

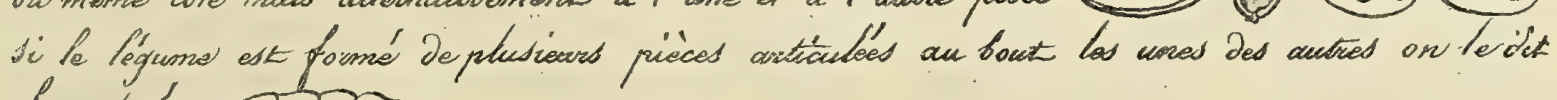
Lomentacé 210

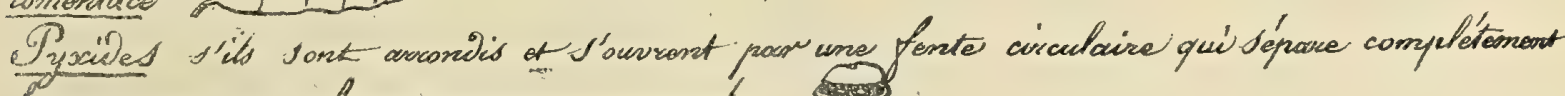
le sommet on une plague comme un oporacte

Candules Dans tous hes autred cad.

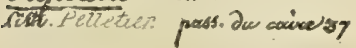





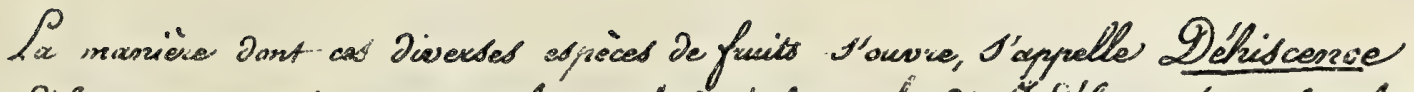

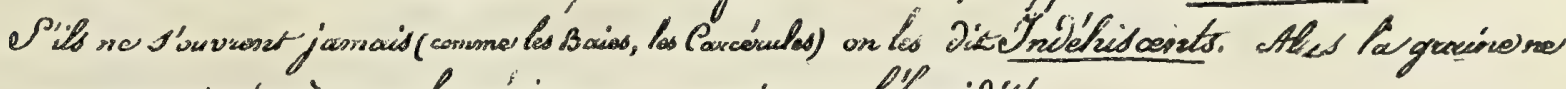

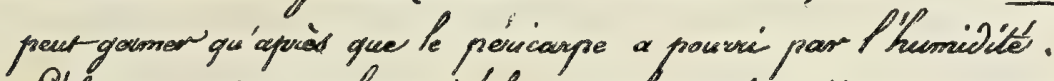

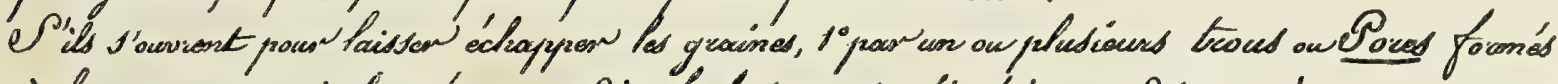

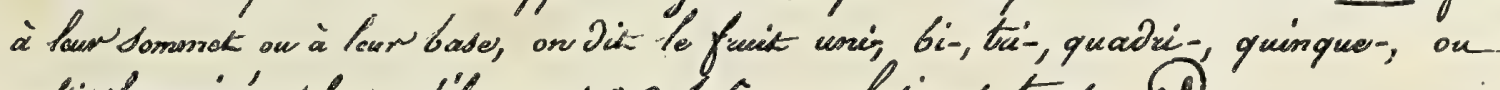
multi-focorminé Jelon' qu' 'il y a 1,2,3,4,5, ow plusieuts trous

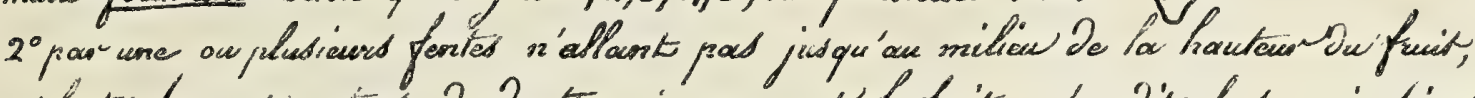

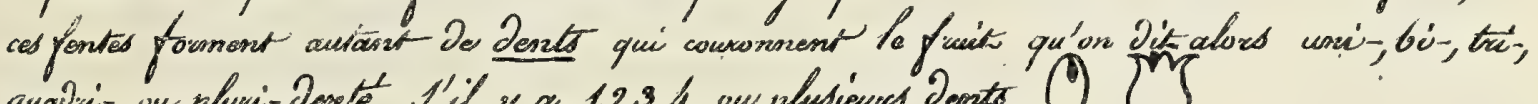

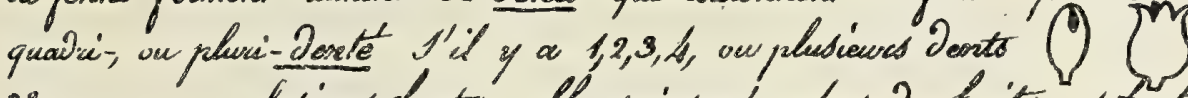

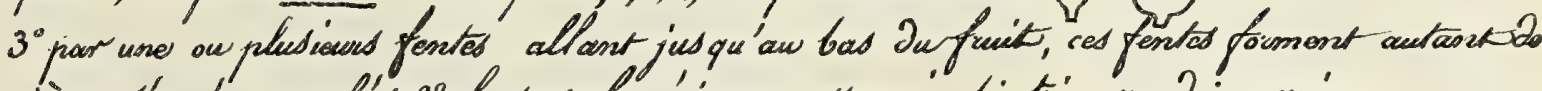

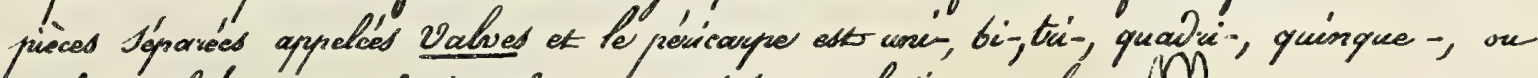
malti- valué (or non valve) sib a $1,2,3,4,5$, ow plusicurs valved (I)

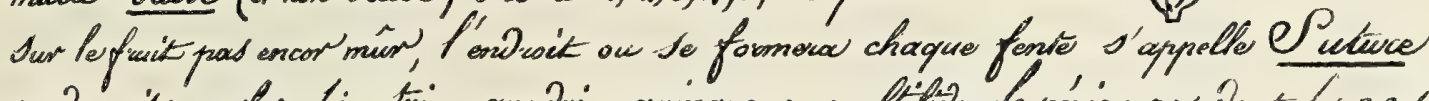

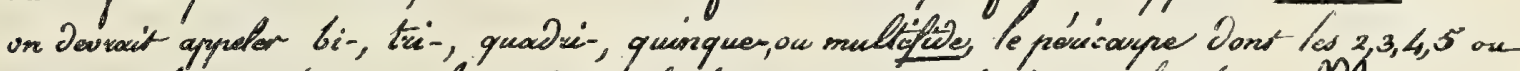

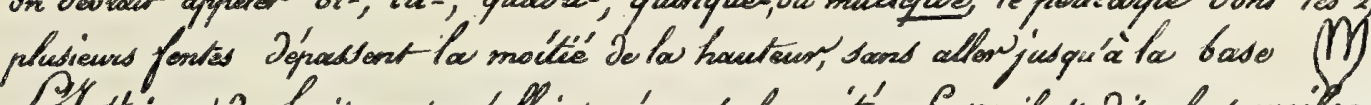

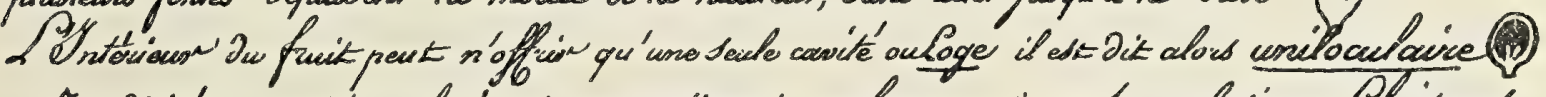

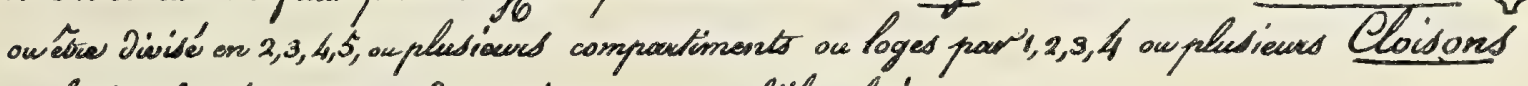
on le Jit alous bi-, tri-, quadie, quinque-, su multiloculavier

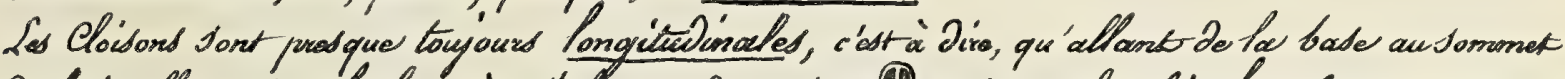

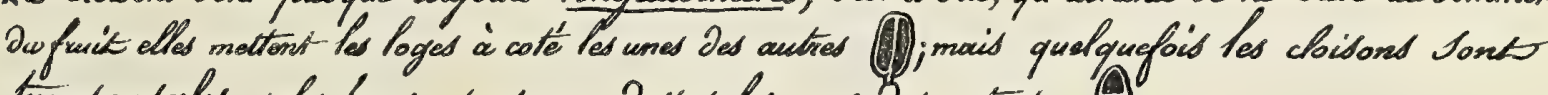
ticoconsversales et les loges Sont aw Jestus las unes des autres.

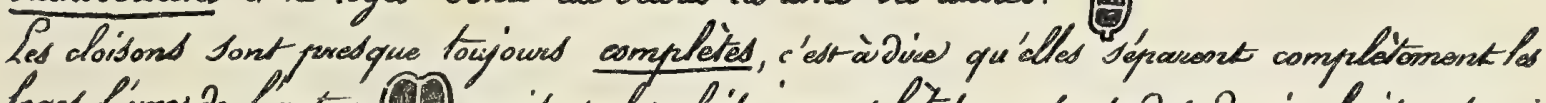

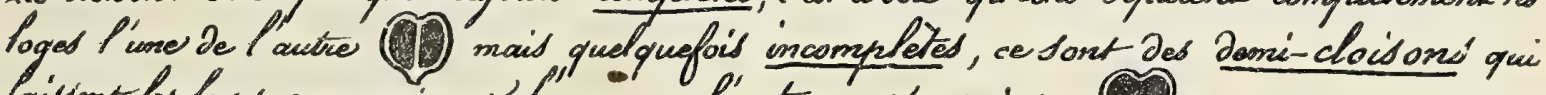

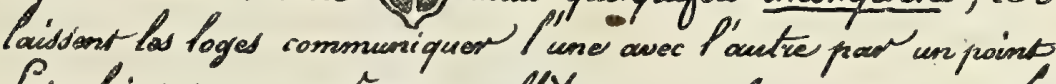

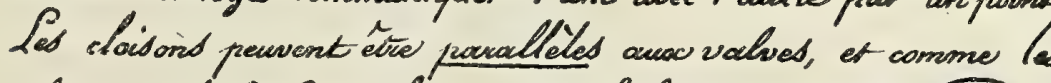

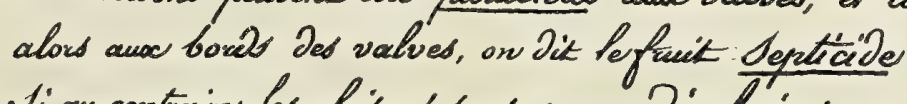

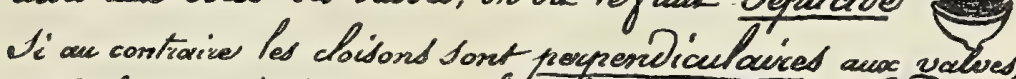
for valeses, les fortes rópondent an miliow

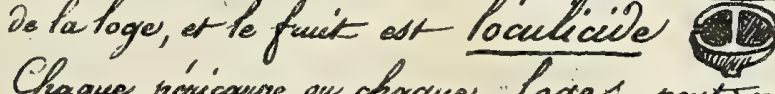

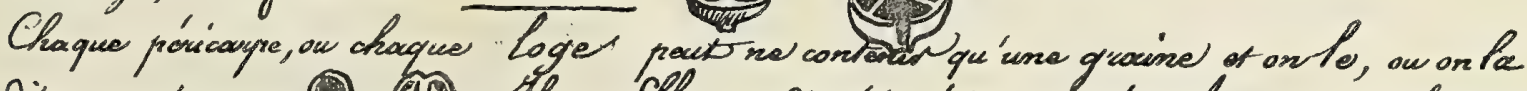

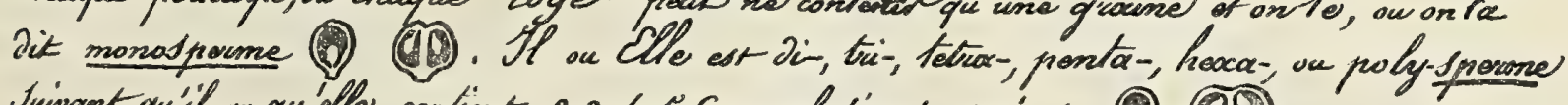

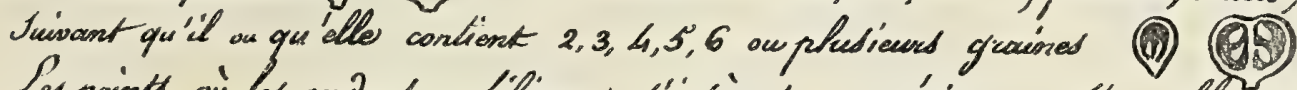

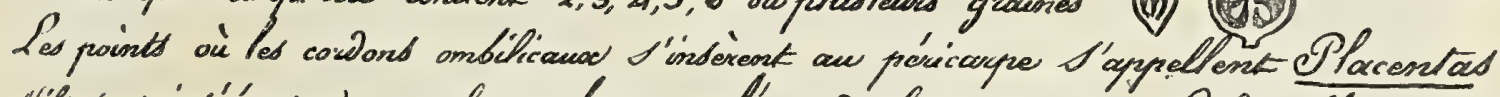

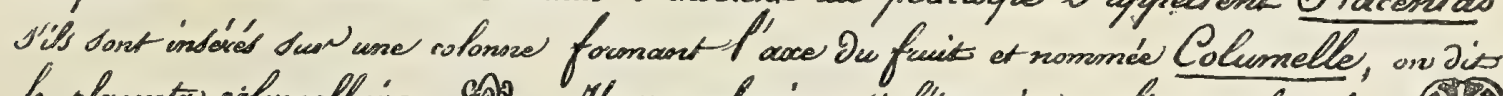

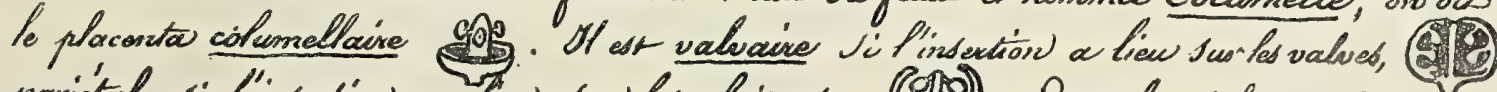

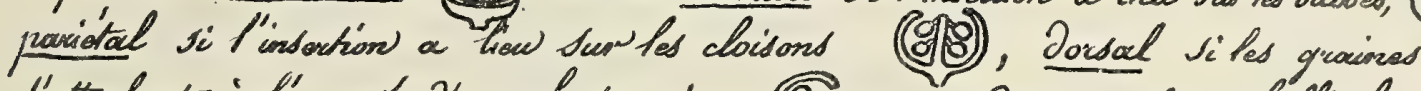

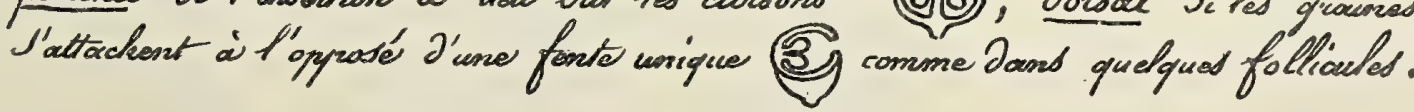

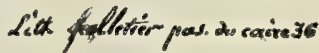



, ?.

721

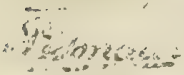

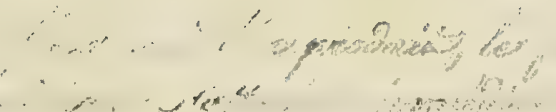

(n)

. I

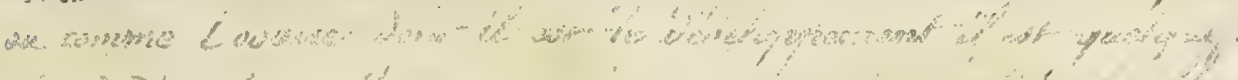

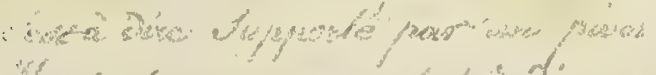
स

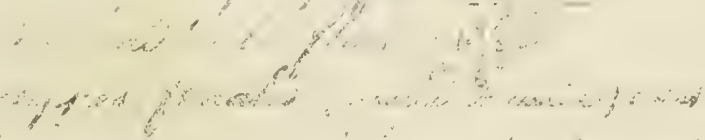

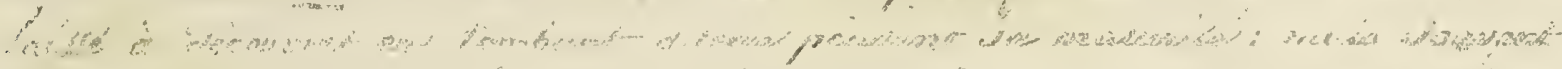

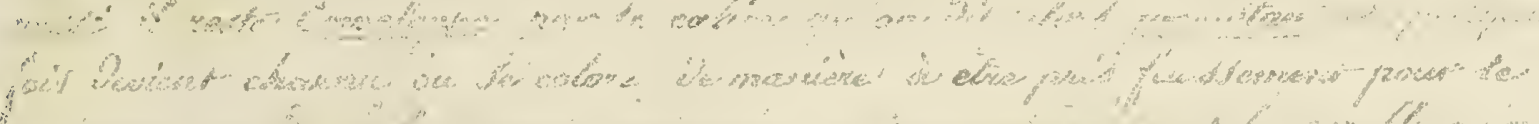
fotsis:

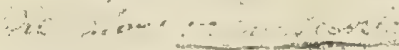

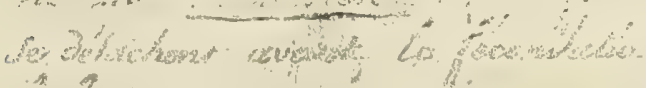

fin

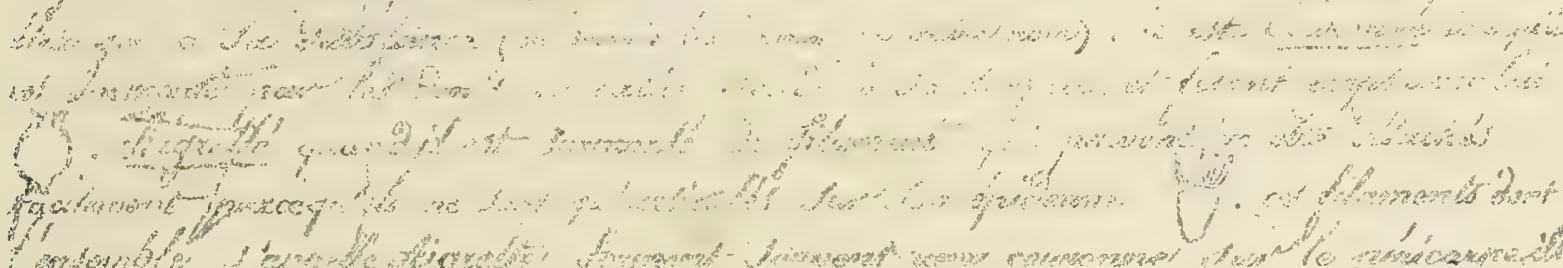

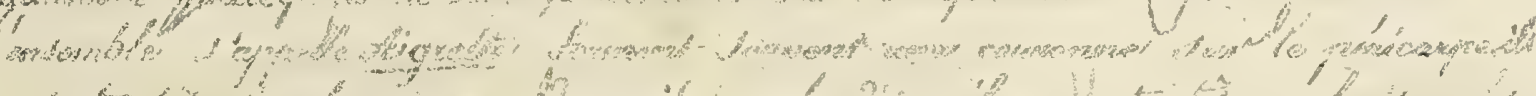

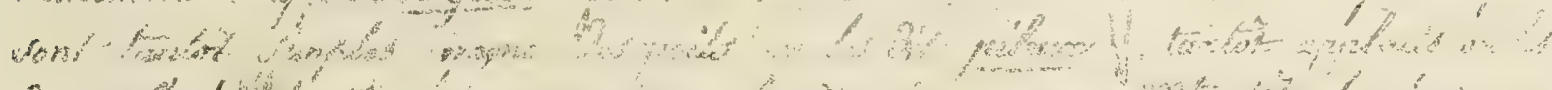
Q

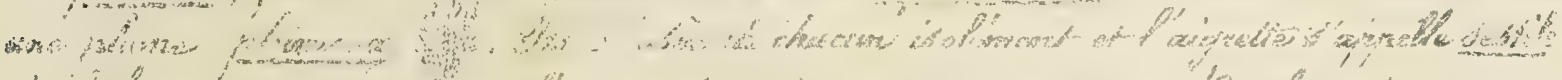
aid if f

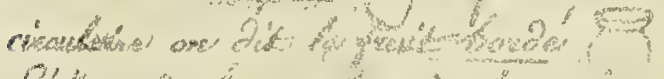

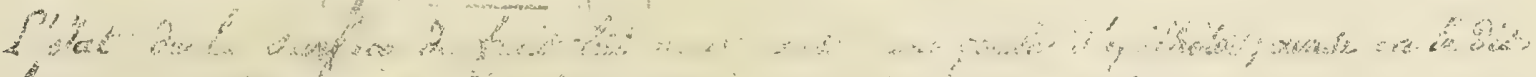

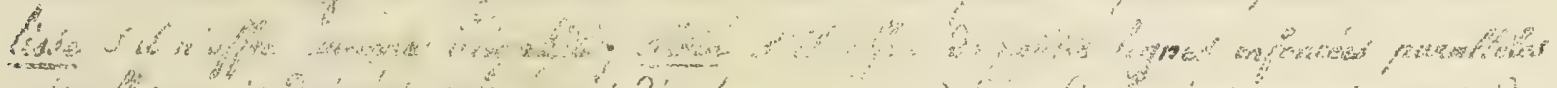

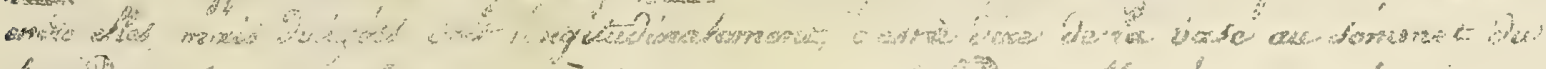

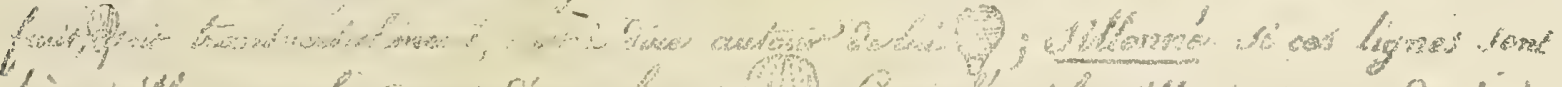

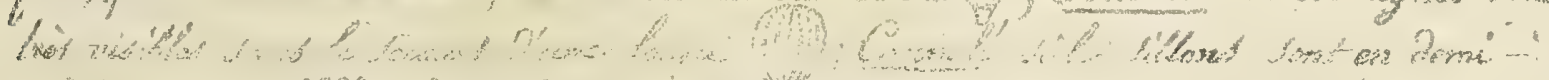

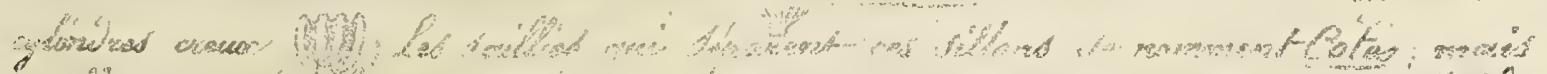

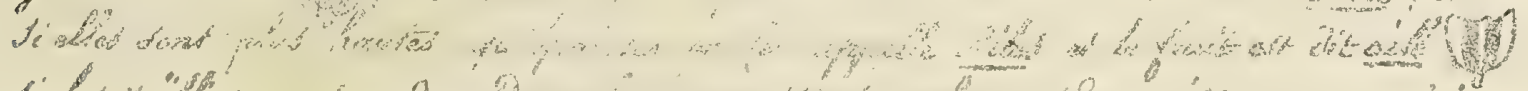

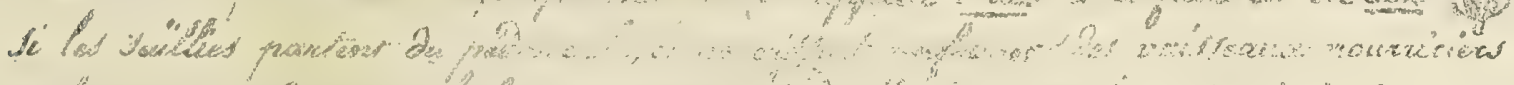

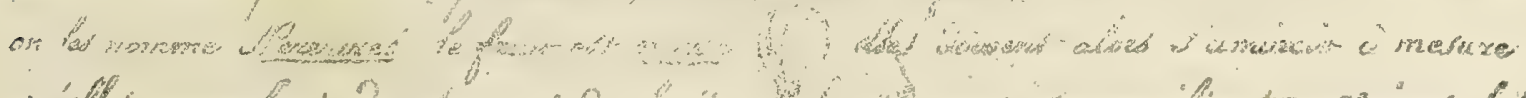

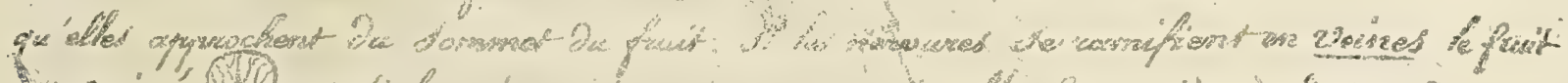

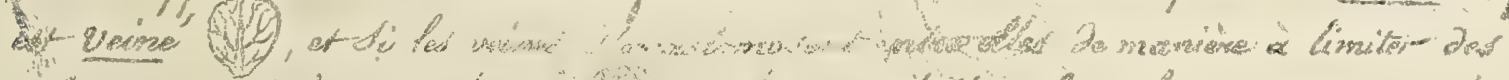

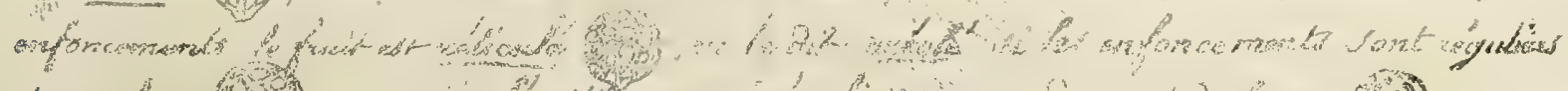

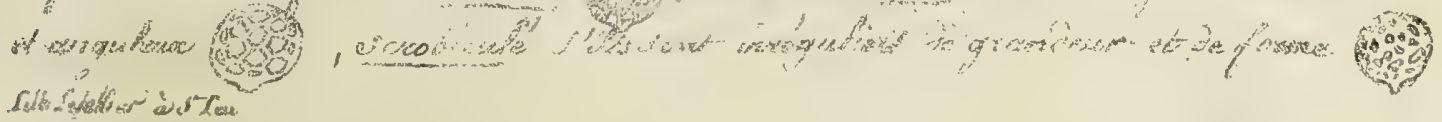






